\title{
THE PLUMS OF NEW YORK
}




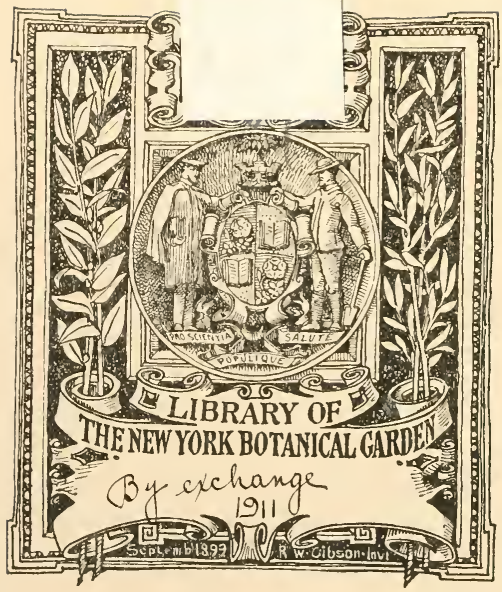


(1) 




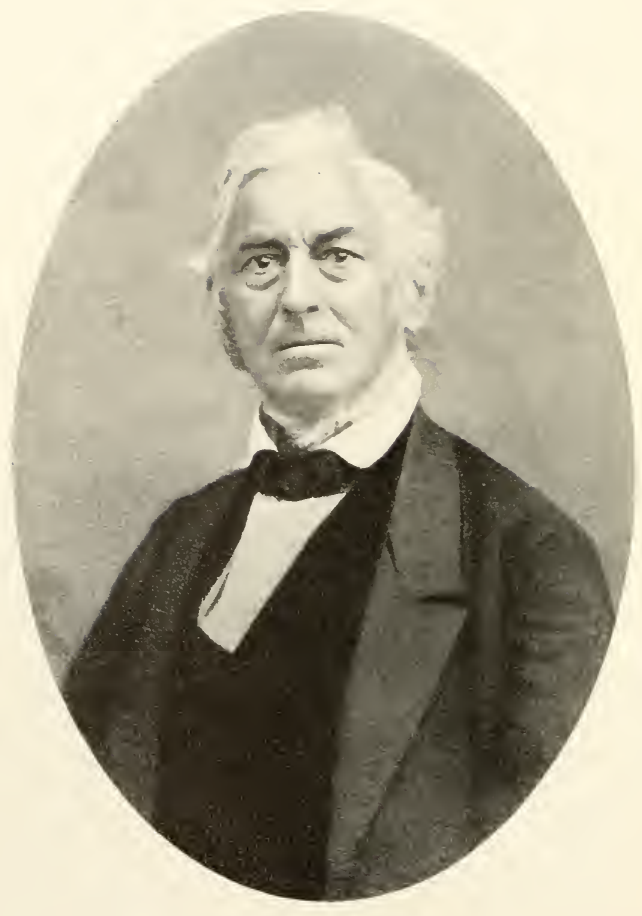

WILIIA. ROBERT PIRICE 

State of New York - Desartment of Agruclulltre

Eighteenth Annual Report - Vol. 3-P'nrt II

\section{THE}

\section{PLUMS OF NEW YORK}

BY

U. P. HEDRICK

ASSISTED BY

R. WELUNGTON

O. M. TAYLOR

LIBRARY

w. H. ALDERMAN

M. J. DORSEY

NEW YOLK

BOTANICAL

UARDEN.

Report of the New York Agricultural Experiment Station for the Year 1910 II 


$$
\begin{aligned}
& P 7 \\
& 1455
\end{aligned}
$$


NEW YURK ALRICLLTL R.IL EXIERIMENT : T.ATION

GENEVA, N. Y, I " nilor 31,1910

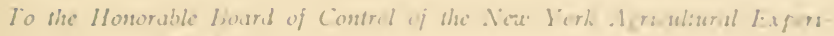
mont Statron:

Gi.Nthma. - I have the honor to transmit herewith Part II of the rejort of this instutution for the year 1910, to be known as The Plums ci Vi. Jork. This constitutes the third in the series of frut publicatrons that is being prepared under your authority:

The data embodied in the volume are the result of long-continued tudies and observations at this instutution as well as throughout the State, to which has been added a large amount of information that commercial flum-growers have very kindly furnished. The attempt has been made to produce a monograph including all the cultivated plums, and it is hoped that the result will be recognized as a worthy advance in the literature of this class of fruits.

IV. II JURD.A.,

Dirictor.

NEW YORK AGRICULTURAL EXPERIMENT STATION.

GENEVA, N. Y.

\section{A Correction in "The Plums of New York."}

On pages 1.11, 142 and 54i, "Altham" should read

"Althann". Kindly note the correction in the book.

$$
\text { (Signed) U. P. HELRICK. }
$$


$1+455$

c. 3

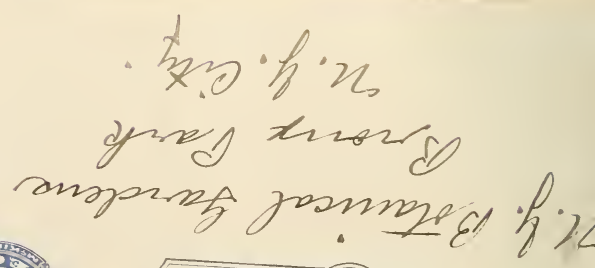

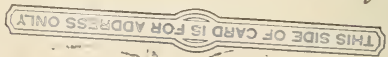


NEW YORK AFRICUITLR.M, EXIRRIMEXT ET.ITION.

(isivi, X. Y.., Inomiter j1, 1010

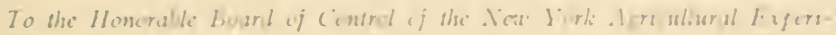
ment stuion:

Cirstums. - I have the honer to transmit herewith l'art II of the nugort of this motitution for the year 1910, to be known as The Plsens if In lork. This constitutes the thard in the series of fruit publ. cations that is being prepared under your authority.

The clata embodied in the volume are the result of long-continued turlies and observations at this institution as well as throughout the State, to which has feen added a large amount of information that commercial flum-growers have very kindly furnished. The attempt has been made to froduce a monograph including all the cultivated plums, and it is hojed that the result will be recognized as a worthy advance in the literature of this class of fruits.

IV. II JORD.AN, Direster. 

The Plums of New York is the third monograph of the fruits of this region published by the New York Agricultural Experiment Station. The aims of these books have been stated in full in The Grapes of New York, but it is considered best to re-state some of these briefly and to indicate some features in which the book on plums differs from the one on grapes.

Broadly speaking, the aim has been to make The Plums of New York a record of our present knowledge of cultivated plums. The book has been written for New York but its contents are so general in character that the work applies to the whole country and more or less to the world. The first chapter is a historical account and a botanical classification of plums; the second, a discussion of the present status of plum-growing in America; while the third and fourth are devoted to varieties of plums. The first and last two of these chapters contain the synonymy and bibliography of the species and varieties of plums. In the foot-notes running through the book biographical sketches are given of the persons who have contributed most to plum culture in America; here may be found also matters pertaining to plums not properly included in the text but necessary for its best understanding. Important varieties, so considered from various standpoints, with the bark and the flowers of several species, are illustrated in colors.

The Plums of New York is a horticultural and not a botanical work. But in a study of the fruit from a horticultural standpoint one must of necessity consider botanical relationships. It is hoped that in this enforced systematic study of plums, however, something has been added to the botanical knowledge of this fruit. In classifying the varieties and species, to show their characters and relationships, the author has chosen to dispose of the groups in accordance with his own views though the arrangement adopted is, for most part, scarcely more than a modification of existing classifications.

Attention must be called to the indefiniteness of species and varieties of plums due chiefly to the extreme responsiveness of the plants to environment. On each side of the specific or varietal types there are wide ranges of variation. Since the relationships between types are often very close it 
is impossible to avoid some confusion in characters, for outliers of the types cannot but overlap. It might be well said that these outliers are connecting links and that groups so connected should be combined, but this would make specific division of the genus and varietal division of the species almost impossible. The groups must, therefore, be separated along more or less arbitrary lines. But such arbitrary separation does not prevent natural groups, if nature be broadly interpreted.

The chicf value of the work in hand lies in its discussion of varieties. In the descriptions the aim has been to give as tersely as possible an idea of all of the characters of the plums described. With very few exceptions the technical descriptions of varieties are original and were made by those who have taken active part in the preparation of this book. Nearly all of the varieties having full descriptions grow on the Station grounds but whenever possible specimens of each variety from different localities have been compared with those growing here.

A special effort has been made to give as exactly as possible the regions in which the species and varieties of plums grow. Such an effort is made under the belief that this knowledge is of great value in the study of the factors which govern the distribution of wild and domesticated plants. If the boundaries of the regions in which a few scores of varieties of the several fruits grow can be accurately established valuable generalizations can be drawn regarding life zones and plant distribution.

The reader should know what considerations have governed the selection of varieties for color-plates and full descriptions. These are: (I) The known value of the variety for the commercial or amateur grower. (2) The probable value of new varieties. (3) To furnish data for the plumbreeder; to show combinations of species or varieties, or new characters, or the range in variation. (4) Some sorts have been described because of historical value-to better show what the trend of plum evolution has been. (5) To indicate the relationships of species and varieties. The varieties are divided into three groups according to their importance as gauged from the standpoints given above.

In botanical nomenclature the code adopted by the American botanists in Philadelphia in $\mathbf{1 9 0 4}$ and modified by the International Botanical Congress at Vienna in 1905 , has been used. For horticultural names, lacking a better code, the revised rules of the American Pomological Society have been followed, though in a few cases we have not seen fit to follow the rules of this society, as the changes required by their strict observance 
would have brought much confusion. Only those who have to work with a great number of varieties of fruit can know the chaotic conditions of our pomological nomenclature. One of the aims of the work in hand is to set straight in some degree the great confusion in plum names.

All synonyms of varieties have been given so far as they could be determined but it did not seem worth while to give all of the references to be found even in standard plum literature. Fewer of these are listed for the leading varieties than in the books on apples or grapes which have preceded, only such being given as have been found of use by the writers or thought of possible use to future plum students. On the other hand some references have been given for all varieties, a task not attempted in The Grapes of New York.

As in the preceding books the color-plates have been given much attention. Work and expense have not been spared to make the plates the best possible with the present knowledge of color-printing. Yet the illustrations are not exact reproductions. The colors are, at best, only approximations; for it is impossible by mechanical processes to reproduce Nature's delicate tints and shades. The camera does not take colors as the human eye sees them; and the maker of the copper plate can not quite reproduce all that the camera has taken. The colors then depend on the judgment of the printer, who by selecting and mingling colored inks, reproduces as nearly as his materials permit, the shades in his eye and mind; but no two persons see exactly the same colors in any object; so his conception may differ much from that of the horticulturist or artist who saw the original plum, as do theirs from each other. Still it is hoped that the color-plates will be of great service in illustrating the text. All of the plums from which the plates were made came from the Station grounds; the illustrations, with a few exceptions which are noted, are of life size, as grown under the conditions existing at this place, and as far as possible all are from specimens of average size and color.

Acknowledgments are due in particular to the plum-growers of Ncw York who have furnished much information for The Plums of New York; to numerous institutions in all parts of the United States who have loaned botanical specimens; to Professor Charles Sprague Sargent for advice, information and the use of the Arnold Arboretum library and herbarium; to W. F. Wight of the United States Department of Agriculture, who has given most valuable assistance in describing the species of plums and in giving their range; to the Station Editor, F. H. Hall, who has had 
viii

PREFACE.

charge of the proof-reading; to Zeese-Wilkinson and Company, New York City, for their care and skill in making the color-plates; and to the J. B. Lyon Company, Albany, New York, for their careful work in the mechanical construction of the book.

$$
\text { U. P. HEDRICK, }
$$

Horticulturist, New York Agricultural Experiment Station. 


\section{TABLE OF CONTENTS}

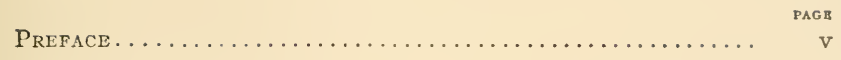

INDEX TO IlLUSTRATIONS. . . . . . . . . . . . . . . . .

Chapter I. E Edible Plunis . . . . . . . . .

Chapter II.-Plum Culture.................. IOo

Chapter III.-Leading Varieties of Plumis........... ${ }^{3} 6$

Chapter IV.-Minor Varieties of Plums............. 39 I

Bibliography, References and Abbreviatrons............ 573

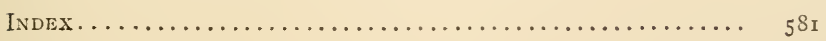





\section{INDEX TO ILLUSTRATIONS}

Portrait of William Robert Prince.............. Frontispiece FACING PAGE

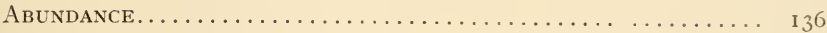

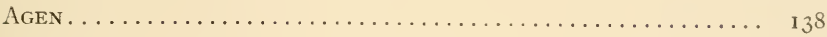

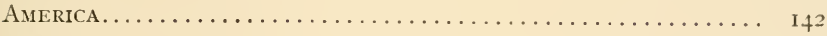

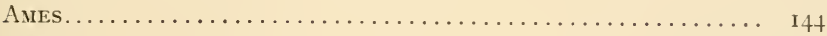

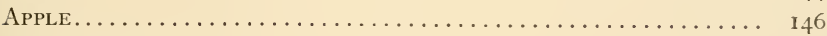

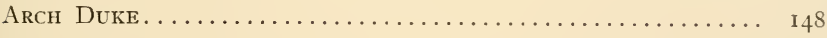

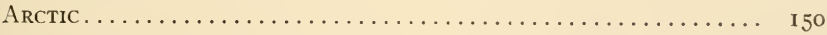

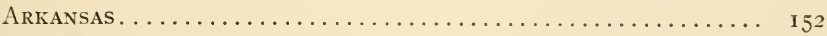

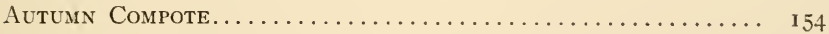

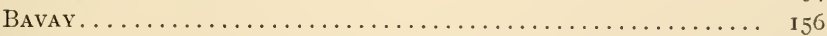

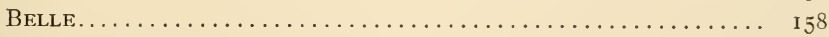

Black Bullace............................ I62

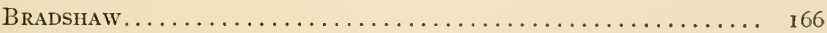

Burbank................................. 170

Снавот................................ 172

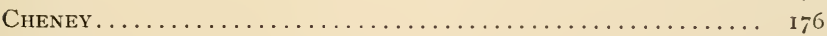

Climax................................ 178

De Caradeuc......................... 88

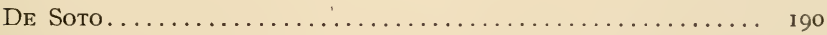

Diamond ................................ 192

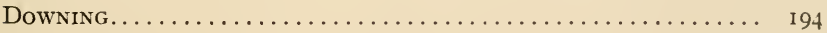

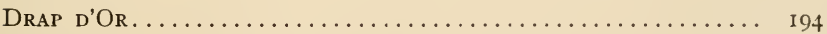

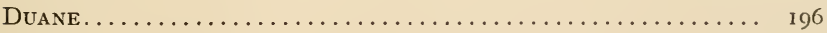

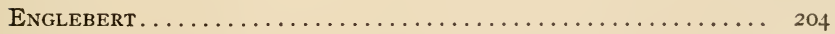

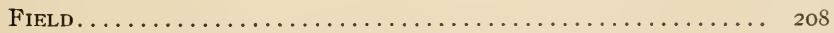

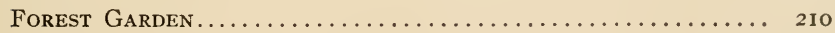

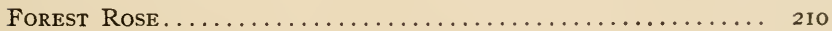


PACING PAGE

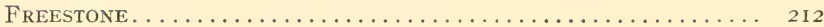

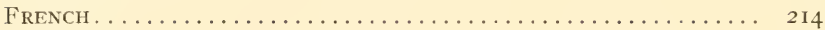

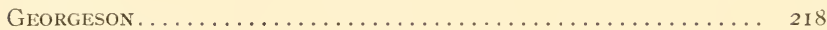

German Prune.............................. 220

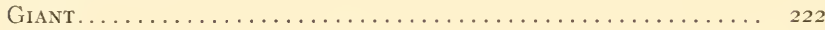

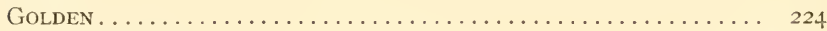

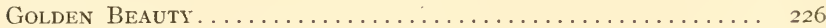

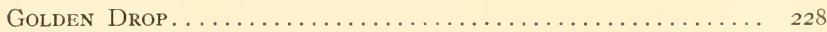

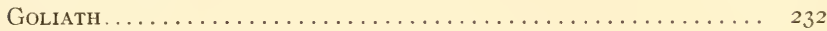

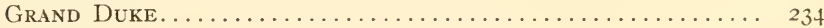

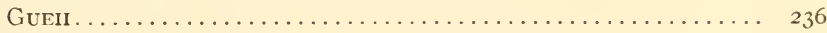

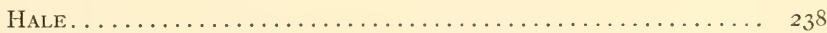

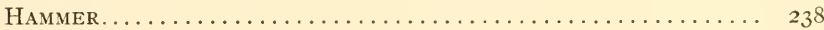

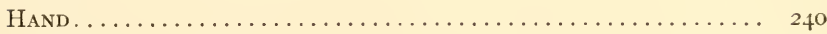

HAWkEYE . . . . . . . . . . . . . 242

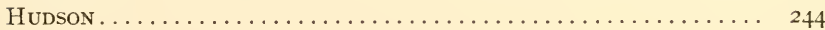

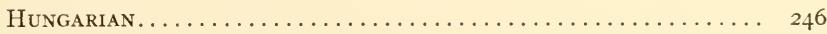

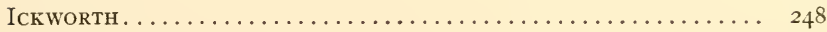

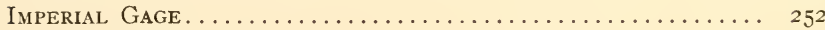

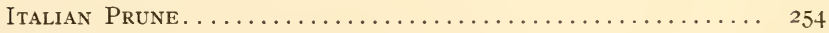

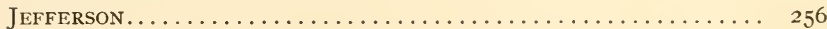

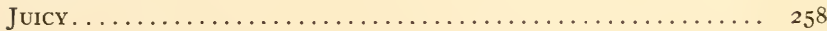

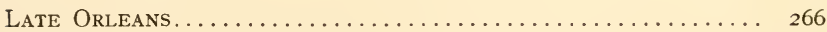

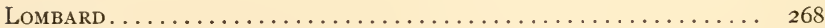

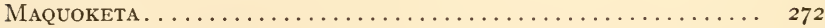

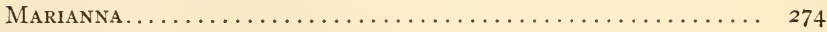

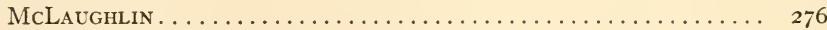

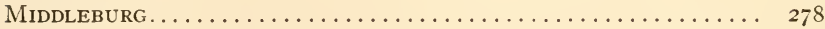

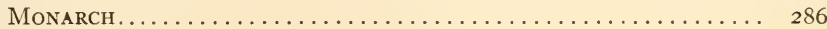

Newman. . . . . . . . . . . . . . . . . . . . . . . . 292

New Ulm. . . . . . . . . . . . . . . . . . . . . . . . . 294

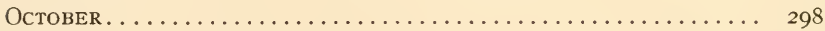

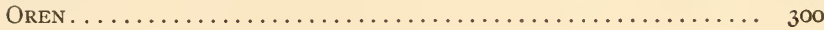




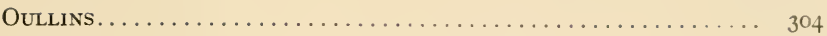

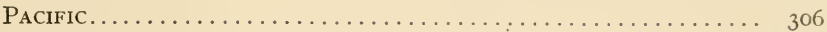

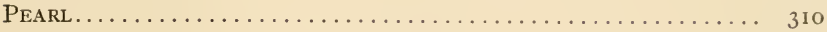

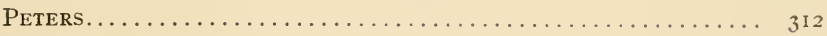

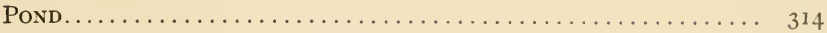

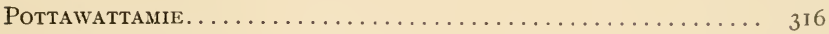

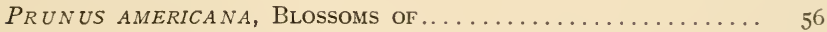

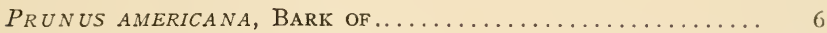

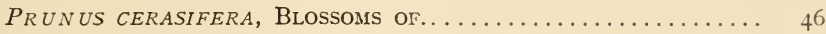

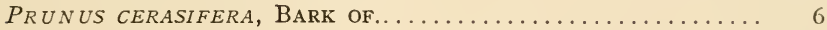

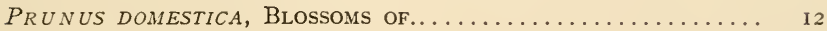

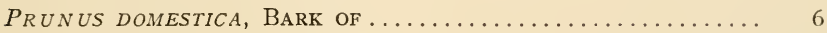

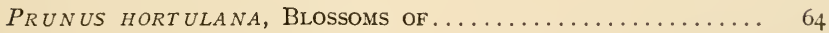

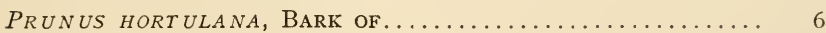

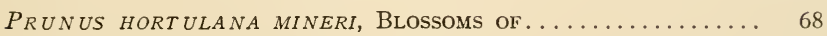

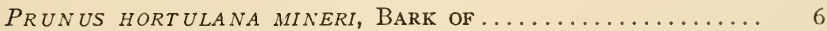

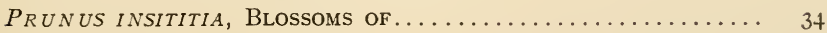

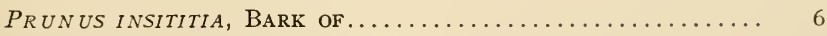

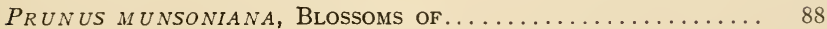

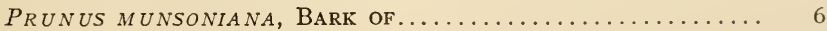

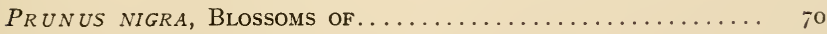

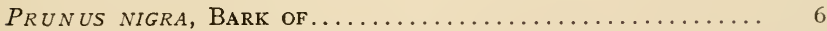

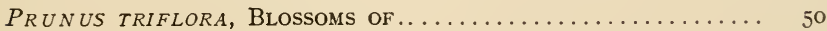

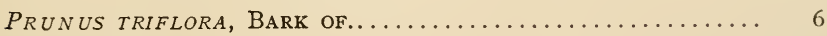

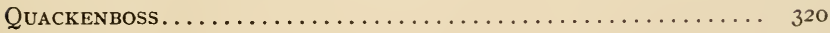

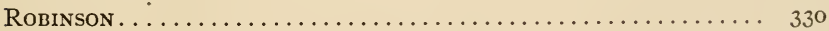

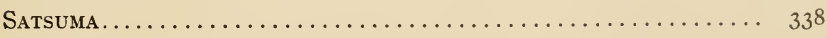

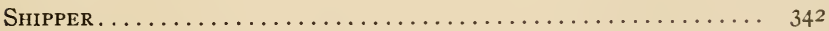

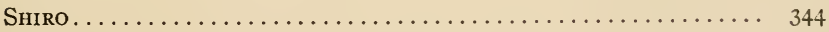

SHROPSHIRE. . . . . . . . . . . . . . . . . . . . . . 344

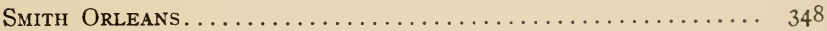

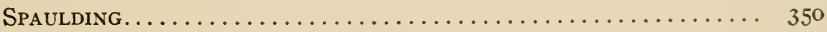

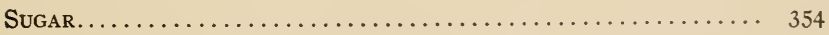




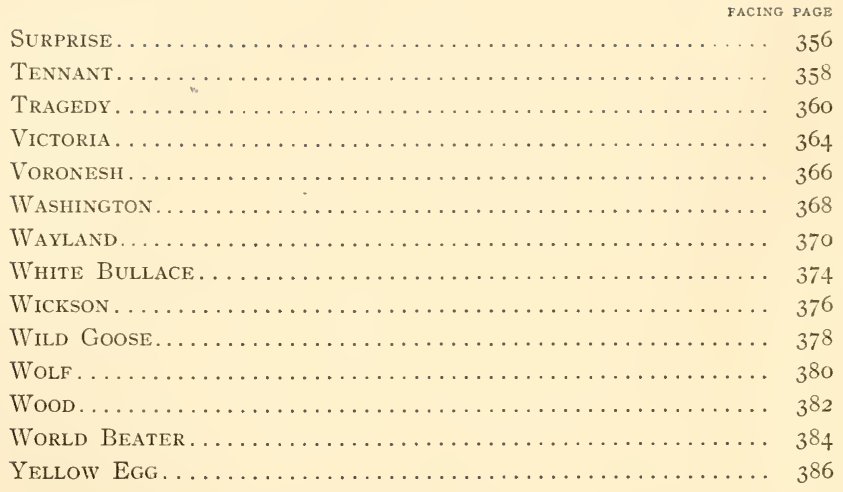




\section{THE PLUMS OF NEW YORK}

\section{CHAPTER I}

\section{EDIBLE PLUMS}

THE GENUS PRUNUS

The great genus Prunus includes plums, cherries, almonds, apricots, peaches, and the evergreen cherries or cherry laurels. Its widely distributed species number a hundred or more for the world, nearly all of which belong north of the equator. The species of the genus are widely distributed in both the eastern and western hemispheres, the flora of eastern America and of western Asia being especially rich in species and individuals. For most part the species of Prunus belong to the Temperate Zone, but several of the evergreen cherries, usually grouped in a section under Laurocerasus, are found in the tropics and sub-tropics.

The species cultivated for their edible fruits are found only in the Temperate Zone of the Northern Hemisphere. Of these the peach and the almond are believed to have come from eastern and southeastern Asia; the apricot is thought to be a native of northern China; the wild forms of the cultivated cherries are Eurasian plants, very generally distributed in the regions to the northward where the two continents meet. The habitats of the cultivated plums are given in detail in the text that follows, as Asia, Europe and America. Presumably the genus had its origin in some of the above regions; but where the center is from which the species radiated can never be known. Indeed, with present knowledge it cannot be said in what region Prunus has most species, is most productive of individuals, or shows highest development and greatest variability,facts which might give some evidence as to the origin of the genus. It is probable that the greatest number of combinations of the above evidences can be shown for Asia and more especially for the Eurasian region, where Europe and Asia meet; yet North America has two score or more indigenous species about half of which are arborescent.

The history of the genus Prunus is one of continual changes. Of the botanists who have done most toward classifying plants, Ray, Tourncfort, Dillenius and Boerhaave, pre-Linnaean botanists, placed only the plum 
in Prunus. Linnaeus adopted the name used by his predecessors for the plum alone, for a genus in which he also placed plums and cherries. Adanson and Jussieu returned to the pre-Linnaean classification but Gaertner followed the grouping of Linnaeus. Necker, DeCandolle, Roemer and Decaisne held that the plum alone belongs in Prunus. Bentham \& Hooker, Gray and his co-workers in the several revisions of his botany, and Engler \& Prant1, great authorities of the Nineteenth Century, extend the genus to include all of the stone-fruits. On the other hand, Britton and Brown, in their recent flora of northern United States and of Canada restrict the group to plums and cherries. Horticulturists have been less divided in their opinions than the botanists and have very generally placed all of the stone-fruits in one genus. The diversity of views as to what plants belong in Prunus, indicated above, suggests that the differences separating the several stone-fruits may not be many nor very distinct. This is true, and makes necessary a discussion of the characters which distinguish these fruits.

The flowers of true plums are borne on stems in fascicled umbels and appear either before the leaves or with or after them. Flowers of the cultivated cherries are similarly borne, though the fascicles are corymbose rather than umbelliferous. But apricot, peach and almond flowers are stemless or nearly so and solitary or borne in pairs appearing before the leaves.

The fruits of plums and cherries are globular or oblong, fleshy, very juicy, with smooth or slightly hairy skins. Peaches, apricots and almonds are more sulcate or grooved than plums and cherries and the first two have juicy flesh, but that of the almond is dry and hard or skinlike, splitting at maturity thereby liberating the stone; these last three fruits are distinguished from plums and cherries by having very pubescent or velvety skins though rarely, as in the nectarine, a botanical variety of the peach, and in a few cultivated apricots, the skins are smooth.

The stone of the plum is usually compressed, longer than broad, smooth or roughened, thickish and with an acute margin along the ventral suture and thinnish or grooved on the dorsal suture. The stone of the cherry is usually globular, always much thickened, smooth or a very little roughened, ridged and grooved on the ventral suture, with a thin, scarcely raised sharp margin on the dorsal suture. The stone of the apricot is similar to that of the plum though thicker walled, with a more conspicuous winged margin, and is sometimes pitted. The stone of the peach is compressed, usually with very thick walls, much roughened and deeply pitted. In 
the almond the stone resembles in general characters the peach-stone, but all almond shells are more or less porous and often fibrous on the inner surfaces. The stone is the part for which the almond is cultivated and is most variable, the chief differences being that some have thick hard shells and others thin soft shells.

The leaves of plums are convolute, or rolled up, in the bud. Cherry, peach and almond leaves are conduplicate, that is are folded lengthwise along the midrib in bud while the leaves of the apricot, like those of the plum, are convolute. The manner in which the leaves are packed in the bud is a fine mark of distinction in stone-fruits. In size and shape of leaves, as well as in the finer marks of these organs, the botanist and pomologist find much to aid in distinguishing species and varieties but little that holds in separating the sub-genera. The last statement holds true with the floral organs also.

The near affinity of the stone-fruits is further shown by the fact that plums and apricots, plums and cherries, and the several species of each of the distinct fruits inter-hybridize without much difficulty. It is a fact well-known that hybrids often surpass their parents in vigor of plant and in productiveness and this has proved true with most of the hybrids in Prunus of which we have accounts, thereby giving promise of improved forms of these plants through hybridizing. The great variation in wild and cultivated native plums is possibly due to more or less remote hybridity.

Prunus is a most variable genus. This is indicated by the several sub-genera, the large number of species and the various arrangements of these groups by different authors. At their extremes sub-genera and species are very distinct, but outside of the normal types, and sometimes in several directions, there are often outstanding forms which establish wellgraded connections with neighboring groups. For example, among the American plums there are but few species between which and some other there are not intermediate forms that make the two species difficult to distinguish under some conditions. There is also a wide range of variation within the species. The modifications within the species are oftentimes such as to change greatly the aspect of the plant; the trees may be dwarf or luxuriant, smooth or pubescent; may differ in branching habit, in leaf-form, in size and color of the flowers, in the time of opening of leaf and flower-buds, in color, shape, size, flesh, flavor and time of ripening of fruit, in the stone and in all such characters as climate and soil environment would be liable to modify. 
This inherent variability is one of the strong assets of the genus as a cultivated group of plants, for it allows not only a great number of kinds of fruits and of species but a great number of varieties. Besides, it gives to the genus grcat adaptiveness to cultural environment, in accordance with climate, location, soil and the handling of the trees. The cultivator is able to modify, too, the characters of members of the genus to a high degree in the production of new forms, but few, if any, groups of plants having produced as many cultivated varieties as Prunus.

The genus Prunus is preeminent in horticulture, furnishing all of the so-called stone-fruits, fruits which for variety, delicious flavor and beauty of appearance, probably surpass those of any other genus, and which, fresh or dried, are most valuable human foods. The seeds of one of the fruits belonging to Prunus, the almond, are commercially important, both for direct consumption and for the oil which is pressed from them; in India a similar oil is obtained from the seeds of peaches and apricots, while in Europe an oil from the seeds of the Mahaleb cherry is used in making perfumes. Various cordials are made from the fruits of the several species, as kirschwasser and maraschino from cherries, zwetschenwasser and raki from plums, and peach brandy from the peach; while fruits and seeds of the several species are soaked in spirits for food, drink and medicinal purposes. The bitter astringent bark and leaves are more or less used in medicine as is also the gum secreted from the trunks of nearly all the species and which, known as cerisin, is used in various trades. The wood of all of the arborescent species is more or less valuable for lumber, for cabinet-making and other domestic purposes.

Prunus is prolific also in ornamental plants, having in common to recommend them, rapidity of growth, ease of culture, comparative freedom from pests, and great adaptability to soils and climates. The plants of this genus are valued as ornamentals both for their flowers and for their foliage. Many cultivated forms of several of the species have single or double flowers, or variegated, colored or otherwise abnormal leaves. while the genus is enlivened by the evergreen foliage of the cherry laurels. Nearly all of the plants of Prunus are spring-flowering but most of them are attractive later on in the foliage and many of them are very ornamental in fruit.

PLUMS.

Of all the stone-fruits plums furnish the greatest diversity of kinds. Varieties to the number of two thousand, from fifteen species, are now 
or have been under cultivation. These varieties give a greater range of flavor, aroma, texture, color, form and size, the qualities which gratify the senses and make fruits desirable, than any other of our orchard fruits. The trees, too, are diverse in structure, some of the plums being shrublike plants with slender branches, while others are true trees with stout trunks and sturdy branches; some species have thin, delicate leaves and others coarse, heavy foliage. In geographical distribution both the wild and the cultivated plum encircle the globe in the North Temperate Zone, and the cultivated varieties are common inhabitants of the southern temperate region, the various plums being adapted to great differences in temperature, moisture and soil in the two zones.

The great variety of plums and the variability of the kinds, secmingly plastic in all characters, the general distribution of the fruit throughout the zone in which is carried on the greatest part of the world's agriculture. and the adaptation of the several species and the many varieties, to topographical, soil and climatic changes, make this fruit not only one of much present importance but also one of great capacity for further development. Of the plums of the Old World the Domesticas, Insititias and probably the Trifloras have been cultivated for two thousand years or more, while the work of domesticating the wild species of America was only begun in the middle of the last century. There are about fifteen hundred varieties of the Old World plums listed in this work, and since the New World plums are quite as variable, as great a variety or greater, since there are more species, may be expected in America.

An attempt is made in The Plums of New York to review the plum flora of this continent, but the species considered fall far short of being all of the promising indigenous plums; not only are there more to be described, but it is probable that species here described will in some cases be sub-divided. The development of the pomological plum-wealth of North America is but begun. Not nearly as much has been done to develop the possibilities of the European plums in America as in the case of the other tree-fruits. Probably a greater percentage of the varieties of Old World plums commonly cultivated came from across the sea, than of the varieties of any other of the orchard-fruits which have been introduced. Much remains to be done in securing greater adaptability of foreign plums to American conditions. Native and foreign plums are also being hybridized with very great advantage to pomology.

The Plums of Now York is written largely with the aim of furthering the development of plums in America, the possibilities of which are in- 
dicated in the preceding paragraph. With this end in view the first task is to name and discuss briefly the characters of plums whereby species and varieties are distinguished, with a statement, so far as present knowledge permits, of the variability of the different characters. It is absolutely essential that the plum-grower have knowledge, especially if he aspires to improve the fruit by breeding, of the characters of the plants with which he is to work. These are in the main as follows:

All species and some horticultural varieties have more or less characteristic trees. Making due allowance for environment-food, moisture and light-many plum groups can be readily distinguished by the general aspect of the plant. Of the gross characters of trees, size is usually most characteristic. A species, for example, is either shrubby or tree-like. Yet under varying environment, size of plant and of the parts of the plant, are probably the first to change. Habit of growth is nearly as important as size and varies but little under changing conditions. A species or variety may be upright, spreading, drooping or round-topped in growth; head open or dense; the tree rapid or slow-growing. Hardiness is a very important diagnostic character, plums being either hardy, half-hardy or tender. Both species and varieties respond in high degree to the test of hardiness, the range for varieties, of course, falling within that of the species. Productiveness, regularity of bearing, susceptibility to diseases and insects, and longevity of tree are all characters having value for species and varieties and with the exception of the first named, are little subject to variation.

The thickness, smoothness, color and manner of exfoliation of the outer bark and the color of the inner bark have considerable value in determining species but are little used in determining horticultural groups. It is well recognized that all plums have lighter colored bark in the South than in the North. The branches are very characteristic in several species. The length, thickness and rigidity of the branch and the length of its internodes should be considered, while the direction of the branch, whether straight or zigzag, are very valuable determining characters and relatively stable ones, seeming to change for most part only through long ranges of climatic conditions. So, too, the arming of a branch with spines or spurs and the structure of such organs are important. The color, smoothness, amount of pubescence, direction, length, thickness and the appearance of the lenticels, the presence of excrescences on the branchlets of the first and second year's growth and the branching angle, are all worthy 


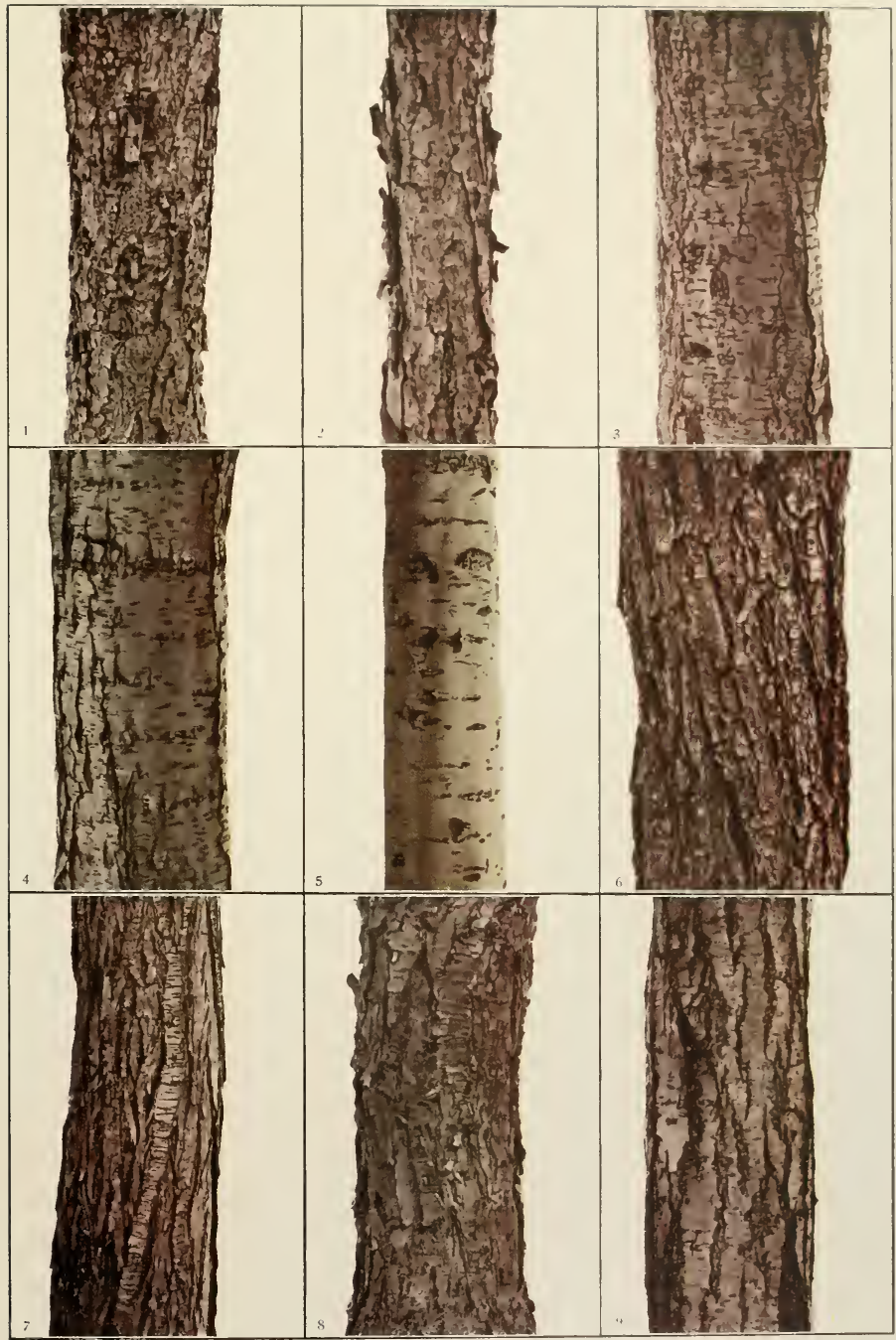

1. P. HORTELAN.A MINERI

2. P. AMERICANA

3. I'. CERISIFER.A
1. P. DOMESTICA

5. I. INSITITI.1

(i. I'. HORTILAI
7. I. MUNisting

8. I". NICIRI

9. I'. TRIFLOR.1 

of consideration though quite too much has been made of these characters, especially of pubescence, in determining species, for they are all extremely variable.

The size, shape and color of leaf-buds and of their outer and inner scales and the margins of the scales differ in different species. Possibly the most evident, and therefore readiest means of identifying species, at least, is by the leaves. It is true that leaves are very variable but always within limits, and either individually or collectively in giving the general aspect to a tree they are characteristic. Modifications of leaves most often occur in very young plants, those growing in bright sunshine or deep shade and on sprouts or suckers, but none of these are usually sufficient to mislead as to species. Leaf-size and leaf-form are the first characters to be noted in determining a plum but these are closely followed in value by leaf-color, leaf-surface, leaf-thickness and leaf-margin. Leaf-size is variable, depending much upon the conditions noted above but leaf-form varies but little in the several species. So, too, the color of leaves is very constant throughout a species, for both surfaces, though impossible to describe accurately in words and very difficult to reproduce in color-printing. Therc is a marked difference in autumnal tints not only of species but of varieties but these are not very constant in any one location and must vary greatly under different environments. The thickness of the leaves of the several species is a distinctive character. Species of plums have very different leaf-surfaces as regards reticulation, rugoseness, pubescence and coriaceousness, all of these characters being quite constant, though it is to be noted that roughness of leaves and pubescence are increased by exposure to the sun and by the influence of some soils. There is, indeed, considerable variation in the pubescence of the leaves of all species of plums in different parts of the country and probably too much has been made of pubescence as a determining character.

The margins of leaves are very characteristic of species and scarcely vary under normal conditions if the teeth at the middle of the sides be taken rather than those toward the base or apex, these very often being crowded, reduced or wanting. The presence of glands, their position, size, shape and color, help to characterize several species and seem to be fairly constant guides. Some species and a great number of varieties have the distinguishing marks of gland-like prickles tipping the serrations in the leaf-margins. Length, thickness, rigidity and pubescence of petiole have some taxonomic value. Stipules usually offer no distinguishing marks other than those mentioned under leaves. 
The blossoms of plums are very characteristic, giving in flowering time a distinctive aspect to all species and distinguishing some horticultural varieties. The flowers of all the species are borne in clusters, differing in number of individuals, according to the species; so, too, the flowers in the different species vary in size, color, in length of their peduncles, and in pubescence, especially of the calyx. Flower-characters are constant, taking them as a whole, yet there are some variations that must be noted. One of the most marked of these is in the time of appearance of the flowers; in the South they appear before the leaves but in the North with the leaves. On the grounds of this Station there are notable exceptions to the latter statement, with varieties of species showing considerable variation in this regard. There are some remarkable variations within species as regards size and color of the corolla and glands and pubescence of the calyx, depending upon the environment of the plant; but on the whole these characters are very constant. The fragrance of the flowers of plums varies from a delicate, agreeable odor to one that is quite disagreeable in some species as in Americana; the odor seems to be a constant character.

Of all structures of the plum the fruit is most variable, yet fruits are sufficiently distinct and constant, especially within species, to make their characters very valuable in classification. Species, whether wild or cultivated, may be distinguished in greater or less degree by the period of ripening of the fruits, though in this regard the cultivated varieties of the several species vary greatly and in the wild state trees of native plums in the same locality, even in the same clump, may vary in ripening as much as from two to four weeks. Species are distinguished by size, shape, color, flesh, flavor and pit among the grosser characters of the structure and by amount of bloom, stem, cavity, apex, suture and skin among the minor characters. The fruit is usually the first part of the plant to respond to changed conditions.

Characters derived from seed structures are generally accounted of much value by botanists in determining species. Such is the case with plums. This Station has a collection of stones of over three hundred cultivated varieties of plums and some specimens of nearly all the different species. The stones illustrated in the color-plates in this book show that this structure is quite variable in size, shape, in the ends, surfaces, grooves and ridges, even within a species; nevertheless in describing the several hundred forms of plums for The Plums of New York the stone has been quite as satisfactory, if not the most satisfactory, of any of the organs of this plant for distinguishing the various species and varieties. 
The reproductive organs of plums afford several charactcrs and would seem to offer means of distinguishing botanical and horticultural groups, but they are so variable in both cultivated and wild plants as to be very misleading. Not only do these organs differ very often in structure but also in ability to perform their functions. Bailey' has called attention to the remarkable self-sterility of some varieties of the native species of plums, due to the impotency of the pollen upon flowers of the same variety. C. W. H. Heideman ${ }^{2}$ made some very interesting observations on what he considers distinct forms of the flowers of the Americana plums, describing for this species all of the six possible variations of flowers enumerated by Darwin in his Different Forms of Flowers in Plants of the Same Species. Heideman thinks that other species of Prunus exhibit similar variations. Waugh ${ }^{3}$ made the pollination of plums a subject of careful and extended study and found much variation in the pistils of plants of the same species, insufficient pollen in some plants, pollen impotent on the stigma of the same flower, and considerable difference in the time of maturity of pollen and stigma in some plums, especially the Americana plums. These variations, most important to the plum-grower, are of more or less use in identifying plums.

After the discussion of the characters of plums we may pass to a detailed description and discussion of the species of plums which now contribute or may contribute cultivated forms to the pomology of the country either for their fruits or as stocks upon which to grow other plums. The following conspectus shows as well as may be the relations of the species of plums to each other.

\section{CONSPECTUS OF SPECIES OF PLUMS.}

A. Flowers in clusters of $\mathrm{I}$ or 2. (Three in P. triflora.) Old World plums

B. Leaves drooping.

C. Shoots and pedicels pubescent.

D. Flowers mostly in twos.

E. Fruits large, more than $I$ inch in diamctcr, variable in shape, often compressed; tree large; stamens about $30 \ldots \ldots \ldots \ldots \ldots \ldots$ r. P. domestica.

E.E. Fruit small, less than $I$ inch in diameter, uniformly oval or ovoid; stamens about 25 ; tree small, compact.........., ... 2. P. insititia.

${ }^{1}$ Bailey, L. H. Cornell Sta. Bul. 38:43. 1892 .

${ }^{2}$ Heideman, C. W. H. Minn. Hort. Soc. Rpt. 187.1895.

Waugh, F. A. Vt. Sta. Bul. 53. 1896. 
D.D. Flowers mostly single.

E. Leaves small, less than 2 inches in length; sometimes a tree; very thomy ........ 3. P. spinosa.

E.E. Leaves large, more than $2 \frac{1}{2}$ inches in length; a shrub; thorns few .......... 4. P. curdica.

C.C. Shoots glabrous or soon becoming so, pedicels glabrous.

D. Pedicels shorter than the calyx-cup; leaves glabrous or sparsely pubescent on the under side along the rib; flowers in pairs.............. P. cocomilia.

D.D. Pedicels more than twice as long as the calyx-cup.

E. Flowers mostly single; leaves hairy along the midrib on the under side; petiole $\frac{1}{5}$ as long as the leaf-blade; a tree............. 6 . P. cerasifera.

E.E. Flowers in threes; leaves glabrous, petiole shining, leaf-margins finely and closely serrate, teeth glandular-pointed; stamens about $25 \ldots 7$. P. monticola. E.E.E. Flowers in threes; leaves glabrous, often shining, leaf-margins finely and closely serrate, teeth glandular-pointed; stamens about $25 \ldots 8$. P. triflora.

B.B. Leaves upright, peach-like, glabrous, veins very conspicuous, under side barbate at axils of veins; separated from all other plums by the leaf-characters and by the large, flattened, brick-red fruits 9. P. simonii.

A.A. Flowers in clusters of 3 or more, rarely 2. American plums.

B. Plants trees. ( $P$. any ustifolia ra rely a tree.)

C. Leaves broad, mostly ovate or obovate.

D. Leaves long-ovate or long-obovate.

E. Flowers white.

F. Leaf-serrations glandless, acute; petiole usually glandless; calyx-lobes entire, glabrous on the outer, pubescent on the inner surface; stamens about 30 ; stone turgid, la rge, pointed at the apex..... ro. P. americana.

F.F. Leaf-serrations glandular, wavy-crenate; petioles glandular; calyx-lobes glandular-serrate, pubescent on the inner surface; stamens about 20; stone turgid, small, prolonged at the ends... Ir. P. hortulana.

E.E. Flowers fading to pink.

F. Leaf-serrations coarse, rounded, glandular only when young; petioles biglandular; calyx-lobes glandular-serrate, not pubescent on the inner surface; stamens about 30 ; fruit red; bloom light; stone flat. . . . . . . . . . .

F.F. Leaf-serrations fine, acute, glandular-pointed; petioles biglandular; calyxlobes entire, pubescent on the outer, tomentose on the inner surface; fruits dark purple; bloom heavy; stone turgid, acute at the ends............ 13. P. alleghaniensis. 
D.D. Leaves round-ovate, obtusely, sometimes doubly serrate; petioles glandless; calyx-lobes pubescent on both surfaces; fruit dark red or purplish; stone turgid, pointed at both ends.................. P. subcordata.

C.C. Leaves narrow, lanceolate-ovate.

D. Leaves flat.

E. Leaves glabrous; fruits globular, usually purple at maturity but sometimes red or orangered; bloom thin; stone turgid, cherry-like.....15. P. umbellata.

E.E. Leaves pubescent.

F. Stone acute at both ends; fruit purple.r6. P. mitis.

F.F. Stone rounded at base; fruits variously colored ................. . P. tarda.

D.D. Leaves more or less folded upward.

E. Fruits small, $\frac{1}{2}$ inch in diameter, cherry-like; leaves lanceolate, upper surface glabrous, lustrous, lower surface pubescent in axils of veins, marginal teeth glandless; petioles biglandular; stone small, ovoid, turgid, cherrylike; rarely a tree; tender in New York.....18. P. angustifolia.

E.E. Fruits large, an inch in diameter, plumlike; leaves lanceolate, peach-like, upper surface glabrous, lower surface pubescent along the midrib; petioles with from 1 to 6 glands; stone compressed and pointed at both ends; usually a tree; hardy in New York......... . . P. munsoniana

B.B. Plants shrubs.

C. Fruits dark purple.

D. Leaves ovate, acute, finely serrated; shoots becoming glabrous; stones pointed at both ends........... P. maritima.

D.D. Leaves oval-orbicular, crenate-serrate; shoots usually pubescent; stone pointed only at the base..21. P. gravesii.

C.C. Fruits red or orange, sometimes yellow but never deep purple.

D. Fruits large, 1 inch in diameter; leaves oblongovate, long-pointed, margin serrate with incurved sometimes glandular teeth, upper surface glabrous, lower surface pilose; petiole with 1 or 2 glands; stone oval, flattened ....................

D.D. Fruits small, $\frac{1}{2}$ inch in diameter.

E. Leaves small, ovate-lanceolate or oval, margins finely and evenly serrate, upper surface glabrous, lower surface soft pubescent; petioles short and stout; fruits variable in color, mostly red; stone turgid, pointed at both ends....2.2. P. gracilis.

E.E. Leaves oblong-ovate, margins coarsely or doubly serrate, glabrous above and sparingly pubescent below; petiole glandular; fruits cherry-red. . . . . . . P. rivularis. 


\section{PRUNUS DOMESTICA Linnaeus}

1. Linnaeus Sp. $P l$. 475. 1753. 2. Duhamel Traite des Arb. 2:93, 95, 96. 1768. 3. Seringe DC. Prodr. $2: 533.1825 . \quad$ 4. Hooker Brit. Fl. $220 . \quad 1830 . \quad$ 5. London Arb. Fr. Brit. $1844 . \quad 6$. De Candolle Or. Cult. Pl. 212.1885 . 7. Schwarz Forst. Bot. $33_{8}$. 1892. 8. Koch, W. Syn. Deut. und Schw. Fl. 1:727. 1892. 9. Dippel Handb. Laubh. 3:636. 1893. 10. Lucas Handb. Obst. 429. 1893. 11. Waugh Bot. Gaz, 26:417-27. 1898. 12. Bailey Cyc. Am. Hort. 1448, 1901. 13. Waugh Plum Cult. 14. 1901. 14. Schneider Handb. Laubh. 1:630. 1906.

P. communis domestica. 15. Hudson Fl. Anglic. 212. 1778. 16. Bentham Handb. Brit. Fl. $1: 236.1865$.

P. aconomica (in part) and $P$. italica (in part). 17. Borkhausen Handb. Forstb. 2:1 $401,1409$. 1803. 18. Koch, K. Dend. 1:94, 96. 1869. 19. Koehne Deut. Dend. 316. x893.

Tree reaching a height of 30 or 40 feet, vigorous, open-headed, round-topped; trunk attaining a foot or more in diameter; bark thick, ashy-gray with a tinge of red, nearly smooth or roughened with transverse lines; branches upright or spreading, straight, stout and rigid, usually spineless; branchlets usually pubescent, light red the first year, becoming much darker or drab; lenticels small, raised, conspicuous, orange.

Winter-buds large, conical, pointed, pubescent, free or appressed; leaves large, ovate or obovate, elliptical or oblong-elliptical, thick and firm in texture; upper surface dull green, rugose, glabrous or nearly so, the lower one paler with little or much tomentum, much reticulated; margins coarsely and irregularly crenate or serrate, often doubly so, teeth usually glandular; petioles a half-inch or more in length, stoutish, pubescent, tinged with red; glands usually two, of ten lacking, sometimes several, globose, greenishyellow; stipules very small, less than a half-inch, lanceolate, narrow, serrate, early caducous.

Flowers appearing after or sometimes with the leaves, showy, an inch or more across, greenish-white to creamy-white; borne on lateral spurs or sometimes from lateral buds on one-year-old wood, 1 or 2 from a bud in a more or less fascicled umbel; pedicels a half-inch or more in length, stout, green; calyx-tube campanulate, glabrous or pubescent, green; calyx-lobes broadly oblong, obtuse, pubescent on both surfaces, glandular-serrate, usually reflexed; petals white or creamy in the bud, oval to obovate, crenate, notched or entire, claw short and broad; stamens about 30 , equal to or shorter than the petals; anthers yellow, sometimes tinged with red; pistils about as long as the stamens, glabrous or pubescent.

Fruit of various shapes, mostly globular or sulcate, of ten necked, blue, red or yellow; stem a half-inch or more long, stout, pubescent; cavity shallow and narrow; apex variable, usually rounded; suture prominent or sometimes but a line or indistinct; skin variable; dots small, numerous, inconspicuous; flesh yellowish, firm, meaty, sweet or acid and of many flavors; stone free or clinging, large, oval, flattened, blunt, pointed or necked, slightly roughened or pitted; walls thick; one suture ridged-the other grooved.

Beside the comparatively well-known groups of Domestica varieties, there are in Europe, with an occasional representative in America, especially in herbaria, numerous other groups either a part of Prumus domestica 


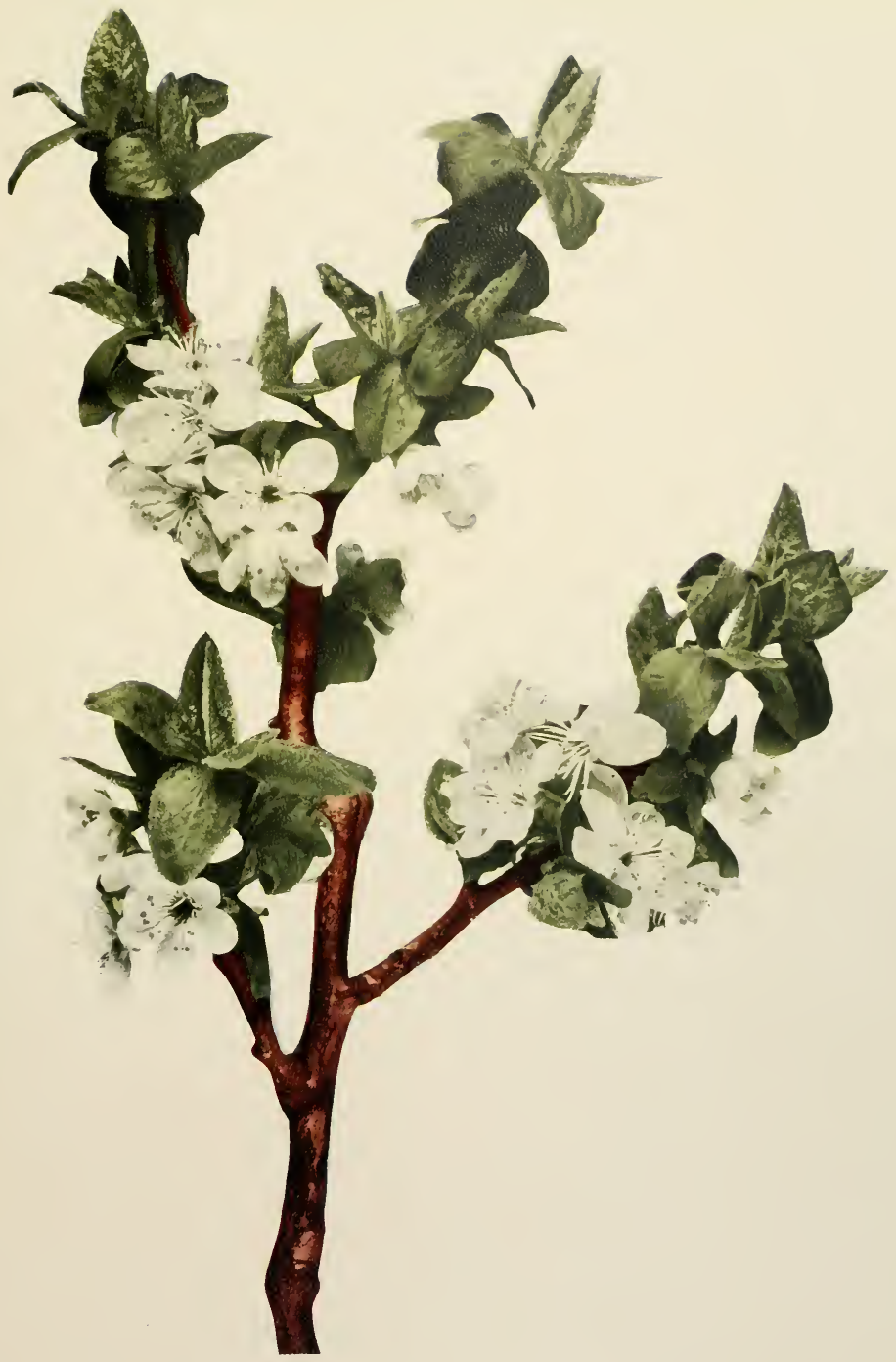



or possibly, in a few cases at least, hybrids betwcen it and other species. European botanists place some of these in distinct species or sub-species; but few, however, even of the recent writers on the botany of the plum, agree at all closely as to the disposition of these edible and ornamental plums which may be doubtfully referred to Prumus domestica. With this disagreement between the best European authorities where thesc plums have long been known, where some of them have originated, and all may be found in orchards, botanic gardens and herbaria, it does not seem wise at this distance to attempt a discussion of such doubtful forms. It is certain, however. that Borkhausen's Prumus italica and Prumus aconomica, as given in the synonymy, are but parts of Prumus domestica, the first including the Reine Claude plums and the latter the various prunes. So, too, a wild form named by Borkhausen, Prumus sylvestris, is probably a part of Prunus domestica.

Bechstein' gave specific names to a number of plums which Schneider ${ }^{2}$ holds are all cultivated forms of Prunus domestica. These names are not infrequently found in botanical and pomological literature, to the great confusion of plum nomenclature. The following are Bechstein's species:Prunus exigua, Prunus rubella, Prumus lutea, Prumus oxycarpa, Prunus subrotunda and Prunus vinaria.

The plum in which the world is chiefly interested is the Old World Prunus domestica. The Domestica plums are not only the best known of the cultivated plums, having been cultivated longest and being most widely distributed, but they far surpass all other species, both in the quality of the product and in the characters which make a tree a desirable orchard plant. How much of this superiority is due to the greater efforts of man in domesticating the species cannot be said, for the natural history of this plum, whether wild or under cultivation, is but poorly known. It is not even certain that these plums constitute a distinct species, there being several hypotheses as to the origin of the Domestica varieties. Three of these suppositions must be considered.

Many botanists hold that what American pomologists call the species is an assemblage of several botanical divisions. The early botanists distributed these plums in botanical varieties of one species. Thus Linnaeus, in 1753, divided Prunus domestica into fourteen sub-species, and Seringe, in ${ }^{825}$, made eight divisions of the species. Both of these men include

${ }^{1}$ Bechstein Forstbot. Ed. 5. 424. 1843 .

'Schneider, C. K. Hand. Laub. 631. 1 go6. 
in this species, among others, plums which we now place in Prunus cerasifora, the Cherry plums, and Prumus insititia, the Damsons and Bullaces. Nearly all subsequent botanists who have not made two or more species of it have recognized from two to several sub-divisions of Prunus domestica. It is possible that what are called the Domestica plums should be distributed among several botanical divisions. But it is difficult to find any differential character sufficiently constant to distinguish more than one species for the several hundred varieties of these plums now under cultivation. Nor are there any cleavage lines sufficiently distinct to indicate that the edible varieties of the one species should be sub-grouped.

In coming to these conclusions the writer has studied about three hundred varieties of Domestica plums growing on the grounds of this Station and about half as many more growing in other parts of the country, the whole number representing all of the various species and sub-species which other workers have made. The differences which have been most used to classify the varieties of Domestica in several botanic divisions have to do chiefly with the fruit, as size, shape, color and flavor, characters so modified by cultivation and selection that they are artificial and transitory and of little value in botanical classification. Moreover, the botanical groups which have been founded on these characters are much more indistinct than ordinarily in botany because of the merging at many points of one group into another. This indistinctness is greatly increasing year by year through the intercrossing of varieties. When the characters of no value to man, and, therefore, little modified by cultivation, are considered, it is scarcely possible logically to place Domestica plums in more than one species or to further sub-divide the one species.

The botanists who have divided the Domestica plums into either greater or lesser botanical groups do not define their divisions with sufficient accuracy to make them clearly recognizable. Neither do they give the habitats of the wild progenitors with sufficient certainty to carry conviction that the groups were brought under cultivation from separate ancestors. Also, the several botanists who hold to the multiple species theory for the Domestica plums do not agree as to the limits of the different groups and give to them very different specific or variety names, showing that they have widely different ideas as a basis for their classification.

A second theory is that Prumus domestica is derived from Prunus spinosa and that Prumus insititia is an intermediate between the two.'

${ }^{1}$ Bailey, L. H. Cyc. Am. Hort. 1447. I901; Hudson Fl. Anglic. 212 , 1778. 
This hypothesis is based upon the supposition that when Domestica plums run wild they revert to the Insititia or Spinosa form. It is not difficult to test this theory. A study of the origin of the several hundred Domestica and Insititia plums discussed in Chapters III and IV of The Plums of New York does not show for any one of them a tendency to reversion or evolution to other species; nor do the descriptions indicate that there are many, if any, transitional forms. During the two thousand years they have been cultivated in Europe the Old World plums have been constant to type. Domestica seedlings vary somewhat but they do not depart greatly from a well marked type. Such very few striking departures as there seem to be are more likely to have ariscn through crossing with other species than through reversion or evolution. This Station has grown many pure seedlings or crosses of varieties of Domestica within the species and has had opportunity of examining many more from other parts of the State, and none of these show reversion to the other two Old World species. Nor, as we shall see, is there much in what is known of the history of these three species to lead to the belief that the Domestica, Insititia and Spinosa plums constitute but one wild species or have arisen from one.

It has been remarked that there are few, if any, transitional forms between the Domestica and other European plums. It is a significant fact that Prumus domestica can be hybridized with other species of plums only with comparative difficulty, species of plums as a rule hybridizing very freely. This is as true with the Insititia and Spinosa as of other plums, there being few recorded hybrids of either of these species with the one under discussion. Quite to the contrary the varieties of the several pomological groups of Domestica plums hybridize very freely. If all were of one species we should expect many hybrids between the Domestica, Insititia and Spinosa plums.

We are now left with the third hypothesis, which is, as we have indicated in a preceding paragraph, that the varieties of Domestica plums belong to one species; or if they have come from more than one species the wild forms have not been distinguished and must have grown under much more nearly similar conditions than is the case with Prunus domestica and any other species. Without knowledge of more than one wild form, and in view of the intercrossing of the varicties of these plums it seems best to consider all as parts of one species, leaving to the pomologist the division of the species into horticultural groups founded on the characters which make the fruit valuable for cultivation. 
Assuming, then, that the plums known in pomology as Domestica plums belong to one species, the original habitat of the species may be sought. In spite of the great number of varieties of plums now grown in Europe and western Asia, and the importance of the fruit both in the green and dried state, the history of the plums cannot be traced with much eertainty beyond two thousand years. Though stones, without doubt those of the Insititia or Damson and the Spinosa or Blackthorn plums, are found in the remains of the lake dwellings in central Europe ${ }^{1}$ the pits of Domestica plums have not yet come to light. In the summer of 1909 the writer, in visiting historic Pompeii, became interested in the illustrations of fruits in the frescoes of the ancient buildings, but neither in the houses of the ruined eity nor in the frescoes in the museums in Naples could he find plums, though several other fruits, as apples, pears, figs and grapes were many times illustrated. An examination of the remains of plants preserved in the museum at Naples taken from under the ashes and pumice covering Pompeii gave the same results. No stone-fruits were to be found, though if widely used these should have been on sale in the markets of Pompeii at the time of the destruction of the eity, which occurred late in August, - the very time of the year at which the examination was made and at which time plums were everywhere for sale in Rome. This observation is but another indication that plums were not well-known before the beginning of Christianity, since Pompeii was destroyed in $79 \mathrm{~A}$. D. In Greek literature the references to plums are few before the Christian era and these are more likely to some form of Insititia, as the Damsons, rather than to the Domesticas.

Pliny gives the first clear account of Domestica plums and speaks of them as if they had been but recently introduced. His account is as follows:" "Next comes a vast number of varieties of the plum, the particolored, the black, the white, the barley plum, so-called beeause it is ripe at Barley harvest, and another of the same color as the last, but which ripens later, and is of a larger size, generally known as the 'Asinina,' from the little esteem in which it is held. There are the onychina, too, the cerina,-more esteemed, and the purple plum; the Armenian, also an exotic from foreign parts, the only one among the plums that recommends itself by its smell. The plum tree grafted on the nut exhibits what we may call a piece of impudence quite its own, for it produces a fruit that has all the appearance of the parent stock, together with the juice of the

\footnotetext{
${ }^{1}$ Heer Pflanz. Pfahlb. 27 , fig. 16.

${ }^{3}$ Bostock and Riley Nat. Hist. of Pliny $3: 294$. IS92.
} 
adopted fruit; in consequence of its being thus compounded of both, it is known by the name of 'nuci-pruna.' Nut-prunes, as well as the peach, the wild plum and the cerina, are often put in casks and so kept till the crop comes of the following year. All the other varietics ripen with the greatest rapidity and pass off just as quickly. More recently; in Baetica, they have begun to introduce what they call 'malina,' or the fruit of the plum engrafted on the apple tree, and 'amygdalina,' the fruit of the plum engrafted on the almond tree, the kernel found in the stone of these last being that of the almond. Indeed, there is no specimen in which two fruits have been more ingeniously combined in one. Among the foreign trees we have already spoken of the Damascene plum, so-called from Damascus, in Siria, but introduced long since into Italy, though the stone of this plum is larger than usual, and the flesh small in quantity. This plum will never dry so far as to wrinkle; to effect that, it needs the sun of its own native country. The myxa, too, may be mentioned as being the fellow countryman of the Damascene; it has of late been introduced into Rome and has been grown engrafted upon the sorb."

While the records are somewhat vague it is probable that the Domestica plums came from the region about the Caucasus Mountains and the Caspian Sea and especially the section east of these mountains and the sea. What seems to be the wild form of this species has been found by several botanists in this great region.' Here the Huns, Turks, Mongols and Tartars, flowing back and forth in tides of war-like migration, maintained in times of peace a crude agriculture probably long before the Grceks and Romans tilled the soil. The plum was one of their fruits and the dried prune a staple product. Here, still, to the east, west and north toward central Asia, plums are among the common fruits and prunes are common articles of trade. Even in the fertile oases of the great central Asian desert, plums are cultivated, but whether domesticated here or brought from elsewhere cannot be told. Koch, ${ }^{2}$ speaking of prunes in particular, gives the following account (translated) of their Asiatic origin:

"According to my investigation Turkestan and the southern Altai Mountains are the place of origin. When in the year 1844 I found myself in Baku on the west coast of the Caspian Sea, I had plenty of opportunity to draw accounts of the fruits of their native lands from the Turkestan and Bokharan merchants, and was astonished over the high cultivation of stone fruits in these places - at the same time I was able to taste dried the most choice because best flavored, the Ali-Bokhara, that is Bokhara

1 Koch, K. Dend. 1:94. 96. 1869. Ledebour. Fl. Ross. 2:5. 1829. Boissier. Fl. Oricnt. 2:652

2 Koch, K. Deut. Obst. I 4 6. 1876 . 
prune. Some of these Bokharan prunes were transplanted a long time ago to Trans-Caucasia and were especially cultivated in the ancient city and residence of the Ruler of the modern Elizabethpol. Unfortunately the cultivation is less now than in earlier times. A further spread toward the west and toward Europe, I have not been able to follow. In Greece, the prunes are even to-day an unknown fruit."

At about the time Pliny wrote, or somewhat before, communication had been opened between the Romans and the countries about the Caspian Sea, and a few centuries later the devastating hordes of Asiatics came westward and for several centuries continued to pour into eastern Europe. What more probable than that they should have carried dried prunes as an article of food in the invasions, and eventually, as they made settlements here and there, have introduced the trees in Europe. It is certain, at any rate, as we shall see, that several of the groups of cultivated plums trace back to the Balkan countries of Europe and the region eastward. There, now as then, the plum is a. standard fruit and prune-making a great industry.

The plum when first known in Europe, as described by Pliny and other early writers, seems to have been a large and well-flavored fruit, indicating that it had been under cultivation for a long while. This, and the fact that the fruit was not known by the earliest writers on agriculture, indicate that the plum was not originally an inhabitant of southern Europe, as some suppose. It is likely that the tree has escaped from cultivation and become naturalized in the localities where it is now supposed to grow wild. Prumus domestica has not been found wild nor under cultivation in eastern Asia, so far as can be learned by the botanical and horticultural explorers of China and nearby regions, Prumus triflora being the domesticated plum of that part of the continent, though it may well be surmised that some of the Domestica plums are cultivated in western China, a region as yet but imperfectly explored for its plants.

Having briefly sketched the origin of the Domestica plums in the Old World we may now consider their history in the New World-a more satisfactory task, as data are abundant and reliable.

The Domestica plums are valuable food-producing trees in America but have not attained here the relative importance among fruits that they hold in Europe. From the earliest records of fruit-growing in the New World the plum has been grown less than the apple, pear, peach or cherry, while in Europe it is a question if it does not rank first or second among the tree-fruits. The comparatively restricted area which the 
Domestica plums now occupy in America is due, perhaps, to the fact that they do not possess in as high degree as the fruits named above the power of adaptation to the trans-Atlantic environment. Without question the feature of environment most uncongenial to plums in America is the climate. The plum thrives best in an equable climate like that of eastern and southern Europe and of western America, and cannot endure such extremes of heat and cold, wet and dry, as are found in parts of eastern America and in the Mississippi Valley. At best this fruit lacks in what is called constitution, or ability to withstand adverse conditions of any kind, whether of climate, culture, insects or fungi. Thus in America this plum suffers severely not only from climate but from several parasites, as curculio, black-knot, leaf-blight, plum-pockets and other pests.

We find, therefore, that in North America the Domestica plums are confined to favored localities on the Atlantic seaboard, the Great Lakes region and the Pacific coast. In the first named area they are to be found thriving to a limited degree in Nova Scotia and parts of Quebec, somewhat in central New England, and particularly well in the fruitgrowing sections of New York, especially in the parts of this State where the climate is made equable by large bodies of water. South of New York, excepting in a few localities in Pennsylvania, but few plums of this species are grown. The Domestica plums are grown with indifferent success in southern Ontario and in Michigan, and now and then an orchard is found to the south almost to the Gulf. In the great Valley of the Mississippi and in the states of the plains this plum is hardly known. Westward in the irrigated valleys of the Rocky Mountains and the Great Basin, the climate is favorable and the European plums are nearly as well-known as in any other portion of the continent excepting the Pacific Coast.

It is in the last named region that the foreign plum reaches its highest development in the New World. The trees in California, Oregon and Washington are very thrifty and the plums are of large size, handsome appearance and of high quality. Both tree and fruit in this farored region are free from most of the insect and fungus troubles with which the eastern plum-growers must contend. Curculio and black-knot, scourges of eastern orchards, are not troublesome on the western coast. In this region the Domesticas, practically the only plums cultivated, succeed on either irrigated or naturally watered lands.

It is probable that some of these plums were introduced into America by the first colonists, but if so, the early records do not show that the fruit 
was much grown in this country until toward the end of the Eighteenth Century. Certainly during the first two centuries of colonization in the New World there were no such plum plantations as there were of the apple, pear and cherry. Among the first importations of plums were those made by the French in Canada, more particularly in Nova Scotia, Cape Breton, Prince Edward Island and in favored situations such as the L'Islet County and the Island of Montreal bordering and in the St. Lawrence River.

Peter Kalm in his Travels into North America in $177 \mathrm{I}$ records the culture of plums as far north as Quebec with the statement that "Plum trees of different sorts brought over from France succeed very well here," adding further, "The winters do not hurt them." 1 There are other records to show that the French, always distinguished for their horticultural tastes, if not the first to grow this fruit in America, at least began its culture at a very early date.

In the voyages undertaken for exploration and commerce soon after the discovery of America by Columbus the peach was introduced in America by the Spanish; for soon after permanent settlement had been made in the South the settlers found this fruit in widespread cultivation by the Indians and its origin could only be traced to the Spaniards who early visited Florida and the Gulf region. William Penn wrote as early as 1683 that there were very good peaches in Pennsylvania; " not an Indian plantation was without them." " The abundance of this fruit was noted by all the early travelers in the region from Pennsylvania southward and westward but though the wild plums are often mentioned there are no records of cultivated plums until the colonies had long been established.

In Massachusetts some plums were planted by the Pilgrims, for Francis Higginson, writing in 1629 , says: "Our Governor hath already planted a vineyard with great hope of increase. Also mulberries, plums, raspberries, corrance, chestnuts, filberts, walnuts, smalnuts, hurtleberries." s The plums were Damsons, as a statement is made a little later that the "Red Kentish is the only cherry and the Damson the only plum cultivated." A further reference to this plum is made by John Josselyn, when, writing of a voyage to New England in $166_{3}$, he says, "The Quinces, Cherries,

\footnotetext{
${ }^{1} \mathrm{Kalm}$, Peter Travels into North America 3:2 +0. $177 \mathrm{x}$.

${ }^{3}$ Watson's Annals of Philadelphia $\mathbf{1}: 17$. $18+4$.

${ }^{3}$ Mass. Hist. Soc. Collections, Ist Ser. r:1 18.
} 
Damsons, set the dames a work, marmalad and preserved Damsons is to be met with in every house."

In 1797 there is the following concise account of the plums cultivated in New England:2

"The better sorts which are cultivated are the horse plum, a very pleasant tasted fruit, of large size; the peach plum, red toward the sun, with an agreeable tartness; the pear plum, so-called from its shape, which is sweet, and of an excellent taste; the wheat plum, extremcly sweet, oval, and furrowed in the middle, not large; the green-gage plum, which is generally preferred before all the rest."

A search in the colonial records of Pennsylvania, New Jersey and Delaware shows no records of cultivated plums in these states until the establishment of the Bartram Botanic Garden near Philadelphia in $I_{72} 8$. Here John Bartram grew fruits, trees and flowers of many kinds received through exchanges of indigenous species with European correspondents. Among the plants sent over from Europe to Bartram were several varieties of plums which were propagated and distributed throughout Pennsylvania and nearby provinces. It must not be supposed, however, that the Domestica plums had not been grown in Pennsylvania previous to Bartram's time. The plum grows fairly well in localities of this region, and without question it had been planted by the early colonists with seeds brought from across the sea. But the absence of references to the plum, where they abound to the apple, pear, peach, quince and cherry, shows that this fruit was not much cultivated by the Quakers and Swedes who settled in the three states watered by the Delaware.

In the southern colonies the Domestica plums grow but poorly, and as the early settlers of these states were chiefly concerned with tobacco and cotton, paying little attention to fruits, we should expect the plum to have been neglected. Then, too, the peach, escaped from the early Spanish settlements, grew spontaneously in many parts of the South, furnishing, with the wild plums of the region, an abundant supply of stonefruits. Yet the plum was early introduced in several of the southern colonies.

Thus Beverly," writing in I $^{2} 22$ of Virginia, says: "Peaches, Nectarines and Apricocks, as well as plums and cherries, grow there upon standard

\footnotetext{
${ }^{1}$ Josselyn, John, Gent. New England Raritics London. 1672.

-Samuel Deane, D.D. The New England Farmer or Georgical Dictionary 265. 1797.

severly, Robert History of Virginia 279. 1722. Reprint $18<5$.
} 
trees," with the further statement that these fruits grew so exceedingly well that there was no need of grafting or inoculating them. Lawson, in his history of North Carolina, written in I7I4, says that the Damson, Damazeen and a large, round, black plum were the only sorts of this fruit grown in that state in $17 \mathrm{I} 4$.

In South Carolina Henry Laurens, who should be accounted a benefactor not only of that State but of the whole country as well, about the middle of the Eighteenth Century grew in Laurens Square in the Town of Amonborough all the plants suitable to that climate that widely extended merchantile connections enabled him to procure. Thus among fruits he grew olives, limes, Alpine strawberries, European raspberries and grapes, apples, pears and plums. John Watson, one of Laurens' gardeners, planted the first nursery in South Carolina. His plantation was laid waste in the Revolution, though it was afterwards revived by himself and his descendants and was still further continued by Robert Squib. The plum in several varieties was largely grown and distributed from this nursery.

Charleston, South Carolina, was at the beginning of the Nineteenth Century the southern center of horticultural activities and the European plum was widely distributed from here at this time. Of the several botanic gardens, really nurseries, in Charleston, one was conducted by André Michaux who was sent by the French Government in 1786 to collect American plants. Another was owned by John Champneys at St. Pauls, near Charleston, and was managed by a Mr. Williamson who grew all of the species of trees, fruits and shrubs, native and foreign, which could be procured. ${ }^{2}$ The third of these gardens was owned by Charles Drayton at St. Andrews in which not only exotic fruits were grown but those of the region as well. The plum trees frequently mentioned in the records of the time as growing in this region came from these nurseries.

In Florida, as has been stated, the peach was introduced by the Spanish explorers, but if the plum were also planted by the Spaniards it quickly passed out with the cessation of cultivation. But later there are records ${ }^{3}$ of this and nearly all of the fruits of temperate and sub-tropic climates having been grown at St. Augustine and Pensacola. In the remarkable colony founded by Dr. Andrew Turnbull at New Smyrna, Florida, in

${ }^{1}$ Lawson, John History of North Carolina 110. 1714 .

2 Ramsey's History of Sowh Carolina 2:128, 129, Ed, $185^{8}$.

${ }^{3}$ Forbes, James Grant Sketches of the Floridas 87, 91, 170. 1821 .

4 In 1763 Dr. Andrew Turnbull established a colony of fifteen hundred Greeks and Minorcans at New Smyrna, Florida, for the cultivation of sugar and indigo. But they cultivated other plants 
$\mathbf{I}_{7} 6_{3}$, the plum was one of the fruits cultivated. It is not probable, however, that the culture of this fruit was ever extensive in Florida as it does not thrive there.

William Bartram, son of John Bartram the founder of the Bartram Botanic Garden, set out on a botanical expedition through the Southern States in 1773 , which lasted five years. He rccords' numerous observations on the horticulture of both the colonists and the Indians. At Savannah, Georgia, he found gardens furnished with all the cultivated fruit trees and flowers in variety. One of the earliest settlements made by the English in Georgia was Frederica, and here he found the peach, fig, pomegranate and other trees and shrubs growing about the ruins; though not specifically mentioned, the plum had probably been planted here with the other fruits. At the junction of the Coose and Tallapoosa rivers in Alabama, there were thriving apple trees, which had been set by the French at Pearl Island in the last named state. Between Mobile and New Orleans, Bartram found peaches, figs, grapes, plums and other fruits growing to a high degree of perfection and such also was the case on a plantation on the Mississippi in Louisiana near Baton Rouge.

These several references to plums show that this fruit was at least tried in early colonial times, but it was not until after the establishment of fruit-growing as an industry that any extensive plantings were made. Pomology really began in America, though it languished for the first halfcentury, at Flushing, Long Island, about I730 with the establishment of a commercial nursery by Robert Prince, first of four proprietors. Just when this nursery, afterwards the famous Linnaean Botanic Garden, began to offer plums cannot be said, but in 1767 one of their advertisements shows that they were selling plum trees. As a possible indication that the fruit was not highly esteemed at this period, an advertiscment of trees for sale from this nursery in the New York Mcrcury of March I.th, 1774 , does not offer plums. But in 1794 the catalog of the nursery offers plums in variety. Indeed, as we shall see, William Prince had at this time taken hold of the propagation and improvement of the Domestica plums with great earnestness.

William Prince, third proprietor of the nursery founded by his grandfather says in his Treatise of Horticulture," "that his father, about the

as well, among the fruits grown there being the grape, peach, plum, fig, pomegranate, olive and orange. Forbes, James Grant Sketches of the Floridas 91, $x 8_{2} 1$.

${ }^{1}$ Bartram, William Travels Through North and South Carolina, Georgia, East and West Florida,

etc. Dublin : 1793 .

${ }^{2}$ Prince, William Trealise of Horticulture $24 . \quad 1828$. 
year I 790 planted the pits of twenty-five quarts of Green Gage plums; these produced trees yielding fruit of every color; and the White Gage [Prince's Imperial Gage], Red Gage and Prince's Gage, now so well known, form part of the progeny of these plums, and there seems strong presumptive evidence to suppose that the Washington Plum was one of the same collection." In 1828 the Prince nursery was offering for sale one hundred and forty varieties of plums which William Prince states " "are a selection only of the choicest kinds, in making which, the commoner fruits have been altogether rejected." Of the kinds grown, there were over twenty thousand trees. ${ }^{2}$ To this nursery, to William Prince and to William Robert Prince, ${ }^{3}$ the fourth proprietor in particular, belong the credit of having given plum-growing its greatest impetus in America.

Other notable nurseries founded at the close of the Eighteenth Century, which helped to establish plum culture in America, were those of the Kenricks, of William Coxe, and of David Landreth and Son. The Kenrick Nursery was founded in 1790 at Newton, Massachusetts, by John Kenrick, under whom and his sons, William and John A., the business was continued until 1870." During a large part of this period the Kenrick Nursery probably grew, imported and disposed of a greater quantity of fruit trees than any other nursery in New England. Coxe's nursery was established in 1806 , at Burlington, New Jersey, but he had been growing fruit for many years previous and was thus a pioneer pomologist before

Ibid. p. 28.

${ }^{2}$ Prince, William Treatise of Horticulture $23 .{ }_{1} 828$.

The frontispiece of The Plums of New York, showing a likeness of William Robert Prince, dedicates the book to this distinguished American pomologist. It is appropriate that the following biographical sketch of Mr. Prince, written for The Grapes of New York, should be reprinted here. ." William Robert Prince, fourth proprietor of the Prince Nursery and Linnaean Botanic Garden, Flushing, Long Island, was born in 1795 and died in 1869 . Prince was withrut question the most capable horticulturist of his time and an economic botanist of note. His love of horticulture and botany was a heritage from at least three paternal ancestors, all noted in these branches of science, and all of whom he apparently surpassed in mental capacity, intellectual training and energy. He was a prolific writer, being the author of three horticultural works which will always take high rank among those of Prince's time. These were: A Treatise on the Vine, Pomological Manual, in two volumes, and the Manual of Roses, beside which he was a lifelong contributor to the horticultural press. All of Prince's writings a re characterized by a clear, vigorous style and by accuracy in statement. His works are almost wholly lacking the ornate and pretentious furbelows of most of his contemporaries though it must be confessed that he fell into the then common fault of following European writers somewhat slavishly. During the lifetime of William R. Prince, and that of his father, William Prince, who died in $18_{42}$, the Prince Nursery at Flushing was the center of the horticultural nursery interests of the country; it was the clearing-house for foreign and American horticultural plants, for new varieties and for information regarding plants of all kinds."

1 Manning, Robert Hist. Mass. Hort. Soc. 3.3. 1880. 
becoming a nurseryman. In his book, A liow of the Cultivation of Fruit Trees, published in 1817 , the first American book on pomology, he says " he had been "for many years actively engaged in the rearing, planting and cultivating of fruit trees on a scale more extensive than has been attempted by any other individual of this country." The third of these nurseries, that of David Landreth and Son, was conducted in connection with the seed establishment of that family founded in Philadelphia in 1784 . Their collection of fruits was among the most extensive of the time and must have forwarded the cultivation of the plum in that region. ${ }^{2}$

A century ago the fruit-growing of the country was largely in the hands of amateurs and patrons of horticulture. Many varieties of plums must have been introduced by these lovers of plants. Among such growers of fruit was William Hamilton of Philadelphia, who introduced the Lombardy poplar in 1784 , and who in 1800 was growing all the plants and fruits procurable in Europe. Ezekiel Henry Derby of Salem, Massachusetts, one of the founders of the Massachusetts Society for Promoting Agriculture, grew many choice foreign plants in his garden, greenhouse, orchard and arboretum, and attained well merited fame as a horticulturist. ${ }^{3}$ Dr. David Hosack, botanist and founder in $180 \mathrm{r}$ of the Elgin Botanic Gardens in what is now New York City, was one of the most distinguished patrons of pomology of his time and grew many new fruits and plants from Europe, afterwards placing them in the hands of the horticulturists of the country.'

These are but a very few of the many men who, having wealth and leisure, were engaged in growing fruits and plants as an avocation but were adding greatly to the material and knowledge of those to whom fruitgrowing was a vocation. As a further example of how much these men contributed to horticulture, a purchase made by a member of the New York Horticultural Society may be cited. At a meeting of the Society held in July, 1822, he mentioned a list of fruit trees which he had purchased in Europe, comprising 784 varieties. $^{5}$

The period during which American pomology may be said to have been in the hands of wealthy amateurs began shortly after the close of the Revolution and did not fully merge into that of commercial pomology until the close of the Civil War. Soon after the beginning of the Nineteenth

\footnotetext{
${ }^{1}$ Coxe, William $A$ View of the Cultivation of Fruit Trees 6. I817.

${ }^{3}$ Landreth's Rural Register and Almanac. 1872 and 1874 .

3 Bulletin of the Essex Institute 2:23.

${ }^{4}$ Downing, A. J. Hovey's Mag. 3:5. I 837 .

- Boston Palladium, Sept. 9, 1822.
} 
Century; horticulture, in fact all agriculture, was greatly stimulated by the publication of agricultural books ${ }^{1}$ and magazines ${ }^{2}$ and the formation of agricultural and horticultural societies. ${ }^{3}$ The frequency of the names of these publications of a century ago in The Plums of New York is an indication of the contributions they made to the culture of the plum.

Having briefly outlined the history of the Domestica plums, we come now to a discussion of what we have under cultivation in this fruit. The Domestica plums, 950 or more mentioned in this text, may be dividedinto several more or less distinct pomological groups. These groups are of interest because in their history the evolution of the plum under consideration is further developed; because such groups are serviceable to plum-growers, as each division has adaptation for particular conditions or particular purposes; and because of their value to the breeder of plums since the largest and best differentiated groups, as a rule, have their characters most strongly fixed and may be relied upon to best transmit them to their offspring.

Groups of plums in pomology are founded for most part upon the characters of the fruit since these are most readily recognized by fruitgrowers. Yet whenever possible, leaf, flower and tree-characters are considered. The name given is usually that of the best known variety in the group though in some of the divisions the name is that of the variety which scems to be intermediate in character between the other members of the group.

The groups of plums recognized by pomologists were far more distinct as we go back in their history. For, in the past, each fruit-growing region

${ }^{1}$ The horticultural books published in America between 1779 and 1825 were: The Gardener's Kalender by Mrs. Martha Logan, Charleston: ${ }_{7779}$; The American Gardener by John Gardiner and David Hepburn, Washington: 1804; The American Gardener's Calendar by Bernard MeMahon, Philadelphia: I806; A View of the Cultivation of Fruit Trees by William Cox, Philadelphia: 1817; The American Practical Gardener by an Old Gardener, Baltimore: i 819; The Gentleman's and Gardener's Kalendar by Grant Thorburn, New York: I821; American Gardener by William Cobbett, New York: 1819; and The American Orchardist by James Thacher, M. D., Boston: 1822.

${ }^{2}$ During the quarter ending in 1825 two agricultural publications were in existence in the United States: The American Farmer, established in Baltimore in 1819 , and the New England Farmer, founded in Boston in 1822 . To these should be added the Massachusetts Agricultural Repository, not a journal in the strict sense of the word but published by the Massachusetts Society for Promoting Agriculture, established in 1793, and continued until the New England Farmer was started $i_{\text {n }}$ 1 $_{22}$. The Repository was the first agricultural periodical of the New World.

3 At least three agricultural societies were founded soon after the close of the Revolution; the Philadelphia Society for Promoting Agriculture and the Agricultural Society of South Carolina were founded in ${ }_{1785}$, and the Massachusetts Society for Promoting Agriculture in 1792, while the first strictly horticultural society, the New York Horticultural Society, was not established until i 8 i 8 . 
had a pomology of its own in which the varieties of any fruit were few and similar, constituting but one, or at most a very few types. The various groups of plums, therefore, largely represent distinct plum-growing regions. With the increase in intercourse between the countries of the world, cultivated plums have been taken from place to place and as new varieties have originated, often from crosses between varieties, the dividing lines between divisions have been more or less broken down. The first of the groups to be considered is:-

The Reine Claude or Green Gage Plums.-This group is so distinctive in several characters that some botanists and pomologists separate it from other Domestica plums as a sub-species or species $^{1}$ and in common parlance its numerous varieties are very generally grouped together as "green gages" as if it were quite a distinct fruit from other plums. It comprises a considerable number of relatively small, round, mostly green or golden plums of so high quality as to make them standards in this respect for all plums. The Reine Claude is one of the oldest types of which there are records. Its varieties reproduce themselves without much variation from seed though there are a few sorts, possibly crosses with some other group, which are doubtfully referred to the Reine Claudes. The later history of these plums is most interesting and is reliable, for the group is recognized and discussed by almost every European or American pomologist who has written in three centuries. ${ }^{2}$ The early history is not so well known.

Where the Reine Claude plums originated no one knows. Koch ${ }^{3}$ says he has eaten wild plums in the Trans-Caucasian region, which must be recorded with the Reine Claudes, but on the next page he advances the theory that the group is a hybrid between Prumus domestica and Prumus insititia. Schneider ${ }^{4}$ puts the Reine Claudes in Prums insititia. The group seems to be a connecting link between the two species namedabove, having so many characters in common with each that it is exceedingly difficult to choose between the two as possible parent species. Prunus domestica probably originated in the Caucasian or Caspian region, and it is likely, as Koch suggests, that the Reine Claudes were brought from there. This is substantiated by the early pomologists, who say these

${ }^{1}$ P. domestica cereola L. (Sp. Pl. 475. 2753), P. claudiana Poir. (Lam. Encycl. 5:677. 2804), P. italica Borkh. (Handb. Forstb. II:1 409 . I $8 \circ 3$ ).

'For a bibliography of this group see an article by Waugh in Gard. Chron. 24:465. 1898.

${ }^{3}$ Koch, K. Deut. Obst. 149.1876.

4 Schneider, C. K. Hand. der Laub. 630. 1926. 
plums came originally from Armenia and were known as the Armenian plums, coming eventually by the way of Greece to Italy. If this statement of its origin be true, Columella' knew the fruit, for he says:

- " then are the wicker baskets cramm'd

With Damask and Armenian and Wax plums."

And so, too, Pliny refers to the $\mathrm{m}^{2}$ in his enumeration of varieties in which he says: "the Armenian, also an exotic from foreign parts, the only one among the plums that recommends itself by its smell."

$\mathrm{Hogg}^{3}$ says the Reine Claudes were brought from Greece to Italy and cultivated in the latter country under the name Verdochia. Hogg does not give his authority and his statement cannot be verified in any other of the modern European pomologies to which the authors of this work have had access. The very complete history of the agricultural and horticultural plants of Italy ${ }^{4}$ by Dr. Antonio Targioni-Tozzetti does not give this name. Be that as it may, some variety of this group was introduced into England under the name Verdoch and at an early date, for in 1629 Parkinson" enumerates it in his sixty sorts describing it as " a great, fine, green shining plum fit to preserve." Rea ${ }^{\circ}$ in 1676 also lists and describes it as does Ray, ${ }^{7}$ i 688 .

It is doubtful if Parkinson, Ray and Rea had the true Reine Claude, however, for the Verdacchio, according to Gallesio, ${ }^{6}$ one of the best Italian authorities, is an obovate-shaped fruit while the Claudia is a round one. Gallesio says the Claudia was cultivated in many places about Genoa under the name Verdacchio rotondo; about Rome and through Modenese, for a long time, as the Mammola; in Piedmont as the Claudia; and in Tuscany as the Susina Regina. Now (1839) he says, "it is known in all Italy under the name Claudia, and has become so common as to be found in abundance in the gardens and in the markets."

The name Reine Claude, all writers agree, was given in honor of Queen Claude, wife of Francis I, the fruit having been introduced into France

${ }^{1}$ Columella ro: lines 404-406.

"The Natural History of Pliny. Translated by John Bostock and H. T. Riley 3:294. London: 1892 .

${ }^{3}$ Hogg, Robert The Fruit Manual Ed. 5:704. 1884.

-Targioni-Tozzetti, Antonio, Cenni storici sulla introdusione di varie piante nell agricoltura cd horticullura Toscana. Florence: 1850.

' Parkinson, John Paradisus Terrestris 576. 1629.

- Rea, John A Complcte Florilege 208. 1676.

${ }^{7}$ Ray Historia Plantarum 2:2529. 1688.

- Gallesio, Giorgio 2: (Pages not numbered). $18_{39}$. 
during the reign of that monarch which began in $\mathrm{I}_{494}$ and ended ${ }_{5477}$, these dates fixing as accurately as possible the origin of the name. Green Gage, the commonest synonym of either the Reine Claude group or of the variety, comes from the fact that this fruit was introduced into England by the Gage family. Phillips ${ }^{1}$ gives the following account of its introduction into England:

"The Gage family, in the last century, procured from the monastery of the Chartreuse at Paris, a collection of fruit trees. When these trees arrived at the Mansion of Hengrave Hall, the tickets were safely affixed to all of them, excepting only to the Reine Claude, which had either not been put on, or had been rubbed off in the package. The gardener, therefore, being ignorant of the name, called it, when it first bore fruit, the Green Gage.'

Because of the high esteem in which the plums of this group have always been held in England the early English colonists probably brought seeds or plants of the Reine Claudes to America. This supposition is strengthened by the fact that Prince, in his efforts in 1790 to improve plums, chose the "Green Gage," planting the pits of twenty-five quarts of plums of this variety. McMahon, in his list of thirty varieties of plums, published in 1806 , gives the names of at least seven varieties belonging to this group. The varieties of the group first came into America, without doubt, under one of the Green Gage names, but afterwards, probably in the early part of the Nineteenth Century, importations from France brought several varieties under Reine Claude names though the identity of the plums under the two names seems to have been recognized in American pomology from the first.

In appearance the trees of this group are low and the heads well rounded. The bark is dark in color and cracks rather deeply. The shoots are thick and do not lose their pubescence. The leaves are large, broad, more or less wrinkled, coarsely crenate and sometimes doubly serrated, a character not usually found in Domestica plums, and bear from one to four glands. The fruit is spherical or ovoid, green or yellow, sometimes with a faint blush, stems short and pubescent, suture shallow, bloom thin, texture firm, quality of the best, flesh sweet, tender, juicy, stone free or clinging.

The leading varieties of the Reine Claude plums are: Reine Claude, Bavay, Spaulding, Yellow Gage, Washington, McLaughlin, Hand, Peters, Imperial Gage, Jefferson and Bryanston.

'Phillips, Henry Comp. Orch. 306.183 I. 
The Prunes.-In western America plum-growers usually speak of any plum that can be cured, without removing the pit, into a firm, long-keeping product as a prune. Such a classification throws all plums with a large percentage of solids, especially of sugar, into this group. But in Europe the term is used to designate a distinct pomological group. ${ }^{1}$ Since we have a number of varieties of plums long known as prunes and to which no other term can be nearly so well applied, it seems wise to follow the established European custom of using the term as a group name as well as for a commercial product which is made for most part from these plums.

The prune, as an article of commerce, all writers agree, originated in Hungary in the Sixteenth Century and was at that time a very important trading commodity with Germany, France and southern Europe. If, as Koch surmises (see page $I_{7}$ ), the prunes originated in Turkestan or farther east-and the statements of other botanists and writers tend to show that his view is correct-the spread of the varieties of this group westward is readily explained. In the migrations of the Huns, from western Asia to eastern Europe, in the first thousand years of the Christian era, some Magyar or Hun intent on cultivating the soil brought with him the prune-making plums which, finding a congenial home, became the foundation of the prune industry of Hungary in the Sixteenth Century. In subsequent commercial intercourse with western Europe the latter region was enriched by these prune-making plums from Hungary.

In America this group is now by far the most important one commercially, though prunes were not introduced into this country until comparatively recent years. The early lists of plums do not include any of the prunes and even as late as I806 McMahon only mentions in the thirty varieties given by him but one, "the Prune Plum." William Prince in 1828 speaks only of the "monstrous prune," " but in such a way as to lead one to believe that neither it, nor any other prune, was then cultivated in America." In ${ }^{3} 8_{31}$ William Robert Prince in his Pomological

${ }_{1}^{1}$ These are the plums which Linnaeus called Prunus domestica galatensis (Sp. Pl. 475. 1 753); Seringe, Prunus domestica pruneayliana (DC. Prodr. 2:533. 1825); and Borkhausen, Prunus oeconomica (Handb. Forstb. 2:1 401.1803 ).

${ }^{2}$ Prince, William A Short Treatise on Horticulture 27. 1828.

3.. Of the prune, or, as they are termed in German, 'Quetsche,' there are a number of varieties, all which are of fine size, and considered as the best plums for drying as prunes; this is one of the largest of the varieties; the principal characteristic of these plums is that the flesh is sweet and agreeable when dried. I am informed that the 'Italian Prune' ranks highest as a table fruit when plucked from the tree. The process of drying prunes seems to be so very easy that I should suppose it might be undertaken in this country with a certainty of success, and so as to totally supersede the importation of that article." Ibid. 
Manual describes from this group only the German Prunc and the "Agen Date," or Agen. Indeed, it was not until the beginning of the prune industry in California, about 1870 , that the varicties of this group began to be at all popular though an attempt was made by the United States Patent Office to start the prune industry on the Atlantic seaboard by the distribution of cions of two prunes in $1854 .^{\prime}$

The growth of the prune industry on the Pacific Coast is one of the most remarkable industrial phenomena of American agriculture. About I 856, Louis Pellier, a sailor, brought to San Jose, California, cions of the Agen from Agen, France. Some time afterward a larger plum, the Pond, was also imported from France, supposedly from Agen, and to distinguish the two, the first was called Petite Prune, by which name it is now very commonly known in the far west. The first cured prunes from this region were exhibited at the California State Fair in $186_{3}$; commercial orchards began to be planted about 1870 , and the first shipments of cured prunes were probably made in $1875^{\circ}$ In 1880 the output per annum was about 200,000 pounds; in 1900 the yearly capacity was estimated to be about $130,000,000$ pounds, valued by the producers at $\$ 450,000 .^{3}$

The typical varieties of this group are the Italian, German, Agen, Tragedy, Tennant, Sugar, Giant, Pacific and the Ungarish.

The distinguishing characters of the group are to be found in the fruit, which is usually large, oval, with one side straighter than the other, usually much compressed with a shallow suture, blue or purple, with a heavy bloom, flesh greenish-yellow or golden, firm, quality good, stone free. The trees are various but are usually large, upright and spreading with elliptical leaves having much pubescence on the under surface.

The Perdrigon Plums. - The Perdrigons constitute an old but comparatively unimportant group of plums." The name comes from an old

1 United States Patent Office Report: xxix. 1854 . The following description of this distribution is of interest: ' The scions of two varieties of prunes, 'Prunier d'Agen,' and 'Prunier Sainte Catherine,' have been imported from France, and distributed principally in the states north of Pennsylvania, and certain districts bordering on the range of the Allegany Mountains, in order to be engrafted upon the common plum. These regions were made choice of in consequence of their being freer from the ravages of the curculio, which is so destructive to the plum tree in other parts as often to cut off the entire crop. It has been estimated that the State of Maine, alone, where this insect is rarely seen, is capable of raising dried prunes sufficient to supply the want: of the whole Union."

2 Wickson, E. J. California Fruits Ed, $2: 8_{2}$, $189 \mathrm{I}$.

${ }^{3}$ Hedrick, U. P. in Bailey's Cyclopedia American Horticulture 1440. I90I.

- Miller says in his Gardener's Dictionary of the variety Perdrigon, "Hakluyt in 1582 , says, of later time the plum called the Perdigwena was procured out of Italy, with two kinds more, by the Lord Cromwell, after his travel." Miller, Phillip Gardener's Dictionary. Edited by Thomas Martyn, 2: (no page). 1707 . 
time geographical division of Italy. ${ }^{-}$The Perdrigon plums, especially the varieties having this name, have been grown extensively for two centuries about Brignoles, France, where they are cured and sold as Brignoles prunes. Since they are much grown in what was formerly the province of Touraine, France, they are sometimes called Touraine plums. The early pomological writers, as the Princes, Kenrick, Coxe, and even Downing, described White, Red, Violet, Early and Norman Perdrigon plums, but these are not now listed in either the pomologies or the nurserymen's catalogs of this country though the group is represented by Goliath, Late Orleans and Royal Tours. These plums might almost be included with the Imperatrice group, differing only in the smaller and rounder fruits.

The Yellow Egg Plums. ${ }^{2}$ - There are but few varieties belonging to this group, but these are very distinct, and include some of the largest and handsomest plums. The origin of varieties of this group can be traced back over three centuries and it is somewhat remarkable that the size and beauty of the Yellow Egg Plums have not tempted growers during this time to produce a greater number of similar varieties. Rea, ${ }^{3}$ in 1676 , described the Yellow Egg under "Magnum Bonum or the Dutch Plum " as " a very great oval-formed yellowish plum, and, according to the name, is good as well as great." The Imperial, which afterward became the Red Magnum Bonum, is mentioned by Parkinson" in 1629 as "Large, long, reddish, waterish and late." Earlier names in France, how early cannot be said, were Prune d'Oeuf, yellow, white, red and violet, or the Mogul with these several colors, and the Imperiale with the three or four colors. Later the name d'Aubert was applied to the Yellow Egg. Though this fruit was first known in England as the Imperiall, and later as the Magnum Bonum, it has been grown for at least two centuries in that country as the Yellow Egg, and under this name came to America in the latter part of the Eighteenth Century. Koch " places these plums in the Date-plum family. The varieties of this group now grown and more or less well-known are Yellow Egg, Red Magnum Bonum, Golden Drop and Monroe.

The characters which readily distinguish the Yellow Egg group are,the large size of the fruit, possibly surpassing all other plums in size, the

\footnotetext{
'In the first edition of Species Plantarum Linnaeus called these plums Prunus domestica pernicona; in the second edition the varietal name was changed to "Pertizone." In the Prodromus Seringe designates the group as Prunus domestica touronensis.

${ }^{2}$ The Prunus domestica aubertiana of Seringe. (DC. Prodr. 2:533. IS25.)

${ }^{3}$ Rea, John A Complete Florilege 209. $\times 676$.

" Parkinson, John Paradisus Terrestris 576. 1629.

${ }^{5}$ Koch, K. Deut. Obst. 560. ${ }_{1876}$.
} 
long-oval shape, more or less necked, yellow or purple color and the yellow flesh. The plums are produced on tall, upright-spreading trees.

The Imperatrice Plums. - This is a poorly defined assemblage of varicties, of which dark blue color, heavy bloom, medium size and oval shape are the chief characters. It is impossible to trace the origin of the group or to refer varieties to it with accuracy. The Imperatrice, of which Ickworth is an offspring, seems to have been one of the first of the blue plums to receive general recognition, and can as well as any other varicty give name to the type. This group contains by far the greatest number of varieties of any of the divisions as here outlined, chiefly because the color, the size, and the shape are all popular with growers and consumers. This has not always been the case, for in the old pomologies, blue plums are comparatively few in number, Parkinson, for instance, giving in his list of sixty in 1629 not more than a half-dozen Domesticas that are blue.

Among the varieties that fall into this group are:-Ickworth, Diamond, Arch Duke, Monarch, Englebert, Shipper, Arctic, Smith Orleans and Quackenboss.

About the only characters that will hold for this large and variable group are those of the fruits as given above, though to these may be added for most of the varieties included in the division, thick skin and firm flesh, clinging stones and poor quality. The trees vary much but are usually hardy, thrifty and productive, making the members of the group prime favorites with commercial fruit-growers.

The Lombard Plums. - Just as the blue plums have been thrown in the last named group, so we may roughly classify a number of red or reddish or mottled varieties in one group. If the oldest name applicable to this group were given it should be called after the Diaper plums, wellknown and much cultivated French sorts of two and three centuries ago. Since they are no longer cultivated, and as the Lombard seems to be a direct offspring of them and is fairly typical of the division, the name chosen is as applicable as any. These plums differ but little from those of the preceding group, except in color and in having a more obovate shape, a more marked suture, smaller size and possibly even greater hardiness and productiveness, and if anything, even poorer quality, though to this last statement there are several marked exceptions. In this group are no doubt many varieties which are crosses between some of the old red plums and varieties of the other groups given. 
The following sorts may be named as belonging here:--Lombard, Bradshaw, Victoria, Pond, Duane, Autumn Compote, Belle, Middleburg and Field.

\section{PRUNUS INSITITIA Linnaeus}

1. Linnaeus Amocn. Acad. 4:273. 1755. 2. Seringe DC. Prodr. 2:532. 1825. 3. Hooker Brit. Fl. 2 20. 1830. 4. Loudon Arb. Fr. Brit. $2: 687$. 1844. $\quad$ 5. Koch, K. Dend. 1:95. 1869. 6. Ibid. Deut. Obst. 144. 1876. 7. De Candolle Or. Cult. Pl. 211. 1885. 8. Emerson Trees of Mass. Ed. 4:512. 1887. 9. Schwarz Forst. Bot. 339. I892. 10. Koch, W. Syn. Deut. und Schw. Fl. 1:726. 1892. 11. Koehne Deut. Dend. 316. IS93. 12. Dippel Handb. Laubh. 3:639. 1893. 13. Lucas. Handb. Obst. 429. 1893. 14. Beck von Managetta Nied. Oester. 819. 1893.

P. communis (in part). 15. Hudson Fl. Anglic. 212. 1778, 16. Bentham Handb. Brit. Fl. $\mathbf{I}: 236$. 1865 .

P. domestica insititia. 17. Schneider Handb. Laubh. I: $63^{\circ}$. 1892. 18. Waugh Bot. Gaz. $27: 478$. 1899 .

Tree dwarfish but thrifty, attaining a height of twenty to twenty-five feet ; trunk reaches eight inches in diameter and bears its head rather low, three to five feet from the ground; bark gray with a tinge of red, smooth, with transverse cracks; branches upright-spreading, rigid, compact, short-jointed, and more or less thorny; branchlets pubescent, slender, reddish-brown or drab.

Winter-buds small, conical, pointed or obtuse, free or appressed; leaves small, ovate or obovate; apex obtuse or abruptly pointed, base cuneate or narrowed and rounded, margins finely and closely, sometimes doubly serrate or crenate, usually glandular; texture thin and firm; upper surface slightly rugose, dark green, slightly hairy; lower surface paler and soft, pubescent; petioles one-half inch long, slender, pubescent, tinged with red; glands few or glandless.

Flowers expand with or after the leaves, one inch or less in size; borne variously but usually in lateral, umbel-like clusters, one, two or rarely three from a bud, on slender pedicels, which are pubescent and one-half inch in length; calyx-tube campanulate, glabrous or nearly so, green or tinged with red; calyx-lobes narrow, obtuse or acute, glandular-serrate, glabrous or pubescent, reflexed; petals white or creamy in the bud, broadly oval, entire or dentate, reflexed, claw short; stamens about twentyfive, as long as the petals; anthers yellow, often tinged with red; pistil glabrous and nearly as long as the stamens.

Fruit ripens from early to late; globular or oval, often necked, less than an inch in diameter, variously colored but usually bluish-black or amber-yellow, with a heavy bloom; skin thin, tough; stem slender, one-half inch long, more or less pubescent; cavity shallow, narrow; apex roundish or flattened; suture indistinct or a line; flesh firm, yellow, juicy, sweet or acid; stone clinging or free, somewhat turgid, ovoid, nearly smooth, ridged on one edge and grooved on the other.

There is a great diversity of opinion among botanists as to what Linnaeus meant to include in his Prunus insititia. His description of the species is not definite and can be made to apply to any one of several very distinct plums. But the botanists who recognize the species usually 

include in it, among cultivated plums, the Bullaces and the Damsons, plums which differ only in the shape of the fruit, the former being round and the latter oval. Some of the texts noted in the references for this species also place the St. Julien and the Mirabelle plums here. In The Plums of New York the authors consider the Bullaces, Damsons, the St. Julien and the Mirabelles as belonging to this species.

It is true that Linnaeus established at an earlier date than the naming of Prumus insititia his Prunus domestica damascena, in which the varietal name indicates that he meant the Damsons, but the description of the variety taken by him from Bauhin's Pinax' making the plum large, sweet and dark purplish, cannot be made to apply to this fruit, nor can it be connected definitely with any other plum; this being true, and since Linnaeus refers to no type specimen, figure, or locality, his Prunus domestica damascena according to current botanical practices in America, should be rejected.

The trees of the Insititia varieties are readily distinguished from the Domestica sorts in having a dwarfer and more compact habit; much smaller and more ovate leaves with more closely serrate margins; branches more finely divided, more slender, with shorter joints, and bearing spines or spinescent spurs; having a more abundant and a more clustered inflorescence, with smaller flowers, a glabrous instead of a pubescent pistil and calyx-tube; reflexed calyx-lobes where in Domestica they are often erect; and flowers appearing nearly a week later. The number of stamens in Prunus domestica averages about thirty; in Prunus insititia, about twenty-five. The fruit-characters of Prunus insititia are even more distinctive. The fruits are smaller, being less than an inch in diameter, more nearly round or oval, more uniform in shape, never strongly compressed as in Domestica, with a less distinct suture and more often with a pronounced neck. The color is usually the Damson purple or the Mirabelle yellow, with no intermediate colors as in Domestica and with few or but slight variations as compared with the other species. The plums are sweet or sour with a very much smaller range in flavor in the case of the Insititias and withal very distinct from that of Prumus domestica. The stones are smaller, more oval and much more swollen.

In variability the Insititia plums are quite the reverse of the Domesticas, almost wholly lacking this quality. These plums have been cultivated over two thousand years, yet there is seemingly little difference

\footnotetext{
'Bauhin Pin. 443 n23.
} 
between the sorts described by the Greeks and Romans at the beginning of the Christian Era and those we are now growing. So, too, one often finds half-wild chance seedlings with fruit indistinguishable from varieties under the highest cultivation. This pronounced immutability of the species is one of its chief characteristics.

There are probably several sub-divisions of Prunus insititia but material does not exist in America for the proper determination of the true place for these forms, and the Old World botanists cannot agree in regard to them. It is probable that Prunus subsylvestris Boutigny ${ }^{1}$ and Prunus pomarium Boutigny ${ }^{2}$ belong to Prunus insititia and almost beyond question Prumus syriaca Koehne ${ }^{3}$ is the yellow-fruited Mirabelle of this species. Prumus insititia glaberrima Wirtg." occasionally found in the herbaria of Europe has, with its small, roundish-obovate leaves, but little appearance of Prunus insititia and may be, as Schneider surmises, ${ }^{\circ}$ a cross between Prunus spinosa and the Myrobalan of Prunus cerasifera.

The Insititia plums are second in importance only to the Domesticas. Their recorded history is older. This is the plum of the Greek poets, Archilochus and Hippona, in the Sixth Century B. C. Theophrastus, the philosopher, mentioned it three hundred years before Christ, as did Pollux, the writer and grammarian, a century before the Savior, while Dioscorides, the founder of botany, during the last named period, distinguishes between this plum and one from Syria, presumably a Domestica. This is one of the twelve kinds of plums described by Pliny (see page 17) who calls it the Damascene, so-called from Damascus in Syria, and says of it, "introduced long since into Italy." It is the Damask plum of Columella when in his tenth book he says:

"then are the wicker baskets cramm'd

With Damask and Armenian and Wax plums."

The yellow plums of the Roman poets, Ovid and Vergil, are probably the Bullaces or Mirabelles of this species. Indeed, its cultivation was probably. prehistoric, for Heer " has illustrated and described stones of a plum found

${ }^{1}$ Bul. Soc. Dauph. fasc. VIII. I 881 .

Ibid.

${ }^{3}$ Dendrol. $316 . \quad$ I893.

${ }^{4}$ Rhein. Reise-Fl. 67. ${ }_{1857}$.

- Handb. Laubh. I: 631. I906.

6 Pickering. Charles Chron. Hist. Plants. 218 . 1879 .

'Heer Pflandz. Piahl, 27, fig. I6c. 
in the lake-dwellings of Robenhausen which can be no other than those of Insititia.

The authentic written history of this plum may be said to have begun with or a little before the Christian Era. The records of the cultivation and development through the early centuries of the present chronology and the Middle Ages to our own day may be found in the herbals, botanies, pomologies, agricultural and general literature of the past two thousand years.

Prunus insititia now grows wild in nearly all temperate parts of Europe and western Asia-from the Mediterranean northward into Norway, Sweden and Russia. The botanists of Europe very generally agree that its original habitat was in southern and southeastern Europe and the adjoining parts of Asia, and that elsewhere it is an escape from cultivation. Hooker" says that Prunus insititia grows in western temperate Himalaya, cultivated and indigenous, from Gurwhal to Kashmir, the type being that of the "common yellow-fruited Bullace." A few botanical writers hold that it is truly wild in the parts of Europe where now found growing. There are also not a few botanists who, as has been stated in the discussion of the Domestica plums, unite the Insititias with the Domesticas, and others who combine these two with the Spinosa plums in one species, Prunus communis. ${ }^{2}$

It is possible that the species is occasionally found naturalized in eastern United States; several botanists so give it.

Wherever the habitat of the Insititia plums may have been, practically all writers from the Greeks and Romans who first mention this fruit to those of the present time, connect the cultivated varieties in one way or another with the old Semite city, Damascus. It is almost certain that the Syrians or Persians were the first to cultivate these plums, and that they were unknown in Europe as domesticated varieties until the Greeks first and the Romans afterward came in intimate contact with the people of the Orient. Thus it is often stated in the old pomologies that Alexander the Great brought these plums from the Orient after his expedition of conquest and that some centuries later Pompey, returning from his invasion of the eastern countries, brought plums to the Roman Empire.

The history of the Insititia plums in America has been given in the main in the discussion of the Domestica plums, for the varieties of the two

1 Hooker Fl. Brit. Ind. 2: 315. I879.

${ }^{2}$ The reader who desires fuller information regarding the botany of this species should consult the references given with the botanical description of Prunus insititia. 
species have never been kept separate by plum-growers, all being grouped together as European plums. It is probable, however, that the Damson plums of this species were earlier introduced and more generally grown than any other of the European plums by the English settlers of America, as the references to plum-growing before the Revolution are largely to the Damsons. The reasons for this early preference for these plums are that they come true to seed while most varieties of the Domestica do not; and trees and cions were not readily transportable in colonial times; and, too, the Damsons have always been favorite plums with the English.

When the first American fruit books were published at the beginning of the Nineteenth Century the Damsons and Bullaces were widely grown, for all writers give a relatively large number of varieties of these plums and speak well of them. Thus McMahon, ${ }^{1}$ in his list of thirty plums gives six that belong here, ending his list with "Common Damson, etc., " as if there were still more than those he enumerates. Prince, in his Pomological Mamual, in $1_{3} 3_{2}$, gives at least eighteen sorts that may be referred to Insititia with the statement that one of them, the Early Damson " appears to have been brought to this country by the early Dutch settlers, or by the French who settled here at the time of the revocation of the Edict of Nantes," adding, "It is much disseminated throughout this section of the country." At the end of the Eighteenth Century Deane's 2 New England Farmer or Georgical Dictionary, in a discussion of plums in general says: "The most common plum in this country is the Damascene plum, an excellent fruit for preserving, which is said to have been brought from Damasam, hence the name."

The hardiness, thriftiness and productiveness of all of the varieties of this species commend them to those who cannot give the care required to grow the less easily grown Domesticas, and in America, as in Europe, these plums are to be found in almost every orchard and in many communities half-wild, thriving with little or no care. The fact that they are easily propagated, growing readily from suckers and coming true to seed is an added reason for their general distribution.

The Insititia plums do not seem to hybridize freely with other speciesat least there are no recorded offspring of such hybrids, though Koch believes the Reine Claudes to be a hybrid group between this species and the Domesticas and there is much evidence in the fruit to show that the

'MeMahon, Bernard Gardener's Calendar 587. I806.

${ }^{2}$ Samuel Deane, D.D. New England Farmer 265. 1797. 
French Damson is part Domestica. The tree-characters of the Insititia plums are such, especially as regards vigor, hardiness, productiveness and freedom from disease, as to seemingly make hybrids with them very desirable. That this species can be hybridized with Domestica, at least, is certain from work done at this Station where we have made a number of crosses between them.

Four groups of plums, the Damsons, Bullaces, Mirabelles and St. Juliens, in all eighty-six varieties mentioned in The Plums of New York, may be referred to this species. There are so few real differences between these divisions, however, that it is hardly possible, logically, to sub-divide Insititia plums into more than two groups. But since the groups of plums given above are so often referred to in pomological works it is necessary to diseuss them.

The Damsons. - The description given the species fits this division of it closely, the differentiating character for the fruit, if any, being oval fruits, while the Bullaces, most nearly like these, are round. The origin of the Damsons, as we have seen, was in Syria and near the ancient city, Damascus, their written history dating back several centuries before Christ. This plum has escaped from cultivation in nearly all the temperate parts of Europe and more or less in the eastern United States, the wild forms often passing under other names, as the Wild, Wheat, Spilling, Donkey, Ass, Hog and Horse plums. The true Damsons have a fine spicy taste, which makes them especially desirable for cooking and preserving, but a very decided astringency of the skin makes most of the varieties of Damsons undesirable to eat out of the hand; this astringency largely disappears with cooking or after a light frost. Nearly all Damsons are sour, though a few sweet Insititias are placed in this group.

Since the seeds grow readily and the sprouts are very managcable, the Damsons, with the other Insititias, are much used as stocks upon which to work other plums, especially the less hardy and less thrifty Domesticas. Although less used now than formerly for stocks it is a question if these plums, or some of their near kin, do not make the best obtainable stocks. There seems to be much difference in the varieties of Insititia in their capacity to send up sprouts. The forms which send up the fewest sprouts are much the best for use as stocks.

Curiously enough, the Damsons are highly esteemed now only by the Americans and English, being grown much less at present in Continental Europe than a century or two ago. Late pomological works and nursery- 
men's catalogs from others than the English or Americans barely mention these plums.

The Bullaces.- It is impossible to distinguish between the tree-characters of the Damsons and the Bullaces, and pomologists are far from agreeing as to what differences in the fruit throw a variety into one group or the other. Some writers call a sour variety of Insititia a Damson, and a sweet one a Bullace; others make color the differentiating character, calling the purple plums Damsons and the light colored ones Bullaces; still others call oval Insititias Damsons and round ones Bullaces. If a distinction is to be made, shape seems to be the character upon which it should be based. The name Bullace applies to the round shape of the fruit, but when first used or by whom given it is impossible to say. It is commonly used in the old herbals and pomologies of both England and Continental Europe, there being many variations of the name, of which bullis and bulloes are most common with the word bullum in frequent use for the fruit of the Bullace tree. The varieties of Bullaces are few in number, and are not largely grown, being known for most part only in fruit collections, the Damsons serving all the purposes for which the Bullaces would be worth growing, and to better advantage.

The Mirabelles.-The Mirabelles are round, yellowish or golden, freestone Insititias, ranging from half an inch to an inch in diameter, very slightly sub-acid or sweet. The trees do not differ from the type of the species unless it be in even greater productiveness than the other groups of Insititia, all of which bear very abundant crops. The fruits represent the highest quality to be found in the varieties of this species, approaching the Reine Claudes of Prunus domestica in richness of flavor. Indeed, the Mirabelles may almost be said to be diminutive Reine Claudes, resembling them not only in quality but in color and in shape, and so closely as to lend color to Koch's ${ }^{1}$ supposition that the Reine Claudes are hybrids between Prunus domestica and Prunus insititia.

In France the Mirabelles are accorded sccond if not first place among plums, being superseded in popularity, if at all, only by the Reine Claudes. They are used in the fresh state and as prunes, and are freely made into conserves, preserves, jellies and jams, being found in the markets in some of these forms the year round. They are much used for pastry, their size being such that one layer of fruit suffices and is none too deep for a good pie or tart. The fermented juice of these plums is somewhat largely used

${ }^{1}$ Koch, Karl Deut. Obst. I50. 1876. 
in the making of a distilled liquor, a sort of plum brandy. The dozen or more varieties of Mirabelles differ chiefly in size of fruit and in time of maturity. The range in size is from half an inch to an inch in diameter and in time of ripening in France from the first of August to the first of October.

The Red Mirabelle frequently referred to in pomological works is Prunus cerasifera, and the name is wrongly so used, for if not first applied to the several varieties of Insititia it now by almost universal usage belongs to these plums. The origin of the word, as now commonly used, dates back over two centuries, being found in the pomological treatises of the Seventeenth Century. The assumption is that Mirabelle is derived from mirable meaning wonderful, and the name was first so used by the French.

Unfortunately the Mirabelles are hardly known in America. These plums have so many good qualities of tree and fruit that American pomology would be greatly enriched if the best Mirabelle varieties were grown in both home and commercial orchards. They should be used in cookery much as are the Damsons, which they surpass for some purposes.

St. Fuliens.-The St. Julien that the writer has seen in American and European nurseries is unmistakably an Insititia. At one time St. Julien stocks were used almost exclusively in New York nurseries, and few large plum orchards are free from trees which have through accident to the cion grown from the stock. Such trees bear fruit so like the Damson that one is warranted in saying that the two are identical, and that St. Julien is but a name used for a Damson when the latter is employed as a stock. The fruit is sweetish with a taste identical with that of the sweet Damsons.

Plum-growers who have had experience with plums on several stocks are almost united in the opinion that the St. Julien is the best of all for the Domesticas, at least. St. Julien stocks were formerly imported in great numbers from France, where it is still largely grown for European use. The name seems to have come in use in France more than a century ago, but why given or to what particular Insititia applied does not appear. There is, however, a distinct variety or type of Insititia used by the French in producing stocks, for French pomologists advise careful selection of mother-plants for the production of the young trees by suckers or layers, and caution growers of stocks in no case to use seeds which bring twiggy, spiny and crooked stocks. ${ }^{2}$ St. Julien plums are seemingly nowhere grown at present for their fruits.

This subject is well discussed in an article by E. A. Carrière in Revue Horticole $43^{8 .} 1892$. 
There are several ornamental forms of plums which are given specific names by European horticulturists, mentioned in the last paragraph in the discussion of the Domestica plums, which some writers place, in part at least, with the Insititias. These plums are not found in America and it is impossible to place them with certainty in either of the two species upon the contradictory evidence of the Europeans.

\section{PRUNUS SPINOSA Linnaeus.}

1. Linnaeus Sp. Pl. 475. 1753. 2. Hudson Fl. Anglic. 186. 1778. 3. Ehrhart Beitr. Nat. 4:16. 1789. 4. Pursh Fl. Am. Sept. 1:333. 1814. 5. Hooker Fl. Bor. Am. 1:167. 1833. 6. Torrey and Gray Fl. N. Am. I:408. 1840. 7. Koch, K. Dend. 1:98. 1869. 8. Ibid. Deut. Obst. 143. 1876. 9. DeCandolle Or. Cult. Pl. 212. 1885. 1o. Schwarz Forst Bot. 339. 1892. II. Koch, W. Syn. Deut. und Schw. Fl. 1:726. 1892. 12. Dippel Handb. Laubh. 3:637. 1893. 13. Koehne Dcut. Dend. 316. 1893. 14. Beck von Managetta Nied. Ocster. 818. 1893. 15. Bailey Cyc. Am. Hort. 1447 fig. 1901. 16. Schneider Handb. Laubh. 1:628. 1906.

Plant low, spreading, much-branched, thorny, shrubby, seldom attaining the dimensions of a small tree; branchlets distinctly pubescent; leaves small, ovate or oblong-ovate, sometimes obovate, numerous, nearly glabrous at maturity, obtuse at the apex, cuneate or rounded at the base, margins closely and finely serrate.

Flowers white, one-third or one-half inch in diameter, expanding before the leaves; borne singly, in pairs or sometimes in threes, in lateral clusters.

Fruit globose, usually less than one-half inch in diameter, dark blue, almost black, with a heavy bloom; flesh juicy, firm, with an acid, austere taste, scarcely edible for a dessert fruit but making a very good conserve; stone turgid or but little flattened, acute on one edge.

European botanists commonly break the species into a number of sub-species, as:-Prumus spinosa typica Schneider, ${ }^{1}$ flower-pedicels and calyx-cup glabrous; Prunus spinosa praecox Wim. and Grab., ${ }^{2}$ pedicels short, blossoms appearing before the leaves; Prums spinosa sessiliflora Beck, ${ }^{3}$ with sessile flowers, possibly the same as the next preceding form; Prumus spinosa coatanea Wim. and Grab.4, blossoming with the leaves and with long pedicels; and Prunus spinosa dasyphylla Schur. ${ }^{\text {, }}$ flower-pedicel and calyx-cup more or less hairy. Besides these botanical sub-divisions there are several horticultural forms as follows:

Prunus spinosa flore-pleno of the nurserymen is a double-flowered form, making a beautiful little shrub or small tree much planted in gar-

${ }^{1}$ Handb. Laubh. 628. 1906.

${ }^{2} \mathrm{Fl}$. Siles. $1: 2,10$. 1829 .

'Fl. Nied. Osir. 819 . I 890 .

- Fl. Siles. $1: 2,10.1829$.

${ }^{5}$ Enum. Pl. Trans. 178 . 1866. 
dens in Europe and somewhat in America. Its blossoms are pure white, about half an inch in diameter and not quite double, as the stamens form an orange cluster in the center of the flower. The flowers are thickly crowded on short spiny branches, the dark color of which forms a striking contrast to the white flower. Prunus spinosa purpurea is another horticultural group, more vigorous than the species, less thorny and with larger foliage. Its branches are erect, purplish in color, striated. The leaves and petioles are at first very pubescent but at maturity glabrous; the upper surface of the leaf is green marked with red, the under a decp reddish-violet. The flowers are a pale rose. One or two variegated forms of this species are also offered by nurserymen.

Schneider holds' Prunus fruticans Weihe' and Prunus spinosa macrocarpa Wallroth ${ }^{3}$ to be crosses between Prunus spinosa and Prunus insititia.

Prunus spinosa, the Blackthorn or European Sloe, is the common wild plum of temperate Europe and the adjoining parts of Asia. It is adventive from Europe to America and is now quite naturalized along roadsides and about fields in many places in eastern United States. Prumus spinosa is considered by some authors the remote ancestor of the Domestica and Insititia plums, but as brought out in the discussion of the last named species, such parentage is very doubtful.

The Spinosa plum is a common and often pestiferous plant in its habitat, the roots forming such a mass that in general it is impossible for any other vegetation to grow in its vicinity. The plant is small, spreading and much branched and bristles with sharp thorns. The leaves are smaller than those of any of the other Old World species, ovate in shape and very finely serrate. The flowers are usually single but sometimes in pairs or threes and are borne in such number as to make a dazzling mass of white; comparatively few of these, however, set fruit. The fruit is round and small, usually less than half an inch in diameter, and, typically, so black as to have given rise to the old saying, "as black as a sloc." The fruits are firm but rather juicy, with an acid, austere flavor, which makes them unfit for eating out of hand until frost-bitten, when the austereness is somewhat mitigated. The stone is much swollen, with one edge acute.

'Handb. Laubh. 1: 630 . I 906.

${ }^{2}$ Flora $9: 748.1826$.

${ }^{3}$ Sched. Crit. 217.1822 . 
European nurserymen now and then offer trees of the Spinosa plum for fruit-growing, sometimes with the statement that the fruit is sweet. But pomologists do not speak highly of these cultivated Spinosas and hold that they are hardly worth cultivation. The wild plums are quite commonly picked for certain markets in Europe, however, especially those in which the Domesticas and Insititias are not common. With plenty of sugar the fruits make a very good conserve. In France the unripe fruit is pickled as a substitute for olives and the juice of the ripe fruit is sometimes used to make or adulterate cheap grades of port wine. In the country districts of Germany and Russia the fruit is crushed and fermented and spirit distilled from it.

The species is quite variable within limits, but since the wild fruits have been used from the time of the lake-dwellers of central Europe, without the appearance of desirable forms, the variations are not likely to give horticultural varieties worth cultivating for table use. The variations in the fruit are usually in color, the size and flavor changing but little. Several ornamental forms are in cultivation, of which the chief ones have been named.

4. PRUNUS CURDICA Fenzl and Fritsch.

1. Fenzl and Fritsch Sitzb. Akad. Wien. Bd. CI. 1:627. 1892. 2. Schneider Handb. Laubh. 1:628. 1906.

The few herbarium specimens that the writer has seen of this species from southeastern Europe strongly resemble Prunus spinosa but Schneider in the above reference describing it from living specimens says that it differs from the species last named as follows: "Lower growth, about onehalf as high, spreading squarrose ramification, much less thorniness; leaves more like domestica, when young hairy on both sides, later above nearly and underneath more or less glabrous; petiole shorter, not exceeding one cm.; blooms later, nearly with the leaves, white, about twentytwo $\mathrm{mm}$. in diameter, borne almost always single in this species; pedicel finely pilose, in Prunus spinosa almost glabrous; stamens fewer, about twenty; fruit blue black, stem longer, exceeding twelve mm."

So far as appears from the few and scant European references to the species it has no horticultural value.

\section{PRUNUS COCOMILIA Tenore.}

I. Tenore Fl. Neap. Prodr. Suppl. $2: 68$. 1811. 2. Schneider Handb. Laubh. I:628. 1906.

Tree shrub-like, top thick, broadly ovate; branches drooping, shoots short; branchlets glabrous, young wood olive or reddish-brown. Buds small, roundish-ovate; leaves 
roundish-obovate, sharply and distinctly serrated, glabrous or upon the ribs on the under side sparsely pubescent. Flowers usually in pairs, opening before or with the leaves, greenish-white, pedicels about the length of the calyx-cups. Fruit yellow, agreeable.

The writer has seen only herbarium specimens of this plant and has taken the description given from European texts. According to Schneider the species has been divided into two varieties by the Italian botanists. Prumus cocomilia typica having oblong-ovate fruit and Prunus cocomilia brutia having round fruit. Schneider holds also that Prunus pseudoarmeniaca Heldr. and Sart. ' from Epirus and Thessaly is a variety of Prumus cocomilia differing chiefly in having more pointed leaves and smaller oblong-roundish red plums. The same author puts in this species still another plum, a hairy-leaved form from Thessaly which he calls Prunus cocomilia puberula. He places here also Prumus ursina Kotschy ${ }^{2}$ which differs only in minor respects from the species, chiefly in having violet-red fruit though Boissier ${ }^{3}$ mentions a yellow-fruited plum which he calls Prumus ursina flava. The last named plums come from Lebanon and North Syria.

\section{PRUNUS CERASIFERA Ehrhart *}

1. Ehrhart Beitr. Nat. 4:17. 1789. 2. Hooker Brit. Fl. 220. 1830. 3. Kooch, K. Dend. I:97. 1869. 4. Koch, W. Syn. Deut. und Schw. Fl. 1:727. 1892. 5. Bailey Cornell Sta. Bul. 38: 66. 1892. 6. Schneider Handb. Laubh. 1:632. 1892. 7. Schwarz Forst. Bot. 339. 4892.8. Dippel Handb. Laubh. I:633. I 893 .

P. domestica myrobalan. 9. Linnaeus Sp. Pl. 475. 1753.

10. Seringe DC. Prodr. $2: 538$. 1825.

P. myrobalan. I1. Loisleur Nouv. Duham. 5:184. 1812.

12. Koehne Deut, Dend. 316. I893.

Tree small or a tree-like shrub, seldom exceeding twenty-five feet in height; branches upright, slender, twiggy, unarmed or sometimes thorny; branchlets soon glabrous, becoming yellow or chestnut-brown; lenticels few, small, orange in color, raised.

Winter-buds small, obtuse, short-pointed, pale reddish-brown; leaves small, shortovate, apex acute, base cuneate or rounded, thin, membranaceous, texture firm, light green, nearly glabrous on both surfaces at maturity, though hairy along the rib on the lower surface, margins finely and closely serrate; petiole one-half or three-quarters of an inch long, slender, usually glabrous, glandless.

Flowers large, three-quarters of an inch in diameter, expanding very early or mostly with the leaves; calyx-lobes lanceolate, glandular, reflexed; petals whitc, sometimes with a blush, ovate-oblong or orbicular, the base contracted into a claw; borne singly, sometimes in pairs, in cymes on long, slender, glabrous peduncles.

${ }^{1}$ Boiss. Diag. 2nd Ser. $96 . \quad 1856$.

${ }^{2}$ Verh. Zool. Bot. Ges. Wien. 435. I 864 .

slor. Or. I1: 625 . 1872 .

- In pre-Linnaean literature Prunus cerasifera is mentioned by Clusius as Prunus myrobalanus (Rar. Plant. Hist. 46 fig. $\mathrm{x} 60 \mathrm{I}$ ), and by Tournefort under the same name (Inst. Rei Herb. 622. 1 700 ). 
Fruit small, one-half inch or a little more in diameter, globular or depressed-globular, cherry-like, red or yellow; skin thin and tender; flesh soft, juicy, sweet and rather pleasantly flavored; stone oval, short-pointed at both ends, somewhat turgid, ridged on one suture and grooved on the other.

Prumus cerasifera, the Cherry plum, first came to notice in pomological literature as the Myrobalan plum, a name used as early as the last half of the Sixteenth Century by Tabernæ-Montanus and given prominence in the Rariorum Plantarum Historum, published by Clusius in r6or. Why applied to this plum is not known. Myrobalan had long before been used, and is still, as the name of several plum-like fruits of the East Indies, not of the genus Prunus, which are used in tanning, dyeing, ink-making and embalming. Until Ehrhart gave it the name Prumus cerasifera in 1789 it was known as the Myrobalan plum by botanists, some of whom, and nearly all horticulturists, have continued the use of the name until the present time.

Not a few of the botanists who have used Myrobalan for this plum have called it a botanical variety of Prunus domestica. Among these were Linnaeus and Seringe. Others, as Loisleur and Poiteau, have preferred the name for the species as distinguished by Ehrhart.

Many of the early botanists, as Tournefort in 1700 , Ehrhart in I 701 , Loudon in 1806 and Loisleur in 1812 , gave the origin of the Cerasifera plums as North America, but upon what authority does not appear. On the other hand many European botanists, including Linnaeus, gave the habitat as Europe or Asia. The supposition that this plum came from North America hardly needs discussion. The plum flora of this continent has been well enough studied so that it can be said that no plant that could by any possibility be the Cerasifera plum grows on this side of the Atlantic. Neither does it seem logical to consider this an off-shoot of Prumus domestica, for fruit and tree-characters are distinctly different, and for a member of the genus Prunus are remarkably constant. Moreover, there is abundant evidence to show that this is a distinct species and that its nativity is in the Turkish and nearby countries in Europe and Asia and that there it has been in cultivation for a long time.

It is very significant that in the old herbals and botanies a frequent name of this fruit is "the Turkish plum." But more specific and almost conclusive proof is that two forms of plums belonging to this species are known to come from the Caucasus region. Prunus divaricata ${ }^{\prime}$ is now consid-

\footnotetext{
${ }^{1}$ Ledebour Ind. Hort. Dorp. Suppl. 6. I 824 .
} 


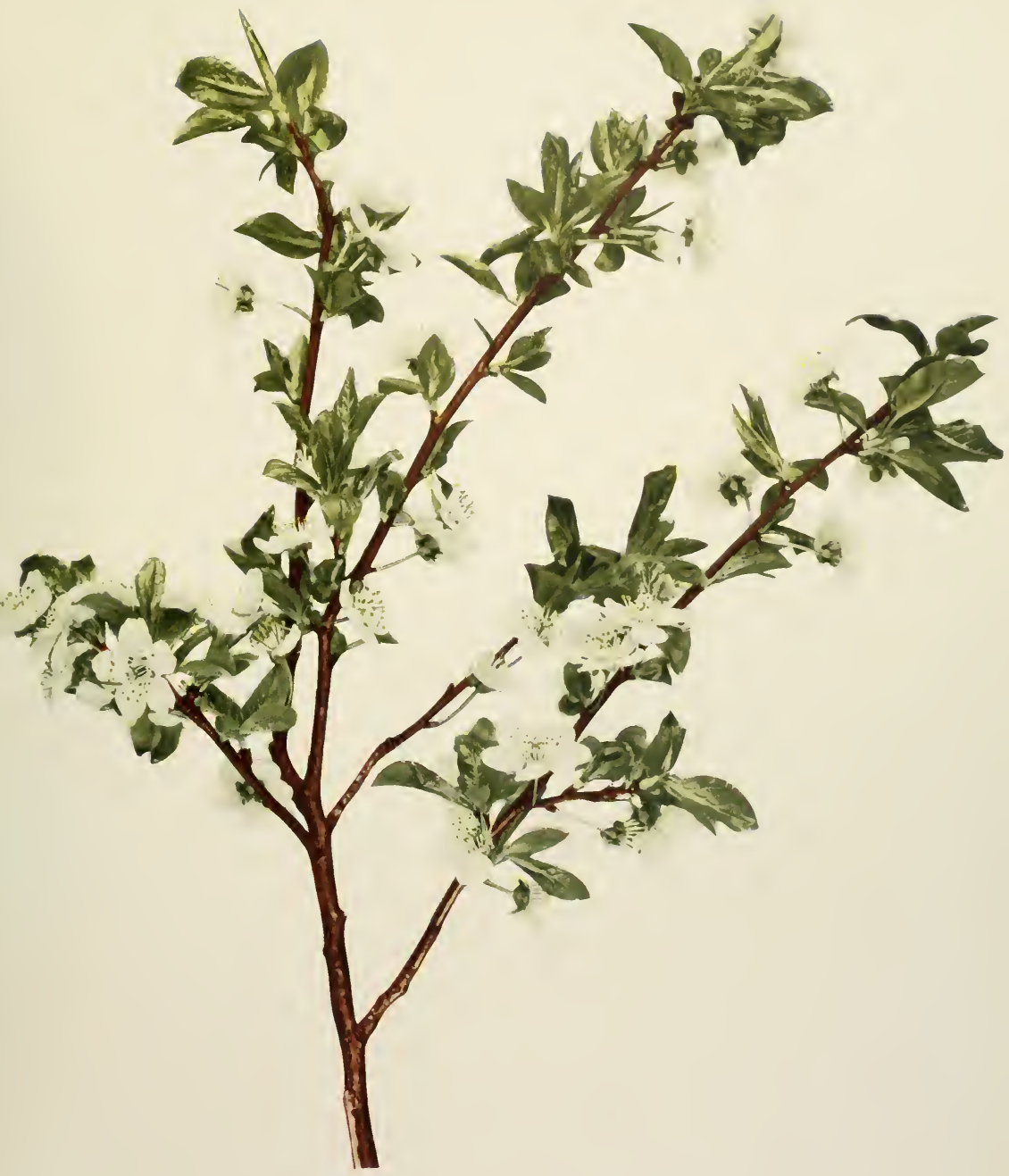



ered by some botanists to be a synonym of Prunus cerasifera and by others to be a botanical variety of the last named species. Ledebour, who named it, found it in the Trans-Caucasian region. It differs from the type only in having much divided, wide-spreading and nearly prostrate branches. The Pissardi plum, a purple-leaved form of this species, originated in Persia. A plum now growing in the Arnold Arboretum raised from sced from Turkestan, presumably from wild stock, is identical with plants of Cerasifera of European origin. And, according to Schneider, ${ }^{2}$ this plum is known in the wild state in Caucasus, Trans-Caucasus, northern Persia and Turkestan.

The Cerasifera plums are small trees, usually upright but in some forms with spreading branches which are commonly unarmed, glabrous and brownish in color. The leaves are ovate and smaller and thinner and with more finely serrate margin than those of the Domestica plums. It blooms prolifically and bears large, white, single or paired flowers, making a most beautiful tree when in flower. The fruit is small, round, and cherrylike, from half an inch to an inch in diameter, usually red but sometimes yellow. The flesh is soft, sweetish or sub-acid and poor. The stone is turgid, smooth and pointed. The species is variable in nearly all tree-characters, and were it not surpassed by other plums for its fruit there would undoubtedly be a great number of varieties cultivated for the markets. There are, however, but few cultivated Cerasiferas, only nineteen being described in The Plums of New York. It is very generally distributed wherever plums are grown, because of the use to which it has been put as stocks for other species. For this purpose it is held in high esteem the world over. In the nurseries of New York it is now used more than any other stock and it is common to find it fruiting here and there from plants set for or used as stocks. In fact practically all the cultivated varieties have arisen as survivals of plants meant for stocks. It is almost certain that the Cerasifera, or Myrobalan, as it is universally known by horticulturists, dwarfs the cion and that it is not equally well suited to all varieties; but it does not "sprout" as badly as some other stocks, is adapted to many soils, and the young trees grow well and are rapidly budded, giving at the start a strong and vigorous orchard tree.

The Cerasifera plums are handsome trees. The foliage is a fresh and beautiful green and whether covered with a mass of flowers or loaded with red or yellow fruit these plums are as handsome as any of our cultivated fruit trees, and as desirable for ornamentals.

2 Schneider Handb. Laubh. 632. 1906. 
The hardiness, thriftiness, freedom from disease and adaptability to soils make the species desirable for hybridizing. A number of breeders of plums have made use of it with some indications of a promising future, several interesting hybrid offspring of this species being described in The Plums of New York.

The small number of varieties of Cerasifera cultivated for their fruit indicates that but little can be expected from this species by plum-growers, since so little has come from it in the shape of edible fruits, though it has been under general cultivation for over three hundred years, at least, as an ornamental and as a stock. Several valuable groups of ornamentals have arisen from Cerasifera, of which the following are most notable :-

In I880 M. Pissard, gardener to the Shah of Persia, sent to France a purple-leaved plum which proved to be a form of Prunus cerasifera. To this plum Dippel ${ }^{1}$ gave the name Prunus corasifera atropurpurea, while horticulturists very generally call it Prunus pissardi. A close study of the purple-leaved plum reveals no character in which it differs from the species except in the color of foliage, flowers and fruit; the leaves are purple, as are also the calyx and peduncles of the flowers, while the fruit is a dark wine-red. These are but horticultural characters and do not seem to be of sufficient importance to establish for this plant a botanical variety. This view is strengthened by the fact that Jack " reports that seeds from the purple-leaved plum have produced plants which agree in all essential particulars with the species; while $\mathrm{Kerr}^{3}$ has grown a purpleleaved plum from a variety of Prunus cerasifora.

Besides this well-known purple-leaved plum nurserymen offer Prumus pendula, a weeping form; Prunus planteriensis, bearing double white and red flowers; Prunus acutifolia, a plum with narrow, willow-like leaves; Prunus contorta, characterized by twisted, contorted foliage; Prumus clegans, Prunus gigantea, and a variety with yellow and another with variegated leaves, etc. All of these are probably horticultural varieties of Prunus cerasifera though some of them cannot be classified with surety.

Schneider " calls Prunus dasycarpa Ehrhart," the Prumus armeniaca dasycarpa of Borkhausen, ${ }^{\circ}$ a cross between Prumus cerasifera and Prumus armeniaca, one of the apricots.

\footnotetext{
${ }^{1}$ Dippel Handb. Laubh. 3:633. 1893.

2 Jack Gar. and For. 5:64. ${ }^{2} 892$.

${ }^{3}$ Bailey Cornell Sta. Bul. 38:34. 1892 .

4 Handb. Laubh. 1:633. 1906.

5 Beitr. Nat. 6:90. 179 I.

- Handb. Forstb. 11:1392. $18 \circ 3$.
} 


\section{PRUNUS MONTICOLA K. Koch}

x. Koch, K. Ind. Sem. Hort. Berol. App. 1854. 2. Schneider Handb. Laubh. 1:632. 1906.

Plant shrub-like, slender, upright, scarcely thorny, new wood more or less olivebrown. Buds short, ovate; leaves roundish or cuneiform, base oblong-ovate, point drawn out, main nerves over six on both sides, the serrations coarse and uniform in size, always glabrous. Flowers mostly in twos; borne on long, slender peduncles; calyx usually glabrous; petals white, odor slight; stamens thirty or more. Fruit small, roundish-oblong, red; stone ovoid, pointed at one end, somewhat turgid.

Prunus monticola is described by the above authors as a shrub-like plum from Asia Minor and Armenia having, so far as can be learned from European texts, little or no horticultural value. The herbarium specimens seen by the writer indicate that this species is closely related to Prumus cerasifera. The description of the species is abbreviated from Schneider.

\section{PRUNUS TRIFLORA Roxburgh}

1. Roxburgh Hort. Bengal 38. 1814. 2. Ibid. Fl. Indica 2:501. 1824. 3. Schneider Handb. Laubh. 1:627. 1892. 4. Bailey Cornell Sta. Bul. 62, 1894. 5. Waugh Plum Cult. 42. I901.

P. domestica. 6. Maximowicz Mel. Biol. 11:678. 1883 .

P. hattan Tamari. 7. Bailey An. Hort. 30. 1889 .

P. communis. 8. Forbes and Hemsley Jour. Linn. Soc. 23:219. 1886-88.

$P$. japonica of horticulturists (not $P$. japonica of Thunberg).

Tree twenty to thirty feet in height, vigorous; trunk six to twelve inches in diameter, straight; bark thick, rough, numerous corky elevations especially on the branches, reddish or cinnamon-brown, peach-like; branches long, upright-spreading, much forked, brash and often splitting at the forks; branchlets thick, straight, glaucous and glabrous, at first light red, growing darker the second year; lenticels few or many, usually small but conspicuous, light in color.

Winter-buds small and obtuse, free or appressed; leaves borne abundantly, small or of but medium size, oblong-obovate, point acuminate or abrupt, prominent, base rounded, firm, thin, membranaceous, margins finely and closely serrated, sometimes in two series, teeth usually glandular; upper surface bright green, glabrous, lower surface dull, whitish, glabrous or slightly pubescent on the veins; veins pronounced; petioles one-half inch in length, stoutish, tinged with red; glands few or several, usually globose, greenish; stipules lanceolate, very narrow, one-half inch long, caducous.

Flowers expanding early, before, with or sometimes after the leaves, first of the plum blossoms to appear, very abundant, three-quarters of an inch in diameter; usually three springing from each flower-bud, often in dense clusters on lateral spurs and lateral buds on one-year-old wood; calyx-tube green, glabrous, campanulatc or obconic; calyxlobes acute to obtuse glandular-serrate, erect, glabrous or pubescent; petals white, oval, entire or crenate, with a short claw or tip; stamens about twenty-five, shorter than the petals; anthers yellow, sometimes tinged with red; pistils glabrous, longer than the stamens; pedicels one-half inch long, slender. 
Fruit varying greatly in season, from very early to late; large, from one to two inches in diameter, globular, heart-shaped or often somewhat conical; cavity deep; apex conspicuously pointed; suture usually prominent; color varies greatly but usually a bright red or yellow, never blue or purple, lustrous, with little or no bloom; dots small, numerous, usually conspicuous; skin thin, tough, astringent; stem one-half inch in length; flesh red or more often yellow, firm, fibrous, juicy; quality variable, of distinct flavor, usually good; stone clinging tenaciously or nearly free, small, rough or lightly pitted, oval to ovate, one edge grooved, the other ridged.

A study of the botanical characters of the many Triflora plums under cultivation fails to show any lines of cleavage whereby the species can be divided. Of plums commonly grown in America it is not very closely related to any unless it be Prumus simonii. There are several plums from eastern and central Asia with which we are not at all familiar in America that may show relationship with Prunus triflora, chief of which are Prumus ichangana Schneider," Prumus thibetica Franchet ${ }^{2}$ and Prumus bokhariensis Royle, ${ }^{3}$ the last a cultivated plum from northern India. These, in herbarium specimens, have some characters reminding one of Prunus triflora, others of Prunus domestica and still others, of Prunus cerasifera.

The Triflora, or Japanese, ${ }^{4}$ plums are now cultivated in all parts of the world where plums are grown; yet outside of Japan and China they have been grown for their fruit less than half a century. Despite the fact that these plums have been grown in Asia for several centuries the wild form is not known. Indeed, there are doubts in the minds of some as to whether it constitutes a distinct species, Maximowicz, an authority on the flora of Japan, among others, holding that it is but a form of Prunus domestica. Roxburgh in naming it gave but little definite information in regard to the species, but the herbarium specimens of his in the Kew Herbarium are readily identified as identical with our Japanese plums. The confusion between Prunus triflora and Prumus domestica seems needless, as the points of difference between these two species are several and very distinct and constant, the resemblances between Prumus triflora and

${ }^{1}$ Fedde Repert. $\mathbf{I}: 50.1905$.

${ }^{2} \mathrm{Pl}$. David $2: 33$. 1888 .

${ }^{3}$ Ill. Bot. His. Mountains and Fl. of Cash. I:239. 1839.

1 Several apricots and the loquat of southern Japan are also called Japanese plums. The name Triflora for common usage avoids this confusion and conforms with the growing usage in horticulture of using the specific name alone.

5 Bailey says, (Cornell Sta. Bul. 62:6. 1894) speaking of these specimens: "I have no hesitation in saying that our Japanese plums are the same." The writer examined the specimens in the summer of 1909 and recognized them at once to be the same as the cultivated Triflora plums. 


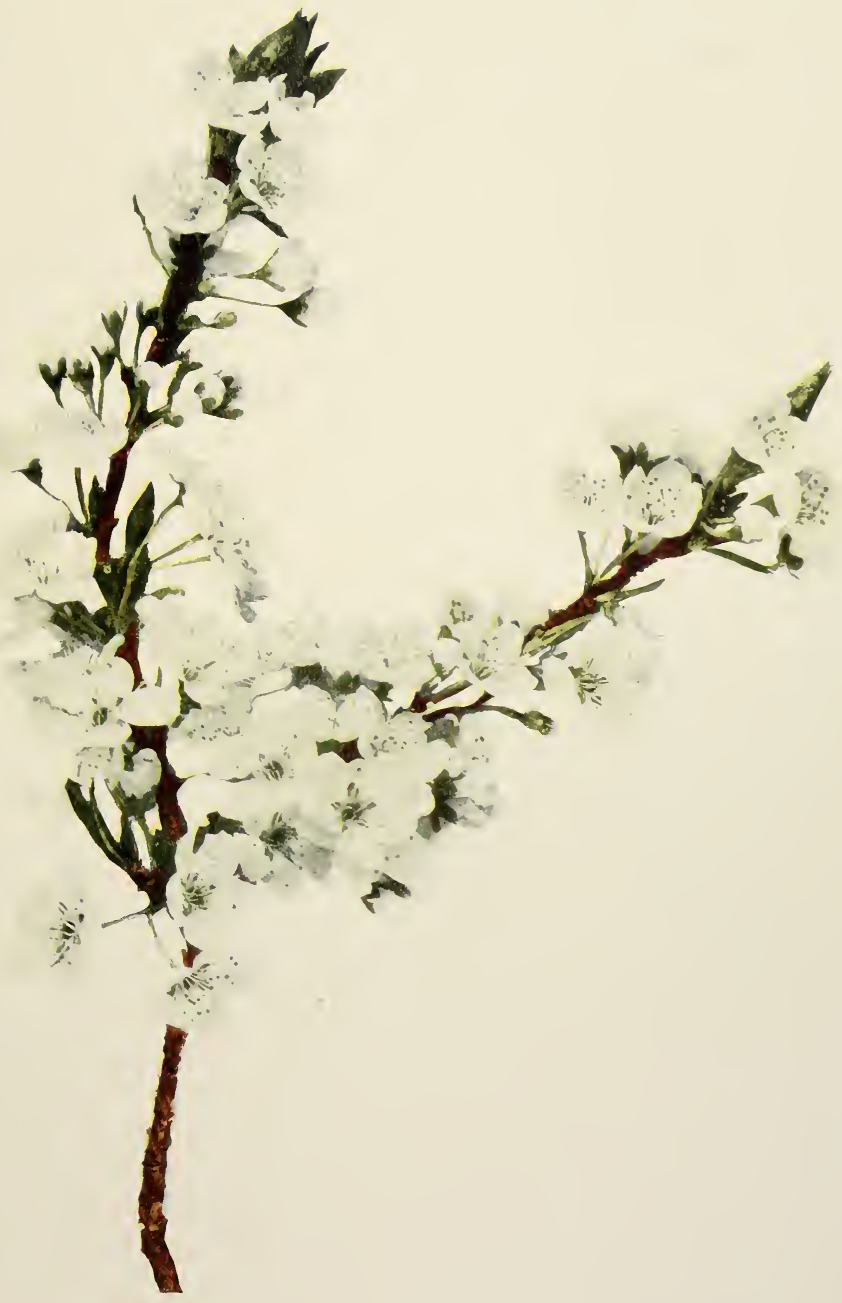



some of the American species being much closer. So, too, the effort, sometimes made, to make more than one species out of Prunus triflora is straining a point, for though the types under cultivation vary considerably yet the variations are not greater than between varieties of other species of the genus Prunus.

Prumus triflora is almost certainly a native of China. According to Georgeson and Sargent, who have made extensive botanical explorations in the forests of Japan, there are no indigenous plum trees in that country. Dr. K. Miyake, botanist at the Agricultural College of the Imperial University, Tokyo, Japan, writes to this Station, ${ }^{1}$ that Prunus triflora does not grow wild in Japan but was introduced there from China from two to four hundred years ago. Bretschneider ' in his treatise on The Study and Value of Chinese Botanical Works says that the plum has been cultivated from ancient times in China and this indicates that the original habitat was in that country. Mr. F. N. Meyer, Agricultural Explorer for the United States Department of Agriculture, who has made extensive agricultural explorations in China, writes ${ }^{3}$ that he has seen many trees of Prunus triflora cultivated in the Chekiang Province and also about Canton but that he had not found the species growing wild. Roxburgh says " that the shrub had been "received from China into our gardens in Bengal." Forbes and Hemsley " state that varieties of this plum are cultivated in China and that it occurs in the wild state in the mountains near Peking as well as on the Tsunglin range in Shensi and Kansu. These writers are, however, uncertain as to where it is truly indigenous.

While the above and practically all evidence points to China as the original home of Prunus triflora it is likely that the habitat of the species cannot be accurately determined until western and southwestern China have been explored by botanists, these regions as yet being almost unknown to foreign scientists.

Notwithstanding the illustrious work of Kaempfer, Thunberg, Siebold and Fortune in sending to Europe the choicest plants of Japan and China, Prunus triflora seems to have reached the Old World through America at a very recent date. At least the species was not cultivated for its fruit in Europe until introduced from the United States as Japanese plums,

1 February 23, 1909.

3 pp. 10, 45 .

'March 12, 1909 .

- Fl. Indica 501. 1824 .

B Forbes and Hemsley Jour. Linn. Soc. 23:219. 1886-88. 
and even yet they are but barely known in European orchards. The species was introduced into this country from Japan about $187^{\circ}$ by a Mr. Hough of Vacaville, California. According to Bailey, ${ }^{1}$ who has given much attention to these plums, Mr. Hough obtained his trees from a Mr. Bridges, United States Consul to Japan. John Kelsey, Berkeley, California, produced the first ripe fruit of the Triflora plums in America in 1876 and 1877 , and impressed by their value began recommending them. Owing to Mr. Kelsey's efforts the propagation of these plums was begun on a large scale about $188_{3}$ by W. P. Hammon \& Co., of Oakland, who commemorated Mr. Kelsey's labors by naming the plum after him. The success of the Kelsey started the importation and origination of varieties and a veritable boom in Japanese plums was soon under way.

This fruit is a most valuable addition to our pomology, no less than ninety-two varieties now being under cultivation in America. At first it was thought desirable only for the southern states, but it proved to be nearly as hardy as the Domestica plums in the northern states and was soon widely distributed north and south. Beyond question it has suffered from over-praise, which has led to over-planting. As was of necessity the case, many untested and worthless varieties were offered fruit-growers, and these, with the failure of some of the extravagant claims for the really meritorious varieties, have given the Triflora plums a bad reputation with many fruit-growers. Now we have cultivated plums of this species for forty years and there has been time for the excitement of their discovery and the consequent reaction to abate making it possible to arrive more nearly at their true place in pomology.

The plums of this species possess several striking features that commend them to fruit-growers. Undoubtedly the most valuable attribute of the Triflora plums as cultivated fruits is their wide range of adaptability. All must admit that this group of varieties is less valuable than the Domestica varieties where both succeed, but the Triflora plums are adapted to a much wider range of country and of conditions than the Domesticas. But even where both types of plums succeed the newer plum introduces several very desirable features quite aside from additional variety which the many distinct sorts furnish. Thus, as a species, the Trifloras are more vigorous, productive, earlier in coming in bearing and more free from diseases, especially black-knot and leaf-blight, than the

\footnotetext{
${ }^{1}$ Cornell Sta. Bul. 62:3. 1894 .
} 
Domestica plums. The Trifloras are also less subject to curculio than most of the native and European species. They keep longer and ship as well as the better known Europeans. As compared with native varieties the plums from Japan are larger, handsomer and better flavored and keep and ship better. Some disadvantages are that they blossom so early as to be often caught by spring frosts; they are quite subject to brownrot; for most part they are tenacious clingstones; the species, all in all, is less hardy to cold than the Domestica plums; lastly, they are inferior in quality to the varieties from Europe. The last fault is so serious that, though the average for the Triflora plums is high, making them unquestionably more desirable inhabitants of the orchard than any of the native species, they cannot compete with the Domesticas where the two types can be equally well grown.

The botanical differences between these Asiatic plums and those from Europe and America are most interesting. In 1859 Asa Gray called attention to the striking resemblances between the east coast floras of Asia and America. The Triflora plum is one of the plants which furnishes substantial evidence of this similarity and of the dissimilarity of the east and west coast floras of the two hemispheres. In general aspect the trees of the Triflora plums in summer or winter are much more like those of the American species than like those from Europe or West Asia; so, too, the fruits are more alike in appearance and in quality, and the peach-like foliage of the Trifloras might easily be mistaken for that of some of our varieties of Hortulana or Munsoniana. In the manner in which the buds are borne and in vernation the resemblance of the Oriental species to the Americanas, Hortulanas and Munsonianas is again most striking. In Asiatic and American species the buds are borne in twos and threes, while in the European species they are more often single or double.

The importance of this similarity of the Triflora plums to the most common American species is seen when Gray's reason for the likenesses between the two floras is considered. This, briefly, is that similar types of post-glacial plants should persist in areas having like geographical positions and like climates; hence east-coast plants in one hemisphere should be expected to be similar to those of the east coast of the other hemisphere and the same with the west coast. Triflora plums are near of kin to American plums, then, because they have been evolved under similar conditions. This is a reason why these plums from Japan are adapted to so wide a range of country in America, and why, too, they 
are so free from the fungus troubles which attack European plums, but from which American plums suffer but little.

As might be expected from their nearness of kin the Triflora plums hybridize readily with the American species and especially with the Hortulanas and Munsonianas, the species they most resemble. Unfortunately an amalgamation of the Oriental plums with the Americanas is not so easily accomplished and that with the Domesticas is still more difficult. Hybrids with Prunus simonii are easily made and the progeny as a rule have much merit. Hybrids of the Trifloras with our native species give most promising results, a number of them being described in The Plums of New York. The fact that the Trifloras have been cultivated for several centuries, at least, means in their hybridization with American species that there is an amalgamation of domesticated characters with the similar but wilder characters of our native species.

It has been very difficult to establish a satisfactory nomenclature for the Triflora plums now grown in America. In spite of the excellent work of Berckmans, ${ }^{1}$ Bailey ${ }^{2}$ and Waugh, ${ }^{3}$ in bringing order out of what was at one time utter confusion, there is still a great deal of uncertainty as to the identification of some varieties. The confusion began with the first extensive importation of these plums from Japan when names which the Japanese applied to classes or groups or the localities from which the plums came were made to apply in America to definite varieties. Many of the names under which the plums were imported have had to be dropped and the varietics boldly renamed. Another source of confusion has been that these, of all plums, seem most variable under changed conditions. Local environment in many instances in America changes somewhat the habit and appearance of varieties, making it difficult to decide whether two or more specimens of the same sort from different localities are identical varieties or distinct. Curiously enough, too, the trees of some varieties of plums seem to bear unlike fruit in different years, especially in the matter of time of ripening; that is, trees of some varieties do not always ripen their fruit in the same sequence, being earlier than another variety one year and possibly later the next. All fruits are more or less variable in this respect, but the Triflora plums are remarkably so, a fact that has added to the confusion in their nomenclature, since it adds to the difficulty of identifying varieties.

\footnotetext{
${ }^{1}$ Berckmans, L. A. Rpt. Ga. Hort. Soc. 15. 1889 .

${ }^{2}$ Bailey, L. H. Cornell Sta. Buls. 62, 106, 139, 175.

s Waugh, F. A. Plum Cult. 190r.
} 
The cultivated varieties of Prunus triflora are also very diverse as regards tree-characters, especially as to vigor, hardiness and time of maturity of the fruit. The differences seem to be horticultural or those that come from cultivation, rather than botanical. Indeed, it seems impossible to place the numerous varieties in horticultural groups that are marked with any great degree of definiteness. A distinction of groups based on color is sometimes made, but the one character is insufficient to have classificatory value. In Japan, according to Georgeson, a division of the species is made with shape as the line of division. He says " "The round plums are designated by the term botankio, while those of an oval or pointed shape are called hattankio." The varieties are sometimes loosely grouped into yellow and red-fleshed sorts. A serviceable classification would have to be founded on several or a considerable number of characters. Such a classification at present is impossible.

\section{PRUNUS SIMONII Carrière}

1. Carrière Rev. Hort. III. $\mathrm{I}_{722^{2}}$

Tree small, of medium vigor, upright, dense, hardy except in exposed locations, unproductive; branches stocky, long, rough, thickly strewn with small lenticels; branchlets slender, long, with internodes of medium length, reddish, glabrous; leafbuds intermediate in size, short, obtuse, free.

Leaves folded upward, oblong-lanceolate to obovate, peach-like, narrow, long, of medium thickness; upper surface dark green, smooth, shining, lower surface pale green, not pubescent, with prominent midrib; margin slightly crenate; petiole short, thick, faintly tinged red, often with four large globose glands on the stalk.

Flower-buds numerous on one-year wood although found on spurs on the older wood; flowers appearing very early, semi-hardy, small, pinkish-white; borne singly or in pairs, often defective in pollen.

Fruit maturing early; one and three-quarters by two and one-quarter inches in size, strongly oblate, compressed; cavity deep, wide, flaring, regular, often slightly russcted; suture variable in depth, frequently swollen near the apex which is flattened or strongly depressed; dark red or purplish-red, overspread with waxy bloom; dots numcrous, small, dark colored, with russet center, ineonspicuous; stem thick, characteristically short being often one-quarter inch long; skin of medium thickness, tough, bitter, adhering to the pulp; flesh rich yellow, medium juicy, tough, firm, very mild sub-acid with a peculiar aromatic flavor; of fair quality; stone clinging, about seven-eighths inch in diameter, roundish, flattened to rather turgid, truncate at the base, tapering abruptly to a short point at the apex, with characteristic rough surfaces; ventral suture narrow, acute or with distinct wing; dorsal suture very blunt or acute, not grooved.

${ }^{1}$ Georgeson, C. C. Amer. Gard. 12:74. I891.

'For references and synonymy see the Simon plum. 
All that is known of the history and habitat of this species is that it came from China in 1867 having been sent to the Paris Museum of Natural History by Eugene Simon, a French consul in China. The spontaneous form has not as yet been found. The general aspect of the tree is more that of the peach than the plum and the drupes are as much like apricots or nectarines as plums but when all characters are considered the fruit can better be classed with the plums than with any of the other stone-fruits named.

Prunus simonii has been widely grown in America both for its fruits and as an ornamental, but it cannot be said that it has become popular for either purpose and only one variety of the species is now under cultivation. As a food product the plums lack palatability and as ornamentals the trees are subject to too many pests. Prumus simonii has been successfully hybridized with Prunus triflora and as secondary crosses its blood has been mingled with that of some of the native species as well. Most of its hybrid offspring have more value than the parent, nearly all of them lacking its disagreeable taste. According to an article published in Revue Horticole ${ }^{1}$ a new form of the Prunus simonii was produced in 1890 from a bud sport, the fruit of which is elongated, a little cordate, slightly unequal, and grooved on one side. So far as can be learned this sport has no very decided merits as a horticultural plant.

\section{PRUNUS AMERICANA Marshall}

r. Marshall $A r b, A m$. II I. I785. 2. Eaton and Wright $N . A m$. Bot. 377. I840. 3. Torrey and Gray $\mathrm{Fl}$. N. Am. 1:407. I840 (in part). 4. Torrey Fl. N. Y. I:I94. 1843 (in part). 5. Emerson Trees of Mass. 449. I846. 6. Nuttal Silva 2:rg. I846. 7. Darlington Fl. Cest. Ed. $3: 72$. 1853. 8. Torrey Pac. R. Rpt. 4:82. 1854. 9. Curtis Rpt. Geol. Surv. N. C. 56. 1860. 10. Ridgway Proc. U.S. Nat. Mus. 65. 1882. I1. Sargent roth Cen. U.S.9:65. 1883 (in part). I2. Watson and Coulter Gray's Man. Ed.6:151. I889 (in part), I3. Coulter Cont. U.S. Nat. Herb. 2:102. 1891. 14. Sargent Silva N. Am. 4:19, P1. 150. 1892, 15. Rydberg Cont. U.S.Nat. Herb. 3:156. 1895. 16. Ibid. 3:494. 1896. 17. Waugh Vt. Sta. Bul. 53:59. 1896. 18. Ibid. Vt. Sta. An. Rpt. 10:100. 1896-7. 19. Chapman Fl. Sou. U. S. 130. 1897. 20. Bailey Ev. Nat. Fr. I82, fig. I898. 21. Waugh Vt.Sta. An. Rpt. 12:231. 1899. 22. Mohr Cont. U. S. Nat. Herb. 6:551. 19or. 23. Bailey Cyc. Am. Hort. 1448 fig. 1901. 24. Rydberg Fl. of Colo. 193. 1906.

Tree attaining a height of thirty feet, slow but strong in growth, often shrubby; trunk thick, sometimes a foot in diameter, short, bearing the head at three to five feet; bark one-half inch thick, dark grayish-brown, outer surface rough, shaggy with large scales, with age becoming smoother, giving a characteristic aspect; branches spreading, crooked, long, rigid, but often pendulous at the extremities, more or less thorny, with lateral, spinescent branchlets; branchlets light green, usually glabrous, sometimes

${ }^{1}$ Carrière, E. A. Rev. Hort. I 52 . I 891. 


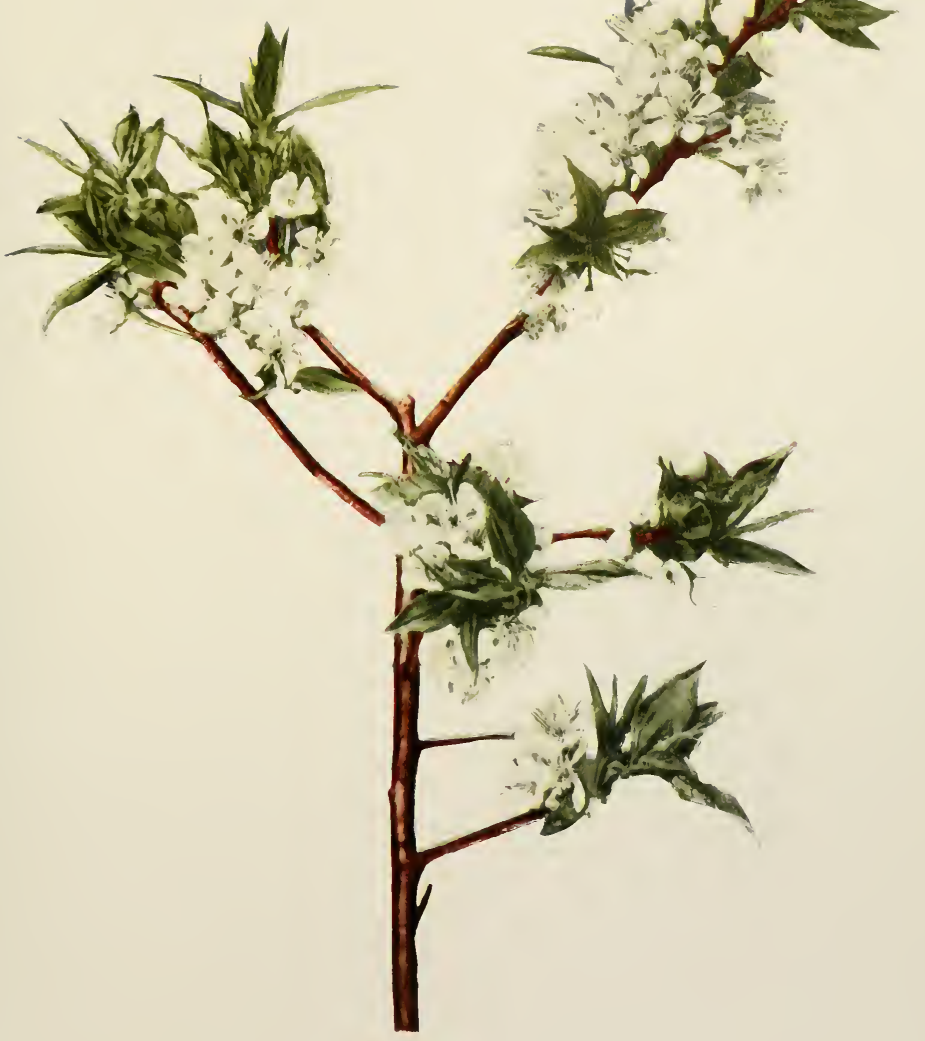



much or little tomentose, at first becoming brownish and later tinged with red; lenticels numerous, large and distinct.

Winter-buds medium in size, short, acute, appressed, reddish-brown; leaves large, obovate, oblong-obovate, or oval, acuminate at the apex and usually rounded at the base, thin and firm in texture, becoming somewhat coriaceous; margins sharply serrate, almost incised, often doubly serrate, the coarse and double serrations characteristic; teeth not glandular; upper surface more or less roughened, light green, the lower one glabrous or slightly hairy, sometimes pubescent, coarsely veined, the midrib grooved on the upper side; petioles slender, two-thirds inch in length, usually glandless; stipules long, sometimes three-lobed, falling early.

Flowers expanding after the leaves, large, an inch in diameter, borne in lateral umbels, two to five-flowered, mostly on one-year-old wood; pedicels one-half inch long, slender, usually glabrous; calyx-tube obconic, entire, glandular, reddish on the outer, green on the inner surface, glabrous; calyx-lobes acuminate, glabrous on the outer and pubescent on the inner surface, reflexed; petals white, sometimes with bright red at the base, rounded and often lanciniate at the apex, contracted into a long, narrow claw at the base; stamens about thirty in number, as long as the petals; anthers small, yellow; pistils glabrous, slender, as long as the stamens; stigma thick and truncate; anthers and pistils often defective; when in full flower emitting a disagreeable odor.

Fruit very variable in ripening period; globose, sub-globose, conical, oval, or sometimes oblique-truncate, usually more than an inch in diameter, red or rarely yellowish, mostly dull, with or without bloom; dots pale, numerous, more or less conspicuous; cavity shallow or almost lacking; suture a line; skin thick, tough, usually astringent; flesh golden-yellow, juicy, meaty, fibrous, sweetish, acid and poor but often good to very good; stone clinging or free, turgid or flattened, the apex pointed, ridged on the ventral and slightly grooved on the dorsal suture, surfaces smooth.

As Prunus americana is more carefully studied throughout the great territory it inhabits, undoubtedly one or more sub-species will be described. The plums of this species in the Mississippi Valley are distinguished from the eastern and typical form by fruits having a length greater than the diameter, by a somewhat different aspect of tree and by flatter seeds which are usually conspicuously longer than broad. All of the cultivated varieties come from the western form. The plant of Prunus americana in the dry plain regions in Kansas and Nebraska becomes shrubby in character while on the alluvial bottom lands along the streams in this region it retains the character of a tree. In the southern limit of its range, the leaves of this species are more or less pubescent on the lower surface. As the species occurs throughout western New Mexico, Colorado, Utah, Wyoming, Montana and Manitoba, it differs enough, possibly, from the eastern types to be considered a sub-species, having a wholly different aspect of tree, 
silvery and somewhat scurfy twigs, smaller, thinner and lighter colored leaves and smaller fruits with more roundish stones.

Prumus americana is the predominating native plum. It is the most widely distributed, is most abundant in individual specimens and has yielded the largest number of horticultural varieties of any of the native spceies. Because of its prominence and comparatively high degree of permanency of characters it may well be considered the type from which has sprung not only its botanical varieties but several other of the American species. Its variability, too, is shown in its many diverse horticultural varieties, and of its adaptability it may be said that it flourishes on nearly all soils and exposures, and is found wild or cultivated from Maine to Florida and northward from Mexico along the eastern slope of the Rocky Mountains well into Canada. The species was well named by Marshall "Americana."

This plum has not played nearly as important a part in the pomology of America as its merits would warrant. It seems to have made an impression almost from the first upon the Europeans who settled America, for it is mentioned in nearly all the early records of the food products of the newly found land, yet its cultivation can hardly be said to have begun until the last half of the Nineteenth Century. But the early descriptions of this and other native plums by the colonial explorers, naturalists and botanists, show but little interest in these fruits as subjects for cultivation, and seem to contain almost no prophecies as to the possible development of a new orchard plant from them. It is probable that the Damsons, which were early introduced in America, and the Domesticas, which came at least before the Revolution, proved so adaptable to the part of the New World in which the colonies were planted that this, even though the best of the wild plums, offered small reward in comparison.

It is certain, however, that from the very first, Americana plums were much used by the early settlers as wild fruits, for the histories of all the colonies and states in which plums are found contain innumerable references to wild plums, usually with some expression showing that they were considered makeshifts until the European plums could be grown. Long before white men came to America the possessors of the continent knew and esteemed these fruits of the woods. According to some of the early writers wild plums of this species, since found where the Americanas are dominant, were planted and rudely cultivated by the natives.' It

${ }^{1}$ The New York Agricultural Experiment Station stands on the site of the old Indian village of Kanadasaga, founded by the Seneca Indians. The records of Sullivan's raid just after the Revolution show that when this village was destroyed by the Whites there were orchards of apples and plums (see Conover's Kanadasaga and Geneva (Mss.) Hobart College) crudely cultivated. On 
is likely, however, that these Indian orchards were more often the result of seeds dropped about camping places and towns rather than regularly planted orcharis. It is not improbable that the wide distribution of this species in the Mississippi Valley and the country about and beyond the Great Lakes is due somewhat to the hand of the Indian, of the voyageur and of the missionary of the French regime.

The common names under which this plum passes in the states where it is found as a wild fruit are indicative of the knowledge possessed of it by the people. The Americana is nearly always the wild plum of eastern America. It shares with several other species the names in various parts of the country of Red Plum, Yellow Plum, the Horse and the Hog Plum. In Iowa this is most often the "native plum;" in Indiana it is the Goose plum; in Georgia, the August plum, while in the states bordering on the Gulf it is often called the Sloe.

The domestication of Americana plums is due to the fact that the plums of Europe will not thrive in the Mississippi Valley, the prairie states, nor, for the most part, in the South. The European species are tender both to cold and heat in these regions and they are attacked by those scourges of plum culture, black-knot, leaf-blight and curculio. If, then, the people in the West and South were to have plums at hand when wanted, the wild species had to be brought under cultivation. Where the two will grow side by side it is doubtful if any would choose to grow the Americanas in preference to the Europeans or even for the sake of variety.

The Americana plum was introduced into European gardens at an early date, for references to it are found in the pomological works of the Eighteenth Century, Duhamel having described it in his great work on pomology in I768, under the name Prunier de Virginie, and later Poiteau ${ }^{1}$ gives a very good description of it under the name Prune de la Gallissionicre. Just how much earlier than these dates it was taken to the Old World cannot be said, but seeds of it are likely to have been taken there by some of the returning explorers of early colonial times. The important fact is that as a cultivated fruit it has made absolutely no headway in competition in Europe with the plums of that continent though it is to be found not infrequently as an ornamental.

the adjoining farm of Mr. Henry Loomis descendants of these old trees still grow. The plums are Americanas, and Mr. Loomis, now in his $94^{\text {th }}$ year, says that when a boy the Indians and Whites alike gathered them, soaked them in lye to remove the astringency of the skins and then cooked, dried or otherwise preserved them.

1 Poiteau $x$ : (Unpaged). 1846. 
The domestication of these plums began less than a century ago, not through direct efforts in breeding them but as the result of the selection of the best of the wild or chance trees found in many widely separated localities. It would be most interesting to follow in detail the introduction of variety after variety of this species into cultivation, giving full credit to the men, many of them pioneers in newly settled countries, through whose efforts the amelioration of the species was begun. But space forbids, and the reader who desires to trace more fully the history and the evolution of these plums must put together the histories of the two or three hundred varieties of Americanas described in the chapters on varieties.

Are the Americanas to compete with the Domesticas, Insititias and Trifloras where all may be grown? It is very doubtful or at least not soon. The Old World plums are so superior, speaking generally, in size, appearance, and flavor, the qualities which appeal to those who eat plums, that the native varieties stand small chance for popular favor. Their place in pomology must long remain the region where the older and more highly developed groups of plums cannot be grown. Though there are now many times more of the Americana plums under cultivation than of the recently introduced Trifloras, the latter are more popular and are likely to remain so in localities where both can be grown.

The range of Prunus americana is seemingly increasing, making it almost impossible to give its present limits. The boundary line of its northern range passes through central New York to central Michigan, southern Wisconsin, Minnesota and South Dakota extending northwestward to Manitoba and reaching its western limit in Utah. It occurs locally southward through Colorado to northern New Mexico. It is rare in Oklahoma and does not occur in Texas, but is represented in Missouri by a pubescent form. East of the Mississippi River the typical species occurs in all of the states from central New York southward to northern Florida. In this great territory it is found in many diverse soils and exposures but responding in all to good soil and congenial environment. In the wild state the Americana plums are most often found along the borders of streams and swamps or in bottom lands where moisture abounds. Sometimes they are found in swamps which may be submerged a part of the year. In spite of a predilection for moist lands, however, the wild plants are not infrequently found on comparatively dry uplands, seeming to prefer soiis containing considerable lime. The wild trees are usually found in thickets, often of considerable extent. 
Under cultivation the range is even greater than for the wild plant. It is only in localities of extreme heat and cold, humidity or aridness, that some of the many Americanas cannot be made to grow under conditions at all favorable for orchards of any of the temperate fruits. So, too, varieties may be found for nearly all soils which permit of cultivation. This freedom from local attachments is one of the chief assets of the species.

The Americana tree is commonly small, often but a bush, and usually with a thick, thorny top. Generally the head attains a height of about fifteen or eighteen feet and sometimes it rises to twenty-five or thirty feet, spreading into many rigid branches which are often pendulous at the extremities. The species may almost always be told by the rough, shaggy, grayish bark, the large, thin, persistent plates of which give a very characteristic shagginess. In the spring the tree is covered with umbelliferous masses of pure white flowers and both at this season and later with its ample foliage or showy fruit, the plant is very ornamental. The leaves are large, oval or obovate, thin, dull and veiny, with very jagged margins.

The fruit is reddish or yellowish or a blending of the two with the red varieties predominating. Often the color is more nearly orange than red or yellow-in fact pure yellow fruits cannot be found. Wild or cultivated the fruits of the Americana plums vary greatly in season, size, shape and flavor. In the orchard the period of maturity covers a range of several weeks, beginning in New York in August and ending in October; in the wild, trees in the same thicket may vary as much as three weeks in ripening their fruit. The size of the cultivated sorts is from that of a Damson to that of some of the Gages, the shape being roundish-oval, or quite oval, sometimes oblique and sometimes truncate at one or both ends and often more or less compressed. The wild fruits usually have a pleasant flavor and this is much improved under cultivation so that when fully ripe the flesh of some sorts is sweet and luscious, hardly surpassed, if the skin be rejected, by the best Domesticas. The skin is usually thick, coriaceous, acerb or astringent, and altogether very unpleasant, making with the tenaciously clinging stones the chief defects of these fruits. In some varieties skin and stones are far less objectionable than in others.

The trees of the varieties we have as yet are not very manageable in the orchard. They make a very slow growth and are hard to control, producing at maturity many leaning trunks which are often crooked, as are also the branches which, with the unkempt heads, give an impression of waywardness and wildness. Nearly all of the varieties over-bear and 
unless thinned the fruits are so small as to be hardly worth harvesting; not infrequently trees die from over-bearing. A few varieties are unfruitful but usually because of defective pollination. Nearly all sucker badly on their own roots, and except in cold regions should be grown on other stocks. In general there are fewer pests to combat with these than with the European plums but yet they are far from being exempt and require on the grounds of this Station quite as much spraying as do other plums.

Waugh, who has given the subject much study, claims that the Americanas are not very strong sexually, ${ }^{1}$ chiefly because of defective reproductive organs. He found in extensive examinations that 21.2 per ct. of the pistils were defective, ranging from nothing in some varieties to 100 per ct. in others. More seldom the anthers were defective and the flowers were sometimes proterandrous (the pollen maturing before the pistil is ready to receive it), and that they were rather frequently proterogynous (the pistils receptive before the pollen is mature). Waugh holds that in planting these plums, provision should be made for cross-pollination, and recommends as sorts most suitable for inter-planting for this purpose, other varieties of the same species.

Plant-breeders have not found that this species hybridizes as readily as most of the other cultivated native plums. This is chiefly due to a seeming lack of affinity for other species. Nevertheless there are numerous Americana hybrids, and it is likely that as the high quality of the fruit and the hardiness of the trees become better known they will be used much more for hybridizing.

The Americana plums are all hardy and some of the varieties can be grown as far north as general agriculture is practiced. These, with the Nigras, will probably always be the chief groups for dry, cold regions between the Great Lakes and the Rocky Mountains. They may also be relied upon in the colder parts of New York and New England. The flowerbuds as well as the trees are hardy, having been known to withstand a temperature of forty degrees below zero. Goff ${ }^{2}$ reports that in the winter of $1896-7$ the flower-buds of Domestica varieties on the grounds of the Wisconsin Experiment Station were almost totally destroyed though the minimum temperature recorded was only twenty-three degrees below zero, but the flower-buds of Americana varieties were not at all injured. Since

1 Waugh, F. A. Plum Cult. 5x, 282-307. 1901.

${ }^{2}$ Goff, E. S. Wis. Sta. Bul. $63: 4$. 1897 . 
the blossoms open comparatively late there is less damage from spring frosts in this than in most other species even of the natives.

The number of varieties of Americana plums is a testimonial to the merits of the species. There are about 260 varieties of them more or less disseminated. There are many divergent types of these and since all are far from what may be eventually expected from the species the number of varieties will undoubtedly greatly increase and in still other directions. In the meantime the great majority have fallen by the wayside. The weeding-out process seems to be in this case the chief agent of progression. A fault with the varieties now before the public is that many of them are so similar that a difference can hardly be detected. The elimination of the great majority of the varieties of this species now in the catalogs and a much more judicious selection of varieties for future dissemination would relieve pomology of the burden it now carries in the numerous sorts of Americanas.

\section{PRUNUS AMERICANA MOLLIS ' Torrey and Gray}

r. Torrey and Gray Fl. N. Am. 1:407. 1840. 2. Sargent roth Cen. U. S. 9:65. 1883. 3. Coulter Cont. U.S. Nat. Herb. 2:102. 1891. 4. Sargent Sil. N. Am. 4:19. 1892. 5. Waugh Bot. Gaz. 26:50. I 898 .

P. americana lanata. 6. Sudworth Nom. Arb. Fl. U. S. 237.1897.

P. lanata. 7. Mackenzie and Bush Trans. Acad. Sci. St. Louis 12:83. 1902.

Prunus americana mollis is a western and southwestern form of Prunus americana, the sub-species being distinguished from the species by the amount and character of the pubescence on the leaves and shoots. The leaves, petioles and shoots of this plum are soft-pubescent, almost tomentose, the tomentum being pale in color and usually very dense; the calyx-lobes are pubescent on both sides and the pedicels are appressed and densely pubescent. According to Bailey, there is a form of this sub-species "with flowers as completely double as those of St. Peter's wreath, or similar spireas." This double-flowering plum we have not seen.

It is impossible to give the range of Prunus americana mollis as the woolly-leaved plum of the west gradually passes into the smooth-leaved species of the east and the two forms are not infrequently mixed in the South and Southwest; or possibly it would be better to say that they run into each other though the extreme forms are sufficiently distinct as to be readily mistaken for separate species. It can only be said

I The Prunus mollis of Torrey (Fl. U.S. 1:470. 1824) was Prunus nigra, as Torrey's specimen, now in the herbarium of Columbia University, plainly shows. 
that it is to be found in the greatest abundance in the region extending from southern Iowa through Missouri. Only two varieties of this plum, Wolf and Van Buren, are in general cultivation, both of which originated in Iowa. In neither fruit nor tree-characters do these differ greatly from the Americana plums.

A plum with pubescent leaves belonging to the Americana series known locally as the Big Tree plum, occurs from western Tennessee, southwestward through the extreme southern portion of Missouri, through Arkansas, southern Oklahoma, extending westward in central Texas, at least, as far as the Colorado River and reaching its southwestern limit in northern Mexico. From specimens of this plum in several herbaria and from studies made of it in the field by W. F. Wight of the United States Department of Agriculture, it would seem that this plum is a distinct species, its chief distinguishing character being the great size attained by the tree. So far as it is known the Big Tree has no cultivated forms unless it be Bilona, supposed to be a hybrid between this species and Prunus triflora, now growing on the grounds of F. T. Ramsey, Austin, Texas.

\section{Ix. PRUNUS HORTULANA Bailey'}

I. Bailey Gar. and For. 5:90. 1892. 2. Sargent Sil. N. Am. 4:23, P1. 151. 1892. 3. Waugh Vt. Sta. An. Rpt. ro:99-105. 1897. 4. Mohr Torrey Bot. Club Bul. 26:118. 1899. 5. Bailey Cyc. Am. Hort. 1 450, fig. Igor. 6. Mohr Cont. U. S. Nat. Herb. 6:551. I901.

P. americana, var. ? 7. Patterson List Pl. Oquawka 5. 1874.

Tree attaining a height of thirty feet or more, vigorous in growth; trunk sometimes a foot in diameter; trunk and branches rough and shaggy becoming furrowed in age; bark gray-brown, thick and containing deposits of red cork cells which show as bright

'A brief account of the life of Liberty Hyde Bailey appeared in The Grapes of New York (page 142), but his work with plums deserves further mention. The foundation of our present knowledge of the cultivated species and races of American and Triflora plums was laid by the comprehensive study of these fruits made by Bailey in the closing decade of the Nineteenth Century. His examination of plums may be said to have begun in 1886 with the setting of an orchard of native plums-probably the first general collection of these plums planted-on the grounds of the Michigan Agricultural College, Lansing, Michigan. The results of his studies have largely appeared in the publications of the Comell Agricultural Experiment Station, the first of which was The Cultivated Native Plums and Cherries published in 1892; The Japanese Plums, 1894; Revised Opinions of the Japanese Plums, 1896; Third Report upon Japanese Plums, 1897; Notes upon Plums, 1897. Beside these bulletins a monograph of the native plums was published in The Evolution of our Native Fruils in 1898 and a brief but complete monograph of the Genus Prunus in the Cyclopedia of American Horticulture in rgor. These are but the chief titles under which his studies of plums have appeared, several minor contributions having been printed from time to time in the horticultural press. While Dr. Bailey has given especial attention to all fruits grown in eastern America, it is probable that pomology is most indebted to him for his long and painstaking work with the difficult Genus Prunus with which he has done much to set the varieties and species in order. 


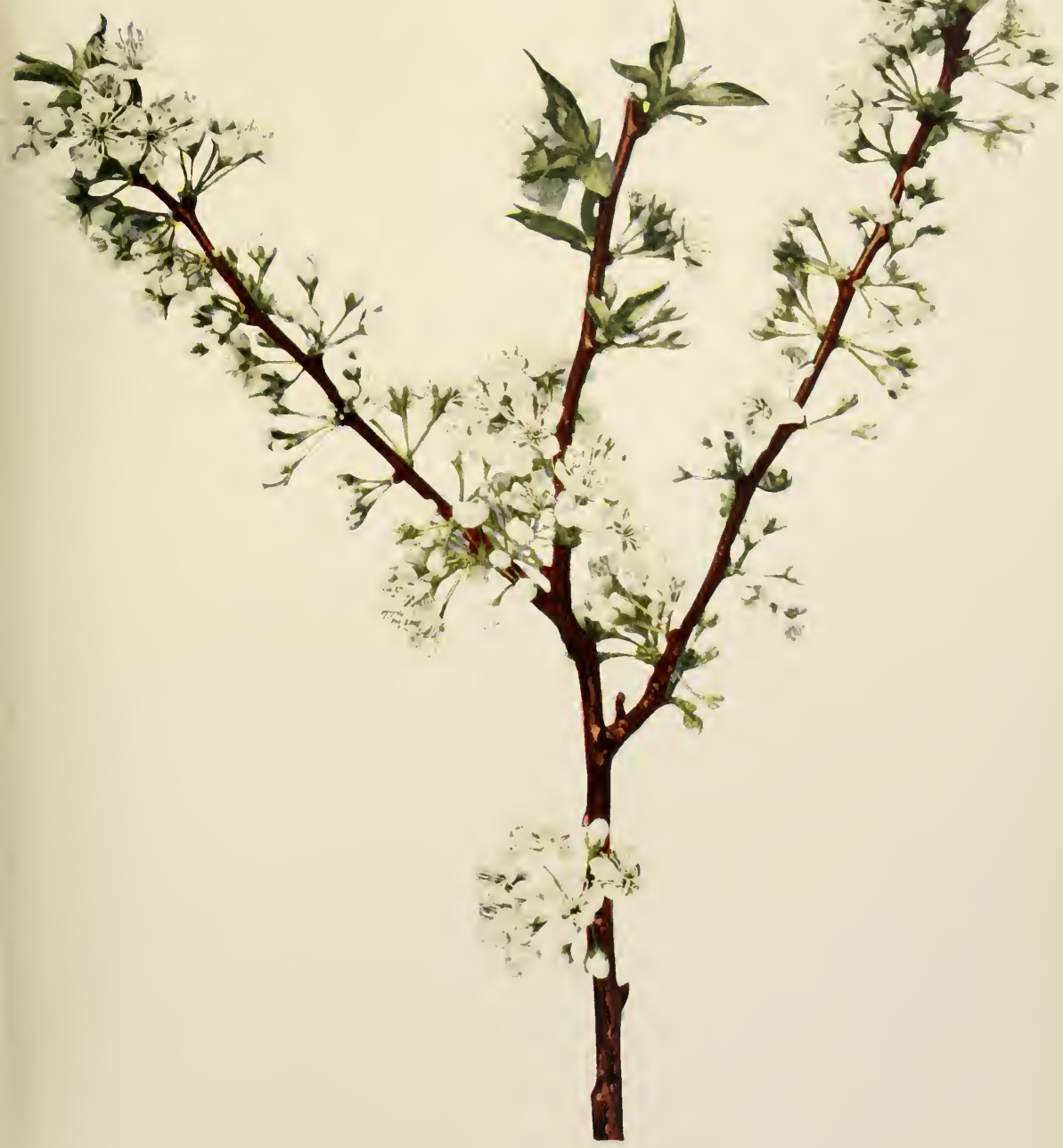



red blotches or as thick layers when the bark is sectioned, these deposits, especially in quantity, characterizing the species; branches very spreading and open, twiggy, slender, thorny; branchlets light green at first, becoming reddish-brown, glabrous and glossy; lenticels few, large, very coarse, raised, characteristic of the species.

Winter-buds plump, very small, obtuse, appressed; leaves one and three-quarters inches wide to five inches in length, long-oval with a tapering, pointed, acuminate apex, peach-like, base abrupt, texture thin, becoming leathery, margins serrate, almost crenate, sometimes in a double series, glandular; upper surface smooth, glossy, glabrous; lower surface light green, almost glabrous except on ribs and veins which are very pubescent, with characteristic orange color, midrib grooved above, rounded below, very prominent; petioles slender, an inch in length, pubescent on the upper side, tinged with red; glands two to eight, small, globose, mostly on the petioles.

Flowers expanding after the leaves, blooming later than any other cultivated plum, three-quarters inch across; odor disagreeable; clusters borne from lateral buds on oneyear-old wood only, characterizing the species, the fruit-spurs making a very long growth, more like branches than the spurs of other species, two to six flowers from a bud; pedicels three-quarters inch long, very slender, glabrous; calyx-tube narrow, campanulate, glabrous, green; calyx-lobes narrow, acute, glandular-serrate, glands red, slightly pubescent on the inner side, erect; petals ovate, slightly crenate, dentate at the apex, tapering into long narrow claws; stamens about twenty in number, yellow; pistils glabrous, equal to or shorter than the stamens.

Fruit very late in ripening; globose, oval, an inch in diameter; color varying from shades of red to shades of yellow; bloom inconspicuous or lacking; dots numerous, small, conspicuous; suture very shallow or only a line; skin thick, tough, astringent; flesh golden-yellow, juicy, coarse, fibrous, firm, flavor mildly sweet, astringent at the pit, strongly aromatic; quality fair; stone clinging to the flesh, turgid, long-oval, small, prolonged at the ends, the surfaces rough and reticulated.

Prumus hortulana as established by Bailey, to quote a part of the original description, " includes a large class of plums represented by Golden Beauty, Cumberland, Garfield, Sucker State, Honey Drop, probably Wild Goose and others." Unfortunately Bailey later added ${ }^{1}$ a number of other plums to the group which the above varieties and some ten or fifteen others comprise, the additions in themselves constituting at least three somewhat distinct groups, and then to account for this omnibus species called it a "brood of natural hybrids." Waugh supports Bailey's conclusions " and divides the species into four groups of hybrids-the Miner group, the Wild Goose group and the Schley or Clifford group. These, Waugh says, "form an unbroken series from Prunus americana to Prunus angustifolia." The fourth of Waugh's groups, " comparatively distinct

\footnotetext{
I Bot. Gaz. 24:462. 1896; Cornell Sta. Bul. 170. 1897; Ev. Nat. Fruits 194-208. 1898.

${ }^{2}$ Gar. and For. 10:340, 350. 1897. Plum Cult. 60-66. 1901.
} 
from the others, is made up of such varieties as Wayland, Moreman, Golden Beauty, Reed, Leptune, Kanawha and others." These plums he designated as the "Wayland group." This disposition of the plums under consideration leaves Prumus hortulana as the name of only a rather loosely related lot of cultivated varieties. It is probable that neither Bailey nor Waugh, had they seen the material now to be had, would have left the species as they did.

There is an abundance of herbarium material to show that Prunus hortulana as originally described by Bailey, with the varieties named as the type, leaving out Wild Goose, which is but doubtfully included, and as represented by Waugh's "Wayland group," is to be found wild in Illinois, western Kentucky, western Tennessee, Missouri and northern Arkansas, Oklahoma and southeastern Kansas. The writer has not seen material from states adjoining those named but the species is probably more widely spread than the range given indicates. Further, the cultivated varieties named by Bailey as members of his species, to which should be added at least American Golden, Benson, Columbia, Crimson Beauty, Dunlap, Kanawha, Leptune, Moreman, Reed, Wayland and World Beater, are so similar in all their characters and constitute a group so distinct from any other species that it is impossible to place them otherwise than in a distinct species. A group of hybrids could hardly be so uniform, and, moreover, these varieties contain characters, like late blooming, late fruiting, color, texture and flavor of fruit, leaf-serrations and deposits of red cork-cells in the bark, which other native species do not have, thereby shutting out the probability of the hybridity theory in which the supposed parents are Prunus amcricana and Prunus angustifolia. Lastly, and most convincing, varieties of the species come true to seed, which of course, would not be the case were these plums hybrids. From seed borne in I 893 this Station has had six seedlings of World Beater and four of Golden Beauty attain the age of sixteen years with more or less fruit for thirteen successive years. The seedlings could hardly be distinguished from the parents and showed no pronounced characters of either of the species of which Prumus hortulana has been supposed to be the hybrid offspring.

Of the sixteen varieties named as certainly belonging to this species, ten came from wild plants or seeds. Two of the remainder came from planted seeds and the origin of the remaining four is not known. One of the varieties from the wild, Golden Beauty, if its history as commonly given is correct, came from the Colorado River in western Texas. The 
Golden Beauty now under cultivation almost certainly belongs to Prunus hortulana, though it differs somewhat from other varieties of the group, but how it could have come from the wild in western Texas, so far from the usual range of the species, is at present unexplainable. This and other idiosyncrasies of distribution were reasons given by Bailey and Waugh for calling this species a group of hybrids. A careful study of localities from which all other Hortulana varieties than Golden Beauty have come shows them to be well within the range of Prunus hortulana. The fact that Golden Beauty is perfectly hardy at Geneva, and according to Waugh fairly so at Burlington, Vermont, suggests either that what we have as Golden Beauty did not originate in south central Texas or that the plant from which it came must have been introduced there within comparatively recent times.

Prunus hortulana gives to American pomology a very distinct and valuable group of plums which fortunately are adapted to a wide range of conditions, especially of climate. The Hortulanas are particularly well suited to the Mississippi Valley and southern states and fruit well as far north and east as New York. The product of Wayland, Kanawha and Golden Beauty, best known of the plums under discussion, is especially suitable for preserves, spicing and jelly, being unsurpassed by any other of our plums excepting the Damsons for these purposes. They are quite too acid and the flesh clings too tenaciously to the stone for dessert plums or even for ordinary culinary purposes. These plums, having firm flesh and tough skins, ship and keep splendidly and since they are the latest of the native plums in ripening, extend the season for this fruit very materially. The Wayland-like plums make very good stocks upon which may be grafted not only the varieties of the same species but those of the other native species as well. A point of especial merit with these plums as stocks is that they do not sucker as do most other species. Unfortunately they cannot be propagated from cuttings and the difficulty of obtaining seed at present precludes their use very generally. The Hortulana plums hybridize freely with other native species and their hybrids are such as to commend this species very highly to plum-breeders for hybridization.

Waugh ${ }^{1}$ has given the name Prunus hortulana robusta to a group of hybrid plums of which Prunus triflora and various native varieties are the parents. For most part these hybrids resemble the American more

${ }^{1}$ Waugh, F. A. Vt. Sta. An. Rpt. 14:277. I900-01. 
than the Asiatic parent. Since these plums differ so among themselves it is doubtful if more can be said as to the characters of Waugh's group than to mention the above resemblance. Some thirty or more varieties fall into this group of which America, Golden, Juicy, Ruby, Waugh and Gonzales are chicf.

PRUNUS HORTULANA MINERI Bailey

1. Bailey Cornell Sta. Bul. 38:23. 1892. 2. Waugh Vt. Sta. An. Rpt. 10:103. 1897. 3. Britton and Brown 2:247. 1897 .

It is impossible from present knowledge to say certainly whether the Miner-like plums put by Bailey into a botanical sub-division of Prunus hortulana are extreme variations of the species or, as Bailey in his last accounts and Waugh at all times have supposed, are hybrids between Prunus hortulana and Prunus americana. It is cortain that all of these plums are intermediate in some characters between the two species named; neither botanists nor pomologists can agree as to whether certain varieties belong to the one or the other botanical division. There are, however, in several herbaria, specimens from the wild, and from different localities, that indicate that there is a distinct plum toward the northern limit of the range of Prunus hortulana which, if a natural hybrid, is of so ancient hybridity that the plants now come measurably true to type. The chief representatives of the Miner-like plums under cultivation, as Miner, Forest Rose, Prairie Flower and Clinton, are so like these wild plums as to lead the writer to believe that Bailey's botanical sub-division is justified and is worth continuing even though a considerable number of the varieties now put with Miner, most of which have originated under cultivation, are hybrids and that the wild plums may have come from natural hybrids of more or less remote time.

The sub-species differs from the species in having shorter, stiffer, less graceful branches; leaves smaller, thicker, rougher and of a bluish-green cast; the blossoms of the two are much the same but those of the subspecies open a few days earlier; the fruits of the sub-species are larger than those of the species, lighter red, have more bloom, are less firm in texture, ripen earlier, yet later than those of any other species, and are quite different in flavor, having more nearly the taste of the fruit of Prunus americana; the stones, as well as the fruits, are very different, being in the sub-species larger, broader, flatter, smoother and less pointed. The differences in fruit and stone, and to some extent in the leaves, can be seen if the color-plates of Forest Rose and Wayland be compared. 


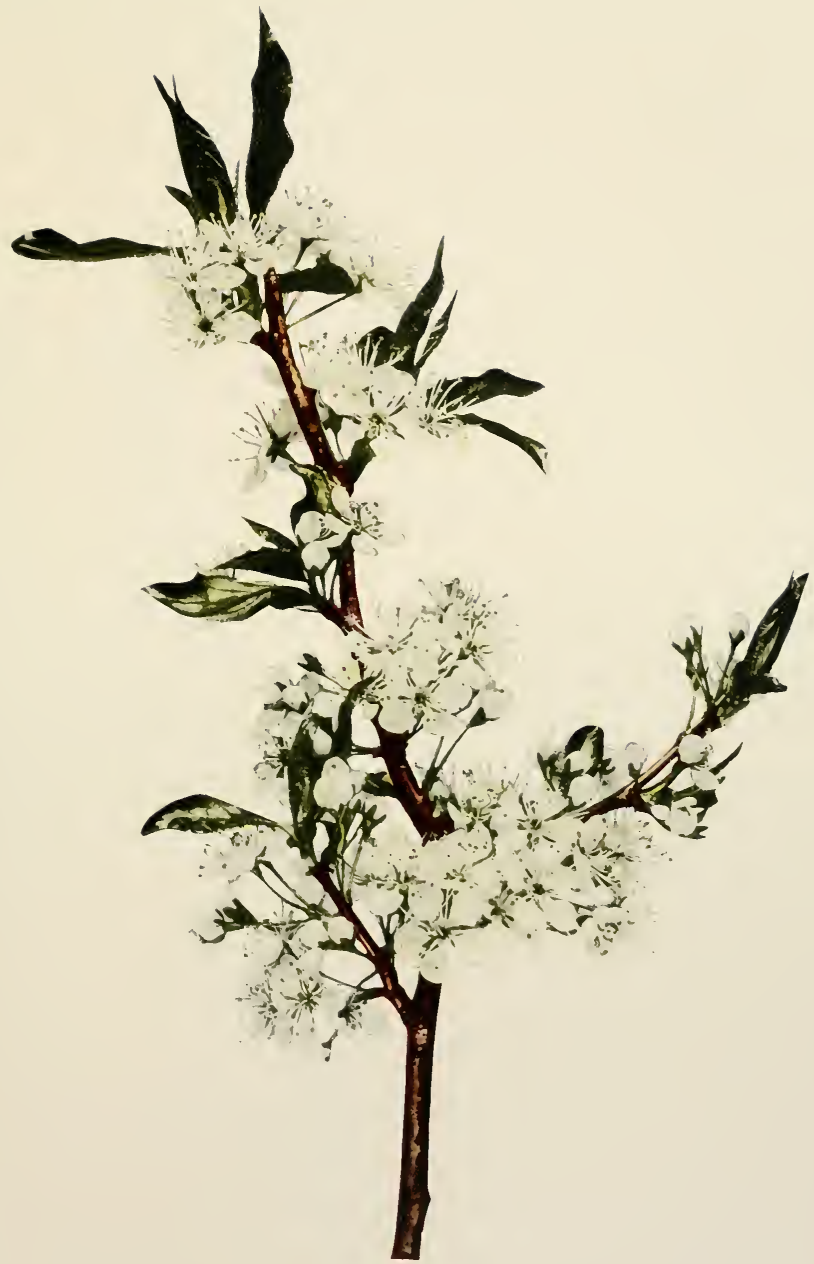



In fruit-growing, the Miner-like plums behave in general much like the Americana plums. In some respects the fruits are an improvement upon those of the Americana varieties. For example the skin in the Minerlike varieties is usually less tough; is brighter in color and the flavor, in most cases, is a little better. These plums seem to be nearly or quite as hardy as the Americanas and are adapted to quite as wide a range of soils. Presumably they have the same value as stocks, though they seem not to have been tried for this purpose and they should have equal value at least in plant-breeding. The trees of the Miner-like plums are rather more amenable to domestication than those of Prumus americana having as orchard plants straighter trunks, more symmetrical and less unkempt tops and making larger trees. The fruits ripen so late as to make the varieties of this group especially valuable in prolonging the season for plums in regions where native varieties are grown exclusively. About twenty varieties of this sub-species are under cultivation.

\section{PRUNUS NIGRA Aiton}

1. Aiton Hort. Kew. 2:165. 1789. 2. Sims Bot. Mag. III7. 1808. 3. Pursh Fl. Am. Sept. 1:33r. 1814. 4. Torrey Fl. U. S. 1:469. 1824. 5. Sargent Silva N. Am. 4:15, P1. 149. 1892. 6. Small Torrey Bot. Club Bul. 21:301. I894.

Cerasus nigra. 7. Loiseleur Nouveau Duhamel 5:32. 1812.

P. americana (in part). 8. Torrey and Gray $F l . N$. Am. 1:407. 1840. 9. Torrey $F l . N . Y$. I:194. 1843. ro. Emerson Trees of Mass. Ed. 2, 2:511. 1846. Ir. Nuttall Silva 2:19. 1852. 12. Sargent roth Cen. U. S. 9:65. 1883. I3. Watson and Coulter Gray's Man. Ed. 6:151. r889. 14. Gray For. Trees N. A. 46, P1. I89 I.

$P$. americana nigra. 15. Waugh Vt. Sta. Bul. 53:60, fig. 1896. 16. Ibid. Vt. Sta. An. Rpt. 10:102. 1897. 17. Bailey Cyc. Am. Hort. 1449. 1901.

P. mollis. 18. Torrey Fl. U. S. I:470. 1824 .

Tree small, seldom exceeding twenty feet in height; trunk attaining six or eight inches in diameter, bearing the head at three to five feet from the ground; bark thin, one-quarter inch thick, from dark red to a light gray-brown, rough, but not shaggy, surface covered with thick scales; branches upright, stout, rigid, forming a compact rather narrow head, armed with stout, spiny spurs; branchlets more or less zigzag, glabrous or tomentose, green, later becoming reddish-brown; lenticels few or many, pale, slightly raised.

Winter-buds of medium size, conical or long-acuminate, reddish-brown; leaves large, broad-oval, ovate or obovate, with a long acuminate apex and cuneate or subcordate base; margins doubly crenate-serrate with teeth tipped with glands which disappear as the leaves mature; thin and firm in texture; upper surface light green, glabrous, the under surface paler, pubescent when young and pubescent at maturity on some soils; midribs coarse but veins rather slender; petioles two-thirds inch long, rather stout, with two, sometimes but one, large, dark red glands near the blade, 
pubescent and tinged with red; stipules lanceolate, sometimes lobed, one-half inch in length.

Flowers expanding early, before or with the leaves, large, sometimes one and one-half inches across; borne in three or four-flowered lateral umbels on slender, glabrous, red pedicels one-half inch or more in length; calyx-tube obconic, outer surface red, inner surface pink; calyx-lobes glabrous on both surfaces or with a few, straight, scattered hairs on the inner surface, pinkish, acute, glandular; petals pink, turning a darker pink in fading, rather broadly ovate, apex rounded, base a short claw, margins erose; stamens with yellow anthers; filaments one-half inch long; pistils glabrous, shorter than the stamens.

Fruit ripening comparatively early; globose or oval, usually somewhat oblong, an inch or more through the long diameter, red, orange or yellowish in color, with little or no bloom; skin thick, tough and astringent; flesh yellow, firm, meaty, often acid or astringent; stone usually clinging, large, oval, compressed, thick-walled, with a sharp ridge on the ventral and a slight groove on the dorsal suture.

It is possible that a group of Nigras, those occurring in western Wisconsin and Minnesota and about the upper extremity of Lake Superior ought to be described as a sub-species since they have a somewhat different aspect of tree and the fruits are a darker shade of red and show more bloom; the calyx is more pubescent and the calyx-glands more sessile. The differences in environment may change these characters, as indicated above, but they seem very constant in the cultivated varieties of the groups, most of which come from the west, and therefore sufficient to segregate this form from the species.

The Nigra is the wild plum of Canada. Its most common name, "Canada Plum," is distinctly applicable and is here supplanted by "Nigra" only for the sake of uniformity. This is undoubtedly the dried plum which Jacques Cartier saw in the canoes of Indians, in his first voyage of discovery up the St. Lawrence in I $534 .^{1}$ These primitive prunes, Cartier says, the Indians called "honesta." In his second voyage, the next year, he enumerates among other fruits the plum, "prunier," growing on the "Ysle de Bacchus," named from its "Vignes." Dried plums, we learn from many later accounts, were a staple article of the winter diet of the savages. That the Indian tended the trees is probable, for the early explorers often record that plantations of plums were found about the aboriginal towns. Undoubtedly the range of this species was greatly extended by the Indians.

The Nigra is the most northern of the American plums, being an inhabitant of a region bounded on the north by a line passing from southern

${ }^{1}$ Hakluyt Voyages 3:258. 


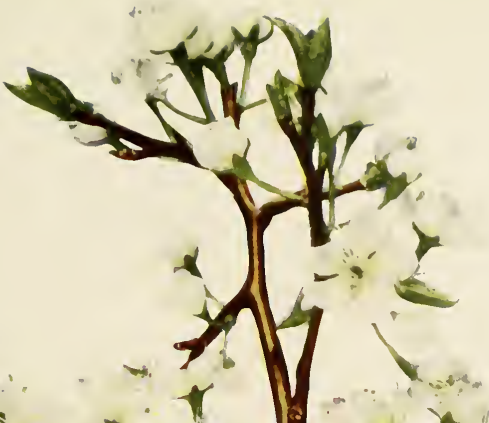

a. +7
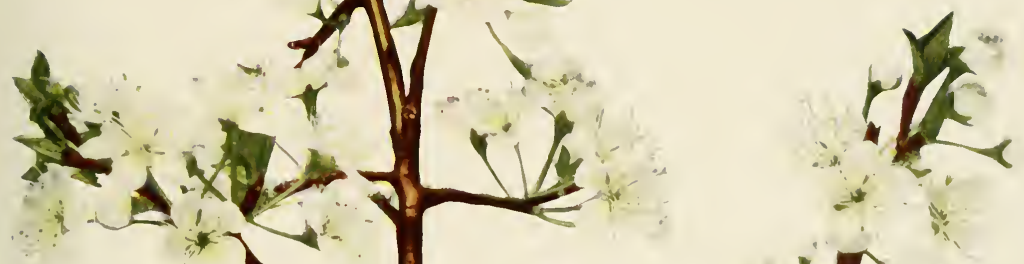

New Foundland westward to the Strait of Mackinac and thence southward to Lansing. Michigan. Its southern boundary can be but illy defined, but the species is common in New England, northern New York, where it is sometimes cultivated about houses, and westward at least as far as the eastern shore of Lake Michigan for the species, while the western form reaches the western boundary of Minnesota at least. Small ${ }^{1}$ reports it as far south in the Appalachian System as northern Georgia. In the great region outlined above it is distributed in more or less scattered localities, being found usually in the valleys of rivers and streams, though often on high lands and in open woods, in the last locations preferring a limestone formation.

There has been much discussion as to whether Prunus nigra should be given specific rank or be united with Prunus americana, either as a part of that species or as a botanical variety of it. Until the revival by Sargent in 1892 of the name given the group by Aiton in 1789 , the botanists of the latter half of the Nineteenth Century had for most part described the two groups under Prunus americana. Since Sargent's re-establishment of the species, botanists have very generally regarded it as worthy of the rank. Bailey and Waugh, the leading horticultural authorities on plums, however, consider Nigra as but a botanical variety of Americana. The taxonomic characters of Prunus nigra seem to the writers of The Plums of New York to be as distinct as those of several other of the native species of Prunus, and since the species now is generally recognized by botanists, we have considered it in this work as distinct from Prunus americana.

The two species may usually be distinguished by the following differences: (I) The general aspect of the trees is very different. The tree of Americana is larger, the top is more spreading, and its branches longer, with more twigs, more slender and more pendulous. The bark on the trunk is lighter-colored and much more shaggy than in Nigra. (2) The wood of Nigra is tougher and the trees do not break as readily as those of Americana. The wood is also lighter in color. (3) The leaves of Nigra are larger, broader and the serrations are not so deeply incised nor so often double. Very distinct and very constant are the glands to be found on the teeth of the serrations on the young leaves of Nigra. These glands disappear as the leaves grow older, leaving a calloused point which makes the serrations of Nigra rounded, while those of Americana are acute, this

\footnotetext{
${ }^{1}$ Torrey Bot. Club Bul. 21 :301. I 894.
} 
being one of the most constant differences. (4) The flowers of Nigra appear several days earlier, are larger and are more pink than those of Americana. (5) The calyx-lobes of Nigra are glandular and the leaf-stalks are bi-glandular, characters usually not found in Americana. The calyx in all its parts is glabrous or at least far less pubescent than in Americana and if present the hairs are short and stiff, whereas in Americana the pubescence is soft. (6) The fruit of Nigra ripens earlier and is darker in color with less bloom and is more oblong than that of Americana. The skin of the plum is thinner and is not so objectionable either cooked or eaten out of hand. (7) The stone of Nigra is usually larger, flatter and more strongly crested. The characters of the two species vary much in different individuals and there are many intermediate forms but the differences seem as constant as between other species of this variable genus.

The Nigra plums are important horticulturally because they can be grown in somewhat colder regions than the Americanas. They not only endure more cold than the last named group, but their tough wood enables them to stand better the weight of snows and the stress of winds. Their earliness, too, prolongs the season for this type of fruit and in regions where the season is short they may be grown with more certainty than other groups. In habits and characters other than those named they are so like the Americana as to need no further discussion. About forty varieties of this species are under cultivation.

\section{i3. PRUNUS ALlEghaniensis Porter}

1. Porter Bot. Gaz. 2:85. 1877. 2. Ibid. Gar. and For. 3:428, fig. 53. 189o. 3. Sargent Sil. N. Am. 4:27, P1. 153. 1892. 4. Bailey Ev. Nat. Fr. 225.1898.

Tree low, slender, straggling, fifteen to eighteen feet in height, or a low shrub; trunk-diameter from five to eight inches; bark dark brown, surface fissured and scaly; branches numerous, upright, rigid, seldom spiny; branchlets pubescent, becoming glabrous and red, turning to dark brown; lenticels many, small, white.

Leaves ovate-oblong or lanceolate, sometimes obovate, apex acute or acuminate, base rounded, margin sharply serrate, teeth fine and tipped with glands, in texture thick and firm; upper surface dark green and glabrous; lower surface light green, glabrous except on the vcins and midrib; petioles short, slender, pubescent; glands two, large, at the base of the blade.

Flowers white, fading to pink, one-half inch across, appearing with the leaves; borne in two to five-flowered umbels; pedicels slender, finely tomentose, from onefourth to one-half inch in length; calyx-tube narrowly obconic; calyx-lobes entire, pubescent on the outer, tomentose on the inner surface; petals rounded but narrowing 
into claws at the base; filaments and ovary glabrous; anthers often reddish; style slender with a funnel-shaped apex.

Fruit matures in summer or early autumn; from one-quarter to three-quarters inch in diameter, sub-globose or ovoid, dark blue or purple with heavy bloom; skin thick and tough; flesh yellow, juicy, acid and somewhat astringent; stone clinging to the flesh, turgid, acute at the ends, thin-walled, ridged on the ventral and grooved on the dorsal suture.

In leaf, flower and tree Prunus alleghaniensis resembles Prunus americana. The species has long been known to be distinct, however, having been first distinguished by J. R. Lowrie of Warriorsmark, Pennsylvania, in $1859,{ }^{1}$ and was published as such in 1877 , when T. C. Porter of Lafayette College described it as Prumus alleghaniensis. It differs from Prunus americana chiefly in the smaller size of the plant, smaller leaves and flowers, in color of flowers which fade to pink in this species, and in fruit-characters. The fruit matures earlier, is much smaller in size, is more globose, and is a dark purple or blue with very heavy bloom. The skin is thick and tough and while the texture of the flesh is as good as that of the wild Americanas the flavor is much more astringent. The stone is more swollen. The plant is commonly but a shrub, usually found along fence rows and the borders of woodlands, but intermingled among old thickets of this kind there are often a few small trees. It is a hardy species, very productive, and seemingly but little attacked by either insects or fungi, being especially exempt from black-knot." In the wild state it produces great numbers of suckers which seem to spring very readily from a bruise or an exposed root.

The range of Prunus alleghaniensis is exceedingly limited. It is found in abundance only in a small territory in central Pennsylvania, being of most frequent occurrence in the barrens of northern Huntingdon County, extending from there north into Center County and northwestward over the Alleghany Mountains into Clearfield and Elk counties. It grows for the most part in elevated lands of the wildest character, being found on low, moist soils, on high and dry barrens and on limestone cliffs, reaching its greatest size in the last situation.

Specimens identified as Prunus alleghaniensis have been found in at least two places in Connecticut and the writer has just seen specimens of a closely allied form collected by W. F. Wight of the United States Depart-

1 Silva of North America 4:28. I 893 .

${ }^{2}$ Jack, J. G. Gard. and For. 7:206. IS94. 
ment of Agriculture a few miles south of Houghton Lake, Roscommon County, Michigan.

This plum is not yet introduced into cultivation and it is doubtful if the wild fruits have sufficient merit to make an attempt at domestication promising. While the wild fruits are locally used for various culinary purposes it is so much inferior to other native plums, being almost uneatable unless cooked, that its cultivation would hardly warrant the effort. Arboretum specimens of the tree show it to be somewhat desirable as an ornamental, being a small, compact, upright plant, very floriferous, and bearing an abundance of rather attractive fruit.

\section{PRUNUS SUBCORDATA Bentham}

I. Bentham Pl. Hartweg. 308. 1848. 2. Torrey Pac. R. Rpt. 4:82. 1854. 3. Brewer and Watson Bot. Calif. r:167. r880 (in part). 4. Lemmon Pittonia 2:68. 189o. 5. Greene Fl. Francis r:49. 1891. 6. Bailey Cornell Sta. Bul. 38:76. r 892. 7. Sargent Sil. N. Am. 4:31, 32, P1. 154. 1892 .

Tree small, rarely attaining a height of twenty-five feet, sometimes a shrub ten or twelve feet high and often a bush but three or four feet in height; trunk medium in length with a diameter of 8 to 12 inches; bark gray-brown and deeply fissured; branches stout and spreading; branchlets glabrous or pubescent, bright red becoming darker red and finally a dark-brown or gray; lenticels minute, whitish.

Leaves round-ovate, sub-cordate or truncate, or sometimes cuneate at the base; margins either sharply or obtusely serrate, sometimes doubly serrate; young leaves pubescent but at maturity nearly glabrous, somewhat coriaceous, dark green on the upper and pale green on the lower surface, with very conspicuous midribs and veins; stipules acute-lanceolate, caducous.

Flowers white, fading to rose, about an inch across; appearing before the leaves; usually borne in threes, often in pairs on short pubescent pedicels; calyx campanulate, with lobes pubescent on the outer and hairy on the inner surface; petals twice the length of the sepals, obovate, and contracted into short claws; filaments and ovary glabrous; style slender and funnel-shaped at the apex.

Fruit ripens in late summer or early autumn; roundish or oblong, about one inch in length, borne on a short, stout stem, dark red or purplish; flesh subacid, well-flavored, clinging to the flattish or turgid stone which varies greatly in size, pointed at both ends, crested on the ventral edge and grooved on the other.

Prunus subcordata, the Pacific or Western plum, is an inhabitant of the region east of the Coast Range from southern Oregon to central California. It is so rarely found on the seacoast as to have escaped the attention of the early botanists and remained unknown until the middle of the Nineteenth Century, when Hartweg, working in the interior of 
California, brought the plant to notice. This wild plum is not common except in the foothills of the Sierra Nevadas in northern California and southern Oregon, where it often forms thickets of small trees along streams, thriving in fresh, fertile, sandy soils, in canons, on hillsides or in the forests of yellow pine which are found in this region. Hammond " writes of it growing here as usually a small tree but often seen as a shrub from four to five feet high. Of the frequency of the occurrence he says: "It often sets the whole countryside ablaze in the autumn, with the abundance of its scarlet and crimson colors, mingled, of course, with red and yellow, and garnished with a sprinkling of green." Sandberg ${ }^{2}$ reports having collected Prunus subcordata as far north and east as Nez Perces County, northern Idaho, in the Craig Mountains at an altitude of about 2,900 feet, but this report is based on an error in determination, the specimen collected by Sandberg being clearly a European species. The tree and the fruit vary greatly according to the locality.

This Subcordata plum is one of the standard food products of the aborigines in the region in which it grows, being eaten either raw or cooked; and it is sometimes dried in considerable quantities at the harvesting places and carried considerable distances to the Indian villages. ${ }^{3}$ The trappers, the first men to enter the habitat of this plum, followed by the goldseekers and ranchers, all knew and esteemed the fruit. The early settlers regarded it as the most useful of all the wild fruits of the Coast and attempts were made at an early date to domesticate it. Of these Wickson says:

"In I 856 there was, on the Middle Yuba River, not far from Forest City, in Sierra County, a wayside establishment known as 'Plum Valley Ranch,' so-called from the great quantity of wild plums growing on and about the place. The plum by cultivation gave a more vigorous growth and larger fruit. Transplanted from the mountains into the valley they are found to ripen earlier. Transplanted from the mountains to a farm near the coast, in Del Norte County, they did not thrive. One variety, moved from the hills near Petaluma in 1858 , was grown as an orchard tree for fifteen years, and improved both in growth and quality of fruit by cultivation. $* * * *$ Recently excellent results have been reported from the domestication of the native plum in Nevada County, and fruit

${ }^{1}$ Gar. and For. $3: 625$. 1890.

2 Sandberg, J. H. Cont. U. S. Nat. Herb. 3:221. 1895.

2 Coville, F. V. Cont. U. S. Nat. Herb. 5 :99. 1897 ; and Chestnut, V. K. Cont. U. S. Nat. IIerb. 7:356. 1902 ,

-Wickson, E. J. Californıa Fruits 52. $189 \mathrm{r}$. 
shown at the State Fair of 1888 gave assurance that by cultivation and by selecting seedlings valuable varieties can be obtained. It is stated that in Sierra County the wild plum is the only plum which finds a market at good prices, and that cultivated gages, blue and egg plums scarcely pay for gathering. The wild plum makes delicious preserves."

In its typical form Prumus subcordata is a shrub and is often only a low bush but under the most favorable conditions it attains the dimension and shape of a small tree. In its roundish, roughish leaves it so closely resembles the Old World types of plums that it becomes the nearest approach to them to be found among our American species. But in the globular, red or purple subacid fruit it betrays its affinity to the American plums, as it does also in the flat, sometimes turgid, smooth stone to which the flesh tenaciously clings. The flowers are white, fading to rose and borne abundantly, making the plant an attractive ornamental in blooming time as it is also in the autumn when the foliage turns to brilliant red, scarlet or crimson with touches of yellow. The fruit is sometimes so poor in quality as to be inedible but on the other hand is sometimes quite equal to some of the cultivated plums, especially in its botanical variety, Kelloggii.

That the fruit is capable of improvement by the selection of seedling varieties and useful in hybridizing with other species can hardly be doubted. Luther Burbank, under date of December 6, 1909, writes in this regard as follows:

"The Prunus subcordata, as it grows wild, bears very heavily even on bushes two and three feet in height, bending the buches flat on the ground when the fruit is ripe. This is a very beautiful sight. The wild ones, although almost invariably bright red and spherical, are sometimes, though rarely found, yellow. When the seed of the yellow fruit is planted a certain portion of red ones are produced, but all, practically, of the same size and quality as the original. The trees of Subcordata in the wild state are greatly variable in growth, generally much more so than in the fruit. The fruit, however, varies much in quality, but it is promiscuously gathered by those living in the vicinity of the plum grounds and considered most excellent for cooking. I commenced working on this species about twentytwo years ago and have not carried it on as extensively as with the Maritima, as I found it subject to plum-pockets, but by very careful selection I have produced most magnificent plums, oval in form or round, sweet as honey or sweet as the French Prune, greatly enlarged in size, tree improved in growth and enormously productive, the different varieties ripening through a long season. Most of these are light and dark red. Some of 
them, when cooked, are far superior to cranberries, having the exact delicious flavor so much liked in this fruit, and the same color.

"From the crosses of Subcordata with the Americana, Nigra, Triflora and other species, some of the most beautiful and highest flavored fruits which I have even seen have been produced. These vary in color from almost pure white to light yellow, transparent flesh color, pink, light crimson, scarlet, dark crimson and purple; in form round, egg-shaped or elongated-oval; trees both upright and weeping, enormously productive, and in one or two cases the fruit, by hundreds of experts, has been pronounced the best plum in flavor of any in existence. Most of these selections are extremely productive."

Wickson ${ }^{1}$ reports that the roots of Subcordata have been used more or less as stocks for other plums but show no marked advantages over the species commonly used for this purpose. Most of those who have experimented with it condemn it as a stock because it dwarfs the cion and suckers badly.

Prunus oregana Greene ${ }^{2}$ is from its description an interesting plum of which, however, it has been impossible to secure a glimpse even of herbarium material and of which we can therefore, only publish Greene's description as follows:

"Evidently allied to P. subcordata, but leaves little more than an inch long, subcoriaceous, pubescent on both faces, in outline oval or broadly elliptic, never subcordate, commonly acutish at both ends, serrulate; flowers unknown; fruits in pairs or threes, on pedicels one-half inch long or more, densely tomentose when very young, more thinly so, yet distinctly tomentulose when half-grown.

"Known only from specimens collected on the Yanex Indian reservation in southeastern Oregon, by Mrs. Austin, in I893; and a most remarkable species, as connecting true Prunus with Amygdalus. But that it is a plum and not an almond is evident."

Without any first-hand knowledge of this species it is thought best to consider it only under the allied species, Prunus subcordata.

\section{PRUNUS SUBCORDATA KELLOGGII Lemmon}

1. Lemmon Pittonia 2:67. 1890. 2. Wickson Calif. Fr. Ed. 2:51. I89x. 3. Greene Fl. Francis I :50. 189r. 4. Bailey Cyc. Am. Hort. 1448, I 901 .

Prunus subcordata kelloggii, named in honor of Dr. Albert Kellogg, an early explorer and settler in California, is distinguished from the species

1 Wickson, E. J. Calif. Fruits Ed. 4:35. 1909.

${ }^{2}$ Pittonia $3: 21$. 1896. 
in being a somewhat taller and more slender plant." The branches and bark are of a characteristic ash-gray, so distinct in color from Prunus subcordata that this is often called the "Gray-branch" plum. The leaves are orbicular or elliptical, not cordate, cuneate at the base and nearly glabrous. The fruit is bright yellow instead of red and larger than that of the species, being an inch or more in diameter with a more nearly free stone. This plum inhabits the region of Mount Shasta where it has been known since the time of the early gold diggers, attracting more attention as a food, and promising more for the cultivator than Subcordata. Botanists seem to have given this plum comparatively little attention and careful study may give it specific rank. Locally, and now somewhat in the trade, it is known as the Sisson plum, after a Mr. Sisson, living near Mount Shasta, who has brought it to notice. At present the Kelloggii seems to be the branch of promise for the improvement of the wild plums of the western coast.

\section{PRUNUS UMBELLATA Elliott}

1. Elliott Sk. Bot. S. C. and Ga. 1:54I. 1821. 2. Sargent roth Cen.U.S. 9:67. 1883. 3. Ibid. Sil. N. Am. 4:33, P1. 155. 1892. 4. Waugh Plum Cult. 91. 1901. 5. Mohr Cont. U. S. Nat. Herb. $6: 55 \mathrm{x}$. I $90 \mathrm{I}$.

Cerasus umbellata. 6. Torrey and Gray Fl. N. Am. 1:409. 1840.

Tree low, sometimes a shrub, seldom over twenty feet in height; trunk short, usually crooked, attaining a thickness of ten inches; bark dark brown and scaly; branches spreading, slender, twiggy but spineless; branchlets at first pubescent but becoming glabrous, bright red turning dark brown the second year; lenticels few, oblong, yellowish.

Leaves oblong-ovate, or oblong-obovate to oblong, thin and membranaceous, acute at the apex but usually obtuse or cordate at the base; margins closely and evenly serrate with glandular teeth, upper surface dark green and glabrous, lower surface pale green and more or less pubescent; petioles stout, glabrous or sometimes pubescent; glands usually two, sometimes wanting, large, dark, at the base of the leaf; stipules lanceolate, small, caducous.

Flowers medium in size, appearing before and with the leaves; usually borne in fourflowered umbels; calyx-tube obconic, its lobes entire, outer surface glabrous or pubescent, the inner densely tomentose; petals white, orbicular, clawed.

Fruit matures in late summer; one-half inch in diameter, nearly round, without cavity or suture, borne on a slender pedicel three-quarters inch long, orange-red or bright red to purple or nearly black, covered with a thin bloom; skin thick and tough; flesh coarse, thick, acid or astringent, scarcely edible; stone nearly free, flattened, acute at both ends, rugose, thin-walled.

${ }^{1}$ The first published account of this plum is a brief non-technical description of it by Dr. Kellogg in Hutching's Mag. 5:7. 1859 . 
Prunus umbellata, the Sloe, Black Sloe or Hog Plum, Oldfield, and sometimes Chickasaw and Bullace of the South, is found along the seaboard from South Carolina to central Florida, thence westward to the Gulf and along its shores to Texas. Inland it is found as far north as middle Georgia, Alabama and Mississippi and southern Arkansas. Though very common in localities in the region outlined, there are vast areas of this territory in which it is scarcely found, preferring bottom lands of rivers and rich, moist soils in some instances and dry, sandy copses, open woods and borders of fields in others. In flower and fruit it is a handsome and conspicuous plant, yet, as the references show, the early botanists did not describe it, and even Elliott, who gave it its name, in $182 \mathrm{I}$, passed it by with a scant description. Its neglect by the several famous botanists of the Eighteenth Century who explored this region must be attributed to their confusing it with Prunus angustifolia and Prunus maritima, one or the other of which is found in most of the region, and to the idiosyncrasies of the distribution of Prunus umbellata.

The fruit of this species is unfit for dessert purposes but is commonly gathered for culinary use and sometimes is offered for sale in the markets of the South, being highly esteemed for pies, jams and jellies. There appear to have been no efforts made to domesticate it, however, and since it is quite inferior in fruit-characters to others of the native plums, efforts to that end are probably not worth while.

\section{PRUNUS UMBELLATA INJUCUNDA (Small) Sargent}

r. Sargent Sil. N. Am. 13:21, 1902 .

Prunus injucunda. 2. Small Torrey. Bot. Club Bul. 25:149. 1898. 3. Mohr Ibid. 26:118. I899. 4. Ibid. Cont. U. S. Nat. Herb. 6:552. 1901. 5. Bailey Cyc. Am. Hort. 1449. I90 I.

Tree low, seldom twenty feet in height, often a straggling shrub; trunk short, crooked, attaining a diameter of eight inches; bark dark brown, nearly black; branches slender, rigid, twiggy and somewhat spiny; branchlets velvety becoming purplish and finally a dull gray; lenticels few, yellowish.

Leaves oblong-ovate to obovate, taper-pointed at the apex and obtuse or rounded at the base, margins closely and finely toothed, thin in texture; upper surface yellowishgreen, wrinkled and more or less pubescent, lower surface densely pubescent and with a prominent yellowish midrib and rather prominent lateral veins; petioles stout, onehalf inch in length, very pubescent; stipules lanceolate, small,caducous.

Flowers medium in size or small, usually appearing before the leaves; in four or five-flowered sub-sessile umbels; pedicels slender, three-quarters inch in length, very

1 Torrey Bot. Club Bul. 25:149. 1898. 
pubescent; calyx-tube obconic, tomentose, with erect, entire, sharply pointed, ciliate, tomentose lobes; petals white, orbicular, clawed; filaments and base of pistil tomentose.

Fruit maturing in late summer, three-quarters inch long, oblong, with but a trace of cavity and suture, dark purple with light bloom; flesh thin, sour and very astringent, skin thick, tough; scarcely edible; stone ovoid, long, flat, roughish, pointed at both cnds with a groove on one edge and a grooved ridge on the other.

In 1898 Small described Prunus injucunda as a new species from what had hitherto been considered a part of Prunus umbellata. Sargent, whom we follow, gives it as a botanical variety of Prumus umbellata. Small says that the two differ as follows: Prumus injucunda has "a more rigid habit and the foliage, including the branchlets, is velvety tomentose. In place of the sub-globose drupe of Prunus umbellata we find an oblong fruit of an extremely bitter taste. The stone is correspondingly lengthened." To these differences may be added tomentose or pubescent leaves, hairy umbels, and tomentose calyx and pistil, as characters not found in Prumus umbellata though there are occasional pubescent individuals in the species.

Small first collected Prumus injucunda in sandy soil in the granite districts about the base of Little Stone Mountain, Georgia, and reports it as occurring about Stone Mountain. Mohr reports the plant on rocky summits and among the sandstone cliffs of Alpine Mountain, Talladego County, Alabama, as a low, unsightly shrub, four feet in height, with short, straggling branches. The wild fruit is seldom fit for domestic use and with so much better material in other species the fruit-grower can hardly afford to spend time in an attempt to domesticate this one.

\section{PRUNUS MITIS Beadle}

1. Beadle Bilt. Bot. Stud. 1:162. 1902. 2. Britton and Brown N. Am. Trees 489 . 1908 .

Tree small, maximum height twenty-five feet; bark dark brown or reddish-gray; branches spreading or ascending, usually unarmed; branchlets glabrous, glaucous; leaves thin, elliptic, oblong-lanceolate, sometimes ovate or obovate, apex acute or acuminate, base narrow or rounded, margin sharply serrate; petioles less than one-half inch, densely pubescent, with two glands at or on the base of the leaf; upper surface bright green, finely pubescent, lower surface paler, also pubescent and with a prominent midrib and veins.

Flowers of medium size, appearing before the leaves; borne in sub-sessile, two to sixflowered umbels; calyx-tube obconic, smooth, its lobes triangular, pubescent on the outer and velvety on the inner surface; petals white, obovate, clawed; pedicels slender, smooth, three-quarters inch long.

Fruit ripening in mid-summer; over one-half inch in length, oblong, dark purple with a heavy bloom; stone ovoid or oval, flattened, nearly one-half inch long, pointed at both ends especially at the apex, and crested on one edge. 
Prunus mitis is a newly named species from Alabama, common in dry soils in the regions where it is found wild. The species has many characters in common with Prumus umbellata, to which it is so closely related that it is difficult to distinguish the two in herbarium specimens. Although nothing is yet known of its horticultural possibilities the apparent relationship does not indicate much value in the plum for the cultivator.

17. PRUNUS TARDA Sargent

I. Sargent Bot. Gaz. 33:108. 1902. 2. Ibid. Sil. N. Am. 13:23, Pl. 632. 1902.

Tree from twenty to twenty-five feet in height; trunk tall, eighteen or twenty inches in diameter; bark light brown, reddish, thick, with flat ridges and plate-like scales; branches spreading, forming an open symmetrical head; branchlets slender, at first light green and tomentose becoming glabrous, light brownish and lustrous, and the second year much darker; lenticels small, dark, scattered.

Leaves oblong to obovate, apex acute and sharp-pointed, base rounded or cuneate, margin finely serrate with incurved, glandular teeth, in texture thick and firm; upper surface glabrous, dark yellow-green, lower surface pubescent, pale green; petioles stout, tomentose or pubescent, short, eglandular or with two stalked, dark glands at the apex; stipules acicular, often bright red, small.

Flowers three-quarters inch across, appearing before and with the leaves; borne in two or three-flowered umbels, on slender, glabrous pedicels; calyx-tube narrowly obconic, hairy above, the lobes acute, entire, villose on the outer, tomentose on the inner surface; petals oblong-obovate with a short claw at the base; filaments and pistils glabrous.

Fruit maturing very late; short-oblong to sub-globose, one-third to one-half inch in length, red, yellow, purple, black or blue; skin tough and thick; flesh thick and acid; stone adhering to the flesh, ovoid, more or less compressed, very rugose, ridged on the ventral and grooved on the dorsal suture, acute at the apex, rounded at the base.

Prunus tarda, locally known as the Sloe, as are many other plums, was named from specimens collected in Igor near Marshall, Texas, by Sargent and others. Sargent, to whom is due what field knowledge we have of the plant, gives its range from where found in Texas to western Louisiana and southern Arkansas. He says that it resembles and is often confounded with Prunus umbellata but may be distinguished from it by its bark, which differs from that of any other American plum tree, being more like that of the chinquapin chestnut with which it grows; by the pubescence on the leaves, not usually found on those of Prumus umbellata; and by its variously colored fruit which ripens much later than that of other plums in the region. From what has been published in regard to the species one gathers little in regard to its horticultural possibilities though the 
statements that it bears great quantities of fruit and is used locally for culinary purposes indicate that it may have some value under cultivation.

\section{PRUNUS ANGUSTIFOLIA Marshall}

1. Marshall Arb. Am. 111. 1785. 2. Torrey and Gray Fl. N. Am. 1:407. 1840. 3. Loudon Arb. Fr. Brit. 2:705. 1844. 4. Sargent 10th Cen. U.S. 9:66. 1883. 5. Watson and Coulter Gray's Man. Ed. 6:152. 1889 (in part). 6. Gray For. Trees N. A. 47, Pl. 189r. 7. Sargent Sil. N. Am. 4:25, P1. 1 52, 1892. 8. Mohr Cont. U. S. Nat. Herb. 6:551. 1901.

P. chicasa. 9. Michaux ${ }^{1} \mathrm{Fl}$. Bor. Am. 1:284. 1803. 10. Nuttall Gen. N. Am. Pl. 1-302. 1818. 11. Elliott Sk. Bot. S. C. and Ga. 1:542. 1821. 12. Hall Pl. Texas 9. 1873. 13. Ridgway Proc. U. S. Nat. Mus. 65. 1882. 14. Chapman Fl. Sou. U. S. 131. 1897.

Plant seldom becoming a true tree, usually, however, forming a small but distinct trunk with a twiggy, bushy top; bark thin, dark reddish-brown, slightly furrowed or roughened, scaly; branches slender, usually zigzag with long, thin thorns or spine-like branchlets; branchlets slender, zigzag, glabrous, glossy, bright red; lenticels few, scattered, yellowish, raised.

Winter-buds small, obtuse, free, brownish; leaves folded upward, lanceolate or oblong-lanceolate, pointed at both ends, thin, membranaceous, margins closely and finely serrate with minute teeth, tipped with glands; upper surface glabrous, lustrous, bright green, lower surface glabrous or pubescent in the axils of the veins, dull, twothirds inch wide and from one to two inches long; petioles one-half inch long, slender, glabrous or tomentose, bright red with two red glands near or on the base of the leaf; stipules one-half inch long, narrow-lobed, serrate with gland-tipped teeth.

Flowers appearing with or before the leaves, small, less than one-half inch across, very numerous; umbels sub-sessile, two to four-flowered, from lateral spurs or buds; pedicels glabrous, slender, one-half inch in length; calyx-tube campanulate, glabrous; calyx-lobes obtuse, glabrous outside, margins ciliate, inner surface pubescent, reflexed; petals creamy in the bud, obovate, apex rounded, narrowing into a claw at the base; filaments and pistils glabrous, the latter shorter than the stamens.

Fruit ripening early; spherical or ovoid, three-quarters inch in diameter, bright red, sometimes yellow, glossy, with little or no bloom; dots numerous, very conspicuous; skin thin; flesh tender, juicy, yellow, subacid; quality rather poor; stone small, clinging, ovoid, turgid, slightly roughened, cherry-like, edges rounded, the dorsal one grooved.

The original home of Prunus angustifolia is not known. The inference is left in most of the botanies that the species is not indigenous in the region east of the Mississippi, but that it was brought by the aborigines from the southwestern section of the Mississippi Valley or possibly the southern Rocky Mountains or Mexico. The chief reason for the belief

${ }^{1}$ The writer has examined the type specimen of Michaux's Prunus chicasa in the herbarium of the Jardin des Plants in Paris and found it, though incomplete and poorly preserved, plainly not Prunus angustifolia but more likely some form of Prunus unbcllata. Undoubtedly, however, the references which follow Michaux's are to Prunus angustifolia. 
that it does not belong where it now grows is the fact that it is usually found near human habitations and on the margins of fields and as it was known to have been cultivated by the Indians, ${ }^{1}$ it is supposed to have escaped from their semi-cultivated plantations. Bailey ${ }^{2}$ dissents from the current view, holding that the plant behaves like a true native in regions where he has known it, Maryland in particular. It seems to the writer that Bartram's supposition, given in the foot-note below, has been followed too closely. A careful study of recent botanical works indicates that the species is indigenous to the southeastern United States.

Whatever the original habitat may have been it is now found in the wild state from southern Delaware to Florida and westward to the Panhandle of Texas and southern Oklahoma. It is usually found on rich soils but is found as well in worn-out fields and pastures, most often in thickets of small trees or thorny shrubs or scraggly bushes, producing under the latter conditions a small fruit so like cherries as to give it the name in some localities "Mountain Cherry" (Maryland), and in others "Wild Cherry" (Louisiana).

There has been much confusion in regard to Prunus angustifolia. The older botanists very generally mistook this species for Michaux's Prunus chicasa which, as stated in the foot-note on page 82 , is almost certainly not the plum under discussion. Practically all horticulturists ascribe to Prunus angustifolia a great number of cultivated varieties which cannot by any possibility belong here; indeed, it is doubtful if the species is cultivated at all other than very locally, and still more doubtful as to whether, as compared with other native plums, it is worth growing. In spite of this confusion the species is one of the most distinct of plums, and its characters are comparatively constant throughout the range. A careful reading of Humphrey Marshall's description of Prunus angustifolia by subsequent botanists might have helped to keep this plum in its place. Marshall wrote of it:

"Prunus angustifolia. Chicasaw Plumb. This is scarcely of so large a growth as the former $[P$. americana], but rising with a stiff, shrubby stalk, dividing into many branches, which are garnished with smooth, lance-shaped leaves, much smaller and narrower than the first kind $[P$.

1" The Chicasaw plumb I think must be excepted, for though certainly a native of America, yet I never saw it wild in the forest, but always in old deserted Indian plantations: I suppose it to have been brought from the S. W. beyond the Mississippi, by the Chicasaws." Bartram Travels Through North and South Carolina, Georgia, East and West Florida, etc. $3^{8}$. 1793.

${ }^{2}$ Bailey Ev. Nat. Fr. 193. 1898. 
americana], a little waved on their edges, marked with very fine, slight, coloured serratures, and of an equal shining green colour, on both sides. The blossoms generally come out very thick and are succeeded by oval, or often somewhat egg-shaped fruit, with a very thin skin, and soft, sweet pulp. There are varieties of this with yellow and crimson coloured fruit. These being natives of the Southern states, are somewhat impatient of much cold."

The tree-characters given by Marshall are hardly those of the plum under cultivation which we have been calling Prumus angustifolia, and his statement that the species is " impatient of much cold " at once separates the cultivated "Angustifolias" from the true species. We shall contrast the tree-characters of the two groups of plums in the discussion of Prunus munsoniana. Of the hardiness of the two it may be said that the cultivated varieties which we have placed in the last named species are for the most part hardy as far north as Burlington, Vermont, while the true Prunus angustifolia cannot be grown to fruiting as far north as Geneva, New York. Its behavior, too, on the northern limit of its range, and the fact that it did not follow the aborigines northward as it seems to have followed them from place to place within its range, show that Prunus angustifolia belongs in the southern states.

This plum was well known by the early colonists of Virginia and southward. John Smith in Virginia, in $1607-9$, and Strachey, writing a few years later, saw " cherries much like a damoizm, but for their taste and cullour we called them cherries." Beverly in his History of Virginia, written in I822, speaks of two sorts of plums, "the black and the Murrey Plum, both of which are small and have much the same relish with the Damasine" ; the latter was probably the Angustifolia. Lawson in his History of Carolina speaks of several plums, ${ }^{1}$ one of which, the Indian plum, must have been the fruit of the present discussion. Bruce ${ }^{2}$ quotes

1"The wild Plums of America are of several sorts. Those which I can give an account of from my own Knowledge, I will, and leave the others till a farther Discovery. The most frequent is that which we call the common Indian Plum, of which there are two sorts, if not more. One of these is ripe much sooner than the other, and differs in the bark; one of the barks being very scaly, like our American Birch. These Trees, when in Blossom, smell as sweet as any Jessamine, and look as white as a Sheet, being something prickly. You may make it grow to what Shape you please; they are very omamental about a House, and make a wonderful fine Shew at a Distance, in the Spring, because of their white Livery. Their Fruit is red, and very palatable to the sick. They are of a quick Growth, and will bear from the Stone in five years, on their Stock." Lawson, John History of Carolina ro5. I 714.

2" The third was known among the later colonists as the Indian cherry and was the product of a tree hardly exceeded by the English peach tree in girth and height, and showing an inclina- 
a letter from William Fitzhugh, written in 1686 , in which the latter speaks of the "Indian Cherry," meaning of course, this plum; for it still passes under the same name.

Of the horticultural possibilities of Prumus angustifolia, little can be said from this Station as the trees cannot be grown here. But since the species has been so long known, and is so near at hand to fruit-growers, without more of its offspring coming under cultivation, it is not likely that it may be counted upon to bring forth much in the future for the orchard. Such trees and fruits of this species as the writer has seen are not at all promising for the cultivator.

\section{PRUNUS ANGUSTIFOLIA WATSONI (Sargent) Waugh ${ }^{1}$}

1. Waugh Vt. Sta. An. Rpt. 12:239. 1899. 2. Bailey Cyc. Am. Hort. 1450 fig. 1901.

P. watsoni. 3. Sargent Gar. and For. 7:134, fig. 1894. 4. Waugh Bot. Gaz. 26:53. 1898. 5. Bailey Ev. Nat. Fr. 218 . 1898 .

Shrub four to ten feet high; branches slender, short-jointed, zigzag, reddish-brown; branchlets at first bright red and lustrous, later becoming brownish-red or sometimes ashy-gray; lenticels few and light-colored; leaves small, ovate, apex acute, base rounded or cuneate, margins finely crenulate; upper surface glabrous, shining, lower surface paler, glabrous; petioles reddish, one-half inch in length, biglandular at the apex.

Flowers in fascicles of two to four, borne with or before the leaves and in great abundance; calyx cup-shaped, the lobes acute, eglandular, ciliate on the margins, pubescent on the inner surface; petals white, obovate, contracted into a claw at the base; filaments glabrous, anthers reddish, style slender, exserted; pedicels one-quarter inch long.

tion for the soil of the valleys of the rivers, and of the narrow bottoms of the smaller streams. This variety was considered to be of extraordinary excellence in flavor; when ripe it was colored a dark purple, and there was only a single cherry to the stalk. There were two varieties of plums, resembling, both in size and taste, the English Damson." Bruce, Philip Alexander Economic History of Virginia in the Seventeenth Century $1: 94$. 1896.

${ }^{1}$ Frank A. Waugh was born in Sheboygan Falls, Wisconsin, July 8, 1869 . On his father's side he is of Scotch descent, though the family has long been in America; his mother came from Germany. He was educated in the public schools of Kansas and in the Kansas State Agricultural College, graduating from the latter place in 1891 . In 1893 he became professor of horticulture in the Oklahoma Agricultural College and horticulturist at the Experiment Station, a place which he held for nearly three years, going late in 1895 to take the same position in the University of Vermont. After eight years of arduous service in Vermont, during which time he became well known by his writings on horticultural, botanical and agricultural subjects, he left Vermont to take charge of horticulture in the Massachusetts Agricultural College and the Hatch Experiment Station. Professor Waugh's study of plums began in the West, Kansas and Oklahoma, but his reports in regard to this fruit have come from Vermont where his work has been mainly done. The chief titles under which his studies have been published in the bulletins and annual reports of the Vermont Station are: The Pollination of Plums, Classification of Plums, A Monograph of the Wayland 
Fruit two-thirds inch in diameter, globose, sometimes oblong, orange-red, bloomless, handsome; skin thin, rather tender; flesh yellow, juicy, tender, pleasant flavor; of comparatively high quality; stone somewhat turgid, compressed at the apex, thickwalled, rounded on the ventral and sometimes on the dorsal suture.

Prumts angustifolia watsoni is the Sand plum of the plains, being an inhabitant of southern and southeastern Nebraska and central and western Kansas and possibly passing into western Oklahoma. It is usually found along the banks of streams and rivers where it often forms shrubby thickets. The wild plums are held in high esteem for dessert and culinary purposes, becoming a commercial product in parts of the region in which they grow, and are occasionally transplanted to the garden or orchard. From such transplantings a half dozen varieties have arisen. The productiveness, hardiness to heat and cold and the size and quality of the fruits should attract plum-growers in the region of its habitat and experimenters elsewhere as well. Waugh ${ }^{1}$ gives the following interesting sketch of the use to which this plum has been put in Kansas:

"Early settlers in Kansas, before their own orchard plantings came into bearing, used to find the sand plums well worth their attention. In July and August everybody for fifty miles back from the Arkansas sand hills used to flock thither to pick, and it was an improvident or an unlucky family which came off with less than four or five bushels to can for winter. Whole wagon loads of fruit were often secured, and were sometimes offered for sale in neighboring towns.

"The fruit gathered from the wild trees was of remarkably fine quality, considering the conditions under which it grew. The plums were quite uniformly large-I would say from memory that they often reached threefourths of an inch to an inch in diameter. They were thin-skinned and of good flavor, not having the unpleasant astringency of the wild Ameri-

Group of Plums, Hybrid Plums, Types of European Plums, Propagation of Plums, The Myrobalan Plums, A Review of the Americana Plums and The Grouping of Japanese-Hybrid Plums. In IgoI he published Plums and Plum Culture, a popular presentation of the various phases of his botanical and horticultural work with this fruit. The titles given do not represent the extent of his studies with this fruit for there were third and fourth reports upon several of the subjects mentioned. In particular he has been helpful to American pomology in the classification of native plums, in his study of sex in plums and in setting forth the hardiness of the various species and groups. Besides his papers on plums, Professor Waugh's chief contributions to horticulture have been a book entitled Fruit Harvesting, Storing, Marketing, another under the title Systematic Pomology and two works on apples. He has also published two books on Landscape Gardening which have given him high standing in this division of horticulture. Professor Waugh will long be remembered in horticulture for the great extent of his work, for his versatility in the profession and for his a bility to present well to both readers and hearers, either technically or popularly, horticultural knowledge.

1 "The Sand Plums" Country Gentleman, Jan. 27, 1898. 
cana plums, which were also sometimes gathered. They were excellent for canning and made the finest of jelly.

"Naturally, the settlers who went every year to the sand hills for plums brought back trees to plant in the gardens they were opening. Almost every farm within the range mentioned above had a few or many of the dwarf trees growing. Some of these were fruitful and worth their room, but most of them have now died out, or are neglected and forgotten. This is because people have paid no attention to their selection, propagation and cultivation. Further than this, however, the sand plum has often failed signally to come up to its record when transferred to cultivation. It seems not to adapt itself readily to a wide diversity of soils and conditions."

The sub-species is easily mistaken for the species; in herbarium specimens it is almost impossible to distinguish between them, but in general the Sand plum differs from Angustifolia in its dwarfer habit, shorter-jointed, zigzag, ashy-gray branches, smaller but thicker leaves, larger, thicker skinned and better flavored fruit which ripens later, and in a smaller and somewhat differently marked stone. In distinguishing the two groups some allowance must be made for the adaptability of plums to different environments.

\section{PRUNUS ANGUSTIFOLIA VARIANS Wight and Hedrick}

Plant a small tree, attaining a height of twenty-five feet; trunk small but welldefined; branches spreading, bushy, sometimes armed with spinescent branchlets; young wood slender, more or less zigzag, usually glabrous, glossy, reddish but approaching a chestnut-brown; lenticels few, scattered, yellowish, raised.

Leaves oblong, oval-lanceolate or rarely slightly obovate-lanceolate, one and onefifth to two and one-fifth inches long, three-quarters to one inch broad, gradually narrowed at the base, acute at the apex; margins very minutely glandular-serrate; upper surface glabrous and somewhat lustrous; lower surface paler, glabrous or sparingly hairy along the midrib and in the axils of the lateral veins; petioles slender, usually reddish, about one-half inch long, pubescent along the upper side, eglandular or sometimes with one or two glands at the apex; stipules small, linear and glandular-dentate.

Flowers appearing from early in March and before the leaves in the South, to the middle of April and with the leaves in the North, in dried specimens about one-half inch broad; pedicels three-eighths to one-half inch long, glabrous; calyx campanulate, the tube glabrous; calyx-lobes usually shorter than the tube, oblong and obtuse, glabrous on the outer surface, glabrous or sometimes sparingly pubescent on the inner, the margin ciliate, eglandular; petals obovate, gradually narrowed toward the base, erose or entire toward the apex.

Fruit globose or sub-globose, varying from red to yellow, usually with a light bloom; stone about one-half inch long, two-fifths inch broad, turgid, ovoid to elliptic-oblong, ob- 
scurcly pointed at the apex or sometimes slightly obtuse, truncate or obliquely truncate at the base, grooved on the dorsal edge, ventral edge with a narrow, thickened and slightly grooved wing, the surfaces irregularly roughened.

Yellow Transparent may be considered a typical variety. Type specimens in the Economic Collection of the Department of Agriculture were collected at the Eastern Shore Nurseries of J. W. Kerr, Denton, Maryland, (flowers) I. Tidestrom, April, ı9ıо; (foliage and fruit) P. L. Ricker No. 2933, June 29, I909.

In the wild, Prumus angustifolia varians forms dense thickets, the larger specimens attaining a height of ten or twelve feet. When budded and grown in the orchard it assumes the form of a small tree with well defined trunk and spreading branches, sometimes armed with rather slender spinescent branchlets. It is distinguished from the species by its usually more robust habit, by its having the young twigs less reddish and approaching a chestnut-brown in color, rather longer leaves, longer pediceled flowers, and by the stone in most cases being more pointed at the apex. Usually in more fertile soil than the species, it occurs locally from southern Oklahoma through eastern Texas southward possibly to the Colorado River, and probably westward to the Panhandle region. As yet, however, its distribution is not well defined.

Nearly all of the early ripening horticultural varieties previously referred to Prumus angustifolia belong to Prunus angustifolia varians. The fruit of the sub-species appears to be superior to that of the species though scarcely equal to that of the other southern plums now cultivated. Hybrids between this form and Prmms munsoniana undoubtedly occur freely both in the wild state and under cultivation. The varieties Eagle and El Paso have probably originated in this way. Nearly all of the plums belonging to this species, some twenty in all, are tender to cold, none, so far as is known, succeeding in the North. African, Cluck, Jennie Lucas and Yellow Transparent may be named as representative varieties.

9. PRUNUS MUNSONIANA' Wight and Hedrick

Prunus angustifolia. I. Bailey Cornell Sta. Bul. 38:58. 1892 (in part). 2. Ibid. Ev. Nat. Fr. I91-194. I 898 (in part). 3. Waugh Vt. Sta. An. Rpt. 10:99, 105. I897 (in part).

Prunus hortulana. 4. Bailey Cornell Sta. Bul. 38:48. 1892 (in part). 5. Waugh Vt. Sta. An. Rpt. 10:99, 103-105. 1896-97 (in part).

Tree medium to large, from twenty to thirty feet in height; trunk six to ten inches in diameter; bark grayish-brown, shaggy, furrowed; branches spreading, rather slender,

${ }^{1}$ Thomas Volney Munson, after whom it has been a pleasure to name this species, though best known as a viticulturist, has also rendered invaluable service to plum-culture. A sketch of his life appeared in The Grapes of New York (page 122) in which his services to viticulture were briefly 


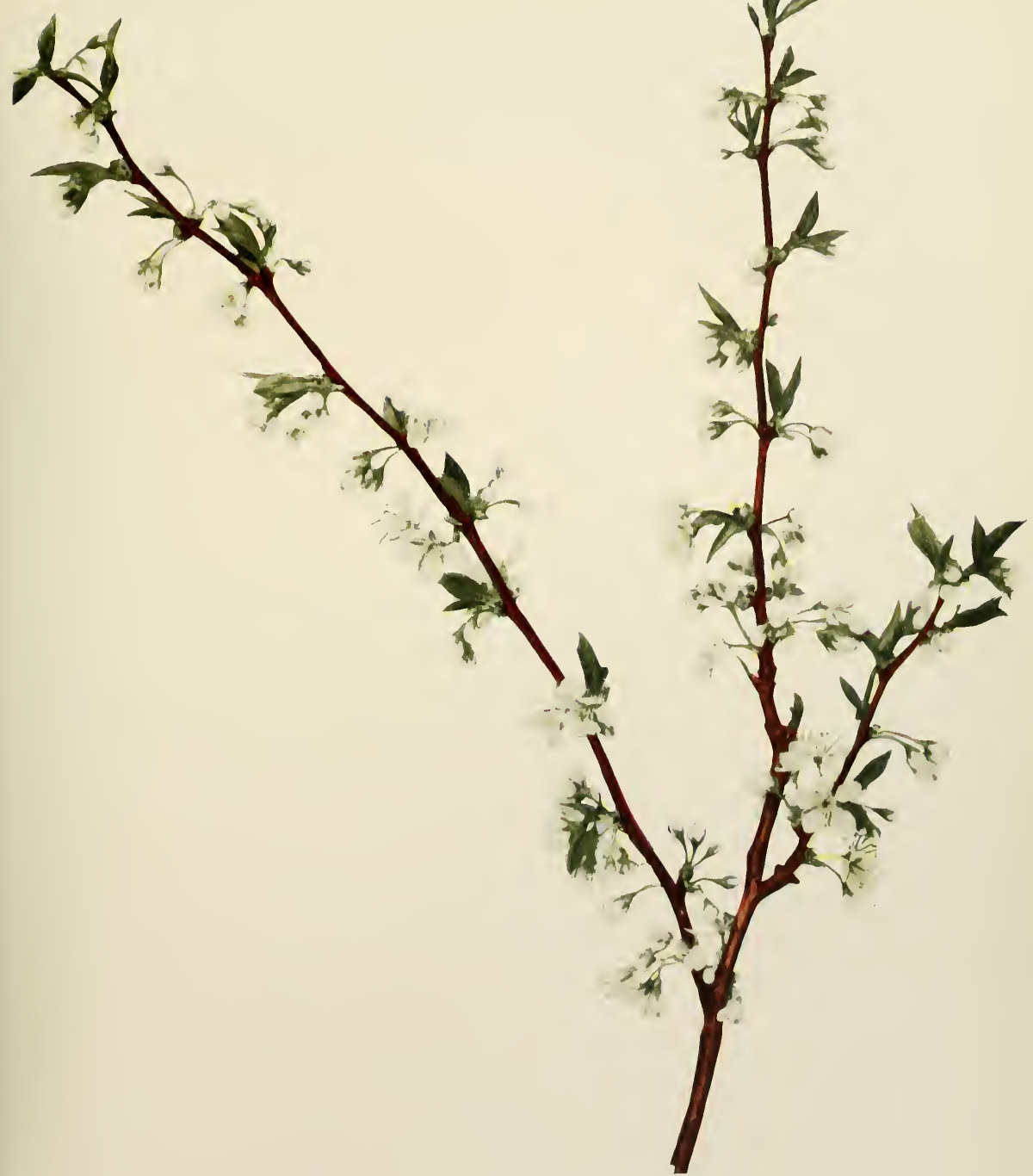



zigzag, little or not at all thorny; branchlets slender, zigzag, reddish, lustrous, glabrous; lenticels numerous, large, raised.

Winter-buds small, short, obtuse, usually free; leaves one and one-quartcr inches wide by four inches long, lanceolate to oblong-lanceolate, sometimes broadly so, somewhat folded, apex acute or tapering, usually rounded at the base, texture thin, margins closely and finely serrate, teeth with small, dark red glands; upper surface bright green, glabrous, lustrous; lower surface dull green, pubescence sparse along the midrib and veins or sometimes tufted in the axils; petioles slender, about threequarters of an inch long, pubescent on the upper surface, reddish, usually with two glands at the base of the leaf-blade; stipules linear, glandular, serrate.

Flowers appearing before or with the leaves, season of blooming late, about threequarters inch across, odor sometimes disagreeable; borne on lateral spurs and buds, two or four flowers in a cluster; pedicels one half inch long, slender, glabrous; calyx-tube campanulate, glabrous, obscurely nerved, about one-fourth length of the pedicel; calyx-lobes as long as tube, ovate-oblong, obtuse at the apex, usually glabrous outside, pubescent inside at least toward the base, glandular-ciliate, erect; petals onethird inch long, white, creamy in the bud, oval or obovate, margins slightly erose, abruptly tapering into a claw, sometimes pubescent; stamens about twenty in number, equal to or shorter than the petals; filaments glabrous; anthers yellow or sometimes tinged red; pistils glabrous, shorter than the stamens.

Fruit ripening early; globose or oval, shortest diameter about an inch, bright currantred, rarely yellow; bloom thin; dots few or numcrous, whitish, large or small, always conspicuous; cavity shallow, narrow; suture a line; apex rounded or slightly depressed; flesh light to dark yellow, juicy, soft or melting, fibrous, sweetish, sour at the pit, aromatic; good; stone clinging to the flesh, varying from about one-half inch in length in the wild fruits to at least three-quarters inch in cultivated varieties, turgid, oval, prolonged and pointed at the apex, usually obliquely truncate at the base, more or less roughened, grooved on the dorsal edge, thick-margined and markedly grooved on the ventral one.

The description of this species is based on both wild and cultivated material, and the variety Arkansas may be considered as a typical

mentioned. While his name is not commonly connected with the study of plums, it is not too much to say that without his aid the publications of those who have written during the last quarter century on native plums would have lacked much of the information they contain in regard to the species of the Southwest. He has an intimate knowledge of the wild plums of Texas and has freely given of it to all who have asked, of ten supplementing information with herbarium specimens or plants. The authors of The Plums of New York wish to give him credit for much of the information, furnished directly or indirectly, in regard to the wild and cultivated plums of the region in which he lives, in recognition of which his name is given to one of the most important species of native plums. Mr. Munson has grown and introduced a number of hybrid plums of note, chief of those of his own growing being Nimon, Minco and Burford. Many of his experiments in hybridizing plums, though unproductive of new varieties, are of much value as a guide to other workers with this fruit. 
representative. Type specimens, deposited in the Economic Collection of the United States Department of Agriculture, were collected by W. F. Wight (flowers) at the New York State Experiment Station, Geneva, New York, No. 2721, May 15, I909, and (foliage) at the Iowa Experiment Station, Ames, Iowa, No. 4I 78 , September I 5, I909.

This species differs from Prunus angustifolia, with which it has long been confused, chiefly in being a much larger plant, a true tree while the other seldom reaches the size of a tree. It has coarser and less twiggy branches, shaggier bark and less red in the color of the young wood. The leaves are larger, thicker, more truly lanceolate in shape, less folded, a lighter green and less glossy. The flowers of the new species are larger, fewer in number, borne in less dense umbels which are not so nearly sessile as those of the older species and are borne on longer pedicels. The calyx-lobes are erect in this species and reflexed in Prumus angustifolia, strongly marked by marginal glands in Prunus munsoniana and eglandular in Prumus angustifolia. The fruits are larger and wholly plum-like in the newly made species and cherry-like in Prunus angustifolia. The stone is very plum-like in Prunus munsoniana but in the older species it might easily be mistaken for the pit of a cherry. The robust form is hardy as far north as Geneva, New York, at least, while the other species cannot be grown much north of Mason and Dixon's line.

Of the varieties which certainly belong to this species by far the greatest number have originated under cultivation. There is herbarium material from uncultivated plants to show that this species is rather common in the northern part of Texas, in eastern Oklahoma and in parts of Missouri. It is a species forming dense thickets in its native habitat, where it is usually found in rather rich soils, with the older central specimens sometimes attaining a height of twenty to twenty-five feet and gradually diminishing in height to the edge of the thicket. When budded and grown in the orchard it forms a well-defined trunk and attains a height of twenty-five feet or more. The branches are little or not at all spinescent, bark of the stem in young specimens reddish or chestnut-brown, and usually rather smooth, becoming scaly and losing its reddish color with age, that of the young twigs usually chestnut-brown. Its natural range, though not yet definitely determined, probably extends from central Tennessee through northern Mississippi, northern Arkansas, central Missouri and southeastern Kansas to the valley of the Little Wichita River in northern Texas. 
The Wild Goose varieties, now placed here, in the past have been considered hybrids more closely resembling Prunus hortulana than any other species. But Wild Goose and some other varieties of its group are not to be distinguished from Prunus munsoniana and beyond question belong in this species. The varieties in this division of Munsoniana are largely seedlings of Wild Goose, each variety possibly with a different male parent since Wild Goose seldom or never fruits unless cross-fertilized. Thus, of these plums, twelve are known seedlings of Wild Goose; seven others originated under cultivation; the origin of fourteen is not known and it is not certain that any beside Wild Goose came from wild plants. From such a record, and from the characters of the plants, it is probable that some of the Wild Goose varieties are horticultural hybrids, many of them from H. A. Terry of Iowa in whose work, with many varieties of several species, hybridity was the rule.

Horticulturally, this is the most important group of native plums for the South; it contains a greater number of cultivated varieties than any other native species excepting Prunus americana, no less than sixty sorts being listed in The Plums of New York, some of which are deservedly the best known of the native plums for either home or market use. For dessert or the kitchen they are particularly valuable, having a sprightly vinous flavor making them very pleasant flavored to eat out of hand or when cooked. Their bright colors, semi-transparent skins and well-turned forms make them very attractive in appearance. Considering the juiciness of most of the varieties, these plums ship and keep well. Unfortunately nearly all of the varieties of this species are clingstones. This group hybridizes more freely than any other of the plums and there are a great number of promising hybrids of which it is one of the parents. Of all plums, these are most in need of cross-pollination, some of the varieties being nearly or, as in the case of Wild Goose, wholly self-sterile. While these plums are especially valuable in the Southern States, some of them are desirable in the North as well, where all will grow at least as far north as central New York. Plums of this species are occasionally but not often used as stocks. Some recommend them for stocks for low or wet lands. The fact that Prunus munsoniana suckers very badly will probably preclude its use largely in propagating.

The leading varieties under cultivation of this species are Arkansas, Pottawattamie, Robinson, Newman, Wild Goose and Downing, all of which are described in full and illustrated in colors in The Plums of New York. 
The first four of these have in the past been referred by botanists and pomologists to Prunus angustifolia and the last two to Prinus hortulana.

\section{PRUNUS MARITIMA Marshall}

I. Marshall Arbust. Am. 112. ${ }_{7} 85$. 2. Wangenheim Amer. 103. 1787. 3. Michaux $F l$. Bor. Am. 1:284. 1803. 4. Pursh Fl. Am. Sept. 332, I814. 5. Nuttall Gen. N. Am. Pl. 1:302. I8I8. 6. Elliott Sk. Bot. S. C. and Ga. 1:543. I821. 7. Torrey and Gray Fl. N. Am. I:408. I840. 8. Torrey Fl. N. Y. I:I94. I843. 9. Emerson Trees of Mass. 449. 1846. Io. Bailey Cornell Sta. Bul. 38:75, fig. No. 9. I892. I1. Waugh Vt. Sta. An. Rpt. 12:234. 1899. I2. Bailey Cyc. Am. Hort. 1449 , fig. I 901 .

P. litoralis. 13. Bigelow $\mathrm{Fl}$. Bost. Ed. $2: 193.1824$.

P. pubescens. 14. Torrey Fl. U. S. $469 . \mathrm{I}_{224}$.

Ccrasus pubescens. 15. Seringe DC. Prodr. 2:538. 1825. I6. Beck Bot. Nor. and Mid. U. S. $96 . \quad 1833$.

Shrub four to ten feet high, sometimes a low tree under cultivation; main branches decumbent and straggling or upright and stout; bark dark brown or reddish, more or less spiny, often warty; branchlets slightly pubescent at first, becoming glabrous, dark reddish-brown, straight or slightly zigzag and rather slender; lenticels few, small, dark.

Winter-buds small, long, acute, with small reddish scales; leaves oval or obovate, short-acute or nearly obtuse at the apex, rounded or nearly acute at the base, margins closely and evenly serrate, thinnish or thickish and somewhat leathery; upper surface glabrous, dull green, lower surface paler and more or less pubescent; petioles less than one-half inch long, stout, tomentose or glabrous; glands two, sometimes more, at the base of the leaves.

Flowers small, appearing before the leaves but the latest of any of the hardy plums; borne in three-flowered umbels closely set along the rigid branches; calyx-tube eampanulate, tomentose; petals white, sometimes pinkish, sub-orbieular, narrowed into a claw at the base; pedicels short, slender, stiff, tomentose.

Fruit maturing in late summer in Massachusetts; one-half inch in diameter, globose, slightly flattened at the ends; cavity shallow, borne on a slender pedicel more than onehalf inch in length, usually dark purple with a heavy bloom but variable, sometimes red or less frequently yellow; skin thick, tough and acrid; flesh crisp, juicy, sweetish; stone free from the flesh, small, turgid, pointed at both ends, cherry-like, acutely ridged on one and grooved on the other edge.

Prumus maritima, or as it has long been known, the Beach plum, is as yet hardly grown as a domesticated fruit. It is destined, however, in the minds of not a few, because of qualities which we shall describe, to play a more important part in the future of the cultivated plum flora than it has in the past. It has several valuable characters that should fit it alike for direct cultivation and for hybridizing with other species. It is surprising that more has not been done to domesticate the Maritima plums 
for they were among the first fruits noticed by early explorers and have always been used by both Indians and Whites for culinary purposes. The fact that Domestica plums thrive in their habitat is the only explanation of the non-amelioration of this plum before this.

September third, I609, Hudson entered the river bearing his name and found "a very good harbor, abundance of blue plums, some currants brought by the natives dried and the country full of great and tall oaks." The blue plum was the Maritima; and from Hudson's time nearly all of the accounts of the New World given by early explorers mention this plum. It is probably one of the plums described by Captain John Smith as a cherry "much like a Damson;" by Edward Winslow in $\mathrm{I} 62 \mathrm{I}$, in a letter to England to a friend, as one of his "plums of three sorts"; by Francis Higginson in his New England's Plantation in 1630 ; described by Thomas Morton in $\mathrm{I}_{32}$ in his New English Canaan as having "fruit as bigg as our ordinary bullis." John Lawson, one of the first of American naturalists, describes them rather more fully as follows:1 "The American Damsons are both black and white, and about the Bigness of an European Damson. They grow any where if planted from the Stone or Slip; bear a white blossom, and are a good fruit. They are found on the Sand-Banks all along the Coast of America. I have planted several in my Orchard, that came from the Stone, which thrive well amongst the rest of my Trees. But they never grow to the Bigness of the other Trees now spoken of. These are plentiful Bearers." These are but a few of the many references to the Beach plum but they are enough to show that the colonists were attracted by this wild plum found on a long stretch of the Atlantic seaboard-probably the first fruit to attract attention from Virginia to New England.

To be more explicit as to its range, Prunus maritima, in its typical form, is an inhabitant of the sea beaches and sand dunes from New Brunswick to the Carolinas, or possibly farther south, growing inland usually as far as recent ocean soil formations extend. As it leaves the seaboard marked variations make their appearance, chief of which are, smaller, more oval, smoother and thinner leaves and smaller fruit. The species has been reported as an inhabitant of the sands at the head of Lake Michigan, ${ }^{2}$ but the writer, who is well acquainted with this region, has never seen it there, nor is it to be found in the chief herbaria of Michigan as having been collected in the state.

\footnotetext{
${ }^{1}$ Lawson, John History of Carolina 105. I 714.

2 Waugh Vt. Sta. An. Rpt. 12:235. 1899. Bailey Cyc. Am. Hort. 1449. I901.
} 
In the region where it is found wild the Maritima plum is a rather common article of trade. The fruit is usually sold by the quart, the price being five or ten cents, and is used for both dessert and culinary purposes though for most part for the latter.

The species is one of the most variable of the true plums and there is, probably must ever be, much disagreement as to its botanical relationships. Several botanical varieties of Prunus maritima have already been named and there are yet groups within the species which seem to be nearly as distinct as those described and possibly worth distinguishing. Since the variations show in the size, color and edible qualities of the fruit, as well as in the characters of the plant, it is to be expected that the species has a horticultural future though at present it has but one cultivated variety-Bassett. Professor J. W. Macfarlane of the University of Pennsylvania has shown well the great range of variations in this plum both from botanical and horticultural aspects. ${ }^{1}$ He holds that these variations are sufficiently distinct to make many varieties of this plum in the wild, to which DeVries agrees with the statement that they indicate "the existence of separate races as elementary species." 2 The plum which Small has described as Prunus gravesii, to be discussed later, is a marked variation of Prunus maritima.

As it grows on the sea-coast Prunus maritima is a low bush three to six feet high, occasionally reaching a height of ten or twelve feet. Usually the plant is straggling but sometimes it is compact or even tree-like. Inland, on better soils, or under cultivation it makes a rather handsome dwarf tree. The flowers are borne in great numbers, completely covering the plant and coming later than most of the plums bloom. The species bears fruit very abundantly, which is always attractive but of quite diverse value for food. The fruit varies in size from a half to three-quarters of an inch in diameter and is almost spherical, though sometimes oval and with or without a distinct suture. The usual color is a rich bluish-black with a waxy bloom, but red, yellow, amber and orange fruits are often found. In taste the Maritima plums range from inedible to nearly as rich a flavor as is found in the best of the Domestica plums. Besides variations in the above and other qualities, Macfarlane calls attention to the range in ripening of the fruit of this plum, showing that it extends over a period of two months, an exceptionally wide variation for a wild plant.

\footnotetext{
${ }^{1}$ Cont. Bot. Lab. University of Pa. 2:216. 1899-1900.

${ }^{2}$ DeVries, Hugo Species and Varicties, etc. 57. 1905.
} 
This plum has a number of qualities that commend it to the fruitgrower. Since in the wild it grows on sandy soils it is not likely under cultivation to make great demands on either the moisture or the fertility of soils. It is very hardy and very productive and seldom fails to bear. It seems to be free or nearly so from some of the pests of cultivated plums. Lastly, the great number of wild varieties of the plums give many starting points from which to breed cultivated varieties. Two objections to the wild fruits are that when the fruit is harvested the juice often exudes from the wound made by the parting from the stem, and secondly, the secretion of some substance forming a dark colored, hard core in the pulp which gives a very bitter taste to the fruit. The last defect is very common in the wild plums and is probably due to the sting of an insect. Under cultivation it may be possible to obtain fruits free from these faults.

It would be desirable if some of the characters enumerated above could be combined with those of other species. Burbank has hybridized the Maritima plum with other species, with promising results. Of these he writes under date of December 6, I909, as follows:

"I first began raising Prunus maritima about I887-twenty-two years ago-collecting myself and having specimens sent me all the way from the coast of Labrador to South Carolina, the finest of which were obtained from the eastern coast of Massachusetts. Among the seedlings, of which I raised and fruited several hundred thousands, were yellow, red, purple and almost black ones, early and late, round, oval, oblate and flattened, with big stones and little stones, free stone and cling stone, and much variety in productiveness and growth of the young bushes, but not one of them the first two or three generations were very much increased in size-probably the largest being about the size of a cranberry or a small hazelnut-and none of them of very exceptional quality, though their habit of blooming late was a tremendous advantage, as they invariably escaped our spring frosts. This, with their unusual hardiness induced me to continue experimenting with them. Finally after some ten years I obtained a very delicious variety, about an inch in length and threequarters of an inch in diameter, tree much increased in size, larger foliage and more productive and producing enormous quantities of most delicious fruit. From this I raised a great many thousand, almost as good and a few of them even better, several hundred of which have been selected and are now bearing on my Sebastopol place. Some of these improved seedling trees grow five to ten times as large as the ordinary Maritima, with larger leaves and in every possible way improved. My greatest success with this species (and one of the most striking occurrences in my work with plums) 
was produced by pollinating one of the somewhat improved Maritimas with Prumus triflora.

"The very first generation, a pluni was produced which is an astonishing grower for a Maritima - almost equal to the Triflora, with large, broad glossy foliage of almost the exact shape of the Maritima, Maritima blossoms, and fruit weighing nearly one-quarter of a pound each, with an improved superior Maritima flavor, Maritima pit in form, but enlarged. The most singular peculiarity of this plum, which is so enormous, is that the trees commence to bloom about with the Triflora and bloom and bear fruit all summer, so that blossoms, young fruit and the enormous deep red ripening fruit can be seen on the trees at the same time."

\section{PRUNUS GRAVESII Small}

I. Small Torrey Bot. Club Bul. 24:44, P1. 292. 1897. 2. Britton and Brown N. Am. Trees 2:249. 1897. 3. Robinson and Fernald Gray's Man. Ed. 7:498. 1908.

Shrub low, slender, attaining a height of four feet; main trunk much branched, with dark, rough bark; branches ascending, slender, leafless, unarmed; branchlets of the season puberulent. Leaves oval-orbicular, orbicular or slightly obovate, rounded, retuse or apiculated at the apex, base truncate or at least obtuse, margins sharply serrate or crenate-serrate; upper surface sparingly pubescent or glabrous, lower surface pubescent, especially on the veins.

Flowers white, one-half inch broad; borne in two or three-flowered, lateral umbels, appearing with the leaves; calyx-tube campanulate, pubescent; petals sub-orbicular, abruptly narrowed at the base; pedicels stout, stiff, pubescent.

Fruit maturing in September; globose, one-half inch in diameter, nearly black, with a light bloom, acid and astringent; stone broadly oval, rounded at the apex, acute at the base.

Prumus gravesii is now known only in Connecticut, where it is found on a gravelly ridge at Groton near Long Island Sound. It grows in the neighborhood of Prunus maritima to which it is evidently closely related. Small in describing the species gives the following differences between the Gravesii and the Maritima plums: (I) Prum gravesii is more slender and delicate in habit, and matures its leaves and fruit earlier in the season. (2) The leaf of Prumus gravesii is small and sub-orbicular while that of the other is larger and more elongated. (3) The new species has smaller flowers with sub-orbicular petals while those of Prumis maritima are broadly obovate and gradually narrowed at the base. (4) The fruit of Prumus gravesii is smaller and more globose and has shorter pedicels. (5) The stone is more turgid and is pointed only at the base; that of Prumus maritima is usually pointed at both ends. (6) Sprouts arising from the 
ground do not produce flowers as they frequently do in the case of Prunus maritima.

The cultivation of this plum has not been attempted and as compared with Maritima it promises little for the fruit-grower.

\section{PRUNUS ORTHOSEPALA Koehne}

r. Koehne Deut. Dend. 311. 1893. 2. Sargent Gar. and For. 7:184, 187 fig. 1894. 3. Bailey Cyc. Am. Hort. 1450. rgor.

Shrub four or five feet high; branches dense and twiggy; stems sometimes armed with slender spines; bark separating in large, loose scales; branchlets stout, slightly zigzag, reddish-brown becoming dark brown.

Winter-buds obtuse, three-lobed at maturity; leaves oblong-ovate, thin and firm, acuminate, long-pointed, two and one-half to three inches long, two-thirds inch broad, unequally cuneate or rounded at the base; margins closely serrate with incurved, calloused or rarely glandular teeth; upper surface glabrous, light green, lower surface paler and pilose; petioles slender, slightly grooved, puberulous, one-half inch long; glands two, large, at the apex of the petiole.

Flowers appearing after the leaves; borne in three or four-flowered fascicles on stout pedicels one-half inch long; calyx-tube turbinate; lobes puberulous on the outer surface, with thick tomentum, often tipped with red on the inner surface; petals narrowly obovate, rounded at the apex, narrowing at the base into slender claws, white or tinged with pink; stamens orange, exserted; style glabrous, thickened at the apex into a truncate stigma.

Fruit globose, an inch in diameter, deep red with a heavy bloom; skin thick; flesh yellow, juicy, of good flavor; stone flattened, oval, slightly rugose, deeply grooved on the dorsal and ridged on the ventral edge.

The history and habitat of Orthosepala are given by Sargent as follows: "The history of this plant as I know it, is briefly this: In June, I 880, Dr. George Engelmann of St. Louis, sent to the Arnold Arboretum a package of seeds marked 'Prunus, sp. southern Texas.' Plants were raised from these seeds and in $\mathbf{I} 888$, or earlier, they flowered and produced fruit, which showed that they belonged to a distinct and probably undescribed species. A name, however, was not proposed for it, and in 1888 , probably, plants or seeds were sent to Herr Spath, of the Rixdorf Nurseries, near Berlin, where this plum was found in flower by Dr. Emil Koehne, who has described it under the name of Prunus orthosepala."

Of the affinity of this species Sargent says: "Prunus orthosepala is a true plum, rather closely related to Prunus hortulana, from which it can be distinguished by the smaller number of glands of the petioles, by the eglandular calyx-lobes, the dark colored fruit and smoother stone." As the writer has seen this plum growing in the Arnold Arboretum, Jamaica 
Plains, Massachusetts, and the City parks at Rochester, New York, it seems well worth cultivating. Mr. J. W. Kerr writes of it as follows:

"I have $P$. orthosepala fruiting here, and with me its fruit is exceptionally fine in quality, sparingly produced-attributable I believe to the fact that no variety stands near enough to it for proper inter-pollination. The trees are rather dwarfish in habit, close-headed, with fine clean foliage. The fruit is globular in form; size equal to fair specimens of Hawkeye or Wyant; skin a greenish-yellow, almost entirely covered with deep red."

W. F. Wight of the United States Department of Agriculture has collected specimens of a cultivated plum, taken from the wild, locally known as the Laire, in Rooks and neighboring counties in Kansas, with foliage very similar to Prumus orthosepela. While the identity of Laire with the species under discussion cannot be established at this time, the reported source of the seeds, "southern Texas," from which Prunus orthosepela was grown may be an error.

\section{PRUNUS GRACILIS Engelmann and Gray}

r. Engelmann and Gray Bost. Jour. Nat. Hist. 5:243. 1845. 2. Torrey Pac, R. Rpt. 4:83. 1854. 3. Britton and Brown Ill. Fl. 2:249, fig. 1897 .

P. chicasa var. normalis. 4. Torrey and Gray Fl. N. Am. 1:407. 1840.

P. normalis 5. Small Fl. S. E. U. S. 572 . 1903.

Shrub low, attaining a height of five or six feet; branches many, straggling, more or less spiny; branchlets at first densely tomentose or soft-pubescent, becoming glabrous; leaves small, ovate-lanceolate or oval, margins finely and evenly serrate, rather thick, texture harsh and firm; upper surface dark green, glabrous or nearly so at maturity, lower surface paler, soft-pubescent becoming nearly glabrous; petiole short and stout.

Flowers white, small, appearing before the leaves; borne in sessile, several-flowered umbels; pedicels short, slender, soft-pubescent.

Fruit globose or oval, very small, not more than one-half inch in diameter, variable in color, mostly in shades of red; stone turgid, nearly orbicular, pointed at both ends.

Prunus gracilis is found in dry, sandy soils from southern Kansas and western Arkansas to central Texas. It grows most abundantly and thrives best in Oklahoma, a fact which leads Waugh to call it the "Oklahoma "plum. All who know the species agree that it is a near approach to Maritima in many of its characters. This plum is very variable and some of its forms seem not to have been well studied. As a fruit plant Gracilis is hardly known in cultivation though Torrey says it is cultivated in the region of its habitat under the name Prairie Cherry. The wild fruit is used more or less locally and is sometimes offered for sale in the markets of western towns. The quality is about the same as that of the 
wild Americanas and under cultivation would probably improve. The small size of plant and fruit are the most unpromising characters though the species is also much subject to black-knot.

\section{PRUNUS RIVULARIS Scheele}

x. Scheele Linnaea 21:594. 1848. 2. Gray $\mathrm{Pl}$. Wright. 1:67. 1852. 3. Hall Pl. Texas, 9 1873. 4. Coulter Cont. U. S. Nat. Herb. 2:101. 1891. 5. Waugh Bot. Gaz. 26:50-52, 1898. 6. Bailey Ev. Nat. Fr. 223.1898.

Shrub three to seven feet high; branches angular, smooth, shining, ash-colored, rough; lenticels small, crowded; leaves oblong-ovate or sometimes ovate, rarely lanceolate, apex acute, margins coarsely or doubly serrate, glabrous above and sparingly pubescent below; petioles glandular, grooved, pubescent; flowers in lateral umbels, in pairs or several-flowered; fruit about one-half inch in diameter, oblong-oval, cherryred; skin thick, smooth and tough, acid.

The preceding description is largely compiled from the authors given in the references, the writer having seen only herbarium specimens. The species is included here largely upon the authority of Professor C. S. Sargent of the Arnold Arboretum and W. F. Wight, who know the plant as described by Scheele in the field. Gray described the plant as "verging to Americana." Bailey says "it evidently bears the same relation to Prunus americana that Prunus watsoni does to the Chickasaw plum." Waugh is "convinced that Prunus rivularis Scheele is nothing more than one of the more distinct sub-divisions of the multiform hortulana group." T. V. Munson writes me that the Waylandi plums belong in this species. Myown opinion is, from the herbarium specimens examined, from correspondence and conversation with those who have seen the plant in the field, that Scheele's species is a good one and quite distinct from the species named by Bailey, Waugh and Munson as allied to it. It is to be looked for along the streams and bottom-lands in the neighborhood of San Antonio and New Braunfels, Texas. The plum is locally known as the Creek plum and in common with other plums is gathered for home consumption. The species seems to offer but few possibilities for the fruit-grower.

1 The references given contain these quotations. 


\section{CHAPTER II}

\section{PLUM CULTURE.}

Ten states produced over 82 per ct. of the plum crop of the United States in 1899 . The census of 1900 shows that in the preceding year the total crop in the country was $8,764,03^{2}$ bushels of which California, Oregon. New York, Washington, Michigan, Iowa, Texas, Arkansas, Ohio and Kansas, named in order of yield, produced $7,429,248$ bushels. All other states yielded I, 334,784 bushels. Of these ten states, three, California, Oregon and Washington, holding first, second and fourth places in production, use by far the greater parts of their crops for prunes. Four others, Iowa, Texas, Arkansas and Kansas, grow the native and Triflora varieties almost exclusively. New York with a crop of 313,668 bushels in I899, Michigan with 213,682 bushels the same year and Ohio with 81,435 bushels, grew the main crop of Domesticas for the states in which plums are not made into prunes.

At the end of the Nineteenth Century the plum ranked third in commercial value among orchard products, being surpassed by the apple and the peach. The increase in number of trees and bushels of fruit for the whole country for the decade ending with i 899 was remarkable, being for trees 334.9 per ct. and for bushels of fruit 243.1 per ct. These great increases were due to very large planting of plums for prunes on the Pacific Coast and to the widespread distribution during these ten years of native and Triflora varieties. It is very doubtful if the percentage of increase has been nearly so great during the present decade. It is likely that the development of rapid transportation and refrigerator service between the great plum-growing region of the far West and the markets of the East has caused a decrease in trees and production in the eastern states.

Plum-growing, as with the growing of all fruits, is confined to localities geologically, climatically and commercially adapted to the industry. If we take New York as an example we find that plums are grown largely only in ten of the sixty-one counties, according to the census of 1900 . These with the number of trees in each are as follows: Niagara 184,133 , Ontario 92,917, Seneca 59,205, Monroe 57,246, Schuyler 48;336, Orleans 41,985, Yates 32,742 , Albany 32,373 , Erie 30,281 , Wayne 30,047 . Over 62 per ct. of all the trees in the State are in these counties and probably they produce more than 90 per ct. of the plums sent to market. 
A canvass of the acreage of four hundred plum-growers in New York shows that the following in order named are the leading commercial varieties: Bradshaw, including Niagara, which is identical, Reine Claude including its several near variations, Italian Prune, German Prune, Lombard, Shropshire, Grand Duke, Washington and Gueii. Abundance and Burbank are as widely distributed as any of these, chiefly owing to the zeal with which nurserymen have sold these varieties, but are seldom grown exclusively in commercial plantations, and their popularity is now on the wane as is also the case with Red June which has been largely planted. Varieties of native plums are hardly grown in New York though now and then they are found in home collections and there are a few small commercial plantations of them.

The fruit of the native and Triflora plums is so inferior to that of the Domestica sorts for market and domestic purposes, that varieties of these are not likely to take the place of the Domestica plums. Producers and purchasers are now familiar with the possibilities of the natives and of the Orientals and have not been greatly attracted by them in New York. It is true, however, that the natives have been chiefly represented by Wild Goose and the Trifloras by Abundance and Burbank-scarcely the best that these groups of plums can produce. It is true, too, that the varieties have been greatly over-praised and that they now suffer from the reaction. Yet the Domesticas command the market and their reliableness in the orchard gives them a popularity in this region which other plums cannot for a long while trench upon.

This brings us to a discussion of the conditions under which plums are now grown in North America and more particularly in New York. Of these, climate, with this fruit, should be first discussed, outranking all others in importance.

\section{CLIMATE}

Climatic conditions determine the culture of the plum not only for a region but for a locality; not only as to whether it is possible to grow plums at all but as to whether this fruit can be grown with reasonable prospects of commercial success in competition with other localities. The constituents of climate which are important in plum-growing are temperature, rainfall and air currents, the last two being largely dependent upon the first. The relationship existing between plums and these factors of climate are fairly well known for they have received attention from the very beginning of plum culture. 
There are four phases of temperature that need to be considered in order to get a clear insight into the climatic conditions which govern production of fruit crops. These are, the daily, monthly and annual changes in temperature and the extremes in temperature. Of these the daily and annual changes are of little importance. All plants are very adaptable to daily variations in climate and are little affected by them. Annual variations are shown by statements of the annual mean temperatures but such statements are of small value to fruit-growers as they may be the result of averaging very divergent temperatures or temperatures very close together. The monthly mean, however, is a very fair criterion of climate for fruit-growing, especially when given with the amount and distribution of rainfall.

But far more important than any of the above phases are the extremes in temperature and more particularly of cold. A plant can not be grown profitably where the temperature, even occasionally, falls below the point where winter-killing results to tree or bud, or where the blossom is injured by frost. Extremes of heat are disastrous usually only when long continued. For each fruit, too, there must be a total amount of heat available to carry it from the setting of the fruit to maturity, in which respect varieties of any fruit may differ materially. Of the injurious effects and of the necessary amounts of heat, however, we know but little.

These general considerations of temperature lead us to their application to the plum and especially to a discussion of the most important of the several factors--hardiness.

Hardiness to cold, a matter of prime importance with all fruits, is especially so with the plum because of the many different species, each with its own capacity for withstanding cold. As the different species are taken from their natural habitat to other regions, there to become acclimatized, and as new forms originate by hybridization, the matter becomes more complicated and more important. Waugh ' has investigated the hardiness of plums and we publish a table given by him showing the hardiness of representative varieties of the species most generally cultivated. We have taken the liberty of adding a few plums not given in the original table and have also made some changes in the nomenclature of the groups.

1 Waugh, F. A. Vt. Sta. An. Rpt. Ir:273. I897-98. 
Table Showing the Hardiness of Representative Varieties of Plums at Various Places. h-hardy; hh-half-hardy; t-tender.

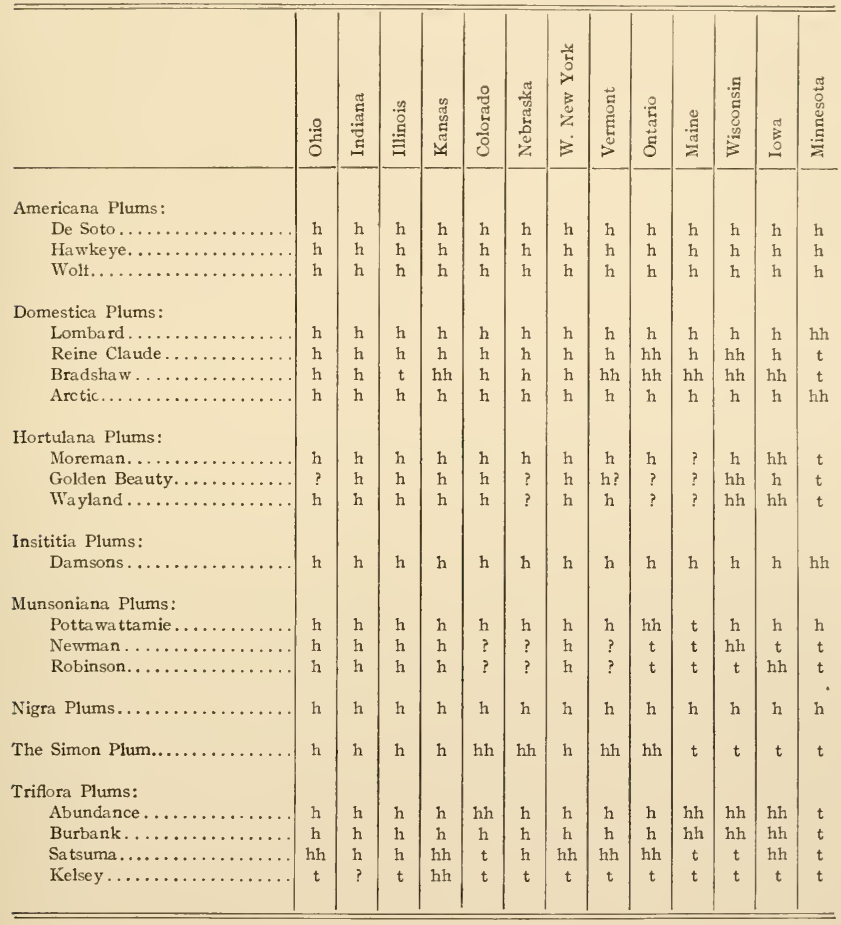

A few general statements in addition to the above table will help to make plain the comparative hardiness of the different groups of cultivated plums. The Nigras may be rated as the hardiest of the plums to be considered though the Americanas are but slightly less hardy. The plums of these species are the hardiest of our tree-fruits and are able to resist nearly as much cold as any other cultivated plant. The Insititias, as represented by the Damsons, at least, come next hardiest after the above species, with varieties of Domestica, as Arctic, Lombard and Voronesh, 
nearly as hardy. So far as resistance to cold is concerned the Domestica plums as a class are less hardy than the apple, ranking in this respect with the pear. Of the Domesticas the Reine Claude plums are as tender to cold as any though some consider Bradshaw as more tender. Between these last sorts and the hardiest varieties there is a great range in capacity to endure cold, as would be expected with so large a number of varieties originating in widely separated climates. The Triflora plums vary more in hardiness than any other of the cultivated species. Speaking very generally they are less hardy than the Domesticas, the hardiest sorts, Burbank and Abundance, being somewhat hardier than the peach, while the tenderest varieties, of which Kelsey is probably most tender, are distinctly less hardy than the peach. Of the remaining plums, the Hortulana, Munsoniana and Watsoni groups, there are great diversities in opinion as to hardiness. Probably all of the varieties in these last groups are as hardy as the peach with a few sorts in each more hardy than the peach. It is to be expected from the more northern range of the wild prototypes that the Hortulana and Watsoni plums are somewhat hardier than Prunus munsoniana.

The rainfall is of comparatively small concern to plum-growers in America, since, with now and then an exception, in eastern America it is sufficient under proper cultivation, and on the Pacific Coast the crop is largely grown under irrigation. Summarized statements of annual rainfall are of little or no importance since almost all depends upon the distribution of the amount throughout the year and upon the manner in which it falls. Monthly and seasonal "means" of precipitation, as in the case of temperature, may be of considerable importance in determining the desirability of a locality for plums.

Air currents are of local or regional occurrence and though not often the determinant of profitable culture of plums have sometimes been important factors in choosing a location to grow this fruit. The occurrence, direction, moisture condition and temperature are the attributes of air currents usually considered. The failure of many plums to grow in the prairie region of the Mississippi Valley and the Great Plains is no doubt due in some measure to winter winds. The problem of varietal adaptation is more or less complicated in any region by the nature of the air currents.

An extremity of any of the constituents of what we call "weather" endangers the plum crop at blossoming time. In New York stresses of 
wcather are probably the predominating causes of the non-setting of fruit on plum trees which bear an abundance of blossoms. This is well shown in a study of the relations of weather to the setting of fruit made by the New York Agricultural Experiment Station in which it is held that several phases of weather at blossoming time cause the loss of plum crops. ${ }^{2}$ Thus late frosts, wet weather, low temperature, strong winds and wide daily ranges in temperature were factors in the loss of fruit crops in all of the failures during a period of twenty-five years. Quite as significant was the fact that in all of the years during this period when there was sunshine and warm, dry weather during blossoming time there were good crops of fruit.

Locations for growing the different varieties of plums are selected with reference to general and local climate. As regards general climate, latitude, altitude and proximity to large bodies of water are the chief determining characters; as regards local climate, the lay of the land has most to do as a determinant. Again, varieties are selected with reference to time of blooming, that they may escape in some degree injurious climatal agencies. Lastly, varieties are selected having greater capacity, from one cause or another, to withstand injurious weather. With all varieties it is found that cultural treatment to induce strong vitality helps a tree to withstand stresses of harmful weather at blossoming time.

The above considerations show that the blossoming dates of plums should be known for the proper culture of this fruit. In the following table averages of the blooming dates of varieties of plums for the eight years just past, 1902 to 1909 , inclusive, are given.

In making use of these dates, consideration must be given to the environment of the orchards at Geneva. The latitude of the Smith Astronomical Observatory, a quarter of a mile from the Station orchards is $42^{\circ}$ $5^{2^{\prime}} 46.2^{\prime \prime}$; the altitude of the orchards is from five hundred to five hundred and twenty-five feet above the sea level; the soil is a stiff and rather cold clay; the orchards lie about a mile west of Seneca Lake, a body of water forty miles in length and from one to three and one-half miles in width and more than six hundred feet deep. The lake has frozen over but a few times since the region was settled, over a hundred years ago, and has a very beneficial influence on the adjacent country in lessening the cold of winter and the heat of summer, and in preventing early blooming.

${ }^{1}$ Hedrick. U. P; The Relation of Weather to the Setting of Fruit. Bul. 299. 1908. 
The dates are those of full bloom. They were taken from trees grown under normal conditions as to pruning, distance apart, and as to all other factors which might influence the blooming period.

An inspection of the table shows that there is a variation of several days between the time of full bloom of the different varieties of the same species. These differences can be taken advantage of in selecting sorts to avoid injury from frost. The same table shows the ripening season of the plums growing on the Station grounds. Now and then the late and very late plums given in the table may be caught by fall frosts in the colder parts of New York or in regions having a similar climate.

Table Showing Blooming Dates and Season of Ripening.

The "blooming date" is that of full bloom.

Under season of ripening "very early" is from July $I_{5}$ to August Io; "early," August Io to August 20; "mid-season," August 20 to September 10; "late," September 10 to September 20; "very late," September 20 to October I.

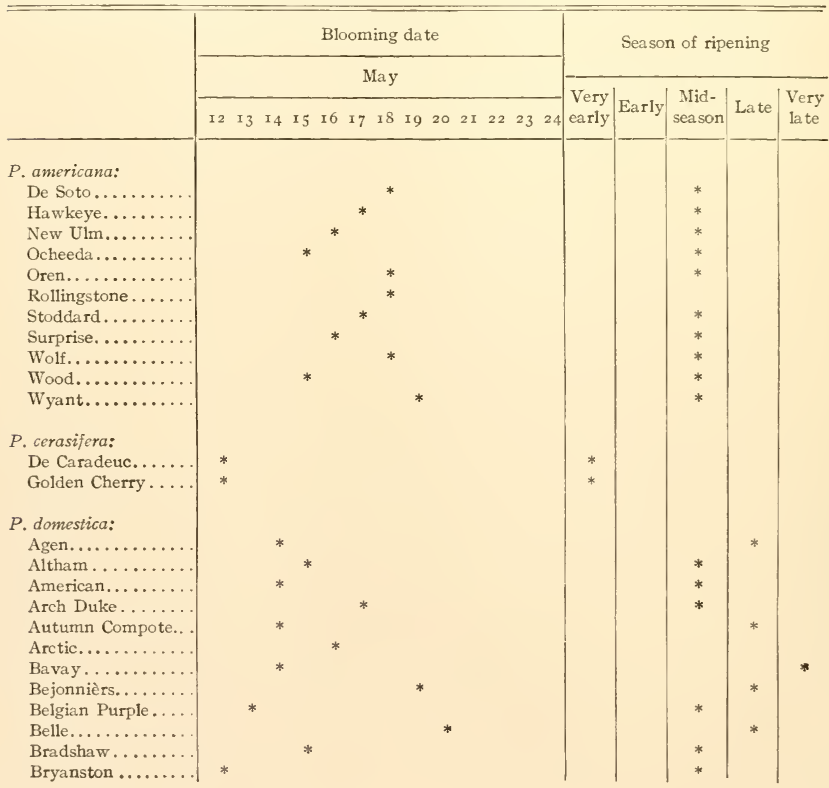


Table Showing Blooming Dates and Season of Ripening-Conimued.

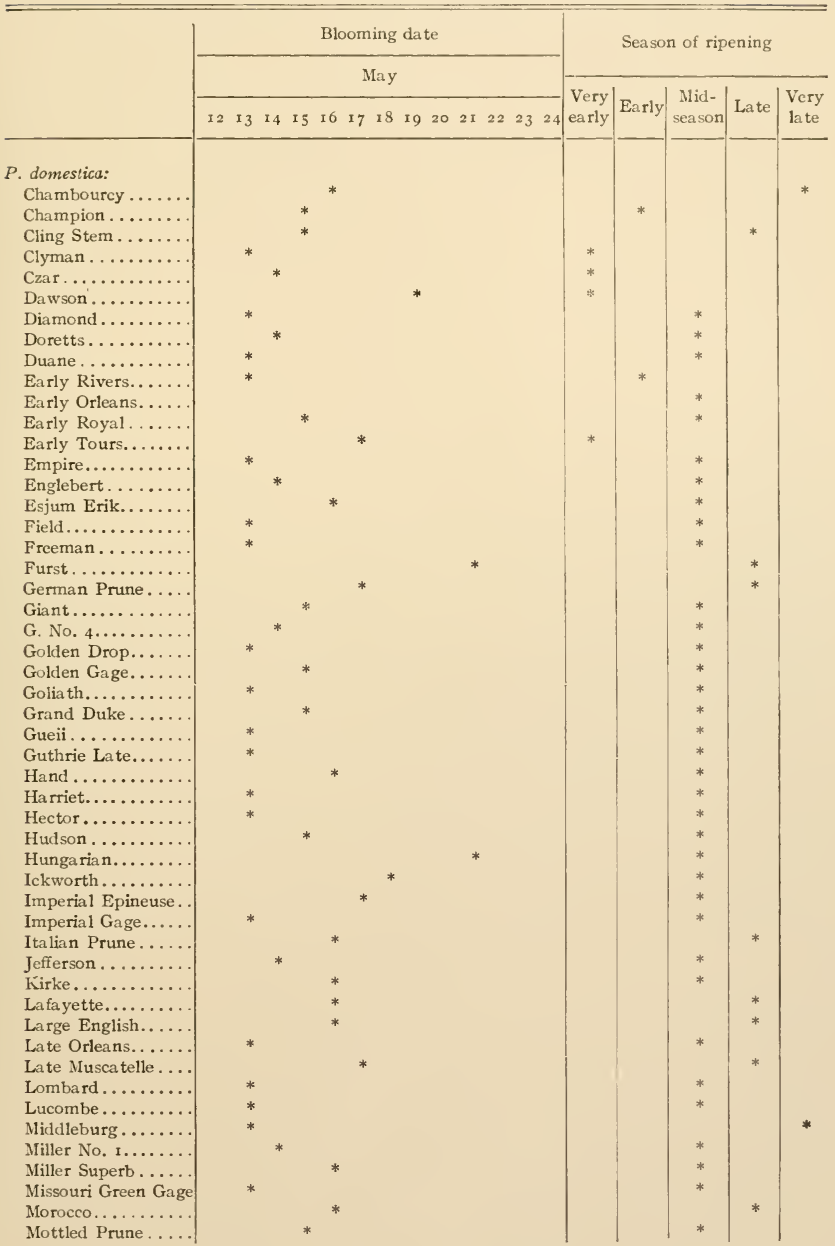


Table Showing Blooming Dates and Season of Ripening-Continued.

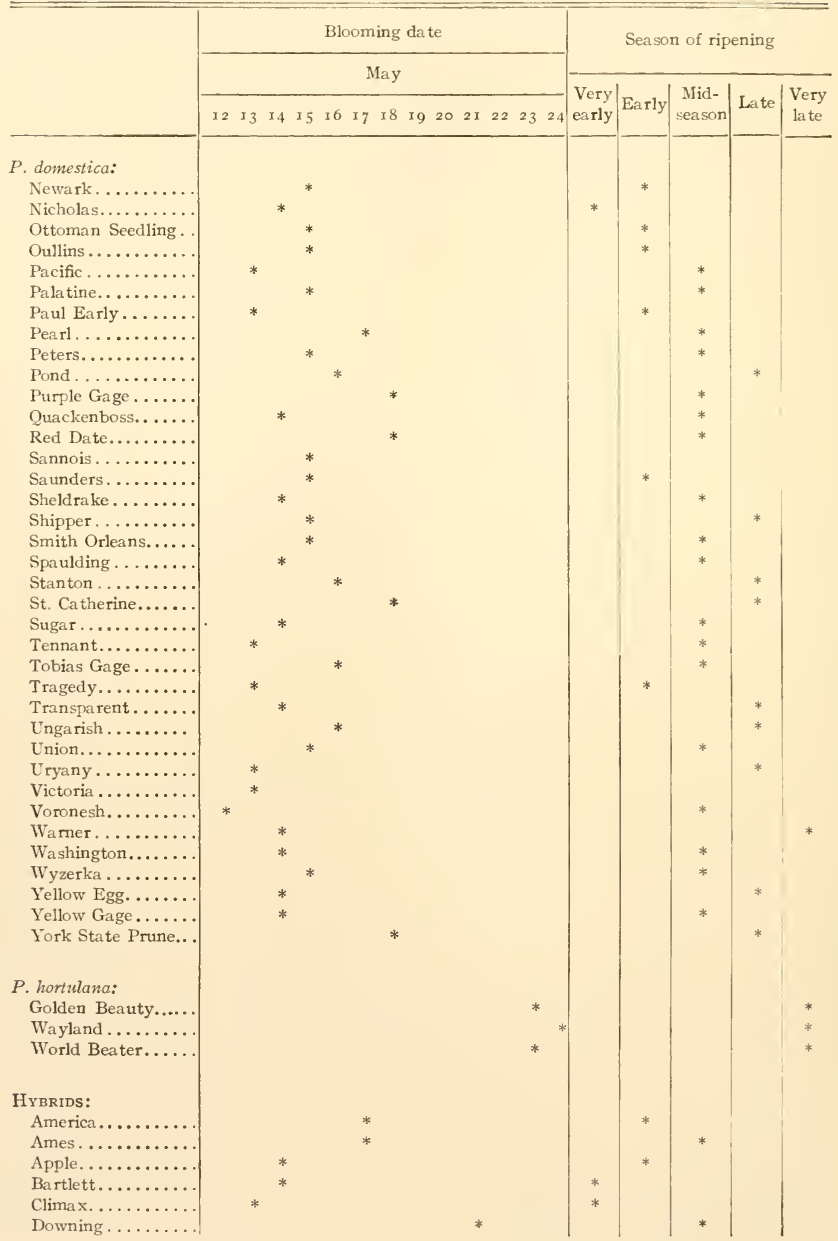


Table Showing Blooming Dates and Season of Ripening-Continued.

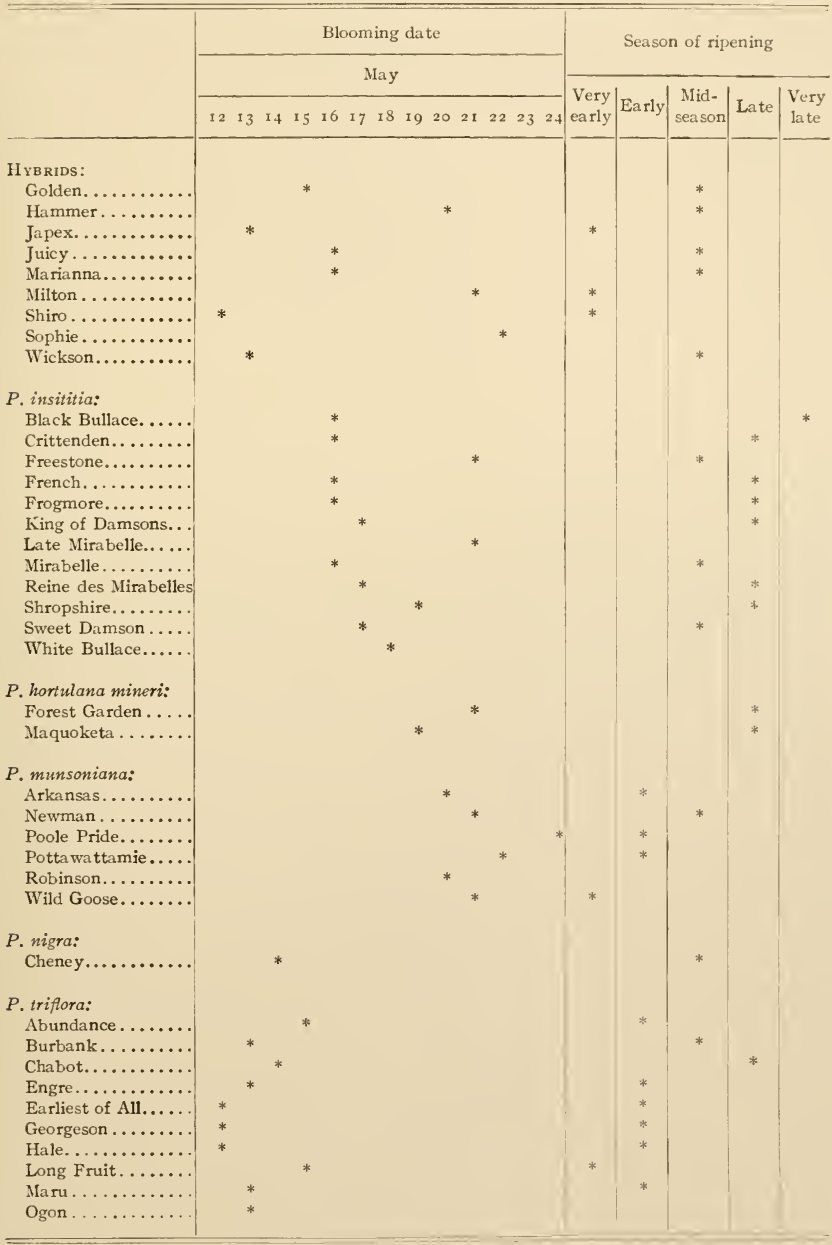


One of the discouragements in plum-growing is the uncertainty which attends the setting of the fruit in some varieties even though the trees bear an abundance of blossoms. Blooming, the prelude of fruiting, had little significance to the fruit-grower until the discovery was made that many varieties of several fruits were unable to fertilize themselves and that failures of fruit crops were often due to the planting of infertile varieties. Investigations as to the self-sterility of pears, plums and grapes have shown blossoming-time to be one of the most important life periods of these fruits. The knowledge obtained by workers in this field has to some degree modified the planting of all orchard-fruits and of none more than of the plums. Indeed, it is held by many that it is hardly safe to plant any excepting the Domestica and Insititia plums without provision for crosspollination.

A variety is in need of cross-pollination when the pollen from its own blossoms does not fecundate the ovules of the variety. There is a delicate and complicated procession during the process of fruit formation and the life of the fruit may be jeopardized by any one of a number of external or internal influences. These deleterious influences are most often unfavorable weather or defects in the reproductive organs of the plants themselves. Of the latter, in the plum there are several rather common ones which cause self-sterility, as impotency of pollen, insufficiency of pollen, defective pistils and difference in the time between the maturity of the pollen and the receptiveness of the stigmas.

It is held that the main cause of the infertility in plums is impotency of pollen on the pistils of the same variety. The pollen may be produced in abundance, be perfect as regards appearance, and potent on the pistils of other varieties but wholly fail to fecundate the ovaries of the variety from which it came. The most marked examples of such impotency are to be found in the native plums though the Triflora sorts are generally accredited with being largely self-sterile and the Domesticas somewhat so. The proof offered to show the impotency of plums is for most part the records of fruit setting under covered blossoms. In this method of testing the impotency of pollen there are several sources of error and the figures given by experimenters probably greatly exaggerate the infertility of plums, but since the experience of plum-growers generally affirms the results in some measure it is well to hold that the native plums at least should be so planted as to secure cross-pollination. It is doubtful if the 
Domestica and Triflora plums are self-sterile and yet the question is an open one as regards some varieties of these spccies.

There is great difference in the quantity of pollen produced by the several groups of plums but it is very doubtful if insufficiency of pollen is a factor of any considerable importance in the self-sterility of this fruit. Yet the matter is worth attention because of its bearing upon the selection of pollinizers. Of the several botanic groups, speaking somewhat generally, the Americanas and Nigras bear most pollen; the Munsoniana plums are abundant pollen bearers; the Trifloras seldom show a shortage but bear rather less than the others named; the Domesticas produce pollen abundantly; while the hybrid groups are the most capricious of all the plums in this respect, some varieties bearing much and others but little pollen. Probably the amount of pollen which the flowers of any tree produce is somewhat modified by the climate in which the tree is growing, by the weather and by the vigor of the tree.

Waugh ${ }^{1}$ and Goff $^{2}$ have shown that self-sterile plums often have abnormal pistils or pistils too weak for the development of fruits. Not infrequently flowers of the plum are without pistils, as occasionally, but less rarely, occurs with the stamens and petals. These abnormalities cannot be very general causes of self-sterility in plums, however, as varieties, or even trees, cannot often be found which are not fruitful if other varieties are growing near them. It is very doubtful if even so much as fifty per ct. of abnormal flowers, seriously jeopardizes a plum crop, as the trees bear, if they blossom at all, several times as many flowers as they can mature plums. But a high percentage of abnormal flowers nearly always indicates a general weakness in fruit-setting.

Another cause often assigned for the failure of plums to set fruit is the difference in time of maturity of stamens and pistils. It is claimed that when these organs do not mature simultaneously the plums do not set unless pollen is supplied from some other source. The task of taking notes at blossoming time on more than three hundred varieties of plums on the grounds of this Station has given abundant opportunity to observe the comparative degrees of maturity of pistils and stamens in varieties of this fruit. In general the pistils mature first, often three or four days before the stamens. Rarely the pollen is disgorged before the stigmas are receptive. But stigmas remain receptive, weather conditions being favor-

1 Waugh, F. A. Vt. Sta. Bul. 53:51. 1896.

${ }^{2}$ Goff, E. S. Wis. Sta. An. Rpt. 18:302. 1901. 
able, for several days and the pollen from all anthers is not shed at once and is produced with such seeming prodigality as to almost insure the retaining of a sufficient amount to pollinate late-maturing stigmas. In view of these considerations, premature or retarded ripening of either pistils or stamens does not seem of great significance in the setting of fruit

From the statements just made it may be seen that the main cause of the failures to set fruit when trees bloom freely must be ascribed to the failure of pollen to fertilize the pistils of the flowers of the same variety. The solution of the problem of self-sterility in the main, then, is to so plant that varieties will be mutually cross-fertilized. In the selection of varieties for such cross-pollination two factors must be considered, simultaneity of blossoming and sexual affinity.

It is evident, if cross-fertilization is to play an important part in fruit-growing, in planting to secure it kinds must be chosen which come into blossom at the same time as those they are expected to fertilize The table on pages 106 to 109 shows the sorts that bloom together or nearly enough so to make cross-pollination possible. It will be found upon examining the table that, under normal conditions and during the average season, varieties of any one species overlap sufficiently for the above purpose unless it be the very early and very late varieties. Variations due to locality and to season must be expected but within the bounds of New York these will be slight. If the table is used for other regions than New York it must be borne in mind that the farther south, the longer the blossoming season; the farther north, the shorter the season. Properly interpreted the table of dates should be a useful guide as to the simultaneity of blooming.

Varieties of plums seem to have sexual affinities. That is, some varieties will fertilize each other very well and some will not, even though they belong to the same species. There seems to be little definite knowledge as to the sexual affinities of plums and it is not, therefore, possible to lay down exact rules for the selection of pollinizers for individual varieties. In the current discussions of cross-pollination it is probable that the importance of "affinities" is over-rated, and yet the subject is worthy of consideration. Waugh and Kerr have given this subject considerable attention for native and Japanese plums and have recommended a list of pollinizers for the several species.' The Domesticas and Insititias, the

1 Waugh, F. A. Plum Cult. 297-300. 1901. 
above writers hold, are best cross-pollinated by varieties from the same species if cross-pollination is essential.

The subject cannot be closed without the expression of the opinion that the lack of cross-pollination as a cause of the uncertainties in the setting of fruit has been over estimated in the planting of plum orchards. This expression of doubt is made because there are serious disadvantages in the planting of mixed orchards of any fruit and the question as to whether these do not outweigh the advantages must ever be considered.

\section{LOCATIONS AND SOILS FOR PLUMS.}

The plum is comparatively easy to suit in the matter of location of orchards, as is shown by the exceedingly wide range of this fruit in New York. Plums are grown with eminent success on the elevated and sloping lands adjoining the Great Lakes, the Central Lakes of western New York and on both banks of the Hudson. Unquestionably there are many other localities than those named about the waterways of the State and also upon the elevated lands in the western interior formed by morainic hills, and upon the slopes of the mountains in eastern New York. Upon any land in the State suited to general farm crops, where the severity of winter is tempered by the lay of the land or proximity to water, and where late spring frosts are infrequent, plums may be grown. The early blooming plums, the Trifloras in particular, require more or less consideration as to the slope of land, a northern exposure to retard blooming-time being best. With other species the direction of the slope makes little difference, though a slope for air and water drainage is always better than a dead level.

The plum is now thriving in New York, and in the country at large, in a great diversity of soils. The chief requisite for the genus in general seems to be good drainage. Given this condition, some sort of plums can be grown on almost any soil found in America not wholly prohibitive of plant growth. Plums can be found which will stand rather more water than any other of the tree-fruits, and since plums can be grafted on several stocks, each having its own adaptation to soils, the adaptability of the genus is still further increased. Yet the several species have somewhat decided soil preferences.

The Domesticas and Insititias, the plums now almost exclusively grown in New York, grow most satisfactorily, all things considered, on rich clay loams. The plum orchards in this State on such soils contain the largest and most productive trees and produce the choicest fruit from 
the standpoints of size, appearance and quality. Yet there are exceptions in which exceedingly fine Domestica plums are grown on light loams. The Station collection of about two hundred varieties of European plums is on stiff clay, but well drained, and the results are uniformly good. The Americanas and Nigras grow very well on much the same soils as the European sorts, speaking from the experience on the grounds of this Station, for varieties of these species are not generally grown in New York. Beyond question the Triflora plums, next most widely grown in New York after the Domesticas, are giving the best results on light soils - those most favorable for the peach. The ideal soil for this species is a sandy or gravelly loam but they are growing well on soils having either more sand or more clay than the ideal types. The Hortulana and Munsoniana plums incline to the comparatively light types of soils named as being best for the Trifloras rather than to the heavier lands on which the European plums are most commonly grown.

Plum-growers are well aware of the necessity of good drainage for this fruit but few seem to realize the importance of warmth in a plum soil. The plum, in common with all stone-fruits, grows best, as a rule, on soils having the power to absorb and retain heat, or if the soil have not these properties the location and the cultivation should be such as to provide as far as possible for "bottom heat."

STOCKS AND PROPAGATION.

A discussion of stocks naturally follows one of soils, for the two are intimately related. The plum can be successfully grown on various stocks and for this reason the practices of nurserymen are diverse, depending upon the cost of the stocks, the ease with which they may be budded or grafted and the adaptability of the tree to the stocks. Unfortunately there is little experimental data to show which of the several stocks is best for the different plums and since growers seldom know what stocks their plums are growing upon they can give almost no information as to the desirability of propagating on this stock or that. Nurserymen know the stocks best adapted to their purpose and from them we have sought information.

A letter of inquiry sent to representative nurserymen in all parts of the United States as to the relative merits of the several stocks for the different species of plums shows that plum propagators in different regions use somewhat different stocks. In New England and the North Atlantic 
States, the Myrobalan seems to be almost the universal choice, the exception being a few propagators who claim that the Japanese sorts should be worked on the peach, especially for sandy soils, and a few others who are using Americana stocks for the American species.

In the Atlantic states south of Pennsylvania and in the Gulf states to the Mississippi the preferences are very diverse, with the majority of the nurserymen in this region favoring the peach, Myrobalan following as a close second choice. For light soils it would seem that the peach is always to be preferred for this great region. The opinions expressed by the veteran plum-grower, J. W. Kerr of Denton, Maryland, on this subject are worth printing in full. He says:

"In this locality for all varieties of the Domesticas that unite thoroughly with it, the peach is preferable as a stock. There are, however, a good many varieties of Domesticas that refuse to unite firmly with the peach. For these the Marianna or the Myrobalan gives best results. For all of the Japanese plums the peach has proved most satisfactory, when the trees are propagated by root-grafting on the whole-root plan. Nearly forty years of experimenting and testing stocks of various kinds gives me a decided preference for the peach as a stock for native plums; results doubtless would be different in colder climates and soils than this, but long and critical experience has conclusively demonstrated the superiority of this stock when used as indicated for the Japanese."

In the interior region between the Atlantic and Gulf States and the Mississippi, the Myrobalan is used almost exclusively for the European plums and most largely for the other species. Several nurserymen from this region, however, state that the St. Julien is better than the Myrobalan for the Domesticas and Insititias but object to them because the stocks cannot be obtained as cheaply. The peach is generally recommended for the Triflora sorts and the statement is several times repeated that the Americanas would be preferred for the native species if stocks of this species could be obtained readily.

In the northern states of the Mississippi Valley, all nurserymen agree that plums must be worked on Americana stocks. In this region the hardy natives only are grown.

South of the northern tier in the states of the plains the Myrobalan is used almost exclusively for the European species, most largely for the Trifloras, with the peach second for this species, and Americana stocks for the native species. Stark Brothers of Louisiana, Missouri, large growers 
of nursery stock in this region, express the opinion that " the right stock for native plums is yet to be found." In Oklahoma, Texas and New Mexico the Marianna is mentioned by several nurserymen as desirable, and is, from these statements, rather more commonly used for stocks in these states at present than in any other region.

On the Pacific Coast propagators use Myrobalan and peach in about equal quantities - the first named for heavy soils and the last for the lighter soils. The native plums are not grown in this region. The almond is mentioned as being desirable in California under some conditions. Some plum-growers in the states of the Pacific propagate their own trees from suckers.

The information given by nurserymen shows that by far the greatest number of plums in the country are grown on Myrobalan stocks. In New York this stock is used almost exclusively. In Europe the writer found that the nurserymen hold that this is a dwarfing stock, and that the trees on it are shorter-lived than on some other stocks. In the nurseries in New York, plums in general, but more especially the Europeans, are larger and finer trees at two years, the selling age, grown on Myrobalan roots than trees grown on other stocks. Nurserymen lodge but two complaints against it; these are that in the South it suckers badly and in the cold states of the Great Plains the roots are killed by the winters. Its advantages from the tree-growers' standpoint are: Cheapness of the stock, which is usually imported from France, large handsome trees in the nursery, ease of budding and a good union with nearly all varieties. Some growers complain that certain varieties overgrow this stock making in the end a badly mal-formed trunk. The Myrobalan plums are very variable, a fact which finds record in nearly all the characters of tree and fruit and this is somewhat against it as a stock. It is for this reason that there are so many "true" and "false" Myrobalans among nurserymen. Many importers hold that this stock is grown in France from cuttings. Such it seems was the old practice but now, if information from France is correct, most of these stocks are grown from seed. Hansen reports that in South Dakota this stock is worthless because it winter-kills. He says" "in experiments at this Station a very small per cent. of Myrobalan stocks survived the first winter and these died the ensuing summer." It is likely that this stock would suffer in the coldest parts of New York.

\footnotetext{
${ }^{1}$ Hansen, N. E. S. D. Sta. Bul. 93:67. r 905.
} 
In this region the St. Julien is probably the next most common stock in plum orchards though trees on it are for most part old, as its use is on the decrease. There is a wide-spread opinion among plum-growers that this is a much better stock for Domestica and Insititia plums than any other. On St. Julien stocks varieties of these species, it is claimed, with much to substantiate the claim, produce trees that are longer-lived, thriftier, hardier, deeper feeders, sprout less and are less susceptible to changes in soils. The chief objections to this stock are: It is more expensive, sometimes scarcely obtainable in France; difficult to bud; the young trees do not make as good growth as on the Myrobalan stocks; and the yearlings are much more susceptible to fungi while in the nursery row, though the latter troubles can be remedied wholly or in part by spraying. Hansen, in the reference given above, says that "the St. Julien and European Sloe (Prunus spinosa) both winter-killed " in South Dakota when used as stocks. The St. Julien stock is propagated from layers when properly grown in France' ${ }^{1}$ but much undesirable stock is now raised from seed. There are fruiting trees of this stock about the nurseries in the neighborhood of this Station which show it to be an Insititia of the Damson type, a type likely to come fairly true to seed yet not sufficiently so as to make seed-grown trees desirable.

The Horse plum was formerly used as a stock by nurserymen a great deal but is now wholly superseded. Indeed, it is so nearly lost to the trade as to make it almost impossible to really know what the plum of this name is. Some describe it as a small-fruited Domestica, others as an Insititia similar to the St. Julien, but the majority of the trees shown by old nurserymen in the nursery region of New York, about the only place in which the stock was used, show it to be a Cerasifera but not Myrobalan. Some of the named varieties of Cerasifera probably sprung from sprouts of this stock. It seems to have had no qualities which would make it worth while to attempt to re-establish the stock.

The testimony of a large number of nurserymen is in favor of the peach as a stock for plums. Budded on the peach, plums of many varieties are grown very successfully on the warm sandy and gravelly soils so well suited to the peach. This stock enables the tree to make a quick growth and come into bearing early, and the roots do not produce sprouts. The budding with the peach is easily done, the young trees make a vigorous

\footnotetext{
1 Carriere, E. A. Prunier Saint Julien. Revue Horticole 438-439. 1892.
} 
growth in the nursery and plums on peach roots can probably be grown at a less cost than on any other stock. Triflora plums in particular make excellent trees worked upon peach stock, the roots are as hardy as the tops and the union is sufficiently congenial to make the resulting tree long-lived. For the Domestica and Insititia plums the peach stock is not so valuable, for with some varieties a good union is not secured and the roots are less hardy than the tops. Among the varieties which nurserymen say will not unite with the peach are: Lombard, Damsons, Yellow Egg and Washington. Peach borers are sometimes troublesome whon plums are budded on peach stocks.

Mr. Kerr, in his statement regarding stocks, on page II5, says that it is his practice to whip-graft the plum on "whole-root" peach roots obtaining eventually the plum on its own roots. This method is certainly well adapted to Mr. Kerr's conditions but whether it would do in heavicr soils and a colder climate is doubtful. One would suspect that some varieties of Domesticas and Insititias at least would sprout badly.

In the South, more particularly Texas and the Southwest, Marianna stocks find favor, though their use seems to be on the decrease. The advantages of this stock are such as appeal to the nurserymen rather than to the plum-grower. These are that the Marianna readily strikes root from cuttings and the growth in the nursery is all that can be desired. Cuttings strike more easily in the South than in the North, hence its popularity in the first named region.

For the colder parts of the Great Plains and as far east as to include Wisconsin, Americana seedlings are the only stocks that will withstand the winter. In this region Americana stocks are, of course, used only for the native plums and data seem to be lacking as to whether other plums cultivated for their fruit could be grown on this stock or not. The W. \& T. Smith Company of Geneva report that they are now using Americana seedlings for native plums for their eastern trade, speaking of them as follows: "We think we get a larger growth and a better root system by using the native (Americana) stocks. We also consider that the Flowering Almonds, Prumus triloba and Prunus pissardi, make a better growth on native stocks." From the last statement one would suspect that it would be feasible to grow other orchard plums than the native species on this stock. As yet Americana seedlings are expensive, and until they cost less their use in competition with the Myrobalan and peach stocks will be almost precluded. The chief fault of the Americana stock is that the trees sucker rather badly. 
Besides the plants discussed above various nondescript members of the genus Prunus are used as stocks for cultivated plums under particular circumstances or for particular purposes. Seedlings of Munsoniana plums are supposed to be preeminently adapted for low wet lands. J. W. Kerr believes that seedlings of Prunus hortulana are excellent stocks for native plums as they never sucker.' The Sand plum (Prunus augustifolia watsoni) offers possibilities as a stock for dwarfing larger growing species. According to Hansen, ${ }^{2}$ who reviews the literature and describes several experiments of his own, the western Sand cherry (Prunus besseyi) dwarfs varieties worked upon it and has the merits of being extremely hardy and of producing trees which bear early and abundantly. As stated in the discussion of Subcordata, stocks of this plum have been used on the Pacific Coast and discarded because it dwarfs trees and suckers badly. According to Wickson, ${ }^{3}$ the apricot and almond are sometimes used as stocks for plums in California and in some instances with considerable success.

Lastly, suckers are not uncommonly used by plum-growers for certain varieties. Thus in the western part of New York, the plum-growing region of the East, several varieties as the Reine Claudes and some of the Damsons are propagated from sprouts taken from the base of old trees. This method can be used, of course, only when the trees are grown upon their own roots. The writer was told by plum-growers in Germany and France that most of the plums in gardens and small plantations, constituting the majority of the plums in the two countries, were propagated from suckers. This method has small merit except that it enables a grower to get a few trees cheaply and perhaps gives a better tree of some varieties for a heavy soil. Beyond question it gives trees with a tendency to sucker-an undesirable attribute.

In the horticultural literature of the time recommendations for topworking plums are rather frequent. It is true that many varieties of plums grow slowly and make crooked growths, especially in the nursery, but in the attempts at grafting in New York the failures are more conspicuous than the successes. If top-working is decided upon, the earlier in the life of the tree it is done, the better. For the Domesticas at least, the Lombard is probably the best stock. The method of top-

Waugh Plum Cult. 247. rgor.

${ }^{2}$ Hansen, N. E. S. D. Sta. Bul. 87. I904. Ibid. 93:68. I905.

Wickson, E. J. California Fruits 348 . r891. 
working is to graft in early spring or bud in late summer. Grafting ought to be used more often than it is to renew the tops of injured trees, as the difficulties in doing this are not much greater than in the case of apples.

PLUM ORCHARDS AND THEIR CARE.

Plum trees in New York are set from twelve to twenty feet apart. The amount of room given seems to depend mostly upon the custom in the locality, though, as all agree, it should depend upon the soil and the variety. The deduction which plum-growers are drawing from these experiences is that the plum should have more room than is generally given it, therefore, wider plantings are more the rule now than formerly. Little attention has been paid to mixed planting for cross-pollination in this State, as the Domesticas are planted almost exclusively and seem under orchard conditions to be self-fertile.

In this region plum trees are usually planted two years from the bud, the exception being the Japanese which are sometimes set at a year from the bud. Plum trees in the past have been headed at three or four feet above the ground but the tendency now is to head them lower-half the above distances, and in orchards so planted there seems to be no inconvenience in tilling with modern implements. In the commercial orchards of the State the heads are formed of four or five main branches and in the case of the Domesticas and Insititias about a central trunk but with the Trifloras the leader is often removed leaving a vase-formed head. After the head is formed the subsequent pruning is simple, consisting of cutting out injured and crossed branches and heading-in long, whip-like growths. The Trifloras receive more pruning than the European varieties, as much of the fruit is borne on the growth of the previous season and it is necessary to keep the bearing wood near the trunk. It is the custom to cut rank growing Trifloras severely but the value of such a procedure is doubtful, as the more such a plum is pruned the more it will need pruning in the years to follow. A better plan seems to be to curtail the food and prune as little as possible, though on rich soils the tree would probably grow out of all bounds unless cut back somewhat year after year.

About the only cultivated native plums to be found in New York, if a few Wild Goose trees here and there are excepted, are on the grounds of this Station. Experience here demonstrates that, prune as you will, certain varieties of the native species will remain crooked, ungainly and unkempt. Pruning some varieties is necessary in order to permit pickers 
to get into the dense, thorny heads; heading-in such varieties would make their tops wholly impenetrable.

In common with all tree-fruits the best plum orchards are tilled. Such tillage usually consists of plowing in the spring followed by frequent cultivation until the middle of August, at which time a cover-crop of clover, oats or barley is sown. The plum seems to require more water than other tree-fruits-it often thrives in comparatively moist land and fails on sandy soils where the peach would grow luxuriantly. Cultivation to save moisture is very necessary for the plum in the experience of New York growers. Grass and grain have proved ruinous in most orchards where tried, though cultivated crops between young trees to pay for keep until fruiting-time are very generally planted. The claim is made by some, and with a show of reason, that there is less of the brownrot in tilled orchards than in neglected ones for the reason that the mummied fruits which carry the fungus through the winter are buried by plowing and with shallow cultivation, at least, do not come to light and life.

Plum-growers very generally recognize the several distinct and valuable purposes which cover-crops serve in orchards. They protect the tree from root-killing, from cold, keep the soil from washing, add humus and, with legumes, nitrogen to the soil, modify the physical structure of the soil and hasten seasonal maturity of the tree. There is one other function which is not so often taken into account. Plum orchards in which covercrops are regularly grown, even though the crop be not a legume, need less fertilizers than those in which no such crop is grown. There are several reasonable suppositions as to why there should be such an effect, but one not usually given sufficient consideration is that cover-crops make available much plant food in the soil. Each plant in the crop collects food from soil and air, most of it otherwise unavailable, and turns it over to the trees.

A discussion of fertilizers naturally follows. Present practices in the use of fertilizers with the plum, as with other fruits, are very diverse. It is impossible to ascertain what considerations have governed the applications of fertilizers in the plum orchards of New York or what the results have been. Too often, it is to be feared, fertilizers have been used as "cure alls" for any or all of the ills to which trees are heirs. Out of the mass of conflicting data as to the effects of fertilizers on plums, the most apparent fact is that much of the fertilizers for this fruit is wasted; this in face of the fact that plums want rich soils. But the plum crop is mostly water, the foliage remains on the ground, the trees grow several years before 
fruiting, their growing season is from early spring until late fall, the roots go deep and spread far, the trees transpire large amounts of water, hence may thrive on diluted solutions of plant food, and now and then there is an off year in bearing for the trees to recuperate.

It does not follow from the above consideration that plums never need fertilizers, but it does seem plain that they need rather less than truck or farm crops and that applications of plant food must be made with exceedingly great care if fertilizing is to be done without waste. There is a growing disposition on the part of plum-growers to experiment very carefully and know that they are getting the worth of their money before using any considerable quantity of fertilizers for their trees.

Thinning the fruit should be a regular practice with plum-growers, but it is the operation in the growing of this fruit about which growers are most careless both as to whether it is done at all and in the manner of doing. Many growers in New York, realizing the great necessity of thinning certain varieties of Triflora, as Burbank and Abundance, follow the practice very regularly with plums of this group; but the Domesticas are seldom well thinned, though some of them, of which Lombard is a conspicuous example, ought nearly always to have anywhere from one-fifth to half of the fruit removed. Growers of some of the native varieties in regions where these sorts are grown say that under cultivation some kinds of these plums will bear themselves to death if a part of the crop be not removed in most years. Those growers in New York who thin, do the work as soon as possible after the June drop has taken place.

\section{HARVESTING AND MARKETING.}

Plum trees in this climate begin to bear when set from three to five years. The Triflora varieties will bear soonest, the Old World varieties next in order, say at four years from setting, and the native sorts, as a rule, come in bearing last. At eight or ten years of age, prolific varieties of the Triflora and Domestica sorts bear in a good year about three bushels of fruit; the Insititia and native varieties, on the Station grounds, at least, do not bear as much, though most of the plums of these two groups bear more regularly than the first named groups.

Plums in this State, and east of the Mississippi generally, are picked and put upon the market just before they reach edible condition; while farther away they must be picked much greener. It is the practice in the East to pick while still somewhat green because the fruit so 
picked is best handled at this stage of maturity and the brown-rot fungus is likely to destroy much of the crop if left until fully matured. Some of the Triflora sorts, Abundance, Burbank and October, for example, are picked from a week to ten days before ripe and yet develop very good color and flavor. The Domesticas need not be, and are not, picked quite so green. In picking, great diversity exists as to ladders, receptacles, and manner of conveyance from orchard to packing house. These need not be discussed here, nor need the methods of picking be spoken of further than to say that while good growers consider it vital not to bruise the fruit nor destroy the delicate bloom, if such injuries can be avoided, pickers in general are not nearly as observant of these important details as they should be.

The plum crop is sent to market, for most part in New York, in six, eight and ten-pound grape baskets with the preference at present for the smallest of these baskets. Occasionally some fruit is packed in four pound baskets. Rarely, and always to the disadvantage of both producer and consumer, plums go to market in the packages in which the fruit is picked. Indeed, it is seldom advantageous to pack the fruit in the field, it being far better to convey it to the packing house where the preparations for shipping may be more carefully made, as the package and the manner of packing advertise the product. Plums coming to this State from the far $W^{\top}$ est are often wrapped individually in tissue paper as a help in safe shipping and to add to their attractiveness but the fruit grown in the State is seldom, if ever, so treated, though it is possible that choice specimens could be profitably wrapped. Of the sorting, grading, facing and marking the packages, little need be said except that they are too rarely well done in present methods, though there is a steady improvement in attending to these important matters.

Few plums are stored longer than a week at most in common storage and three weeks or a month is quite the limit for most varieties in cold storage. Late plums and in particular some of the prunes might well be stored longer than is now the custom if proper precautions are taken, as is shown by the experience at this Station where a considerable number of the Domestica and Insititia varieties are annually 'rept in common storage for a month or longer without unusual precautions. Some of the new varieties offered to growers, as Apple and Occident, are recommended as keeping for several weeks after picking. There is a most marked difference in the keeping qualities of this fruit and it is certain that varie- 
ties can now be selected for long keeping and that there is a fine opportunity for breeding sorts that will keep even longer than any we now have.

Marketing, the actual selling, is a business quite by itself, and since it is one which has changed greatly in the past few years and is destined to change even more in the near future, a few observations on the subject are worth putting on record. A well developed local market is undoubtedly the best selling place for the plum producer, as in it the sales are directly to the consumer, eliminating expensive middlemen. The westward spread of manufacturing industries, the workers in which use up the westerngrown fruit, is making better local markets for eastern plums, a point worth noting, for many New York plum-growers have ceased planting, indeed have been removing trees, fearing western competition.

By far the greater part of the plum crop now finds its way to consumers through the following costly distributive system: ist. Local buyers who ship to centers of consumption. 2nd. Transportation companies.

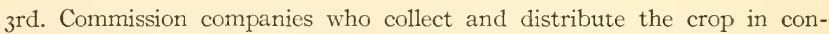

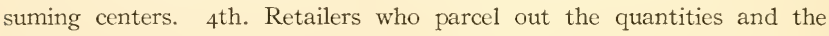
qualities demanded by the consumer. The great defect in handling the crop is, that there are too many men and too much machinery to do the work cheaply-moreover, the risks of depreciation are great, and the fruit is not handled on a large scale chiefly because of a lack of capital by the grower or local buyer. These defects in the present distribution of plums in New York make the price received by the grower about half that paid by the consumer and the selling of the crop a more or less speculative business. The plum industry, as is the case with all fruits, is greatly hampered by the present marketing systems.

Unfortunately there is yet but a small outlet for surplus plums as manufactured products. As a rule the commercial outlook is best for those fruits of which the surplus can be turned into by-products. The only outlet for the plum in the East is in canning, as this region is unable to compete with the West in the making of prunes ${ }^{1}$ and as the several

\footnotetext{
${ }^{1}$ A prune is a dried plum. The requisite for a prune-making plum is that it have a large proportion of solids, particularly sugar. Comparatively few varieties of plums bear sufficient amounts of solids so that they may be successfully cured into a firm, long-keeping product. Only varieties of the Domesticas are used in making prunes, though possibly some of the Insititias might be so used. Prunes are chiefly used in cookery though some of the finer grades from France are sold as confections.

Prunes are either dried in the sun as in Californı; partially cooked in ovens and the curing completed indoors, as in European countries; or wholly dried in evaporators, as in the Pacific
} 
plum products of the Old World are not in demand in the New World. Beyond question there are a number of products, as preserves, jellies from the native plums, glacé fruits, plum butter, marmalades and the like, which could be made profitable for the markets and thus a great help in utilizing surplus plums.

DISEASES.

Plums are subject to a considerable number of fungus diseases, several of which are often virulent, the virulence depending on locality, season, weather and variety. Happily for the plum industry, knowledge of plant pathology has made such advancements in recent years that nearlyall of the diseases of this fruit are now controlled by preventive or remedial measures.

Northwest. Sun-drying is the most economical method where the climate permits. The half cooking does not make so attractive a product but when skillfully done the prunes are possibly more palatable, as the cooked flavor is liked by consumers. Beyond question the best prunes are made, however, all things considered, in well-managed evaporators. In evaporators the changes of curing take place most perfectly and uniformly so that, as a rule, the prune looks better, keeps longer, is not so tough and has a more natural taste of the green fruit.

In prune-making the fruit is allowed to remain on the trees until ripe enough to fall to the ground, as the maximum proportion of solids is thus obtained. After picking, the plums are passed over graders to remove rubbish and to secure uniformity in size, this being essential to obtain evenness in curing, since the small fruits dry more rapidly than large ones. Usually before evaporation begins the fruit is dipped in boiling lye or pricked by needles in a pricking machine to make tender the tough skin and so allow the moisture to escape more readily. The dipping consists of immersing the fruit for a minute or less in a solution of lye in the proportion of 1 pound of concentrated lye to from 10 to $5 \circ$ gallons of water maintained at the boiling point. The fruit is carried mechanically through the lye vat and a rinser by a modified endless chain, or it may be dipped in wire baskets. After rinsing the plums a re ready for curing.

Exposure to the sun in curing varies from five to twelve days, depending upon the heat of the sun and the size and the variety of the plum. Curing in evaporators varies with the fruit and with the make of the machine. In general the temperature in the evaporator is from $120^{\circ}$ to $140^{\circ}$ at the start, increasing to from $160^{\circ}$ to $180^{\circ}$ and decreasing when the prunes are taken out. Too much heat at first causes the cells of the fruit to burst, thereby producing drip and discoloration. Important factors in evaporating in machines are the circulation of air, convenience, cost of fuel and power. The time required for curing ranges from twelve hours for a small plum to forty-eight hours for a large, juicy one. If not cured enough fermentation and molding result; if cured too much the weight is lessened, the quality is injured, the prune is harsh and coarse and has a dried up appearance.

When sufficiently dried the prunes are put in bins or piles to sweat, a process taking from one to three weeks, after which they are graded, processed and packed. In grading, the prunes are separated into sizes indicating the number of prunes required to make a pound, as $30^{\prime}$ 's to $40^{\prime} \mathrm{s}, 40^{\circ} \mathrm{s}$ to 50 's and so on to the smallest size, I20's to 130's. The processing is done by dipping the prunes in boiling water and glycerine or by steaming or by using some special preparation in the final dipping or by rattling in a revolving cylinder. Processing is reputable if it adds bea uty to the color, or kills insects' eggs or sterilizes the prunes. It is disreputable when the aim is to add to the weight. The best prunes are packed in boxes, in which process lining with paper, filling 
One of the commonest and most striking of the diseases of the plum is black-knot' ${ }^{1}$ (Plowrightia morbosa (Schw.) Saccardo) characterized by wartlike excrescences on shoots and branches. In early summer these knots are dark green, soft and velvety, but as the fungus ripens in the fall the color changes to a carbon-like black and the knots become hard and brittle. The disease is usually confined to one side of the twig or branch so that death of the affected part does not ensue at once. Black-knot is an American malady, at one time confined to the eastern part of the continent where in some localities its ravages forced the abandonment of plumgrowing. The fungus is now endemic to wild or cultivated plants in practically all the plum-growing regions of the continent, but it is still epidemic only in the East, the South and West being practically free from the disease. Unless especially virulent black-knot is controlled by cutting out the diseased wood. Usually eradication is not possible without several prunings during a season.

Much has been made of the supposed immunity of some varieties of plums to black-knot. In the vicinity of this Station, where the disease is always present and often rampant, the differences in immunity are not very marked in varieties of the same species. The Trifloras are less at-

facing, pressing and labeling are important details. A well cured prune is soft and spongy, the pit is loose but does not rattle, the skin is bright, the product is free from drippings or exudation, the flesh is meaty, elastic, and of a bright, lively color.

The custom has been to bleach light colored prunes with sulphur fumes. This process injures the quality and possibly makes the product somewhat poisonous. Sulphuring is now regulated by the Federal Pure Food Law.

If poorly managed or if the plums are not of the best, several difficulties are encountered in curing prunes. Thus, a syrupy liquid sometimes oozes from the prunes, besmearing and making unattractive the final product. Again, the finished prunes may be covered with globules of sugar. rendering them sticky and destroying the lustre. Fruit grown on poor soils, on unhealthy trees or picked green may cure into small prunes of an abnormal shape called "Frogs" or they may ferment and swell up in large soft prunes called "Bloaters."

The plum chiefly used in California in making prunes is the Agen, usually called Petite, a prune curing into a bright amber-colored product. This plum is easily cured, and the prune from it needs little sugar in cooking. In the states north of California the Italian Prune is the favorite, producing a dark red, almost black product, more tart but on the whole rather better flavored than the prune from the preceding variety. Other varieties more or less used are Golden Drop, the product from which is known as the Silver Prune; Reine Clatde, which makes a fancy product often used as a confection; Yellow Egg, which sells as the Silver Prune when evaporated; the German Prune, making a product much like the Italian Prune; "Hungarian Prune," from a very large plum and making a fancy product but very difficult to cure; the Tragedy Prune, an early plum of the Italian type; Golden Prune, much like the Silver and possibly better; and the Champion, Willamette, Pacific, Tennant, Steptoe and Dosch, all of the Italian type.

${ }^{1}$ Farlow, W. G. The Black Knot, Bulletin Bussey Institution 440-453. 1876. Halsted, B. D. Destroy the Black Knot, etc. N. J. Sta. Bul. 78:1-14. 1891 . 
tacked, however, than any other group of plums, and the Insititias rank next in immunity. No variety of the Domesticas has yet proved to be free from the disease but strong claims are made that Middleburg and Palatine are relatively free.

Next in order of seriousness among the diseases which attack cultivated plums is the brown-rot ${ }^{1}$ (Sclerotinia fructigena (Persoon) Schroeter) known also very commonly as the ripe-rot and sometimes as peach-blight. The disease is most conspicuous on the ripe fruits of the various drupes and is popularly supposed to be confined to the fruits alone. Such is not the case, for it also attacks, and very vigorously oftentimes, the flowers and shoots. The presence of the disease on the fruits is known by a dark discoloration of the skin which is afterward partly or wholly covered by pustule-like aggregations of grayish spores. The decayed fruits may fall to the ground, or as is more usual in the case of plums, they hang to the tree and as the juice evaporates become shriveled mummies, each mummy being a storehouse of the fungus from which infection spreads the following season. The twigs, flowers and leaves are known to be suffering from inroads of the parasite when they are blackened as if nipped by frost. In warm, damp weather the rot spreads with great rapidity and fruits touching in clusters or in boxes stored for shipping are well placed to spread the epidemic. Destruction of the mummy-like fruits and all other sources of infection, and spraying with bordeaux mixture are now practiced as preventives, but so far as the crop is concerned with but indifferent success. A better remedy than we now have is eagerly looked for by growers of fruits.

The hosts of this fungus show varying degrees of susceptibility to it, the peach and the sweet cherries being more subject to it than plums. Similarly, among plums some species and varieties are more susceptible than others. Thus the Trifloras and Americanas, the latter especially in the South, are injured more by the brown-rot than other species. The idiosyncrasies of varieties in this regard are best shown in the discussions of the individual sorts.

Several interesting and sometimes destructive diseases of plums are caused by various species of the fungal genus Exoascus. ${ }^{2}$ The most common of these, and the most striking and destructive, is plum-pockets (Exoascus

\footnotetext{
1 Smith, E. F. Peach Rot and Peach Blight Journ. Myc. 5:123-134. 1889. Quaintance, A. L. The Brown Rot, etc. Ga. Sta. Bul. 50:237-269, figs. I-9. 1900.

${ }^{2}$ Atkinson, G. F. Leaf Curl and Plum Pockets Cornell Sta. Bul. 73:319-355, Pls. I-20. 2894.
} 
pruni Fuckel), which causes prominent deformities of the fruit. These give the disease the common name or less frequently "bladders" and "curl." The fungus attacks the developing fruits at an early stage of their growth and causes the production of a spongy mass in the fleshy tissue which greatly enlarges and distorts the plum. The stone in a diseased plum is but rudimentary or very often not at all developed. Less prominently but quite as frequently, the leaves are attacked, showing as they unfold more or less red or yellow with a very decided curling and arching of the leaf-blade. The disease usually spreads from the leaves to the shoots, the infected shoots with their rosettes of mal-formed leaves giving the tree a most unsightly appearance. Prevention at present consists of removing the diseased parts and spraying with bordeaux mixture when the buds begin to swell. Munsoniana and Hortulana plums seem to be most susceptible to this disease. Atkinson ${ }^{1}$ has described several species of Exoascus on the different species of wild plums, some of which are liable to be found on the cultivated varieties of the native plums. They are all very similar to Exoascus pruni, differing chiefly, in the eyes of the layman, in forming smaller pockets. Sturgis ${ }^{2}$ records an attack of one of the leaf-curl fungi, distinct from the plum-pockets fungus, on varieties of Triflora in Connecticut, which seemed to him to be of scientific and economic importance.

The leaves of the different species of cultivated plums are attacked by several fungi which produce diseased spots on the foliage, which for most part drop out, causing a shot-hole effect. These diseases pass under such descriptive names as "shot-hole fungus," "leaf-spot," and "leafblight." The fungus probably responsible for most of this trouble is best known as the shot-hole fungus ${ }^{3}$ (Cylindrosporium padi Karsten). The Domestica and Triflora varieties are very susceptible to this fungus, which, on the foliage of the first, causes spots for most part, while on the latter the spots on the leaves are nearly always followed by holes. Varieties of the native species, especially those of Americana and Nigra, are relatively free from this disease. Another of these shot-hole fungi is Cercospora circumscissa Saccardo " much less common than the former, but still to be considered and especially on the foliage of Americana. All of these dis-

1 Ibid.

${ }^{3}$ Sturgis, W. C. A Leaf Curl of the Plum Conn. Sta. Rpt. 19:183, P1. 2. I 895.

${ }^{3}$ Arthur, J. C. Plum Leaf Fungus N. Y. Sta. An. Rpt. 5:276-281, Pls, 6-10. 1887.

- Duggar, B. M. Fungous Diseases of Plants $3{ }^{1} 4$, figs. $147,148.1909 . \quad$ Pierce, N. B. A Disease of Almond Trees Jour. Myc. 7:66-67, Pls, II-I4. I892. 
eases of the foliage are prevented to some degree by the proper use of bordeaux mixture, which, on the Triflora plums at least, must be used with great care to avoid injury. Cultivation has a salutary effect as it destroys the diseased leaves which harbor the fungi.

Another disease of plum foliage, occurring rarely on the fruit, is the plum-leaf rust ' (Puccinia pruni-spinosae Persoon) which produces so considerable a number of spore cases on the underside of the leaves as to give the foliage a brownish cast and to cause defoliation in severe infections. The fungus is most apparent in the fall and most troublesome in warm, moist climates. Bordeaux is used as a preventive.

Stewart and Rolfs have shown that trunks and branches of plums affected by sunscald in New York are almost invariably infested by a fungus" (Valsa leucostoma Persoon) which in the Old World is known as the "die back" of the peach. The disease manifests itself on plums chiefly by affected areas much depressed at the boundary between the living and the dead bark, these areas usually, not always, having connection with sunscald injuries on the trunk. The disease is accompanied by more or less gumming.

In common with nearly all rosaceous plants, in nearly all countries, the plum is sometimes seriously injured by the powdery mildew ${ }^{\text {(Podo- }}$ sphaera oxyacanthae DeBary). The affected leaves have a grayish appearance caused by the parts of the fungus which project beyond the leaf tissue; when badly diseased the leaves are more or less arched and curled. Mildew is seldom prevalent enough on plums to require treatment.

The crown gall," (Bacterium tumefaciens Smith and Townsend) is a parasite on all of the fruits of the order Rosaceae and is especially common on nursery stock, attacking plums in many soils but rarely, however, to the great injury of the plant. These galls are perennial structures of very varying duration. They are to be found on the roots, usually at the collar of the plant, and vary from the size of a pea to that of a man's fist, forming at maturity, rough, knotty, dark-colored masses. Means of

${ }^{1}$ Scribner, F. L. Leaf Rust of the Cherry, etc. U. S. Dept. Agr. Rpt. 353-355, Pl. 3. I887. Hedrick, U. P. Prune Rust Oreg. Sta. Bul. 45:67. I897.

'Stewart, F. C. N. Y. Sta. Bul. I9r:323-324. 1900. Rolfs, F. M. Die Back of Peach Trees Science 26:87. 1907 .

'Duggar, B. M. Fungous Diseases of Plants 226.1909.

- Smith, E. F. and Townsend, C. O. A Plant Tumor of Bacterial Origin Science 25:671-673. 1907. Toumey, J. W. Cause and Nature of Crown Gall Ariz. Sta. Bul. 33:1-64, figs. $\mathrm{x}-3 \mathrm{I}$.

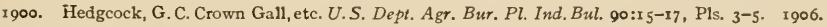


prevention or cure are not established though all agree that soils may be inoculated with the disease from infected stock; hence the necessity of discarding diseased trees at transplanting time.

Smith found in Michigan and Clinton in Connecticut a disease of the fruit called bacterial black spot ${ }^{1}$ (Pseudomonas pruni Smith) of the same generic origin as the crown gall but widely different in nature. The writers and the growers who found the infected fruit, saw the disease only on the Triflora plums. It attacks the green fruits which show conspicuous, black-purple, sunken spots sometimes as large as half an inch in diameter. The injuries are usually isolated and quite superficial but nevertheless, spoil the fruit.

The plum in common with other stone-fruits often suffers from an excessive flow of gum, for which trouble the name gummosis ${ }^{2}$ is now generally applied. The disease is to be found wherever plums are grown but it is much more destructive on the Pacific than on the Atlantic seaboard. So far as is now known gummosis is secondary to injuries caused by fungi, bacteria, insects, frost, sunscald, and mechanical agencies. The disease is least common in species and varieties having hard wood; on trees on soils favoring the maturity of wood; under conditions where sun and frost are not injurious; and, obviously, in orchards where by good care the primary causes of gumming are kept out. Stewart ${ }^{3}$ has recorded an interesting case of gum-pockets in the fruit, but could assign no cause.

Mechanical injuries from the sun, frost and hail are troubles with which nearly all plum-growers must contend at one time or another. In this region the Reine Claude and Triflora plums suffer much from sunscald but none are wholly immune, though Lombard is possibly most so. These injuries from the elements of weather are often mistaken for diseases, and are so often followed by fungal parasites and insects as to make it difficult to distinguish the primary from the secondary trouble. Lowheading of the trees is the best preventive of these trunk injuries.

Plums are somewhat subject to attacks of the well-known peach scab - (Cladosporium carpophilum Thumen). The scab appears in numerous, small, sooty, circular spots of brownish color, often confined to one

\footnotetext{
${ }^{1}$ Smith, E. F. Science $17: 456-7$. 1903. Ibid. $21: 502$. 1905. Clinton, G. P. Report of Botanist Conn. Sta. Rpt. 273. 1905.

'Hedrick, U. P. Gumming of the Prune Tree Oreg. Sta. Bul. 45:68-72. I897.

- Stewart, F. C. N. Y. Sta. Bul. 191:324-326. 1900.

1 Pammel, L. H. New Fungous Diseases of Iowa Jour. Myc. 7:99-100. 1892.
} 
side of a fruit but in other cases distributed over the whole surface. None of the cultivated species are free from the disease but the Munsoniana, and Hortulana varieties are most susceptible to it. Pear blight, ${ }^{2}$ (Bacillus amylovorus (Burrill) DeToni) commonly thought of as a disease of the pear and apple has been found on various plums, and the yellows of the peach, cause unknown, is often quite destructive to Triflora plums. According to Smith the peach rosette, ${ }^{2}$ cause unknown, attacks both wild and cultivated plums in the South and is quickly fatal. The disease was prevalent on the wild Angustifolias, on two varieties of Triflora, Kelsey and Botan, but the observer had not seen rosette on varieties of Domestica.

Waugh describes a trouble which he calls "flyspeck fungus" s found on fruits sent from the Southern States, in which small areas are thickly dotted with black spots; also a fruit-spot on plums from Texas caused, as he states, by an undetermined Phoma." Starnes of Georgia describes a malady of the Triflora plums called "wilt," " cause unknown, which he states is the most serious obstacle to the culture of this plum in the South. In this peculiar disease the foliage passes directly from a green, healthy state into a wilted and then parched condition, the death warrant being signed when a tree is once affected. In Oregon and Washington the Italian Prune is subject to a leaf-curl " which begins in mid-summer and curls the leaves conduplicately without withering but shriveling somewhat. As the season advances the leaves turn yellow and many of them drop. Neither cause nor cure is known. Smith described a plum-blight " of native plums in Georgia which " destroys large branches or even whole trees in mid-summer in the course of a few weeks."

\section{INSECTS.}

Cultivated plums furnish food for a great number of insects. Many of the destructive insect pests of the several cultivated species of Prunus are known to have come from the wild plants of the genus, but others, and possibly the majority, come from over the seas. No less than forty

${ }^{1}$ Jones, L. R. Studies upon Plum Blight Vt. Ex. Sta. Rpt. 15:231-239. 1902.

${ }^{2}$ Smith, E. F. The Peach Rosette Jour. Myc. 6:144. 1891.

-Waugh, F. A. Plum Cult. 329. 1901.

- Ibid.

- Stames, H. N. Japan and Hybrid Plums Ga. Sta. Bul. 68:22-24. 1905.

- Hedrick, U. P. Curl-leaf of the Italian Prune Oreg. Sta. Bul. 45: $7^{2-i 4 . ~} 1897$.

' Smith, E. F. Field Notes Jour. Myc. 6:108. 1891 . 
species of insects may be enumerated as pests of the plum and many more can be counted as occasional parasites on one or another of the species. Of the formidable pests the plum curculio is probably the most troublesome. The plum curculio ' (Conotrachelus nenuphar Herbst) is a rough, grayish snout-beetle somewhat less than a quarter of an inch in length, an insect so familiar to fruit-growers as hardly to need a description. The female beetle pierces the skin of the young plums and places an egg in the puncture. About this cavity she gouges out a crescent-shaped trench, the puncture and trench making the "star and crescent" of the Ottoman Empire, hence the common name of the beetle, "The Little Turk." The egg-laying process may be repeated in a number of fruits and from each egg a larva hatches within a week and burrows to the stone, making a wormy fruit. Most of the infested plums drop. In years past plum-growers relied upon jarring the beetles from the trees in the early morning, but the treatment was too expensive, and poisoning with an arsenate is now the chief means of combating the pest. Rubbish and vegetation offer hiding places for the insectsand hence cultivated orchards are more free from curculio. Thin skinned varieties are damaged most by the insect but there are no "curculio-proof " plums.

A larger snout-beetle than the curculio, the plum gouger ${ }^{2}$ (Anthonomus scutellaris LeConte), occasionally does much damage to plums. The work of the gouger may be told from that of the curculio by the absence of the crescent cut about the puncture made for the egg, and from the fact that the larvæ of this pest chiefly infest the stone and those of the other insect the flesh of the plum. The remedies are the same for the two insects though the gouger is more easily destroyed.

Among the several borers which are more or less destructive to species of Rosaceae only the peach borer ${ }^{3}$ (Sanninoidea exitiosa Say.) may be counted as a troublesome pest of the plum. The larvæ of this insect are frequently to be found in both wild and cultivated plum trees and must be combated in nearly all plum orchards east of the Rocky Mountains. The prevention of the work of the borer is best accomplished by thorough cultivation, the use of coverings of tar and poisonous washes and mounding the trees. Destruction is effectively carried out only by digging out the borer with knife or wire. The lesser peach borer ' (Sesia pictipes Grote

\footnotetext{
${ }^{1}$ Riley, C. V. An. Rpt. State Entomol. Mo. 1:50-56. I869; 3:11-29. I871.

2Ibid. 3:39-42. 187 I.

3 Beutenmtiller, W. Sesiidae of America, etc. 266-271. 1901.

Ibid. 291-292. 1901.
} 
\& Robinson) attacks the plum and in New York has been found particularly injurious to the Wickson plums. The flat-headed apple tree borer " (Chrysobothris femorata Fabricius) is frequently found in the wood of wild plums and is sometimes a pest of the several cultivated species. It is treated as is the peach borer. The shot-hole borer " (Eccoptogaster rugulosus Ratzeburg) a diminutive insect which deposits its eggs in the trunks or large branches of various members of the genus Prunus, may be regarded as an effect rather than a cause of disease, for it seldom injures perfectly healthy plum trees. The peach bark-beetles (Phlcotribus liminaris Harris) is somewhat similar in its work to the shot-hole borer and like it is found for most part only in diseased and decrepit trees.

The plum aphis ' (A phis prunifolii Fitch) is sometimes very destructive to varieties of the native plums, especially the Americanas, and occasionally injures or even kills the young trees of the Domestica sorts. It is not a formidable foe in New York, and it is the exception when trees must be treated for it, the treatment being any of the contact solutions used against sucking insects. The cherry aphis " (Myzus cerasi Linnaeus) and the green peach aphis ' (Mysus persica Sulzer) are much less common than the plum aphis on plum trees, but are sometimes abundant on foliage of this fruit and are combated in the same way as the more common aphis. Gillette enumerates two other aphids as attacking the plum in Coloradothe rusty brown plum louse ${ }^{7}$ (Aphis setarice Thomas) and the mealy plum louse * (Hyalopterus arundinis Fabricius).

Several scale insects infest the plum. Chief of these is the dreaded San José scale ' (Aspidiotus perniciosus Comstock) known and feared by all fruit-growers in the United States. The lime and sulphur solution is now the most common and probably the most effective spray for this insect. The European fruit lecanium ${ }^{10}$ (Lecanimm corni Bouche) occasionally does a great deal of damage in New York and now and then destroys the whole crop in an orchard. The winter treatment for San Jose

1 Riley, C. V. An. Rpt. State Entomol. Mo. x:46-47. I869.

'Lowe, V. H. N. Y. Sta. Bul. 180:122-128. 1900.

'Wilson, H. F. The Peach-tree Barkbeetle U. S. D. A. Bur. Ent. Bul. 68:91-108. 1909.

Hunter, W. D. The Aphididæ of N. A. Ia. Sta. Bul. 6o:ro3. rgor.

Ibid. $107,108$.

Ibid. 108, 109.

' Gillette, C. P. A Few Orchard Plant Lice Gol. Sta. Bul. 133:41. I9o8.

${ }^{8}$ Ibid: 39 ,

- Marlatt, C. L. The San Jose or Chinese Scale U. S. D. A. Bur. Ent. Bul. 62:1-89. 1906.

${ }^{10}$ Lowe, V. H. The New York Plum Lecanium N. Y. Sta. Bul. 136.583. 1897 . 
scale is used to control this pest, but usually such treatment is supplemented by a summer spray about July first with such contact sprays as whale oil soap and kerosene emulsion. Of the other scales² which feed upon plums and now and then become pestiferous the following may be named: The fruit pulvinaria (Pulvinaria amygdali Cockerell), the mealy bug (Psendococcus longispimus Targioni), the scurfy scale (Chionaspis furfura Fitch), the West Indian peach scale (Aulacaspis pentagona Targioni), the Putnam scale (Aspidiotus ancylus Putnam), the cherry scale (Aspidiotus forbesi Johnson), the walnut scale (Aspidiotus juglans-regice Comstock), Howard's scale (Aspidiotus howardii Cockerell), the European fruit scale (Aspidiotus ostreceformis Curtis), the red scale of California (Chrysomphalus aurantii Maskell), the oyster-shell scale (Lepidosaphes ulmi Linnaeus), and the soft scale (Coccus hesperidum Linnaeus).

Wild plums of several species seem to be favorite feeding grounds for the tent caterpillar ${ }^{2}$ (Malacosoma americana Fabricius), but cultivated plums are not so often attacked; the spraying with arsenites usually given for the curculio is fatal to this pest as well. The spring cankerworm $^{2}$ (Paleacrita vernata Peck) and the fall canker-worm ${ }^{4}$ (Alsophila pometaria Harris) are other caterpillars which often do much damage unless checked by destructive measures, of which the best are the arsenical sprays. The larvæ of a considerable number of other moths and butterflies are often found on plum foliage but seldom in such numbers as to require systematic destruction.

The eye-spotted bud-moth " (Tmetocera ocellana Schiffermuller) is a rather serious pest in plum nurseries where the larvæ eat into the young buds at the time they are opening, often destroying the shoots. Sometimes the larvæ are found destroying buds on old trees. The arsenical sprays are used to destroy this pest. The peach twig-moth (Anarsia lineatella Zeller) is now and then found in plum twigs but is seldom classed as a plum pest.

The clover mite ' (Bryobia pratensis Garman) formerly considered a serious pest of the plum only in the far West, is now abundant in plum

\footnotetext{
${ }^{1}$ For references to these scales see Fernald, Mrs. M. E. Coccidae of the World Mass.
} Sta. Bul. $88: 1-360$. 1903.

${ }^{2}$ Lowe, V. H. The Apple-tree Tent Caterpillar N. Y. Sta. Bul. 152:279-293. I898.

${ }^{3}$ Riley, C. V. An. Rpt. State Entom. Mo. 2:94-103. 1870.

${ }^{4}$ Ibid. 7:83-90. I 875 .

B Saunders, W. Insects Injurious to Fruits 95, 96. $188_{3}$.

'Riley, C. V. and Marlatt, C. L. The Clover Mite Insect Life 3:45-53. I8go. 
orchards in New York. It can be controlled by applications of lime and sulphur. The bumble-flower beetle " (Euphoria inda Linnaeus) is reported by Goff to be occasionally very injurious to plums in Wisconsin. Remedies seem not to have been tried. The larvæ of the cherry slug? (Selandria cerasi Peck) is not infrequently found doing damage to plum foliage and occasionally the larvæ of one or two other saw-flies feed on the plum. These are all overcome by the use of arsenical sprays. At least one of the curious insects know as " case-bearers " attacks the plums. The troublesome one is the pistol case-bearer" (Coleophora malivorella Riley), which is not often a pest but has sometimes done considerable damage. Attempts to check this insect with the arsenical sprays have usually proved successful. The plum tree is a host-plant of the hop aphis * (Phorodon humtli Schrank). So much does this insect feed on the plum that the destruction of plum trees in the vicinity of hop fields is recommended to hop-growers by Riley.

\footnotetext{
${ }^{1}$ Saunders, W. Insects Injurious to Fruits $159 . \quad 188_{3}$.

Ibid. I 50-153. $188_{3}$.

'Lowe, V. H. The Pistol Case-bearer N. Y. Sta. Bul. 122:221-232. I897.

4Riley, C. V. Insect Life 1:133. I889.
} 


\section{CHAPTER III}

\section{LEADING VARIETIES OF PLUMS.}

\section{ABUNDANCE}

\section{Prunus triflora}

x. Am. Pom. Soc. Rpt. 96. 1887. 2. Am. Gard. 9:360. 1888. 3. Ga. Hort. Soc. Rpt. 51, 52, 53. 99. 1889. 4. Bailey Ann. Hort. 103. 1889. 5. Am. Pom. Soc. Rpt. 106, 125. 1891. 6. Am. Gard. 13:700. 1892. 7. Rural N. Y. 52:666. 1893. 8. Cornell Sta. Bul. 62:19, 27, 32. 1894. 9. Tex. Sta. Bul. 32:488. 1894. 10. Rev. Hort. 160. 1895. 11. Mich. Sta. Bul. 118:52. 1895. 12. Cornell Sta. Bul. 106:41, 43, 44, 47, 48, 49. 1896. 13. Va. Sto. Bul. 67:96. 1896. 14. Cornell Sta. Bul. 131:195. 1897. 15. Ibid. 139:37, 38, 39, 40. 1897. 16. Am. Pom. Soc. Cat. 26. 1897. 17. Cornell Sta. Bul. 175:141, 142, 143. 1899. 18. Waugh Plum Cult. 132, 135. 1901. 19. Mich. Sta. Bul. 169:242, 248. 1899. 20. Ont. Fruit Exp. Sta. Rpt. 15. 1902. 21. Ohio Sta. Bul. 162:254, 255. 1905. 22. Texas Nur. Co. Cat. 9. 1907. 23. Ga. Sta. Bul. 68:7, 28.1905.

Abundance 7. Babcock (?) 15, 17. Babcock 12, 16, 18. Botan 1, 2, 3, 5, 6, 10. Botan 12, 16, 18. Botankio 12. Botankio 3. Burbank No. 2. I1, I2. Chase 12. Chase 14, 15, 17. Douglas 9, 15, 18. Douglas 17. Hattankio 8, 15. Hattonkin 12. Hytankayo 8, 9. Munson 8, Munson 9, 18. Oriole 22. Sweet Botan 7. Sweet Botan 15. Yellow Fleshed Botan 3, 6, 8, 1 7, 23. Yellow Fleshed Botan 5. Yellow Japan 12. Yellow Japan 8, 14.

Though Abundance has been in America only a quarter of a century, it is now about as well known as any other plum, being probably the best known of the Triflora plums. The two chief assets which have given the variety its great popularity so quickly are adaptability to a wide diversity of soils and climates and, as its name implies, abundance of fruit, for it bears not only heavily but yearly. As a market plum Abundance has been overplanted since it ships and keeps poorly, is much subject to brown-rot, matures unevenly and drops rather too readily as it ripens. Whether for market or home use, the fruit of this variety should be picked before it is quite ripe as it develops in flavor best when so picked and the dropping and rot are thus avoided to some extent. It is an exceedingly variable plum and undoubtedly several well marked strains could be selected, some of which are not as hardy or otherwise as valuable as others. While Abundance has passed the heyday of its popularity it is still one of the most desirable of the Triflora plums.

This variety was imported from Japan by Luther Burbank in I884, and was introduced by John T. Lovett, Little Silver, New Jersey, under the name Abundance, in I888. A large number of Japanese plums that have since been introduced have proved to be either identical or so nearly like the Abundance that much confusion has arisen. Abundance was first known as Botan, but that name was dropped as it refers to a group 


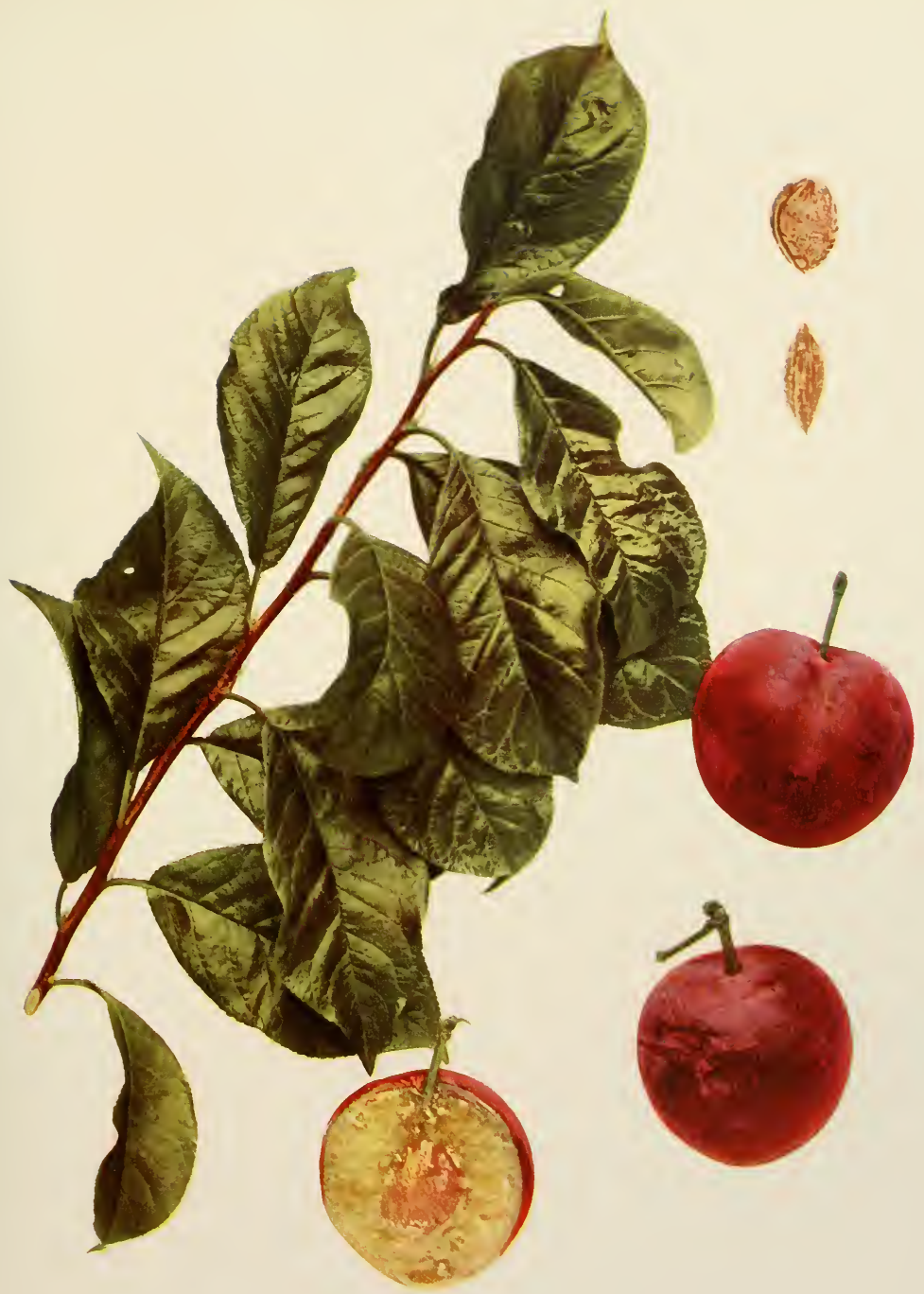



of plums in Japan rather than to a variety. Babcock, which is said to have been imported by Burbank in $\mathrm{I}_{88} 5$ and named for Colonel E. F. Babcock, a nurseryman of Little Rock, Arkansas, has been described by Bailey as indistinguishable from Abundance. Botankio, described in the Georgia Horticultural Society Report for 1889, proved to be the Abundance as tested at the Cornell Experiment Station. The Chase plum, also disseminated in New York under the name Yellow Japan, was bought by the R. G. Chase Company, Geneva, New York, for the Abundance, but as it was thought to blossom and fruit later than that variety, it was distributed as a new plum; in 1897 Bailey considered it the same as Chabot, but in 1899 he stated that it and Abundance were identical. The Douglas plum is also identical. Dr. J. T. Whitaker of Tyler, Texas, imported this variety and introduced it in I 886 under the name of Hytankayo. Bailey, who tested Whitaker's variety from trees obtained from T. V. Munson, Denison, Texas, found a yellow-fruited strain and to distinguish the purple form named the latter Munson. ${ }^{1}$ As this name had been applied to a native plum, R. H. Price, of the Texas Experiment Station, in I894 renamed the variety calling it Douglas. ${ }^{2}$ There have been two types of this Douglas plum disseminated; Bailey, in I 899 , found no difference between it and Abundance except that the Douglas seemed to have a little drier flesh; others testing Douglas found it to be identical with the Chabot. Burbank No. 2, imported by Luther Burbank in $188_{5}$ ancl introduced by him in 1889 , is very similar if not identical with the Abundance. Oriole, recently introduced by the Texas Nursery Company, Sherman, Texas, is so nearly like Abundance as to be unworthy of a separate name. The American Pomological Society added Abundance to its fruit catalog list in 1897 .

Tree large, vigorous, vasiform, open-topped, hardy in New York, very productive, susceptible to attacks of shot-hole fungus; branches rough, dark ash-gray, inclined to split when overloaded, with few, slightly raised lenticels; branchlets slender, short, with short internodes, red early in the season changing to dark brown, glossy, glabrous, with numerous, inconspicuous, small lenticels; leaf-buds small, short, conical, plump, free.

Leaves folded upward, narrow-obovate or oblanceolate, peach-like, one and threeeighths inches wide, three and one-quarter inches long, thin; upper surface light green, smooth, glabrous, with grooved midrib; lower surface pale green, pubescent on the midrib and larger veins; apex taper-pointed, base cuneate, margin very finely

\footnotetext{
${ }^{1}$ Cornell Sta. Bul. 62:27. 1894 .

2Tex. Sta. Bul. 32:488. 1894.
} 
serrate, with small, brownish glands; petiole three-eighths inch long, slightly pubescent along one side, reddish, glandless or with from one to five small, globose, green or reddish glands usually on the stalk.

Blooming season early; flowers appearing with the leaves, medium in size; borne in clusters on lateral buds and spurs, in pairs or in threes; pediccls of medium length and thickness, slightly pubescent, greenish; calyx-tube green, obconic, glabrous; calyxlobes obtuse, with ciliate margins, glabrous, erect; petals broadly oval, entire, abruptly clawed; anthers yellowish; filaments of average length; pistil glabrous, equal to the stamens in length.

Fruit early, season short; one and three-eighths inches in diameter, roundishovate, halves nearly equal, slightly compressed; cavity medium in depth and width, abrupt, regular; suture shallow, distinct; apex pointed; color pinkish-red changing to darker red, mottled, with thin bloom; dots numerous, of medium size, russet, conspicuous; stem one-half inch long, glabrous, parting easily from the fruit; skin thin, tough, bitterish, separating readily; flesh yellow, very juicy, tender and melting, sweet except next to the pit, pleasantly aromatic; good; stone clinging, three-quarters inch by one-half inch in size, oval, somewhat compressed, pointed, rough, ridged along the ventral suture; dorsal suture grooved.

\section{AGEN}

\section{Prunus domestica}

x. Kraft Pom. Aust. 2:38, Tab. I89 fig. I. I796. 2. Lond. Hort. Soc. Cat. I43, I47, I52, 153. 1831. 3. Prince Pom. Man. 2:75, 100. 1832. 4. Poiteau Pom. Franc. 1. 1846. 5. Downing Fr Trees Am. 309. 1845. 6. U. S. Pat. Off. Rpt. 30. 1854. 7. Thompson Gard. Ass't 519. I 859 . 8. Am. Pom. Soc. Cat. 86. 1862. 9. Oberdieck Deut. Obst. Sort. 427. I881. 1o. Hogg Fruit Man. 683. I884. I1. Mas Le Verger 6:8 r, fig. I866-73. 12. Cal. State Bd. Hort. 291. 1885-86. I3. Cat. Cong. Pom. France 343. 1887. 14. Cal. State Bd. Hort. 49, 50. 1887-88. 15. Ibid. 233, 235 , 340. 1890. 16. Ibid. 96, 105, PI. 1. 1891. 17. Guide Prat. 160, 353. 1895. 18. Oregon Sta. Bul. 45:24. 1897. 19. Cornell Sta. Bul. 13r:19r. 1897. 20. U. S. D. A. Div. Pom. Bul. 7:315, 316. PI. IV, fig.4. 1898. 21. Mich. Sta. Bul. 169:241, 242. I899. 22. Cal. Fr. Gr. Con. 29. Igо1, 23. Waugh Plum Cult. 94, 95 fig. 1901. 24. Baltet Cult. Fr. 495, fig. 331, 506, 507, fig. 336. I 908 25. Wickson Cal. Fruits 225. 1908. 26. Cal. Fr. Grower 40:18, 19, fig. 1909.

Agen 22. Agener Kaiserzwetsche 17. Agen Date 3. Agen Datte 5, ro. Agener Pflaume 17. Agener Pflaume 9. Agen Prune 21. California 20. California 16. D'Agen 2, I0, II, I7, 24. D'Agen 3, 5, 8, 13, 20. D'Ast 13, 17. Date 21. Datte 17. De Brignole 17. D'Ente 13, 17, 24. D'Ente d'Agen 13. Datte Violette 1, 13, 17. Die Blaue Dattelpflaume 17. Die Blaue Dattelpfla ume r. Du Roi 17. French 20. French Prune 15, 18, 23, 25. French Prune (?) 2, 12, 14, 15, 26. Lot d'Ente 18. Petite 20. Petite d'Agen $\mathrm{I}_{4}, 20,26$. Petite Prune I8. Petite Prune 23. Petite Prune d'Agen 25. Prune d'Agen 5, 6, 7, 8, 15, 17, 19, 25. Prune d'Agen 14, 16, 18, 23. Prune de Brignole (of some) 5, 7, 17. Prune d'Ante 3. Prune d'Ast 5, 7, 10, 11. Prune d'Ente 7, 12, I8. Prunier d'Agen 3. Prunier d'Agen 6. Prune d'Ente 22. Prune du Roi ro. Robe de Sergent 3, 5, 7, 8, I1, 13, 17, 18. Robe de Sargent 10, 12. Roi d'Agen 2. Saint Maurin 2, 4. St. Maurin 5, 7, 10, I7. Saint Mauriniana 4. Violette Dattelswetsche 17.

Agen is the plum par excellence for prune-making in France and America. Several qualities make it admirably fit for curing into prunes. 


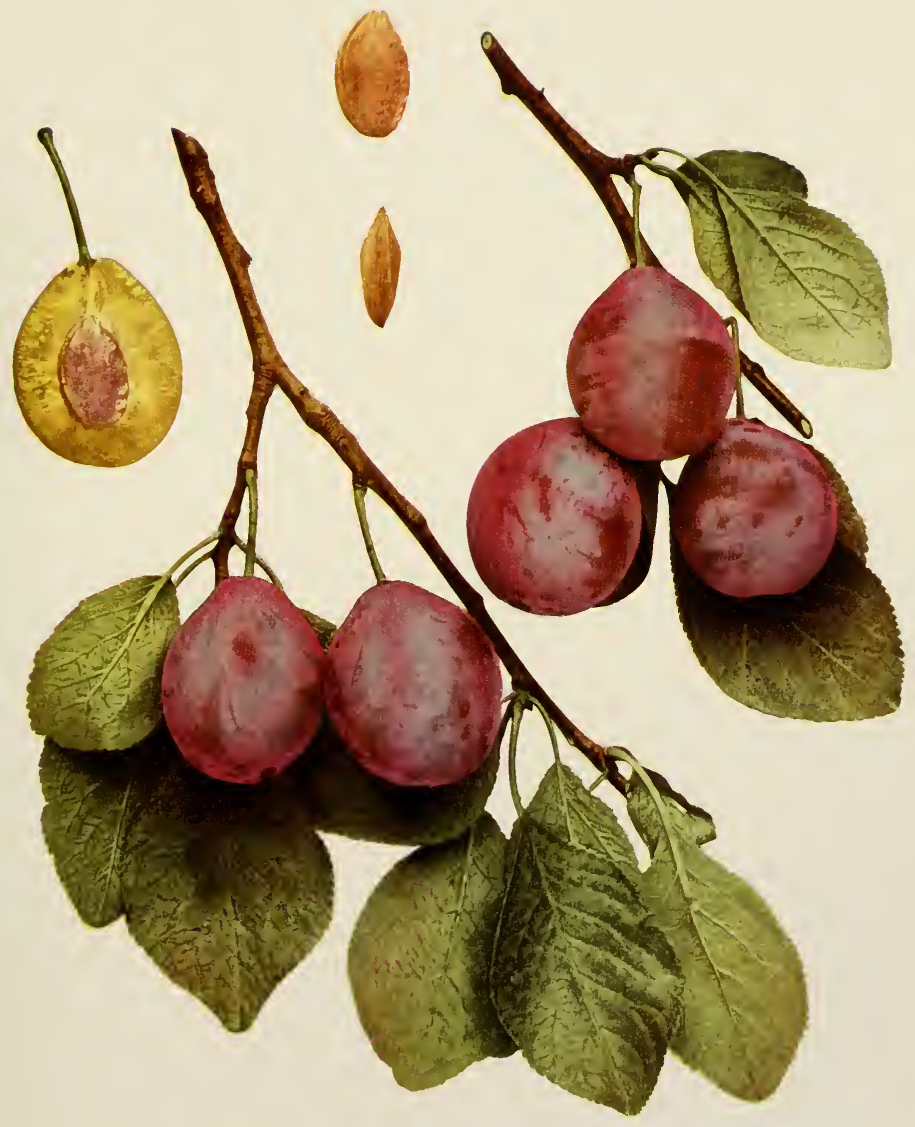



To begin with, it has a high percentage of sugars and solids so that the plum cures readily into a firm, sweet, long-keeping prune which in cooking needs comparatively little sugar; again, the trees bear regularly, abundantly and the plums are uniform in size,-productiveness, regular bearing and uniformity of size of fruit being necessary attributes of a good prunemaking plum; lastly, it hangs well on the tree as it ripens and afterwards so that the curing really begins on the tree. Besides making most excellent prunes, the Agen is a very good dessert plum-one of the best-and ought to be in every home orchard and, where it attains sufficient size, in every commercial plantation. Lack of size is the defect in this variety which has kept it from being more largely grown outside of prune-making regions. If by pruning, thinning and other cultural treatment the size of the plums could be increased, the Agen should prove a valuable commercial fruit in New York.

The name of this variety is derived from Agen, a region in France where it is extensively grown. Tradition says that on their return from the Crusades, the Benedictine monks brought with them from Turkey or Persia what was then known as the Date plum and planted it in the garden of their abbey on the River Lot, in the vicinity of Bordeaux, France, and that afterwards this became the Agen. Its first recorded importation into the United States was made in 1854 by the United States Patent Office, though it was described by Prince as early as $183^{2}$. The most important introduction was made, however, in 1856 , when Louis Pellier of San Jose, California, introduced Agen on the Pacific Coast, where it soon became and still is the leading plum, though with curious persistency the fruitgrowers there call it the "French Prune" and the "Petite Prune." In I862 this variety was added to the fruit catalog list of the American Pomological Society. There are many strains of Agen in America, due to the numerous importations of grafts from various parts of France, where the plum orchards are frequently grown from seedlings or from sprouts; some of these strains are worthy of varietal recognition.

Tree of medium size, upright-spreading, dense-topped, hardy, very productive; branches ash-gray, smooth, with numerous, large, raised lenticels; branchlets slender, short, with short internodes, greenish-red changing to dark brownish-drab, dull,pubescent, with small lenticels; leaf-buds of medium size and length, conical, free.

Leaves folded upward, obovate or oval, one and three-quarters inches wide, three and one-quarter inches long, velvety; upper surface with few fine hairs and a narrow, grooved midrib; lower surface pale green, thickly pubescent; apex abruptly pointed, 
base acute, margin doubly serrate; petiole one inch long, slender, pubescent, tinged red, with two or three small, globose, greenish-brown glands usually on the stalk.

Season of bloom intermediate in time and length; flowers appearing after the leaves, one and one-eighth inches across, white; borne on lateral spurs, singly or in pairs; pedicels five-eighths inch long, thick, glabrous except for a few short hairs, greenish; calyx-tube green, campanulate, pubescent; calyx-lobes obtuse, somewhat pubescent within, with glandular margin, reflexed; petals broadly oval or obovate, entire, tapering to short, broad claws; anthers yellowish; filaments five-sixteenths inch long; pistil glabrous, equal to the stamens in length.

Fruit late, season short; one and one-half inches by one and one-eighth inches in size, obovate, the base necked, halves equal; cavity shallow, narrow, flaring; suture very shallow, indistinct; apex roundish or flattened; color reddish or violet-purple, overspread with thin bloom; dots numerous, small, brown, obscure, clustered about the apex and interspersed between russet flecks; stem thick, seven-eighths inch long, glabrous, adhering well to the fruit; skin thin, tough; flesh greenish-yellow, tender, sweet, aromatic; very good to best; stone semi-free or free, seven-eighths inch by one-half inch in size, oval, flattened, with pitted surfaces, rather abrupt at the base and apex; ventral suture somewhat narrow, furrowed, with distinct wing; dorsal suture widely grooved.

\section{AITKIN}

\section{Prunus nigra}

I. Minn. Hort. Soc. Rpt. 426. 1896. 2. Wis. Sta. Bul. $63: 24,27,28$ fig. $11,43.1897 .3$. Jewell Nur. Cat. 1899-1906. 4. Waugh Plum Cult. 169. 1901. 5. Can. Exp. Farm Bul. 43:29. 1903. 6. Ia. Hort. Soc. Rpt. 227. 1904.

Aitken 4. Beatty 6 incor.. Itasca $x$ incor..

Aitkin is very favorably mentioned in the references given above and undoubtedly has value for the Northwest. It was listed in the catalog of the American Pomological Society in 1899 . The variety was found growing wild in Aitkin County, Minnesota, by D. C. Hazelton on land adjoining his farm. It seemed to possess merit and was introduced in I 896 by the Jewell Nursery Company of Lake City, Minnesota. Because of having originated near Itasca Lake, it has been confused with the Itasca plum, which preceded it by nearly ten years. The following description is a compilation:

Tree vigorous, productive, ripening its wood very early; fruit earliest in season of its group; large for its class, oval, deep red, with no bloom; skin thin, not astringent; flesh yellow, juicy, sweet and rich; good; stone large, oval, flattened, clinging. 


\section{ALHAMBRA}

$[($ Prunus triflora $\times$ Prunus cerasifera $\times$ Prunusdomestica $] \times[$ (Prunus simonii $\times$ Prunus triflora $) \times($ Prunus americana $\times$ Prunus nigra $)]$

I. Vt. Sta. Bul. 67:5. 1898. 2. De Vries Plant Breeding 213. 1907.

Although it is over a decade since Alhambra was offered to fruitgrowers, it has made little headway in popularity and is chiefly of interest because of its breeding. It is not often that we can trace the pedigree of a plant for more than one or at the most two generations, but in Alhambra we are particularly fortunate. Luther Burbank, the originator, began by crossing Kelsey and Pissardi, and the offspring from this cross was fertilized with Agen pollen. This tri-hybrid was in turn fertilized with pollen from a complex hybrid of a cross of Prumus simonii and Prumus triflora pollinated by a cross of Prunus americana and Prunus nigra. As might be expected, the offspring of this final cross was extremely variable and from it was selected the Alhambra. The variety was named by the originator in 1898 .

The fruit as described by Waugh is "egg-shaped, large or very large; cavity medium shallow, abruptly rounded; suture shallow; apex pointed; color dark, dull red; dots many, small, yellowish; bloom thin, purplish; skin firm; flesh yellow inside, reddish outside; stone medium to large, flat, pointed, nearly smooth, clinging; flavor brisk subacid; quality first rate."

\section{ALTHAM}

\section{Prunus domestica}

1. Jour. Hort. N. S. 17:228, 1869. 2. Lange Allgem. Garten. 2:419. 1879. 3. Oberdieck Deut. Obst. Sort. 432. 1881, 4. Lauche Deut. Pom. 19, P1. IV. 1882. 5. Hogg Fruit Man. 692. 1884. 6. Mathieu Nom. Pom. 420. 1889. 7. Gaucher Pom. Prak. Obst. 94, Pl. 1894. 8. Soc. Nat. Hort. France Pom. 550 fig. 1904. 9. Cat. Cong. Pom. France 468 , fig. 1906. 10. Baltet Cult. Fr. 490 , fig. 328 . 1908 .

Althan's Reine Claude 6, 7. Althann's Reine Claude 2, 3, 4, 6. Althahn's Rote Reine-Claude 6, 7. Althann's Reine Claude 7. Count Althann's Gage 5. Count Althann's Gage 6, 7. Graf Althan's Reme-Claude 6. Graf Althann's Reine-Claude 7. Hathen's Red Gage 1. Reine-Claude Ronge de Hathen 1. Reine-Claude d'Althann 5, 6,7. Reine-Claude Comte Althan 5, 6. Reine-Claude de Comte Hathem 5, 6. Reine-Claude du Comte Hathem 6, 7. Reine-Clande du Comte d'Althan 8. ReineClaude Althan's 5, 6, 7. Reine-Clande Comte d'Althan 6. Reine-Claude d'Althan 8. Reine-Claude d'Althan 6, 7, 10. Reine-Claude Rouge Comte Althan 6, 7. Reine-Claude Rouge du Comte Hethau 6. Reine-Claude rouge du comte Hethan 7. Reinette Claude Comte d'Althan 9. Reinette Claude d'Althan 9.

Altham is an excellent plum for dessert or home use. The color is a trifle too dull for market purposes and yet it is better colored than McLaughlin, which sells fairly well. The fruit is the type of the last named 
plum but is later. In Europe this variety is well known and highly esteemed for its quality, but unfortunately it is almost unknown in America. The variety is well worth trial in this country as a fine plum of the Reine Claude group. Altham is a seedling of Reine Claude, raised by Herr Prochaska, gardener to Count Michael Joseph Althann, of Swoyschitz, in Bohemia. It was noted in the English Fournal of Horticulture for 1869 as a new plum sent out by Thomas Rivers.

Tree of medium size, upright-spreading, dense-topped, productive; leaf-scars promincnt; leaves folded upward, obovate, two and one-quarter inches wide, nearly four inches long, very thick, leathery; margin doubly crenate, with few, small, dark glands: petiole thick, with from one to four globose, yellowish-green glands on the stalk; season of bloom intermediate, short; flowers appearing after the leaves, one inch across, yellowish at the apex of the petals; borne on lateral buds and spurs, singly or in twos.

Fruit mid-season; one and one-half inches by one and five-eighths inches in size, oblate, strongly truncate at the base, compressed; color dark purplish-red over a yellow ground, covered with thick bloom; dots russet surrounded with a dark red ring; stem adhering strongly to the pulp; flesh light golden-yellow, firm but tender, sweet, mild, pleasant; very good to best; stone semi-clinging, seven-eighths inch by five-eighth inch in size, flattened, irregular-oval, with pitted surfaces, contracted at the base into a short oblique neck; ventral suture prominent, heavily furrowed, often with distinct wing; dorsal suture wide, deep.

\section{AMERICA}

\section{Prunus munsoniana $\times$ Prunus triflora}

1. Burbank Cat. 3. 1898 2. Vt. Sta. Bul. 67:5. 1898. 3. Rural N. Y. 59:706. 1900. 4. Vt. Sta. An. Rpt. 14:273. 1900. 5. Mich. Sta. Bul. 205:37 1903. 6. Del. Penin. Hort. Soc. Rpt. 36. 1905. 7. Ohio Sta. Bul. $162: 254,255$. 1905. 8. Ga. Sta. Bul. 68:8, 35. 1905.

America is illustrated and described in full chiefly because it is the most promising cross between Prunus munsoniana and Prunus triflora. The fruit of the variety is unusually attractive in appearance, goldenyellow with a red cheek and waxy lustre turning currant-red when ripe, ships exceptionally well and is of very good quality for cooking, but is without merit as a dessert plum. The trees are large, very vigorous, as hardy as either of its parents or possibly more so, and enormously productive. The qualities of fruit and tree are such that the variety ought to succeed in commercial plantations where any but the hardiest native plums are cultivated. America is almost phenomenally free from rot, considering its parentage.

This variety is one of Luther Burbank's productions, grown from a seed of Robinson fertilized by pollen from Abundance. It was introduced 


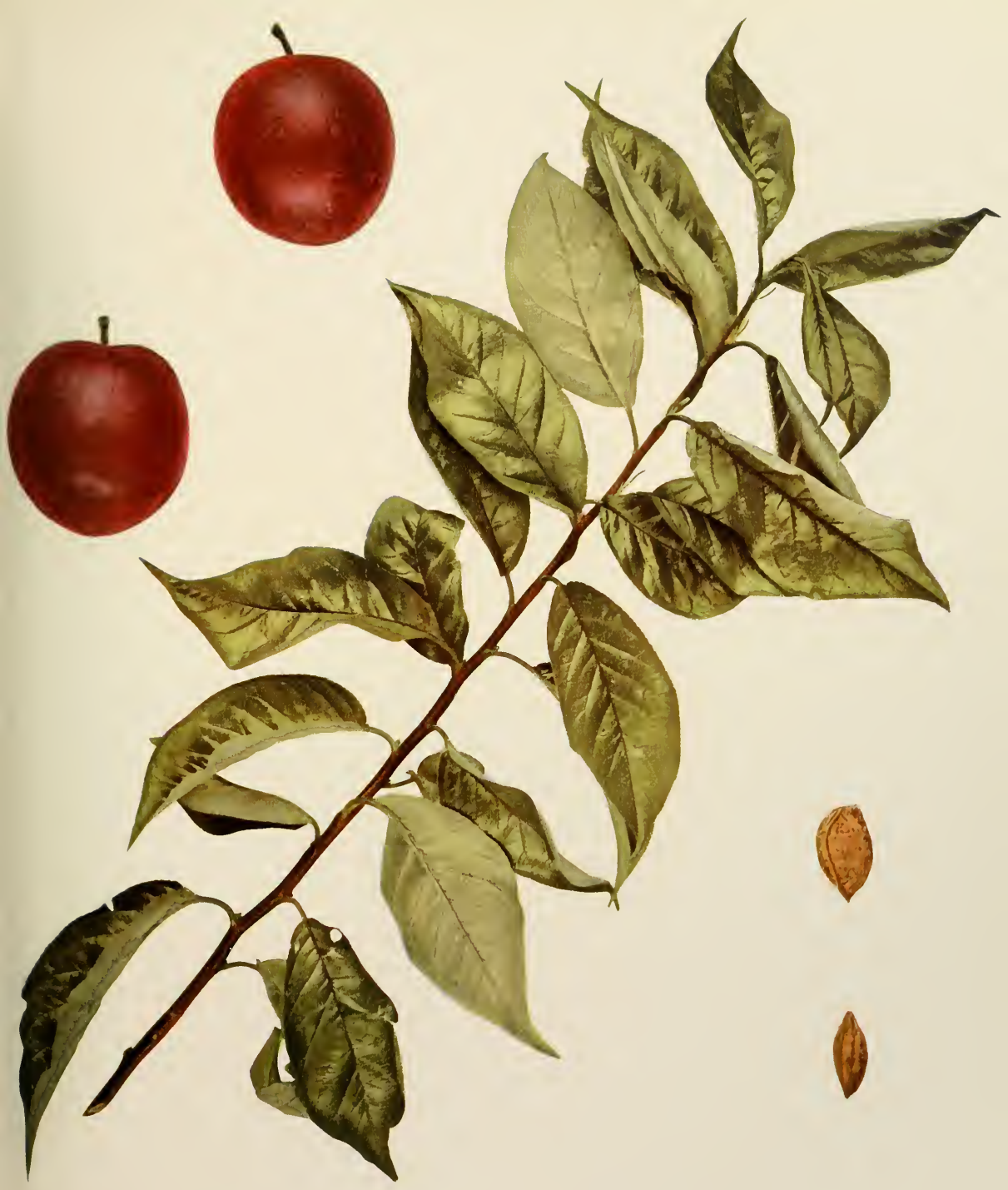



by the originator in 1898 and has been since that time well tested at several places in the eastern states and is very generally well spoken of for a plum of its kind for the East.

Tree large, vigorous, spreading, somewhat open-topped, hardy, very productive; branches roughish and with cracked bark, slightly zigzag, dark ash-gray, with numerous, conspicuously raised lenticels ; branchlets willowy, long, with short internodes, green with a reddish tinge changing to dark chestnut-red, glossy, glabrous, with numerous, small, raised lenticels; leaf-buds small, short, conical, free.

Leaves folded upward, broadly lanceolate, peach-like, one and one-half inches wide, three and one-fourth inches long, thin; upper surface reddish late in season, smooth and glossy, with deeply grooved midrib; lower surface light green, sparingly pubescent along the midrib and larger veins which are more or less red; apex taperpointed, base abrupt, margin finely and doubly crenate and with numerous, small, dark glands; petiole one-half inch long, tinged red, pubescent along one side, glandless or with one or two small globose, reddish glands on the upper part of the stalk.

Blooming season intermediate and long; flowers appearing after the leaves, onehalf inch across, white; borne in clusters on short lateral spurs and buds, in pairs or in threes; pedicels five-sixteenths inch long, slender, pubescent, green; calyx-tube greenish, obconic, glabrous; calyx-lobes obtuse, with a trace of red along the margin, glandular-serrate, glabrous, with marginal hairs, erect; petals small, roundish, entire, tapering abruptly to narrow claws; anthers yellowish; filaments three-sixteenths inch long; pistil glabrous, longer than the stamens.

Fruit early, season of medium length; one and three-eighths inches in diameter, roundish-oval, halves equal; cavity shallow, flaring; suture shallow, a distinct line; apex roundish; color clear, dark, currant-red over golden-yellow, mottled, with thin bloom; dots numerous, small, whitish, inconspicuous; stem slender, one-half inch long, glabrous, adhering to the fruit; skin thin, bitterish, separating readily from the pulp; flesh yellow, juicy, fibrous, somewhat tender, sweet, not high in flavor; fair in quality; stone clinging, seven-eighths inch by one-half inch in size, oval, pointed, with pitted surfaces, broadly ridged along the ventral suture; dorsal suture grooved.

\section{AMERICAN}

Prunus domestica

1. Oregon Sta. Bul. 61:17, 18. 1900.

American Seedling $x$.

American originated with a Mr. Peterson of Elkton, Douglas County, Oregon, as a sprout from an old tree. It has never been extensively disseminated, but seems to be a variety of considerable promise. The fruit as grown on the Station grounds resembles Hand rather closely; is large for a plum of its type, is a handsome golden color, is high in quality and will probably keep and ship well. Too little is known of its tree-characters to recommend it unqualifiedly. 
Tree above medium in size, vigorous, round-topped, dense. productive; branches numerous; branchlets thick, marked by grayish scarf-skin; leaves flattened, oval or obovate, two and one-quarter inches wide, four and one-half inches long, dark green; margin serrate or crenate; blooming season intermediate, short; flowers appearing after the leaves, one and three-eighths inches across, singly or in twos, fragrant.

Fruit mid-season; very large, roundish-oblate, truncate, golden-yellow, indistinctly streaked with green, mottled, covered with thin bloom; flesh light golden-yellow, tender, sweet, pleasant flavor; good to very good; stone clinging, one inch by three-quarters inch in size, broadly oval, flattened, surfaces pitted; dorsal suture wide, deep.

\section{AMERICAN EAGLE}

\section{Prumus americana}

1. Cornell Sta. Bul. 38:36. 1892. 2. Am. Pom. Soc. Cat. 37. 1899. 3. Can. Exp. Farms Rpt. 105. 1900. 4. Waugh Plum Cult. 142. 1901. 5. Can. Exp. Farm Bul. 43:28. 1903. 6. Ohio Sta. Bul. $162: 254,255$. 1905 .

Of the origin of this very good Americana variety little is known except that it probably came from Missouri, as it was introduced, in the fall of 1859 , by the Osceola Nursery Company, Osceola, Missouri. Although an old variety it was not listed by the American Pomological Society until 1899. In regions where Americana plums are grown, American Eagle ought to be better known, its chief defect being the dull color of the fruit.

Tree vigorous, spreading; leaves large; petiole glandular. Fruit mid-season; large, varies from roundish-oval to nearly oblate, dark red, covered with thick bloom; stem short, pubescent; flesh yellow, juicy, fibrous, sweet, aromatic, with characteristic Americana flavor; of good quality; stone clinging, three-eighths inch by one-half inch in size, roundish, turgid, conspicuously winged; surface smooth.

\section{AMES \\ Prunus americana $\times$ Prunus triflora}

1. Vt. Sta. An. Rpt. 12:220. 1899. 2. Ia. Hort. Soc. Rpt. 112. 1899. 3. Ia. Sta. Bul. 46:261. 1900. 4. Waugh Plum Cult. 203. 1901. 5. Budd-Hansen Am. Hort. Man. 293. 1903. 6. S. Dak. Sta. Bul. 93:9. 1905. 7. Ill. Hort. Soc. Rpt. 422. 1905. 8. Rural N. Y. 65:730. 1906.

De Soto $\mathrm{x}$ Oregon No. 3 6. Japan Hybrid No. 32 .

Though Ames has been known to the public scarcely ten years, its good qualities have given it relatively high rank among Americana plums with which it must be compared. Though supposed to be a cross between Prumus americana and Prumus triflora, the variety shows few, if any, traces of the Triflora parentage, except, possibly in the shape and color of the fruit. The variety is distinguished from other Americana plums by reddish 


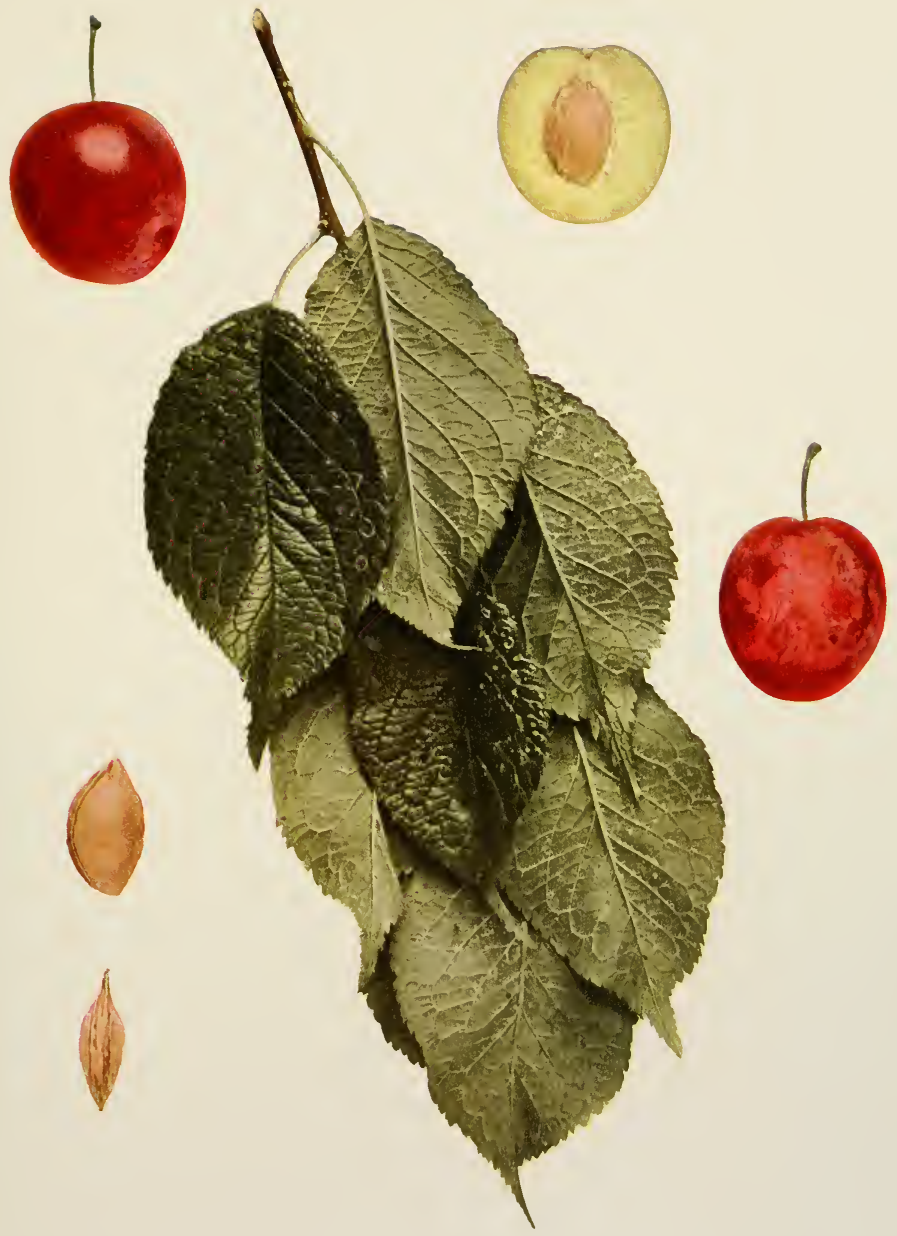



dots on the fruit instead of the yellowish dots commonly found on the plums of this species. The fruit of Ames is very attractive in color, the quality is fair, it keeps and ships well and it is fairly free from rot, characters which make it desirable where the native plums are grown.

This variety was produced by Professor J. L. Budd * of Ames, Iowa, by crossing De Soto with pollen of a "large Japanese plum received from Oregon." For a long while it was known as De Soto x Oregon No. 3 and as Japan Hybrid No. 3, but was named Ames by Professor John Craig, now of Cornell University.

Tree of medium size, spreading, dense-topped, hardy, productive; branches roughish, thorny, the trunk shaggy, dark ash-brown, with numerous, large, raised lenticels; branchlets willowy, thick, long, with long internodes, green changing to dark chestnutred, glossy, glabrous, thickly strewn with conspicuous, large, raised lenticels; leafbuds small, short, obtuse, plump, appressed.

Leaves falling early, flattened, oval, two inches wide, four inches long; upper surface dark green, glabrous, slightly rugose; lower surface light green, pubescent; apex taper-pointed, base abrupt, margin coarsely serrate, the serrations ending in hair-like

${ }^{1}$ Professor Joseph Lancaster Budd was a native of New York, having been born July 3, 1835 , at Peekskill, Westchester County. On his father's side he was of French ancestry, but his mother was of English descent, a member of the Lancaster family, early settlers on the Hudson River. He was educated in the public schools of Monticello, Monticello Academy and at Hiram College, though he did not finish at the last named institution because of financial distress at home. In 1857 the young man moved west and for a year taught in an academy at Rockford, Illinois, and in the Wheaton schools of the same state. In $185^{8}$ he moved to Benton County, Iowa, where he established the Benton County Orchards and Nurseries. He soon became identified with horticulture in Iowa, especially through its State Horticultural Society, an organization of which he was secretary from 1873 to 1885 and from 1892 to 1895 , serving in all seventeen years. In 1876 he was elected to the chair of Horticulture and Forestry in the Iowa Agricultural College, a position which he held until 1899 , when he retired as professor emeritus, having spent twenty-two years in pioneer work in this college. In $188_{2}$ Professor Budd visited Russia to study the hardy plants of that country and imported from there many varieties of fruit, as well as other plants, which he thought suited to the climate of the Northwest. After his return his work was largely given up to originating and testing varieties which he thought would prove of value to the States of the Plains. He was preeminent in America for his work with Russian fruits and was one of the first to see the possibilities of our native plums. The frequency with which his name is mentioned in this book as a breeder of hardy fruits indicates his interest in securing plums adapted tc the region in which he lived. The horticultural library of Charles Downing, by the wish of the owner, was given to the Iowa Agricultural College with the expectation that Professor Budd would revise Downing's famous Fruits and Trees of America. Ill health prevented the accomplishment of this task, although as senior author he published, in 1902, the American Horticultural Manual in two volumes. During the greater part of his active life he was a constant correspondent of the horticultural press. Professor Budd was a teacher as well as a pomologist and did much for American pomology in imparting to the men who came in contact with him both knowledge and enthusiasm. He died in Phoenix, Arizona, December 26, 1904 . 
tips, eglandular; petiole seven-eighths inch long, slender, pubescent, tinged red, glandless or with from one to thrce globose, greenish-red glands.

Blooming season medium in time and length; flowers appearing after the leaves, nearly one inch across, white; borne in clusters on lateral buds and spurs, in threes or fours; pedicels one-half inch long, slender, glabrous, greenish; calyx-tube green, campanulate, glabrous; calyx-lobes narrow, somewhat acute, reflexed, pubescent on the inner surface, the margin faintly pubescent and with a trace of red; petals small, oval, somewhat dentate, tapering below to long, narrow, slightly hairy claws; anthers yellowish; filaments five-sixteenths inch long; pistil glabrous, equal to the stamens in length, frequently defective.

Fruit mid-season, one and seven-sixteenths inches by one and five sixteenths inches in size, ovate or oval, sides compressed, halves equal; cavity shallow, narrow, flaring; suture a line; apex roundish; color light to dark red over a yellow ground, covered with thin bloom; dots numerous, small, brownish-red; stem slender, glabrous; skin medium in thickness and toughness, adhering; flesh golden-yellow, juicy, coarse, fibrous, tender and melting, semi-sweet; of fair quality; stone nearly free, one inch by five-eighths inch in size, irregular-oval, flattened and elongated at the base, abruptly pointed at the apex, very smooth; ventral suture winged and furrowed; dorsal suture acute.

\section{APPLE}

\section{Prunus triflora $X$ ?}

x. Burbank Cat. 2. I898. 2. Vt. Sta. Bul. 67:6. 1898. 3. Vt. Sta. An. Rpt. 12:220. 1899. 4. Am. Gard. $21: 36$. 1900. 5. Waugh Plum Cult. 203. 1901. 6. Ga. Sta. Bul. 68:12, 35. 1905. 7. Mass. Sta. An. Rpt. 17:161. 1905.

The Apple is a conspicuous plum; its shape, color, size, flavor; its firm, blood-red flesh and long-keeping quality, all distinguish it. Even the tree is marked with its robust growth, flat-topped head, peculiar, light brown bark, handsome foliage and wood that can be propagated from cuttings with surprising ease. It is difficult to predict the future of this interesting plum, but probably it will remain for most part a curiosity. Its peculiar flavor is not pleasant at first taste and it is doubtful if many will learn to like it. Unpalatability is the defect of the variety which will most often be counted against it. In general the Apple is inferior for dessert or kitchen to the Satsuma, itself none too good, which it most nearly resembles of all plums. In the Station collection tree and fruit are quite susceptible to both fungus and insect pests and the fruits ripen unevenly. The fruit of the variety keeps and ships remarkably well and these qualities may be its saving grace, both so well developed as to make it valuable for breeding purposes when these characters are desired.

In his catalog for ${ }^{2} 898$ Burbank announces the Apple as a new plum and says, "Among the welcome surprises found three years ago among 


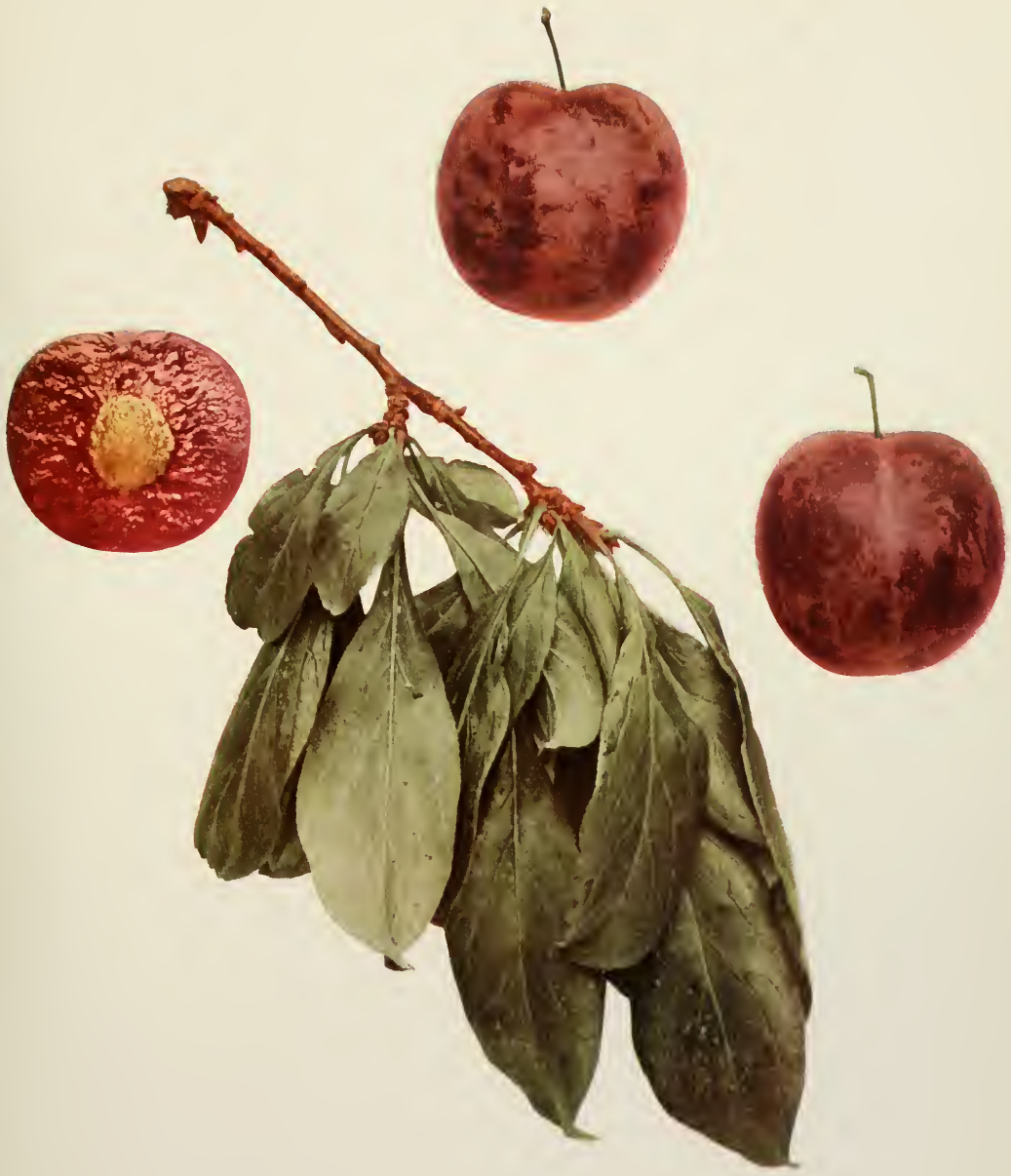



a lot of some twenty-five thousand plum seedlings was this one, bearing a cruel load of enormous plums when only two years old. **** It was at once named Apple from the very close resemblance in form, color general appearance, and rare keeping qualities. $* * * *$ Its parentage is not known, except that it is a second generation seedling from cross-bred seedlings, and no doubt Satsuma and probably Robinson are in its line of ancestry." Satsuma characters are readily detected in tree and fruit and especially its hard, red flesh, but in no way is its descent from Robinson apparent.

Tree of medium size, flat-topped, spreading, dense-topped, slow-growing, semihardy, productive; branches rough and thorny, with numerous fruit-spurs, dark ashgray, reddish and with numerous lenticcls; branchlets often with a rosette of flowerbuds on the apex of the shoots, slender, with short internodes, greenish-red changing to dark brown, glossy, glabrous, with numerous, conspicuous, large, raised lenticels; leaf-buds small, short, obtuse, plump, appressed.

Leaves folded upward, obovate or oblanceolate, one and one-quarter inches wide, three and three-quarters inches long, thin, leathery; upper surface purplish-red late in the season, glossy, glabrous, with grooved midrib; lower surface light green, pubescent at the base of the veins; apex acutely pointed, base cuneate, margin finely and doubly crenate and with small amber glands; petiole five-eighths inch long, pubescent, red along one side, with from three to ten large, conspicuous, reniform, red or yellowish glands on the stalk.

Blooming season early and of medium length; flowers appearing before the leaves, white; borne in clusters on lateral buds and spurs, in threes or fours; pedicels medium in length and thickness, glabrous; calyx-tube obconic, glabrous; calyx-lobes narrow, obtuse, glandular-ciliate, glabrous, erect; petals oval, entire, short-clawed; anthers yellowish; filaments of medium length; pistil glabrous, shorter than the stamens, often defective.

Fruit mid-season; one and one-half inches long, one and three-quarters inches wide, roundish-oblate, compressed, halves equal; cavity medium in depth and width, flaring, with concentric russet rings; suture shallow; apex depressed and at one side; color dull dark red, with waxy bloom; dots numerous, large, russet, conspicuous, clustered about the apex; stem five-eighths inch long, glabrous; skin tough, bitterish, separating from the pulp; flesh dark red, juicy, firm but tender, sweet, with pleasant mild flavor, aromatic; good; stone clinging, three-quarters inch by five-eighths inch in size, oval or obovate, turgid, pointed, roughish, winged on the ventral, deeply furrowed on the dorsal suture.

\section{APRICOT}

\section{Prunus domestica}

I. Parkinson Par. Ter. 578. 1629. 2. Rea Flora 209. 1676. 3. Quintinye Com. Gard. 67, 69. 1699. 4. Duhamel Trait. Arb. Fr. $2: 93$, Pl. XIII. 1768. 5. Knoop Fructologie 2:52, 53, 54. 1771. 6. Kraft Pom. Aust. 2:28, Tab. 173 fig. 1; 2:34, Tab, 183 fig. 1. 1796. 7. Prince Pom. Man. 7 1. 
1832. 8. Kenrick Am. Orch. 255. 1832, 9. Thomas Am. Fruit Cult. 327. 1849. 1o. Elliott Fr. Book 424. 1854. I1. Noisette Man. Comp. Jard. $2: 498$. 1860. 12. Downing Fr. Trees Am. 896, 952. 1869. 13. Mas Pom. Gen. 2:133. 1873. 14. Le Bon Jard. 338. 1882. 15. Hogg Fruit Man. 684. 1884. 16. Mathieu Nom. Pom. 42I, 43I, 454. I889.

Apricocke I. Apricock Plum 2. Abricot de France 5. Abricot Blanc 16. Abricot Blanche 5. Abricot ordinaire 5. Abricote 5. Abricotc blanc 7, 12. Abricotée 4, 13. Abricotée 6, 7, 10, 12, 16. Abricotée Perdrigon 6. Abricotée Blanche 7, 12, 15, 16. Apricot Plum of Tours 7. Abricote de Tours 7. Abricotée de Tours 7, 10, I 2, 13, 15, 16. Apricot Plum 8. Apricot Plum of Tours 10, 12, 16. Abricotée Blanc 12. A prikosenartige Pfaume 13. A pricot 13. Aprikosenartige Pflaume 16. Apricot Plum 16. Aprikosen Perdrigon 16. Die Abrikosenartige Pflaume 6. Die Morillenpflaume 6. French Apricot 9. Frïhe Gelbe Kaiser Pfaume 16. Gelbe Apricosenartige Pflaume 13. Gelbe Dauphins 16. Gelbe Reine-Claude 16. Gelbe Aprikosenpflaume 16. Lieflander Gelbe Pfaume I6. Morillen Pflaume 16. Old Apricot 12, 13, 15, 16. Prune-Abricot Ir. Prune Abricotée I4. Prune Abricotée Blanche II. Prune Abricotée de Tours 8. Prune Abricote 8. Prune d'Abricot Ordinaire 5. Prune d'Abricot Blanch 5. Prine d'Abricot bigarree 5. Prune d'Abricot de France 5. Prune d' Abricot r6. Red Apricot ro incor. Reine-Claudenartige Aprikosen Pflaume r6. Susina Massina Piccola 16. The New Apricot Plum 16. Virginale 5. White Apricot Plum 7, 12. Wahre Aprikosen Pflaume I6. White apricot 12, 16. Weisse Aprikosen Pfaume I6. Yellow Apricot 10, I 2, I3, I5, I6.

Since John Parkinson described the "Apricocke" plum in 1629 , several types of this variety have appeared in literature and these have become so badly confused that it is impossible to separate them. However, as the variety is nearly extinct, and will probably never be revived, this confusion is happily of historic rather than of economic interest. Nearly all writers recognize at least two types, one of which is superior to the other. The better of these can readily be identified as the "Abricotée " of Duhamel, and should be considered the true Apricot. Little is known of the early history of this variety other than that it was very generally distributed throughout Europe early in the Seventeenth Century. The American Pomological Society rejected Apricot in 1858 , though it is doubtful if they had the true type. This variety is not to be confused with the Prunus simonii, commonly called "Apricot," or the native plum of that name.

The following description is compiled: tree large, vigorous, productive; fruit mid-season; large, roundish or slightly elongated, with prominent suture, yellow, blushed with red, overspread with thin bloom; flesh yellow, sweet, pleasant, slightly musky; good; stone small, free.

\section{ARCH DUKE}

Prunus domestica

x. Hogg Fruit Man. 684. 1884. 2. Ont. Fr. Gr. Assoc. Rpt. 35. 1891. 3. U.S. D. A. Pom. Rpt. 45. 1895. 4. W. N. Y. Hort. Soc. Rpt. 42:83. 1897. 5. Cornell Sta. Bul. 131:182, 1897. 6. Mich. Sta. Bul. 169:241, 242. I899. 7. Ibid. 187:77, 78. 1901. 8. Waugh Plum Cult. 95. 1901. 9. Thompson Gard. Ass't 4:156. 1901. xo. Ohio Sta. Bul. $162: 242,243$ fig., 254, 255. 1905.

Late Diamond $\mathbf{r}$. 


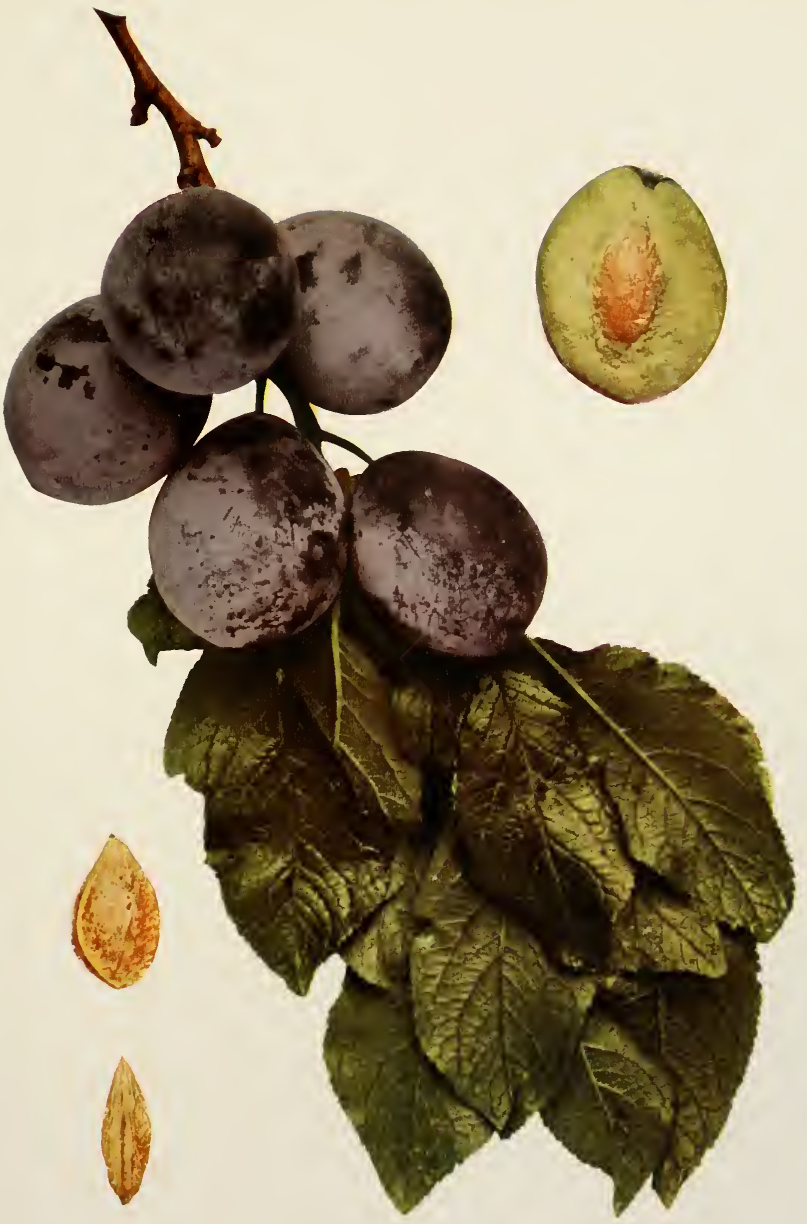



Arch Duke ought to become one of the leading plums for the market in New York. The qualities which fit it for a high place among commercial varieties are: large size, handsome color - a rich, dark purple with thick bloom - and firmness of flesh and skin so that it both keeps and ships well. The accompanying color-plate does not do the variety justice, either in beauty, color or size of fruit. Arch Duke compared with Grand Duke, known by all plum-growers, is nearly as large, neck thicker, the same color, bloom heavier, quality higher, flesh firmer, stone free and ripens earlier. The tree-characters, like the fruit-characters, are all good. While this variety is suitable for both home and market use it appears after a thorough test in many parts of the State for nearly twenty years to be especially well adapted for a market fruit.

Arch Duke was raised by Thomas Rivers, Sawbridgeworth, England, from seed of De Montfort, and was sent out in 1883 . It was first noted in America by the Ontario Fruit Growers' Association in I89r and was imported into the United States by S. D. Willard' ${ }^{2}$ of Geneva, New York, about I 892 .

Tree of medium size, upright-spreading, hardy in New York except in exposed locations, very productive; branches smooth, dark ash-gray, with small, raised lenticels; branchlets of medium thickness and length, with long internodes, greenish-red changing to brownish-red, glossy, covered thinly with bloom and with sparse pubescence; lenticels numerous, very small, obscure; leaf-buds large, long, pointed, free; leaf-scars swollen.

${ }^{1}$ Samuel D. Willard was born August 24, 1835, near Cayuga, New York. He was educated in the district school, Canandaigua Academy, and Temple Hall, Geneseo, having been graduated at the last named place in 1854 . After a successful business career of a decade and a half following his schooling, Mr. Willard engaged in the nursery business in Geneva, New York. He prospered in tree-growing and soon embarked in fruit-growing as well, rapidly attaining distinction as a nurseryman and as a fruit-grower. He early began to specialize in plum culture and soon became one of the leading growers of plums, one of the chief authorities on varieties, and one of the largest importers of new sorts. In 1897 , with Dr. L. H. Bailey as co-author, Mr. Willard prepared Bulletin ${ }_{3} \mathrm{I}$, Notes upon Plums, of the Cornell University Agricultural Experiment Station. In this bulletin Mr. Willard put on record the results of his long experience in growing plums and gave descriptions of seventy varieties, nineteen of which he had imported from Europe. Besides this bulletin he has published but little on plums, but his spoken words regarding them may be found in nearly every report of the two horticultural societies of New York since 1880 , as they are also to be found in the reports of horticultural societies in neighboring states and the provinces of Canada. Besides his work in horticultural societies, Mr. Willard was one of the earliest and foremost institute speakers in New York. He was, too, for many years active in the development of the state fair in New York, having charge of the horticultural department, a position which he also held at the Pan-American Exposition in Buffalo in rgor. For nearly a half-century Mr. Willard has been prominent in his profession in the state and nation; he is known by all eastern fruit-growers and his vigorous and enthusiastic utterances in the press, from the platform and in conversation have made him a favorite a uthority with the fruit-growers of this generation. 
Leaves folded upward, oval or obovate, one and five-eighths inches wide, three and fivc-eighths inches long, thickish, stiff; upper surface dark green, glossy, glabrous, with grooved midrib; lower surface silvery-green, sparingly pubescent; apex and base acute, margin doubly serrate, with small, dark glands; petiole three-quarters inch long, pubescent along one side, tinged red, usually with two large, globose, greenish-yellow glands on the stalk or on the base of the leaf.

Blooming season intermediate in time and length; flowers appearing after the leaves, one and one-eighth inches across, in the bud creamy-yellow changing to white when expanded; borne in scattering clusters on lateral buds and spurs, singly or in pairs; pedicels nine-sixteenths inch long, glabrous, green; calyx-tube greenish, campanulate, glabrous; calyx-lobes obtuse, pubescent on both surfaces, glandular-serrate and with marginal hairs, slightly reflexed; petals obovate or oval, crenate, with short, broad claws; anthers ycllowish, with a trace of pink; filaments five-sixteenths inch long; pistil glabrous, equal to the stamens in length.

Fruit latc, season very short; one and three-quarters inches by one and threeeighths inches in size, long-oval, slightly compressed and necked; cavity shallow, narrow, compressed, abrupt; suture shallow and rather broad, prominent; apex elongated; color reddish-purple changing to dark blue at full maturity, overspread with thick bloom; dots numerous, small, brownish-russet, inconspicuous; stem often inserted at one side of the base, five-eighths inch long, glabrous, adhering well to the fruit; skin tough, adhering; flesh deep golden-yellow often a little reddish, juicy, coarse, firm, but somewhat tender, sweet, pleasant and sprightly; good; stone free, the cavity larger than the pit, one and one-eighth inches by five-eighths inch in size, long-oval, necked, abruptly tipped at the apex, often reddish, rough; ventral suture broad, blunt, slightly furrowed; dorsal suture with an indistinct shallow groove.

\section{ARCTIC}

\section{Prunus domestica}

I. Downing Fr. Trees Am. 3d App. 182. I881. 2. Am. Pom. Soc. Cat. 38. r 88 r. 3. Country Gent. 49:106. 1884. 4. Am. Pom. Soc. Rpt. 96. 1887. 5. Mich. Pom. Soc. Rpt. $289,290$. 1839. 6. Gard. \& For. 6:526. 1892. 7. Can. Hort. 16:301. 1893. 8. Mich. Sta. Bul. 103:35. 1894. 9. Ont. Fr. Exp. Sta. Rpt. 120. 1896. 10. Cornell Sta. Bul. 131:189. I897. 11. Ohio Sta. Bul. х13:160. 1899. 12. Wich. Sta. Bul. 169:241, 242. 1899. 13. Can. Exp. Farm Bul. 43:33. 1903. 14. Budd-Hansen Am. Hort. Man. 304. 1903. 15. Ga. Sta. Bul. 67:278. I904. 16. Ohio Sta. Bul. 162:256, 257. 1905.

Moore Arctic 8, 15. Moore's Arctic 1, 2, 3, 4, 5, 6, 7, 9, 10, I1, 16. Moore's Arctic, 13, 14.

Arctic is very generally supposed to be preeminent in two qualities, hardiness and productiveness. On the grounds of this Station it is both hardy and productive and from its behavior here it might well be recommended for these qualities, but as to its hardiness elsewhere pomologists do not agree. In the references given above, Downing says it is the hardiest plum known; in Michigan it is reported very tender in the nursery row; 


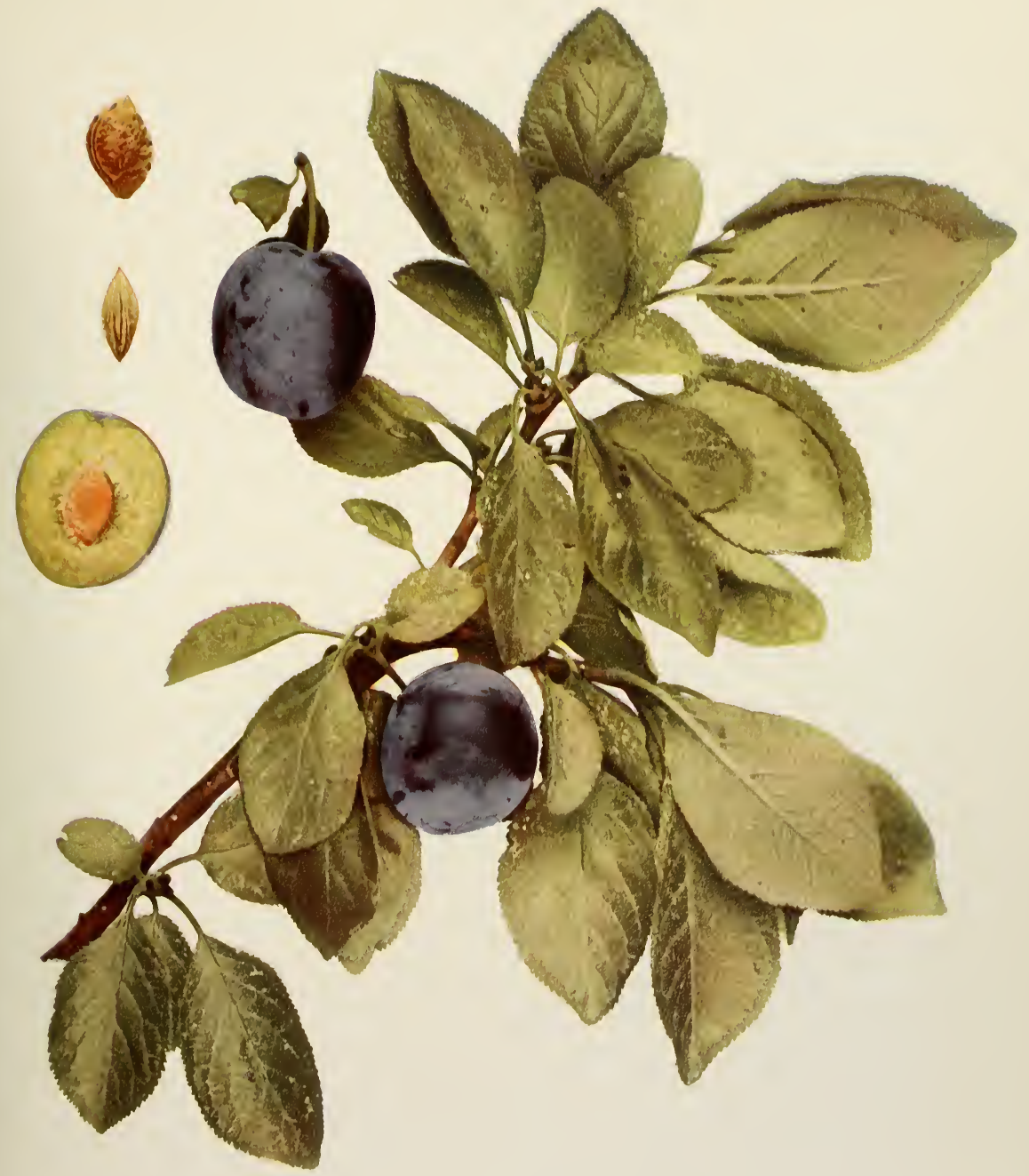

ARCTIC 

a Canadian writer says it is not hardy enough for Canada; and it is reputed in the prairie states to be not hardier than Lombard. The place of its origin, where few plums are grown, and the fact that it is one of but few that can be grown in parts of Canada and New Brunswick establish the claim that it is one of the hardiest of the Domesticas, possibly not more so, however, than Lombard, Voronesh and a few others. The small size and mediocre quality of the fruit and the dwarfish trees should rule Arctic out where less hardy varieties can be grown.

This variety was first noted in $\mathrm{I} 88 \mathrm{I}$ by Downing who says it originated on the grounds of A. T. Moore, Ashland, Maine, about forty miles north of Bangor. The parentage of Arctic is unknown. According to the originator, it was grown from a seed of a medium sized blue plum bought at a fruit-stand in Boston. In I88 I Arctic was added to the American Pomological Society catalog, where it still remains.

Tree small, of medium vigor, upright-spreading, very hardy, productiye, an early bearer, subject to attacks of fungi; branches somewhat rough, dark ash-gray, with small lenticels; branchlets strongly inclined to develop spurs and blossom-buds, short, slender, with short internodes, greenish-red changing to dark brownish-drab, dull, sparingly pubescent, with inconspicuous, raised lenticels; leaf-buds short, obtuse, appressed.

Leaves obovate or oval, two inches wide, three and three-eighths inches long; upper surface dark green, covered with numerous hairs, the midrib grooved; lower surface silvery-green, pubescent; apex abruptly pointed or acute, base acute, margin finely serrate, with small, black glands; petiole five-eighths inch long, tinged red, pubescent, with from one to four globose, green glands usually at the base of the leaf.

Blooming season of medium length; flowers appearing after the leaves, one and three-sixteenths inches across, in the bud creamy-yellow changing to white as the petals expand; borne in clusters on lateral buds and spurs, singly or in pairs; pedicels fiveeighths inch long, pubescent, greenish; calyx-tube green, campanulate, pubesccnt; calyx-lobes narrow, obtuse, pubescent on both surfaces, serrate, with ciliate margins, reflexed; petals narrow-obovate or oval, crenate, short-clawed; anthers yellowish; filaments one-half inch long; pistil pubescent at the base, shorter than the stamens.

Fruit mid-season, ripening period long; one and three-eighths inches by one and one-quarter inches in sizc, oval or ovate, slightly swollen on the suture side, compressed, halves equal; eavity very shallow and narrow, abrupt; suture shallow, indistinct; apex roundish; color dark purple becoming purplish-black at full maturity, covered with thick bloon; dots numerous, small, russet, inconspicuous, clustered about the apex; stem slender, seven-eighths inch long, pubescent, adhering to the fruit; skin of medium thickness and toughness, separating readily; flesh light yellow, juicy, coarse and fibrous, somewhat firm but tender, sweetish, mild; fair in quality; stone nearly free, characteristically small, seven-eighth inch by one-half inch in size, oval, flattened at the apex, acute at the base, rough and pitted; ventral suture ridged, faintly winged; dorsal suture broadly and shallowly grooved. 


\begin{abstract}
ARKANSAS
Prunus munsoniana

1. Am. Pom. Soc. Rpt. 162. 1881. 2. Cornell Sta. Bul. 38:60, 86. 1892. 3. Tex. Sta. Bul. 32:478. 1894. 4. Wis. Sta. Bul. 63:27. 1897. 5. Waugh Plum Cult. 192, 194 fig. 1901. 6. Budd-Hansen Am. Hort. Man. 293. 1903. 7. Ia. Hort. Soc. Rpt. 488.1904.

Arkansas Lombard 1, 2, 3, 4, 7. Arkansas Lombard 5, 6.
\end{abstract}

Arkansas, as the synonymy shows, originally, and even now, usually has Lombard as a suffix, but the name is misleading as the plum is in no wise like a Lombard and following the rules of the American Pomological Society it has been dropped in The Plums of New York. On the grounds of this Station, Arkansas is one of the most valuable plums of its species, being unusually attractive in size, color and shape and one of the best in quality of its kind. Its chief fault is a lack of robustness in the tree. While it would not prove profitable as a market plum in New York, it could be well planted in a commercial orchard in regions where native plums must be grown, and in New York it would at least add a pleasing variety to any collection of plums. This variety was brought to notice by T. V. Munson in I88I. It originated in Arkansas and was introduced by J. D. Morrow \& Sons of that state.

Tree small, flattened, spreading, dense-topped, symmetrical, hardy, productive, somewhat subject to shot-hole fungus; trunk shaggy; branches rough, zigzag, sparingly thorny, dark ash-gray, with numerous lenticels; branchlets slender, with very short internodes, greenish-red changing to reddish-brown, glossy, glabrous, with few, conspicuous, raised lenticels; leaf-buds small, short, obtuse, free.

Leaves folded upward, lanceolate, peach-like, one and one-quarter inches wide, three and one-half inches long, thin; upper surface light green, smooth, glabrous, with grooved midrib; lower surface pale green, sparingly pubescent along the midrib and larger veins; apex taper-pointed, base acute, margin finely serrate, with light brown glands; petiole one-half inch long, slender, pubescent on one side, dull red, with from one to six small, globose, yellow or brownish-red glands.

Blooming season late and long; flowers appearing after the leaves, five-eighths inch across, in the buds creamy-yellow changing to white as they unfold; with a strong disgreeable odor; borne in very dense clusters on lateral buds and spurs, in threes or fours; pedicels one-half inch long, slender, glabrous, greenish; calyx-tube green, campanulate, glabrous; calyx-lobes short, sparingly pubescent on the inner surface, glandular-serrate, faintly hairy and with a trace of red on the margin, erect; petals obovate, crenate, with narrow claws, somewhat hairy at the base; anthers yellowish; filaments nearly one-quarter inch in length; pistil glabrous, slightly shorter than the stamens.

Fruit early, season very long; one inch by seven-eighths inch in size, roundishovate, halves slightly unequal; cavity shallow, flaring, regular; suture an indistinct 


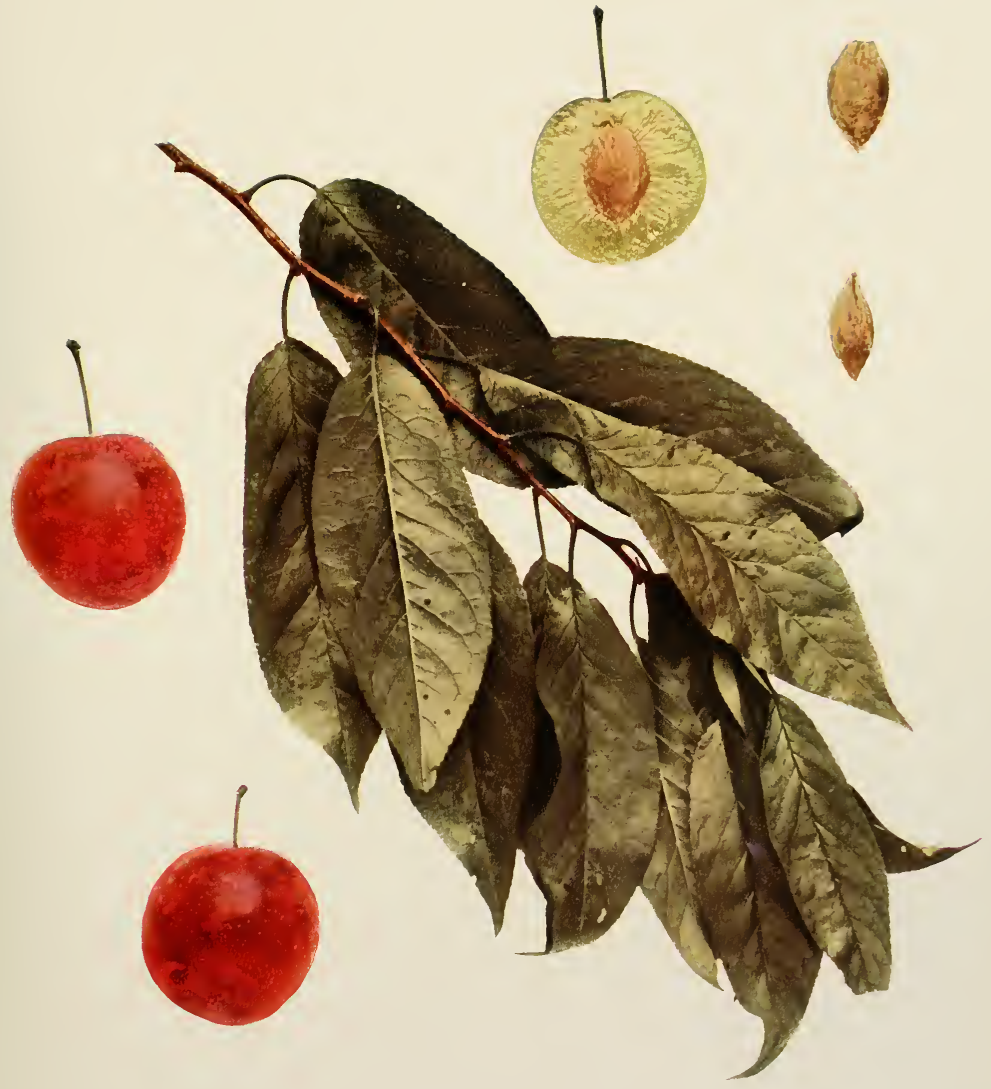



line; apex roundish or pointed; color bright currant-red, with thin bloom; dots smallish, white, conspicuous, clustered about the apex; stem very slender, five-eighths inch long, glabrous, not adhering to the fruit; skin thin, tough, bitter, separating readily; flesh orange-yellow, juicy, fibrous, somewhat tender and melting, sweet at the skin but sour at the center, aromatic; good; stone clinging, three-quarters inch by one-half inch in size, oval, flattened and prolonged at the base, sharp-tipped at the apex; ventral suture acute, faintly ridged; dorsal suture acute.

\section{AUTUMN COMPOTE}

\section{Prunus domestica}

I. McIntosh Bk. Gard. 2:533. 1855. 2. Gard. Chron. 26:364. 1866. 3. Hogg Fruit Man. 351. 1866. 4. Downing Fr. Trees Am. 897. 1869. 5. Mas Le Verger 6:71, fig. 36. 1866-73.

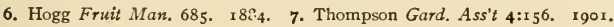

Autumn Compote 5. Compote d'Automne 5.

This plum is well and favorably known in England, but it is scarcely grown in America, though it has much in the character of its fruit at least to recommend it. The plums are attractive in appearance and while not of the highest flavor are yet far above the average in the qualities which make a good dessert fruit, while for culinary purposes it ranks among the best. The trees are productive, hardy and fairly vigorous and may be especially noted as holding their crop well. Autumn Compote is a seedling of Cooper, raised by Thomas Rivers, Sawbridgeworth, England, about i 840 .

Tree of medium size and vigor, spreading, rather low and open-topped, hardy, very productive; branches smooth, dark brownish-gray, with lenticels intermediate in number and size; branchlets few, slender, very short, with long internodes, greenishred changing to dark brownish-red, dull, sparingly pubescent early in the season, becoming heavily pubescent later, with few, inconspicuous, small lenticels ; leaf-buds long, pointed, free.

Leaves drooping, folded backward, long-oval or obovate, two and one-eighth inches wide, four and one-fourth inches long, thick; upper surface dark green, smooth, hairy, with deeply grooved midrib; lower surface pale green, pubescent; apex acute, base tapering, margin crenate, eglandular; petiole thick, one-half inch long, tinged red, glandless or with from one to four globose, greenish-yellow, large glands usually on the stalk.

Season of bloom medium, short; flowers appearing after the leaves, one and onequarter inches across, in the buds creamy-yellow changing to white as the flowers open; borne in clusters on short lateral spurs, singly or in pairs; pedicels nearly one-half inch long, glabrous, green; calyx-tube greenish, campanulate, glabrous; calyx-lobes broad, obtuse, glandular-serrate, sparingly pubescent on both surfaces, reflexed; petals oval, narrowly dentate, with very short and broad claws; anthers yellowish; filaments nearly seven-sixteenths inch long; pistil glabrous, longer than the stamens. 
Fruit late, ripening period of medium length; one and five-eighths inches by one and three-eighths inches in size, oval or slightly ovate, halves unequal; cavity shallow, narrow, abrupt; suture shallow, a distinct line; apex roundish or slightly pointed; color purplishred over a yellow ground, covered with bloom of medium thickness; dots numerous, small, light russet, conspicuous; stem glabrous, adhering to the fruit; skin thin, tender, separating readily; flesh golden-yellow, dry, firm but tender, sweet, not high in flavor; fair in quality; stone clinging but not tenaciously, one inch by five-eighths inch in size, irregularly and broadly ovate, flattened, roughish, slightly compressed and necked at the base, blunt or acute at the apex; ventral suture narrow, winged, strongly furrowed; dorsal suture acute or faintly furrowed.

\section{BARTLETT}

\section{Prunus triflora $\times$ Prunus simonii}

1. Cal. State Bd. Hort. 53. 1897 . 2. Vt. Sta. Bul. 67:7. 1898. 3. Burbank Cat. 1899 . 4. Can. Hort. $25: 41$ r. 1902. 5. Ga. Sta. Bul. 68:6. 1905. 6. De Vries Plant Breeding 226. 1907.

Bartlett was grown by Burbank from a cross of Prumus simonii with Delaware, the latter one of his earliest hybrids. The originator disposed of the variety in 1899 and it immediately became popular with nurserymen and was soon offered for sale in all parts of the United States. Fruitgrowers have not received it so well, however, and most of those who have tried it have discarded it or hold the variety as a curiosity. The fruit is attractive in appearance and the Bartlett pear flavor is agreeable, but the skin cracks badly in this State and the flesh is too soft for shipping. The tree with its stiff, upright branches resembles a Lombardy poplar and with its bright, glossy green foliage is an attractive ornamental. It is still further peculiar in bearing thick clusters of flowers at the ends of lateral spurs.

Tree lacking in size and vigor, upright, open-topped, not very hardy, productive; branches rough, with numerous fruit-spurs; branchlets slender, short, glabrous throughout the season; leaf-buds plump; leaves folded upward, oblanceolate, one and one-half inches wide, three and one-quarter inches long, thin; margin finely serrate, in two series, eglandular or with small, dark glands; petiole slender, with from one to four small glands; blooming season early, long; flowers appearing before the leaves.

Fruit very early; one and three-eighths inches by one and one-quarter inches in size, long-cordate to slightly oval, dark purplish-red over yellow, covered with thick bloom; skin tender, bitter; flesh yellow, not very juicy, tender, sweet, with a peculiar but pleasant flavor; of good quality; stone clinging, seven-eighths inch by one-half inch in size, elongated-ovate, narrow, blunt at the base, long drawn out at the apex, the surfaces rough. 


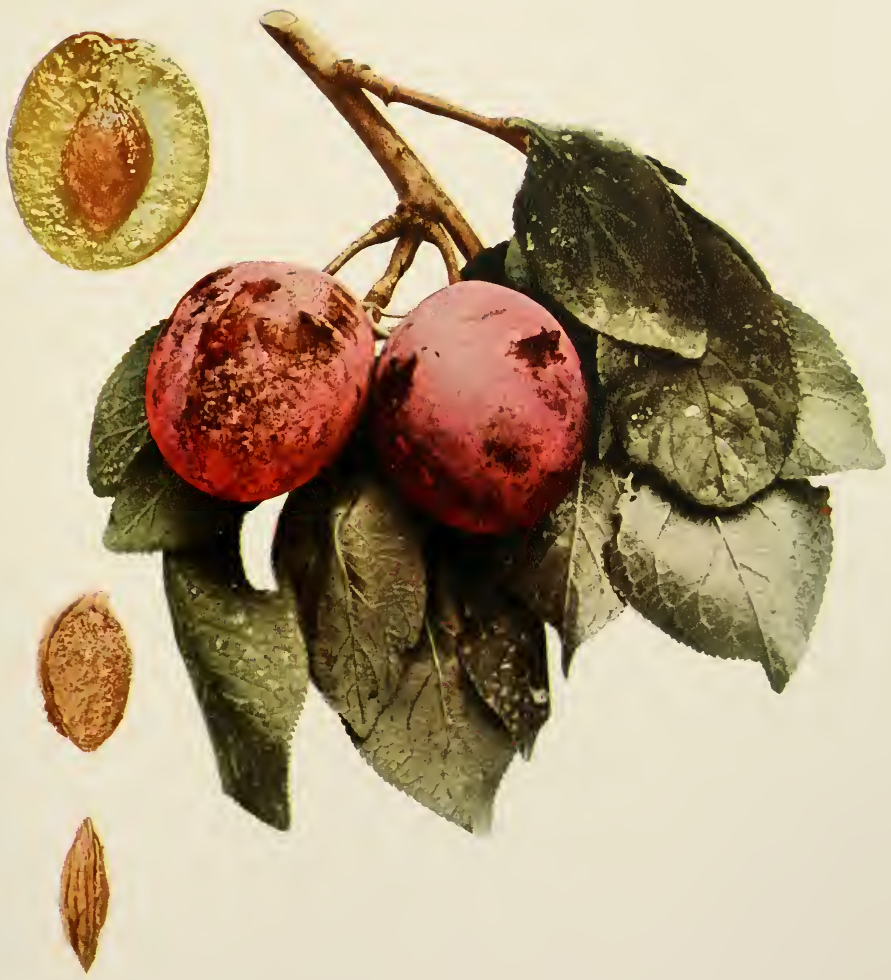





\section{BASSETT}

\section{Prunus marilima}

1. Gard. Mon. 17:335. 1875. 2. Cornell Sta. Bul. 38:75. 1892, 3. Bailey Ev. Nat. Fruits 214. I898. 4. Waugh Plum Cult. 229. 1901. 5. Ohio Sta. Bul. 162:254, 255. 1905. 6. S. Dak. Sta. Bul. 93 :10. 1905 .

Bassett's American 2, 3. Bassett's American 4.

Bassett, the best known of the few cultivated varieties of Prumus maritima, was found growing wild in New Jersey and was turned over to a nurseryman, Wm. F. Bassett of Hamilton, New Jersey, who introduced it in 1872 . After its introduction it became somewhat popular in the West, gaining quite a reputation as being "curculio proof." However, its marked inferiority to varieties of other species, in both size and quality, has now banished it from all commercial plantings. The following description is compiled.

Tree vigorous, spreading. Fruit late mid-season; very small, roundish, dull red, covered with thin bloom; skin thick, tough; flesh greenish-yellow; quality poor; stone of medium size, roundish, smooth, free.

\section{BAVAY}

\section{Prunus domestica}

I. Gard. Chron. 6:65. 1846. 2. Mag. Hort. 12:340. 1846, 3. Horticulturist 1:527, 1846. 4. Lee Gen. Farmer 10:24I. 1849. 5. Thomas Am. Fruit Cult. 328. 1849. 6. Elliott Fr. Book 423. 1854. 7. Am. Pom. Soc. Cat.210. 1856. 8. Downing Fr. Trees Am. 370. fig. 1857. 9. U.S. D. A. Rpt. 190, P1. XII. 1865. 10. Hogg Frut Marr. 379. 1866. I1. Downing Fr. Trees Am. 897. 1869. 12. Pom. France 7:No. 6. 1871. 13. Mas Le Verger 6:93, fig. 47. 1866. 14. Oberdieck Deut. Obst. Sort. 437. 1881. 15. Cat. Cong. Pom. France 363. 1887. 16. Rev. Hort. 515. 1888. 17. Nathieu Nom. Pom. 422. 1889. 18. Mich. Sta. Bul. 129:32, 33. 1896. 19. Cornell Sta. Bul. 131:191. 1897. 20. Nich. Sta. Bul. 169:241, 242. 1899. 21. Waugh Plum Cult. 96. 1901. 22. Va. Sta. Butl. 134:40. 1902. 23. Ohio Sta. Bul. 162:241. 1905.

Bavay's Green Gage 17, 21. Bavay's Green Gage II. Bavay's renkloie 12. Bavay's Reine Claude 17. Bavays Reine-Claste 13. De Bavay 15. Monstreuse de Bavay 15. Monstrueuse de Bavay 10, I1, 12, 17. Prune de Bavay 12, 17. Queen Claude of Bavay 6. Reine Claude 21, 23. ReineClaude de Bavay 2, 3, 4, 5, 7, 8, 9, 10, 12, 13, 15, 16, 19. Reine-Claude de Bavay 6, II, 13 1 17, 18, 21. Reine-Claude Monstreuse de Bavey I. Reine-Claude Monot 17 . Reine-Claude von Bavays 14. St. Claire so. Saint Cluir 11, 17. Sainte-Claire 17. Saint-Claire 12.

Bavay is one of the best of the green plums-a worthy rival in all respects and in some superior to its parent Reine Claude. It is unexcelled as a dessert plum and its delicious flavor is retained in cooking, making the somewhat rare combination of a first rate dessert and a first rate culinary fruit. Bavay is not only satisfactory in the qualities which make it desirable to the consumer but it is a good market plum for it both keeps 
and ships well. The flavor is not quite equal to that of Reine Claude, one of the best of all plums in quality, but in tree-characters the Bavay surpasses the older variety. The trees bear young, annually and heavily, sometimes too heavily, and while not as hardy, as large, as robust or as long-lived as could be wished, yet in these respects they are superior to those of most of the varieties of Reine Claude plums. Some horticulturists recommend that the Bavay be top-worked on a more vigorous, hardy and longer-lived stock but the behavior of trees so treated in this vicinity makes top-working a very doubtful expedient. Lombard is usually recommended as a stock upon which to work it. Bavay is indispensable in home orchards and can be recommended for much more general planting in commercial orchards.

This variety is a seedling of Reine Claude produced by Major Esperin of Malines, Belgium, about I832, and dedicated by him in 1843 , to M. De Bavay, Director of the Royal Nurseries, at Vilvordes, near Brussels. Though this variety is distinct from its parent in tree-characters, in having a later season, smaller fruit and a different flavor, the two plums have become confused by many nurserymen and horticulturists. In 1856 , the American Pomological Society placed Bavay on its fruit catalog list where it still remains.

Tree of medium size and vigor, upright-spreading, open-topped, hardy, very productive, somewhat susceptible to sunscald; branches smooth except for the few, large, raised lenticels, light ash-gray; branchlets medium in thickness and length, with internodes of variable length, dull brownish-red, pubescent, with numerous, inconspicuous, small lenticels; leaf-buds large, long, pointed, appressed.

Leaves folded backward, oval, or slightly obovate, wide, long, thick; upper surface nearly smooth, covered sparsely with hairs; lower surface thickly pubescent, especially along the midrib and larger veins; apex acute; margin crenate, glandless; petiole thick, long, tinged lightly with red, glandless or with from one to three globose, greenishyellow glands on the stalk or base of the leaf.

Blooming season intermediate in time and length; flowers appearing after the leaves, one and one-eighth inches across, whitish or creamy at the apex of the petals; borne on lateral buds and spurs, singly or in pairs; pedicels three-eighths inch long, pubescent, green; calyx-tube greenish, obconic, pubescent at the base; calyx-lobes rather broad, obtuse, pubescent on both surfaces, glandular-serrate, reflexed; petals broadly obovate, crenate, tapering below to short, broad claws; anthers yellowish; filaments three-eighths inch long; pistil pubescent on the ovary, longer than the stamens.

Fruit late, season long; of medium size, roundish-oval, halves equal; cavity intermediate in depth and width, abrupt; suture a line; apex roundish; color greenishyellow changing to dark straw-yellow, obscurely streaked and splashed, covered with 


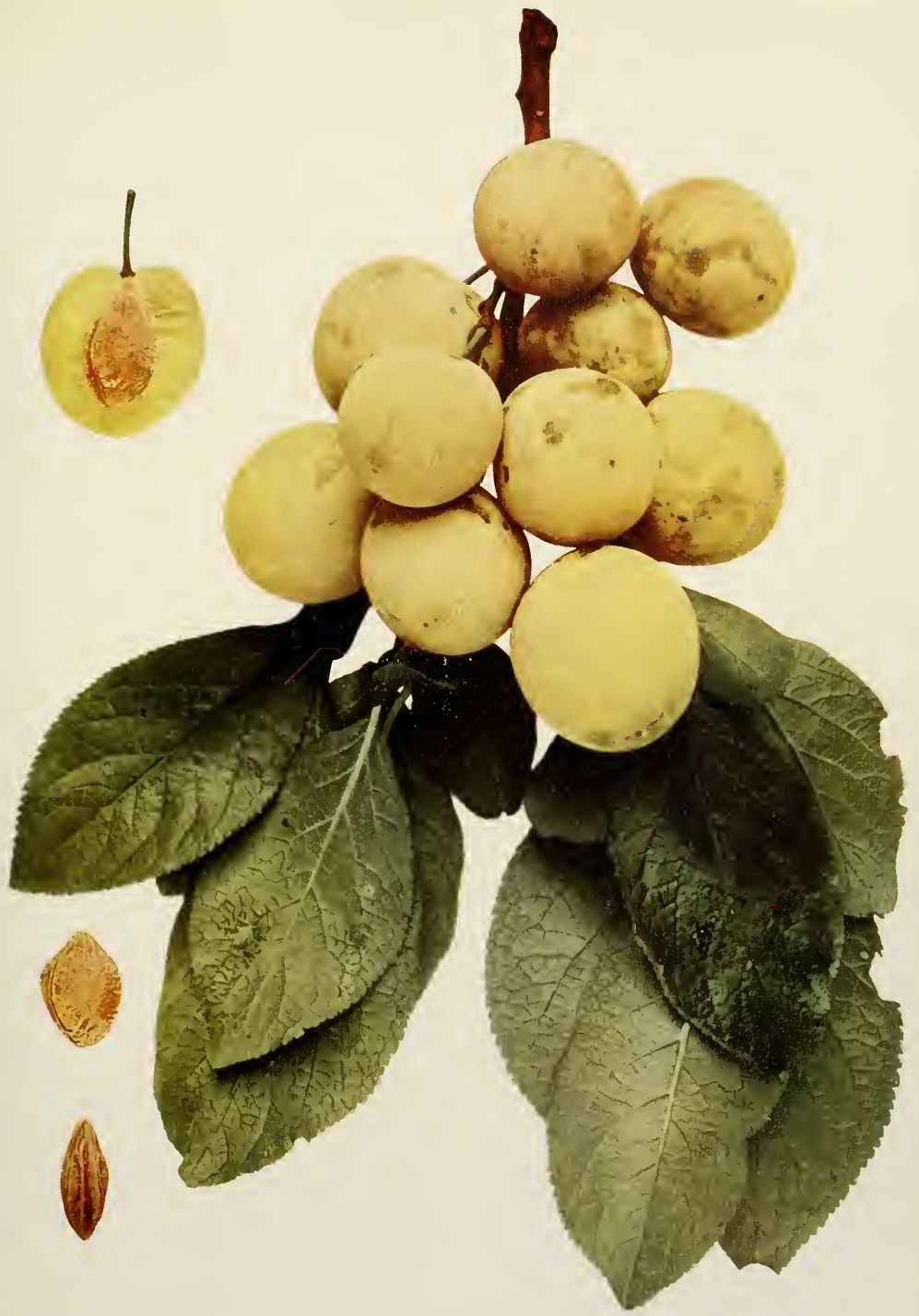



thin bloom; dots numerous, small, grayish, obscure, clustered about the apex; stem thick, short, pubescent, adhering well to the fruit; skin rather tough, separating readily; flesh rich golden-yellow, juicy, slightly fibrous, tender, sweet, pleasant flavor; very good; stone free, seven-eighths inch by five-eighths inch in size, oval, slightly necked, blunt at the apex, with pitted surfaces; ventral suture winged, deeply furrowed; dorsal suture widely and deeply grooved.

\section{BEJONNIERES}

\section{Prunus insititia}

I. Downing Fr. Trees Am. 898. 1869. 2. Cat. Cong. Pom. France 472. 1887. 3. Ibid. 453. 1906.

Des Béjonnières 2, 3. Prune des Béjonnières r.

This variety is so highly prized in France that it is here recommended for trial even though the trees as they grow in this part of New York have not been productive. It is too small for a dessert plum but might become of value here if used as in France for tarts, spices, preserves and drying. The plum originated about 1827 in the nursery of André Leroy, Béjonnieres, Angers, France.

Tree medium in size and vigor, upright-spreading, unproductive; leaf-scars swollen; leaves oval, medium in width and length; margin with small dark glands, finely serrate; petiole with none or from one to six glands, usually on the stalk; flowers appearing after the leaves, tinged creamy-white as they open; borne on lateral buds and spurs, in pairs or in threes.

Fruit late, season of medium length; one and three-eighths inches by one and one-quarter inches in size, obovate, a little necked, yellow, blotched with red on the exposed cheek, covered with thin bloom; stem long; apex strongly depressed; flesh pale yellow, firm but tender, sweet, aromatic; very good; stone semi-clinging, threequarters inch by one-half inch in size, oval.

\section{BELGIAN PURPLE}

\section{Prumus domestica}

1. Downing Fr. Trees Am. 373. 1857. 2. Hogg Fruit Man. 351. 1866. 3. Pom. France 7: No. 27 . 1871, 4. Mas Le Verger 6:105. 1866-73. 5. Am. Pom. Soc. Cat. 36. 1877. 6. Cat. Cong. Pom. France 340. 1887. 7. Guide Prat. 153, 352. 1895.

Blene de Perk 4. Bleue de Bergues 3, 7. Blewe de Belgique 1, 7. Bleu de Perque 1. Blane von Belgien 4, 7. Bleu de Bergues 6. Blewe de Peck 6. Belgian Purple 4, 6, 7. Bleue de Belgique 7. Belgische Damascene 7. Bleue de Perck 7. Bleu de Belgique 6. Fertheringham 3 incor. Prune Bleue de Belgique 3.

Belgian Purple is a medium grade plum of little value for dessert but rather highly esteemed for culinary purposes, especially in Europe. It probably has but a small place in American pomology. Concerning 
the origin of the variety, nothing is known although it is generally believed to have originated in Belgium prior to 1850 .

Tree large, vigorous, round and dense-topped, not always hardy, very productive; branchlets numerous, thick, pubescent throughout the season; leaf-scars prominent; leaves flattened or folded upward, oval, one and five-eighths inches wide, three and one-half inches long; margin serrate or crenate; petiole five-eighths inch long, glandless or with from one to two small glands usually at the base of the leaf; flowers nearly one inch across, white, with a peculiar greenish and creamy tinge near the apex of the petals and often splashed with pink towards the base; borne on lateral buds and spurs; calyx-tube thickly pubescent.

Fruit mid-season; medium to below in size, roundish-oval, purplish-black, overspread with thick bloom; flesh rich, golden-yellow, medium juicy, firm, sweet, mild; fair to good; stone nearly free, of medium size, oval, flattened, often with a distinct wing.

\section{BELLE}

\section{Prunus domestica}

1. Horticulturist 10:71. 1855. 2. Downing Fr. Trees Am. 394. 1857. 3. Flor. \& Pom. 144, P1. 1863. 4. Hogg Fruit Man. 351, 384. 1866. 5. Mas Le Verger 6:27, fig. 14. 1866-73. 6. Le Bon Jard. 341. 1882. 7. Barry Fr. Garden 410. 1883. 8. Decaisne \& Naudin Man. Am. des Jard. 4: 382. 9. Mathieu Nom. Pom. 449, 45 1. 1889. Io. Garden 50:295. 1896. II. Rivers Cat. 33. 1898. 12. Fish Hardy-Fr. Bk. 2:55. 13. Thompson Gard. Ass't 4:156. 1901. 14. Waugh Plum Cult. 96. г $90 \mathrm{r}$.

Autumn Beauty II. Autumn Beauty 9. Belle de Septembre 9, II, I4. Belle de Septembre 1, 3, 4, 7, 10, 12, 13. Gros Rouge de Septembre 3, 4, 9. Laurence Early 9. Regina nova 6. ReineClande Ronge 9. Reine-Clande Rouge de Septembre 5, 9. Reine-Claude Rouge of September 2 Reine-Claude Rouge de Van Mons 5, 6, 8. Reine-Clande Rouge de Van Mons 9. Reine-Claude Ronge Van Mons 4, 9. Reine Nova (Berre) 9. Reina Nova 2, 3, 4, 9. Rote Claude 9. Reine Nova 9. Schöne September Königsplaume 9. Van Mons Königspflaume 9. Van Mons Königspflaume 5. Van Mons Red 9. Van Mons' Red 4. Van Mons Red Gage 5, 9.

Belle is an unusually large, handsome plum but unfortunately is not of very high quality. It is much like Pond but is brighter red, a little smaller, less necked, the stem is shorter, the apex more blunt and it is more of a clingstone. European authorities say that Belle is second to none for culinary purposes and its handsome appearance gives it value across the seas as a dessert plum. As Belle grows on the grounds of this Station-it seems not to be found elsewhere in New York-the tree-characters are quite above those in the average variety of plums and when considered with the fine, late fruits, indicate that the variety might be grown with profit for market purposes. It well deserves to be tried by commercial plum-growers.

Belle came from Brussels, Belgium, and was propagated by the famous horticulturist, Van Mons. Nothing further is known of its origin. 


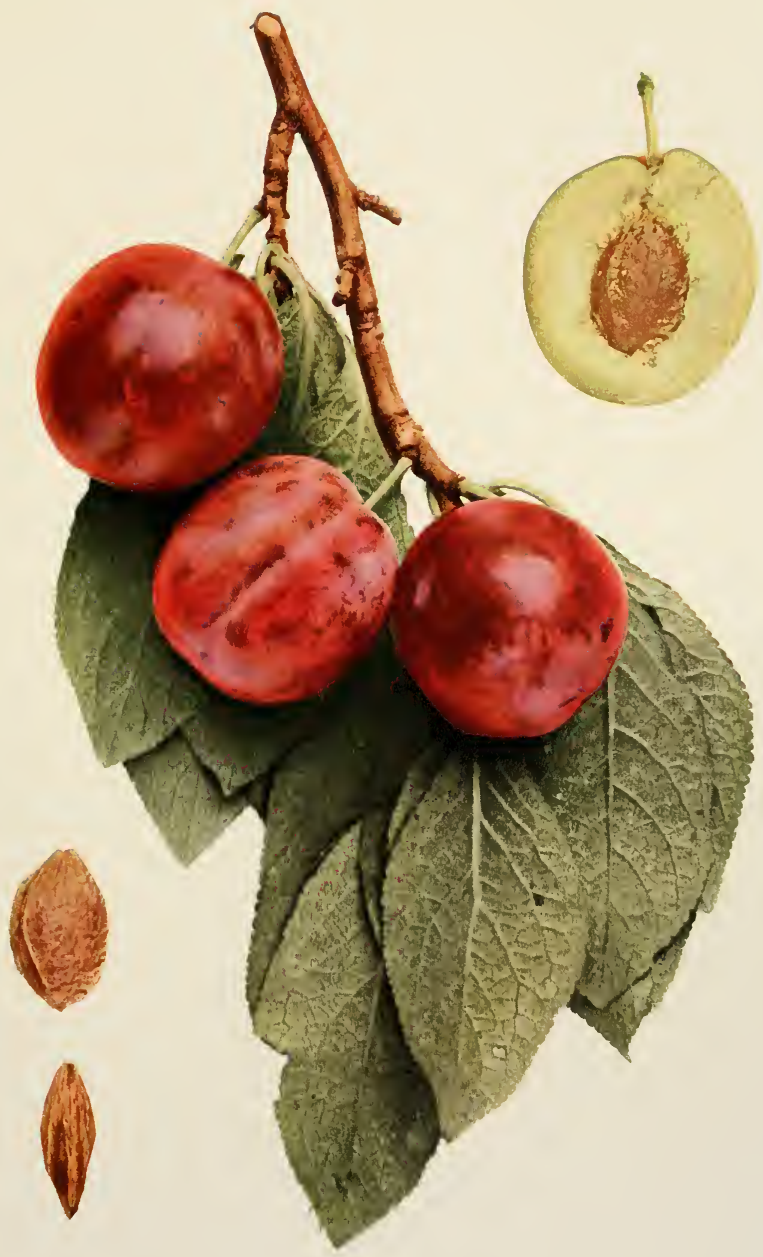

BELLE 

Tree above medium in size, vigorous, upright, open-topped, hardy, productive; branches smooth, dull dark ash-gray, with small, numerous, raised lenticels; branchlets thick, with short internodes, green changing to brownish-red, often marked with scarfskin, dull, very pubescent early in the season becoming less pubescent as maturity advances, with numerous, small lenticels; leaf-buds of medium size and length, conical, free.

Leaves flattened or folded upward, obovate, one and seven-eighths inches wide, four and one-half inches long, thick, leathery; upper surface dark grcen, with deeply grooved midrib, sparingly hairy; lower surface silvery-green, pubescent; apex acute, base cuneate, margin shallowly but broadly crenate, with few small dark glands; petiole one and one-eighth inches long, thick, pubescent, tinged with light red, glandless or with one or two small, globose, yellowish glands on the stalk or base of the leaf.

Blooming season late and long; flowers appearing after the leaves, one and oneeighth inches across, the buds cream-tipped changing to white on expanding; borne on lateral buds and spurs, usually singly; pedicels about seven-sixteenths inch long, thick, pubescent, green; calyx-tube greenish, campanulate, glabrous except towards the base; calyx-lobes above medium in width, obtuse, slightly pubescent on both surfaces, glandular-serrate, erect; petals broadly ovate, crenate, with short, broad claws; anthers yellowish; filaments five-sixteenths inch long; pistil glabrous, equal to the stamens in length.

Fruit late, season of medium length; one and seven-eighths inches by one and threequarters inches in size, roundish-oval, slightly compressed, halves nearly equal; cavity shallow, flaring; suture shallow, rather wide, prominent; apex roundish or depressed; color light purplish-red over a greenish-yellow ground, overspread with thin bloom; dots numerous, small, russet, inconspicuous; stem one-half inch long, thickly pubescent, adhering strongly to the fruit, with fleshy ring about the base; skin of average thickness and toughness, sour, separating from the pulp; flesh pale yellow, juicy, coarse, firm, sweet at the skin, but tart at the center, pleasant, aromatic; good; stone clinging, one and three-sixteenths inches by three-quarters inch in size, oval, turgid, blunt at the apex, with rough and pitted surfaces; ventral suture winged, with few but prominent ridges; dorsal suture widely and deeply grooved.

\section{BERCKMANS}

\section{Prunus triflora}

1. Ga. Hort. Soc. Rpt. 53, 99. 1889. 2. Cornell Sta. Bul. 62:20, 1894. 3. Ga. Hort. Soc. Rpt. 95. 1895. 4. Cornell Sta. Bul. 106:43, 44. 1896. 5. Rural N. Y. 56:614. 1897. 6. Am. Pom. Soc. Rpt. 26. 1897. 7. Cornell Sta. Bul. 175:138, 143. 1899. 8. Rural N. Y. 62:582, 1903. 9. Ga. Sta. Bul. $68: 9,28.1905$.

Botan of some 2, 4. Botan White 6. Sweet Botan I. Sweet Botan 2, 3, 4. True Sweet Botan 2, 4, 9. White-fleshed Botan 1. White-fleshed Botan 2, 4, 8, 9.

This variety was introduced by Luther Burbank in 1887 from imported stock. P. J. Berckmans ${ }^{1}$ of Augusta, Georgia, who had secured some

1 Prosper Julius A. Berckmans was one of the noted horticulturists and pomologists of the generation just passing. He was born at Aerschat, near Antwerp, Belgium, October 13, $188_{30}$, 
Botan trees from Burbank, noted that this plum differed from the rest and, in order to distinguish it, named it Sweet Botan. The nomenclature of Botan was confused and indefinite and Bailey, in I894, renamed the new plum Berckmans. As it is very similar to Abundance, still more confusion has arisen in regard to it. Compared with Abundance, Berckmans is more spreading in growth; fruit less pointed, with dryer and more insipid flesh; color brighter red and the stone usually freer; but it is neither as productive nor as free from rot. In 1897 the American Pomological Society placed the variety on its fruit list. As Berckmans is inferior to Abundance and ripens at the same season, it is not worth recommending for general planting. It is to be regretted that so distinguished a horticulturist as Mr. Berckmans is not to have his name perpetuated in a better plum than the one named in his honor.

\section{BERGER}

\section{Prunus triflora}

1. Cornell Sta. Bul. $62: 20,21$ fig, 31. 1894. 2. Ibid, $106: 45,62,67.1896$. 3. Ibid, $139: 46$. 1897. 4. Ibid, $175: 132,133$ fig. 26. 1899. 5. Texas Sta. Bul. $32: 486$ fig. 7, 490, 492, 1899.6. W. N. Y. Hort. Soc. Rpt. 92. 1899. 7. Ohro Sta. Bul. 162:248 fig., 254, 255.1905.

Honsmomo 1, 2, 3, 4, 5. Red Nagate 1, 2 incor. Satsuma 1, 2 incor. Shiro Smomo 1, $2,5$. Strawberry 1, 3, 6. Strawberry 2, 4. Uchi Bene 6. Uchi-Beni 1, 2, 5. Uchi-Beni 3, 4. UraBeni 1, 2, 3, 4, 5.

his father being Dr. Louis Edouard Berckmans, author of the splendid pomological work, Album de Pomologie, and as noted in Europe as was the son in America, in horticulture and pomology. The younger Berckmans was educated in Tours, Belgium and Paris, attaining distinction as a student in botany. In $185^{\circ}$ father and son came to America and the following year settled at Plainfield, New Jersey. Six years later the son moved to Augusta, Georgia, and established near that place a horticultural plantation, which he called "Fruitlands," the nursery of which has become famous throughout the world. Soon after locating in Georgia, Mr. Berckmans became interested in horticultural organizations and later his activities were extended to the promotion of horticulture in the Nation. In 1859 he became a member of the first horticultural society in Georgia. In 1876 he helped to organize and was the first president of the Georgia State Horticultural Society, a position which he held until his death. In 1860 he became a member of the American Pomological Society and was at once intrusted with important committee work in that organization. His work here was done so well that in 1887 he was elected president of the society and later was four times reelected. Mr. Berckmans was a member of a number of state and national horticultural and scientific organizations other than those named and was an honorary member of many similar societies in Europe. In 1893 he was chosen to make the opening address of the Horticultural Congress held at the World's Fair in Chicago that year. Mr. Berckmans was eminent in entomology as well as in botany and horticulture and was interested in all the sciences. Through much reading, study and travel he became versed in literature and art as well as science. Mr. Berckmans' fellow-workers in horticulture, his business associates and the patrons of his nursery, justly esteemed him for his amiability, integrity and public spiritedness. At his death, November 8, 1910, a well spent life was ended. 
At first sight Berger is a wholly insignificant plum, being no larger than a sweet cherry; but the variety is so distinct in several characters that every collection should have a trec or two of it and the plum-breeder will find it most interesting and valuable. Its peculiarities are: A flavor quite distinct from that of any other Triflora plum; its cherry-like appearance; early ripening, maturing in this State shortly after the middle of July; its pronounced upright habit of growth; its light green foliage; and its habit of bearing its fruit close to the old wood. In common with many other Japanese varieties, the nomenclature of Berger is badly confused. According to Bailey, who received specimens of this variety from various sections of the country, H. H. Berger \& Company of San Francisco sent out this plum under several names. Berckmans of Georgia received it as Red Nagate; N. S. Platt of Connecticut as Satsuma; to another person in the South it came as Shiro Smomo, while T. V. Munson of Texas grew it under the name of Berger, a term finally adopted by Bailey. In the meanwhile, Stark Brothers of Louisiana, Missouri, introduced a plum very similar to this under the name Strawberry but the variety was dropped by them in 1893 . Whether or not this "Strawberry" or "Uchi-Beni," as it was sometimes called, was really the Berger it is impossible to say but it is certain that both of these names have been applied to the Berger. The following description is a compilation.

Tree vigorous, upright, open-topped, medium hardy; leaves narrow, light colored; blooming season early; flowers white, small.

Fruit very early; unusually small, roundish but truncate at the ends, attractive light to dark red, covered with thick bloom; flesh firm, meaty, light yellow, sweet, of pleasant flavor; fair to good; stone very small and cherry-like, free, with smooth surfaces.

\section{BLACK BULLACE}

\section{Prunus insititia}

x. Parkinson Par. Ter. 576, 578. 1629. 2. Gerard Herball 1498. 1636. 3. Miller Gard. Dict. 3:1754. 4. Abercrombie Gard. Ass't 13. 1786. 5. Deane N. E. Farmer Dict. 266.1797 .6$. Miller Gard. Dict. 3:1807. 7. Lond. Hort. Soc. Cat. 144. 1831. 8. Phillips Com. Orch. 306. 1831. 9 Prince Pom. Man. 2:105. 1832. xo. Hogg Fruit Man. 689. 1884. x. Jour. Hort. 27:476. 1874. 12. Garden 59:226. 1901 .

Black Bulleis I. Bullesse 2, Earley's November II.

This variety is interesting chiefly as an early type of the Insititia plums, its thorny branches, wayward growth, small and austere fruit, all bespeaking a wild fruit. The plums when ripened by frost are not unpleasant to taste and are borne in prodigious quantities. The variety, how- 

one-half inch long, pubescent, adhering to the fruit; skin of medium thickness and toughness, slightly astringent, adhering somewhat; flesh greenish-yellow, juicy and fibrous, firm, sour or agreeably tart late in the season; stone clinging, three-quarters inch by one-half inch in size, irregularly oval or ovate, slightly necked at the base, acute at the apex, with pitted surfaces; ventral suture swollen, blunt; dorsal suture acute or partially furrowed.

\section{BLACKMAN}

\section{Prunus hortulana $\times$ Prunus persica}

x. Gara. Mon. 24:82, 1882. 2. Ibid, 29:45, 302. 1887. 3. Cornell Sta. Bul. 38:77. 1892.

Blackman is supposed to be a hybrid between the Wild Goose plum and a peach. According to Bailey, a Mrs. Charity Clark secured plum pits from an orchard of Wild Goose and Washington plums in Rutherford County, Tennessee, about $186_{5}$ and gave them to Dr. Blackman of Nashville of that State. One of the seedlings appeared promising and was disseminated by a local nurseryman under the name Blackman. A rival nurseryman in attempting to procure cions of this variety inadvertently cut them from an adjacent tree, a barren seedling from the same lot of seed. Unfortunately the spurious Blackman received a wide distribution while the true variety remained practically unknown. Afterwards in order to avoid confusion the original Blackman was rechristened Charity Clark under which name it is now known. The tree of the second Blackman is strong and vigorous but rarely produces its plum-like fruit. The foliage is about midway in character between the plum and peach; the fruit-buds are formed abundantly but seldom open. From a horticultural standpoint, the variety is of course worthless but the hybrid, one of the first of its kind, is interesting and worth recording.

\section{BLEEKER}

\section{Prunus domestica}

1. Prince Pom. Man. 25. 1828. 2. Kenrick Am. Orch. 255. 1832. 3. Manning Book of Fruits 104. 1838. 4. Downing Fr. Trees Am. 273. 1845. 5. Am. Pom. Soc. Cat. 54. 1852. 6. Thompson Gard. Ass't 515. 1859. 7. Downing Fr. Trees Am. 899. 1869. 8. Mas Le Verger 6:21. 1866-1873. 9. Hogg Fruit Man. 686. 1884. 10. Mathieu Nom. Pom. 423. I889. I1. Guide Prat. 158, 364. 1895. 12. Waugh Plum Cult. 96. 1901.

Bleecker's I1. Bleecker's German Gage r. Bleecker's German Gage 2. Bleecker's Gage 2, 4. 5, 6, 7. Bleecker's Gage 9, 10, I 1, 12. Bleeker's Gage 3. Blucher's Gage 6. Bleecker's Yellow 7, Bleeker's 10. Bleecker's Yellow Gage 7, 8, Ir. Bleecker's Gage S. Bleeker's Yellow 9. Bleeker's Gelbe Zwetsche II. Bleeker's Gelbe Zwetsche ro. Bleeker's Yellow Gage 9, ro. Bleeker's Gelbe Reine-Claude 10. Bleeker's Gelbe Renklode 11. Bleeker's Yellow 10. German Gage 4, 6, 7, 9, 10, I1. Jaune de Bleeker Io, II. Reine-Claude de Bleeker Io. Reine-Claude de Bleecker 8, II. 
Just why this old and one time popular plum is now so seldom grown cannot be said. It is a delicious dessert plum of the Reine Claude group, much like Yellow Gage but distinguished from it by a longer and stouter stalk. Its tree-charaeters in New York are good and the fruit in all the qualities that make plums desirable is as good as that of most of its class. The variety originated with a Mrs. Bleeker of Albany, New York, about I8 10 from a pit given her by Rev. Mr. Dull of Kingston, New York. This stone had come from Germany and was thought to have been that of a German prune but this is probably an error as the seedlings of that variety come true or nearly so. Bleeker was listed in the catalogs of the American Pomological Society from I 852 to 1897 .

Tree large, vigorous, upright-spreading, open-topped, productive; trunk and branches thick and covered with rough bark; branches slightly pubescent; leaves two and one-quartcr inches wide, four inches long, oval, stiff; upper surface somewhat rugose; margin serrate; petiole five-eighths inch long, thick, tinged red, with from two to three glands usually on the stalk.

Fruit early; nearly one and one-half inches in diameter, roundish-oval, greenishyellow, striped and splashed with green becoming golden-yellow at full maturity, overspread with thin bloom; fiesh golden-yellow, dry, coarse, firm, sweet, mild; of good quality; stone semi-clinging, one inch by five-eighths inch in size, obovate, acute at the apex, medium turgid, with pitted surfaces.

\section{BLUE PERDRIGON}

\section{Prunus domestica}

I. Parkinson Par. Ter. 576. 1629. 2. Rea Flora 208. 1676. 3. Quintinye Com. Gard. 67 , 68, 69. 1699. 4. Langley Pomona 92, Pl. 23 fig. 4. 1729. 5. Duhamel Trait. Arb. Fr. 2:85. 1768. 6. Prince Pom. Man. 2:66. 1832. 7. Downing Fr. Trees Am. 290. 1845. 8. Floy-Lindley Guide Orch. Gard. 280, 293, 383. 1846. 9. U. S. Pat. Off. Rpt. 287 . 1853. Io. Hogg Fruit Man. 687. 1884. II. Mathieu Nom. Pom. 452. 1889. 12. Guide Prat. 154, 361. 1895.

Blue Perdrigon 6, 7, 11, 12. Brignole Violette 7, 10, 11, 12. Battle Monument 10, 11. Blaue Fasanen Pflaumc I1, 12. Blauer Perdrigon 11, 12. Blew Perdrigon 2, 3. 4. Perdrigon 1, 3, 9. Perdrigon Violet 5, 12. Perdrigon Violet 6, 8, 11. Perdrigon Violette 7, 10. Perdigon 8. Perdigevena 8. Violet Perdrigon 4, 6, 7, то, II. Violet Perdrigon 6, 8. Violetter Perdrigon II. Violette Fasanen Pflaume 11. Violette Huhner Pflaume II. Violette Rebhuhn Pfaume II. Violette Fasanenpflaume 12. Violette Huhnerpflaume 12. Violetter Perdrigon 12 . Violettes Rebhuhnerei II, 12.

Early records indicate that the Blue Perdrigon was introduced into England from Italy. Hakluyt, writing in $\mathrm{I}_{5} 82$, says, "Of late time the Plum called the Perdigevena was procured out of Italy, with two kinds more, by the Lord Cromwell, after his travel." Gough, in his British Topography, states that Lord Cromwell introduced the "Perdrigon plum " 
into England in the time of Henry VII. From these accounts it would seem that this plum was established in England some time during the latter part of the Fifteenth Century. For three hundred years it thrived so well in England that writers had no hesitation in pronouncing it their best plum. From England it came early to America. Probably it was included in the shipment of plum pits ordered from England by the Governor and Company of the Massachusetts Bay Colony in New England in 1629 . In spite of its Old World reputation, however, it never found favor here and is now rarely if ever seen even in collections. The older writers mentioned a Black Perdrigon which they considered distinct from the variety under discussion. Inasmuch as all plums until recently were propagated from seed, it is more than likely that there were all gradations in color and that some attempted to classify the darker seedlings as a distinct variety. This hypothesis is borne out by the fact that after grafting and budding became the common method of propagation the so-called Black Perdrigon became extinct. The following description is a compilation.

Tree vigorous, but not always productive; young shoots pubescent; fruit midseason; medium in size, obovate, compressed on the suture side, purple or blue, with thick bloom; stem slender; skin thick, very tough; flesh greenish-yellow, firm, rich, sweet, aromatic; good; stone small, flattened, clinging; fruit hangs on the tree until it shrivels.

\section{BODDAERT}

\section{Prunus domestica}

1. Downing Fr. Trees Am. 2d App. 156. 1876. 2. Am. Pom. Soc. Cat. 36. 1877. 3. Hogg Fruit Man. 687. 1884. 4. Mathieu Nom. Pom. 423. 1889. 5. Lucas Vollst. Hand. Obst. 472.1894. 6. Waugh Plum Cult. 97. I901.

Boddaert's Green Gage 1, 3. Boddart's Green Gage 2. Boddaert's Reine Cla ude 4. Boddaert's Green Gage 4, 6. Reine-Claude de Boddaert 4. Reine-Claude Boddaert I, 3, 4. Reine-Cla ude von Boddaert 4.

Boddaert has much to commend it, the fruit being surpassed by that of but few other plums of its type-that of the Reine Claude. The plums are large, attractive and of very good quality. Since the variety has been known so long it must be that the tree has some fatal defect; otherwise it would be more largely grown. Boddaert is probably a Reine Claude seedling and is of foreign origin, the details of its early history not being known. Downing, in 1876 , first mentioned the variety in America; the following year it was placed on the fruit list in the American Pomological Society catalog. 
Tree large, medium in vigor, upright-spreading, open-topped, productive; trunk rough; branches smooth, except for a few, raised lenticels; branchlets of medium thickness, brash, thinly pubescent; leaves oval, two and one-quarter inches wide, four inches long, thick and leathery; upper surface dark green, rugose; margin crenate, with small dark glands; petiole pubescent, thick, tinged red, usually with two globose glands.

Fruit mid-season; about one and one-half inches in diameter, roundish-ovate, strongly compressed, yellow, mottled with green before full maturity, overspread with thin bloom; stem thickly pubescent; flesh light yellow, dry, meaty, tender, sweet; good in quality; stone semi-free or free, seven-eighths inch by five-eighths inch in size, oval or ovate, turgid, with pitted surfaces.

\section{BRADSHAW}

\section{Prunus domestica}

1. Mag. Hort. 12:341. 1846. 2. Horticulturist 10:15, 253. 1855. 3. Am. Pom. Soc. Rpt. 190, 214 . 1856. 4. Cultivator 8:25 fig. I860. 5. Mas Pom. Gen. 2:3, fig. 2. 1873. 6. Mich. Pom. Soc. Rpt. 303. I878. 7. Am. Pom. Soc. Rpt. 61, Ir8. I883. 8. Hogg Fruit Man. 709. I884. 9. Rural N. Y. 44:103. I885. Io. Me. Pom. Soc. Rpt. I30. I888. I1. Ibid. I44. I889. I2. Mathieu Nom. Pom. 434. 1889. 13. Nich. Sta. Bul. 103:32, 33, fig. 6. I894. 14. Guide Prat. 157, 359. I895. 15. Cornell Sta. Bul. 131:182, I897. I6. Mich. Sta. Bul. 169:242, 244. I899. 17. W. N. Y. Hort. Soc. Rpt. 44:91. 1899. 18. Thompson Gard. Ass't 4:158. 1901. 19. Waugh Plum Cult. 97. 1901. 20. Ont. Fruit Exp. Sta. Rpt. x6, I7 fig. 1902. 21. Va. Sta. Bul. 134:40. 1902. 22. Can. Exp. Farm Bul. 43:33. 1903. 23. Ohio Sta. Bul. 162:239, 254, 255, 256.1905.

Black Imperial 5, 14. Blue Imperial 5, 14, 19, 20. Bradshaw 9, 14. Grosse Schwarze Kaiser Pflaume 12. Hart Prune 17. Large Black Imperial 8, 14, 18. Large Black Imperial 2, 3, I2. Mooney 9, 17. Niagara 7, 9, 10, I1. Niagara 13, 15, 17, ?19, 20, ?22, 23.

Bradshaw leads all other plums in number of trees in New York, according to a survey of the leading orchards made in the preparation of The Plums of New York. A study of the variety does not justify this popularity. The trees grow rather slowly and are slow in coming into bearing; the fruit is not especially high in quality and in many regions is attacked by brown-rot too freely for profitable orchard culture. To offset these faults the trees are large and well formed, bear regularly and heavily, are hardy, robust and healthy, the best of recommendations, and the plums are large, attractive in appearance and keep and ship well especially if picked a little green. The variety, curiously enough, is not nearly as badly attacked by San José scale as other plums. Probably one of the reasons why Bradshaw is so largely grown in New York is that it is easily handled in the nursery and quickly makes a very good nursery tree. Bradshaw does not deserve the high place it holds with plum-growers, and must give way sooner or later to better varieties for commercial orchards. The value of the crop is greatly lessened in New York because it ripens in the midst of the peach season. 


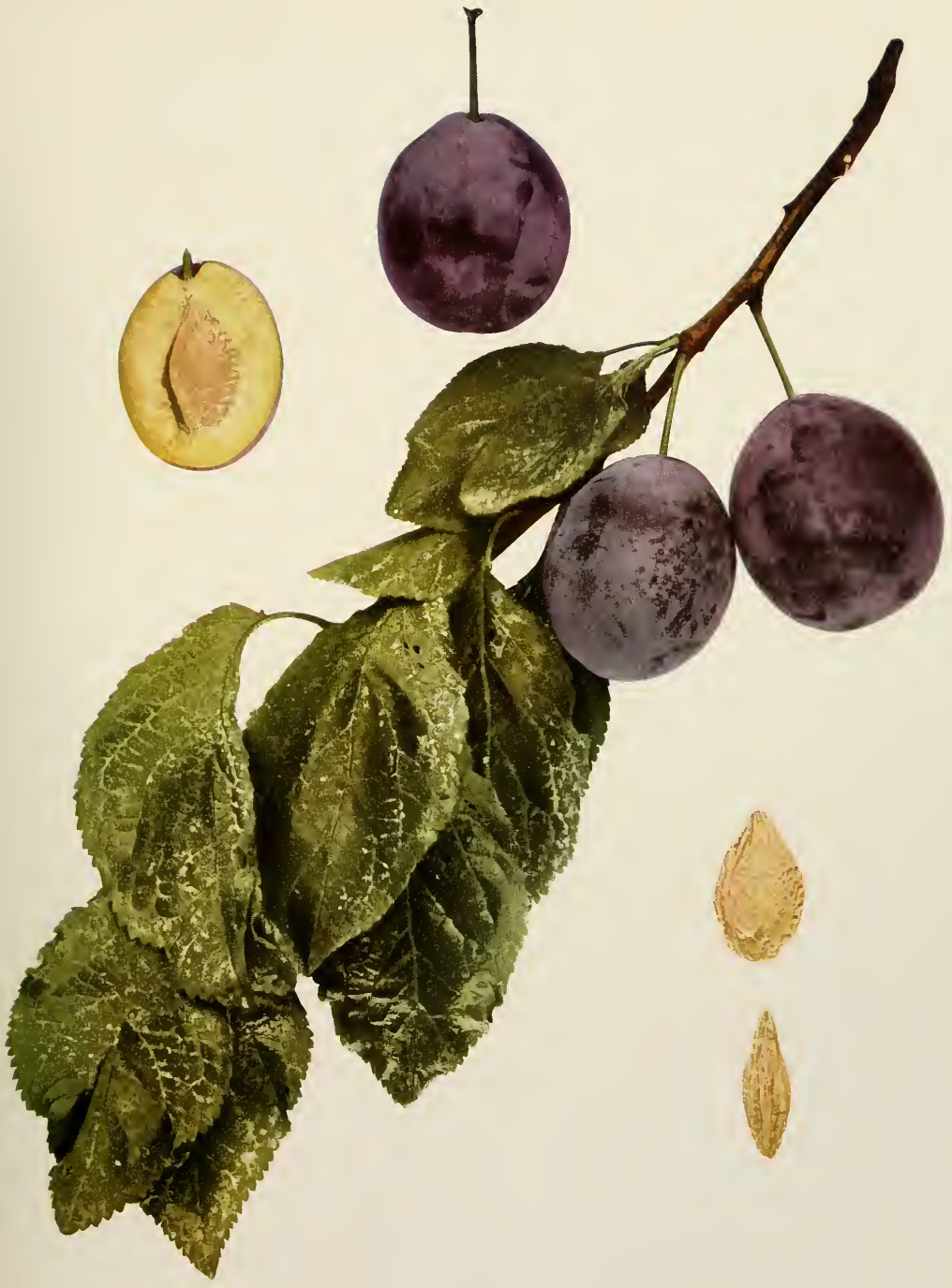



Unfortunately, the origin of this plum is not known. The Europeans and some Americans have held that it came from America but, since it is identical with the Large Black Imperial, it must be of foreign origin. It was named by C. M. Hovey in 1846 , and was described in his Magazine of Horticulture with the following explanation: "For the want of a name to distinguish a very large and excellent plum, exhibited for three or four years in succession, by E. E. Bradshaw, Esq., Charlestown, we have called it the Bradshaw plum." Barry, in 1855 , states in the Horticulturist that he "received it from Wm. Kenrick, a nurseryman in Newton, Massachusetts, under the name of Large Black Imperial; but as it has been described in Hovey's Magasine as Bradshaw, we have adopted that name in our catalog." Though the name Bradshaw is incorrect according to the rule of priority, it would now cause too much confusion to change it.

Niagara, a well known variety in this State, is identical with Bradshaw in all characters, in spite of a supposedly distinct origin. According to Mr. George Atwood of the State Department of Agriculture, a Mr. Moody of Lockport exhibited, about I870, the Mooney plum, afterwards named the Niagara. Being interested in the variety, Mr. Atwood visited Mooney, at Lockport, the man from whom Moody had secured his stock. In Mooney's yard were found several bearing trees, which had been grown from sprouts taken from the original seedling tree, grown in Canada. These trees could not be told from the Bradshaw. If the Niagara is distinct as to origin, it is probably a seedling of Bradshaw. Bradshaw was recommended to fruit-growers as a promising variety by the American Pomological Society in 1856 and has since remained on the fruit list of the society.

Tree large, vigorous, broad-vasiform, dense-topped, hardy, very productive; branches smooth except for the numerous, small, raised lenticels, dark ash-gray; branchlets short, with long internodes, greenish-red changing to brownish-red, often with heavy gray scarf-skin, dull, sparingly pubescent, with obscure, small lenticels; leafbuds variable in size and length, pointed, free.

Leaves drooping, folded backward, obovate or oval, two inches wide, four and one-quarter inches long, thickish; upper surface dark green, rugose, pubescent, with a shallow groove on the midrib; lower surface grayish-green, thickly pubescent; apex acute, base abrupt, margin not regular, varying from coarsely crenate to serrate, eglandular or with few, small, dark glands; petiole three-quarters inch long, pubescent, reddish, glandless or with from one to three large, globose, greenish-brown glands on the stalk or at the base of the leaf.

Season of bloom short; flowers appearing after the leaves, one and three-sixteenths inches across, the buds creamy changing to white as the flowers expand; borne on lateral 
buds and spurs, singly or in pairs; pedicels nearly eleven-sixteenths inch long, pubescent, green; calyx-tube greenish, campanulate, pubescent only at the base; calyx-lobes wide, obtuse, pubescent on both surfaces, glandular-serrate, margins ciliate, reflexed; petals broadly oval, erose, with short, broad claws; anthers yellowish; filaments sevensixteenths inch long; pistil pubescent at the base, shorter than the stamens.

Fruit mid-season; two inches by one and three-quarters inches in size, oval or obovate, compressed, halves equal; cavity shallow, narrow, abrupt, with a fleshy ring around the stem; suture very shallow; apex roundish or flattened; color light purplish-red changing to dark reddish-purple at maturity, covered with thick bloom; dots numerous, small, russet, inconspicuous, clustered about the apex; stem thick, seven-eighths inch long, pubescent, adhering strongly to the fruit; skin thin, somewhat tough, sour, separating readily; flesh dull yellow, often with a trace of red when fully mature, juicy, fibrous, somewhat tender, sweet, pleasant; good; stone semi-free, flattened, one and one-quarter inches by three-quarters inch in size, irregularly oval, necked at the base, blunt at the apex, strongly roughened and pitted, often with numerous, small, deep pits near the margins of both ventral and dorsal sutures; ventral suture strongly furrowed and winged; dorsal suture with a deep, narrow groove.

\section{BRYANSTON}

\section{Prunus domestica}

I. Lond. Hort. Soc. Cat. 144. 1831. 2. Jour. Hort. N. S. 17:286. 1869. 3. Downing Fr. Trees Am. 902, 1869. 4. Am. Pom. Soc. Cat. 24. 1871. 5. Barry Fr. Garden 411. 1883. 6. Hogg Fruit Man. 688. 1884. 7. Tenn. Sta. Bul. 3:No. 5, 88. 1890. 8. Guide Prat. 155. 1895. 9. Thompson Gard. Ass't 4:157. 1901. 10. Waugh Plum Cult. 98. 1901. 11. Mass. Sta. An. Rpt. 17:158. 1905.

Bryanstone 11. Bryanston Gage 1, 2, 6, 9. Bryanston's Gage 3, 5, 7. Bryanston's Gage 10. Bryanstone Gage 4. Reine-Claude Bryanston 8.

The fruits of Bryanston fall not a little short, all things considered, of being as good as those of several other of the varieties in the Reine Claude group of which this plum is a member. For this reason Bryanston is not often rated by horticulturists as one of the best plums, but the large, vigorous trees growing on the Station grounds are so especially desirable for this variety, in a group which taken as a whole is noted for poor trees, that it is here described among the leading plums. The fruit is larger than that of Reine Claude but is less attractive in color and shape and the quality is not as high. It is later than the variety with which it has just been compared and the crop is not borne as regularly. While this plum can hardly be recommended for extensive orchard plantings, it yet has too many merits to be forgotten.

This variety is said to be the result of crossing Reine Claude and Golden Drop at Bryanston Park, Blandford, England. It was first noted 
in the London Horticultural Society fruit catalog in I83I but no information in regard to the date of its origin seems to have been published. In I 87 I the American Pomological Society added it to its fruit catalog list but dropped it in 1897 .

Tree very large and vigorous, round-topped, open, hardy, very productive; branches smooth, becoming rough near the trunk, ash-gray, with lenticels of medium size and number; branchlets somewhat slender, short, with long internodes, greenish-red changing to dull reddish-brown, marked by scarf-skin, dull, glabrous, with few, inconspicuous, small lenticels; leaf-buds above medium in size and length, pointed, free; leaf-scars prominent.

Leaves folded backward, oval or obovate, one and five-eighths inches wide, three and one-quarter inches long, leathery; upper surface dark green, sparingly hairy, with a shallow groove on the midrib; lower surface yellowish-green, pubescent; apex abruptly pointed or acute, base acute, margin crenate, bearing small, dark glands; petiole onehalf inch long, pubescent, with a little red, glandless or with one or two small, globose, yellowish glands.

Blooming season intermediate in time, short; flowers appearing with the leaves, one and one-eighth inches across, white, creamy at the apex of the petals in the newly opened flowers; borne on lateral buds and spurs, singly or in pairs; pedicels one-half inch long, thick, pubescent, greenish; calyx-tube green, campanulate, pubescent at the base; calyx-lobes broad, obtuse, pubescent on both surfaces, glandular-ciliate, somewhat reflexed; petals roundish-ovate, erose; anthers yellow; filaments about onequarter inch long; pistil glabrous except at the base, slightly longer than the stamens; stigma large.

Fruit mid-season; one and five-eighths inches by one and one-half inches in size, irregular roundish-truncate, halves unequal; cavity shallow, narrow, abrupt; suture usually shallow, prominent; apex flattened or depressed; color dull yellow with greenish streaks, sometimes with pinkish blush about the cavity, mottled, overspread with thin bloom; dots numerous, small, inconspicuous; stem thick, three-quarters inch long, pubescent, adhering well to the fruit; skin thin, tough, sour, separating readily; flesh greenish-yellow, juicy, firm but tender, sweet, aromatic; very good; stone nearly free, seven-eighths inch by five-eighths inch in size, broadly oval, turgid, slightly contracted at the blunt base, roundish at the apex, with rough and pitted surfaces; ventral suture broad, with a distinct but small wing; dorsal suture widely and deeply grooved.

\section{BURBANK}

\section{Prunus triflora}

1. Ga. Hort. Soc. Rpt. 53, 99. 1889. 2. U. S. D. A. Rpt. 392. 1891. 3. Wickson Cal. Fruits 360. 1891. 4. Cornell Sta. Bul. 106:46, 63. 1896. 5. Ala. Col. Sta. Bul. 85:445. 1897. 6. Am. Pom. Soc. Cat. 26. 1897. 7. Am. Gard. 19:75, 132, 220, 792. 1898. 8. Mich. Sta. Bul. 169:242, 249. 1899. 9. Cornell Sta. Bul. 175:143. 1899. 10. Waugh Plum Cult. 134. 1901. 11. W. N. Y. Hort. Soc. Rpt. 88, 1902, 12. Can. Hort. 25:272. 1902, 13. Budd-Hansen Am. 
Hort. Man. 308. 1903. 14. Ga. Sta. Bul. 68:11, 28. 1905. 15. Ohio Sta. Bul. 162:256. 1905. 16. DeVries Plant Breeding 170. 1907.

Persing Nos. I \& 2, I5. Russian plum 20M. 4. Wassu 4. Wassu 9.

Probably Abundance holds first place among the Triflora plums in New York but Burbank is a close second and in many localities has first preference. Abundance is in the lead chiefly because the trees of this variety are larger and better formed and bear more fruit than those of Burbank. To offset the advantages of Abundance the fruit of Burbank is of better quality, more handsomely colored, keeps and ships better and is less susceptible to brown-rot. The fruit of Burbank ripens a week or more later than that of Abundance, which in most seasons is a slight advantage for the first-named variety. The trees of this plum are distinguished from those of all other plums by their low, spreading habit, flat top and somewhat drooping branches, characters which make them more or less difficult to handle in the orchard and very difficult to manage in the nursery. The wood of Burbank is brittle, true of all Trifloras, but a serious defect in this one. In common with other varieties of its species, Burbank is less troubled with curculio and black-knot than the European plums. The fruit of this variety begins to color some days before ripe and should be picked before fully matured if it is to be kept or shipped. Usually the best specimens of Burbank come from thinned trees and thinning is a necessary operation in all commercial orchards. The variety does not thrive in the South, being poor in quality and rotting badly. In New York, Burbank is not being planted nearly so largely as a few years ago, the Domesticas being much more profitable than this or other Triflora plums. It is a very desirable variety for home plantations in New York.

Burbank was produced from a plum pit sent to Luther Burbank ${ }^{1}$ by

\footnotetext{
${ }^{1}$ Luther Burbank, known the world over for his work in bringing into being new plant forms, was born in Lancaster, Massachusetts, March 7,1849 . He was educated in the common schools and in the local academy, his school-training being supplemented by much reading in the well-stocked library of which every New England town boasts. After leaving school, some time was spent in a factory in Worcester, Massachusetts, but, following a strong natural inclination to work with plants, he left the factory to grow vegetables and seeds. It was while so engaged that he grew the Burbank potato, most widely known and most valuable, if gauged by the monetary value of the crops pro. duced, of all of his new plants. In $1875 \mathrm{Mr}$. Burbank went to California and a few years later began in a small way the plant-breeding nursery at Santa Rosa in which most of his work has since been done. The years preceding this beginning and several following it constitute a time of hard labor, sickness and of financial distress through which only a man of remarkable strength of character could have lived and kept the desire to continue his work. Following a decade, more or less, of difficulties after the start at Santa Rosa, Mr. Burbank's career as a world-wide figure in plant-breeding may be said to have begun. One cannot briefly catalog the new forms of plants
} 


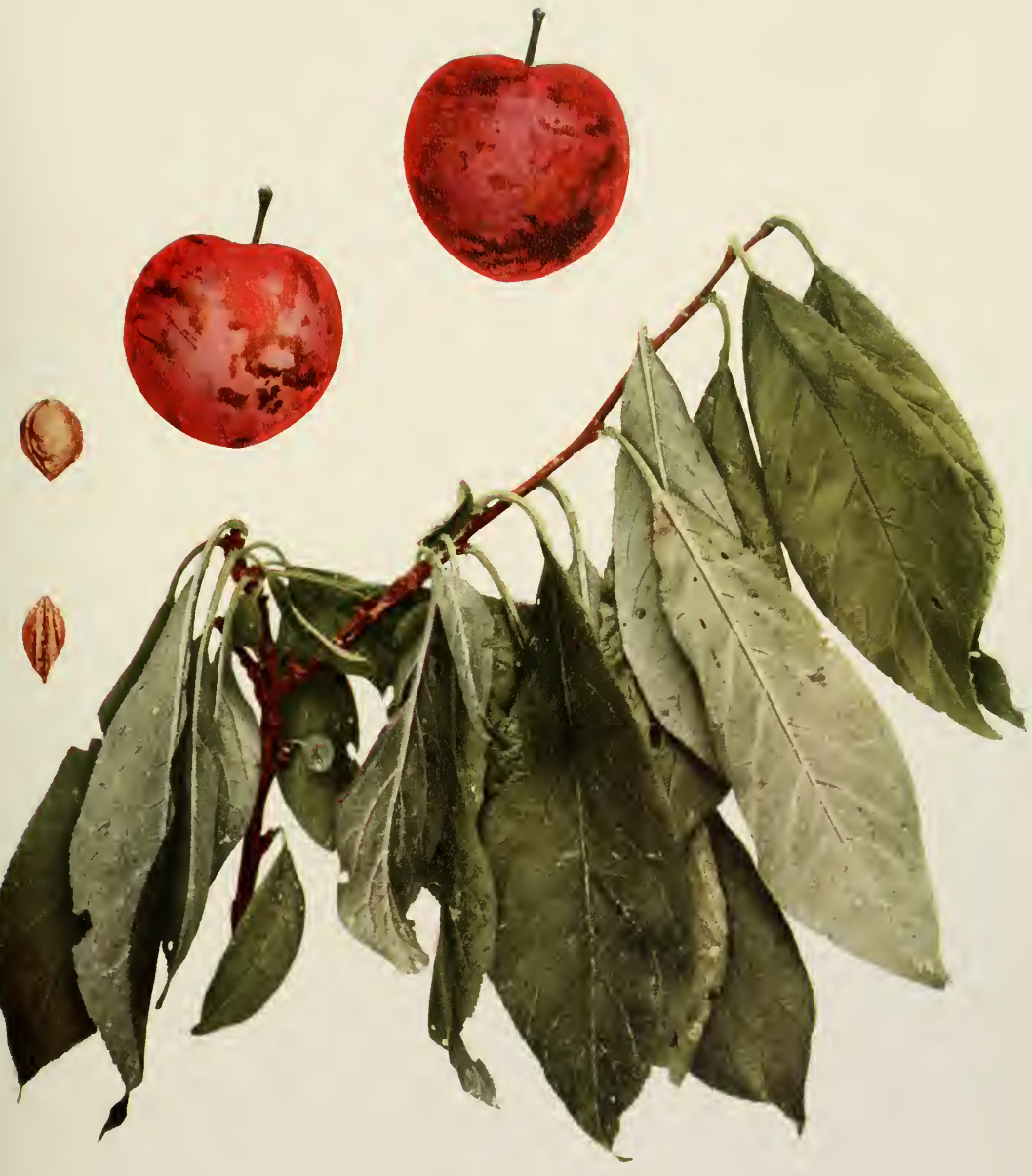



a Japanese agent in $1883 \cdot{ }^{1}$ The fruit of this variety proved to be very superior and Mr. Burbank sent specimens of it to the Division of Pomology, United States Department of Agriculture in 1887 , where it was named in honor of the introducer. Wassu, introduced by J. L. Normand, and the Russian plum, 20 M, sent out by Professor J. L. Budd proved to be indistinguishable from the Burbank as tested by Bailey, but Kerr ${ }^{2}$ thinks the Wassu is a distinct variety. The American Pomological Society added Burbank to the fruit list in its catalog in 1897 .

Tree large, vigorous, distinguished by its low, sprawling habit and flat open top, unusually hardy for a Japanese variety, very productive, healthy; branches somewhat roughish, dark ash-gray, thickly covered with fruit-spurs, with few, large, raised lenticels; branchlets medium in thickness and length, with short internodes, greenish-red changing to dark brown, with gray scarf-skin, glossy, glabrous, with raised lenticels of medium size and number; leaf-buds short, obtuse, free.

Leaves folded upward, broadly oblanceolate, peach-like, one and one-eighth inches wide, three and three-quarters inches long, thin; upper surface light green, smooth, pubescent only on the deeply grooved midrib; lower surface glabrous, pubescent on the midrib; apex taper-pointed, base cuneate, margin finely and doubly serrate, with small amber or reddish glands; petiole nine-sixteenths inch long, sparingly hairy on one side, tinged red, with from one to four small, reniform or globose glands mostly on the stalk.

that have gone forth from his private place in California; they must number well into the hundreds; his biographer, in 1905 , said that Mr. Burbank has worked with over two thousand five hundred distinct species (Harwood, W. S., New Creations in Plant Life I. 1905). Among these have been practically all of the species of plums now under cultivation, from which have been obtained, according to Mr. Burbank, hundreds of thousands of plum-seedlings of which the breeder has selected a score or more of very distinct sorts, all interesting and a few of them very valuable. The many other fruits, flowers and forage plants which Mr. Burbank has sent out, each involving the handling of countless seedlings, cannot be mentioned here. Nor can his methods and results be discussed, except to say that in them he is a unique figure in plant-breeding and that they have been such that he has exercised a powerful influence toward the improvement of plants. The practical results of Mr. Burbank's work ha ve been as great or greater than those secured by any other person in plant-breeding, yet they have been magnified out of all bounds in the popular press and his work has ween caricatured by calling the man a wizard and ascribing to him occult knowledge. Of the plants introduced by Mr. Burbank the proportion of really valuable commercial ones seems now to be small, but what he has done cannot be measured by money values; he has awakened universal interest in plant-breeding; has demonstrated that things unheard of before his time can he done with plants; and, all in all, his contributions in new forms of plants to horticulture and agriculture, in their intrinsic and educational value, make him the master worker of the times in improving plants.

${ }^{1}$ Statement in a letter from Mr. Burbank.

${ }^{2} \mathrm{Mr}$. Kerr in a letter written in r 909 says: "Wassu, as I have it, is radically different from descriptions of both Waugh and Bailey. The tree is as slovenly in habit as is that of the Burbank -there all resemblance ceases.". 
Blooming season early and short; flowers appearing with the leaves, white; borne in dense clusters on the lateral buds and spurs, in threes; pedicels one-quarter inch long, thick, glabrous; calyx-tube green, obconic, glabrous; calyx-lobes broad, obtuse, glandular-serrate, glabrous, erect; petals broadly oval, entire, short-clawed; anthers yellowish; filaments one-quarter inch long; pistil glabrous, longer than the stamens.

Fruit early, season long; variable in size, large when the tree is not overloaded, one and three-quarters inches in diameter, roundish-conic, halves equal; cavity deep, abrupt, regular; suture shallow; apex roundish; color dark red over a yellow ground, mottled, with thick bloom; dots numerous, large, russet, conspicuous; stem five-eighths inch long, glabrous, parting readily from the fruit; skin thin, tough, sour, separating from the pulp; flesh deep yellow, juicy, tender, firm, sweet, aromatic; good; stone clinging, three-quarters inch by five-eighths inch in size, roundish-oval, turgid, blunt but sharp-tipped, roughish, with a slightly winged ventral suture; dorsal suture acute.

\section{CHABOT}

\section{Prunus triflora}

1. Ga. Hort. Soc. Rpt. 29. 1886. 2. Ibid. 52, 99. 1889. 3. Am. Gard, 12:501. 1891. 4. Ibid. 13:700. 1892. 5. Rev. Hort. 132, Pl. 537. 1892. 6. Cornell Sta. Bul. 62:20, 22, 28. 1894. 7. Ibid. r 06:44, 48, 51, 60. 1896. 8. Rogers Cat. 9. 1896. 9. Cornell Sta. Bul. 139:38. 1897. ro. Am. Pom. Soc. Cat. 26. 1897. I1. Cornell Sta. Bul. 175:150. 1899. I2. Waugh Plum Cult. 134, I35 fig. 1901. 13. Can. Exp. Farm Bul. 43:37. 1903. 14. Ohio Sta. Bul. 162:250, 254, 255, 256, 257. 1905. 15. Ga. Sta. Bul. 68:1 2, 14, 28, 29, 30, 31, 32. 1905.

Babcock 15. Babcock ?15. Bailey 3, 4, 6, 7. Bailey 9, 11, 12, 15. Chase 9, 15. Chabot 15. Douglas 15. Furugiya 7, 15. Furugiya 11, 12, 15. Hytankayo 14. Hytankayo 15. Hon-smomo 15. O-Hatankyo 11. Orient 6, 7. Orient 14. O-hattankio 15. Paragon 8. Red Nagate of some 7. Uchi Beni of some II. Yellow Japan 9, II, I2.

When properly handled the fruits of Chabot are far the most attractive of the many Triflora plums. They are large, beautifully molded and handsomely mottled in shades of red over yellow with occasional splashes of russet and a heavy but delicate bloom. To secure the best coloring, the fruit must be picked before ripe and be matured in dark storage. Early picking is necessary also because the season of ripening is very long and the fruit drops badly if permitted to hang to the trees until fully ripe. There should be at least three pickings for this variety. Unfortunately, the quality of Chabot belies its appearance, being at best not above the average. The fruits are firm and ship well and keep rather better than those of any other plum of its species. The trees are hardy and dependable in bearing but not as productive as could be wished. The blossoms of Chabot open later than those of most other Trifloras, enabling this sort occasionally to escape frosts which injure other varieties of this species. The stamens are often short, undeveloped and wholly or in part sterile. 


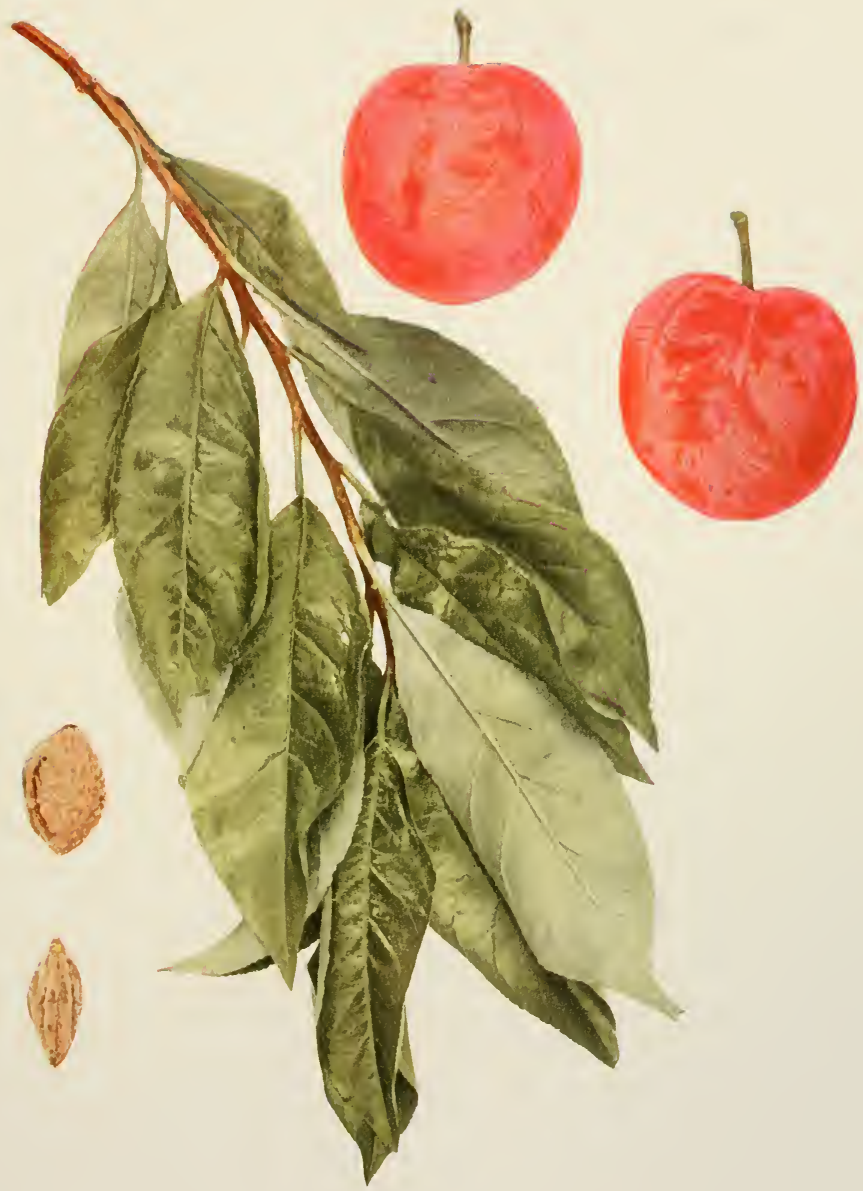



Because of its attractive fruit this variety might well be grown more than it is for the markets.

Chabot was imported from Japan by a Mr. Chabot of Berkeley, California, and was introduced to the trade by Luther Burbank in I886. As with Abundance, the nomenclature of Chabot is badly confused. Several names that have been found to be synonymous with the former have also been applied to the latter. J. L. Normand, Marksville, Louisiana, imported trees from Japan, among which was a tree that was different from any growing on his grounds. He named this variety after Bailey and introduced it in I89I. Later this was found to be identical with Chabot. Furugiya, another introduction by Normand, is undoubtedly Chabot. H. N. Starnes of the Georgia Experiment Station, who has tested many of the Japanese plums, published in Bulletin 68 of his station, the additional synonyms: Chase, O-hattankio, Hytankayo, Douglas, Hon-smomo and Babcock. Orient, introduced by Stark Brothers, Louisiana, Missouri, in 1893, is Chabot as tested at the New York and Ohio experiment stations. Paragon, introduced by the Rogers Nursery Company, Moorestown, New Jersey, has also proved to be identical. In 1897 the American Pomological Society added this variety to its fruit catalog list.

Tree large, vigorous, vasiform or upright-spreading, open-topped, slow-growing, hardy, productive, susceptible to attacks of shot-hole fungus; branches roughish, the fruit-spurs numerous, dark ash-gray, with raised lenticels variable in size; branchlets slender, with short internodes, greenish-red changing to dark chestnut-red, glossy, glabrous, with numerous, conspicuous, rather large, raised lenticels; leaf-buds small, short, obtuse, somewhat appressed.

Leaves folded upward, obovate or oblanceolate, peach-like, one and one-quarter inches wide, three inches long, thin; upper surface light green, smooth, with a shallow, grooved midrib; lower surface pale green, glabrous except at the base of the veins; apex acutely pointed, base cuneate, margin finely serrate, with small, amber or dark red glands; petiole one-half inch long, slender, slightly pubescent along the upper surface, heavily tinged with red, glandless or with from one to six small, globose or reniform, greenish-brown glands usually on the stalk.

Blooming season intermediate and long; flowers appearing with the leaves, white; borne in clusters on lateral spurs in pairs or in threes; pedicels three-eighths inch long, pubescent, greenish; calyx-tube green, obconic, pubescent at the base; calyx-lobes obtuse, glandular, somewhat serrate, pubescent at the base, erect; petals broadly oval, entire, with narrow, long claws; anthers shrivelled; filaments nearly sessile or oneeighth inch long; pistil glabrous, longer than the stamens; stigma small.

Fruit mid-season, ripening period long; one and five-eighths inches in diameter, cordate or roundish, halves equal; cavity deep, flaring, with concentric, russet rings; 
suture distinct; apex roundish or pointed; color light and dark shades of red over yellow, mottled, with occasional splashes of russet and with a thick but delicate bloom; dots numerous, small, russet or yellow, conspicuous unless obscured by the bloom, clustered around the apex; stem thick, one-half inch long, adhering to the fruit ; skin medium in thickness, tender, bitter, separating easily; flesh golden-yellow, very juicy, coarse and fibrous, tender, somewhat melting when fully ripe, sweet, although somewhat tart at the center, sprightly, with characteristic Triflora flavor; good; stone clinging, three-quarters inch by one-half inch in size, oval, turgid, slightly necked, with pitted surfaces; ventral suture wide; dorsal suture unfurrowed.

\section{CHALCO}

\section{Prunus simonii $\times$ Prunus triflora}

x. Burbank Cat. 4. 1898. 2. Rural N. Y. 57:184, 653. 1898. 3. Vt. Sta. Bul. $67: 8$. 1 898 . 4. Vt. Sta. An. Rpt. 14:273. 1901. 5. Ga. Sta. Bul. 68:12, 35. 1905.

Chalco has been extensively advertised by several nurseries but, from the reports received, it is doubtful if it will ever be grown commercially. The trees, in the East at least, are slow in coming into bearing; the fruits are small; and the flavor such that consumers will have to learn to like it although it is much better in quality than the Simon plum, one of its parents, being quite free from the bitterness of this parent. The tree is rather better than that of the Simon plum or of the Wickson, the two plums with which it must be compared. The amateur may care to plant Chalco but here its usefulness ends. Burbank in introducing this plum in $\mathbf{I} 898$, stated that it was the first fruit offered after twelve years' work in crossing Prunus simonii with Prunus triflora and American species. The parentage of Chalco is given as a Simon-Burbank cross. The following description is compiled:

Tree vigorous, upright or somewhat vasiform, very productive; leaves large, dark green. Fruit matures shortly before Burbank; large when well grown, oblate, dark red; flesh yellowish, firm, very juicy, aromatic, sweet; good; stone small, oval, slightly flattened, semi-free.

\section{CHAMBOURCY}

\section{Prunus domestica}

x. Rev. Hort. 39. 1898. 2. Soc. Nat. Hort. France Pom. 560, fig. 1904. 3. Can. Exp. Farms Rpt. 433. 1905. 4. Cat. Cong. Pom. France 473 fig. 1906.

Reine-Claude Tardive De Chambourcy 2. Reine-Claude Tardive Latinois I. Reine-Claude Tardive de Chambourcy I. Reine-Claude Latinois 2, 4. Reine-Cloude tardive r. Reine-Clande Verte 4. Reine-Claude Tardive 2, 4. Reine-Claude de Chambourcy 3. Tardive de Chambourcy 4.

This fruit was found at the beginning of the Nineteenth Century at Chambourcy, France, in the garden of M. Bourgeois; no record of its par- 
ents seems to have been made. M. Latinois introduced it into commerce in $1885^{-1886}$ and consequently his name became attached to the variety. The plum is not well known in America, there being only one published American reference. This Station received the variety for testing in 1899 from the United States Department of Agriculture. It has value on account of its high quality and its lateness, and is worthy of extensive testing.

Tree small, upright-spreading, dense-topped, productive; branchlets develop fruit-spurs near the base; leaf-buds strongly appressed; leaves folded upward, longoval or obovate, one and five-eighths inches wide, three and three-quarters inches long, somewhat leathery; margin doubly serrate or crenate, with small dark glands; blooming season intermediate in time and length; flowers appearing after the leaves, over one inch across; borne in thin clusters on lateral buds and spurs, singly or in pairs.

Fruit very late, season of medium length; nearly one and one-half inches in diameter, roundish, slightly truncate, yellowish-green, with a delicate bloom and a pink blush on the exposed cheek; flesh greenish-yellow, very juicy, firm but tender, sweet, aromatic, of high flavor; very good to best; stone semi-free or free, three-quarters inch, by one-half inch in size, irregular-oval, flattened, rather blunt at the base and apex, with roughened surfaces; ventral suture strongly furrowed, often with a distinct wing.

\section{CHAMPION}

\section{Prunus domestica}

1. Wickson Cal. Fruits 360. 1891. 2. Oregon Hort. Soc. Rpt. 347. 1893. 3. Am. Pom. Soc. Rpt. 150. 1895. 4. Oregon Sta. Bul. 45:30. 1897.

Champion Prune, $x, 2,3$.

The Champion was introduced with the expectation that it would be a valuable fruit for curing into prunes. It has not proved to be a good plum for prune-making, as it is too juicy, about three-fourths of its bulk evaporating, but the western plum-growers have found it a very good plum for shipping in the fresh state. It is very attractive in appearance, firm, free of stone, sweet and pleasant and withal of rather high quality. The tree-characters, as the plums grow in Geneva, are in the main very good, falling short, if at all, in productiveness. They are such as to lead to the recommendation of a trial for this plum by plum-growers in general in New York.

This variety is a seedling of the Italian Prune produced by Jesse Bullock, Oswego, Oregon, about 1876 , and introduced by C. E. Hoskins, Springbrook, Oregon. Since the Italian Prune comes nearly true to seed it is very doubtful if this variety is a pure-bred seedling judging from the characters of the fruit as given below: 
Tree of medium size and vigor, upright-spreading, open-topped, hardy, productive, an early bearer, subject to sun-scald; branches ash-gray, rather smooth, with few, small lenticels; branchlets short, with very short internodes, greenish-red changing to brownish-red, dull, sparingly pubescent throughout the season, with few inconspicuous, small lenticels; leaf-buds below medium in size, short, obtuse, free, plump.

Leaves folded upward, oval, one and five-eighths inches wide, three inches long; upper surface somewhat rugose, covered with numerous, fine hairs, with a shallow groove on the midrib; lower surface silvery-green, pubescent: apex abruptly pointed or acute, base acute, margin crenate, with small black glands; petiole one-half inch long, green, pubescent, with from one to three medium to large, globose, brownish glands mostly at the base of the leaf.

Blooming season intermediate in time and length; flowers appearing after the leaves, one inch across, white with a yellowish tinge at the apex of the petals; borne on lateral spurs, singly or in pairs; pedicels five-eighths inch long, with a few scattering hairs, green; calyx-tube greenish, campanulate, sparingly pubescent; calyx-lobes obtuse, pubescent on both surfaces, glandular-serrate, somewhat reflexed; petals roundish, crenate, tapering to short, broad claws; anthers yellow; filaments three-eighths inch long; pistil glabrous, slightly shorter or equal to the stamens in length.

Fruit earlier than Italian Prune; about one and one-half inches in diameter, roundish, compressed, halves equal; cavity very shallow, abrupt, narrow, regular; suture shallow; apex roundish, with a slight depression at the pistil-point; color dark purplishblack, with thick bloom; dots small, russet, somewhat conspicuous, clustered about the apex; stem five-eighths inch long, sparingly pubescent, parting readily from the fruit; skin thick, tough, sour, adhering but little; flesh attractive yellow, juicy, firm, sweet, pleasant flavor; very good; stone free, the cavity larger than the pit, threequarters inch by one-half inch in size, irregular-oval, the surface distinctly roughened and pitted; ventral suture swollen, rather narrow, often with a wing; dorsal suture with a shallow, narrow, indistinct groove.

\section{CHENEY}

\section{Prunus nigra}

1. Wis. Hort. Soc. Rpt. 15, 38. 1885. 2. Minn. Hort. Soc. Rpt. 126. 1890. 3. Cornell Sta. Bul. $3^{8}: 36,86$. 1892. 4. Ia. Sta. Bul. 31:346. 1895. 5. Wis. Sta. Bul. 63:24, $3^{1}$ fig. I3. 1897. 6. Am. Pom. Soc. Cat. 24. 1897. 7. Gard. \& For. 10:367. 1897. 8. Colo. Sta. Bul. 50:33. 1898. 9. Minn. Hort. Soc. Rpt. 412. 1899. ro. Waugh Plum Cult. 169. 1901. 11. Budd-Hansen Am. Hort. Man. 294. 1903. 12. Can. Exp. Farm Bul. 43:29. 1903. 13. La. Hort. Soc. Rpt. 488. 1904. 14. Ohio Sta. Bul. 162:254, 255. 1905. 15. S. Dak. Sta. Bul. 93:11. 1905. 16. Ia. Sta. Bul. II4:I29. I910.

Cherry 16 incor.

Cheney is of little value except towards the northern limits of fruit culture in America where, because of its great hardiness, it is a most desirable fruit-plant. Of the varieties illustrated and described among the leading plums in this text, Cheney is the sole representative of Prumus nigra, 

the wild plum of Canada and of northern United States. The accompanying description shows that while the fruit of this variety is not such as to recommend it where other species can be grown, the tree has some characters most desirable wherever plums are grown-hardiness, vigor, productiveness and good form - so that this variety might well be used in breeding plums. The trees are very ornamental whether in flower, full leaf or fruit, but especially when in full bloom as they bear a great profusion of large white flowers which change to a pleasing pink before falling. This plum, according to a letter from the discoverer, E. Markle, of La Crosse, Wisconsin, was found in the brush on a ridge, in Vernon County, Wisconsin, about twenty-five or thirty years ago. Mr. Markle thought it must have sprung from a seed dropped by an early voyager of the Mississippi River as there were no similar plums in the region. Noting its good qualities Mr. Markle introduced the variety, the date of introduction being about 1887. The American Pomological Society added Cheney to its fruit catalog list in 1897 , where, however, it remained but two years.

Tree large, vigorous, spreading, dense-topped, hardy, productive, bears early, somewhat susceptible to disease; branches numerous, dark brownish-gray, very thorny, with large lenticels; branchlets long, with long internodes, greenish-red changing to dull reddish-brown, dull, thickly pubescent early in the season, the pubescence decreasing at maturity, with raised lenticels which are variable in size; leaf-buds smallish, short, conical, free.

Leaves folded upward, oval, one and three-quarters inches wide, three and fiveeighths inches long, thin; upper surface dark green, nearly smooth, pubescent only along the midrib which is deeply grooved; lower surface yellowish-green, pubescent along the midrib and larger veins; apex taper-pointed, margin crenate, usually in two series, sometimes with small, dark glands; petiole one-half inch long, rather slender, pubescent, tinged red, glandless or with from one to three small, globose, greenish-yellow glands usually on the stalk.

Blooming season intermediate in time and length; flowers appearing after the leaves, showy, about one inch across, white changing to pink; borne in clusters on lateral spurs, in pairs or in threes, very fragrant; pedicels nine-sixteenths inch long, pubescent, green with a trace of red; calyx-tube obconic, glabrous, red on the outer surface but green within and pinkish along the margin; calyx-lobes obtuse or acute, serrate, with small red glands and with marginal hairs, narrow, sparingly pubescent on the inner surface, reflexed; petals broadly oval, crenate, often toothed, tapering below to long narrow claws; anthers yellowish; filaments nearly one-half inch in length; pistil glabrous, shorter than the stamens.

Fruit mid-season, ripening period very long; medium in size, irregular roundishoval, strongly oblique, halves equal; cavity shallow, regular, flaring; suture shallow 
or a line; apex roundish, somewhat oblique; color at first yellowish-green with a light carmine blush changing to deep carmine on a yellow ground, covered with thin bloom; dots numerous, very small, russet, inconspicuous, densely clustered about the apex; stem slender, five-eighths inch in length, slightly pubescent, adhering to the fruit; skin thick, tough, sour, separating readily; flesh deep yellow, very juicy, fibrous, tender and melting, sweet next to the skin but tart at the center, not high in flavor; fair in quality; stone adhering, seven-eighths inch by five-eighths inch in size, broadly oval, distinctly flattened, blunt-pointed, with ridged and furrowed surfaces; ventral suture acute, narrow; dorsal suture slightly furrowed.

\section{CLIMAX}

\section{Prunus triflora $\times$ Prunus simonii}

1. Rural N. Y. $57: 653,818$. 1898. 2. Cal. State Board Hort. 52, 1897-98. 3. Vt. Sta. Bul. 67:9. 1898. 4. Vt. Sta. An. Rpt. 12:222. 1899. 5. Burbank Cat. 2. 1899. 6. Nat. Nur. 8:117. 1900. 7. Vt. Sta. An. Rpt. 14:273. 1901. 8. Rural N. Y. 62:643. 1903. 9. Mich. Sta. Sp. Bul. 30:18. 1905. 10. Ga. Sta. Bul. 68:8, 35. 1905. I1. Ga. Hort. Soc. Rpt. 66. 1907.

Royal I. Royal I, 3, 4 .

It is hard to judge as to the merits of this variety. From the behavior of the trees on the grounds of this Station where we have had fruit of it for eight years, we should say at once that Climax has no place in the plum-growing regions of the East but others who have grown it speak so well of it, the fruit in particular, that the unfavorable opinion of the variety formed here may be unjust. Some of the expressions regarding this fruit in the foregoing references may be dismissed at once as the most wildly extravagant and absurd to be found in plum literature. From its behavior on these grounds and in the plum-growing regions of the East in general, it seems certain that Climax cannot stand the vicissitudes of the climate, suffering both in winter and summer. The trees, in size, vigor and habit of growth, are inferior to those of most Triflora varieties, and those under observation in this part of New York are not as productive as the standard Trifloras with which Climax must be compared. The fruit is handsome in shape and color, more so in color than the accompanying illustration shows, and is of good quality. Unfortunately it is very susceptible to the brown-rot, so much so that because of this defect alone Climax could hardly become a profitable commercial plum in this region. It has been quite well tested in various parts of New York and has proved so uniformly disappointing in tree-characters, in particular, that it cannot be recommended as other than a plum for the home collection where, because of its beauty and quality, it is most desirable. 


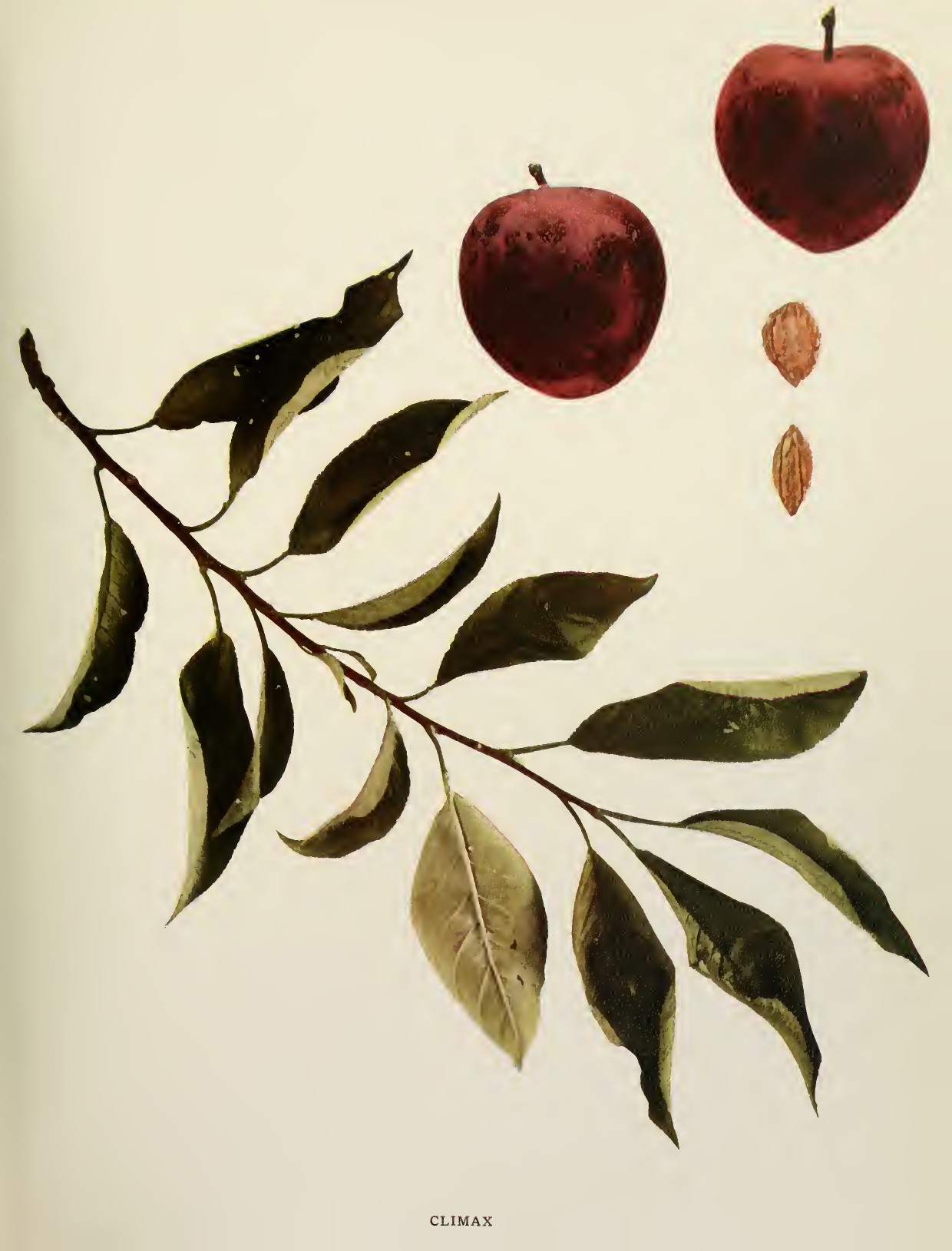



Climax is another of Luther Burbank's plums, having been introduced in 1899 . The originator states that it is a selected hybrid between the Simon and Botan plums. The variety was first described as the Royal but since this name had been previously given to a European plum it was renamed Climax.

Tree large, vigorous, upright-spreading, somewhat straggling, dense-topped, semihardy, medium productive; branches dark ash-gray, short and stout, with numerous lenticels; branchlets short, with very short internodes, brownish chestnut-red, glossy, glabrous, with numerous conspicuous, small, raised lenticels; leaf-buds small, short, obtuse, plump, free.

Leaves folded upward, oblanceolate, peach-like, one and one-quarter inches wide, three and three-eighths inches long, thin; upper surface light green, smooth, with a grooved midrib, glabrous; lower surface light green, glabrous except on the midrib and larger veins; apex taper-pointed, base cuneate, margin finely serrate or crenate, with small, dark brown glands; petiole nine-sixteenths inch long, sparsely pubescent, tinged red, glandless or with from one to seven small, globose or slightly compressed, reddish glands.

Blooming season early and of medium length; flowers appearing with the leaves, white; borne in clusters of three, on lateral spurs; pedicels, long, thick, glabrous, green; calyx tube greenish, obconic, glabrous; calyx-lobes obtuse, with a few hair-like glands, glabrous, erect; petals roundish-oval, entire; anthers deep yellow; filaments short; pistil glabrous, equal to the stamens in length; stigma very small.

Fruit very early, season short; one and three-quarters inches in diameter, cordate or roundish, slightly compressed, halves unequal; cavity deep, abrupt, regular, marked with faint, reddish, radiating streaks; suture deep, broad; apex pointed; color dark red, mottled; bloom of medium thickness; dots numerous, variable in size, russet, conspicuous, clustered about the base; stem thick, nine-sixteenths inch long, glabrous, parting readily from the fruit; skin thick, bitter, with a tendency to crack, separating easily from the pulp only when fully ripe; flesh yellowish, very juicy, somewhat fibrous, tender and melting, sweet, pleasant flavored, aromatic; good; stone adhering, seveneighths inch by five-eighths inch in size, somewhat long-oval, pointed, roughish, conspicuously winged and grooved on the ventral suture; dorsal suture slightly grooved.

\section{CLING STEM}

\section{Prunus domestica}

I. N. Y. Sta. Rpt. 9:347. 1890 .

This plum belongs to the Reine Claude group, a group in which there is room for new varieties only at the top. Cling Stem is inferior, falling short chiefly in quality, for a plum of its type, and it is doubtful if it is worth general planting. This Station alone seems to have tested the 
variety, hence the rather full description which follows of a plum which cannot be recommended. The variety was sent here in 1890 from North Ferrisburg, Vermont, by L. M. Macomber.

Tree large and vigorous, spreading, dense-topped, very productive; branches rough, the bark marked by concentric rings, with numerous spurs and with many, small, raised lenticels; branchlets short, pubescent; leaf-scars swollen; leaves folded upward, oval, one and three-quarters inches wide, three inches long, rather thick and leathery; margin doubly crenate, eglandular or with small, dark glands; petiole pubescent, tinged red, glandless or with from one to three globose glands usually at the base of the leaf; blooming season of medium length; flowers over one inch across, white with yellowish tinge near the apex of the petals; borne on lateral buds and spurs, singly or in pairs.

Fruit mid-season; one and one-half inches by one and five-eighths inches in size, nearly roundish, dull light yellow, sometimes mottled with red on the exposed cheek, overspread with thin bloom; skin thin, sour ; flesh greenish-yellow, tender and melting, sweet near the surface but acid at the center, mild, pleasant, but not high-flavored; stone clinging, three-quarters inch by five-eighths inch in size, nearly round, turgid; surfaces pitted; ventral suture broad, heavily furrowed, with a short, distinct wing.

\section{CLYMAN}

\section{Prunus domestica}

I. U. S. D. A. Rpt. 574. I888, 2. Cal. State Board Hort. 236, 239, Pl. II figs. 3 and 4. 1890. 3. Wickson Cal. Fruits 358. 1891. 4. Am. Pom. Soc. Cat. 25. 1897. 5. N. Mex. Sta. Bull. 27:124. 1898. 6. Ohio Sta. Bul. 113:158. 1899. 7. Waugh Plum Cult. 98. 1901. 8. Ohio Sia. Bul. r62:236, 237 fig., 254, 255. 1905.

Clyman has special merit as one of the earliest good Domesticas. The fruit resembles that of Lombard somewhat, but is smaller and is much better in quality. As grown in California the Clyman commands high prices for shipping eastward. Whether it could be grown profitably in the East remains to be seen but it deserves to be rather widely tested for an early home and market plum. In New York it has a few serious faults: the plums are susceptible to rot, they drop as soon as ripe and the trees seem not to be quite hardy at Geneva; though in the Ohio reference given above they are said to be "rather hardier than those of most other European sorts." Otherwise than in hardiness the trees at this place are quite satisfactory. The variety is characterized by very long stamens. Clyman is well deserving of trial with the possibility that it may prove to be the best of our early Domesticas.

This plum was raised from a Peach plum stone planted in 1866 , by Mrs. Hannah Clyman, Napa City, Napa Valley, California. The original 
tree was cut down but several suckers were taken from the roots and planted in an orchard. These bore fruit for many years, never failing to mature a crop. In I886, Leonard Coates, a nurseryman and fruit-grower of Napa City, became interested in the plum on account of its extreme earliness and offered it to his customers. The American Pomological Society added Clyman to its fruit catalog list in 1897.

Tree rather large, vigorous, round and dense-topped, semi-hardy in New York, productive; branches ash-gray, nearly smooth, with numerous, small, raised lenticels; branchlets thick, rather long, with internodes of medium length, greenish-red changing to brownish-red, dull, heavily pubescent throughout the season, with numerous, indistinct, small lenticels; leaf-buds of medium size and length, conical, appressed; leafscars prominent.

Leaves folded backward, obovate, one and seven-eighths inches wide, three and one-quarter inches long; upper surface dark green, rugose, sparingly hairy; lower surface pale green, pubescent; apex abruptly pointed or acute, base acute, margin serrate or crenate, covered with small dark glands; petiole nearly seven-eighth inch long, pubescent, reddish, glandless or with from one to three globose, greenish-yellow glands variable in size and position.

Blooming season early and short; flowers appearing after the leaves, one and oneeighth inches across, white, the buds creamy at the apex when unfolding; borne in clusters on lateral spurs, singly or in pairs; pedicels about one-half inch long, thick, pubescent, greenish; calyx-tube green, campanulate, pubescent; calyx-lobes narrow, obtuse, pubescent on both surfaces, serrate, reflexed; petals obovate, dentate, tapering to short, broad claws; anthers yellow; filaments about seven-sixteenths inch long; pistil pubescent near the base, equal to the stamens in length.

Fruit very early, season short; one and one-half inches by one and three-eighths inches in size, oval, halves equal; cavity narrow, abrupt, regular; suture shallow and often indistinct; apex roundish or slightly depressed; color dark purplish-red, covered with thick bloom; dots numerous, small, russet, inconspicuous; stem five-eighths inches long, pubescent, adhering poorly to the fruit; skin tender, sour, separating readily; flesh pale yellow, dry, firm, sweet, mild but pleasant; of good quality; stone free, seven-eighths inch by five-eighths inch in size, somewhat flattened, irregular-oval, with pitted surfaces, tapering abruptly at the base, nearly acute at the apex; ventral suture of medium width, usually rather blunt; dorsal suture with a wide, deep groove.

\section{COLUMBIA}

\section{Prunus domestica}

1. Mag. Hort. 8:90. 1842. 2. Downing Fr. Trees Am. 292. 1845. 3. Cole Am. Fr. Book 216. 1849. 4. Thomas Am. Frutt Cuit. 334. 1849. 5. Am. Pom. Soc. Cat. 86. 1862. 6. Mas Pom. Gen. 2:159. 1873. 7. Hogg Fruit Man. 691. 1884. 8. Wash. Hort. Soc. Rpt. 135. 1893.

Columbian Gage 2, 4. Columbra Pfaume 6. Columbia Gage 7. 
When grown on strong soils and in some climates, Columbia is possibly a plum of value and sometimes of superiority, but in New York in the average plantation it falls far short of other fruits of its type-that of the Reine Claude. The trees are productive and the fruit large and handsome but not of highest quality and moreover drops badly and is very susceptible to the brown-rot. Columbia originated early in the second quarter of the Nineteenth Century with L. V. Lawrence of Hudson, New York, from seed of Reine Claude.

Tree large, medium in vigor, upright-spreading, open-topped, productive; trunk stocky, rough; branches thick; branchlets pubescent; leaves folded upward, one and seven-eighths inches wide, four and one-quarter inches long, oval, thick, leathery; upper surface rugose; margin serrate or crenate, with small, dark glands; petiole thick, tinged red, pubescent, with from one to three globose glands.

Fruit mid-season; when well grown nearly one and one-half inches in diameter, roundish-oval, the smaller specimens rather ovate, dark purplish-red, overspread with thick bloom; stem surrounded by a fleshy ring at the cavity; skin tender, sour; flesh golden-yellow, dry, firm, sweet, mild; of good quality; stone semi-free or free, seven-eighths inch by three-quarters inch in size, roundish-oval, flattened; ventral suture prominent; dorsal suture widely and deeply grooved.

\section{COMPASS}

Prunus besseyi $\times$ Prunus hortulana mineri

1. Northwestern Agr. 348, x895. 2. Vt. Sta. Bul.67:10. I898. 3. Ia. Sta. Bul. 46:266. 1900. 4. Budd-Hansen Am. Hort. Man. 294. 1903. 5. S. Dak. Sta. Bul. 93:1 3. 1905.

Compass Cherry 2. Hendeman Sand Cherry.

In I89 I H. Knudson of Springfield, Minnesota, pollinated the Sand Cherry with pollen from the Danish Morello cherry and the Miner plum. The seed of the resulting cross, beyond question that of the Sand Cherry and the plum, was planted on August seventh of the same year and, in I894 produced fruit for the first time. In 1893 C. W. H. Heideman of New Ulm, Minnesota, secured a cion from this tree and another the following year. In 1895 Heideman introduced as his own, under the name of Heideman Sand Cherry, a hybrid between the Sand Cherry and a plum. In the controversy which followed it developed that the two hybrids were identical and that Knudson was the real originator. Subsequently C. W. Sampson of Eureka, Minnesota, introduced Knudson's plum under the name Compass. The variety is of interest to plant-breeders and may have some commercial value in the Northwest but is worthless for its fruit in New York. 
Tree inferior in size, spreading, open-topped, productive; branches and branchlets slender, the branchlets marked by very conspicuous, large, raised lenticels; leaf-buds plump; leaves folded upward, one and one-eighth inches wide, three inches long; margin serrate; petiole tinged red, glandless or with from one to three globose glands usually on the base of the leaf; blooming season late, of medium length; flowers appearing after the leaves, seven-eighths inch across, creamy-white as the buds unfold; borne on lateral spurs, in threes and fours.

Fruit early, season short; seven-eighths inch by three-quarters inch in size, ovate or roundish-oval, light red changing to dark red at maturity, the skin speckled with small red dots before fully ripe; skin tough, astringent; flesh light greenish-yellow, very juicy, melting, sub acid except near the skin; poor; stone clinging, five-eighths inch by three-eighths inch in size, large, elongated-oval, with smooth surfaces.

\section{COPPER}

\section{Prunus domestica}

r. Coxe Cult. Fr. Trees 234. 1817. 2. Prince Pom. Man. 2:93. 1832. 3. Elliott Fr. Book 425. 1854. 4. Downing Fr. Trees Am. 9o6. 1869. 5. Am. Pom. Soc. Cat. 36. 1875. 6. Cornell Sta. Bul. 131:183. 1897. 7. Waugh Plum Cult. 98. 1901.

Copper 2. French Copper 3, 4. French Copper 1, 2, 6.

It is supposed that Copper came from France but very little is actually known regarding its history. The round early variety described by Coxe and Prince is distinct from the Copper now grown in this country. It is probable that the Copper of Downing and of the American Pomological Society are either distinct, or are early strains of the fruit described here, since both are mid-season plums while the variety of the following description is distinctly late. This old sort has been recommended of late by nurserymen and some plum-growers and it may be worth putting on the markets again as the trees are extremely productive, the fruit ships well, and its extreme lateness might extend the plum season. The fruit is not fit for dessert but makes an attractive, dark red, well-flavored sauce.

Tree variable in size and vigor, round and dense-topped, productive; branches numerous, with large lenticels; branchlets twiggy, marked with scarf-skin, glabrous throughout the season; leaves folded upward, obovate or oval, one and one-half inches wide, three and one-half inches long; upper surface rugose; margin serrate or crenate, eglandular or with small dark glands; petiole pubescent, tinged red, glandless or with one or two globose glands; blooming time mid-season, short; flowers appearing after the leaves, seven-eighths inch across; borne singly or in pairs.

Fruit very late, season of medium length; one and one-half inches by one and three-eighths inches in size, roundish-oval, slightly necked; cavity almost lacking; 
color a metallic brownish-purple, overspread with thick bloom; skin thick, tough, somewhat astringent; flesh dull yellow, medium juicy, firm, moderately sweet; poor; stone free, seven-eighths inch by one-half inch in size, irregular-ovate, abruptly contracted at the base, with roughened surfaces; dorsal suture prominent.

\section{CRITTENDEN}

\section{Prunus insititia}

1. Hogg Fruit Man. 695. I884, 2. Mathieu Nom. Pom. 426. I889. 3. Am. Gard. 14:146. 1893. 4. Gunde Prat. 163, 353. 1895. 5. Rural N. Y. 55:622, 1896. 6. Cornell Sta. Bul. 131: 184. 1897. 7. Garden 53:266. 1898. 8. Waugh Plum Cult. 127, 128. I901.

Crittenden's Damson 2. Crittenden's Prolific Damson 2. Crittenden's I. Crittenden's Prolific I. Cluster I. Cluster 3, 8. Cluster Damson 2. Cluster Damson 4. Damson Cluster 4. Farleigh Damson 6. Farleigh Prolific 7. Farleigh 5. Prolific 1. Prolific Damson 2.

This Damson came to notice early in the last century in the orchard of James Crittenden of East Farleigh, Kent, England. In both Europe and America it seems to be as well known under the names Farleigh and Cluster as under its true name. Crittenden ranks high among the Damsons in England but in America it is not a great favorite; just why is hard to say. It is likely that it fails in some tree-character, for, with the exception of being a little too tart, the fruit has few faults.

Tree of medium size, upright-spreading, open-topped, productive; branches very thorny and spinescent; branchlets pubescent throughout the season; leaf-buds plump; leaves folded upward, obovate or oval, one and one-eighth inches wide, two and onehalf inches long, thin; margin finely serrate, with small dark glands; petiole one-half inch long, glandless or with one or two glands; blooming season intermediate in time and length; flowers appearing after the leaves, seven-eighths inch across, densely clustered; borne usually in twos, fragrant.

Fruit late, season of medium length; seven-eighths inch by three-quarters inch in size, oval, slightly necked, purplish-black, overspread with very thick bloom; flesh greenish-yellow, medium juicy, firm but tender, sour, sprightly; probably good for preserves; stone clinging, five-eighths inch by three-eighths inch in size, oval, acute at the base, with surfaces nearly smooth.

\section{CZAR}

\section{Prunus domestica}

r. Hogg Fruit Man. 693. 1884. 2. Ellwanger \& Barry Cat. 27. 1886. 3. Gard, Chron. xo: 333. I891. 4. Guide Prat. I 53. 359. I895. 5. Cornell Sta. Bul. 131:183. 1897. 6. Rivers Cat. 34. 1898. 7. Mich. Sta. Bul. 169:242, 244. I899. 8. Ohio Sta. Bul. x13:159. I899. 9. Waugh Plum Cult. 99. I901. Io. Thompson Gard. Ass't 4:157. I901. I1. Nicholson Dict. Gard. $3: 166$. 12. Garden 68:303. 1905. 13. Ohio Sta. Bul. 162:236, 237 fig., 254, 255. 1905.

Le Czar 4. The Czar 2, 6, II. The Czar 4. 
Czar seems to have a very good reputation in Europe, in England especially, as a culinary fruit but in America it is but second rate for cooking and cannot be called a dessert plum at all. Its earliness might make it valuable were it not for the fact that Clyman is as early and in nearly all other respects is a better plum. The Czar, like Clyman, is not quite hardy and lacks somewhat in productiveness. The stone of Czar is usually covered with a granular, gummy exudation about the apex and its flowers are peculiar in being more or less doubled. It is doubtful if this variety is worth planting in New York. This plum was raised by Thomas Rivers, Sawbridgeworth, England, from a Prince Englebert seed fertilized by Early Prolific. It first fruited in 1874 and was named for the Czar of Russia who visited England during the same year. Ellwanger \& Barry, of Rochester, New York, offered it for sale in the United States in 1886.

Tree intermediate in size and vigor, round and open-topped, not always hardy, moderately productive; branches covered with many fruit-spurs, smooth except for the numerous raised lenticels and transverse cracks in the bark; branchlets covered with thick pubescence throughout the season, with numerous small lenticels; leaf-buds large, strongly free; leaves folded upward, oval, one and three-quarters inches wide, three inches long; petiole one-half inch long, thick, pubescent, eglandular or with one or two large, yellowish-green glands at the base of the leaf; blooming season intermediate in time, short; flowers appearing after the leaves, one inch or more across, white, with a yellowish tinge at the apex of the petals; borne in clusters on lateral spurs, in pairs or in threes; filaments five-sixteenths inch long; pistil glabrous except at the base, slightly longer than the stamens.

Fruit very early, season short; one and one-half inches in diameter, irregular roundish-oval, compressed, dark purplish-black, overspread with thick bloom; flesh yellow, coarse and somewhat granular, fibrous, tender, sweet, pleasant flavor; good; stone free, three-quarters inch by five-eighths inch in size, oval or slightly ovate, blunt at the base, somewhat acute at the apex, with ridged and roughened surfaces; ventral suture wide, broadly furrowed, with a short blunt wing; dorsal suture acute or with a narrow, shallow, indistinct groove.

\section{DAMSON}

\section{Prunus insititia}

I. Parkinson Par. Ter. 578. 1629. 2. Gerard Herball 1496, 1498. 1636. 3. Quintinye Com. Gard. 67. 1699. 4. Langley Pomona 94. 1724. 5. Forsyth Treat. Fr. Trees 21 . 1803. 6. Am. Gard. Cal. 588. 1806. 7. Phillips Com. Orch. 306. 1831. 8. Lond. Hort. Soc. Cat. 145, 146. 183 r. 9. Downing Fr. Trees Am. 297. 1845. 10. Thomas Am. Frut Cult. 342. 1849. I1. Am. Pom. Soc. Cat. 86. 1862. 12. Hooper W. Fr. Book 244. 1857. 13. Mas Pom. Gen. 2:69. 1873. 14. Manning Hist. Mass. Hort. Soc. 4. 1880. 15. Hogg Fruit Man. 695. 1884. 16. De Candolle Or. Cult. Plants 212, 1885. 17. Mathieu Nom. Pom. 438, 1889. 18. Am. Gard. 14:146, 147. 1893. 
August Pfaume 1 7. Blacke Damascene ?1. Blew Damson 1, Black Damascene 5. Black Dam. son ?8. Black Damson 9, I1, 17. Blew Damask 3. Black Damosine 4. Blue Damsan 10, Ir. Bullace 17. Common Damson 6, 15. Common Damson 8, 9, 10, 11, 13, 17. Damascene 2. Damascene 7. 16. Damson 17. Damas Noir ?8. Damascus ?8. Damas Commun 13. Early Damson of many 9, 10, 17. Haber Pflaume 17. Hafer Schlehe 17. Jakobs Pflaume 17. Kleine Blaue Julians Pflaume 17. Kreke 17. Krieche 17. Purple Damson 9, 10, 17. Prunus Insititia 17. Round Damson 8, 15. Round Black Damson ?8. Small Round Damson 8. Sankt-Julians Pflaume 17. Schlehen Pfaume 17. Wahre Schlehen Damascene 17. Zipperle 17. Zipperlein 17.

The common Damson, the Damson of the ancients, probably little changed since before Christ's time, is still worthy of cultivation even though a score or more of its offspring are offered to take its place. In productiveness, vigor of tree and hardiness it is scarcely surpassed by any of its kind and while its fruits are smaller and more astringent than the best of its offspring they are not surpassed for the chief use of all Damsons-the making of preserves. The chief asset of the Damson is its great adaptability to various soils and climates, surpassing all newcomers of its type in this respect. So while undoubtedly some of the improved Damsons surpass the parent variety under many conditions, there yet remain localities in which the original stock is possibly most valuable.

The Damson takes its name from Damascus from whence it was brought into Italy at least a century before the Christian era. What is a Damson? In England and America it is an oval, usually black, Insititia The European continental countries have an entirely different conception of a Damson from that of the English and Americans. The Germans speak of our common plums as Damson-like, while the French use the term Damas indiscriminately. The English, however, have not always made a sharp distinction for Parkinson in 1629 speaks of the great Damaske or Damson Plummes as sweet prunes imported from France and Gerard in r6 36 described the Damson tree as synonymous to the Plum. The term Damson is applied to a group as well as to a variety. For a further history of this plum in Europe and America see the index for references to the Damson in Chapter I.

\section{DAWSON}

\section{Prunus domestica}

Dawson Seedling. American Prune.

Dawson is a prune-like plum characterized by an elongated neck, a peculiar putty-like color of flesh and by large size. The quality is very good and the trees in all characters are well up to the average of those of the plums on the Station grounds. The plum is worthy a more exten- 
sive trial than it has yet had. The following history of the variety is given by its originator: In 1884, P. P. Dawson of Payette, Idaho, planted a lot of Italian prune pits. In I89 I one of the seedlings produced fruit which was so distinct as to size that Mr. Dawson deemed it worthy of propagation. The variety was introduced by Mr. Dawson and A. F. Hitt, Weiser, Idaho, about 1898 .

Tree above medium in size, vigorous, round and dense-topped, productive; branchlets thick, short, twiggy, marked with scarf-skin; leaf-scars prominent; leaves flattened, oval, two and one-quarter inches wide, four inches long, dark green, rugose; margin doubly crenate, eglandular or with small dark glands; petiole pubescent, glandless or with one or two small glands usually at the base of the leaf; blooming season late, short; flowers appearing with the leaves, white with yellowish tinge; petals fringed at the apex.

Fruit mid-season, ripening period short; medium in size, strongly obovate, distinctly necked, dark reddish-purple, overspread with medium thick bloom; flesh light but dull yellow, tinged red near the surface, dry, firm, medium sweet, mild but pleasant; of good quality; stone clinging, above medium in size, long-oval or ovate, flattened, distinctly necked, with roughened surfaces; ventral suture broad, blunt.

\section{DECAISNE}

\section{Prunus domestica}

1. Gard. Chron. 23:46r. 1863. 2. Mas Pom. Gen. 2:43. 1873. 3. Cat. Cong. Pom. France 4Ir. 1887. 4. Guide Prat. 159. 1895.

Decaisnes Pflaume 2. Prune Decaisne I, 2.

Though a supposed seedling of Golden Drop this variety has all of the ear-marks of one of the Reine Claude group. It is inferior to several other plums of the last named group and is not worth recommendation. Decaisne was originated about 1846 by Jamin and Durand, nurserymen, at Bourg la-Reine, near Paris, France, from seed of Golden Drop. In the United States, it has been mainly distributed by Ellwanger \& Barry of Rochester, New York, and by the California Nursery Company of Niles, California.

Tree intermediate in size and vigor, upright-spreading, rather open-topped, productive; trunk rough; leaves two inches wide, four inches long, oval, thick, leathery; upper surface rugose; lower surface thinly pubescent; petiole with from two to three large, globose or reniform glands.

Fruit mid-season or later; one and seven-eighths inches by one and five-eighths inches in size, oblong-oval, greenish-yellow, overspread with thin bloom; skin sour; flesh greenish-yellow, tender, mild; good; stone clinging, one inch by seven-eighths inch in size, broad-oval, with pitted surfaces; ventral suture rather prominent, heavily grooved, with a short but distinct wing; dorsal suture wide, deep. 


\section{DE CARADEUC}

\section{Prunus cerasifera}

1. Am. Pom. Soc. Rpt. 86. 1871. 2. Am. Pom. Soc, Cat. 38. 1877. 3. Barry Fr. Garden 418. 1883. 4. Cornell Sta. Bul. 38:66, 71,86 . 1892. 5. Bailey Ev. Nat. Fruits 212.1898 .6$. Vt. Sta. An. Rpt. 13:369. 1900. 7. Waugh Plum Cult. 230. r901. 8. Budd-Hansen Am. Hort. Man. 3 10. 1903. 9. Ga. Sta. Bul. 67:274. 1904. 10. Ga. Hort. Soc. Cat. 13. 1905.

Caradeuc $\mathrm{I}$.

De Caradeuc is without value in this climate for its fruit and is described at length and illustrated in The Plums of New York only because it is one of the few representatives of Prunus cerasifera cultivated for its fruit. The plums are garnet-red, very attractive in appearance and are borne so much earlier than those of other species that the variety may be worth planting in home orchards to lengthen the season and for the sake of variety. This plum is grown rather commonly in the South where the fruits are said to keep well and not rot. The trees are handsome ornamentals bearing remarkably rich, green foliage and a profusion of white flowers which are followed by beautifully colored fruits. The variety can be recommended for lawn or park where a small, compact, flowering tree is wanted.

De Caradeuc originated with A. De Caradeuc, Aiken, South Carolina, between 1850 and 1854 . Mr. De Caradeuc brought plum trees from France and planted them in the vicinity of several native plum trees. From the seed of the former he produced this variety. The originator believed his new plum to be a hybrid but practically all students of plum botany think that it is a pure offshoot of Prunus cerasifera. The variety was introduced by P. J. Berckmans of Augusta, Georgia. In I 877 De Caradeuc was placed on the American Pomological Society fruit catalog list where it is still maintained.

Tree very large, vigorous, spreading, open-topped, variable in productiveness; trunk rough; branches slender, roughish or smooth, dark ash-gray, with numerous, large, raised lenticels; branchlets very numerous, twiggy, slender, medium to long, with long internodes, tinged with red when young, changing to dull reddish-brown, glossy, glabrous, with few, small lenticels; leaf-buds very small and short, obtuse, appressed.

Leaves numerous on the branchlets, becoming scattering in the interior of the tree, folded upward, oval, one and one-eighth inches wide, two inches long, thin; upper surface dark green, sparingly pubescent, smooth, with broadly grooved midrib; lower surface pale green, pubescent; apex acute, base broadly cuneate, margin often in two series of fine serrations, without glands; petiole slender, one-half inch long, slightly 


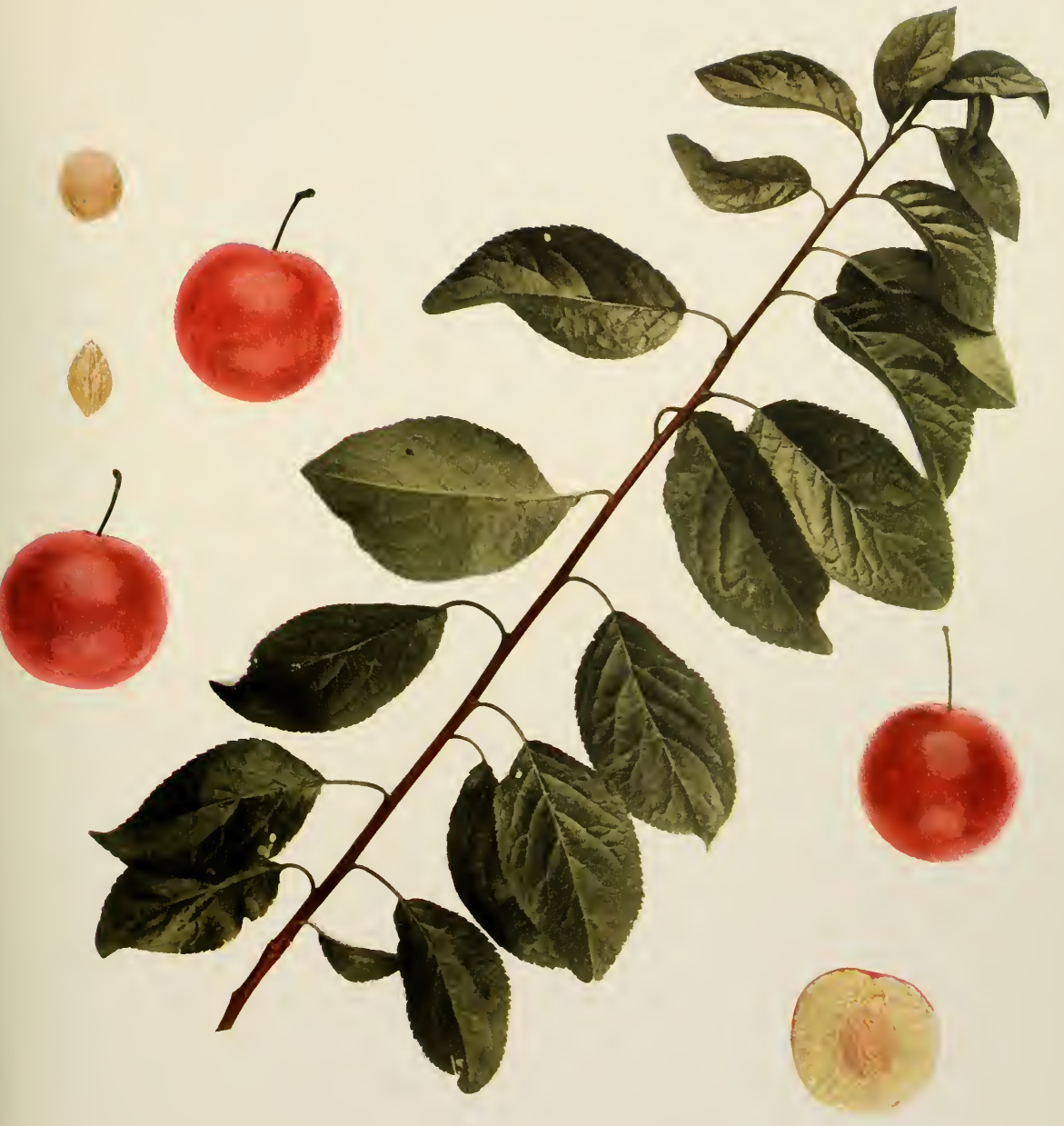

DE CARADEUC 

pubescent, tinged red, eglandular or with one or two very small, globose, greenish glands usually at the base of the leaf.

Blooming season rather early, short; flowers appearing after the leaves, seveneighths inch across, white; borne on lateral buds and spurs; pedicels eleven-sixteenths inch long, below medium in thickness, glabrous, green; calyx-tube reddish, campanulate, glabrous; calyx-lobes broad, obtuse, slightly glandular-serrate, pubescent, strongly reflexed; petals roundish or ovate, crenate, not clawed; anthers yellow; filaments one-quarter inch in length; pistil glabrous, longer than the stamens, somewhat defective.

Fruit very early, season short; one and one-quarter inches in diameter, roundish, halves usually equal; cavity shallow and narrow, abrupt, regular; suture a dark red line; apex roundish; color light or dark crimson-red over a yellow ground, overspread with thin bloom; dots few, light russet, clustered about the apex; stem slender, eleven-sixteenths inch in length, glabrous, adhering well to the fruit; skin thin, tough, parting readily; flesh medium yellow, very juicy, fibrous, tender and melting, slightly sweet, lacking in flavor; inferior in quality; stone clinging, five-eighths inch by onehalf inch in size, roundish-oval, turgid, blunt, with somewhat pitted surfaces; ventral suture acute, furrowed; dorsal suture distinctly and broadly grooved.

\section{DE SOTO}

\section{Prunus americana}

1. Ill. Hort. Soc, Rpt. $225.1877 . \quad$ 2. Ia. Hort. Soc. Rpt. 356. 1879. 3. Ibid. 159. 1880. 4. Ibid. 237. 1882. 5. Am. Pom. Soc. Cat. 42. 1883. 6. Ia. Hort. Soc. Rpt. $3_{66}$ 1 $888_{3}$. 7. Ill. Hort. Soc. Rpt. 63. 189o. 8. Cornell Sta. Bul. $38: 37,86$. 1892. 9. Wis. Sta. Bul. $63: 24,35,36$ fig. 16. 1897. Io. Waugh Plum Cult. 147. 1901. 11. Budd-Hansen Am. Hort. Man. 295. 1903. 12. Can. Exp. Farm Bul. 43:30. 1903. 13. S. Dak. Sta. Bul. 93:15. 1905.

Traer 3. Trayer 4 .

De Soto probably holds first place among the Americana plums in the favor of fruit-growers. The qualities which commend it are: A tree rather better suited to the orchard than other varieties of Prunus americana having little of the waywardness of most sorts of its species and somewhat the manner of growth of the European plums. The trees, too, are enormously productive, so much so that in many cases their vitality is weakened by over-bearing unless thinned. The fruits of De Soto, while not as large nor as brilliantly colored as some of the Americanas, are not surpassed by any of the native plums in quality and keep and ship as well as any. The variety becomes, therefore, a market sort of value in some regions. The fruits are a little more subject to curculio than those of most of the native plums and the trees blight in the South somewhat and do not stand the drouths of the Mississippi Valley as well as some other varieties. Notwithstanding these defects, speaking generally, the De Soto may be recommended as one of the best of its species. 
De Soto was found on the bank of the Mississippi River near De Soto, Wisconsin. The first settler to call attention to the plum was a Mr. Tupper who settled on the land where it was found in 1853 or 1854 . The Trayer Brothers bought the place in 1855 and in clearing the farm they removed all the plum trees except a grove of what was at first called Trayer, afterwards De Soto. Later Stephen Heal came into possession of the property and in 1864 Elisha Hale, Lansing, Iowa, commenced to cultivate and disseminate the variety. De Soto was placed on the American Pomological Society fruit catalog list in 1883 , dropped in 1891 , and restored again in 1897 .

Tree small, intermediate in vigor, spreading, open-topped, perfectly hardy, produces heavy crops annually, bears young; branches rough and shaggy, somewhat zigzag, thorny, dark ash-brown, with inconspicuous, small, raised, lenticels; branchlets numerous, long, green, changing to dull reddish-brown, pubescent at first, becoming glabrous late in the season, with conspicuous, large, raised lenticels; leaf-buds below medium in size, pointed, appressed.

Leaves falling early, folded upward, oval, one and three-quarters inches wide, four inches long; upper surface dark green changing to greenish-yellow, glossy, with scattering hairs and a narrow, grooved midrib; lower surface finely pubescent; apex taper-pointed, base somewhat abrupt, margin very coarsely and deeply doubly serrate, petiole five-eighths inch long, of medium thickness, pubescent, tinged red, glandless or with one or two globose, brownish glands on the stalk.

Blooming season medium to late and of average length; flowers appearing after the leaves, one and one-eighth inches across, white; borne in clusters on lateral buds and spurs, in twos and threes; pedicels eleven-sixteenths inch in length, below medium in thickness, covered with short, thick pubescence, greenish; calyx-tube green, campanulate, pubescent; calyx-lobes somewhat acute, eglandular, thickly pubescent on both surfaces, with a swollen ring at the base of the lobes, semi-reflexed; petals oblong or ovate, erose, tapering abruptly into long, narrow claws; anthers yellowish; filaments three-eighths inch in length; pistil glabrous, equal to or shorter than the stamens.

Fruit mid-season, ripening period short; one and one-half inches in diameter, roundish, varying to oval or ovate, compressed, often strongly truncate at the base; cavity shallow or medium, abrupt; suture very shallow or a line; apex roundish or somewhat pointed; color yellowish-red becoming a light or dark crimson over an orangeyellow ground, overspread with thin bloom; dots very numerous, small, light russet, inconspicuous; stem rather slender, three-quarters inch long, sparingly pubescent; skin thick, tough, very astringent, clinging to the pulp; flesh golden-yellow, very juicy, fibrous, tender and melting, of medium sweetness, mild; fair to good; stone nearly free, seven-eighths inch in size, oval, turgid, blunt-pointed, smooth; ventral suture bluntly acute and with slight furrows; dorsal suture acute, not furrowed. 


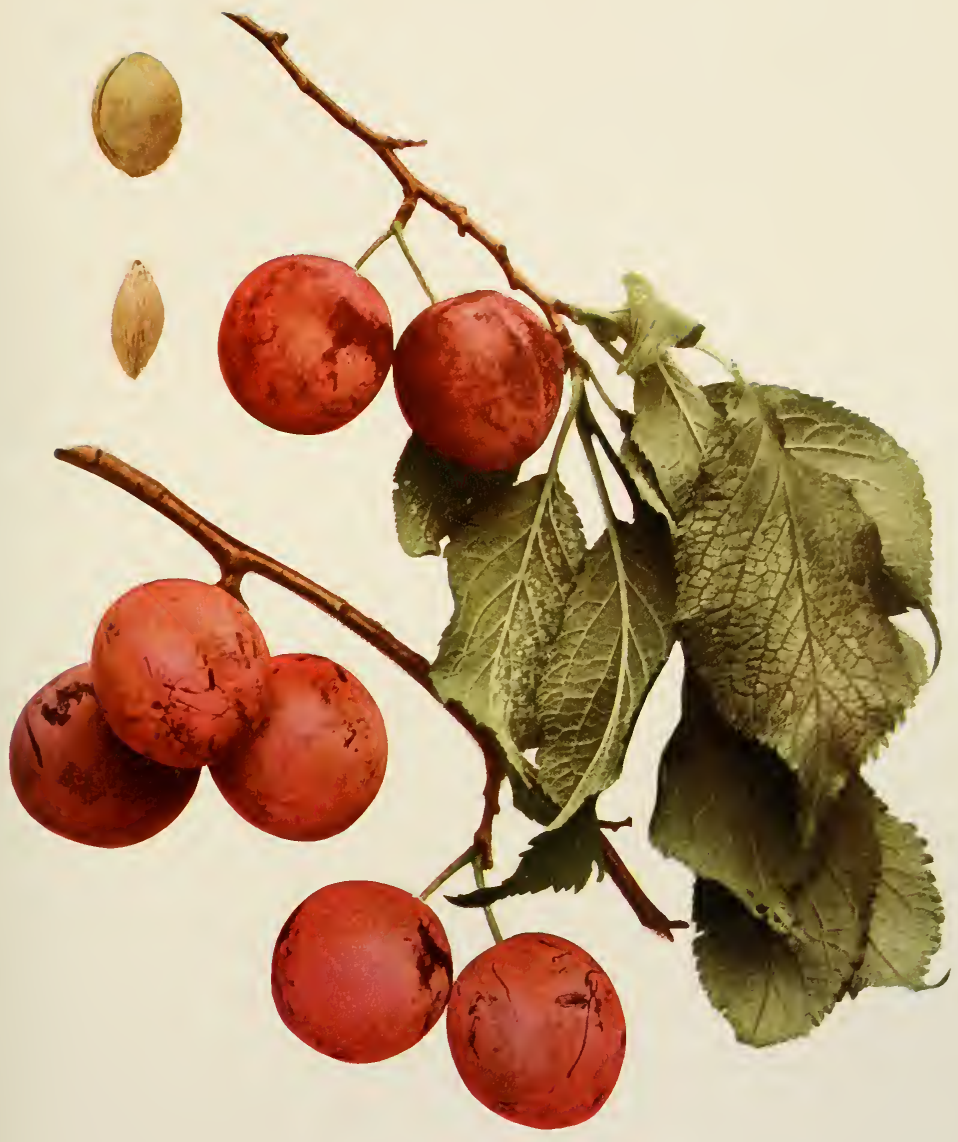





\section{DIAMOND}

\section{Prunus domestica}

1. Lond. Hort. Soc. Cat. 146. 1831. 2. Kenrick Am. Orch. 259. 1832. 3. Downing Fr. Trees Am. 298. 1845. 4. Lee Gen. Farmer 6:141. 1845. 5. Am. Pom. Soc. Cat. 222, 244. 1858.6. Hogg Fruit Man. 696. 1884. 7. Mich. Hort. Soc. Rpt. 327. 1889. 8. Guide Prat. 159, 355. 1895. 9. Mich. Hort. Soc. Rpt. 382 . 1895. 1o. Cornell Sta. Bul. 131:183, fig. 40 VI. 1897 . II. Am. Pom. Soc. Cat. 25. 1897. 12. Vt. Sta. An. Rpt. 12:214, $217.1899 . \quad$ 13. Mich. Sta. Bul. 169:244. 1899. 14. W. N. Y. Hort. Soc. Rpt. 92. 1899. 15. Garden 56:168. 1899. 16. Can. Exp. Farm Bul. 43:33. 1903. 17. Can. Exp. Farms Rpt. 423. 1903.

Black Diamond 9. Black Diamond 11,13 . Diamant 8. Diamantpflaume 8. Dymond 15. Kentish Diamond 17 . Kingston 14 incor. Smith's Prune 7. Smith Prune 14.

To judge Diamond by appearance would be a grievous error. It is a large, beautifully colored, well-formed plum, tempting the palate; but one taste out of hand is a sufficiency. The flesh is coarse and the flavor not at all pleasant to one accustomed to good plums. Hogg says, in the reference given, that Diamond is one of the best preserving and cooking plums but in this case we doubt Hogg's judgment unless, as may be, Diamond is much better in England than in America. The firm flesh and tough skin of the variety commend it as a market plum and the trees are above the average in size, vigor, hardiness and productiveness-all characters excepting quality bespeaking the favor of plum-growers. It is planted largely for the markets where, of course, it sells upon its appearance.

According to Downing, this variety was raised from seed by an Englishman, in Kent, named Diamond. Kenrick and Hogg, however, state that it was raised in the nursery of a Mr. Hooker, in Kent. The London Horticultural Society briefly described this variety in its fruit catalog for $\mathrm{I}_{3} \mathrm{I}$ so that its origin antedates that year. The American Pomological Society rejected Diamond for its catalog in $185^{8}$ but placed it in its fruit list in 1897 .

Tree above average in size and vigor, upright-spreading, somewhat dense-topped, hardy, very productive; branches ash-gray, roughish, with numerous, small lenticels, the bark marked with transverse lines; branchlets of medium thickness and length, with long internodes, greenish-red changing to dark brownish-red, dull, somewhat pubescent, with numerous, small lenticels; leaf-buds large, long, pointed, appressed.

Leaves folded upward, obovate or oval, one and seven-eighths inches wide, three and one-quarter inches long; upper surface dark green, with few hairs and with a grooved midrib; lower surface pubescent; apex obtuse to acute, base acute, margin serrate, with small, brown glands; petiole five-eighths inch long, slender, pubescent, reddish, with from one to four small, globose or reniform, greenish-yellow glands on the stalk or base of the leaf. 
Blooming season early or medium, short; flowers appearing aftcr the leaves, one inch across, the buds yellow-tipped changing to white on expanding; borne on lateral spurs, in pairs; pedicels five-eighths inch long, somewhat slender, pubescent, green; calyx-tube greenish, campanulate, pubescent; calyx-lobes broad, obtuse, pubescent on both surfaces, glandular-serrate, reflexed; petals broadly oval or roundish, entire or slightly crenate, tapering to short, broad claws; anthers roundish, yellow; filaments five-sixteenths inch in length; pistil lightly pubescent at the base, longer than the stamens.

Fruit mid-season, ripening period short; one and seven-eighths inches by one and three-quarters inches in size, oval, slightly necked, swollen on the ventral side, compressed; cavity very narrow and abrupt; suture shallow, often a line; apex roundish or pointed; color deep reddish-purple changing to dark purplish-black at full maturity, with thick bloom; dots numerous, small, russet, inconspicuous; stem slender, one inch long, finely pubescent, adhering well to the fruit; skin thin, rather sour, separating readily; flesh pale or golden-yellow, sometimes with a faint red tinge next the skin, not juicy, coarse, firm but rather tender, mild subacid to nearly sweet, not high in flavor; of fair quality; stone with a trace of red, semi-clinging, one and one-eighth inches by fiveeighths inch in size, long-oval, necked at the base, abruptly sharp-pointed at the apex, with pitted surfaces; ventral suture rather broad, lightly furrowed; dorsal suture widely grooved.

\section{DOUBLE FLOWERING GAGE}

\section{Prunus domestica}

I. Duhamel Trait. Arb. Fr. 2:92. 1768. 2. Knoop Fructologie 57. 1771. 3. Kraft Pom. Aust. 2:32, Tab. 179 fig. 2. 1796. 4. Prince Pom. Man. 2:49. 1832. 5. Mag. Hort. 9:165. 1843. 6. Downing Fr. Trees Am. 316. 1845. 7. Poiteau Pom. Franc. 1:1846. 8. Mas Pom. Gen. 2:47. I873. 9. Gurde Prat. 163,363 . I895.

Die grosse Königin Klaudia Pflaume mit halbgefullter Bluthe 3. Dauphin à Fleurs semidoubles 5. Dauphin à Fleurs doubles 5. Dauphin d̀ fleurs semi-doubles 5. Double-blossomed 5. Double-blossomed Plum 6. Gelbe Reneclode Mit Gefullter Bluthe 8. Prune a Fleurs Doubles 8. Prunier à fleurs semi-double 8. Prunier à fleur semi-double 1, 7. Prune à Fleurs Doubles 2. Prunier à fleur semi-double 4. Prune Semi-double 4. Prune à fleurs semi-double 4. Reine-Clande Semi-Double 8. Renne-Claude à fleur semi-double 4. Reine-Clande à Fleurs Semi-double 5, 9. ReineClaude mit Halbgefullter Bluthe 9. Semi-double flowering Reine Claude 4.

This is an ornamental variety of the Reine Claude type first noted by Duhamel in 1768 . It was probably well known in Europe at this time for a little later it was mentioned by Knoop of Holland and Kraft of Austria. Duhamel described two varieties; one with small fruit which was insipid when over-ripe, and the other large and of good flavor. In 1846 , Poiteau thought the latter was probably identical with a variety growing at Luxembourg but he did not think the former was extant. In the third edition of the London Horticultural Society's catalog, yellow and purple forms were mentioned, showing that the variety has been represented by more 


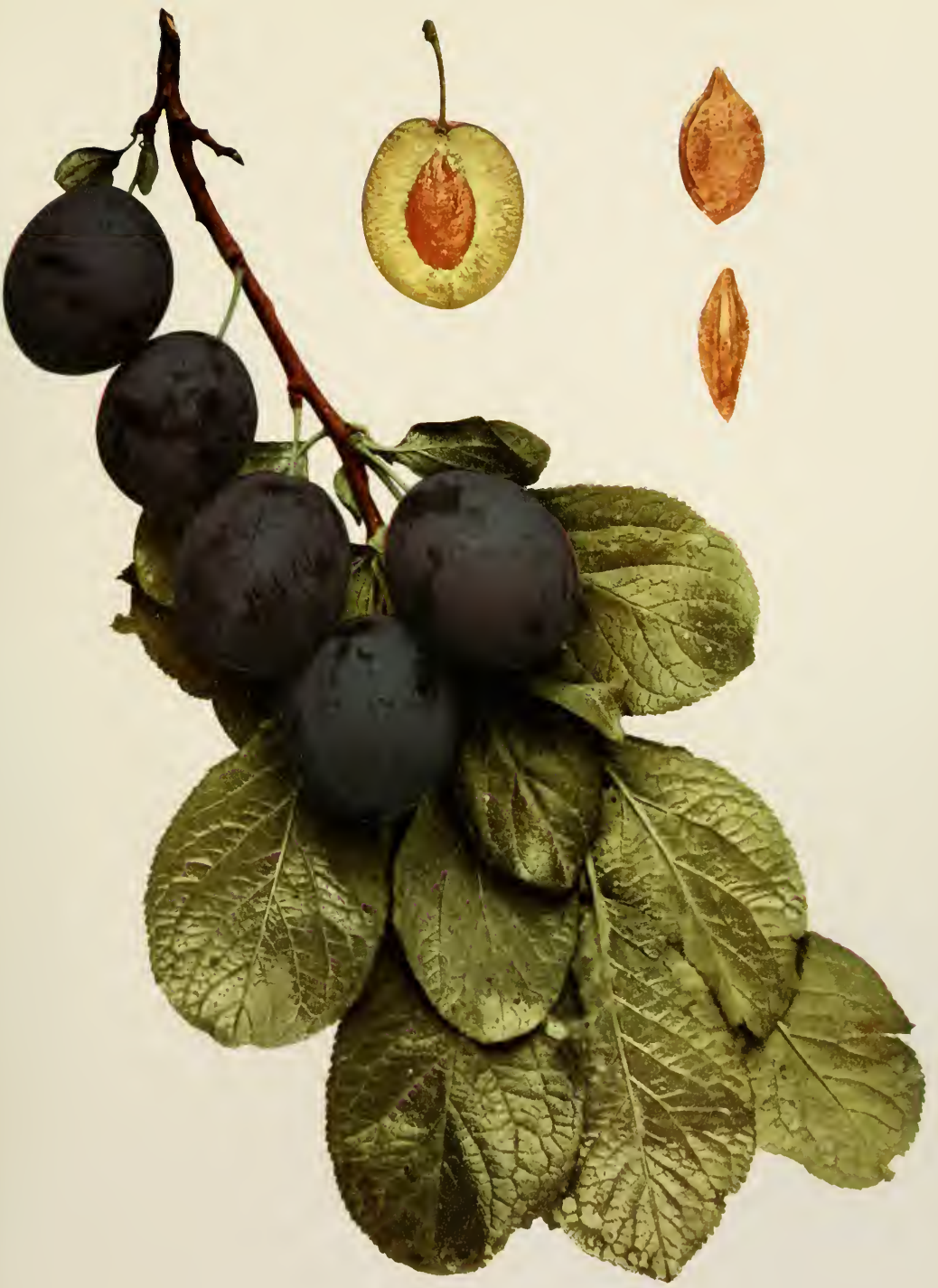


than one type. It is worthy of note that the double blossoms, except in strong soils, are apt to degenerate and become single. The following description is compiled.

Tree irregular and spreading, unproductive; branches brown on the shaded side and blood-red on the sunny side; flowers large, semi-double, with from twelve to eighteen petals; fruit mid-season; large, spherical; suture shallow, sometimes a line; flesh greenish-yellow, tender, soft, juicy, sweet, agreeably aromatic; clingstone.

\section{DOWNING}

\section{Prunus munsoniana}

1. Ia. Hort. Soc. Rpt. $287.1887 . \quad$ 2. Ibid. $275,448.1893 . \quad$ 3. Ibid. 334. 1894. 4. Wis. Sta. Bul. 63:24, 30. 1897. 5. Am. Pom. Soc. Cat. 24. 1897. 6. Waugh Plum Cult. 185. 1901. 7. Wis. Sta. Bul. 87:12. 1901. 8. Ia. Sta. Bul. 46:269. I900. 9. Ia. Hort. Soc. Rpt. 445. I903. 10. Ohio Sta. Bul. 162:247 fig., 254, 255. 1905. I1. S. Dak. Sta. Bul. 93:15. 1905.

Charles Downing $1,2,3,4,7$. Charles Downing 5, 6, 8, I1.

Downing is one of the best varieties of its species. The trees are large, usually productive, not often sterile as are some of its near of kin sorts and for a southern plum the variety is remarkably hardy, never having suffered in Geneva from cold. The only fault that can be found with the tree is that the foliage is quite susceptible to the shot-hole fungus. The fruit is particularly attractive with its bright, solid, garnet-red skin, golden flesh and sweet, pleasant flavor. Unfortunately the flesh is a little too fibrous and clings too tenaciously to the stone for pleasant eating. Downing adds a pleasing variety to any collection of plums and in some regions ought to sell with profit to the grower for the markets.

H. A. Terry of Crescent, Iowa, grew Downing from seed of the Wild Goose, which the originator thinks was fertilized by some Americana variety. The Downing, however, shows no traces of Americana parentage. It is reported as originating in 1882 and first fruiting in 1885 . The American Pomological Society placed this variety on its fruit catalog list in 1897 .

Tree large, spreading, flat-topped, hardy in New York, variable in productiveness; branches rough, dark gray, with a few large lenticels; branchlets slender, with very short internodes, greenish-red changing to dull reddish-brown, glossy, somewhat pubescent, with numerous, small, slightly raised lenticels; leaf-buds small, short, obtuse, appressed.

Leaves folded upward, broadly lanceolate, peach-like, one and three-eighths inches wide, three inches long, thin; upper surface reddish late in the fall, smooth, glabrous, with deeply grooved midrib; lower surface glabrous except along the midrib and larger 
veins; apex taper-pointed, margin very finely serrate, eglandular or sometimes with small dark glands; petiole thirteen-sixteenths inch long, slender, tinged with red, pubescent along one side, glandless or with from one to five small, globose, yellowishred glands usually on the stalk.

Blooming season medium to late, long; flowers appearing after the leaves, one and one-sixteenth inches across, the buds yellow-tipped changing to white when expanded, with a strong, disagreeable odor; borne in dense clusters on lateral buds and spurs, in threes; pedicels eleven-sixteenths inch in length, very slender, glabrous, greenish; calyxtube green, obconic, glabrous; calyx-lobes below medium in width, acute, finely pubescent on the inner surface only, somewhat reflexed, glandular-serrate, the glands numerous and dark colored; petals oval, narrow, long, crenate, tapering beneath to long, narrow claws; anthers pale yellow, with a faint reddish tinge; filaments seven-sixteenths inch in length; pistil slender, glabrous, shorter than the stamens.

Fruit mid-season, ripening period short; about one and one-eighth inches in diameter, rather large for its class, roundish-ovate, not compressed, halves equal; cavity shallow, narrow, flaring; suture very shallow and obscure; apex roundish or slightly conical; color garnet-red, with thin bloom; dots numerous, variable in size, grayish-yellow, conspicuous, clustered around the apex; stem slender, about three-eighths inch in length, glabrous, parting readily from the fruit; skin thin, slightly astringent, adhering but little; flesh golden-yellow, juicy, coarse, fibrous, tender and somewhat melting, very sweet next the skin but tart toward the center, aromatic; good; stone clinging, three-quarters inch by one-half inch in size, oval, somewhat oblique, turgid, roughish; ventral suture narrow, strongly winged; dorsal suture acute, unfurrowed.

\section{DRAP D'OR}

\section{Prunus insititia}

1. Quintinye Com. Gard. 2:69. I699. 2. Langley Pomona 94, 97, P1. 24 fig. 5. 1729. 3. Duhamel Trait. Arb. Fr. 2:96. 1768. 4. Knoop Fructologie 57. 1771. 5. Coxe Cult. Fr. Trees 233 fig. 2. 1817 . 6. Lond. Hort. Soc. Cat. 146. 18 31 . 7. Prince Pom. Man. 2:75. 18 $3_{2}$. 8. Kenrick Am. Orch. 261. 1832. 9. Mag. Hort. 9:163. 1843. Io. Downing Fr. Trees Am. 274. 1845. 11. Poiteau Pom. Franc. 1:1846. 12. Floy-Lindley Guide Orch. Gard. 297, 383. 1846. 13. Thompson Gard. Ass't 516. 1859. 14. Hogg Fruit Man. 359, 371, 387. 1866. 15. Pom. France 7 :No. 12. 1871. 16. Am. Pom. Soc. Cat. 36 , 1875. 17. Cat. Cong. Pom. France 350.1887. 18. Mathieu Nom. Pom. 428. 1889. 19. Guide Prat. 153, 359. 1895. 20. Soc. Nat. Hort. France Pom. 538 fig. 1904. 21. Baltet Cult. Fr. $489,503.1908$.

Cloth of Gold 2, 5, 7, 12, 14, 18, 19. Cloth of Gold Plum 15. Damas Jaune 15, 18, 19. Doppelte Mirabelle 18. Drap d'Or I, 2. Drap d'Or Pflaume 15. Drap d'Or 7, 15, 18, 19, 20, 21. Double Drap d'Or 17. Double Mirabelle 17. Glauzende gelbe Mirabelle 15. Glänzende Gelbe Mirabelle 18, 19. Gold Pflaume 18. Goldfarbige Pflaume 15, 18, 19. Goldstoff 18. Goldzeng 18. Grosse Mirabelle ?7, 15, 18, 19, 21. Grosse Mirabelle 8, 21. Grosse Mirabelle Drap d'Or 18, 19. Mirabelle 15, 17. Mirabelle Double 19, 21. Mirabelle Double 3, 5, 6, 7, 10, 12, 13, 14, 18. Mirabelle Double de Metz 20. Mirabelle de Nancy 19, 21. Mirabelle de Nancy 14, 18. Mirabelle Drap d'Or 15, 18, 19. Mirabellen 15. Mirabelle grosse double de Metz 15, 18, 19. Mirabelle Grosse de Nancy 20. Mirabelle Grosse 15, 17, 20, 21. Mirabelle la grosse 7, 15, 18, 19. Mirabelle Grosse 6, ?7, 10, 13, 14, 15, 19. Mirabelle Perlée 15, 18, 19. Mirabelle von Metz 15. Perdrigon Hatif 15, 20, of 


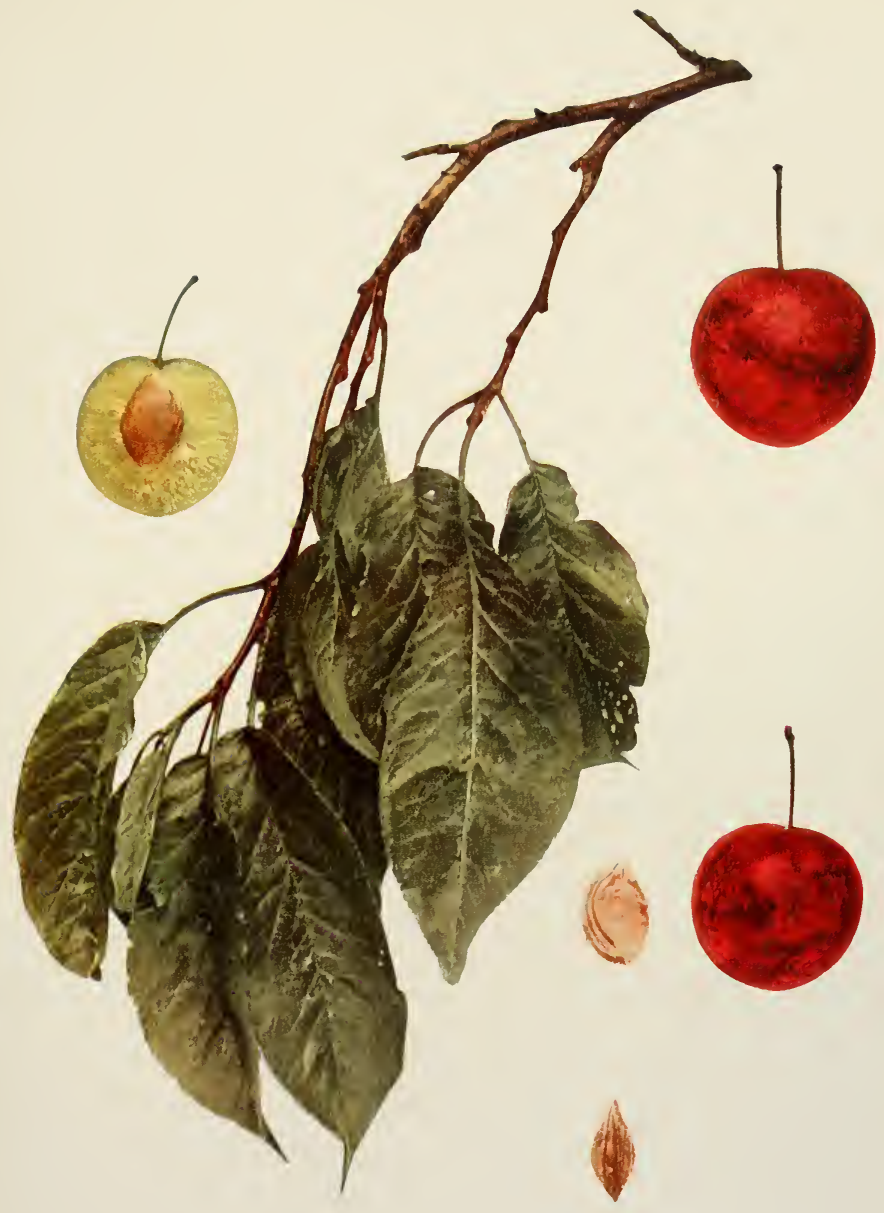

DOWNING 


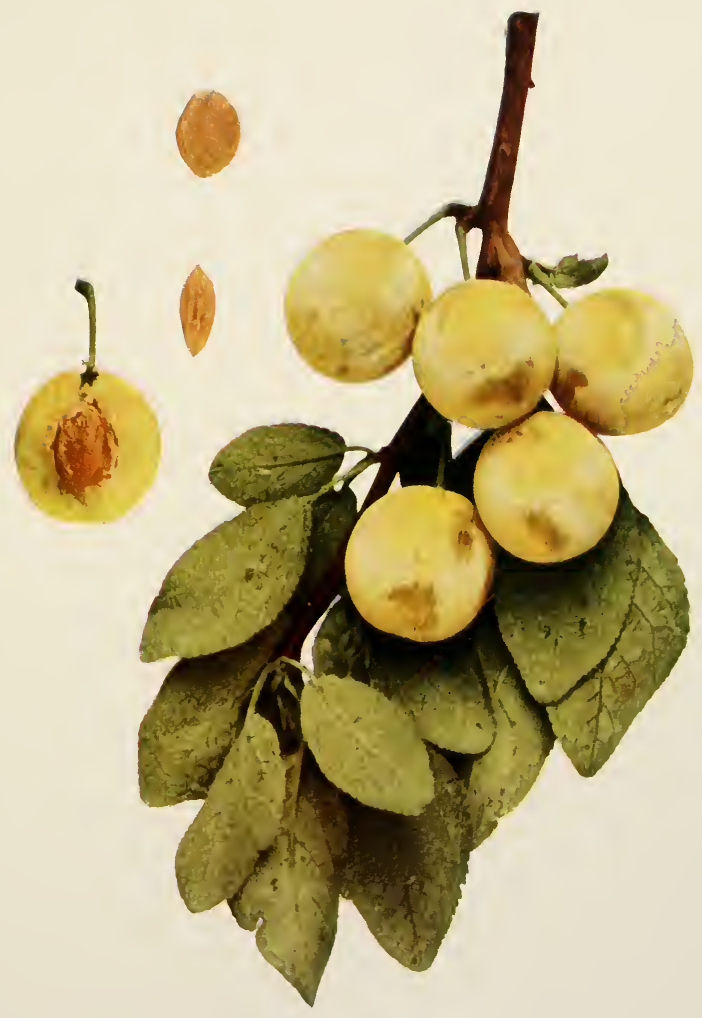



some 17, 18, 19. Perdrigon Jaune 20. Yellow Damask ?14. Yellow Damask 14, 18. Yellow Gage of some 5. 7. Yellow Perdrigon 9, 10, 13, 14, 15, 18, 19.

Drap d'Or represents a type of the plum hardly known in America but very populer in continental Europe and most popular of all plums in France, the chief plum-growing country of the Old World. It is probable that the division of Prumus insititia represented by Drap d'Or, the Mirabelle plums, will thrive in America as well as the commonly grown Damsons of the same species. These plums certainly deserve to be far more generally planted than they now are. It is certain from the behavior of the few trees of the Mirabelle group now growing in New York that they have very decided merit. Drap d'Or is probably not the best of the yellow, sweet Insititias but it is at least well worth trial.

According to Pomologie De La France, this variety was cited by Merlet in 1675 and is of old and uncertain origin. Merlet placed the Mirabelle and the Drap d'Or in the Damas class, but Poiteau thought that the latter was probably a cross between Reine Claude and Mirabelle since it resembled the former in quality and shape and the latter in color and size. Yellow Damask, Mirabelle de Nancy, Yellow Perdrigon, Gross Mirabelle and others have proved to be identical with the Drap d'Or as tested in Europe. Whether all of the other synonyms mentioned are the true Drap d'Or is a question; their number indicates that there are many variations in this type of the plum. The American Pomological Society placed Drap d'Or in its catalog list in 1875 and withdrew it in 1899 .

Tree small, upright-spreading, dense-topped, hardy, productive; branches ashgray, with a brownish tinge, smooth, with very few, small lenticels; branchlets of average thickness and length, greenish-red changing to brownish-red, dull, sparingly pubescent throughout the entire season, with few, obscure, small lenticels; leaf-buds of medium size and length, conical, appressed.

Leaves folded upward, oval, one and one-fourth inches wide, two and one-half inches long; upper surface slightly roughened, covered with numerous hairs, the midrib grooved; lower surface silvery-green, pubescent; apex pointed or acute, base abrupt, margin serrate or crenate, eglandular or with small dark glands; petiole one-half inch long, pubescent, tinged red, glandless or with from one to three globose, greenish-yellow glands usually on the stalk.

Flowers fifteen-sixteenths inch across, the buds creamy changing to white when expanded; borne in clusters on lateral spurs, usually in pairs; pedicels nine-sixteenths inch long, sparingly pubescent, greenish; calyx-tube green, campanulate, nearly glabrous; calyx-lobes obtuse, pubescent on both surfaces, glandular-serrate, somewhat reflexed; petals broadly oval, crenate or sometimes notched at the apex, tapering 
below to short, broad claws; anthers yellowish; filaments five-sixteenths inch long; pistil glabrous, equal to the stamens in length.

Fruit mid-season; one and one-eighth inches by one inch in size, roundish-oval, compressed, halves equal; cavity shallow, narrow, flaring; suture very shallow, often a line; apex roundish or depressed; color greenish-yellow changing to golden-yellow, somewhat mottled and blotched, occasionally with a faint bronze blush on the exposed cheek, overspread with thin bloom; dots numerous, small, whitish, inconspicuous; stem slender, sparingly pubescent, adhering well to the fruit; skin thin, separating readily; flesh light golden-yellow, moderately juicy, coarse, firm but tender, sweet, mild; of good quality; stone free, five-eighths inch by one-half inch in size, oval, flattened, nearly smooth, blunt at the base and apex; ventral suture wide, blunt, smooth; dorsal suture shallowly grooved.

\section{DUANE}

\section{Prunus domestica}

1. Prince Treat. Hort. 25. 1828, 2. Kenrick Am. Orch. 260. 1832. 3. Prince Pom. Man. 2:100. 1832, 4. Downing Fr. Trees Am, 297. 1845. 5. Horiculturist I:II5, 116 fig. 36. I846. 6. Floy-Lindley Guide Orch. Gard. 419. 18.46. 7. Thomas Am. Fruit Cult, 343. 1849. 8. Elliott Fr. Book 418. I 854 . 9. Horticulturist 10:253. I855. Io. Am. Pom. Soc. Rpt. I91. I856. 11. Hooper W. Fr. Book 244, 250. 1857. 12. Bridgeman Gard. Ass't 3:127. 1857. I3. Downing Fr. Trees Am. 910. 1869. 14. Mich. Pom. Soc. Rpt. 303. 1878. 15. Mas Le Verger 6:77, fig. 39. 1866-73. 16. Mich. Sta. Bul. 103:32, 1894. 17. Cornell Sta. Bul, 131:184, 1897. 18. Ohio Sta. Bul. 162:254, 255. I905. I9. Waugh Plwm Cult. 100, 102 fig. I901.

Apricot 5 incor. Dame Aubert Violet 12. Duane's Plum 5 incor. Duane's Purple 5, 6, 7, 8, 9, 10, I1, I3, 14, 16, 17. Duane's Purple 15, 19. Duane's Purple French I, 2, 3, 4. Duane's French Purple 12. Duane's Large Purple 3. Duane's Large Orleans 3. Duane's Purple French 8, 9. English Pond's Seedling 8. Pourprée De Duane 15. Pourprêe Duane 13. Purple Magnum Bonum of some 12, I3. Purple Egg of some 12. Red Magnum Bonum of some 9.

This handsome, purple plum, very well shown in the color-plate, is one of the half-dozen leading fruits of its kind grown in New York, favorably known the country over and in Europe as well. Its popularity is due to its large size, well-turned shape, royal purple color, and firm, golden flesh, characters which fit it admirably for the store and the stand. But appearance is the only asset of the fruit so far as the consumer is concerned - the flesh is dry, tough, sour and clings to the stone, making a plum unfit for dessert though it does very well for culinary purposes. The fruit ripens slowly and colors a week or more before ripe; it is at its best only when fully mature. The trees excel in size, vigor and productiveness and are usually hardy and bear their crops well distributed and not clustered as in most varieties of plums. In minor characters, the trees are distinguished by large leaves, pubescence on the under side and by grayishdrab shoots covered with dense pubescence. Duane is generally found 


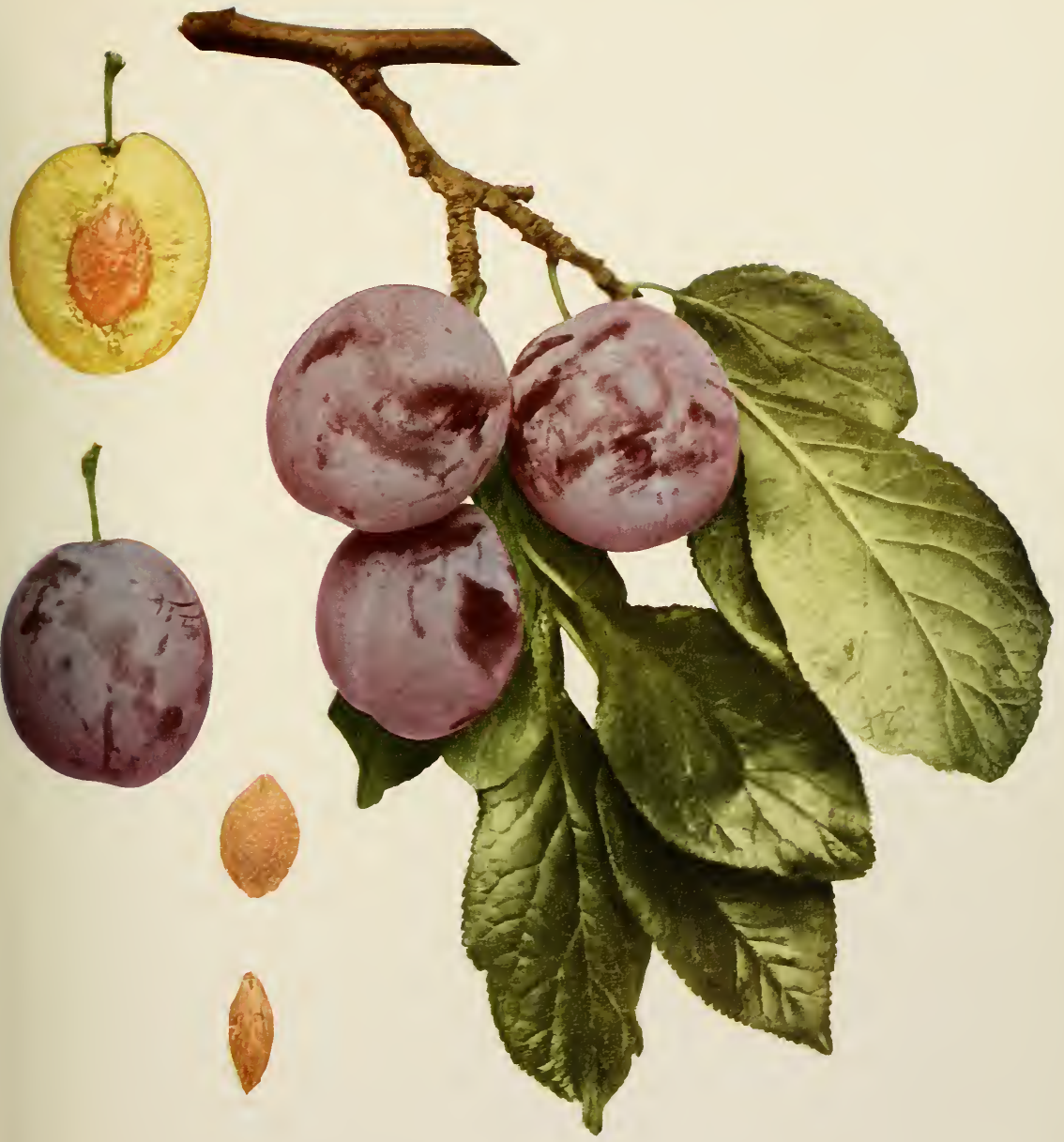



to be a very profitable market plum and if it were only better in quality we could heartily join in recommending it.

Duane originated as a seedling in the garden of James Duane, Duanesburgh, New York, about 1820 . For several years, the variety was distributed by the Prince nurseries under the name Duane's Purple French. This error was caused by Judge Duane's accidentally sending William Prince, of Flushing, grafts of this seedling instead of a French plum ${ }^{2}$ which he had imported in 1820 . When this mistake was discovered by Downing and Tomlinson about 1846 , the word French was dropped and the plum became known as Duane's Purple and later, according to the rules of the American Pomological Society, as Duane. In 1856 , it was listed by the American Pomological Society as promising well and in 1862 it was placed on the list of the fruit catalog.

Tree large, vigorous, round and dense-topped, hardy and productive; branches ash-gray, smooth except for the numerous small, raised lenticels; branchlets medium to thick, variable in length, with short internodes, greenish-red changing to dark brownishdrab, dull, thickly pubescent, with raised lenticels intermediate in number and size; leaf-buds of average size and length, conical or pointed, free.

Leaves folded backward, obovate or oval, one and one-half inches wide, three and one-half inches long; upper surface dark green, pubescent, rugose, with a narrow groove on the midrib; lower surface silvery-green, pubescent; apex acute, base cuneate, margin serrate, eglandular or with small amber glands; petiole one-half inch long, pubescent, tinged with red, eglandular or with one or two small, globose, greenish-brown glands on the stalk or base of the leaf.

Blooming season rather early, of average length; flowers appearing before the leaves, one inch across, white; developing from lateral buds, singly or in pairs; pedicels nine-sixteenths inch long, thick, pubescent, greenish; calyx-tube green, campanulate, pubescent: calyx-lobes broad, obtuse, pubescent on both surfaces, glandular-serrate, erect; petals roundish, entire, short-clawed; anthers yellowish; filaments one-quarter inch long; pistil pubescent on the ovary, longer than the stamens.

Fruit mid-season, ripening period of average length; one and three-quarters inches by one and five-eighths inches in size, broadly oblong-oval or obovate, compressed, halves unequal; cavity shallow, narrow, abrupt; suture variable in depth; apex roundish or depressed; color dark reddish-purple changing to purplish-black on the sunny side, overspread with thick bloom; dots numerous, light russet; stem three-quarters inch long, pubescent, adhering well to the fruit; skin below medium in thickness, tough, sour, separating readily; flesh pale yellow, lacking in juice, firm, sour unless fully ripe; of fair quality; stone adhering, seven-eighths inch by five-eighths inch in size, oval, with pitted surfaces, blunt at the base and apex; ventral suture wide, blunt; dorsal suture with a broad, deep groove.

'This French plum proved to be the well-known Peach. See Horticulturist I: $115 . \quad 1846$. 


\section{EARLIEST OF ALL}

\section{Prunus triflora}

1. Gard. Mon. 368. 1887. 2. Cornell Sta. Bul. 62:32, 1894. 3. Normand Cat. 2. 1895-96. 4. Thomas Am. Fruit Cult. 516. 1897. 5. Cornell Sta. Bul. 175:130, fig. 24. 1899. 6. Waugh Plum Cult. I35. I $90 \mathrm{I}$.

Earliest of All 4. Wasse Sumomo 5, 6. Wasse Sumomo 3. Yosobe 1. Yosete 4. Yosebe 5. 6. Yosobe 2. Yosebe 2.

Earliest of All was imported by H. H. Berger of San Francisco from Japan under the name Yosebe, which later became changed to Yosobe, and in $1897 \mathrm{~L}$. H. Bailey gave the variety the name Earliest of All te avoid the confusion in the earlier nomenclature. The Wasse Sumomo introduced by J. L. Normand, Marksville, Louisiana, in I895, is the Earliest of All. The variety may have some value because of its extreme earliness. It is, however, too small, too unattractive in color and too poor in quality ever to be other than a kitchen plum.

Tree intermediate in size and vigor, vasiform, unproductive; branchlets dark red, marked with thick scarf-skin; leaf-scars prominent; leaves reddish late in the season, narrow-obovate, one and one-half inches wide, three inches long; margin finely serrate, with small, reddish-black glands; petiole tinged red, glandless or with from one to seven glands usually on the stalk; blooming season early ; flowers appearing before the leaves, white with a little pink; borne in threes and fours.

Fruit very early; one inch in diameter, roundish or roundish-oblong, light or dark pinkish-red, covered with thin bloom; flesh light yellow, rather dry, soft, inferior in flavor; of poor quality; stone clinging, five-eighths inch by three-eighths inch in size, flattened, oval.

\section{EARLY ORLEANS}

\section{Prunus domestica}

1. Duhamel Trait. Arb. Fr. 2:80, P1. XX fig. 1. 1768. 2. Forsyth Treat. Fr. Trees 21.1803. 3. Lond. Hort. Soc. Cat. ${ }_{5} 5$, 151 . 1831. 4. Prince Pom. Man. 2:62, 68. $188_{32}$. 5. Kenrick Am. Orch. 260, 269. 1832. 6. Downing Fr. Trees Am. 304. 1845. 7. Floy-Lindley Guide Orch. Gard. 286, 289, 294, 382, 383. 1846. 8. Poiteau Pom. Franc. 1:1846. 9. Thompson Gard. Ass't 516. 1859. 10. Hogg Fruit Man, 360 . 1866. I1. Pom. France 7 :No. 16. 1871. 12. Mas Le Verger 6:85. 1866-73. 13. Mathieu Nom. Pom. 430. 1882. 14. Traité Prat. Sech. Fruits 172. 1893. 15. Guide Prat. 152, 360. 1895. 16. Soc. Nat. Hort. France Pom. 542 fig. 1904.

Altesse du Roi 16. Damascena Dominicalis Praecox 13, 15. De Monsieur 16 . De Monsieur Hative 15. Du Roi 15. Early Monsieur 12. Early Monsieur 4, 5. Early Orleans I1, 12, 13, 15. Frihe Hermpflaume 13. Frühe Herrnpflaume I1. Frühe Herzogspflaume I1, 13, 15. Frühe Hernnpflaume 12. Frühe Herrnpflaume 15. Grimwood Early Orleans 10, 13. Grimwood's Early Orleans 3, 6, 9, I1, 15. Hampton Court 3, 6, 7, 9, 10, 11, 13, 15. Königspflaume 11, ?13, ?15. Monsieur $\mathrm{II}_{1} \mathrm{I}_{3}$ \& $\mathrm{I}_{5}$ incor. Monsieur Hâtif $\mathrm{I}_{1}, 7, \mathrm{II}_{1}, \mathrm{I}_{2}, \mathrm{I}_{5}$. Monsieur Hatif $3,4,5,6,7,9,10,12, \mathrm{I}_{3}, \mathrm{I}_{6}$. Monsieur Hative 4. Monsieur Hatif de Montmorency 3, 6, 9. I0, II, 13, 14, 15. New Early Orleans 
3, 6, 9, 11, 13, 14, 15. New Orleans 3, 6, 9, 10, 13, 15, 16. Neu Orleans 11. Orleans 3. Prune de Monsieur Hatif 13. Prune de Monsieur Hâtif 8. Prune de Monszeur Hative 12. Prunus damascena domincalis praecox 11. Prune du Roi 14. Prune du Roi 11, 13. Red Orleans I1, 13, 15. Wilmot's Early Orleans 4, 7. Wilmot's Early Orleans 3, 9, 10, 11, 13, 15. Wilmot's Large Orleans 3, 4, 6. Wilmot's Late Orleans ?7. Wilmot's New Early Orleans 3, 5, 6. Wilmot's New Early Orleans 7. Wilmot's Orleans $3,7,10,11,13,14,15$.

Early Orleans has been planted very little in America and then chiefly because of its reputation in Europe. While it appears to be a very good plum in most respects as it grows on the Station grounds, being attractive in appearance, of good flavor, a freestone and firm enough to ship well, it surpasses in none of these characters and the fruit is so small as to make it a poor competitor among the purple plums of its season. It does not deserve the reputation in America that pomologists have given it in Europe. In France the Early Orleans, under the name of Prune du Roi, is used in prune-making but it seems not to have been so used in America.

Early Orleans is old and of unknown origin. Duhamel in 1768 considered it a variety of the Orleans, differing only in the time of ripening but there are additional differences as can be seen in the descriptions of the two. It is true, however, that these two plums are very similar. According to Kenrick, Wilmot's New Early Orleans was raised by John Wilmot, an Englishman. Though it may be of separate origin it is practically identical with the Early Orleans.

Tree small, upright-spreading, hardy, productive; branches ash-gray, smooth, with small, inconspicuous, oval lenticels; branchlets thick, with rather short internodes, covered with thin bloom and marked with scarf-skin, dull brownish-drab, pubescent, with a medium number of small, raised lenticels; leaf-buds intermediate in size and length, conical, free, plump; leaf-scars enlarged.

Leaves folded upward, two and one-quarter inches wide, four inches long, roundishoval or obovate, thick ; apex abruptly pointed, base acute, margin crenate and with small, dark glands; upper surface light green, sparingly pubescent and with a grooved midrib; lower surface silvery-green, pubescent; petiole three-quarters inch long, thick, pubescent, faintly tinged red, with from one to three large, globose glands mostly on the stalk.

Season of bloom intermediate in time and length; flowers appearing after the leaves, nearly one-half inch across, white, the buds yellow-tipped as they unfold; borne in clusters on short lateral spurs, in pairs; pedicels one-half inch long, thick, pubescent, green; calyx-tube greenish, campanulate, thinly pubescent; calyx-lobes broad, obtuse, glandular, pubescent on both surfaces, reflexed; petals roundish, entire, not clawed; filaments five-sixteenths inch long; pistil glabrous, equal to the stamens in length. 
Fruit early, season short; one and one-quarter inches in diameter, roundish-oval, slightly truncate, halves equal; cavity shallow, narrow, abrupt; suture shallow or a line; apex roundish to flattened or sometimes depressed, often oblique; color dark reddish-purple, covered with thick bloom; dots numerous, small, russet, inconspicuous; stem of average thickness, five-eighths inch long, pubescent, adhering well to the fruit; skin thin, tough, not astringent, separating readily; flesh lemon-yellow, juicy, coarse, firm, sweet, mild but pleasant; very good; stone free, three-quarters inch by five-eighths inch in size, oval, slightly oblique, blunt-pointed, with rough and slightly honey-combed surfaces.

\section{EARLY RIVERS}

\section{Prunus domestica}

I. Downing Fr. Trees Am. 314. 1845. 2. Horticulturist 4:40, 1849. 3. Elliott Fr. Book 419. 1854. 4. Downing Fr. Trees Am. 912. 1869. 5. Am. Pom. Soc. Rpt. 99. 1871. 6. Mas Pom. Gen. 2:117. 1873. 7. Jour. Hort. 30:273. 1876. 8. Oberdieck Deut. Obst. Sort. 409, 411. 1881. 9 Hogg Frunt Man. 699. 1884. 10. Mathieu Nom. Pom. 447. 1889. 1r. Lucas Vollst. Hand. Obst. 470. 1894. 12. Guide Prat. 152, 356. I895. 13. Rivers Cat. 35. I898.

Early Fruchtbare 1 2. Early Prolific 4. Early Rivers 4, 10, 12. Early Prolific 2, 3, 6, 10, I2, 13. Fortile Prócoce 10. Fertile Précoce 6, 12. Fruhe Fruchtbare 6. Frühe Fruchtbare 8. Prolifique Hative 10, 12. Rvers' Early No. 2 1, 2, 3, 4, 10. Rivers' Early Prolific Plum 2. Rivers' Early Prolific 4, 9, 10, 12. Rivers' Early 6. River's Early 5. Rivers' Blue Prolific 7. Rivers' No, 2 9, 10, 12. Rivers Frthipfla ume 8, I1, Rivers' Frühe Fruchtbare Io.

Early Rivers is widely known because of its earliness, productiveness, regularity of bearing and desirability for culinary purposes. In New York, however, the plums are so small and drop so badly as they ripen that the variety is worthless for commercial purposes. Hogg, in the reference given above, notes the following peculiarity of the trees of this variety: "The original tree throws up suckers, which, when removed and planted out, do not bloom for several years; but scions taken from the original tree and grafted, bloom the second year. A curious fact is that the grafted trees fruit abundantly, and the branches are so brittle they break off; in those raised from suckers the branches never break. The grafted trees in spring are full of bloom, sparing of shoots, and very few leaves; the suckers are more vigorous in growth, have no bloom, but an abundance of foliage, even when six years old." This variety is a seedling of Early Tours raised by Thomas Rivers of Sawbridgeworth, England, about i834. It was first disseminated under the names Early Prolific and Rivers' Early No. 2 but, in I866, Hogg with the permission of the originator, renamed it Early Rivers under which name it is now generally known.

Tree medium in size and vigor, round-topped, productive; branchlets thick, short, pubescent throughout the season; leaves roundish-oval or obovate, one and threequarters inches wide, nearly three inches long, leathery; margin crenate or serrate, 
with few, small, dark glands; petiole pubescent, with from one to three small glands usually on the stalk; blooming season intermediate, short; flowers appearing after the leaves, seven-eighths inch across; borne on lateral buds and spurs, singly or in twos; petals roundish.

Fruit early, season short; one and one-quarter inches by one and one-eighth inches in size, roundish-oval or ovate, dark purplish-black, overspread with thick bloom; flesh dull yellow, firm, sweet, mild, pleasant; of good quality; stone semi-free, threequarters inch by one-half inch in size, rather flat, oval, with rough and pitted surfaces.

\section{EARLY ROYAL}

\section{Prunus domestica}

1. Lond. Hort. Soc. Cat. 153. 183x. 2. Mag. Hort. 6:93. 1840. 3. Downing Fr. Trees Am. 313. 1845. 4. Thomas Am. Fruit Cult. 341, fig. 260. 1849. 5. Am. Pom. Soc. Cat. 86. 1862. 6. Mathieu Nom. Pom. 452. 1889. 7. Thompson Gard. Ass't 4:159. r9or.

Early Royal 3, 4, 6. Marian 6. Mirian 3, 4. Mivian 2. Miviam 6. Miriam 7. Royal Hâtive 1, 2, 5, 7. Royale Hâtive 3, 4. Royale Hative 6. Violette Kỏnigspflaume 6.

While the fruits of Early Royal are not remarkably attractive in color, shape or size, the quality is high and its flesh is so firm that the variety should ship well. This sort is worthy of more extensive trial than it has yet had in America. Early Royal is a French variety introduced by M. Noisette of Paris, about 1830 . Thompson made the first complete description of the variety in 1839 from the fruits of a tree in the gardens of the London Horticultural Society. Although recommended in the catalog of the American Pomological Society in 1862 it has not been extensively planted in this country.

Tree large, vigorous, spreading, rather open, productive; branches and trunk roughish; branchlets thickly pubescent; leaf-scars enlarged; leaves folded upward, oval or obovate, one and three-quarters inches wide, three and three-eighths inches long; margin serrate, with small, dark glands; petiole thickly pubescent, with one or two smallish glands; blooming season intermediate in time and length; flowers appearing with the leaves, one inch across, white, tinged yellow at the apex of the petals; borne on lateral buds and spurs, singly or in pairs.

Fruit mid-season, ripening period long; about one and three-eighths inches in diameter, roundish-ovate, dark reddish-purple, marked by irregular russet streaks, covered with thick bloom; dots conspicuous; stem thick, pubescent; flesh greenishyellow, rather dry, firm, very sweet, mild, pleasant flavor; very good; stone nearly free, three-quarters inch by five-eighths inch in size, roundish-oval, blunt at the apex and base, with but slightly roughened surfaces; ventral suture prominent and with short wing; dorsal suture with a wide, shallow groove. 


\section{EARLY TOURS}

\section{Prunus domestica}

1. Duhamel Trait. Arb. Fr. 2:67, 69. 1768. 2. Kraft Pom. Aust. 2:31, Tab. 177 fig. 2. 1796. 3. Lond. Hort. Soc. Cat. 151. 1831. 4. Prince Pom. Man. 2:64. 1832. 5. Kenrick Am. Orch. 265. 1832. 6. Poiteau Pom. Franc, 1:1846. 7. Floy-Lindley Guide Orch. Gard. $282,283.1846$. 8. Hogg Fruit Man. 376. 1866. 9. Downing Fr. Trees Am. 937. 1869. 10. Mas Le Verger 6:143. 1866-73. I1. Mathieu Nom. Pom. 443. 1889. 12. Guide Prat. 156, 361. I895.

Blue Perdrigon of some 3, 9, 11,12 . Die fribhe Pflaume von Tours 2. De Monsieur 12 incor. Damas de Tours 8, 9, 11. Early de Tours 5. Early Tours 7, 9, I1. Early Violet 3, 7, 9, II, I2. Gros Damas de Tours I. Hative de Tours 12. Madeleine 11, ?12. Monsieur I1 incor. Noire Hative 3, 8, 9, I1, 12. Perdrigon Violet of some 3, 9, I1, 12. Précoce de Tours I, 3, 5, 6, 7, 8, 9, 10, 11, 12. Précoce de Tours 2, 4. Prune de la Madeleine 4, 9, 11. Prune noire Hative 4. Prune de Gaillon 8, 9, I1. Prune de Monsieur II incor. Saint Jean ?11, 12. Violette de Tours 8, I1. Violette Hative 9, 11. Violet de Tours 9, 11, 12. Violette Hative 7. Violet 7.

Duhamel described this variety, Gros Damas de Tours and Gros Noire Hative in the same publication, his descriptions of the three varieties being nearly identical. Following Duhamel many horticultural authorities continued to separate the varieties, but Downing, Floy-Lindley and Mathieu give Damas de Tours as a synonym of Early Tours, and Thompson, Hogg, Downing, Mathieu and the Guide Pratique give Noire Hative as a synonym, while Prince holds Prune Noire Hative to be synonymous.

With this great similarity in the names and descriptions, it seems doubtful if these are separate varieties, but not having the fruit of the three to compare, it has been thought best in The Plums of New York to follow the nomenclature of the oldest authorities. Several writers have also named the Blue Perdrigon and the Perdrigon Violet as identical with Early Tours but neither can be, as all descriptions indicate that both are at least a month later in ripening than the variety under discussion.

Early Tours is considered in continental Europe one of the best early plums for dessert. It is said when fully ripened to be a veritable sweetmeat. As the variety grows in the Station collection it can hardly be lauded as highly as in Europe. Yet it is at least worthy of a place in a home orchard as a delicious early plum.

Tree intermediate in size, upright-spreading, rather open-topped, productive; branchlets thickish, pubescent; leaves falling early, folded upward, obovate or oval, one and seven-eighths inches wide, three and one-quarter inches long; margin crenate; petiole pubescent, glandless or with from one to three glands usually on the stalk; blooming season intermediate in time and length; flowers appearing after the leaves, one and one-eighth inches across; borne on lateral spurs or from lateral buds. 
Fruit very early; one and one-quarter inches by one and one-eighth inches in size, slightly oval, dark purplish-black, covered with thick bloom; skin thick, tough, sour; flesh greenish-yellow, firm, sweet, pleasant flavored; good to very good; stone semifree, three-quarters inch by one-half-inch in size, irregular oval.

\section{EARLY YELLOW}

\section{Prunus domestica}

1. Parkinson Par. Ter. 575, 576. 1629. 2. Rea Flora 206, 207. 1676. 3. Ray Hist. Plant. 2:1688. 4. Quintinye Com. Gard. 70. 1699. 5. Langley Pomona 90, P1. 20 fig. 1. 1729. 6. Duhamel Trait. Arb. Fr. 2:66. 1768. 7. Forsyth Treat. Fr. Trees 19. 1803. 8. Floy-Lindley Guide Orch. Gard. 297, 382. 1846. 9. Downing Fr. Trees Am. 925. 1869. 10. Country Gent. 41:518. 1876. 11. Mathieu Nom. Pom. 424. 1889. 12. Guide Prat. 152, 354. 1895.

Amber Primordian 1, 2. Amber Primordian 3, 8, 9, I1, 12. Avant Prune blanche 9, II, 12. Bilboa 9, I1. Catalonia 1, 2, 3, 12. Castellan 4. Catalonian 8, 9, 10, I1, 12. Cerisette Blanche 9, 11, 12. Castelane II, 12. Catalane I1, 12. Catalonische Pfaume 11, 12. Catalonischer Spilling 12. Catalonischer Spilling I1. Catalonische Kricke II. De Catalogne 6, II. De Catalogne I2. D'Avoine 9, 12. Die gelbe fruhzeitige Pfaume 12. Early Yellow 9, 10, 11, 12. Early John 9, I1. Early White Plum 11, 12, Gelbe Spindel Pfaume 11. Gelber Kleiner Spilling Ir. Gelbe Frühzeitige I1. Gelbe fruhe Pflaume II, 12. Jaune précoce II, I2. Jaune de Catalogne 9, II, I2. Jaune Hâtive 6,8. Jaune Hative I I, 12. Jaunhâtive 7. Jean Hâtive 9. Jean-håtive 5. Jean White Ir, 12. Kleine gelbe Früh Pflaume 11, 12. London Plumb 5. London Plum 9, 11, 12. Monsieur Jaune 1 I incor., 12. Prune de Catalogne 8, 9, Ir. Prune de St. Barnabe 8, 9. Prune d'Avoine II. Pickett's July 9, I1, 12. Prune Monsieur Jaune 9. Prune d'Altesse blanche 9, ? I1. Primordian 10, II, 12. Prunus Catalana I1, I2. Prunus Catelana 11. Prunus Catalonica I1, 12. St. Barnabie 9. Saint Barnabe 11, 12. Siebenbürger Pflaume? I1, I2.

The Early Yellow goes back as far as the history of plum-growing in northwestern Europe is recorded. Because of its synonyms it is thought to have originated in Spain whence it was gradually taken northward, crossed the boundary and spread through the fertile valleys of France. Early in the Seventeenth Century it was firmly established in England and was described by Tradescant and Parkinson. From that time till the present it has kept a place in European and American horticulture, in spite of the introduction of hundreds of improved varieties. It is described as follows:

Tree hardy, moderately vigorous and productive; branches long, slender, upright until bent down with fruit; branchlets pubescent. Fruit very early, small, obovate; stem short, slender; color pale yellow, with thin bloom; flesh yellow, tender, sweet, moderately juicy, pleasant; good; freestone.

\section{EMPIRE}

\section{Prunus domestica}

I. N. Y. Sta. An. Rpt. 9:347. 1890. 2. Cornell Sta. Bul. 131:184. 1897. 3. Ohio Sta. Bul. 162:24I fig., 254, 255. 1905. 4. Rice Bros. Cat. I5. 1908.

Empire State 4. Rood 1, 2. 
It is possible that Empire deserves more attention from fruit-growers than it has had. It is attractive in appearance, pleasant in flavor and gives promise of shipping well. Wherever the variety proves productive, as it is to a fair degree on the grounds of the Station, this plum might well be grown. Empire was grown by Ezra Rood, Cortland, New York, about I875, from seed purchased at the State Fair. In I890, E. Smith \& Sons of Geneva found this plum in Mr. Rood's yard and procured cions of it, afterwards introducing the variety under the name Rood. The year that they made the discovery, John Hammond, also of Geneva, found the same variety at another place in Cortland and secured cions from which he subsequently disseminated the plum under the name Empire, by which it is now generally known.

Tree intermediate in size and vigor, spreading, open-topped, productive; branches covered with short, thick, fruit-spurs; branchlets short and stubby, pubescent throughout the season; leaf-scars prominent; leaves folded upward, oval or obovate, one and onehalf inches wide, three and one-quarter inches long, thick, stiff; margin crenate, eglandular or with small dark glands; petiole thick, reddish, with a few large, globose or reniform glands; blooning season intermediate in time and length; flowers appearing after the leaves, over one inch across, yellowish-white; borne singly or in twos.

Fruit mid-season, ripening period very long; about one and five-eighths inches in diameter, round, dark reddish-purple, covered with medium thick bloom; dots numerous, conspicuous; stem thick, surrounded by a fleshy ring at the cavity; skin sour; flesh golden-yellow, dry, firm but tender, sweet, mild, pleasant in flavor; of good quality; stone nearly free, seven-eighths inch by three-quarters inch in size, oval, turgid, with roughened surfaces; ventral suture broad, with short but distinct wing; dorsal suture wide, deep.

\section{ENGLEBERT}

\section{Prunus domestica}

1. Horticulturist 10:71. 1855. 2. Downing Fr. Trees Am. 392. 1857. 3. Cultivator 6:312 fig. I858. 4. Hogg Fruit Man. 376. 1866. 5. Thomas Am. Fruit Cult. 344. 1867. 6. Am. Pom. Soc. Cat. 24. 1871. 7. Mas Le Verger 6:61. 1866-73. 8. Barry Fr. Garden 415. 1883. 9. Cat. Cong. Pom. France 357. 1887. 10. Wickson Cal. Fruits 354. 1891. 11. Guide Prat. I54, 361. 1895. 12. Cornell Sta. Bul. 131:19o. 1897. 13. N. Mex. Sta. Bul. 27:125. 1898. 14. Mich. Sta. Bul. 169:242, 244. 1899. 15. Waugh Plum Cult. 1ог, 103 fig. 1901. 16. Va. Sta. Bul. 134:42. 1902 .

Englebert 9. Prince Englebert 1, 2, 3, 4, 5, 6, 7, 8, 11, 12. Prince Engelbert 10, 13. Prince Englebert 15, 16. Prinz Engelbert I1.

In common parlance Englebert is a prune, its origin, shape, color and firm golden-yellow flesh all marking it as such, but in prune-making regions it is usually marketed in the green state, if grown at all, and is little used in curing. It cannot be said to be much more popular as a plum than it 


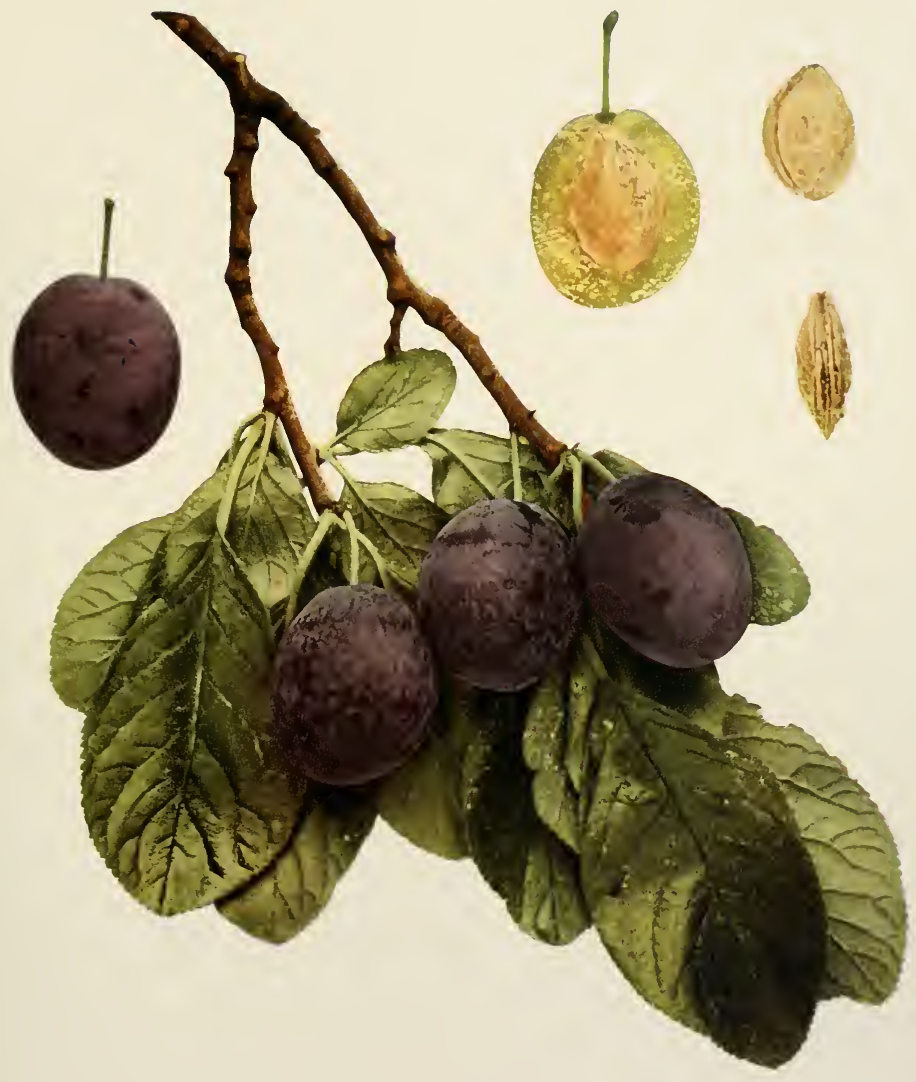



is as a prune, chiefly because it is not of high quality, but also because it is none too attractive in color, size or shape, cutting a rather poor figure in comparison with a great number of other Domestica plums. The variety fails in tree as well as in fruit. The trees are variable in size, suffer from cold in exposed situations and while rather productive bear their crops in clusters hard to pick and well placed to insure infection from brown-rot when that disease is epidemic. For some reason the fruit of this variety shrivels at this Station not only after being picked, but while still on the tree. In New York, Englebert has been thoroughly tested, has been found wanting and is not now recommended.

This variety was obtained from a seed of the "Date Prune," by M. Scheidweiler, Professor of Botany at Ghent, Belgium. ${ }^{1}$ The date of origin has not been given, but it was probably produced about the middle of the last century since it was described as a new fruit in the Horticulturist for 1855. Englebert was added to the American Pomological Society catalog fruit list in 187 I under the name Prince Englebert, but in 1897 , according to the rules of the Society, the name was simplified to Englebert.

Tree variable in size, vasiform, dense-topped, hardy except in exposed locations, productive; branches ash-gray, smooth except for the numerous, long-oval, raised lenticels; branchlets thick, rather short, with internodes above medium in length, green changing to dark brownish-drab, dull, heavily pubescent throughout the season, with few, inconspicuous, small lenticels; leaf-buds small, short, obtuse, appressed.

Leaves folded upward, oval or obovate, one and seven-eighths inches wide, three and one-quarter inches long; upper surface covered with very fine hairs, with a shallow groove on the midrib; lower surface pale green, finely pubescent; apex roundishpointed, base obtuse, margin finely crenate, eglandular or with small dark glands; petiole three-quarters inch long, pubescent, faintly tinged red, glandless or with one or two small, globose, greenish-yellow glands at the base of the leaf.

Blooming season early to medium, of average length; flowers appearing after the leaves, about one inch across, white except for a yellowish tinge near the apex of the petals; borne in clusters on lateral buds and spurs, usually in pairs; pedicels one-half inch long, below medium in thickness, pubescent, greenish; calyx-tube green, campanulate, pubescent; calyx-lobes obtuse, sparingly pubescent on both surfaces, glandularserrate and with marginal hairs; petals broadly oval or roundish, crenate, abruptly tipped with short, broad claws; stamens often inclined to revert to petals; anthers yellowish; filaments five-sixteenths inch long; pistil glabrous, longer than the stamens.

Fruit mid-season, ripening period short; one and five-eighths inches by one and three-eighths inches in size; oval, swollen on the suture side, halves equal; cavity shallow, narrow, abrupt; suture a line; apex bluntly pointed or roundish; color dark purplish-

I Mas Le Verger 6:61, 1866-73. 
black, overspread with thick bloom; dots numerous, russet; stem three-quarters inch long, pubescent, adhering well to the fruit; skin thin, sourish, separating readily; flesh golden-yellow, juicy, coarse, rather firm, sweet, pleasant-flavored, sprightly; good; stone one and one-eighth inches by five-eighths inch in size, oval or broadly ovate, strongly flattened, with roughened and deeply pitted surfaces, blunt at the base and apex; ventral suture narrow, strongly grooved, not prominent; dorsal suture acute, with a shallow, often indistinct groove.

\section{ENGRE}

\section{Prunus triflora}

I. Normand Cat. r89ז. 2. Kerr Cat. 1894-1900. 3. Cornell Sta. Bul. 175:131. 1899. 4. Tex. Sta. Bul. 32:488, 1899.

This variety is one of the earliest of the Triflora plums and although the flavor is not as agreeable as that of the best sorts of its species, as Burbank or Abundance, it is much better than that of Earliest of All, with which it competes in season. Almost nothing is known regarding the history and origin of Engre. It was first mentioned in I890 in the catalog of J.L. Normand, Marksville, Louisiana, and in all probability is one of his numerous importations from Japan. The origin of the name is not known.

Tree of medium size, vasiform, dense-topped, productive; branches slightly thorny, with numerous fruit-spurs; branchlets very short and stubby, glabrous; leaf-buds plump; leaves reddish when young, oblanceolate, one and three-eighths inches wide, three inches long; margin doubly crenate, with small brownish glands; petiole tinged red, glandless or with one or two small, reniform glands on the stalk; blooming season early; flowers appearing with the leaves, five-eighths inch across; borne on lateral buds and spurs, in twos or in threes; calyx-lobes red at the margin; anthers pinkish.

Fruit very early; about one and one-quarter inches in diameter, roundish; cavity deep; color dark pinkish-red, covered with thin bloom; dots numerous, conspicuous; skin astringent; flesh yellowish, tender and melting, sweet near the surface, but sour next the pit, low in flavor; poor; stone clinging, five-eighths inch by one-half inch in size, roundish-oval, turgid; ventral suture broad, blunt.

\section{ESPEREN}

\section{Prunus domestica}

I. Mag. Hort. 15:298. 1849. 2. Downing Fr. Trees Am. 380 . 1857. 3. Flor. \& Pom. 4, Pl. 1863. 4. Downing Fr. Trees Am. 916. 1869. 5. Pom. France 7: No. 1. 1871. 6. Nas Le Verger 6:65. 1866-73. 7. Lauche Deut. Pom. 12. 1882 .

Cloth of Gold Esperen 4. Cloth of Gold 2, 7. Drap d'Or of Esperin 1, 2. Drap d'Or d'Esperen 3, 6, 7. Drap d'Or Esperen 4. Drap d'Or d'Esperen 5. Drap d'Or of Esperen 6. Esperen's Goldpflaume 7. Golden Esperen 5, 7. Golden Esperen 4. Golden Esperen Plum 3. 
Were there not so many handsome, well-flavored plums of the Reine Claude group, Esperen might well be recommended to the amateur at least, for it is first class in appearance and quality. But the fruits are small and the tree-characters are not such that the variety can compete with the standard Reine Claude plums. Esperen was produced from seed in I 830 by Major Esperen of Malines, Belgium; it was first fruited in I844, and was introduced in 1847 by Louis Van Houtte of Ghent, Belgium. It obtained the designation Drap d'Or from its close resemblance to that variety.

Tree large, vigorous, upright-spreading, productive; trunk stocky, rough; branches rough, with numerous, large, raised lenticels; branchlets brash; leaves flattened, two and one-half inches wide, five inches long, obovate or oval; margin serrate; petiole thick, tinged red, pubescent, with from two to five large, globose glands.

Fruit mid-season; about one and one-half inches in diameter, roundish-oval; cavity shallow, narrow, often lipped; color yellow streaked and mottled with green, overspread with thin bloom; skin thin, tender, rather sour; flesh yellow, tender, sweet, aromatic; of good quality; stone free, one inch by five-eighths inch in size, oval, with pitted surfaces; ventral suture blunt; dorsal suture wide, deep.

\section{EXCELSIOR}

\section{Prunus triflora $\times$ Prunus munsoniana}

I. Glen St. Mary Cat. 1891-2. 2. Am. Pom. Soc. Cat. 26. 1897. $\quad$ 3. Vt. Sta. Bul. 67:11. 1898. 4. Ga. Sta. Bul. 68:9, 36. 1905 .

Excelsior has not fruited on the Station grounds and is placed in the list of leading varieties because of the prominence given it in the above references. The variety was originated by G. L. Tabor, Glen Saint Mary, Florida, in 1887 , from seed of Kelsey supposed to have been pollinated by Wild Goose, although some authorities believe De Caradeuc to have been the male parent. It seems to be a promising variety and was mentioned in the last three catalogs of the American Pomological Society.

Tree vigorous, vasiform; branches slender; leaves of medium size, narrow; margin finely crenulate, glandular; petiole short, with from one to three small glands; flowers small, scattered; fruit early; of medium size, roundish, dark red with heavy bloom; skin tough; flesh firm, yellowish with red tinge towards the center; quality good; stone of medium size, compressed, clinging.

\section{FIELD}

\section{Prunus domestica}

1. Mich. Hort. Soc. Rpt. 288. 1889. 2. Am. Gard. 14:50, 395. 1893. 3. Rural N. Y. 55: 622. 1896. 4. Cornell Sta. Bul. 131:184. 1897. 5. Mich. Sta. Bul. 169:244. 1899. 9. Ibid. 
187:77, 78. 1901. 7. Waugh Plum Cult. ror, 104 fig. 1901. 8. Ohio Sta. Bul. x62:239, 240 fig., 254,255 . 1905 .

Early Bradshaw 2.

This offspring of Bradshaw resembles its parent in tree, and in size, color and shape of fruit, though not so closely as to be readily mistaken for the older variety. Differences which distinguish the fruits of the two are: The Field is a trifle smaller, the fruit is more nearly round, lacking the prolonged neck of Bradshaw and is more plump at the base, the parent plum being markedly obovate; Field is earlier than Bradshaw, the latter difference accounting for the synonym, "Early Bradshaw." The quality is not such as to commend either of these plums, but of the two Field is slightly the better. In tree-characters, Bradshaw excels in having a larger tree and in being more productive. The foliage of Field is very good, it ripens its wood well and begins to bear while young, but it is inclined to a biennial bearing habit which makes the average in quantity of fruit a little too low for a market plum which Field is, if worth planting at all. A good quality of this variety is that it withstands the brownrot very well. It is doubtful if Field is worthy of a place in the fruit-growing regions of New York, unless, perhaps, where a plum of the Bradshaw type, but a little earlier, is wanted. Like Bradshaw, Field is comparatively little attacked by San José scale.

Field is a seedling of Bradshaw grown in Schoharie County, New York. It was first noted by S. D. Willard of Geneva, New York, in 1889 , as "a variety worthy of cultivation."

Tree of medium size and vigor, upright-spreading, dense-topped, hardy, productive; branches ash-gray, smooth except for the numerous, small, raised lenticels; branchlets slender, short, with internodes of medium length, greenish-red changing to brownishdrab, with a trace of red, dull, pubescent becoming slightly less so at maturity, with numerous, inconspicuous, small lenticels; leaf-buds below medium in size, short, obtuse, appressed.

Leaves folded backward, obovate, two and one-sixteenth inches wide, four and three-eighths inches long; upper surface dark green, nearly glabrous, with shallowly grooved midrib; lower surface sparingly pubescent; apex abruptly pointed, base acute, margin serrate, with a few, smallish, black glands; petiole seven-eighths inch long, thick, tinged with red, sparingly pubescent.

Season of bloom intermediate, short; flowers appearing after the leaves, one inch across, white, with a yellowish tinge at the apex of the petals; scattered on lateral buds and spurs, singly or in pairs; pedicels five-eighths inch long, thick, with few, short, scattering hairs, greenish; calyx-tube green, campanulate, glabrous; calyx-lobes above medium in width, obtuse, slightly pubescent on both surfaces, glandular-serrate, 


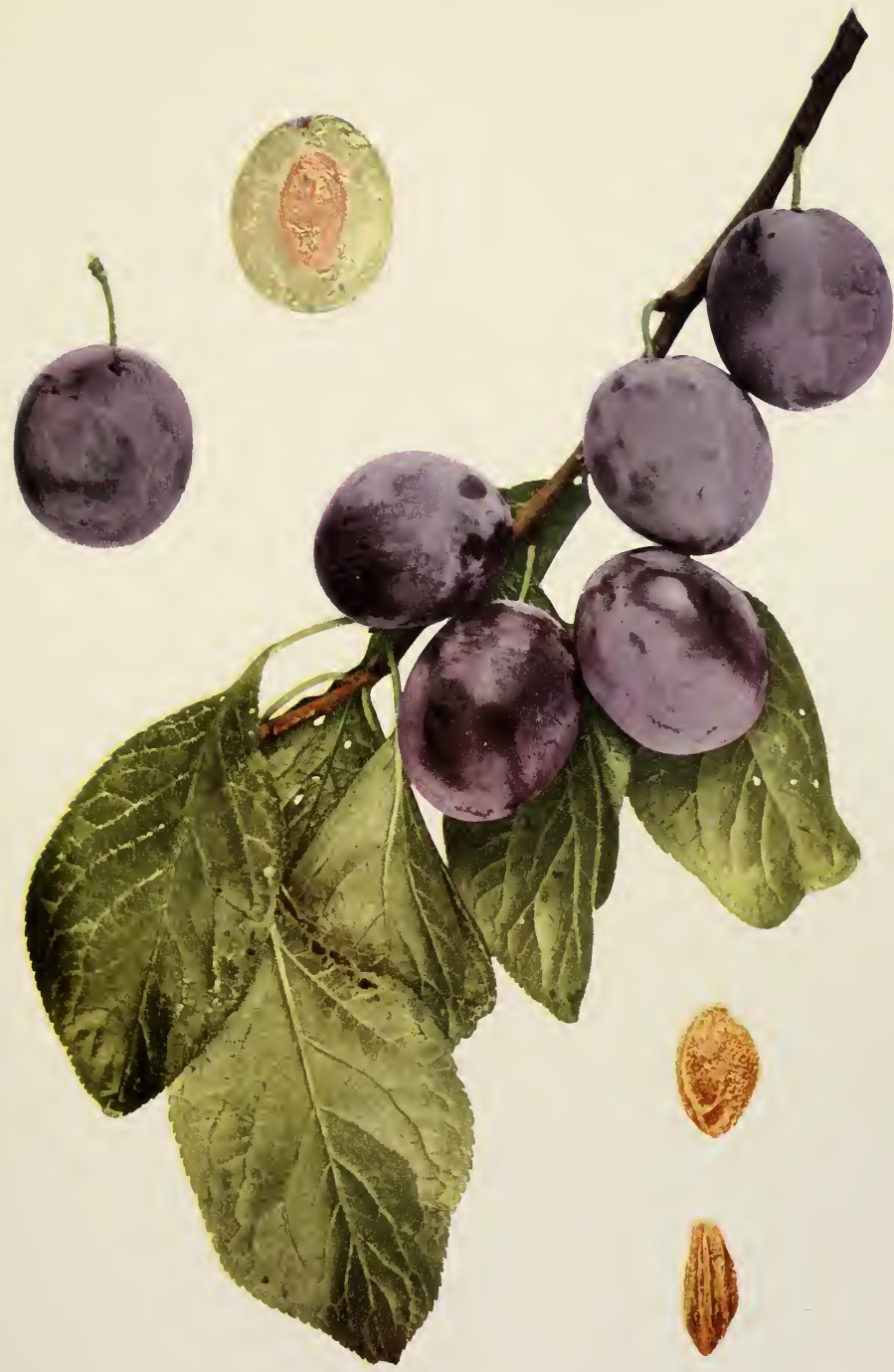

FIELD 

somewhat reflexed; petals broadly oval, entire, tapering below to short, broad claws; anthers yellowish; filaments three-eighths inch long; pistil glabrous, shorter than the stamens.

Fruit mid-season, period of ripening short; one and seven-eighths inches by one and five-eighths inches in size, oblong-oval, compressed, halves equal; cavity shallow, narrow, abrupt; suture shallow, broad; apex roundish; color dark purplish-red, overspread with very thick bloom; dots numerous, small, russet, clustered about the apex; stem three-quarters inch long, sparingly pubescent, adhering well to the fruit; skin thin, slightly sour, separating readily; flesh greenish-yellow, medium juicy, sweetish, mild; of fair quality; stone clinging, one inch by five-eighths inch in size, ovate with roughened and deeply pitted surfaces, blunt at the apex and base; ventral suture broad, distinctly furrowed; dorsal suture acute.

\section{FOREST GARDEN}

\section{Prunus hortulana mineri}

I. Minn. Hort. Soc. Rpt. 81. 1882. 2. Am. Pom. Soc. Cat. 42. 1883. 3. Minn. Hort. Soc. Rpt. 412. 1889. 4. Ia. Hort. Soc. Rpt. 55. 189o. 5. Cornell Sta. Bul. 38:37, 86. 1892. 6. Mich. Sta, Bul. 118:53. 1895. 7. Wis. Sta. Bul. 63:24, 37. 1897. 8. Wis. Hort. Soc. Rpt. 136. 1899. 9. Waugh Plum Cult. 148. 1901. 10. Can. Exp. Farm Bul. 43:30. 1903. I1. Ohio Sta. Bul. 162: 254, 255. 1905. I2. S. Dak. Sta. Bul. 93:17, 49 \& 54 P1. I905.

Forest Garden is placed by most horticulturists in Prunus americana, but the trees growing on the Geneva Station grounds belong to the Miner group of Prunus hortulana and the herbarium specimens of foliage and flowers sent from other stations make it probable if not certain that the trees here are true to name. This variety is little grown in the East, but it is widely distributed in the central West where both in tree and fruitcharacters it seems adapted to the needs of the climate and soil. It is one of the latest of its group, maturing at a good time for shipping, for which it is further adapted by its tough skin and firm flesh. While Forest Garden is not preeminently a dessert plum, it has a spicy flavor that makes it pleasant eating and it is admirably adapted for culinary purposes, especially for preserving.

This variety is from a wild plum found in the woods bordering on the Cedar River, near Cedar Rapids, Iowa, by Thomas Hare, and introduced by H. C. Raymond, of the Forest Garden Nurseries, Council Bluffs, Iowa, about 1862. The American Pomological Society placed the variety on its fruit catalog list in $188_{3}$, dropped it in $189 \mathrm{I}$, and replaced it in 1897 .

Tree medium to large, often very vigorous, spreading, with sprawling habit, inclined to be flat-topped, perfectly hardy, variable in productiveness, bearing young, somewhat susceptible to shot-hole fungus; trunk small in proportion to the size of the 
tree, shaggy; branches rather rough, zigzag and inclined to split, thorny, dark ashbrown, with numerous, small lenticels; branchlets thick, long, willowy, with short internodes, greenish changing to dark chestnut-red, glossy, with thin pubescence when young, which disappears in autumn, with conspicuous, numerous raised lenticels; leafbuds small, short, obtuse, plump, appressed.

Leaves falling early, folded upward, elongated-oval, or obovate, peach-like, one and three-quarters inches wide, four and one-quarter inches long, thin and leathery; upper surface smooth, with a shallow, grooved midrib; lower surface silvery-green, pubescent; apex taper-pointed, base somewhat abrupt, margin doubly crenate, glandular; petiole three-quarters inch long, sparingly pubescent, faintly tinged with red, usually with two conspicuous, globose, brownish glands below the base of the leaf.

Blooming season late and long; flowers appearing with the leaves; seven-eighths inch across, white, with a strong, disagreeable odor; borne in dense but scattering clusters on lateral buds and spurs, in threes or in fours; pedicels nine-sixteenths inch in length, slender, glabrous, greenish; calyx-tube green, narrowly campanulate or obconic, glabrous; calyx-lobes narrow, obtuse, slightly pubescent, margined with few hairs and with dark-colored glands, slightly reflexed; petals oval, erose, tapering to long claws of medium width; anthers yellowish; filaments seven-sixteenths inch in length; pistil glabrous, shorter than the stamens.

Fruit variable in season which is usually late and short; about one and one-eighth inches in diameter, rather large, roundish-ovate or nearly oval, slightly compressed, halves equal; cavity shallow, wide, flaring; suture a line; apex roundish or somewhat pointed; color light or dark red, with thin bloom; dots numerous, russet, conspicuous; stem slender, five-eighths inch long, glabrous, detaching from the fruit at maturity; skin thick, tough, slightly astringent, adhering ; flesh dark golden-yellow, juicy, coarse, fibrous, melting, sweetish next the skin but rather sour toward the center, with a strong and peculiar flavor, aromatic; fair to good; stone clinging, three-quarters inch by five-eighths inch in size, oval, turgid, blunt and slightly flattened at the base, ending in an abrupt but sharp point at the apex, nearly smooth; ventral suture narrow, faintly ridged; dorsal suture acute.

\section{FOREST ROSE}

\section{Prunus hortulana mineri}

1. Mich. Pom. Soc. Rpt. 290. 1889. 2. Ia. Hort. Soc. Rpt. 55. 18go. 3. Cornell Sta. Bul. 38:55, 86. 1892. 4. Mich. Sta. Bul. 123:19. 1895. 5. Ia. Sta. Bul. 31:346. 1895. 6. Colo. Sta. Bul. 50:36. 1898. 7. Ohio Sta. Bul. 113:154. 1899. 8. Waugh Plum Cult. 173. 1901. 9. BuddHansen Am. Hort. Man. 296. rgo3.

Forest Rose, like Forest Garden, belongs to Prumus hortulana mineri, the two being similar in many respects. Forest Rose, however, is not as attractive in color as the other variety, the difference not being well brought out in the color-plates, is smaller and does not keep nor ship quite as well. The variety under discussion is better in quality than Forest Garden and better 


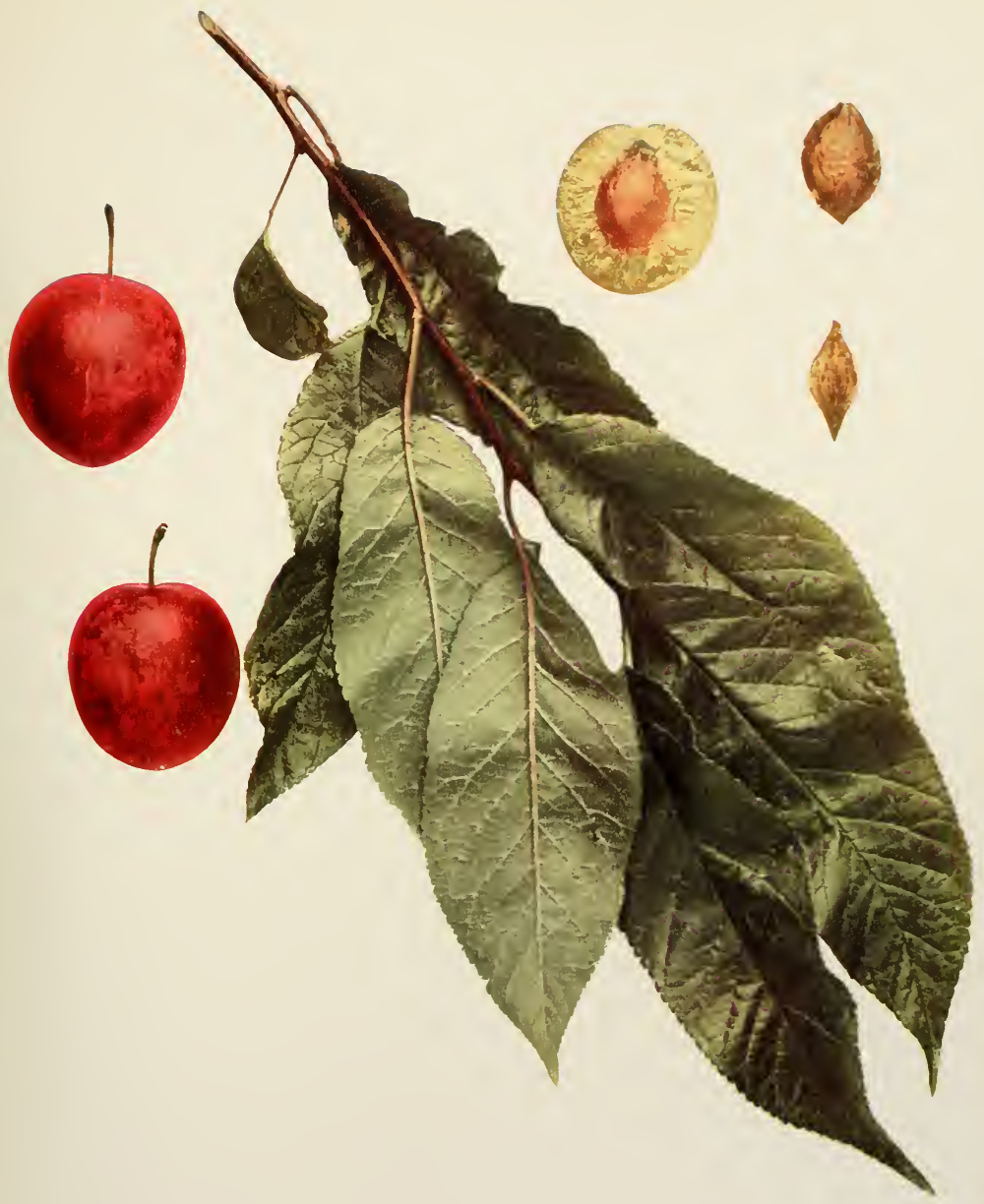





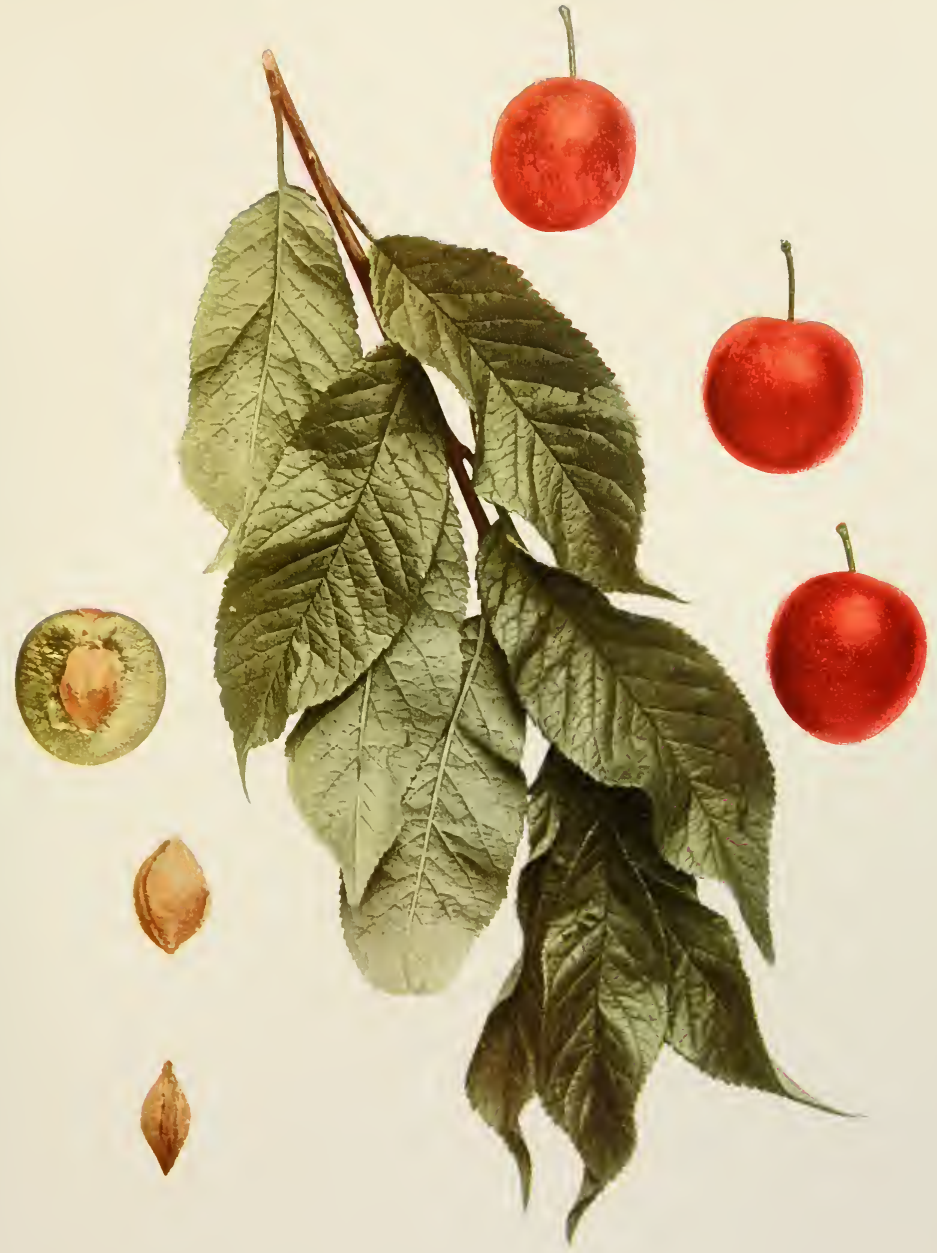



adapted than the last named variety for the home orchard at least. While somewhat variable in productiveness, in most localities it bears annually and abundantly. The trees are rather more thorny than most of its species.

This variety is said by $\mathrm{H}$. A. Terry of Crescent, Iowa, to be a seedling of Miner, grown by Scott \& Company, a Missouri nursery firm, and introduced by William Stark, Louisiana, Missouri, in 1878 . Terry offers no evidence to show that this plum is a seedling of Miner and there is a question as to whether more is really known of its parentage other than that it came from Missouri.

Tree medium to large, intermediate in vigor, upright-spreading, open-topped, hardy, variable in productiveness somewhat susceptible to attacks of shot-hole fungus; trunk very rough and shaggy; branches rough, thorny, dark ash-gray, with numerous lenticels; branchlets numerous, slender, variable in length, with internodes of medium length, green changing to dull reddish-brown, glossy, glabrous, with numerous, small, raised lenticels; leaf-buds small, short, obtuse, appressed.

Leaves falling early, folded upward, elongated-oval or obovate, one and one-half inches wide, four inches long, thin; upper surface dull red in the fall, rugose, glabrous, with the midrib and larger veins deeply grooved; lower surface light green, somewhat pubescent along the midrib; apex acuminate, base acute, margin crenate or serrate, with small, dark glands; petiole slender, five-eighths inch in length, sparsely pubescent along one side, tinged with red, glandless or with from one to three small, globose or oval, greenish-brown glands on the stalk.

Flowers seven-eighths inch across, white, with a disagreeable odor; borne in dense clusters on lateral buds and spurs, in pairs or in threes; pedicels five-eighths inch long, below medium in thickness, glabrous, greenish: calyx-tube green, narrowly campanulate, glabrous; calyx-lobes short and narrow, acute, serrate, somewhat reflexed, glabrous on the outer surface, but more or less pubescent on the inner surface and along the margin, which is strewn with red glands; petals oval, dentate, tapering below into narrow, lightly pubescent claws of medium length; anthers light yellow; filaments one-half inch in length; pistil glabrous, shorter than the stamens.

Fruit late, season short; one and one-eighth inches by one inch in size, roundishoval; cavity shallow, narrow, flaring; suture a line; apex roundish; color dull crimson overspread with thin bloom; dots very numerous, small, gray, conspicuous; stem slender, three-quarters inch long, smooth, not adhering to the fruit; skin thick, tough, astringent, inclined to crack under unfavorable conditions, adhering; flesh dull apricotyellow, juicy, fibrous, tender and melting, sweet next to the skin but tart toward the center, aromatic; fair to good; stone clinging, five-eighths inch by one-half inch in size, oval, acute at the apex, with pitted surfaces; ventral suture somewhat blunt. 


\section{FOTHERINGHAM}

\section{Prunus domestica}

1. Rea Flora 208, 1676. 2. Langley Pomona 91. 1729. 3. Miller Gard. Dict. 3:1754. 4. Forsyth Treat. Fr. Trees 19. 1803. 5. Downing Fr. Trees Am. 299. 1845. 6. Floy-Lindley Guide Orch. Gard. 286, 383. 1846. 7. Thompson Gard. Ass't 517. 1859. 8. Hogg Fruit Man. 701. 1884. 9. Waugh Plum Cult. 102. 1901.

Foderingham 1. Fotheringay 8. Foderingham Plum 2. Grove House Purple 5, 7, 8. Red Fotheringham 8, Sheen 2, 5, 6, 7,8.

Fotheringham is probably one of the oldest varieties of plums now cultivated. Although but little if at all grown in this country, it has maintained its place among standard English varieties for at least two and a half centuries. The exact time of its origin is not certain, but it was undoubtedly during the first half of the Seventeenth Century as Hogg records a reference made to it by Rea in 1665 . It was first grown extensively at Sheen, in Surrey, England, about 1700 by Sir William Temple, who gave it the name Sheen. The variety is described as follows:

Tree hardy, vigorous, productive. Fruit matures just before Reine Claude; of medium size, obovate; suture distinct; stem one inch long; color reddish-purple with thin bloom; flesh greenish-yellow, sweet, sprightly; good; freestone.

\section{FREEMAN}

Prunus domestica

As this variety grows in the Station orchard it is a remarkably fine plum. The fruits are attractive, of high quality and the tree-characters are for most part very good. It is certainly a desirable plum for any home plantation, and if it proves as productive elsewhere as about Geneva, it may well be worth growing in commercial orchards.

Freeman is a chance seedling found in the yard of a Mr. Freeman of Cortland, New York, about 1890 and shortly afterwards introduced by E. Smith \& Sons of Geneva, New York, but is as yet hardly known by plumgrowers.

Tree intermediate in size and vigor, upright-spreading, productive; branchlets slender, pubescent; leaves oval, one and one-half inches wide, two and three-quarters inches long; margin serrate or almost crenate, eglandular or with small dark glands; petiole reddish, glandless or with from one to four globose glands; blooming season intermediate, short; flowers appearing after the leaves, creamy-white, usually in scattering clusters at the ends of lateral spurs; borne singly or in twos. 


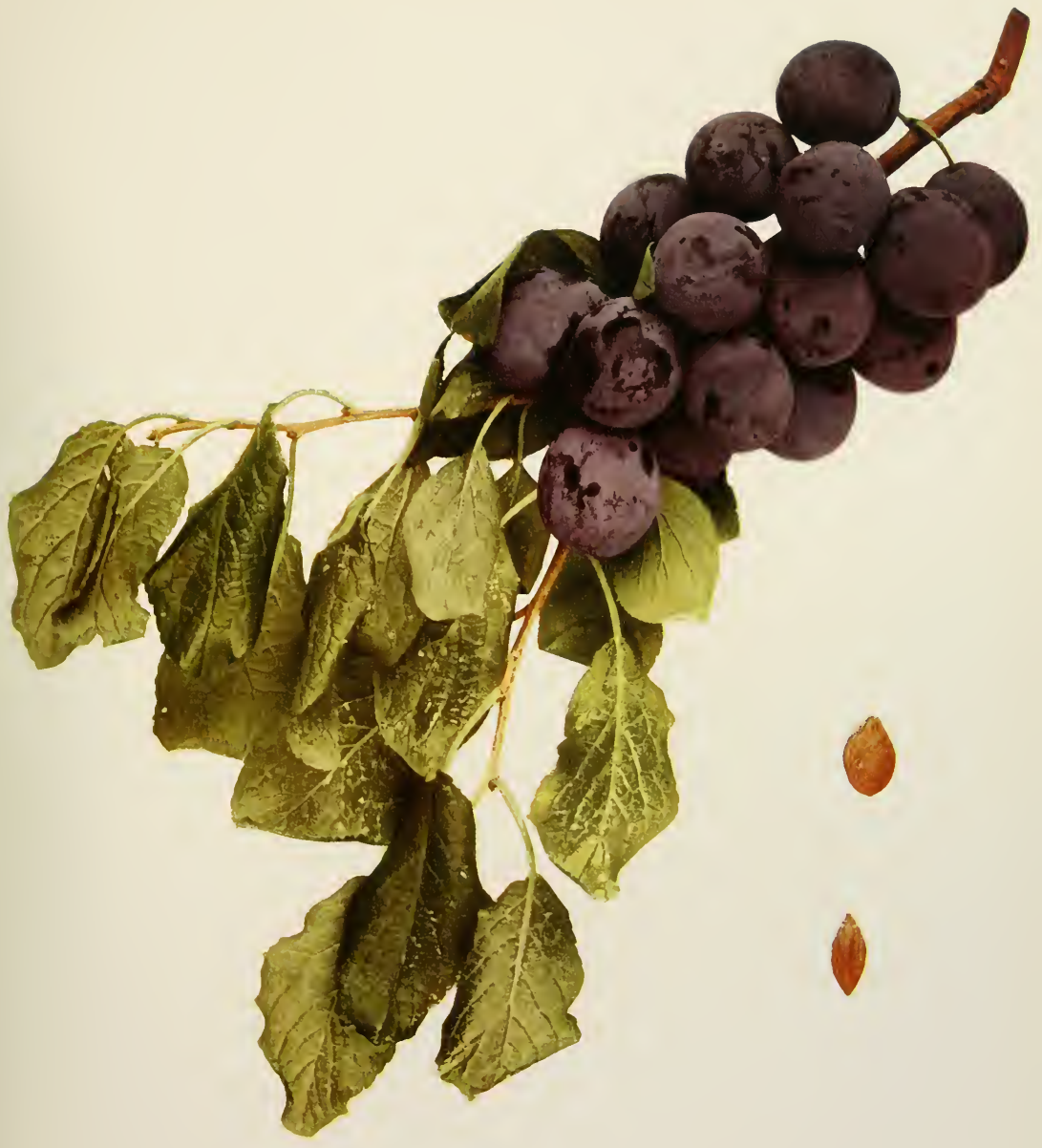



Fruit mid-season, ripening period short; about one and one-half inches in diameter, roundish or roundish-oval; cavity very shallow, small, often lipped; color golden-yellow, blushed and mottled with red on the exposed cheek, covered with thin bloom; flesh light golden-yellow, firm but tender, sweet, pleasant flavor; very good to best; stone dark colored, free, seven-eighths inch by five-eighths inch in size, irregular-oval, somewhat flattened, abruptly contracted at the base, with surfaces roughened; ventral suture prominent.

\section{FREESTONE}

\section{Prunus insititia}

r. Am. Gard. 14:148. 1893. 2. Waugh Plum Cult. 129. 1901.

Freestone Damson 2.

Freestone is a Damson separated from other Damsons chiefly in being sweeter and more free of stone. It is so inferior to varieties of its species in several particulars as to have little value for commercial planting. The fruits are smaller and the pits larger in proportion to the amount of flesh than with several better known Damsons and the trees do not bear as large crops as plums of this species should; these faults of fruit and tree condemn the plum. To offset the defects in the tree, freedom from blackknot and immunity to leaf-blight may be mentioned as compensating somewhat. Still Freestone is hardly to be mentioned as worth planting in either home or commercial orchard. The origin of this Damson is unknown. Stark Brothers, Louisiana, Missouri, who introduced the variety about I 889 , describe it as " a selected sort which is very hardy, free from insects, and productive."

Tree of medium size and vigor, upright-spreading, vasiform, hardy, not always productive; branches dark ash-gray, thorny; leaves folded upward, oval, one and one-quarter inches wide, two and one-quarter inches long; upper surface dark green, rugose; lower surface silvery-green, pubescent; margin finely serrate, eglandular or with small, brownish glands; petiole five-eighths inch long, glandless or with one or two small glands; blooming season late and of medium length; flowers appearing after the leaves, seven-eighths inch across, the buds creamy, changing to white when expanded; borne in clusters on lateral buds and spurs, usually in pairs; anthers reddish; filaments fivesixteenths inch long; pistil shorter than the stamens.

Fruit late, season long; seven-eighths inch in diameter, roundish-oval; cavity very shallow and narrow; flesh yellowish-green, juicy, tender, sweet, mild; fair in quality; stone free, tinged red, five-eighths inch by one-half inch in size, oval, turgid, with roughened surfaces, acute at the base, blunt at the apex; ventral suture broad, blunt; dorsal suture with a broad, shallow groove. 


\section{FRENCH}

\section{Prunus insitilia}

1. Mich. Hort. Soc. Rpt. 289 . 1889. 2. Ibid. 64. 189r. 3. Cornell Sta. Bul. 131:184 fig. 401 . 1897. 4. Mich. Sta. Bul. 169:245. 1899. 5. Waugh Plum Cult. 129. 1901.

French Damson 4. French Damson 1, 2, 3.

Far better than the Freestone just discussed is the French Damson, which in some respects surpasses all other plums in its group. Thus it is the largest of the Damsons, so large, indeed, as to lead many to believe that it may be a hybrid with some Domestica plum, the size of the trees, blossoms and foliage also leading to such a supposition. This excellent Damson is largely grown for the market in western New York, good quality as well as size and appearance aiding in selling the product. The fruits have but one defect, the pit is large for the amount of flesh. Curiously enough in some seasons the stone clings and in others is perfectly free. It is in tree-characters that the French plum best shows its superiority over other Damsons. The trees are large, the largest of the Damsons in New York, hardy, bear abundantly and annually and carry their foliage so well that fruit and wood usually ripen perfectly even when the trees are not sprayed. The season is a little after that of the more commonly grown Shropshire, which in most years is an advantage. French, while becoming popular, is still too little known in New York, where its behavior warrants quite general planting.

S. D. Willard, a nurseryman of Geneva, New York, probably introduced French in this country; at least it was brought to notice mainly through his recommendation. The origin is unknown, but it is probably an introduction from France and may be an old variety renamed. The figure of Prune Petit Damas Violet given by Poiteau is so very similar as to suggest that French may be identical with that sort.

Tree large, vigorous, spreading, dense-topped, hardy, productive; branches numerous, ash-gray, roughish, thorny, with lenticels variable in size; branchlets inclined to develop spurs at the base, rather slender, short, with short internodes, greenish-red changing to dark brownish-drab, dull, somewhat zigzag, thickly pubescent, with inconspicuous, small lenticels; leaf-buds intermediate in size and length, pointed, free.

Leaves folded upward, long-oval, one and one-quarter inches wide, three inches long; upper surface dark green, covered with fine hairs, with a grooved midrib; lower surface pubescent; apex abruptly pointed, base abrupt, margin serrate or nearly crenate, with a few, small, dark glands; petiole eleven-sixteenths inch long, rather slender, pubescent, faintly tinged with red, usually having two very small, globose, greenishbrown glands on the stalk or base of the leaf. 


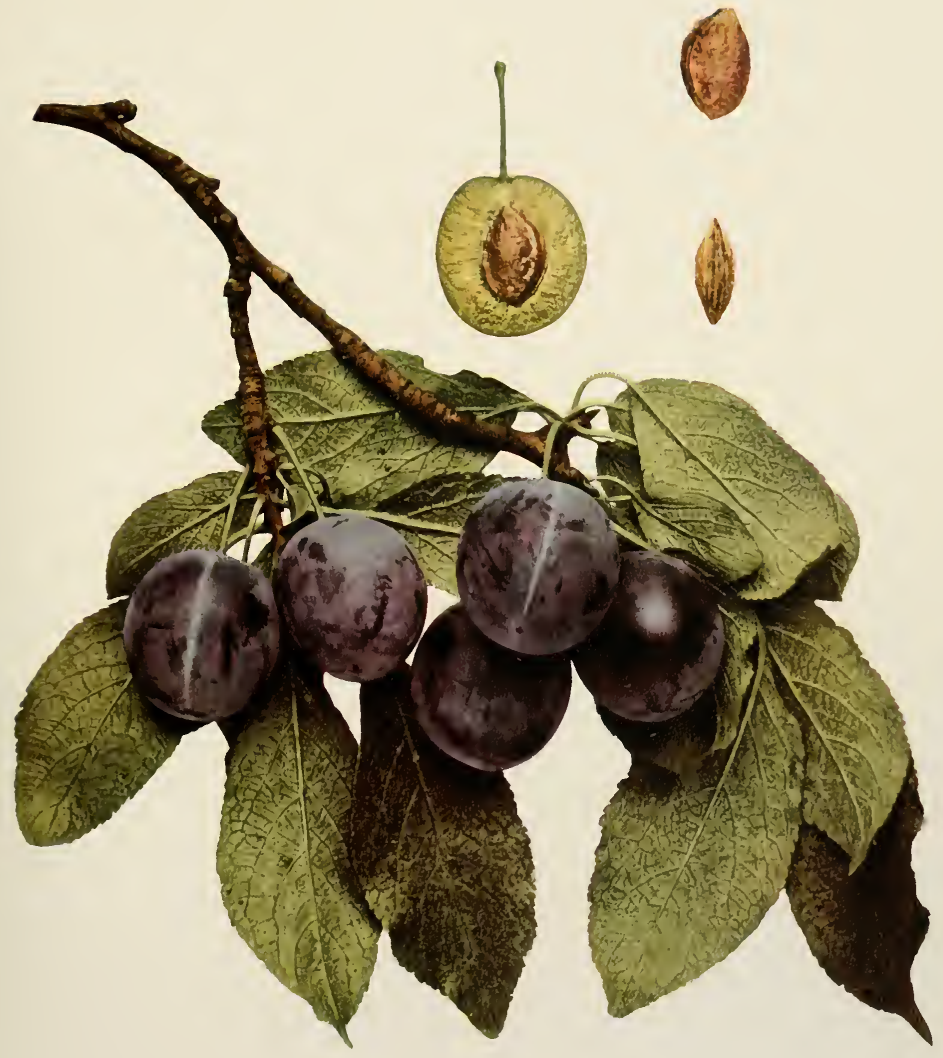



Blooming season intermecilate in time and length; flowers appearing after the leaves, one and five-sixteenths inches across, white; borne on lateral spurs, usually in pairs; pedicels five-eighths inch long, slender, covered with short pubescence, greenish; calyx-tube gieen, campanulate, glabrous; calyx-lobes narrow, obtuse, glabrous on the outer surface, thinly pubescent along the margin and at the base of the inner surface, glandular-serrate, reflexed; petals oval, dentate or fringed, tapering below to short, broad claws; anthers distinctly reddish; filaments seven-sixteenths inch in length; pistil glabrous, equal to the stamens in length.

Fruit late; one and one-half inches by one and one-eighth inches in diameter, ovate, halves equal; cavity very shallow, narrow, flaring; suture a line; apex roundish; color dull black, overspread with thick bloom; dots numerous, small, brownish, inconspicuous; stem slender, three-quarters inch long, sparingly pubescent, adhering well to the fruit; skin thin, tough, separating readily; flesh greenish, juicy, fibrous, tender, sweet, pleasant and sprightly; good; stone variable in adhesion, seven-eighths inch by one-half inch in size, oval, roughened, acute at the base, blunt at the apex; ventral suture rather narrow, heavily furrowed and somewhat winged; dorsal suture with a shallow groove of medium width.

\section{FROGMORE}

\section{Prunus insititia}

x. Flor. \& Pom. 265, P1. 1876. 2. Mich. Hort. Soc. Rpt. 289. 1889. 3. Can. Exp. Farm Bul. 2nd Ser. 3:51. 1900. 4. Waugh Plum Cult. 130. 1901.

Frogmore Damson 1, 2. Frogmore Prolific Damson 3.

Frogmore may be considered among the best of the Damsons in quality for the culinary purposes to which this fruit is commonly put. The flesh is tender, sweet and good, but adheres rather too tightly to the stone. The tree of Frogmore is all that could be desired in productiveness and quite equals most other Damsons in general and probably surpasses them all, at least on the grounds at this Station, in length of time that the fruit hangs on the tree. The habit of growth of this variety varies from that of Prunus insititia as commonly found, the leaves being larger, the tops more spreading and the branches less thorny. The variety has hardly been tried enough in New York to warrant either recommending or condemning it. According to the Florist and Pomologist, published in 1876 , this variety originated a few years previous to the date of publication in the Royal Gardens at Frogmore, England.

Tree inferior in size and vigor, round-topped, open, hardy, very productive; branches thorny, the bark on the older branches splitting transversely to the direction of growth, making grooves or rings about three inches apart and two inches or more in length; branchlets slender, almost glabrous throughout the season, covered with light bloom; 
leaves bright red on first opening, somewhat folded backward, obovate, one and threeeighths inches wide, three and one-half inches long; upper surface dark green, rugose; lower surface silvery-green, pubescent, margin eglandular; petiole five-eighths inch long, slender, greenish, glandless or with one or two small, globose, yellowish-green glands usually at the base of the leaf; blooming season intermediate in time and length; flowers appearing after the leaves, one inch across, white, in scattered clusters on lateral spurs; borne singly or in pairs; anthers yellow with tinge of red; filaments five-sixteenths inch long; pistil glabrous, equal to the stamens in length.

Fruit late, season of medium length; one and one-eighth inches by one inch in size, roundish-oval, compressed, purplish-black, overspread with thick bloom; flesh golden-yellow, juicy, tender, sweet; good; stone clinging, three-quarters inch by onehalf inch in size, oval, smooth, somewhat acute at the base and apex; ventral suture blunt or with a short, narrow wing; dorsal suture with a narrow, shallow groove.

\section{FROST GAGE}

\section{Prunus domestica}

1. Prince Pom. Man. 2:52. 1832. 2. Mag. Hort. 4:45. 1838. 3. Hoffy Orch. Comp. 2:1842. 4. Downing Fr. Trees Am. 300. 1845. 5. Horticulturist 3:446. 1848. 6. Cole Am. Fr. Book 2 I9 1849. 7. Am. Pom. Soc. Rpt. 54. 1852. 8. Hogg Fruit Man. 362. 1866.

American Damson S. Frost Plum 4, 6, 8. October Gage 3.

Frost Gage is too small for market purposes and moreover the fruit withers rather quickly after picking; the quality is above the average. The plum is not a Gage, only green fruits being entitled to this name. At one time this was one of the most popular commercial varieties in the Hudson Valley, but because of its susceptibility to black-knot it has lost favor with growers. Downing in 1838 traced the history of this variety to a tree standing on the farm of a Mr. Duboise, Dutchess County, New York, Mr. Dubois stating that the original had been planted by his father. It is doubtful if this is the first tree, however, for in 1849 Charles Hamilton of Canterbury, Orange County, reported trees of Frost Gage thirty to forty years old on his place.

Tree of medium size, upright, very productive; branchlets thick; leaves flattened, oval or obovate, one and one-half inches wide, two and three-quarters inches long; margin crenate or serrate, with few, small, black glands; petiole short, usually with one or two glands; blooming season intermediate, short; flowers appearing after the leaves, white, with a little yellowish tinge: borne on lateral buds and spurs, singly or in twos.

Fruit late; about one and one-eighth inches in diameter, roundish, dark purplishblack, covered with thick bloom; stem slender, persistent; skin tough, sour; flesh greenish-yellow, juicy, firm, sweet, mild; fair to good; stone clinging, small, irregularovate, somewhat oblique. 


\section{FURST}

\section{Prunus domestica}

1. Mas Le Verger 6:45. 1873. 2. Lange Allgem. Garten. 2:421. 1879. 3. Oberdieck Deut. Obst. Sort. ${ }_{113}$. 1881. 4. La uche Deut. Pom. 8, Pl. 1882. 5. Guide Prat. 159, 363. 1895.

Eugen Fürsts Frihzwetsche 4, 5. Fürst's Frühzwetsche 2, 3, 4. Fürst's Frühzwetsche 1, 4, 5. Quetsche Prócoce de Fürst $1,5$.

Furst would undoubtedly be well worthy of very general cultivation in plum orchards were it not for the fact that it is very similar to the Italian Prune. The two fruits differ only in season, the Furst being a few days earlier, and in the tendency of the variety under discussion to shrivel about the neck. It may be that Furst will succeed in some localities where the Italian Prune is not a success.

Furst was propagated by the Baron of Trauttenberg, Prague, Bohemia, who had received it from Professor Pater Hackl, Leitmeritz, Bohcmia, under the name Furst, given in honor of Eugene Furst, son of the founder of the School of Horticulture of Frauendorf, Bavaria. Furst Damson has been confused with this variety, but it is a different plum. Its fruits are distinctly necked and much inferior in quality, and its shoots are glabrous, while in this variety they are not. The United States Department of Agriculture introduced Furst in I90I and through them this Station received cions for testing.

Tree of medium size, round-topped, productive; branchlets thick, marked with slight scarf-skin; leaf-scars very prominent; leaves folded upward, obovate, two and one-half inches wide, four and one-half inches long; margin doubly serrate or almost crenate, eglandular or with small dark glands; petiole thick, pubescent, glandless or with from one to three globose glands usually on the stalk; blooming season late; flowers one and one-eighth inches across, white, the opening buds tipped with yellow; borne on lateral buds and spurs, singly or in twos.

Fruit late; one and seven-eighths inches by one and one-half inches in size, oval, slightly necked, purplish-black, covered with thick bloom; dots numerous, reddish, conspicuous; stem thick; flesh greenish-yellow, juicy, very fibrous, firm, sweet, mild, with pleasant aroma; good to very good; stone one and one-eighths inches by fiveeighths inch in size, free, irregular-oval, with rather long, tapering, oblique apex, the surfaces heavily pitted; ventral suture prominent, often winged; dorsal suture wide.

\section{GEORGESON}

Prunus triflora

1. Ga. Hort. Soc. Rpt. 52, 99. 1889. $\quad$ 2. Am. Gard. 12:308, 501, 574. 1891. 3. Ibid. 13:700. 1892. 4. Cornell Sta. Bul. 62:23, 27. 1894. 5. Tex. Sta. Bul. 32:488, 489. 1894. 6. Ga. Hort. 
Soc. Rpt. 94. 1895. 7. Cornell Sta. Bul. 106:51, 58. 1896. 8. Ibid. 139:40, 44. 1897. 9. Am. Pom. Soc. Cat. 26. 1897. 10. Cornell Sta. Bul. 175:145. 1899. I1. Waugh Plum Cult. 136. 1901. 12. Ga. Hort. Soc. Rpt. 13. 1904. 13. Mass. Sta. An, Rpt. 17:160. 1905. 14. Ohio Sta. Bul. 162: $250,254,255,256,257$. I 905 . 15. Ga. Sta. Bul. 68:10, 30, 32, 33. I 905 .

Hattonkin No.1. 3, 4, 7. Hattankin No.r. 5. Hattonkin 7, I1. Hattankio 7. Hattankio ?1. Hattankio No.1, 6, 9, 12, 15. Hattonkin No.1. 2. Mikado 10, I1, 12, 15. Normand 4, 5 , 7, 8, 14. Normand Yellow 2, 3. Normand Japan 3. Normand's Japan 4, 5. Normand Yellow 4, 5, 7. Normand ?15. White Kelsey 10, II, I5. Yeddo 10, II, I5.

Georgeson is not worth the trouble it has caused pomologists in straightening out its nomenclature; and Professor Georgeson deserves to have his name attached to a far better plum. The rich yellow color of the fruit makes this a particularly handsome plum, but here praises end. The flesh is so astringent and clings so tenaciously to the stone as to unfit the variety for either dessert or culinary use. Moreover, the fruits are exceedingly variable in color, size and shape, in the last character ranging from flattish to round, with sometimes round and sometimes pointed apex. The tree has too much of the sprawling habit of Burbank to make it a good orchard plant. This plum, and those that have been confused with it, can be spared without great loss to American pomology.

Georgeson was imported by H. H. Berger \& Company, San Francisco, California, and brought to notice chiefly by J. L. Normand, Marksville, Louisiana, who named it for Professor C. C. Georgeson, then of Manhattan, Kansas, a student of Japanese fruits. In the Georgia Horticultural Society Report for 1889 , L. A. Berckmans mentions two types of Hattankio, one of which may be this variety. Normand, in I89I, said that he received two varieties of Hattonkin from different sources and in order to separate them he numbered the earlier, No. I, the later No. 2. Bailey and Kerr, however, in I894, published Hattonkin No. I as a synonym of Georgeson and Hattonkin No. 2, the later, as a synonym of the Kerr. The Georgia Horticultural Society accepted this latter nomenclature in their report published in 1895 . The Mikado, White Kelsey and Yeddo as tested by this Station have proved to be identical with Georgeson, but as tested by Kerr, ${ }^{1}$ the Mikado alone is the same. Normand, which is said to have been imported and introduced in $\mathrm{I} 89 \mathrm{I}$ by J. L. Normand, is also indistinguishable from this variety. In 1897 , Georgeson was placed on the American Pomological Society fruit catalog list.

${ }^{1}$ Mr. Kerr writes: "As I have them here, Yeddo and White Kelsey are the same. If there is a difference between Georgeson and Mikado, I have failed to discover it, but Georgeson and White Kelsey or Yeddo a re plainly distinct. The former is larger, rounder and more greenish in skin color." 


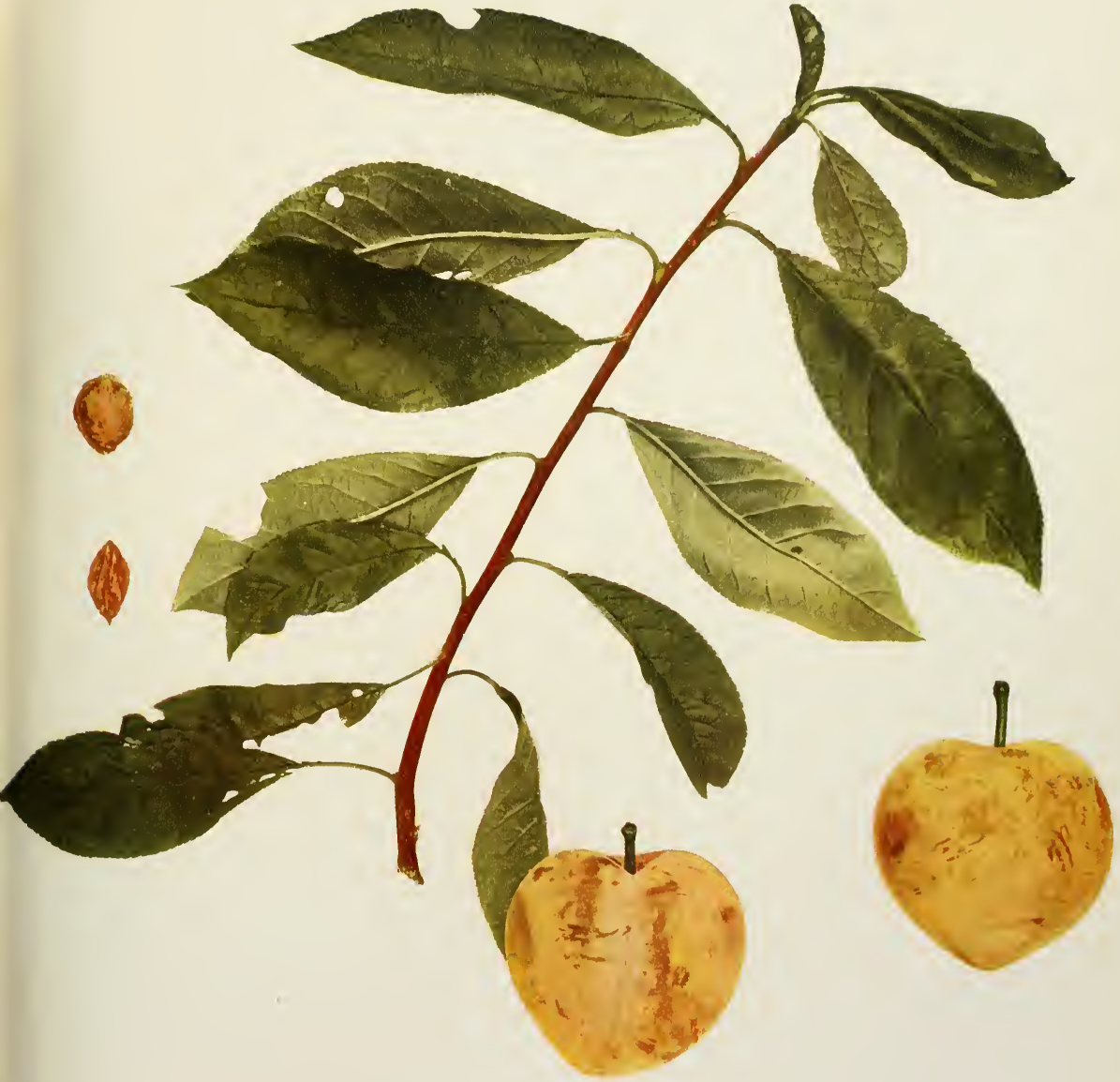




$$
\text { - }
$$


Tree medium in size and vigor, upright-spreading or broad-vasiform, not always hardy, productive; branches roughish, slightly thorny, often with bark cracked longitudinally, zigzag, dark ash-gray; branchlets glabrous, with characteristic raised lenticels; leaf-scars enlarged; leaves folded upward, broadly oblanceolate or obovate, one and three-eighths inches wide, three and three-quarters inches long, thin; margin crenate or serrate, with small, amber glands; petiole five-eighths inch long, reddish, with from one to ten brownish-red glands usually on the stalk; blooming season early to medium, of average length; flowers appearing before the leaves; borne in clusters on lateral spurs, in pairs or in threes; petals pinkish at the base; anthers reddish; pistil longer than the stamens.

Fruit early, ripening period short; one and five-eighths inches in diameter, roundishcordate; cavity deep, wide, usually with concentric, russet lines; color greenish-yellow changing to deep yellow as the fruit reaches full maturity, with thin bloom; flesh goldenyellow, fibrous, firm, sweetish except near the center; fair to good; stone clinging, five-eighths inch by one-half inch in size, oval, turgid, with pitted surfaces; ventral suture broad, slightly ribbed; dorsal suture acute.

\section{GERMAN PRUNE}

\section{Prumus domestica}

1. Knoop Fructologie 2:53, 61. 1771. 2. Coxe Cult. Fr. Trees 235, fig. 7. 1817. 3. Lond. Hort. Soc. Cat. 152. 1831. 4. Prince Pom. Man. 2:77, 78. 1832. 5. Downing Fr. Trees Am. 310. 1845. 6. Floy-Lindley Guide Orch. Gard. 286, 383. 1846. 7. Poiteau Pom. Franc. $1: 1846$. 8. Thomas Am. Fruil Cult. 335. 1849. 9. Am. Pom. Soc. Cat. 214.1856. 10. Hooper W. Fr. Book 245. 1857. 11. Thompson Gard. Ass't 519. 1859. 12. Hogg Fruil Man. 378. 1866. 13. Pom. France 7:No. 17. 1871. 14. Mas Pom. Gen. 2:171. 1873. 15. Lange Allgem. Garten. 2:418. 1879. 16. Lauche Deut. Pom. 1:1882. 17. Mathieu Nom. Pom. 434. 1889. 18. Wickson Cal. Fruits 355. 1891. 19. Guide Prat. 155, 362. 1895. 20. Cornell Sta. Bul. 131:185, fig. 43. 1897. 21. Oregon Sta. Bul. 45:29 fig. 1897. 22. Waugh Plum Cult. 102. 1901. 23. Ohio Sta. Bul. 162: 254, 255. 1905.

Altesse ordinaire ${ }^{13}, 17,19$. Backpflaume 17, 19. Bawernpflaume ${ }_{17}, 19$. Common Quetsche 3. 5. $11,17,18,19$. Couetsche 4, 19. Coutche 17. Coutch 13, 19. Coutsche Ordinaire 17, 19. Covetche 5. Covetsche 17. Damas Gros 3, 5, 11, 17, 19. Damask 3, 5, 11, 17, 19. Damas Lang 1. Damas Violet of some 3, 11, 17, 19. Damas Violet Gros of some 3, 5, 11, 17, 19. Deutsche Blawe Herbstzwetsche 17, 19. Die Hauszwetsche 19. D'Allemagne 19. Die Hauszwetsche 16. Dutch Prune ro. Early Russian 11, 12, 13, 17, 19. Enkelde Backspruim 17. Enkelde Blackpruim 19. Fellemberg 13, 17 incor., 19. Gcmeine Zwetsche 13, 14, 17, 19. Gemeine Hauswetsche 14. German Plum 4. 14. German Prune 3, 5, 11, 12, 13, 14, 17, 19. German Quetsche 12, 13, 17, 19. Grosse German Prune 3. Grosse Hausplaume 17, 19. Hauszwetsche 15. Hauszwetsche 13, 14, 16. Hauspflaume 14, 17. Imperatrice Violette Grasse of some 3, 5, I1, 17, 19. Imperatrice Violette of some 3. 5, 11, 13, 17, 19. Koetsche 13, 17, 19. Large German Prune 4, 17. Leipzig 3, 12, 13, 17, 19. Leipsic 5. Leipsiger Zwetsche 16,17 , 19. Monsieur tardif ? 19. Monsieur Tardif 17. Prunte d'Allemagne la commune 4. Prune d'Allemagne 3, 5, 11, 12, 13, 16, 17. Prune d'Allesse $\mathrm{x}$. Prune Imperatrice Violette 7. Prune Plum ? 2. Prune Allemand 4. Prunier Allemand 4. Prune Plum 4. Prune Quetsch 7. Prunus Oeconomica 17. Prune Zwetschen 14. Quastche 7. Quetsch 7, 13, 19. Quetsche 4, 6, 8, 14, 17, 19. Quetsche ? 1, 3, 5, 6, 11, 12. Quetsch Allemande 1. Quetsch Hongroise I. Quetschen 4. Quetcshe Commune 4, 13, 14, 16, 17. Quetsch Longue ? I. 
Quctsche d'Allemagne Grosse 3, 5, 11, 17, 19. Quetsche Commune 19. Quetsche d'Allemagne 3, 17, 19. Quetsche D'Allemagne 13. Quetsche des Allcmands 7. Quetsche Grosse 3, 5, 17, 19. Quetsche de Lorraine I3, 14, I7, 19. Quetsche de Metz 13, 16, I7, 19. Quetsche Domestique 14. Quetsche de Malogne 13, 17, 19. Quetzen 6, 17. Sweet Prune 5, 11, 12, 13, 17, 19. Teutsche blaue Zwetsche 16, 17, 19. Wahre Zwetsche 16. Wetschen 13, 17, 19. True Large German Prune 4, 5. 17, 19. Turkish Quetsche 5, 11, 12, 13, 17, 19. Zwespe 17, 19. Zwetsche 3, 5, 7, 11, 12, 13, 14, 17. 1). Zwetschen 4. Zwetschke 3, 11, 17, 19.

Although one of the oldest plums under cultivation, probably the oldest of the prune type, the German Prune is still as largely grown, the world over, as any; and is seemingly more widely disseminated than any other plum. It is a little difficult, in America at least, to see why this fruit holds its popularity so long, for it is surpassed by other plums in many horticultural characters, and when all of its characters, most of which are very good, are combined there are still plums which it does not excel. In most of the attributes which gratify the senses, color, size, shape, taste and smell, it falls below expectations for a plum so universally planted. Undoubtedly the wide distribution of this plum is due somewhat to its many variations. The fruit comes almost true to seed and is often propagated by planting pits, a practice which has given many slightly different strains of this variety, each with somewhat different adaptations.

In the Old World the number of strains of this plum, especially in Germany, is legion, so many that it is probably impossible to segregate them at this late date. In America, while there are a number of these more or less distinct strains it is yet possible to distinguish the chief ones. In New York, the most commonly grown German Prune is the Rochester strain and since it agrees most closely with the fruit described in the best works on pomology, it is the strain described and illustrated in this work. The trees from which this description was made came from Ellwanger and Barry, Rochester, New York, who have long maintained a stock tree of this strain. Another German Prune, fruit of which we have not been able to obtain, is the Dansville strain grown in the nurseries of Dansville, New York. Still another of these plums is the Weedsport German Prune ${ }^{2}$ so like the Rochester type as to be hardly worth distinguishing. The Latz German Prune is a very distinct strain; it is larger, thicker and broader than the type here described and is more of a clingstone. In some respects this is the best of the German Prunes. All accounts agree

\footnotetext{
'Introduced by Wiley and Company of Cayuga, New York in 1892. See Cornell Sta. Bul. 131:193, fig. 47. 1898.
} 


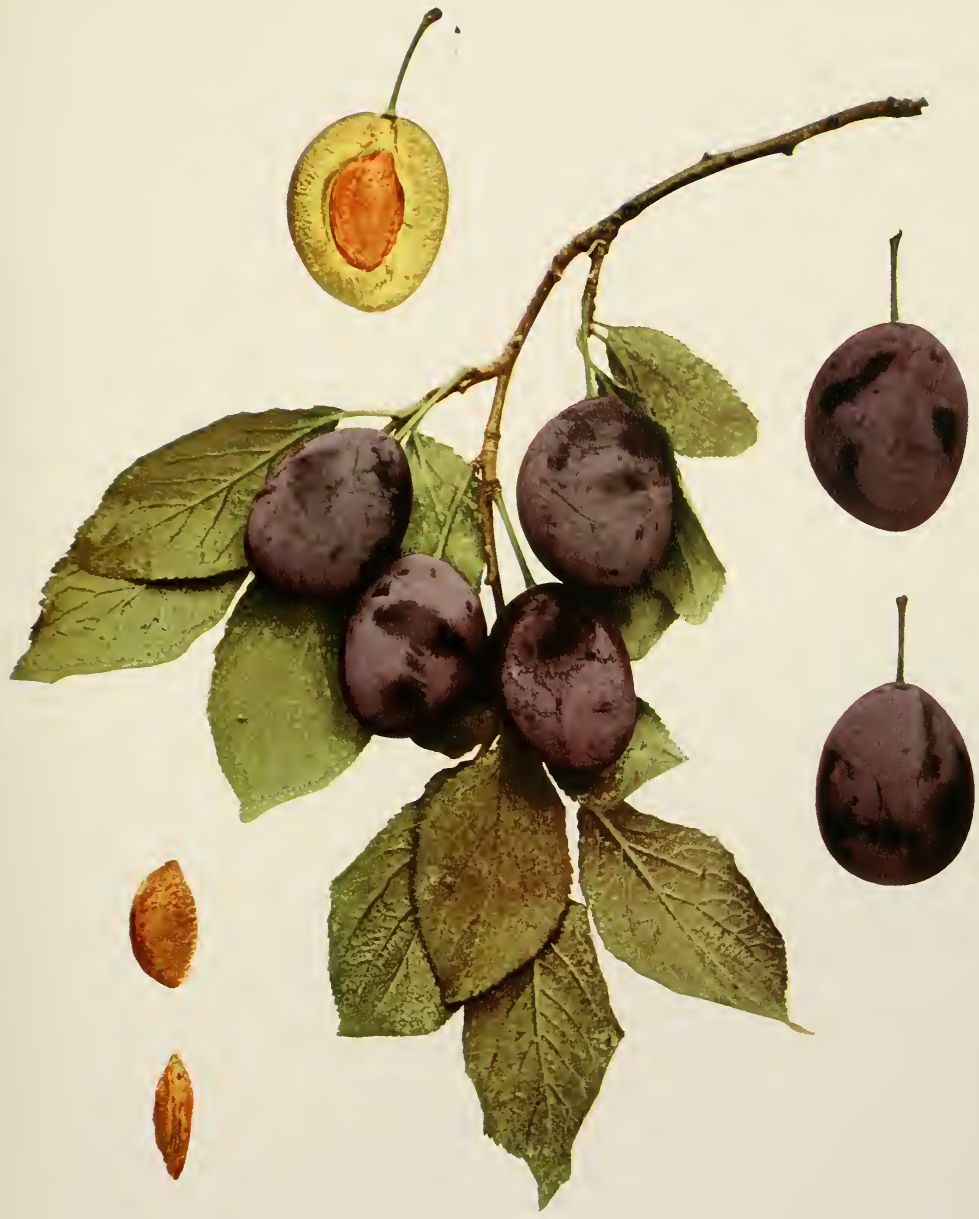

GERMAN PRUNE 
that this plum was introduced into America from Prussia by a Mr. Latz about $185^{\circ}$.

All of these German Prunes are characterized by large, hardy, vigorous, healthy, productive trees, characters so marked that one can say at once that it is the tree that gives the German Prune its great value. The fruit is excellent for all culinary purposes, especially for canning, and cures into a small but very good, tart, meaty, freestone, elastic prune. The chief objection to the plum for these purposes is that the fruits run small. The plums are too tart to have much value as dessert fruits. This variety is likely to remain a standard for some time in New York but will eventually be superseded by a larger fruit.

The origin of this plum is uncertain. German writers very generally hold that it came from Asia whence it was carried during the Crusades to Europe. Lauche, a German authority, says, "In the Sixteenth Century, the first dried prunes were introduced into Italy, Switzerland and Germany from Hungary. The tree on the contrary is said not to have been introduced by us until the end of the Seventeenth Century." A Prune Plum was noted in America by Coxe in 1817 , but it is impossible to say whether he meant the German Prune. Prince, however, in 1832 , described the variety under its present name. In 1856, the American Pomological Society placed the German Prune on the list of the varieties promising well and six years later added it to its fruit catalog. The German Prune is used only in the fresh state in New York, but on the Pacific Coast, in some one of its several types, it is one of the half-dozen leading sorts for curing.

Tree medium to large, vigorous, round and dense-topped, hardy, usually very productive; branches ash-gray, somewhat rough, with lenticels variable in size; branchlets slender, short, with internodes of medium length, green changing to brownish-red, dull, glabrous, with numerous, small, obscure lenticels; leaf-buds intermediate in size and length, conical, free.

Leaves falling early, oval or obovate, one and one-half inches wide, three inches long, thinnish, velvety; upper surface pubescent, slightly rugose, with a shallow groove on the midrib; lower surface yellowish-green, heavily pubescent; apex abruptly pointed or acute, base acute, margin finely serrate, with small glands; petiole one-half inch long, pubescent, tinged with red, glandless or with one or two small, globose glands usually at the base of the leaf.

Blooming season intermediate in time and length; flowers appearing after the leaves, nearly one inch across, inconspicuous on account of their greenish-yellow color, which characterizes the variety; borne on lateral spurs, singly or in pairs; pedicels 
five-eighths inch long; below medium in thickness, pubescent, greenish; calyx-tube green, campanulate, lightly pubescent at the base; calyx-lobes long, narrow, acute, thinly pubescent on both surfaces, glandular-serrate, erect; petals narrow, long-oval or obovate, erose, tapering to broad claws of medium length; anthers yellowish; filaments seven-sixteenths inch long; pistil very pubescent at the base, equal to the stamens in length.

Fruit late, ripening period very long; one and five-eighths inches by one inch in size, oval. slightly swollen on the ventral side, halves unequal; cavity very shallow, narrow, flaring; suture a faint line; apex pointed; color purplish-black, overspread with thick bloom; dots numerous, small, brown, inconspicuous, clustered about the base; stem below medium in thickness, five-eighths inch long, adhering well to the fruit; skin tough, separating readily; flesh yellowish-green, medium juicy, firm, sweetish, mild, pleasant flavor; good to very good; stone free, seven-eighths inch by one-half inch in size, the cavity larger than the pit, flattened, obliquely long-oval, pointed at the apex and base, with rough and pitted surfaces; ventral suture narrow, conspicuously winged; dorsal suture narrowly and shallowly grooved.

\section{GIANT}

\section{Prunus domestica}

I. Gard. \& For. 7:420. I894. $\quad$ 2. Burbank Cat. 5, fig. 1895. 3. Cal. State Board Hort. 47. 1897-98. 4. Cornell Sta. Bul. 131:185. 1897. 5. Mich. Sta. Bul. 169:245. 1899. 6. Am. Pom. Soc. Cat. 39. 1899. 7. Am. Gard, $21: 36$. 1900. 8. Mich. Sta. Bul. 187:77, 78, 1901.

Giant Prune 4, 7, 8. Giant Prune 5, 6.

Giant is distinguished for its large size and attractive color. The accompanying color-plate shows the color and shape very well, but the fruit is a little too small. Unfortunately Giant is somewhat inferior in quality, a disappointment to all, as with Agen for a parent high quality was to be expected. In quality, as in all fruit-characters, the variety resembles the male parent, Pond. The flesh is coarse, fibrous, lacking in juice, clings more or less to the stone and rots quickly under unfavorable conditions. The trees, too, lack somewhat in both vigor and productiveness. Introduced as a prune, it was supposed that this variety would prove a great boon to prune-makers, but it does not cure well and is now hardly used for drying. Giant is proving to be one of the very best shipping plums, as would be expected because of its firm, dry flesh. It is unfortunate that so attractive a plum cannot be unqualifiedly recommended, but it is doubtful if it is worth planting on a commercial scale in New York.

Giant was grown by Luther Burbank, Santa Rosa, California, from a seed of Agen fertilized by Pond, the Hungarian Prune of the Pacific Coast. The stock of this variety was offered for sale to nurserymen in 


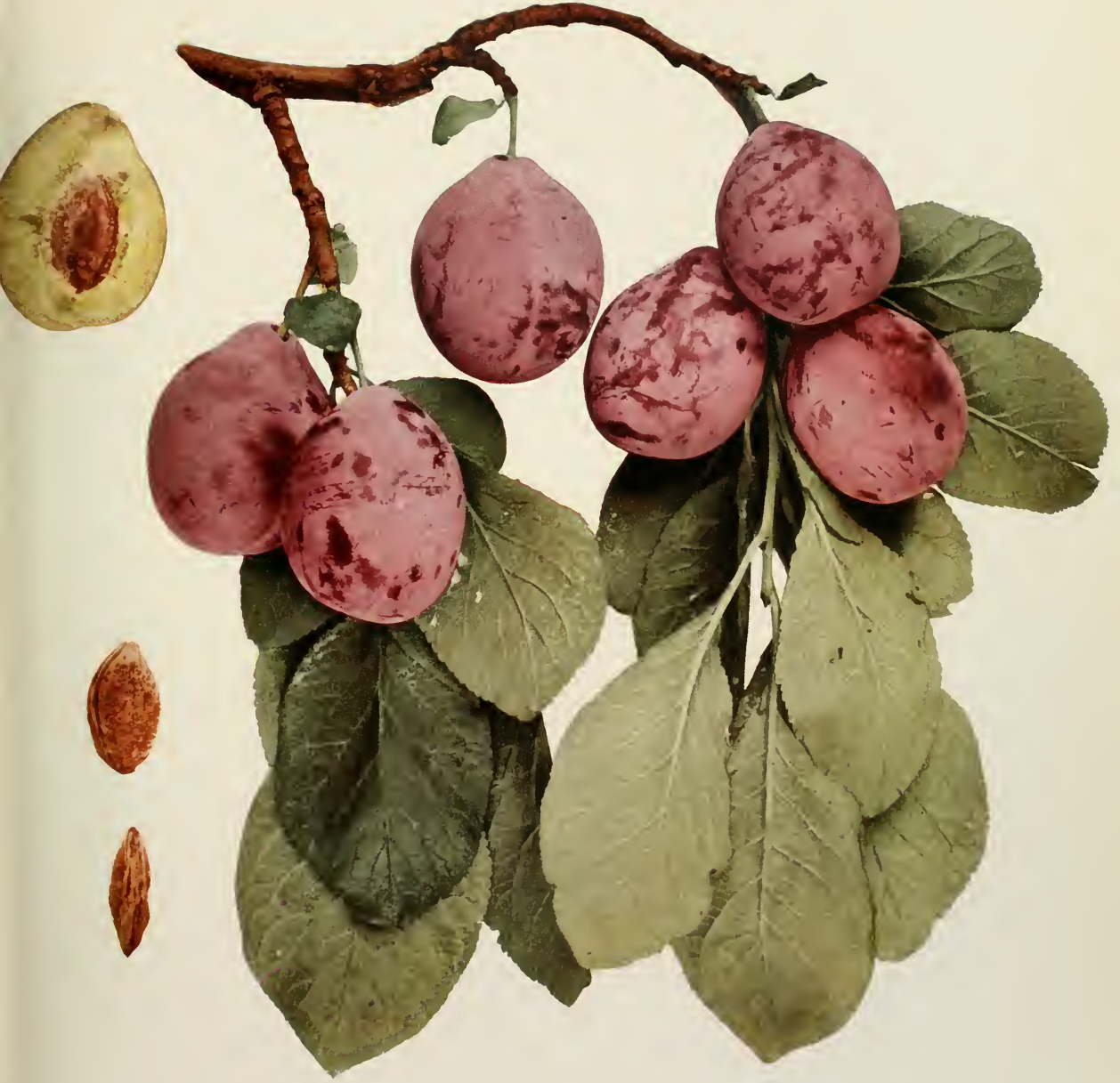



I 893 and I 894 , but not to fruit-growers until I 895 , and then by the originator. The American Pomological Society placed it on their fruit catalog list in 1899 as a promising variety for this region and southern California.

Tree medium in size and vigor, round and dense-topped, hardy, usually productive; branches short, stocky, dark ash-gray, with large lenticels; branchlets short, with internodes of medium length, greenish-red changing to dark brownish-red, dull, thinly pubescent, heavily marked with scarf-skin and with few, small, inconspicuous lenticels; leaf-buds small to medium, short, conical, appressed.

Leaves folded backward, obovate or oval, two and one-quarter inches wide, three and three-quarters inches long; upper surface pubescent only along the midrib; lower surface pale green, lightly pubescent on the midrib and larger veins; apex abruptly pointed or acute, margin serrate or crenate, usually with small, dark glands; petiole three-quarters inch long, tinged red along one side, sparingly pubescent, glandless or with from one to four greenish-brown glands usually on the stalk.

Blooming season intermediate in time and length; flowers appearing after the leaves, one and three-sixteenths inches across, creamy in the buds, changing to white on opening, borne in scattering clusters on short. lateral buds and spurs, singly or in pairs; pedicels three-eighths inch long, thick, glabrous, greenish; calyx-tube green, campanulate, glabrous or lightly pubescent; calyx-lobes broad, obtuse, pubescent on both surfaces, glandular-serrate, reflexed; petals oval, somewhat erose, with short, broad claws; anthers yellowish; filaments five-sixteenths inch long; pistil glabrous, longer than the stamens.

Fruit mid-season, period of ripening short; two inches by one and one-half inches in size, obovate, slightly necked, compressed, halves unequal; cavity shallow, narrow, abrupt; suture shallow; apex roundish or depressed; color light to dark purplish-red, overspread with bloom of medium thickness; dots numerous, smallish, russet, inconspicuous; stem seven-eighths inch long, thinly pubescent, adhering well to the fruit; skin of medium thickness and toughness, adhering but slightly to the pulp; flesh light golden-yellow, variable in juiciness, coarse, somewhat fibrous, firm, rather sweet, mild fair in quality; stone semi-clinging or clinging, one and one-eighth inches by five-eighthe inch in size, long-oval, flattened, with rough and pitted surfaces; ventral suture strongl: furrowed; dorsal suture with a shallow groove.

\section{GLASS}

\section{Prunus domestica}

1. Downing Fr. Trees Am. 3rd App. 18x. 1881. 2. Am. Pom. Soc. Cat. 39. 1899. 3. Mich. Sta. Bul. 169:245. I899. 4. Waugh Plum Cull. 104. 1901, 5. Can. Exp. Farm Bul. 43:34. 1903. 6. Am. Pom. Soc. Rpt. 57. 1907.

Glass Seedling 2. Glass Seedling 4, 5, 6 .

Although found in some collections in the United States, Glass has never attained commercial importance in this country, probably because 
its place is taken by the Quackenboss, which it very closely resembles. The fruit is large and attractive in color and shape, but it is not high in quality and it must be rated among Domestica plums as only a mediocre fruit. The tree is said generally to give better satisfaction than the fruit. This variety originated with Alexander Glass, Guelph, Ontario, and has been cultivated extensively by Canadian growers to whom its productivity and hardiness recommend it.

Tree large, vigorous, upright-spreading, open, productive, hardy; branches rough, stocky; branchlets rather slender, pubescent; leaves folded backward, obovate or oval, one and three-quarters inches wide, three and one-half inches long; margin finely serrate; petiole reddish, pubescent, with from one to three smallish, globose glands usually at the base of the leaf.

Fruit mid-season; one and one-half inches by one and three-eighths inches in size, oblong-oval, purplish-black, overspread with thick bloom; stem adhering firmly to the fruit; skin thin, tender, rather sour; flesh light yellow, juicy, firm, sweet, mild; of fair quality; stone clinging, one inch by five-eighths inch in size, irregular-oval, with oblique apex, the surfaces rough and pitted; ventral suture prominent, winged.

\section{GOLDEN}

\section{Prunus munsoniana $\times$ Prunus triflora}

1. U.S. D. A. Rpt. 263. 1892. 2. Burbank Cat. 17. 1893. 3. Am. Pom. Soc. Rpt. 74. 1895. 4. Am. Gard, 18:715. 1897. 5. Cal. State Board Hort. 53. 1897-98. 6. Vt. Sta. Bul. 67:12. 1898. 7. Ohio Sta. Bul. 113:161. 1899. 8. Am. Gard. 21:36. 1900. 9. Vt. Sta. An. Rpt. 14:274. 1901. 10. Mich. Sta. Sp. Bul. 30:18 1905. I1. Mass. Sta. An. Rpt. 17:161. 1905. 12. Ga. Sta. Bul. $68: 8,36.1905 . \quad$ 13. U. S. D. A. Yearbook 500. 1905.

Gold 3, 4, 7, 8, 10, 11. Gold 6, 9, 13. Late Klondike 5.

It would be hard to name another plum as showy as Golden. Large for its group, beautifully turned, it presents a most striking appearance long before it is ripe, with its bright yellow skin and crimson cheek, the whole plum turning to a brilliant currant-red with a delicate bloom at maturity. But the plum is little more than showy. The flavor is not good, the flesh is fibrous, excessively juicy and adheres to the stone, the skin is tough and astringent. In spite of the juiciness the plum ships well, owing to the tough skin, but the fruits are much attacked by brown-rot and the skin cracks badly under unfavorable conditions. The trees are rather small, uncertain in bearing, often enormously productive but do not hold the crop well, and the plums ripen unevenly. Strange to say, considering the parentage, the variety is hardy, according to Waugh standing the winters at Burlington, Vermont, almost perfectly. In tree and fruit the 


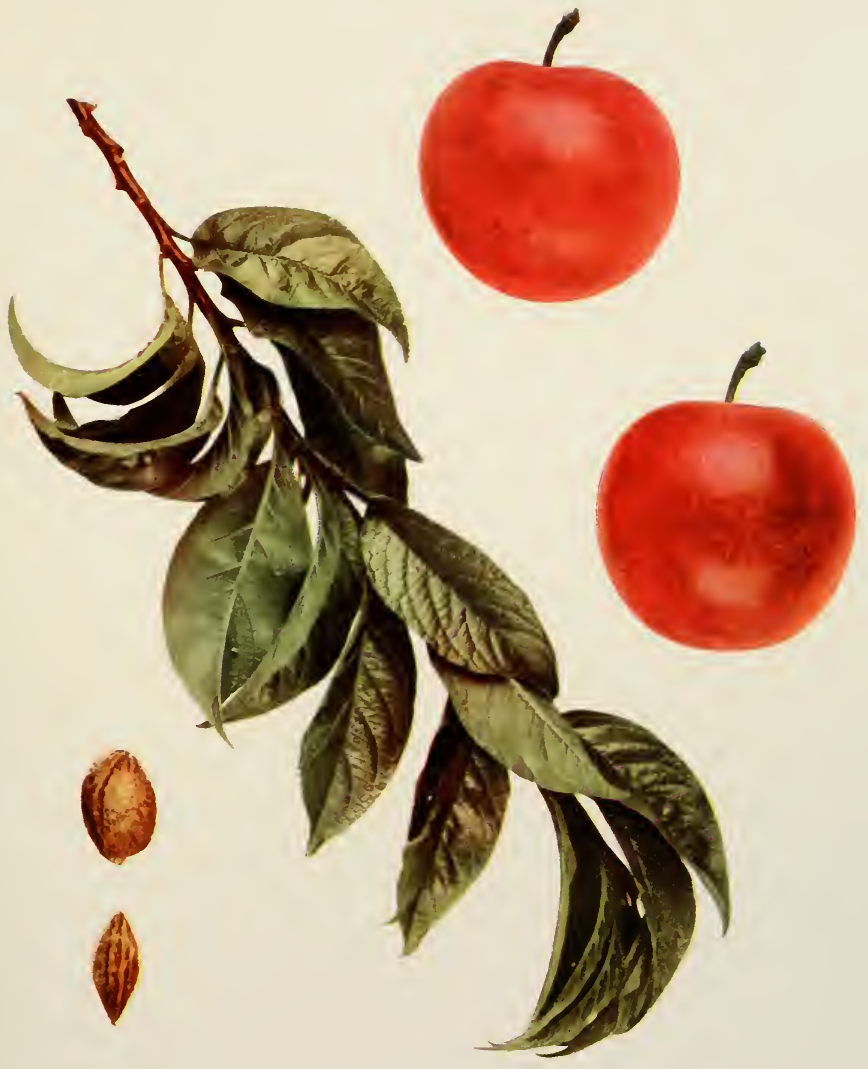



variety is more like its American parent than the Asiatic one. Golden can never be a money-maker in New York, but it is worth having in a home orchard for its handsome appearance.

The original tree of this variety was grown in 1887 or I 888 by Luther Burbank, Santa Rosa, California, from a seed of Robinson fertilized by pollen of Abundance. In 1892 , the variety was erroneously described in the United States Department of Agriculture Report as a seedling of Kelsey fertilized by Burbank. The same year it was named Golden by Burbank and in 1893 it was offered for sale in his catalog, New Creations in Fruits and Flowers. Soon after, the original tree and the right of introduction were purchased by Stark Brothers Nurseries and Orchards Company, Louisiana, Missouri, and in 1894 the variety was catalogued and disseminated under the name Gold. This name was registered as a trade-mark in the United States Patent Office in 1905, but as the prior application and publication of Golden entitles it to precedence according to the nomenclature of the American Pomological Society, the name Gold has generally been dropped by pomologists. The confusion as to the origin and nomenclature of this variety has been increased by its parentage being published ${ }^{1}$ as a cross of Robinson and Kelsey and by the California shippers labeling it Late Klondike.

Tree variable in size and vigor, usually small, somewhat vasiform, medium dense, hardy in all but the coldest localities, an uncertain bearer unless grown under favorable conditions, when it becomes very productive, susceptible to attacks of shot-hole fungus; trunk shaggy, sometimes gnarly; branches strong, unusually rough, grayish-brown, with longitudinal cracks in the bark, with very numerous, small, raised lenticels; branchlets willowy, numerous, long, with short internodes, green changing to dull reddishbrown, marked with gray scarf-skin, glossy, glabrous, with numerous, conspicuous, large, raised lenticels; leaf-buds small, short, conical, free.

Leaves usually flattened, broadly lanceolate, peach-like, one inch wide by three and one-half inches long, thin, somewhat rigid; upper surface light green, smooth, glabrous, with deeply grooved midrib; lower surface pale green, thinly pubescent; apex taper-pointed, base acute, margin serrate or crenate, with numerous, small, dark red glands; petiole slender, three-eighths inch in length, tinged red, sparingly pubescent along one side, glandless or with from one to seven small, globose, yellowish-green glands usually on the stalk.

Blooming season long; flowers appearing after the leaves, three-quarters inch across, white; borne in clusters on short lateral spurs and buds, in pairs or in threes; pedicels seven-sixteenths inch long, slender, glabrous, green; calyx-tube greenish,

Cornell Sta. Bul. 106:52. 1896. 
campanulate, glabrous; calyx-lobes narrow, acute, sparingly glandular-serrate and pubescent, with scattering marginal hairs, erect; petals oval, entire, clawed; anthers yellowish; filaments one-quarter inch long; pistil glabrous, longer than the stamens.

Fruit mid-season, ripening period very long; medium to sometimes large, roundishoblate, halves equal; cavity deep, flaring, regular; suture a line; apex roundish or pointed; color golden-yellow blushed or overspread with bright red, with thin bloom; dots numerous, very small, whitish, inconspicuous, thickly sprinkled around the apex; stem five-eighths inch long, glabrous, adhering fairly well to the fruit; skin rather tough, astringent, inclined to crack under unfavorable conditions, separating readily; flesh golden-yellow, unusually juicy and fibrous, tender and melting, sprightly, sweet next the skin but tart near the center; fair in quality; stone adhering, three-quarters inch by one-half inch in size, oval, turgid, flattened at the base, abruptly sharp-pointed at the apex, with pitted surfaces; ventral suture slightly winged; dorsal suture broadly grooved.

\section{GOLDEN BEAUTY}

\section{Prunus hortulana}

I. Am. Pom. Soc. Rpt. 162. I881. 2. Rural N. Y. 43:53. 1884. 3. Popular Gard. 4:38. I888. 4. Am. Gard. 10:175. 1889. 5. Cornell Sta. Bul. 38:48, 49, 86. 1892. 6. Kerr Cat. 3. I894. 7. Mich. Sta. Bul. 118:53. 1895. 8. W. N. Y. Hort. Soc, Rpt. 41:55. 1896. 9. Am. Pom. Soc. Cat. 26. 1897. 10. Wis. Sta. Bul. 63:39, 42, 48, 1897. I1. Vt. Sta. An. Rpt. I1:284. 1898. 12. Colo. Sta. Bul. 50:42, 1898. 13. Ohio Sta. Bul. 113:155. 1899. 14. Ibid. 162:247, 254, 255. 1905.

Honey Drop 8, 10, 14. Honey Drop 5, II. Missouri Apricot 5, 6, 8, 10, II, I2, I3.

From the fruit-grower's standpoint, Golden Beauty is of little interest. The plums are so small and the quality so poor that the variety is not worth planting either for the home or for money-making. It is true that the firm, juicy fruits are very good for table use, in jellies in particular, and that they may be shipped long distances, but these characters cannot offset the handicap of small size and poor quality. The variety is of interest to botanists because it seems to be a wanderer out of the range of the species to which it belongs. As the history which follows seems to show, Golden Beauty was found in a part of Texas where Prumus hortulana does not grow (see the discussion of this species) and quite as remarkable if it really comes from so warm a part of Texas is the fact that it should be perfectly hardy here and even farther north. There is a mystery yet to be cleared up about this plum. The variety is very ornamental in flower, foliage and fruit.

According to current account, Golden Beauty was found wild by a German on the Colorado River in western Texas during the Civil War. After the war, the German planted his new plum in a yard in Victoria County, Texas, where it attracted the attention of Gilbert Onderdonk, Mission Valley, southern Texas. Onderdonk, noting its merits, propagated 


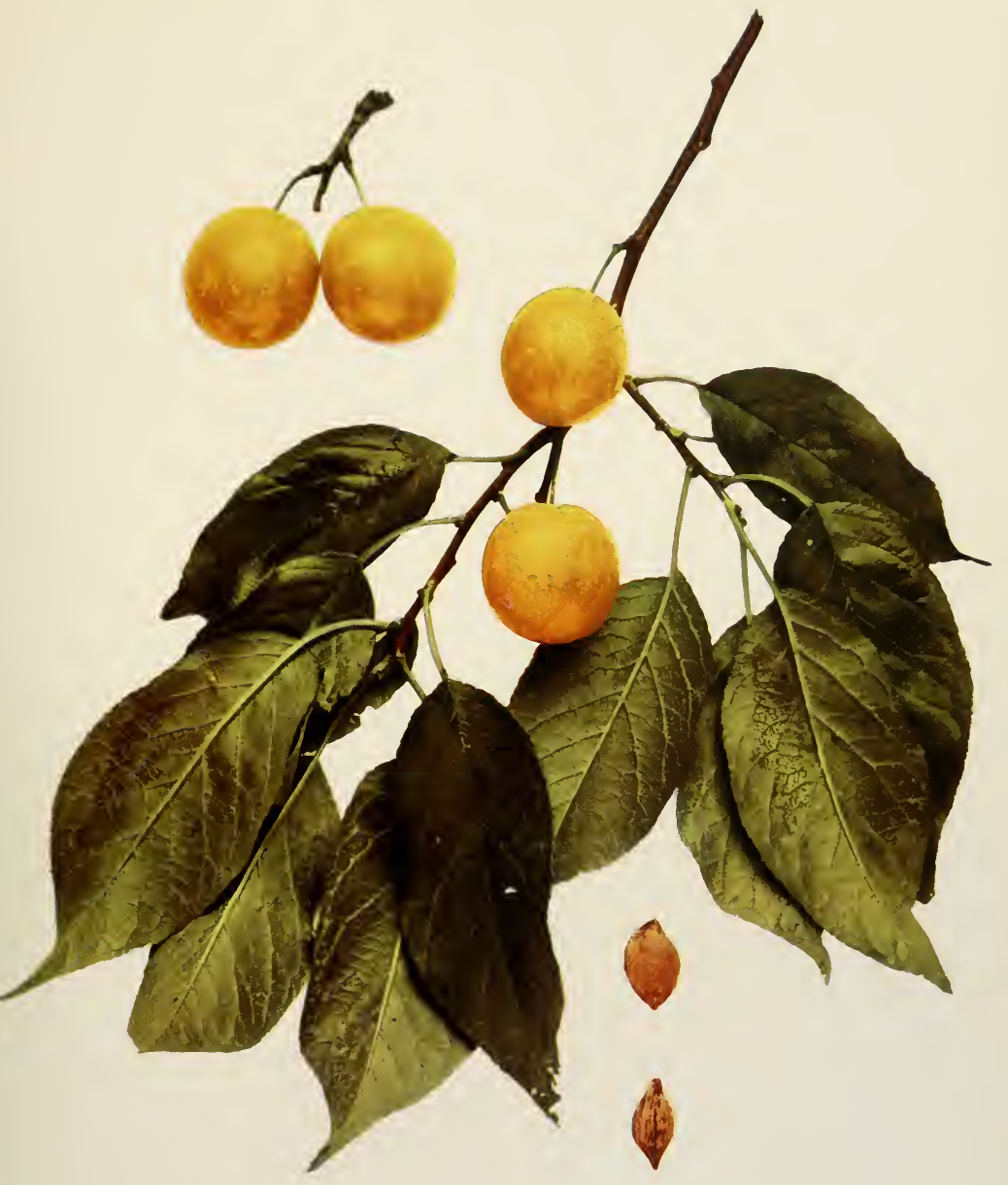

GOLDEN BEAUTY 

and introduced it in 1874 . In 1886 , Stark Brothers, of Missouri, introduced the Missouri Apricot, the Honey Drop of some, which they claimed was found wild in Missouri. Several pomologists have noted the close similarity of this variety to Golden Beauty and as tested at this Station they are identical in all respects and are therefore placed under the older name. In 1897 the American Pomological Socicty placed this plum on its fruit catalog list.

Tree above medium in size, vigorous, somewhat irregular in habit, usually spread. ing, low, dense and flat-topped, hardy, variable in productiveness, somewhat subject to attacks of shot-hol fungus; trunk rough, shaggy; branches roughish, thorny, zigzag, dark ash-gray, with numerous lenticels of medium size; branchlets long, slender, twiggy, with short internodes, green changing to greenish-brown, shining, glabrous, with numerous, conspicuous, large, raised lenticels; leaf-buds small, very short, obtuse, plump, appressed.

Leaves folded upward, narrowly oval, one and seven-eighths inches wide, four inches long, thin; upper surface smooth, glabrous, with a grooved midrib; lower surface light green, sparingly pubescent along the midrib and larger veins; apex acuminate, base abrupt, margin irregularly and doubly crenate, with small, dark brown glands; petiole seven-eighths inch long, slender, green, thinly pubescent along one side, glandless or with from one to eight very small, globose, blackish glands scattered mostly below the base of the leaf.

Blooming season late and of medium length; flowers appearing after the leaves, seven-eighths inch across, white; borne in clusters on lateral buds and spurs, with from four to six flowers in each umbel; pedicels nine-sixteenths inch in length, slender, glabrous, greenish; calyx-tube green, obconic, glabrous; calyx-lobes acute, erect, thinly pubescent within, glandular-serrate, the glands reddish; petals ovate or roundish-oval, erose, tapering below into long, narrow, pubescent claws; anthers light yellow; filaments five-sixteenths inch in length; pistil glabrous, shorter than the stamens.

Fruit very late, season of medium length; one inch in diameter, roundish to roundishoval, somewhat compressed, halves equal; cavity shallow, narrow, slightly flaring; suture very shallow or a line; apex roundish or pointed; color orange-yellow, mottled, overspread with thin bloom; dots characteristic, numerous, large and small, yellowish, decidedly conspicuous producing a somewhat mottled appearance, clustered about the apex; stem very slender, five-eighths inch in length, glabrous, adhering poorly to the fruit; skin thick, tough, adhering to the pulp; flesh golden-yellow, juicy, coarse, fibrous, tender, mildly sweet, with a faint apricot flavor, somewhat acid when cooked; fair in quality; stone adhering, five-eighths inch by one-half inch in size, turgid, oval, abruptly pointed at the base and apex, smooth and with a coating of yellowish-brown, cottony substance; ventral suture broad, lightly furrowed; dorsal suture acute or with a shallow furrow. 


\section{GOLDEN CHERRY}

\section{Prunus cerasifera}

I. Hoffy Orch. Com. 2:1842. 2. Downing Fr. Trees Am. 295. 1845. 3. N. Y. Sta. Rpt. 15: 293. 1896. 4. Bailey Ev. Nat. Fruits 212. 1898. 5. Can. Exp. Farms Rpt. 401 . 1898.

Golden Cherry Plum 2. Market Plum 1. Youngken Golden 3. Youngken's Golden Cherry 4. Yunkin Golden 5 .

This plum is one of the few cultivated representatives of Prunus cerasifera. It offers some attractions because of real merit and because it adds variety to the list of plums for fruit-growers. Some of its qualities are strongly marked and the variety might prove of value in plant-breeding. Golden Cherry originated with Samuel Reeves, Salem, New Jersey, as a seedling of Myrobalan, in the early part of the last century.

Tree large, vigorous, spreading, dense-topped, unproductive; branches slender, sparingly thorny; branchlets twiggy; leaves oval, one inch wide, one and seven-eighths inches long; margin finely serrate, with few small glands; petiole reddish, eglandular; blooming season early, of medium length; flowers appearing before the leaves, well distributed on lateral buds and spurs.

Fruit very early; one and one-quarter inches in diameter, greenish-yellow changing to pale yellow with a tinge of red, overspread with thin bloom; flesh pale yellow, very juicy, melting, sweet next to the skin but rather tart at the pit, aromatic; good; stone clinging, five-eighths inch by one-half inch in size, oval, with a nearly smooth surface.

\section{GOLDEN DROP}

\section{Prunus domestica}

1. Pom. Mag. 2:57, P1. 1829. 2. Lond. Hort. Soc. Cat. 144. 1831. 3. Kenrick Am. Orch. 256. 1832. 4. Downing Fr. Trees Am. 273. 1845. 5. Floy-Lindley Guide Orch. Gard. $295,383$. 1846. 6. Thomas Am. Fruit Cult. 332, fig. 258. 1849. 7. Mag. Hort. $15: 486,487$ fig. 42.1849. 8. Hovey Fr. Am. 1:81, 1851. 9 Am. Pom. Soc. Cat. 54. 1852. 10. Elliott Fr. Book 4 10. 1854. 11. Ann. Pom. Belge 43, Pl. 1855. 12. Thompson Gard. Ass't 515. 1859. 13. Nas Le V'erger 6:29, fig. 15. 1866-73. 14. Hogg Fruit Man. 691, 729. 1884. 15. Mathieu Nom. Pom. 425. 1889. 16. Guide Prat. 155, 357. 1895. 17. Oregon Sta. Bul, $45: 26$ fig. 1897. 18. Colo. Sta. Bul. 50:34. I898. 19. Am. Pom. Soc. Rpt. 2 11. 1899. 20. Ohio Sta. Bul. 113:158, Pl. XV. I899. 21. Mich. Sta. Bul. 169:242, 244. 1899. 22. Waugh Plum Cult. 104 fig. 1901. 23. Va. Sta. Bul. 134:42. 1902. 24. Ohio Sta. Bul. 162:242, 254, 255. 1905.

Bury Seedling I, 2, 3, 4, 5, 7, 8, 10, I1, I2, 14, 15, 16. Coe 16, 21 . Coe's 1, 2, 7, 8, 14, I5, 16. Coe Golden Drop 16, 23. Coe Golden Drop 21. Coe's Golden Drop Plum 1, 5, 1r. Coe's Golden Drop 5, 8, 13, 15, 16, 17, 22, 24. Coe's Golden Drop 2, 3, 4, 6, 7, 8, 9, 10, 12, 14, 18, 20. Coe's Golden Drop Plum 13. Coe's Plum 12, 13, 16 . Coe (Pride) 15. Coc's Imperial 1, 2, 4, 5, 7, 8, I0, II, 12, I4, I5, 16. Coe's Rothgefleckte Pflaume 13, I6. Coe's Rotgefleckte Pflaume 15. Coe's Plum 5. Cooper's Large 15, 16 incor. Coe's Seedling 3. De Coe 16. Fair's Golden 15, 16. Fair's Golden Drop 2, 4, 5, 7, 8, 10, 11, 14, 15, I6. Golden Drop I, 2, 7, 8, 12, 14, 15, 16. Golden Drop Plum 16. Golden Gage 2, 4, 7, 8, 10, II, I2, I4, I5, 16. Goutte d'Or 13. Goutte d'Or I3, 16. 


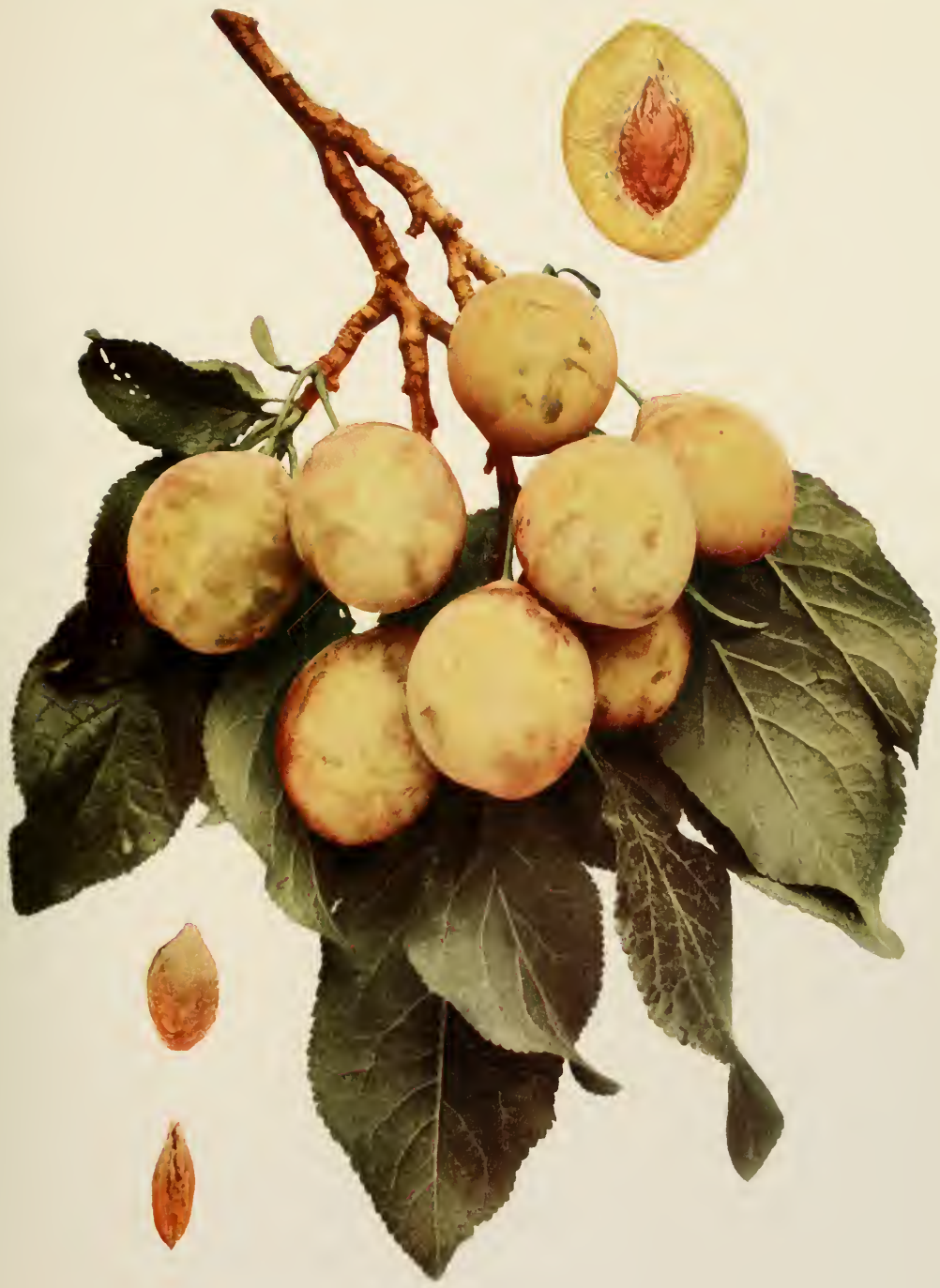



Goutte d'Or de Coe 15, 16. King of Plums 8. New Golden Drop 1, 2, 4, 5, 7, 8, 10, 11, 12, 15 I6. Nouvelle Goutte d'Or 15, 16. Parmentier ? 15, 16. Prune Goutte D'Or De Coé I1. Semis de Bury 15, 16. Silver Prune 17, 19. Silver Prune 22. The Coe's Plum 1. Waterloo of some 7, 8, ? 14, 15.

Unfortunately this fine old plum, the largest, handsomest and best of the yellow plums, is fit only for the amateur in New York and in the hands even of the most careful of amateurs it does not reach the perfection in either appearance or quality that is expected of it in Europe or on the Pacific Coast of America. In spite of special efforts to obtain specimens for illustration which would do this variety justice, the color-plate of Golden Drop is far from satisfactory as regards either size or color of the fruit. In this region trees of Golden Drop lack constitution and while hardy in tree, the fruit-buds are often caught by the cold. From lack of vigor and from injury by freezing, the variety is not productive. The trees, too, are slow in growth and the fruit needs a long season to reach perfect maturity, often failing to ripen in parts of New York where other plums mature well. Again, the trees are subject to nearly all the ills to which plums are heir and have a somewhat precarious existence because of insects and diseases though the fruit is not as subject to brown-rot as is that of the Yellow Egg with which this variety is usually compared. Golden Drop is seemingly fit for all purposes to which plums are put-for dessert, cooking, canning, preserving and prune-making. For the last named purpose it is unsurpassed for a light colored prune of large size, readily selling at a fancy price in delicatessen stores. The fruit when carefully picked and handled keeps for a month or more, shrivelling somewhat but retaining its flavor and pleasing flesh-characters. A task for the plant-breeder is to breed a plum, of which one of the parents should be Golden Drop, which will give to this region a plum as good as the Golden Drop in regions where it is at its best. With all of its defects in the North and East, it is yet worth growing for the home and often for the late market.

Jervaise Coe, a market gardener, at Bury St. Edmunds, Suffolk, England, raised Golden Drop from a seed about I809. Lindley (References, 5) says, "He [the originator] informed me it was from the stone of Green Gage, the blossom of which, he supposed, had been fertilized by the White Magnum Bonum, the two trees of which grew nearly in contact with each other in his garden." From a study of the fruit-characters this supposition is very probable. C. M. Hovey in discussing the synonyms of this variety writes, "The French have disseminated it considerably under the name of Waterloo; trees received under that name have fruited in our collection this year, 
and proved to be the Golden Drop." Robert Hogg, in his Fruit Mamual, published in $\mathbf{1 8 8 4}$, described Waterloo as a separate variety, found at Waterloo, Belgium, and introduced by Dr. Van Mons; the descriptions of the two are practically identical. The Silver Prune, well known on the Pacific Coast, at one time supposed to be a new variety, turned out upon investigation to be Golden Drop, though the growers there continue to call it by the new name they have given it. The variety under discussion came to America in 1823 , when Knight, of England, sent a tree of it to John Lowell of Massachusetts. In $185_{2}^{2}$, the American Pomological Society valued it sufficiently to place it on the list of the fruits worthy of general cultivation.

Tree medium to large, vigorous, spreading or roundish, open-topped, hardy, productive; branches ash-gray, roughish, with few, large lenticels; branchlets short, stout, with internodes variable in length, greenish-red changing to dull brownish-red becoming drab on the older wood, glabrous carly in the season but becoming pubescent at maturity, with numerous, small lenticels; leaf-buds large, long, pointed, free.

Leaves folded upward, oval or obovate, one and three-eighths inches wide, two and three-quarters inches long, thickish; upper surface dark green, slightly rugose, pubescent, with the midrib but faintly grooved; lower surface silvery-green, pubescent; apex abruptly pointed or acute, base acute, margin serrate, eglandular or with small, dark glands; petiole one-half inch long, pubescent, tinged red, with from two to three globose, greenish-yellow glands usually at the base of the leaf.

Season of bloom medium, short; flowers appearing after the leaves, one inch across, white, borne in clusters on lateral spurs, singly or in pairs; pedicels five-eighths inch long, lightly pubescent, greenish; calyx-tube green, narrowly campanulate, pubescent; calyx-lobes obtuse, sparingly pubescent on both surfaces, glandular-serrate, reflexed; petals oval, dentate, tapering to short, broad claws; anthers yellowish; filaments fivesixteenths inch long; pistil glabrous, equal to the stamens in length.

Fruit very late, season of average length; two inches by one and one-half inches in size, oval, tapering at the base to a short neck, slightly compressed, halves equal; cavity very shallow and narrow, abrupt; suture shallow and wide; apex depressed; color golden-yellow, occasionally with a faint bronze blush, showing greenish streaks and splashes before full maturity, overspread with thin bloom; dots numerous, small, russet, conspicuous; stem three-quarters inch long, thinly pubescent, adhering well to the fruit; skin tough, rather adherent; flesh light golden-yellow, juicy, intermediate in firmness and tenderness, rather sweet, mild, pleasant flavor; good to very good; stone free, one and three-eighths inches by three-quarters inch in size, oval or ovate, slightly flattened, irregularly ridged and roughened, acute at the base and apex; ventral suture wide, often conspicuously winged; dorsal suture widely and deeply grooved. 


\section{GOLIATH}

\section{Prunus domestica}

1. Prince Treat. Hort. 26. 1828. 2. Lond. Hort. Soc. Cat. 147, 153. 1831. 3. Kenrick Am. Orch. 260. 1832. 4. Mag. Hort. 9:164. 1843. 5. Downing Fr. Trees Am. 300, 1845. 6. FloyLindley Guide Orch. Gard. 287,383 . 1846. 7. Thomas Am. Fruil Cult. 343. 1849. 8. McIntosh Bk. Gard. 2:531. 1855. 9. Hooper W. Fr. Book 245. 1857. 1o. Cultivator 8:25 fig. 1860. 11. Am. Pom. Soc. Cat. 86. 1862. 12. Hogg Fruit Man. 363. 1866. 13. Mas Pom. Gen. 2:15, fig. 8. 1873. 14. Mathieu Nom. Pom. 432. 1889. 15. Waugh Plum Cull. 105 fig. 190x.

Caledonian 1,2 , of some $5 \& 8, x_{1}, x_{2}, x_{3}, x_{4}$. Emperor 9. Goliath 1,3 . Goliath 9, $x_{3}$. Nectarine $\mathrm{I}$, of some $2 \& 8, \mathrm{II}_{\mathrm{I}} \& \mathrm{I} 4$ incor. Pfirschenpflaume $\mathrm{I}_{4}$. Prune-Pêche ? $\mathrm{1}_{4}$. Saint Cloud 2 ,

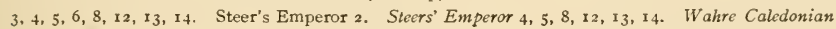
13, 14. Wilmot's Late Orleans 2, 5, 8, 12, 13, 14.

This old English plum has never been popular in America and is now scarcely known on this continent. It is a large, handsome, purple plum, as the illustration well shows, but seldom fit for dessert. "Seldom fit" because it is quite variable in quality in some seasons and under some conditions. It is an excellent culinary plum and its firm, thick, meaty flesh fits it well for shipping. On the grounds of this Station the trees behave very well in all respects and usually bear very full crops of plums that would tempt purchasers in any market. It has all of the characters usually ascribed to a money-maker variety of any fruit and why not more grown in commercial orchards cannot be said.

Nothing is known of the origin of this plum except that it is English. William Prince, in 1828 , wrote: "This plum is of very large size, and has attracted much notice in England; but it is only recently introduced to this country, where it has not yet produced fruit that I am aware of." The Nectarine plum was confused with the Goliath in the early part of the Nineteenth Century, but Robert Thompson, ${ }^{1}$ the English horticulturist, separated them so satisfactorily that they have ever since remained distinct in plum literature. He found that this variety had pubescent shoots and fruit-stalks, while the same parts of the Nectarine were glabrous, and that the season of Goliath is considerably later. The American Pomological Society placed Goliath on its fruit list in 1862 , but dropped it in $187 \mathrm{I}$.

Tree large, vigorous, round-topped, dense, hardy, very productive; branches stocky, with fruit-spurs numerous, ash-gray, smooth except for the large, raised lenticels; branchlets somewhat thick, short, with internodes of medium length, green changing to dull brownish-drab, heavily pubescent throughout the season, with few, inconspicuous, small lenticels; leaf-buds of average size and length, conical, free.

Leaves somewhat flattened, obovate, two inches wide, three and five-eighths inches long; upper surface dark green, nearly glabrous, with a grooved midrib; lower surface

1 Pom. Mag. 3:148. 1830. 
heavily pubescent; apex obtuse or acute, base acute, margin finely serrate, eglandular or with few, small dark glands; petiole one-half inch long, thick, heavily pubescent, with a faint red tinge, glandless or with from one to three large, globose, greenishyellow glands usually at the base of the leaf.

Blooming season early to medium, short; flowers appearing after the leaves, one inch across, white; borne on lateral spurs, singly or in pairs; pedicels nine-sixteenths inch long, pubescent, greenish; calyx-tube green, campanulate, lightly pubescent; calyxlobes, broad, obtuse, somewhat pubescent, glandular-serrate, erect; petals unusually large, roundish, finely crenate, not clawed; anthers yellowish; filaments five-sixteenths inch long; pistil glabrous, longer than the stamens, with a large style and stigma.

Fruit mid-season, ripening period short; one and five-eighths inches by one and one-half inches in size, roundish-oblong, somewhat oblique, truncate, compressed, halves unequal; cavity narrow, abrupt, usually russeted; suture a line; apex flattened or depressed; color dark purplish-red, lighter colored on the shaded side, overspread with thick bloom; dots characteristic, numerous, large, russet, conspicuous, clustered about the apex; stem thick, three-quarters inch long, thickly pubescent, adhering well to the fruit; skin thin, sour, separating readily; flesh golden-yellow, rather dry, firm, sweet, of mild, pleasant flavor; fair to good; stone free, seven-eighths inch by three-quarters inch in size, roundish-oval, somewhat flattened, blunt at the base and apex, roughened and irregularly furrowed; ventral suture wide, winged, heavily furrowed; dorsal suture with a wide groove variable in depth.

\section{GONZALES}

\section{Prunus triflora $\times$}

1. Kerr Cat. 1899-1900. 2. Vt. Sta. Bul. 67:13. 1898. 3. Ohio Sta. Bul. 162:252. 1905. 4. Penin. Hort. Soc. Rpt. 36. I905. 5. Stark Bros. Cat. 1906.

Gonzales 5. Red Gold 4. Red Gold 5.

Judging from the several published descriptions, Gonzales is a very promising plum, for the South at least. The writers have not seen the variety in the North, but there appear to be no reasons why it should not succeed in some northern soils and climates. It is a chance seedling found in Gonzales, Texas, about I894, and was introduced by F. T. Ramsey, Austin, Texas, in 1897 . About all that can be determined regarding its parentage is that it is the product of some Japanese variety pollinated by a native. In I90I, Waugh used this variety to typify a new species, Prumus hortulana robusta, composed of a number of hybrids between Prumus triflora and native species. The following description is compiled:

Tree vigorous, upright-spreading, open; leaves narrow, oval, tapering at both ends; upper surface glabrous; margin minutely glandular, finely crenulate; petiole short and slender, with two glands. 

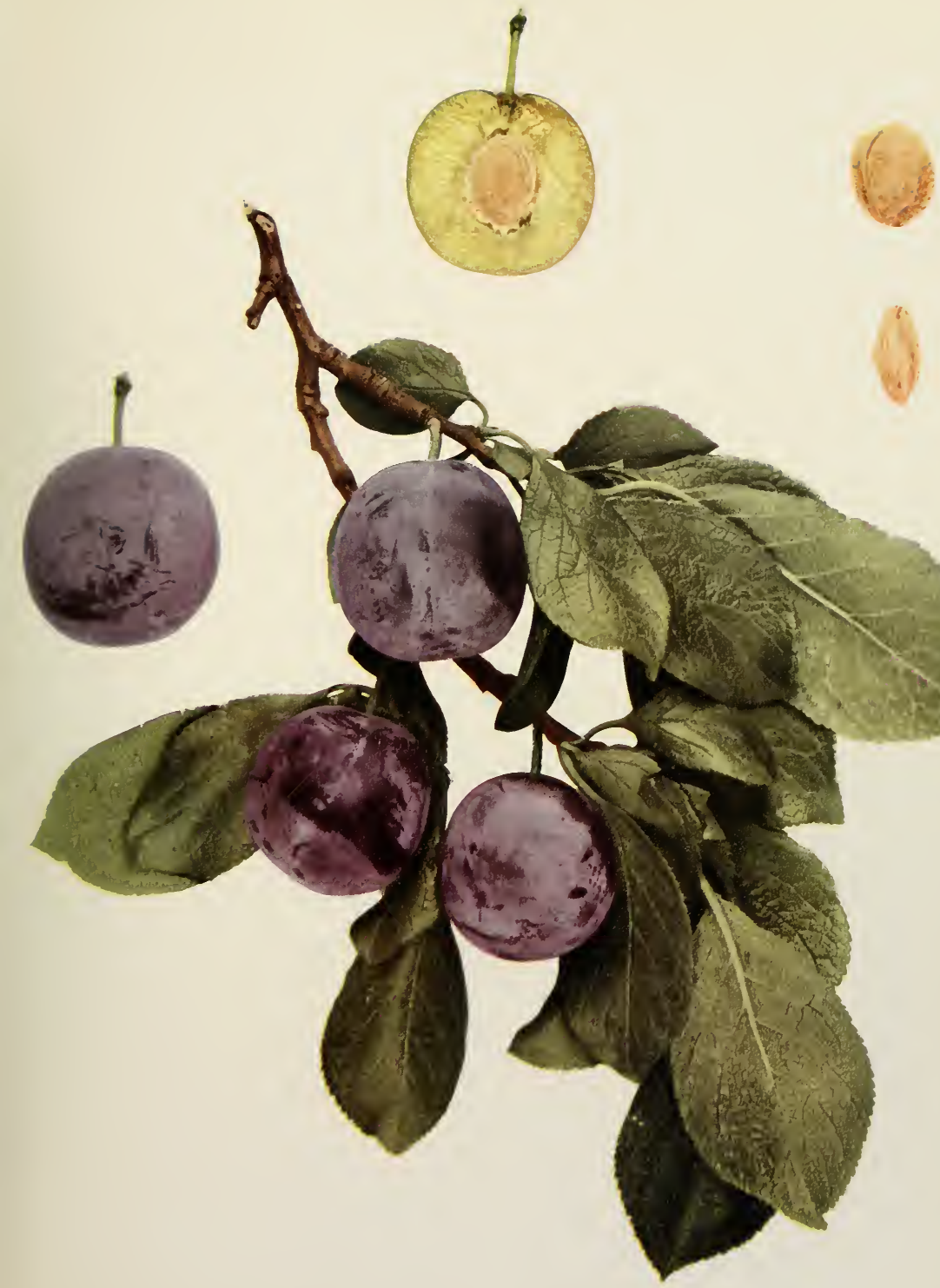
Fruit mid-season; resembles Burbank in size and shape; skin toughish; color bright red, sometimes striped and splashed with dark red; flesh yellow, tinged red, firm, sweet; good; stone of medium size, oval, clinging.

\section{GRAND DUKE}

\section{Prunus domestica}

I. Hogg Fruit Man. 703. 1884. 2. Nathieu Nom. Pom. 432, 434. 1889. 3. W. N. Y. Hort. Soc. Rpt. 39:100. 1894. 4. Can. Hort. 18:117, Pl. 1895. 5. Cornell Sta. Bul. 131:186, fig. 40 IV. I896. 6. W. N. Y. Hort. Soc. Rpt. 42:83, 1897. 7. Am. Pom. Soc. Cat. 25. 1897. 8. Mich. Sta. Bul. 169:245. 1899. 9. Ohio Sta. Bul. 113:159, Pl. XVI. 1899. 1о. Can. Exp. Farm Bul. 2nd Ser. 3:52. 1900. 11. Waugh Plum Cult. 106 fig. 1901. 12. Ohio Sta. Bul. 162:243 fig., 244, $254,255.1905$.

Grossherzog's Pflaume 2. Grand-Duc 2. Grand Duke 2.

Grand Duke, now probably the favorite late shipping plum in this region, is, as stated in the history given below, a comparatively new pium in America. Its great popularity, gained in less than a quarter of a century, is due to much advertising by nurserymen coupled with such intrinsic qualities as large size, the true prune shape which seems most pleasing in some markets, handsome plum-purple and more than all else a firm, meaty flesh which fits the variety excellently for shipping. The flavor, as seems most often to be the case with these large blue plums, is not pleasant and the plum is not more than a second rate dessert fruit though it is very good in whatever way cooked for the table. The trees grow poorly in the nursery and even in the orchard are seldom large and vigorous enough to be called first class, though usually hardy. Some years ago plum-growers were advised to top-work this and other weak-growing plums on stronger stocks, but those who have tried such top-working usually condemn it because it is expensive and ineffective and because it so often gives a malformed tree. The trees come in bearing slowly but bear regularly and abundantly and hold the crop well, the plums being unusually free from rot and hanging in good condition a long time. Grand Duke deserves its popularity as a market plum and probably no better variety can be selected in New York for the last of the season.

Grand Duke is another of the many valuable plums produced by Thomas Rivers, of Sawbridgeworth, England. It was grown from an Autumn Compote stone and was sent out in 1876 . When it was first introduced into America is not known, but in 1888 cions of it were distributed by Ellwanger and Barry ${ }^{1}$ of Rochester, New York. In 1897 , the American

${ }^{1}$ Can. Hort. 18:117. 1895. 
Pomological Society added this variety to its fruit catalog list and recommended it for this State and neighboring regions with similar climatic conditions.

Tree above medium in size, moderately vigorous, upright to slightly spreading, usually hardy, productive; branches ash-gray, with small, numerous lenticels; branchlets slender, short, with internodes of medium length, greenish-red changing to brownishred, many twigs retaining a tinge of green, shining, glabrous, with numerous, small lenticels; leaf-buds large, long, pointed, strongly appressed; leaf-scars large.

Leaves nearly flat, obovate, one and one-half inches wide, three inches long, thick; upper surface shining, slightly rugose, pubescent only along the grooved midrib; lower surface yellowish-grecn, lightly pubescent; apex taper-pointed, base acute, margin serrate, eglandular or with small, dark glands; petiole three-quarters inch long, nearly glabrous, slightly tinged red along one side, glandless or with from one to three globose yellowish glands on the stalk and base of the leaf.

Blooming season intermediate, short; flowers appearing after the leaves, one inch across, white; borne in clusters on short lateral spurs and buds, singly or in pairs; pedicels one-half inch long, slender, glabrous, greenish; calyx-tube green, campanulate, glabrous; calyx-lobes lightly pubescent, glandular-ciliate, slightly reflexed; petals obovate, entire, short-clawed; anthers yellowish; filaments one-quarter inch long; pistil pubescent at the base, longer than the stamens.

Fruit late, season medium; unusually large when well grown, two and one-eighth inches by two inches in size, elongated-oval or slightly obovate, halves unequal; cavity shallow, narrow, abrupt; suture wide, variable in depth; apex flattened, somewhat depressed or occasionally with a short, blunt tip; color dark reddish-purple or purplishblack, overspread with thick bloom; dots numerous, small, brownish, inconspicuous; stem three-quarters inch long, adhering well to the fruit; skin variable in toughness, somewhat astringent, separating readily; flesh golden-yellow, juicy, firm, sweet, mild, not high in flavor; good; stone clinging, sometimes tinged red, one and one-eighth inches by seven-eighths inch in size, irregularly oval, slightly flattened, roughish, acute at the base and apex; ventral suture broad, slightly winged; dorsal suture with a broad, shallow groove.

\section{GUEII}

\section{Prunus domestica}

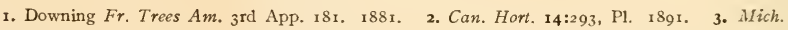
Sta. Bul. x03:34, fig. 6. 1894. 4. Cornell Sta. Bul. x31:187. 1897. 5. Ont. Fr. Exp. Sta. Rpt. 120. 1898. 6. Mich. Sta. Bul. 169:242, 245. 1899. 7. Ohio Sta. Bul. 113:159. 1899. 8. Am. Pom. Soc. Cat. 39. 1899. 9. Waugh Plum Cult. 107. 1901. 10. Va. Sta. Bul. 134:42, 43 fig. 14. I902.

Big Blue 1. Blue Magnum Bonum 1, 9. Bradshaw I incor. Geuii 3. Gueii I. Guii r, 6. Gweii I.

Gueii is one of the standard plums of its season in New York, ranking among the first half-dozen in number of trees growing in the State, with 


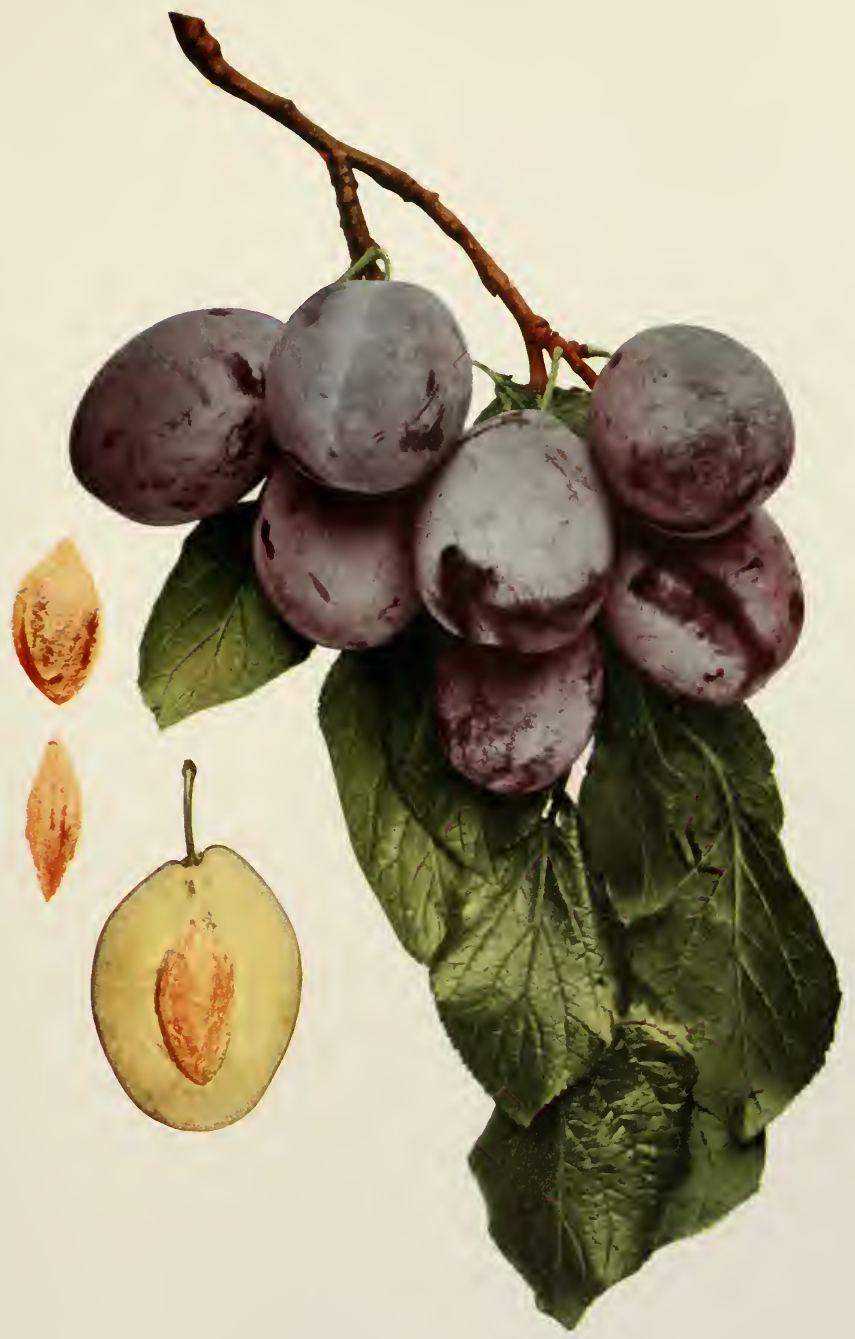



many growers holding that it is the best general purpose plum of all Domesticas. The popularity of Gueii is due to its being a money-maker, as few would care to grow it for home consumption. The quality of Gueii is poor, especially for dessert, and it cannot even be called a particularly goodlooking plum, though the illustration scarcely does the plum justice, especially in size. But the variety bears early and abundantly; the trees are large, vigorous, healthy and hardy and the plums are hardly surpassed for shipping, especially at the time at which the crop comes upon the market, about mid-season, the best shipping plums maturing a little later. The fruit is quite subject to brown-rot, a matter of more moment in other regions than in New York, and yet in some seasons very important in this State. The stone, curiously enough, sometimes clings rather tightly and under other conditions is wholly free. It could be wished that so popular a market plum were better in quality, but since high quality is seldom correlated in plums with fitness to ship well, it would be unfair to condemn Gueii for a market fruit because it cannot be eaten with relish out of hand.

This plum, according to all accounts, originated with a Mr. Hagaman, Lansingburgh, New York, about i 83o. It was brought to notice by John Goeway (Gueii) and was soon called by his name. For years it was not much grown and it was not until I 899 that it was placed on the fruit catalog list of the American Pomological Society.

Tree large, vigorous, spreading, open-topped, hardy, very productive; branches ashgray, roughened by longitudinal cracks and by numerous, conspicuous, raised lenticels of various sizes; branchlets thick, of medium length, with short internodes, green changing to dark brownish-drab, dull, thickly pubescent throughout the season, with numerous, inconspicuous, small lenticels; leaf-buds short, conical, free.

Leaves obovate or oval, one and seven-eighths inches wide, four inches long, thick; upper surface dark green, with scattering fine hairs and with a grooved midrib; lower surface silvery-green, thickly pubescent; apex abruptly pointed or acute, base variable but usually acute, margin doubly crenate, with small black glands; petiole five-eighths inch long, thick, pubescent, tinged red.

Blooming season short; flowers appearing after the leaves, one and one-eighth inches across, whitish; borne in clusters at the ends of spurs, singly or in pairs; pedicels thirteen-sixteenths inch long, pubescent, greenish; calyx-tube green, campanulate, pubescent towards the base; calyx-lobes broad, obtuse, pubescent on both surfaces, glandular-serrate, reflexed; petals roundish, entire, with very short, blunt claws; anthers yellow; filaments three-eighths inch long; pistil glabrous, equal to the stamens in length.

Fruit intermediate in time and length of ripening season; medium to above in size, somewhat ovate, halves cqual; cavity below medium in depth and width, abrupt, rarcly sutured; apex bluntly pointed; color dark purplish-black, overspread with thick bloom; 
dots numerous, small, russet, inconspicuous, clustered about the apex; stem medium in thickness and length, pubescent, adhering well to the fruit; skin thin, tender, slightly astringent, separating readily; flesh greenish-yellow changing to light golden-yellow, dry, firm but tender, sweet, mild, somewhat astringent towards the center; fair in quality; stone variable in adhesion but usually clinging, large, ovate or oval, blunt at the base and apex, strongly roughened and pitted; ventral suture faintly winged; dorsal suture acute or lightly grooved.

\section{GUTHRIE LATE}

\section{Prunus domestica}

1. McIntosh Bk. Gard. 2:532. 1855. 2. Downing Fr. Trees Am. 919. 1869. 3. Hogg Fruil Man. 705. 1884. 4. Mathieu Nom. Pom. 434. 1889. 5. Rivers Cat. I8gs. 6. Am. Gard. Mag, 21:173. 1900.

Guthrie's Minette I. Guthrie's Late Green 6. Guthrie Green 6. Guthrie's Late Green 2. 3, 4. Minette 2, 3, 4. Verte Tardive de Guthrie 4.

Guthrie Late has never attained commercial importance in the United States, being found only in collections ; but in England, according to Hogg, it is a very fine dessert plum, rivalling the Reine Claude in quality and ripening a month later. On the grounds of this institution it has failed because the fruits are small, dull in color and do not keep well. Of the several varieties produced from seed of Reine Claude by Charles Guthrie, Taybank, Dundee, Scotland, about the middle of the last century, Guthrie Late is the best known.

Tree large, vigorous, round-topped, dense, productive; branches stocky; branch lets pubescent; leaf-buds large, short, with a peculiar brush-like apex; leaves folded upward, oval, 'one and seven-eighths inches wide, three and one-half inches long, thick, rugose; margin crenate, eglandular or with small, dark glands; petiole thick, glandless or with from one to four globose glands; blooming season short; flowers appearing after the leaves, one inch across, white tinged with yellow at the apex of the petals; borne on lateral buds and spurs, singly or in pairs.

Fruit mid-season, ripening period long; of medium size, roundish-truncate, dull greenish-yellow, often irregularly splashed and striped with green, overspread with thin bloom; skin thin, slightly astringent; flesh light golden-yellow, rather dry, fibrous, somewhat tender, sweet, pleasant in flavor; of good quality; stone free, seven-eighths inch by five-eighths inch in size, ovate or oval, medium turgid, with rough surfaces.

\section{HALE}

\section{Prunus triflora}

I. Burbank Cat. 19. 1893. 2. Ibid. I894. 3. Cornell Sta. Bul. 106:52. 1896. 4. Ga. Hort. Soc. Rpt. XI. 1897. 5. Am. Pom. Soc. Cat. 41. 1899. 6. Cornell Sta. Bul. 175:147, 148, fig. 37. 


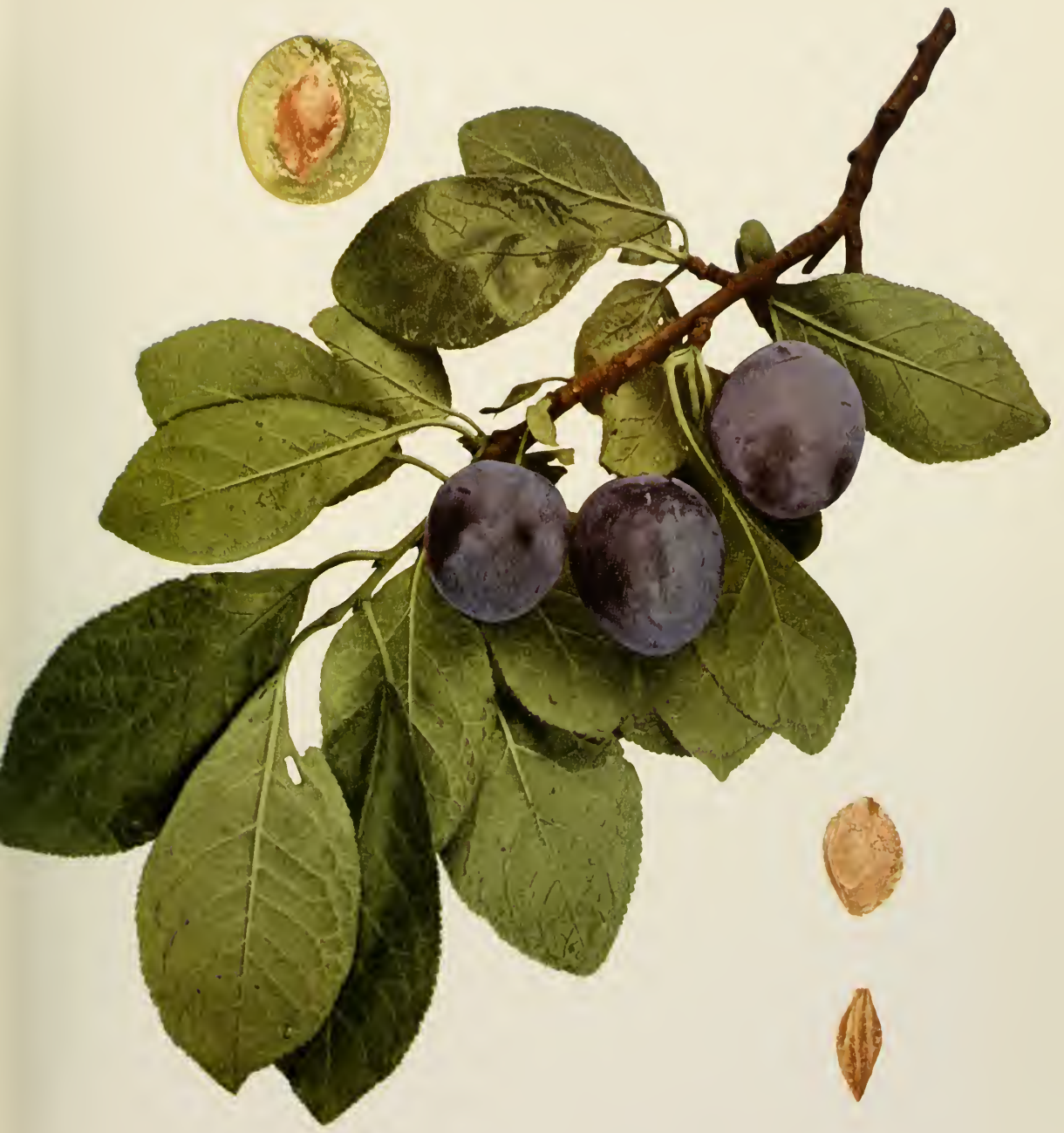



1899. 7. Am Gard $21: 36$ 1900. 8. Waugh Plum Cult. 136. 190r. 9. Mich. Sta. Bul. 187:77, 79. 1901. I0. W. N. Y. Hort. Soc. Rpt 89. 1902. II. Ohio. Sta. Bul. 162:254, 255. 1905. I 2. Ga. Sta. Bul. 68:10, 30. 1905. 13. Mlass. Sta. An. Rpt. 17:160. 1905.

J 1. $J_{3}$ Prolific 2. Prolific 3, 8, 12.

It is doubtful if the average person who grows the Hale would recognize it as shown in The Plums of New York, as it is supposed to be a yellow plum; nevertheless the illustration is a good one so far as the fruits go at least. When mature on the trees the fruits are yellow with a faint blush, but in storage the color quickly changes into a pale red, becoming, when the plum is at its best in appearance and quality, a light currant-red. Hale, though large and handsome of fruit, is of questionable value, failing both in fruit and tree. The flavor of this plum is good in the judgment of most fruit connoisseurs, but others find it a little too sweet and somewhat mawkish near the skin and close about the pit. All agree, however, that the flesh clings too tightly to the stone for pleasant eating and that the texture is too tender for good shipping. But it is the tree that fails most markedly. Even on the grounds of this Station, where the peach is practically hardy, Hale is but semi-hardy, failing most often because with the best of care the wood does not ripen properly. The habit of growth is not particularly good, the trees are slow in coming in bearing, are not regularly productive and are readily infected by brownrot and the fruits much infested by curculio. On the whole, it is to be regretted that Mr. Hale did not choose a better plum to bear a name so distinguished in horticulture.

Luther Burbank offered this plum, a cross between Kelsey and Satsuma, for sale under the name J, in 1893 , and the following year as Prolific. J. H. Hale, South Glastonbury, Connecticut, purchased the variety in I894, and introduced it as the Hale in 1896 . In I 899, the American Pomological Society considered it worthy a place on its fruit catalog list.

Tree above medium in size, vigorous, vasiform, open-topped, semi-hardy, variable in productiveness; branches smooth except for the numerous, small, raised lenticels, somewhat thorny, dark ash-gray, the fruit spurs numerous; branchlets willowy, of medium thickness and length, with short internodes, greenish-red changing to light brown, shining, glabrous; lenticels numerous, small; leaf-buds small, short, obtuse, plump, free.

Leaves sparse, folded upward, oblanceolate or narrowly obovate, one and threequarters inches wide, three and one-half inches long, thin; upper surface glabrous except for scattering hairs, with a grooved midrib; lower surface light green, glabrous except along the midrib and larger veins; apex acute or abruptly pointed, base acute, 
margin finely serrate or crenate, eglandular; petiole nine-sixteenths inch long, slender, tinged red, glandless or with from one to four globose or reniform, greenish-yellow glands on the stalk.

Blooming season early and of medium length; flowers appearing before the leaves, white; borne in thin clusters on lateral buds and spurs, singly or in pairs; pedicels long, glabrous, greenish; calyx-tube green, campanulate, glabrous; calyx-lobes obtuse, with numerous hair-like glands, nearly glabrous, erect; petals roundish-ovate, entire, not clawed; anthers yellowish; filaments short; pistil glabrous except at the base, much longer than the stamens.

Fruit early, scason short; one and three-quarters inches in diameter, roundish, halves equal; cavity of medium depth and width, abrupt, regular; suture a line; apex roundish; color light or greenish-yellow, more or less blushed with red on one side, becoming red at maturity, mottled, with thin bloom; dots numerous, small, whitish, conspicuous only where the skin is blushed; stem slender, five-eighths inch long, glabrous, detaching easily from the fruit; skin thin, tough, adhering; flesh yellowish, very juicy, fibrous, tender, melting next the skin but firmer at the center, sweet except near the pit; good in quality; stone adhering, three-quarters inch by five-eighths inch in size, roundish-oval, flattened, blunt but with a small, sharp tip, rough; ventral suture narrow and rather conspicuously winged; dorsal suture grooved.

\section{HAMMER}

\section{Prumus hortulana mineri $\times$ Prunus americana}

I. Cornell Sta. Bul. 38:79. I892, 2. Ia. Hort. Soc. Rpt. 275, 448. 1893. 3. Ibid. 334. 1894. 4. Wis. Sta. Bul. 63:24, 39. I897. 5. Colo. Sta. Bul. 50:36. 1898. 6. Ia. Sta. Bul. $46: 274$. I90o. 7. Waugh Plum Cult. 150. 1901. 8. Ont. Fr. Gr. Assoc. 144. 1901. 9. Ga. Sta. Bul. 67:274. 1904. 10. S. Dak. Sta. Bul. $93: 18$. 1905. I1. Ohio Sta. Bul. 162:254, 255. 1905.

Hammer is one of the best native plums. On the Station grounds the trees of this variety make the best orchard plants of any of the native varieties, being large, vigorous, shapely and hardy, falling short only in being a little uncertain in bearing. The fruits are good in quality, handsome in appearance and keep and ship well, but crack badly in unfavorable weather and, according to some writers, are quite subject to brownrot. Hammer extends the season of the Americana plums considerably, for though a hybrid, it may best be ranked with the Americanas, and is well worth planting in home orchards in New York, where the native plums are too seldom found; in particular, this variety can be recommended for the colder parts of this State where Domestica and Insititia plums are not hardy.

Hammer is one of H. A. Terry's numerous productions and was grown from a seed of the Miner evidently fertilized by an Americana. The blood 


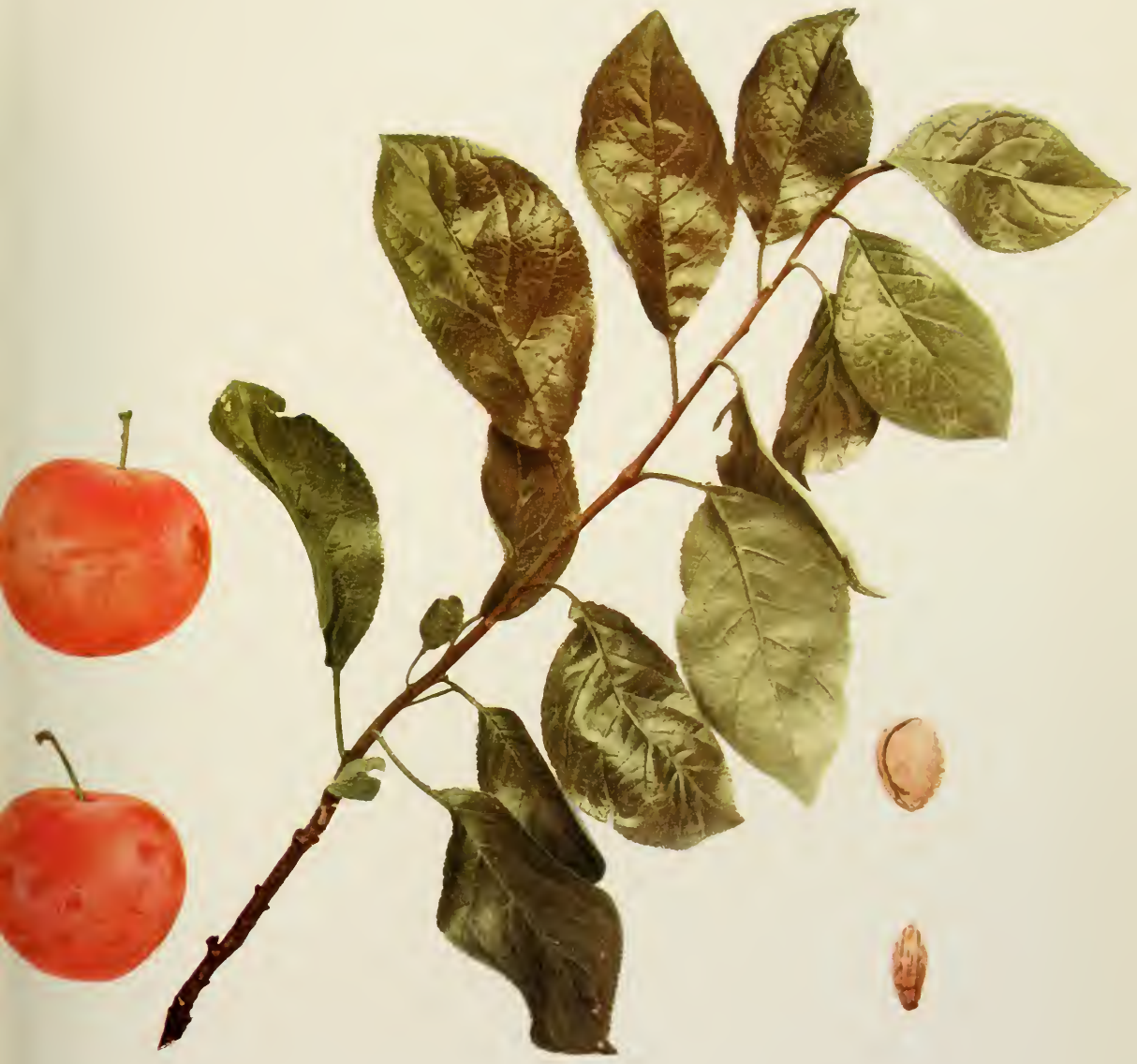





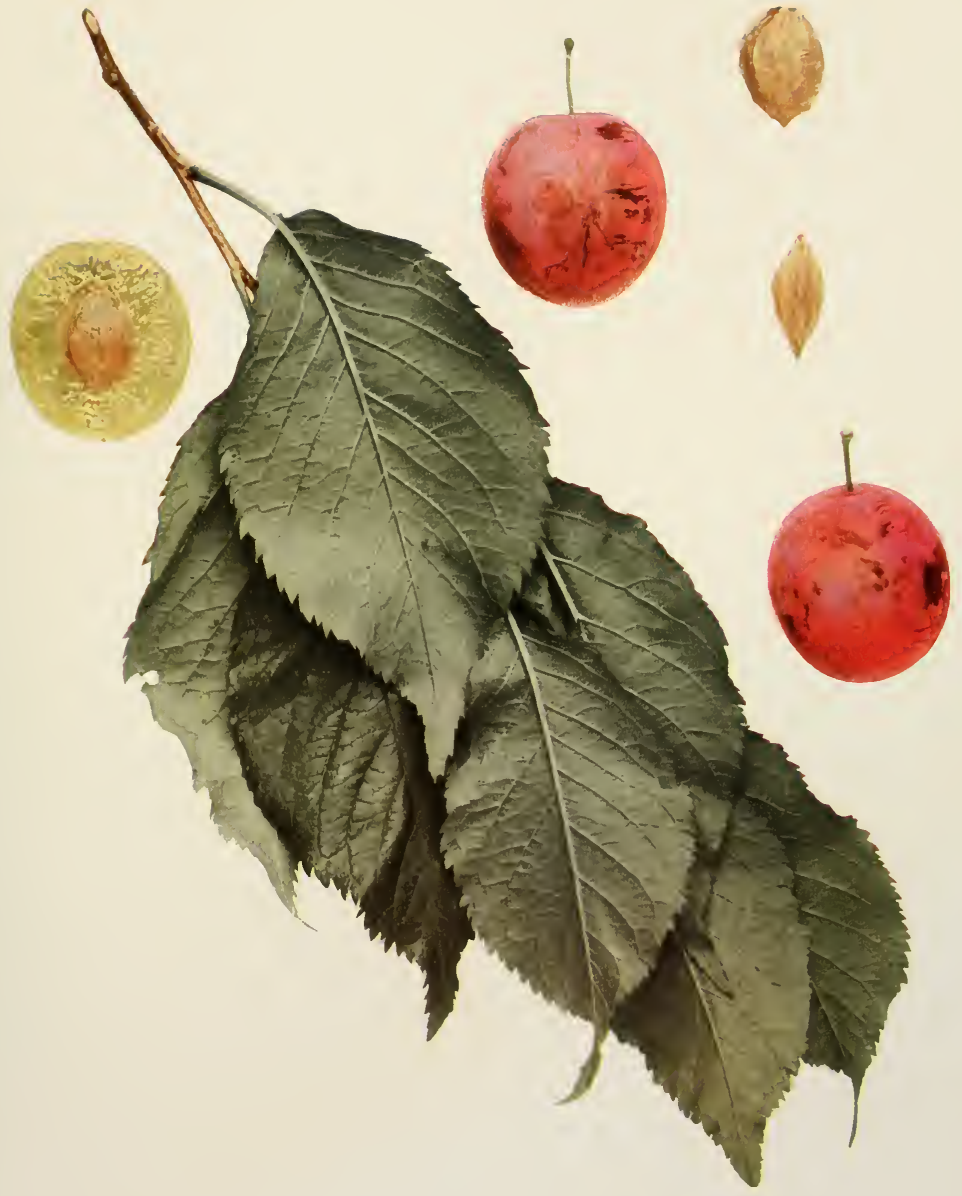



of the latter is shown by its hardiness and its broad, Americana-like foliage. The variety first fruited in 1888 and was sent out in 1892 .

Tree very large, vigorous, round-topped, widely spreading, hardy at Geneva, an uncertain bearer; trunk and larger limbs shaggy; branches long, rough, brash, thorny, dark ash-gray, with many, large lenticels; branchlets thick, very long, with long internodes, grcen changing to dull reddish-brown, glabrous, with raised lenticels of medium number and size; leaf-buds small, short, obtuse, plump, free.

Leaves folded upward, oval or slightly obovate, two and one-eighth inches wide, four inches long, thin; upper surface somewhat rugose; lower surface pale green, very lightly pubescent along the midrib; apex taper-pointed, base obtuse, often unsymmetrical, margin coarsely and doubly serrate, eglandular; petiole three-quarters inch long, sparingly pubescent along one side, tinged red, glandless or with from one to four small, globose, greenish-brown glands on the stalk.

Blooming season medium to late, long; flowers appearing after the leaves, fifteensixteenths inch across, white, with a disagreeable odor; borne in clusters on lateral buds and spurs, in twos or in threes; pedicels five-eighths inch in length, slender, glabrous, grcenish; calyx-tube green, campanulate, glabrous; calyx-lobes narrow, obtuse, thinly pubescent within, glandular-serrate and with marginal hairs, somewhat reflexed; petals ovate or oval, irregularly crenate, tapering below into claws of medium length and breadth; anthers yellowish; filaments seven-sixteenths inch in length; pistil glabrous, cqual to or shorter than the stamens in length.

Fruit mid-season, ripening period of average length; one and one-quarter inches in diamcter, roundish-oval, slightly compressed, halves equal; cavity very shallow, narrow, flaring; suture an indistinct line; apex roundish; color crimson overspread with thick bloom; dots numerous, very small, light russet, inconspicuous; stem slender, five-eighths inch long, glabrous, not adhering to the fruit; skin thick, tough, inclined to crack under unfavorable conditions, separating readily; flesh golden-yellow, juicy, fibrous, tender and melting, sweet, strongly aromatic; good; stone semi-free, threequarters inch by five-eighths inch in size, flattened, roundish-oval, somewhat compressed at the base, abruptly pointed at the apex, rough; ventral suture rather narrow, faintly ridged; dorsal suture with a narrow, shallow groove.

\section{HAND}

\section{Prunus domestica}

x. Horticulturist $2: 436.1847$. 2. Ibid. $6: 21$ fig., $187,294.1851$. 3. Am. Pom. Soc. Rpt. 19o, 214. 1856. 4. Downing Fr. Trees Am. 382. 1857. 5. Hogg Fruit Man. 362. 1866. 6. Mas Pom. Gen. 2:19, fig. 10. 1873. 7. Ont. Fr. Exp. Sta. Rpt. 120. 1896. 8. Cornell Sta. Bul, 131:185. 1897. 9. Waugh Plum Cull. 108 fig. 1901. 10. Budd-Hansen Am. Hort. Man. 314, $3 \times 5$ fig. 1903. Ix. Mass. Sta. An. Rpt. 17:159. 1905.

Gen. Hand 1, 2. General Hand 2, 3, 5, 6, 7, 8. Genl. Hand 4. General Hand 9, 10. Montgomery 3 incor.

Unproductiveness and uncertainty in bearing keep this magnificent yellow dessert plum from being one of the most commonly grown of all 
plums in America. Even with these handicaps, it has maintained its popularity for a century, is grown in all collections and shown in all exhibitions of note. It is the largest of the Reine Claude plums, well molded, a goldenyellow and when allowed to become fully ripe is most excellent in flavor and pleasing in all the flesh attributes of a good dessert plum. It is not as high in quality as some other of the Reine Claude plums, as, for example the Washington, with which it is often compared, for it is a little coarser in flesh and not as sprightly, but it is better than is commonly thought, because it is seldom allowed to reach its best flavor by full maturity. The trees on the Station grounds are all that could be asked for even in bearing; and elsewhere size, vigor and hardiness are usually satisfactory but productiveness is a weak point. The amateur should always plant this variety and it would seem as if it were more often worth planting in commercial orchards.

The history of this variety is well known. The original tree grew on the place of General Hand, on the Conestoga River, about a mile from Lancaster, Pennsylvania, and first fruited about 1790 . Thirty years later a Mr. Miller procured grafts and succeeded in growing them. The variety was brought to the notice of fruit-growers by E. W. Carpenter, a nurseryman of Lancaster, Pennsylvania, who sent grafts to his brother, S. Carpenter, of Lancaster, Ohio, and Robert Sinclair, Baltimore, Maryland. To the latter the introduction of the Hand has been incorrectly attributed. In I 856, Hand was listed in the fruit catalog of the American Pomological Society.

Tree large, vigorous, spreading, dense-topped, hardy, variable in productiveness; branches dark ash-gray, rough, with small lenticels; branchlets of medium thickness and length, with long internodes, green changing to brownish-red, pubescent early in the season, becoming less so at maturity, with few, inconspicuous, small lenticels; leaf-buds large, long, obtuse, appressed; leaf-scars large.

Leaves folded backward, obovate or oval, two and three-eighths inches wide, four and one-half inches long; upper surface dark green, rugose, slightly hairy, with a shallow, grooved midrib; lower surface pale green, pubescent; apex and base acute, margin finely and doubly serrate; petiole three-quarters inch long, thickish, pubescent, tinged red, with from one to four small, globose, green'sh-brown glands on the stalk or base of the leaf.

Blooming season intermediate in time, short; flowers appearing after the leaves, one and one-quarter inches across, white; borne sparsely on lateral buds and spurs; pedicels seven-eighths inch long, very pubescent, greenish; calyx-tube green, campanulate, pubescent; calyx-lobes broad, obtuse, pubescent on both surfaces, glandular- 


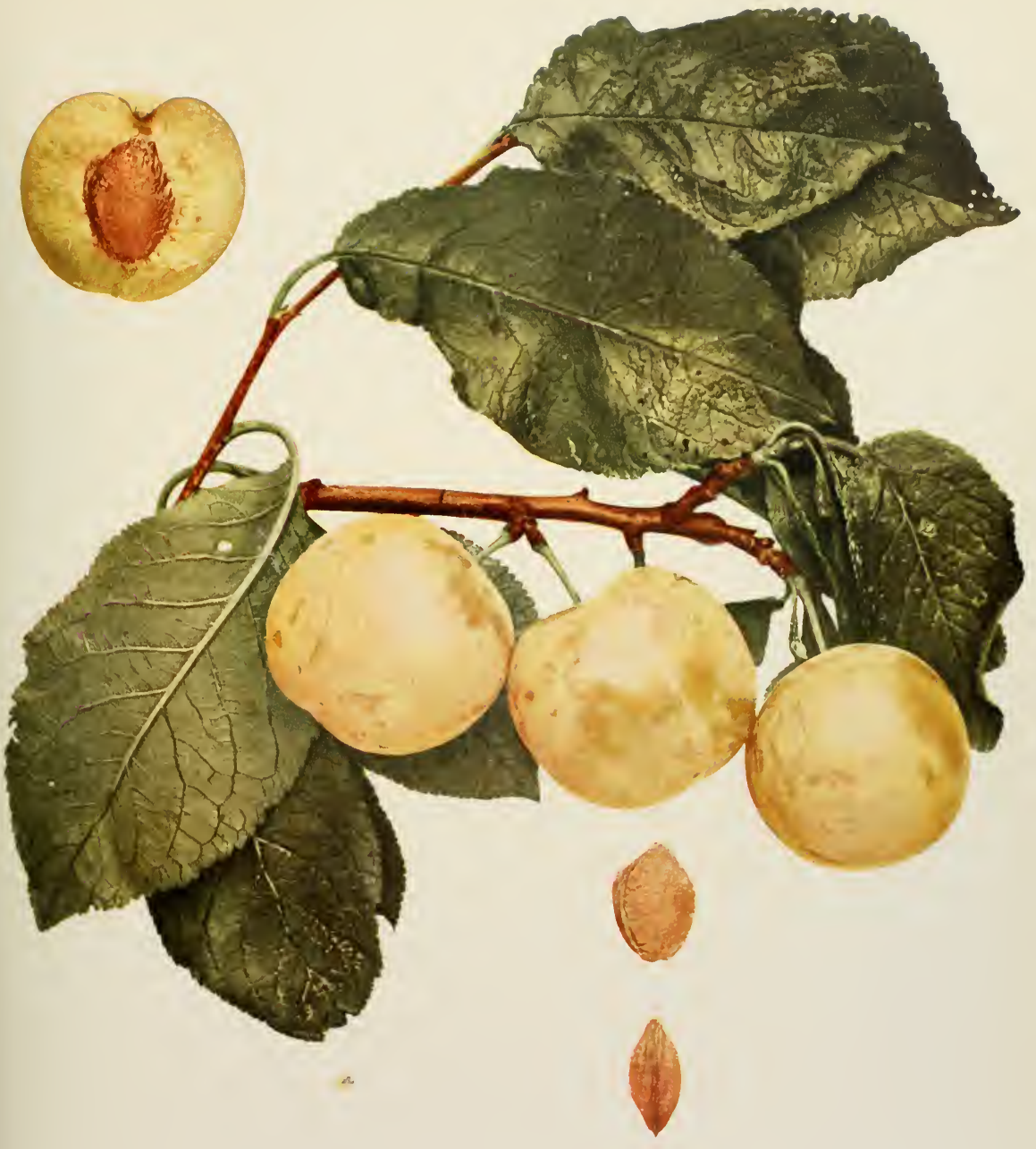



serrate, reflexed; petals roundish or obovate, slightly crenate, with short, broad claws; anthers yellowish; filaments three-eighths inch long; pistil lightly pubescent at the base, equal to the stamens in length.

Fruit mid-season, ripening period long; one and three-quarters inches in diameter, roundish-truncate or oblate, halves equal; cavity deep, flaring; suture shallow, distinct; apex flattened or depressed; color yellow, obscurely striped and mottled with green, overspread with thin bloom; dots numerous, whitish, inconspicuous, clustered about the apex; stem unusually long, averaging one and five-sixteenths inches in length, very pubescent, adhering strongly to the fruit; skin thick, tough, slightly astringent, separating readily; flesh golden-yellow, juicy, somewhat fibrous, firm, sweet, with pleasant, mild flavor; very good; stone semi-free or free, the cavity larger than the pit, seven-eighths inch by three-quarters inch in size, broadly oval, turgid, blunt at the base and apex, slightly roughened; ventral suture broad, sometimes winged; dorsal suture broadly and deeply grooved.

\section{HARRIET}

\section{Prunus domestica}

\section{Gard. Chron. 18:44I. 1882. 2. Hogg Fruit Man. 705. 1884.}

Harriet is little known in America, but as the variety grows on our grounds it appears to be somewhat desirable. The type is that of Reine Claude, the fruit being slightly yellower; the quality is very good and the tree-characters are good. It is doubtful, however, in spite of these attributes to recommend it, whether, with the multiplicity of plums of this type, the variety in question can make headway in the United States. Harriet was originated by Thomas Rivers, Sawbridgeworth, England, about I 870. While considerably grown in England, it can hardly be said to be one of the leading varieties in that country.

Tree medium in size and vigor, spreading, open, productive; branchlets thick, very short, pubescent throughout the season; leaf-buds large, long, tipped brush-like at the apex; leaves folded upward, oval, one and one-half inches wide, two and three-quarters inches long, the young leaves bright red when opening; margin serrate or almost crenate; petiole tinged red, glandless or with one or two glands usually at the base of the leaf; blooming season intermediate, short; flowers appearing after the leaves, one inch across; borne on lateral buds and spurs, singly or in pairs.

Fruit mid-season, ripening period long; about one and three-eighths inches in diameter, roundish-oblate, somewhat oblique, golden-yellow, sometimes mottled with red, overspread with thin bloom; flesh golden-yellow, firm, sweet, pleasant in flavor; of very good quality; stone clinging, five-eighths inch by one-half inch in size, oval, turgid, with slightly roughened surfaces. 


\section{HAWKEYE}

\section{Prunus americana}

I. Ia. Hort. Soc. Rpt. 287.1887 . 2. U.S. D. A. Rpt. 44 r. 1889 . 3. Ia. Hort. Soc. Rpt. 55 , 85. 189o, 4. Cornell Sta. Bul. 38:38, 86. 1892, 5. Wis. Sta. Bul. 63:40, 41. 1897. 6. Am. Pom. Soc. Cat. 24. 1897. 7. Colo. Sta. Bul. 50:37. 1898. 8. Ia. Sta. Bul. 46:274. 1000. 9. Waugh Plum Cult. 151. 1901. 1o. Ont. Fr. Gr. Assoc, 144. 1901. 11. Wis. Sta. Bul. 87:13. 1901. 12. S. Dak. Sta. Bul. 93:19. 1905. 13. Ohio Sta. Bul. 162:254, 255. 1905.

This variety is a very satisfactory and widely planted Americana. It is typical of its species; and its foliage, fruit and pit in the color-plate herewith presented all represent Prumus americana very well. The fruit of Hawkeye is more satisfactory than the tree, being both attractive in appearance and pleasant to eat either out of hand or cooked; the chief fault of the fruit is that it seems to be easily infected with brown-rot. The trees are crooked in body and quite too straggling and at the same time too dense in growth to make good orchard plarits. It requires very careful pruning and training to keep the trees at all manageable. In some of the references given above it is stated that Hawkeye on its own roots is a better tree than otherwise propagated. This variety belongs in the middle west but it might be grown for home use in northern New York where it is too cold for the European plums.

Hawkeye is a seedling of Quaker grown by H. A. Terry, ${ }^{1}$ Crescent, Iowa. It first fruited in I 882 and the following year was introduced by

${ }^{1}$ H. A. Terry was born in Cortland County, New York, July 12th, 1826. His parents were from New England having come as pioneers to New York from Worcester, Massachusetts. The spirit of pioneering seems to have been strong in the Terry family for in $18{ }_{3} 6$ the parents moved again to Livingston County, Michigan. The son, leaving his parents in 1845 , again went westward to Knox County, Illinois, and still again in 1846 farther west to Pottawattamie County, Iowa. After this there were still more wanderings in which Mr. Terry and his family, he having married in 1848 , were as far east as New Haven, Connecticut, for two years and aga in west to several places in Iowa. He finally engaged in the nursery business at Crescent, Iowa in 1857 ; he lived here for over fifty years, giving to the world his best services in the production of new fruits and flowers, and here his death occurred February 14 th, 1909. Mr. Terry was noted as a peony and a plum specialist. Of plums he is the originator of over fifty sorts nearly all from the native species-a record unsurpassed in point of numbers for new varieties by any other plum-breeder. Several of Mr. Terry's plums are of surpassing merit for varieties of their species; among these may be named such well-known sorts as Gold, Hammer, Hawkeye, Nellie Blanche, Crescent City, Downing and Milton. Most of his varieties are ofispring of Prunus americana but there are a few from Prunus munsoniana and Prunus hortulana. Unfortunately there is little in regard to Mr. Terry's method of breeding plums on record for he seems to have written or spoken little for publication. He was long a prominent member of the Iowa State Horticultural Society and for a number of years had charge of one of the experiment stations of this society. Of his work with peonies, of which he produced more than one hundred named sorts, and with other plants, space does not permit discussion. The last half of his life of more than four score years was a tireless effort to improve the fruits and flowers of the Mississippi Valley. 


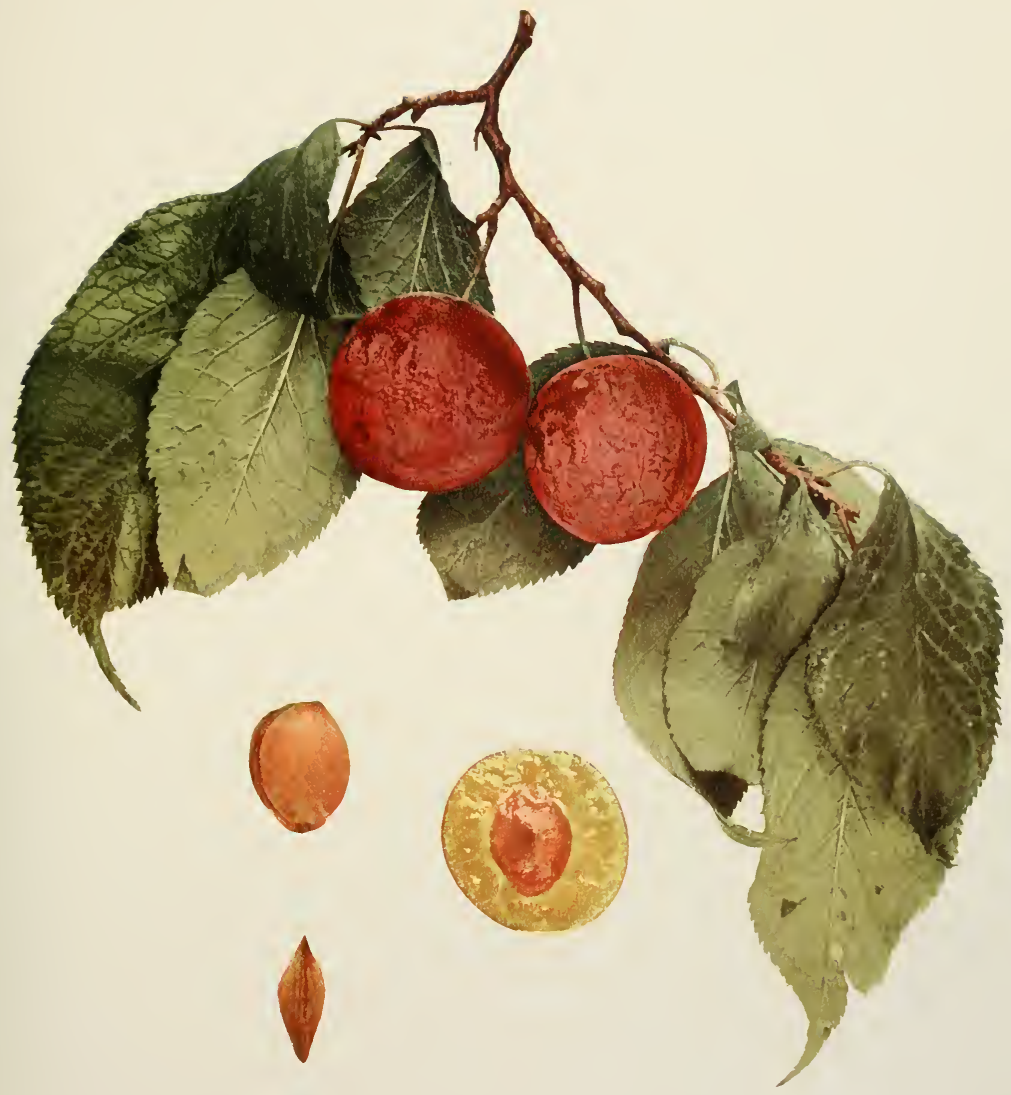


the originator. In the Iowa Horticultural Society Report for 1887 , Mr. Terry stated that the original tree had borne five crops in succession and he believed it to be the most valuable variety in cultivation for the West and Northwest. The American Pomological Socicty placed this plum on its fruit catalog list in 1897 .

Tree large, vigorous, rather upright at first, becoming spreading, low-headed, hardy, usually productive, but variable in some locations, susceptible to attacks of shot-hole fungus; branches numerous, dark brown, rough, thorny, with numerous, large lenticels; branchlets long, willowy, with internodes of medium length, green, changing to dull reddish-brown, shining, glabrous, with numerous large, raised lenticels; leat-buds small, short, pointed, appressed.

Leaves tinged red late in the season, nearly flat, oval or slightly obovate, two inches wide, four inches long, rather thin; upper surface dark green, smooth, glabrous, with midrib and larger veins deeply grooved; lower surface light green, lightly pubescent along the midrib and larger veins; apex taper-pointed, base very abrupt, margin coarsely and doubly serrate, the serrations often becoming spiny, eglandular; petiole rather slender, nine-sixteenths inch in length, tinged with pink, sparingly pubescent along one side, glandless or with one or two globose, greenish-brown glands.

Blooming season intermediate in time and length; flowers appearing with the leaves, showy on account of the numerous, pure white, flat petals, with a somewhat disagreeable odor; borne in clusters on lateral buds and spurs, in pairs; pedicels seven-sixteenths inch in length, glabrous, green with a distinct reddish tinge on one side; calyx-tube red, broadly obconic, glabrous; calyx-lobes short, obtuse, pubescent on both surfaces, eglandular, with a hairy, serrate margin, somewhat reflexed; petals ovate, crenate, but somewhat fringed, long and narrowly clawed; anthers yellowish; filaments fivesixteenths inch long; pistil glabrous, shorter than the stamens.

Fruit mid-season, ripening period of medium length; about one and one-eighth inches in diameter, roundish-oval or ovate, not compressed, halves equal; cavity unusually shallow, very narrow; suture an indistinct line; apex roundish; color dull carmine, covered with thin bloom; dots numerous, gray or reddish, nearly obscure, with almost none around the base; stem slender, below medium in length; skin thick, tough, astringent, adhering; flesh pale, dull yellow, very juicy, slightly fibrous, watery and melting, sweet at first with a tart and somewhat astringent after-taste; good; stone adhering to the pulp, seven-eighths inch by five-eighths inch in size, roundish-oval, flattened, smooth, blunt at the base and apex, conspicuously winged on the ventral suture, with a deep but narrow groove on the dorsal suture.

\section{HUDSON}

\section{Prunus domestica}

r. Mich. Hort. Soc. Rpt. 289 . 1889. 2. Mich. Sta. Bul. 103:35 i 894. 3. Ohio Hort. Soc. Rpl. 30:168. 1896-97. 4. Cornell Sta. Bul. 131:181 fig. 40 III, 187. 1897. 5. Am. Pom. Soc. Cat. 25. 1897. 6. Can. Exp. Farm Bul. 2nd Ser. 3:52. 1900. 7. Waugh Plum Cull. 109. 1901. Hudson River Purple 6. Hudson River Purple Egg 1, 3, 4. Hudson River Purple Egg 2, 5, 7. Purple Egg 2. 
Hudson is limited in cultivation, belonging almost wholly to the Hudson River Valley where it has long been somewhat of a favorite for both home and market planting. The variety has few qualities of fruit to commend it especially outside of the region where it is now grown and even here its value is probably overrated. The fruits are of only medium size, not markedly attractive in appearance and the quality is below the average among standard plums. The trees are for most part very good in constitution and habit of growth and in particular bear very well; they have the faults of not bearing early and of being subject to black-knot. The variety, and perhaps it is well, is being less planted than formerly.

Nothing is known of the origin of the Hudson except that it has been grown in the Hudson River Valley for a good many years. About 1870 it attracted the attention of S. D. Willard of Geneva, New York, who, thinking it a valuable acquisition, commenced its propagation. In 1897 , it was listed by the American Pomological Society as a successful variety for this region. J. R. Cornell, a well informed fruit-grower of Newburgh, New York, in a letter written February $2 \mathrm{I}$, I9ro, says, "I recall Hudson very distinctly as it was grown when I was a small boy over fifty years ago. I would not be surprised, if the facts could be obtained, to learn that the variety came from Europe, in fact, I incline to that opinion."

Tree large, vigorous, spreading, very productive, hardy; branches ash-gray, smooth except for the small, raised lenticels; branchlets slender, with long internodes, greenishred changing to brownish-red, dull, glabrous early in the season becoming lightly pubescent at maturity, with small, inconspicuous lenticels; leaf-buds below medium in size and length, conical, strongly appressed.

Leaves flattened, obovate or oval, two inches wide, three and three-quarters inches long; upper surface dark green, smooth, sparsely hairy along the grooved midrib; lower surface silvery-green, faintly pubescent; apex acute, base abrupt, margin serrate, eglandular or with small dark glands; petiole five-eighths inch long, thick, lightly pubescent, glandless or with from one to three greenish-yellow glands.

Blooming season short; flowers appearing after the leaves, one and one-eighth inches across, white; borne in scattering clusters on lateral spurs, singly or in pairs; pedicels nine-sixteenths inch long, glabrous except for a few scattering hairs; calyxtube green, campanulate, pubescent at the base; calyx-lobes obtuse, lightly pubescent on both surfaces, glandular-serrate, reflexed; petals obovate, crenate, tapering to short, broad claws; anthers yellowish; filaments three-eighths inch long; pistil glabrous, longer than the stamens.

Fruit late, season of medium length; one and five-eighths inches by one and oneeighth inches in size, long-oval, halves unequal; cavity shallow, narrow, abrupt, regular; suture shallow; apex slightly pointed; color dark reddish-purple changing to 


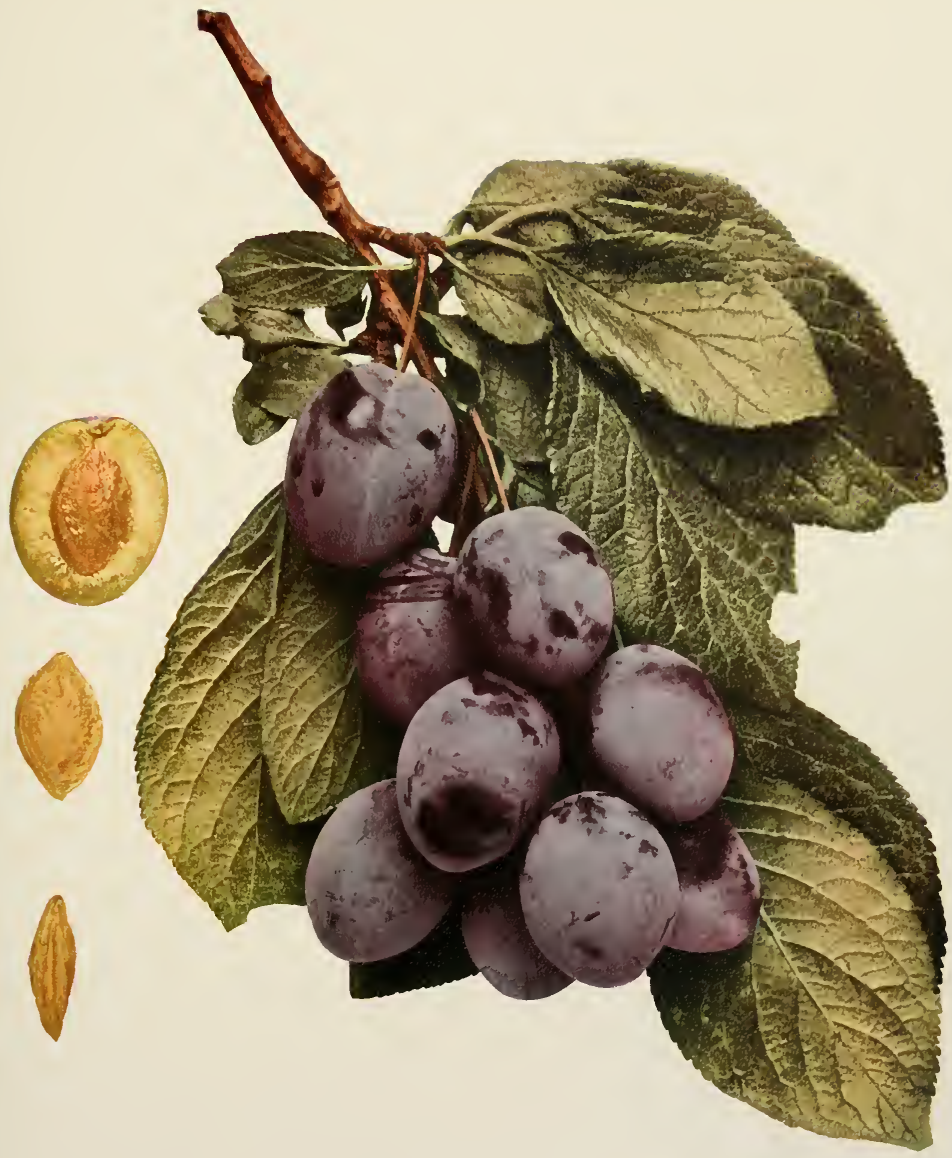



purplish-black, overspread with thick bloom; dots numerous, small, russet, inconspicuous; stem slender, one inch long, sparingly pubescent; skin thin, tender, sour, separating readily; flesh golden-yellow, juicy, rather tender, sweet next the skin but sour towards the center, aromatic; good; stone one and one-eighth inches by five-eighths inch in size, sometimes reddish, ovate, roughened and faintly pitted, acute at the base and apex; ventral suture wide, with numerous ridges; dorsal suture with a wide, shallow groove.

\section{HULINGS}

\section{Prunus domestica}

1. Prince Treat. Hort. 23. 1828 , 2. Kenrick Am. Orch, 261. 1832. 3. Downing Fr. Trees Am. 277. 1845. 4. Horticulturist I:I66. 1846. 5. Am. Pom. Soc. Cat. 86. 1862. 6. Hogg Fruit Man. 705. 1884. 7. Mathieu Nom. Pom. 435. 1885. 8. Guide Prat. 158, 366. 1895.

Gloire de New York, 6, 7, 8. Huling's Superb 7, 8. Huling's Superb I, 2, 3, 4, 5, 6. Huling's Treffliche 7. Keiser 2. Keyser's Plum 3, 6, 7, 8. Superbe de Huling 8.

Hulings is one of the largest of the Reine Claude group of plums and a remarkably fine fruit in every respect. It is particularly agreeable to the taste because of its sprightliness, which so many plums of its type lack. As this variety grows in New York it has much to recommend it for commercial plantations. Its lack of popularity among planters is due somewhat to the wholesale substitution by nurserymen of spurious varieties for it. Hulings originated early in the last century with a Mr. Keyser of Pennsylvania who grew it from seed, but Dr. W. E. Hulings of the same state brought it to public notice.

Tree large, vigorous, upright-spreading, dense-topped, productive; branchlets brasn, thick, pubescent; leaves unusually large, obovate, three inches wide, six and one-half inches long, thick, leathery, rugose; margin crenate or serrate; petiole thick, tinged red, pubescent, with from one to three globose glands.

Fruit maturing in mid-season; about one and seven-eighths inches in diameter, roundish, dull greenish-yellow, overspread with thin bloom; skin thin, somewhat sour; flesh greenish, firm but tender, sprightly; good to very good; stone clinging, one and one-eighth inches by three-quarters inch in size, broad-oval, medium turgid, with short, thick, slightly oblique apex; ventral suture often winged; dorsal suture wide, deep.

\section{HUNGARIAN}

\section{Prunus domestica}

1. Knoop Fructologie 2:61. 1771. 2. Willichs Dom. Enc. 4:190. 1803. 3. Lond. Hort. Soc. Cat. $1_{43},{ }_{4} 48.183_{3}$. 4. Downing Fr. Trees Am. 2nd App. 156. 1876. 5. Oberdieck Deut. Obst. Sort. 404. 1881. 6. Mas Le Verger 6:51, fig. 26. 1866-73. 7. Koch Deut. Obst. 568. 1876. 8. Hathieu Nom. Pom. 452. I889. 9. Cal. State Board Hort. III fig. Ir. I8gr. 10. Lucas Vollst. Hand. Obst. 474. 1894. 11. Lange Allgem. Garten. 2:421. 1897. 12. Mich. Hort. Soc. Rpt. 465. 1893. 13. Oregon Sta. Bul. 45:33. 1897. 14. Waugh Plum Cult. 109. 1901. 
Autriche Violette $(P r, d c)$ 8. Blane Dattel Pflaume 8. Blue Egg-Plum ? 2. Datte de Hungrie $I_{3}$. Dattelswetsche 6. Datte Violette 8. Date de Hongrie 14. Datte de Hongrie 4, 14. Date Plum 7. D'Autriche 3. Frühe Dattelzwetsche 10. Grosse u. Lange Fruh Zwetsche 8. Grosse Früh Zwetsche 8. Hungarian Date 9. Hungarian Prune? 3, 14. Hungarica 7. Hungarian Prune 4. 11, 12. Hungarian Plum 2. Lange Violette Dattel Zwetsche 8. Osterreichische Pflaume 8. Prune-Datte 3, 6. Prune Datte Violette 3.. Prune d'Autriche 6, 8. Quetsche de Hongrie 8. Quetsche Datte Violette 8. Quetsche Datte 6, 8. Quetsche-Datte Violette 6. Quetsche Hongroise 1. Quetsche de Hongrie 6. Sabcl Pflaume 8. Späte Dattel Pflaume 8. Ungarische Pflaume 8. Ungarische Dattelzwetsche 5. Ungarishe Sabel Pfaume 8. Violette Dattelzwetsche 6. Violette Dattelzwetsche 8. Turkische Zwetsche 8. Ungarische Zwetsche 8. Virginische Ludwig's Pfaume 8.

This plum, representing a type hardly known in America, may be a descendant of a species distinct from Prunus domestica, and if not, must at least be considered a well-marked division of the species named. It differs but little from typical Domestica varieties in habit of growth but the leaves are smaller, distinctly folded, and droop, giving an aspect to the tree distinct from the Domesticas in general. But it is the fruit that differs most. Fruit and stone are more elongated than in other varieties of its supposed species and the stone is larger, flatter, more pitted and more pointed at the base and apex. The stem, too, is longer than in the average Domestica. These differences in leaf, fruit and pit may be well seen if the color-plate of this variety be compared with those of well-recognized Domesticas. It is doubtful if Hungarian is worth cultivating in New York though it is larger than the commonly grown German Prune, with which it must be compared, and is fully equal if not better in quality but its type is unknown and consumers hesitate to buy the unknown. It is well worth a place in private collections.

Nothing is known of the history of this plum other than that it has been long under cultivation and that, as its name suggests, it came from Hungary. As in the case of many of the varieties which came from Hungary there are several strains of this plum. The variety that is known in America as Hungarian was reported by Downing in 1876 , as originating in Belgium, a mistake, as this is known to have been widely spread for a long time in Europe and European authorities trace it back to Hungary. The Ungarish of Budd, the Hungarian Prune of the Pacific Coast which is Pond Seedling, and the Date Plum, a yellow plum of Downing, all passing under the name "Hungarian," are distinct varieties.

Tree large, vigorous, upright-spreading, dense-topped, hardy, productive; branches ash-gray, smooth, with few, small lenticels; branchlets thick, long, with internodes of average length, greenish-red changing to brownish-red, dull, sparsely pubescent, with few, small, inconspicuous lenticels; leaf-buds of medium size and length, conical, appressed. 


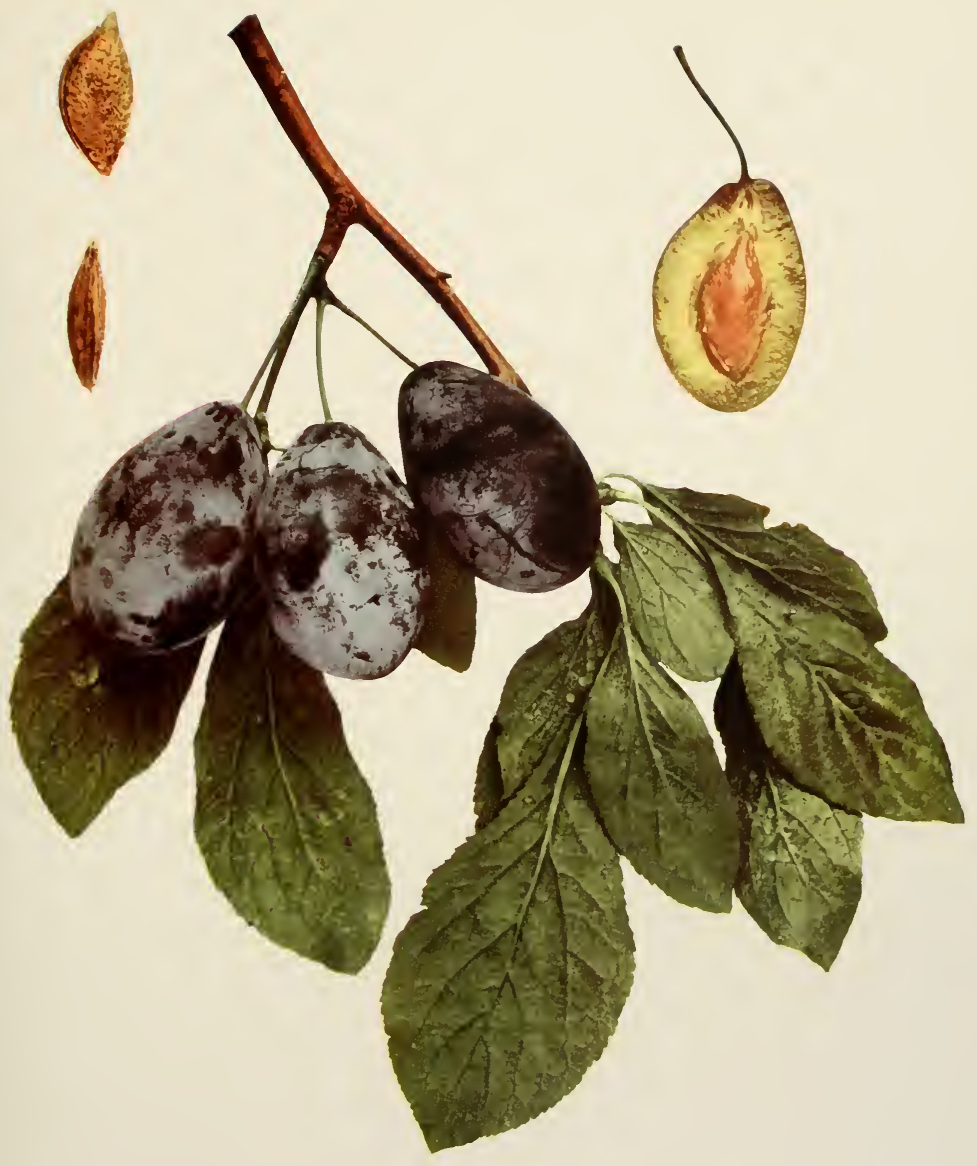



Leaves drooping, folded upward, oval or obovate, one and five-eighths inches wide, three and one-quarter inches long, thick; upper surface dark green, rough, hairy, with a deeply, narrowly grooved midrib; lower surface pale green, pubescent; apex and base acute, margin serrate, eglandular or with small brown glands; petiole nine-sixteenths inch long, pubescent, tinged red, glandless or with one or two globose, greenish-yellow glands usually at the base of the leaf.

Blooming season intermediate in time and length; flowers appearing after the leaves, seven-eighths inch across, the buds tinged yellow, changing to white on opening, not clustered but distributed on lateral spurs, singly or in pairs; pedicels seven-eighths inch long, very slender, pubescent, greenish; calyx-tube green, campanulate, pubescent; calyx-lobes narrow, acuminate, thickly pubescent on both surfaces, glandular-serrate, reflexed; petals narrowly ovate, serrate, converging at the base into narrow claws; anthers yellowish; filaments seven-sixteenths inch long; pistil glabrous, equal to the stamens in length, small, slender.

Fruit late, season short; one and five-eighths inches by one inch in size, distinctly oblong, somewhat necked, swollen on the suture side, compressed, halves unequal; cavity very shallow and narrow, abrupt; suture shallow; apex pointed; color dark reddish-purple, overspread with thick bloom; dots numerous, small, russet, inconspicuous; stem slender, one and one-eighth inches long, pubescent, adhering well to the fruit; skin thin, tough, slightly sour, separating readily; flesh yellowish-green, juicy, firm but tender, sweet, mild; good to very good; stone semi-free to free, one and one-eighth inches by one-half inch in size, irregular long-oval, flattened, necked at the base, acute at the apex, with thickly pitted surfaces; ventral suture wide, blunt; dorsal suture with a wide, deep groove.

\section{ICKWORTH}

\section{Prunus domestica}

I Gard. Chron. 1:734. 1841. 2. Ibid. 2:176. I842, 3. Downing Fr. Trees Am. 302. 1845. 4. Thomas Am. Fruit Cult. 345. 1849. 5. Elliott Fr. Book. 420. 1854. 6. Thompson Gard. Ass't 517. 1859. 7. Mas Le Verger 6:57, P1. 29. 1866-73. 8. Barry Fr. Garden 413. 1883. 9. Hogg Fruit Man. 706. 1884. I0. Mathieu Nom. Pom. 435. 1889. 11. Wickson Cal. Fruits 358. 1891. 12. Cornell Sta. Bul. 131:187. 1897. 13. Waugh Plum Cult. 110. 1901.

Ickworth Imperatrice $\mathrm{I}_{2}, 2,3,4,5,6,8,9,10, \mathrm{II}, \mathrm{I2}$. Ickworth Imperatrice $\mathrm{I}_{3}$. Imperatrice Ickworth ro. Imperatrice Jckworth 7. Jckworth Imperatrice 7 . Knight's No.6. 3, 5, 9, го.

Ickworth is hardly known in America though in England it is a favorite late plum noted as being one of the best of all plums for late keeping. In New York the plums of this variety are too small for the market and are not high enough in quality for a home plum; moreover, the plums do not always ripen in this latitude. In California Ickworth has been found to make a very good prune and to ship very well in the green state but here again small size debars it from great commercial value. The habits of growth of Ickworth are very good and so markedly so that when 
considered with the late keeping qualities of the fruit, one wishes that this variety might be bred with a larger plum of better quality with the hope of an offspring from the union of especial value as a late plum.

Knight, the noted English pomologist, raised this plum from the Imperatrice fertilized by Golden Drop and named it after Ickworth Park, near Bury St. Edmunds. Knight aimed in raising this and other plums to produce a fruit containing sufficient sugar to keep well and not shrivel. In Ickworth he succeeded to a high degree.

Tree large, rather vigorous, upright-spreading, hardy, productive; branches dark ash-gray, roughened by the numerous, large, raised lenticels; branchlets of medium thickness and length, with internodes of average length, green changing to brownishdrab, dull, lightly pubescent, with numerous, inconspicuous, small lenticels, leaf-buds small, short, conical, appressed.

Leaves folded upward, obovate or oval, one and three-eighths inches wide, three inches long, thick, leathery; upper surface dark green, shining, pubescent only along the grooved midrib; lower surface silvery-green, sparingly pubescent; apex abruptly pointed or acute, base acute, margin crenate, with small dark glands; petiole one-half inch long, thick, greenish, pubescent along one side, glandless or with from one to four large, reniform or globose, yellowish-brown glands usually on the stalk.

Season of bloom intermediate, long; flowers appearing after the leaves, one inch across, white; borne in thin clusters on lateral buds and spurs, singly or in pairs; pedicels seven-sixteenths inch long, below medium in thickness, glabrous, greenish; calyxtube green, campanulate, glabrous; calyx-lobes broad, obtuse, lightly pubescent, with few glands and marginal hairs, erect; petals roundish or roundish-oval, finely crenate, tapering below to short, broad claws; anthers yellowish; filaments one-quarter inch long; pistil glabrous, longer than the stamens.

Fruit very late, season long; one and three-eighth inches by one and one-quarter inches in size, oval or roundish-oval, sometimes slightly compressed, halves unequal; cavity shallow, narrow, abrupt; suture shallow, wide; apex one-sided, roundish or depressed; color purplish-red changing to purplish-black, mottled, overspread with thick bloom, dots numerous, very small, inconspicuous, scattered between irregular flecks and nettings; stem thirteen-sixteenths inch long, lightly pubescent, adhering well to the fruit; skin thick, tender, adhering; flesh dull yellowish, juicy, sweet, mild, pleasant; good; stone usually clinging, seven-eighths inch by one-half inch in size, irregularly oval, flattened, faintly pitted, acute at the base, blunt at the apex; ventral suture wide, heavily furrowed, swollen; dorsal suture widely and shallowly grooved.

\section{IMPERATRICE}

Prunus domestica

x. Quintinye Com. Gard. 67, 69. 1699. 2. Langley Pomona 95, P1. XXV fig. III. 1729. 3. Duhamel Trait. Arb. Fr. 105, P1. XVIII. 1768. 4. Kraft Pom. Aust. 2:45, Tab. 200 fig. 2. 


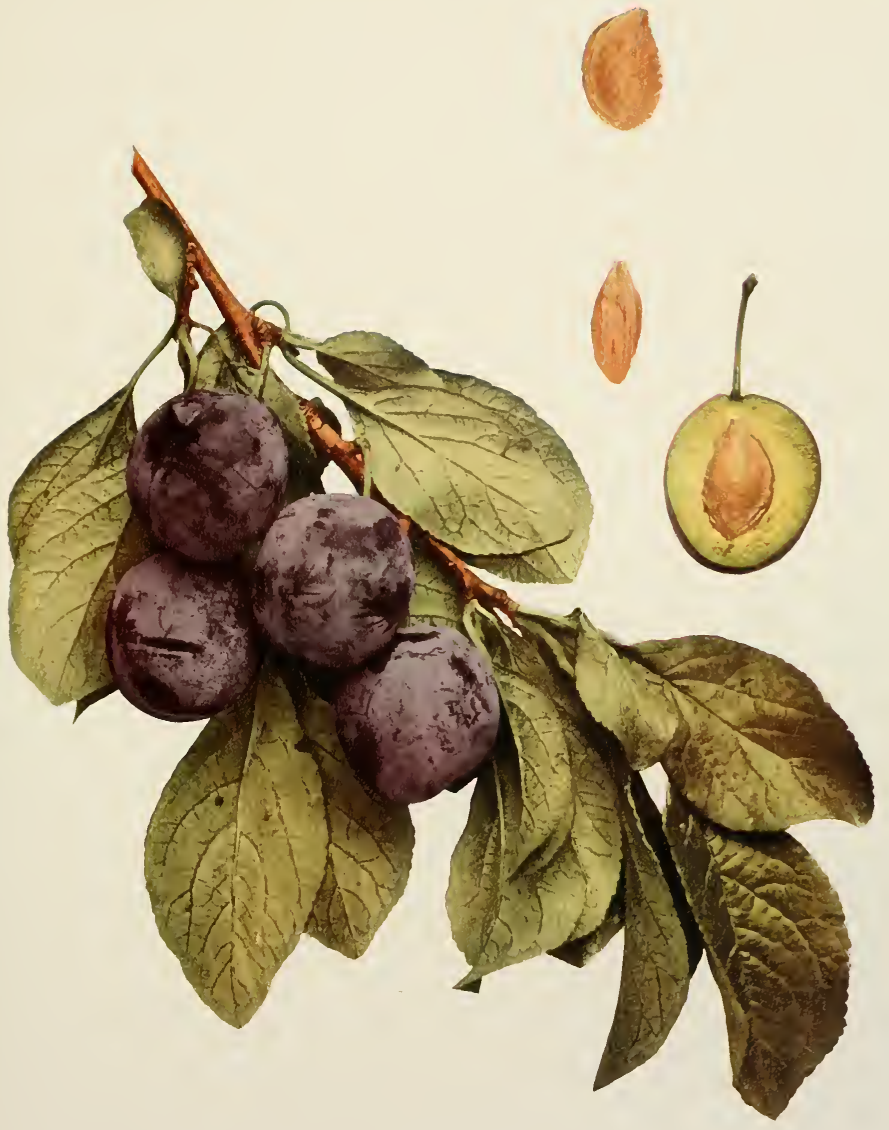



1796. 5. Miller Gard. Dict. 3. 1807. 6. Forsyth Treat. Fr. Trees 20. 1803. 7. Pom. Mag. I: 33. 1828. 8. Lond. Hort. Soc. Cat. 148. 1831. 9. Prince Pom. Man. 2:60. 1832. 10. Downing Fr. Trees Am. 290. 1845. 11. Floy-Lindley Guide Orch. Gard. 287, 383. 1846. 12. Thomas Am. Fruit Cult. 344. 1849. 13. Elliott Fr. Book 416. 1854. 14. McIntosh Bk. Gard. $2: 529.1855$. 15. Thompson Gard. Ass't 515. 1859. 16. Mas Pom. Gen. 2:101. 1873. 17. Am. Pom. Soc. Cat. 36. 1877. 18. Hogg Fruit Man. 687. 1884. 19. Mathieu Nom. Pom. 423, 452. 1889. 20. Guide Prat. 161, 358. 1895 .

Blue Perdrigon, of some 2. Blaue Kaiserin 19. Blue Imperatrice 9, 10, 12, 13, 14, 15, 17 , 18. Blue Imperatrice 16, 19. Die Veischenfarbige Kaiserinnplaume 4. Empress 1. Empress 5. 6, 9, 18, 19. Fürsten Zwetsche 19. Fürstenzwetsche 20. Hoheitsplaume 19, 20. Imperatrice Blue 8. Imperatrice $7,8,9,10,12,13,14,15,18,19$. Imperatrice Violette $3,16,20$. Imperatrice Violette 4, 7, 8, 9, 10, 11, 13, 14, 15, 18, 19. Late Red Imperial 9. Late Violet, of some 2. Prinzessin Pflaume 19. Prune d'Altesse ? 9. Red Magnum Bonum 9. Red Imperial 9. Smith's large October ? 9. The Imperatrice Plum 7. Veritable Imperatrice 8, 10, 13, $14,15,19$. Violette 8 , 10, 13, 1 4, 15, 19. Violette Kaiserin 19. Violette Kaiserin 16, 20. Violct Empress 9, 19.

Imperatrice has been long known and widely grown but the variety has no especial cultural value in the United States, the fruit being too small and too poor in quality. If it has any merit, it is keeping quality, the fruit hanging well on the tree and keeping well, even improving after picking.

This is an old variety, well known in Austria, France and England during the Seventeenth and Eighteenth Centuries. Like most long-known varieties its nomenclature is badly confused. Writers have confounded it with Semiana, the Perdrigons, German Prune and other plums of similar appearance. Duhamel regarded this variety as Perdrigon Late, holding that the true Imperatrice is nearly round. Calvel, also, describes a roundish plum under this name in his Traite Complet sur les Pepinieres. It is probable, however, that both Duhamel and Calvel were mistaken as all other authors describe an obovate plum. This variety was introduced into America early in the last century but has never become popular. It is of interest, nevertheless, since it has been a leading European variety, is a parent of a number of other varieties and its name is given to a group of plums. The American Pomological Society added it to its fruit catalog list in 1877 , but dropped it in 1883 .

Tree large, vigorous, upright-spreading, productive; leaves obovate or oval, two and one-quarter inches wide, four and one-quarter inches long, slightly rugose; margin crenate; petiole one inch long, thick, tinged red, pubescent, glandless, or with one or two small glands usually at the base of the leaf.

Fruit late; one and one-half inches by one and three-eighths inches in size, roundish or ovate, purplish-black, overspread with medium thick bloom; flesh golden-yellow, rather dry, firm but tender, sweet; of fair quality; stone free, one inch by three-quarters inch in size, roundish-ovate, the surfaces often granular and with a reddish tinge. 


\section{IMPERIAL EPINEUSE}

Prunus domestica

1. Cal. State Bd. Hort. 48, 50. 1897-98. 2. U. S. D. A. Div. Pom. Bul. 7:316. 1898. 3. Can. Exp. Farm Bul. 2nd Ser. 3:53. 1900. 4. Bailey Cyc. Hort. 1378. r9or. 5. Wickson Cal. Fruits 221, 224. 1908 .

Clairac Mammoth 1, 5. Imperial Epineux 3.

Imperial Epineuse is well worthy a trial in New York. It is not surpassed in quality by any other plum of its color. It is one of the largest plums in the Prune group and is made further attractive by a handsome reddish-purple color which is lighter or darker according to the exposure of the plums to the sun. As grown in two orchards near Geneva the treecharacters are exceptionally good; the crop is so borne on the main limbs as to be protected from the sun and the tree is particularly large and vigorous, its strong upright growth being a striking characteristic of the variety. If the variety proves to be as valuable elsewhere in the State in all characters as it is here it cannot but make a very desirable plum for the market.

The Imperial Epineuse was found growing as a chance seedling about I870 in an abandoned monastery near Clairac, in the Valley of Lot, the great prune district of France. It was first brought to the United States by Felix Gillett of Nevada City, California, who received the variety with several others in $188_{3}$, three years previous to a similar importation made by John Rock of Niles, California. After testing the variety Mr. Gillett mentioned it, without a name, in his catalog in I 888 but owing to the scarcity of the trees was unable to introduce it to the trade until i 893 when it was sent out under the name "Clairac Mammoth," from the name of its place of origin. In I 895 E. Smith \& Sons of Geneva, New York, received this variety from Gillett and grew it under the name "Clarice Mammoth".

Tree large, vigorous, spreading, fairly productive; branches numerous, covered with many fruit-spurs; branchlets twiggy, marked with scarf-skin; leaf-buds large, very free, broad at the base; leaves folded backward, obovate, one and three-quarters inches wide, three and one-half inches long, thick, rugose, glabrous except along the deeply and widely grooved midrib; petiole one inch long, tinged red, glandless or with from one to three globose glands; blooming season intermediate in time and length; flowers appearing after the leaves, one inch across, singly or in threes.

Fruit rather late, season short to medium in length; large, slightly obovate, purplish-red, darker on the sunny side, mottled, overspread with thick bloom; flesh greenish-yellow, fibrous, rather tender, sweet, agrecable in flavor; good to very good; stone clinging, one inch by five-eighths inch in size, irregular-oval, flattened, obliquely but bluntly contracted at the base, with pitted surfaces; ventral suture narrow, prominent, often distinctly winged. 


\section{IMPERIAL GAGE}

Prunus domestica

1. Am. Gard. Cal. 588. 1806. 2. Prince Treat. Hort. 25, 26. 1828. 3. Lond. Hort. Soc. Cat. 147, 148. 1831. 4. Prince Pom. Man. 2:56. 1832. 5. Kenrick Am. Orch. 209. 1835. 6. Mag. Hort. 6:123. 1840. 7. Cultivator xo:167 fig. 1843. 8. Downing Fr. Trees Am. 278 fig. 107. 1845. 9. Floy-Lindley Guide Orch. Gard. $302,383.1846$. Io. N. Y. Agr. Soc. Rpt. 343 fig. 1847. 11. Thomas Am. Fruit Cult. 325,326 fig. 254. 1849. 12. Mag. Hort. 16:454. 1850. 13. Am. Pom. Soc. Cat. 54. 1852 . 14. Elliott Fr. Book 411 . 1854 . 15. U. S. Pat. Off. Rpt. 148, P1. 5 fig. x. 1864. 16. Barry Fr. Garden 413. 1883. 17. Mathieu Nom. Pom. 443. 1889. I8. Wicl:son Cal. Fruits 355. 1891. 19. Mich. Sta. Bul. 103:34. 1894. 20. Guide Prat. 154, 364. 1895. 21. Cornell Sta. Bul. 131:187. 1897. 22. Va. Sta. Bul. 134:42, 1902. 23. Ohio Sta. Bul. 162: 239, 254, 255. 1905 .

Flushing Gage 7, 8, 11, 12, 14, 15, 17, 20. Flushing Gage 3, 9. Harper 22. Imperial Gage 17, 20. Imperial Green Gage 7. Jenkinson's Imperial 6, 14, 15. Prince's Gage 4, 12, 17. Prince's Imperial Gage 4, 5, 6, го. Prinzens Kaiser Reine Claude 20. Prince's Kaiser Reine-Cla ude 37. Prince's Imperial Gage 8, 11, 14, 15, 17, 20. Prince's White Gage 4, 12, 17. Reine-Claude de Flushings 20. Reine-Claude Imperiale 20. Reine-Claude Imperiale 17. Reine-Claude Verte Imperiale 17. Reine-Claude Imperiale de Prince 17, 20. Reine-Claude Blanche de Boston 17, 20. RcineClaude Verte Superieure 20. Superior Gage 9. Superior Green Gage 12, 14, 15, 17, 20. Superior Green Gage ? 3. Superiour Green Gage 8. White Gage ? 1, 2, 20. White Gage 14, 15 . White Gage of Boston 7, 8, 11, 17 .

Probably there is more contradictory evidence as to the value of Imperial Gage than of any other American grown plum. It is down in some of the fruit books as being the largest of all the Reine Claude plums and in others as being too small to be desirable; in some, as being of highest quality and in others as being quite too insipid to be called a dessert fruit. These contradictions have arisen because the variety grows quite differently in different soils. The Imperial Gage is best adapted to light sandy soils, growing largest and being best in quality on such soils and making the poorest show of all on heavy clay. The illustration in The Plums of New York shows it as it grows on an unsuitable soil-small, poorly colored, worthless for a money-crop and not very desirable for home use. The technical description is also based on trees grown and fruit produced on soil to which it is illy-dapted. The trees from which these fruits came are nearly perfect in habits of growth, vigorous, hardy, healthy and bearing large crops of plums-such as they are. On suitable soils the variety possesses all the qualities that constitute a fine plum, the product being adapted alike for dessert, canning, home and market. It has an especially agreeable flavor in all the various culinary preparations in which it can be used. Its capriciousness does not warrant its being largely planted but for selected locations it will prove a most valuable fruit. 
The Princes in their nursery at Flushing, Long Island, New York, about the year I790, planted the pits of twenty-five quarts of the Green Gage plum and from these produced, among others, a plum which they called the White Gage. William R. Prince, in order to distinguish this variety from the other Gage plums, changed the name to Prince's Imperial Gage, now shortened to Imperial Gage. In $185^{2}$, the American Pomological Society placed it on its catalog list of recommended fruits.

Tree large, vigorous, upright-spreading, open-topped, hardy, very productive; branches ash-gray, smooth, with conspicuous, transverse cracks in the bark, with lenticels of medium size; branchlets slender, short, with internodes above medium in length, greenish-red changing to dark brownish-red, dull, sparingly pubescent throughout the season, with small, inconspicuous lenticels; leaf-buds medium in size and length, conical, appressed.

Leaves folded upward, oval or slightly obovate, one and seven-eighths inches wide, three and one-quarter inches long, thick; upper surface dark green, rugose, pubescent, with a shallow groove on the midrib; lower surface yellowish-green, pubescent; apex abruptly pointed, base acute, margin crenate, with small dark glands; petiole one-half inch long, thick, pubescent, purplish-red along one side, glandless or with one or two small, globose, yellowish-green glands usually on the stalk.

Blooming season short; flowers one and one-eighth inches across, white; borne on lateral buds and spurs, singly or in pairs; pedicels three-quarters inch long, pubescent, greenish; calyx-tube green, campanulate, pubescent, with a swollen ring at the base; calyx-lobes above medium in width, obtuse, pubescent on both surfaces, glandularserrate, slightly reflexed; petals broadly obovate, crenate, tapering below to short, broad claws; anthers yellowish; filaments three-eighths inch long; pistil glabrous, longer than the stamens; stigma large.

Fruit intermediate in time and length of ripening season; one and nine-sixteenths inches in diameter, oval or slightly ovate, compressed, halves equal; cavity very shallow and narrow, abrupt; suture shallow, often a line; apex roundish or depressed; color dull greenish-yellow, with obscure green streaks, mottled and sometimes faintly tinged red on the sunny side, overspread with thick bloom; dots numerous, small, grayish, obscure, clustered about the apex; stem three-quarters inch long, pubescent, adhering well to the fruit; skin thin, tender, separating readily; flesh golden-yellow, juicy, firm but tender, sweet, mild; good to very good; stone nearly free, one inch by five-eighths inch in size, oval, flattened, with pitted surfaces; rather blunt at the base becoming acute in the largest fruits, very blunt at the apex; ventral suture wide, ridged; dorsal suture widely and deeply grooved.

\section{ITALIAN PRUNE}

\section{Prunus domestica}

1. Lond. Hort. Soc. Cat. 152. 1831. 2. Prince Pom. Man. 2:78. 1832. 3. Kenrick Am. Orch. 262. 1832. 4. Manning Book of Fruits 106. 1838 . 5. Am. Pom. Soc. Cat. $214,220.1856$. 


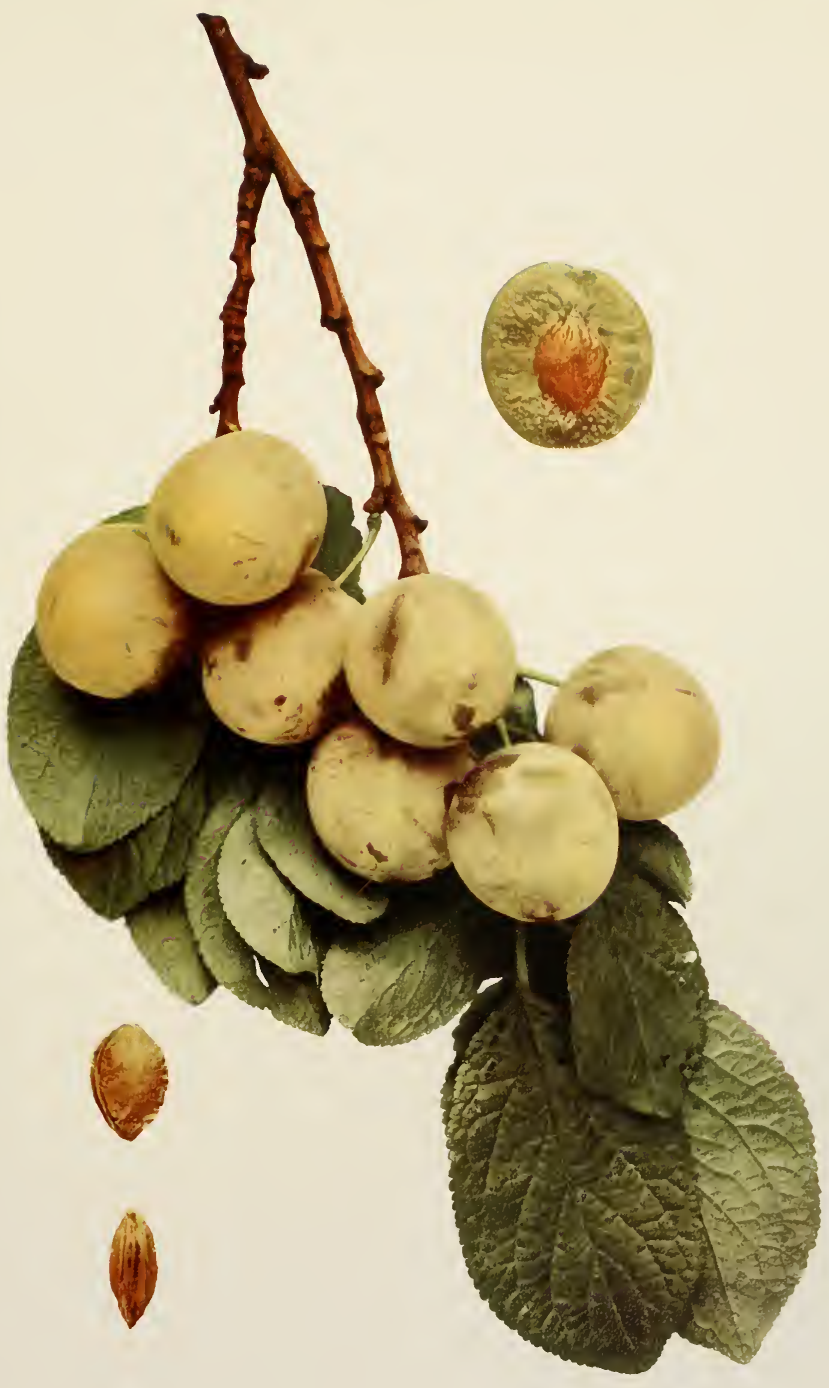



6. Downing Fr. Trees Am. $3^{81}$. 1857. 7. Cultivator 8:52 fig. 1860. 8. Hogg Fruit Man. 366. 1866. 9. Downing Fr. Trees Am. 924. 1869. 10. Pom. France 7:No. 22, fig. 1871 . 11. Mas Le Verger 6:69, fig. 35. 1866-73. 12. Oberdieck Deut. Obst. Sort. 442, 188x. 13. Lauche Deut. Pom. No. 2, P1. 4, 22, 1882. 14. Barry Fr. Garden 412. 1883. 15. Cat. Cong. Pom. France 360. 1887. 16. Mathieu Nom. Pom. 436. 1889. 17. Wickson Cal. Fruits 358. 1891. 18. Guide Prat. 155, 362. 1895. 19. Oregon Sta. Bul. 45:23 fig. 1897. 20. Cornell Sta. Bul. 131:187, fig. 44. 1897. 21. Wash. Sta. Bul. 38:7, 8. 1899. 22. W. N. Y. Hort. Soc. Rpt. 44:92. 1899. 23. Wa ugh Plum Cult. III fig. 1901. 24. U.S. D. A. Div. Pom. Bul. 10:6. rgor. 25. Mass. Sta. An. Rpt. 17:1 58.1905

Altesse Double 8, 9, 10, 15, 18. August Zwetsche 16. Auguste Zwetsche 10, 18. Blaue Riesenzwetsche 16, 18. Bleue d'Italie 15. Couetsche d'Italie 18. Cowetsche Fellenberg 10, 18. D'Italie 18. Double Blackpruim 16, 18. Fausse Altesse 16, 18. Fellemberg 14. Fellemberg 8, 16, 18. Fellenberg 5, 9, 11, 16, 18, 19, 20, 23. Fellenburg 22. Fellenberg 5, 6, 7, 9, 17. Fellenburg 25. Feltemberg 10, 18. Fellenberg Quetsche 16, 18. Fellenberger Zwetsche 12, 13, 16, 18, Grosse Fruh Zwetsche ? 16. German Prune 19, 22. Italienische Blave Zwetsche 11, 16. Italianische blane zwetsche 18. Italian Guetsche 10, 18. Italian Prune 6, 7, 10, 11, 16, 17, 18, 25. Italian Quetsche 8, 9, 15, I6. Italianische Zwetsche 18 . Italienische Pflaumen Zwetsche 16. Italienische Zwetsche I $_{1}, \mathbf{I}_{3}$. Italianische Zwetsche 10. Italianische blanc Zwetsche 10. Italienische Zwetsche 12, 13, 16. Large German Prune 17. Prune d'Italie 8, 9, 10, 16. Pflaume mit dem Pfirschenblatt 18. Pfaume Mit dem Pfirsichblatt 16. Prune Suisse 6. Quetsche 18. Quetsche Bleue d'Italie 10, 11, 16, 18. Quetsche d'Italie 1, 10, 11, 15, I8. Quetsche d'Italie 3, 8, 9, 11, 16. Schweizer Zwetsche 12, 13, 16. Schweizerzwetsche 18. Swiss Prune 17, 19, 22. Semiana 8, 10, 16, 18. Turkish Prune 22. Zwetsche von Dätlikon 16,18 .

The Italian Prune is one of the most widely grown of all plums. Its home is Italy and it is grown in all of the plum regions of continental Europe; is well known in England; is third or fourth in popularity in the Atlantic States of America; is by long odds the leading plum in the Pacific Northwest where it is chiefly used in prune-making and is grown somewhat for prunes and for shipping green in California. There are several reasons why this plum is so popular. To begin with, it is finely flavored whether eaten out of hand, stewed or otherwise prepared for the table or cured as a prune. The fruit is a little too tart to be ranked as a firstrate dessert plum and yet it is one of the best of the prunes for this purpose, though it must be fully ripe to be fit for dessert; in cooking it changes to a dark, wine color, very attractive in appearance, with a most pleasant, sprightly flavor; as a cured prune the flesh is firm and meaty, yet elastic, of good color and a perfect freestone, making when cooked the same attractive looking, fine-flavored, sprightly sauce to be had from the green fruits; the prunes from this variety, too, are noted for long-keeping. In the uncured state the variety keeps and ships well. The trees are usually large, hardy, productive, well formed and bear regularly; yet they are not ideal and the variety fails chiefly in tree-characters. The trees are often capricious to soil and climate, do not always bear well, seem to be susceptible to diseases, are preyed upon by insects and suffer in particular from dry 
or hot weather. Were all of these troubles of the tree to befall the variety at one time it would of necessity give way to better sorts, but happily they are to be found for most part in illy adapted conditions or in certain seasons; the Italian Prune well cared for in locations to which it is suited must long remain one of the leading plums despite the faults of the trees.

The Italian Prune originated in Italy at least a century ago and has long been common in northern Italy, especially in the vicinity of Milan. The London Horticultural Society catalog for $183_{3}$ first mentions it in England and the following year it was described in America by Prince as an excellent prune recently introduced from Europe. The American Pomological Society recommended it in 1856 as worthy of further testing and in 1862 it was added to the fruit catalog list of this society. The origin of the name Fellenberg, a very common synonym, is explained by Lauche ${ }^{1}$ who says: "It came to Germany through a Mr. Fellenberg and is therefore spread under his name and also under the names Schweizerzwetsche and Fellenberger Zwetsche." He further adds that the variety " is still not known in Germany as it deserves, considering its quality, size and productiveness."

Tree of medium size, rather vigorous, spreading or upright, low-topped, hardy, usually productive; branches ash-gray, smooth, with small, raised lenticels; branchlets short, with internodes of medium length, greenish-red changing to brownish-drab, pubescent, with small lenticels; leaf-buds of medium size and length, conical, appressed; leaf-scars large.

Leaves folded upward, obovate or oval, two inches wide, four and one-half inches long; upper surface dark green, pubescent; lower surface silvery-green, heavily pubescent; apex and base acute, margin doubly crenate, with small, dark glands; petiole five-eighths inch long, above medium thickness, pubescent, tinged red, with from one to three globose, greenish-brown glands usually on the stalk.

Season of bloom intermediate and short; flowers appearing after the leaves, one and three-sixteenths inches across, in the buds tinged yellow, changing to white when expanded; borne on lateral spurs, rarely on lateral buds, singly or in pairs; pedicels three-quarters inch long, thick, pubescent, greenish; calyx-tube green, campanulate, pubescent at the base; calyx-lobes long and narrow, acute or narrowly obtuse, pubescent on both surfaces and along the glandular-serrate margin, reflexed, inclined to curl at the tips; petais oval or obovate, dentate, tapering to broad claws of medium length; anthers yellowish; filaments seven-sixteenths inch long; pistil pubescent at the base, equal to the stamens in length.

Fruit late, season short; one and seven-eighths inches by one and one-half inches in size, long-oval, enlarged on the suture side, slightly compressed, halves unequal;

\footnotetext{
${ }^{1}$ La uche Deut. Pom. No. 2. 1882.
} 


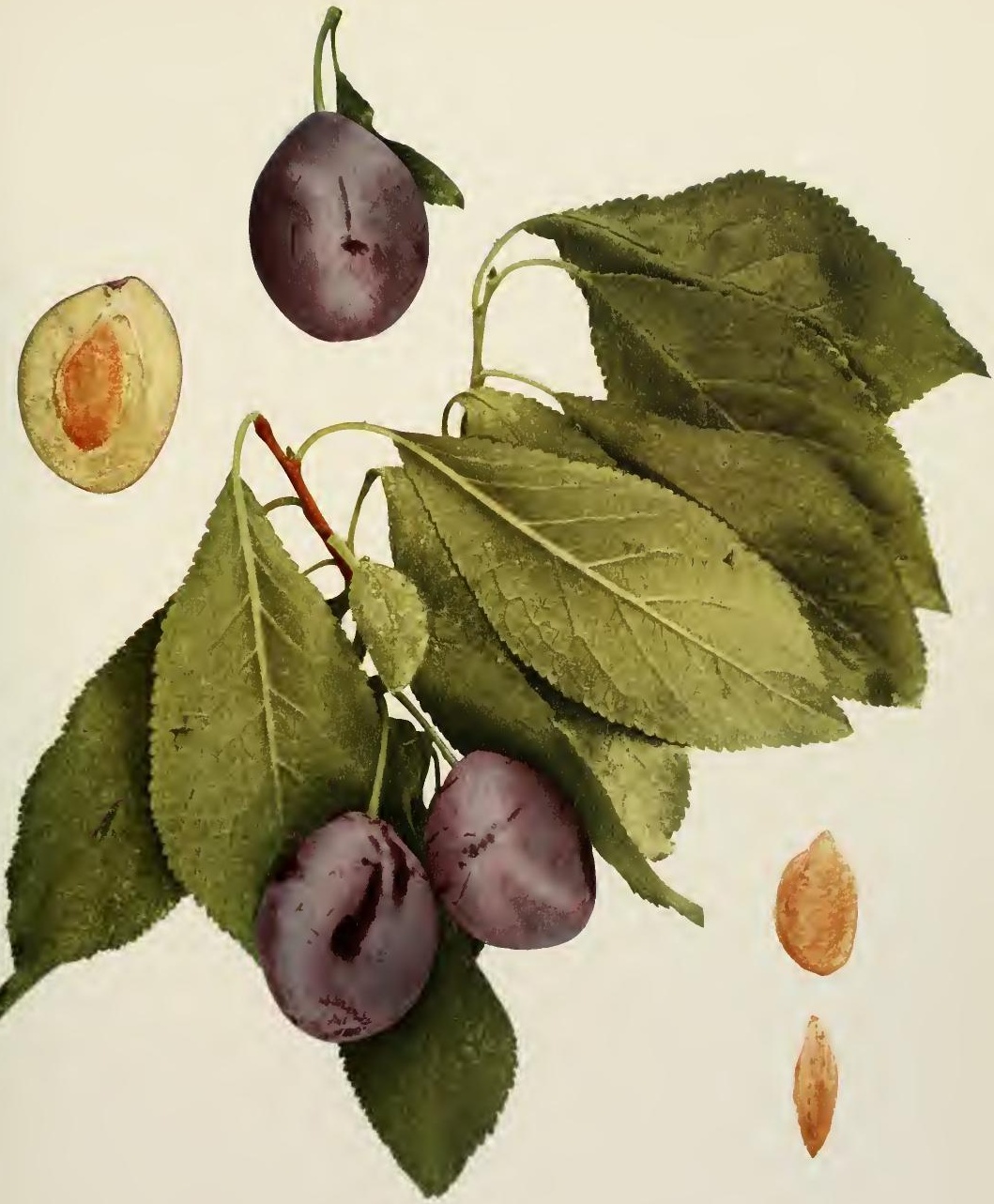



cavity very shallow and narrow, abrupt; suture shallow to medium; apex bluntly pointed; color purplish-black, overspread with very thick bloom; dots numerous, small, light brown, somewhat conspicuous; stem inserted at one side of the base, one inch in length, pubescent, adhering well to the fruit; skin thin, somewhat tough, scparating readily; flesh greenish-yellow changing to yellow, juicy, firm, subacid, slightly aromatic; very good to best; stone free, smaller than the cavity, one inch by five-eighths inch in size, irregular-oval, flattened, roughened and pitted, necked at the base, abruptly tipped at the apex; ventral suture prominent, heavily ridged, sometimes strongly winged; dorsal suture widely and deeply grooved.

\section{JAPEX}

Triflora $\times$

I. N. Y. Exp. Sta. Rpt. $12: 611$. 1893.

Japanese Seedling X. 1 .

This plum, parentage unknown, was received from Burbank by the New York Experiment Station in 1893 for testing, under the name Japanese Seedling $\mathrm{X}$. While in no way wonderfully remarkable, its earliness, attractive color, good quality and productiveness have been such that it has been retained, the cumbersome name having been changed to Japex. The majority of the characters of the variety are plainly those of Triflora, yet the fruits in appearance would lead one to call it a Domestica.

Tree very large, vigorous, vasiform, very productive; branches slender, sparingly thorny; leaf-scars thick; leaf-buds unusually short; leaves obovate or ovate, two and one-quarter inches wide, four inches long; margin finely serrate varying to crenate, with few dark glands; blooming season short; flowers appearing before the leaves; borne in clusters on lateral buds and spurs, singly or in pairs.

Fruit very early, season short; one and one-eighth inches in diameter, roundish, dark purplish-red or purplish-black, covered with medium thick bloom; flesh light yellow, very juicy, somewhat melting, sweet next to the skin, but tart near the pit, aromatic; good; stone clinging, three-quarters inch by one-half inch in size, oval.

\section{JEFFERSON}

\section{Prunus domestica}

1. Downing Fr. Trees Am. 279,280 fig. 108. 1845. 2. Horticulturist $1: 11,93.1846 .3$. Floy-Lindley Guide Orch. Gard. 420. 1846. 4. Thomas Am. Fruit Cult. 325, 326, fig. 251 . 1849. 5. Mag. Hort. 16:453 fig. 25. 1850. 6. Hovey Fr. Am. 2:1, P1. 1851. 7. Am. Pom. Soc. Cat. 54. 1852. 8. Ellintt Fr. Book 411. 1854. 9. Thompson Gard. Ass't 518, P1. 1. 1859. 10. Mas Le Verger 6:17, P1. 9. 1866-73. 11. Pom. France 7:No. 28. 1871. 12. Hogg Fruit Mant. 707. 1884. 13. Gaucher Pom. Prak. Obst. No. 95, Col. pl. 1894. 14. Cornell Sta. Bul. 131:188. 1897.

Bingham incor. 2, 8. Prune Jefferson II. 
Jefferson has long been popular in America and is highly spoken of by English, French and German pomologists as well, possibly ranking highest in the Old World of all Domesticas which have had their origin in America. The popularity of the variety is waning, however, chiefly because it is lacking in the essentials demanded in a market fruit. There can be no question as to the standing of Jefferson as to quality - it is one of the best of all dessert plums. Grown under favorable conditions and when fully ripe, it is a golden-yellow with a delicate blush and bloom, large for a plum in the Reine Claude group, a well-turned oval in shape, withal one of the handsomest plums. The color-plate maker did not do it justice. It fails as a market variety because the trees are late in coming in bearing, not always certain in bearing, a little particular as to soils and not quite hardy though one of the hardiest of all Reine Claudes. Both tree and fruit are too delicate for the market-grower and the market-men. As to its value for private places and fruit connoisseurs there can be no doubt-it is one of the choicest. It would seem that there should be a place for Jefferson for the fancy trade in the markets, as it would grace the show-window of any delicatessen store; but unfortunately there are few fruit-growers in America to cater to such a trade.

Jefferson was raised by a Judge Buel, Albany, New York, about I825. The originator presented a tree of this variety to the Massachusetts Horticultural Society in 1829 , and in 1841 trees were given to the London Horticultural Society which fruited in 1845 . The parentage of the variety is unknown; Floy thought it was a seedling of Washington; Elliott suggested that it was "from a seed of Coe's Golden Drop, which in growth and wood, it closely resembles." In $185^{2}$, the American Pomological Society placed this variety on its catalog list of fruits worthy of general cultivation.

Tree medium to large, vigorous, spreading, open-topped, hardy at Geneva, productive; branches ash-gray, smooth, with small, numerous, lenticels; branchlets slender, short, with long internodes, greenish-red changing to dark brownish-red, dull, lightly pubescent, with inconspicuous, small lenticels; leaf-buds large, long, pointed, appressed.

Leaves folded upward, obovate, one and three-quarters inches wide, three and threequarters inches long, thick; upper surface sparingly pubescent, with a grooved midrib; lower surface yellowish-green, pubescent; apex and base acute, margin serrate, with small, dark glands; petiole three-quarters inch long, tinged purplish-red along one side, glandless or with from one to three small, globose, yellowish glands usually on the stalk.

Season of bloom medium, short; flowers appearing after the leaves, one and oneeighth inches across, white; borne on lateral spurs, singly or in pairs; pedicels three- 

quarters inch long, pubescent, greenish; calyx-tube green, campanulate, glabrous, with a swollen ring at the base; calyx-lobes obtuse, pubescent on both surfaces, glandular-serrate and with fine marginal hairs, erect; petals roundish or obovate, dentate, tapering to very short and broad claws; anthers yellowish; filaments five-sixteenths inch long; pistil pubescent at the base, equal to the stamens in length.

Fruit mid-season, ripening period long; one and five-eighths inches by one and one-half inches in size, roundish-oval, not compressed, halves equal; cavity shallow, narrow, abrupt; suture very shallow, indistinct; apex roundish; color greenish-yellow, changing to bronze-yellow, sometimes with faint pink blush on the exposed cheek, often indistinctly streaked and mottled with green before full maturity; dots numerous, very small, gray or reddish, inconspicuous; stem seven-eighths inch long, thinly pubescent, adhering well to the fruit; skin thin, tough, slightly adhering; flesh deep yellow, juicy, firm but tender, sweet, mild, pleasant; very good; stone semi-free, one inch by three-quarters inch in size, flattened, broadly oval, abruptly tipped, with a short neck at the base, blunt at the apex, with rough and pitted surfaces; ventral suture heavily furrowed, winged; dorsal suture with a wide, deep groove.

\section{JUICY}

\section{Prunus munsoniana $\times$ Prunus triflora}

I. Burbank Cat. 20. 1893. 2. Cal. State Bd. Hort. 53. I897. 3. Vt. Sta. Bul. 67:15. I898, 4. Ohio Sta. Bul. I13:16r. 1899. 5. Conn. Pom. Soc. Rpt. 155. 1900. 6. Ohio Sta. Bul. 162:256. 257. 1905. 7. Mass. Sta. An. Rpt. 17:161. 1905.

Juicy has been widely tested and in general is considered of very little cultural importance, failing chiefly because of the inferior quality of the plums. The variety is an interesting cross, however, and has given a tree so much more vigorous and so much better adapted to orchard purposes than its native parent, quite equalling the Triflora parent in treecharacters, as to suggest the value of this cross for improving the trees of our native plums. This plum, like Golden, was grown by Luther Burbank from a seed of Robinson fertilized by pollen of Abundance. In I 893 the originator sold the new variety to John Lewis Childs, Floral Park, New York, who introduced it the following year. The variety has not escaped without some confusion as to its origin for its parentage has been published as a cross between Robinson and Kelsey.

Tree very large, vigorous, spreading, open-topped, productive; branches sparingly thorny; leaves broadly oblanceolate or oval, one and one-quarter inches wide, three inches long; margin finely serrate or sometimes crenate, with dark reddish-glands; petiole short, slender, with from two to five globose glands on the stalk; blooming

I Cornell Sta. Bul. 106:53. I896. 
season of medium length; flowers appearing after the leaves, three-quarters inch across; borne in dense clusters on lateral buds and spurs, in threes or fours; anthers so numerous as to give a yellowish color to the flower-clusters.

Fruit mid-season, period of ripening long; one and three-quarters inches by one and three-eighths inches in size, nearly round, dark golden-yellow with bright red blush, covered with thin bloom; flesh golden-yellow, very juicy, melting, sweet next to the skin, but tart at the pit, aromatic; of fair quality; stone clinging, five-eighths inch by one-half inch in size, oval, turgid, with slightly pitted surfaces.

\section{KELSEY}

\section{Prunus triflora}

1. Gard. Mon. 24:339. 1882. 2. U.S. D. A. Rpt. 272. 1886. 3. Gard. Mon. 29:305, 335. 367. 1887. 4. U.S. D. A. Rpt. 635, 652. 1887. 5. Am. Pom. Soc. Rpt. 95, 126. 1887. 6. Ga. Hort. Soc. Rpt. 35. 1888. 7. Ibid. 51, 99. 1889. 8. Rev. Hort. 502, 542. 189o. 9. Am. Pom. Soc. Rpt. 105, 106, 125. 189x. 10. Am. Gard. 13:700. 1892. 11. Cornell Sta. Bul, 62:3, 24. 1894. 12. Tex. Sta. Bul. 32:488 fig., 489. 1894. 13. Cornell Sta. Bul. 106:53. 1896. 14. Ala. Col. Sta. Bul. 85:447. 1897. 15. Am. Pom. Soc. Cat. 4r, 1899. 16. Waugh Plum Cult. 137. 1901. 17. N. C. Sta. Bul. 184:120. 1903. 18. Ga. Sta. Bul. 68:15, 31. 1905.

Botankin 7. Botankin 3. Hattankio 7. Kelsey's Japan 2, 3, 5. Sinomo 7. Togari 7.

Kelsey is distinguished as the largest, the latest and the tenderest to cold of all Triflora plums in America. The variety is not much hardier than the fig and cannot be safely planted north of Washington and Baltimore. The tree is vigorous, well formed and productive, having for its worst fault susceptibility to shot-hole fungus. The plums are large, very attractive in color and the flesh is firm, the plums being well fitted for shipping, with a rich, pleasant, aromatic flavor making the fruit very good in quality. In the South both curculio and brown-rot attack the fruits rather badly. It is unfortunate that this plum cannot be grown in this latitude. Kelsey, the first of the Triflora plums introduced into America, was brought into the country by a Mr. Hough of Vacaville, California, in 1870 , through the United States consul in Japan. John Kelsey of Berkeley, California, obtained trees from Hough and propagated it in his nursery to a limited extent. The first fruit was shown by Kelsey in 1877 , though fruit is said to have been produced in 1876 . In $188_{3}, W$. P. Hammon and Company, Oakland, California, secured stock of this plum from the heirs of Mr. Kelsey and the following year extensive sales were made. The plum was named in honor of the man who did most to bring it before the public. The American Pomological Society added the Kelsey to its fruit catalog list in 1889 . The following description is compiled.

Tree vigorous, upright, vasiform, tender, productive, an early and regular bearer; leaves somewhat scant, small, lanceolate, narrow; blooming season early; fruit very 


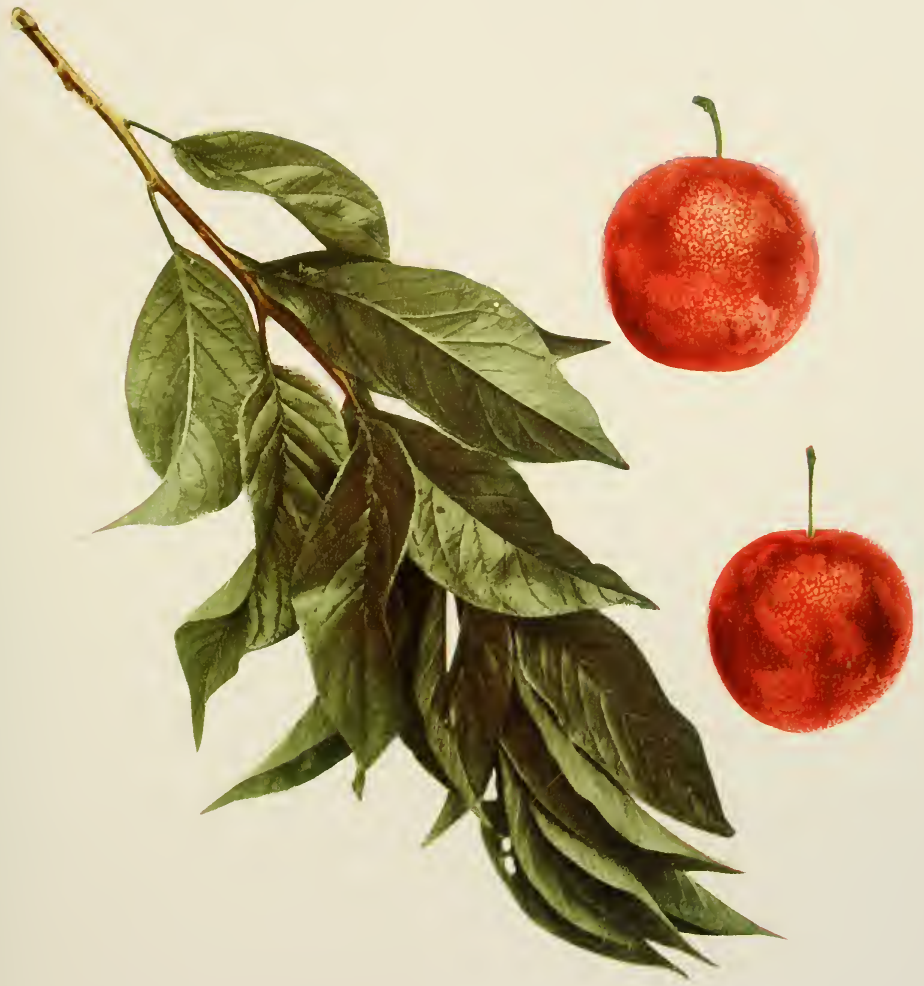



late, season long; keeps and ships unusually well; large, cordate, conical, halves unequal; suture variable in depth; apex pointed; color rather unattractive yellow, tinged and splashed with red, often overspread with purple, with attractive bloom, more or less marked with conspicuous dots; stem sometimes adhering poorly to the fruit; skin tender; flesh delicate yellow, juicy, firm and meaty, rich, pleasant, aromatic; good to very good; stone clinging unless well ripened, small, in an irregular cavity larger than the pit.

\section{KERR}

\section{Prunus triflora}

1. Ga. Hort. Soc. Rpt. 52. 1889. 2. Am. Gard. 12:307, 501. 189r. 3. Ibid. 13:700. 1892. 4. Kerr Cat. 1894. 5. Cornell Sta. Bul. 62:25. 1894. 6. Ga. Hort. Soc. Rpt. 95. 1895. 7. Ala. Sta. Bul. 85:443. 1897. 8. Am. Pom. Soc. Cat. 4r. 1899. 9. Cornell Sta. Bul. 175:1 36. I899. 1o. Waugh Plum Cult. 137. 1901. 11. Ga. Hort. Soc. Rpt. XIII. 1904. 12. Ohio Sta. Bul. $162: 256,257$. 1905 .

Hattankio 1. Hattankio 7. Hattankin No, 2, 2, 3. Hattonkin No. 2. 4, 5, 10. Hattonkin 9. Hattankio No. 2. 6, Ir. Hattankio Oblong 9, Ir. Hattankio ro. Hattan ro. Hytankio ro. Hytan-Kayo ro.

Kerr is about the best of the yellow Trifloras and is one of the best of all early plums of its species. It is very productive, sometimes overbearing, and should always be thinned. The quality of the plums is good and the fruits are attractive in appearance. The faults of the variety are that the fruits drop as they ripen, though they color if picked green, and in some localities the tree-characters are poor. This variety was imported from Japan by Frost and Burgess, Riverside, California, and was distributed under the group name Hattankio No. 2 or Hattonkin No. 2. As Georgeson was also distributed under the same name, though under a different number, confusion resulted. To better distinguish between the two, L H. Bailey, in I894, named Hattonkin No. 2 Kerr, in honor of J. W. Kerr, the noted plum specialist, of Denton, Maryland. In r899 the variety was placed on the fruit catalog list of the American Pomological Society. The following description is compiled.

Tree large, vigorous, upright, very productive; leaves large, thick; blooming season late. Fruit early; of medium size unless thinned, when it becomes large, variable in form, but usually heart-shaped, yellow with thin bloom; skin thick; flesh yellow, firm, subacid, sweet; fair to good; stone clinging, of medium size, oval, turgid.

\section{KING DAMSON}

\section{Prunus insititia}

1. Watkins Nur. Cat. 48. 1892 ?. 2. Am. Gard. 14:146, 147. 1893. 3. Garden 53: 265. 1898. 4. Can. Exp. Farm Bul. 2nd Ser. 3:51. 1900. 5. Thompson Gard. Ass't 4:161. 1901.

Bradley's King 5. Bradley's King of Damsons 3. King of Damsons I, 2. 
The fruit of King Damson runs large for a Damson and the flavor is agreeable, so agreeable that the variety is really a very good dessert fruit late in the season. This Damson is little grown in America and deserves much wider cultivation. A peculiarity of the plum is that there is always more or less doubling of the petals. Very little is known regarding the history of this excellent variety, but it seems probable that it originated in Kent, England, where it is much grown.

Tree small, lacking in vigor, upright-sprcading, dense-topped, usually productive; branchlets slender, pubescent; leaves folded upward, oval or slightly obovate, one inch wide, two and three-quarters inches long; margin serrate, usually with small dark glands; petiole with one or two glands on the stalk; blooming season intermediate, short; flowers appearing after the leaves, usually with more than five petals, one inch across, white with a yellow tinge at the apex; borne on lateral spurs or from lateral buds, singly or in pairs.

Fruit late, season long; one and one-eighth inches by seven-cighths inch in size, oval, slightly necked, black, with thick bloom; flesh greenish-yellow, juicy, firm, sprightly becoming sweet late in the season; of good quality; stone clinging, five-eighths inch by three-eighths inch in size, irregular-ovate, slightly necked.

\section{KIRKE}

\section{Prunus domestica}

1. Pom. Mag. 3:111, Pl. 1830. 2. Lond. Hort. Soc. Cat. 149. 1831. 3. Kenrick Am. Orch. 263. $188_{32}$. 4. Downing Fr. Trees Am. 306. 1845. 5. Floy-Lindley Guide Orch. Gard. $281,382$. 1846. 6. Mag. Hort. 15:488 fig. 43. 1849. 7. Thompson Gard. Ass't ${ }_{5} 18$, Pl. I. 1859 . 8. Mas Le Verger 6:15, fig. 8. 1866-73. 9. Am. Pom. Soc. Cat. 36. 1875. 1o. Pom. France $7:$ No. 26. 1871. 11. Flor. \& Pom. 47. 1876. 12. Oberdieck Deut. Obst. Sort. 430. 1881. 13. Lauche Deut. Pom. 16, P1. IV. 1882. 14. Hogg Fruit Man. 708. 1884. 15. Guide Prat. 154, 358. 1895. 16. Gard. Chron, 24:19. 1898. 17. Gaucher Pom. Prak. Obst. No. 96, Col. Pl. 1894. 18. Rev. Hort. 500. 1898. 19. Soc. Nat. Hort. France Pom. 536, 1904.

De Kirke 15. Kirke's 2, 4, 6, 7, 9, 14, 17. Kirke's 8, 10, 15, 17. Kirke's Pflaume 12, 13. Kirke's Pflaume 8, 10, 15, 17. Kirke's Plum 1, 5, 8, 10, 11, 16, 18. Kirk's Plum 3, 5. Kirke 17. Kirke's Plum I5, 17, 19. Prune de Kirke 18. Prune de Kirke 8, 10, 17. Prune Kirke 19.

All English descriptions of this variety rank it very high both as a dessert and a culinary plum. The variety stands well among the purple plums growing on the grounds of this Station, but since it has been grown in America eighty years, attaining a reputation only of being mediocre in most characters, it is probably not worth planting largely. It has many more worthy competitors in its class and season. Hogg, in the reference given, says the variety was introduced by Joseph Kirke, a nurseryman at Brompton, near London, who, he says, "told me he first saw it on a fruit stall near the Royal Exchange, and that he afterwards found the 
trees producing the fruit were in Norfolk, whence he obtained grafts and propagated it. But its true origin was in the grounds of Mr. Poupart, a market gardener at Brompton, on the spot now occupied by the lower end of Queen's Gate and where it sprung up as a sucker from a tree which had been planted to screen an outbuilding. It was given to Mr. Kirke to be propagated and he sold it under the name it now bears." The variety was introduced into America between 1830 and 1840 . The American Pomological Society placed Kirke upon its list of rejected fruits in 1858 , added it to the recommended list in 1875 , and displaced it in 1899.

Tree large, vigorous, upright-spreading, hardy, productive; branchlets with long internodes, dull, marked with yellowish-brown searf-skin; leaf-buds large, long, pointed, free; leaves flattened, obovate or oval, one and three-quarters inches wide, three and five-eighths inches long, thick, dark green; margin crenate, eglandular or with small, dark glands; petiole one inch long, tinged red, glandless or with from one to four small, yellowish-green glands; blooming season intermediate, short; flowers appearing after the leaves, one inch across; borne on lateral spurs, singly or in pairs; filaments sevensixteenths inch long; pistil glabrous, shorter than the stamens.

Fruit mid-season, ripening period long; about one and five-eighths inches in diameter, roundish-ovate, dark purplish-black, overspread with thick bloom; flesh greenishyellow, fibrous, firm, sweet, mild and pleasant; good to very good; stone nearly free, one inch by three-quarters inch in size, ovate or oval, flattened, roughened and deeply pitted, tapering abruptly to a short, pointed apex; ventral suture narrow, with a short but distinct wing; dorsal suture with a wide groove.

\section{LAFAYETTE}

\section{Prunus domestica}

I. Prince Pom. Man. 2:96. 1832. 2. Tucker's Gen. Farmer 3:153. 1839. 3. Elliott Fr. Book 427. 1854. 4. Am. Pom. Soc. Rpt. 222, 244. 1858. 5. Hogg Fruit Man. 368. 1866. 6. Downing Fr. Trees Am. 916. 1869. 7. Guide Prat. 160, 359. 1895.

Gifford's Lafayette 1, 4, 6. Gifford's LaFayette 2, 3.

Lafayette originated in New York sometime in the first quarter of the last century with a Mr. Gifford from a stone of the Orleans. It did not become popular and was rejected by the American Pomological Society in $185^{8}$, but just why it failed is not apparent, judging either from the descriptions given in the above references or by its behavior in the orchard at this Station. The fruit is good, though not remarkable for the richness of its flavor, its size is large and the color attractive. Moreover it is so late as to stand almost alone in its season. A retrial of this old sort commercially might be worth while. The tree is interesting because of a marked tendency in the flowers to develop petals from the stamens. 
Tree of medium size, round-topped, productive; branchlets stocky, with long internodes; leaf-scars large; leaves folded upward, oval or obovate, two inches wide, four inches long, rugose; margin crenate, with small, dark glands; petiole pubescent, tinged red, having at the most three small glands usually on the stalk; blooming season intermediate in time and length; flowers appearing after the leaves, one and one-quarter inches wide, creamy-white; borne in pairs; calyx-lobes long and slender.

Fruit very late, season long; one and one-half inches by one and three-eighths inches in size, oval, purplish-black, overspread with very thick bloom; flesh greenish-yellow, medium juicy, tender, sweet, mild and pleasant; of good quality; stone free or nearly so, one inch by five-eighths inch in size, irregular-oval, flattened, with an acute and slightly oblique apex.

\section{LAIRE}

\section{Prunus orthosepala?}

Laire is cultivated locally in Rooks and neighboring counties in Kansas and is highly spoken of by those who grow it. The description of the variety is made from information sent from the United States Department of Agriculture. For a further account of this plum the reader is referred to the discussion of Prumus orthosepala, page 97. The name is derived from that of the man who first brought the plums under cultivation some twenty or twenty-five years ago.

Tree dwarfish, dense-topped, not very productive; branches spiny, zigzag; branchlets thick, reddish-brown changing to dark brown; leaves oblong-ovate, light green. acuminate, with margins closely serrate and seldom with glandular teeth; petiole slender, one-half inch long, with two glands at the apex; flowers white or tinged with pink, appearing after the leaves; borne in threes or in fours; pedicels thick, one-half inch long; petals narrowly clawed; stamens orange.

Fruit mid-season; one and one-eighth inches in diameter, roundish, greenish-yellow overlaid with deep red, covered with thick bloom; skin thick; flesh yellow, meaty, juicy, mild subacid; good to very good; stone clinging, five-eighths inch by nine-sixteenths inch in size, flattened, oval, with rugose surfaces: grooved on the dorsal and ridged on the ventral suture.

\section{LARGE ENGLISH}

\section{Prunus domestica}

I. Oberdieck Deut. Obst. Sort. 443. 1881. 2. Mathieu Nom. Pom. 429, 433. I889.

Englische Zwetsche 2. Grosse Englische Zwetsche 2. Grosse Englische Zwetsche 1, 2. Grosse Englische Pflaumen Zwetsche 2. Grosse Zwetsche ?2. Schweizer Zwetsche 2 incor.

This appears to be a most excellent plum closely resembling the Italian Prune and surpassing that well-known variety in some respects. As compared with Italian Prune, the fruit of Large English runs larger, is 
slightly more conical, having the ventral swelling near the base, thus giving it more of a shoulder. The flavor is sweeter and richer than that of the Italian Prune. There appear to be practically no differences between the trees, the foliage and the flowers of the two kinds. Wherever the Italian is successfully grown it may be well worth while to try the Large English. The relation the word English has to this prune is unknown. Oberdieck, in $188 \mathrm{I}$, wrote that this variety resembled the Italian Prune in frut, but differed in that it had a noticeably broader leaf; he adds "it has bcen incorrectly called the Swiss Prune and is much spread in Germany under the name of Italian Prune." E. R. Lake, of the United States Department of Agriculture, brought it to America, in I90I, from the Pomological Institute, Reutlingen, Wurtemburg, Germany. Lake's stock was tested at this Station and the variety agrees with Oberdieck's description.

Tree of average size. vigorous, upright-spreading, dense-topped, productive; branchlets with long internodes; leaf-scars enlarged; leaves folded upward, oval or obovate, nearly one and three-quarters inches wide, three and one-half inches long, thick, rugose; margin crenate or almost serrate, eglandular or with small dark glands; petiole pubescent, tinged red, with from two to four globose glands; blooming season intermediate in time, short; flowers appearing after the leaves, one inch across; petals long, narrow, white, in the buds tipped with yellow; borne singly or in pairs; stamens tend to become petals.

Fruit late, season of medium length; one and three-quarters inches by one and one-half inches in size, long-ovate, purplish-black, with thick bloom; dots numerous, conspicuous; flesh yellowish with a trace of red at full maturity at both skin and stone, juicy, very sweet, aromatic, with a pleasant flavor; very good to best; stone free, the cavity larger than the pit, often brownish-red, one inch by five-eighths inch in size, irregular-oval, flattened, with an oblique apex; ventral suture prominent, usually with a distinct wing; dorsal suture with a wide, deep groove.

\section{LATE MIRABELLE}

\section{Prunus insititia}

1. Lond. Hort. Soc. Cat. 150. 1831. 2. Barry Fr. Garden 339. 1851. 3. Downing Fr. Trees Am. 388. 1857. 4. Hogg Fruit Man. 353. 1866. 5. Downing Fr. Trees Am. 901. 1869. 6. Pom. France 7: No. 20. 1871. 7. Mas Le Verger 6:7. 1866-73. 8. Cat. Cong. Pom. France 352. 1887. 9. Mathieu Nom. Pom. 442, 449. 1889. 10. Guide Prat. 162, 360. 1895. 11. Baltet Cult. Fr. 493. 1908 .

Bricetta 9. Bricetta 5. Bricet 5, 9. Bricette 6, 8, 10. Brisette 6,7, 10. Bricette 4. Die Brisette 9. Kleine Brisette 9. La Bricette 9. Mirabelle Tardive $1,3,6,7,8$, 10, I1. Mirabelle Tardive 4, 5, 6, 9. Mirabelle d'Octobre 2. Mirabelle d'Octobre 4, 5, 6, 8, 9, 10. October Mirabelle 9. Petit Bricette 5, 9. Petite Bricette 4, 6, 10. Runde Brisette 9. Späte Mirabelle 6, 8, 9, 10.

In France, where all of the Mirabelles are highly esteemed, the Late Mirabelle is much grown because of its season. The variety is practically 
unknown in America, but, judging from its behavior at Geneva, well deserves widespread trial, as do all the Mirabelles. The history of this variety is unknown other than that it is an old sort, having been mentioned in the London Horticultural Society catalog as long ago as 1831 . In 1851 , Barry, of Rochester, New York, described the Mirabelle d'Octobre, which is identical with Late Mirabelle, and said that it had been recently introduced from France.

Tree medium in size and vigor, very hardy, productive; branches smooth; leaves small, oval, one and one-quarter inches wide, two inches long; margin finely serrate, with few, dark glands; petiole slender, glandless or with one or two glands at the base of the leaf.

Fruit late; small, roundish-oval, greenish-yellow, often with a light blush on the sunny side, covered with thin bloom; stem short, slender; flesh yellow, very juicy, aromatic, sweet; good; stone semi-free.

\section{LATE MUSCATELLE}

\section{Prunus domestica}

1. Lucas Vollst. Hand. Obst. 470. 1894. 2. Can. Exp. Farm Bul. and Ser. 3:53. 1900. 3. U. S. D. A. Div. Pom. Bul. 10:22, 1901.

Late Muscatel 2. Späte Muskateller 3. Späte Muskatellerpflaume 1.

This variety was obtained by the United States Department of Agriculture from the Pomological Institute at Reutlingen, Germany, in 1900, and was soon after sent to this Station to test. In some respects, in fruitcharacters in particular, the variety is promising, but not sufficiently so to recommend it to fruit-growers, even for trial.

Tree of medium size and vigor, upright-spreading, productive; branchlets thick; with short internodes, pubescent; leaf-scars prominent; leaves drooping, folded upward, obovate, one and five-eighths inches wide, three and three-eighths inches long, leathery; margin crenate, eglandular or with few, small, dark glands; petiole thick, pubescent, glandless or with from one to three glands; blooming season intermediate in time; and length; flowers appearing after the leaves, one inch across; borne in scattering clusters, singly or in pairs; petals white, creamy-white as they open; anthers tinged red.

Fruit late, season short; medium in size, roundish, slightly truncate, purplishbrown, splashed and mottled with russet about the base, overspread with thick bloom; flesh greenish-yellow, sweet; good to very good; stone often reddish, clinging, threequarters inch by one-half inch in size, somewhat flat, irregular-oval, with slightly pitted surfaces. 


\section{LATE ORLEANS}

Prunus domestica

1. Lond. Hort. Soc. Cat. 151. 1831. 2. Mag. Hort. 164. 1843. 3. Jour. Hort. N. S. 15: $30 x$. 1868. 4. Downing Fr. Trees Am. 927. 1869. 5. Guide Prat. 161, 360. 1895. 6. Garden 49:268. 1896. 7. Rivers Cat. $33 . \quad 1898$.

Black Orleans 1, 2, 5. Late Black Orleans 3, 4. Late Black Orleans 5. Late Orleans 5. Monsieur Noir Tardif 5. Orleans Late Black 5.

This is another variety having only a European reputation to recommend it in America. The fruits of Late Orleans are handsome in color and shape, but are not large enough to enable them to compete in the markets with other late purple plums and are so poor in quality as to be worthless as dessert fruits. In Europe the variety is rated high for culinary purposes and fruit-growers there like it because it hangs well to the tree and keeps and ships well. The trees are very satisfactory in practically all respects. It is doubtful if the variety is worth further trial in America.

Late Orleans was mentioned in the catalog of the Horticultural Society of London in $183 \mathrm{r}$, but was not described. No account seems to have ever been published of its origin, but it is probably related to or descended from the Orleans since they are very similar in tree and shape of fruit, differing only in size and color of fruit.

Tree large, vigorous, round-topped, hardy, very productive; branches smooth, dark ash-gray, with numerous, small lenticels; branchlets medium to slender, with long internodes, greenish-red changing to dull reddish-brown, dull, pubescent, marked with gray scarf-skin and with small lenticels; leaf-buds intermediate in size and length, conical, appressed.

Leaves flattened, oval or obovate, one and one-quarter inches wide, two and onequarter inches long; upper surface sparingly pubescent, with a deeply grooved midrib; lower surface heavily pubescent along the midrib; apex abruptly pointed, base broadly cuneate, margin finely crenate, with small, dark glands; petiole one-half inch long, slender, pubescent, faintly tinged with red, glandless or with from one to four small, globose, yellowish glands usually on the stalk.

Flowers appearing after the leaves, one inch across, white; borne on lateral buds and spurs, singly or in pairs; pedicels one-half inch long, glabrous, greenish; calyxtube, green, obconic, glabrous; calyx-lobes obtuse, pubescent, glandular-serrate and with marginal hairs, erect; petals roundish or broadly ovate, entire, short-clawed; anthers yellow with a reddish tinge; filaments five-sixteenths inch long; pistil glabrous, equal to the stamens in length.

Fruit late, season long; about one and one-half inches in diameter, roundish, slightly compressed, halves equal; cavity shallow, narrow, flaring; suture a line; apex roundish; color dark purple, overspread with thick bloom; dots few, reddish-brown; stem three- 
quarters inch long, pubescent at the base, adhering well to the fruit; skin toughish, slightly astringent, separating readily; flesh golden-yellow, dry, tender, sweet, mild; fair in quality; stone clinging, one inch by five-eighths inch in size, oval, flattened, slightly roughened, blunt at the base and apex; ventral suture rather narrow, blunt; dorsal suture widely and deeply grooved.

\section{LAWRENCE}

\section{Prunus domestica}

x. Cultivator x0:167. 1843. 2. Am. Pom. Soc. Cat. 54 1852. 3. Elliott Fr. Book 412. 1854. 4. Downing Fr. Trees Am. 928, 1869. 5. Pom. France 7: No. 29. 1871. 6. Mas Le Verger 6:75. 1866-73. 7. Hogg Fruit Man. 710. 1884. 8. Cat. Cong. Pom. France 349. 1887. 9. Guide Prat. 364. 1895. 10. Waugh Plum Cult. 112. 1901.

Favorite de Lawrence 6, 9. Lawrence Favorite 5. Lawrences Reine Claude 9. Lawrence's Favorite I, 2, 3, 4, 7. Lawrence's Gage $1,3,4,6,7,9$. Lawrence's Favorite 6, 8, 9, 10. Lawrence Gage 8. Prune Lawrence Gage 5. Reine-Claude de Lawrence 6, 9. Reine-Claude de Lawrence 4, 5, 8.

This variety is surpassed in the quality of its fruits by few plums. The trees bear young and abundantly and the fruit hangs well on the tree; unfortunately, the plums do not ship nor keep well and the variety thus fails as a market sort. It is, however, a delicious dessert fruit, deserving to be grown in every plum connoisseur's garden. Lawrence is a seedling of Reine Claude, and was grown by L. V. Lawrence of Hudson, New York, some time during the second quarter of the last century. As its large size and superior quality became known its popularity increased, until it was cultivated not only in America, but to some extent throughout western Europe. During the last twenty-five years, however, it has waned in popularity, having been superseded by better commercial varieties, though it still ranks high as a dessert plum. The American Pomological Society placed Lawrence in its catalog in $185_{2}^{2}$, and retained it there until 1899.

Tree large, vigorous, upright-spreading, productive; trunk and branches rough, with large lenticels; branchlets brash, dark reddish-brown, pubescent; leaves folded upward, oval, two inches wide, three and three-quarters inches long, thick, leathery, rugose; margin doubly serrate, with small glands; petiole pubescent, usually with two small glands.

Fruit medium early; one and three-eighths inches in diameter, roundish, greenishyellow, covered with thin bloom; skin thin, tender, slightly astringent; flesh yellowish, fibrous, tender, sweet, aromatic; very good; stone free, seven-eighths inch by fiveeighths inch in size, oval, turgid, nearly smooth.

\section{LINCOLN}

\section{Prunus domestica}

1. Lovett Cat. fig. 44. 1890-1900. 2. Rural N. Y. 56:595 fig. 253, 598. 1897. 3. Mich. Sta. Bul. 169:242, 246. 1899. 4. Ohio Sta. Bul. 113:159. I899. 5. Can. Exp. Farm Bul. 2d Ser. $3: 53$. 


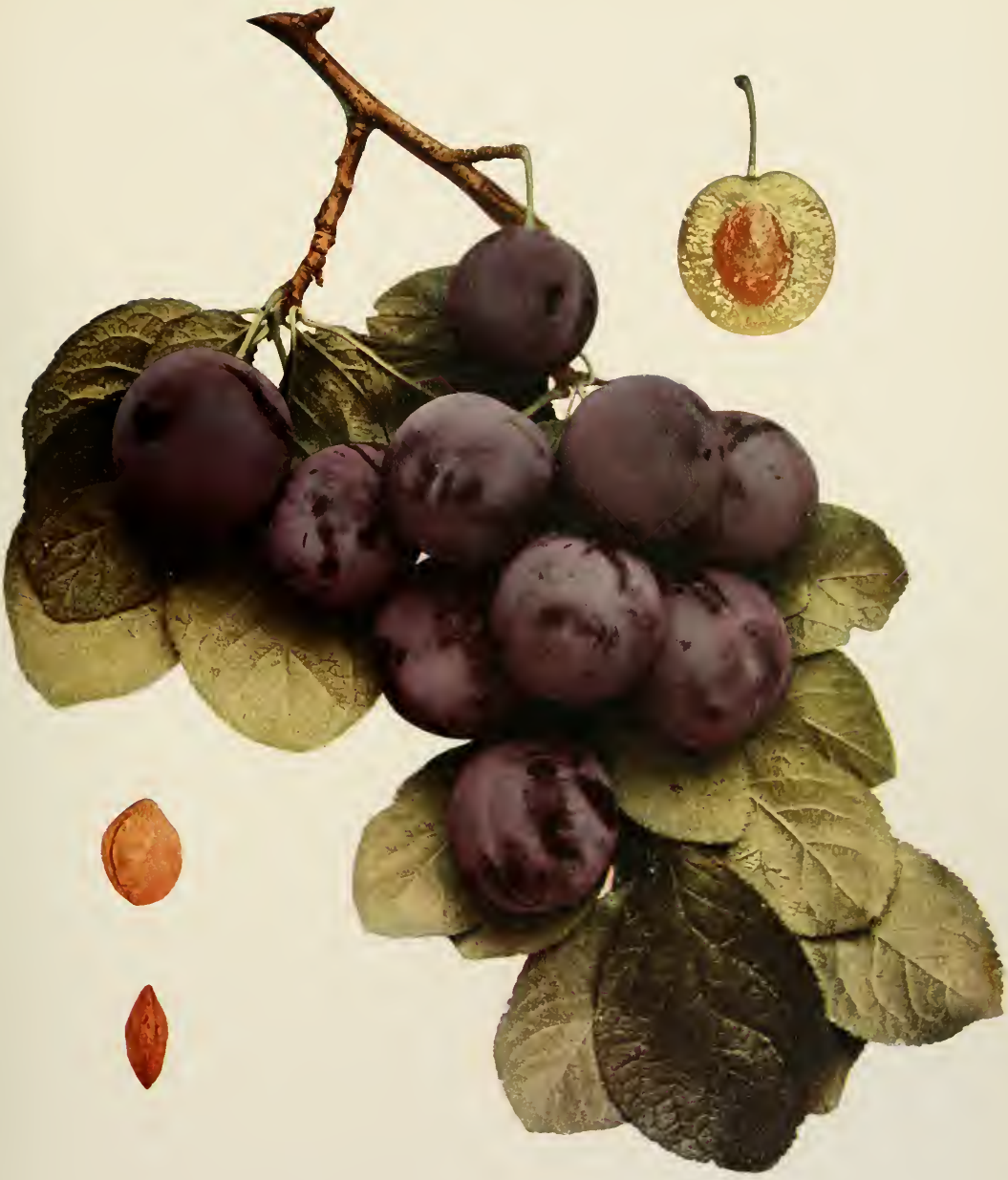



1900. 6. Waugh Plum Cult. 114. 190r. 7. Budd-Hansen Am. Hort. Man. 317, 318 fig. 1903. 8. Am. Pom. Soc. Rpt. 254. 1903. 9. Ohio Sta. Bul. 162:236, 238 fig., 256, 257. 1905. 10. Mass. Sta. An. Rpt. 17:159. 1905.

Lincoln has never been popular in New York, but in Pennsylvania and New Jersey it is well thought of for home use and the markets. The trees in this State grow slowly and when fully grown are rather inferior. This is one of the sorts recommended to be top-worked on better growing varieties but, as has been said before in these notes, top-working in New York is far more often a failure than a success with plums. The fruit of this variety is unusually attractive in size and color and for quality it may be named among the best of the red plums. Unfortunately, the variety is readily infected by the brown-rot which when epidemic cannot be controlled. Lincoln has been so well tested in New York without becoming popular with plum-growers that it is hardly worth recommending for further trial, though the fruits in particular have much merit.

This plum originated in York County, Pennsylvania, about fortyfive years ago, supposedly from seed of the Reine Claude, and was named after Abraham Lincoln. If it be a Reine Claude seedling it comes from a cross with some other variety, since it shows many characters not in Reine Claude. Lincoln was introduced by J. T. Lovett and Company, Little Silver, New Jersey.

Tree of medium size, vigorous, upright-spreading, but somewhat variable in habit, dense-topped, hardy, productive; branches ash-gray, rough; branchlets somewhat slender, short, with long internodes, greenish-red changing to brownish-red, dull, sparingly pubescent throughout the season, overspread with thin bloom, with small, inconspicuous lenticels; leaf-buds large, long, pointed, free; leaf-scars prominent.

Leaves somewhat folded backward, oval or obovate, two inches wide, four inches long, rather stiff; upper surface slightly rugose, pubescent only in the shallow, grooved midrib; lower surface silvery-green, pubescent; apex abruptly pointed, base acute, margin doubly crenate, with small, dark glands; petiole nearly one inch long, pubescent, reddish, with from one to four rather large, globose or reniform, yellowish glands variable in position.

Season of bloom medium; flowers appearing after the leaves, over one inch across, white; borne on lateral spurs and buds, singly or in pairs; pedicels about seven-eighths inch long, slender, pubescent, greenish; calyx-tube green, campanulate, thinly pubescent; calyx-lobes broad, acute, somewhat pubescent on both surfaces, glandular-serrate, with marginal hairs, reflexed; petals oval, crenate, with claws of medium width; anthers yellow; filaments three-eighths inch or more in length; pistil glabrous, shorter than the stamens.

Fruit early, season short; somewhat variable but averaging about two inches by one and five-eighths inches in size, oblong-oval, slightly necked, halves usually equal; 
cavity very shallow, narrow, abrupt; suture shallow; apex roundish or depressed; color light or dark red over a yellow ground, overspread with thin bloom; dots numerous, small, light russet; stem one inch long, lightly pubescent, adhering poorly to the fruit; skin thick, rather sour, separating readily; flesh greenish-yellow, juicy, coarse and fibrous, firm but tender, sweet, mild, pleasant; good to very good; stone nearly free, one and one-eighth inches by five-eighths inch in size, long-oval, flattened, necked at the base, blunt at the apex, with markedly rough and deeply pitted surfaces; ventral suture narrow, distinctly furrowed, with a short wing; dorsal suture with a narrow groove of medium depth.

\section{LOMBARD}

\section{Prunus domestica}

1. Kenrick $A m$. Orch. 268.1832 . 2. Ibid. 224. I 841 . 3. Downing Fr. Trees $A m .303$ fig. 124. I845. 4. Thomas Am. Fruit Cult. 345 fig. 265. 1849. 5. Goodrich N. Fr. Cult. 84. I849. 6. Elliott Fr. Book 412. I854. 7. Am. Pom. Soc. Rpt. 190, 210. 1856. 8. Downing Fr. Trees Am. 929 fig. 1869. 9. Mas Le Verger 6:151, fig. 76. 1866-73. ro. Country Gent. 48:981, 1883. r1. Mathieu Nom. Pom. 423. 1889. 12. Guide Prat. 160, 359. 1895. 13. Mich. Sta. Bul. 169:242, 246. 1899. 14. Ia. Sta. Bul. 46:279. 1900. 15. Waugh Plum Cult. I14 fig. 1901. 16. Can. Exp. Farm Bul. 43:34. 1903. 17. Ohio Sta. Bul. 162:240, 256, 257. 1905.

Beekman's Scarlet 3, 6, 8, I I, I2. Bleecker's Scarlet 3, 4, 6, 8, I2. Bleeker's Scarlet II. Bleeker's Rotepflatume Ir. Bleekers Rothe Pflaume 12. Bleeckers Rothe Pflaume 9. Lombard 11. Lombard Plum 1. Montgomery Prune 8, Ix. Prune Rouge De Bleeker 9, Ix. Rouge de Bleecher 12. Spanish King ? I4, I5. Variegated Plum I.

The Lombard plum is known by all. It is not as largely planted in New York as a few other varieties, but it is probably more widely grown than any other plum if the whole continent be considered. The preeminently meritorious characters which enable it to take first place in American plumgrowing are: The elasticity of its constitution whereby it adapts itself to widely different soils and climates; the robustness, healthiness, productiveness and regularity in bearing of its trees; the fact that the fruits are comparatively free from the scourge of the crescent sign, plum-curculio; and, lastly, its showy fruits tempting to the eye and readily salable. The tree-characters of Lombard are all good, making so superior a tree that it, more than any other variety, is recommended as a stock upon which to graft weak-growing plums. It is a virile variety and from it have come a considerable number of offspring mostly from self-fertilized seeds which have given us several nearly related varieties and strains. There are also a few very good cross-bred plums of which Lombard was one parent. Lombard would be preeminently the plum "for the millions" were it not for a fatal fault-it is very poor in quality. Canned, cooked, preserved or spiced, it does very well, but as a dessert fruit it falls in a 


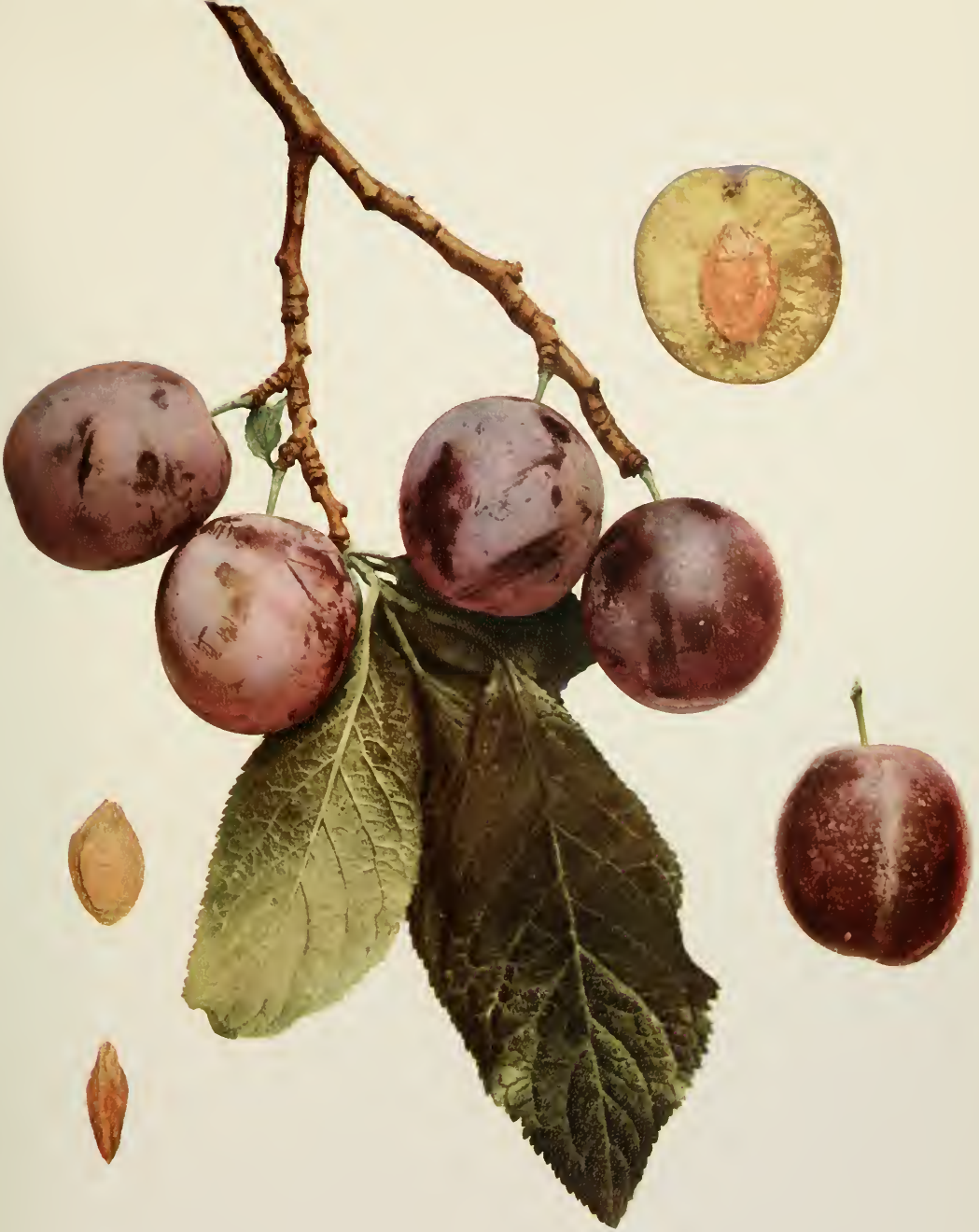



category with the Ben Davis apple and Kieffer pear, "good-looking but poor." The variety ripens so early as to come in direct competition with the peach and this hurts it not a little as a market plum. To be at its best the crop should be thinned and should be allowed to ripen fully on the trees. Lombard is now much used in the canneries in New York and is also planted in home orchards where only hardy plums stand the climate. In the markets it is usually a low-priced plum.

Lombard was raised by Judge Platt, Whitesboro, New York, from seed received from Amsterdam (References, 2). Another writer (References, Io) reports that the trees were brought over from Holland by some of the earliest Dutch settlers of Utica and Whitesboro. The name was given to the plum about 1830 by the Massachusetts Horticultural Society in honor of Daniel Lombard of Springfield, who was the first to propagate the variety in that state. It was previously well known in New York as Bleecker's Scarlet (References, 3), but was never formally described under that name which must, therefore, though the older, be discarded. In 1856 , it was placed on the recommended list by the American Pomological Society. Several varieties, as Communia, Tatge, Spanish King and Odell, are very similar, if not identical to the Lombard and, consequently, have caused much confusion in the nomenclature of the variety. This similarity is probably explained by the fact that the Lombard produces seedlings very nearly true to type. Professor J. L. Budd, in a letter written in 1898 to this Station, says, "The fruit of Communia is much like that of Lombard, but this can be said of a hundred or more east European varieties." Professor Budd had traveled much in Europe and knew plums very well. His statement, therefore, is entitled to credence and indicates, together with other circumstances, that Lombard is one of an old group of plums the varieties of which are very similar.

Tree of medium size, round-topped, very hardy, productive; branches stocky, dark ash-gray, smooth, with few, small lenticels; branchlets thick, medium to long, with long internodes, greenish-red changing to dull brownish-red, marked with gray scarf-skin, glabrous early in the season, becoming pubescent at maturity, with a few, inconspicuous, small lenticels; leaf-buds of medium size and length, conical, appressed; leaf-scars prominent.

Leaves long-oval or long-obovate, one and five-eighths inches wide, three and onehalf inches long, medium to thick; upper surface dark green, thinly pubescent, with a grooved midrib; lower surface silvery-green, lightly pubescent; apex acute, base somewhat tapering, margin often doubly serrate, eglandular or with small, dark glands; 
petiole one-half inch long, thick, tinged red, pubescent, glandless or with one or two globose, yellowish-green glands usually at the base of the leaf.

Blooming season short; flowers appearing after the leaves, one inch across, the buds creamy-yellow, changing to white on expanding; borne in clusters on short, lateral spurs, singly or in pairs; pedicels nine-sixteenths inch long, slender, nearly glabrous; calyx-tube greenish, campanulate, pubescent only at the base; calyx-lobes obtuse, pubescent on both surfaces, glandular-serrate, strongly reflexed; petals oval, entire or occasionally notched at the apex, short-clawed; anthers yellow; filaments fivesixteenths inch long; pistil pubescent only on the ovary, longer than the stamens.

Fruit mid-season, ripening period long; one and three-quarters inches by one and five-eighths inches in size, oval or roundish-oval, slightly compressed, halves unequal; cavity narrow, abrupt, roundish; suture usually a line; apex roundish or flattened; color light to dark purplish-red, overspread with thick bloom; dots numerous, small, light russet; stem slender, three-quarters inch long, adhering well to the fruit; skin thin, tender, separating readily; flesh yellowish, juicy, slightly fibrous, firm and sweet, mild; inferior in quality; stone semi-free to free, one inch by five-eighths inch in size, da1 k colored, oval, flattened, roughened; base and apex acute; ventral suture slightly furrowed, acute; dorsal suture widely and rathér deeply grooved.

\section{LONG FRUIT}

Prunus triflora

1. Wild Bros. Cat. 27. 1892. 2. Cornell Sta. Bul. 62:26. 1894. 3. Am. Pom. Soc. Cat. 26. 1897-99. 4. Waugh Plum Cult. 138. 1901.

Long Fruited 1 .

Long Fruit is noted among the leading varieties of plums in The Plums of New York chiefly to condemn it. On the grounds of this Station and elsewhere in New York where tested, the trees are unproductive, the crop drops badly and the fruits are small and poor in quality. The variety was imported from Japan in 1885 by Luther Burbank.

Tree large, vigorous, vasiform to spreading, unproductive; branches roughened by numerous raised lenticels; branchlets slender, with short internodes, glabrous, marked by scarf-skin; leaves oblanceolate, somewhat peach-like, one inch wide, two and one-half inches long, thin; margin finely crenate, with small, amber glands; petiole slender, tinged with red, glandless or with from one to five small glands usually on the

stalk; blooming season early; flowers appearing after the leaves, seven-eighth inch across; borne singly or in pairs; calyx-tube much swollen at the base.

Fruit early; one inch by one and one-eighth inches in size, roundish-oblate; cavity deep; color dark red over a yellow ground, covered with thin bloom; stem slender, adhering poorly to the fruit; skin thick, somewhat astringent; flesh greenish-yellow or pale yellow, tender, sweet, mild; poor in quality; stone semi-clinging, small, one-half inch by three-eighths inch in size, roundish-oval, turgid, blunt at the base, the apex terminating abruptly in a small, sharp point, with smooth surfaces. 


\section{LUCOMBE}

\section{Prunus domestica}

r. Pom. Mag. 3:99. 1830. 2. Downing Fr. Trees Am. 28r. 1845. 3. Floy-Lindley Guide Orch. Gard. 284, 383. 1846. 4. Am. Pom. Soc. Cat. 222. 1858. 5. Hogg Fruit Man. 711 . 1884. 6. Guide Prat. 163, 358. 1895. 7. Waugh Plum Cult. 117. 1901. 8. Budd-Hansen Am. Hort. Man. 320.1903 .

Incomparable de Lucombe 6. Lucombe's Nonesuch 2, 3, 5. Lucombe's Nonsuch I, 4. Lu combe's Nonsuch 6, 7. Lucombe's Unvergleichliche 6. Lucombe's Nonesuch 8, Luccombe's Nonesuch 3. Nonsuch 7. Nonesuch 8.

This old plum has a reputation of high excellence and is well entitled to it. Despite the fact that it must compete for favor with such estimable plums as Reine Claude, Washington and Hand, belonging to the same group with these, it is still much grown in England and is well thought of for home use in America. Hardly in accordance with its reputation, it was rejected by the American Pomological Society in 1858 for a place in its list of fruits. Lucombe originated as a seedling about 1825 with a Mr. Lucombe of Lucombe, Prince and Company, nurserymen, at Exeter, England, and was first described by Lindley in 1830 in the Pomological Magazine.

Tree large, of medium vigor, upright-spreading, productive; branches covered with numerous fruit-spurs; twigs very short, with heavy pubescence; leaves one and three-quarters inches wide, three and one-quarter inches long, dark green; margin finely serrate or crenate, with small, dark glands; petiole pubescent, glandless or with one or two small glands usually at the base of the leaf; blooming season intermediate, short; flowers appearing after the leaves; petals with a yellowish tinge as the buds unfold; borne on long naked spurs with tufts of leaves and flowers at the ends, singly or in pairs.

Fruit mid-season, period of ripening long; one and three-eighths inches by one and one-half inches in size, roundish-oblate or roundish-obovate, greenish-yellow, becoming golden-yellow, indistinctly splashed and streaked with green, covered with thin bloom; flesh golden-yellow, firm, sweet, pleasant, mild; very good; stone free, three-quarters inch by five-eighths inch in size, roundish, slightly necked, with pitted surfaces.

\section{MAQUOKETA}

\section{Prunus hortulana mineri}

I. Mich. Pom. Soc. Rpt. 290. 1889. 2. Ia. Hort. Soc. Rpt. 55,85. 1890. 3. Cornell Sta. Bul. 38:40. 1892. 4. Mich. Sta. Bul. 118:53. 1895. 5. Ibid. 123:20. 1895. 6. Ia. Sta. Bul. 31:346. 1895. 7. Wis. Sta. Bul. 63:46. 1897. 8. Budd-Hansen Am. Hort. Man. 298. 1903. 9. Ga. Sta. Bul. 67:277. 1904. 10. Ohio Sta. Bul. 162:256, 257 . 1905.

Maquoketa is distinguished as one of the best of the native plums for culinary purposes. Nearly all of the plums brought in from the wild 
in America have so much astringency, most of it coming from the skins, that they are unpalatable to some. Now and then a variety is nearly free from this disagreeable taste and Maquoketa is one of these. The quality, as a dessert fruit, is very good for a native and the fruits keep and ship well. In the South the plums are subject to both curculio and brown-rot. The trees, like those of nearly all of the Miner-like plums, are rather better formed and more adaptable to orchard conditions than those of other species. After the Americana and Nigra plums, Maquoketa is one of the hardiest of our native varieties, growing even in Minnesota. The variety belongs in the South and Middle West and there are few, if any, places in New York where it is worth growing.

The origin of this plum is uncertain. It is reported in the references given as a native found on the banks of the Maquoketa River in eastern Iowa and also as a Miner seedling grown under cultivation. It has been known to fruit-growers since about 1889 .

Tree of medium size and vigor, spreading, low-topped, open, hardy, variable in productiveness, susceptible to attacks of shot-hole fungus, the trunk shaggy; branches slender, rough, zigzag, with few thorns, dark, dull ash-gray, with numerous lenticels; branchlets slender, long, with internodes of medium length, green, changing to dull reddish-brown, glabrous, with numerous, conspicuous, small, slightly raised lenticels; leaf-buds very small, short, obtuse, appressed.

Leaves falling early, folded upward, broadly lanceolate, peach-like, one and threequarters inches wide, four and one-half inches long; upper surface light green, changing to a dull red late in the fall, glossy, glabrous, with a narrowly grooved midrib and veins; lower surface silvery-green, thinly pubescent; apex taper-pointed, base rather abrupt; margin with serrations in two series, with very small, black glands; petiole fiveeighths inch long, tinged with dull red, hairy, with from one to four globose, rather large, dark brownish-yellow glands.

Blooming season late and of medium length; flowers appearing after the leaves, one inch across, yellowish as the buds begin to open, changing to white, with a disagreeable odor; borne in clusters on lateral spurs and buds, varying from two to four flowers in a cluster; pedicels five-eighths inch long, slender, glabrous, greenish; calyx-tube green, narrowly campanulate, glabrous; calyx-lobes narrow, slightly obtuse, nearly glabrous on the outer surface, but pubescent within, serrate, with dark colored glands and marginal hairs, reflexed; petals oval or ovate, with long, tapering claws of medium width, sparingly hairy at the base; anthers yellowish; filaments seven-sixteenths inch in length; pistil glabrous, slender, shorter than the stamens.

Fruit late, ripening period short; below medium in size, ovate or roundish-ovate, halves equal; cavity shallow, rather wide, rounded, flaring; suture a distinct line; apex roundish or slightly pointed; colors some time before fully ripe becoming dark 


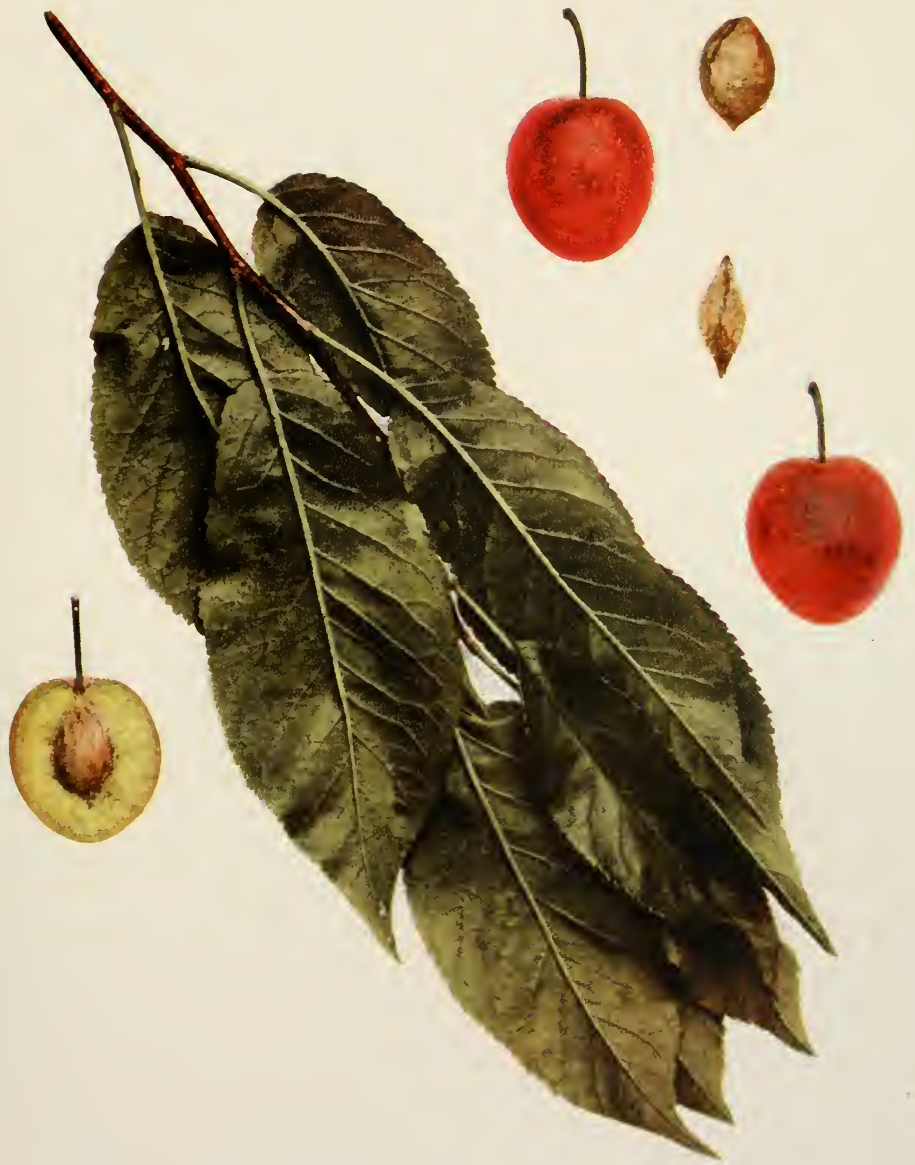



carmine, covered with thin bloom; dots numcrous, small to medium, light brown, clustered about the apex; stem rather slender, glabrous, parting readily; skin thick, tough, astringent, semi-adherent, removing a thin layer of pulp when detached; flesh deep yellow, juicy, coarse, fibrous, nearly melting next to the skin, becoming firmer toward the center, sweet at first but astringent near the pit, with a strong flavor; inferior in quality; stone adhering, of medium size, oval, turgid, bluntly pointed at the base and apex, with slightly roughened surfaces; ventral suture acute, ridged; dorsal suture a narrow, shallow groove.

\section{MARIANNA}

Prunus cerasifera $\times$ ?

I. Ga. Hort. Soc. Rpt. 28, 1886. 2. Gard. Mon. 29:148. 1887. 3. Am. Pom. Soc. Cat. 38. 1889. 4. Neb. Hort. Soc. Rpt. 56. 1889. 5. Ill. Hort. Soc. Rpt. 63. 189o. 6. Cornell Sta. Bul. 38:66, fig., 71, 83, 86. 1892. 7. Tex. Sta. Bul. 32:479, 480 fig. 1894. 8. Rev. Hort. 278 . 1894. 9. Rural N. Y. 54:600. 1895. 10. Mich. Sta. Bul. 152:210. I898. Ix. Bailey Ev. Nat. Fruits 208, 21 3. I898. 12. Vt. Sta. An. Rpt. 13:336-369. 1900. 13. Waugh Plum Cult. 36, 232. 190r. 14. Ga. Sta. Bul. 67:277. 1904. 15. S. Dak. Sta. Bul. 93:67. 1905.

Marianna has little or no value for its fruit. It is illustrated and discussed at length in The Plums of New York for two reasons. First, because it has long been an enigma which has baffled both horticulturists and botanists; second, because it is extensively used as a stock upon which other kinds of plums are propagated. In $\mathrm{i} 88_{4}$, a plum of unknown species was introduced to the trade. Some said the new variety belonged to Prumus cerasifera and others that it was an offspring of some native species. The characters of the first named species are so apparent in Marianna that all are now agreed that this variety is from either a self or a cross-fertilized seed of Prunus cerasifera; if the latter the other parent must have been some native species, the particular variety possibly being Wild Goose, one of the Munsoniana plums. Its behavior on these grounds, its robustness and semi-sterility and its not fitting exactly into any known species, mark it as a hybrid. A curious character peculiar to this variety is that it grows very readily from cuttings and for this reason it is a cheap stock for plums of all kinds and is used even for peaches and apricots. Besides rooting readily, the Marianna does not sprout and may be budded as late or later than the peach. It is chiefly used in propagation in the South, but, for reasons stated in the discussion of stocks in Chapter II, the Marianna is not now employed by nurserymen as largely as formerly, though there are still conditions in which it is the best of stocks. The tree is a handsome ornamental at any season of the year and its broad, spreading top makes it a good shade tree. 
Marianna originated as a seedling in a mixed orchard belonging to Charles G. Fitze, Marianna, Polk County, Texas; its parentage is unknown. The originator considered it a seedling of Wild Goose, but, it is probably an offspring of DeCaradeuc and, as stated in the foregoing paragraph, undoubtedly a hybrid. In 1884 , Charles N. Eley, Smith Point, Texas, introduced the Marianna to fruit-growers; in 1889 it was placed on the fruit catalog list of the American Pomological Society.

Tree large, vigorous, broad, spreading, open and flat-topped, hardy, unproductive, comparatively free from insects or diseases; trunk rough; branches numerous, usually smooth, but sometimes roughened by the cracking of the bark, thorny, dark ash-gray, with numerous, very large, raised lenticels; branchlets slender, twiggy, with internodes of medium length, green changing to dull reddish-brown, with gray scarf-skin, glabrous, with conspicuous, large, raised lenticels; leaf-buds very small and short, obtuse, appressed.

Leaves folded upward, elongated-oval, one and one-eighth inches wide, two and five-eighths inches long, thin; upper surface smooth, glabrous, with a shallow groove on the midrib; lower surface pale green, lightly pubescent along the midrib and larger veins; apex and base acute, margin very finely serrate, with small, black or amber glands; petiole slender, three-quarters inch long, pubescent along one side, usually tinged red, glandless or with from one to three very small, globose, greenish-brown glands variable in position.

Blooming season intermediate in time and length; flowers appearing after the leaves, three-quarters inch across, white; borne in clusters on lateral spurs, in twos or in threes; pedicels three-eighths inch long, slender, glabrous, greenish; calyx-tube green, campanulate, glabrous; calyx-lobes acute, sparingly pubescent, ciliate, erect; petals very small, separated from each other, broadly oval, entire, tapering to narrow claws; anthers yellowish; filaments three-sixteenths inch long; pistil glabrous, equal to the stamens in length.

Fruit early, season of medium length; one and one-eighth inches or more in diameter, oval or roundish-oval, often not compressed, halves equal; cavity shallow, narrow, abrupt, regular; suture a line; apex roundish or blunt-pointed; color bright, light red changing to darker red, overspread with thin bloom; dots numerous, small, light russet, conspicuous, clustered about the apex; stem slender, five-eighths inch long. glabrous; skin tough, bitter, inclined to crack under unfavorable conditions, parts readily; flesh yellow, tinged red under the skin and next to the stone, unusually juicy, fibrous, watery and melting, sweet next to the skin, but acid near the pit, sprightly; inferior in quality; stone clinging, three-quarters inch by one-half inch in size, elongatedoval, blunt-pointed, surfaces pitted; ventral suture blunt, wide, slightly ridged; dorsal suture widely and deeply grooved. 


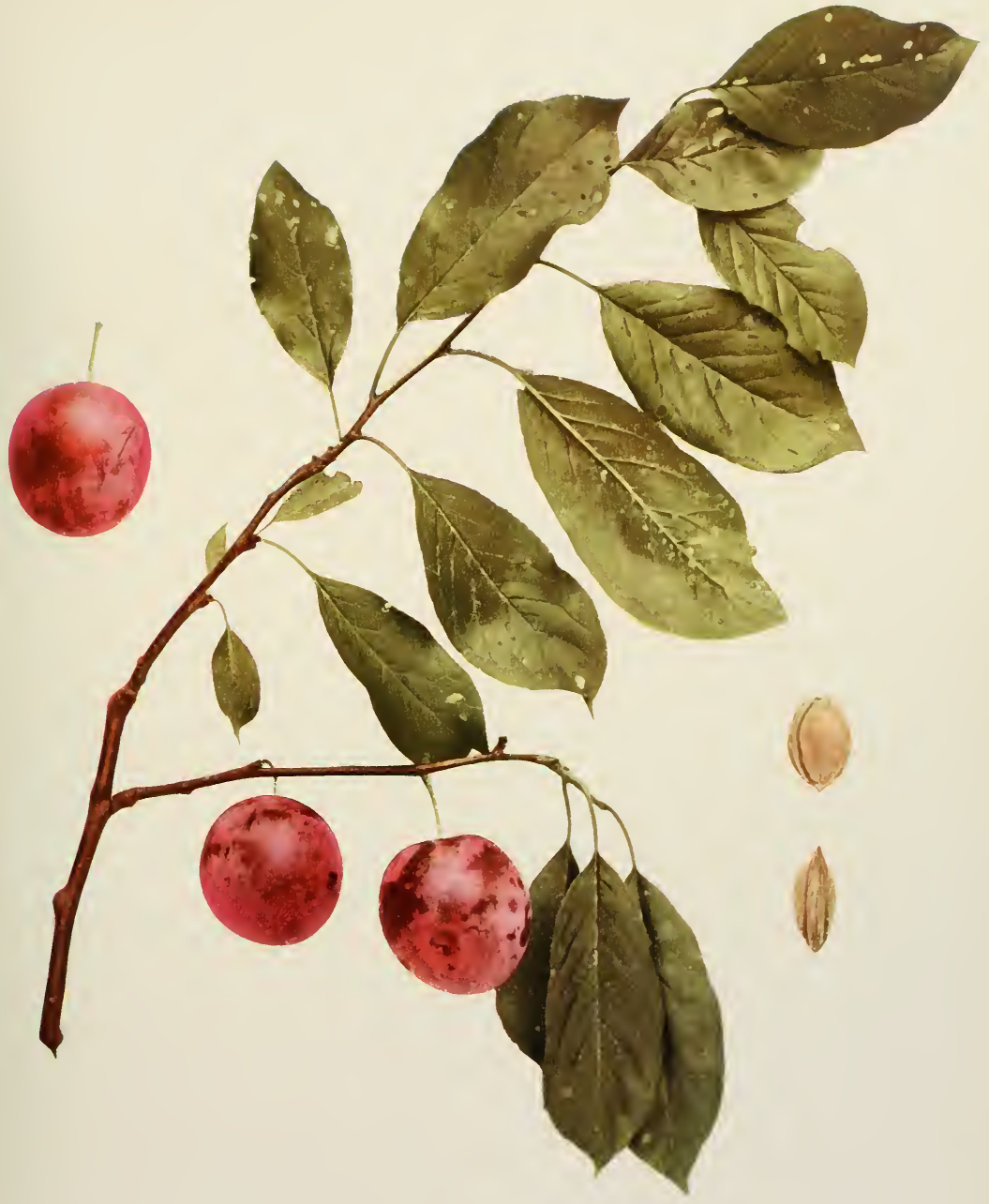





\section{MARU}

\section{Prunus triflora}

1. Ga. Hort. Sac. Rpt. 29. 1886. 2. Ibid. 53, 99. 1889. 3. Am. Pom. Soc. Rpt. 105, 106. 1891. 4. Rev. Hort. 515. 189r. 5. Ibid, 278. 1894. 6. Cornell Sta. Bul. 62:26. 1894. 7. Tex. Sta. Bul. 32:489. 1899. 8. Cornell Sta. Bul. 106:57. 1896. 9. Rural N. Y. 56:615. 1897. xo. Cornell Sta. Bul. 175:143. 1899. I1. Mich. Sta. Bul. x69:242, 249. 1899. 12. Waugh Plum Cult. 138. 1901. 13. Ga. Sta. Bul. 68:9. 31. 1905

Maru is much in evidence in plum literature, the concensus of opinion being that it is little short of worthless. Its quality is not high and it comes in season about with Abundance which surpasses it in nearly all characters. The variety was introduced by Luther Burbank and is said to have been imported by him about 1885 . In Japan this name is applied to any round plum, but so far in America it has been restricted to this variety.

Tree large, lacking in vigor, broad-vasiform, dense-topped, unproductive, somewhat susceptible to attacks of shot-hole fungus; trunk and branches rough; branchlets twiggy, marked with thin, russety scarf-skin, glabrous, with large, prominent lenticeis; leaves folded upward, oblanceolate, peach-like, thin, one and three-eighths inches wide, three inches long; upper surface yellowish-green late in the season; margin very finely serrate, with small glands; petiole with from one to six glands usually on the stalk; blooming season early; flowers appearing after the leaves, three-quarters inch across; borne in clusters on lateral spurs, in threes or fours; pistil longer than the stamens.

Fruit early, about one and one-quarter inches in diameter, roundish-cordate, dull red, with medium thick bloom; flesh deep yellow, tender and melting, sweet next the skin, but slightly astringent near the pit; poor in quality; stone clinging, five-eighths inch by one-half inch in size, oval or roundish, turgid, with rough surfaces.

\section{MAYNARD}

\section{Prunus triflora $\times$ Prunus simonii}

1. Vt. Sta. An. Rpt. x2:226. 1899. 2. Nat. Nur. 11:5. 1903. 3. Oregon Nur. Cat. 24. 1903. 4. Can. Hort. 28:285. 1905 .

The habit of the tree of Maynard is commendable and the plums are very acceptable to those who care for the Triflora fruits. The season follows Climax, a period when there is a dearth of Triflora plums. Maynard has been so widely advertised that it is hardly necessary to say that it is worthy of trial. The variety was first fruited in 1897 by Burbank after which it was tested by him for five years and was then sold to the Oregon Nursery Company by whom it was introduced in 1903. It was named by the originator in honor of Professor T. S. Maynard, then in charge of horticulture in the Massachusetts Agricultural College. 
Tree large, vigorous, upright, open-topped, productive; branchlets thick, dark chestnut-red; leaves obovate, one and one-half inches wide, three and one-half inches long, thin; margin finely serrate, with small, dark glands; petiole slender, glandless or with one or two small glands usually at the base of the leaf.

Fruit early; about one and three-eighths inches in diameter, roundish-truncate, dark red, changing to purplish-black, overspread with thick bloom; flesh reddish, with a tinge of yellow near the pit, fibrous, tender and melting, sweet, aromatic; good to very good; stone semi-clinging, three-quarters inch by five-eighths inch in size, broadly oval, turgid, blunt at the base and apex, with pitted surfaces; ventral suture prominent, with deep furrows and with a narrow, blunt wing; dorsal suture acute or with an indistinct groove.

\section{McLAUGHLIN}

\section{Prunus domestica}

I. Horticulturist 1:195 fig. 54. 1846. 2. Cole Am. Fr. Book 209 fig. 1849. 3. Thomas $A m$. Fruit Cult. 332. I 849 . 4. Mag. Hort. 16:456, 457 fig. 28 . I 850. 5. Hovey Fr. Am. 2:47, PI. I 85 I. 6. Am. Pom. Soc. Rpt. 36, 55. 1852. 7. Am. Pom. Soc. Cat. 231. 1854. 8. Cultivator 6:52 fig. 1858. 9. Flor. \& Pom. 200. I870. 10. Mas Le Verger 6:137, fig. 69. 1866-73. 11. Am. Gard. 14:299 fig. 1893. 12. Gaucher Pom. Prak. Obst. 97, Co1. Pl. 95. 1894. 13. Cornell Sta. Bul. 131:189. 1897. 14. Mich. Sta. Bul. 169:242, 246. 1899. 15. Waugh Plum Cult. I15, I16 fig. I901. 16. Va. Sta. Bul. 134:43. 1902. 17. Mass. Sta. An. Rpt. 17:159. 1905.

M'Laughlin 2. McLaughlin's Gage Plum 9. MacLaughlin 12. MacLanglin I2.

McLaughlin stands well up with the best of plums in quality and when well grown is very attractive in appearance. Its flesh is sweet and yet not so sweet as to cloy the appetite; in flavor it is rich and delicate and while somewhat like that of Reine Claude, is different, so that the variety has a taste quite of its own; though the juice is abundant, the flesh is not watery; the texture is neither too coarse nor too fine, too fibrous nor too mealy, but in a fruit rightly matured is most pleasantly melting. There are few other plums in which the characters pleasing to the taste exist in such nice proportions. McLaughlin is a little smaller than some other plums of its group, but is quite large enough for a dessert plum. Unless at its best, it is not as attractive in color as Jefferson, Washington, Reine Claude and some others of its type, but at its very best, it is unsurpassed by any other plum in coloring; it has in perfection the delicate yellow skin which belongs to the Reine Claudes upon which is marbled tints of white, yellow and crimson, the blending of which the illustration shows but poorly. The fruit of McLaughlin has its imperfections, however. The flesh clings tenaciously to the stone, is too melting to keep or ship well and rots badly on the tree. These defects debar the variety in America, with present market demands, from commercial plantations. The tree 


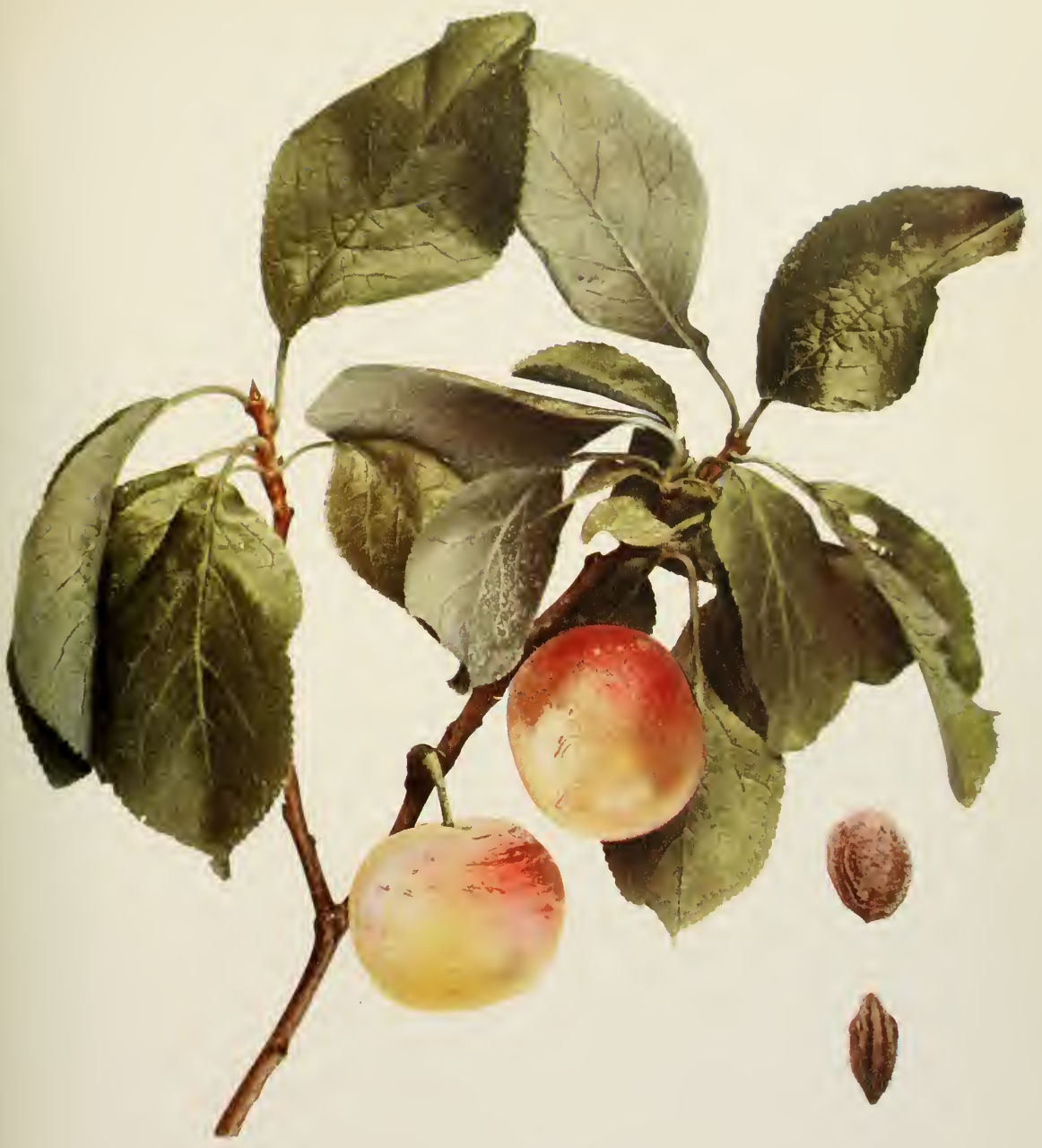



is above the average in size and vigor and is as hardy as any, more so than most of the Reine Claude varieties. It comes in bearing early and is rather productive. The place for this plum, from the summary of its characters, is apparent at once-in the home orchard and in the collection of the fruit connoisseur.

McLaughlin was raised by James McLaughlin of Bangor, Maine, first fruiting about 1840 . The parentage of the variety is disputed, but no one doubts that it contains Reine Claude blood, though the tree is too vigorous to have been raised from the Reine Claude self-pollinated. Judging from the tree-characters, it may have sprung from the Washington or Imperial Gage fertilized by the Reine Claude. The American Pomological Socicty, in 1852 , placed the McLaughlin with the plums that promised well, and at the next meeting added it to the recommended list.

Tree of medium size, variable in vigor, spreading, open-topped, hardy, medium to productive; branches stocky, ash-gray, smooth, with small, indistinct lenticels; branchlets few, thick, short, with short internodes, greenish-red changing to brownish-drab, lightly pubescent, with numerous, small lenticels; leaf-buds above medium in size, long, pointed, appressed; leaf-scars swollen.

Leaves oval, two inches wide, three and one-half inches long, thick; upper surface dark green, glossy, covered with fine hairs; lower surface pale green, pubescent; apex abruptly pointed, base acute, margin crenate, with small, black glands; petiole fiveeighths inch long, thick, pubescent, tinged red, with one or two small, globose, yellowish glands usually at the base of the leaf.

Season of bloom intermediate, short; flowers appearing after the leaves, fifteensixteenths inch across, white, with yellow tinge near the apex of the petals; borne on lateral spurs and buds, singly or in pairs; pedicels one-half inch long, thick, very pubescent, greenish; calyx-tube green, obconic, pubescent; calyx-lobes narrow, obtuse, sparingly pubescent on both surfaces, glandular-serrate and with marginal hairs, reflexed; petals obovate, crenate, tapering below to short, broad claws; anthers yellowish; filaments one-quarter inch long; pistil glabrous except at the ovary, longer than the stamens.

Fruit early, season short; one and five-eighths inches by one and seven-eighths inches in size, roundish-oblate, compressed, halves equal; cavity shallow, narrow, abrupt; suture shallow; apex flattened or depressed; color greenish-yellow, blushed and mottled with red, overspread with thick bloom; dots numerous, small, light colored; stem thick, three-quarters inch long, pubescent, adhering well to the fruit, surrounded at the cavity by a fleshy ring; skin tough, slightly adhering; flesh light yellow, juicy, sweet, mild and pleasant; very good; stone clinging, one inch by three-quarters inch in size, irregular broad-oval, very blunt at the base and apex, heavily wrinkled and deeply pitted; ventral suture narrow, distinctly furrowed, winged; dorsal suture widely and deeply grooved. 


\section{MIDDLEBURG}

Prunus domestica

1. W. N. Y. Hort. Soc. Rpt. 31:60. 1886. 2. Mich. Hort. Soc. Rpt. 288. 1889. 3. Cornell Sta. Bul. 131:189. 1897. 4. Ont. Fr. Exp. Sta. Rpt. 119. I898. 5. Mich. Sta. Bul. 169:242, 246. 1899. Ibid. $187: 77,79$. 1901.

Middleburgh $\mathrm{r}$.

It is somewhat remarkable that so good a plum as Middleburg should have so long escaped the attention of fruit-growers and even of pomologists. Not even Downing has recorded it, though he lived not more than a hundred miles from the place of its origin, which must have taken place in his time. The fruits may be surpassed somewhat by other purple plums in appearance but few of them are better in quality, either for dessert or for cooking. It is especially valuable too, because it ripens late, hangs well to the tree and ships and keeps well, in the latter respect equalling the best of the prunes. Out of a collection of about three hundred sorts on the Station grounds, this would undoubtedly be chosen as the favorite purple plum of its season. The trees, while of only medium size, are robust, healthy, hardy and usually productive. In Schoharie County, eastern New. York, where this variety originated and has long been grown, black-knot is usually epidemic and Middleburg and Palatine are said to be the sorts most free from the disease-so free that neither is much troubled by it. From its behavior here it is certain that, belying the looks of either fruit or tree, Middleburg will improve upon acquaintance and that when well known it will be wanted in home collections at least and more than likely some commercial fruit-growers will find it profitable.

Middleburg came from Middleburg, Schoharie County, New York, where it was found as a chance seedling. Mr. S. D. Willard, of Geneva, first called attention to the variety in I886 at a meeting of the Western New York Hortcultural Society. Its origin is much older than the date given, as it has been extensively grown in Schoharie County for a halfcentury or more.

Tree above medium in size, vigorous, round and open-topped hardy, productive; branches ash-gray, smooth, with small lenticels; branchlets of medium thickness and length, with long internodes, greenish-red, changing to brownish-red, overspread with light bloom, dull, somewhat pubescent, with few, inconspicuous, small lenticels; leafbuds of medium size and length, pointed, appressed.

Leaves folded upward, oval, one and one-half inches wide, three and one-half inches long, rather thick, stiff; upper surface dark green, sparingly pubescent on the grooved 


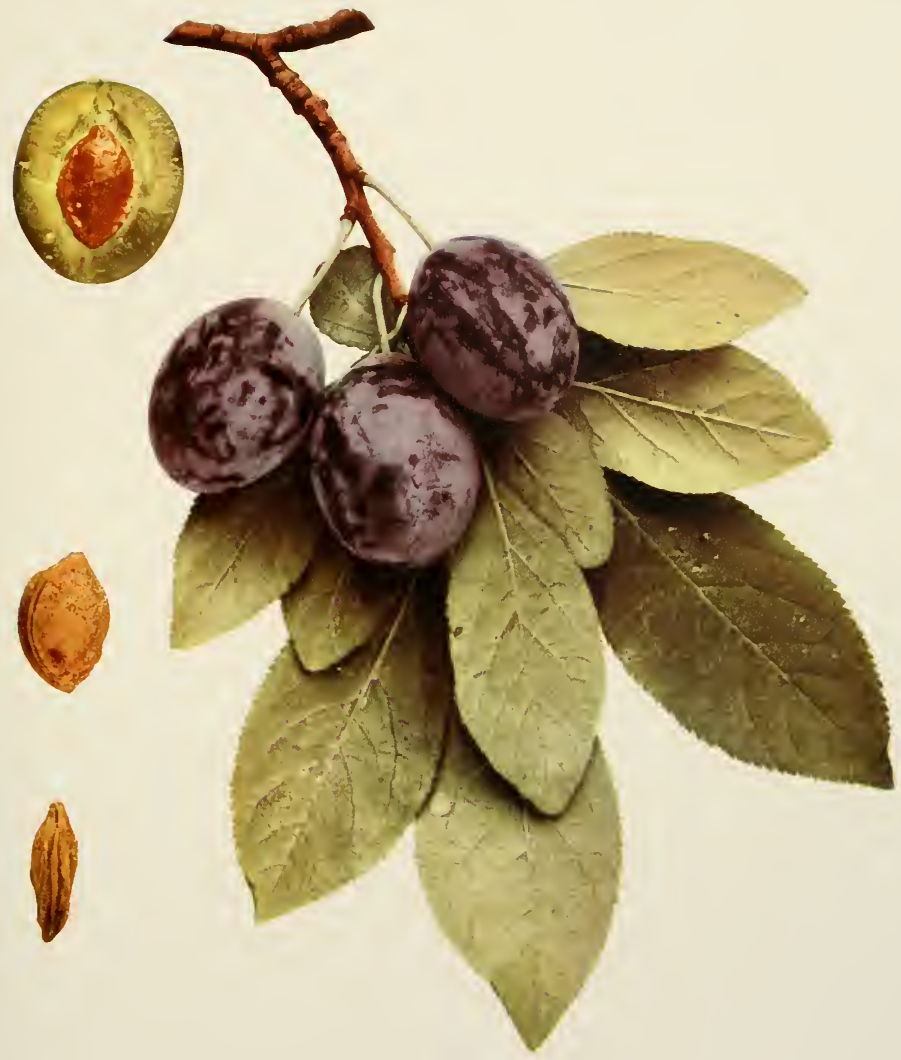



midrib and larger veins; lower surface silvery-green, pubescent; apex and base acute, margin doubly serrate, with a few, small, dark glands; petiole eleven-sixteenths inch long, pubescent, tinged red, glandless or with from one to three small, globose, greenishbrown glands on the stalk or base of the leaf.

Blooming season early to medium, short; flowers appearing after the leaves, one inch across, white, borne in scattering clusters on lateral spurs, singly or in pairs; pedicels three-quarters inch long, overspread with fine, short pubescence, greenish; calyxtube green, campanulate, pubescent at the base; calyx-lobes obtuse, thinly pubescent on both surfaces, glandular-serrate, somewhat reflexed; petals roundish or obovate, entire, with short, abrupt claws; anthers yellowish; filaments five-sixteenths inch long; pistil glabrous, equal to the stamens in length, with a large, pubescent ovary.

Fruit very late, season long; one and five-eighths inches by one and one-half inches in size, distinctly oval, compressed, halves equal; cavity very shallow, narrow, flattened; suture usually lacking; apex roundish; color varies from light to deep purplish-red, overspread with thick bloom; dots numerous, small, russet, inconspicuous; stem one inch long, thinly pubescent, adhering well to the fruit; skin thin, slightly sour, separating readily; flesh light yellow, rather juicy, somewhat coarse, firm, sprightly when first mature, becoming sweetish, strongly aromatic, pleasant flavored; very good; stone semi-free or free, one inch by five-eighths inch in size, irregular-oval, with pitted surfaces, slightly acute at the base and apex; ventral suture narrow, winged, faintly ridged; dorsal suture acute or with a shallow, narrow groove.

\section{MILLER SUPERB}

\section{Prunus domestica}

Of the two hundred and more varieties of plums which have fruited on the Station grounds, Miller Superb is one of the finest for dessert. The variety is of the Reine Claude group and is fully up with the best of these plums-all noted for high quality. In size and appearance, the plums resemble those of the well-known Bavay though usually larger. This plum originated with Colonel Charles Miller of Geneva, New York, when, is not known. About i 889, M. F. Pierson of Stanley, New York, secured cions of the plum from Colonel Miller and named the variety Miller Superb. It has never been introduced and is grown locally only to a very limited extent. Its large size, productiveness and superior quality should recommend it strongly for more general cultivation.

Tree of medium size and vigor, upright-spreading, open-topped, productive; branches rough as they approach the rough trunk; leaf-scars enlarged; leaves flattened, oval, two inches wide, three and three-quarters inches long; margin serrate or crenate, with few, small, dark glands; petiole long, thick, reddish, pubescent, with from one to three glands usually at the base of the leaf; blooming season of medium length; 
flowers appearing after the leaves, one inch or more across, white with yellowish tinge; borne on lateral buds and spurs, singly or in pairs.

Fruit intermediate in time and length of ripening season; one and three-quarters inches by one and five-eighths inches in size, roundish-oval or roundish-ovate, goldenyellow, mottled and splashed with green and sometimes with a blush on the exposed cheek, overspread with thin bloom; dots conspicuous; flesh light golden-yellow, juicy, firm but tender, sweet, pleasant in flavor; very good; stone clinging or semi-clinging, one inch by five-eighths inch in size, ovate or oval, somewhat flattened, usually winged; dorsal suture grooved.

\section{MILTON}

\section{Prunus munsoniana $\times$ ?}

I. Ia. Hort. Soc. Rpt. 287 . 1887 . 2. Ibid. 393. 1892. 3. Ibid. 334. 1894. 4. Neb. Hort. Soc. Rpt. 201. 1897. 5. Wis. Sta. Bul. 63:24, 48, 1897. 6. Am. Pom. Soc. Cat. 40. 1899. 7. Ia. Sta. Bul. 46:280. 1900. 8. Ala. Col. Sta. Bul. 112:178. 1900. 9. Terry Cat. 6. 1900. 1o. Waugh Plum Cult. 187. 1901. I1. Can. Exp. Farm. Bul. 43:31. 1903. 12. Ia. Hort. Soc. Rpt. 445. 1903. 13. Ga. Sta. Bul. 67:277. 1904. 14. Miss. Sta. Bul. 93:15. 1905. 15. Ohio Sta. Bul. I62:256, 257. 1905. 16. Ill. Hort. Soc. Rpt. 420. 1905.

The special merits of Milton, as compared with other native varieties, are that it blooms late and ripens early. It thus escapes frosts, when, for example, its parent, Wild Goose, might be injured; and its early ripening prolongs the season for native plums. The fruits are large, of very good quality, though a little too juicy for pleasant eating or to ship well, very attractive in appearance, and, more important than all else for the regions in which it is likely to be grown, it is comparatively free from rot. Unfortunately, the flesh clings most tenaciously to the stone even after cooking. In its fruit-characters, Milton strongly resembles one of the Mineri plums, but the tree is very much like that of Wild Goose, its known parent. In New York, Milton is one of the best of the native plums but it is hardly so considered in the Middle West, where these plums are most grown, judging from the discussions of it in the references given above.

Milton, a seedling of Wild Goose grown by $\mathrm{H}$. A. Terry, Crescent, Iowa, first fruited in 1885 . The originator believed that the other parent was an Americana, but from the characters of the tree it was more likely one of the Mineri plums. The American Pomological society added Milton to its fruit catalog list in I899.

Tree of medium size and vigor, round and dense-topped, symmetrical, hardy at Geneva, productive, healthy; branches brash, rough, thorny, dark brownish-gray, with numerous, large, narrow and much elongated lenticels; branchlets very slender, willowy, medium to long, with internodes of average length, greenish-red, changing 
to dull reddish-brown, thinly pubescent, with numerous, conspicuous, small, slightly raised lenticels; leaf-buds small, short, obtuse, free.

Leaves folded upward, broadly lanceolate or oblanceolate, peach-like, one inch wide, three inches long, thin; upper surface smooth, with a grooved midrib; lower surface thinly pubescent on the midrib and larger veins; apex taper-pointed, base slightly acute, margin serrate or crenate, with numerous, minute, dark glands; petiole seven-sixteenths inch long, slender, reddish, lightly pubescent, glandless or with from one to four small, globose, yellowish-brown glands usually on the stalk.

Blooming season late and long; flowers appearing after the leaves, three-quarters inch across, the buds creamy when opening, changing to white, odor disagreeable; borne in thin clusters on lateral spurs and buds, singly, in pairs, or in threes; pedicels threequarters inch long, very slender, glabrous, greenish; calyx-tube green, obconic, glabrous; calyx-lobes narrow, slightly obtuse, pubescent within, with dark colored glands and marginal hairs, erect; petals oval, entire or deeply indented, tapering below to long, narrow claws margined with few scattering hairs near the base; anthers yellow with a faint trace of red; filaments five-sixteenths inch long; pistil slender, glabrous, equal to the stamens in length.

Fruit very early, season short; one and three-sixteenths inches by one inch in size, oval, slightly compressed, halves equal; cavity shallow, narrow, abrupt, regular; suture a distinct line; apex roundish or slightly pointed; color dark red, covered with thin bloom; dots very numerous, medium to large, russet, conspicuous; stem slender, seveneighths inch long, adhering fairly well to the fruit; skin thin, tough, astringent, separating readily; flesh yellowish, the juice given off readily leaving a tough, fibrous pulp, sweet next the skin, but rather acid at the center, of pleasant flavor; fair to good; stone adhering, three-quarters inch by one-half inch in size, long-oval, slightly elongated at the base and apex, somewhat flattened, surface broken into irregular ridges; ventral suture blunt, faintly ridged; dorsal suture a narrow, shallow groove.

\section{MINER}

\section{Prunus hortulana mineri}

1. Horticulturist 22:332. 1867. 2. Am. Jour. Hort. 5:145. 1869. 3. Downing Fr. Trees Am. 031. 1869. 4. Ia. Agr. Soc. Rpt. 332. 1871. 5. Gard. Mon. 13:347, 348. 1871. 6. Ia. Hort. Soc. Rpt. 152. 1873. 7. Ibid. 90. 1874. 8. Am. Pom. Soc. Cat. 36. 1875. 9. Minn. Hort. Soc. Rpt. 81. 1882. 10. Cornell Sta. Bul. 38:55, 56, 58, 81, 86. 1892. I1. Mich. Sta. Bul. I18:54. 1895. 12. Guide Prat. 163, 359. 1895. 13. Vt. Sta. An. Rpt. 10:99, 103. 1897. 14. Thomas Am. Fruit Cult. 49r. 1897. 15. Colo. Sta. Bul. 50:41. 1898. 16. Waugh Plum Cult. 173. 1901. 17. Minn. Hort. Soc. Rpt. 208. 1901. 18. Ga. Sta. Bul. 67:278. 1904. 19. S. Dak. Sta. Bul. $93: 25$, 57 fig. 1905 .

Chicasaw Chief 4, 10, 14. General Jackson 4, 10, 14. Gillett 3, 14. Hinckley 3, 6, 10, 14. Hinckley 5, 7. Isabel 3, 14. Minner 12. Old Hickory 4, 10, 14. Parsons ?10, 14, 16. Robinson 3, 14. Townsend 3, 6, 14. William Dodd 4, 10, 14.

Miner has the distinction of being the first of the native plums to be named and of being the typical plum in the sub-species to which its 
name has been given. Though lacking but a few years of having been in the hands of civilization a century (the Indians from whom it appears to have been taken had possibly cultivated it longer), Miner is still a standard variety and while not the best of the group of which it is the type, it is one of the best. This variety has the further distinction of being, after Wild Goose, the parent of inore cultivated offspring than any other of our native plums and must be credited with having transmitted its characters, those of the tree being especially good, to a high degree. Miner is one of the parents of more than two score of named native plums in nearly all of which the resemblances to each other and to the parent are very marked. The variety is not grown, so far as is known, in New York and the trees on the grounds of this Station not being in bearing, it was impossible to illustrate the fruit in The Plums of New York though to do so was greatly desired. In the Middle West, Miner is probably as widely disseminated and as largely grown as any other plum, being particularly adapted to the northern limits of the cultivation of its species. The tree of this variety is robust, healthy, probably better in habit of growth for orchard management than any other of the native plums, and usually productive. The fruits are good in quality, attractive in appearance, comparatively curculio-proof and are especially suited for culinary uses. The variety is unproductive unless cross-fertilized.

Several accounts are given of the origin of Miner, none of which can be accurately verified at this late date. When all of the data is compared and that which is reliable is put together, the history of the variety runs about as follows: In I8I 3 William Dodd, an officer under General Jackson, found this plum growing in a Chicasaw Indian plantation at a place called Horse Shoe Bend, on the Tallapoosa River, Alabama. The plums were so attractive in size and excellent in quality that he saved seeds of the variety and in I8I4 planted them in Knox County, Tennessee. When the trees came in bearing and their merits were discovered, the new plum was at once in demand and was rather widely distributed in Knox and neighboring counties under the names "Old Hickory" and "General Jackson." In $\mathrm{I}_{23}$ or I 824 , Dodd moved to Springfield, Illinois, taking sprouts of this plum with him. Dodd's young trees did not thrive and he asked a brother in Tennessee who was moving to Illinois, to bring more sprouts of the new plum. The brother, instead of going to Springfield, went to Galena, Illinois, taking with him the sprouts of Old Hickory. These fell into the hands of Judge Hinckley, who distributed them among 
his friends, one of whom, a Mr. Townsend, propagated the variety rather extensively. At Galena, from the circumstances just noted, the variety was called "Hinckley" and "Townsend." Mcanwhile, the trees which the first Mr. Dodd had taken to Springfield came into bearing and the variety was propagated and distributed in the neighborhood as "William Dodd " and "Chicasaw Chief." A relative of the Townsends, at Galena, took trees of this plum to Lancaster, Wisconsin, where they were propagated by a man named Joel Barber. Barber named the plum after his father-in-law, a Mr. Miner, and this name, out of the dozen or more that have been given it, is the one under which the plum is now universally known. During the process of dissemination the variety received several other local names as Isabel, Gillett, Robinson and Parsons.

Tree large, vigorous, spreading, hardy at Geneva, unproductive unless cross-pollinized; branches smooth, reddish-brown, thorny; branchlets slender, long, with long internodes, greenish-red, changing to brownish-red, glossy, glabrous, with numerous, small, grayish lenticels; leaf-buds small, short, obtuse, appressed.

Leaves falling late, long-oval or obovate, peach-like, one and five-eighths inches wide, four inches long, thick; upper surface roughish, glabrous except for a few hairs on the narrowly grooved midrib; lower surface very thinly pubescent; apex acuminate, base abrupt and nearly acute, margin serrate, with small glands; petiole five-eighths inch long, pubescent on the upper surface, often tinged red, with from two to four reniform or globose, dark amber glands usually on the stalk.

Flowers late, often self-sterile, medium to large.

Fruit somewhat late; medium in size, roundish-ovate or roundish-oblong; cavity shallow, narrow, regular; suture indistinct; apex pointed; color dull, dark red, appearing some time before maturity, covered with thin bloom; dots numerous, minute, yellowish, conspicuous at first, becoming duller; stem slender, long, adhering strongly to the fruit; skin thick, tough, somewhat astringent; flesh pale amber yellow, juicy, nearly tender, mild, aromatic; good in quality; stone adhering, small to medium, roundishoval, flattened, pointed at the base and apex, with nearly smooth surfaces.

\section{MIRABELLE}

\section{Prunus insititia}

1. Merlet Abrege des bons fruits 1675. 2. Rea Flora 207. 1676. 3. Quintinye Com. Gard. 68, 70. 1699. 4. Langley Pomona 93, P1. XXIII fig. VIII. 1729. 5. Miller Gard. Dict. 3:1754. 6. Duhamel Trait. Arb. Fr. 2:95, PI. XIV. 1768. 7. Knoop Fructologie 2:52, 58, x771. 8. Lond. Hort. Soc. Cat. 149. 183r. 9. Prince Pom. Man. 2:76. 1832. 10. Poiteau Pom. Franc. I:1846. Ir. Downing Fr. Trees Am. 282 fig. 110. 1845. 12. Thomas Am. Fruit Cult. 330. 1849. 13. Thomp son Gard. Ass't 518. 1859. 14. Hogg Fruit Man. 371. 1866. 15. Jour. Hort. N. S. 15:359. 1868. 16. Pom. France 7:No. 14. 1871. 17. Mas Le Verger 6:13, fig. 7. 1866-73. 18. Oberdieck Deut. Obst. Sort. 425. 1881. 19. Mathieu Nom. Pom. 431, 432. 1889. 20. Gaucher Pom. Prak. Obst. 
93, Pl. 69. I894. 21. Guide Prat. 163, 361. 1895. 22. Garden 50:364. 1896. 23. U. S. D. A. Div. Pom. Bul. то:1 1. 1901. 24. Baltet Cult. Fr. $489,49^{2}$ fig. 326, 503. 1908.

Aprikosenartige Mirabelle $16,19,20,21$. Damascena Armeniacea 21 . Damaseena Armeniaca 19. Damas Vert 7. De Mirabelle 21. Gelbe Mirabelle 16, 17, 21. Gelbe Mirabelle 18, 19, 20. Geperlte Mirabelle 19. Green Damask ? 3. Kleinste Mirabelle 19. Kleine Mirabelle 19, 20, 21. La Mirabelle 9, 19, 20, 21. Lerchenei 19, 20. Little Mirabelle 9, 19, 20. Mirababelle 20. Mirabel 3. Mirabelle abricotie 16, 19, 20, 21. Mirabelle 14, 17, 19, 21. Mirabelle Blanche 7. Mirabelle Blanche 14, 16, 19, 20, 2 1. Mirabelle de Metz 15, 19, 20, 24. Mirabelle de Vienne 14, 16, 19, 20, 21. Mirabelle Jaune 7, 8, II, 13, 14, 16, 19, 20, 21. Mirabelle Perle 14, 20. Mirabelle Perlie 7, 16, 19, 20, 21. Mirabelle Petite 8, 9, I1, 13, 17, 19, 21. Mirabelle précoce 16, 17, 19, 20?, 21?. Mirabelle Petite 14. Mirabelle Simple? 7. Mirabolle Verte 16, ?21. Mirabelle Verte ?7. Petit Drap d'Or 9, 19, 20. Petite Mirabolle 9, 16, 19, 20. Petite Mirabelle 16, 17, 21, 24. P. Damascena Armeniacea 16. Prune de Mirabclle 9, 17, 19. Prune de Mirabelle 10. Small Mirabelle 9. Small Mirabelle 19, 20. Syrische Pflaume 19, 20. The Green Damosine Plum?2. White Mirabelle 14, 16, 19, 21. White Mirable 4. Wiener Mirabelle 19, 20.

Mirabelle, though described in an American fruit book as early as I 832 and mentioned in nearly every pomology since, is hardly known in America. In Europe, especially in France, it is one of the favorite varieties and is in great demand for canning, preserves, compotes, tarts and prunes. The trees of this variety on the grounds of this Station grow very well, producing fine crops of fruit, as it is probable they would do wherever the Damsons can be grown. The small, round, yellow fruits are attractive in appearance, and the sweet, pleasant flavor of the variety should fit it admirably in this country for the purposes for which it is so largely grown by the French. The trees are small but vigorous and healthy, the last two qualities having suggested in Europe their use as stocks, to which purpose they are sometimes put in France when a dwarfing stock is needed. European writers say that the variety may be reproduced from seed.

Mirabelle is a very old plum; it was noted by the pomological writers in the latter part of the Seventeenth Century and since that date it has held a conspicuous place in all of the European plum literature. This variety, though probably sparingly introduced in America at different times, has never been widely cultivated and is not now offered for sale by any of the nurserymen whose catalogs have been consulted for The Plums of New York.

Tree small, round and open-topped, hardy; branches dark ash-gray, smooth, with numerous, small lenticels; branchlets slender, of medium length, dull brownish-red, thorny, glabrous, with numerous, small, indistinct lenticels; leaf-buds of medium size and length, conical, free.

Leaves falling early, one and one-half inches wide, three inches long, folded upward, oval, rather thin; upper surface medium green, smooth, with few hairs scattered along 
the grooved midrib; lower surface silvery-green, pubescent; apex acute, base abrupt, margin crenate, with small, black glands; petiole one-half inch long, tinged red along one side, glandless or with from one to three small, globose glands usually on the stalk.

Flowers appearing in mid-season, after the leaves, seven-eighths inch across, white with a yellow tinge as the buds unfold; borne on lateral spurs and buds, in twos or threes; pedicels three-quarters inch long, slender, thickly pubescent, greenish; calyxtube green, broadly obconic, glabrous except at the base; calyx-lobes of medium width, obtuse, glandular-serrate, pubescent on both surfaces; reflexed; petals oval, crenate, tapering to short, broad claws; anthers yellow with a tinge of red; filaments threeeighths inch long; pistil glabrous, equal to the stamens in length.

Fruit mid-season, period of ripening of medium length; seven-eighths inch in diameter, roundish-oval, slightly necked, swollen on one side, compressed, halves equal; cavity very shallow and narrow, abrupt; suture indistinct; apex roundish or depressed; color light golden-yellow, sometimes blushed and mottled with red on the exposed check, overspread with thick bloom; dots numerous, small, whitish, inconspicuous, clustered at the apex; stem slender, three-quarters inch long, pubescent, adhering poorly to the fruit; skin thin, tough, not astringent, separating readily; flesh light yellow, not very juicy, firm, but tender, sweet, mild, but pleasant; good to very good; stone free, fiveeighths inch by three-eighths inch in size, oval, blunt, broadly ridged along one edge, roughish.

\section{MIRACLE}

\section{Prunus insititia $\times$ Prunus domestica}

1. Rural N. Y. 62:594. 1903. 2. W. N. Y. Hort. Soc. Rpt. 25. 1904. 3. Rural N. Y. 64:280. 1905. 4. Oregon Nur. Cat. 4. 1906. 5. DeVries Pl. Br. 228, $19 \circ 7$.

Unfortunately, so far as is known, this much-talked-of plum has not been fruited in New York. About 1887, Luther Burbank imported from a French nurseryman a tree of the Prunier San Noyeau or Stoneless plum known as a curiosity in Europe for at least three centuries. With this fruit he crossed several of the best European varieties, producing hybrids which first fruited in 1893 . Although there were several stoneless fruits in this lot, none were of any value and it was not until I 899 that one appeared worthy of consideration. In this seedling, developed from Agen pollen, the stone is represented by a small, hard scale near the base of the kernel. Burbank sold the new plum in I903 to the Oregon Nursery Company by whom it was introduced in 1906. The following description is compiled:

Tree somewhat dwarfish, producing a roundish, compact head, very productive. Fruit larger than Agen, oblong, dark blue covered with thick bloom; cavity medium; stem short; flesh yellow, sweet, juicy; good; stone lacking, the kernel lying naked in the flesh. 


\section{MONARCH}

\section{Prunus domestica}

1. Gard. Chron. 19:815. 1883. 2. Rev. Hort. 252, Pl. 1892, 3. Guide Prat. 163, 360. 1895. 4. Cornell Sta. Bul. 131:181 fig. $40 \mathrm{~V}, \mathrm{x} 89,1897$. 5. Rural N. Y. 57:670, 671 fig. 310. 1898. 6. Mich. Sta. Bul. 169:242, 247. 1899. 7. Am. Pom. Soc. Cat. 39. 1899. 8. Waugh Plum Cult. I16. I901. 9. Thompson Gard. Ass't 4:158 fig. 956. 1901. 10. Garden 62:298. I902. 11. Gard. Chron. 36:282. 1904. 12. Ohio Sta. Bul. 162:242 fig., 256, 257. 1905.

Monarque 3. Prune Monarque 2.

No plum of recent introduction has so quickly attained popularity as the Monarch. Of the great number of plums imported from the Old World, this is one of the few which has proved worthy of a place with the best American varieties for American conditions, an illustration of the importance of testing all foreign fruits. The plate shows the fruit of this variety well, though the plums look smaller in the illustration than in nature - an illusion always accompanying the reproduction in exact size of the photograph of a round object. The nicely turned form and the rich purple color of this plum make it a handsome fruit. While the quality is not of the best, Monarch ranks high among purple plums as a dessert fruit, few plums of this color being especially palatable to eat out of hand. The variety is not remarkable for any of its tree-characters, yet they average well with other plums and, with those of the fruit, make a variety quite above the average and give it a place among the best commercial sorts. Monarch is now so widely disseminated and so largely grown in New York, that we shall know shortly whether it is to hold the high place it has so quickly taken among market plums in this State.

Monarch, a seedling of the Autumn Compote, was grown by Thomas Rivers, Sawbridgeworth, England and was introduced by the originator in 1885 . English publications described and figured this variety in 1883 but there are no notices of it in American pomological literature until I 897. Two years later it was placed on the fruit list of the American Pomological Society catalog and recommended for the north-eastern section of the United States. Notwithstanding the fact that the variety is relatively new, it is now offered for sale by nearly every nurseryman in this country.

Tree of medium size and vigor, upright-spreading, open-topped, hardy at Geneva, usually productive; branches ash-gray, smooth, with small lenticels; branchlets of medium thickness and length, with internodes of average length, greenish-red, changing to brownish-drab, dull, thickly pubescent, with obscure, small lenticels; leaf-buds large, long, pointed, appressed; leaf-scars somewhat swollen. 


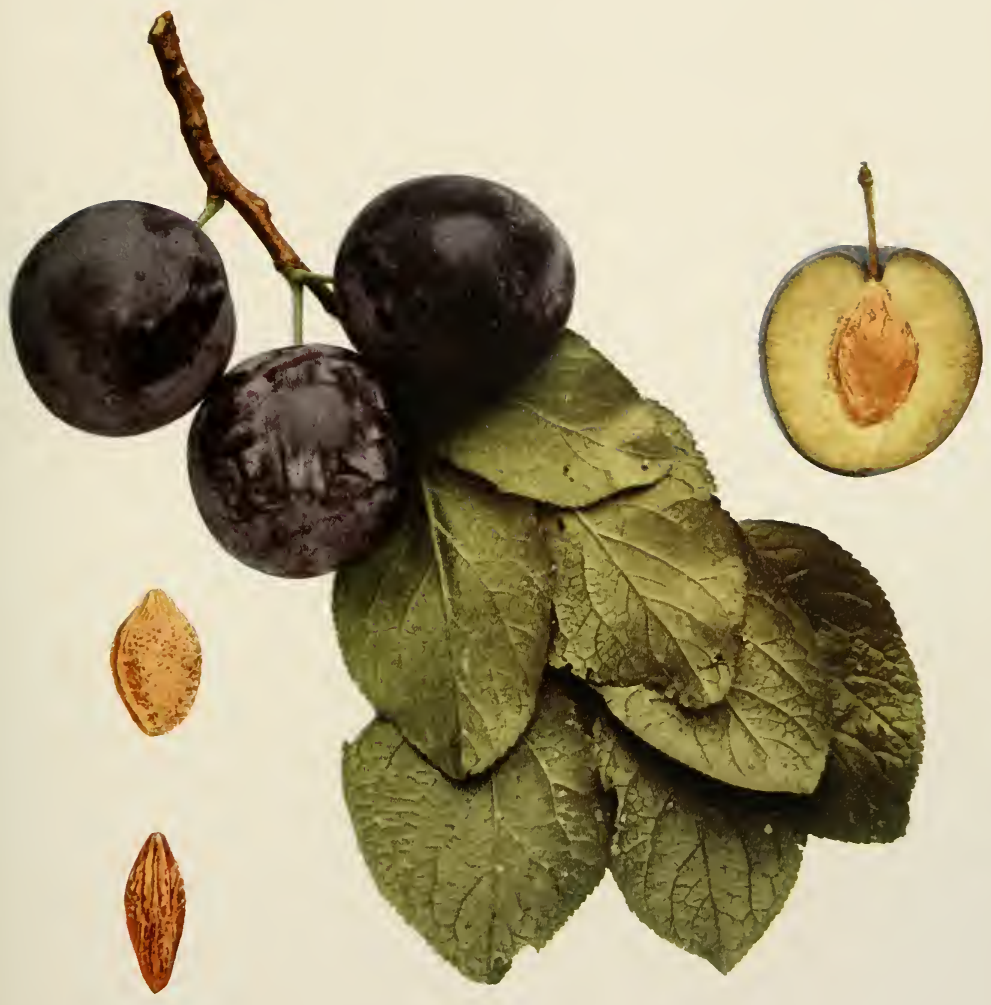



Leaves broadly oval, wide, medium in length, thick, somewhat stiff; upper surface rugose, covered thinly with hairs; lower surface pubescent; apex abruptly pointed, margin serrate or crenate, eglandular; petiole short, thick, heavily pubescent, lightly tinged red, glandless or with one or two large, reniform or globose, greenish-brown glands usually on the stalk.

Season of bloom intermediate in time and length; flowers appearing with the leaves, one and one-eighth inches across, white; pedicels three-quarters inch in length, thick, pubescent, green; calyx-tube greenish, campanulate, pubescent; calyx-lobes broad, obtuse, thickly pubescent on both surfaces, glandular-serrate, reflexed; petals oval, crenate, tapering to short and very broad claws; anthers yellow; filaments five-sixteenths inch long; pistil pubescent, longer than the stamens.

Fruit late; two inches by one and three-quarters inches in size, roundish-oval, halves unequal; cavity deep, medium to narrow, abrupt; suture shallow, often a line; apex roundish or flattened; color dark purplish-red, often with russet flecks scattered over the surface, overspread with thick bloom; dots numerous, small, reddish-brown, conspicuous, clustered about the apex; stem thick, three-quarters inch long, pubescent, adhering well to the fruit; skin thin, tender, slightly astringent, separating readily; flesh golden-yellow, juicy, somewhat fibrous, tender, sweet next to the skin, pleasantly tart towards the center, aromatic; good; stone clinging, one inch by five-eighths inch in size, long-oval, turgid, roughened and pitted, pointed at the base, blunt at the apex; ventral suture rather wide, shallowly furrowed, blunt; dorsal suture with a wide, shallow groove.

\section{MONROE}

\section{Prunus domestica}

x. Am. Pom. Soc. Rpt. 189, 210.1856. 2. Downing Fr. Trees Am. 389. 1857. 3. Thomas Am. Fruit Cult. 356. 1867. 4. Barry Fr. Garden 414 . 1883. 5. Guide Prat. $163,364$. 1895. 6. Cornell Sta. Bul. 131:189. 1897. 7. Waugh Plum Cult. 116. 1901. 8. Budd-Hansen Am. Hort. Man. 2:320. 1903.

Monroe Egg 1, 6. Monroe Egg 2, 7, 8. Monroe Gage 1, 2, 5, 7, 8. Monroe Gage 4. ReineClaude de Monroe 5 .

The fruit of Monroe is small and the trees produce well only in alternate years, defects that its high quality cannot overcome. Monroe originated with a Miss Durham, Penfield, Monroe County, New York, about the middle of the last century. At one time it was quoted by nearly all nurserymen but the variety is fast disappearing.

Tree large, vigorous, upright-spreading, hardy, productive; branchlets covered with fine pubescence; leaves oval, one and three-quarters inches wide, three and onehalf inches long, thick, rugose; margin finely serrate; petiole tinged red, pubescent, with from one to three small glands.

Fruit matures in mid-season; one and three-eighths inches by one and onequarter inches in size, oval, sometimes necked, golden-yellow, often mottled on the 
sunny side with red, overspread with thin bloom; stem adhering poorly to the fruit; flesh golden-yellow, tender, sweet, mild; of very good quality; stone semi-free or free, three-quarters inch by one-half inch in size, long and slightly irregular-oval, acute at the base and apex, with nearly smooth surfaces; ventral suture prominent, blunt.

\section{MOREMAN}

Prunus horiulana

I. Montreal Hort. Soc. Rpt. 91. 1885. 2. Corncll Sta. Bul. 38:49, 86. 1892. 3. Mich. Sta. But. 123:20. 1895. 4. Vt. Sta. An Rpt. 11:285. 1898. 5. Bailey Ev. Nat. Fruits 177, 206. 1898. 6. Am. Pom. Soc. Cat. 40. 1899. 7. Ia. Sta. Bul. 46:280. 1900. 8. Kan. Sta. Bul. 1or:135, 137. 19०1. 9. Ohio Sta. Bul. 162:256, 257. 1905.

Mooreman $\mathrm{r}$.

Moreman is the hardiest of the Hortulana plums and possibly worthy of keeping before plum-growers for this reason. Its fruit-characters are not as satisfactory as those of several other varieties of its species. Dr. Wayland of Cadiz, Kentucky, according to T. V. Munson, grew a lot of seedlings from pits of wild plums found in his vicinity and either from this lot or from a seedling from them, came the Moreman. The variety was introduced by W. F. Heikes in $\mathrm{r} 88 \mathrm{r}$. It was listed in the catalog of the American Pomological Society in 1899 . The following description is compiled.

Tree vigorous, spreading, hardy, productive; leaves of medium size, coarsely serrate; petiole usually glandless. Fruit late; small, roundish, bright red, bloomless; stem long, slender; dots numerous, yellow; flesh firm, yellow, pleasant in flavor; quality fair; stone small, roundish, clinging.

\section{MOROCCO}

\section{Prunus domestica}

I. Parkinson Par. Ter. 576. 1629. 2. Rea Flora 207. 1676. 3. Ray Hist. Plant. $2: 1528$. 1688. 4. Langley Pomona 91, P1. XX fig. III. 1729. 5. Miller Gard. Dict. 3:1754. 6. Knoop Fructologie 56. 1771. 7. Abercrombie Gard. Ass't 13. 1786. 8. Forsyth Treat. Fr. Trees 19. 1803. 9. Pom. Mag. 3:103. 1830. 10. Lond. Hort. Soc. Cat. 145, 146, 150. 1831. Ir. Prince Pom. Man. 2:82. 1832. 12. Downing Fr. Trees Am. 306. 1845. 13. Floy-Lindley Guide Orch. Gard. 282, 382. 1846. 14. Thomas Am. Fruit Cult. 338. 1849. 15. Loudon Enc. Gard. 921 . 1834. 16. Ga. Hort. Soc. Rpt. 28. 1876. 17. Hogg Fruit Man. 714. 1884. 18. Ma thieu Nom. Pom. 430. 1889 .

Black Morocco 7. Black Morocco 9, 10, 12, 13, 14, 17, 18. Black Damask 9, 10, 12, 13, 14, 17, 18. Black Damascus 13. Damas Noir 5. Damas Noir Hâtif 6, 10. Damas Hatif 10. Damas noir hatif I1. Early Damask 5, 8. Early Black Damask 9, 10, 13. Early Damson 10. Early Morocco 10, 12, 13, 14, 17, 18. Early Damask 9, 10, 11, 12, 13, 14, 15, 17, 18. Early Black Damask I1. Early Black Morocco 12, 18. Frühe Schwarze Pflaume 18. Frühe Platte Damascene 18. Italian Damask 12 incor., 14. Mogul 16. Morocco 16, 18. Marokko Pfaume 18. Morocco Plumb 4. Morocco 5, 8, 9. Noire Hatif i 8. Saint Cyr 11 
This variety is not popular in New York nor does it deserve to be, as there are many better plums of its season. Its faults are small size, an insipid flavor and poor keeping qualities. Morocco is one of the oldest of the cultivated plums. It has been known in Europe for three centuries at least and is undoubtedly much older, its early history not having been written. It is not known when the variety was introduced into this country but it has been grown in the Southern States for many years under the name Mogul. About I894, it was reintroduced from England by the W. \& T. Smith Nursery Company of Geneva, New York, under the name Mogul.

Tree large, vigorous, round-topped, rather tender to cold, productive; branchiets covered with heavy pubescence; leaves oval, one and three-quarters inches wide, three inches long; margin finely serrate or crenate; petiole short, thick, with one or two globose glands usually at the base of the leaf; blooming season intermediate in time and length; flowers appearing after the leaves, one and one-eighth inches across, white or creamy as the buds unfold; borne on lateral buds and spurs, singly or in pairs.

Fruit late, ripening period short; below medium in size, round to oval or obovate, purplish-black, covered with thick bloom; dots conspicuous; flesh light goldenyellow, rather dry, moderately firm, sweet next to the skin, but rather acid near the center; poor; stone clinging, medium to small, oval or ovate, flattened, with rough surfaces.

\section{MOTTLED PRUNE}

Prunus domestica

This plum is placed among the leading varieties only that a full description of it may be put on record. The fruit is attractive in color but is inferior in quality. These defects are so prominent that the variety can hardly become popular. The Mottled Prune originated in Waterloo, New York, as a chance seedling in 1887 ; it was introduced by E. Smith \& Sons, Geneva, New York.

Tree large, round and open-topped, very productive; branches stocky; branchlets heavily pubescent; leaves folded backward or flattened, oval or obovate, one and threequarters inches wide, three and one-half inches long, thick and leathery, rugose; margin crenate, with few, small, dark glands; petiole thickly pubescent, dull dark red, glandless or with from one to three smallish glands usually on the stalk; blooming season intermediate in time and length; flowers appearing after the leaves, one inch across, white; borne in scattering clusters on lateral buds and spurs, singly or in pairs; pedicels very pubescent.

Fruit mid-season, ripening period short; one and three-quarters inches by one and one-half inches in size, ovate, dark purplish-red, somewhat mottled, covered with thick 
bloom; dots numerous, conspicuous; flesh pale yellow, juicy, firm, sweet, mild; of fair quality; stone free, one inch by three-quarters inch in size, oval, flattened, strongly roughened; ventral suture deeply furrowed, often with a short wing; dorsal suture with a narrow, shallow groove.

\section{MYROBALAN}

\section{Prunus cerasifera}

1. Parkinson Par. Ter. 576, 578. 1629. 2. Gerard Herball 1498, 1500. 1636. 3. Rea Flora 209. 1676. 4. Ray Hist. Plant. 2:1528. 1688. 5. Duhamel Trait. Arb.Fr. 2:IrI, P1. XX fig. 5 . 1768. 6. Knoop Fructologie 55, 56. 1771. 7. Forsyth Treat. Fr. Trees 20. 1803. 8. Miller Gard. Dict. 3:1807. 9 Coxe Cult. Fr. Trees 232. 1817. 10. Lond. Hort. Soc Cat. 144, 150. I831. 11. Prince Pom. Man. 2:80. 1832. 12. Hoffy Orch. Comp. 2:1842. 13. Downing Fr. Trees Am. 294. 1845. 14. Floy-Lindley Guide Orch. Gard. 285. 1846. 15. Poiteau Pom. Franc. 1. 1846. 16. Jour. Roy. Hort. Soc. N. S. 15:360. 1868. 17. Hogg Fruit Man. 690. 1884. 18. Gard. \& For. 1:178. 1888. 19. Mathieu Nom. Pom. 448. 1889. 20. Cal. State Board Hort. 112, 113. 1891. 21. Corncll Sta. Bul. 38:66. 1892. 22. Rev. Hort. 204. 1894. 23. Neb. Hort. Soc. Rpt. 177. 1895.24. Guide Prat. 157, 353. 1895. 25. Bailey Ev. Nat. Fruits 190 fig. 27, 209. 1898. 26. Vt. Sta. An. Rpt. 12:211, 212, 215. 1899. 27. S. Dak. Sta. Bul. 93:66. 1905.

Arabische Kirsche 19. Asiatische Kirsche 19. American Cherry Plum 11. Cerisette 11. 18, 19. Gerizette II. Ciriselle 6. Cerisette 6, II. Cerisette Blanche 6. Cerise 19. Cherry I, II. Cherry Plum 7, 8, 11, 16, 19, 20. Cherry 13, 14, 17. Cherry Plum 9, 10, 18. De Virginie 10, 13, 14. Damasine 24. D'Amerique Rouge 10, 13, 14. Early Scarlet 10, I1, 13, 17, 19. European Cherry Plum 11. Muscadine ?1. Kirschpflaume 18, 19. Kleine Kirschpflaume 24. Mirobalan 2. Mirabilon 3. Mirabolan 5 Myrobolan 13. Mirabolanenpflaume 19 Myrobalans 7. Mirabolane 19. Mirobalan 9, 11. Myrobalane 19. Mirabolan 14. Myrobalan 10, 11, 14, 17, 18, 19. Mirabelle Rouge 24. Mirabelle Rouge 10. Miser Plum 19. Miser 12, 13, 14, 17. Prune d'Amerique Rouge 19. Prune Cerise I1. Prune Cerizette 8. Prunus Myrobalana I1, 14, 19, 23. Prunus Cerasifera 10, 11, 13, 14, 19. Prune Ceriset 11. Prune de Virginie 19. Prunier Myrobolan 15, 22. Prune Cerisette 15. Prunus Cerasifera fructu majore 19. Prunus Myrobolana 13. Queene Mother ?1. Red Mirobalane I. Rote Kirschpflaume 19. Red Mirabelle 12. Rothe Mirabelle 24. Stambul Erik oder Irek 19. Turkische Kirsche 19. Virginian Cherry 10, 13, 14, 17, 19. White Mirobalane 1. The Myrobalane Plum 4.

Myrobalan is a group name rather than a varietal one. Plums of this group are grown from seeds and many varieties have appeared during the last three centuries, differing in color, shape, stone and in many minor characters. The red and reddish-purple plums and the round ones are apparently the most numerous though there are frequent references to the White Myrobalan and to heart-shaped fruits in this group. For a further discussion of these plums see Prumus cerasifera. The Myrobalan plums are used largely as stocks in the propagation of plums and closely allied plants; occasionally they are used for culinary purposes though with rather poor results. 


\section{NECTARINE}

Prunus domestica

I. Pom. Mag. 3:148, 1830 . 2. Lond. Hort. Soc. Cat. 150. 183x. 3. Kenrick Am. Orch. 264. 1832. 4. Downing Fr. Trees Am. 306. 1845. 5. Horticulturist I:115. 1846. 6. Cole Am. Fr. Book 215. 1849. 7. Thompson Gard. Ass't 518. 1859. 8. Mathieu Nom. Pom. 448. 1889. 9. Guide Prat. 162, 365. 1895 .

Bradshaw 6. Caledonian 1, 2, 3. Calvel's Pfirschenpflaume 8. Goliath of some 8. Howel's 3. Howcll's Large 1, 2, 4, 7, 8. Jenkin's Imperial 2, 4, 7, 8, 9. Louis Phillipe 4. Louis Philippe 6, 7 8, 9. Large Early Black 6. Nectarine 1, 8, 9. Nectarine Plum 3, 7. Peach Plum 4, 7, 9. Peach 2, 8. Prune Pêche 1, 2, 3, 4, 7, 8. Pêche de Calvel 8. Prune d'Abricot 8. Pêche of some 9. Rothe Nectarine 9. Rote Nectarine 8. The Nectarine Plum I.

Much confusion has existed regarding the identity of the Nectarine, Peach and Goliath plums. These names have been interchanged indiscriminately for the three plums and it is now difficult to separate the varieties, especially as they are very similar. The Goliath, however, may be separated from the other two by its pubescent shoots, which the others do not have. The Peach plum is the largest of the three and has a reddish cast whereas the Nectarine and Goliath are dark purple. The earlier writers knew a Nectarine as a synonym of Peach but it was not until 1830 that the Nectarine was finally described as a separate variety. Nectarine is of unknown origin. The following description is compiled.

Tree vigorous, round-topped, productive; leaves large, oval; branches glabrous. Fruit early; large, roundish, flattened at the ends, dark purple with thin bloom; flesh greenish-yellow, tinged red at maturity, rather coarse, sprightly; fair to good; stone of medium size, compressed, oval, semi-clinging.

\section{NEWARK}

\section{Prunus domestica}

This fruit has little to recommend it to the commercial plum-grower; it is small in size and unattractive in color; the quality, however, is very good and the variety is worth planting for home use. Newark originated in Newark, New York, and in 1895 was bought by E. Smith \& Sons of Geneva, New York, who disseminated it two years later.

Tree medium in size and vigor, upright-spreading, rather open, very productive; branches rough; branchlets marked by scarf-skin, leaf-scars prominent; leaves flattened, somewhat drooping, oval or obovate, one and three-quarters inches wide, three and onehalf inches long, thick, rugose; margin coarsely serrate, with small, dark glands; petiole thick, pubescent, glandless or with one or two smallish glands usually on the stalk; blooming season intermediate in time and length; flowers appearing after the leaves, 
one inch or more across, white with yellowish tinge at the apex of the petals; borne singly or in pairs; anthers yellow with a trace of red.

Fruit early, season short; one and one-half inches by one and three-eighths inches in size, oval, dull yellow mottled with red at full maturity, covered with thin bloom; dots numerous, conspicuous; flesh light greenish-yellow, rather dry, firm, sweet, mild; good to very good; stone free, three-quarters inch by one-half inch in size, irregularoval, flat, with finely pitted surfaces; ventral suture usually winged; dorsal suture with a shallow, narrow, indistinct groove.

\section{NEWMAN}

\section{Prunus munsoniana}

I. Horticulturist 22:271. 1867. 2. Downing Fr. Trees Am. 934. 1869. 3. Am. Jour. Hort. 5:142. 1869. 4. Mich. Pom. Soc. Rpt. 39. 1874. 5. Am. Pom. Soc. Cat. 36. 1875. 6. Barry Fr. Gardon 418. 1883. 7. Ia. Hort. Soc. Rpt. 286. 1887. 8. Cornell Sta. Bul. 38:63, 86. 1892. 9. Mich. Sta. Bul. 123:20. 1895. 10. Wis. Sta. Bul. 63:49. 1897. 11. Me. Sta. An. Rpt. 12:66 1896. 12. Bailey Ev. Nat. Fruits 200 fig., 201. 1898. 13. Rural N. Y. 59:450. 1900. 14. Ia. Sta. Bul. 46:282. 1900. 15. Ohio Sta. Bul. 162:256, 257 . 1905.

Warren ? 8.

Newman is one of the oldest but still one of the standard varieties of its species. Its fruits are characterized by a firm, meaty flesh, which fits it well for shipping and storing; the plums are also attractive in shape and color but are too small and too low in quality to make the variety a first-rate one. The trees are large and vigorous and in all respects very satisfactory orchard plants. Both fruits and trees are usually reported as fairly free from diseases and insects. While the variety is gradually going out it still has some value for its crops and ought to make a good parent from which to breed a race of vigorous, firm-fleshed Munsonianas.

The origin of this plum is uncertain. In 1867 a Mr. Elliott of Cleveland, Ohio, reported in the Horticulturist that he had received samples of the "Newman Plum" from D. L. Adair, Esq., of Hawesville, Kentucky, and gave a brief description of the fruit which seems to tally with that of the variety under discussion. The American Pomological Society added this plum to its fruit catalog list in 1875 and removed it in 1891 .

Tree large, vigorous, spreading, low and flat, dense-topped, hardy at Geneva, productive, subject to attacks of shot-hole fungus, the trunk shaggy; branches dark ash-gray, rough and shaggy, thorny, zigzag, with numerous, rather inconspicuous, large, elongated lenticels; branchlets very slender, twiggy, with internodes of average length, greenish-red, changing to dark brown, glabrous, with few, conspicuous, large, raised lenticels; leaf-buds small, short, obtuse, plump, nearly free.

Leaves lanceolate, peach-like, one and one-quarter inches wide, four inches long, thin; upper surface smooth, glabrous, with a grooved midrib; lower surface glabrous 


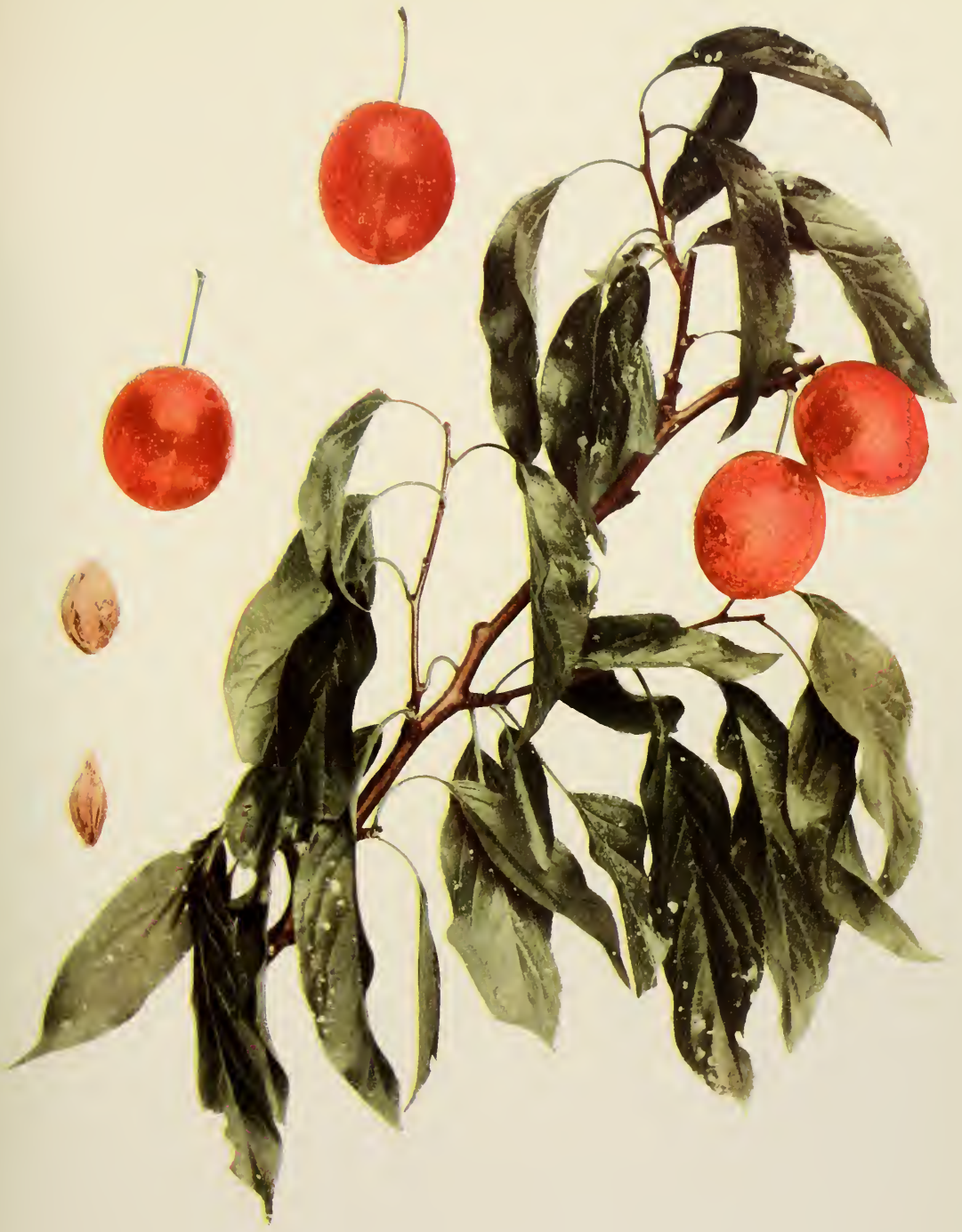



except along the midrib and larger veins; apex taper-pointed, basc acute, margin finely crenate, with small, amber glands; petiole slender, seven-eighths inch long, lightly pubescent along one side, reddish, glandless or with from one to four very small, globose, yellowish-red glands on the stalk.

Blooming season late and long; flowers appearing after the leaves, three-quarters inch across, in the buds tinged yellow, changing to white on expanding, odor disagreeable; borne in clusters on lateral spurs and buds, in twos or in threes; pedicels elevensixteenths inch long, slender, glabrous, greenish; calyx-tube green, campanulate, glabrous; calyx-lobes small, narrow, slightly obtuse, pubescent on the inner surface, glandular-serrate and with marginal hairs, erect; petals ovate or oval, crenate, tapering at the base into long, narrow claws; anthers yellow, tinged with red; filaments five-sixteenths inch long; pistil slender, glabrous, equal to the stamens in length.

Fruit mid-season, ripening period very long; one inch by seven-eighths inch in size, strongly oval, not compressed, halves equal; cavity shallow, narrow, flaring; suture a distinct dark red line; apex depressed; color bright currant-red, with thin bloom; dots grayish, rather conspicuous, clustered near the apex; stem very slender, seven-eighths inch long, glabrous, adhering well to the fruit; skin thin, very tough, astringent, separating readily; flesh deep yellow, juicy, tender and melting, sweetish next to the skin, but tart at the center; fair in quality; stone clinging, five-eighths inch by three-eighths inch in size, long-oval, turgid, necked at the base, blunt-pointed at the apex, with finely pitted surfaces; ventral suture narrow, inconspicuous; dorsal suture with a narrow, shallow groove.

\section{NEW ULM}

\section{Prunus americana}

1. Minn. Hort. Soc. Rpt. 126. 189o. 2. Wis. Sta. Bul. 63:49 fig., 50. 1897. 3. Ia. Hort. Soc. Rpt. III. 1899. 4. Am. Pom. Soc. Cat. 37. 1899. 5. Ia. Sta. Bul. 46:282 fig. 19oo. 6. Waugh Plum Cult. 158. 1901. 7. Ont. Fr. Gr. Assoc. 143. 1901. 8. S. Dak. Sta. Bul. $93: 26$. 19०5. 9. Ill. Hort. Soc. Rpt. 422. 1905. 10. Ia. Sta. Bul. 114:141. 1910.

Snooks Io.

New Ulm is worthy of attention because of its large, handsome, wellformed fruits. The plums are further distinguished by a peculiar flavor, somewhat suggesting that of the mandrake, pleasant to some but disagreeable to others. The flesh is a little too juicy for pleasant eating but the fruits ship well, the tough, thick skin firmly holding its contents. The fruits, however, do not keep well, for, despite the thick skin, the spores of the brown-rot find entrance and thrive so that the variety rots badly. The trees are hardy and productive but ill-shaped and hard to manage in either the orchard or the nursery for which reason the culture of the variety is discouraged by nurserymen and it is now almost impossible to buy New Ulm trees. The illustration of this variety shows well the characters of the western type of Prunus americana in leaf, fruit and stone. 
New Ulm was raised from seed of a wild variety that grew in the neighborhood of the originator and introducer, C. W. H. Heideman, New Ulm, Minnesota. The fruit was exhibited at the Minnesota State Fair in 1890 where it attracted much attention, being the largest plum of fifty varieties exhibited. In 1899 the American Pomological Society placed the variety on its fruit catalog list. The Minnesota State Horticultural Society, in spite of the fact that this plum has gained a good reputation for its size and productiveness, removed it from its recommended fruit list in 1904 because of the difficulty of growing the trees in the nursery.

Tree of medium size, spreading and drooping, irregular, low and dense-topped, undesirable in habit of growth, hardy, usually productive, subject to attacks of shothole fungus; branches very rough and shaggy, zigzag, thorny, dark ash-gray, with large lenticels; branchlets thick, long, willowy, with long internodes, green, with a faint yellow tinge, changing to light and dark, dull reddish-brown, glabrous, with numerous, conspicuous, large, raised lenticels; leaf-buds small, pointed, strongly appressed.

Leaves drooping, folded upward, oval or ovate, two inches wide, four and threeeighths inches long, thin; upper surface dark green, changing to reddish-yellow late in the season, glabrous, with a grooved midrib; lower surface silvery green, lightly pubescent; apex taper-pointed, base abrupt, margin coarsely and doubly serrate, eglandular; petiole slender, five-eighths inch long, pubescent, tinged with red which deepens in color at the base, glandless or with from one to three globose, greenish-brown glands usually on the stalk.

Flowers intermediate in time and length of blooming season, appearing after the leaves, showy on account of the numerous pure white petals, one and one-sixteenth inches across, white; borne in dense clusters on lateral spurs and buds, usually in threes; pedicels seven-sixteenths inch long, thick, glabrous, greenish; calyx-tube red, campanulate, glabrous; calyx-lobes long, narrowly obtuse, lightly pubescent on the inner surface, thickly pubescent along the glandular-serrate margin, erect; petals oval, entire or incised, tapering below to narrow claws of medium length and with reddish base; anthers yellow; filaments seven-sixteenths inch in length; pistil glabrous, much shorter than the stamens.

Fruit mid-season, intermediate in length of ripening period; about one and three-eighths inches in diameter, roundish-ovate, halves equal; cavity markedly shallow, very narrow; suture a line; apex roundish or slightly pointed; color carmine over a yellow ground, overspread with thin bloom; dots very numerous, russet; stem five-eighths inch long, glabrous, adhering somewhat to the fruit; skin thick and tough, astringent, adhering strongly; flesh golden-yellow, very juicy and fibrous, granular, tender and melting, sweet with a strong aromatic flavor; good; stone adhering, seveneighths inch by nine-sixteenths inch in size, oval, slightly flattened, blunt at the base, pointed at the apex, with smooth surfaces; ventral suture distinctly winged; dorsal suture narrow, shallow, grooved. 


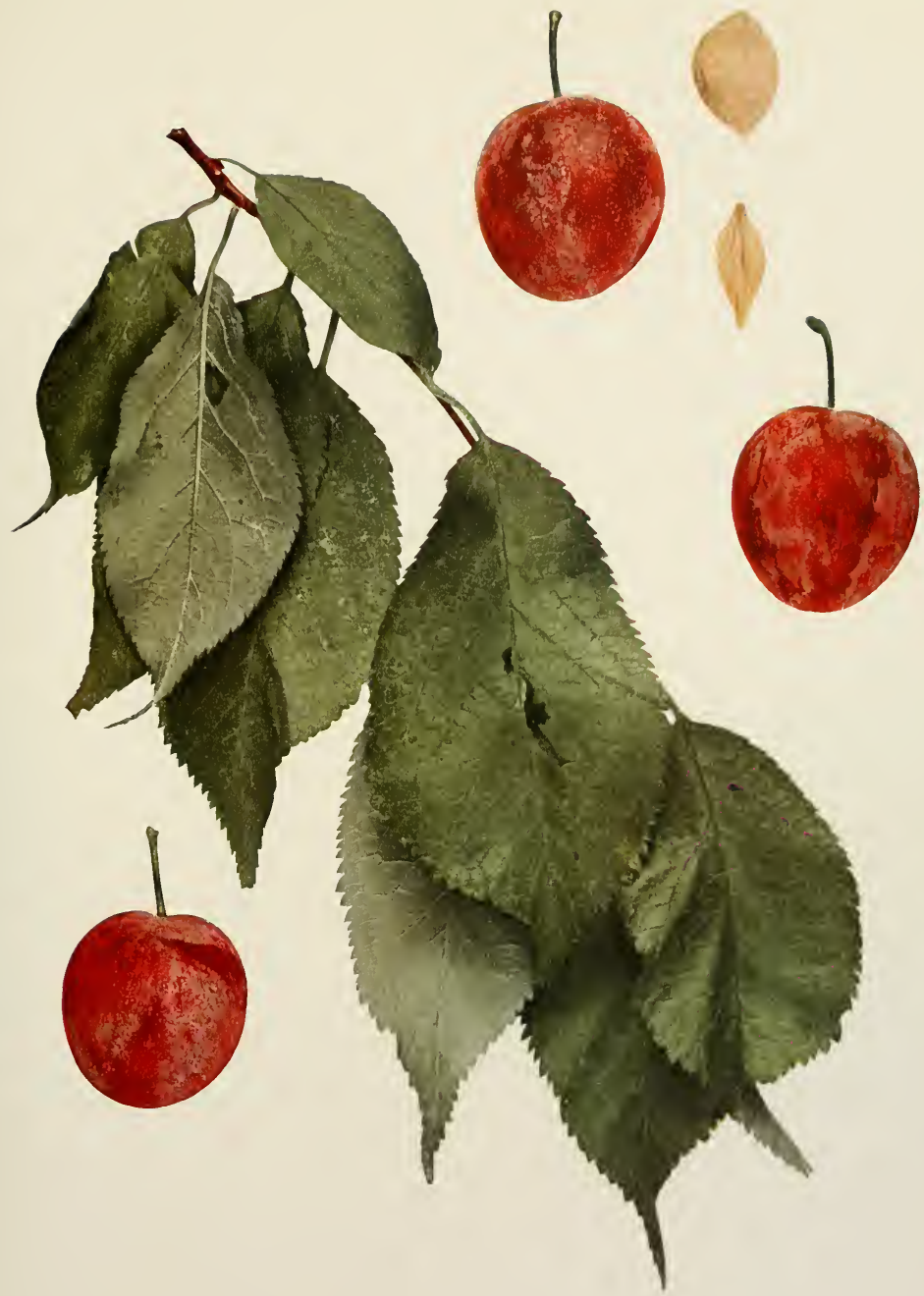

NEW ULM 



\section{NICHOLAS}

Prunus domestica

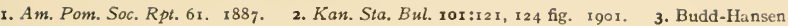
Am. Hort. Man. 327. 1903 .

Arab No. 2 Bielaya Nicholskaya I. White Nicolas I. White Nicholas 2, 3.

Although a fairly good early dessert plum it is doubtful if Nicholas has any commercial value as it is inferior in most characters of fruit and tree to standard varieties; in particular it drops badly as it begins to ripen. "White," as formerly and usually now put in the name, is a misnomer, as the fruit is red; how it came to be applied to this fruit does not appear. Nicholas was imported from Dr. Regel of St. Petersburg, Russia, by Professor J. L. Budd of the Iowa Experiment Station in the winter of $188 \mathrm{I}-$ 82 and in 1888 was sent out for testing under the name Arab No. 2.

Tree of medium size, round-topped, productive; trunk rough; branches smooth except for the raised lenticels and longitudinal cracks in the bark; branchlets slender; leaves falling early, folded upward, obovate or oval, one and five-eighths inches wide, three and three-eighths inches long, rugose; margin serrate, with few, small, dark glands; petiole pubescent, tinged red, sometimes with several small glands; blooming season intermediate in time, short; flowers appearing after the leaves, one inch or more across, white, tinged with yellow near the apex of the petals; borne on lateral buds and spurs, in scattering clusters, singly or in pairs.

Fruit early, one and three-eighths inches by one inch in size, long-oval, dark red, covered with thick bloom; stem adhering poorly to the fruit; flesh light yellow, juicy, fibrous, tender, sweet, mild; good; stone free, one inch by five-eighths inch in size, flattened, oval, somewhat obliquely acute at the base, with granular surfaces; ventral suture prominent, rather narrow, blunt; dorsal suture with a narrow, shallow groove.

\section{OCCIDENT}

\section{Prunus triflora}

x. Rural N. Y. 57:653. 1898. 2. Am. Gard. 19:826, 1898. 3. Burbank Cat. 1899. 4. Vt. Sta. An. Rpt. 12:229. 1899. 5. Rural N. Y.60:658 fig., 662. 1901. 6. Budd-Hansen Am. Hort. Mar. 320. 1903. 7. Ga. Sta. Bul. 68:11, 37. 1905. 8. Rural N. Y. 65:730. 1906.

Burbank's Sultan 6. Garnet I. Garnet 2. Occident 8. Oval Blood (unpublished). Sultan $2,3,5,8$. Sultan 4,7 .

Occident differs little from Apple in horticultural characters and need not be discussed at length as the reader can readily turn to the color-plate and description of the last named variety. At best this sort can hardly be called more than a curiosity, though an interesting one, of use, if at all, only for cooking and as a long-keeping, rot-resistant plum. It will add 
novelty to any amateur's collection because of the size, shape, color, flavor and red flesh of the fruits.

This variety was grown by Burbank and introduced by him in 1899 under the name Sultan. H. E. Van Deman, in the Rural New Yorker (References, I), says that Occident is a cross between Wickson and Satsuma and that the name Garnet which he suggested, owing to the color of its flesh and skin, had been accepted by Mr. Burbank. About two months later the Division of Pomology of the United States Department of Agriculture called attention to the fact that "Garnet" had been previously given to another variety and the name was changed to Sultan. Waugh in I899 substituted "Occident" for Sultan as the latter is the name of a European plum; Waugh's name has been accepted by all recent writers. Occident undoubtedly contains Satsuma blood but it has but few characters that suggest Wickson, and if a cross, which is likely, the other parent is undeterminable. The following description is compiled:

Tree vigorous, slow of growth, straggling, somewhat variable in habit, late in coming into bearing, productive; leaves numerous, large.

Fruit ripens with Burbank, keeps and ships unusually well, resistant to rot; large, roundish; cavity of medium depth; suture shallow, distinct; color dark red over a greenish ground; dots many, yellowish; stem thick, short, adhering to the fruit; skin somewhat thin, tough, slightly astringent; flesh dark red, firm, sweet, rather acid, changing to subacid as maturity advances, sprightly; good to very good; stone free or semi-clinging, of medium size, roundish, turgid, winged, rough.

\section{OCHEEDA}

\section{Prunus americana}

r. Cornell Sta. Bul. 38:41. 1892. 2. Wis. Sta. An. Rpt. I1:344. 1894. 3. Ia. Hort. Soc. Rpt. 34:112. 1899. 4. Am. Pom. Soc. Cat. 37. 1899. 5. Waugh Plum Cult. 159. 1901. 6. Can. Exp. Farm Bul. 43:31. 1903. 7. Ill. Hort. Soc, Rpt. 420. 1905. 8. S. Dak. Sta. Bul. 93:28. 1905. Ocheda 7 .

This variety is generally regarded as one of the valuable native plums but in New York it is surpassed by a number of other plums of its species in size of fruit and color though the quality is very good. We must rank it in this State as second rate among Americanas. Ocheeda was found by P. L. Hardow in 1872 growing wild on the banks of Ocheeda Lake, Minnesota, and in 1892 was introduced by H. J. Ludlow of Worthington, Minnesota.

Tree large, vigorous, spreading, open-topped, unproductive; branches shaggy, thorny, with large lenticels; branchlets willowy, pubescent; leaves folded upward, 
oval, nearly two inches wide, three and one quarter inches long; margin coarsely and doubly serrate; petiole densely covered with short hairs; blooming season intermediate in time and length; flowers appearing after the leaves, seven-eighths inch across, dull white; borne in scattering clusters almost entirely on one-year-old wood, many lateral buds remaining undeveloped, the bare limbs carrying tufts or clusters of blossoms, in threes or fours; petals long-obovate, nearly three times as long as wide, tapering to long claws, reddish at the base; stigma distinctly reddish when the flowers first open.

Fruit mid-season, ripening period long; one inch by seven-eighths inch in size, ovate or roundish-ovate, slightly oblique, dull light to dark carmine over a yellow ground, somewhat mottled, overspread with thick bloom; skin slightly astringent; flesh dark golden-yellow, tender, melting, sweet, aromatic, pleasant in flavor; fair to good; stone dark colored, nearly free, three quarters inch by one-half inch in size, roundish-oval, turgid with smooth surfaces; ventral suture markedly winged.

\section{OCTOBER}

\section{Prunus triflora}

r. Cornell Sta. Bul. 106:58. 1896. 2. Cal. State Bd. Hort. 52. 1897-98. 3. Am. Gard. 20: 162 fig. 1899. 4. Rural N. Y. 59:104, 690. 1900. 5. Am. Gard. 21:36, 660. 1900. 6. Nat. Nur. 8:109, 123. 1900. 7. Waugh Plum Cult. 139. 1901. 8. Rural N. Y.62:756. 1903. 9. Ohio Sta. Bul. 162:250 fig., 256, 257 , 1905. 10. Mass. Sta. An. Rpt. 17:160. 1905.

October Purple $1,2,3,4,5,6,8,9$, 10. October Purple 7 .

There are but few late plums in Prumus triflora worth cultivating and one of the needs of horticulture is a late plum of superior quality in this species. At present October is the nearest approach to the plum desired but because of several faults it falls considerably short of filling the need. The fruits are large, attractive-looking, fairly suitable for dessert, very good for culinary purposes, hang well to the tree and keep and ship much better than the average Triflora variety; but still they are not far enough from mediocrity to make the variety especially desirable. The trees are well shaped, usually robust and healthy and the fruit is well borne on lateral spurs distributed over the old wood; but in New York, at least, the trees are very tardy in coming in bearing and cannot be depended upon to bear satisfactory crops regularly - a fatal fault in a Triflora plum. October might be sparingly planted in New York to the pleasure of the amateur and possibly to the profit of the commercial fruit-grower who has a good local market.

October is said to be a cross of Satsuma and a seedling Triflora plum; it was first fruited by Luther Burbank in 1892 and was introduced by Stephen Hoyt's Sons, New Canaan, Connecticut, in 1897 . The variety was named October Purple by Burbank but "Purple " has been dropped in accordance with the rules of the American Pomological Society. 
Tree variable in size and vigor, upright-spreading, open-topped, hardy for a Triflora, not uniform in productiveness, healthy; branches rough, dark, dull ash-gray, with numerous, small lenticels; branchlets slender, long, with internodes of average length, greenish-red changing to dull reddish-brown, often with a green tinge on the winter shoots, glabrous; lenticels numerous, small; leaf-buds small, short, obtuse, free.

Leaves falling early, sparse, folded upward, oval or obovate, one and three-eighths inches wide, three and one-quarter inches long, thin and leathery; upper surface slightly rugose, with a broad groove on the lightly pubescent midrib; lower surface very thinly pubescent; apex and base acute, margin glandular, doubly serrate or crenate; petiole one-half inch long, hairy along the upper side, green, with from one to three small, globose, yellowish glands variable in position.

Blooming season early to medium, of average length; flowers appearing before the leaves, thirteen-sixteenths inch across, white; borne in dense clusters on lateral spurs and buds, in pairs; pedicels one-half inch long, slender, glabrous, greenish; calyxtube green, campanulate, glabrous; calyx-lobes obtuse, glandular-serrate, with numerous hairs along the edge, pubescent, somewhat erect; petals broadly ovate, entire, tapering to short, blunt claws; anthers yellow; filaments three-sixteenths inch long; pistil glabrous, longer than the stamens.

Fruit mid-season or later, ripening period long; one and seven-eighths inches in diameter, roundish-cordate or slightly oblate, halves unequal; cavity deep, wide, flaring, with streaks radiating from the cavity; suture shallow or a line; apex roundish to slightly pointed; color dark red over a yellowish-green ground, with bloom of medium thickness; dots numerous, large, russet, conspicuous, clustered about the apex; stem somewhat slender, five-eighths inch long, glabrous, adhering well to the fruit; skin thin, tough, sour, separating readily; flesh light yellow frequently tinged with red, very juicy, slightly fibrous, variable in firmness, sweet, mild, lacking the strong characteristic Triflora flavor; good; stone clinging, seven-eighths inch by five-eighths inch in size, roundish-oval, blunt but with a small tip, somewhat rough, ridged along the ventral, grooved on the dorsal suture.

\section{OGON}

\section{Prunus triflora}

1. Ga. Hort. Soc. Rpt. 29. 1886 . 2. Ibid. 35, 58. 1888. 3. Ibid. 53, 99. 1889. 4. Col.. O.. Hort. Soc. Rpt. 81. 1892. 5. Cornell Sta. Bul. 62:27, 28 fig. 1894. 6. Ga. Hort. Soc. Rpt. 95. I895. 7. Cornell Sta. Bul. 106:59. 1896. 8. Ibid. 131:194. 1897. 9. Ibid. 139:45. 1897. 1o. Am. Pom. Soc. Cat. 26. 1897. I1. Rural N. Y. 57:562. 1898. 12. Colo. Sta. Bul. 50:43. 1898. 13. Wich. Sta. Bul. 169:242, 249. 1899. 14. Cornell Sta. Bul. 175:138 fig. 1899. 15. Ohio Sta. Bul. I13:157. 1899. 16. Waugh Plum Cult. 139. 1901. 17. Ga. Sta. Bul. 68:6 32. 1905. 18. Miss. Sta. Bul. $93: 15$. 1905.

Ogan 5. Ogden 1. Ogon 5. Shiro Smomo 6. Yellow Nagate 2.

Ogon, the Japanese for gold, is the name for one of the comparatively few varieties of Prunus triflora having a yellow color. This variety is further distinguished by being the only freestone sort of its species under 
cultivation in America. Ogon also has a flavor quite distinct, resembling somewhat that of the apricot, which is agreeable to some and not so to others; as the variety grows on the grounds of this Station it cannot be considered of high quality even for an early plum. The fruits crack rather badly on the tree and seem to be unusually susceptible to the attacks of curculio. In some of the references given, it is reported as making a poor tree and as having a weak constitution, and practically all agree that the variety is unproductive. These faults preclude its use in commercial plantations. The variety is distinct and interesting not only in its fruits but in its flowers which bear comparatively few stamens, many of which are abortive and show all degrees between perfect stamens and perfect petals.

Ogon was imported from Japan by H. H. Berger and Company, San Francisco, California. It was first mentioned as the Ogden in the Georgia Horticultural Society Report for 1886 and in the 1888 report of the same Society it was described as a new fruit. In 1897 , the American Pomological Society added Ogon to its fruit catalog list.

Tree medium to large, vigorous, vasiform, dense-topped, hardy at Geneva, unfroductive; branches slender, roughened by numerous spurs, sparingly thorny, dark gray, with numerous, small lenticels; branchlets sometimes swollen at the tips, of medium thickness and length, with internodes of average length, dark brown often with some green, partly overspread with gray scarf-skin, glossy, glabrous; lenticels medium in number and size, raised; leaf-buds small, short, obtuse, plump, free.

Leaves few, oblanceolate, peach-like, variable in size, averaging one and oneeighth inches wide, four inches long, thin; upper surface light green, shining, glabrous, narrowly grooved along the midrib; lower surface light yellowish-green, glabrous except at the base of the veins; margin finely crenate, with small, dark amber glands; petiole one-half inch long, glandless or with from one to four globose, greenish glands on the stalk.

Blooming season early and of medium length; flowers appearing after the leaves, thirteen-sixteenths inch across, white; borne in clusters on lateral spurs and buds, in threes or in fours; pedicels five-sixteenths inch long, glabrous, greenish; calyx-tube green, obconic, glabrous; calyx-lobes narrow, acute, slightly glandular-serrate, faintly pubescent, erect; petals broadly ovate, entire, tapering below to short claws; anthers yellowish, with a little pink; filaments three-sixteenths inch long; pistil glabrous, equal to the stamens in length.

Fruit early, season short; one and one-quarter inches by one and three-quarters inches in size, roundish-oblate, oblique, halves equal; cavity narrow, regular, flaring; suture variable in depth, prominent; apex roundish or slightly flattened; color lemonyellow, with thin bloom; dots numerous, small, whitish, inconspicuous; stem slender, 
one-half inch long, glabrous, separating readily; skin thin, tough, astringent, inclined to crack, slightly adhering; flesh pale or amber-yellow, not as juicy as many of the Trifloras, firm and meaty, sweet, mild; of fair quality; stone free, five-eighths inch by one-half inch in size, roundish-oval, turgid, blunt but with a small short tip, oblique, slightly pitted; ventral suture faintly ridged and furrowed; dorsal suture not grooved.

\section{ORANGE}

\section{Prunus domestica}

1. Lond. Hort. Soc. Cat. 150. 1831. 2. Downing Fr. Trees Am. 282. 1845. 3. Cole Am. Fr. Book 214. I849. 4. Mas Le Verger 6:25. 1866-73. 5. Mathieu Nom. Pom. 442. 1889. 6. BuddHansen Am. Hort. Man. 320 . 1903.

Orange 5. Orange Gage 2, 5, 6. Pomeranzen $Z$ wwetsche 5. Wager 5, 6.

Orange belongs to the Reine Claude group. Taking its characters all in all it cannot compete with even the average varieties of the plums with which it should be compared. This variety was introduced by A. J. Downing who secured it from a Mr. Teller of Rhinebeck, Dutchess County, New York. Although Rhinebeck is probably its place of origin, it is not likely that Teller first grew the variety since it was quite generally disseminated in that vicinity at the time of its introduction. It is fast passing from cultivation.

Tree large, vigorous, upright, productive; branches roughened by the raised lenticels; branchlets numerous, pubescent; leaves oval or slightly obovate, two inches wide, four inches long, thick; margin crenate or serrate, with small grands; petiole tinged red, pubescent, with from two to three globose glands.

Fruit matures in mid-season; about one and one-half inches in diameter roundish-truncate, light amber-yellow with a blush, overspread with thin bloom; stem slender, adhering strongly to the fruit; flesh pale yellow, firm, sweet; of good quality; stone free or nearly so, one inch by five-eighths inch in size, obovate, acute at the apex, blunt at the base, with thickly pitted surfaces; ventral suture wide, usually blunt but sometimes distinctly winged; dorsal suture with a deep groove.

\section{OREN}

Prunus americana

x. Ia. Sta. Bul. 46:285 fig. 1900. 2. Waugh Plum Cult. 174, 1901. 3. Budd-Hansen Am. Hort. Man. 299. т903.

Bartlett r. Bingaman ז.

Waugh places Oren with the "Miner-like" plums but as the variety grows here it is a typical western Americana-the characters of this species in leaf, fruit and stone being well shown in the accompanying plate. It 


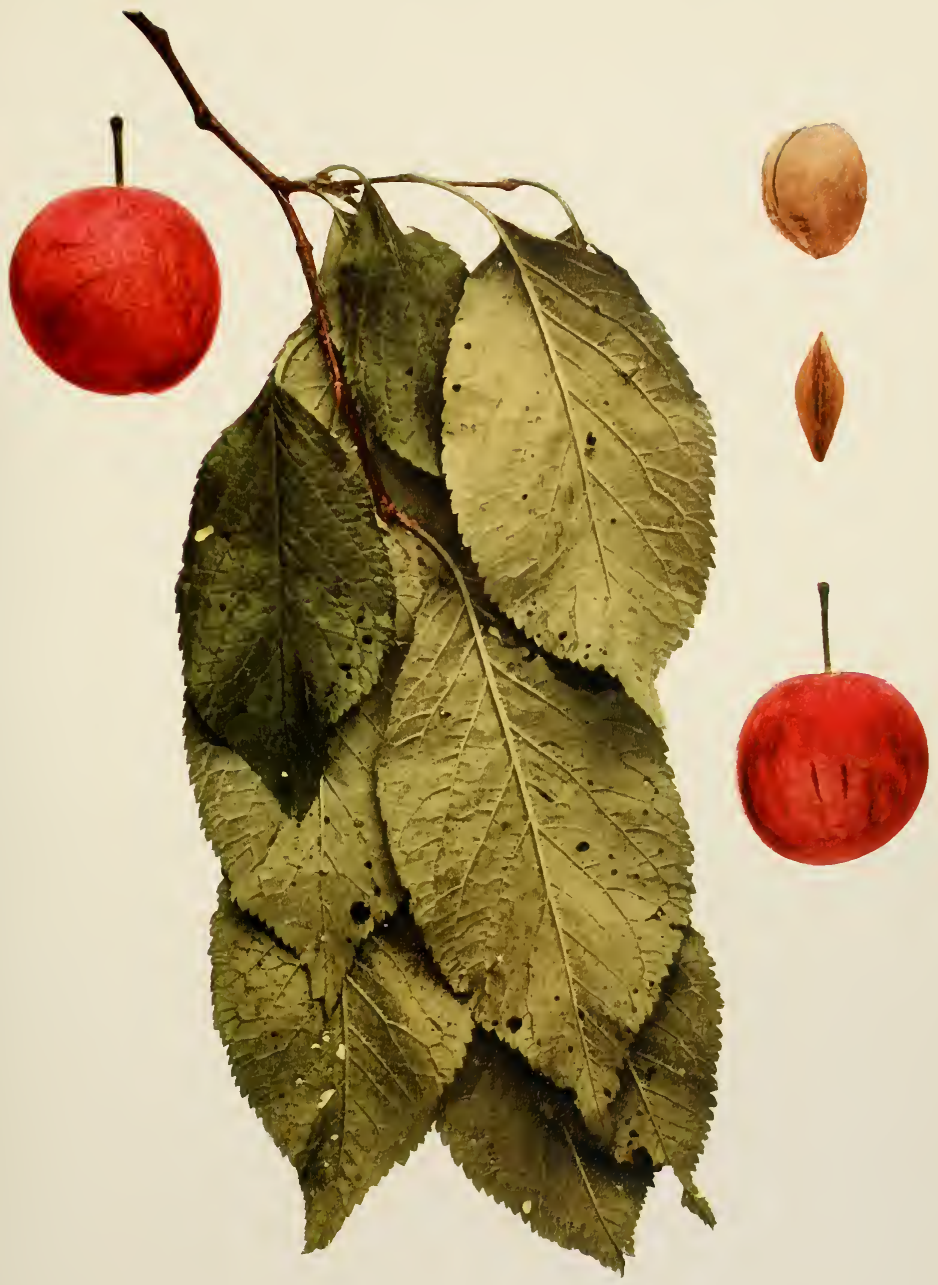

OREN 

is one of the best of the Americanas in both fruit and tree. The fruits are large and of good shape, perhaps a little dull in color and not quite as good in quality as a few other Americanas but still averaging very well in all fruit-characters. The flesh is very nearly free from the stone. The trees are typical of the species, shaggy of trunk and limb, straggling and unkempt in growth of top, but hardy, robust, healthy and reliable in bearing. It would seem as if this variety is rather too good to be allowed to pass out of cultivation until there are more Americanas that are better.

Oren was taken from the wild in Black Hawk County, Iowa, about I 878 , by J. K. Oren. Mr. Oren grew trees of this plum on his farm and permitted all who came to take sprouts, cions and seed until the variety was very generally disseminated locally. Who introduced it to the trade and when is not known.

Tree small, spreading, low, dense-topped, hardy, often unproductive; branches roughish, slightly zigzag, thorny, dark ash-brown, with small lenticels; branchlets slender, long, twiggy, with internodes of average length, green changing to dark ehestnut-brown, glabrous, with large, conspicuous, raised lenticels; leaf-buds small, short, obtuse, free.

Leaves falling early, oval or obovate, two inches wide, three and three-quarters inches long; upper surface dark green changing to golden-yellow late in the season, smooth and shining, with a narrow, grooved midrib; lower surface silvery-green, lightly pubescent; apex taper-pointed, base abrupt, margin coarsely serrate, the serrations ending in sharp points, eglandular; petiole five-eighths inch long, thick, tinged red, thinly pubescent, glandless or with one or two prominent, greenish-brown glands.

Blooming season late and of medium length; flowers appearing after the leaves, one and one-eighth inches across, white; borne in clusters on lateral spurs and buds, in pairs or in threes; pedicels five-eighths inch long, slender, glabrous, green, tinged with red; calyx-tube red, campanulate, enlarged at the base, glabrous; calyx-lobes narrow, somewhat obtuse, pubescent on both surfaces and on the margin, reflexed; petals ovate, somewhat crenate or fringed, tapering below to long, narrow claws, sparingly hairy along the edge of the base; anthers yellow; filaments three-eighths inch long; pistil glabrous, shorter than the stamens.

Fruit intermediate in time and length of ripening season; one and three-sixteenths inches in diameter, roundish, usually truncate and slightly oblique, compressed, halves equal; cavity very shallow, flaring; suture a line; apex roundish or flattened; color dull light or dark red over a yellow ground, mottled, with thick bloom; dots numerous, very small, light russet, inconspicuous; stem slender, five-eighths inch long, glabrous; skin tough, astringent, adhering; flesh dark golden-yellow, juicy, fibrous, soft and melting, sweet; fair to good; stone semi-free, seven-eighths inch by five-eighths inch in size, irregularly roundish or ovate, flattened, blunt at the base and apex, with smooth surfaces; ventral suture strongly winged; dorsal suture acute, with a narrow and shallow groove. 


\section{ORLEANS}

\section{Prunus domestica}

1. Quintinye Com. Gard. 68. I699. 2. Langley Pomona 91, P1. XX fig. 4. 1729. 3. Miller Gard. Dict. 3:1754. 4. Duhamel Trait. Arb. Fr. 2:78, P1. VII. 1768. 5. Knoop Fructologie 2:52, 55, 56, 57. 1771. 6. Forsyth Treat. Fr. Trees 19. 1803. 7. Kraft Pom. Aust. 2:32, Tab. 179 fig. r. 1796. 8. Brookshaw Pom. Brit. P1. XI. 1817. 9. Lond. Hort. Soc. Cat. 145, 150. 1831. 10. Prince Pom. Man. 2:62,67, 85. 1832. I1. Poiteau Pom. Franc. 1:1846. 12. Floy-Lindley Guide Orch. Gard. $289,290,383.1846 . \quad$ 13. Thomas Am. Fruit Cult. 339. 1849. 14. Elliott Fr. Book 428. $1854 . \quad$ 15. Thompson Gard. Ass't 519. 1859. 16. Downing Fr. Trees Am. 935. 1869. 17. Mas Pom. Gest. 2:37, fig. 19. 1873. 18. Am. Pom. Soc. Cat. 36. 1875. 19. Oberdieck Deut. Obst. Sort. 414. 1881. 20. Mathieu Nom. Pom. 435. 1882. 21. Hogg Fruit Man. 715. 1884. 22. Guide Prat. 156, 360. 1895 .

Anglaise Noire 16, 17, 20, 21, 22. Angloise Noire 5. Brignole ? 1. Brugnole ? 1. Brignole Violette 17, 20, 22. Brignole Violette ? 5. Common Orleans 10, 16, 17, 20. Damas Rouge 10. Damas Rouge 5, 9. Damas Violet ? 5. De Monsieur 17, 22. Die Hermpflaume 7. English Orleans 10, 16, 17, 20. French Orleans 8. Hernnpflaume 17. Hermpfla ume 19. Hermpflaume 22. Herzog von Orleans 20, 22. Italian Damask of some 14. Large Red Orleans ro. Late Monsieur 10, 16, 17, 20. Monsieur 4, 9, 10, 12, 17, 22. Monsicur 10, 13, 14, 15, 16, 20, 21. Monsieur Ordinaire 9, 10, 14, 15, 16, 17, 20, 21, 22. Old Orleans 10, 13, 14, 15, 16, 17, 20, 22. Orleans 17, 20, 22. Orleans Red Damask 20. Prune de Monsieur 10, 16, 20. Prune de Monsieur 11. Prune d'Orleans 16, 17, 20, 21. Prunelle ? 5. Prune Monsieur 7. Red Damask 10. Red Damask 9. 10, 12, 13, 14, 15, 16, 17, 18, 20, 21, 22. Red Orleans 10, 16, 17, 20. Red Orleans Plum 6.

In Europe Orleans is one of the most renowned of the plums cultivated. A proof of its popularity is the great number of names, as shown in the synonymy given above, under which it passes in England and on the continent. This variety, however, is almost unknown in America though described by all of the older American pomologists and probably introduced time and again during the last hundred years in our orchards. The French fruit books say that the variety thrives better in southern than northern France and nearly all of the European writers state that it does best in high, dry, light, warm soils. It is likely that our climate, and the soils in which plums are generally grown in America, are not suited to this sort. Unfortunately this Station has no trees of this variety and the brief description given is a compilation.

The Orleans has been cultivated for more than two hundred years. Langley said of it in 1729 " The Orleans Plumb tho a common, is yet a very valuable Plumb, as well for its fine firm juicy Pulp when well ripened, as its being a constant and plentiful bearer." The Red Damask and the Brugnole mentioned by Quintinye in 1699 are probably the Orleans; but the Prune de Monsieur of Knoop and the Monsieur of Tournefort, which are yellow, are distinct. The variety is evidently of French origin. Mas 
in his Pomologie Generale, 1873, states that it first bore the name Brignole Violette, but later was given the name it now bears in honor of Monsieur, Duke of Orleans, brother of Louis XIV. Damas Rouge is an old synonym, though Duhamel described it as a distinct variety. Hermpflaume is the common name of the Orleans in Germany and Austria, while in France, it is often called the Monsieur. It has never been common in America, yet it was entered on the American Pomological Society catalog list in 1875 .

Tree large, vigorous, hardy, productive, bearing annually; branches grayish, pubescent; leaves large, ovate, with crenate margins; flowers large, blooming early; petals roundish, imbricated.

Fruit early mid-season; medium in size, roundish-truncate, sides unequal; cavity usually shallow, wide; suture distinct; apex flattened; color dark or purplish-red, overspread with thin bloom, with a sprinkling of pale reddish dots; stem thick, short; skin tender; flesh yellowish, juicy, usually melting when properly matured, sweet near the skin but sprightly toward the center, pleasant-flavored; good; stone free, small, oval, flattened, with roughish surfaces.

\section{OULLINS}

\section{Prunus domestica}

I. Hogg Fruit Man. 374. 1866. 2. Downing Fr. Trees Am. 935. 1869. 3. Pom. France 7: No. 15. 1871. 4. Mas Le Verger 6:43. 1866-73. 5. Am. Pom. Soc. Cat. 38. 1877. 6. Cat. Cong. Pom. France 366. 1887. 7. Mathieu Nom. Pom. 446. 1889. 8. Waugh Plum Cull. 117. 190r. 9. Thompson Gard. Ass't 4:158. I901.

Massot 6, 7. Monstrueuse d'Oullins 2, 7. Ouillin's Gage 2, 7. Oullins Golden x. Oullin's Golden 2, 9. Oullin's Golden 3, 4, 6, 7. Oullin's Golden Gage 2, 7. Oullins Golden Gage 5. Oullin's Green Gage 8. Prune-Massot 3. Reine-Claude d'Oullins $1,2,7,9$. Reine-Claude D'Oullins 3, 4, 6. Reine-Claude Prêcoce 1, 2, 3, 6, 7, 9. Reine-Claude von Oullins 7. Roi-Claude 3, 7.

Oullins came to America with the best of recommendations from European growers but it has fallen so far short of its reputation in Europe that it was dropped from the fruit list of the American Pomological Society and is gradually disappearing from cultivation. The fault is in the fruit which is but indifferent in quality for a plum of the Reine Claude group. In Europe the variety is rated as one of the best dessert sorts; in America it is hardly second-rate in quality. This difference may be due to differences in climate and soil; more probably, it is due to the greater number of better Reine Claude varieties grown in America with which it must compete. Hand, Jefferson, Washington, McLaughlin, Yellow Gage, Spaulding and Imperial Gage, the cream of the Reine Claude plums, are all Americans similar to Oullins but much better in quality. Oullins is hardly surpassed by any of its group in tree-characters and might well be used 
for breeding purposes as there are so few sorts of its kind having satisfactory trees.

This variety, probably a Reine Claude seedling, was found at Coligny, France, on the estate of M. Filliaud; it was propagated by M. Corsaint, gardener to the Baron de Toisy, near Cuiseaux (Department of Saoneet-Loire) and was introduced at Oullins (Department of Rhone) by M. Massot, nurseryman. The name is seldom spelled correctly in American fruit books, being either written with an apostrophe and s or with both left off, these spellings coming from the supposition that the name comes from that of a man, a mistake as the history shows. Oullins was placed on the American Pomological Society catalog fruit list in 1875 but was dropped when the catalog was revised in 1897 .

Tree large, vigorous, spreading, open-topped, hardy, productive; branches ashgray, somewhat rough, with numerous, large, raised lenticels; branchlets stout, the bark rough, medium to above in thickness, short, with short internodes, greenishred changing to brownish-red, dull, lightly pubescent, overspread with faint bloom, with numerous, small lenticels; leaf-buds large, long, pointed, free; leaf-scars swollen.

Leaves oval or obovate, two inches wide, four and one-quarter inches long, thick; upper surface dark green, covered with fine hairs, the midrib grooved; lower surface pale green, pubescent; apex acute or abruptly pointed, base acute, margin serrate or crenate, with small black glands; petiole three-quarters inch long, thick, pubescent, tinged red, with from two to four globose, greenish-brown glands variable in size, usually on the stalk.

Blooming season medium to late, of average length; flowers appearing after the leaves, one and one-quarter inches across, white, with a faint yellowish tinge; arranged on lateral spurs, singly or in pairs; pedicels eleven-sixteenths inch long, pubescent, greenish; calyx-tube green, campanulate, pubescent; calyx-lobes broad, obtuse, pubescent on both surfaces, glandular-serrate, reflexed; petals broadly obovate, crenate, tapering to short, broad claws; anthers yellowish; filaments three-eighths inch long; pistil glabrous, equal to the stamens in length.

Fruit early, season short; medium to below in size, roundish, halves equal; cavity shallow, below medium in width, abrupt; suture an indistinct line; apex flattened or depressed; color greenish-yellow changing to dull light yellow, overspread with thin bloom; dots numerous, small, whitish, inconspicuous, clustered about the apex; stem of medium thickness and length, adhering well to the fruit; skin thin, slightly astringent, separating readily; flesh greenish-yellow or pale yellow, somewhat dry, firm, sweet, not high in flavor; good; stone half-free or free, three-quarters inch by five-eighths inch in size, broadly oval, flattened, roughened and pitted, blunt at the base and apex; ventral suture rather narrow, furrowed, with a distinct but not prominent wing; dorsal suture broadly and deeply grooved. 



\section{PACIFIC}

\section{Prunus domestica}

I. U.S. D. A. Rpt. 292. 1893. 2. Am. Pom. Soc. Rpt. 150. 1895. 3. Oregon Sta. Bul. 45: 31. 1897. 4. Oregon Hort. Soc. Rpt. 474. 1898. 5. Am. Pom. Soc. Cat. 40. 1899. 6. Waugh Plum Cult. 117. 1901. 7. Oregon Agriculturist 17:No. 24, 370. 1908.

Pacific 3. Pacific Prune 2, 3. Willamette 4, 5, 7. Willamette Prune 3.

No part of America is so well adapted to plum culture as the Pacific Coast and especially the inter-mountain valleys in Oregon. From the last-named State, though fruit-growing is a very recent development, a number of meritorious plums have been added to pomology. One of the best of these, as they grow in New York, is the Pacific, the fruits of which are well shown in the color-plate. Few purple plums are more beautiful than this in color and shape, few equal it in size and very few of its color excel it in quality. The trees are unusually robust, perfectly hardy and productive. In Oregon the Pacific has not proved a good prune-making plum but is reported as standing eastern shipment very well, which, if true, indicates that this plum would succeed as a market fruit in New York. Pacific is well worth trying in New York as a commercial variety.

This plum is hopelessly confused with the Willamette. The following is an abridged account of the two fruits as written us by H. M. Williamson, Secretary of the Oregon State Board of Horticulture, and one of the leading authorities on fruit-growing on the Pacific Coast.

"About I875 Jesse Bullock of Oswego, Oregon, sent to Germany for pits of the Italian or Fellenberg prune, and planted the pits received in a nursery row. When the trees from these began to bear, Mr. C. E. Hoskins went to Mr. Bullock's place, examined the fruit and selected trees which seemed promising, giving to each tree a number. From at least six of these trees he took scions, propagated them, and named them Bullock No. I, Bullock, No. 2, etc. He finally decided that only two of these, Bullock No. I and Bullock No. 6, were of sufficient value to justify their further propagation. Bullock No. I was named Champion and Bullock No. 6, Willamette. Mr. Hoskins told me these names were given by the State Horticultural Society, but I find no record of this action. He propagated and sold a good many trees of both varieties, but more of the Willamette than of the Champion.

"Mr. Hoskins was strongly of the opinion that the Pacific is identical with the Willamette. I am as strongly of the opinion that they are distinct varieties. I base my opinion, first, upon the history of the origin of the Pacific given me by Henry Freeboro, Portland, Oregon, who introduced 
it; and, second, upon what appear to me to be marked differences in the two prunes. A number of years ago I went to Mr. Freeboro's place when prunes were ripe and obtained from him a supply of Pacific prunes grown on trees propagated by him from scions taken from the original Pacific tree. I took these prunes to Springbrook and compared them with the Willamette grown on Mr. Hoskins' place. I was thoroughly convinced that the two were decidedly different in character, but Mr. Hoskins did not think so. I noticed first a marked difference in the habits of growth of the trees. The Pacific trees were of unusually vigorous growth and had a decided upright tendency. The Willamette trees were very similar to the Italian in vigor and had the rather spreading habit of growth of the Italian. The Pacific prunes are larger in size than the Willamette and vary much more in size. One of the most decided indications of difference is the far greater tendency to brown-rot of the fruit of the Pacific than is the case with the fruit of the Willamette. This has been observed when scions of the Willamette and of the Pacific have been grafted on the same tree for the purpose of comparison. I have never seen a well dried specimen of the Pacific, but this may have been the fault of the men who dried the specimens I have seen. The Willamette dries easily for a prune of its size and gives a larger percentage of dried to fresh fruit than the Italian, according to Mr. Hoskins.

"I believe the Willamette is well worthy of more attention in the Willamette Valley, whereas the Pacific, on account of its extreme susceptibility to the brown-rot, does not appear to be a safe variety here, although when perfect it is a magnificent prune for eating fresh, and one of the very largest known. I am told that in eastern Oregon where climatic conditions keep out the brown-rot, the Pacific is proving one of the best varieties for shipping fresh. At the present time the two varieties are much confused. When the Pacific prune was introduced, Mr. Hoskins and other recognized authorities, pronounced it the Willamette, and nurserymen therefore obtained scions from Willamette treees and sold the propagated trees as Pacifics, and in a more limited way the reverse was done. The greater part of the trees supposed to be Pacifics are in fact Willamettes."

At this Station we have the two plums under discussion, the Pacific having been obtained from Fred E. Young, nurseryman, Rochester, New York, and the Willamette, under the name Pacific, from the Oregon Wholesale Nursery Company, Salem, Oregon. The differences between the two plums in New York are essentially those given by Mr. Williamson as distinguishing characters in Oregon.

Tree of medium size, upright-spreading, open-topped, hardy, productive; branches ash-gray, smooth, with small, raised lenticels; branchlets above medium in thickness, 


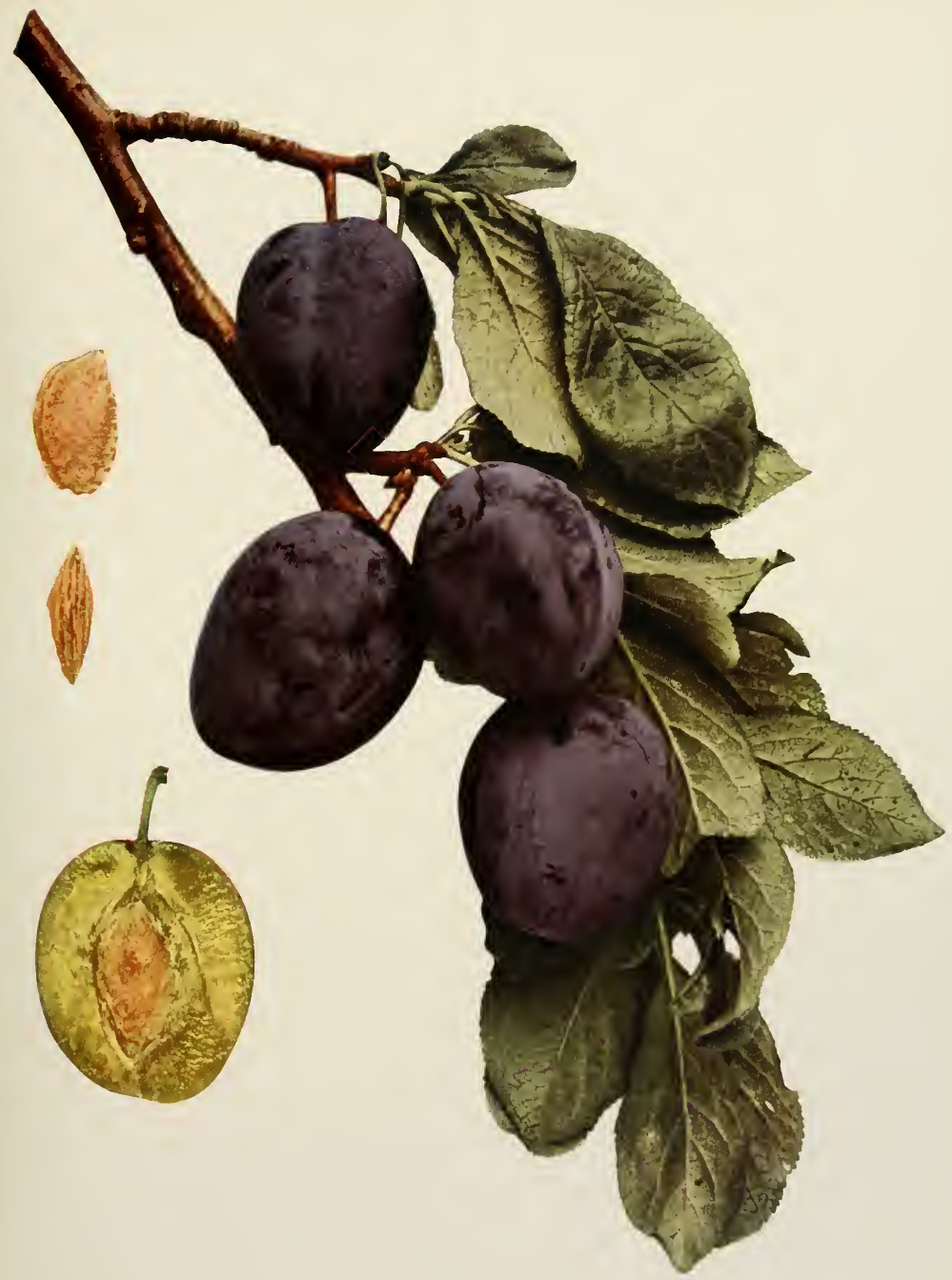


short, with short internodes, grecnish-red changing to brownish-red, covered with heavy bloom and sparingly pubescent, with indistinct small lenticels; leaf-buds plump, of medium size and length, obtuse, free.

Leaves obovate, two inches wide, four inches long, the oldest thick and leathery; upper surface dark green, covered with fine hairs, with a widely and deeply grooved midrib; lower surface pale green, pubescent; apex acute or obtuse, base acute, margin crenate, with small dark glands; petiole seven-eighths inch long, thick, pubescent, tinged red, with from two to four large, globose, yellowish-green glands usually on the stalk.

Blooming season of medium length; flowers appearing after the leaves, one and three-sixteenths inches across, white; borne on lateral spurs and buds, singly or in pairs; pedicels five-sixteenths inch long, thick, pubescent; calyx-tube green, campanulate, pubescent only at the base; calyx-lobes broad, obtuse, lightly pubescent on both surfaces but heavily pubescent along the serrate margin, reflexed; petals oval, dentate, tapering to short, broad claws; stamens inclined to develop into rudimentary petals; anthers yellow; filaments seven-sixteenths inch long; pistil glabrous, equal to the stamens in length.

Fruit intermediate in time and length of ripening season; two inches by one and five-eighths inches in size, ovate, halves equal; cavity shallow, narrow, flaring; suture shallow, indistinct; apex bluntly pointed; color bluish, overspread with thick bloom; dots small, brown, conspicuous, clustered about the apex; stem thick, one-half inch long, pubescent, adhering well to the fruit; skin thin, tough, separating readily; flesh pale golden-yellow, juicy, firm, sweet, spicy; good; stone free, one inch by five-eighths inch in size, flattened, irregularly broad-oval, obliquely contracted at the base, blunt at the apex, with rough and pitted surfaces; ventral suture narrow, with numerous deep furrows, usually blunt; dorsal suture widely and deeply grooved.

\section{PALATINE}

\section{Prunus domestica}

This plum, scarcely known outside of two counties in New York, is of distinctly good quality and if all accounts are true is fairly immune to black-knot. In size and appearance the fruits are superior to many other Reine Claude plums, with which it must be compared, so much so that the variety is probably worth growing outside the region where the following interesting history shows it has been cultivated for nearly a century and a half.

Palatine, according to Mr. Washington Garlock of New York, originated in 1760 when a family of Palatines by the name of Best came from Germany to the United States and settled in Livingston Manor (East Camps) now Columbia County, New York. They brought with them plum pits which they planted and from them secured one tree. In $1_{7} 6_{2}$ 
they moved to Schoharie County, New York, taking with them the seedling tree. In their new home they propagated the variety, which they named Palatine, and disseminated it so industriously that it became thoroughly established throughout Montgomery and Schoharie counties and attained great popularity because of its apparent freedom from blackknot. That this popularity is merited is attested by the fact that after one hundred and fifty years it is still extensively grown in that vicinity.

Tree large, vigorous, spreading, dense-topped, productive; branches thick; branchlets lightly pubescent; leaves flattened, slightly drooping, obovate, one and five-eighths inches wide, three and one-quarter inches long, thick, rugose; margin coarsely crenate, eglandular or with few, small glands; petiole pubescent, glandless or with one or two small glands; blooming season intermediate in time, short; flowers appearing after the leaves, more than one inch across, white with yellow tinge at the apex of the petals; borne singly; calyx-lobes thickly pubescent on both surfaces, strongly reflexed.

Fruit intermediate in time and length of ripening season; about one and one-half inches in diameter, roundish or roundish-oval, dull yellowish-green becoming greenishyellow at full maturity, mottled and indistinctly blushed on the sunny side, overspread with thin bloom; skin thin, slightly sour; flesh light golden-yellow, juicy, fibrous, firm, sweet, pleasant in flavor; good to very good; stone dark colored, free or nearly so, seven-eighths inch by one-half inch in size, oval, with thickly pitted surfaces; ventral suture blunt or with a short, narrow wing; dorsal suture wide, shallow.

\section{PAUL EARLY}

\section{Prunus domestica}

x. N. Y. Exp. Sta. Rpt. 12:611. 1893. 2. W. N. Y. Hort. Soc. Rpt. 42:83. 1897.

Paul's Earliest I, 2.

This variety seems to be under test only at this Station where it has fruited for a number of years. It is so similar to Early Rivers, a variety of small account in America, as to be an almost worthless addition to the list of plums. Paul Early originated with and was sent out by J. M. Paul, North Adams, Massachusetts, about I 888 .

Tree very large, vigorous, round-topped, dense, very productive; branches covered with numerous fruit-spurs; branchlets twiggy, thickly pubescent; leaf-buds strongly appressed; leaves flattened, obovate or oval, two and three-eighths inches wide, four inches long; margin crenate, with few, small, dark glands; petiole reddish, pubescent, glandless or with one or two large glancis; blooming season intermediate in time, short; flowers appearing before the leaves, one inch across; borne in scattering clusters, usually in pairs; pedicels very thick and pubescent; anthers tinged red.

Fruit very early, season short; one and three-eighths inches by one and one-quarter inches in size, roundish-oval, dark purplish-black, overspread with thick bloom; 
skin tender, slightly sour; flesh greenish-yellow becoming yellowish, tender, sweet near the surface but sour next the pit, mild; good; stone clinging, seven-eighths inch by five-eighths inch in size, irregular-oval, with roughened and thickly pitted surfaces; ventral suture prominent, seldom winged; dorsal suture with a narrow, shallow groove.

\section{PEACH}

\section{Prunus domestica}

I. N. E. Farmer Dict. 266. 1797. 2. Prince Treat. Hort. 27. 1828. 3. Prince Pom. Man. 2:106. 1832. 4. Downing Fr. Trecs Am. 307. 1845. 5. Horticulturist I:113, 114 fig. 34, 147. 1846. 6. Poiteau Pom. Franc. I:1846. 7. Thomas Am. Fruit Cull. 335,336 fig. 262. 1849. 8. Horticulturist 6:132. 1851. 9. Elliott Fr. Book 422. 1854. 1o. Downing Fr. Trees Am. 367. 1857. II. Hooper W. Fr. Book 250. 1857. I2. Am. Pom. Soc. Cat. 86. 1862. 13. Hogg Fruit Man. 375. 1866. 14. Mas Le Verger 6:73, P1. XXXVII. 1866-73. 15. Pom. France 7: No. 7. 1871. 16. Gard. Chron. N. S. 17:144. 1882. 17. Mich. Hort. Soc. Rpt. 466. 1883. I8. Wickson Cal. Fruits 353. 1891. 19. Wash. Hort. Soc. Rpt. 136. 1893. 20. Guide Prat. 156, 361. 1895. 21. Cat. Cong. Pom. France 462 fig. 1906.

Apricot Plum 5 incor. Caledonian 15, 20. Calvels Pfirschenpflaume 14, 20. D'Abricot (of Strects of Paris) 20. Duane's Purple 5 incor, 6, 11. Howell's Large 15, 20, 21. Jenkin's Imperial 15. 20. Large Peach 16. Large Peach Plum 3. Nectarine 15, 20. Nectarine Rouge 21. Peach 15,20. Pcach Plum 3, 5, 14, 20. Peach Plum 7, 8, 9, 10, 11, 12, 17. Pêche 14, 15, 20, 21. Pêche de Calvel 20. Prune Pêche 3, 7, 9, 10, I4, I8. Prune Pêche 4, 5, 6, 20. Prune-Pêche De Calvel I4. Reine-Claude De Berger 13, 16. Rothe Nektarine 15, ?20.

Peach, the largest early plum, is not high in quality but is justly esteemed where it can be grown for its earliness, large size and handsome appearance. Unfortunately this variety is capricious beyond most other plums as to climate and soils and refuses to thrive unless its needs are very well supplied in the matter of environment. In America it seems to find congenial soil and climate only on the Pacific Coast, and even then refuses to bear well except on strong, rich soils. In New York, even when grown upon soils similar to those upon which it does well elsewhere, the fruits are few and lacking in quality, though the trees are large, vigorous and about all that could be desired in a good plum tree. It may be possible to grow Peach in favorable locations in the East; in which case, a plum of its appearance and quality, coming as early in the season as it ripens, would make a most desirable addition to the list of plums. From its behavior elsewhere the situation that would suit it best in New York is a sunny exposure with a warm, rich, clay loam.

The origin of the Peach is unknown. Poiteau was unable to find any reference to it in the Eighteenth Century European literature and thought, therefore, that it must have been unknown to this period. Samuel Deane mentions a Peach plum in New England in 1797. It is doubtful, 
however, whether it is the Peach of this discussion, the name having been applied indiscriminately to several varieties, the Goliath, Nectarine and Apricot in particular. Prince, in 1832 , described a Large Peach Plum which he said " had been introduced a few years since" but as his variety is oval and a clingstone, it is not the same as the Peach of Poiteau, the one discussed here, this plum being nearly round and a freestone. Judge James C. Duane of Schenectady, New York, seems to have first imported the Peach plum, with several others, from France, in 1820 . The name of this variety was lost during the shipment and as the invoice called for an Apricot Plum, the names Apricot and Duane's Plum became locally applied to what afterwards turned out to be the Peach. C. H. Tomlinson of Schenectady and A. J. Downing in 1846 made a careful study of these imported plums and showed conclusively that this Apricot or Duane's Plum was. the Peach of the French. In 1862 , the American Pomological Society added Peach to the fruit catalog list and recommended it for the eastern and western sections of New York.

Tree large, very vigorous, spreading, round or flat-topped, hardy, medium in productiveness; branches stocky, smooth, dark ash-brown, with lenticels of medium number and size; branchlets thick, with internodes one inch long, light brown, covered with short, heavy pubescence; leaf-buds large, of medium length, conical.

Leaves large, oval, of average thickness; upper surface dark green; lower surface pale green, pubescent; apex obtuse, margin doubly crenate, with small glands; petiole three-quarters inch long, thick, pubescent, with a trace of red, usually with two, small, globose, greenish glands at the base of the leaf.

Fruit early; thick-set, without a neck, one and seven-eighths inches in diameter, roundish, slightly angular, halves equal; cavity deep, wide, compressed; suture shallow, distinct; apex flattened or depressed; color dark purplish-red, overspread with thin bloom; dots numerous, large, conspicuous; stem eleven-sixteenths inch long, glabrous, adhering well to the fruit; skin tough, adhering; flesh golden-yellow, medium juicy, firm, subacid, mild; good; stone free, one inch by three-quarters inch in size, roundish-oval, flattened, with rough and pitted surfaces, blunt at the base and apex; ventral suture wide, prominent, often distinctly winged; dorsal suture with a wide, deep groove.

\section{PEARL}

\section{Prunus domestica}

I. Burbank Cat. 5. 1898. 2. Am. Gard. 21:36. 1900. 3. Waugh Plum Cult. I18. r9or.

One can grow seedlings of some plums with considerable certainty of getting respectable offspring-plums worth having in an orchardbut the chances of growing a variety of superior qualities are small indeed. 


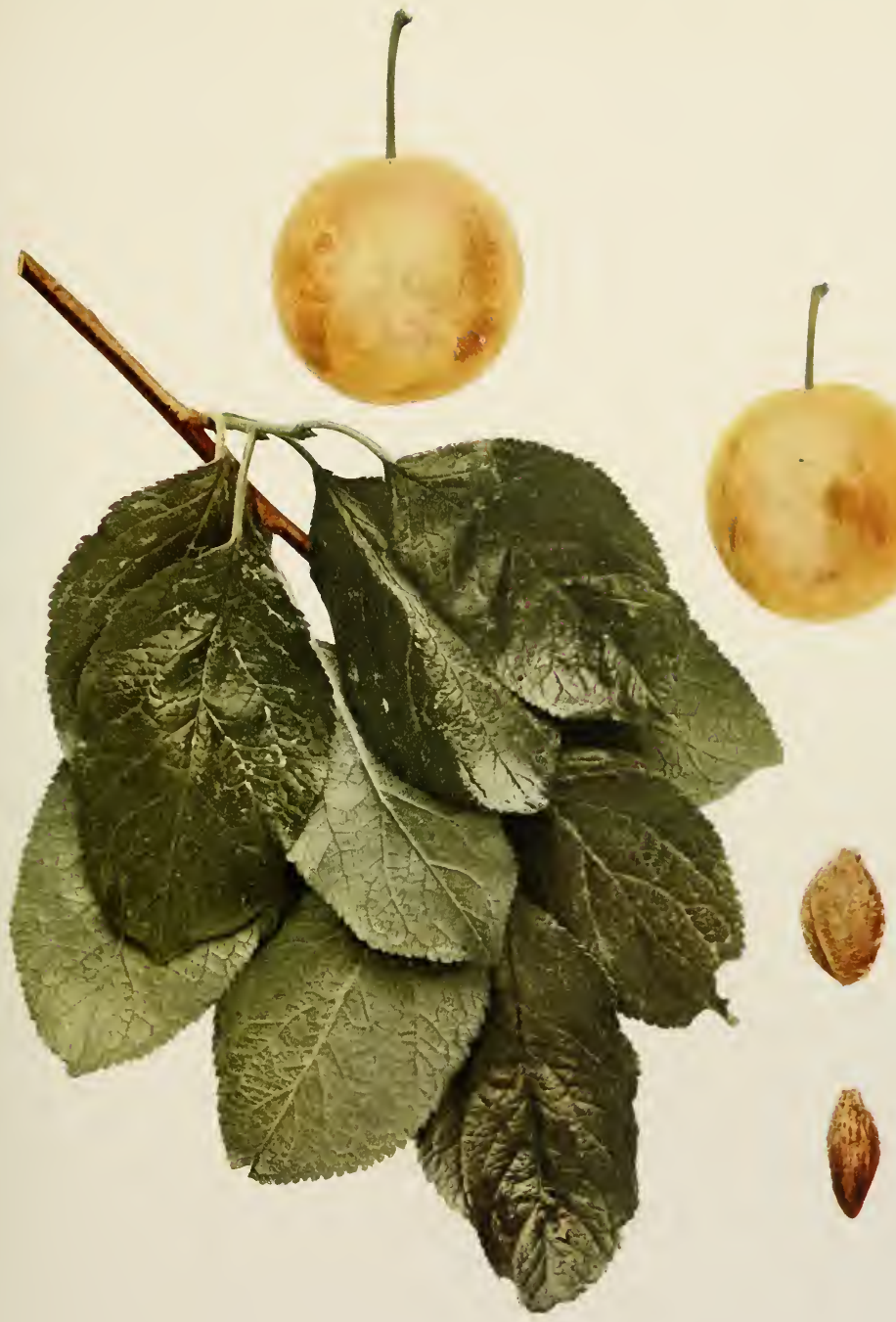



It is a piece of good luck, a matter almost wholly of luck, when, as in this case, but one parent is known, to secure as fine a fruit as the Pearl plum. The variety now under notice is one to be pleased with if it came as a chance out of thousands; its rich, golden color, large size, fine form, melting flesh and sweet, luscious flavor, place it among the best dessert plums. In the mind of the writer and of those who have assisted in describing the varieties for The Plums of New York, it is unsurpassed in quality by any other plum. The tree-characters, however, do not correspond in desirability with those of the fruits. The trees, while of medium size and seemingly as vigorous and healthy as any, are unproductive. In none of the several years they have been fruiting at this Station have they borne a large crop. If elsewhere this defect does not show, the variety becomes at once one of great value. The fruits of Pearl are said to cure into delicious prunes - to be readily believed by one who has eaten the fresh fruits. This variety ought to be very generally tried by commercial plum-growers and is recommended to all who grow fruit for pleasure.

Pearl is a recent addition to the list of plums and though its history is well known its parentage is in doubt. In 1898 , Luther Burbank introduced the variety as a new prune grown from the seed of the well-known Agen. The male parent is not known but from the fruit and tree, one at once surmises that it was some variety of the Reine Claude group, its characters being so like those of the plum named that no one could suspect that it came from the seed of a plum so far removed from the Reine Claude as the Agen.

Tree of medium size, vigorous, vasiform, dense-topped, hardy, unproductive; branches ash-gray, with numerous, small, raised lenticels; branchlets twiggy, thick, long, with long internodes, greenish-red changing to brownish-red, very pubescent early in the season becoming less so at maturity. with numerous, small, raised lenticels; leaf-buds large, above medium in length, conical, appressed; leaf-scars prominent.

Leaves broadly oval, one and seven-eighths inches wide, three and one-half inches long, thick, leathery; upper surface dark green, rugose, covered with fine hairs, with a grooved midrib; lower surface pale green, pubescent; apex abruptly pointed, base abrupt, margin serrate or crenate, with small, black glands; petiole seven-eighths inch long, thick, pubescent, tinged red, glandless or with from one to three small, globose, brownish glands on the stalk.

Blooming season intermediate in time and length; flowers appearing after the leaves, showy on account of their size, averaging one and five-eighths inches across, white, with a tinge of yellow at the apex of the petals; borne on lateral spurs and buds, usually singly; pedicels one-half inch long, thick, strongly pubescent, greenish; calyx- 
tube green, campanulate, pubescent; calyx-lobes broad, obtuse, pubescent on both surfaces, glandular-serrate and with marginal hairs, strongly reflexed; petals obovate or oblong, entire, tapering to short, broad claws; anthers yellow; filaments nearly one-half inch long; pistil glabrous, shorter than the stamens.

Fruit intermediate in time and length of ripening season: one and three-quarters inches by one and one-half inches in size, roundish-oval, compressed, halves unequal; cavity shallow, narrow, abrupt; suture a line; apex depressed; color golden-yellow, obscurely striped and splashed with dull green, mottled, overspread with thin bloom; dots numerous, small, whitish, inconspicuous, clustered about the apex; stem thick, three-quarters inch long, thickly pubescent, adhering well to the fruit; skin tough, separating readily; flesh deep yellow, juicy, a little coarse and fibrous, firm but tender, very sweet, with a pleasant, mild flavor, aromatic; very good to best; stone clinging, one inch by five-eighths inch in size, long-oval, slightly necked at the base, bluntly acute at the apex, with rough surfaces; ventral suture broad, blunt; dorsal suture with a wide, shallow groove.

\section{PETERS}

\section{Prunus domestica}

x. Prince Pom. Man. 27. 1828 . 2. Lond. Hort. Soc. Cat. 151. 18 31 . 3. Cultivator 8:52 fig. 1860. 4. Thomas Am. Fruit Cult. 375 fig. 392. I 867. 5. Downing Fr. Trees Am. 937. 1869. 6. Mich. Hort. Soc. Rpt. 289 . 1889. 7. Mich. Sta. Bul. 103:35. 1894. 8. Cornell Sta. Bul. 131: 190 fig. 45, 194. 1897. 9. Waugh Plum Cult. 118 fig. 1901. 10. Budd-Hansen Am. Hort. Man. 321,322 fig. 1903 .

Peter's Large Yellow I, 2. Peter's Yellow Gage 10. Peters' Yellow Gage 3, 4, 6, 7. Peter's Yellow Gage 5, 8. Peters Yellow Gage 9.

Peters is an excellent old plum probably ranking in quality with the best varieties in the group to which it belongs-a sufficient recommendation to make it desirable in any home collection of fruit. This variety, however, is not equal in appearance to any one of several other sorts in its group, lacking size and color. The trees are large, hardy, robust and healthy, surpassing in these respects most of the other Reine Claude sorts. The tree-characters have made this variety a prime favorite in western New York for two generations, one pomologist after another recommending it for this section. The fruits are not sufficiently attractive to sell well, however, and the variety is now going out of cultivation except for the amateur. While a very good plum it does not appear to be worth growing in competition with Hand, Washington, McLaughlin, Jefferson, Spaulding and the latest comer among these high-quality plums, Pearl.

Of the origin of this old plum we have no certain information. William Prince, the first pomologist to mention it, gave a brief description of the variety in his "A Short Treatise on Horticulture" published in 1828 


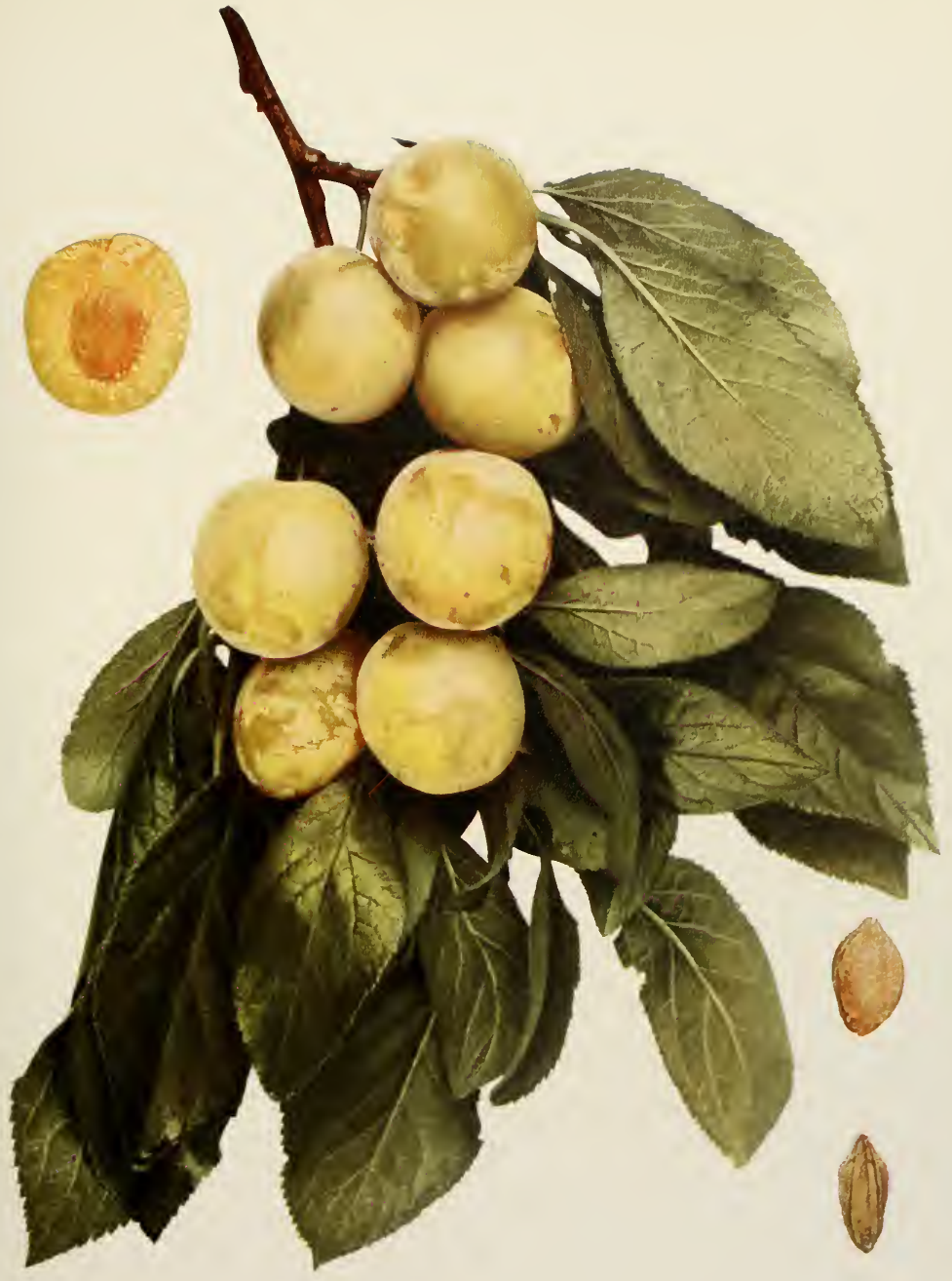



but says nothing in regard to its history. In 1831 the London Horticultural Society listed it in its fruit catalog but otherwise the variety is not mentioned in the European pomologies.

Tree very large, vigorous, round and dense-topped, hardy, productive; branches thick, ash-gray, smooth exccpt for the numerous, rather large, raised lenticels; branchlets thick, short, with short internodes, greenish-red changing to dark brownish-drab, dull, pubescent throughout the season, with numerous, inconspicuous, small lenticels; leaf-buds medium in size and length, pointed, free.

Leaves flattened, obovate or oval, two inches wide, four inches long; upper surface covered with numerous hairs, with a shallow groove on the midrib; lower surface silvery-green, heavily pubescent; apex abruptly pointed or acute, base rather abrupt, margin slightly crenate, eglandular or with few, small, dark glands; petiole threeeighths inch long, thick, tinged red, pubescent, glandless or with one or two small, globose or reniform, greenish-brown glands usually on the stalk.

Blooming season intermediate in time and length; flowers appearing with the leaves, one and one-eighth inches wide, white, creamy at the apex; borne on lateral spurs or buds, singly or in pairs; pedicels about one inch long, below medium in thickness, pubescent, greenish; calyx-tube green, obconic, pubescent; calyx-lobes broad, obtuse, pubescent on both surfaces, glandular-serrate and with fine marginal hairs, reflexed; petals roundish-oval or obovate, dentate to slightly crenate; anthers yellow, with a slight trace of red; filaments three-eighths inch long; pistil glabrous, longer than the stamens.

Fruit late, season rather short; about one and one-half inches in diameter, roundish, compressed, halves equal; cavity very shallow, narrow, abrupt; suture shallow; apex flattened or depressed; color dull yellowish-green, often blushed or mottled on the sunny side, covered with thick bloom; dots numerous, large, whitish, conspicuous; stem one and one-eighth inches long, pubescent, adhering well to the fruit; skin thin, tough, separating readily; flesh golden-yellow, juicy, somewhat fibrous, firm but tender, sweet next the skin but sour near the center, with pleasant flavor; very good; stone clinging, one inch by three-quarters inch in size, oval, turgid, somewhat acute at the base and apex, with pitted surfaces; ventral suture wide, indistinctly furrowed, often with a short wing; dorsal suture widely and deeply grooved.

\section{POND}

\section{Prunus domestica}

1. Lond. Hort. Soc. Cat. 151. 1831. 2. Mag. Hort. 9:165. 1843. 3. Horticulturist 6:560 fig. 185x. 4. Gard. Chron. 13:228. 1853. 5. Am. Pom. Soc. Cat. 214. 1856. 6. Ann. Pom. Belge 9, fig. 1857. 7. Cultivator 8:52 fig. 1860. 8. Thomas Am. Fruit Cult. 343. 1867. 9. Downing Fr. Trees Am. 937 fig. 1869. 10. Pom. France 7 :No. 2. 1871. 11. Mas Le Verger 6:5, fig.3. 1886-73. 12. Mich. Hort. Soc. Rpt. 466. 1883. 13. Hogg Fruit Man. 717.1884. 14. Cal. State Bd. Hort. Rpt. 292. 1885-86. 15. Mathieu Nom. Pom. 442. 1889. 16. Mich. Hort. Soc. Rpt. 465. 1893. 17. Guide Prat. 155, 366. 1895. 18. Oregon Sta. Bul. $45: 29$ fig. 1897. 19. Cornell 
Sta. Bul. 131:190. 1897. 20. W. N. Y. Hort. Soc. Rpt. 92. 1899. 21. Ohio Sta. Bul. x13:160, P1. XVI fig. 1899. 22. Va. Sta. Bul. 134:44. 1902. 23. Budd-Hansen Am. Hort. Man. 322. 1903. Chili (Kerr unpublished). Diamant 15 incor. Diamantplaume 17 incor. Dorr's Favorite 12. English Pond's Seedling 3. Farleigh Castle 13, 15. Fonthill 4, 9, 10, 12, 13, 15, 17, 23. Gros Prune 14. Grosse Prune d'Agen 18, 20. Hungarian 18. Hungarian 20. Hungarian Prune 16, 19. Hungarian Prune 14. Oswego 20. Oswego 19. Plum de l'Inde ?3. Plum de l'Inde 9, 15. Pond's Purple 9, 10, 13, 15, 17. Pond's Seedling (English) 11, 14, 17. Pond's Seedling 1, 2, 4, 5, $6,7,8,9,10,11,13,16,21$. Pond's Seedling 14, 15, 17, 18, 19, 23. Pond Seedling 20. Pond's Samling 15, 17. Pourprie de Pond 10, 15, 17. Pride of Waterloo 20. Semis de Pond 10, 15. Semis de Pond 17.

Pond is preeminent among plums for its large size. It is distinguished also by its form and its color, both being pleasing as well as distinctive. The three characters, size, form and color make this one of the handsomest of all plums. Despite the efforts of the color-plate makers, the peculiar red of this plum is not well shown in the illustration - to the disparagement of the fruit. At one time Pond was very largely grown in New York but the fruits are not as perfect, grown here, as on the Pacific Coast and the trees are not regular in bearing. The eye is pleased with Pond but the palate is sadly disappointed; at best it is not even second-rate. The fruits, however, ship and keep well, as is demonstrated by the large quantities of this variety annually sent from California to the East for sale on fruit-stands where its showiness perennially beguiles the uninformed fruit-buyer. There is a fine opportunity for some one to cross this splendidappearing plum with one of good quality in the hope of getting an offspring as handsome but of better quality.

This variety was obtained from seed by Mr. Pond, an English amateur grower of fruits, concerning whom there seems to be no further information. The London Horticultural Society mentioned the variety as long ago as in 1831. Another Mr. Pond, a nurseryman in Massachusetts, grew a variety very similar in appearance to the English plum and permitted his name to be given it to the great confusion of the nomenclature of the two. The Hungarian prune of the Pacific Coast is Pond, why so-called does not appear; with this as with several other plums the Pacific Coast fruit-growers persist in using a name known to have been wrongly applied to an old and well-known variety elsewhere called rightly. Oswego, a supposed seedling grown in Oswego, New York, is identical with the Pond as tested by this Experiment Station and by local growers. The American Pomological Society placed this fruit on 1ts catalog list in 1856 .

Tree of medium size, vigorous, upright, hardy, variable in productiveness; branches light gray, smooth, with small, raised lenticels; branchlets of medium thickness and 


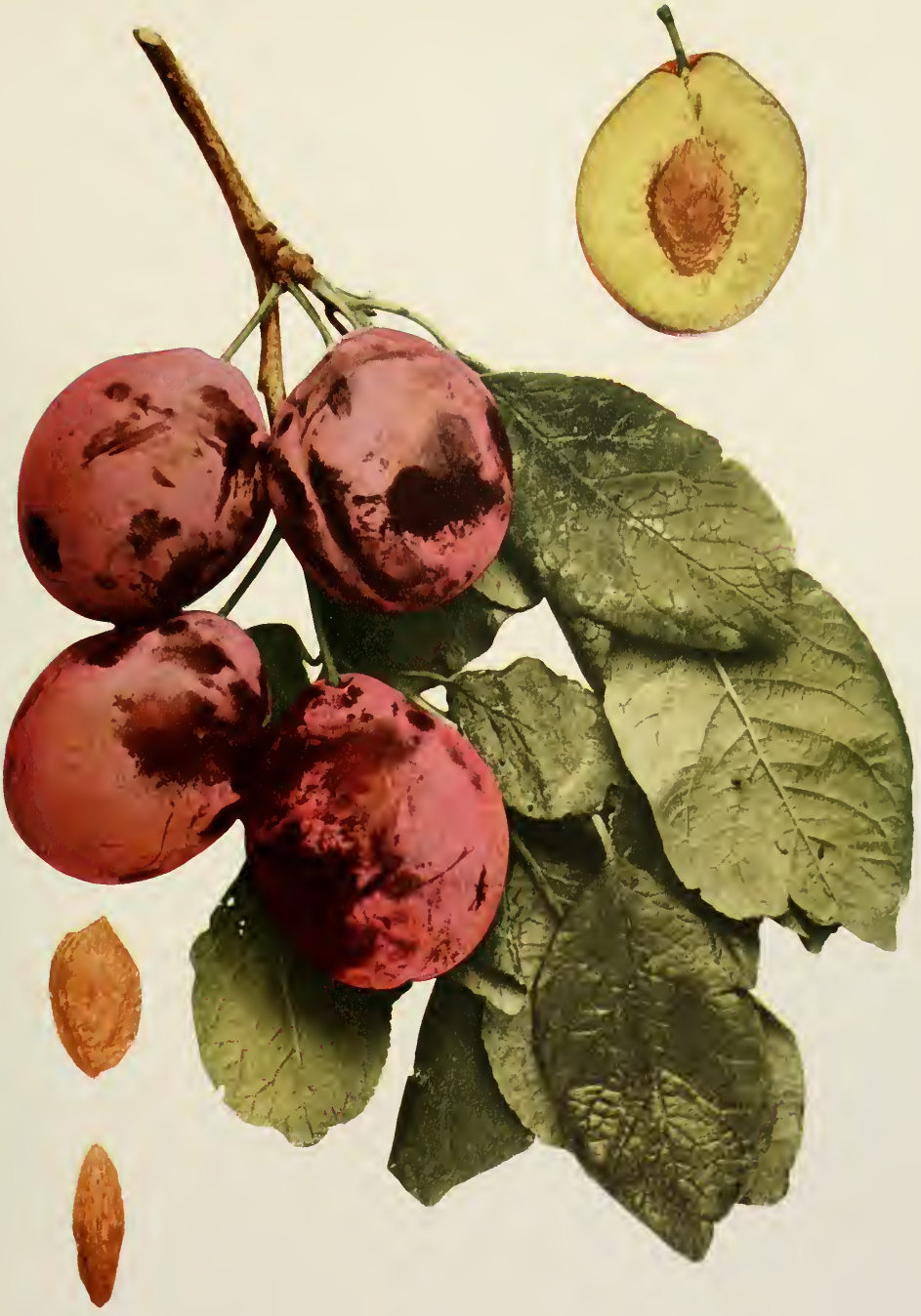



length, with internodes of average length, greenish-red changing to brownish-drab, dull, sparingly pubescent, with inconspicuous small lenticels; leaf-buds large, long, conical, free; leaf-scars plump, often much enlarged at the apex of the twigs.

Leaves somewhat folded backward, oval, two and one-quarter inches wide, four inches long, thick, leathery; upper surface dark green, finely pubescent, rugose, with a grooved midrib; lower surface silvery-green, pubescent; ' apex abruptly pointed cr acute, base abrupt, margin crenate or serrate, with small dark glands; petiole fiveeighths inch long, thick, pubescent, tinged red, with one or two globose, yellowish glands variable in size, usually on the stalk.

Season of bloom intermediate in time and length; flowers appearing after the leaves, one and five-sixteenths inches across, white; borne in thin clusters on lateral spurs and buds, singly or in pairs; pedicels thirteen-sixteenths inch long, pubescent, greenish; calxy-tube green, campanulate, pubescent; calyx-lobes broad, obtuse, lightly pubescent on both surfaces, margins with few glands and hairs, reflexed; petals roundish, crenate, tapering to short, broad claws; filaments seven-sixteenths inch long; pistil glabrous, equal to or shorter than the stamens.

Fruit late, season short; two inches by one and three-quarters inches in size, obovate or oval, frequently with a slight neck, halves equal; cavity shallow, narrow, abrupt; suture very shallow, often a line; apex roundish; color varies from reddishpurple to purplish-red, overspread with thick bloom; dots numerous, small, reddishbrown, obscure, larger in size but fewer in number towards the base; stem thick, seveneighths inch long, heavily pubescent, adhering well to the fruit; skin tough, separating readily; flesh attractive golden-yellow, not very juicy, fibrous, firm, of average sweetness, mild, not highly flavored; fair in quality; stone semi-free to free, one and onesixteenths inches by nine-sixteenths inch in size, long-oval, flattened, the surfaces roughened and deeply pitted, tapering towards the base and apex; ventral suture heavily furrowed, with a distinct but not prominent wing; dorsal suture usually widely and deeply grooved.

\section{POOLE PRIDE}

\section{Prunus munsoniana}

I. Am. Pom. Soc. Rpt. 108. 1885. 2. Cornell Sta. Bul. 38:50. 1892. 3. Ia. Hort. Soc. Rpt. 334. 1894. 4. Wis. Sta. Bul. $63: 24,53$. 1897. 5. Ibid. 87:15. 190r. 6. Waugh Plum Cult. 186. 1901. 7. Budd-Hansen Am. Hort. Man. 299. 1903. 8. Ohio Sta. Bul. 162:245 fig., 256, 257. 1905 .

Kroh 1, 6. Kroh 3, 7. Poole 2, 7. Poole 6. Poole's Pride 3, 4, 5. Poole's Pride 2, 6, 7.

As compared with other native plums growing on the grounds at this Station, Poole Pride has considerable merit. It is very attractive in appearance, it seems to have all the characters of a long-keeping and a good-shipping sort of its species and the trees are large, vigorous, hardy, healthy and productive. It is, however, lacking in the very important character of flavor though the texture of the flesh is all that could be desired. Its very peculiar flavor, incomparable with any other plum or fruit, 
while disagreeable to the writer, might be liked by some. The flesh of this plum is so transparent that the pit can be readily seen when the skin is removed. To those growing native plums, Poole Pride is recommended for trial.

This variety was raised by $\mathrm{P}$. H. Kroh, Anna, Illinois, and was exhibited by him under the name Kroh at the American Pomological Society meeting in 1885 . Three years later the same plum was introduced by Stark Brothers, Louisiana, Missouri, under the name of Poole's Pride. The latter name has been so much more widely used that it has been retained even though the former is correct according to the rule of priority.

Tree large, vigorous, open and round-topped, hardy, productive, healthy; branches rough, zigzag, with few thorns, dark ash-gray, with numerous, small lenticels; branchlets twiggy, slender, above medium in length, with short internodes, greenish-red changing to light chestnut-red, glabrous, with numerous, very conspicuous, large, raised lenticels; leaf-buds small, short, obtuse, plump, appressed.

Leaves folded upward, ovate or obovate, peach-like, one and three-eighths inches wide, three and one-half inches long, thin and leathery; upper surface dull red late in the season, smooth, glossy, with a narrow groove on the midrib; lower surface lightly pubescent; apex taper-pointed, base rather abrupt, margin finely crenate, with small dark glands; petiole seven-eighths inch long, slender, hairy, light purplish-red, with from one to four small, globose, reddish-brown glands on the stalk.

Blooming season late and long; flowers appearing after the leaves, five-eighths inch across, white; borne in clusters on short lateral spurs and buds; pedicels ninesixteenths inch long, very slender, glabrous, green; calyx-tube greenish, campanulate, glabrous; calyx-lobes narrow, obtuse, heavily pubescent within and along the margin which is serrate and covered with reddish glands, erect; petals small, ovate or roundish, crenate, tapering into long pubescent claws; anthers yellowish; filaments fivesixteenths inch long; pistil glabrous, shorter than the stamens.

Fruit early, season very long; one inch in diameter, roundish-oval, not compressed, halves equal; cavity very shallow and narrow; suture a distinct line; apex roundish; color clear, dark, currant-red, with thin bloom; dots few, large, light russet, conspicuous, clustered about the apex; stem slender, five-eighths inch long, glabrous, but overspread with a grayish bloom, adhering to the fruit; skin thin, tough, separating from the pulp; flesh semi-transparent, dark amber-yellow, very juicy, fibrous, tender and melting, sweet, with a strong, peculiar flavor not pleasant; of fair quality; stone adhering, five-eighths inch by three-eighths inch in size, long-oval, slightly flattened, compressed at the base, pointed at the apex, roughish; ventral suture blunt, faintly ridged; dorsal suture acute, entire.

\section{POTTAWATTAMIE}

\section{Prumus munsoniana}

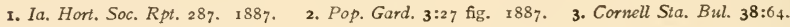
86. 1892. 4. Mich Sta. Bul. 123:20. 1895. 5. Ia. Sta. Bul. 31:346. 1895. 6. Wis. Sta. Bul. 

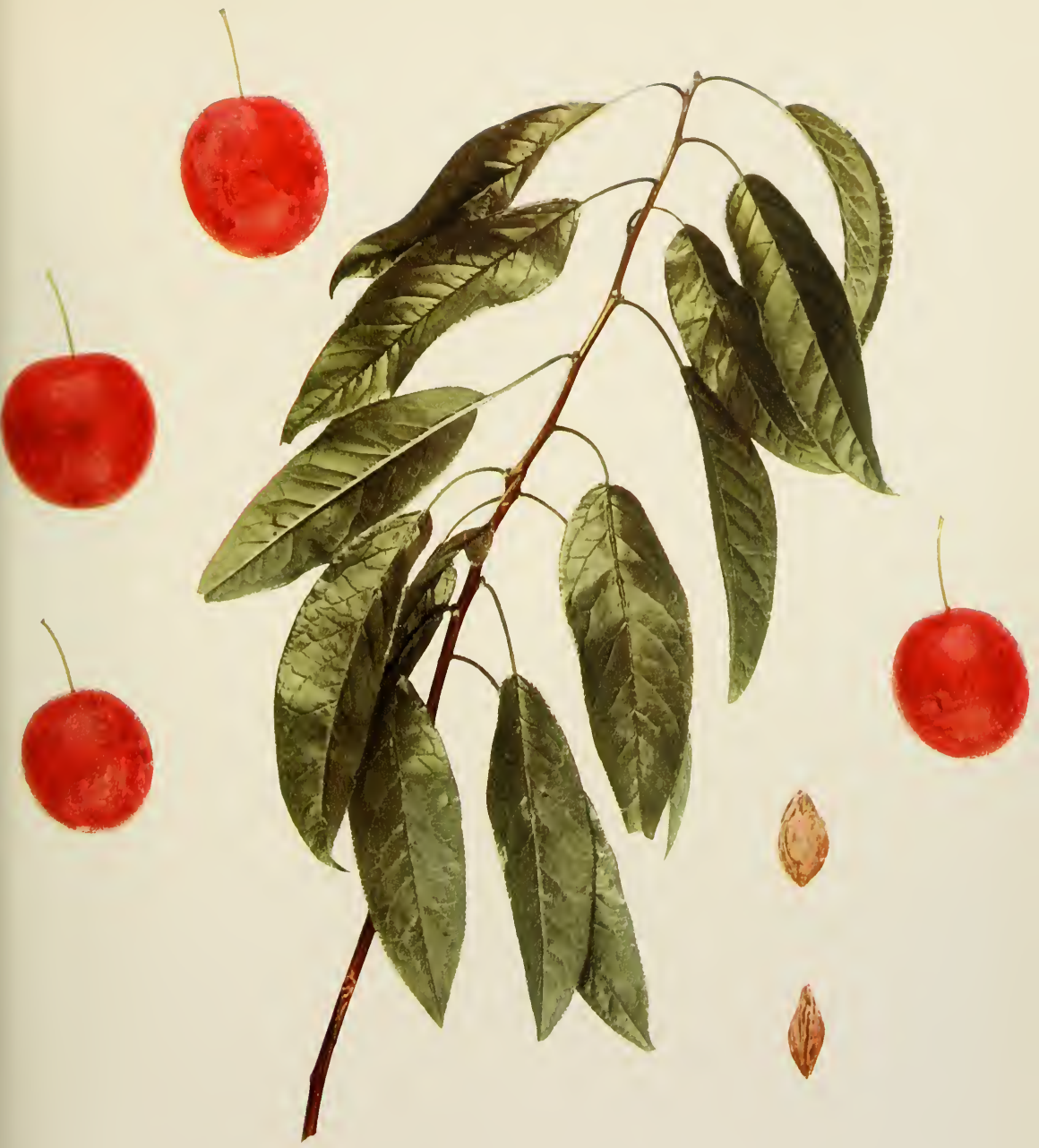

63:53. 1897. 7. Am. Pom. Soc. Cat. 25. 1897. 8. Ohio Sta, Bul. 113:156. 1899. 9. Ia. Sta. Bul. 46:287. 1900. ro. Waugh Plum Cult. 199 fig. 1901. 11. Ga. Sta. Bul.67:279. 1904.

The plum under notice is possibly of greater cultural value than any other of its species especially for northern latitudes. It is of high quality for a native plum, the texture of the fruit being especially pleasing in eating, and though melting and juicy it keeps and ships very well because of a tough skin. It escapes both the curculio and the brown-rot to a higher degree than most of its kind. The trees, though dwarfish at maturity, are vigorous, productive and among the hardiest of the Munsoniana plums, growing without danger of winter injury to tree or bud as far north as the forty-fourth parallel. Pottawattamie is deservedly one of the best known of the native plums and if varieties of its species are to be grown in New York, is as desirable as any.

Pottawattamie, according to the most authoritative accounts, was taken from Tennessee to Iowa with a lot of Miner trees. It came under the notice of J. B. Rice, Council Bluffs, Iowa, in 1875 , and was introduced by him and named after one of the counties of his State.

Tree medium in size, strong and vigorous when young becoming spreading and somewhat dwarfish when older, round-topped, hardy at Geneva, usually productive; branches dark brown, zigzag, thorny, roughened by the numerous, raised lenticels of various sizes which are often narrow and much elongated; branchlets slender, long, with internodes of medium length, greenish-red changing to dark chestnut-red, glabrous, with numerous, conspicuous, large, raised lenticels; leaf-buds small, short, obtuse, free.

Leaves flat or folded upward, lanceolate, peach-like, one and one-eighth inches wide, three and one-quarter inches long, thin; upper surface light green, reddish late in the season, smooth, glossy, with a grooved midrib; lower surface pale green, lightly pubescent along the midrib and larger veins; apex taper-pointed, base abrupt, margin finely serrate or crenate, with small, reddish glands; petiole one inch long, slender, tinged red, thinly pubescent, glandless or with from one to five very small, globose, reddish-yellow glands usually on the stalk.

Blooming season late and long; flowers appearing after the leaves, five-eighths inch across, creamy-white as the buds unfold changing to whitish, with a disagreeable odor; borne in clusters from lateral buds, in threes, fours or fives; pedicels five-eighths inch long, very slender, glabrous, greenish; calyx-tube green, broadly obconic, glabrous, calyx-lobes narrow, somewhat acute, pubescent on the inner surface, serrate, with reddish glands and hairy margin, erect; petals small, oval, slightly toothed, narrowly clawed; anthers yellowish; filaments one-quarter inch long; pistil glabrous, shorter than the stamens.

Fruit early, season of medium length; variable in size ranging from seven-eighths inch to one and one-eighth inches in diameter, roundish-oval, slightly compressed, 
halves equal; cavity very shallow and narrow, abrupt; suture indistinct; apex roundish or depressed; color clear currant-red, with thin bloom; dots few, medium to large, whitish, somewhat conspicuous, clustered about the apex; stem very slender, threequarters inch long, glabrous, adhering poorly to the fruit; skin tough, cracking under unfavorable conditions, separating readily; flesh deep yellow, juicy, fibrous, tender and melting, sweet next the skin but sour at the center, of pleasant flavor; fair to good in quality; stone clinging closely, five-eighths inch by three-eighths inch in size, narrow, long-oval, turgid, smooth, flattened and necked at the base, abruptly sharp-tipped at the apex; ventral suture acute, inconspicuous; dorsal suture blunt, faintly grooved.

\section{PURPLE GAGE}

\section{Prunus domestica}

1. Pom. Mag. 3:129, P1. 1830. 2. Lond. Hort. Soc. Cat. 152, 153. 1831 . 3. Downing Fr. Trees Am. 308 fig. 127. 1845. 4. Poiteau Pom. Franc. 1. 1846. 5. Thomas Am. Fruit Cult. 339. 1849. 6. Am. Pom. Soc. Cat. 54. 1852. 7. Ann. Pom. Belge 3:71, P1. 1855. 8. Thompson Gard. Ass't 519, Pl. 1. 1859. 9. Hogg Fruit Man. 377. 1866. 10. Pom. France 7:No. 9. 1871. Ix. Mas Le Verger 6:3 fig. 2. 1866-73. 12. Cat. Cong. Pom. France 367. 1887. 13. Mathieu Nom. Pom. 452. 1889. 14. Guide Prat. 155, 364. 1895 .

Blane Reine-Claude 10, 11, ${ }_{3}$ incor., 14. Die Violette Königin Claudia 13. Die Violette Kónigin Claudie 1. Die Violette Köning Claudie 3. Die Violette oder blane Renoclode 10, 14. Die Violette oder Blaue Reneclode I1, 13. Purple Gage 2, 8, 10, I1, 12, 13, 14. Prune Reine Claude Violette 4, 10. Reine-Claude Alex. Dumas 14. Reine-Claude Violette 2, 7, 8, $11,12,14$. Reine-Claude Violette 1, 3, 5, 9, 13. Violet Queen Claude 3, 5. Violet Gage 8, 9, 10, 12, 13 14. Violette ReineClaude 13. Violet Gage 2. Violette Queen Claude $1_{3}$. Violet oder Blaue Reneclode 13.

Purple Gage is worthy of attention as one of the best flavored of all purple plums. In all but color of fruit it is a true Gage, to say which is a sufficient characterization as to quality. In size it averages larger than most of the Gages or Reine Claude plums, and in color is a rich dark purple as attractive as any of the purple plums. Another good quality of the fruit is that of hanging to the tree until it shrivels at which time it is richest in flavor. Unfortunately the trees, while averaging very well in other respects, are not productive and the variety cannot be recommended for money-making though it well deserves a place in home orchards.

Purple Gage is a European variety of unknown origin, though in the Catalogue descriptif des fruits adoptes par le Congres pomologique for 1887 , it is said to have been raised by M. Galopin of Liege, Belgium. As it was not mentioned by Duhamel in his Traite des Arbres Fruitiers in 1768 , it is thought to have been unknown at that date. English and American authors generally apply the name Purple Gage to this variety but in continental countries the name Reine Claude Violette is most common. It was imported into America early in the last century and in $185^{2}$ was 
added to the recommended list of fruits in the American Pomological Society catalog.

Tree large, vigorous, round-topped, hardy, not very productive; branches numerous, light ash-gray, with few, small, raised lenticels; branchlets thick, above medium in length, with rather short internodes, greenish-red changing to brownish-red, marked with much scarf-skin, glabrous throughout the season, with few, small, slightly-raised lenticels; leaf-buds of medium size and length, conical, appressed; leaf-scars greatly enlarged.

Leaves folded upward, oval, one and three-quarters inches wide, three and onehalf inches long, thick, stiff; upper surface dark green, distinctly rugose, lightly pubescent, with a shallow groove on the midrib; lower surface silvery-green, covered with thick pubescence; apex abruptly pointed or acute, base rather abrupt, margin serrate or crenate, eglandular or with small dark glands; petiole three-quarters inch long, thick, greenish, pubescent, glandless or with one or two rather large, globose, yellowish-green glands variable in position.

Blooming season late, of medium length; flowers appearing with the leaves, nearly one and one-quarter inches across, white; borne from lateral buds, usually singly; pedicels five-eighths inch long, thick, pubescent, greenish; calyx-tube green, campanulate, glabrous; calyx-lobes narrow, obtuse, lightly pubescent on both surfaces, glandular-serrate, reflexed; petals obovate or oval, crenate, short-clawed; anthers yellow; filaments nearly one-half inch long; pistil glabrous except at the base, shorter than the stamens.

Fruit intermediate in time and length of ripening season; one and one-half inches by one and three-eighths inches in size, roundish or ovate, slightly compressed, halves equal; cavity shallow, narrow, abrupt; suture very shallow, often a line; apex variable in shape; color dark purple or purplish-black, overspread with thick bloom; dots numerous, russet, conspicuous when the bloom is removed, clustered about the apex; stem five-eighths inch long, thinly pubescent, adhering well to the fruit; skin thin, separating readily; flesh dull yellow, juicy, somewhat fibrous, firm but tender, sweet, of pleasant flavor; very good; stone semi-clinging, seven-eighths inch by five-eighths inch in size, irregular-oval, flat, often contracted at the base into a long narrow neck, blunt at the apex, with markedly rough and pitted surfaces; ventral suture swollen, rather wide, distinctly furrowed, often with a prominent wing; dorsal suture with a wide and deep groove.

\section{QUACKENBOSS}

\section{Prunus domestica}

I. Downing Fr. Trees Am. 393. 1857. 2. Cultivator 6:269 fig. 1858. 3. Thomas Am. Fruit Cult. 345. 1867. 4. Downing Fr. Trees Am. 941. 1869. 5. Am. Pom. Soc. Cat. 24. 1871. 6. Mas. Pom. Gen. 2:1 51, fig. 76. 1873. 7. Barry Fr. Garden 415 . 1883. 8. Mich. Sta. Bul. 103:34, fig. 6. 1894. 9. Ont. Fr. Exp. Sta. Rpt. 52. 1895. 10. Cornell Sta. Bul. 131:191, fig. 40 II. 1897 11. Waugh Plum Cult. 119. 1901. 12. Va. Sta. Bul. 134:44. 1902.

Quackenbos 9, 12. 
Though not a leading variety, Quackenboss is a prominent one in the list of commercial sorts for New York. Its fruits possess to a high degree the characters which make a good market plum; they are of large size, averaging nearly an inch and a half in diameter; round-oval, a better shape for the markets than the prune shapes; very prepossessing in color - a handsome, dark purple with heavy bloom; the flesh is tender and juicy with a sweet, pleasant flavor making it one of the good purple plums, though not one of the best in quality. The tree is large, vigorous, hardy, with a round and spreading top. This gives it great bearing capacity but though productive in the Station orchard, the variety does not have the reputation of being fruitful and fails chiefly as a commercial sort for this reason. It is a late-maturing variety and comes on the market at a time when plums are wanted for home canning, the demand for this purpose, for which it is most suitable, helping greatly its sale. The variety has two peculiarities; the petals are comparatively distinct from each other giving the flower, or a tree in flower, an odd appearance; and the leaves are remarkably variable in size.

It is not quite certain when or where this variety first came to notice. C. Reagles, a competent authority, of Schenectady, New York, in describing the Quackenboss for The Cultivator in I858, says "There is a seedling tree of this identical sort in the garden of Mr. S. C. Groot of this city, which is about thirty years old." If true, this puts its origin in Schenectady at about 1828 . But beyond question a Mr. Quackenboss of Greenbush, New York, introduced the variety, though some years later, and it has taken his name. In I87 I, the American Pomological Society placed the Quackenboss on its recommended fruit list.

Tree very large and vigorous, round-topped, hardy, productive; branches numerous, ash-gray, the trunk rough but the limbs smooth, with smallish raised lenticels; branchlets thick, with long internodes, greenish-red changing to brownish-drab over red, dull, pubescent, with numerous, small lenticels; leaf-buds of medium size and length, pointed, free.

Leaves flattened, obovate or oval, variable in size averaging one and seven-eighths inches wide by three and five-eighths inches long; upper surface very dark green, nearly glabrous, with a grooved midrib; lower surface pale green, pubescent; apex obtuse, base tapering, margin finely serrate, with small black glands; petiole five-eighths inch long, pubescent, faintly tinged red, glandless or with from one to four small, globose, greenish-yellow glands usually on the stalk.

Blooming season intermediate in time and length; flowers appearing after the leaves, one and one-eighth inches across, white, with a yellow tinge at the tips of the 

opening buds; scattered on lateral spurs, singly or in pairs; pedicels three-quarters inch long, above medium in thickness, finely pubescent, greenish; calyx-tube green, campanulate, glabrous; calyx-lobes obtuse, lightly pubescent, glandular-serrate, reflexed; petals obovate, crenate, with broad claws of medium length; anthers yellow with a reddish tinge; filaments seven-sixteenths inch long; pistil glabrous except on the ovary, shorter than the stamens.

Fruit late, season short; one and five-eighths inches by one and three-eighths inches in size, roundish-oval, compressed slightly, halves equal; cavity narrow, abrupt; suture shallow, often lacking; apex roundish or depressed; color bluish-black, with thick bloom; dots numerous, small, yellowish-brown, inconspicuous; stem threequarters inch long, pubescent, adhering well to the fruit; skin tender, somewhat astringent; flesh deep yellow, juicy, tender, sweet, of pleasant, mild flavor; good; stone semifree, one inch by five-eighths inch in size, flattened, irregular-oval, tapering to a long, narrow neck at the base, bluntly acute at the apex, with rough and pitted surfaces; ventral suture prominent, heavily furrowed, distinctly ridged; dorsal suture acute, of ten with a narrow, indistinct, shallow groove.

\section{RED APRICOT}

\section{Prunus domestica}

1. Ḱnoop Fructologie 2:52, 54. 1771. 2. Kraft Pom. Aust. 2:27, Tab. 172 fig. 1. 1796. 3. Prince Pom. Man. 2:72. 1832. 4. Poiteau Pom. Franc. 1.1846. 5. Goodrich N. Fr. Cult, 83 . 1849. 6. Mas Pom. Gen. 2:127, fig. 64. 1873. 7. Hogg Fruit Man. 720. 1884. 8. Mathieu Nom. Pom. 447. 1889. 9. Lucas Vollst. Hand. Obst. 474. 1894.

Abricot Rouge I. Abricote Rouge 3. Apricot Plum 5. Abricotée Rouge 6. Abricot Rouge 6, 7, 8. Abricotée Rouge 7, 8. Die Aprikosenpflaume 2. Fürstenzeller Pflaume 8. Fürstenzeller Reine-Claude 8. Prune d'Abricot Rouge 1, 8. Prune d'Abricos 2. Prune d'Abricot rouge r. Prune Abricotée Rouge 4. Red Apricot Plum 3. Rothe Aprikosenpflaume 6. Red Apricot 6, 8. Rote Aprikosenpflaume 8. Rote Aprikosenzwetsche 9.

This plum, well known in Europe, is probably not now grown in America and it may not deserve recognition here except for its historical interest. Red Apricot is probably an inferior off-shoot of the Apricot plum although no definite record of its lineage is obtainable. It does not seem to have been known until nearly one hundred and fifty years after the Apricot was brought to notice. Kraft figured and described a long prune-like red plum under this name but because of its shape his plum was undoubtedly spurious. The variety was rejected by the American Pomological Society in 1856 . It is described as follows:

Tree vigorous, shoots glabrous; fruit mid-season, large, roundish; color red over yellow; suture shallow; cavity small; stem an inch long, stout; flesh yellow, dryish, inferior in flavor; poor; freestone. 


\section{RED DATE}

\section{Prunus domestica}

1. Parkinson Par. Ter. 576. 1629. 2. Rea Flora 208. 1676. 3. Ray Hist. Plant. 2:1529. 1688. 4. Kraft Pom. Aust. 2:43, Tab. 196 fig. 2. 1796. 5. Lond. Hort. Soc. Cat. 147. 183 1. 6. Mathieu Nom. Pom. 447. 1889 .

A Fleur Double 5. Dattel Pflaume 6. Dattel Zwetsche 6. Die grosse rothe Feigenpflaume 4. Figue Grose Rouge 5. Figue Grosse Rouge 6. Früh Zwetsche 6. Grosse Rote Feigen Pflaume 6. Lange Violette Dattel Zwetsche 6. Lange Violette Dattel Pflaume 6. Prune figue grosse rouge 4. Prune d'Autriche 6. Prune Figue 6. Prune Datte 6. Purpur Pflaume 6. Red Date-plum 3. Rote. Dattelzwetsche 6. Rote Feigen Pflaume 6. Turkische Zwetsche 6. Ungarische Zwetsche 6. Wilmot's Russian 5. Zucker Zwetsche 6.

Red Date is an interesting variety because of its very peculiar shape which is that of an elongated curved date. Its flavor is agreeable and all of the characters of fruit and tree are as good as in the average variety; yet it can probably be counted as nothing more than an interesting curiosity. Parkinson described the Red Date as long ago as 1629 and it seems to have maintained a place in horticulture since then. The variety was imported from France in I90I by the United States Department of Agriculture from which source trees were obtained by this Station.

Tree of medium size, upright-spreading, dense-topped, productive; branches thorny; branchlets developing many laterals on the new wood at right angles to the direction of growth, thickly pubescent; leaf-buds free; leaves folded backward, obovate, one and one-half inches by three and one-quarter inches long; margin crenate, with small dark glands; petiole pubescent, rather long, glandless or with from one to three small glands; blooming season intermediate in time and length; flowers appearing after the leaves, seven-eighths inch across; borne in scattering clusters on lateral buds and spurs, singly or in pairs.

Fruit mid-season; one and five-eighths inches by one inch in size, long irregularoval, enlarged on the suture side, dark purplish-red, with thick bloom; flesh goldenyellow, rather dry, firm, sweet, mild; of fair quality; stone free, one and one-eighth inches by one-half inch in size, very long and narrow, somewhat oblique, acute and oblique at both base and apex; ventral suture blunt; dorsal suture with a long, narrow, deep groove.

\section{RED DIAPER}

\section{Prunus domestica}

1. Quintinye Com. Gard. 67, 68, 69. 1699. 2. Miller Gard. Kal. 184. 1734. 3. Knoop Fructologie 2:57. 176r. 4. Duhamel Trait. Arb. Fr. 2:102, P1. XX fig. 12. 1768. 5. Kraft Pom. Aust. 2:36, Tab. 185 fig. 2. 1796. 6. Willichs Dom. Enc. 300. 1803. 7. Pom. Mag. 1:6, P1. 1828. 8. Prince Pom. Man. 2:69, 90. 1832 . 9. Downing Fr. Trees Am. 298. 1845. 1o. Floy-Lindley Guide Orch. Gard. $285,287,288,383$. I 846. I1. Poiteau Pom. Franc. 1:1846. 12. Horticulturist 3:29. 1848. 13. Thomas Am. Fruit Cult. 335, fig. 26r. 1849. 14. Horticulturist 4:195. I849. 
15. Ann. Pom. Belge 75 Pl. 1853. 16. Bridgeman Gard. Ass't 128, 129, 130. 1857. 17. Pom. France 7: No. 10. 1871. 18. Mas Pom. Gen. 2:135, fig. 68. 1873. 19. Le Bon Jard. 339. 1882. 20. Hogg Fruit Man. 697. 1884. 21. Cat. Cong. Pom. France 345. 1887. 22. Mathieu Nom. Pom. 447. 1889. 23. Guide Prat. $158,365.1895$.

Amalia Pfaume 22, 23. Bunte Herzformige Pfaume 17, 22. Cyprische Pfaume 22, 23. Diaprée de Roche Corbon 22. Dame Aubert Rouge 22, 23. Diademe Imperial 22. De Chypre 23. Diademe Imperiale 23. Diaper 1, 10. Die Blutfarbige Pflaume 5. Diaprée Rouge 3, 4, 9, 17, 18, 19, 20, 21. Diaprée Rouge 5, 8, 10, 13, 16, 18, 22. Diapre Rouge 8, 22, 23. Die Rothe Eierpfla ume 14. Diaper Rouge 16. Diaper 57,20, 22. Die Blutfarbege Pflaume 17. Diaprea rubra 17. Diademe 19. De Briancon 21. Gluhende Kohle 22. Hoheits Pflaume 22, 23. Imperial Diadem 8, 9, 13, 20, 22. Imperial Diadem 10, 16. Imperial Diademe 17, 21. Imperatrice 19. La Roche-Corbon 22. La Courbon 17. Mimms 10, 16. Mimms 9, 13, 17, 20. Mimms Plum 10, 16, 22. Mimms Plum 7, 8. Mimms Pfaume 22. Matchless 22. Prune Diaprée Rouge 11. Prune Imperatrice 15. Prune Diademe 15. Prune de Briancon 17. Prune de Chypre 22. Prinzessin Pflaume 22, 23. Roche-Carbon 22. Rote Diaprée 22. Rouge Corbon 22. Rote Eier Pflaume 22. Rote Cyprische Pflaume 22. Rote Marunke 22. Rote Osterci 22. Rote Masche 22. Rote Ross Pflaume 22. Rothe Eierpflaume 23. Rothe Marunke 23. Roche Corbon 1. Roche Courbon 2. Roche Corbon 4, 5, 8, 9, 10, 16, 17, 18, 20, 21, 22. Roch-courbon 6. Red Diaper 6, 10, 16, 17, 20, $21,22$. Roche Courbon 8. Red Egg Plum 14. Reine de Chypre 14. Red Imperial 16. Rothe Diaprée I7. Rothe Violen Pfaume 17. Red Diaper Plum 17. Rothe Eierpflaume 17. Rothe Susse Pfaume 17. Rothe Diapre 18 . Virginische Pfaume 17.

Red Diaper is of historical value only, as it is now rarely found. It does not seem to have been known as long as Violet Diaper and may be an off-shoot of the older variety. It probably originated in France, one of its synonyms, Roche Corbon, having been derived from a small village near Tours. The Mimms plum said to have been raised from a stone of the Blue Perdrigon about 1800 by Henry Browne, North Mimms Place, Hertfordshire, England, and the Imperial Diadem said to be a seedling of about the same date raised at Duckenfield, near Manchester, England, are identical with Red Diaper in spite of their supposed separate origin. The Chypre, or Prune de Chypre, thought by some to be a synonym of this variety, is undoubtedly distinct, as it is a clingstone and is earlier. The following description is compiled.

Tree of slow growth in the nursery, hardy, vigorous and productive in the orchard. Fruit mid-season; large, obovate; cavity slight; stem one-half inch in length; skin brownish-red; bloom thin; dots very numerous, brownish, conspicuous; flesh greenishyellow, firm, fine-grained, sweet; good; stone small, free.

\section{RED JUNE \\ Prunus triflora}

1. Am. Pom. Soc. Rpt. 106. 1891. 2. Cornell Sta. Bul. 62:28. 1894. 3. Ga. Hort. Soc. Rpt. 95. 1895. 4. Cornell Sta. Bul. ro6:60. 1896. 5. Ala. Col. Sta. Bul. 85:444. 1897. 6. Correll Sta. Bul. 139:45. 1897. 7. Rural N. Y.56:615. 8897. 8. Am. Pom. Soc.Cat. 26. 1897. 9. Mich. 
Sta. Bul. 169:242, 243, 249, 250. 1899. 10. Cornell Sta. Bul. 175:136. 1899. I1. U.S. D.A. Rpt. 386. 1901. 12. Waugh Plum Cult. 140. 1901. 13. Budd-Hansen Am. Hort. Man. 324. 1903. 14. Can. Exp. Farm Bul. 43:37. 1903. 15. Mass. Sta. Ann. Rpt. 17:160. 1905. 16. Md. Hort. Soc. Rpt. 85. 1905. 17. Ga. Sta. Bul. 68:5, 32. 1905 .

Botan I4. Hylankayo II. Long Fruit 3. Nagate no Botankyo I0, II, 17. Red Nagate I, 2, 3, 6, 9. Red Nagate 4, 5, 11, 12, 13, 17. Red June 2, 3. Shiro Smomo 2, 4, 7, 11, 12, 14. Shiro Smomo 9.

Red June is variously estimated by fruit-growers and pomologists. A concensus of the opinions of those who have had actual experience with the variety shows that it closely follows Abundance and Burbank in popularity among the Trifloras. The variety is distinguished from all other plums by its fruit-characters; the plums are distinctly cordate in shape with a deep cavity and a very pointed apex; the color is a mottled garnetred overlaid with thin but very distinct and delicate bloom; the flesh is a light yellow, firm enough to endure transportation well, peculiarly aromatized, sweetish and not wholly agreeable in flavor and ranking rather low in quality; the stone adheres tightly to the flesh. The trees are large, vigorous, spreading, hardy, healthy and productive-very good for the species to which the variety belongs. Other good qualities of the variety are that it blooms late for a Triflora, and that the fruits are comparatively immune to curculio and brown-rot and hang to the trees exceptionally well for an early plum. This is one of the Triforas that varies in season of ripening, a peculiarity of several of the varieties of this species, but usually the fruits ripen a week or more before Abundance. Red June is reported to be somewhat self-sterile and in need of cross-pollination. This variety ought to have value as an early market plum in New York.

Red June was imported from Japan by H. H. Berger and Company, San Francisco, California, under the name Shiro Smomo, about 1887 . Stark Brothers, Louisiana, Missouri, obtained the variety in 1892 and introduced it as the Red June in 1893 . In 1897 it was added to the fruit catalog list of the American Pomological Society. The nomenclature of this variety is much confused. The true Japanese Red Nagate (Red Nagate is one of the synonyms of Red June) has red flesh while this one has not; this variety, to which the name Shiro Smomo is most often applied, is not a Smomo plum nor is it white, (Shiro is the Japanese for white) affording another instance of the confusion in the American application of the Japanese names of the Triflora plums.

Tree large, vigorous, upright-spreading, hardy, productive, healthy; branches rough, thorny, dark brown, with numerous lenticels of medium size; branchlets slender. 
long, with short internodes, dark brown, marked with considerable scarf-skin, glabrous, with numerous large, raised lenticels; leaf-buds small, medium in length, conical, free.

Leaves folded upward, oblanceolate, one inch widc, two and three-quarters inches long, thin; upper surface glabrous, with a lightly grooved midrib; lower surface light green, thinly pubescent along the midrib and larger veins which are tinged red; apex taper-pointed, base acuminate, margin finely serrate, with small glands; petiole onehalf inch long, slender, tinged red, slightly hairy along one side, with from one to three small, brown glands usually at the base of the leaf.

Blooming season intermediate in time and length; flowers appearing before the leaves, white; borne in clusters on lateral buds and spurs, in twos or in threes " pedicels of medium length and thickness, glabrous except for occasional hairs, greenish; calyxtube green, campanulate, glabrous; calyx-lobes narrow, obtuse, sparingly glandular, with marginal hairs, glabrous on the outer side, thinly pubescent on the inner side, erect; petals oval, entire, tapering at the base to short claws; anthers light yellow; filaments short; pistil glabrous, longer than the stamens.

Fruit early, one and one-half inches by one and three-eighths inches in size, roundishovate to roundish-cordate, sides unequal; cavity large, deep, narrow, regular, abrupt; suture deep, distinct; apex very pointed; color garnet-red, mottled; bloom thin; dots numerous, small, russet; stem one-half inch long, adhering to the fruit; skin above medium in thickness, tender, slightly astringent, separating easily; flesh light yellow, fibrous, somewhat meaty, sweet except near the center; good; stone clinging, fiveeighths inch by one-half inch in size, irregular-oval, slightly flattened, pointed at both ends, with pitted surfaces; ventral suture prominently winged, narrow; dorsal suture not grooved.

\section{RED MAGNUM BONUM}

\section{Prunus domestica}

1. Parkinson Par. Ter. 576, 577. 1629. 2. Rea Flora 208. 1676. 3. Langley Pomona 92, P1. XX fig. V. 1729. 4. Duhamel Trait. Arb. Fr. 2:98, P1. XV. 1768. 5. Kraft Pom. Aust. 2:31, Tab. 178 fig. I. 1796. 6. Willichs Dom. Enc. 4:300. 1803. 7. Prince Pom. Man. 2:59. 1832 . 8. Hoffy Orch. Com. fig. 1841. 9. Floy-Lindley Guide Orch. Gard. 292. 1846. 10. Horticullurist 4:1 94. 1849. 11. Ann. Pom. Belge 99, Pl. 1853. 12. Elliott Fr. Book 428, 429. 1854. 13. Noisette Man. Comp. Jard. 2:499. 1860. 14. Downing Fr. Trees Am. 943. 1869. 15. Mas Pom. Gen. 2:139, fig. 70. 1873. 16. Hogg Fruit Man. 721. 1884. 17. Am. Pom. Soc, Rpt. 61. 1887. 18. Mathieu Nom. Pom. 445, 448. 1889. 19. Ia. Hort. Soc. Rpt. 87. 1890. 20. Guide Prat. 158, 358. 1895 .

Askew's Purple Egg 12, 14, 16, 18. Blaue Kaiserpflaume 15, 18, 20 incor. Blaue Eier Pflaume 18 incor. Bockshoden 18,20 . Bocksdutten 18, 20. Bonum Magnum 18 incor., 20. Blue Imperatrice 7 incor., 8. Copper Plum 8. Die Kaiserliche veilchenfarbige Pflaume 5. Die Rothe Kaiserpflaume 10. Dame Aubert 13. Dame Aubert Violette 14, 16, 18, 20. Die Rothe Eiperflaume 14. Dame Aubert Rouge 17. Dame Aubert Rouge 19. D'Oeuf Violette 20. Early Forcing 12. Florence 12, 14, 16, 18, 20. Frühe Treib Zwetsche 18. Frühe Trezbrwetsche 20. Great Imperial Plum 18, 20. Grosse Früh Zwetsche 18 incor. Grosse Ungarische Zwetsche 18 incor. Imperiall $t$. Imperial 3, 6. Impćriale Violette $5,7,8,9,10,14,16,18,20$. Impériale Violette 4, 15, 20. Imperial Violet 7. Impériale $7,14,16,18,20$. Imperiall 9. Imperial 9, 14, 18. Impiriale Rouge 10, 14, 16. 18. Imperial Rouge 12, 18. Imperial Violet 14, 18. Impinale Hative 18, 20. Impériale rouge 
20. Large Orlean 7. Mogul Rouge 16, 18. Oeuf Rouge 16, 18. Prune d'Oeuf Violette 18. Prinzessinpflaume 15. Prune-figue I3. Prune Impériale Violette 11. Prune d'oeuf 7, 14, 18. Purple Egg 7, 12, 14, 16, 18. Prune-oenf 7. Purple Magnum Bonum 12, 14, 18. Red Magnum Bonum 8, 12, 20. Red Magnum 6. Red Imperiale 7, 8, 12, 14, 16, 18, 20. Red Bonum Magnum 3, 7, 18, 20. Red Egg Plum 10. Red Egg 12. Red 1mperial 12. Red Egg 14, 16, 18. Red Aubert 17. Rote Eicr Pflaume 18. Rote Kaiserpflatume 18. Rote Kaiser Zwetsche 18. I16 Riga 19. Rothe Kaiserpflaume 20. Rothe Kaiserzwetsche 20. Shepler ?14, ?18. Sainte-Catherine (Belgien) 18, 20. The Imperial Plum 2. Violette oder Blane Kaiserpflaume 15.

Once popular, Red Magnum Bonum is now but of historical interest. Three centuries ago this variety was cultivated in England by John Tradescant under the name Imperiall. It was mentioned by all of the early horticultural writers and it seems clear that the variety was well established in Europe at least as early as the beginning of the Seventeenth Century. As all plums at that time were propagated from seed, a large number of sub-varieties of this sort were produced and as these became established the nomenclature of the variety became much involved. In 1729 Langley called it the Red Magnum Bonum, a name it has since retained. It is not known when the variety was introduced into this country but its first appearance in American literature was in 1803 . After its introduction nurserymen sold any large red plum as Red Magnum Bonum and it became difficult to find the true variety. Professor J. L. Budd apparently reintroduced this plum in $188 \mathrm{I}-1882$ under the name Dame Aubert Rouge. Although very extensively grown in America at one time it has never been a favorite because of its poor quality. The American Pomological Society rejected it in 1858 from a list of candidates for its catalog. The following description is compiled.

Tree hardy, vigorous, productive; young shoots glabrous. Fruit mid-season; large, oval, deep red in the sun, pale red in the shade, covered with thin bloom; stem one inch long; flesh greenish, firm, slightly coarse, dry, brisk subacid; of fair quality; stone oval, free.

\section{REINE CLAUDE}

\section{Prunus domestica}

I. Quintinye Com. Gard. 67, 68, 69. 1699. 2. Langley Pomona 93, Pl. XXIII fig. 7. 1729. 3. Duhamel Trait. Arb. Fr. 2:89, P1. XI. 1768. 4. Knoop Fructologie 2:62. 1771. 5. Kraft Pom. Aust. 28, Tab. 173 fig. 2, 41, Tab. 193 fig. 2. 1796 . 6. Forsyth Treat. Fr. Trees 20. 1803. 7. Miller Gard. Dict. 3. 1807. 8. Coxe Cult. Fr. Trees 237, fig. 14. 1817. 9. Phillips Com. Orch. 306. 1831. 10. Lond. Hort. Soc. Cat. 147, 148. 1831 . I1. Prince Pom. Man. 2:48. 1832. 12. Ga1lesio Pom. Ital., P1. 1839. 13. Downing Fr. Trees Am. 276 fig. 106. 1845. 14. Floy-Lindley Guide Orch. Gard. $283,382,419$. 1846. 15. Poiteau Pom. Franc. 1:1846. 16. Horticulturist 2: 178, 179 fig. 30, 291. 1847. 17. Thomas Am. Fruit Cult. 326 fig. $253,329.1849 . \quad 18$. Hovey Fr. Am. 2:69, Pl. 1851. 19. Am. Pom. Soc. Cat. 54. I852. 20. Elliott Fr. Book 4 I0. 1854. 21. Thompson Gard Ass't 517. 1859. 22. Downing Fr. Trees Am. 917. 1869. 23. Mas Le Verger 
6:55, fig. 28. 1866-73. 24. Pom. France $7:$ No. 5. 1871. 25. Oberdieck Deut. Obst. Sort. 434 1881. 26. Lauche Deut. Pom. 20, P1. IV 20. 1882. 27. Hogg Fruit Man. 703. 3884. 28. Ma thieu Nom. Pom. 433. 1889. 29. Guide Prat. $154,363.1895 . \quad$ 30. Bailey Sur. Unlike $176,243.1896$. 31. Cornell Sta. Bul. 131:186. 1897. 32. Botanical Gazette 26:423. 1898. 33. Gard. Chron. 3rd Ser. 24:465. 1898. 34. Waugh Plum Cult. 22, 106, 107 fig. I901.

Abricot Verd 5, 9. Abricot Vert 3, 7, 10, 18, 13, 34, 21, 22, 23, 24, 27, 28, 29. Abricotée Sageret ?22, 28. Aloise's Green Gage 22, 24, 27, 228, 29. Blanche Grosse Espece ro. Bonne Verte 5. Bradford Gage 13, 20, 21, 22, 28, 29. Bradford Green Gage 27, 28. Bradford Queen Gage 24, ?29. Brugnon Green Gage 10, 18, 21, 22, 24, 27, 28, 29. Brugnon Gage 20, 22, 28, 29. Bruyn Gage 33. 17, 18 incor., 20, 22, 28, 29. Burgnon Gage 13, 24. Cant's Late Green Gage 22, 28. Claudia 12. Damas Gris 24, 28, 29. Damas Verd 9. Damas Vert 7, 10, 13, 18, 21, 22, 24, 27, 28, 29. Dauphine $5,7,10,11,13,14,18,21,22,23,24,27,28,29$. Die grosse Königin Claudiapflaume, die grüne Abrikose 5. Die Königin Klaudia 5. Dauphine 3. Dauphiny 6. Drap d'Or of some 10, 18, 28, 29. Echte Grasse Reine-Claude 28, 29. Gage Verte 28, 29. Great Green Damask 22, 27, 28. Great Green Damaski 24, 29. Great Queen Claudia 11. Green Gage 2, 6, 8, 10, 11, 13, 14, 17, 18, 19, 20, 21, 22, 27, 30, 31, 33, 34. Green Spanish 14, 18. Gros Damas Vert 11, 22, 28, 29. Grosse Konigin Claudiapflaume 5. Green Gage 7, 9, 23, 24, 28, 29, 32, 34. Goring's Golden Gage $22,24,27,28,29$. Grosse Reine $10,13,18,20,21,22,24,27,28,29$. Grosse Grüne Reine-Claude 25, 28. Grosse Reine-Claude 7, 25, 26, 28. Grosse Reine-Claude 3, 5, 10, 11, 13, 14, 18, 20, 21 , 22, 23, 24, 25, 29. Gros Reine-Claude 14. Grüne Aprikose 5, 28, 29. Grüne Abrikose 5. Grüne Reineclaude 25. Gute Grüne 28, 29. Huling's Reine-Claudia 22, 28 . Huling's Reine Clande Ix. Ida Gage 22. Ida Green Gage 16. Ida Green Gage 20, 22, 24, 27, 28, 29. Isleworth Green Gage 13, 18,20, 21, 22, 24, 27, 28, 29. Isleworth Green Gage 10. King of Plums 20. Königin Claudia 28, 29. Königin Ḱlaudia 5. Large Queen Claude II. La Grosse Reine-Claude II. Large Queen Claudia 6. Large green claudia 11. Livingston Manor 22, 28. Louis Brun ?22, ?28. Mammola 12. Mirabelle Vert Double 22, 24, 27, 28, 29. Murray's Reine Claudia 22, 28. Murray's Reine Claude I1, 14, 22, 27. Prune de Reine Claude 15. Prunus Domestica Cereola 32. Prunus Domestica var. cereola 33. Prunus Domestica var. Claudiana 32. Queen Claude 2. Queen Claudia I:, 22, 24, 27, 28, 29. Reine-Claude Ancienne 23, 24, 28, 27. Reine-Claude Blanche Grosse Espece ro. Reireclaude d'oree 29. Reine-Claude Blanche La Grosse I1, 22. Reine-Claude 8, 10, I1, 13, 17, I8, $20,21,22,27,28,33$. Reine Claud 1. Reine-Claudia 2. Reine-Claude Blanche ro. Reine-Claude Doríe 22, 23, 24, 25, 28, 29. Reine-Claude Dore 18, 22. Reine-Claude Grosse 27, 28. Reine-Claude Verde Perdrigon 5. Reine-Claude Verte 23, 29. Rensselaer Gage 20, 22. Rensselvar Gage $24,29$. Rensselaar Gage 27, 28. Reine-Claude Verte Tiquetée 28, 29. Reine-Claudia Blanche La Grosso 22, 28. Royal Green Gage 28, 29. Schuyler Gage 20, incor. 22, 24, 27. Schuyler's Gage ?3 3, 20, 28, 29. Sucrin Vert 10, 11, 13, 18, 21, 22, 24, 27, 28, 29. Sultaneck Erik ?28, 29. Susina Regina 12. Triomphe Garcon 24, 28, 29. Triomphe Valet 24, 28, 29. Trompe Garcon 22, 27, 28, 29. Tromp-Valet 7. Trompe Valet 22, 27, 28, 29. Verdacia 27, 28. Verdacchia rotonda 12. Verdoch 27, 32, 34. Verdochia 32. Verdochio 22, 24, 27, 28, 29. Verducia 22. Verte Bonne 3, 7, 9, 10, $11,34,18,21,22,23,24,28,29$. Vert Bonne 13, 22, 27. Verte d'Espagne $23,28,29$. Verte Tiquetée 22, 24, 27, 28, 29. Vilmot's Green Gage 29. Vilmot's Late Green Gage 29. Wilmot's Green Gage 10, 11, 18, 20, 21, 22, 24, 27, 28. Wilmot's Late Green Gage 11, 18, 20, 21, 22. Wilmot's Late Green Gage 10, 13, 18, 20, 21, 22, 28, 29. Wilmot's New Green Gage 10, 11, 13, 18, 20, 22, $28,29$. Waterloo 20.

In the pomological literature since Quintinye in 1699 , Reine Claude has been the standard in quality for plums. For the qualities that gratify or assist in gratifying the sense of taste,-richness of flavor, consistency and texture of flesh, abundance of juice and pleasant aroma,- the Reine 
Claude is unsurpassed. It is, however, now probably equalled in quality by several of the great number of similar varieties which have originated in America and for which American plum-growing is justly distinguished. Under ordinary cultivation the Reine Claude is not a remarkably handsome plum but when grown on thrifty trees, the crop thinned, foliage and fruit kept free from pests and the fruits sufficiently exposed to the sun to color well, it is a beautiful fruit, its size, form and color all adding to its beauty. The tree is only of moderate size in the orchard and in the nursery is so small and wayward that nurserymen hesitate to grow it. The trees, though small, are productive and bear regularly, the chief defect being the susceptibility to sunscald whereby the bark on the trunk is killed and the beginning of the end is marked. The short life of the trees of this variety is largely due to this injury to the bark and has led to top-working on Lombard and other stocks, an operation successful only when done early in the life of the stock. Another serious fault is that the fruit cracks badly if showers occur at ripening time. Reine Claude is still one of the most profitable plums grown in New York and whether for the commercial or home plantation deserves a place in the plum orchard.

For a complete history of this variety the reader is referred to the discussion of the Reine Claude group of plums. The Bavay, a distinct variety, is called the true Reine Claude by many nurserymen and horticultural writers. Green Gage is a synonym of the Reine Claude and is preferred by some writers for this plum but since "Reine Claude" is as well known and much older it has been retained in The Plums of New York. The American Pomological Society placed this variety on its fruit catalog list in ${ }_{1} 8_{52}$.

Tree of medium size and vigor, round-topped, hardy, productive; trunk and branches of medium thickness and smoothness; branches ash-brown, with few lenticels; branchlets short, with short internodes, reddish-brown, lightly pubescent; leaf-buds large, long, conical or pointed, free; leaf-scars prominent.

Leaves four and one-half inches long, two inches wide, oval, thick, leathery; upper surface dark green, smooth, covered with fine, scattering hairs; lower surface pale green, pubescent; apex acute, margin often doubly crenate, glandular; petiole three-quarters inch long, tinged red, glandless or with one or two small, globose, greenish glands variable in position.

Fruit mid-season; one and three-quarters inches by one and five-eighths inches in size, roundish-oval, halves equal; cavity narrow, regular, abrupt; suture shallow, broad; apex pubescent, roundish or slightly depressed; color yellowish green, indistinctly streaked with green, becoming golden-yellow at full maturity, sometimes mottled on 
the sunny side with red, overspread with thin bloom; dots very numerous, small, grayish, conspicuous, clustered about the apex; stem thick, three-quarters inch long, pubescent; skin tough, adhering to the pulp; flesh greenish-yellow or golden-yellow, juicy, firm, sweet, mild; very good; stone semi-clinging, one inch by three-quarters inch in size, oval, turgid, tapering at the base, blunt at the apex, with thickly pitted surfaces; ventral suture wide, distinctly furrowed, often with a short wing; dorsal suture with a very wide and deep groove.

\section{ROBINSON}

\section{Prunus munsoniana}

1. Ind. Hort. Soc. Rpt. 134. 1883. 2. Am. Pom. Soc. Rpt. 151. 1891. 3. Cornell Sta. Bul. 38:64, 86. 1892. 4. Me. Sta. An. Rpt. 12:67. 1896. 5. Am. Pom. Soc. Rpt. 89. 1897. 6. Wis. Hort. Soc. Rpt. 137. 1899. 7. Wis. Sta. Bul. 87:15. 1901. 8. Waugh Plum Cult. 199. 1901. 9. Kan. Sta. Bul. ror:131. 1901. 10. Ga. Sta. Bul. 67:280. 1904. 11. Ohio Sta. Bul. 162:256, 257. 1905 .

Robinson has long been one of the best known of its species though it is probably inferior in fruit-characters at least to several other Munsoniana sorts. The plums are attractive in coloring but small in size and comparatively low in quality. The trees are capricious in growth and not as hardy as some others of the species but where they can be grown are always productive. The variety is rated by some authors among those that need cross-pollination to insure large crops. Robinson may be worth growing in the South and in the States of the Plains but it cannot be recommended for any purpose in New York.

This variety is a seedling grown by a Mr. Pickett of Putnam County, Indiana, from a seed brought with him from North Carolina about 1835 . In 1879 , Dr. J. H. Robinson read a paper before the Indiana Horticultural Society on Chicasaw plums, and gave a very flattering description of this plum, which he had been growing since 1872 . Later it was named by the Putnam County Horticultural Society in honor of Dr. Robinson. This name was used as a synonym of Miner by Downing in I869 but at the present time that usage has almost disappeared in plum literature.

Tree variable in size, often large, vigorous, spreading, not uniform in habit, somewhat open and flat-topped, hardy, medium to productive; trunk shaggy; branches very rough, zigzag, thorny, dark ash-gray, with numerous, large, narrow and strongly elongated, raised lenticels; branchlets slender to medium, with internodes medium to below in length, grecnish-red changing to dull, dark chestnut-red, glabrous, with numerous very conspicuous, large, raised lenticels; leaf-buds small, short, obtuse, free.

Leaves folded upward, lanceolate, peach-like, one and five-sixteenths inches wide, three and one-half inches long, thin; upper surface dark green, glabrous, with 
deeply grooved midrib; lower surface glabrous except along the midrib and larger veins; apex taper-pointed, base obtuse, margin very finely serrate, with small, dark red glands; petiole slender, five-eighths inch long, reddish, lightly pubescent along one side, glandless or with from one to seven small, globose, reddish-brown glands on the stalk and on the base of the leaf.

Blooming season medium to late, long; flowers appearing with the leaves, elevensixteenths inch across, whitish, somewhat self-fertile; borne in clusters on lateral buds and spurs, in twos, threes or fours; pedicels seven-sixteenths inch long, slender, glabrous, greenish; calyx-tube green, narrow-campanulate, glabrous; calyx-lobes narrow, slightly obtuse, glandular, pubescent and with marginal hairs, erect; petals ovate or oval, small, narrow, slightly crenate, tapering below to long, narrow claws; anthers yellowish; filaments one-quarter inch long; pistil glabrous, slightly shorter than or equal to the stamens in length.

Fruit early, season very long; less than an inch in diameter, roundish or roundishoval, halves equal; cavity of medium depth and width, abrupt; suture a line; apex roundish; color clear currant-red, overspread with thick bloom; dots scattering, large, russet, conspicuous, clustered around the apex; stem slender, five-eighths inch long, glabrous, adhering to the fruit; skin tough, bitter, separating readily; flesh goldenyellow, very juicy, somewhat fibrous, tender and melting, sweet next the skin, with some astringency near the center, of mild but pleasant flavor; fair in quality; stone clinging, five-eighths inch by three-eighths inch in size, oval, turgid, very slightly flattened and necked at the base, abrupt-pointed at the apex, roughish; ventral suture blunt, slightly ridged; dorsal suture with a rather broad groove of medium depth.

\section{ROLLINGSTONE}

\section{Prunus americana}

r. Rural N. Y. 44:645. 1885. 2. Minn. Hort. Soc. Rpt. 279. 1885. 3. N. J. Hort. Soc. Rpt. 186. 1885. 4. Wis. Hort. Soc. Rpt. 32. 1885. 5. Minn. Sta. Bul. ro:73 fig. 189o. 6. Cornell Sta. Bul. 38:41, 86. 1892. 7. Am. Pom. Soc. Cat. 24. 1897. 8. Wis. Sta. Bul. 63:56, 58 fig. 28. 1897. 9. Colo. Sta. Bul. 50:45. I898. 10. Ohio. Sta. Bul. 113:153. 1899. Ir. Waugh Plum Cult. 162. 1901. 12. Ga. Sta. Bul. 67:280. 1904. 13. Ohio Sta. Bul. 162:256, 257. 1905.

Minnesota 2. Rolling Stone 3, 4.

Rollingstone is an old Americana sort which has been kept in cultivation chiefly because it is of very good quality for one of its species. The fruit is rather dull in color and small but not unattractive in appearance; the plums are little troubled by either the brown-rot or the plum curculio and ship very well because of the tough skin. The tree is dwarfish with a crooked trunk, shaggy bark, unkempt top and very twiggy - a typical Americana and most difficult to grow into a good orchard plant. The variety is characterized by long, conspicuous stamens, stigmas frequently defective and by very large leaves. The variety has little or no value in New York. 


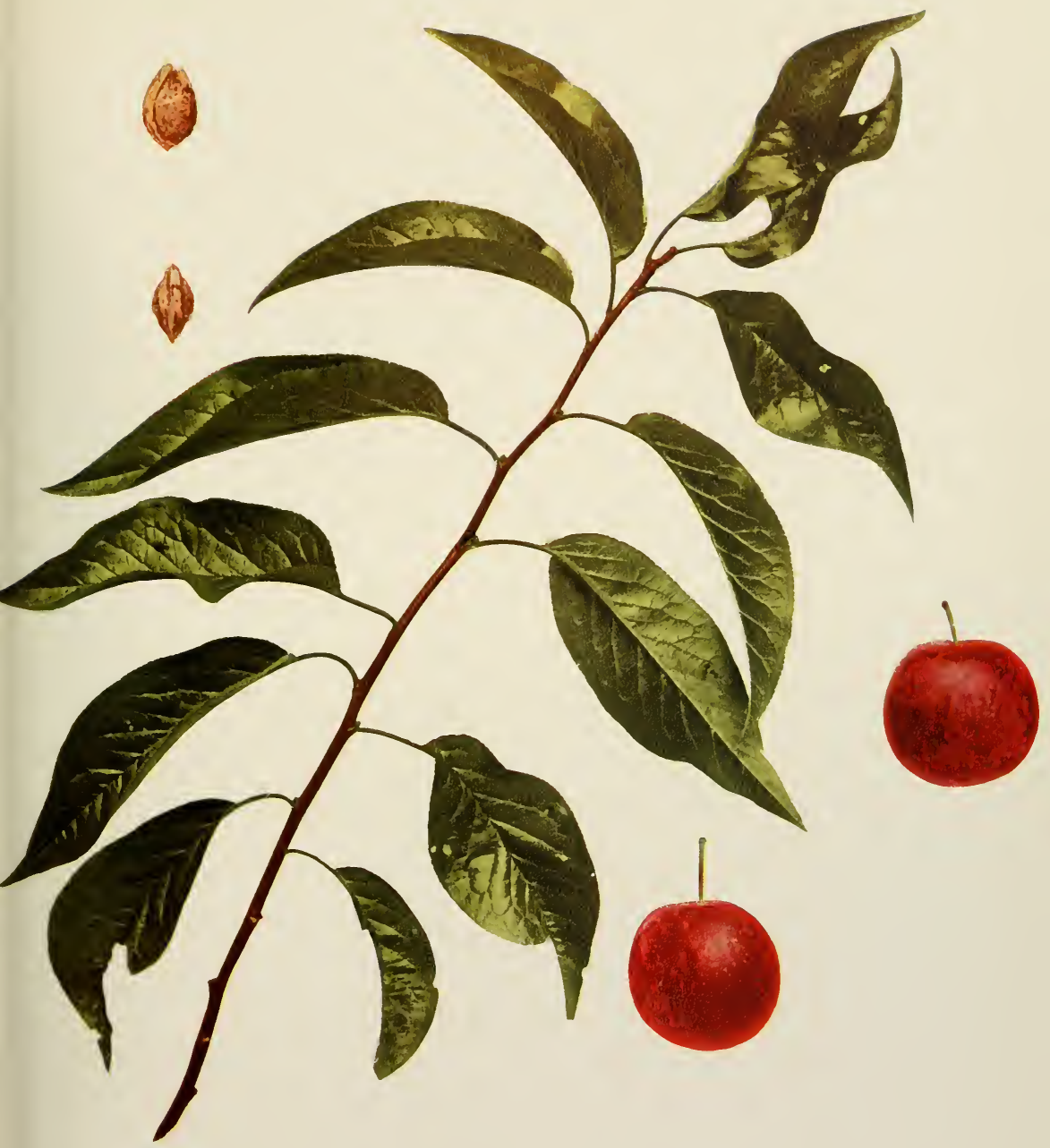

ROBINSON 

Rollingstone was found near an old Indian camping ground on the Rollingstone Creek, Winona County, Minnesota, by Mr. O. M. Lord, ${ }^{2}$ Minnesota City, about 1852. Mr. Lord planted trees of this plum in his garden and found that they improved greatly under cultivation, so much so that they soon became very popular in the local market. About I882 he introduced the Rollingstone to fruit-growers in general. Mr. H. M. Thompson of St. Francis, according to the Minnesota Horticultural Society Report for $188_{5}$, sent this plum out under the name Minnesota but fortunately it has not been distributed under its synonym widely enough to cause much confusion. In 1897 the American Pomological Society added Rollingstone to its fruit catalog list.

Tree dwarfish, variable in vigor, spreading, flat-topped, hardy, productive, healthy; trunk shaggy; branches dark ash-gray, thorny, rough, zigzag, with numerous, rather large lenticels; branchlets slender, twiggy, medium to short, with internodes of average length, greenish turning to dark brown, glossy, glabrous, with conspicuous, small, raised lenticels; leaf-buds medium in size and length, appressed.

Leaves falling early, folded upward, obovate or long-ovate, one and one-half inches wide, three and one-half inches long, thin; upper surface smooth, glabrous, with a narrow groove on the midrib; lower surface silvery green, lightly pubescent, the veins prominent;

${ }^{3}$ Orville Morell Lord was born in China, Wyoming County, New York, April 20, 1826. When he was eleven years of age the Lord family moved to Lapeer, Michigan, where the subject of this sketch attended the district school and then for a time was in a private school at Pontiac, Michigan. In $1852 \mathrm{Mr}$. Lord moved to Winona County, Minnesota, where he built a saw mill, and for some years owned and managed a lumber yard. It was only after middle life that he became interested in horticulture and he then chose the native plums as fruits with which to work. He was not a breeder of plums and the Rollingstone, brought in from the wild and sent out by him in 1882 , is the only addition to pomology, in the way of a new variety, made by him. The work with this fruit which has given him a name as a plum specialist was in testing hardy varieties. He tried thoroughly all the native plums to be obtained, and much of the present information as to the hardiness of plums for the cold northwest is due to knowledge gained from Mr. Lord's experimental orchard. He became a member of the Minnesota State Horticultural Society in 1884 and in 1889 was made an honorary life member of this organization. For some years he was a Farmers' Institute lecturer on horticulture and was for a time horticultural editor of Farm, Stock and Home. He was not only known in the Northwest as a plum specialist but carried on correspondence with plum growers throughout the whole country giving much valuable information regarding this fruit. Beside giving attention to plums he tested many apples for his region and was the originator of one or two varieties now very generally grown in his State. During his life he filled several places of public trust, being a member of the Territorial Legislature in $1853-4$ and of the State Legislature in $1873-4$. He also served at various times in minor offices in his County and in his State being at the time of his death a member of the Forest Reserve Board of Minnesota. With Peter Gideon he was one of the pioneer fruit-growers in the Northwest and while he has left few fruits of his own breeding and few records in print of the work he did, yet his long and faithful service in developing fruit-growing in the Northwest makes him one of the men of note in American pomology. Mr. Lord died July 21, 1906. 
apex taper-pointed, base rather acute, margin coarsely and doubly serrate, eglandular; petiole slender, five-eighths inch long, tinged red, sparingly pubescent, glandless or with one or two small, globose, reddish glands on the stalk.

Blooming season late and short; flowers appearing after the leaves; three-quarters inch across, the buds creamy-white changing to white as the flowers expand; borne in clusters on lateral buds and spurs, in threes or in fours; pedicels seven-sixteenths inch long, below medium in thickness, glabrous, green; calyx-tube reddish-green, obconic, glabrous; calyx-lobes narrow, acute, eglandular, glabrous on the outer surface but lightly pubescent within, heavily pubescent on the margin and with irregular deep serrations, erect; petals oval or slightly ovate, dentate, tapering below into narrow claws reddish at the base; stamens conspicuous; anthers yellow; filaments threeeighths inch long; pistil glabrous, equal to the stamens in length; stigma often abortive.

Fruit mid-season or earlier, ripening period short; about one inch in diameter, roundish, halves equal; cavity shallow, flaring, marked before maturity with lightcolored, radiating streaks; suture a line; apex roundish; color dark purplish-red, with thin bloom; dots numerous, small, light russet, inconspicuous; stem slender, ninesixteenths inch long, adhering poorly to the fruit; skin thick, tough, semi-adherent; flesh orange-yellow, juicy, slightly fibrous, tender and melting, sweet, strongly aromatic; good; stone semi-free, five-eighths inch by one-half inch in size, roundish-oval, flattened, smoothish, blunt at the base and apex; ventral suture acute, faintly ridged; dorsal suture acute, with a narrow, shallow, indistinct groove.

\section{ROYAL TOURS}

\section{Prunus domestica}

1. Duhamel Trait. Arb. Fr. 2:81, Pl. XX fig. 8. 1768. 2. Kraft Pom. Aust. 2:35, Tab. I84 fig. 2. I796. 3. Downing Fr. Trees Am. 313. 1845. 4. Elliott Fr. Book 423. 1854. 5. Mas Le Verger 6:53, fig. 27. 1866-73. 6. Lange Allgem. Garten, 2:420. I879. 7. Le Bon Jard. 2:341. 1882. 8. Cat. Cong. Pom. France 368. 1887. 9. Mathieu Nom. Pon. 438. 1889. 1o. Guide Prat. 160, 365. 1895. I1. Waugh Plum Cult. 120, x21. I901.

Damas de Tours 7. Die königliche Pflaume von Tours 2. Diel's Königspflaume 9 incor. Dicls Königpflaume ro. Frühe Herrn Pflaume 9 incor., ro. Kings plum of Tours 6 . Königsplaume von Tours 5, ro, Königspflaume von Tours 9. Königliche Pflaume von Tours 9, 10. Königs Pfaume 9 incor., 10. Königliche Grosse Pfaume 9, 10. Königin von Tours 9, 10. Moroccopflaume 10: Morocco 9 incor. Prune Royale de Tours 5, 9. Rothe Königspflaume ro. Roi 10. Royale 8, 10. Royale de Tours 1, 3, 5, 7, 8, 10. Royale de Tours 2, 4, 9, 10, Ir. Royal Tours 3, 4, 9. Royal of Tours 4. Royal red Plum 8, ro. Worth II.

This excellent variety should be grown generally in America for home use, at least, if it proves nearly as desirable as it is rated in Europe. Royal Tours is an old French sort supposed to have originated in the neighborhood of Tours, France. Although highly esteemed in Europe, it has not gained favor in this country and is rarely found here. Waugh states that in 1899 he secured specimens of it from North Carolina where it was grown locally under the name Worth. The following description is compiled. 
Tree strong, vigorous; branches thick, short, smooth; fruit early mid-season; of medium size, irregularly roundish, swollen on one side, dark reddish-purple covered with thick bloom; cavity deep; suture prominent; stem short, thick; skin thick, firm; dots conspicuous; flesh greenish-yellow, firm, sweet; very good; stone large, oblong, rough, clinging.

\section{RUTLAND PLUMCOT}

\section{Prunus triflora $\times$ Prunus armeniaca}

r. Burbank Cat. ${ }_{3}$ fig. 1901. 2. De Vries Pl. Br. 218.1907 . 3. Fancher Creek Nur. Cat. ro fig. r 909 .

Plumcot $\mathrm{x}, 2$.

One of the interesting novelties of recent plum-breeding is the Plumcot grown by Luther Burbank' from a cross between the plum and the apricot. Not having seen the fruit of this remarkable cross we are unable to judge of its value to the plum-grower. Out of a large number of extremely variable seedlings of this cross Burbank selected this, the Rutland Plumcot, named in honor of an Australian admirer of the fruit. The variety was introduced by the Fancher Creek Nursery in 1906 and 1907. The following description is partly compiled.

Tree vigorous, spreading, open, not a heavy bearer; branches thorny; branchlets rather slender, with short internodes, dull red; leaves folded upward, oval, one and five-eighths inches wide, two and seven-eighths inches long, rather stiff; margin finely and doubly crenate, glandular; petiole greenish-red, with from one to four globose glands.

The fruit in California attains a large size; suture and cavity deep; skin fuzzy like an apricot, purple; flesh deep red, subacid; quality fair; stone large, broad-oval.

Of this fruit Burbank writes to this Station under date of December 6, I gog, as follows:

"I have this season also about 65,000 or 75,000 Plumcot seedlings,-a wholly new fruit which promises great things for localities where it can be grown. These Plumcots vary more astonishingly from seed than anything which $I$ have ever produced. No pure Apricots or pure Plums are produced, but every possible variety and every possible combination and all qualities a re brought out strongly. The range of colors is astonishing,-some new combinations of colors never before seen in fruits have been produced. The best California judges of fruits-the great growers and shippers-have pronounced some of these varieties the best fruit ever produced on this earth. Most of these fruits have a beautiful downy skin-many of them smooth-flesh orange, yellow, white, crimson or green; pits peculiar. The fruits vary from about the size of a medium peach down to the size of Green Gage plums, though the various ones are of every possible size, form, flavor, color, time of ripening, etc. The trees, in some cases, grow faster than any other fruit tree. Sometimes branches grow on even quite young trees twelve feet in length and an inch in diameter in a single season. Others are quite slow growers or even dwarfs." 


\section{SAINT CATHERINE}

Prunus domestica

x. Quintinye Com. Gard. 67, 68, 69. 1699. 2. Langley Pomona 94, Pl. 24 fig. 6. 1729.3. Miller Gard. Dict. 3. 1754. 4. Duhamel Trait. Arb. Fr. $2: 97$, Pl. XX fig. 5, 109, Pl. XIX. 1768. 5. Knoop Fructologie 2:55. 1771. 6. Lond. Hort. Soc. Cat, 153. 1831. 7. Prince Pom. Man. 2:76, 103. 1832. 8. Kenrick Am. Orch. 267. 1832. 9. Gallesio Pom. Ital. $2:$ PI. 1839. 10. Downing Fr. Trecs $A m, 283$ fig. I12. 1845. 11. Floy-Lindley Guide Orch. Gard. 298, 383. 1846. I2. Poiteau Pom. Franc. 1:1846. 13. U. S. Pat. Off. Rpt. XXX. 1854. 14. Ann. Pom. Belge 65, P1. 1855. 15. Thompson Gard. Ass't 520, 1859. 16. Am. Pom. Soc. Cat. 86. 1862. 17. Pom. France $7:$ No. 23. 1871. 18. Mas Le Verger 6:89, fig. 45. 1866-73. 19. Hogg Fruit Man. 724. 1884. 20. Mathieu Nom. Pom. 431. 1889, 21. Wickson Cal. Fruits 356 fig. 1891. 22. Guide Prat. 161, 365. 1895. 23. Oregon Sta. Bul. 45:33 fig. 1897.

Bricet 7. Bricette 4, 7, 12, Bricette 7, 19. Brisette 20, 22, Catherine (Prune de Ste.) 5. Catharinenpflaume 18,20, 21. De Sainte-Catherine 22. Gelbe Catharinenpflaume 20. Gelbe Catharinenpflaume 18, 22. Gelbe Katharinenpflaume 17,22. Gute Kathe 20. Mirabelle Tardive 7. Petite Bricette 7. Pruneau de Tours 18. Prune de Sainte Catherine 7, 17, 20. Prune Sainte Catherine 13. Prune Sainte-Catherine 18. Prune Sainte-Catherine Jaune 18. Prunjer Sainte-Catherine 14. Pruneaux de Tours 13. St. Catharine 1, 2, 7, 8, 16, 19, 23. Saint Catherine 7. Sainte Catherine 11, 20. Sainte-Catharine 3, 4, 12, 17, 18, 22. Sainte-Catherine de Tours 17, $20,22$. Sainte-Catherine jaune 20, 21. Sainte-Catherine ordinaire 17, 20, 22. St. Katharine 1. Späte Mirabelle 20 incor., 22. Susina Di Santa Caterina 9. Torlo d'Ovo 9. Torlo d'Uovo 9. Yellow St. Catharine 7 .

This plum is grown only on the Pacific Coast in America and even there is to be found but locally and is now passing from cultivation. It is, however, one of the well-known sorts in Europe, especially in France where it is used for prune-making. It appears to be of the Reine Claude group in which group America has so many plums of surpassing merit that this one has no place on this side of the Atlantic. It is included in The Plums of New York largely because of its historic interest and because there seems to be no complete description of it made from trees and fruits grown on this continent.

The origin of this old plum is unknown. It was first mentioned by Quintinye in 1699 . Wherever it originated, it is now grown most extensively in France and is known to commerce as the Prune of Tours. The people in Northern Italy cultivate it under the name Torlo d'Ovo (References, 9). The Belgians have used Saint Catherine incorrectly for the Imperiale Violette (References, 14). In America, according to Kenrick, it was not uncommon around Boston in $\mathrm{I}_{3} 3_{2}$ but it evidently did not receive much recognition, for the United States Patent Office reimported it from France in 1854 and distributed it in the northeastern part of this country. The American Pomological Society added it to its fruit catalog list in 1862 and dropped it in 1899 . 
Tree large, vigorous, round-topped, usually hardy, productive; branches sparingly thorny, light ash-brown, smooth except for the few raised lenticels; branchlets thick, long, with long internodes, greenish-red changing to dark reddish-brown, marked with scarf-skin, nearly glabrous throughout the season, with few, conspicuous, large. raised lenticels; leaf-buds of medium size and length, conical or pointed, broad at the base, appresscd.

Leaves folded upward, oval, one and one-half inches wide, three inches long; upper surface lightly pubescent, with a grooved midrib; lower surface silvery-green, pubescent; apex and base acute, margin crenate, with small, dark glands; petiole three-quarters inch long, thick, with a red tinge, pubescent, glandless or with from one to three conspicuous, globose, bright yellow glands variable in size, usually on the stalk.

Season of bloom intermediate, long; flowers appearing after the leaves, one inch across, white, the buds tinged yellow as they open; borne on lateral spurs, in twos or in threes; pedicels nearly one inch long, slender, with thin pubescence, greenish; calyx-tube green, campanulate, glabrous; calyx-lobes small, narrow, acute, pubescent on the inner surface, erect; petals oval, entire, not clawed; anthers yellow with a tinge of red; filaments three-eighths inch long; pistil glabrous, equal to the stamens in length, often abortive.

Fruit late, intermediate in length of ripening season; small, obovate or oval, slightly necked, truncate at the base, compressed, halves equal; cavity shallow, narrow, flaring; suture varies from shallow to deep, often prominent; apex depressed; color dull green, changing to golden-yellow, overspread with thin bloom; dots numerous, small, gray, inconspicuous, clustered about the apex; stem slender, very long, often one and one-eighth inches in length, glabrous, adhering well to the fruit; skin thick, tough, clinging slightly; flesh light golden-yellow, juicy, fibrous, sweet, mild, pleasant, not high in flavor; good; stone clinging, three-quarters inch by one-half inch in size, oval, flattened, slightly acute at the base and apex, with roughened surfaces; ventral suture finely grooved, blunt; dorsal suture with a wide, shallow groove.

\section{SAINT JULIEN}

\section{Prunus insititia}

x. Miller Gard. Dict. 3. 1754. 2. Lond. Hort. Soc. Cat. 153. 1831. 3. Prince Pom. Man. 2:73. 1832. 4. Noisette Man. Comp. Jard. 2:500. 1860. 5. Downing Fr. Trees Am. 946. 1869. 6. Hogg Fruit Man. 725. 1884. 7. Mathieu Nom. Pom. 449. 1889. 8. Rev. Hort. 438. 1892. 9. Trait. Prat. Sech. Fruits 170. 1893. 10. Bot, Gaz, 26:425. 1898 .

Common Saint Julien 3. Common Saint Julien 5, 7. French St. Julien 3, 5, 7. Gros SaintJulien 3. Gros Saint-Julien 4. Kleine Blaue Julians Pfaume 7. Large Saint Julien ?3. Petit Saint Julien 4. Petit Saint Julien 3, 5, 7. Prunus Insititia var 7. Prunus Domestica Juliana Io. Prunier Saint-Julien 8. St. Julien 6. St. Julian 3. Saint Julien 3. Saint Julien Petit ?2. SaintJulien Petit 3, 5, 7. The St. Julian Plum 1. Weichharige Schlehen Damascene 7.

The Saint Julien plums, as we now use the name, constitute a division of Prunus insititia used as propagating stocks. Whether the name was ever applied to a specific variety can not be said. Miller, in I 754, described 
a "St. Julian" and gave its chief use as a stock for plums, peaches and Bruxelles Apricot. Later writers recommend them chiefly, if not only, as stocks though in France it is said the fruits are dried and sold by the pharmacists and herbahists under the name Prunus medicines (medicinal prunes). Carriere, in Revue Horticole 1892 , speaks very highly of these plums as stocks and describes them as follows:

"Tree vigorous, with branches spreading-straggling, relatively short, branched at the extremity. Leaves numerous, slightly roughened by the prominence of the numerous nerves on the lower surface, short, oblong, usually rounded at the apex, attenuated at the base, where are found a few very small glands; petiole about two centimeters long, yellowish, lengthening out into a prominent midrib; buds short, oval, pointed, deep reddish-brown; dark green above, pale green below, bordered regularly with very close, short, slightly inclined teeth.

Fruits very abundant, pedunculate, spherical or oblong, peduncle a little bent, rather strong, nearly three centimeters long, inserted in a very small cavity, regularly rounded. Skin strongly attached to the flesh, even, glossy, purplish-black, more or less glaucous; flesh free from the seed, pulpy, very juicy, soft, greenish, sweet, leaving a taste a little strong, but not disagreeable; seed short oval, elliptical, flattened, ten millimeters in width, nearly fifteen to sixteen millimeters in length, with grayish-red surface roughened by small, regular projections. Matures from July to September."

\section{SAINT MARTIN}

\section{Prunus domestica}

1. Lond. Hort. Soc. Cat. 144, 153. 1831. 2. Prince Pom. Man. 2:74. 1832. 3. Downing Fr. Trees Am. 295 fig. II9. 1845. 4. Poiteau Pom. Franc. 1. 1846. 5. Mag. Hort. $14: 151$ fig. 15. 1848. 6. Thomas Am. Fruit Cult. 336 fig. 260, 337. I849. 7. Elliott Fr. Book. 423. I854. 8. Thompson Gard. Ass't 515. 1859. 9. Am. Pom. Soc. Cat. 40. 1867. 10. Guide Prat. 162, 365. I 895 .

Catherine violette 8, 10. Coe's Fine Late Red 8. Coe's Fine Late Red 1, 5, 7, Iо. Coe's Late Red 3,6, 9. Coe's Late Red 5, 6, 7, ro. Coê's sehr spate rothe Pflanme ro. De la Sannt-Martin ı. Oktoberpflaume ro. Prune de la St. Martin 3. Prunier de Saint Martin 2, 5, 7. Red St. Martin 2, 7. Red Saint Martin 5, 6, 7. Rouge tardive de Coè ro. Saint Martin Rouge 5. SantMartin Rouge 1, 2, 3, 6, 7, 10. Saint Martin 2, 3, 5. St. Martin 2, 6, 7, 8. St. Martin Rouge 8. Violette d'Octobre ıо. Violette Octoverpflaume 8. Violette Oktoberpflaume ro.

Saint Martin is an old French variety now hardly worth growing, brought into England by a Mr. Coe who called it Coe's Fine Late Red, a name continued by the London Horticultural Society in its catalog. In the United States, too, it became quite generally known as Coe's Late Red in spite of the efforts of Prince, Downing and Elliott to have it pass under its true name. The variety was mentioned in the American Pomological Society's catalogs from i 867 to 1897 . It is described as follows: 
Fruit very late; of medium size, roundish, bright purplish-red with thin blue bloom; suture distinct; cavity shallow; stem of moderate length and thickness; flesh yellow, with a vinous flavor; fair to good; freestone.

\section{SATSUMA}

\section{Prunus triflora}

I. Gard. Mon. 366, 367. 1887. 2. U. S. D. A. Rpt.652, Pl. I fig., 636. 1887. 3. Gard. \& For. 1:471. 1888, 4. Bailey Ann. Hort. 103. 1889. 5. Am. Pom. Soc. Rpt. 105, 106, 125. I89r. 6. Ga. Hort. Soc. Rpt. 54. 1892. 7. Cornell Sta. Bul. 62:29. 1894. 8. Rev. Hort. 458. 1894. 9. Ga. Hort. Soc. Rpt. 96. 1895. 10. Guide Prat. 165, 366. 1895. I1. Cornell Sta. Bul. 106:46, 53. 1896. 12. Ala. Col. Sta. Bul. 85:446. 1897. 13. Cornell Sta. Bul. 139:38, 42. 1897. 14. Am. Pom. Soc. Cat. 26. 1897. 15. Mich. Sta. Bul. 169:243, 250 . 1899. 16. Cornell Sta. Bul. 175:15r. 1899. 17. Ohio Sta. Bul. 113:158. 1899. 18. Waugh Plum Cult. 14r. 1901. 19. Mich. Sta. Bul. 187:77, 80. 1901. 20. Ga. Sta. Bul. 68:14, 33, 34. 1905. 21. De Vries Pl. Br. 170. $x 907$.

Beni Smono No. 4 ?6. Blood Plum 7, 9, 16, 18, 20. Blood Plum? x. Blood Plum No. 4 ?9, 13. Blood Plum No. 4 ?r. Honsmomo Ir. Honsmomo ?9, 11. Japan Blood Plum 3. Sanguine 10. Satsuma Blood 4. Yonemomo 5, 7, 9, 16, 20. Yonesmomo 5, 20.

There is a group of several varieties of Triflora plums unique in having the flesh deep red in color and very firm and juicy. Of these red-fleshed plums, Satsuma was the first to be introduced into fruit-growing in America and is one of the parents of most of the others. While the fruit is not as large nor as handsome in color as in some of its offspring, it is still one of the best varieties for quality of fruit and its trees are possibly as good as those of any of the other sorts of red-fleshed Trifloras. Satsuma, besides being one of the best of its class in quality for either dessert or culinary purposes, keeps and ships very well and if the plums are of sufficient size and have been allowed to color properly, the variety makes a good showing on the markets. Too often, however, it is so unattractive as it reaches the market that it does not sell well. In the South the plums are said to be much attacked by brown-rot but they are not more susceptible here than other plums. The trees are rather above the average for the species in size, habit, health, hardiness and productiveness though they bear sparingly when young. They bloom early in the season and are distinguished from other Triflora sorts by having many spurs and short branches along the main branches. Satsuma might possibly be found worth growing commercially in a very small way in some parts of the State.

Satsuma was raised from the same lot of plum pits from which the Burbank came, the seeds having been sent to Luther Burbank by a Japanese 
agent in 1883 . In 1887 Burbank's tree was the only bearing one in America but since then it has been tested in all of the large plum regions, having been introduced by Burbank in 1889 . In 1897 it was added to the fruit catalog list of the American Pomological Society. Even though this plum is very distinct, with its solid red flesh, it is much confused with other sorts. A Japanese in a letter" to L. A. Berckmans says "Beni-Smomo comprises a group of red-fleshed plums. In Satsuma, my native home, Hon-smomo and Yone-smomo are the most noted and familiar fruits of this group, the first is the smallest in size and deepest in color, while the second is the largest and most highly esteemed. In some districts, plums in this group are called Uchi-Beni, which means red inside." Hon-smomo or Blood Plum No. 4 was separated from the Satsuma or Yonemomo by the Georgia Horticultural Society but Bailey found them indistinguishable.

Tree medium to large, vigorous, upright-spreading, usually quite hardy, moderately productive, bearing heavier crops as the tree becomes older; branches grayish-brown. branchlets medium to above in thickness and length, with short internodes, dark chestnut-red, glabrous, with slightly raised lenticels of medium number and size; leaf-buds small, short, conical, appressed.

Leaves somewhat lanceolate, four inches by one and one-half inches in size, of medium thickness; upper surface dark green, with a shallow, grooved midrib; lower surface light green, glabrous; margin finely and doubly crenate, glandular; petiole three-quarters inch long, tinged red, with from one to three reniform, greenish-yellow glands variable in size, usually at the base of the blade.

Blossoms white; borne in pairs or in threes; pedicels nine-sixteenths inch long, slender, glabrous, greenish; calyx-tube green, obconic, glabrous; calyx-lobes medium in width, acute, somewhat serrate, with dark colored glands, glabrous, erect; petals tapering below to claws of medium length, reddish at the base.

Fruit mid-season or later; one and seven-eighths inches by two inches in size, variable in shape, ranging from roundish-cordate to somewhat oblate, flattened at the base, compressed, halves unequal; cavity deep, narrow, abrupt, compressed; suture variable in depth, prominent; apex pointed or roundish; color dark dull red, with thin bloom; dots numerous, of medium size, russet, somewhat conspicuous, clustered about the apex; stem slender, three-eighths inch long, glabrous; skin of medium thickness and toughness, bitter, semi-adherent; flesh dark purplish-red, juicy, tender at the skin, becoming tough at the center, sweet, with an almond-like flavor; of good quality; stone semi-clinging or clinging, seven-eighths inch by five-eighths inch in size, oval, strongly pointed, rough, tinged red; ventral suture narrow, winged; dorsal suture grooved.

'Am. Pom. Soc. Rpt. 105. I891. 


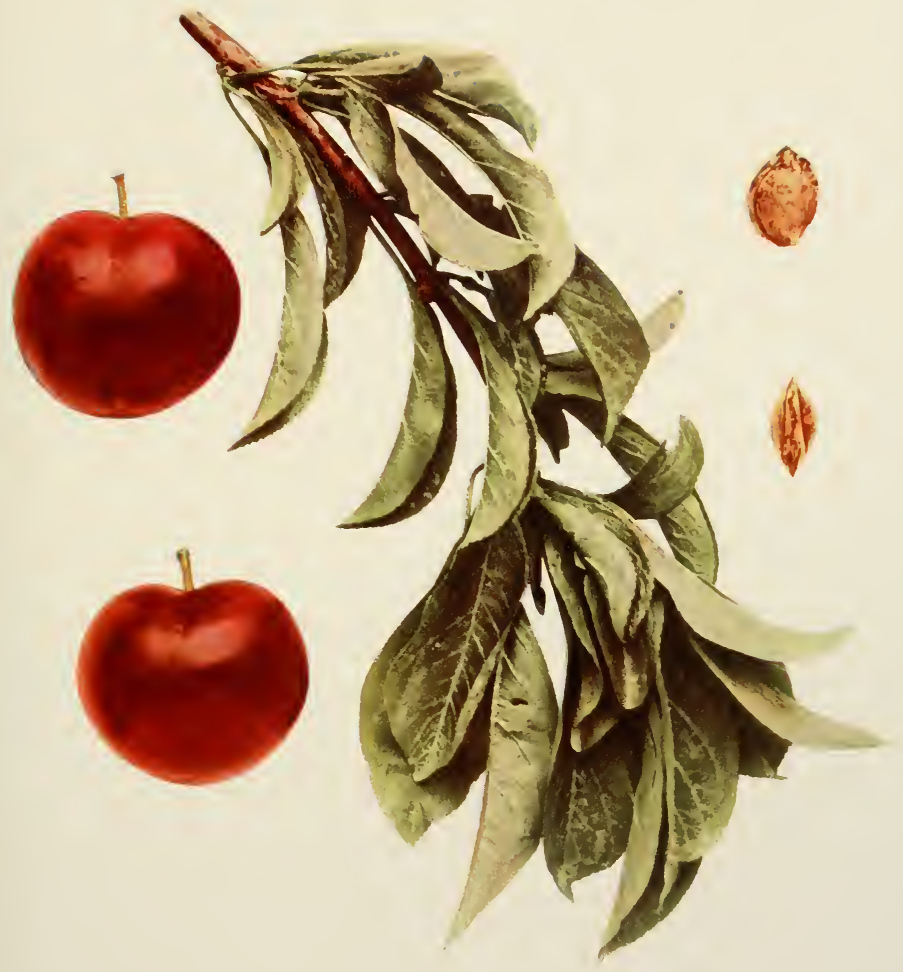





\section{SAUNDERS}

\section{Prunus domestica}

r. Am. Pom. Soc. Rpt. 143. 1885. 2. Can. Horl. 14:92, 223. 1891. 3. Ibid. 19:253. 1896. 4. Ont. Exp. Sta. Rpt. 45, 46. 1899. 5. Can. Hort. 27:244. 1904.

Saunders Seedling 5 .

The American Pomological Society recommends this variety for trial with the statement that the quality is of the best and that it is almost free from black-knot. But on the grounds of this Station, fruiting for several years, the plums have been inferior in size and somewhat so in quality and all told much less attractive than a number of other sorts of the same season. Saunders originated with John Arris of Belleville, Ontario, Canada. It was first exhibited before the Fruit-Growers' Association of Ontario at St. Catherines in $188_{3}$. In I $88_{4}$, upon its being again exhibited before the same association, it was named Saunders in honor of the society's noted president. The variety was mentioned in the catalog of the American Pomological Society in 1897 .

Tree of medium size, round-topped, very productive; branchlets brash, slender, very pubescent; leaves flattened, obovate or oval, one and three-quarters inches wide, four inches long, somewhat velvety, rugose; margin finely serratc, eglandular or with small dark glands; petiole pubescent, glandless or with from one to three small glands; blooming season intermediate in time and length; flowers appearing after the leaves, one and one-quarter inches across, white; borne on lateral buds and spurs, usually singly; pedicels very pubescent.

Fruit early, season short; one and one-half inches by one and one-eighth inches in size, oblong-oval, greenish-yellow changing to golden-yellow, covered with thin bloom; skin thin, tender, slightly sour, cracking when fully mature; flesh yellowish, tender and melting, sweet, mild; of good quality; stone free, one inch by five-eighths inch in size, long-oval, flattened, with rough surfaces ventral suture winged; dorsal suture with a narrow, shallow groove.

\section{SERGEANT}

\section{Prumus domestica}

I. Cal. State Bd. Hort. 49, 51. 1887. 2. Ibid. $234,235$. 189o. 3. Ibid. 105. х89ז. 4. Wickson Cal. Fruits 357. 1891. 5. U, S. D. A. Div. Pom. Bul. 7:316, Pl. IV fig. 2. 1898. 6. Am. Pom. Soc. Cat. 39. 1899. 7. Waugh Plum Cult. г21. 1901.

Prune d'Ente 2. Prunier Datte I. Robe de Sergent 2, 5, 6. Robe de Sergeant 7. Robe de Sergent I, 3, 4 .

In France, from whence Sergeant was imported to California, Sergeant, Agen and Prunier Datte are held to be identical. But in America 
only the first and last are identical, the Agen being quite distinct. It would seem that the French should know their own plums and that their nomenclature should be accepted but the Sergeant is now so widely distributed in America as distinct that we give a brief description of the plum. There may be more than one type of the Agen in France or American nurserymen may have received wrongly named varicties.

Tree upright, with branches and branchlets thickish, more robust than Agen; foliage large, lancet-shaped, glossy, much broader and more shiny than Agen; fruit mid-season; of medium size, roundish-oval, enlarged on one side; skin deep purple to blackish with a thick bloom; flesh greenish-yellow, juicier than Agen, sweet, high flavored; quality good; stone partially clinging; valuable for preserving and drying.

\section{SHARP}

\section{Prunus domestica}

1. Lond. Hort. Soc. Cat. 153. 1831. 2. Downing Fr. Trees Am. 315. 1845. 3. Ann. Pom. Belge 63 , P1. 1859.4 4. Cultivator 8:25 fig. 1860. 5. Downing Fr. Trees Am. 948. 1869.6. Guide Prat. 160, 358. 1895. 7. Jour. Roy. Hort. Soc. 21: Pt. 2, 222. 1897. 8. Waugh Plum Cult. 122, 123 fig. 1901.

Alderton 5. Dolphin 5. Dauphin 5. Denyer's Victoria ?2, 5, 7. Empereur de Sharp 3, 6. Imperial de Sharp 5. Imperiale de Sharp 6. Prune Imperiale de Sharp 3. Queen Victoria ?2. Royal Dauphine 5. Sharp 8 incor. Sharp's Emperor 1,2 incor., 4, 5 incor. Sharp's Emperor 3, 6, 8 incor. Sharpe's Emperor 7. Sharps Kaiserpflaume 6. Victoria 5, 8 incor.

Sharp was briefly described in the London Horticultural Society catalog in $\mathrm{I} 83 \mathrm{I}$. Later, in $\mathrm{I} 845$, A. J. Downing described the variety but thought it identical with the Victoria, as did other writers, as will be seen by referring to the Victoria. H. A. Pearson in the foumal of the Royal Horticultural Society, comparing these two sorts says, "Sharp's Emperor is a second rate plum, resembling Victoria, in appearance, but very inferior in point of cropping and quality, a decided clingstone, often gumming at the stone, and ripening a fortnight later than its supposed synonym, not worthy of cultivation." August Royer in the Annals de Pomologic Belge et Etrangere also separated the two varieties but describes them both as freestones. While there is a lack of uniformity in the descriptions yet the total evidence weighs in favor of two types which are very similar. The Victoria is probably the better plum of the two.

\section{SHELDRAKE}

Prunus domestica

Although extremely vigorous and productive this variety is so inferior in quality as to be of doubtful value. Sheldrake originated as a chance 
seedling on the shore of Cayuga Lake near the town of Sheldrake, New York. It was discovered and propagated by J. T. Hunt of Kendaia, New York, and has been under test at the Geneva Station since I895.

Tree large, vigorous, round-topped, productive; branchlets thick, with long internodes, pubescent; leaves drooping, somewhat flattened, oval, nearly two and one-half inches wide, four and one-quarter inches long; margin serrate with few, small, dark glands; petiole pubescent, tinged red, thick, glandless or with from one to four rather large glands usually at the base of the leaf; blooming season intermediate in time, short; flowers appcaring after the leaves, nearly one and one-quarter inches across; borne singly or in pairs.

Fruit rather early; one and one-half inches by one and three-eighths inches in size, roundish-oblong; cavity very deep, abrupt; color purplish-black, overspread with thick bloom; dots conspicuous; stem thickly pubescent; skin thin, tender, slightly acid; flesh yellow, tender, sweet next the skin, but sour near the center, inferior in flavor; poor in quality; stone dark-colored, semi-clinging, one inch by three-quarters inch in size, broadly ovate or irregularly oval, flattened, with roughened and granular surfaces; ventral suture prominent, blunt.

\section{SHIPPER}

\section{Prunus domestica}

I. Gard. Mon. 24:339. 1882. 2. W. N. Y. Hort. Soc. Rpt. 31:60. 1886. 3. Cornell Sta. Bul. 131:r91, fig. 42. 1897. 4. Mich. Sta. Bul. 169:243, 247. 1899. 5. Can. Exp. Farm Bul. 2nd Ser. 3:56. 1900. 6. Mich. Sta. Bul. 187:77, 79. 1901. 7. Waugh Plum Cult. 119. rgor.

Pride 7. Shipper Pride 4. Shippers' Pride 7. Shipper's Pride I, 2, 3, 5, 8.

This plum has never become an important commercial variety in New York yet it is offered for sale by a surprisingly large number of nurserymen. The variety has too many faults to succeed in competition with the many good plums of its color and season. The flesh is dry and the plums often shrivel on the tree, characters which fit it for shipping, but which when taken with poor quality and small size make it of little value after it reaches the market. Moreover it fruits sparingly under many conditions, though productive here, and the plums ripen somewhat unevenly and are susceptible to brown-rot. Some pomologists give a rather better estimate of the variety than that expressed here, but from all data at hand the value of the plum is not underestimated in the above statements. There are a great many better plums for New York than Shipper.

This variety was introduced by Mr. H. S. Wiley of Cayuga, New York. The plum was found by Mr. Wiley in a private garden at Port Byron, New York, about 1877 . The man upon whose place it grew thought that it 
came from a stone of one of the several varieties in his garden but $\mathrm{Mr}$. Wiley is not sure of this origin and suggests that it may have sprouted from a root.

Tree large, vigorous, round-topped, hardy, productive; branches thick, ash-gray, smooth except for the raised lenticels; branchlets of medium thickness and length, with long internodes, green changing to brownish-drab and with a red tinge, dull, covered with thick pubescence throughout the season, with inconspicuous lenticels of medium number and size; leaf-buds small, short, conical, appressed.

Leaves many, flattened or folded upward, obovate or oval, one and three-quarters inches wide, three and one-half inches long, thick, leathery; upper surface dark green, hairy, with a grooved midrib; lower surface silvery-green, thick, pubescent; apex abruptly pointed or acute, base acute, margin serrate or crenate, eglandular or with small dark glands; petiole one-half inch long, thick, pubescent, with a red tinge, glandless or with one or two globose, yellowish-green glands usually at the base of the leaf.

Season of bloom intermediate in time and length; flowers appearing with the leaves, nearly one and one-quarter inches across, white; borne on lateral buds and spurs, singly or in pairs; pedicels three-quarters inch long, pubescent, greenish; calyx-tube green, campanulate, pubescent; calyx-lobes obtuse, lightly pubescent on both surfaces, glandular-serrate and with marginal hairs, reflexed; petals broadly oval or obovate, slightly crenate or occasionally notched, with short, broad claws; anthers yellow; filaments five-sixteenths inch long; pistil glabrous, shorter than the stamens.

Fruit late, intermediate in length of ripening season; one and one-half inches by one and three-eighths inches in size, ovate, swollen on the suture side, compressed, halves equal; cavity shallow, abrupt; suture shallow; apex bluntly pointed; color purplish-black, overspread with thick bloom; dots small, russet, somewhat conspicuous; stem seven-eighths inch long, pubescent, adhering well to the fruit; skin thin, tender, separating readily; flesh greenish-yellow, rather tart, firm, sweet, mild in flavor; inferior in quality; stone semi-clinging, often with red tinge near the edge, seven-eighths inch by three-quarters inch in size, irregular roundish-ovate, turgid, rough, blunt at the base and apex; ventral suture wide, ridged, distinctly winged; dorsal suture wide, deep.

\section{SHIRO}

Prunus simonii $\times$ Prunus triflora $\times$ Prunus cerasifera $\times$ Prunus munsoniana

r. Cal. State Bd. Hort. 53 fig. 1897. 2 Burbank Cat. 1899. 3. Waugh Plum Cult. 225. 1901. 4. Rural N. Y. 62:582. 1903.

Late Klondike r.

Shiro has been in the hands of fruit-growers too short a time to permit a just estimate of it to be made. As the variety grows on the grounds of this Station, the fruits are large and handsome in form and color, as is well shown in the illustration. The flavor lacks character and is almost insipid but the flesh is tender, melting and juicy and so translucent that the pit 

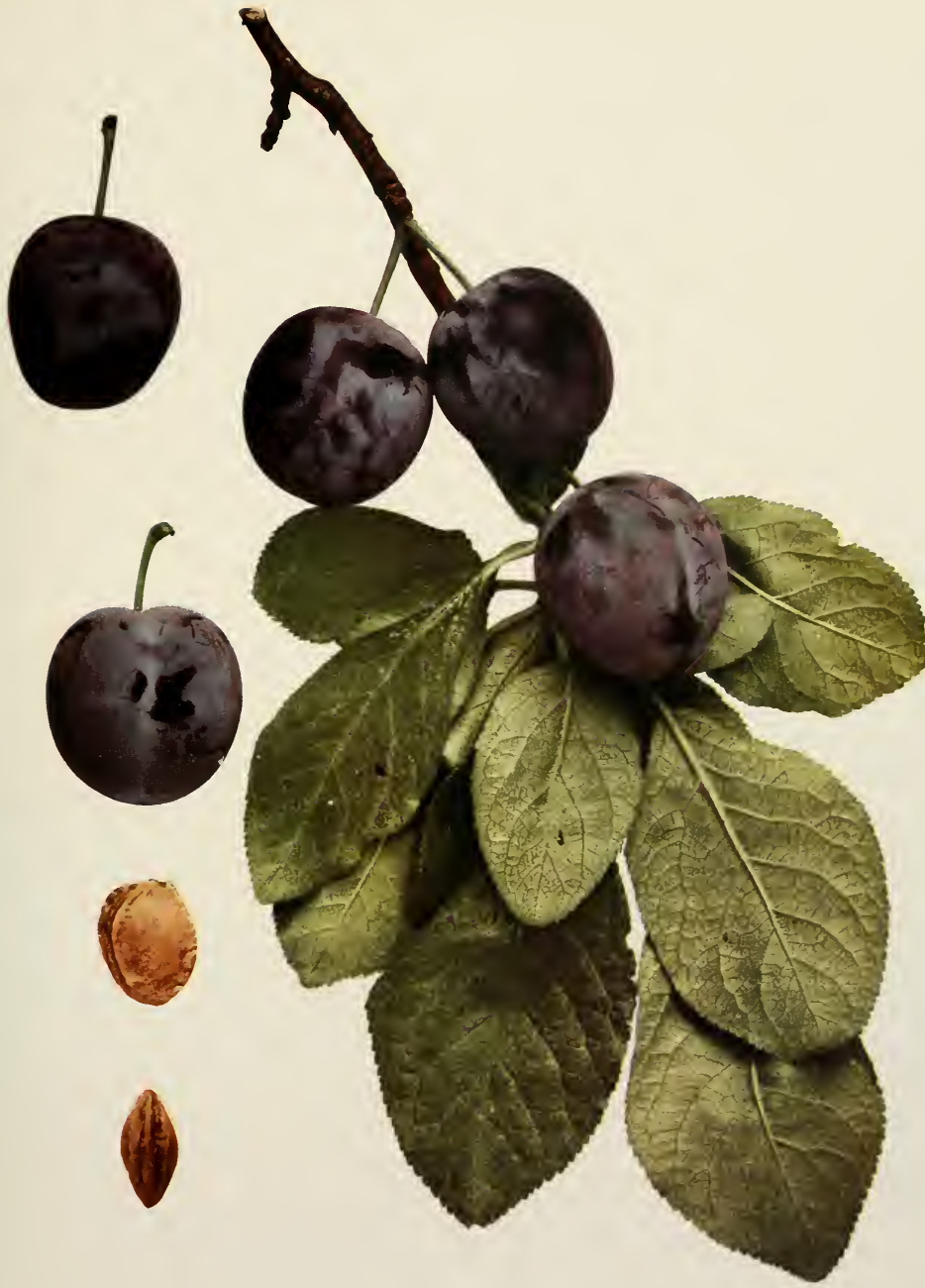

can be seen through the flesh. Despite the flavor, the plum is pleasant to eat and may be ranked as good in quality. Those who have had experience say that the variety ships very well if not fully mature but quickly goes down after ripening; the plums are also quite susceptible to brownrot. The trees of this variety at Geneva are quite as vigorous, hardy, and productive as any of the sorts which Mr. Burbank gives as progenitors of Shiro and will generally, it is believed, surpass any of them in thesc respects. It may here be remarked that of the four species from which Shiro is supposed to have come, it most resembles Prunus triflora in both tree and fruit though the leaves have some resemblance to those of Prumus cerasifera. Shiro is still, so far as New York is concerned, in the list of plums deserving trial but with the chances against its becoming of great value either for home or commercial plantations.

This is another of Burbank's plums and is said to be a descendant of Robinson, (Prumus munsoniana,) Myrobalan, (Prunus cerasifera), and Wickson, (a cross of Prunus triflora and Prumus simonii) from seed of Wickson. Burbank in his catalog for 1889 says that the tree resembles a Myrobalan in foliage, growth and general appearance. But as the variety grows at this Station it has all the appearances of a Triflora. Shiro was described in the California State Board of Horticulture Report for 1898 and the following year it was introduced by the originator.

Tree large, vigorous, upright-spreading, tender to cold, productive; branches smooth, somewhat thorny, dull ash-gray, with few, small lenticels; branchlets slender, above medium in length, with short internodes, greenish-red changing to brownishdrab, glabrous, with inconspicuous, scattering, small lenticels; leaf-buds small, very short, obtuse, strongly appressed.

Leaves folded upward, obovate, one and five-sixteenths inches wide, two and threequarters inches long, leathery; upper surface faintly rugose, glabrous, with a grooved midrib; lower surface lightly pubescent along the midrib and larger veins; apex acutely pointed, base rather acute, margin finely crenate, with small, dark glands; petiole three-eighths inch long, pubescent along one side, greenish-red, glandless or with one or two small, globose, yellowish glands on the stalk.

Blooming season early and of medium length; flowers appearing before the leaves, white; borne in clusters on lateral buds and spurs; pedicels short, glabrous, greenish; calyx-tube green, campanulate, glabrous; calyx-lobes obtuse, glandular-serrate, glabrous on the outer side, sparingly pubescent within, with a pink margin, erect; petals roundish, entire, tapering to short, abrupt claws; anthers yellow with a reddish tinge; filaments below medium in length; pistil glabrous, longer than the stamens.

Fruit very early, season short; one and one-half inches in diameter, roundishconic, with halves equal; cavity intermediate in depth and width, flaring, regular; 
suture an indistinct line; apex roundish; color light yellow becoming deeper yellow as the season advances, occasionally with a blush of pink, with thin bloom; dots numerous, very minute, whitish, inconspicuous; stem three-eighths inch long, adhering to the fruit; skin thin, tough, sour, occasionally cracking, separating readily, although a thin coating of flesh is left clinging to the skin; flesh light yellow, semi-transparent, the stone being faintly visible, very juicy, fibrous, somewhat melting, sweet, mild, lacks character in flavor; good; stone clinging, seven-eighths inch by five-eighths inch in size, broadly oval, flattened, slightly elongated at the base, with rough surfaces; ventral suture faintly ridged and furrowed; dorsal suture very lightly grooved.

\section{SHROPSHIRE}

Prunus insititia

x. Rea Flora 209. 1676. 2. Lond. Hort. Soc. Cat. 146. I831 3. Prince Pom. Man. 2:90. 1832. 4. Loudon Enc. Gard. 921 . I834. 5. Downing Fr. Trees Am. 297. 1845. 6. Floy-Lindley Guide Orch. Gard. 282, 383. 1846. 7. Thompson Gard. Ass't 520. 1859. 8. Hogg Fruit Man. 377. 1866. 9. Am. Pom. Soc. Cat. 36. 1875. 10. Hogg Fruit Man. 695. 1884. 11. Mich. Hort. Soc. Rpt. 289. 1889. 12. Am. Gard. 14:146 fig., 147, 148, 1893. 13. Cornell Sta. Bul. 131:192 fig. 46. 1897. 14. Garden 53:265. 1898. 15. Mich. Sta. Bul. 169:243, 247. 1899. 16. Waugh Plum Cult. 130 fig. 1901. 17. Va. Sta. Bul. 134:44. 1902, 18. Ga. Sta. Bul. 67:281 fig. 1904.

Cheshire 14. Damascene 8, 10, 14. Damson Plum 3. Long Damson 2. Long Damson 7, 8, 10. Pruine Damson? 1. Prune Damson 2, 4, 5, 7, 14. Prune Damson 6, 8. Prune ro. Shropshire Damson ?6, 8, 10, 15, 16, 17. Shropshire Damson 2, 3, 4, 7, 9, 11, 12, 13, 18.

In America, Shropshire is probably the best known of the Damsons, being found not only in nearly all commercial plantations but in the smallest home collections as well. The qualities which make it so generally a favorite are for most part those of the tree, the French surpassing it in size and in quality of the fruit. The trees of the variety under notice are not surpassed by any other Insititia in size, vigor, hardiness and health nor are they, except in size, by any other European plum. Shropshire is enormously productive, bearing its load of fruit year after year until it is a standard among fruits for productivity and reliability in bearing. The trees have but one defect,- unless sprayed the foliage falls prey to fungi and drops early. The trees are comparatively easy to manage in such orchard operations as pruning, spraying and harvesting as they are not so thick-topped, twiggy and spiny as other Damsons. The fruit is of very good size and while in no sense a dessert plum may be eaten out of hand with relish when fully ripe or after a light frost-a point worth considering where only Damsons can be grown. It is one of the best of its kind for culinary purposes. This old variety is still to be recommended for both home and market. 


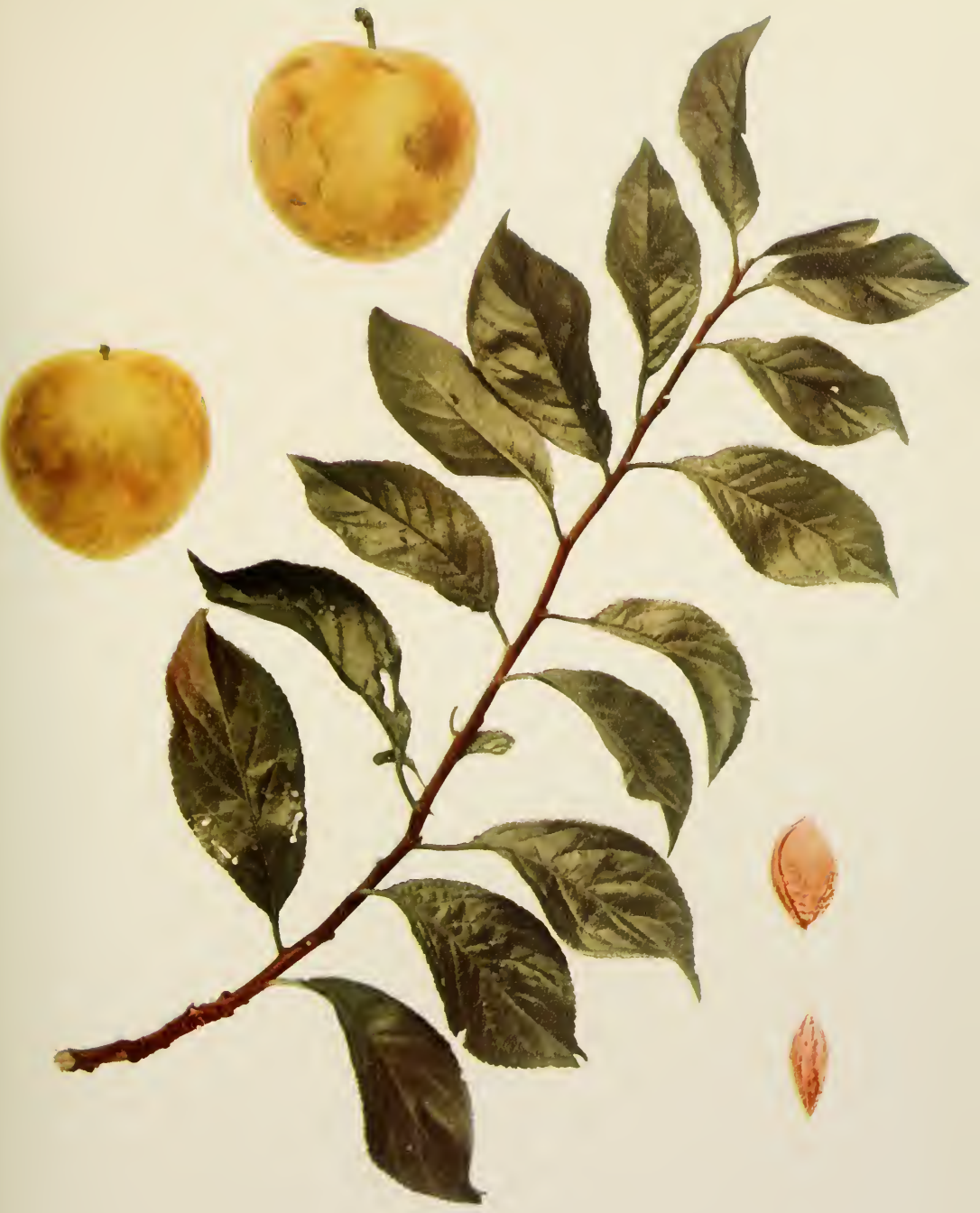





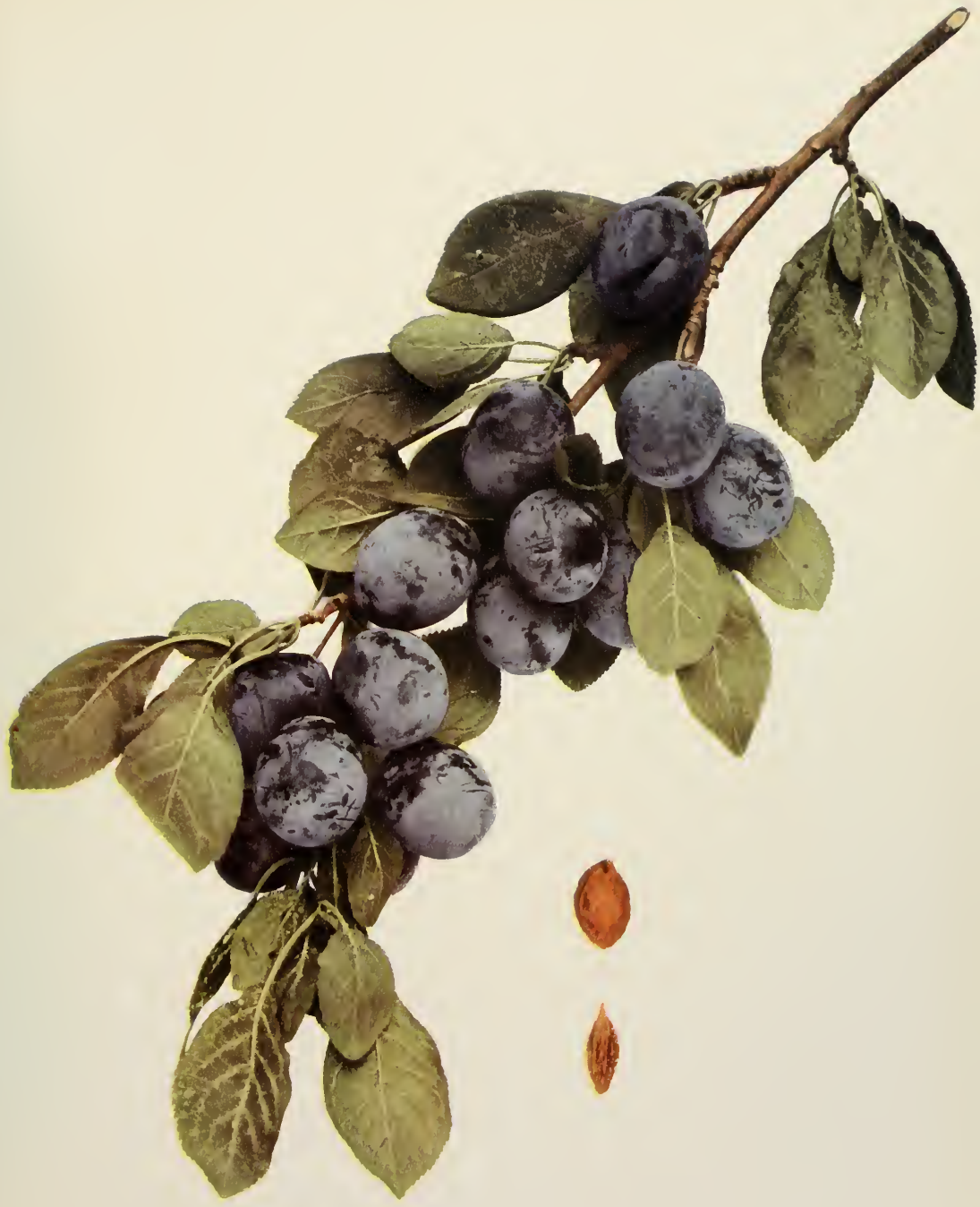



Shropshire originated in England, sometime in the Seventeenth Century. It was noted by American writers early in the Nineteenth Century and in 1875 was placed on the American Pomological Society's fruit catalog list. Shropshire is a more familiar name in fruit literature than the references given indicate, being found in practically every English discussion of plums since 1676 and in all American notices of this fruit since Prince wrote in 1832 . For a fruit so long under cultivation, it has few synonyms.

Tree large, vigorous, vasiform, hardy, productive; main branches numerous, ashgray, smooth except for numerous scars from small spur-like branches, with many, small lenticels; branchlets twiggy, slender, with short internodes, green changing to dark brownish-drab, dull, covered with heavy pubescence throughout the season, with numerous, small lenticels; leaf-buds below medium in size, short, conical, appressed.

Leaves flattened, obovate, about one inch wide, two inches long, thin; upper surface dark green, pubescent along the grooved midrib; lower surface a paler green, with thin pubescence; apex obtuse or acute, base acute, margin finely serrate, eglandular; petiole one-half inch long, slender, greenish-red, with little pubescence, glandless or with one or two small, globose, greenish-yellow glands usually at the base of the leaf.

Season of bloom medium; flowers seven-eighths inch across, white; borne in clusters on lateral buds and spurs, singly or in pairs; pedicels three-eighths inch long, slender, glabrous, greenish; calyx-tube green, campanulate, glabrous; calyx-lobes narrow, acute, glabrous, the margin glandular-ciliate, reflexed; petals roundish-oval, entire, short-clawed; anthers yellow; filaments five-sixteenths inch long; pistil glabrous, shorter than the stamens.

Fruit late, season long; one and one-half inches by one inch in size, oval, compressed, halves equal; cavity shallow, narrow, flaring; suture an indistinct line; apex roundish; color purplish-black, overspread with thick bloom; dots numerous, small, russet, inconspicuous; stem slender, one-half inch long, glabrous, adhering to the fruit; skin thin, tender, adhering; flesh golden-yellow, juicy, firm but tender, agreeably tart at full maturity, sprightly, pleasant; stone clinging, three-quarters inch by one-half inch in size, oval, acute at the base, blunt at the apex, with nearly smooth surfaces; ventral suture broad, blunt; dorsal suture acute, with a narrow, shallow, indistinct groove.

\section{SIMON}

\section{Prunus simonii}

I. Rev. Hort. 111. 1872. 2. Horticulturist $27: 196$. 1872. 3. Ia. Hort. Soc. Rpt. $374,378$. 1881. 4. Ibid. 321 . 1884, 5. Rural N. Y. $45: 689$ fig. 389 . 1886. 6. Ibid. $46: 766$. 1887. 7. Ga. Hort. Soc. Rpt. 53, 99. 1889. 8. Nathieu Nom. Pom. 444. 1889. 9. Cal. State Bd. Hort. Rpt. 236 , P1. II figs. I and 2,238 , 189o. 1o. Rev. Hort. 152 fig. 40. r 89 x. 11. Penin. Hort. Soc. Rpt. 68. 189r. 12. Cornell Sta. Bul. 51:55. 1893. 13. Mich. Sta. Bul. 103:35. 1894. 14. Guide Prat. 164. 362. 1895. 15. Neb. State Hort. Soc. Rpt. 175. 1895. 16. Kan. Sta. Bul. 73:192. 1897. 17. Vt. Sta. Bul. 67:29. 1898. 18. Am. Pom. Soc. Cat. 41. 1899. 19. Waugh Plum Cult. 14, 38, 234. 1901. 
Apricot Plum 12, 19. Apricot Plum 9, 11. Plum Simon 2. Prune Eugene Simon 8. Prunier de Simon 8, 14. Prunus simoni 4, 7, 17. Prunus Simonii 2. Prunus Simonii 1, 3, 6, 8, 10, 11, 14, 16, 19. Prunus simoni 8. Simon 19. Simon's Chinese Apricot Plum 7. Simon's Peach 15. Simon's Plum 5.

The Simon plum, a horticultural variety, constitutes the species Prunus simonii and has been fully discussed in the chapter of this text dealing with the botany of the plum. It is given further notice only to introduce the horticultural references and history and to estimate briefly its value in fruit-growing. As to the latter it may be said that the fruit is for most people unpalatable, and therefore of little worth as an edible product. Some of the crosses of which this variety is one parent are well known and esteemed in pomology and the Simon plum undoubtedly has value for plum-breeding in the future. The tree, where it succeeds, is a handsome ornamental. In New York the variety seems hardy wherever the peach can be grown and thrives on the same types of soils-sands, gravels and light loams. The tree is subject to diseases and unless well sprayed is liable to be short-lived. The variety can be recommended in New York only to the breeder of plums and for those who want the tree as an ornamental or a curiosity.

This interesting and distinct plum was obtained in China by Eugene Simon, a French consul, who sent it to the Paris Museum of Natural History in I 867. Later it was disseminated by the nurseries of Simon Brothers at Plantieres-Les-Metz. The date of its introduction into America is unknown, though it was offered for sale by the eastern nurseries as early as I88ז. Ellwanger and Barry of Rochester secured their stock from France a few years previous to the date given but whether they were the only importers cannot be said. In 1899 the American Pomological Society added Simon to its catalog list. The variety is fully described under its species.

\section{SIMPSON}

\section{Prunus domestica}

1. Ohio Sta. Bul. 113:161, 1899. 2. Ibid. 162:256, 257. 1905.

The fruit of Simpson is too small and is so much below the average of its type, that of the Yellow Egg, in quality that it is not worth general introduction. It is given attention here chiefly as a matter of record. Although unquestionably a Domestica, Simpson was found growing wild in the woods west of Peoria, Illinois. It was introduced by H. Augustine of Normal, Illinois, about r 888 . 
Tree large, very vigorous, upright-sprcading, dense, very productive; branchlets slender, with long internodes, thickly pubescent; leaf-buds large, long; leaves flattened, oval, intermediate in width and length; margin serrate, eglandular; petiole pubescent, glandless or with from one to three globose glands usually on the stalk; flowers one inch across, borne in scattering clusters, singly or in pairs; calyx-lobes thickly pubescent on both surfaces.

Fruit mid-season; one and one-half inches by one and thrce-eighths inches in size, oval, golden-yellow, covered with thin bloom; flesh golden-yellow, juicy, firm but tender, sweet, mild; good; stone semi-free, seven-eighths inch by one-half inch in size, oval, acute at the base; ventral suture usually winged; dorsal suture widely and deeply grooved.

\section{SMALL REINE CLAUDE}

\section{Prumus domestica}

I. Duhamel Trait. Arb. Fr, 2:91. 1768. 2. Kraft Pom. Aust. 39, Tab. 189 fig, 2. 1796. 3. M'Mahon Am. Gard. Cal. 587. I806. 4. Lond. Hort. Soc. Cat. 147,148 , 154. 1831. 5. Prince Pom. Man. 2:49. 1832. 6. Mag. Hort. 9:x6.4. 1843. 7. Downing Fr. Trees Am. $288 . \quad 1845$. 8. Floy-Lindley Guide Orch. Gard. $284,383.1846 .9$. Thomas Am. Fruit Cult. 330. 1849.1 10. Downing Fr. Trees Am. 913. 1869. Ir. Mas Pom. Gen. 2:93. 1873. 12. Oberdieck Deut. Obst. Sort. 435. 1881, 13. Hogg Fruit Man. 732. 188,. 14. Mathieu Nom. Pom. 437. 1889.

Die kleine Königin Claudia 2. English Yellow Gage 9, 10. English Yellow Gage I1, 14. Gonne's Green Gage 6, 7, 10, 13, 14. Gonne's Green Gage 4. Kibitzenei 14. Kleine Dauphine 14. Kleine Reine-Claude 12, 14 . Kleine Weisse Damascene 12, 14. Kleine Reine-Claude 11. Kleme Grüne Reine-Claude I1, 12, 14. Little Reine Claude 5. Little Queen Claude 7, 9, 10, I1, 13, I4, Little Queen Claude 8. Little Queen Claudia 3. Little Queen Clandia 5. Petite Reine-Claude 1. I1. Petite Reine-Claude 2, 5, 7, 8, xo. Petit Damas Vert 13, 14. Reine-Claude Petite Espece 14. Reine-Clande Blanche Petite Espece 5, 6, 7, 10. Reine-Claude Blanche 6, 7, 10, 14. Reine-Claude Petite 13, 14. Reine Claude (of some) 6. Small Green Gage 5, 7, 10, 14. Small Queen Claude 5. White Gage 6, 7, 10, 13, 14. White Gage 4. Yellow Gage 4, 6, 7, 13. Yellow Gage 11, 14.

Small Reine Claude, an old variety of unknown origin, is now probably obsolete. Thomas and Downing described it as an English Yellow Gage but it cannot be found that it is ever so called in Europe. Since the variety was known in France and Austria in the latter part of the Eighteenth Century it is quite certain that it originated on the continent. From its name and close resemblance to the Reine Claude it is safe to state that it is a seedling of that sort. It is described as follows:

Tree of normal vigor; branches smooth; flowers small; fruit medium in sizc, nearly spherical, truncated on the stem side and slightly on the apex; suturc wide and distinct, thus differing from the Reine Claude; stem medium in length; cavity shallow; skin tender, yellowish-green, often splashed with red on the sunny side; flesh greenishyellow, fine, a little firm, sweet, rich and pleasant; freestone; ripens earlier than the Reine Claude. 


\section{SMITH ORLEANS}

\section{Prunus domeslica}

I. Prince Treat. Hort. 27. 1828, 2. Prince Pom. Man, 2:68. 18 32 . 3. Mag. Hort. 9:410. 1843. 4. Downing Fr. Trees Am. 304,305 fig. 125. 1845. 5. Mag. Hort. 14:152, 153 fig. 16. 1848.6 . Cole Am. Fr. Book 214 fig. 1849. 7. Thomas Am. Fruit Cult. 343. 1849. 8 Elliott Fr. Book 424. 1854. 9. Am. Pom. Soc. Cat, 2 10. 1856 . 10. Hooper W. Fr. Book 252. I857. II. Hogg Fruit Man. 382. 1866. 12. Ma thieu Nom. Pom. 450. 1889. 13. Ont. Fr. Exp. Sta. Rpt. 52. 1895. 14. Cornell Sta. Bul. 131:192. 1897.

Cooper's 5. Cooper's Large 5. Cooper's Large Red 5. Cooper's Red 6. Duane's Purple 3 incor. La Delicieuse 8. Large Orleans 3. Large Purple 3 incor. Monsieur de Smith 12. Purple Magnum Bonum 3. Red Magnum Bonum incor. 3, 4, 5, 6, 12. Smith's large Orleans 2. Smith's Orleans 1, 2, 3, 4, 6, 7, 8, 9, 10, 11, 13, 14. Smith's Orleans 5, 12. Smith's Orleans Pflaume 12. Smith's Herrn Pflaume 12. Violet Perdrigon incor. 3, 4, 5, 6, 12. Violetter Perdrigon 12 incor.

In the middle of the last century, Smith Orleans was considered about the best plum of its color in America. But the fruit is not high in quality, the texture of the flesh is coarse and it ripens at a time when fruits are plentiful, for which reasons it has ceased to be regarded with favor by either the amateur or the professional fruit-grower. The trees, however, seem to have some remarkably desirable characters and it may be that the variety should be retained for some locations and purposes and to breed from, at least. If the older pomologists have written truly few plums are adapted to a greater range of climates and soils than this one; so, too, the trees are usually spoken of as of large size, vigorous, healthy, of great productiveness and as holding the crop well. The trees in the soil and climate of this Station are quite as the older writers describe them and were the fruit only better in quality and somewhat more attractive in appearance, the variety could he highly recommended for a market plum and as a fruit for culinary purposes in the home orchard.

William Prince, in 1828 , in his Treatise on Horticulture, briefly described Smith Orleans, and seventeen years later A. J. Downing gave a short history of the variety. It is a seedling of the Orleans raised about ${ }^{8} 825$ by a Mr. Smith of Gowanus, Long Island, New York. By an error the variety was sent out as the Violet, or Blue Perdrigon, a smaller and very different fruit. Charles M. Hovey of Massachusetts, who secured trees of the Cooper from Prince, about I $_{3} \mathrm{I}$, believed this variety to be identical with the Smith Orleans in all characters. Downing could not agree with him but the present writers find that the two varieties are so much alike that it is impossible to distinguish between them. As is suggested under Cooper, they may be identical or they may have come true to seed from the same parent. The American Pomological Society recommended this plum for general cultivation in 1856 . 


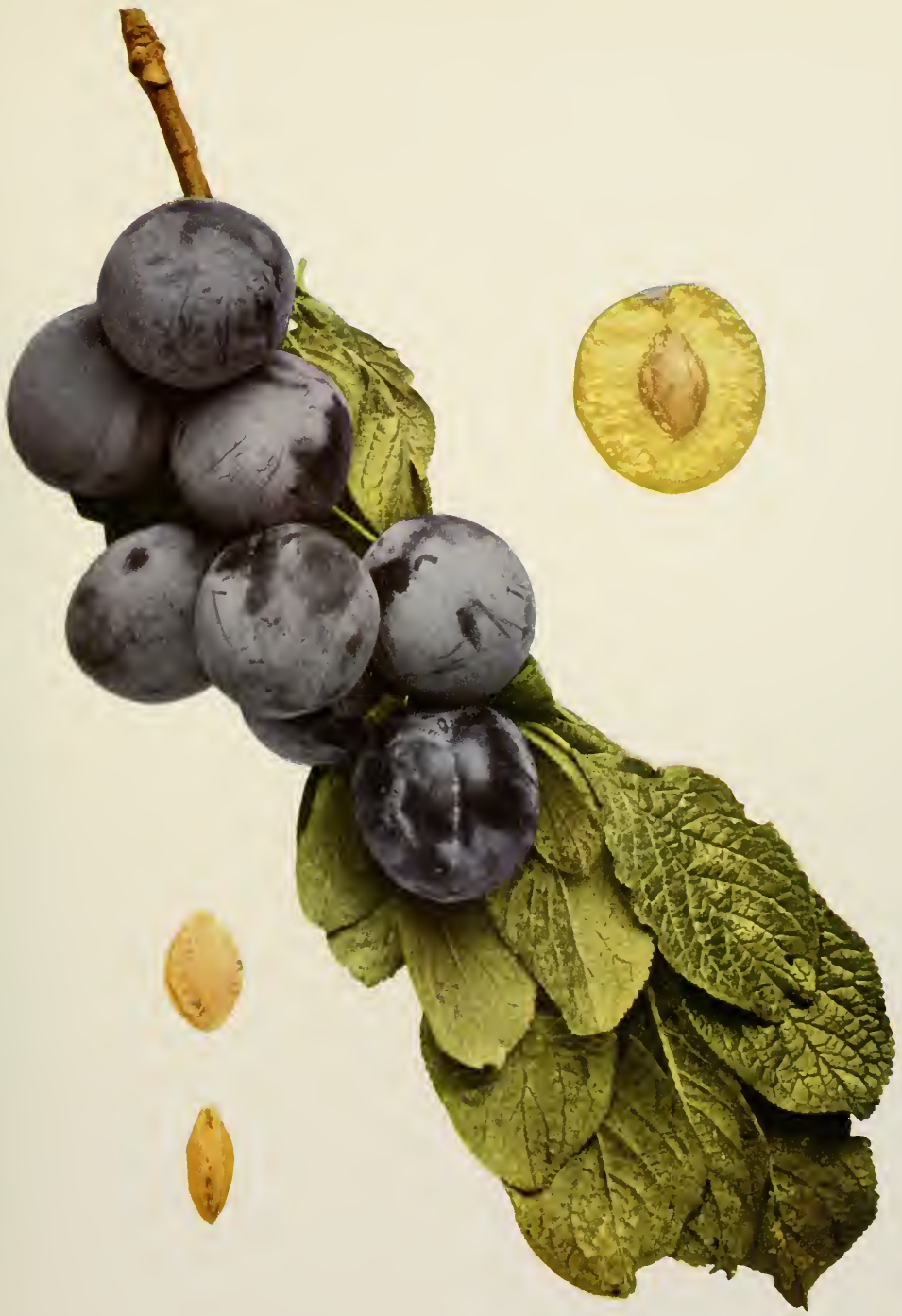



Tree large, vigorous, spreading, open-topped, very productive ; trunk rather rough; branches smooth, with few lenticels; branchlets of medium thickness and length, with long internodes, green changing to dark brownish-red, covered with thin bloom, lightly pubescent early in the season becoming almost glabrous at maturity, with few, small lenticels; leaf-buds of medium size and length, conical, appressed.

Leaves flattened or somewhat folded backward, obovate, two inches wide, three and five-eighths inches long, thick, velvety; upper surface dark green, rugose, with but few hairs along the narrow, deeply grooved midrib; lower surface silvery-green, covered with thick pubescence; apex abruptly pointed or acute, base acute, margin crenate, with few small, dark brown glands; petiole one-half inch long, heavily pubescent, tinged red along one side, glandless or with one or two small, globose, yellow glands usually at the base of the leaf.

Season of bloom medium, short; flowers appearing with the leaves, one and onequarter inches across, white, with a yellow tinge; borne in clusters on lateral buds and spurs; pedicels five-eighths inch long, pubescent, greenish; calyx-tube green, campanulate, with few scattering hairs; calyx-lobes above medium in width, obtuse, sparingly pubescent on both surfaces, glandular-serrate and with marginal hairs, reflexed; petals broad-obovate or oval, crenate, tapering to long claws of medium width; anthers yellow, filaments seven-sixteenths inch long; pistil glabrous, shorter than the stamens.

Fruit intermediate in time and length of ripening season, one and five-eighths inches by one and one-half inches in size, oval, compressed, halves somewhat unequal; cavity shallow, narrow, abrupt; suture very shallow or sometimes a line; apex roundish or depressed; color dark purplish-black, overspread with thick bloom; dots numerous small, russet, inconspicuous; stem three-quarters inch long, pubescent, adhering to the fruit; skin below medium in thickness, tender, sour, separating readily; flesh pale yellow, juicy, tender, sweet, of pleasant flavor; good; stone elinging, one inch by fiveeighths inch in size, oval, with very rough and deeply pitted surfaces, usually somewhat flattened, tapering abruptly at the base, blunt at the apex; ventral suture wide, blunt; dorsal suture with a groove variable in depth and width.

\section{SOPHIE}

\section{Prunus munsoniana}

1. U.S. D. A. Rpt. 263 , PI. VI. 1892. 2. Kerr Cat. $1894 . \quad$ 3. Waugh Plum Cult. 189.1901.

Sophie is fast being lost sight of among the multitudes of native plums recently introduced. Without any very distinct merits it yet stands high among plums of its kind. The variety is a seedling of Wild Goose at first supposed by the originator, J. W. Kerr, ${ }^{1}$ of Denton, Maryland, to have

$1 \mathrm{~J}$. W. Kerr, one of the best informed and most enthusiastic cultivators of native and Triflora plums, was born in York County, Pennsylvania, Jantary 23, 1842. He is of Scotch-Irish lineage paternally and of English ancestors maternally. His education at the village school was supplemented by several years teaching and much reading and study in lorticultural literature, fondness for which seems to have been inborn. In his carly manhood Mr. Kerr engaged in growing 
been pollinated by a German Prune which stood near. This is hardly the case, however, as no trace of Domestica blood can be detected in the variety. It is mentioned by the American Pomological Society in its catalog for I899.

Tree large, very vigorous, spreading, open-topped, productive; branches thorny, shaggy, with long and unbranched limbs; branchlets willowy, slender; leaves folded upward, oval, one and three-quarters inches wide, three and one-quarter inches long, thin; margin shallowly crenate, with small, dark glands; petiole slender, pubescent, with from one to three small glands; blooming season late, long; flowers appearing after the leaves, nearly three-quarters inch across, white, pinkish as they open, with a disagreeable odor; borne in twos or threes; anthers yellow with an orange-red tinge.

Fruit maturing later than Wild Goose; large, one and three-eighths inches by one and one-eighth inches in size, obovate, slightly necked, pear-shaped, bright red, covered with thin bloom; dots conspicuous; stem slender, long; flesh deep yellow, juicy, coarse and fibrous, subacid, flat; of fair quality; stone clinging, three-quarters inch by three-eighths inch in size, somewhat angular, irregular-obovate, with a peculiar elongated, flattened, oblique base; apex abruptly acute; surfaces rough.

\section{SPAULDING}

\section{Prunus domestica}

I. Lovett Cat. 41, Col. P1. 1888. 2. Corncll Sta. Bul. 131:192. 1897. 3. Mich. Sta. Bul. I69:243, 248. 1899. 4. Am. Pom. Soc. Cat. 39. 1899. 5. Kan. Sta. Bul. 101:121, 122, PI. V. 1901. 6. Waugh Plum Cult. 122. 1901. 7. Ohio Sta. Bul. 162:239. 1905.

Among the plums of comparatively recent introduction Spaulding holds a conspicuous place. It is particularly highly spoken of for its good quality and while not recommended for commercial orchards is often mentioned as very desirable for home use. As Spaulding grows at this Station, it does not sustain the reputation it has elsewhere. It is of the Reine Claude group of plums and while of high quality is not as good a dessert plum as several other similar sorts. Moreover, the fruits are small and too light in color to be especially attractive in appearance. The plums,

trees for sale, a business with which he soon combined a fruit plantation in which he collected and tested all the plums that could be grown in his climate, comprising the great majority of the varieties of American species and of the Oriental plums. This work began in 1870 , since which time no man has done more to popularize and improve native plums than Mr. Kerr. His most valuable work has been in testing varieties, where his knowledge of this fruit, his judgment and his sense of discrimination have made his opinion, as set forth in his nursery catalog and in the reports of horticultural societies, authoritative. He has, too, done considerable work in breeding plums, Choptank, Sophie and Maryland probably representing the best of his endeavors in originating new plums. It is a duty and a pleasure to acknowledge here the great services rendered by Mr. Kerr in the preparation of The Plums of New York. 


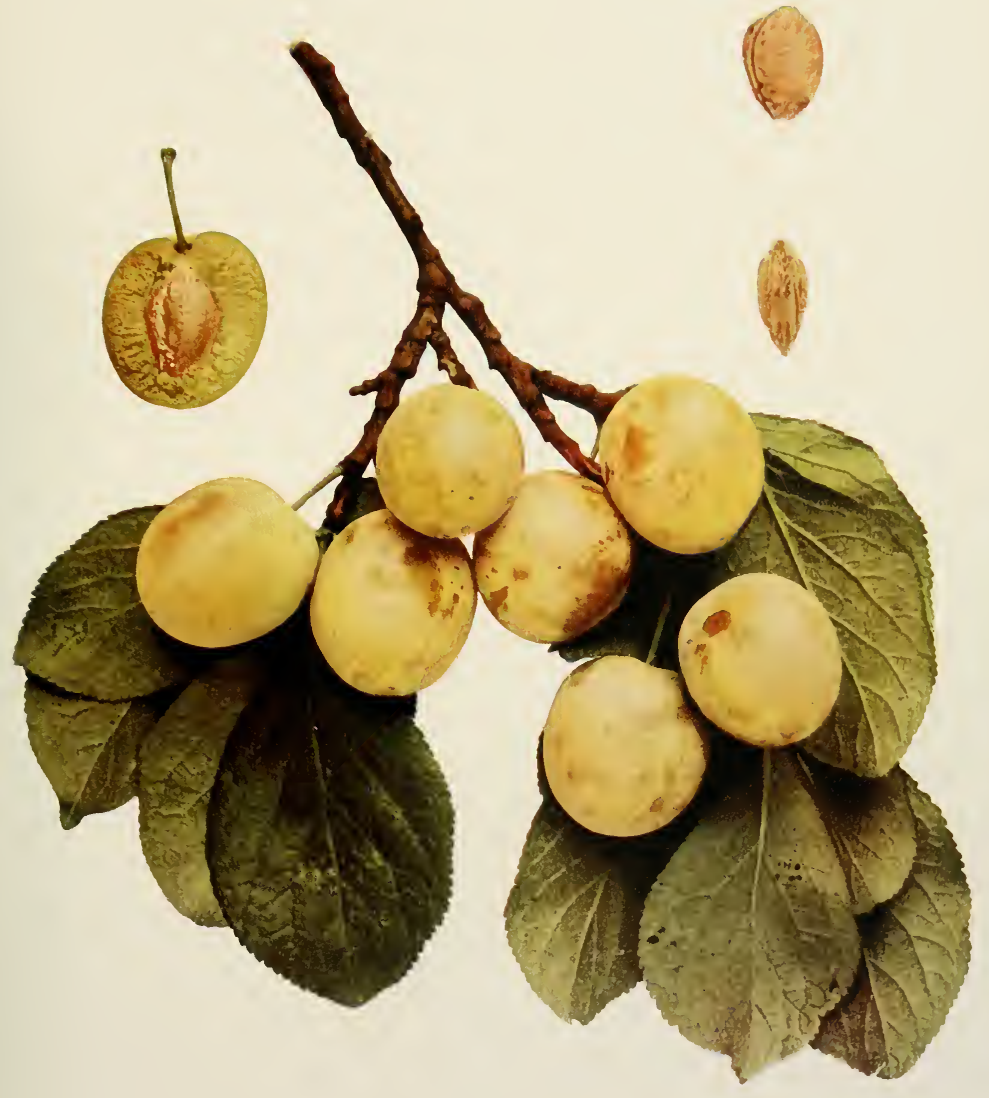

SPAULDING 

too, are quite susceptible to brown-rot. The tree-characters of this variety are in the main very good but not at all out of the ordinary. It is very doubtful whether this sort can compete for any purpose with such similar plums as Hand, Jefferson, Washington, Bavay, Reine Claude, McLaughlin and Imperial Gage. It may be worthy a trial elsewhere in New York with the hope that it will more nearly approach the reputation that it has in other states than it does at Geneva-at best it cannot be more than a home variety.

Spaulding was brought to the notice of fruit-growers by J. T. Lovett, Little Silver, New Jersey, who introduced the variety in I888. The plum came to Mr. Lovett from Francis Garriel with the statement that it originated as a seedling in the yard of Mr. Garriel's father in the Bowery, New York City. From the resemblance of Spaulding to the Imperial Gage it is probable that they are closely related. In I 899 the variety was placed on the fruit catalog list of the American Pomological Society as a successful variety in the north-eastern part of the United States and the neighboring parts of Canada.

Tree large, vigorous, upright-sprcading, dense-topped, hardy, productive; branches ash-gray, smooth except for the raised lenticels of various sizes; branchlets of medium thickness and length, with long internodes, greenish-red changing to brownish-red, dull, lightly pubescent throughout the season, with obscure, small lenticels; leaf-buds of medium sizc and lcngth, conical, appressed; leaf-scars prominent.

Leaves folded upward, nearly two inches wide, three and one-quarter inches long, thick; upper surface dark green, rugose, glabrous, with a shallow groove on the midrib; lower surface silvery-green, pubescent; apex abruptly pointed or acute, base acute, margin serrate or crenate, with small, dark glands; petiole ncarly five-eighths inch long, thick, pubescent, tinged red, with from one to four small, globose, greenish glands usually on the stalk.

Blooming season intermediate in time and length, one inch or more across, white with a yellowish tinge at the apex of the petals in the newly opened flowers; borne on lateral spurs, singly or in pairs; pedicels three-eighths inch long, thick, pubescent, greenish; calyx-tube green, campanulate, lightly pubescent; calyx-lobes obtuse, pubescent on both surfaces, glandular-serrate, reflexed; petals oblong, crenate, not clawed; anthers yellow; filaments one-quarter inch long; pistil glabrous or occasionally with a few hairs near the base, longer than the stamens; stigma large.

Fruit mid-season, ripening period long; one and five-eighths inches by one and three-eighths inches in size, oblong-oval or ovate, compressed, halves equal; cavity small, shallow, abrupt; suture shallow, often a line; apex roundish; color dull greenishyellow, with stripes and splashes of light green, overspread with thick bloom; dots numerous, small, whitish, inconspicuous; stem three-quarters inch long, lightly pubes- 
cent, adhering well to the fruit; skin thin, tender, separating readily; flesh greenishyellow, juicy, fibrous, tender, sweet, mild, pleasant; very good; stone semi-free or free, seven-eighths inch by five-eighths inch in size, ovate, turgid, slightly pitted, blunt at the base, nearly acute at the apex; ventral suture rather broad, slightly furrowed, with a distinct but short wing; dorsal suture widely and deeply grooved.

\section{STANTON}

\section{Prunus domestica}

1. Gard. Mon. 29:116. 1887. 2. Mich. Hort. Soc. Rpt. 288, 1889. 3. Cornell Sta. Bul. 131: 192. 1897.

Stanton's Seedling 2

This plum appears to be a very good late variety in several respects; it is a long-keeping fruit, is of very good quality for dessert and is a fine plum for canning and preserving. Its faults are that it is tardy in coming into bearing and the fruits drop badly from the trees as they begin to ripen; in localities where these faults are marked the variety is worthless. Stanton originated as a chance seedling in Albany County, New York, from whence it was sent to Hammond and Willard of Geneva, New York, who introduced it about 1885 .

Tree very large and vigorous, round-topped, variable in productiveness; branches slender, marked by transverse cracks in the bark; leaf-scars enlarged; leaves folded upward, oval or obovate, one and one-half inches wide, three inches long; margin finely and doubly crenate, with few, dark glands; petiole short, glandless or with from one to three small glands usually on the stalk; blooming season intermediate in time and length; flowers appearing after the leaves, one and one-eighth inches across, borne in scattering clusters on lateral buds and spurs, singly or in pairs.

Fruit late, season long; about one and one-quarter inches in diameter, roundishoblate, truncate, purplish-black, overspread with very heavy bloom; flesh bright goldenyellow, fibrous, very sweet, rather high-flavored; good to very good; stone semi-free, three-quarters inch by five-eighths inch in size, irregular roundish-oval, turgid, with a blunt and oblique base, the surfaces nearly smooth; ventral suture enlarged, often with a short, distinct wing; dorsal suture shallow.

\section{STODDARD}

\section{Prunus americana}

I. Ia. Hort. Soc. Rpt. 78. 1892. 2. Am. Pom. Soc. Rpt. 88. 1895. 3. Am. Pom. Soc. Cat. 38. I899. 4. Ia. Sta. Bul. 46:289. 1900. 5. U. S. D. A. Rpt. 478 , Pl. LXII. 1902.

Baker 2. Stoddart I, 2.

Stoddard is usually rated as one of the best of the Americana plums and its behavior on the grounds of this Station sustains its reputation. 
The firmness of the fruit makes it a good shipping plum of its kind and season. This variety was discovered by B. F. Stoddard of Jesup, Buchanan County, Iowa, about 1875 , growing in a garden owned by Mrs. Caroline Baker who stated that her husband secured the trees from the woods, presumably along the Maquoketa River. The variety was subsequently introduced by J. Wragg and Sons of Waukee, Iowa, at dates variously reported from I 890 to I 895 .

Tree large, vigorous, spreading, open-topped, productive; trunk shaggy; branches slender, thorny; branchlets slender, with conspicuous, large, raised lenticels; leaves falling early, flattened, oval or obovate, two and one-quarter inches wide, four inches long; margin coarsely serrate, eglandular; petiole tinged red, glandless or with from one to three glands usually on the stalk; blooming season late; flowers appearing with the leaves, one inch across, white.

Fruit intermediate in time and length of ripening season; about one and threeeighths inches in diameter, roundish-oblate; suture a distinct red line; color light to dark red over a yellow ground, mottled, covered with thick bloom; skin astringent; flesh dark golden-yellow, very juicy, tender and melting, rather sweet next the skin but tart near the center, with a characteristic flavor; good; stone clinging, seveneighths inch by five-eighths inch in size, roundish to broad-oval, strongly flattened, with smooth surfaces; ventral suture narrow, winged.

\section{STONELESS}

\section{Prunus insititia}

1. Duhamel Trait. Arb. Fr. $2: 1$ 10, P1. 20 fig. 14. 1768. 2. Kraft Pom. Aust. 2:42, Tab. 194 fig. 2. 1796. 3. Mag. Hort. 9:165. 1843. 4. Poiteau Pom. Franc. x. 1846. 5. Mas Pom. Gen. 2:121, fig. 61. 1873. 6. Hogg Fruit Man. 726. 1884. 7. Mathieu Nom. Pom. 450, 1889.

Die Pflaume ohne Stein 2. Jean Morceau 3. Kirke's Stoneless 6, 7. Pflaume Ohne Steine 5. Pitless 5, 7. Prune Sans-Noyau 4. Sans-Noyau I, 5. Sans Noyau 3, 6, 7. Steinlose Zwetsche 7. Stoneless 5,7 .

This curious plum is attracting attention because of the publicity given it by Burbank in his breeding work. The variety is at least three hundred years old. It was known to Merlet, writing in the Seventeenth Century, and has been mentioned in plum literature many times since. The plum is remarkable because of the entire absence of a stone, the kernel lying naked in a cavity much larger than itself. The variety is worthless but presents opportunities for breeding purposes that should not be overlooked. Judging from the fruit-characters as given below it belongs to Prunus insititia. The Stoneless is supposed to have been introduced into England from the Royal Gardens at Versailles by George London. It was long sold as Kirke's Stoneless, having been much advertised by Kirke, a nurseryman at Brompton, England. It is described as follows: 
Fruit small, oval, dark purple, with thick bloom; flesh greenish-yellow, harsh and strongly acid at first but assuming a more pleasant flavor as it shrivels upon the tree.

\section{SUGAR}

\section{Prunus domestica}

I. Cal. State Bd. Hort. 47. 1897-98. 2. Burbank Cat. 5 fig. 1899. 3. Waugh Plum Cult. 124. I9or. 4. U.S. D. A. Rpt. 275, P1. XXXVI fig. 2. 1903.

Sugar Prune 1, 4.

The introduction of Sugar to the Atlantic States was preceded by very flattering accounts of it from the originator, Mr. Burbank, and from Pacific Coast plum-growers. Possibly our expectations were too high; for we have been greatly disappointed in this plum as compared with its parent, Agen, as the two varieties grow at Geneva-it should be said at once that neither grows nearly as well in New York as in California. The fruits of Sugar on the Station grounds are not larger than those of the Agen, while in California it is said to be twice or three times as large; the flavor is not as pleasant and the flesh is fibrous in the offspring and not so in the parent at Geneva, though in California the Sugar is said to be of better quality than the Agen. As the two grow here, Sugar is rather more attractive in appearance and ripens earlier, the latter character a distinct advantage since Agen is very late in New York. The trees of the two plums are much alike though those of Agen are larger and more productive than those of Sugar as grown in New York. There are, however, but two trees of the latter variety on the Station grounds and these are young, set in 1899 , so that too much importance must not be attached to the comparison of the trees. Sugar is worth further trial in New York under other conditions of soil and climate but it is extremely doubtful whether it will surpass the Agen in this State.

This plum, a seedling of the well-known Agen, was introduced by its originator, Burbank, in 1899 . The California Experiment Station in analyzing this plum found it to be richer in sugar than the Agen and states that it is larger and more easily dried. Sugar has become of great commercial importance in the California prune districts and has been top-grafted on other plums and even on almonds to the extent of hundreds of acres in that State and in Oregon. As yet it is only under trial in New York.

Tree of medium size, usually vigorous, spreading, dense-topped, hardy, productive; branches ash-gray, tinged red, smooth except for the numerous, small, raised lenticels; branchlets slender, with long internodes, green changing to brownish-red, dull, sparingly 


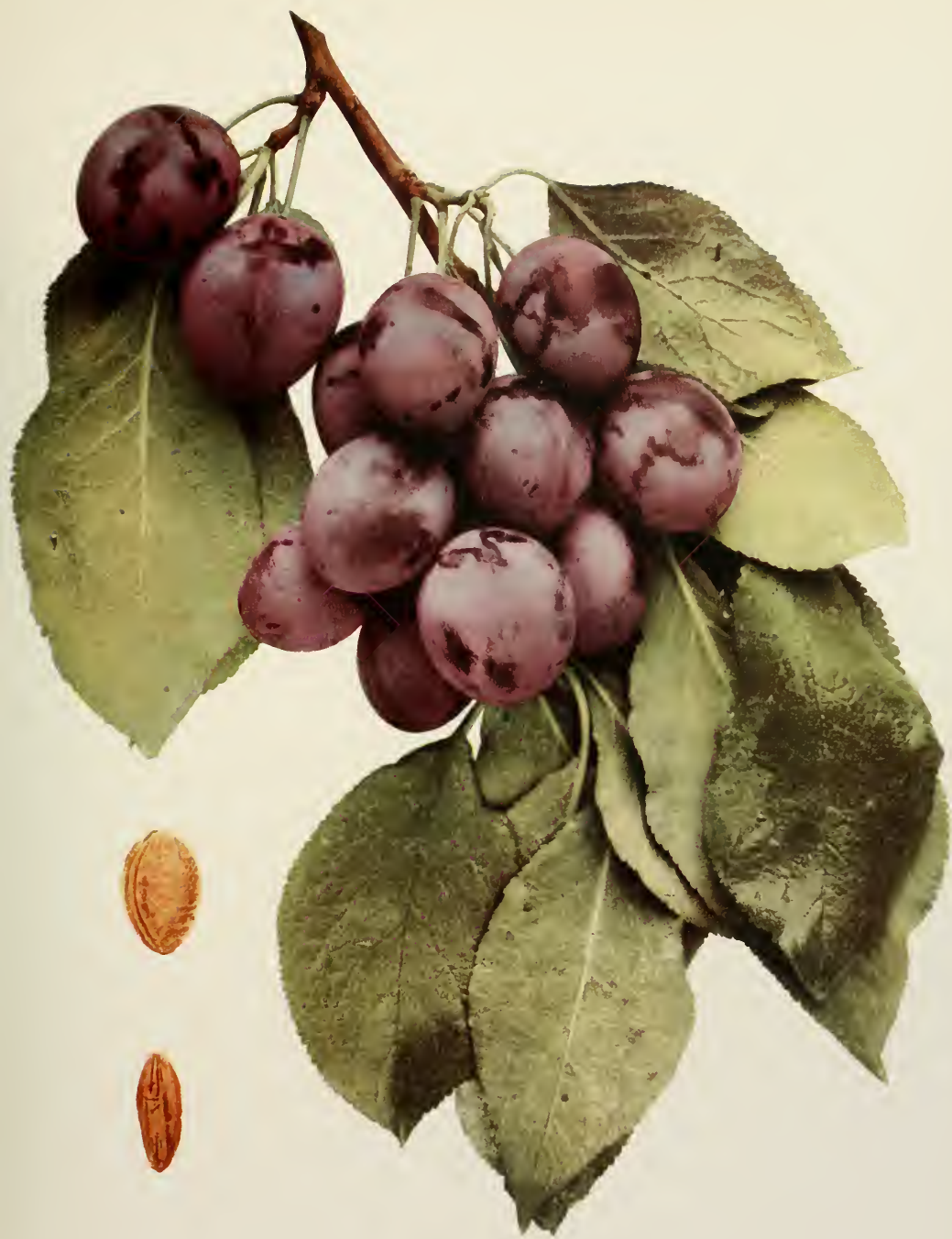



pubescent throughout the season, with numerous, inconspicuous, small lenticels; leafbuds large, long, somewhat pointed, strongly appressed.

Leaves folded backward, obovate or oval, two and one-half inches wide, five inches long; upper surface dark green, rugose, covered with numerous hairs, the midrib narrowly grooved; lower surface pale green, overspread with thick pubescence; apex abruptly pointed or acute, base acute, margin serrate, with small dark glands; petiole nearly one inch long, covered with thick pubescence, lightly tinged with red, glandless or with from one to three small, globose, greenish-yellow glands at the base of the leaf.

Flowers large, intermediate in time of bloom; calyx-tube green; stamens longer than the pistil.

Fruit intermediate in time and length of ripening season; small, ovate or oval, halves equal; cavity shallow, narrow, abrupt; suture shallow, often a line; apex roundish or pointed; color dark reddish-purple changing to purplish-black, covered with thick bloom; dots numerous, small, light russet, inconspicuous; stem slender, long, pubescent, adhering; skin thin, tender, separating readily; flesh golden-yellow, juicy, coarse, fibrous, tender, sweet, mild; good to very good; stone light colored, with a tinge of red, thin, of medium size, ovate, flattened, with rough and pitted surfaces, blunt at the base, acute at the apex; ventral suture rather narrow, distinctly furrowed, slightly winged; dorsal suture with a wide, deep groove.

\section{SURPRISE}

\section{Prunus hortulana mineri ?}

I. Wis. Sta. Bul. $63: 6 \mathrm{I}$ fig. 30.1897 . 2. Ia. Hort. Soc. Rpt. 112. 1899. 3. Am. Pom. Soc. Cat. 38. 1899. 4. Wis. Hort. Soc. Rpt. 69. 1900. 5. Ia. Sta. Bul. 46:289. 1900. 6. Wis. Sta. Bul. 87:18. 1901. 7. Waugh Plum Cull. 175. 1901. 8. Ia. Hort. Soc. Rpt. 228. 1904. 9. Ill. Hort. Soc. Rpt. 426. 1905. Io. S. Dak. Sta. Bul. $93: 39$. 1905.

Surprise is one of the best of the native plums in the Station orchard. The fruits are very attractive in appearance and while not of the rich flavor of the Domesticas they are yet of pleasant flavor with an abundance of juice which together make this a most refreshing fruit. The fruits keep well and would probably ship well. The color is a peculiar red which serves to identify the variety; on the whole the fruits resemble the Americanas while the trees are rather more of the Miner type. The variety is productive in New York and is so spoken of in Wisconsin by Goff, ${ }^{1}$ but

1 Emmett Stull Goff was born at Elmira, New York, Sept. 3, $185_{2}$. He was educated in the public schools and in the Elmira Free Academy, graduating from the last named place in 1869. The following years were spent on his father's farm until in r880 he became Associate Editor of an agricultural paper, but finding the work uncongenial he returned to the farm for a short time leaving aga in to accept in $\mathbf{r} 8 S_{2}$ a position at the New York Agricultural Experiment Station which had just been established. Here for seven years Professor Goff gave his attention to vegetables. His classification of a number of vegetables, the pea, tomato, cabbage and onion in particular. are still standard in American vegetable culture. During his work at this Station he did much 
in Iowa it is said not to bear abundantly. If a native plum is wanted in New York, this variety is worthy a trial.

Surprise, according to the originator, Martin Penning of Sleepy Eye, Brown County, Minnesota, is the best of a thousand or more seedlings grown from pits of De Soto, Weaver and Miner sown in 1882 . In 1889 , Penning introduced this plum and ten years later it was added to the fruit catalog list of the American Pomological Society. The parentage of the variety is unknown but it has usually been thought that the botanical characters indicate that it is a seedling of Miner. As the tree grows here, (they came to the Station from Mr. Penning,) it appears to be a hybrid of Prunus americana and Prunus hortulana mineri, characters of both species being evident.

Tree large, vigorous, upright, dense-topped, hardy, productive; trunk roughish; branches smooth, zigzag, thorny, dark ash-gray, with numerous, small lenticels; branchlets slender, medium to long, with long internodes, green changing to dark chestnutred, with brownish-gray scarf-skin, glossy, glabrous, with numerous, conspicuous, small, raised lenticels; leaf-buds small, short, obtuse, plump, appressed.

Leaves falling early, folded upward, oval or ovate, two inches wide, four and onehalf inches long, thin; upper surface light green, glabrous, smooth, with a grooved midrib; lower surface pale green, lightly pubescent ; apex taper-pointed, base abrupt, margin often coarsely and doubly serrate, with amber glands which are not persistent; petiole thirteen-sixteenths inch long, slender, reddish, sparingly pubescent along one side, glandless or with from one to five small, globose, yellowish-brown glands usually on the stalk.

Blooming season intermediate in time and length; flowers appearing with the leaves, three-quarters inch across, creamy-white, with a disagreeable odor; borne in clusters from lateral buds, in threes or in fours; pedicels three-eighths inch long, slender, glabrous, green; calyx-tube greenish, campanulate, glabrous; calyx-lobes narrow, acute, pubescent on the inner surface, serrate and with reddish glands, erect; petals

pioneer work in spraying plants and invented a device for mixing kerosene and water. In 1889 Professor Goff moved to Madison, Wisconsin, where he became professor of horticulture in the University of Wisconsin and horticulturist of the Wisconsin Experiment Station. Here for fourteen years he gave his attention to various phases of fruit-growing and vegetable-growing. His bulletin 87 on "Native Plums" is the outcome of several years' experiments in testing and breeding plums of such of our native species as will grow in Wisconsin. His work with plums is particularly valuable, as he was able, in his location, to do much to ascertain the degree of hardiness of many varieties of the species of cultivated plums. From his work with sterility and fertility of varieties came valuable recommendations regarding the cross-pollination of such varieties as a re self-sterile. He is the author of Principles of Plant Culture and Lessons on Fruit-growing, text books much used in high schools and agricultural colleges. Professor Goff was a modest and retiring man but singularly independent of view in all things regarding his work and all things that concerned mena serene, lofty-minded, unselfish man. His death occurred at Madison, June 6 th, $19{ }^{\circ}$. 


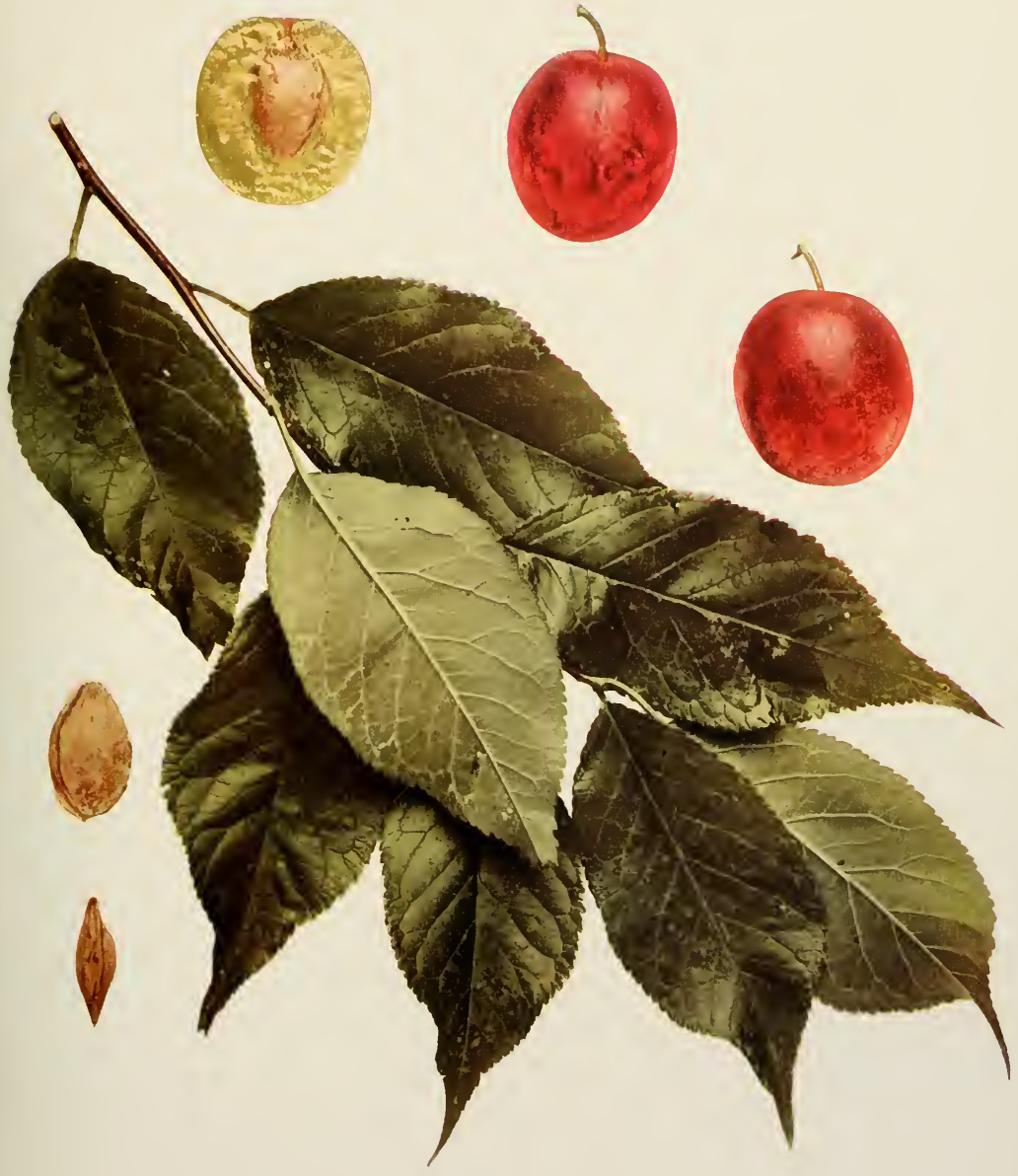



roundish-ovate, entire, narrowly clawed; anthers yellowish; filaments one-quarter inch long; pistil glabrous, equal to the stamens in length.

Fruit mid-season, ripening pcriod short; one and three-eighths inches by one and one-eighth inches in size, halves equal; cavity shallow, flaring; suture very shallow, distinct; apex roundish or depressed; color dark red, covered with thin bloom; dots numerous, medium to large, russet, conspicuous, clustered about the apex; stem onehalf inch long, glabrous, adhering to the fruit; skin thick, tough, clinging; flesh goldenyellow, juicy, fibrous, somewhat tender, sweet, insipid; quality fair; stone clinging, one inch by five-eighths inch in size, oval, flattened, pointed at the base and apex, with smooth surfaces.

\section{TENNANT}

\section{Prunus domestica}

1. Bailey Ann. Hort. 133. 1893. 2. Oregon Sta. Bul. 45:32. 1897. 3. Am. Pom. Soc. Cat 40. 1899. 4. Can. Exp. Farm Bul. 2nd Ser. 3:57. 1900. 5. Waugh Plum Cult. 124. 1901. 6 Budd-Hansen Am. Hort. Man. 326. 1903.

Tennant Prune 1. Tenant Prune 4.

It is surprising that a variety of so much merit, especially of so great beauty, as Tennant, should not have been more widely tried in New York. In the survey of plum culture in this State in the preparation of the text for The Plums of New York, it could not be learned that the Tennant had been tried in more than four or five places. In size and beauty of form and coloring. all well shown in the illustration, Tennant has few superiors in the collection of plums growing at this Station. While it is not sufficiently high in quality to be called a first-rate dessert fruit it is more palatable than most of the purple plums. It ripens at a good time of the year, several days before the Italian Prune, and should, from the nature of its skin and the firmness of its flesh, both ship and keep well. A fault of the fruit as it grows here, a fault not ascribed to it elsewhere, is that it shrivels soon after ripening. Our trees are large, vigorous, healthy, hardy and productive - almost ideal plum-trees. This variety should be very generally tried in commercial plantations in New York and may well be planted in home collections for a culinary fruit at least. On the Pacific Coast it is cured for prunes, its meaty flesh fitting it very well for this purpose.

This is another promising plum from the Pacific Northwest. Tennant originated with Rev. John Tennant of Ferndale, Washington, and was introduced in 1893 by McGill and McDonald, Salem, Oregon. The variety is fairly well known in the region of its origin but is practically unknown in New York. It was listed in the American Pomological Society catalog in 1897 as successful in the Pacific Northwest. 
Tree large, vigorous, round-topped, open, hardy, productive; trunk slightly roughened; branches stocky, smooth, with lenticels of medium number and size; branchlets thick, long, with long internodes, greenish-red changing to brownish-drab, with green patches and considerable scarf-skin, somewhat glossy, sparingly pubescent throughout the season, with small lenticels; leaf-buds large, long, pointed, appressed; leaf-scars prominent.

Leaves folded backward, oval or obovate, one and three-quarters inches wide, three and one-half inches long, thick, stiff; upper surface dark green, rugose, sparingly hairy, with a grooved midrib; lower surface silvery-green, with thick pubescence; apex abruptly pointed to acute, base acute, margin crenate, eglandular or with small, brown glands; petiole five-eighths inch long, thick, tinged red along one side, hairy, glandless or with one or two rather large, globose, brownish glands variable in position.

Blooming season early to medium, short; flowers appearing after the leaves, one inch or more across, white, the buds tinged yellow; borne on lateral spurs; pedicels one-half inch long, thick, pubescent, greenish; calyx-tube green, often with a swelling around the base, campanulate, pubescent; calyx-lobes broad, obtuse, pubescent on both surfaces, with thick, marginal hairs, erect; petals roundish-oval, entire, tapering to short, broad claws; anthers large, yellow; filaments five-sixteenths inch long; pistil pubescent at the base, equal to the stamens in length; stigma large.

Fruit intermediate in time and length of ripening season; one and three-quarters inches by one and five-cighths inches in size, roundish-truncate or roundish-oblong, with irregular surface which is somewhat ridged, halves equal; cavity narrow, abrupt, slightly compressed; suture variable in depth, distinct; apex deeply depressed; color dark reddish-purple, overspread with thick bloom; dots numerous, variable in size, whitish, conspicuous, clustered about the apex; stem thick, three-eighths inch long, pubescent, adhering well to the fruit; skin tough, adhering slightly to the pulp; flesh dark golden-yellow, somewhat dry, coarse, tough, firm, sweet, mild but pleasant; of good quality; stone clinging, seven-eighths inch by five-eighths inch in size, irregularoval, flattened, obliquely necked, blunt at the apex, with deeply pitted surfaces, roughish; ventral suture prominent, heavily furrowed, not winged; dorsal suture usually with a narrow, shallow groove.

\section{TRAGEDY}

\section{Prunus domestica}

1. Cal. State Bd. Hort. 236, Pl. II fig. 5, 237. 1890. 2. Ibid. rog fig. 8. 1891. 3. Wickson Cal. Fruits 358. 1891. 4. N. Mex. Sta. Bul. 27:125. 1898. 5. Am. Pom. Soc. Cat. 40. 1899. 6. Waugh Plum. Cult. r24. r $90 \mathrm{r}$.

Tragedy Prune $1,3,4$.

Tragedy is another western plum which, like the Tennant, has not been well tested in the East. It is an older plum than the Tennant and somewhat better known in New York but still the reports of it are not sufficient in number or of great enough range to enable a fair opinion to 


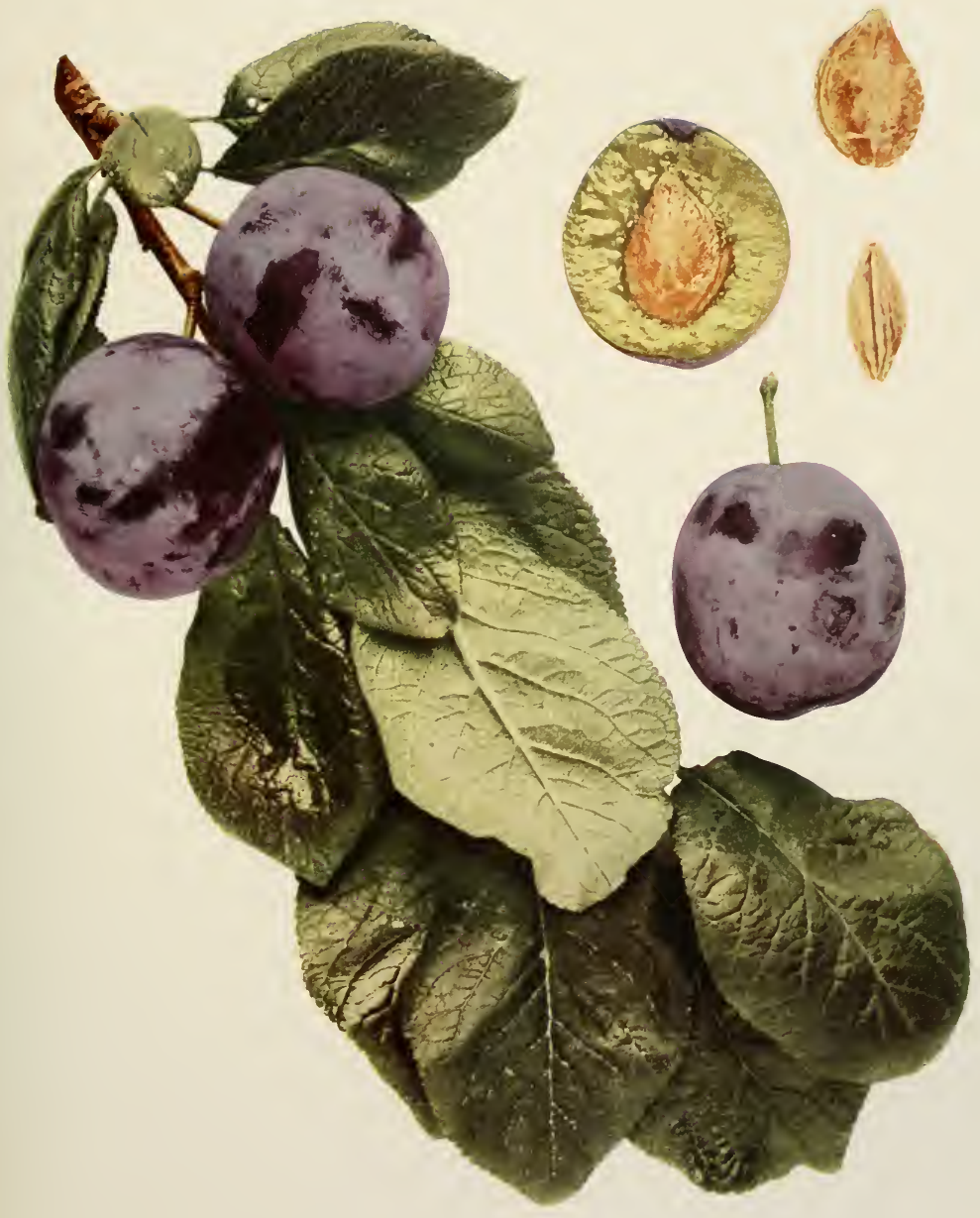



be given as to its merits. As the variety grows at Geneva the fruits are very attractive in appearance-above medium size, a dark, rich purple color, and having the full, rounded form much liked by consumers in a dessert plum. The flesh is juicy, tender and sweet so that the quality may be called good; possibly the flesh is a little too soft for long shipping or long keeping as it grows here, though in one of the California references it is spoken of as "valuable for eastern shipment." The trees are very satisfactory except that in New York they are not quite as reliable in bearing as could be wished. A fault, as the variety grows here and which may be local, is that a large proportion of the pits are cracked and all are soft and granular. The tree is reported by some as "scale proof" but unfortunately this statement can neither be denied nor affirmed. A plum with the good qualities possessed by Tragedy, should be better known in New York.

The following history is contributed by Professor E. J. Wickson, Berkeley, California. Tragedy originated as a chance seedling on the farm of O. R. Runyon, near Courtland, Sacramento County, California, probably in the late seventies. It was first offered to the trade in dormant buds by W. R. Strong and Company of Sacramento in I887. Since the German Prune and Duane Purple grew on the place of its origin and as it shows characters of both, it has been noted as a probable cross of these varieties. The name Tragedy is understood to have been given to the fruit by Mr. Runyon because the plum was noted to be desirable on or about a day upon which a certain event held to be tragical occurred in the neighborhood. In 1899 , the American Pomological Society considered Tragedy worthy a place in its list of fruits.

Tree large, vigorous, round-topped, hardy, variable in productiveness; branches ash-gray, usually smooth, with raised lenticels of various sizes; branchlets twiggy, thick, medium to short, with short internodes, greenish-red changing to dark brownishdrab, covered with thick pubescence, with obscure, small lenticels; leaf-buds intermediate in size and length, obtuse, plump, appressed.

Leaves folded backward, oval or obovate, one and three-quarters inches wide, three and three-quarters inches long; upper surface dark green, glabrous except for the few hairs on the deeply and narrowly grooved midrib; lower surface pubescent; apex acute or obtuse, base acute; petiole five-eighths inch long, thick, pubescent, faintly tinged red, glandless or with one or two small, globose, greenish-brown glands usually at the base of the leaf.

Blooming season early, short; flowers appearing with the leaves, seven-eighths inch across, white; borne on lateral buds, usually in pairs; pedicels one-half inch long, thick, pubescent greenish; calyx-tube green, with roughened surface, campanulate, 
glabrous; calyx-lobes acute, lightly pubescent, serrate, with many glands and marginal hairs, reflexed; petals broadly oval, crenate, short-clawed; anthers bright yellow; filaments nearly five-sixteenths inch long; pistil pubescent at the base, much longer than the stamens.

Fruit early, season short; one and five-eighths inches by one and three-eighths inches in size, oval, swollen on the suture side, compressed, halves unequal; cavity narrow, abrupt, regular; suture shallow, often an indistinct line; apex roundish; color dark purplish-black, covered with thick bloom; dots numerous, variable in size, russet, inconspicuous; stem five-eighths inch long, pubescent, adhering well to the fruit; skin of medium thickness and toughness, somewhat sour, separating readily; flesh greenishyellow, juicy, tender, sweet, mild; good; stone clinging, one inch by five-eighths inch in size, irregular-oval, flattened, obliquely necked; apex acute; surfaces pitted, roughish; ventral suture narrow, prominent, not winged; dorsal suture narrowly and deeply grooved.

\section{TRANSPARENT}

Prunus domestica

1. Downing Fr. Trees Am. 395. 1857 . 2. Flor. \& Pom. 56, Col. Pl. fig. 1862. 3. Hogg Fruit Man. $3_{83}$. 1866. 4. Downing Fr. Trees Am. 950. 1869. 5. Jour. Hort. N. S. 17:258. 1869. 6. Am. Pom. Soc. Rpt. 9r. 1869. 7. Am. Pom. Soc. Cat. 24. 1871. 8. Pom. France 7 :No. 25. 1871. 9. Mas Pom. Gen. 2:31, fig. 16. 1873. 10. Cat. Cong. Pom. France 365. 1887. 11. Mathieu Nom. Pom. 428. 1889. 12. Guide Prat. 154, 364. 1895. 13. Nicholson Dict. Gard. 3:166.

Waugh Plum Cult. 124. 1901. 15. Soc. Nat. Hort. France Pom. 554 fig. 1904.

Diaphane 4, 12. Diaphane Lafay 4. Durchscheinende Reineclaude 9, 12. Durchscheinende Reine-Claude 11. Prune Diaphane 9. Prune Diaphane Laffay 4, 11. Reine-Claude De Guigne 9. Reine-Claude Diaphane 1, 8, 9, 10, 12, 15. Reine-Claude Diaphane 2, 3, 4, 5, 11. Reine-Claude Transparente 9, 11, 12, 15. Reine-Claude Transparent 4. Transparent Green Gage 6. Transparent Gage 3, 4, 7, 8, 13. Transparent Gage 8, 9, 10, 11, 12, 14, 15. Transparent Gage Plum 2, 5 .

In Europe Transparent is considered one of the best of all dessert plums but either it does not do as well in America or the American bred plums of the Reine Claude group, to which this variety belongs, are much better on this continent than in the Old World. At any rate in our soil and climate there are a dozen or more Reine Claude plums as good or better in quality than Transparent and much superior in other characters. It is, however, worth planting by the connoisseur for its quality and because of the transparency of skin-in the latter respect it is unique among Domestica plums. The flower-buds of this variety have a remarkable tendency to produce leaves in the place of floral organs.

Transparent is an old French variety. M. Lafay, a rose-grower at Bellevue, near Paris, raised it from the seed of the Reine Claude and named it Reine Claude Diaphane. It was grown previous to 1836 , for, during this year, Thomas Rivers of England, while visiting M. Lafay, was told of 


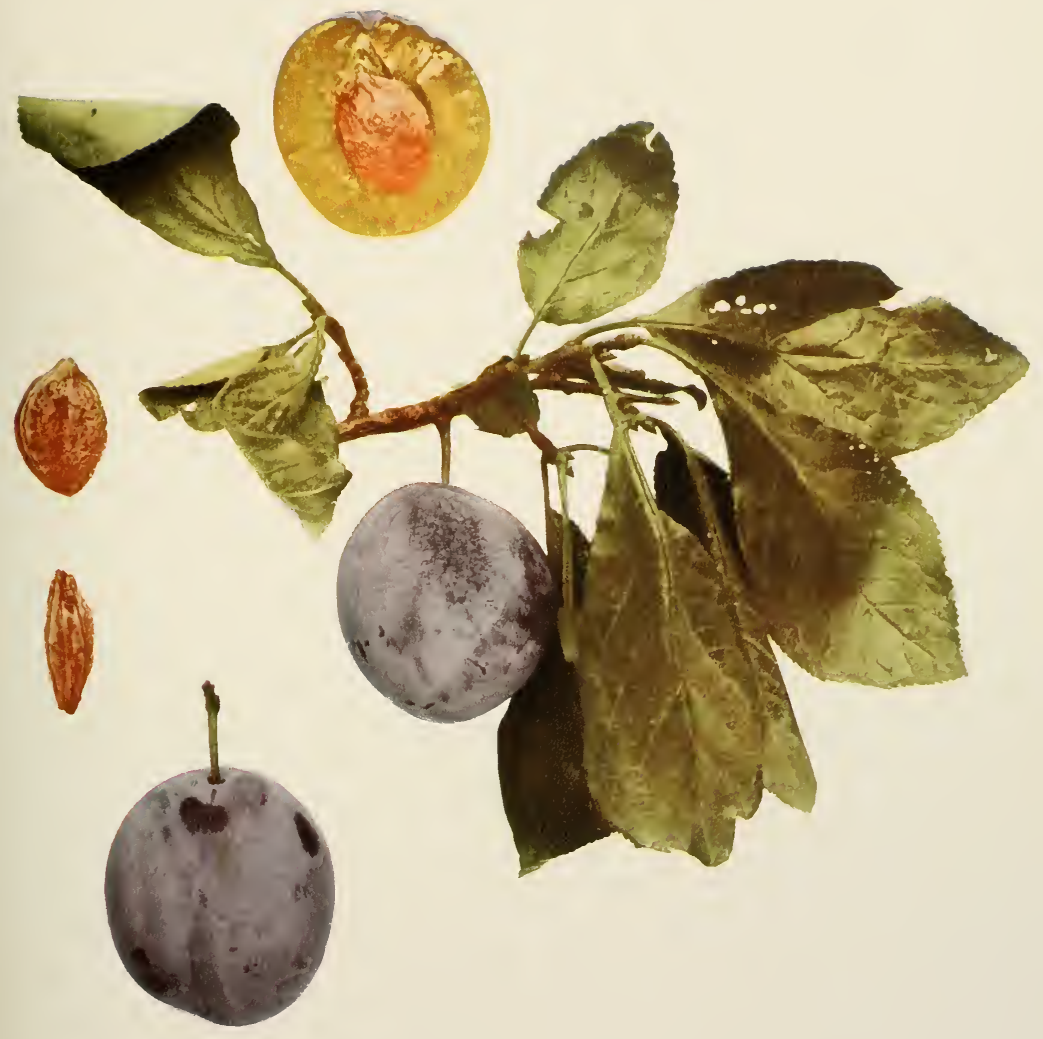



its origin. In $187 \mathrm{I}$, the American Pomological Society listed Transparent in its catalog as worthy of culture. The color of this variety leads to the suspicion that Reine Claude is not the only parent.

Tree large, vigorous, spreading, open-topped, hardy, productive; branches slender, ash-gray, roughish towards the trunk, with small lenticels; branchlets above medium in thickness, short, with internodes of average length, green changing to brownish-red often retaining some green, dull, pubescent, with small lenticels; leaf-buds of medium size and length, conical, somewhat appressed.

Leaves folded upward, obovate or oval, two and one-half inches wide, five inches long, above average thickness; upper surface rugose, nearly glabrous, with a grooved midrib; lower surface pubescent; apex abruptly pointed or acute, base acute, margin often doubly serrate or crenate, with small, dark glands; petiole seven-eighths inch long, thick, pubescent, faintly tinged red, glandless or with from one to four rather large, globose or oval, greenish-brown glands usually on the stalk.

Season of bloom medium, short; flowers appearing after the leaves, one and oneeighth inches across, white; borne in scattering clusters on lateral buds and spurs, singly or in pairs; pedicels five-eighths inch long, thick, pubescent, greenish; calyxtube green, campanulate, glabrous; calyx-lobes obtuse, lightly pubescent, glandularserrate, reflexed; petals obovate, crenate, tapering to short, broad claws; anthers yellow with a tinge of red; filaments three-eighths inch long; pistil glabrous, shorter than the stamens, often in pairs.

Fruit late, intermediate in length of ripening season; one and three-eighths inches by one and one-half inches in size, oblate, compressed; halves equal; cavity wide, flaring; suture a line; apex flattened or depressed; color red over a dark amberyellow ground, mottled, covered with thin bloom; dots numerous, grayish or light russet, conspicuous, decreasing in number but increasing in size towards the cavity; stem thick, three-quarters inch long, pubescent, adhering well to the fruit; skin thin, adhering but slightly; flesh golden-yellow, juicy, fibrous, tender, very sweet, aromatic, pleasant; very good to best; stone clinging, five-eighths inch by one-half inch in size, roundish-oval, turgid, blunt at the base and apex, with slightly pitted surfaces; ventral suture, wide, blunt, faintly grooved; dorsal suture with a deep groove of medium width.

\section{UNGARISH}

Prunus domestica

1. Ia. Agr. Col. Bul. 50, 51. 1886. 2. Ia. Hort. Soc. Rpt. 86. 1890. 3. Mich. Sta. Bul. 118: 53. 1895. 4. Kan. Sta. Bul. 101:117, 119, 120 fig. 1901. 5. Waugh Plum Cult. 109. 1901. 6. Can. Exp. Farms Rpt, 102. 1902. 7. Budd-Hansen Am. Hort. Man. 326. 1903. 8. Can. Exp. Farms Rpt. 433. 1905 .

Hungarian 3, 36. Hungarian Prune 3. Hungarian Prune 4. Hungary 1. Ungarische 8. Ungarish Prune 2, 7. Quetsche de Hongrie 1. Zwetsche Ungarische 1.

Budd's Ungarish as grown at the New York State Experiment Station is nearly identical with the Italian Prune. The only differences to 
be detected are that the Italian Prune is a trifle smaller, a little more firm, not as broad and not quite as sweet as the Ungarish. The pit of the latter is usually tinged with red, while that of the former is rarely so colored. If the Ungarish prove as productive as the Italian Prune it may be more desirable because of its larger size. In I883 Professor J. L. Budd of the Iowa Experiment Station imported trees under the name Quetsche de Hongric or Zwetsche Ungarische from C. H. Wagner of Riga, Russia and from Wilhelm Wohler of Wilna, Russia. Budd disseminated the variety as Hungary, a name soon changed to Hungarian Prune and later to Ungarish. This is not to be confused with the true Hungarian so well known in Europe as the Quetsche de Hongrie.

\section{UTAH}

\section{Prunus besseyi $\times$ Prunus watsoni}

1. Dieck in Dippel Laubholzkunde 3:634. I893. 2. Cornell Sta. Bul. 70:262, P1. II fig. 3. 1894. 3. Tex. Sta. Bul. 32:490. I894. 4. Vt. Sta. Bul. 67:21. 1898. 5. Waugh Plum Cult. 225. I 901 .

Black Utah Hybrid 2, 4, 5. Utah Hybrid 1, 2, 3, 4, 5 .

This interesting natural hybrid was grown by J. E. Johnson at Wood River, Nebraska, some time previous to is7o. Mr. Johnson planted seed of the native dwarf cherry which had grown near Sand plums and which supposedly had been pollinized by the plums. The resulting plants proved to be intermediates between the cherry and the plum and are now generally thought to be natural hybrids. From these seedlings, one was selected and propagated. Shortly afterwards Mr. Johnson moved to Utah taking his new hybrid with him and from there distributed it as Utah. In I893 a German botanist, Dieck (References, I), described this hybrid and gave it the specific name Prunus utahensis. The plant has no commercial value. It is described as follows:

Tree a dwarfish tree-like bush three or four feet in height; branches and branchlets zigzag after the habit of Prunus watsoni: leaves small, narrow-ovate, pointed at the cnds; margins crenulate, glandless, sometimes small glands on the petioles; fruit early, small, round, dark mahogany-red, covered with bloom; skin very bitter; flesh melting; pleasant flavor; quality poor; stone small, round like that of a cherry.

\section{VICTORIA}

\section{Prumus domestica}

1. Lond. Hort. Soc. Cat. 153. I831. 2. Downing Fr. Trees Am. 315. I845. 3. Ann. Pom. Belgc 45, Pl. I856. 4. Thompson Gard. Ass't 516. I859. $\quad$ 5. Cultivator $8: 26$ fig. I 860 . 6. Am. Pom. Soc. Cat. 88. 1862. 7. Thomas Am. Fruit Cult. 349 fig. 379. 1867. 8. Downing Fr. Trees 
Am. 948. 1869. 9. Pom. France 7: No. 13. I871. 10. Mas Le Verger 6:23, fig. 12, 1866-73. 11. Oberdieck Deut. Obst. Sort. 419. I88x. 12. Hogg Fruit Man. 728. 1884. 13. Mathieu Nom. Pom. 438. 1889. 14. Gaucher Pom. Prak. Obst. No. 98 fig. 1894. 15. Guide Prat. 159, 367. 1895. 16. Cornell Sta. Bul. 131:193. 1897. 17. Jour. Roy. Hort Soc. 21:222. 1897. 18. Mich. Sta. Bul. 169:243, 248, 1899. 19. Garden 57:267. 1900. 20. Waugh Plum Cult. 122, 123 fig. 1901. Alderton 4, 6, 8, 9, 12, 13, 14, 15. Dauphin 8, 13. Denyer's Victoria $?_{2}, 3,6,8,9,12,1_{3}, 1_{4}$, 15. Denyer's Victoria 4. Dolphin 8, 13. Imperial de Sharp 8, 13. Königin Victoria I1, I3, I5. Königin Victoria 9, 14, 15. La Victorine 1. Prune Reine Victoria 3. Qucen Victoria ?2, 3, 13, 14, 15. Queen Victoria 9. Reine Victoria 9, 10, 13, 14, of some 15. Royal Dauphine 8, I3. Sharp 20. Sharp's Emperor 2, 8. Sharp's Emperor 3, 9, I0, I 2, I3, by error 15, 20. Sharpe's Emperor 17 incor. Victoria-Pflaume I4. Sharp's Kaiserpflaume I3. Victoria 8, 9, I3, I4, 20. Victoria's Kaiserawetsche 14,15 .

For some reason Victoria, long known in America, has never attained great popularity in this country. It is a large plum attaining nearly the size of Pond, though the color-plate does not so show it, and has much the same color as the plum with which we have just compared it. Here resemblances cease for Victoria is not the same shape as Pond, is a little better in quality, is earlier and quite different in tree-characters. It would seem that this wot1d make a good market plum as it is firm enough in flesh to ship well, as grown here keeps remarkably well, is better in quality than the average market plum and is handsome, though Americans seem to care little for red plums, preferring the yellow sorts and still more the purple kinds. Unfortunately, Victoria does not always color well in our climate. The trees of this variety at this Station, while productive, are not large nor robust, and the foliage is a little too susceptible to fungi. These defects of the tree may account for the lack of poptlarity of the variety in New York though even if they are to be found in all localities, which is probably not the case, this plum is still worth growing to some extent for home or market.

The origin of this plum and even its right to the name under which it is discussed here are matters of controversy. The London Horticultural Society in I83 mentioned La Victorine in its catalog but since no description was given it cannot be identified as Victoria. Sharp's Emperor which has been confused with this variety, was described in the same publication. These two varieties were considered as identical by Charles Downing, Hogg, Mas and others; while Royer ${ }^{1}$ who tested Sharp's Emperor, obtained from Liegel, thought it to be distinct, as did Thomas, the Guide Pratique and Pearson of England. Hogg in describing the Victoria says, "This is a Sussex plum, and was discovered in a garden

${ }^{1}$ Aug. Royer Annales De Pomologie Belge et Etrangere 6.3. 1859 
at Alderton in that county. It became known as Sharp's Emperor, and was ultimately sold by a nurseryman named Denyer, in the year 1844 at Brixton, near London, at a high price as a new variety under the name of Denyer's Victoria." Pearson in the Fournal of the Royal Horticultural Socicty for 1897 says the reason that Hogg and other authorities had called these varieties identical is that they had not seen the true variety. At this Station we have not seen Sharp's Emperor but judging from the descriptions it is distinct though very similar. The American Pomological Society placed Victoria on its fruit list in 1862 but in $187 \mathrm{I}$, Sharp's Emperor was substituted as the correct name with Victoria as a synonym. This change was probably made to comply with Downing's nomenclature of 1869 . A review of the whole controversy cannot but lead to the conclusion that Victoria is the correct name and it appears also to be in most common use.

Tree of medium size and vigor, upright-spreading, hardy, productive; branches ash-gray, smooth, with few large lenticels; branchlets thick, short, stout, with short internodes, greenish changing to dark brownish-drab, dull, with thick pubescence, with few inconspicuous, small lenticels; leaf-buds large, long, conical or pointed, free.

Leaves folded backward, obovate, two and three-eighths inches wide, five inches long, thick, stiff; upper surface dark green, rugose, with a narrow groove on the midrib, sparingly hairy; lower surface medium green, thickly pubescent; apex abruptly pointed, base cuneate, margin serrate or crenate, eglandular or with small dark glands; petiole one inch long, covered with thick pubescence, tinged red on one side, glandless or with from one to three globose or reniform, yellow glands usually on the stalk.

Season of bloom medium, short; flowers appearing with the leaves, one and oneeighth inches across, white, the buds tinged yellow; borne in clusters on lateral buds and spurs, singly or in pairs; pedicels nearly three-eighths inch long, thick, heavily pubescent; calyx-tube green, campanulate, pubescent; calyx-lobes medium to narrow, obtuse, glandular-serrate, thickly pubescent on both surfaces, reflexed; petals roundishobovate, entire or occasionally notched, tapering to short, broad claws; anthers yellow; filaments one-quarter inch long; pistil glabrous, longer than the stamens.

Fruit mid-season, ripening period of medium length; one and seven-eighths inches by one and one-half inches in size, long-oval, oblong, compressed, halves equal; cavity shallow, narrow, flaring; suture variable in depth, prominent; apex roundish or depressed; color dark red, mottled before full maturity, covered with thick bloom; dots numerous, russet, conspicuous; stem thick, three-quarters inch long, very pubescent, adhering strongly to the fruit; skin thin, tender, adhering but slightly; flesh light yellow, juicy, coarse, firm, sweet, mild but pleasant; good; stone free, one and oneeighth inches by three-eighths inch in size, broad-oval, strongly flattened, deeply pitted, roughish, blunt at the base and apex; ventral suture narrow, distinctly winged; dorsal suture widely and deeply grooved. 


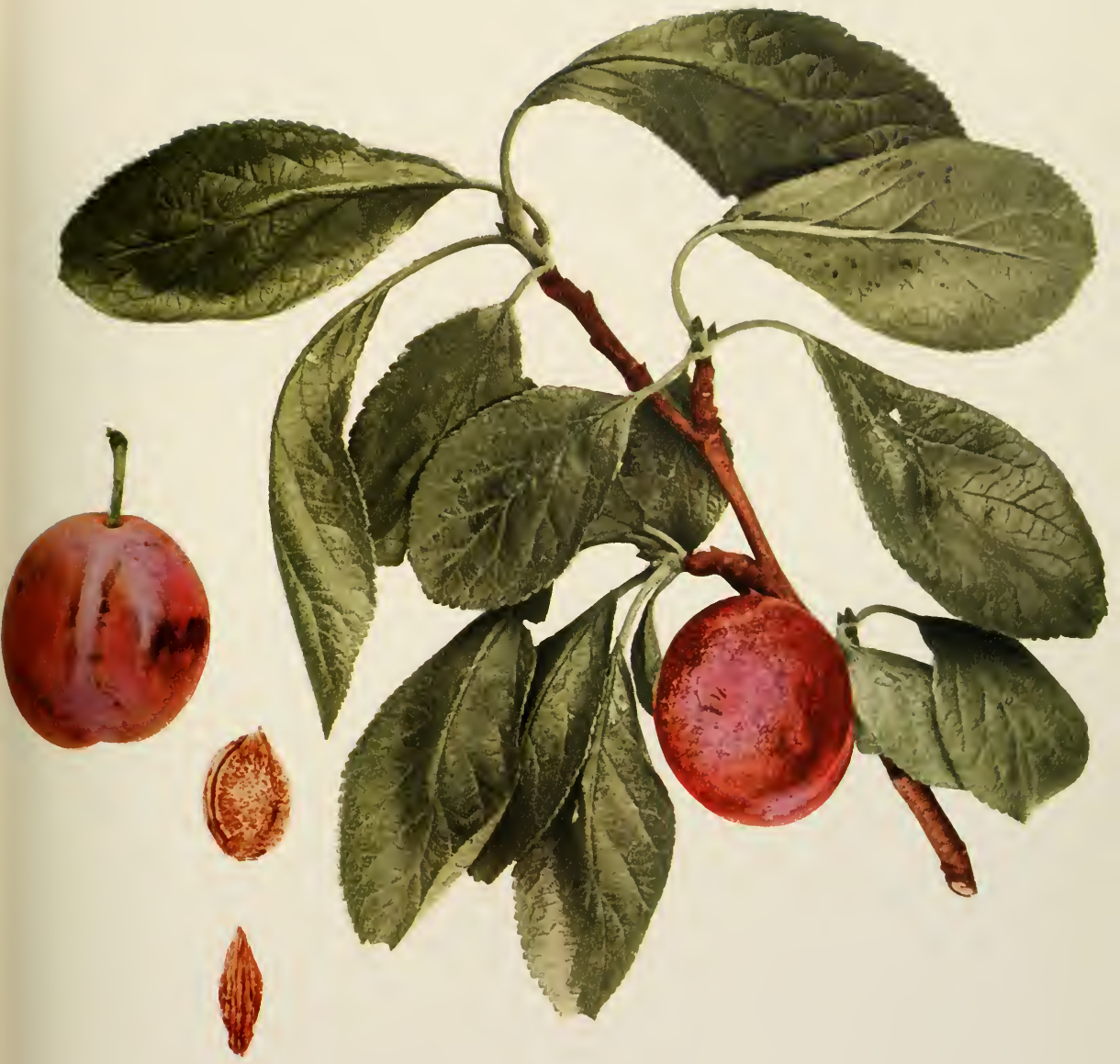




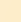




\section{VIOLET DIAPER}

\section{Prunus domestica}

I. Parkinson Par. Ter. 576, 578. 1629. 2. Langley Pomona 93, Pl. XXIII fig. II. 1729. 3. Duhamel Trait. Arb. Fr. 2:101, P1. XVII fig. 1768. 4. Prince Pom. Man. 2:70, 92. 1832. 5. Elliott Fr. Book 425. 1854. 6. Koch Deut. Obst. 572. 1876. 7. Le Bon Jard. 339. 1882. 8. Hogg Fruit Man. 690. 1884. 9. Mathieu Nom. Pom. 452. 1889. 10. Guide Prat. 157, 355. 1895 .

Black Diapred I. Blane Diaprée 9, го. Blaue Herzformige Pfaume 9, го. Buntfarbige Violette Pflaume 9, xо. Cheston 1, 9. 10. Cheston 4, 5, 8. Cheston Matchless 5. Cheston's Plumb 2. Dennie x. Diaprée noire 7. Die Violette Diaprée ro. Diaprée Violette 3, 10. Diaprée Violette 4, 8, 9. Diapre Violet 4. Friars 1. Friars 8. Friar's Plum 9. Matchless 4, 5, 9, 10. Purple Diaper 6. Violet Diaper 5, 9. Violette Diaprée 9. Violette Violen Pflaume 9, 10. Veilchen Pflaume 9, 10.

Violet Diaper was cultivated at the beginning of the Seventeenth Century and has maintained itself in Europe until the present time although never attaining nor deserving the popularity of the Red Diaper. Matchless, cited as a synonym, is manifestly incorrect as the true Matchless is a yellow plum; but since it has been used so long and by so many writers as a synonym, it seems best to mention it as such. This plum is not grown in America. It is described as follows:

Fruit early; of medium size, oval; suture faint; cavity almost lacking; skin free; dark purple, covered with thick bloom; flesh yellow, firm, sweet; good; freestone.

\section{VORONESH}

\section{Prunus domestica}

1. Am. Pom. Soc. Rpt. 76. 1883. 2. Ibid. 6r. 1887. 3. Am. Gard. 11:625 fig. I. I89o. 4. Waugh Plum Cult. Ir6. 1901. 5. Budd-Hansen Am. Hort. Man. 327,329 . 1903.

Moldavka 1, 2, 3, 4. Voronesh Yellow 3, 5. Yellow Moldavka 5. Yellow Voronesh 2.

Voronesh is a Russian sort supposed to be ironclad as to cold. It is perfectly hardy at Geneva, the trees are also very productive and the fruits are attractive enough in size and color to meet market demands but the flavor is so insipid as to make the plum unfit for dessert and hardly fit for kitchen use. It is given the honor of a color-plate because it is a somewhat distinct type. In I88 I Professor J. L. Budd secured from J. E. Fisher, Voronesh, Russia, a variety which he introduced as Voronesh Yellow. At the same time he imported a variety from Fisher under the name Moldavka which proved to be identical with his Voronesh Yellow, though Budd held that while they were very similar the Moldavka was more oval than Voronesh. 
Tree of medium size, round-topped, productive; leaves drooping, folded backward, narrow-obovate, two and one-quarter inches wide, four and one-half inches long, thick; margin doubly serrate, with small, yellowish glands; petiole one-half inch long, tinged red, pubescent, somctimes with two globose, yellowish-red glands usually on the stalk near the base of the leaf; blooming season early, short; flowers appearing after the leaves, fully one and one-eighth inches across, dull white; borne on lateral buds and spurs, singly or in pairs.

Fruit mid-season, ripening period short; one and seven-eighths inches by one and one-half inches in size, ovate, necked, slightly enlarged on the suture side, dark lemonyellow, with thin bloom; dots very numerous, of medium size, white, conspicuous; stem adhering strongly to the fruit; skin tough, sour; flesh dark amber-yellow, very tender, sweet, mild; poor; stone free, one and three-eighths inches by five-eighths inch in size, long-oval, flattened, somewhat necked, acute at the apex, the surfaces smooth or partially honeycombed; ventral suture prominent.

\section{WALES}

\section{Prunus domestica}

1. Gard. Chron. 5:837. 1845. 2. Mag. Hort. 12:340. 1846. 3. McIntosh Bk. Gard. 529. 1855 . 4. Downing Fr. Trees Am. 392. 1857. 5. Thompson Gard. Ass't 515. 1859. 6. Ann. Pom. Belge 7, P1. 1859. 7. Mas Pom. Gcn. 2:119, fig. 60. 1873. 8. Flor. \& Pom. 253, P1. 1875. 9. W. N. Y. Hort. Soc. Rpt. $21: 20$. 1876. Io. Hogg Fruit Man. 718. I884. Ix. Mathieu Nom. Pom. 443. 1889. 12. Ont. Fr. Exp. Sta. Rpt. 96, 120. 1896. 13. Cornell Sta, Bul. 131:19o. 1897. 14. Am. Pom. Soc. Cat. 26. 1897. 15. Ohio Sta. Bul. 113:160. IS99. 16. Waugh Plum Cult. 125. I901.

Chapman's Prince of Wales, 3, 5. Chapman's Prince of Wales 4, 10, II. Chapman's Prince of Wales' Plum r. Prince Albert? Ix. Prince De Galles 7. Prince De Galles 6, Ir. Prince of Wales 2, 4, 8, 9, 10, 12, 13, 15. Prince of Walcs 7, 11, 14, 16. Prinz Von Wales 11. Prune Prince of Whales 6 .

Wales, more commonly known as the Prince of Wales, seems to have much merit yet it has long been grown in America, probably three-quarters of a century, without attaining distinction with fruit-growers. In recent years it has been favorably commented upon in a number of publications and seems to be better known and more grown than formerly. Whether this tardily-given recognition is not too late is a question. So many good plums have been introduced both at home and abroad in the last few decades that a sort dating back nearly a century must be meritorious, indeed, to stand the competition. As Wales grows in New York, it is rather too poor in quality to recommend it for a home variety and the plums are too small, as they generally grow, for a good commercial fruit. The trees are enormously productive and are very satisfactory in other characters as well. In a bulletin from the Cornell Station (References, I3) this variety is said to have " much to commend it for general favor:" 

while in Ohio (References, 15) it is thought that Wales "ought to become popular."

Wales, a seedling of Orleans, was raised by a Mr. Chapman, Brentford, Middlesex, England, in I830. It was exhibited before the London Horticultural Society in 1845 where it was awarded a prize. The following year, Hovey, the American pomologist, (References, 2) described the variety but the date of the first importation to this country is unknown. It was not until I 897 that the variety was sufficiently known to be placed on the fruit catalog list of the American Pomological Society.

Tree large, vigorous, slightly vasiform, open-topped, hardy, very productive; branches ash-gray, smooth except for the numerous, small, slightly raised lenticcls, often marked by concentric rings; branchlets of medium thickness and length, with long internodes, green changing to brownish-red, dull, thinly pubescent, with numerous, inconspicuous, small lenticels; leaf-buds large, long, conical or pointed; leaf-scars prominent.

Leaves folded upward, roundish-ovate or oval, two and one-half inches wide, three and one-half inches long; upper surface dark green, somewhat rugose, covered with numerous hairs; lower surface pale green, thickly pubescent; apex and base abrupt, margin crenate, eglandular or with small dark glands; petiole one-half inch long, pubescent, tinged red, glandless or with from one to three small, globose, yellowish-brown glands usually at the base of the leaf.

Blooming season short; flowers one inch across, white, with a yellow tinge; usually borne in pairs; pedicels eleven-sixteenths inch long, thick, pubescent, greenish; calyxtube green, campanulate, lightly pubescent toward the base; calyx-lobes broad, obtuse, pubescent on both surfaces, glandular-serrate and with marginal hairs, erect; petals broadly oval, crenate, tapering to short, blunt claws; filaments five-sixteenths inch long; pistil glabrous except on the ovary, longer than the stamens; stigma large.

Fruit late, season short; one and fivc-eighths inches by one and one-half inches in size, roundish-oval, halves equal; cavity narrow, abrupt; suture a line; apex roundish; color reddish-purple, overspread with thick bloom; dots few, large, often tinged red, conspicuous; stem thick, one-half inch long, pubescent, adhering well to the fruit; skin tough, separating readily; flesh golden-yellow, juicy, tender, sweet, mild; good; stone semi-free or free, seven-eighths inch by five-eighths inch in size, oval, turgid, blunt at the base and apex, with slightly pitted surfaces; ventral suture narrow, often acute or with a slight wing; dorsal suture widely and deeply grooved.

\section{WANGENHEIM}

\section{Prunus domestica}

1. Cultivator 8:26 fig. 1860. 2. Mas Le Verger 6:157, fig. 79. 1866-73, 3. Am. Pom. Soc. Cat. XXIV. 1871. 4. Mathieu Nom. Pom. 453. 1889. 5. Guide Prat. 159, 367. 1895. 6. Waugh Plum Cult. 125. 1901 . 
Die Wangenhcim 4. De Wangenheim 5. Prune de Wangenheim 4. Prune Wangenheim Hative 4. Quetsche Pricoce de Wangenheim 2, 4, 5. Von Wangenheim Pfaume 2, 4, 5. Wangenheims Frührwetsche 2, 5. Wangenheims Früh $\mathrm{Z}$ wetsche 4. Wangenheim Hâtive 4.

This variety, very well known and highly esteemed in Germany, has been grown to some extent in America both on the Pacific and Atlantic Coasts and in neither region has it proved equal to standard plums. According to Dittrich, Wangenheim originated at Beinheim, a small place near Gotha, Saxe-Cobourg, Germany.

Tree large, vigorous, upright-spreading, productive; trunk rough; branches rough, stocky; branchlets nearly glabrous; leaves folded upward, slightly rugose; margin finely serrate, with small glands; petiole tinged red, pubescent, with from one to three small glands usually at the base of the leaf.

Fruit mid-season; one and one-quarter inches by one and one-eighth inches in size, ovate, purplish-red, covered with thin bloom, yellowish, rather dry, firm, sweet, mild; of good quality; stone very free, three-quarters inch by one-half inch in size, irregularoval, flattened, with faintly pitted surfaces; ventral suture distinctly winged; dorsal suture with a narrow, shallow groove.

\section{WASHINGTON}

\section{Prunus domestica}

I. Prince Treat. Hort. 24, 1828 . 2. Pom. Mag. I:16, P1. 1828. 3. Lond. Hort. Soc. Cat. I 54. I8 8 I. 4. Prince Pom. Man. 2:53. $\mathrm{IB}_{32}$. 5. Floy-Lindley Guide Orch. Gard. $298,38_{3}, 418$. I 846. 6. Cole Am. Fr. Book 210. I849. 7. Thomas Am. Fruit Cult. 326 fig., 327. 1849. 8. Hovey Fr. Am. 1: 87 , Col. P1. 1851. 9. Am. Pom. Soc. Cat. 54. 1852. 1o. Elliott Fr. Book 415. is 84. I1. Ann. Pom. Belge 4:23, P1. 1856. I2. Thompson Gard. Ass't 520. 1859. 13. Downing Fr. Trees Am. 951. 1869. 14. Pom. France 7:No. 24. 1871. 15. Mas Le Verger 6:59. 1866-73. 16. Hogg Fruit Man. 729. 1884. I7. Mathieu Nom. Pom. 453. I889. 18. Mich. Sta. Bul. 103: 32, 33, fig. 1894. 19. Cornell Sta. Bul. 131:193. 1897. 20. Va. Sta. Bul. 134:44. 1902. 21. Can. Exp. Farm Bul. 43:36. 1903.

Anglesio 17. Bolmar 3, 6, 7, 8, 10, 12, 13, 14, 16, 17. Bolmar's Washington 3, 7, 8, 10, 11, 12, 14, 16, 17. Bolmar's Washington 5. Bolmer 1, 4, I3, I7. Bolmer's Washington 1, 4, I3. Bolmore's Washington 4. Double Imperial Gage 1, 4. Franklin 3, 4, 5, 8, 10, II, 12, 13, 14, 16, I7. Imperial Gage (of Albany) 4. Irving's Bolmar 10, 13, 16, I7. Irving's Bolmer 14. Jackson I1, 13, 14, I7. Lonis Philippe 14. Louis Philipp 17. New IWashington 3, 4, 5, 8, 10, 11, 13, 14, 17. Parker's Mammoth 10, 13, 16, I7. Philippe 1, 11, I3, 14, I7. Prune Washington Jaune I1. Superior Gage I, 4, 8. Superior Green Gage 4, 8. The Washington Plum 2, 8. Washington 5, 8. Washington Bolmar 8. Washington Gage 4. Washington Jaune ${ }^{3} 3,14,17$. Washington Mammot 14, 17. Washington Yellow 17.

Washington holds high rank among the Reine Claude varieties, plums unsurpassed for dessert purposes. The fruits are large in size for one of this group; handsome in form and color (in the latter respect the colorplate does not do the variety justice); abundant in juice yet firm and 

meaty enough in flesh to keep and ship well; fine in flavor though not quite equalling some others of its group in this character. The trees are large, hardy, vigorous and healthy, remarkable for their broad, glossy, abundant leaves, bear bountiful crops annually and at a favorable period of maturity. Washington thus has a combination of characters which few of its group, with which only it must be compared, possess. The variety, however, is not without defects; the fruits are subject to brown-rot, so much so that its value as a commercial variety is greatly lessened; the quality varies greatly in different locations and even in different years, - the latter very noticeable on the Station grounds; the trees are slow in coming in bearing and the crops are small for some years after fruiting begins. From the above considerations it may be seen that while this variety is almost always worth planting in a home collection, the location for it as a commercial fruit needs to be chosen with some care.

There are two accounts of the origin of this variety. William Prince gives its history as follows (References, I): "It has always been the custom at the establishment of the author, at Flushing, to plant annually the seeds of the finest fruits, for the purpose of originating new varieties; and, about the year 1790 , his father planted the pits of twenty-five quarts of the Green Gage plum; these produced trees yielding fruit of every colour; and the White Gage, Red Gage, and Prince's Gage, now so well known, form part of the progeny of those plums; and there seems strong presumptive evidence to suppose that the Washington Plum was one of the same collection." Michael Floy gives a different history of the Washington (References, 5 ). He states that he received the variety in 1818 from a Mr. Bolmar of New York who in turn had purchased his trees from a market woman in 1814 . The purchased trees were produced as suckers from the roots of a Reine Claude tree which had been killed below the graft by lightning on the Delancey farm, now the Bowery, in New York City. In I8I9, a few of the trees, budded the previous year by Floy, were sent to England. The American Pomological Society added the Washington to its fruit catalog list in $185^{2}$. Taking in consideration the evidence of other writers and further facts offered in other accounts by the Princes, father and son, it seems almost certain that the first history is correct and that Bolmar's trees had their origin in the Prince nursery.

Tree large, vigorous, round and open-topped, hardy, very productive; branches dark ash-gray, rough becoming shaggy on the trunk, with small lenticels; branchlets below medium in thickness and length, with long internodes, green changing to brownish- 
red, thinly pubescent, with small lenticels of average number; leaf-buds of medium size and length, pointed, free.

Leaves flattened, oval, two and one-half inches wide, four and one-quarter inches long, leathery, somewhat velvety; upper surface dark green, lightly pubescent, with a shallow groove on the midrib; lower surface medium green, thickly pubescent; apex abruptly pointed or acute, base abrupt; margin serrate, eglandular; petiole five-eighths inch long, green, pubescent, glandless or with one or two smallish, globose, greenishyellow glands at the base of the leaf.

Blooming season intermediate in time and length; flowers appearing after the leaves, one and five-sixteenths inches across, white, with yellow near the apex; borne on lateral buds and spurs; pedicels three-eighths inch long, thick, covered with fine pubescence, greenish; calyx-tube green, campanulate, pubescent ; calyx-lobes broad, obtuse, pubescent on both surfaces, glandular-serrate and with marginal hairs, erect; petals broad-ovate or oval, crenate, tapering into short, broad claws; anthers yellow; filaments three-eighths inch long; pistil glabrous, longer than the stamens.

Fruit intermediate in time and length of ripening season; one and three-quarters inches by one and five-eighths inches in size, roundish-oval, compressed, halves equal; cavity shallow, narrow, flaring; suture shallow; apex roundish; color greenish-yellow or light yellow, with green stripes and splashes, occasionally with a faint blush on the sunny side, covered with thin bloom; dots numerous, white, inconspicuous, clustered about the apex; stem one-half inch long, covered with thick pubescence, adhering strongly to the fruit; skin thin, slightly sour, separating readily; flesh greenish-yellow, juicy, firm but tender, sweet, mild, pleasant flavor; good to very good; stone free, not filling the cavity, one inch by three-quarters inch in size, oval, turgid, roughened, somewhat blunt at the base and apex; ventral suture wide, marked by deep furrows, with a distinct but short wing; dorsal suture widely and deeply grooved.

\section{WAYLAND}

\section{Prunus hortulana}

1. U.S. D. A. Rpt. 573 , Pl. 5 fig. 2. 1888. 2. Am. Gard. 10:175 fig., 243. 1889. 3. Cornell Sta. Bul. 38:51, 87. 1892. 4. Wis. Sta. Bul. 63:24, 62, 1897. 5. Vt. Sta. An. Rpt. 10:99, 103. 1897. 6. Ibid. I1:281, 286 fig. 1898. 7. Ia. Hort. Soc. Rpt. 228. 1904. 8. Ga. Sta. Bul. $67: 28_{3}$. 1904. 9. Ohio Sta. Bul. 162:258. 1905 .

Wayland is of little interest to plum-growers who grow the Domestica varieties without difficulty but in the South and Middle West it is an important representative of a valuable species. The trees withstand the hot, dry weather in the region south of central Iowa and Nebraska rather better than do those of varieties of other species and its fruits are borne in such quantities and so late that this and its kindred sorts become important plums. The fruits are quite too firm of flesh, too sour and too small to be of value for dessert purposes but they are most excellent for jellies, marma- 


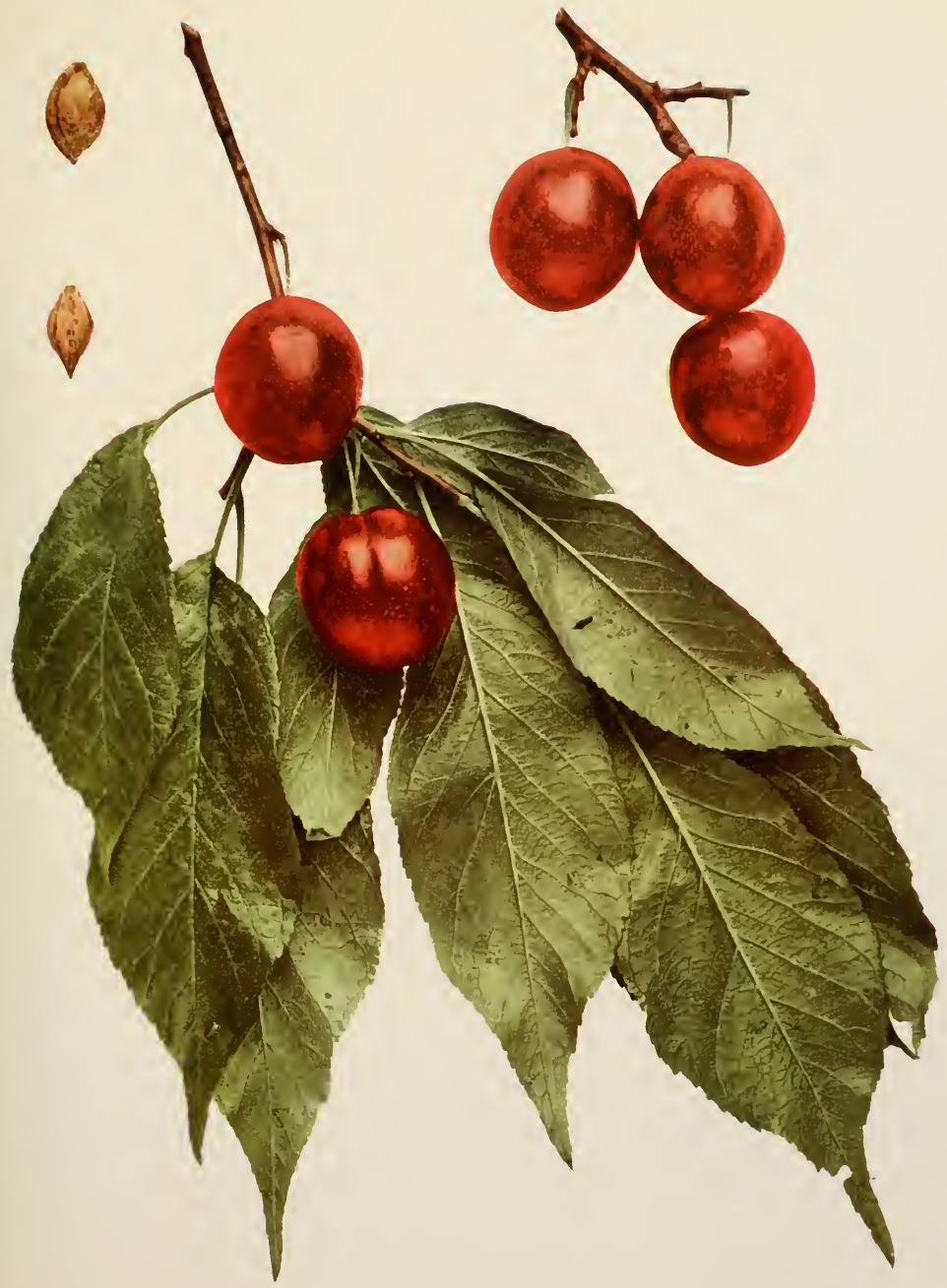



lades and preserves-any of the uses to which the Damsons are commonly put. They are, too, best adapted for long-keeping and shipping of any of the native plums. Except in size, the plums are hardly surpassed in the characters that make a fruit handsome among the native plums. The trees are large, robust and hardy in central New York, usually free from attacks of insects and fungi and, with their abundant, glossy foliage, are strikingly ornamental. Wayland is of value for New York, however, when all characters are considered, only in furnishing variety, in extending the season for native plums and as an ornamental.

Wayland was found in a plum thicket on the premises of Professor H. B. Wayland, Cadiz, Kentucky. It was sent by him about I875 to J. S. Downer and Sons, Fairview, Todd County, Kentucky, who named and introduced it. There has been much discussion as to the botanical status of this variety, various writers having put it in at least three distinct species and Waugh and Bailey have used it as the type of the Wayland group of Prunus hortulana.

Tree very large and vigorous, spreading, somewhat drooping, flat-topped, open, hardy at Geneva, productive; trunk shaggy; branches rough, dark ash-gray, with inconspicuous lenticels, medium in number and size; branchlets slender, twiggy, long, with internodes of average length, green, changing to light chestnut-red, glossy, glabrous, with numerous, conspicuous, large, raised lenticels; leaf-buds very small, short, obtuse, plump, appressed.

Leaves folded upward, ovate or long-oval, peach-like, one and seven-eighths inches across, five inches long, thin; upper surface smooth and glossy, with a grooved midrib; lower surface sparingly pubescent; apex acuminate, base abrupt, margin unevenly serrate, glandular; petiole one inch long, slender, pubescent along one side, with a tinge of red, with from one to five very small, globose, brownish glands usually on the stalk.

Blooming season late and long; flowers appearing after the leaves, thirteen-sixteenths inch across, white, with disagreeable odor; borne in clusters on lateral buds and spurs, in threes, fours or fives; pedicels fifteen-sixteenths inch long, very slender, glabrous, green; calyx-tube greenish, narrowly campanulate, glabrous; calyx-lobes narrow, acute, erect, lightly pubescent within, serrate and with dark-colored glands; petals ovate or oval, irregularly crenate, tapering into long, narrow claws with hairy margins; anthers yellowish; filaments three-eighths inch long; pistil glabrous, shorter than the stamens.

Fruit very late, season long; one and one-eighth inches by one inch in size, roundishovate narrowing somewhat toward the stem, conical, slightly compressed, halves equal; cavity medium to deep, narrow, abrupt; suture usually very shallow and wide, often a distinct line; apex pointed; color dark currant-red, with inconspicuous, thin bloom; 
dots numerous, small to medium, conspicuous, densely clustered about the apex; stem very slender, five-eighths inch long, glabrous, not adhering to the fruit; skin thick, tough, clinging but slightly; flesh attractive light yellow; moderately juicy, coarse, fibrous, rather tender, mildly sweet next the skin but astringent towards the pit; fair to good; stone clinging, five-eighths inch by three-eighths inch in size, long-oval, somewhat elongated at the base and apex, turgid, with rough and pitted surfaces; ventral suture wide, blunt, faintly ridged; dorsal suture acute, with a narrow, indistinct groove.

\section{WEAVER}

\section{Prunus americana}

1. Mich. Pom. Soc. Rpt. 267. 1874. 2. Am. Pom. Soc. Cat. 44. 1883. 3. Mich. Hort. Soc. Rpt. 268. 1885. 4. Minn. Sta. Bul. 5:36, 37 fig. 1889. 5. Cornell Sta. Bul. 38:45, 86. 1892. 6. Can. Hort. 16:409, P1. 1893. 7. Mich. Sta. Bul. 123:21. 1895. 8. Wis. Sta. Bul. 63:24, 62 . 1897. 9. Colo. Sta. Bul. 50:46. 1898. 1o. Ia. Sta. Bul. 46:291. 1900. 11. Waugh Plum Cult. r66 fig. 1901. 12. Budd-Hansen Am. Hort. Man. 302. 1903. 13. Can. Exp. Farm Bul. 43:32. 1903. 14. Ga. Sta. Bul. 67:283. 1904. 15. S. Dak. Sta. Bul. 93:41. 1905.

Weaver is an old and well-known Americana, once one of the most popular of its species because of its hardiness and productiveness. It is still listed by many nurserymen and is widely distributed throughout the country but it is now rapidly passing out of cultivation, being superseded by sorts producing larger and better colored fruits.

This variety was found growing wild on the Cedar River, in Iowa, by a Mr. Weaver. In I873, Ennis and Patten, Charles City, Iowa, began its sale to fruit-growers. The American Pomological Society placed the Weaver on its fruit catalog list in $188_{3}$, dropped it in $189 \mathrm{I}$, and replaced it in 1897 . The following description is partly compiled.

Tree large, vigorous, well formed, upright-spreading, unusually hardy, productive; branches long, slender; branchlets slender, long, with short internodes, reddish-brown, glabrous, with numerous, conspicuous lenticels of medium size; leaf-buds small, conical, of average length.

Leaves falling late, four and one-half inches long, two and one-half inches wide, obovate or oval, firm, thick, leathery; upper surface dark green, slightly roughened, glabrous, with narrow midrib; lower surface pale green, pubescent on the midrib and larger veins; apex acuminate, base somewhat acute, margin deeply and coarsely serrate; petiole five-eighths inch long, stout, reddish, slightly pubescent along one side, usually with two large, globose, reddish-brown glands on the stem.

Flowers large, prominently stalked; calyx-lobes conspicuously glandular, lightly pubescent within.

Fruit mid-season or later; one inch by three-quarters inch in size, large for a native, oval or roundish-oblong, compressed, halves unequal; cavity medium to shallow, narrow, rather abrupt; suture shallow. distinct; apex roundish or depressed; color not 
uniform, yellowish overlaid with purplish-red, mottled, covered with thin bloom; dots numcrous, small, often purplish, inconspicuous; skin thick, very tough, astringent, adhering to the pulp; flesh decp yellow, juicy, firm and meaty, sweet, mild; fair to good; stone variable in adhesion, three-quarters inch by three-cighths inch in size, long and narrow, somewhat oval, flattened, obscurely pointed at the base and apex, smooth.

\section{WHITE BULLACE}

\section{Prunus insititia}

1. Parkinson Par. Ter. 576. 1629. 2. Abercrombie Gard. Ass't 13. 1786. 3. Forsyth Fr. Trees Am. 2 I. 1803. 4. Lond. Hort. Soc. Cat. 344. 183 r. 5. Prince Pom. Man. 2:105. 1832. 6. Floy-Lindley Guide Orch. Gard. 300, 383. 1846. 7. Hogg Fruit Man. 385. 1866. 8. Downing Fr. Trees Am. 952. 1869. 9. Thompson Gard. Ass't 4:160, 161 fig. 960. 1901. 10. Can. Exp. Farms Rpt. 48r. 1904.

Bullace 5. Bullace 7. White Bulleis $\mathrm{r}$.

The origin of this old sort is unknown. It was cultivated more than three hundred years ago for Parkinson described it as common in his time. He savs of it "The White and the blacke Bulleis are common in most Countries, being small round, lesser than Damsons, sharper in taste, and later ripe." It is probably one of the first of the cultivated plums. White Bullace is illustrated and described in full in The Plums of New York chiefly as a means of comparison between the plums of three centuries ago and those of the present. It has little value now for any purpose, though the Europeans still grow it rather commonly and from seeds, cions or suckers as convenience may dictate.

Tree of medium size and vigor, upright-spreading, dense-topped, hardy, unproductive; branches ash-gray, nearly smooth, with numerous, small, inconspicuous lenticels; branchlets thick, above medium in length, with short internodes, greenish-red changing to dark brownish-red, dull, with thick pubescence throughout the season, with few, small lenticels; leaf-buds small, short, stubby, obtuse, strongly appressed.

Leaves flattened, obovate, one and five-eighths inches wide, two and three-eighths inches long, thick; upper surface dark green, rugose, with few hairs along the narrow, grooved midrib; lower surface silvery green, pubescent; apex abruptly pointed or acute, base acute, margin doubly serrate, eglandular; petiole one-half inch long, green, pubescent, glandless or with one or two small, globose, greenish-yellow glands variable in position.

Blooming season medium to late, of average length; flowers appearing after the leaves, three-quarters inch across, white, scattered on lateral spurs; usually borne singly; pedicels one-quarter inch long, thick, densely covered with short hairs, green; calyx-tube reddish-green, campanulate, glabrous; calyx-lobes acute, lightly pubescent on both surfaces, glandular-serrate, reflexed; petals obovate, entire, with short, broad claws; anthers yellow with red tinge; filaments five-sixteenths inch long; pistil glabrous, nearly equal to the stamens in length. 
Fruit late, ripening season of medium length; about one inch in diameter, roundish, compressed, truncate at the base; cavity rather deep and wide, abrupt; suture a line; apex flattened or depressed; color deep amber-yellow, sometimes with faint pink blush on the exposed cheek, overspread with moderately thick bloom; dots numerous, white, inconspicuous; stem one-half inch long, covered with scant pubescence, adhering strongly to the fruit; skin thin, astringent, slightly adhering; flesh deep golden-yellow, juicy, coarse, fibrous, firm, sour; poor in quality; stone clinging, five-eighths inch by one-half inch in size, ovate, turgid, blunt at the base, acute at the apex, slightly roughened; ventral suture broad, blunt, shallowly furrowed; dorsal suture with a wide, shallow groove.

\section{WHITE DAMSON}

\section{Prunus insilitia}

I. Parkinson Par. Ter. 578 . 1629. 2. Quintinye Com. Gard. 67, 69. 1699. 3. M'Mahon Am. Gard. Cal. 588. 1806. 4. Coxe Cult. Fr. Trees 238 , fig. 15. 1817 . 5. Lond. Hort. Soc. Cat. 146. I8 $8_{3}$. 6. Prince Pom. Man. 2:88. 18 $8_{32}$. 7. Downing Fr. Trees Am. 287. 1845. 8. FloyLindley Guide Orch. Gard. 300. 1846. 9. Thomas Am. Fruit Cult. 334. 1849. 10. Elliott Fr. Book 430. 1854. I1. Am. Pom. Soc. Rpt. 190, 214. 1856. 12. Hogg Fruit Man. 385. 1866. 13. Downing Fr. Trees Am. 952. 1869. 14. Waugh Plum Cult. 131. 1901.

Frost Plum 6, 13. Late Cluster 6, 13. Late White Damson 6. Late Yellow Damson 7, 9 , 10, 13. Shailcr's White Damson 7, 10, 12, 13. Shailer's White Damson 5. Small Round Damson 5. White Damascene 4. White Damascene 6, 7, 10, 13. White Damask 2. White Damson 6. White Prune Damson 7, 8, 10, 13. White Winter Damson 6, 13. White Winter Damson 3. Winter Damson 6. Yellow Damson 9.

This old plum, known since the beginning of the Seventeenth Century, is chiefly of historic interest. Downing thought this a very desirable addition to our list of plums but nearly all other pomologists who have seen the fruit of the variety think it of small importance. Unfortunately it is not in the collection at this Station and can be neither recommended nor condemned from first hand knowledge. This plum was first noted in America by M'Mahon in 1806 , and fifty years later it was added to the American Pomological Society list of promising varieties. For some reason, perhaps for its color, it has never become so well known as the purple Damsons. Perhaps from the division of Prunus insititia made in The Plums of New York, this variety should be known as a Mirabelle rather than as a Damson. The following description is a compilation:

Tree vigorous, very productive; branches long, slender. Fruit matures the last of September, season long; small, oval, pale yellow sprinkled with reddish-brown dots, covered with thin bloom; flesh yellowish, sprightly, pleasant flavored; good to very good; stone clinging. 


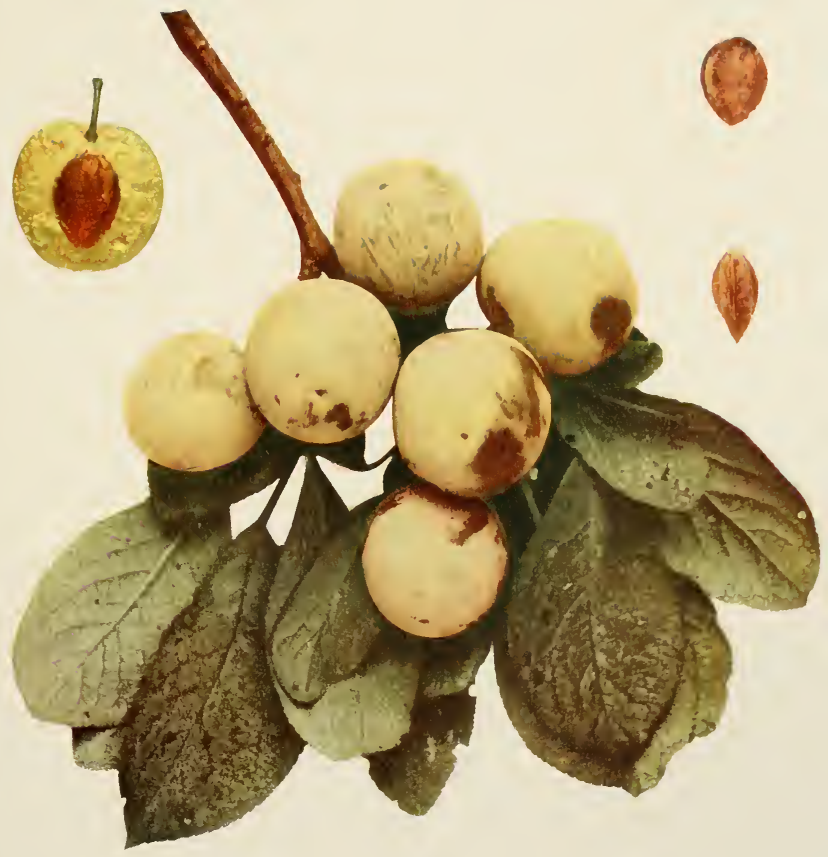

WHITE BULLACE 



\section{WHITE IMPERATRICE}

\section{Prunus domestica}

1. Kraft Pom. Aust. 2:33, Tab, 181 fig. 2; 2:44, Tab. 197 fig. 2. I 796. 2. Duhamel Trait. Arb. Fr. 2:106. 1768. 3. Pom. Mag. 1:38, P1. 1828. 4. Prince Pom. Man. 2:61. 1832. 5. Downing Fr. Trees Am. 285. 1845. 6. Floy-Lindley Guide Orch. Gard. 300, 383. 1846. 7. Poitea Pom. Franc. 1. 1846. 8. Thomas Am. Fruit Cult. 329. 1849. 9. Hogg Fruit Man. 730. 1884. ro. Nathieu Nom. Pom. 454. 1889.

Die Weisse Kaiserpflaume 3, 4, 6, 10 incor. Die Weisse Kaiserpfla ume 1. Die Weisse Kaiserinnpflaume 1. Imperatrice Blanche $\mathrm{x}, 2,3,4,5,6,8,9$, 10. The White Imperatrice Plum 3. Prune Imperatrice Blanche 7. White Imperatrice 3, 10. White Empress 5, 8, 10 . Weisse Ka iserpfla ume ro.

Kraft in his Pomona Austriaca, I796, described a Weisse Kaiserpflaume and a Weisse Kaiserinnpflaume and gave Imperatrice Blanche as a synonym to both of them. The latter he gave as a variety of the Weisse Kaiserpflaume but it is probable that they are the same since no other author noted the distinction, and, in fact, the differences mentioned are wholly insignificant. According to Downing this variety was little known in this country in 1845 and it is doubtful if it is now known at all. It is described as follows:

Compared with the Saint Catherine, which it resembles, it is found to differ in that its stone is free and its flavor less high; branches smooth; leaves smaller and less shining; fruit matures in September; of medium size, obovate; suture indistinct; cavity narrow; skin yellow, spotted with a little red; bloom thin; flesh yellow, crisp, juicy, sweet.

\section{WHITE PERDRIGON}

\section{Prunus domestica}

I. Rea Flora 208. 1676. 2. Langley Pomona 92, 93, Pl. XXIII figs, V \& VI. I 729. 3. Niller Gard. Dict. 3. 1754. 4. Duhamel Trait. Arb. Fr. 2:84, Pl VIII. 1768. 5. Kraft Pom. Aust. 2:4I, Tab. 193 fig. 1. 1796. 6. Lond. Hort. Soc. Cat. 151. 1831. 7. Prince Pom. Man. 2:52, 64. 1832. 8. Downing Fr. Trees Am. 287. 1845. 9. Floy-Lindley Guide Orch. Gard. 298, 301, 383. 1846. 10. Hogg Fruit Man. 386 . I866. I1. Mathieu Nom. Pom. 454. 1889.

Brignolle 11. Brignole 6, 8, 10, 11. Die weisse Duranzen pflaume 5. Diaprie Blanche Ir. Maître Claude 2, 3, 7, 9. Perdrigon blanc 4. Perdrigon blanc 5, 6, 7, 8, 9, 10, xi. Maitre Claude 8, 10, II. Weisser Perdrigon I1. Weisse Diaprice I1. Weisses Rebhuhnerei Ir. Prune-Pêche (of some) II. White Perdrigon 11 .

White Perdrigon is an old French variety grown extensively in the vicinity of Brignoles, France where it is used in the manufacture of the famous Brignoles Prunes. Because of its use for this purpose, it has been badly confused with a similar variety, the Brignole, which derived its name from the town of Brignoles, where it was first grown. The variety is probably not known in America and might be worth introducing. It is described as follows: 
The White Perdrigon is a mid-season, medium-sized, oval plum, tapering slightly towards the base; suture shallow; cavity small; stem slender; skin rather tough, pale yellow, with thin bloom; dots numerous, small, whitish; flesh greenish-yellow, melting, juicy, sweet, aromatic; good; stone small, long-oval, free.

\section{WICKSON}

\section{Prunus triflora $\times$ Prunus simonii}

I. U.S. D. A. Rpt. 263. 1892. 2. Burbank Cat. 21 fig. 1893. 3. Gard. \& For. 7:420. 1894. 4. Cornell Sta. Bul. ro6:63. 1896. 5. Cal. State Bd. Hort. 53. 1897-8. 6. Cornell Sta. Bul. 139: 46 fig. 120. 1897. 7. Can. Hort. $21: 30$ fig. 1272. 1898. 8. Vt. Sta. An. Rpt. 12:229. 1899. 9. Cornell Sta. Bul. 175:148, 149 fig. 38. 1899. ro. Am. Pom. Soc. Cat. 41. 1899. 11. Kan. Sta. Bul. 1ог:125. 1901. 12. Mich. Sta. Bul. 187:77, 80. 1901. 13. Wa ugh Plum Cult. 227. 1901. 14. U. S. D. A. Rpt. 387. 1901. 15. Ga. Sta. Bul. 68:13, Pl. IV, 37. 1905. 16. Md. Hort. Soc. Rpt. 85. 1905. 17. Am. Pom. Soc. Rpt. on Plums etc. 65. 1905.

Eureka 5. Perfection 1, 2. Perfection 4, 14.

It is difficult to estimate the value of Wickson in American pomology. Probably no plum of recent introduction has been on the one hand so highly lauded and on the other so condemned as this one. Its remarkable size, the largest of the Oriental plums if not the largest of all plums; its handsome color and distinct form; the firm flesh and peculiar flavor, generally considered pleasant; the narrow upright tree with its long lanceolate leaves, mark the variety as a new and for some parts of the country a valuable addition to pomology. The contradictory evidence as to its desirability arises from the fact that it can be well grown in comparatively few plum-growing regions, most of these being on the Pacific Coast and in the South. In New York, the Wickson has small value other than in private collections. The variety is a little tender in tree and bud, hardy only in favored parts of this State and not at all where the peach cannot be grown; it blooms too early to be safe from frost; it is susceptible to brown-rot; the trees are late in coming in bearing and are not reliable in fruiting; the fruits ripen unevenly; and the trees are not of good form for heavy crops. In California, however, the Wickson is one of the leading Japanese sorts, possibly the leading one, and is seemingly growing in favor. Starnes, one of the pomological authorities of the South, in his bulletin on Fapan and Hybrid Plums, speaks of Wickson as a "grand plum " and as one of the best for Georgia. It is to be hoped that from the same cross which produced Wickson or from breeding this variety with some other, a plum of this type well suited to New York may sometime be offered the plum-growers of this State. 


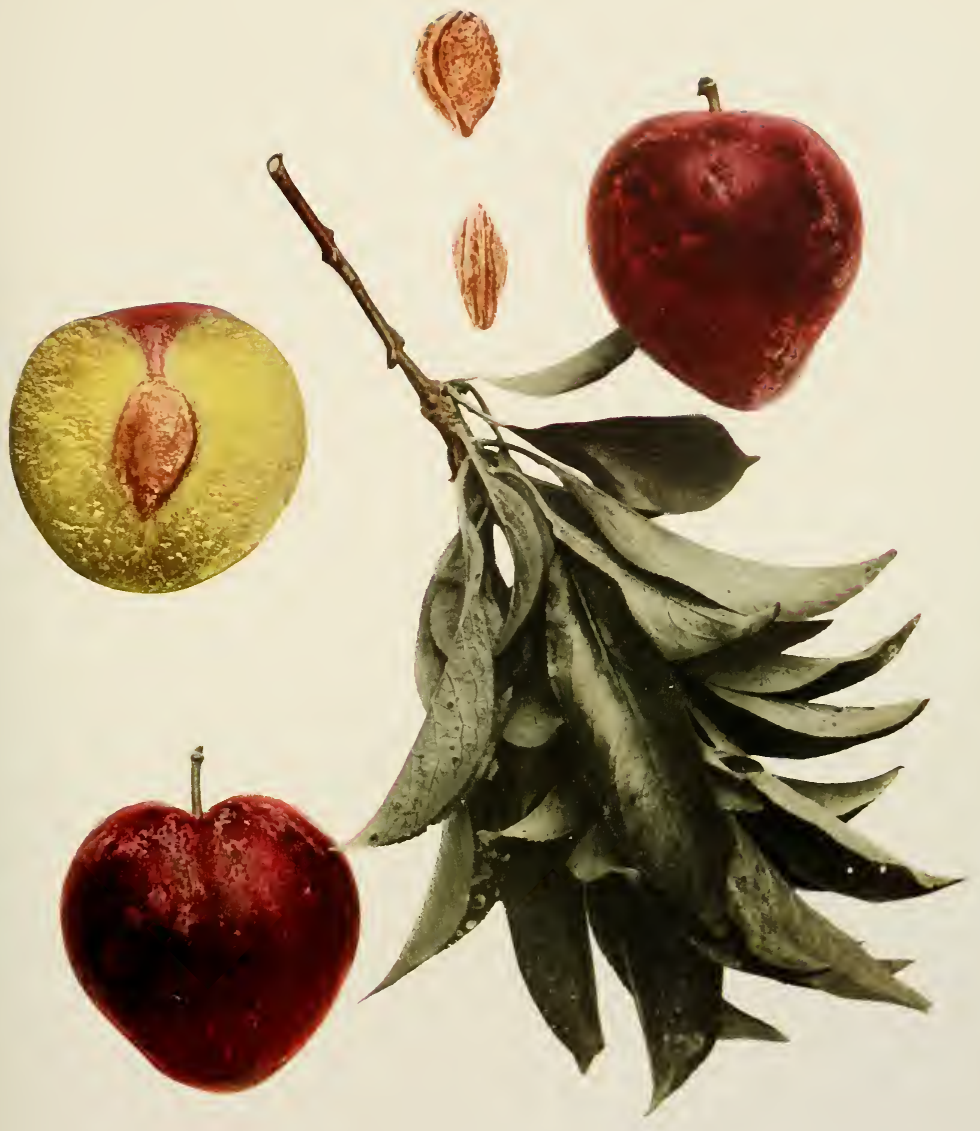



Wickson is one of the best known of Burbank's many plums. The variety was first described in the report of the Secretary of Agriculture in 1892 under the name Perfection and as a seedling of Kelsey crossed by Burbank. In 1893 and 1894 Burbank offered for sale the control and the stock of this variety but found no buyers and in 1895 introduced it himself. The parentage of the variety is in doubt. Burbank considered it a Kelsey-Burbank cross; the Pacific Rural Press described it as offspring of Kelsey and Satsuma; Bailey, Waugh and the workers at this Station believe it to have Prumus simonii characters. The foliage, flowers, the tree, the fruiting habit, the texture of the flesh, all indicate Simon as one of its parents. According to the report of the Secretary of the California State Board of Horticulture shipments of this plum were made to New York in the season of 1897 under the name of Eureka. In 1899 it was placed on the fruit catalog list of the American Pomological Society.

Tree medium to large, vigorous, with narrow, upright head, dense-topped, tender to cold, an uncertain bearer; branches medium in smoothness, the fruit-spurs numerous, dark ash-gray with tinge of brown, with lenticels of medium size; branchlets thick and long, with short internodes, greenish-red changing to light chocolate-brown, glossy, glabrous; lenticels numerous, raised, variable in size; leaf-buds small, short, obtuse, free.

Leaves folded upward, lanceolate or oblanceolate, one inch wide, three inches long, thin; upper surface dark green, glossy, glabrous, with a slightly grooved midrib; lower surface pale green, glabrous, except along the midrib; apex taper-pointed, base cuneate, margin finely serrate, with reddish glands; petiole three-eighths inch long, lightly pubcscent along one side, faintly tinged red, glandless or with from one to nine small, reniform, greenish or yellow glands variable in position.

Blooming season early and of medium length; flowers appearing after the leaves, intermediate in size, white; borne in clusters on lateral spurs, in pairs or in threes; pedicels of medium length and thickness, glabrous, greenish; calyx-tube green, obconic, glabrous; calyx-lobes acute, erect, glandular-ciliate; petals oval, entire, short-clawed; anthers yellowish; filaments below medium in length; pistil glabrous, longer than the stamens.

Fruit early mid-season, period of ripening long; variable in size, the larger fruits about two and one-eighth inches in diameter, obliquely cordate, halves unequal; cavity dcep, abrupt, with yellowish concentric rings; suture often prominent and deep, with a prolonged tip at the apex; color dark red over a yellow ground, indistinctly splashed with darker red, mottled with thin bloom; dots numerous, small, yellow, inconspicuous, densely clustered about the apex; stem thick, eleven-sixteenths inch long, glabrous; skin thin, tender, separating easily; flesh amber-yellow, juicy, coarse, somewhat fibrous, firm, sweet, pleasant but not high in flavor; good; stone clinging, one inch by five-eighths inch in size, oval or ovate, pointed, with pitted surfaces; ventral suture winged; dorsal suture grooved. 


\section{WILD GOOSE}

\section{Prunus munsoniana}

I. Gard. Mon. 9:105. 1867. 2. Am. Jour. Hort. 5:147. 1869. 3. Am. Pom. Soc. Rpt. 60. 1869. 4. Am. Hort. An. 78. 1870. 5. Country Gent. 35:166. 1870. 6. Am. Pom. Soc. Rpt. I16. 1871. 7. Ibid. 44. 1875. 8. Am. Pom. Soc. Cat. 36. 1875. 9. Am. Pom. Soc. Rpt. 152, 153 , 154. 1883. 10. Mathieu Nom. Pom. 454. 1889. I1. Cornell Sta. Bul. 38:51, fig. 3, 86. 1892. 12. Tex. Sta. Bul. 32:482, fig. 4. 1894. 13. Vt. Sta. An. Rpt. x0:99, 104. 1897. 14. Wis. Sta. Bul. 63:24, 63 fig. 31. 1897. 15. Ala. Col. Sta. Bul. 112:178. 1900. 16. Waugh Plum Cull. 189, 190. 1901. 17. Ga. Sta. Bul. 67:284. 1904. 18. S. Dak. Sta. Bul. 93:42. 1905. 19. Ohio Sta. Bul. $162: 258$. 1905 .

Nolen Plum 10. Swwanee 9. Suwanee ?16.

Wild Goose is the first of the native plums to be generally grown as a distinct variety though Miner was first known and named. Wild Goose, too, is probably a parent of more sorts than any other variety of the several cultivated native species, most of its offspring so strongly resembling it that its name has been given to a group of its closely related sorts. In spite of the great number of native plums that have been introduced in recent years, Wild Goose is still a favorite-probably more trees of it are now cultivated than of any other native plum. Its good qualities are: bright attractive color; tender and melting flesh with a sprightly and refreshing flavor; a tough skin which fits the variety well for shipment and long-keeping; comparative freedom from brown-rot and curculio and a large, hardy, healthy and, when cross-pollinated, a very productive tree. Wild Goose has been more extensively planted in New York than any other plum of its kind and in a few cases has proved a fairly profitable commercial sort. It is doubtful if it is now the best of its species for this State but it can at least be recommended for home plantings and in some localities as a market plum. Wherever planted there should be some other native sort blooming at the same time for cross-pollination.

The following account of the origin of this variety, more romantic than credible, is told with several variations. About I820, M. E. McCance, who lived near Nashville, Tennessee, shot a wild goose on his farm; his wife, in dressing the goose, found a plum seed in the craw, which, planted in the garden, produced the Wild Goose tree. The merits of the new fruit seem to have been discovered by' J. S. Downer, Fairview, Kentuckv, and James Harvey of Columbia, Tennessee. The former propagated, named and began the dissemination of Wild Goose to fruit-growers. Many varieties have been sent out for this plum and much confusion has arisen as to what the true variety is. Since the characters of Wild Goose, even when cross-pollinated, are transmitted to its offspring to a remarkable degree, the name now applies to a class of plums rather than to a variety. The 


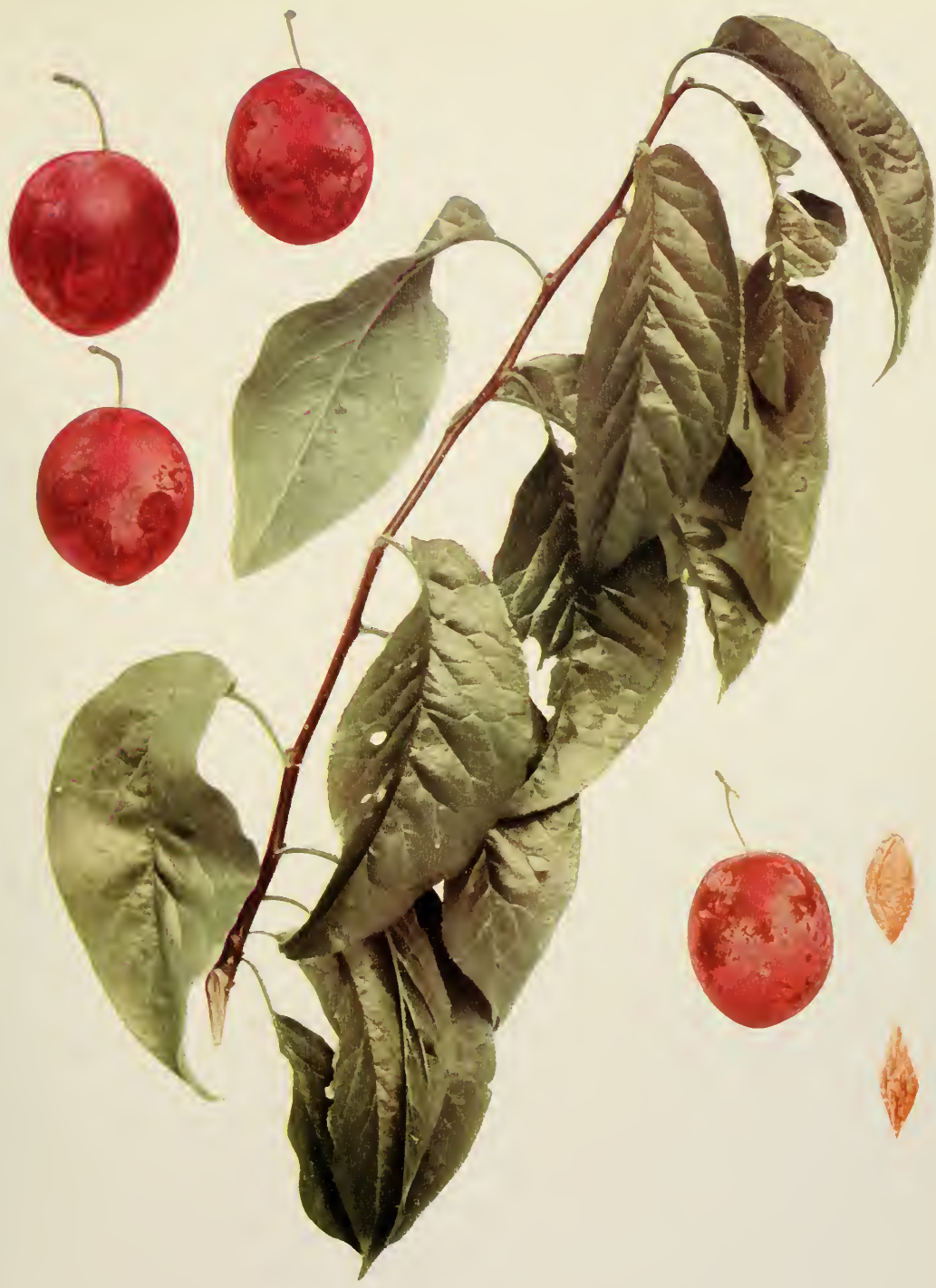



American Pomological Society placed this variety on the fruit catalog list of the Society in 1875 , dropped it in 1891 , and replaced it in 1897.

Tree very large and vigorous, wide-spreading, flat-topped, hardy in New York, productive; branches rough and shaggy, dark ash-gray, with numerous, large, elongated lenticels; branchlets slender, long, with internodes of medium length, greenish-red changing to dull reddish-brown, glossy, glabrous, with many, conspicuous, large, raised lenticels; leaf-buds small, short, obtuse, free.

Leaves folded upward, lanceolate, peach-like, four and one-quarter inches long, one and one-half inches wide, thin; upper surface light or dark green changing to reddish late in the season, smooth, glabrous, with a grooved midrib; lower surface pale green, glabrous except along the midrib and larger veins; apex taper-pointed, base abrupt, margin finely serrate, with small, reddish-black glands; petiole five-eighths inch long, slender, pubescent along one side, tinged red, glandless or with from one to six globose, yellow or reddish-brown glands on the stalk and base of the leaf.

Blooming season late and long; flowers appearing after the leaves, three-quarters inch across, white, with disagreeable odor; borne in clusters on lateral buds and spurs, in threes or fours; pedicels five-eighths inch long, slender, glabrous, green; calyx-tube greenish, narrowly campanulate; calyx-lobes narrow, glabrous on the outer surface, lightly pubescent within, entire, heavily pubescent and with reddish glands on the margin, erect; petals ovate, entire, long and narrowly clawed; anthers yellow, with a tinge of red; filaments five-sixteenths inch long; pistil glabrous, equal to the stamens in length.

Fruit very early, season of medium length; one and three-eighths inches by one and three-sixteenths inches in size, oval, halves equal; cavity small, narrow, shallow, rather abrupt; suture an indistinct line; apex roundish or pointed; color bright red, with thin bloom; dots few in number, light russet, somewhat conspicuous, clustered about the apex; the stem attached to a stem-like growth from the fruit-spurs gives the appearance on the tree of a jointed stem, very slender, three-quarters inch long, glabrous, not adhering well to the fruit; skin tough, slightly astringent, separating readily; flesh yellowish, very juicy and fibrous, tender and melting, sweet next the skin but sour at the center, sprightly; fair to good; stone adhering, seven-eighths inch by three-eighths inch in size, long and narrow-oval, flattened, slightly necked at the base, acute at the apex, roughened; ventral suture wide, blunt, ridged; dorsal suture acute or with a shallow, indistinct groove.

\section{WILLARD}

\section{Prunus triflora}

I. Ohio Hort. Soc. Rpt. 81. 1893. 2. Cornell Sta. Bul. 62:31. 1894. 3. Ibid. 106:64. 1896. 4. Ibid. 131:194. 1897. 5. Am. Pom. Soc. Cat. 26. I897. 6. Mich. Sta. Bul. 177:42, 43. I899. 7. Cornell Sta. Bul. 175:134 fig. 27 . 1899. 8. Rural N. Y. 57:515, 530, 595. 1898. 9. Waugh Plum Cult. 140. 1901. 1о. Ga. Sta. Bul. 68:33. 1905. I1. Ill. Hort. Soc. Rpt. 420. 1905.

Botan No. 26 2, 3, 9. Botan 1. Botan No. 26 r. Willard Plum I. Willard Japan 8. 
Willard is about the earliest of the Triflora plums that can be shipped to the markets. When this is said all is said; as the variety has little else to recommend it, being very inferior in quality and having a reputation of being subject to shot-hole fungus. S. D. Willard, Geneva, New York, procured cions of this variety from California about I 888 from an importation made by Burbank from Japan. According to Willard, the plum was received under the name Botan and he labelled it No. 26 to avoid confusion; in 1893 , it was named Willard by W. F. Heikes of the Huntsville Nurseries, Huntsville, Alabama. The American Pomological Society placed the variety on its fruit catalog list in 1897 .

Tree medium to large, vigorous, vasiform, productive; leaves falling early, folded upward, oblanceolate, one and three-eighths inches wide, three and three-quarters inches long, thin, glabrous; margin finely and doubly serrate, with very small glands; petiole three-quarters inch long, with from one to five reniform glands usually on the stalk.

Fruit early, of medium size, roundish or somewhat oblong, blunt at the apex, dark red when well grown, covered with thick bloom; stem short, thick, adhering poorly to the fruit; skin sour; flesh greenish-yellow, rather firm, sweet, low in flavor; poor in quality; stone variable in adhesion, of medium size.

\section{WOLF}

\section{Prunus americana mollis}

x. Ia. Hort. Soc. Rpt. 367.1883 . $\quad$ 2. Rural N. Y. 44:645. 1885. 3. Am. Pom. Soc. Cat. 40. 1889. 4. Cornell Sta. Bul. $38: 45$ fig. 2, 87. 1892. 5. Nich. Sta. Bul. 118:54. 1895. 6. Wis. Sta. Bul. 63:24, 64. 1897. 7. Colo. Sta. Bul. 50:47. 1898. 8. Waugh Plum Cult. 167. 1901. 9. Ga. Sta. Bul. $67: 284$ fig. 1904. Io. S. Dak. Sta. Bul. 93:42. 1905. I1. Ia. Sta. Bul. 114:148 fig. I9io.

Wolf Free 4, 6. Wolf Freestone 11.

Wolf has long maintained a high place among the standard Americana plums, with which it is usually classed though put in a sub-species, and from which it differs chiefly in having much more pubescence on foliage, floral organs and branchlets. It is noted for its great hardiness, reliability in bearing, attractive and well-flavored fruits and in being one of the few freestones of its kind. This plum is remarkably well adapted for the northern part of the Mississippi Valley and there alone it is worth planting extensively. In New York it might prove valuable in the coldest parts of the State where the Domesticas and Insititias cannot be grown.

This variety was raised from a pit of a wild plum planted on the farm of D. B. Wolf, Wapelle County, Iowa, about 1852. Professor J. L. Budd 


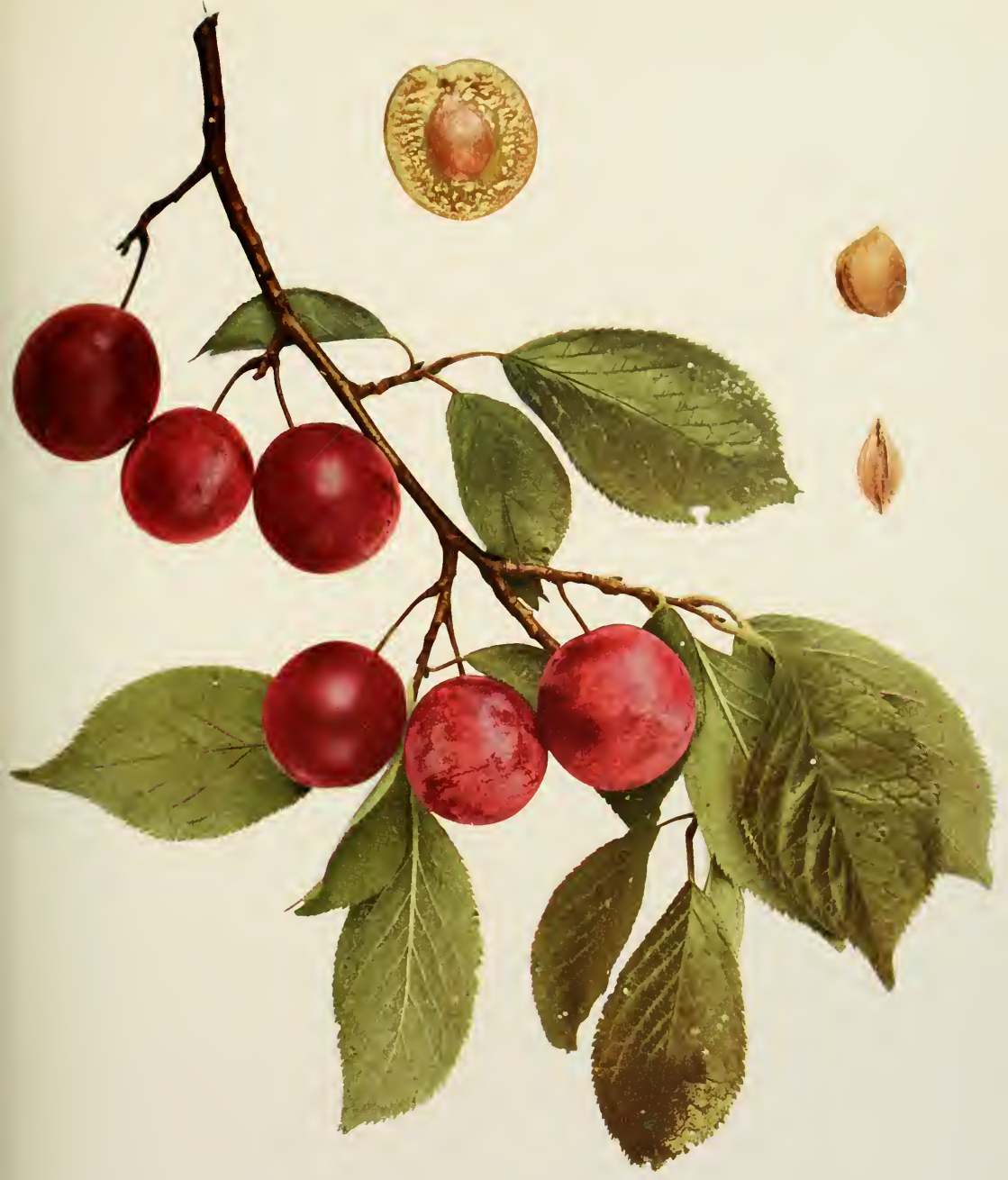



of the Iowa Agricultural College stated in 1885 that for over a quarter of a century the original tree had not failed to produce a partial or large crop annually on the grounds of the originator. A spurious clingstone type of the Wolf has been propagated in some nurseries but this false plum is readily distinguished from the true freestone type. The variety was added to the American Pomological Society fruit catalog list in 1889 , dropped in $189 \mathrm{I}$, and replaced in 1897 .

Tree large, vigorous, spreading, low, and open-topped, hardy, productive, healthy; branches rough and shaggy, thorny, dark ash-gray, with numerous, small lenticels; branchlets somewhat slender, short, twiggy, with internodes below medium in length, green changing to dull brownish-drab, overspread with thick pubescence, with numerous, small lenticels; leaf-buds very small, short, conical, strongly appressed.

Leaves falling early, oval, one and seven-eighths inches wide, three and seveneighths inches long, thin; upper surface medium green, lightly pubescent, with a narrow groove on the midrib; lower surface silvery-green, pubescent; apex taper-pointed, margin coarsely and doubly serrate, eglandular; petiole one-half inch long, velvety, tinged red, glandless or with one or two small, globose, yellowish glands on the stalk or base of the leaf.

Blooming season of average length, late; flowers opening after the leaves, one inch across, the buds tinged yellow changing to white as the flowers expand; borne on lateral buds and spurs; pedicels nine-sixteenths inch long, thickly pubescent, green; calyxtube greenish-red, campanulate, covered with short, fine pubescence; calyx-lobes narrow, acute, heavily pubescent on both surfaces, with few marginal glands, reflexed; petals inclined to curl, long-oval, fringed, long and narrowly clawed; anthers yellowish; filaments three-eighths inch long; pistil sparingly hairy on the ovary, equal to or shorter than the stamens, frequently defective.

Fruit mid-season, ripening period short; less than one inch in diameter, roundishoval or somewhat obovate, compressed, halves equal; cavity frequently yellowish, shallow, narrow, abrupt; suture an indistinct line; apex roundish or flattened; color dull crimson, thickly mottled, overspread with thick bloom; dots numerous, small, russet, inconspicuous; stem slender, glabrous, adhering poorly to the fruit; skin thick, tough, slightly roughened, astringent, adhering; flesh golden-yellow, very juicy, fibrous, tender and melting, sweet next the skin, but astringent toward the center; fair to good; stone semi-free to free, five-eighths inch by three-eighths inch in size, roundish-obovate, tapering at the base, blunt at the apex, with smooth surfaces; ventral suture winged; dorsal suture acute, or with a faint, narrow groove.

\section{WOOD}

\section{Prunus americana}

1. Minn. Hort. Soc. Rpt. 60. 1894. 2. Wis. Sta. Bul. 63:64. 1897. 3. Minn. Hort. Soc. Rpt. 433. 1898. 4. Waugh Plum Cult. 168. 1901. 
Wood is one of the comparatively new Americanas and seems to have considerable merit, especially for cold climates. It is attractive in color; above the average size; good in quality, though not the best of its species; and the trees in habit of growth and in productiveness are better than most Americanas. It is sufficiently early to fit into the short seasons of northern latitudes very well. Wood is one of the sorts that can be recommended for the coldest parts of this State.

This variety, according to a letter from the originator and introducer, Joseph Wood of Windom, Minnesota, is a seedling from a choice plum found growing on the bank of the Des Moines River, Cottonwood County, Minnesota. It was not mentioned in pomological literature previous to 1894 and is of too recent origin to be widely distributed or well known.

Tree of medium size, spreading, hardy, dense-topped, an annual and abundant bearer; trunk shaggy; branches roughish, thorny, zigzag, brownish ash-gray, with numerous, small lenticels; branchlets slender to medium, above the average length, twiggy, with short internodes, greenish-red changing to dark brown, lightly pubescent when young becoming glabrous in the fall, with numerous, conspicuous, large, much raised lenticels; leaf-buds of medium size and length, conical, appressed.

Leaves falling early, ovate, two inches wide, four inches long, thin; upper surface light green, rugose, glabrous, with a narrow groove on the midrib; lower surface silverygreen, pubescent; apex taper-pointed, base abrupt, margin coarsely serrate, with long, taper-pointed teeth, eglandular; petiole five-eighths inch long, slender, tinged red, lightly pubescent, glandless or with one or two small, globose, greenish-red glands on the stalk.

Blooming season intermediate in time and length; flowers appearing after the leaves, eleven-sixteenths inch across, white; borne in clusters on lateral buds and spurs, in threes or fours; pedicels three-eighths inch long, slender, glabrous, green; calyx-tube greenish, narrowly campanulate, glabrous; calyx-lobes narrow, acute, lightly pubescent, occasionally tipped with red, serrate, with many marginal hairs, reflexed; petals oval, notched, tapering at the base to narrow claws of medium length; anthers light yellow; filaments five-sixteenths inch long; pistil glabrous, longer than the stamens, often defective.

Fruit mid-season, ripening period short; one and one-quarter inches in diameter, oblate, compressed, oblique, halves equal; cavity of average depth and width, flaring; suture a line; apex flattened or depressed; color dark red over a yellow ground, mottled, with thin bloom; dots numerous, minute, light russet, inconspicuous; stem one-half inch long, glabrous, detaches from the fruit when ripe; skin thick, tough, sour, adhering; flesh orange-yellow, juicy, coarse, fibrous, tender and melting, sweet, lacking in flavor; fair in quality; stone free, three-quarters inch by five-eighths inch in size, roundish, flattened, slightly oblique, blunt and flattened at the base, roundish at the apex, smooth; ventral suture acute, not ridged; dorsal suture acute, sometimes indistinctly grooved. 


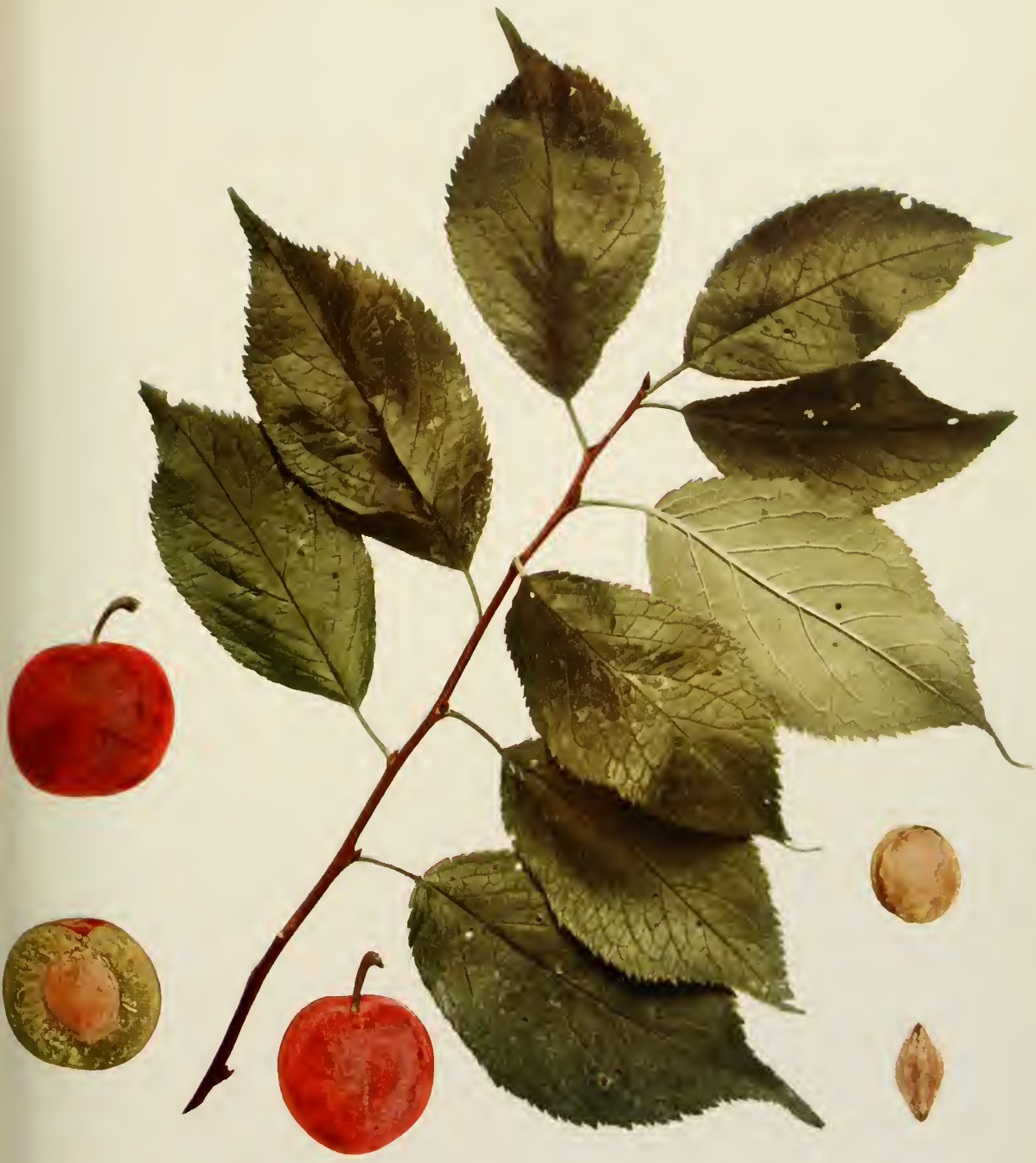





\section{WORLD BEATER}

\section{Prunus hortulania}

1. Cornell Sta. Bul. 38:52. 1892. 2. Wis. Sta. Bul. 63:65. 1897. 3. W. N. Y. Hort. Soc. Rpt. 41:54. 1896. 4. Waugh Plum Cult. 182. 1901.

World Beater is very similar to Wayland, differing chiefly in being a week earlier and, as the color-plate shows, the plums are a little smaller and more oval. In tree-characters, as the two grow at this Station, World Beater is perhaps the better plum. This variety has the same place in pomology as Wayland, a place which it fills possibly a little better. It may be recommended for culinary purposes and as a late plum for regions where the peach is hardy. Plums of this species have small value in New York except for the sake of variety.

World Beater was grown from a seed of a plum found near Nashville, Tennessee, in 1838 , by $\mathrm{J}$. H. Tinsley and planted in Lincoln County, Kentucky. About ten years later trees of the variety were taken to Clay County, Missouri, and were further propagated but the variety remained practically unknown until the fall of 1890 when it was introduced by Stark Brothers of Missouri.

Tree large, vigorous, spreading, open and flat-topped, hardy where the peach can be grown, productive; branches rough and shaggy, somewhat thorny, dark ash-gray, with numerous, large lenticels; branchlets medium to above in thickness and length, twiggy, with internodes of average length, green changing to dark chestnut-red, glossy, glabrous, with few, conspicuous, large, raised lenticels; leaf-buds very small and short, obtuse, plump, appressed.

Leaves folded upward, broadly lanceolate, peach-like, one and three-quarters inches wide, four and one-half inches long, thin; upper surface smooth, glossy, with a shallow groove on the midrib; lower surface pubescent on the midrib and larger veins; apex acuminate, base abrupt, margin serrate, glandular; petiole one inch long, slender, tinged red, pubescent on one side, with from two to six small, globose, brownish glands scattered on the stalk or base of the leaf.

Blooming season late and long; flowers appearing after the leaves, three-quarters inch across, white, with a disagreeable odor; borne in clusters from lateral buds, in twos, threes or fours; pedicels three-quarters inch long, very slender, glabrous, green; calyx-tube greenish, campanulate, glabrous; calyx-lobes narrow, acuminate, slightly pubescent towards the base of the inner surface, serrate and with reddish glands, erect; petals ovate, crenate, fringed, with pubescent claws of medium width; anthers yellowish; filaments five-sixteenths inch long; pistil glabrous, equal to the stamens in length.

Fruit very late, season short; one inch by seven-eighths inch in size, roundish-ovate or oval, not compressed, halves equal; cavity narrow, shallow, rather abrupt; suture a 
line; apex pointed; color carmine, bloomless; dots medium in number, small, whitish or sometimes reddish, somewhat conspicuous; stem slender, medium to above in length, glabrous, not adhering to the fruit; skin thick, tough, astringent, adhering slightly; flesh light yellow, juicy, coarse, melting near the skin but firmer and fibrous next the pit, sweet except near the center, strongly aromatic; fair to good; stone often tinged red, adhering, three-quarters inch by three-eighths inch in size, oval, turgid, angular, pointed at the base and apex, roughish; ventral suture wide, blunt, ridged; dorsal suture acute or with an indistinct, shallow groove.

\section{WYANT}

\section{Prunus americana}

x. Ia. Hort. Soc. Rpt. 327. 1885. 2. Ibid. 85. 189o. 3. Cornell Sta. Bul. 38:46. 1892. . 4. Ia. Hort. Soc. Rpt. 448. I893. 5. Ia. Sta. Bul. 31:345. 1895. 6. Kan. Sta. Bul. 73:192. 1897 . 7. Wis. Sta. Bul. 63:24, 65 fig. 32, 66. 1897. 8. Am. Pom. Soc. Cat. 24. 1897. 9. Colo. Sta. Bul. 50:47. 1898. 10. Ia. Sta. Bul. 46:292. 1900. xx. Waugh Plum Cult. 167 fig., 168. 1901. x2. Can. Exp. Farm Bul. 43:32, 1903. 13. Ga. Sta. Bul. 67:284, 285 fig. 1904. 14. S. Dak. Sta. Bul. $93: 44,49$ fig. 1905 .

Wyant is one of the standard Americana plums, ranking well with the best of them in both fruit and tree-characters. While it is almost beyond question a true Americana (from its history it could hardly be otherwise,) it has a number of characters that mark it as a departure from the usual type of Prunus americana. The calyx-tube is bright red, a character found only in a few other varieties of this species; the stamens are much longer than is usual in the species and much more numerous; the pistils are often defective; the flowers are borne in greater profusion; the plums do not have the distinctive Americana taste; the flesh is less juicy than usual; the skin is free and the stones are nearly free and have pitted surfaces. Some of these characters are so valuable in a native plum that Wyant may well be used to breed from. The trees from which the description here given was made came from C. L. Watrous, Des Moines, Iowa, and to the best of our belief are true to name.

This variety, according to a letter from J. E. Wyant, Shellsburg, Iowa, was found by J. B. Wyant of Janesville, Iowa, while hunting for wild plums in 1866 on the Cedar River near his home. The following year he transplanted the tree to his yard. About $1874, \mathrm{~J}$. E. Wyant told R. Royce of Shellsburg, Iowa, proprietor of the Benton County Nursery, of this tree. Royce secured cuttings from the original tree and began propagating the plum. Fruits were sent to Professor J. L. Budd, Ames, Iowa, who named it Wyant. The variety was introduced by Mr. Royce 


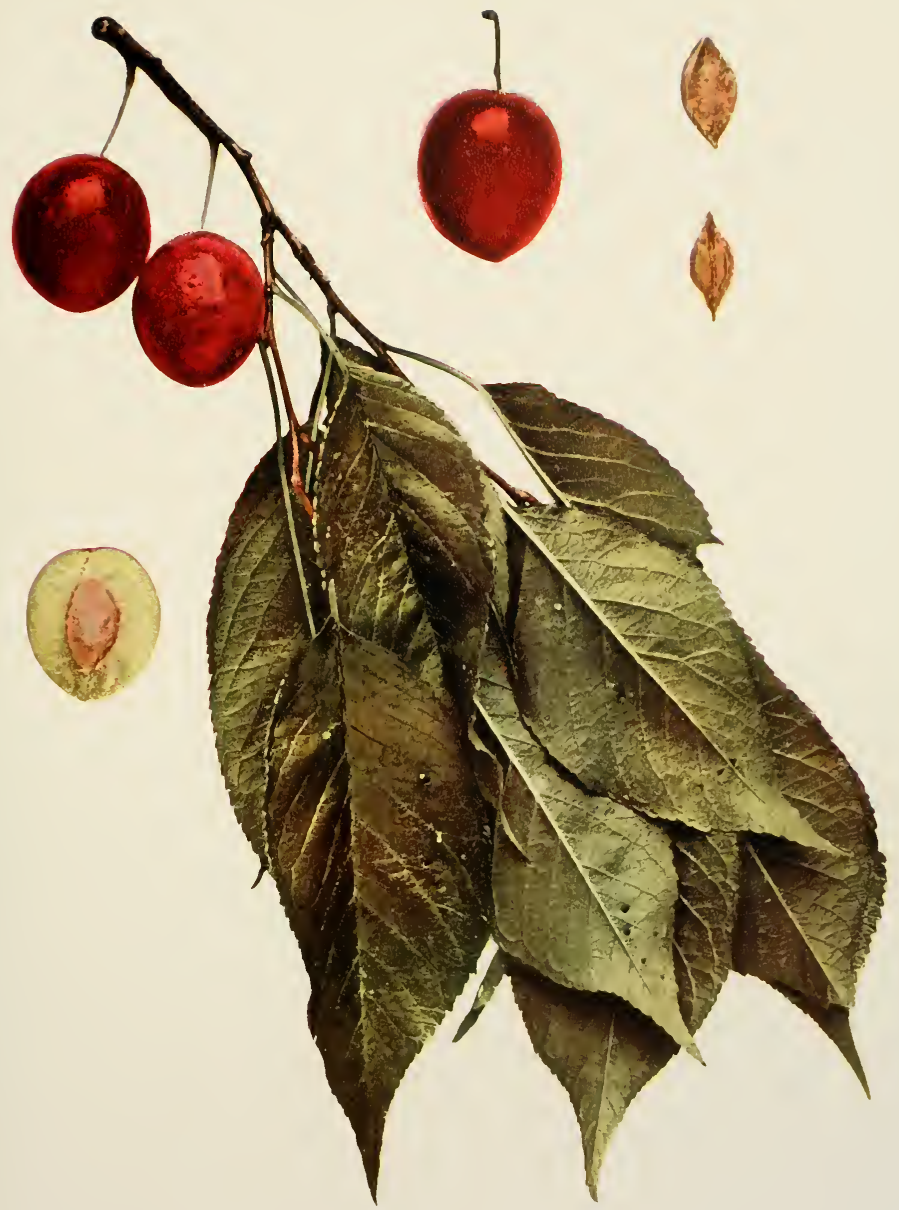



and was disseminated by him and by Professor Budd. In 1897 it was added to the fruit catalog list of the American Pomological Society.

Tree small, spreading and straggling, flat-topped, very hardy, productive, healthy; branches rough and shaggy, zigzag, thorny, dark ash-gray, with numerous, large lenticels; branchlets willowy, slender, long, with long internodes, greenish-red changing to reddishbrown, glossy, glabrous, with conspicuous, raised lenticels of average sizc and number; leaf-buds small, pointed, strongly appressed.

Leaves falling early, folded upward, oval, one and five-cighths inches wide, three and one-quarter inches long, thin; upper surface green, smooth, glabrous, grooved on the midrib and larger veins; lower surface silvery-green, lightly pubescent; apex acuminate, base abrupt, margin coarsely and doubly serrate, the serrations sharp-pointed, not glandular; petiole one-half inch long, tinged red, pubescent, glandless or with from one to five globose, yellowish-green glands on the stalk.

Blooming season medium to late, of average length; flowers appearing with the leaves, showy on account of the many blossoms and peculiar appearance caused by the numerous long stamens, whitish, with disagreeable odor; borne in dense clusters on lateral buds and spurs, one to four flowers in each cluster; pedicels one-half inch long, slender, glabrous, green, faintly tinged with red; calyx-tube red, obconic, glabrous; calyx-lobes narrow, acute, lightly pubescent on the inner surface, serrate and with numerous marginal hairs, erect; petals small, narrow-ovate, crenate, with narrow, long claws; stamens very numerous; anthers yellowish; filaments three-eighths inch long; pistil slender, glabrous, shorter than the stamens, often defective.

Fruit mid-season, ripening period short; one and one-quarter inches in diameter, not symmetrical in shape, oblong-obovate to nearly ovate, oblique, somewhat truncate, halves equal; cavity shallow, narrow, flaring; suture a line; apex slightly flattened; color dark carmine over a yellow ground which largely disappears as maturity advances, with thin bloom; dots numerous, very small, light russet, inconspicuous; stem slender, one-half inch long, glabrous, dehiscent; skin thin, tender, separating readily; flesh dark golden-yellow, juicy, tender and melting, sweet, with the Americana flavor less marked than in other varieties; of fair quality; stone nearly free, seven-eighths inch by five-eighths inch in size, broadly oval, flattened, blunt at the base, somewhat pointed at the apex, with pitted, dark colored surfaces; ventral suture blunt or slightly winged, shallowly ridged; dorsal suture acute, with shallow, narrow, distinct groove.

\section{YELLOW EGG}

\section{Prunus domestica}

I. Rea Flora 209. 1676. 2. Ray Hist. Plant. 2:1528, 1529. 1688. 3. Langley Pomona 95, P1. XXV fig. VI. 1729. 4. Miller Gard. Dict. 3. 1754. 5. Duhamel Trait. Arb, Fr. 2:107, P1. XX fig. 10. 1768. 6. Knoop Fructologie 2:59. 177 1. 7. Kraft Pom. Aust. 2:29, Tab. 175 fig. 1; 38 , Tab. 188 fig. 1. 1796. 8. Forsyth Treat. Fr. Trees 20, 21. 1803. 9. Coxe Cult. Fr. Trees 233 , fig. 8. 1817. 1o. Lond. Hort. Soc. Cat. 149. 1831. I1. Prince Pom. Man. 2:57, 58, 1832.12. Kenrick Am. Orch. $258,269 . \quad 1832$. 13. Floy-Lindley Guide Orch. Gard. 299, 301. 1846. 14. Poi- 
teau Pom. Franc. I: fig. 1846. 15. Thomas Am. Fruit Cult. 333. 1849. 16. Elliott Fr. Book 424. 1854. 17. Thompson Gard. Ass't 520. 1859. 18. Am. Pom. Soc. Cat. 88. 1862. I9. Downing Fr. Trees Am. 954 fig. 1869. 20. Pom. France 7:No, 18, 1871. 21. Koch Deut. Obst. 560. 1876. 22. Hogg Fruit Man. 730. 1884. 23. Mathieu Nom. Pom. 431. 1889. 24. Fell Cat. 49. 1893. 25. Guide Prat. 163, 354. 1895. 26. Corncll Sta. Bul. 131:193. 1897.

Aechte Gelbe Eierpflaumc 25. Albert's Damascene 23, 25. Alberius Damen Pfaume 20, 23, 2.5 Askew's Goldon 20. Askew's Golden Egg 16, 19, 22, 23, 25. Aubcriana 21. Bonum Magnum I1, 20, 22, 23, 25. Bonum Magnum 1, 2. Col. Young's Secdling 16. Dame Aubert 10, I 1, I3, I 7, I9, 22, 23, 25. Dame Ambert 16. Dame Aubert 5, 12. Damas Aubert 7, 23, 25. Dame Aubert Blanche 10, 17, 19, 20, 22, 23, 25. Dame Ambert Blanche 16. Dame Aubert Grosse Luisante 11. Dame Ambert Jaune 16. Dame Aubert Jaune 10, 11, 17, 19, 20, 23. Darwin Peach 24. Die Alberius Damenpflaumc 7. De Besançon 25. De Monsieur 25 incor. Die Grosse Weisse Glanzende 7. Die Kaiserliche Weisse Pflaume ?7. D'OEuf 25. D'OEuf Blanche 25. Dutch Plum 1, I1. Dutch Plumb 3. Echte Gelbe Eicr Pfaume 23. Edle Gelbe Eger Pfaume 20. Edle Gelbe Eier Pfaume 23, 25. Egg Plum 4, 8, 9, 10, I1, 12, 13, 16, 17, 19, 20, 22, 23, 25. Eier Pfaume 23, 25. Gelbe Egcr Pflaume 20, 23, 25. Gelbe Egg 20, 23, 25. Gclbe Malonke 23, 25. Gelbe Ungarische Eicr Pfaume 23, 25. Gelbe Marunke 23, 25. Gelbe Eierpflaume 23. Gelbe Eierpflaume 20, 25. Grosse Weisse Glanzende 20, 23, 25. Great Mlogul ?2. Grosse Datte ?5. Grosse-Luisante 5, 7, 10, 11, 13, 14, 16, 17, 19, 20, 22, 23, 25. Gros Luisante 12. Gelbe Ungarische Eyerpflaume 20. Grosse Prune Blanche 20, 23, 25. Grosse Maronke 25. Grosse Marouk 20, 23, 25. Grosse Glanzende Alberts Pfaume 23, 25. Grosse Glanzende 20, 25. Grosse Glanzende Pfaume 23. Grosse Gelbe Eier Pflaume $23,25$. Grosse Marunke 23. Grunliche Dattel Pflaume von Besançon 23, 25. Hick's large Egg? I I. Impériale Blanche ?5. Impiriale Blanche?7, 10, 11, 12, 13, 17, 19, 20, 22, ?23, 25. Imperial Blanc I1. Large Yellow Egg 11. Magnum Bonum 19. Monsieur's Plum ?4, ?8. Monsieur's Plum ?4. Mogul 9. Monsieur 11. Mogul 4, 8, 11, 23. Mogul Plum 25. Mogule Plumb 3. Mogule ir. Mogol Plum 20, 23, 25. Mogols Pfaume 20, 23, 25. Mogul's Pflaume 23, 25. Prune de Mlonsieur? 4, 6. Prune de Monsieur 23 incor. Prune OEuf 20. Prune Dame Aubert 14, 20. Pruned'Oeuf 20, 23. Prune d'Oeuf blanche 6, 23. Prune d'Inde Blanc 19. Prune De Besançon 20, 23. Prune Dame d'Aubert 21. Prune d'Inde Blanche 23. Supreme ?14. Wentworth 13 . Wentworth ?8, 10, 11, 12, 16, 17, 19, 23, 25. Wentworth Plumb ?3. White Imperial 9, II, 15, 16, 19, 23. White Imperial II. White Imperial Bonum Magnum 4, 8. White Holland 3, 4, 8, 10, 11 , 12, 16, 17, 19, 23, 25. White Magnum Bonum 9, 11, 13, 15, 16, 19, 20, 23, 25. Weisse Kaiser Pflaume 23, 25. Weisse Hollandische Pflaume 23, 25. White Bonum Magnum 3, 11, 20, 23, 25. White Egg Plum I1. White Magnum Bonum 10, 12, I 7, 18, 22, 23. White Mogul 10, 12, 13, 16, 19, 20, 22, 23, 25. White Egg 15. White Egg 16, 19, 23, 25. Weisser Kaiscr 23, 25. Weisse Magnum Bonum 20, 23, 25. Weisse Kaiserin 23 incor. Yellow Magnum Bonum 10, 15, 16, 17, 18, 19, 22, 23, 25. Yellow Bonum Magnum 20, 23, 25. Young's Superior Egg ?11. Yellow Egg 18, 23, 25.

The characters of Yellow Egg were given in the discussion of the group which bears its name and but little more needs to be said of the variety. As the largest and handsomest of the yellow plums it is worth consideration by either the amateur or the commercial fruit-grower in New York. At best. however, it is fit only for cooking and is none too good for culinary purposes. The trees are very satisfactory on all but very light soils. As has been suggested before, this plum ought to be crossed with varieties of better quality with the hope of getting as handsome a fruit but one which could be used for dessert purposes. 


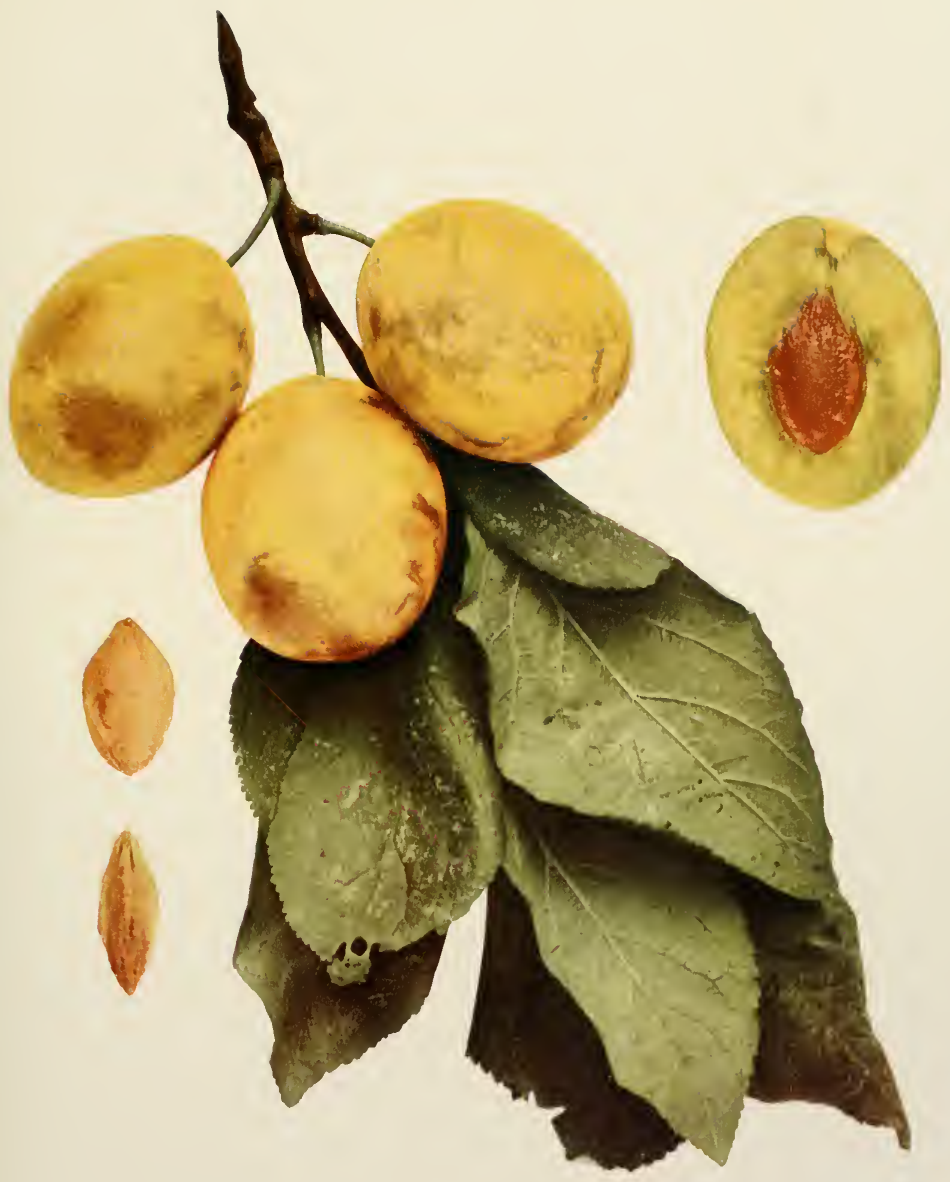



The references and synonyms show that Yellow Egg is a plum with an interesting history, but unfortunately the accounts of its origin and subsequent history have been but poorly preserved. Rea, in 1676 , described the Yellow Egg as the Bonum Magnum or Dutch Plum; we may infer from this that the English obtained the variety from Holland. Knoop of Holland, in $177 \mathrm{I}$, described the variety under the name Prune d'Oeuf Blanche, indicating a French origin. Knoop describes the Prune De Monsieur as similar and this plum has ever since been held as doubtfully identical. Duhamel, in Traite des Arbres Fruitiers, 1768, described Yellow Egg as the Dame Aubert. Kraft in Pomona Austriaca, 1796, gave it as the Die Grosse Weisse Glanzende, oder Die Albertus Damenpflaume. These references show that Yellow Egg was well known at an early date. Because of its close resemblance to many varieties, probably due to the propagation of seedlings from it, much confusion exists in the nomenclature of Yellow Egg. White Imperial was separated by Duhamel and Prince; but Miller, Thompson and most of the subsequent writers give it as the same. Duhamel believed the Imperial Blanche (White Imperial) to be the Grosse Datte. So, too, the Wentworth was at first separated but, later, was recorded as identical. Koch calls Yellow Egg one of the Datterpflaumen (Date Plums) though he states that there is another Date Plum known by Tragus more than three hundred years ago as Prunidactyla. De Candolle seems to hold to the names Dame d'Aubert and Aubertina for this plum. Professor Budd in exploring southwest Russia and Poland found a Dame Aubert differing from our Yellow Egg only in minor characters which he was told came from central Asia.

The exact date of the importation of Yellow Egg to this country is unknown. Coxe, in 1817 , described it as the Mogul and later Prince gave it the name Yellow Egg. Owing to this change in name, we find America now and then given as its place of origin by both American and English writers. In 1862 , the American Pomological Society added it to its fruit catalog list under the name White Magnum Bonum but in 1871 , the name was changed to Yellow Egg. The Darwin Peach, sent out by Fell, a nurseryman in England, has proved to be identical at this Station and its distributor, in a recent letter, states that this plum, which has been growing on his place thirty years, " is apparently identical to the White Magnum Bonum" which is of course Yellow Egg.

Tree, large, vigorous, round-topped, open, hardy, very productive; trunk roughish; branches numerous, ash-gray, nearly smooth, with rather large lenticels; branchlets 
slender, short, with long internodes, greenish-red changing to dull brownish-red, dull, lightly pubescent throughout the season, covered with thin bloom, with few, inconspicuous, small lenticels; leaf-buds above medium in size, long, pointed, free.

Leaves flattened or somewhat folded backward, oval, two and one-half inches wide, four and one-quarter inches long, leathery; upper surface dark green, pubescent, slightly rugose, with grooved midrib; lower surface medium green, thickly pubescent; apex abruptly pointed or acute, base acute, margin doubly serratc, with few dark glands; petiole five-eighths inch long, thick, reddish-purple, pubescent, glandless or with one or two globose, yellowish-green glands variable in position.

Blooming season short; flowers appearing after the leaves, one inch across, white, with a yellowish tinge at the tip of the petals; borne on lateral buds and spurs, singly or in pairs; pedicels one-half inch long, covered with thick pubescence, greenish; calyxtube green, campanulate, pubescent; calyx-lobes broad, obtuse, pubescent, glandularserrate, reflexed; petals roundish-oval, crenate or sometimes slightly notched, tapering to short, broad claws; anthers yellow; filaments three-eighths inch long; pistil pubescent, longer than the stamens; stigma oblique.

Fruit late, season short; two inches by one and five-eighths inches in size, longoval, compressed, halves nearly equal; cavity of medium depth, narrow, abrupt; suture shallow, often a line; apex roundish; color golden-yellow, covered with thick bloom; dots numerous, small, white, inconspicuous; stem slender, one and one-quarter inches long, pubescent, adhering well to the fruit, surrounded at the cavity by a fleshy collar; skin thin, slightly astringent, scparating readily; flesh golden-yellow, rather juicy, moderately coarse, firm, of average sweetness, mild; good; stone semi-free or free, one and one-quarter inches by three-quarters inch in size, oval, rather flat, acute at the base and apex, with roughened and pitted surfaces; ventral suture wide, heavily ridged, often distinctly winged; dorsal suture widely and deeply grooved.

\section{YELLOW GAGE}

\section{Prunus domestica}

x. Prince Treat. Hort. 25. 1828. 2. Prince Pom. Man, 2:108. 1832. 3. Downing Fr. Trees Am. 287,288 fig. II 5. I 845 . 4. Thomas Am. Fruit Cult. 329. 1849. 5. Cole Am. Fr. Book 208 fig. 1849. 6. Horticulturisl 7:403. 1852. 7. Am. Pom. Soc. Rpt. 36, 55. 1852. 8. Elliott Fr. Book 414. I854. 9. Am. Pom. Soc. Rpt. 2 10. 1856. ro. Bridgeman Gard. Ass't 3:126. I857. 11. U. S. Pat. Off. Rpt. 190, P1. XIII. 1865. 12. Mas Pom. Gen, 2:163, fig. 82. 1873. 13. Barry Fr. Garden 4I7. 1883. 14. Mathieu Nom. Pom. 443. 1889. 15. Waugh Plun Cult. I26. I9or.

American Wheat ro. American Yellow Gage of some 3, 4, 8, 11, I4. American Yellow Gage 10. Auserlesene Gelbe Reine-Claude i4. Harvest Gage 6, 8, II, I4. Prince's Gage I. Prince's Gelbe

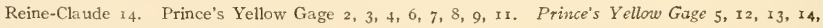
15. Reine-Claude Jaune De Prince I2. IWhite Gage of some 3, 8, Ir, I4.

Yellow Gage belongs to the Reine Claude, or as it is so often called, the Green Gage group of plums. There are now a great number of these plums under cultivation in America, most of which have origmated in this country and nearly all of which, as we have said before, are better 
than similar kinds from Europe. It is difficult to select from the numerous first-rate plums of this group the best varieties to retain in home or commercial orchards. Among these, however, Yellow Gage should be kept for the home orchard at least. It is a rather large fruit, with a beautiful color-golden-yellow often with a faint blush, with a firm and juicy yet tender flesh and a most refreshing admixture of sweet and sour together with the richness which characterizes the Reine Claude plums. The fruits come, too, at a time when the market is not overstocked with these fine plums and the season is particularly long. A review of the treecharacters in the description which follows shows that in the main they are good though some complain that the variety is not productive. This precariousness in bearing, together with the tender skin which keeps Yellow Gage from standing shipment well, probably precludes the variety from a high place in a commercial list but does not prevent its being a most desirable plum for home planting.

This excellent old variety was probably one of the first plums to originate in America. It came from a Reine Claude pit planted, with many others, by William Prince ${ }^{1}$ in ${ }_{1} 783$ in the celebrated Prince nurseries at Flushing, Long Island. Despite its early origin and fine qualities it has never had

1 William Prince, born in 1725 , was the second proprietor of the famous Prince nursery at Flushing, Long Island, a nursery established by his father, Robert Prince, about $173^{\circ}$. The first of the American Princes was one of the Huguenots who settled at New Rochelle and on the north shore of Long Island, bringing with them a great number of French fruits and the love of the French people for horticulture. The nursery, one of the first, and certainly the most important one in America at this time, grew rapidly until the Revolutionary War. The establishment was of such public importance that during a part of the war the British placed a guard over it to protect it from depredation. With the establishment of peace came an increased trade and the nursery soon attained even greater prominence than before the war. An effort was made by William Prince, then in charge, to import all of the valuable European fruits beside which he grew many seedlings, selecting carefully from them new varieties. Thus in 1790 twenty-five quarts of Reine Claude plum pits were planted from which came Yellow Gage, Imperial Gage and probably the Washington plum. Prince died ir 1802 , his business having been divided between two sons; Benjamin Prince keeping the original place under the name The Old American Nursery and William Prince occupying a new place called the Linnean Botanic Garden and Nursery. William Prince seems not to have had the inclination to write as did his son and grandson but had, even more than they, business energy. His European exportations and importations made his name famous in horticulture abroad as well as at home. To him Americans owe the introduction of many varieties of foreign fruits and omamental plants; his was the first of the great nurseries of the country, soon to be followed by others, to import and exchange plants with foreign countries; his is the first recorded attempt to breed fruits in America on an extensive scale and the fact that the three plums sent out by him are still valuable varieties indicates his judgment as to worth in fruits. The reputation made by his son, William Prince, the second, and by William Robert Prince, a grandson, as writers on horticultural subjects, is in large measure due to the information acquired for them and the training given them by the William Prince of this sketch. 
much recognition from pomologists. Downing described it in 1845 but neither Manning nor Kenrick in their excellent books on fruits mention this plum. The American Pomological Society in $185^{2}$ listed it with the varieties of plums promising well and in $185^{6}$ placed it on the list of those worthy of general cultivation.

Tree very large and vigorous, spreading, dense-topped, hardy, productive; trunk roughish; branches dark ash-gray, smooth except for the numerous, raised lenticels of various sizes; branchlets medium to below in thickness, short, with internodes of average length, greenish-red changing to brownish-red, dull, lightly pubescent, with inconspicuous, small lenticels; leaf-buds large, long, conical, free; leaf-scars prominent.

Leaves long-oval or obovate, two inches wide, four and one-quarter inches long, thick, somewhat leathery; upper surface dark green, covered with fine hairs, the midrib grooved; lower surface silvery-grcen, sparingly pubescent; apex and base acute, margin serrate, with few small, dark glands; petiole five-eighths inch long, pubescent, tinged red, with from one to three smallish, globose, greenish-yellow glands variable in position.

Blooming season intermediate in time and length; flowers appearing after the leaves, one and one-eighth inches wide, white, fragrant; borne on lateral spurs, singly or in pairs; pedicels seven-eighths inch long, with short, thin pubescence, greenish; calyxtube green, enlarged at the base, campanulate, lightly pubescent; calyx-lobes narrow, obtuse, lightly pubescent on both surfaces, glandular-serrate, reflexed; petals oval, entire, tapering to short, broad claws; anthers yellow; filaments one-quarter inch long; pistil glabrous, longer than the stamens.

Fruit mid-season, ripening period of medium length; one and one-half inches by one and three-eighths inches in size, oval, slightly compressed, halves nearly equal; cavity shallow, narrow, abrupt; suture shallow; apex roundish or depressed; dull yellow, faintly splashed and streaked with green, sometimes tinged on the sunny side with light red, overspread with thin bloom; dots numerous, small, white, inconspicuous, clustered about the base; stem three-quarters inch long, thinly pubescent, adhering well to the fruit; skin thin, rather sour, separating readily; flesh golden-yellow, juicy, firm but tender, sweet, mild, of pleasant flavor; very good; stone free, the cavity larger than the pit, one inch by five-eighths inch in size, oval, turgid, roundish, abruptly contracted at the base, blunt at the apex; ventral suture broad, blunt, faintly ridged; dorsal suture widely and deeply grooved. 


\section{CHAPTER IV}

\section{THE MINOR VARIETIES OF PLUMS}

\section{Abbaye d'Arton. Domestica. 1. Cat. Cong. Pom. France 445. I906.}

This variety came from a chance seedling found in the ruins of the Abbaye d'Arton at Valreas, France; it was propagated in 1897 by M. Valdy of Valreas. Tree very productive; fruit large, obovate; suture obscure; stem short; pale red, darker on the sunny side; bloom thick; flesh yellow, juicy, sweet; good; freestone; mid-season.

Abricotee de Braunau. Domestica. 1. Hogg Fruit Man. 349. 1866. 2. Oberdieck

Deut. Obst. Sort. 429. 1881. 3. Hogg Fruit Man. 683. 1884. 4. Mathieu Nom.

Pom. 423. 1889 .

Abricotée de Braunau 4. Braunauer Aprikosenartige 2. Braunauer Aprikosenartige Pflaume 4. Braunauer Aprikosenartige Damascene 4. Braunauer Neue Kernfrucht 2. Reine-Claude Braunau 3, 4 .

Dr. Liegel of Braunau, Germany, originated this variety about 181o. Fruit large, roundish; suture distinet; greenish; bloom rather heavy; dots distinet, reddish; flesh yellow, firm, juicy, sweet; good; stone free; mid-season.

Abricotee de Lange. Domestica. r. Mas Pom. Gen. 2:103, fig. 52. 1873.

Langes Aprikosenpflaume x.

Dr. Liegel of Braunau, Germany, grew this variety and named it after Lange of Altenburg. Fruit of medium size, roundish; suture slight; yellow, blushed in the sun; flesh yellow, tender, sweet, aromatic; good; clingstone; mid-season.

Abricotee de Trauttenberg. Domestica. r. Mas Pom. Gen. 2:35, fig. 18. 1873. 2. Mathieu, Nom. Pom. 453. I 889 .

Abricotée de Trauttenberg 2. Abricotée Rouge de Trauttenberg 2. Trauttenbergs A prikosenpflaume I. Von Trauttenberg's Aprikosenpflaume 2.

Liegel raised the Abricotée de Trauttenberg from a stone of the Red Apricot and named it after Baron Emmanuel of Trauttenberg, Prague. Fruit medium in size, oval, red; flesh yellow, firm, aromatic; good; freestone; mid-season.

Abricot Princesse. Domestica. Mentioned in Knoop Fructologie 2:54. I 771 .

Admirable. Domestica. Mentioned in Forsyth Treat. Fr. Trees 21.1803.

Admiral. Domestica. r. Kenrick Am. Orch. 257. 1832. 2. Downing Fr. Trees Am.

293. 1845. 3. Thomas Am. Fruit Cult. 345. 1849 .

Corse's Admiral 1, 2, 3 .

Originated by Henry Corse, Montreal, Canada. Inferior in quality but hardy, productive and showy; rarely grown. Fruit of medium size, oval, sides unequal, light purple; dots yellow; bloom thin; stem long, pubescent; flesh greenish-yellow, juicy; clingstone; mid-season.

Admiral Schley. Americana. I. Ia. Sta. Bul. 46:260. 1890. 2. Terry Cat. 1900.

Originated by H. A. Terry of Crescent, Iowa. Fruit roundish, yellow, washed with deep bronze-red; dots small, numerous, yellow, distinct; bloom thin; skin tough; 
flesh deep yellow, juicy, rich, sweet; very good; stone large, oval, flattened, clinging. Apparently an improvement over Hawkeye.

Advance. Americana. I. Waugh Plum Cult. 142. 1901. 2. Kerr Cat. 1902-3.

Grown by Theodore Williams, Benson, Nebraska, and introduced by J. W. Kerr, Denton, Maryland, in 1902. Fruit large, oval; cavity very shallow; suture a line; apex slightly depressed; dark red; dots many, conspicuous, yellow; good; clingstone; tree vigorous and productive; said to be resistant to rot.

African. Angustifolia varians. I. Am. Pom. Soc. Rpt. r60. 1881. 2. Cornell Sta. Bul. 38:60, 86. 1892. 3. Waugh Plum Cult. 192, 193 fig. 1901.

Originated with $\mathrm{G}$. Onderdonk $\mathrm{k}^{1}$ of Texas and introduced by him in 1870 ; said to be one of the best varieties of this species. Tree small, spreading; fruit medium to large, roundish to oblong, dull, dark red; dots large and small, white; skin thin, tough; flesh yellow, soft, juicy, subacid; good; stone clinging; mid-season.

Alabama. Triflora $\times$ ?. 1. Cornell Sta. Bul. 175:154. 1899. 2. Waugh Plum Cult. 201. Igor.

Normand No. 52

Sent out by J. L. Normand, Marksville, Louisiana. Fruit of medium size, heartshaped, light yellow with pink cheek; bloom thin; mid-season; fruits drop before ripe but mature after falling; good; tree spreading, twiggy; branches smooth, glossy, zigzag.

Albany Beauty. Domestica. 1. Lond. Hort. Soc. Cat. 146. 1831, 2. Thomas Am.

Fruit Cult. 327. 1849. 3. Mathieu Nom. Pom. 420. 1889.

Belle d'Alhany 3. Denniston's Aliany Beauty 2, 3. Denniston's Albany I.

${ }^{1}$ Gilbert Onderdonk was born in Sharon, New York, September 30,1829 . As a boy he showed a taste for horticulture and while a lad planted seeds of potatoes, made selections and developed several varieties more or less widely grown in the middle of the last century. Mr. Onderdonk was educated in the Cortland Academy at Cortland, N. Y., and in the State Normal College at Albany, After having taught in the district schools of New York for a few years, he found it necessary to go to a warmer climate because of bronchial trouble and in $185_{1}$ moved to Texas, where he became a cowboy, a rancher and finally a fruit-grower. In the region in which he had settled there were wild grapes and wild plums in abundance. The luxuriance of growth and the number of these fruits so impressed him with the possibilities of fruit culture in southwestern Texas that he began planting fruit trees. Of necessity these came from the north and for most part failed. Not to be discouraged, Mr. Onderdonk began the improvement of the wild varieties about his home. From 1855 to the present time his work has been the testing for the region in which he lives, of every variety of fruit to be had in Europe and America, and the improvement of the wild fruits growing about him. The plum, in particular, has received attention from Mr. Onderdonk, and his chief work with this fruit has been the hybridization of Triflora and Munsoniana varieties from the crossing of which he has grown some valuable plums. In 1887 , the United States Department of Agriculture employed Mr. Onderdonk to work with plums, grapes and peaches in the southwest, the results of which are to be found in the reports of the Department immediately following the year mentioned. He has also done considerable work for the French in sending resistant vines to France. Mr. Onderdonk is one of several workers in horticulture who have unremittingly served Texas and the southwest in the production of new varieties of fruits and in testing varieties from other regions. The value of the foundation these men have laid for horticulture in the southwest cannot now be estirnated. 
Produced in the garden of Isaac Denniston, Albany, New York, about 1835 . Fruit below medium in size, oval with a slight neck, greenish-yellow with reddish spots on the sunny side; flesh yellow, juicy, rich, sweet; good; stone free, small, pointed; midseason; tree hardy; productive.

Alberta. Nigra ? I. Can. Exp. Farms Rpt. 426. 1900.

A seedling raised at Indian Head Experimental Farm, Northwest Territory, Canada. Fruit large; fairly productive; early.

Alexander. Species ? I. Ill. Hort. Soc. Rpt. 135. 1903. 2. Ibid. 424.1905.

Alexander's Late 2.

Mentioned as a late native plum; productive; resistant to rot; clingstone.

Alibuchari. Domestica. I. Mag. Hort. 9:163. 1843. 2. McIntosh Bk. Gard. 2:534. 1855.

An old European prune. Size medium, oval, purple; fair in quality; freestone; shrivels on the tree; hardy; productive.

Alice. Americana mollis. 1. Terry Cat. 1900.

Originated by H. A. Terry, Crescent, Iowa, from seed of Van Buren. "Tree a fine upright grower, with large, light red fruit of best quality."

Allen. Species ? 1. Cornell Sta. Bul. 38:78. 1892. Allen's Yellow 1.

An obsolete variety from Kansas of medium size, round, yellow and red; skin thick; clingstone.

Allfruit. Simonii $\times$ Triflora. r. Vt. Sta. Bul. 67:5. I898. 2. Waugh Plum Cult. 202. 1901 .

Grown by Luther Burbank: named in 1898 . Described by Waugh as follows: "Fruit oblate, medium size; cavity deep, rounded; stem short; suture rather shallow; color pale red with many large and small yellowish dots and a thin white bloom; skin medium thick; flesh medium firm, bright yellow; flavor sweet and rich, fragrant; good to best; stone medium to large, slightly flattened, semi-cling; leaf large, oval, pointed, rather finely double crenulate and minutely glandular, rather thick, glistens as if varnished; petiole short, glandular."

Allie. Nigra ? 1. Can. Exp. Farms Rpt. 426. 1900.

A seedling raised at Indian Head Experimental Farm, Northwest Territory, Canada. Tree productive; fruit of medium size; skin red; flavor good; early.

Aloe. Domestica. 1. Montreal Hort. Soc. Rpt. 55. 1878.

Mentioned as an old Scottish variety; is not hardy at Montreal, Canada.

Alois Reine Claude. Domestica. Mentioned in Mathieu Nom. Pom. 420. I889.

Alois' Reine-Claude. Reine-Claude d'Alois. Reine-Claude Aloise.

Aloo Bokhara. Domestica ? 1. Horticulturist 3:144. 1848 .

A variety noted by Sir Alexander Burnes, while traveling in Bokhara, as having a sweet kernel. He states that the stone, when ripe, can be seen through the skin.

Alpha. Maritima. 1. Kerr Cat. 1899. 2. Ohio Sta. Bul. 162:254, 255. 1905.

A variety selected from wild trees by $\mathrm{E}$. W. Winsor of New Jersey and sent to J. W. Kerr, Denton, Maryland, who introduced it in 1899 . Very small, roundish, purple; no cavity nor suture; flesh greenish-yellow; poor; freestone; early; tree small, compact, very productive. 
Alpha-Americana. Americana. 1. Ia. Hort. Soc. Rpt. 86. 1900.

A seedling of De Soto pollinated by Weaver; grown by N. K. Fluke, Davenport, Iowa, in 1890 . Fruit large, oval with a truncate base, clear yellow, mottled with light red, lilac blush; suture distinct; flesh yellow, firm and meaty; fair in quality; stone of medium size, flattened, free; mid-season.

Amaryllis. Insititia. 1. Can. Exp. Farm Bul. 43:33. 1903.

Originated by August Dupuis, Village des Aulnaies, Province of Quebec, in 1890 from seed of Mirabelle. Fruit large, roundish; cavity medium, abrupt; suture distinct; apex rounded; greenish-yellow; dots indistinct; flesh yellow, juicy, sweet, rich; good; clingstone.

Amber. Domestica? I. Parkinson Par. Ter. 577, 578. 1629. 2. Quintinye Com. Gard. 68. 1699.

Described by Parkinson in 1629 as a small, round, yellow freestone plum of mediocre quality; classified by him as "Prunum Ambarinum."

Amber Primordian. Domestica. I. Parkinson Par. Ter. 575. 1629. 2. Rea Flora 206. 1676.

Mentioned by Parkinson in 1629 as an early, small, round, yellow, watery, worthless plum.

Ambre Tardif. Domestica. Mentioned in Mathieu Nom. Pom. 421.1889.

Ambrée Tardive.

Amelie Blanche. Domestica. I. Knoop Fructologie 2:54. 1771 .

Tree productive; fruit of medium size, roundish, yellow; obsolete.

Amelie Noire. Domestica. I. Knoop Fructologie 2:54. ${ }_{177}$ I.

Of ancient and unknown origin. Tree productive; fruit of medium size, roundish, purplish-black; flesh dry; flavor fair; early.

Amelioree. Domestica. I. U. S. D. A. Pom, Bul, ro:20. 1901.

D'Agen Ameliorée 1.

Ameliorée originated in eastern France and differs from Agen only in being more vigorous; foliage and fruit larger and the season earlier.

American Golden. Hortulana. 1. Mo. Hort. Soc. Rpt. 182. 1895. 2. Vt. Sta. An. Rpt. II:283. I 898 .

James B. Wild of Sarcoxie, Missouri, introduced this variety as a seedling found in his neighborhood. Tree vigorous; fruit of medium size, round; suture a line; cavity very shallow; stem medium; bright golden-yellow; dots numerous, large, white; bloom thin; skin thick, tough; flesh yellow, firm, sweet but sprightly; good; stone of medium size, turgid, clinging; late.

American Magnum Bonum. Domestica. I. Downing Fr. Trees Am. 896. 1869.

Probably a seedling of Red Magnum Bonum from which it differs in that the young shoots are pubescent, the stone clinging and the fruit better in quality.

American Prune. Domestica. I. Wood Bros. Cat. 1898. Probably a synonym. American Violet. Domestica. I. Le Bon Jard. I:342. 1882. 2. Can. Exp. Farm Bul. 2d Ser., 3:49. I900. P. violette americaine I.

Tree weak in growth, productive; fruit large, roundish-oval, light purple; bloom thick; flesh yellow, sweet, juicy; quality good; mid-season. 
American Wheat. Domestica. I. Downing Fr. Trees Am. 289. 1845. 2. Thomas Am. Fruit Cult. 346. 1849. 3. Mas Pom. Gen. $2: 129.1873$.

American Wheat 3. Froment American 3.

A very small, round, pale blue plum with thin bloom; flesh greenish, melting, juicy, sweet; poor; clingstone; mid-season; tree productive; leaves small, light colored.

Ancient City. Domestica. I. Cultivator 6:270 fig. 1858. 2. Downing Fr. Trees Am. 941. I869. 3. Hogg Fruit Man. 684. 1884.

Reagles' Ancient City ז, 2.

Raised by C. Reagles, Schenectady, New York, supposedly from seed of Washington. Fruit large, roundish; suture deep; sides unequal; yellow, tinged with green, mottled with crimson specks next to the sun; bloom thin; stem of medium length, thick; flesh yellow veined with white, firm, coarse; good; freestone.

Anderson. Americana. I. Wis. Sta. Bul. 63:27. 1897. 2. Ia. Hort. Soc. Rpt. 488, 1904. Anderson's Early Red $\mathbf{I}$.

Found growing on the Turkey River near Sioux Rapids, Iowa, by Mrs. Vincent Anderson, about I 865. Trees productive; fruit of medium size; good; mid-season.

Angelina Burdett. Domestica. I. Gard. Chron. 13:600. 1853. 2. Mas Le Verger 6:37. 1866-73. 3. Gaucher Pom. Prak. Obst. 91. 1894.

Raised from seed by Henry Dowling of Woolston, England, about I 845 . Tree vigorous, hardy and productive; fruit of medium size, roundish; suture deep, one side enlarged; skin thick; dark purple with brown dots and heavy bloom; flesh greenishyellow, rich, juicy, sprightly; stone small, obovate, free; mid-season.

Angouleme. Domestica. 1. Waugh Plum Cult. 95. 1901. Reine-Claude d'Angouleme 1.

Similar to Reine Claude.

Anna. Americana. 1. Montreal Hort. Soc. Rpt. 9o. I 885.

A variety grown from a wild plum root secured in Wisconsin by Mr. Charles Gibb of Montreal, Canada.

Anna Maria. Domestica. I. Downing Fr. Trees Am 896. I869.

Originated by S. D. Pardee, New Haven, Connecticut. Fruit below medium in size, roundish-oval; suture lacking; pale greenish-yellow splashed with darker green; stem short; cavity small; flesh pale green, juicy, melting, rich, sugary; good; stone nearly free; tree moderately vigorous, spreading, productive.

Anna Spath. Domestica. I. Lange Allgem. Garten. 2:421. 1879. 2. Oberdieck Deut. Obst. Sort. 40 I. 1881. 3. Mathieu Nom. Pom. 421. 1889. 4. Can. Exp. Farm Bul., 2d Ser. 3:49. 1900. Anna Spaeth 3.

Originated with M. Spath at Baumschulenweg, Germany, about 1870 . Tree vigor ous; fruit of medium size, roundish-oval, flattened at both ends; skin tough, free; brownish-black; dots brownish; bloom thick; flesh greenish-yellow, very juicy, mild; good; freestone; season late.

Annual Bearer. Americana. r. Wis. Sta. Bul. 87:11. Igor.

A seedling grown by Edson Gaylord, Nora Springs, Iowa. Fruit large, oblong; suture distinct; purplish-red on a yellow ground; dots numerous, small; bloom heavy; 
skin thick, tough; stone strongly flattened, oval, pointed, sharp on both sides; flesh rich; flavor good; mid-season.

Apple. Americana. Patten No. 4 .

A seedling of Hawkeye; fruit large, roundish, dark red; dots conspicuous; suture a line; skin tender; flesh juicy, soft, fibrous, sweet; fair; clingstone; mid-season.

Apple. Domestica. 1. Cole Am. Fr. Book 210. 1849. 2. Downing Fr. Trees Am. 373. 5857 . Apple Plum I, 2.

Originated in the garden of D. U. Pratt, Chelsea, Massachusetts. Fruit large, flattened like an apple; sides unequal; suture distinct; stem short; cavity broad, deep; reddish-purple; bloom heavy; dots yellow; flesh greenish-yellow, tender, slightly coarse, sweet, sprightly; skin astringent; semi-clinging; mid-season.

Apricot. Americana. 1. Kerr Cat. 1894. 2. Colo. Sta. Bul. 50:32. 1898.

Tree bushy; fruit medium in size, roundish; suture slight; skin thick; red over yellow; bloom thin; flesh reddish-yellow, juicy, sweet; quality fair; stone large, flattened, clinging; mid-season.

Aprikosenartige Mirabelle. Insititia. 1. Oberdieck Deut. Obst. Sort. 426. 1881. 2. Mathieu Nom. Ponr. 421. 1889. Mirabelle Abricotée 2.

Said to be a synonym of Mirabelle; Oberdieck claims that this variety has firmer and sweeter flesh, and that its shoots are glabrous.

Arab. Domestica. 1. Ind. Hort. Soc. Rpt. 29. 1885. 2. Mich. Sta. Rpt. 111.1887.

Noted in the preceding references as imported from eastern Europe.

Arctic. Nigra? 1. Can. Exp. Farms Rpt. 426. 1900.

A variety selected from wild plants by Thomas Frankland, Stonewall, Manitoba, and tested at the Experimental Farm, Indian Head, Northwest Territory, Canada. Fruit large, red; late.

Ashes Seedling. Species? Mentioned in N. Y. Sta. Rpt. 9:347. 1890.

Ashridge Black. Domestica. 1. Lond. Hort. Soc. Cat. 143. I831. 2. McIntosh Bk. Gard. 2:529. 1355 .

An English variety not cultivated in this country. Medium in size, roundish, purple, firm; quality fair; a good kitchen variety; tree hardy and productive.

Assiniboia. Nigra? 1. Can. Exp. Farms Rpt. 426. 1900.

A seedling raised at the Experimental Farm, Indian Head, Northwest Territory, Canada; now discarded. Fruit of medium size; early.

Aston. Domestica. 1. Lond. Hort. Soc. Cat. 143. 1831.

A small, round, purple, clingstone plum of mediocre quality; obsolete.

Aston Green Gage. Domestica. Mentioned in Lond. Hort. Soc. Cat. 147. I8 31 .

Atkins. Americana. 1. Ia. Sta. Bul. 46:262. 1900. 2. Waugh Plum Cult. 143. 1901. Beatty 1, 2.

Originated with James Beatty at Atkins, Benton County, Iowa, and introduced by $R$. Royce of the same place in 1894 under the name Beatty. It became confused with the Beaty of Texas and Waugh renamed it, giving it the name of the place of its origin. Fruit large, oval, slightly compressed; cavity small; suture a line; red on a 
yellow ground; dots small, numerous; bloom thin; flesh yellow; good; clingstone; mid-season.

A-248. Munsoniana $\times$ Triflora. 1. Burbank Cat, 22, 1893, 2. Vt. Sta. Bul. 5:67. 1898.

An early, dark crimson, heart-shaped plum of medium size, yellow flesh and inferior quality.

Aubert. Domestica. 1. Am. Pom. Soc. Rpt. 61. 1887. 2. Ia. Hort. Soc. Rpt. 86. IS9o. 3. U. S. D. A. Rpt. 292, Pl. V c and d. 1893. 4. Am. Pom. Soc. Cat. 25. 1897. 5. Budd-Hansen Am. Hort. Man. 328. 1903.

Dame Aubert Jaune 1, 2. Dame Aubert Jaune 3. Riga II5 2. Yellow Aubert ?1, 3, 5. Yellow Aubert 4.

Introduced from Russia by J. L. Budd of the Iowa Experiment Station in I882. According to the introducer this variety was found in southwest Russia and Poland; said to have come from central Asia. Evidently related to the Yellow Egg, differing in being earlier and of better quality.

Auburn. Domestica. 1. Downing Fr. Trees Am. 897. 1869.

A variety said by Downing to be a native of western New York. Fruit medium in size, oval; suture shallow; skin light reddish-purple with a thin bloom; stem short; flesh coarse, orange-yellow, not juicy, sweet, pleasant; good; freestone; early.

Auchtertyre. Domestica. I. Lond. Hort. Soc. Cat. I43. 1831.

A small, oval, purple, early plum; quality medium; freestone; obsolete.

August. Nigra. I. Bailey Ann. Hort. 20. 1889. 2. Wis. Sta. Bul. 63:27. 1897.

August Red 1.

A large purplish-red variety introduced by J. W. Kerr, Maryland. Fruit oblong; clingstone; tree upright, vigorous, unproductive; foliage resembling that of an apricot. August Zwetsche. Domestica. Mentioned in Mathieu Nom. Pom. 421. 1889.

Liegel's August Zwetsche.

Aunt Ann. Domestica. 1. Hogg Fruit Man. 351. 1866, 2. Downing Fr. Trees Am. 918. 1869. 3. Mas Pom. Gen. 275. 1873.

Guthrie's Aunt Ann 1. Guthrie's Aunt Ann 2. Aunt Ann 2, 3. Tante Anne 3. This variety was grown in Scotland by a Mr. Guthrie. A large, round, greenishyellow plum; flesh rich, juicy; freestone; tree hardy, productive.
Aurora. Hortulana.
I. Kerr Cat. 1900-03.
Moreman's Cherry 1.

Originated by Theodore Williams of Nebraska and introduced in 1898 by J. W. Kerr of Maryland under the name "Moreman's Cherry?" in 1900, Mr. Kerr changed the name to Aurora. Fruit large, round, cherry-red deepening to dark red; clingstone; season late; tree vigorous, productive.

Austrian Quetsche. Domestica. 1. Lond. Hort. Soc. Cat. 152. 1831. 2. Prince Pom. Man. 2:78. 1832. 3. Downing Fr. Trees Am. 311. 1845.

Bremen Prune 2, 3. Quetsche de Breme 3.

A strain of the German Prune from which it differs in being a little later and of somewhat better flavor.

Autumn Gage. Domestica. I. Cultivator 10:167. 1843. 2. Ann. Pom. Belge 7:43, P1. 1859. 3. Hogg Fruit Man. 3So. I866. 4. Mas Le Verger 6:33, fig. 186673. 5. Mathieu Nom. Pom. 435. 1889. 
Autumn Gage 3, 5. Herbst Reine Claude 5. Prune Autumn Gage 2. ReineClaude d'Automne 2, 5. Reine-Claude d'Automne 4. Roc's Autumn 3. Roe's Autumn Gage 3, 5.

Raised by Wm. Roe, Newburgh, New York. Tree spreading, hardy, productive; fruit of medium size, oval; suture shallow; stem of medium length; pale yellow with a thin bloom; flesh greenish-yellow, juicy and sweet with a rich and excellent flavor; stone long, compressed, pointed at both ends, free; season late.

Azure. Domestica. I. Mas Pom. Gcn. $2: 67$, fig. 34. 1873. Reine-Claude Azurée 1.

Mas states that this variety grew in his garden from a sucker. Tree vigorous, medium in productiveness; fruit medium in size, roundish-oblate; suture a line; skin tender; purplish-black; stem long, slender to medium; cavity deep; flesh green, fine, tender, soft, juicy, sweet, aromatic; freestone; mid-season.

Bailey. Americana. I. Kerr Cat. 1901-1902.

A variety sent J. W. Kerr, Denton, Maryland, by the Division of Pomology, United States Department of Agriculture, for testing. Tree vigorous, upright, productive; fruit above medium in size, oblong, very dark red; good; clingstone; said to be free from rot.

Bailey. Domestica. I. Corncll Sta. Bul 62:20. 1894.

Known only from a plate in the possession of the Rochester Lithographing Company, made some time prior to $\mathbf{1 8 8 6}$, representing this plum and stating that it "has not failed to bear for twenty-five successive years."

Baker. Insititia. I. Mich. Sta. Bul. 177:41, 43. 1899. 2. Ibid. 187:77, 78. 1901.

Baker Damson I.

Tree upright, vigorous, unproductive; fruit small, roundish-ovate; stem slender, inserted in a slight cavity; dark blue or black; flesh greenish-amber, juicy; good; stone small, roundish, clinging.

Baker. Domestica. I. Am. Pom. Soc. Rpt. 1ог. r8g1. 2. Cornell Sta. Bul. 131: 182. I897. 3. Brown Bros. Cat. I 900.

Baker's German Prune I, 3.

A seedling of the German Prune which had its origin at Collingwood, Canada, with a Mr. Baker. Tree hardy, an annual bearer, productive; fruit resembles the Italian Prune in color and quality but is a trifle smaller and two weeks later.

Baldwin. Americana. I. Ia. Hort. Soc. Rpt. 333. 1888. 2. S. Dak. Sta. Bul. 93:9, 5 I fig. 1905 .

A wild variety found by D. L. Royer of Iowa. Tree vigorous ; fruit large, round; apex flat; cavity deep, narrow; dark red, mottled with dull yellow; bloom heavy; dots whitish, minute, numerous; skin thick, astringent; flesh dark yellow, flavor pleasant, acid; good; stone semi-free, rounded, thick, of medium size.

Ballonartige Gelbe Zwetsche. Domestica? Mentioned in Mathieu Nom. Pom. 421, r889. Damas-Ballon Jaune. Damas-Ballon Panachée Varicte.

Ballonartige Rote Damascene. Domestica? Mentioned in Mathieu Nom. Pom. 421. ז889.

Damas-Ballon Rouge.

Bankalari Fruh Damascene. Domestica? Mentioned in Mathieu Nom. Pom. 421. 1889. Bankalari's Rote Frïh Damascene I. 
Banker's Gage. Domestica. 1. Lond. Hort. Soc. Cat. 147. 1831. 2. Kenrick Am. Orch. 202. 1835 .

Originated in New York. Fruit large; flavor good; adapted to drying.

Bant Spate Reine Claude. Domestica. Mentioned in Mathieu Nom. Pom. 422, 1889. Bant's Late Green Gage.

Baraboo. Americana. 1. Wis. Sta. Bul. 63:28. I897. 2. Ia. Sta. Bul. 46:262. 1900.

Found wild near Baraboo, Wisconsin, about 1860 and introduced by William Toole of the same place in 1897 . Tree vigorous, spreading, symmetrical; fruit of medium size, round, dull yellow, overlaid with red; flesh firm, mild, sweet; quality fair; midseason; drops badly and is a poor keeper.

Barbary. Domestica. I. Parkinson Par. Ter. 576. 1629. 2. Rea Flora 207. 1676. Banberry 2.

A large, egg-shaped, early, productive, black plum.

Barkhausen Violette Reine Claude. Domestica. Mentioned in Mathieu Nom. Pom. 422. 1889 .

Barkley. Americana? 1. Letter from Kerr. Teeter I.

From Pennsylvania; fruit medium in size, green, blushed with red; good.

Barnsback. Americana. 1. Wis. Sta. Bul. 87:1 1. 1901. 2. S. Dak. Sta. Bul. 93:9. 1905. Barnsbeck 2.

Originated at Vermilion, South Dakota. Fruit large, roundish; suture a line; yellowish overspread with light red; sparsely dotted; heavy bloom; skin medium thick, astringent until fully ripe; flesh pale yellow or reddish, juicy, sweet; good; stone nearly free: mid-season.

Baronne Helen Trauttenberg. Domestica. x. Mathieu Nom. Pom, 422. 1889. 2. Guide Prat. 163, 352. 1895 .

A variety said to resemble Italian Prune.

Basaricatta. Domestica. 1. Gallesio Pom. Ital. 2 :Pl. 1839. Collo-Torto 1.

An Italian variety described by Gallesio in his Pomona Italiana. Fruit long, pruneshaped, necked; skin golden-yellow; flesh yellow, firm, sweet and agreeable; a good shipper.

Bastle. Species? 1. Tex. Sta. Bul. $32: 490 . \quad 1899$.

Reported as very weak in growth and as having failed to produce fruit.

Batchelor Damson. Insititia. I. N. Y. Sta. Rpt. 12:611. 1893.

Received for testing at the New York Experiment Station.

Bazalicza. Domestica. 1. Mas Le Verger 6:139. 1866-73. 2. Oberdieck Deut. Obst. Sort. 441. 1881. 3. Mathieu Nom. Pom. 422. 1889. 4. Can. Exp. Farms Rpt. 402. 1898. 5. Can. Exp. Farm Bul. 2d Ser., 3:51. 1900.

Quetsche de Bazalicza 1. Bazalicza Zwetsche 1. Bazalicza Zwetsche 2, 3. Bazallicza's Grosse Blaue Zwetsche 3. Quetsche de Bazalicza 3. Bazalicza's Prune 4. Bazalicza Damson 5.

Raised by Liegel of Braunau, Germany, from seed of Red Magnum Bonum. Tree vigorous, productive; fruit above medium size, oblong-oval; suture shallow, halves usually unequal; skin free; dark purple; bloom thin; flesh yellow, swect; excellent; clingstone; early. 
Beach Plum. Maritima.

"Beach Plum" is the common name for Prunus maritima.

Beals. Domestica.

A seedling raised by George F. Beals, of Viscalia, California, and sent to Nelson Smith of Geneva, New York, for testing. Fruit large, egg-shaped, lop-sided; suture shallow; skin thick; blue, of ten purplish; dots yellow; flesh firm, yellow, juicy, sweet; stone large, oval, rough; mid-season.

Bean. Americana. 1. Minn. Hort. Soc. Rpt. 128. 189o. 2. Wis. Sta. Bul. 63:28. 1897 .

Found wild by H. Knudson, Springfield, Minnesota. Fruit below medium in size, oblong; apex flattened; suture depressed; pale yellow tinged with crimson; dots faint; skin astringent unless fully ripe; flesh pale yellow or reddish, juicy, sweet, rich; stone large, oblong, rough, pointed, grooved on the back; mid-season.

Beaty. Angustifolia varians. I. Cornell Sta. Bul. 38:36, 60. 1902. 2. Thomas Am.

Fruit Cult. 489. 1897. 3. Tex. Sta. Bul. 32:478. 1899. 4. Waugh Plum Cult. 192. I901.

Beauty's Choice 1. Beaty Choice 2. Beauty 3. Beaty's Choice 4. El Paso 4. El Paso 1.

Originated under cultivation with Lee Beaty, Luling County, Texas, and introduced by him in 1877 . Tree irregular, spreading; fruit of medium size, roundish; cavity shallow; light red; bloom thin; dots numerous; flesh yellow; good; stone oval, turgid, clinging.

Bechstein Spitzpflaume. Domestica. Mentioned in Mathieu Nom. Pom. 422. 1889.

Blaue Zipper. Prumus Oxycarpa. Rosinen Pflaume. Spitz Pflaume. Spitzige Rote Pflaume. Rote Zwetsche incor. Rote Zipper.

Bedford. Nigra? I. Can. Exp. Farms Rpt. 426 . 1900.

A seedling raised at Indian Head Experimental Farm, Northwest Territory, Canada. Fruit of medium size.

Beer Plum. Domestica. I. Ia. Hort. Soc. Rpt. 86. I890.

One of the many Domesticas imported from Europe by Professor J. L. Budd. This one is small and fit only for culinary purposes.

Bell. Species? 1. Tex. Dept. Agr. Bul. 12:102. igro. Bell's October r.

A variety said to be of value near Plainview, Texas.

Belle de Hardy. Domestica. I. Nathieu Nom. Pom. 422. 1889. 2. Guide Prat. $163,35^{2}, 1895$.

Said to resemble Agen.

Belle de Louvain. Domestica. 1. Downing Fr. Trees Am. 392. 1857. 2. Ibid. 898 . 1869. 3. Lucas Vollst. Hand. Obst. 47 1. I894. 4. Guide Prat. $157,352.1895$. Large Black Imperial? 4. Plum of Louvain 1. Prune de Louvain 2. Schōne von Lowen 3. Schöne von Lowen 4.

A seedling found in the nursery of Van Mons at Louvain, Belgium, about 1840 . Tree vigorous, a biennial bearer; fruit large, long-oval; suture distinct; deep purple with delicate bloom; flesh firm, yellowish, juicy, rich; mid-season; valuable for culinary purposes. 
Belle de Paris. Domestica. Mentioned in Can. Exp. Farm Bul. 2d Ser, 3:49. I900. Belle de Riom. Domestica. I. Lond. Hort. Soc. Cat. 144. 1831. 2. Mas Pom. Gen. $2: 83$. $\quad 8_{73}$.

This variety is thought to have originated in the vicinity of the French village of Riom, in the early part of the Nineteenth Century. Tree vigorous, productive; fruit medium, oval; suture indistinct; skin intense purple; dots white; flesh greenish-yellow, melting, rich, sweet, aromatic; very good; stone oval, free; late.

Belle de Schoeneberg. Domestica. I. Mathieu Nom Pom. 449. 1889. 2. Guide Prat. 1 $5^{8}, 35^{2}, 1895$.

Belle de Schoneberg I. Gloire de Schöneberg I, 2. Rotgefleckte Gold Pflaume I. Rothgefleckte Goldpflaume 2. Schöne von Schöneberg I. Schöne von Schöneberg 2.

Tree neither vigorous nor productive; fruit large, roundish, reddish-violet; flesh yellow, sweet, agreeable; good; early.

Belsiana. Cerasifera. 1. Cat. Cong. Pom. France 471. I887.

A wild plum resembling Myrobalan, selected by the Arabs and introduced into France in 1878 by G. Luizet, to whom it was sent by Ferdinand Lombard, horticulturist at Mustopha, Algieria. Fruit of medium size, round; suture indistinct; cavity shallow; skin papery; amber-yellow, with a rose tint on the sunny side; flesh amberyellow, melting, sweet; stone slightly clinging; early.

Belvoir. Domestica. I. Hogg Fruit Man. 680, 686. I884.

Fruit above medium in size, round; suture faint; skin thin; black with russet markings and dots; flesh yellow, tender, rich; freestone; late.

Bender. Americana. 1. Kerr Cat. 1896-7. 2. Waugh Plum Cult 143. 1901. 3. Wis.Hort.Soc.Rpt. 121. 1902. 4.S. Dak.Sta.Bul.93:10. 1905. Paul Wolf 4.

Reported to have been grown near Chaska, Minnesota, by Paul Wolf. Tree very vigorous, productive; fruit large, oblong, conical, irregular; suture indistinct; dark red with thick bloom; dots numerous, small; skin thick, tough; flesh light yellow, very firm, meaty; fair to good; stone long, pointed, early.

Benedetto. Domestica? Listed in Mathieu Nom. Pom. 422. 1889. Beni-Detto. Benedict. Domestica. 1. Downing Fr. Trees Am. 899. 1869.

Originated in Pennsylvania. Tree vigorous; fruit small, oval; suture distinct; pale yellow, dotted and splashed with red on the sunny side; bloom thin; flesh pale yellow, juicy, pleasant; good; clingstone.

Beni Botan. Triflora. I. Va. Sta. Bul. I29:111. I901.

A variety imported by the Department of Agriculture

Benschoten. Domestica.

Pits were left in the cellar of a Mr. Benschoten of Woodstock, Ulster County. New York, by a German emigrant, and from them the above variety was grown. Fruit above medium in size, oval, cream color, mottled with crimson; flesh golden-yellow, sugary, aroma like that of an apricot; season late.

Benson. Hortulana. 1. Kerr Cat. 14. 1898. 2. Am. Pom. Soc. Cat. 40. 1899. 3. Waugh Plum Cult. 177. 1901. 4. Ill. Hort. Soc. Rpt. 422. 1905.

Moreman Prune 1. Benson Market 4. 
Benson originated with Theodore Williams of Benson, Nebraska; was first called Moreman Prune but was renamed and introduced by J. W. Kerr in 1898 . Tree vigorous; fruit medium in size, roundish; cavity shallow; stem slender; suture distinct; deep cherry-red, with numerous, yellowish dots; bloom thin; flesh yellow; quality fair; stone medium in size, oval, clinging; season late.

Berlepsch. Domestica. 1. Mas Pom. Gen. 2:175. 1873. 2. Mathieu Nom. Pom. 422. 1889 .

Berlcpsch's Grosse Grüne Reine-Claude 2. Berlepchs Renclode Grosse Grine r. Grosse Reine-Clande de Berlepsch 2. Grosse Reine-Claude Verte De Berlepsch 1.

A seedling raised by Liegel of Braunau, Germany. Tree vigorous, medium in productiveness; fruit of the same flavor and quality as the Reine Claude, of which it is probably a strain to be distinguished by earlier maturity, slightly more depressed form and a paler-colored skin.

Berlet Fruh Damascene. Domestica? Listed in Mathieu Nom. Pom. 422. 1889.

Bernsteinzwetsche. Domestica. I. Mathieu Nom. Pom. 422. 1889. 2. Guide Prat. 163, 351. 1895 .

Ambre de Provence 2. Ambre de Provence 1. Bernsteinzwetsche 2.

Mentioned in the references cited without description.

Berryhill. Americana. I. Meneray Cat.

Originated with H. A. Terry, Crescent, Iowa; introduced by F. W. Meneray, Council Bluffs, Iowa. Tree productive; fruit large, red over a yellow ground; skin thin, tender; flesh firm; good; clingstone.

Berry Plum. Species? 1. Cornell Sta. Bul. 38:78. 1892.

Mentioned as a variety growing on the grounds of the New York State College of Agriculture.

Best Black Blood. Triflora. I. Rural N. Y. 59:655 fig. 245. 1900.

Originated by Burbank and described by him as being productive and vigorous; leaves resembling Simon; fruit large; flesh juicy and firm.

Best of All. Hortulana mineri $\times$ Triflora. 1. Vt. Sta. Bul. 67:7. 1898. 2. Rural N. Y. 65:730. 1906. Bestovall 1 .

This is a seedling of Miner pollinated by Abundance originating with T. V. Munson, Denison, Texas. Tree vigorous, prolific; fruit of medium size, round, dark red; flesh firm, meaty; good; late.

Beta. Maritima. I. Kerr Cat. 1899-1900.

Selected from wild plants by E. W. Winsor of New York. Fruit yellow, small and round; very prolific; early.

Betterave. Domestica. I. Noisette Man. Comp. Jard. 2:496. 1860.

Tree large and vigorous; fruit large, round, pale yellow, juicy, not pleasant.

Beztercser Grosse Zwetsche. Domestica. I. Mathieu Nom. Pom. 422. 1889. 2. Guide Prat. $163,35^{2}$. 1895 .

Mentioned in the preceding references; said to resemble Washington.

Biconical. Triflora $\times$ ? I. Vt. Sta. An. Rpt. 14:270. 1901.

A cross between Abundance and "a Chicasaw," originating with A. L. Bruce, 
Texas. Leaves Triflora-like with peculiar double, crenulate, glandular margins. Fruit conical, of medium size; cavity shallow; suture faint; skin thin; bright red; bloom moderate; flesh soft, yellow, subacid; quality fair; stone medium in size, round-oval, clinging.

Biery. Triflora. I. U. S. D. A. Pom. Rpt. 45. 1895.

Received from California by J. J. Bicry, Covington, Louisiana, wrongly labeled Long Fruit. Fruit spherical, medium in size; cavity deep; suture indistinct; color yellow, blushed with red, patched with russct and with minute, russet dots, skin thin, separating easily from the tender, juicy, yellow flesh; good; stone medium in size, oval, clinging; early.

Big Rose. Domestica. r. U. S. D. A. Div. Pom. Bul. 1o:21. 1901.

A variety of English origin introduced into Oregon about 1900.

Bilona. Triflora $x$ ?

Bilona, as yet unintroduced, originated with H. A. Biles, Roanoke, Texas, and is thought by F. T. Ramsey of Austin, Texas, to be a seedling of Chabot probably crossed with some native variety. Tree resembles Chabot; fruit red, coloring long before ripe; quality said to be very good.

Bingham. Domestica. 1. Prince Treat. Hort. 27. 1828. 2. Prince Pom. Man. 2 :1or. 1832. 3. Downing Fr. Trees Am. 272. 1845. 4. Am. Pom. Soc. Rpt. 87. 1854.
5. Mathieu Nom. Pom. 422, 1889.
Bingham's Pflaume 5.

Originated in Pennsylvania. Fruit large, oval, yellow, occasionally with carmine dots on the sunny exposure; suture distinct; cavity narrow and deep; flesh yellowish, juicy, pleasant; good; clingstone; early; at one time highly esteemed.

Biondeck. Domestica. 1. Koch Deut. Obst. 572. 1876. 2. Lauche Deut. Pom. 10, Pl. IV. 1882. 3. Mathieu Nom. Pom. 422. I889.

Biondeck's Frühzwetsche 1, 2, 3. Biondeck's rothe Frühzwetsche 2. Bionleck's Rote Frïh Zwetsche 3. Précoce Biondeck 3. Quetsche Précoce de Biondeck 3.

Liegel produced this variety from a seed of Early Yellow and named it after his friend Biondeck, of Baden, near Vienna. Tree large, productive; fruit oval, medium, light red; flesh yellowish, sweet, highly flavored; freestone; early; considered valuable for drying.

Birchland. Americana. 1. Can. Exp. Farm Bul. 2d Ser. 3:49. 1900.

A variety from Minnesota reported as unsatisfactory in British Columbia.

Bittern. Domestica. 1. Mich. Hort. Soc. Rpt. 289. 1889. 2. U. S. D. A. Pom. Rpt. 25. 1894. 3. Cornell Sta, Bul. I31:182. 1897. Biltern 3.

A seedling grown by Francis Rivers, Sawbridgeworth, England. Tree productive; fruit above medium or large, oval, purple, with a heavy bloom; dots few, inconspicuous; skin thick, acid; flesh greenish-yellow, firm, juicy, brisk subacid; good; stone long, of medium size, oval, clinging; early.

Bixby. Americana. I. Ia. Hort. Soc. Rpt. 436. 1888. 2. Ia. Sta. Bul. 46:262. 1892 . 3. Wis. Sta. Bul. 63:29. 1897 .

Found on the homestead of Rev. N. W. Bixby, Clayton County, Iowa, in 1847 ; introduced by C. H. True, Edgewood, Iowa, in 1880 . Tree spreading, vigorous; fruit 
large, roundish-oval; cavity narrow, shallow; suture a line; apex rounded; yellow more or less covered with bright red; dots numerous, small, yellow; skin thick, tender; flesh yellow, sweet but not rich in flavor; good; stone large, flattened, clinging; mid-season. Black Arabka. Domestica. 1. Am. Pom. Soc. Rpt. 61. 1887. 2. Ia. Hort. Soc. Rpt. 86. 1890 .

Tchernaya Arabskaya 1. Mixed Arab 2. Black Arab 2. Black Prune 2.

One of the foreign varieties tested by the Iowa Agricultural College.

Black Ball. Domestica. Mentioned in Lond. Hort. Soc. Cat. 144. 1831.

Black Damask. Domestica. 1. Miller Gard. Dict. 1754. 2. Am. Gard. Cal. 587. 1806.

3. Downing Fr. Trees Am. 374. 1857 .

Small Damas I. Little Black Damask I. Small Black Damask 2.

Black Damask has been confused by the old writers with the common Damson. This plum is a Domestica with a sweet, pleasantly flavored flesh suitable for dessert purposes and ripens much earlier than the Damson.

Black Damask Hasting. Insititia. 1. Quintinye Com. Gard. 68. I699.

Mentioned by Quintinye as having a "sharp and sourish taste."

Black Hawk. Americana. 1. Ia. Sta. Bul. 4:95. 1889. 2. Wis. Sta. Bul. 63:29. 1897.

3. Am. Pom. Soc. Cat. 37. 1899. 4. Waugh Plum Cult. 143. 1901.

A wild variety found in Black Hawk County, Iowa. Tree hardy, vigorous, and productive; fruit large, flattened, more convex on the ventral side; suture distinct; deep red; skin thick, tough; flesh yellow, tender, rich; good; stone free, mid-season; listed in the fruit catalog of the American Pomological Society in 1899.

Black Hill. Domestica. 1. Lond. Hort. Soc. Cat. I44. 1831.

Cultivated in the Gardens of the London Horticultural Society.

Black Pear. Domestica. I. Rea Flora 208. 1676. 2. Langley Pomona 96. I 729.

A variety of early European origin now obsolete. Fruit pear-shaped; skin dark red or black; juicy when fully ripe.

Black Perdrigon. Domestica. I. Abercrombie Gard. Ass't I3. 1786. 2. Willich Dom. Enc. 4:194. 1803.

Probably a strain of Blue Perdrigon.

Black Prune. Domestica. I. Ia. Agr. Col. Bul. 51. 1886. 2. Am. Pom. Soc. Rpt. 61. 1887. 3. Ia. Hort. Soc. Rpt. 86. 1890. 4. Ia. Sta. Bul. 31:349. 1895. Arab No. I (Budd unpublished). Black Prune No. I 3. Black Prune No. 14. Black Vengerka 2. Tchernaya vengerskaya $1,2$.

Black Prune was imported by J. L. Budd of the Iowa Experiment Station from Dr. Regel, St. Petersburg, Russia, in $188_{1-2}$, under the name "Tchernaya vengerskaya." It was received at this Station for trial under the name "Arab No. 1." It is a small prune of fair quality when eaten out of hand, but becomes sour in cooking.

Black Prunella. Domestica. I. Rea Flora 207. 1676. 2. Ray Hist. Plant. 1529. I688.

An old European plum. Fruit small, black and very sour; once valued in England for preserves.

Blaisdon. Domestica. 1. Watkins Cat. 1892?

Blaisdon's Red r.

Fruit nedium in size, red; mid-scason. 
Blaue Reine Claude. Domestica. Mentioned in Mathieu Nom. Pom. 423. 1889.

Liegel's Blane Reine Claude. Reine-Clande Blene. Reine-Claude Violette. Schwarze Reine-Claude.

Blaugh. Americana. r. Ont. Fr. Exp. Sta. Rpt. 6:46. 1899.

A vigorous variety which originated in the Allegheny Mountains. Fruit above medium in size, light purple; bloom heavy; flesh yellow, juicy; good; stone clinging; late; promising.

Bleeker Large Red. Domestica. I. Cultivator $x: 306$. 1844 .

Mrs. Bleeker's Large Red I.

Grown by a Mrs. Bleeker of New York from stones received from Germany. Fruit large, bluish-red, melting and rich; mid-season. Downing gave Bleecker's Scarlet as a synonym of the Lombard, but he could not have had this plum in mind.

Bleue de Perse. Domestica. Mentioned in Mathieu Nom. Pon. 423. I889.

Blood Plum. Triflora. I. Ga. Hort. Soc. Rpt. 54. 1892. 2. Ibid. 96. 1895.

Beni-Smono No. 3 ?r. Blood Plum No. 32 .

Tree open, straggling, early blooming; fruit small; flesh deep red, juicy, sweet; middle of July.

Blubenthal. Insititia? r. Can. Exp. Farmis Rpt. 40 I. 1898.

Blubenthal Damson I.

According to the preceding reference the largest of the Damsons. Fruit heartshaped, deep purple; bloom heavy; flesh green, juicy, sprightly; mid-season.

Blue Apricot. Domestica. I. Can. Exp. Farm Bul. 2d Ser. 3:49. I 900.

Fruit above medium in size, roundish, flattened at the ends; suture well defined; skin bluish-purple; dots few; flesh greenish-yellow, juicy, sweet; stone small, roundish, free; early.

Blue Egg. Domestica. I. Lange Allgem. Garten, 2:421. 1879. 2. Oberdieck Deut. Obst. Sort. 406. 188r. 3. Mathieu Nom. Pom. 422. 1889.

Bamberger Eier Pfanme 3. Blaue Eierpflaume 2, 3. Blaue Kaiser Pflaume 3. Dame-Aubert Rouge 3. Eier Pflaume 3. Grosse Blaue Eier Pflaume 3. Violette Kaiser Pflaume 3 incor.

A European variety similar to the German Prune. Tree large; fruit large, obovate to oval; skin reddish-bluc; flesh yellow, aromatically sweet; freestone; mid-season. Blue Eye. Domestica. I. Kerr Cat. 1894.

Mentioned as of German origin by J. W. Kerr, who obtained the varicty from Charles Luedloff, Carver, Minnesota.

Blue Matchless. Domestica. Mentioned in Forsyth Treat. Fr. Trees 21 . 1803.

Bluemont. Angustifolia watsoni. I. Am. Pom. Soc. Rpt. 126. 1889. 2. Bailey Ev. Nat. Fruits 222. 1898 .

Introduced by E. Gale of Manhattan, Kansas, about 1860. Fruit of medium size, round, flattened, dull red with heavy bloom; flesh yellow, coarse; flavor fair; clingstone; early.

Blue Moldavka. Domestica. I. Ont. Fr. Gr. Assoc. I:17, 74. I894, 2. Ia. Sta. Bul. 31:347. 1895. 3. Kan Sta. Bul. Ior:119, 120 fig. 190r. 4. Budd-Hansen Am. Hort. Man. 2:306. 1903. 5. Can. Exp. Farm Bul. 43:38. 1903.

Moldavka 1, 3. Voronesh Blue 5. 
Blue Moldavka was recived from Russia by J. L. Budd of the Iowa Experiment Station about 1882 in a lot of sprouts labeled Moldavka. Tree hardy and productive; fruit large, oblong; suture a line; cavity of medium size; stem short; dark purple; bloom thick; dots numcrous, russet; flesh greenish-yellow, firm, dry; flavor not high; quality fair; stone semi-clinging; mid-season.

Blue Plum. Domestica. I. Horticulturist 7:404. 1852, 2. Downing Fr. Trees Am. 900. 1869 .

Fruit of medium size, roundish-oval; suture obscure; skin dark blue with light bloom; flesh yellowish-green, juicy, sweet and refreshing; clingstone; early.

Blue Primordian. Domestica. 1. Parkinson Par. Ter. 575. I629. 2. Rea Flora 206. ${ }_{1} 676$.

An old variety of the same shape as the Red Primordian but smaller and of a violetblue color; of good taste; ripens early, productive.

Blue Prolific. Domestica. I. Flor. and Pom. 89. 1876. 2. Hogg Fruit Man. 722. I884.

3. Guide Prat. $156,35^{6}$. 1895.

Blue Prolific 3. Fertile Bleue 3. Rivers' Blue Prolific 2. Rivers' No. 4 I.

Tree hardy, productive; fruit below medium in size, oval, slightly narrowed at the stem end; cavity and suture shallow; dark purple, with thin bloom; flesh dull greenish-yellow, juicy; flavor brisk and agreeable; a cooking plum; stone clinging; ripens early.

Blute Prune. Domestica. I. Hoffy Orch. Comp. 2. 1842.

Hoffy published a colored engraving of this variety, but did not describe it. Fruit long-oval; suture deep; dark blue.

Blue Rock. Domestica. I. Can. Exp. Farms Rpt. 423. 1903.

A secdling from Thomas Rivers, England. Tree upright, productive; fruit of medium size, round; carity small; suture distinct; dark purple; dots small, gray; flesh yellow, juicy, swcet, rich; clingstone; early.

Blue Tweens. Domestica. 1. Horticulturist 25:204. 1870. 2. Am. Pom. Soc. Rpt. 52. I871.

A seedling, raised by G. P. Peffer of Pewaukee, Wisconsin, about 1855 . Tree hardy, slow in growth; fruit in pairs, giving rise to the name; flesh yellowish-green, adhering to the stone on one side; flavor sprightly subacid; late.

Blue Violet. Domestica. Mentioned in Ray Hist. Plant. 2:1528. 1688.

Blum. Domestica. 1. Cultivator 3d Ser. 8:280 fig. 1860. 2. Downing Fr. Trees Am. 900. 1869 .

A seedling from North Carolina resembling Nelson's Victory in color and shape. Size above medium, oval, dull orange with numerous small brown dots; flesh yellowishbrown, juicy; good; early.

Bohemian Prune. Domestica. x. Kerr Cat. 1894.

Introduced by J. W. Kerr, who secured plants from Charles Luedloff, Carver, Minnesota. Tree upright, vigorous, productive; fruit large, roundish-oval, dark purple; good.

Bomberger. Americana. 1. Terry Cat. 1900. 2. Wis. Sta. Bul. 87:12. г90г.

A variety grown by $\mathrm{H}$. A. Terry of Crescent, Iowa, from seed of Harrison; first fruited in 1897 . Tree upright, vigorous, productive; fruit large, roundish; suture 
faint; yellow overlaid with red; flcsh tender, sweet, rich; good; stone round, smooth, abruptly pointed; mid-season.

Bongoume. Triflora. I. Normand Cat, 1891 .

Sold by J. L. Normand, Marksville, Louisiana, as a Japanese plum resembling an apricot.

Bonne Bouche. Domestica. I. Thompson Gard. Ass't 4:156. 1901.

Of French origin. Fruit medium, greenish-yellow; flesh golden-yellow, tender, juicy; flavor delicious; mid-season; valuable for dessert.

Bonne de Bry. Domestica. I. Can. Exp. Farm Bul. 2 d Ser. 3:50. 1900. 2. Can. Exp.

Farms Rpt. 480. 1904. 3. Soc. Nat. Hort. France Pom. $5^{26}$ fig. 1904.

Originated in the valley of the Marne near Bry-sur-Marne, France. Tree vigorous; fruit below medium, globular; suture shallow; skin dark purple; heavy bloom; flesh greenish, juicy, sweet, tender; good for canning; stone very small; very early.

Bonnemain de la Digue. Domestica? I. Mathieu Nom. Pom. 423. I889.

Found in the reference given above and in Journal de la Societe Nationale et Centrale d'Horticulture de France 562. 1875 .

Bonne Rouge. Domestica. Listed in Lond. Hort Soc. Cat. 144. 1831.

Bonnet d'Eveque. Domestica. I. Hogg Fruit Man. 353. 1866. 2. Downing Fr.

Trees Am. 900. 1869. 3. Mathieu Nom. Pom. 422. 1889. 4. Guide Prat. I63, 352. I 895 .

Bischofsmütze 3. Bonnet d'Eveque 3. Die Bischofsmütze 4.

Tree vigorous, upright; fruit medium, obovate, dark purple; flesh rich; freestone; good; late.

Bossland. Hortulana mineri $\times$ (Domestica? $\times$ Hortulana). I. Ia. Sta. Bul. 46:263. I 900.

A cross between Miner and a seedling of Quackenboss and Wayland, originating with Theodore Williams, Benson, Nebraska, in 1893 . Tree vigorous, spreading; fruit medium, dark red; flesh coarse, dry; stone semi-clinging; mid-season.

Boulouf. Domestica. I. Downing Fr. Trees Am. 901. 1869. 2. Hogg Fruit Man. 688. I884. 3. N. Y. Sta. An. Rpt. 15:291. 1896.

Bouloff 3 .

Large, roundish-oval; suture a line; stem short and thick; red covered with thick bloom; dots brownish; flesh yellow, juicy and sweet; good.

Bouncer. Americana. I. Can. Exp. Farm Bul. 43:29. I903.

A seedling of Yosemite Purple grown at the Central Experimental Farm, Ottawa, about 1900. Fruit large, roundish; suture a line; uniform deep purplish-red; dots numerous, yellow, distinct; moderate bloom; flesh deep yellow, juicy, sweet and rich; good; clingstone; mid-season.

Bower. Domestica. 1. Am. Pom. Soc. Rpt. 122. 1860. 2. Gard. Mon. 3:314. 1861. Bower's Gage I, 2 .

A seedling raised by a Mr. Bower of Philadelphia about $185^{\circ}$. Tree lacking in vigor; fruit oblong, yellow, like Lawrence; probably of Reine Claude parentage; good.

Bowle. Domestica. I. Parkinson Par. Ter. 576. 1629. 2. Rea Flora 207. 1676. Bole 2.

Described by Rea as of "middle size, black, flat on one side and well tasted." 
Brackett. Americana. 1. Terry Cat. 1900.

One of H. A. Terry's varieties coming from a seed of Harrison. Tree strong, upright and productive; fruit large, pale yellow overspread with dark red; flesh yellow, firm; good; stone semi-clinging.

Brahy. Domestica. 1. Hogg Fruit Man. 353. 1866. 2. Downing Fr. Trees Am. 9o1. 1869. 3. Mathicu Nom. Pom. 445. 1889.

Brahy's Green Gage 1, 2. Brahy's Green Gage 3. Reine-Claude de Brahy I, 2, 3. Reine-Claude von Brahy 3 .

Supposed to have been raised by M. Brahay Eckenholm, at Herstal, near Liege, Belgium. Fruit very large, round; suture distinct; skin yellowish-green, with fine bloom; flesh rich yellow, tender, juicy, very rich flavor; mid-season; a trifle later than Reine Claude, which it otherwise resembles.

Brainerd. Americana. 1. Cornell Sta. Bul. 38:36. 1892. 2. Waugh Plum Cult. 144. 1901. Brainerd's Best 2,

A wild variety found in Ramsay County, Minnesota, prior to 1884 . Fruit small; poor; worthless.

Brandon Ruby. Nigra. Mentioned in Can. Exp. Farm Bul. 43:39. 1903.

Brandy Gage. Domestica. 1. Hogg Fruit Man. 371. 1866. 2. Fell Cat. 1893.

3. Guide Prat. 163, 352, 1895. 4. Garden 62:433. 1902.

Impériale de Mann 3. Mann's Imperial I, 3. Mann's Brandy Gage I, 3.

A variety of European origin resembling a small Golden Drop. Fruit small, yellow, with heavy bloom; flesh melting and sweet; good; early.

Brant of Naples. Domestica. I. Can. Hort. Soc. An. Rpt. 19:253. 1896.

Mentioned as hardy. This variety may be the same as Beauty of Naples.

Brauman. Domestica. 1. Can. Exp. Farms Rpt. 547. 1901.

An unproductive German variety. Fruit medium in size, globular; stem short; suture a line; skin greenish-yellow; flesh green, coarse, dry, sweet, pleasant; stone clinging; early.

Braunauer Damascenenartige Pflaume. Species? Mentioned in Mathieu Nom. Pom. 423. 1889 .

Breck. Triflora $X$ ? I. Vt. Sta. Bul. 67:7. 1898. 2. Waugh Plum Cult. 204.1901. First offered for sale in 1899 by F. T. Ramsey of Austin, Texas. Fruit oblong or slightly conical, medium in size; stem short; suture lacking; bright red. indistinctly striped; dots many, small, white, inconspicuous; bloom light; flesh red, fibrous; clingstone; much like Wild Goose, but somewhat firmer.

Brevoort Purple. Domestica. r. Kenrick Am. Orch. 203. r835. 2 Am. Pom. Soc. Cat. 222, 244. 1858. 3. Downing Fr. Trees Am. 901 , 1869. 4. Mathieu Nom. Pom. 448, 1889 .

Brevoort's Purple 4. Brevoort's Purple Bolmar I. Brevoort's Purple Washington 1, 3, 4. Brevorts 2. Brevort's Purple 3. Brevort's Purple 4. Brevorts' Purple Bolmar 4. Brevorts Purple Bolmar 3. New York Purple 3, 4. Rote Washington 4. Rouge de Brevoort. 4. Washington 4. Washington Purple 3, 4 .

A seedling grown by Henry Brevoort of New York from a stone of Washington planted in I8r9. Fruit large, oval; suture distinct at the base; skin reddish-purple; 
flesh yellow, soft, juicy, vinous; clingstone; mid-season; rejected by the American Pomological Socicty.

Briancon. Domestica? 1. Lond. Hort. Soc. Cat. 144. 1831. 2. Prince Pom. Man.

2:105. 1832. 3. Poiteau Pom. Franc. I. 1846.

De Briançon I, 3. Prune de Briancon 3. Prune de Brigantiaca 2, 3.

A variety indigcnous to the Alps in southeastern France. Trees grow to the height of eight or ten feet; fruit small, nearly round, smooth, yellow, with reddish tinge; flesh yellow; freestone. The stone contains a bitter kerncl, from which is extracted a valuable oil. Prince considered the tree a hybrid between the plum and the apricot.

Brignole. Domestica. 1. Miller Gard. Dict. 3. 1754. 2. Knoop Fructologie 2:55. 1771. 3. Lond. Hort. Soc. Cat. 151. 1831. 4. Prince Pom. Man. $2: 67.188_{2}$. 5. Floy-Lindley Guide Orch. Gard. 295, 383. 1846.

Prune de Brignole I. Brignole Plum I. Brignole Jaune 2. Perdrigon de Brignole Gros 3. Perdrigon de Brignole ?4. Brignole Jaune 5. Prune de Brignole 5.

The Brignole plum is named from Brignoles, a town in France where it is used with the White Perdrigon for the famous Brignoles Prunes. Duhamel and several others have confused the two varieties but they seem to be distinct. The Brignole is larger, its skin less tough, flesh more yellow and the season later than White Perdrigon.

Brignole Violette. Domestica. I. Knoop Fructologie 2:55. 1771. 2. Quintinye Com. Gard. 68, 69. 1699. 3. Cal. State Bd. Hort. Rpt. 107. 1891.

Brugnole 2. Brignole 2. Brignole 3.

This seems to be a purple strain of the Brignole which has found its way into California. Fruit oval, medium in size, violet; dots light yellow, yellow spots on the sunny side; flesh greenish-yellow, tender, juicy, sweet; freestone; best adapted to a warm climate.

Brill. Cerasifera. 1. Gard. Mon. 17:305. 1875. 2. Vt. Sta. An. Rpt. 13:368. 1900.

3. Waugh Plum Cult. 230. 1901. 4. Ga. Sta, Bul. 67:272. 1904.

This plum is thought to have originated in Mississippi and was introduced by J. T. Whitaker, Tyler, Texas. Tree vigorous, with an upright-spreading habit; fruit small, round; cavity broad, shallow; stem long, slender; suture a line; bright red with yellow dots; bloom thin; skin thin; flesh yellow, soft, juicy; quality fair; stone small, clinging; early; listed in the American Pomological Society catalog of fruits for 1875 but removed in 1883 .

Bristol. Domestica. I. Ill. Hort. Soc. Rpt. 212.1904.

Bristol, as tested in Illinois, is very similar to, if not identical with the Lombard.

Briton Seedling. Domestica. I. Montreal Hort. Soc. Rpt. 92. 1885.

An unproductive seedling of Canadian origin. Fruit of medium size, very dark blue; bloom heavy; flesh greenish, firm, juicy, sweet and pleasant; late.

Brittlewood. Americana. I. Wis. Sta. Bul. 63:30. 1897. 2. U. S. D. A. Yearbook 477,478 , P1. LXII. 1902.

Brittlewood No. I 2.

Theodore Williams of Benson, Nebraska, grew this variety from seed of Quaker pollinated by Harrison. Tree large, vigorous, spreading; fruit large, nearly round, 
symmetrical; cavity small, shallow; stem medium; suture shallow; dark red when fully ripe; dots numerous, small; bloom thick; skin thick, tenacious; flesh yellowish, meaty, juicy, mild subacid, rich; good; stone oval, large, clinging; mid-season.

Brittlewood No. 3. Americana. 1. Kerr Cat. 5. 1898.

From the same source as Brittlewood but from the reciprocal cross. The two varieties are similar in all respects except that Brittlewood No. 3 is about a week earlier. Britzer Egg. Domestica. 1. Can. Exp. Farms Rpt. 548. 1901.

Originated in Germany. Tree productive; fruit bclow medium size, egg-shaped; stem short; suture wide, shallow; yellow; bloom thin; flesh yellow, juicy, sweet, pleasant; stone large, semi-clinging; mid-season.

Brock. Species? r. Can. Hort. 18:350. I895. General Brock r.

A seedling grown by J. K. Gordon of Whitby, Ontario. Said to be early and attractive.

Brodie. Domestica. I. Can. Exp. Farm Bul. 43:33. 1903.

A seedling tree known in the family of R. Brodie, Montreal, Quebec, for three generations. Fruit below medium, almost round, dark purple; dots obscure; suture a line; flesh greenish-yellow, sweet, rich; good; mid-season.

Brompton. Domestica, I. Lond. Hort. Soc. Cat. 144. 183 I.

An old variety formerly much used as a stock.

Brooklyn. Americana. I. Terry Cat. I goo.

A seedling of Harrison grown by H. A. Terry, Crescent, Iowa. Tree vigorous, spreading, productive; fruit large, oblong, dark red over a yellow ground; flesh firm, yellow; good; stone semi-clinging.

Brunner Zwetsche. Domestica. 1. Mathieu Nom. Pom. 424. 1889.

Undescribed by Mathieu who took the name from Wiener Garten-Zeitung 286 . 1884.

Brunswick. Munsoniana. I. Lovett Cat. 44. 1893. 2. Budd-Hansen Am. Hort. Man. 294. 1903. 3. Ohio Sta. Bul. 162:245, 254, 255. 1905.

According to the Lovett Nursery Company, this plum originated in Missouri and was introduced by them. Fruit above medium, roundish-oval; stem of medium length, slender; bright red on a yellowish ground; flesh yellow, meaty, sweet; good; early. Brussels. Domestica. Mentioned in Lond Hort. Soc. Cat, 144. I831.

Bryan. Americana. I. Waugh Plum Cult. I44. $190 \mathrm{r}$.

W. J. Bryan r. Colonel Bryan I.

One of H. A. Terry's numerous seedlings which fruited first in 1896 . Fruit large, oblong, rich, dark red; flesh firm; good.

Buchanan. Domestica. Mentioned in Lond. Hort. Soc. Cat. I44. I831.

Buchner Konigspflaume. Domestica. Listed in Mathieu Nom. Pom. 424. 1889, Braunaner Königs Pflaume. Braunaner Violetter Perdrigon. Royale de Braunau. Budd. Americana. I. Terry Cat. I goo. Prof. Budd r.

Originated with H. A. Terry of Iowa and first fruited in 1897 . Tree upright, productive; fruit large, bright red, with numerous white dots; flesh firm; good; midseason. 
Buel. Domestica. I. Downing Fr. Trees Am. 272. 1845. 2. Ann. Pom. Belge 8:59, Pl. 1860. 3. Mathicu Nom. Pom. 424. 1889.

Buel's Favorite 1. Bucl's Liebling's Zwetsche 3. Buel's Favorite 3. Favorite de Buel 3. Prune Buel's Favorite 2.

Raised about 1840 by Isaac Denniston of Albany and named after the distinguished agriculturist, Judge Buel. Fruit large, ovate, broadest toward the stem; stalk long and thick; pale green, thickly sprinkled with lighter dots and speckled red near the stalk; flesh greenish-yellow, firm, juicy and rich; good; stone nearly free; mid-season.

Buffalo Bill. Species? 1. Letter from F. T. Ramsey.

Selected from the wild plums of Texas.

Buhl-Eltershofen. Domestica. Mentioned in Mathieu Nom. Pom. 424. I889.

Buhl-Eltershofen Zwetsche.

Buhler. Domestica. I. Lucas Vollst. Hand. Obst. $473 . \quad 1894$.

Buhler's Early Prune I.

Fruit of medium size, egg-shaped, beautiful blue; table and market plum; early.

Bulah No. 4. Hortulana mineri. 1. Ia. Sta. Bul. 46:263. 1900.

A seedling from a Miner tree pollinated by wild plums, from J. F. Wagner, Bennett.

Cedar County, Iowa, in I894. Fruit medium to large, dark red; late.

Bullman. Domestica. 1. Can. Exp. Farms Rpt. 464. 1900.

A vigorous variety from Germany. Fruit above medium, oval; suture deep; sides unequal; yellow with red dots; flesh greenish-yellow, juicy, sweet, pleasant; freestone; early.

Bulgaria. Domestica? I. Mathieu Nom. Pom. 424. I889.

Mathieu refers this variety to Pomologische Monatshetfe 323. 1887.

Bulgarian. Domestica. 1. Cal. Sta. Bd. Hort. 292. 1885-6. 2. Ibid. 107 fig. 1891.

3. Wickson Cal. Fruits 357. 1891. 4. N. Mex. Sta. Bul. 27:126. 1898.

Belgarian Prune I.

A variety grown chiefly in the vicinity of Haywards, Alameda County, California, for drying. Tree vigorous, bears early and regularly, productive; fruit above medium, roundish-obovate, having a short neck; suture shallow; apex slightly compressed; stem slender, one inch long; cavity narrow and shallow; dark purple; flesh greenishyellow, sweet and rich with a pleasant flavor; good; stone semi-clinging; season early.

Bullock. Domestica. I. Quintinye Com. Gard. 69. 1699. Bullock's Heart 1.

Described as an "extream large plum."

Bull Plum. Domestica. I. Quintinye Com. Gard. 68. I699.

Ilentioned by Quintinye as a "dry plum."

Bunker Hill. Domestica. I. Bailey Ann. Hort. 196. 1891. 2. Me. Sta. An. Rpt. I2: 64. 1896. 3. Vt. Sta. Bul. 134:41. 1902.

Plattman's Bunker Hill I.

Orignated at the Yates County Nurseries near Seneca Lake, New York, by J. H. Plattman, from a seed of a plum which grew near a Washington and a Reine Claude. Tree upright, vigorous and productive; fruit medium to large, blue; good; mid-season. Bunte Fruh Pflaume. Domestica. Nentioned in Mathieu Nom. Pom. 424. I8s9. 
Bunter Perdrigon. Domestica. I. Lange Allgem. Garten. 2:419. 1879. 2. Lauche

Deut. Pom. 18, Pl. 4. 1882. 3. Mathieu Nom. Pom. 424. 1889.

Der Bunter Perdrigon 2. Perdrigon Bariole 3.

A European variety called Bunter because of its variegated colored fruit. Tree large; fruit medium, violet-blue on the sunny side, red and green on the shaded side; flesh greenish, juicy, sprightly; quality fair; freestone; recommended for table and drying purposes in Germany.

Burbank First. Triflora. 1. Rural N. Y. 65:730. 1906.

Burbank's First I.

Tree vigorous, productive; fruit small, red and yellow; early; inferior.

Burbank No. I. Triflora. 1. Cornell Sta. Bul. 62:22, 1894.

One of Burbank's seedlings said to resemble Berckmans.

Burbank No. 7. Triflora $\times$ Domestica. 1. Mich. Sta. Bul. 118:52. 1895. 2. Ibid. 169: 249. 1899 .

Tree vigorous, round-topped, branches upright; fruit roundish-ovate; cavity narrow, deep, suture broad, shallow; greenish-yellow; flesh pale yellow, sweet, juicy, sprightly, highly flavored; stone turgid, roundish-oval, semi-clinging; mid-season.

Burbank No. I1. Triflora $\times$ Domestica? I. Mich. Sta. Bul. 129:32, 34. 1896.

Both tree and fruit give indications of an admixture of Domestica. Tree not productive; fruit large; flavor good.

Burbank $\times$ Redick. Triflora $\times$ Americana. r. Ia. Hort. Soc. Rpt. 228.1909.

A hybrid from Theodore Williams, Benson, Nebraska, published in the preceding reference under the name of its parents. It resembles the Burbank very closely and is said to be somewhat more hardy than that variety but inferior in quality.

Burchardt Gelbe Fruh Zwetsche. Domestica. I. Mathieu Nom. Pom. 424. I889.

Listed by Mathieu from Wiener Garten-Zeitung 286. I884.

Burettes. Domestica. I. Downing Fr. Trees Am. 374. 1857. 2. Ann. Pom. Belge

$5: 47$, P1. 1857. 3. Mas Le Verger 6:1 5 . I866-73.

Burrettes I. Des Burettes 3. Prune Des Burettes 2.

Originated by M. Gregoire of Burrettes, Belgium, and first reported in 1849. Tree vigorous, hardy ; fruit large, irregularly oval; suture faint; dull greenish-yellow with rose-purple on the sunny exposure; flesh green, fine, melting; juice abundant, sweet, agreeably aromatic; good; freestone.

Burford. Triflora $\times$ Munsoniana. I. Munson Cat. I906-7.

A seedling of Burbank crossed with Clifford from T. V. Munson, Denison, Texas. Tree weeping; branches more slender than those of Burbank; fruit large, round, light, bright red; stone small.

Burgundy Prune. Domestica. 1. Downing Fr. Trees Am. 374. 1857. 2. Mathieu

Nom. Pom. 424. I889. 3. Wickson Cal. Fruits 357. 1891.

Burgunder Zwetsche 2. Prune de Bourgoyne 1, 2. Burgundy Prune 2. Susina Torla d' Nova di Borgogna 2 incor.

Fruit medium, egg-shaped with a neck; suture indistinct; reddish-black; dots minute, numerous; flesh juicy, sugary, pleasant; freestone; mid-season. 
Burlington Gage. Domestica. I. Goodrich N. Fr. Cult. 83. 1849. 2. Downing Fr. Trees Am. 902. I869.

Raised from seed of some unknown "Blue Gage," brought from Connecticut about I80o, and planted by Mrs. Ozias Buel of Burlington, Vermont. Tree hardy, vigorous, productive; fruit medium in size, roundish-oval, dark purplish-blue, with abundant bloom; flesh greenish-yellow, juicy, rich; freestone; early; formerly considered valuable. Burnet. Domestica. I. Lond. Hort. Soc. Cat. 144. 1831. 2. Mag. Hort. 9:163. I843.

Fruit small, roundish, purple; freestone; mid-season; similar to Wine Sour.

Bursoto. Triflora $\times$ Americana. 1. Vt. Sta. An. Rpt. 10:106. 1897. 2. Waugh Plum Cult. 144. 1901 .

A hybrid of Burbank with De Soto, grown and named by Theodore Williams of Benson, Nebraska, about 1890 . Tree of the Americana type; fruit large, oblique, oval; cavity lacking; stem short, thick; light red and yellow; dots small, white; skin thick; flesh yellow, juicy; good; stone semi-clinging; early.

Byefield. Domestica. I. Downing Fr. Trees Am. 272 . 1845.

Fruit small, round; suture a line; light yellow, with red spots around the stem; flesh yellow; clingstone; good; early; rejected by the American Pomological Society in 1888. Caddo Chief. Angustifolia varians. I. Am. Pom. Soc. Rpt. 162. IS81. 2. Cornell Sta. Bul. 38:60, 86. 1892. 3. Tex. Sta. Bul. 32:479. 1894. 4. N. Mex. Sta. Bul. 27:124. 1898. 5. Waugh Plum Cult. 193. 1901.

Found wild in Caddo Parish, Louisiana, and introduced by G. W. Stones, Shreveport, Louisiana. It is favorably reported from the South but not generally recommended, although the American Pomological Society included it in their catalog of fruits in 1897 . Tree low-branching, hardy and productive; fruit of medium size, roundish-oblong; suture shallow; cavity medium deep; skin thick, tough; bright red; flesh reddish-yellow, firm, sweet and juicy; poor; stone large, round, clinging; season early.

Caldwell Golden Drop. Domestica. 1. Downing Fr. Trees Am. 902, 1869.

Caldwell's Golden Drop r.

Possibly an American strain of the Golden Drop. Fruit large, oval, sides often unequal; suture distinct; yellow marbled with crimson in the sun, with thin bloom; stem slender; cavity small; flesh yellow, juicy, sugary, rich; good; clingstone; early. Caldwell White Gage. Domestica. I. Downing Fr. Trees Am. 903. I869.

Caldwell's White Gage I.

A productive variety of American origin. Fruit of medium size, oval, narrowing slightly at the apex; suture shallow; apex pointed; greenish-yellow, dotted with purple in the sun; bloom thick; stem long; flesh greenish-yellow, coarse, juicy, sugary; good; clingstone; mid-season.

California. Americana. 1. Kerr Cat. 1894. 2. Waugh Plum Cult. 145. 190 r.

California Seedling 2. Cal. Seedling 1 .

Fruit of medium size, slightly oblate; cavity medium deep, flaring; stem long; suture a line; bright red; dots many, minute; skin thick, tough; flesh yellow; good; stone roundish, flattened, clinging; mid-season. 
Cambell. Domestica. 1. Downing Fr. Trees Am. 903. 1869.

Cambell's Seedling ז. McCauley's Seedling r.

Fruit large, oval; suture shallow; pale yellow, splashed with green, dotted and marbled with crimson in the sun; bloom light; cavity small; flesh pale yellow, coarse, juicy, sweet; good; semi-clinging; mid-season.

Campbell. Species? 1. Gard. Mon. 25:49, 83, $188_{3}$.

A seedling found growing on a Mr. Campbell's farm near Abingdon, Virginia. Very latc and a long keeper.

Canada Blue. Domestica. r. Lutts Cat. I890?

Mentioned as a "small, round, early, blue plum, very productive and excellent for preserving."

Canada Orleans. Domestica. 1. Downing Fr. Trees Am. 3rd App. 180. 1881. 2. Mich. Pom. Soc. Rpt. 466. 1883. 3. Cornell Sta. Bul. 131:183. 1897.

Canada Egg ?1. Canada Egg 2.

Probably originated in the vicinity of Hamilton, Ontario, where it is chiefly grown. Fruit medium to large, reddish-purple, with heavy bloom; flesh yellow, juicy, melting, sweet, rich; early.

Canadian Apricot. Nigra.

The common wild plum of Canada.

Candelaria. Domestica. r. Clarke Prune Industry 41. 1893. Candelaria Prune 1.

About 1881 W. B. Simpson discovered that a supposed Golden Drop tree on the farm of S. A. Clarke, Salem, Oregon, was not true to name. It seemed of value and was named Candelaria from the name of the farm. Fruit large, yellow; flesh solid, subacid; very good; has not been extensively propagated.

Caper. Triflora $\times$ Cerasifera? 1. Vt. Sta. An. Rpt. 12:221. 1899.

Grown between 1890 and 1895 by J. S. Breece, of North Carolina. Waugh states that the fruit and foliage suggest the species mentioned above. Fruit of medium size, oval; cavity shallow; dark red; dots many, minute; skin thick, tough; flesh firm, red, sprightly, subacid; fair in quality; stone large, turgid, clinging.

Capitaine Kirchhof. Domestica. I. Mathieu Nom. Pon. 424, 434. 1889. 2. Guide Prat. 161, 353. 1895.

Capitaine Kirckhof 1. Capitaine Kirckkof 2. Hauptmann Kirchhof's Pflaume I, 2. Kirchlof's Pflaume 1, 2. Prune de Kirchhof 1.

Found by M. Oberdieck of Schaferhof on the estate of a Captain Kirchhof near Nienburg (Hanover). Tree productive; fruit of medium size, round, purplish-brown; bloom thick; flesh yellow, fine, juicy; sweet, aromatic; good; late.

Captain. Hortulana? r. Kerr Cat, 1894. 2. Vt. Sta. An. Rpt. 11:283. 1898.

Columbia 1. Columbia 2.

Introduced about $18_{92}$ by $A$. M. Ramsey and Son of Austin, Texas, under the name Columbia but changed by Waugh in 1898 to Captain to avoid confusion with an older Columbia. Tree vigorous, productive; fruit medium in size, spherical, bright goldenyellow; dots many. conspicuous, whitish; suture a line; skin thin, tough; flesh firm, yellow; good; stone small, clinging; late. 
Capt. Bacon. Americana. r. Meneray Cat.

$\Lambda$ seedling of Weaver grown by II. A. Terry. Tree vigorous; fruit large, red over ycllow; flesh yellow, coarse, rich; freestone; a culinary variety.

Capt. Watrous. Americana. I. Terry Cat. 1900.

A seedling of Harrison grown by H. A. Terry who plucked the first fruit in 1897 . Tree vigorous and productive; fruit large, roundish, yellow overspread with bright red; good.

Caro. Americana mollis. I. Can. Exp. Farm Bul. 43:29, 38. 1903.

A seedling of Wolf which originated at the Central Experimental Farm, Ottawa, Canada, in 1895 . Fruit large, roundish; suture distinct; bright red, showing yellow in patches; dots numerous, yellow, distinct; bloom light; skin thick; flesh deep yellow, juicy, sweet, rich; good; mid-season.

Caroline. Americana? I. Minn. Hort. Sac. Rpt. 412. 1899. 2. S. Dak. Sta. Bul. 93 :II. 1905.

A seedling grown by C. W. H. Heideman, New Ulm, Minnesota. Fruit of medium size, yellowish-red; good; season of Forest Garden; subject to plum-pocket and unproductive.

Carpenter. Species? I. S. Dak. Sta. Bul. 93:11. 1905.

A seedling from Vermilion, South Dakota.

Carson. Domestica.

According to a letter from G. B. Brackett of the United States Department of Agriculture, Carson is a strain of Lombard.

Carstesen. Nigra. I. Can. Exp. Farm Bul. 43:29. 1903.

A seedling grown by H. P. Carstesen, Billings Bridge, Ontario. Tree vigorous, productive; fruit of medium size, roundish; cavity narrow; suture obscure; apex rounded; yellow, nearly covered with deep red; dots obscure; bloomless; skin thin, tender; flesh yellow, juicy, sweet; good; stone flat, roundish, nearly free; early.

Carver. Americana. r. Kerr Cat. 1896-1900. 2. Waugh Plum Cult. 145. 1901.

Introduced by Charles Luedloff, Cologne, Minnesota. Fruit small, roundish-oval; cavity shallow; stem slender; suture a line; red, sometimes mottled; dots many, small; skin tough; flesh yellow; quality fair; clingstone; late; unpromising.

Catalano. Domestica. 1. Gallesio Pom Ital. 2: P1. 1839.

Susino Catalano I. Prunus Catalanica 1. Catalana-Susina 1. Catelane 1.

This Italian variety is much larger than the Early Yellow, known also as the Catalonia. They may be related, however, for Gallesio says that there are many varieties from Catalonia which are similar in shape and taste. Fruit large, oblong, slightly necked; skin greenish and greasy; pulp green, soft, tender, juicy and pleasant.

Catalana Propria. Domestica. I. Gallesio Pom. Ital. 2: Pl. 1839.

Catalana Toscana 1 .

A good strain of Catalano grown in Italy.

Catelano Giallo. Domestica. 1. Gallesio Pom. Ital. 2: P1. 1839.

Buon-Boccone I. Buon-Bocconi I.

This variety is figured under the name Buon-Boccone and described under Catelano 
Giallo. As early as 1839 it was well known in parts of Italy and was then ranked next to the Reine Claude in quality. Fruit large, oval, dull yellow, tinged with red; pulp yellow, tender, sweet and highly flavored.

Catelano Violaceo. Domestica. I. Gallesio Pom. Ital. 2: Pl. 1839.

Catelana Morella? 1. Susina Vecchietti ז. Susino Vecchietti 1.

Gallesio described this plum as a strain of the Catelano and adds that it is grown in abundance at Florence. Tree medium in size; fruit large, oval; suture distinct; violet; pulp yellowish, tender, juicy, sweet and highly flavored.

Catherine. Domestica. I. Can. Exp. Farm Bul. 2d Ser. 3:50. 1900.

Tree strong, moderately productive; fruit above medium size, egg-shaped; suture a line; cavity small; reddish-purple; bloom thin; flesh greenish-yellow, firm, juicy, sweet; pleasant; good; stone large, clinging; mid-season.

Cel. Cerasifera $\times($ Triflora $\times$ Simonii). r. Vt. Sta. Bul. 67:8. 1898 .

Originated and named by Luther Burbank, who states that it is a cross between Myrobalan and Wickson. Fruit of medium size, egg-shaped; cavity rounded; suture indistinct; apex pointed; bright, transparent yellow; flavor resembling the Americanas; good; stone of medium size, clinging.

Centennial. Species? I. Ia. Hort. Soc. Rpt. 308. 1884.

Originated in 1877 by George U. Oberholtzer, Sioux City, Iowa. Fruit of medium size; skin firm; good; ten days later than Miner.

Centralia. Domestica. 1. Wild Bros. Cat. 1892? 2. Can. Exp. Farm Bul. 2d Ser. 3:50. 1900 .

A vigorous variety from $\mathrm{J}$. B. Webster of Centralia, Illinois.

Cerney Perdrigon. Domestica. 1. Quintinye Com. Gard. 69. 1699. 2. Langley Pomona 93, 97. 1729 .

Cernay Perdrigon 2.

A variety long since obsolete. Fruit roundish, slightly flattened, red; good.

Ceur de Beuf. Domestica. 1. Quintinye Com. Gard. 69. 1699.

Mentioned by Quintinye in 1699 as a violet-red plum. Its relationship to Coeur de Boeuf is unknown.

Chabot Blood. Triflora $\times$ Simonii. I. Cornell Sta. Bul. 106:49. 1896 .

Fruit of medium size, dull red or cinnabar; flesh firm, brick red, very juicy, sweet, aromatic; late.

Champion. Americana. I. U. S. D. A. Rpt. 392. 1891. 2. Terry Cat. 1900. 3. Waugh Plum Cult. 145 fig. 1901 .

A seedling of Hawkeye grown by H. A. Terry; first fruited in 1891 . Fruit large, roundish; suture a line; red over yellow; dots many, conspicuous; skin firm; flesh yellow, firm; flavor not high; quality fair; stone large, oval, flattened, clinging; late. Chancellor Gage. Domestica. I. Lond. Hort. Soc. Cat. I47. I831.

Fruit of medium size, round, yellow; quality fair; a table plum.

Chapin. Domestica. I. Downing Fr. Trees Am. 903. 1869.

Grown by Aaron Chapin, Hartford, Connecticut. Tree vigorous; fruit of medium size, oval; suture shallow; stem long, slender; cavity deep; light reddish-purple; flesh yellow, juicy, vinous; good; semi-clinging; late. 
Chariot. Species? I. Harrison Cat. 1897.

Probably misnamed.

Charity Clark. Munsoniana $\times$ Prunus persica. I. Cornell Sta. Bul. 38:77. 1892.

Blackman I.

For a history of this variety see Blackman.

Charlotte. Domestica. 1. Prince Treat. Hort. 25. 1828. 2. Prince Pom. Man. $2: 59$.

1832. Tomlinson's Charlotte 1,2 . Charlotte 2.

Prince says this is "a seedling of Yellow Egg raised by Judge Tomlinson." Tree very vigorous; fruit shaped like its parent, yellow; flesh sweet with an agreeable flavor; early.

Charmer. Nigra? I. Can. Exp. Farms Rpt. 426 1900.

A seedling raised at Indian Head Experimental Farm, Northwest Territory, Canada.

Fruit large, red, bitter; early.

Chautauqua. Nigra? I. Can. Exp. Farm Bul. 43:38. 1903.

A variety grown on the Experimental Farm at Ottawa, Canada.

Chauviere. Domestica. I. Rev. Hort. 535. I89r.

Reine-Claude Chauviere I. Belle de Doue I incor.

Grown by M. Chauviere, a Frenchman, who had purchased it under the false name of Belle de Doue. Trees variable in productiveness; fruit roundish-oblate; suture shallow; skin changes from marbled greenish-yellow to dark red, dotted and stained with cinnabar-red; flesh yellowish-green, soft, juicy, honey-like, very agreeable; clingstone.

Cheresoto. Prunus besseyi $\times$ Americana. Cir. S. Dak. Exp. Sta. I9ro.

Cheresoto originated with N. E. Hansen of the South Dakota Experiment Station as a result of a cross of Prumus besseyi with De Soto. After fruiting for one year it was introduced in rgro. Fruit small, oval; apex pointed; black; bloom heavy; flesh yellowish-green, sprightly; clingstone.

Cherokee. Americana. 1. Cornell Sta. Bul. 38:78. r892. 2. Waugh Plum Cult. 145. $190 \mathrm{r}$.

Said to have been found wild in Kansas. Fruit medium in size, roundish-oblong; skin blotched red, thick; clingstone.

Cherry. Nigra. I. N. J. Hort. Soc. Rpt. r86. 1885. 2. Ia. Sta. Butl. 46:264. 1900.

Found wild near Chaseburg, Vernon County, Wisconsin, in 1870 by E. Markle of LaCrosse, Wisconsin; introduced by the discoverer. Tree hardy, productive, an early bearer; fruit resembles that of De Soto except that it is larger and about twenty days earlier in ripening.

Chester. Domestica. I. Can. Exp. Farms Rpt. 547. 1901.

An unimportant seedling from the British Columbia Experiment Station not to be confused with the Chester of Forsyth. Tree vigorous, unproductive; fruit medium in size, obovate; cavity narrow, deep; suture shallow; reddish-pink with numerous golden dots; flesh firm, juicy, sprightly, slightly coarse; stone large, clinging; mid-season.

Chester. Domestica. I. Forsyth Treat. Fr. Trees 20. 1803.

Mentioned by Forsyth as very productive; fruit rich; season late. 
Chester County Prune. Domestica. I. Downing Fr. Trees Am. 903. r869.

From Chester County, Pennsylvania. Tree vigorous; branches slender; fruit of medium size, oval; suture faint; cavity small; stem long, slender; black with thick bloom; flesh greenish, sweet; good; freestone; mid-season.

Chestnut. Domestica. I. Lond. Hort. Soc. Cat. I44. I831.

Fruit purple, oblong; size and quality medium; clingstone; a table plum.

Chicrigland. Species? 1. Vt. Sta. Bul.67:9. 1898, 2. Vt. Sta. An. Rpt. 14:270. 1901.

Grown by T. V. Munson, from seed of a plum grown by F. T. Ramsey, Lampasas County, Texas. Tree vigorous; branches zigzag, drooping; fruit oval, small; cavity of medium depth, rounded; suture faint; dull red over yellow; surface a trifle fuzzy; dots many; bloom heavy; skin thin, tender, not astringent; flesh soft, yellow, mild acid, aromatic; quality fair; stone clinging.

Chinook. Nigra? I. Can. Exp. Farms Rpt. 426. 1900.

A seedling raised at the Experimental Farm, Indian Head, Northwest Territory, Canada. Fruit of medium size, red; carly.

Chippewa. Americana. I. Ia. Hort. Soc. Rpt. 85. I890. 2. Cornell Sta. Bul. 38:37. 1892. 3. Ia. Sta. Bul. 31:346. 1895. Chippeway 2.

A dwarf variety from Chippewa Falls, Wisconsin, often bearing when only two feet in height. Fruit small, deep red; skin medium thick; flesh firm, sweet; stone free, small, pointed, rough; worthless.

Choptank. Munsoniana. 1. Bailey Ann. Hort. 133. 1893. 2. Am. Pom. Soc. Cat.

40. 1899. 3. Ohio Sta. Bul. 113:154. I899. 4. Waugh Plum Cult. 184. 1901.

A seedling of Wild Goose grown by J. W. Kerr, Denton, Maryland; introduced in 1893; listed in the American Pomological Society catalog of fruits in 1899 . Tree vigorous, prolific and hardy; foliage large, ornamental; fruit above medium to large, variable in shape, roundish-oblong to oval; cavity shallow; stem long; suture distinct; skin thin, tough; bright red; dots numerous, light colored; bloom thin; flesh yellow, firm, rather acid but of good quality; stone medium in size, oval, flattened, clinging; medium early. Christian. Domestica. 1. Parkinson Par. Ter. 576. I629. 2. Rea Flora 209. 1676. Nutmeg 1, 2.

Shrubby in growth; fruit small, dark red; late; obsolete.

Christie. Americana. I. Ia. Sta. Bul. 46:264. r 900. 2. Waugh Plum Cult. 145. 1901.

Taken from the woods by W. Christie, Villisca, Iowa, in 1887 . Fruit round, truncate, medium in size; apex flattened; cavity wide; suture lacking; yellow, covered with red; bloom light; skin thick; flesh yellow, melting, flavor sweet, luscious; very good; stone circular, thick, semi-clinging.

Churchill. Domestica. I. N. Y. Sta. An. Rpt. I2:611. I893.

A seedling found by G. W. Churchill on the shores of Lake Cayuga. Fruit large, blue; quality poor; not valuable.

Chypre. Domestica. 1. Duhamel Trait. Arb. Fr. 2:82. 1768. 2. Kraft Pom. Aust. 2:37, Tab. 187 fig. 2. 1796. 3. Prince Pom. Man. $2: 96.1832$. 4. Hogg Fruit Man. 690 . I 884 . 
Cyprian 3. Die Pflaume aus Cypern 2. De Chypre 3. De Chypre 4. Prune de Chypre 1. Prune de Chypre 2, 3.

Chypre is an old varicty of unknown origin. Fruit of medium size, round; suture shallow; cavity large: purple; bloom thick; flesh firm, greenish, sweet when fully ripe; quality fair; stone clinging; early.

Cinnamon. Domestica. I. Ray Hist. Plant. 2. I688.

An old and unimportant variety now obsolete.

Cistena. Prunus besseyi $\times$ Cerasifera. Cir. S. Dak. Exp. Sta. 1910.

Introduced in 1909 by the originator, N. E. Hansen of South Dakota Experiment Station. It shows the glossy, purple foliage of the Pissardi plum, one of its parents, and may be of some value as an ornamental.

City. Americana. 1. Minn. Hort. Soc. Rpt. 128, 1890. 2. Wis. Sta. Bul. 63:32. 1897. 3. Ont. Fr. Gr. Assoc. Rpt. 144. 1901. 4. Waugh Plum Cult. 146. 1901.

This variety came from the seed of a wild plum growing one-half mile from Springfield, Minnesota; introduced by $\mathrm{H}$. Knudson in 1890 . Tree upright when young but with a weeping tendency when older, vigorous, hardy and productive; fruit large, nearly round; cavity of medium width, deep; suture a distinct line; dark dull red over yellow; dots numerous, small, yellow, distinct; bloom heavy; skin thick, tough, slightly astringent; flesh yellow, firm, juicy, sweet; good; stone of medium size, oval, flattened, semiclinging; medium to late.

Clara. Munsoniana. I. Am. Gard. 14:51. 1893. 2. Tex. Sta. Bul. 32:482. 1894.

A large and attractive seedling of Wild Goose grown and introduced by G. Onderdonk, Texas.

Clarendon. Angustifolia watsoni. I. Bailey Ev. Nat. Fruits 223. 1898.

One of several seedlings secured from northern Texas by F. T. Ramsey.

Clark. Species? I. Cornell Sta. Bul. 38:48. 1892. 2. Budd-Hansen Am. Hort. Man. 294. I903.

A wild seedling found in Anne Arundel County, Maryland. Tree moderatcly vigorous, not hardy in the North; fruit of medium size, roundish, bright red; dots numerous; stem short; cavity broad, deep; skin tough; flesh yellow, firm; inferior. Cleavinger. Domestica. 1. U.S.Pat. Off.Rpt. 274 . 1854. 2. Hoffy N. Am. Pom. 1860.

Originated about 1845 with $\approx$. Mr. Fernsler of Philadelphia from the stone of an unnamed seedling; introduced by Wm. S. Cleavinger of West Philadelphia. Tree vigorous; fruit large, oval; suture distinct; dark purple; stem short, thick, surrounded by a fleshy ring; flesh deep yellow, coarse, juicy, vinous, slightly subacid; good; midseason.

Cleveland. Munsoniana. I. Wis. Sta. Bul. 63:49. 1897. 2. Can. Exp. Farm Bul. 2d Ser. 3:50. 1900. 3. Terry Cat. 1900. Mrs. Cleveland I, 3.

A seedling of Wild Goose grown by H. A. Terry, Crescent, Iowa, in 1883 . Tree vigorous, spreading and productive; fruit large, oblong, slightly pointed at the ends, light mottled red; good; clingstone; very early.

Clifford. Munsoniana. 1. Cornell Sta. Bul. 38:80. 1892. 2. Kerr Cat. 1894. 3. Waugh Plum Cult. 184. 1901. Mrs. Clifford 1, 3. Mrs. Clifford 2. 
A seedling of Wild Goose grown by Mrs. Clifford of Denison, Texas, and introduced by T. V. Munson and Son of the same place. Tree hardy, vigorous, spreading, productive; fruit large, pear-shaped, sometimes with a very distinct neck; suture shallow; bright scarlet with very small yellow dots; flesh yellow, firm, sweet, aromatic; good; clingstone; a little later than Wild Goose.

Climax's Brother. Triflora $\times$ Simonii. 1. Rural N. Y. 59:655. 1900.

One of Burbank's numerous crosses, having the same parents as Climax. The tree is an upright grower like Simon and the fruit resembles this parent in form and size; not as highly colored as Climax; unknown as yet by plum-growers.

Clinton. Hortulana mineri. 1. Am. Pom. Soc. Rpt. 162. г881. 2. Cornell Sta. Bul. 38:55, S6. 1892. 3. Am. Pom. Soc. Cat. 26. 1897. 4. Waugh Plum Cult. 172. 1901 .

Fruit of medium size, roundish; cavity shallow; stem slender; suture a line; dull red; dots numerous; bloom thin; flesh yellow; quality fair; clingstone; late. Mentioned in the American Pomological Society's Catalog from 1897 to 1899.

Cluck. Angustifolia varians. 1. Kerr Cat. 1895. 2. Am. Pom. Soc. Cat. 38. 1899. 3. Waugh Plum Cult. 194. 1901. 4. Ga. Sta. Bul. 67:273. 1904.

Originated with George Cluck, Austin, Texas; introduced in 1896 by F. T. Ramsey. Tree vigorous, productive; blooms very late; fruit of medium size, roundish-oblong; cavity shallow; bright red with many small, yellow dots; skin tough; flesh yellow, soft; quality fair; stone medium, oval, turgid, clinging; mid-season.

Cluster. Domestica. Mentioned in Ray Hist. Plant. 2:1528. 1688.

Cochet. Domestica. 1. Lucas Vollst. Hand. Obst. 471. 1894. 2. Can. Exp. Farm Bul. 2d Ser. 3:50. 1900.

Cochets Pflaume 1. Cochet Pere r.

Tree vigorous and productive; fruit large, oval, yellow with reddish dots; suture medium; flesh yellowish, rich, sweet, pleasant; early.

Coeur de Boeuf. Domestica. I. U. S. D. A. Div. of Pom. Bul. ro:rg. rgor.

Beef's Heart I. Prunier de Carcassone.

Coeur de Boeuf originated in 1879 at Carcassonne, France, as a seedling of a variety introduced from the province of Lerida, Spain, in 1854 . The following description was made from a tree under test on the grounds of this Station: Tree vigorous, hardy; fruit of medium size, roundish; cavity medium in size and depth; stem slender; suture medium; dark brownish-red, covered with minute russet dots; bloom heavy; skin medium thick; flesh yellowish, meaty, juicy, sweet, rich; good to very good; stone small, oval, semi-clinging; mid-season.

Coe Violet. Domestica. 1. Downing Fr. Trees Am. 905. 1869. 2. Cat. Cong. Pom. France 34r. 1887. 3. Mathieu Nom. Pom. 425. 1889.

Coe à Fruit Violet 3. Coe's Golden Drop Violette r, 3. Coe's Violet I, 3. Coe's Violette 2. Coe Violette 3. Goutte d'Or Violette 3.

A variation from Golden Drop. Tree vigorous; fruit large, oval; suture distinct; cavity small; stem long, thick; light reddish; dots brown, numerous; flesh yellowish, sweet, juicy; good; clingstone. 
Coferer. Domestica. x. Parkinson Par. Ter. 578, 1629 . Coferers I.

Parkinson describes this plum as, "Flat like a Peare Plum, early ripe and black, of a very good relish."

Coinage. Americana. x. Terry Cat. 1900.

Said by its originator, H. A. Terry, to be a scedling of Gold Coin. Fruit large, slightly oblong, pale yellow ground, nearly covered with dark red; flesh firm; clingstone.

Coletta. Angustifolia varians. 1. Cornell Sta. Bul. 38:60, 86. 1892. 2. Waugh Plum Cult. 194. 1901. 3. Ga. Sta. Bul. 67:273. 1904.

This plum was grown by G. Onderdonk of Texas; introduced in 1874 . Tree slow in growth, hardy, somewhat open and thorny; leaves small, foliage sparse; fruit medium in size, round, bright red; skin tough; flesh yellow, soft; poor; clingstone; very early. Coleus. Triflora $\times$ Cerasifera? 1. Vt. Sta. Bul. 67:10. 1898.

Originated with J. S. Breece, North Carolina. Tree ornamental, vigorous; leaves large, reddish, conspicuously veined; fruit small, globular; suture faint; dull deep red; dots faint; skin thick and tough; flesh medium firm, red; flavor flat; quality very poor; stone small, flattened, clinging.

Colman. Americana. 1. Ia. Sta. Bul. 46:264. 1900. 2. Terry Cat. 1900

Collman $\mathbf{r}$.

H. A. Terry first fruited this variety in 1895 . Tree upright, healthy, fairly productive; fruit large, round, brilliant red; good; clingstone; mid-season.

Colorado Queen. Americana. x. Kerr Cat. 1894. 2. Waugh Plum Cult. 146. I901. 3. Olio Sta. Bul. $162: 254,255$. 1905 .

Colorado 2.

Introduced by J. W. Kerr, Denton, Maryland. Fruit of medium size, roundish; cavity lacking; suture a line; dull red with a light bloom; flesh light yellow; quality fair; stone of medium size; clinging; early.

Combination. Triflora $X$ ? 1. Burbank Cat. 1901.

Grown by Luther Burbank. Tree uniform in growth; fruit large, roundish; cavity deep; suture distinct; stem short; light crimson; flesh straw color, sweet with slight pineapple flavor; early.

Comfort. Americana. I. Kerr Cat. 1894. 2. Ia. Sta. Bul. 46:265. 1900. 3. Can. Exp. Farm Bul. 43:29. 1903.

Introduced by J. Wragg \& Sons, Waukon, Iowa, in 1879 . Fruit small, roundish; cavity narrow, shallow; suture a line; apex rounded; red; dots numerous; bloom thin; skin thick, tough; flesh dark yellow, firm, juicy, sweet; good; stone semi-clinging; mid-season; mentioned in the Catalog of the American Pomological Society for 1899. Communia. Domestica. x. Ia. Hort. Soc. Rpt. 87. 189o. 2. Ia. Sta. Bul. 46:265. 1900. 3. Kan. Sta. Bul. 1or:117, 118, Pl. III fig. 119. Igor. 4. Budd-Hansen Am. Hort. Man. 309. 1903.

Introduced from Denmark by a German colony located at Communia, Clayton County, Iowa. It resembles the Lombard so closely that they are often confused. The tree is said to be hardier and a slower grower than the Lombard, and its fruit of deeper blue and of higher quality. Subject to rot. 
Compass. Prunus besseyi $\times 1$ Iortulana mineri. I. Vt. Sta. Bul. 67:10. 1898. 2. Budd-Hansen Am. Hort. Man. 294. 1903. 3. S. Dak. Sta. Bul. 93:13. 1905. Compass Cherry r.

A hybrid widely known in the West which originated in 1891 under cultivation with H. Knudson of Springfield, Minnesota from a seed of Prunus besseyi pollinated by Miner; introduced by C. W. Sampson, Eureka, Minnesota, in 1897. Tree vigorous, branches slender; fruit small, roundish-oval, slightly flattened; cavity distinct; suture a line; brownish-red, with light bloom; skin tough; flesh greenish-yellow, juicy, tender, acid; quality fair; clingstone.

Comptine. Americana. 1. Kerr Cat. 1894. 2. Waugh Plum Cult. 146. 1901.

Originated at Knoxville, Iowa. Tree low, spreading; fruit very small, round, light red; dots many, minute; flesh yellow; very poor; stone small, oval, clinging. One authority states that the color is yellow.

Comte Gustave d'Egger. Domestica. I. Downing Fr. Trees Am. 905. 1869. 2. Mathicu Nom. Pom. 432. 1889.

Comte Gustave d'Egger 2. Egger'sche Eier Zwetsche 2. Graf Gustav von Egger 2.

An Austrian varicty grown by $M$. Liegel of Braunau from seed of Abricotée. Tree moderately vigorous; fruit small, oblong-oval; suture broad, deep, distinct; skin pale ycllow, bronzed in the sun and tinged with violet; flesh yellowish, fine, sweet, juicy, delicious; freestone.

Consul. Americana mollis. I. Can. Exp. Farm Bul. 43:30. 1903.

A seedling of Wolf grown at the Central Experimental Farm, Ottawa. Fruit roundish, large; cavity narrow, medium in depth; suture a line; deep red; dots moderately numerous, yellow, distinct; bloom light; skin thick, tough; flesh deep yellow, juicy, sweet; good; stone semi-clinging; late.

Cooch. Domestica. I. Can. Hort. 21:406. I898.

A seedling grown by a Mr. Cooch of Ottawa, Canada, in 1889 . Fruit large; halves unequal; suture distinct; cavity shallow; dark red; flesh greenish-yellow, juicy, soft, sweet; good; late.

Cook. Cerasifera. I. Kerr Cat. igoo. Cook's Early I.

Fruit medium, roundish to oblong, red; clingstone; early.

Cook Choice. Americana. I. Cornell Sta. Bul. 38:78. 1892. 2. Ia. Hort. Soc. Rpt. 276. 1893. 3. Mich. Sta. Bul. 129:34. I896.

Cook 3. Cook's Choice 1. Cook's Favorite 3. The Cook's Choice 2

This is an accidental seedling grown by H. A. Terry of Iowa in 1885 . Tree vigorous; fruit medium, round, red; skin thin; flesh yellow; good; stone clinging; mid-season; a good culinary variety.

Cooper. Hortulana mineri $\times$ Munsoniana. 1. Kerr Cat. 1o, 1900.

A cross between Forest Garden and Pottawattamie. It is reported by J. W. Kerr as being "a large, slightly oblong, red, clingstone variety, ripening mid-season."

Cooper. Domestica. I. McMahon Am. Gard. Cal. 587. 1806. 2. Coxe Cult. Fr. Trees 236. 1817. 3. Prince Pom. Man. 2 :97. 1832. 4. Downing Fr. Trees Am. 291. 1845. 5. Floy-Lindley Guide Orch. Gard. 288, 302,383 1846. 6. Mag. Hort. I4:152. 1848, 7. Elliott Fr. Book 417. 1854. 8. Hogg Fruit Man. 691. 1884. 9. Guide Prat. 160, 357. 1895 . 
Cooper's 6. Cooper's Grosse Pflaume 9. Cooper's Grosse Rothe Zwetschi 9. Cooper's Large I, 4, 5, 8. Cooper's Large 3, 6, 9. Cooper's Large American 3, 4, 5, 7, 8, 9. Cooper's Large Red 3. Cooper's Large Red 4, 5, 6, 7, 8, 9. Cooper's Large Red American 9. Coopers Plum 2. Cooper's Plum 3, 5. Cooper's Red 7. Grosse De Cooper 9. Grosse rouge de Cooper 9. La Delicieuse 5. La Delicieuse ?4, 8, 9. Lady Lucy 8. Red Magnum Bonum 6 incor. Smith's Orleans 6. Violet Perdrigon 6 incor.

Cooper is said to have originated at the beginning of the Nineteenth Century from a seed of Orleans planted by Joseph Cooper of Gloucester County, New Jersey. The variety was imported into England about 1820 and became known in Europe under the name La Delicieuse which was corrupted into Lady Lucy. This variety is so similar to the Smith Orleans that it is impossible to separate them. They may be identical, or they may have come true to seed from the same parent.

Cope. Domestica. 1. U. S. Pat. Off. Rpt. 274. 1854. 2. Downing Fr. Trees Am. 906. 1869 . Cope's Seedling 1.

A seedling raised by John Cope of Southwark, Philadelphia, some time prior to I850. Fruit large, long-oval, dark purple; stem long, slender; flesh dry, somewhat acid; good for cooking; freestone.

Cornemuse. Domestica. I. Lond. Hort. Soc. Cat. 145. $183 \mathrm{r}$.

Fruit medium in size, purple, obovate; quality fair; freestone.

Corymbus. Species? I. Vt.Sta.An.Rpt.12:222. 1899. 2. Waugh Plum Cult. 207. I901. The Beauty I.

A variety first called "The Beauty" by the originator, A. L. Bruce of Texas, who gives the parentage as Smelt Cherry $\times$ Abundance. Fruit small, heart-shaped; cavity shallow; suture shallow; apex pointed; dark wine-red; skin strong; flesh soft, yellow, rich, sweet; good; stone small, round, smooth, clinging.

Cottrell. Americana. 1. Cornell Sta. Bul. 38:37. 1892. 2. Am. Pom. Soc. Cat. 37. I899. 3. Waugh Plum Cult. I46. I901. 4. Can. Exp. Farm Bul. 43:30. I903. Cottrell was raised as a seedling by R. T. Cottrell, Dover, Olmstead County, Minnesota, and was introduced by O. M. Lord of the same state in I888. Fruit large, roundish; suture a line; cavity narrow; apex rounded; skin thin, not adherent; mottled red over yellow; bloom medium; dots numerous, small; flesh yellow, juicy, sweet; good; stone flattened, strongly and sharply margined, clinging; mid-season.

Couler. Americana? I. Ia. Hort. Soc. Rpt. 235. I882.

A variety from William Couler, Chickasaw County, Iowa; "a large plum of fair quality, but cracking badly before ripening; season just before Miner."

Coulommiers. Domestica. I. Rev. Hort. 9r. I86r. 2. Mathieu Nom. Pom. 426. r889. Coulomniers Pflaume 2. Prune de Coulommiers 2.

Mentioned without a description.

Coulon Reine Claude. Domestica. I. Mathieu Nom. Pom. 426. 1889.

Coulon's Reine Claude I. Reine Claude Coulon I.

Tree vigorous, productive; fruit of medium size, roundish; cavity small; suture distinct; yellow; bloom thin; flesh yellowish, firm, sweet; good; early.

Coul Orleans. Domestica. Mentioned in Lond. Hort. Soc. Cat. 150. $183 \mathbf{x}$. 
Court Royal. Domestica. Mentioned in Lond. Hort. Soc. Cat. 145. 1831. Cowperthwait Green Gage. Domestica. Mentioned in Lond. Hort. Soc. Cat. 148. 1831 . Cox. Domestica. 1. Downing Fr. Trees Am. 906. 1869. Cox's Seedling r.

A seedling from a Mrs, Cox, York, Pennsylvania. Tree vigorous and upright; fruit very large, roundish-oval, slightly compressed; suture broad, shallow; yellow, sometimes splashed with green; cavity narrow, deep; flesh greenish-yellow, coarse, juicy, sweet; good; freestone; early.

Crable. Americana? I. Waugh Plum Cult. 232. I901.

A variety from Iowa. Fruit medium in size; obovate; cavity shallow; stem long, slender; suture a line; apex pointed; orange with crimson blush; dots many, minute, white; skin tough; flesh yellow; good; stone large, elliptical, slightly winged, clinging. Craig. Americana. 1. Terry Cat. I900. Prof. Craig 1.

A seedling of Harrison, grown by H. A. Terry, Crescent, Iowa. Fruit large, bright yellow tinged with red; flesh yellow, rich; quality good; semi-clinging.

Crescent. Hortulana mineri. 1. Ia. Hort. Soc. Rpt. 287. 1887. 2. Terry Cat. 1900. 3. Waugh Plum Cult. 172. I 901 . Crescent City I.

Originated with H. A. Terry, Crescent, Iowa, from seed of Miner about 1880; first fruited in 1885 . Fruit of medium size, oval; cavity shallow; suture a line; dull red; dots many; bloom thin; flesh yellow; quality fair; stone large, oval, clinging; mid-season.

Crimson. Nigra. I. Ia. Sta. Bul. 46:266. 1900.

Introduced by H. Knudson, Springfield, Minnesota. Fruit above medium, light red; skin thin; good; stone long, large, flattish; very early.

Crimson Beauty. Hortulana. I. Kerr Cat. 1897. 2. Vt. Sta. An. Rpt. II:283. 1898.

Fruit of medium size, oblong, cherry red; clingstone; earlier and more vigorous than Golden Beauty.

Crimson Drop. Domestica. 1. Am. Gard.22:765. I901. 2. RuralN. Y.61:354. 1902.

Brown's Crimson Drop 1,2 .

This variety is said to be a sport from Golden Drop, which it resembles closely except in color, which is a deep rich red.

Croft Early. Domestica. I. Elliott Fr. Book 425. I854. Croft's Early I.

Fruit small, reddish-blue; flesh yellow, dry; poor. Reported by Elliott as unworthy of further culture.

Cruger Scarlet. Domestica. 1. Mag. Hort. $1: 365$. 1835. 2. Downing Fr. Trees Am. 293. 1845. 3. Elliott Fr. Book 4I7. 1855. 4. Mathieu Nom. Pom. 426. I889.

Cruger's 2, 3. Cruger's Früh Pflaume 4. Cruger's Plum 4. Cruger's Rote Pflaume 4. Cruger's Scarlet 2, 3. Cruger's Scarlet 4. Cruger's Scarlet Gage 2, 3, 4. Cruger's Seedling 2, 3. Cruger's Seedling I, 4. Kruger's Seedling.

Raised by Henry Cruger, West Point, New York, from a seed of Washington. Fruit of medium size, roundish-oval, compressed; suture obscure; red in the sun, lilac on the shaded side; bloom light; dots numerous, yellow; cavity shallow; stem short, stout; flesh deep orange, dry, mild, agreeable; good; nearly free; mid-season. Mentioned in the American Pomological Society Catalog from 1875 to 1897 . 
Csaszar Sziloa. Domestica. I. Mich. Sta. Bul. 152:209. 1898. 2. Mich. Sta. Sp. Bul. 30:18. 1905 .

Imported from Hungary. Fruit large, roundish-ovate, compressed, dark purple; flesh tender, juicy, greenish-yellow, mild, vinous; quality fair; clingstone.

Culberson. Hortulana mineri $\times$ Hortulana. I. Vt. Sta. An. Rpt. 12:223. 1899.

2. Waugh Plum Cult. 208. 1901.

Mammoth July $1,2$.

A cross between Miner and Crimson Beauty grown by A. L. Bruce, Basin Springs, Texas, and called Mammoth July, but renamed by Waugh in 1899 . Fruit above medium, spherical or slightly pointed, dark red; dots numerous, yellow; skin thick, tough; flesh yellow; very good; stone small, round, flattened, clinging.

Cumberland. Hortulana. 1. Ga. Hort. Soc. Rpt. 50. 1885. 2. Cornell Sta. Bul. 38 : 48,86, 1892. 3. Am. Pom. Soc.Cat. 26. 1897. 4. Waugh Plum Cult. 178.1901.

Cumberland originated with Philip Schley, who in 1864 collected pits from trees growing on the Cumberland Mountains in Tennessee and from them grew this plum. Tree vigorous and productive; fruit of medium size, oblong, bright yellow; dots conspicuous; skin thick; flesh firm, meaty; good; clingstone; season late; this variety is similar to Golden Beauty.

Curlew. Domestica. 1. Cornell Sta. Bul. 131:183. 1897. 2. Rivers Cat. 35. 1898.

Originated by Thomas Rivers at Sawbridgeworth, England. Tree very productive, not hardy in this vicinity; fruit medium in size, roundish-oval, purple; flesh greenish-yellow, juicy, sweet; firm; early.

Curry. Munsoniana. 1. Ia. Sta. Bul. 46:266. 1900. 2. Budd-Hansen Am. Hort. Man. 295. 1903 .

A seedling grown by S. L. Curry, Welden, Iowa. Fruit large, oval, compressed; cavity deep; dark purplish-red; surface rough, dull; dots small, gray; bloom heavy; skin thick. not astringent; flesh yellow, firm, slightly astringent; good; stone large, flat, winged; early.

Cyca Mono. Triflora. I. Va. Sta. Bul. 129:112. 1901.

Imported by the United States Department of Agriculture.

Cyclone. Americana. I. Kerr Cat. 1899. 2. Terry Cat. 1900.

Grown from seed of Harrison by H. A. Terry, Crescent, Iowa; first fruited in 1897 . Tree vigorous, spreading, fairly productive; fruit large, dark red; good; mid-season. Cydemarine. Domestica. Mentioned in Lond. Hort. Soc. Cat. 145. 1831.

Daisy. Munsoniana $\times$ Triflora. 1. Vt. Sta. An. Rpt. 12:223. 1899. 2. Waugh Plum Cult. 208. I901.

A varicty grown by J. S. Breece, North Carolina. Fruit large, heart-shaped; suture indistinct; bright red, with many minute yellow dots; flesh firm, yellow, sprightly; good. Dahlgreen. Americana. 1. Wis. Sta.Bul.63:35. 1897. 2. Waugh Plum Cult. 147. 1901.

A variety introduced by Chas. Luedloff, Cologne, Minnesota. Fruit medium in size, oblong, mottled red; mid-season.

Dakota. Americana. 1. Kerr Cat. I goo.

Fruit medium in size, round, mottled with dull purplish-red; clingstone; fruit cracks and is much injured by rot. 
Dalrymple. Insititia. I. Hogg Fruit Man. 695. 1884. 2. Mathieu Nom. Pom. 426. Iss9. 3. Am. Gard. 14:146, 148 fig. 1892. Dalrymple Damson 2.

Dalrymple closely resembles the Shropshire Damson but is hardier and the tree is smaller.

Damas Ambre, Domestica? Mentioned in Lond. Hort. Soc. Cat. x45. $183 x$.

Damaschino Estivo. Domestica. 1. Gallesio Pom. Ital. 2:, P1. I839.

Damaschino d'Estate $\mathrm{r}$. Zuccherino $\mathrm{x}$.

According to Gallesio this is a strain of the Damaschino Settembrino and is common in parts of Italy. Flowers small and white, unfolding in clusters; fruit obovate like the Settembrino, but slightly larger and its skin, which is yellow, is more easily removed. Damaschino Settembrino. Domestica. I. Gallesio Pom. Ital. 2:, Pl. 1839.

Susino Damaschino Settembrino I.

An old Italian variety. Of the two plums which bear the name Damaschino this is the smaller and the more savory. Fruit small, obovate, golden-yellow; pulp fleshy and sugary.

Damas de Diffenbach. Domestica. I. Mas Pom. Gen. 2:165. x873. 2. Mathieu Nom. Pom. 427. 1889 .

Damas de Dieffenbach 2. Damas Noir de Dieffenbach 2. Dieffenbachs Damascene 2. Sieffenbachs Schwarze Damascene 2. Diffenbachs Damascene 1.

Liegel obtained this variety from a seed of the Saint Jean and dedicated it to Diffenbach, head gardener of the Botanical Garden in Vienna, Austria. Tree of medium vigor, small; fruit small, roundish-ovate; halves often unequal; suture shallow; purplish-black with a thick bloom; stem short; cavity shallow; flesh yellow, tender, juicy, sweet and slightly aromatic; freestone; mid-season.

Damas de Provence. Domestica. I. Prince Pom. Man. 2:86, 1832, 2. Kenrick Am. Orch. 258. 1832. 3. Poiteau Pom. Franc. I:1846. 4. Hogg Fruit Man. 357. 1866. 5. Downing Fr. Trees Am. 939. 1869. 6. Mathieu Nom. Pom. 443. I889. Damas de Provence 5, 6. Damas de Provence hâtif 1, 4, 5, 6. Damask of Provence 2. Early Damask of Provence I, 5, 6. Provence Damask 1, 6. Provence Damask 5. Provencer Königspflaume 6. Prune Damas de Provence 3. Prumus provincialis 3.

Damas de Provence is an old European variety; fruit of medium size, roundish; suture deep; cavity small; reddish-purple; bloom thick; flesh greenish, sweet; quality poor; freestone; very early.

Damas d'Ete. Domestica. x. Mas Pom. Gen. $2: 113$. I873. 2. Guide Prat. 353. I895.

Summer Damson I, 2 .

Mas thought this variety was of English or American origin but there seems to be no reason for this conclusion. Tree small, very productive; fruit small, oval, purplishblack; flesh greenish, fine, juicy, sweet, highly flavored; clingstone; early.

Damas Dronet. Domestica. 1. Duhamel Trait. Arb. Fr. 2:75. 1768. 2. Kraft Pom. Aust. 2:40, Tab. 191 fig. 2. 1796. 3. Prince Pom. Man. 2:86. 1832. 4. Downing Fr. Trees Am. 9ro. 1869. 5. Hogg Fruit Man. 693. 1884.

Damas Dronct 2, 4. Damson Dronet $\mathrm{x}$. Die kleine langlichte Damaskuspflaume I Dronet Damask 3. 
Damas Dronet is an old French variety. Fruit small, oval; suture a line; stem slender; cavity narrow, deep; greenish-yellow; bloom thin; skin not adherent; flesh greenish, firm, sweet; good; stone small, free; mid-season.

Damas Dronet de Merlet. Domestica. 1. Duhamel Trait. Arb. Fr. 2:75. 1768.

Duhamel states that this is distinct from the Damas Dronet described by him on the same page.

Damas Jaune Musque. Domestica. I. Mas Pom. Gen. 2:57. I873.

Muskirte Gelbe Damascone 1.

A foreign variety first mentioned by Christ, a German writer. Tree vigorous. productive; fruit medium in size, usually ovoid; suture shallow or a mere line; skin tender, not adherent, yellow, with a thin bloom; stem long, slender; cavity shallow; flesh yellow, tender, firm, juicy, sweet, of musky flavor; freestone; very early.

Damas Noir de Tours. Domestica. I. Forsyth Treat. Fr. Trees 21. 1803.

Mentioned by Forsyth in the preceding reference. It may be the same as Précocc de Tours, but we have no proof.

Damas Rouge de Biondeck. Domestica. I. Baltet Cult. Fr. 490. 1908.

Mentioned by a French writer as early and good.

Damas Rouge Hatif. Species? I. Mathieu Nom. Pom. 448. 1889. 2. Guide Prat. I63, 354. 1895 .

Damas Rouge Hatif I. Haferkrieche 1, 2. Rote Früh Damascene 1. Rothe Frïh Damascene 2.

A variety of little merit.

Damatie Rouge. Domestica. Listed in Lond. Hort. Soc. Cat. I45. 1831 .

Damson Royal. Insititia. 1. Floy-Lindley Guide Orch. Gard. $282 . \quad$ I846.

Described in the preceding reference as similar to "Prune Damson," but larger.

Damas Violet. Domestica. 1. Duhamel Trait. Arb. Fr. 2:70. 1768. 2. Kraft Pom. Aust. 2:44, Tab. 199 fig. I. 1796. 3. Quintinye Com. Gard. 68. 1699.

4. Willich Dom. Enc. I80. 1803. 5. Mag. Hort. 9:163. 1843. 6. Poiteau Pom. Franc. 1:1846. 7. Hogg Fruit Man. 729. 1884.

Damas Violet 2, 4, 7. Damas Violet Tardif ?5. Die veilchenfarbige Damascenerpflaume 2. Ladies' Plum 4. Long Violet Damask 3. Prune Gros-Damas Violet 6. Violet Damask 7 .

An old variety of unknown origin concerning which there has been much confusion. Parkinson, in 1629 , and a few later writers have made it synonymous to Queen Mother, but it differs from this variety in that Damas Violet has pubescent shoots and oval fruit, while the Queen Mother has glabrous shoots and round fruit. Tree vigorous, productive; fruit medium, purplc; flesh yellow, firm, sweet and briskly flavored, separates from the stone; season early.

Damson Riley. Insititia. I. Stark Cat. 29. I910.

A variety from Ohio said to have been grown for about twenty years. Introduced by Stark Brothers, Louisiana, Missouri, in 1910.

Dana Yellow Gage. Domestica. I. Downing Fr. Trees Am. 275. 1845. 2. Cole Am. Fr. Book. 215. 1849. 3. Mas Pom. Gen. 2:109. 1873. 
Dana's Gage 2. Dana's Yellow Gage 3. Reine-Claude Jaune De Dana 3.

Dana Yellow Gage was raised by a Rev. Mr. Dana of Ipswich, Massachusetts. Fruit of medium size, oval, pale yellow; bloom thin; flesh sweet, juicy, clingstone; mid-season.

Daniel Weeping. Species? r. Vt. Sta. Bul. 67:10. 1898.

A hybrid which originated with a Dr. Daniel in Louisiana; introduced by J. L. Normand. Tree bushy, spreading and drooping; leaves thick and tough, ovate, acutely pointed, glandular.

Danish Damson. Insititia. 1. Kerr Cat. 25. 1897. 2. Ia. Sta. Bul. 46:266. 1900. 3. Budd-Hansen Am. Hort. Man. 310. 1903. 4. S. Dak. Sta. Bul. 93:15 1905. Kreger 1. Kreger 2. Krueger 3.

H. Knudson, Springfield, Minnesota, imported this variety in the spring of 1884 and introduced it a few years later. It seems to be grown only in Iowa, Minnesota, South Dakota and adjoining states, being practically unknown in the East. Fruit small, roundish, dark blue; good; freestone; mid-season.

Darst. Domestica. I. Mag. Hort. 11:112. 1845 .

A seedling originated at Dayton, Ohio, in the garden of a Mr. Darst. Fruit medium in size, of excellent quality.

Date. Domestica. 1. Parkinson Par. Ter. 575, 576. 1629. 2. Rea Flora 208. 1676. 3. Quintinye Com. Gard. 68,69. 1699. 4. Duhamel Trait. Arb. Fr. 2:1 13. 1768.

5. Downing Fr. Trees Am. 908. 1869. 6. Koch Deut. Obst. 560. 1876.

Date Plum 5. Dattelpflaumen 6. Dattelzwetsche 5. D'Autriche 5. Great Date 3. Ienua 1. Prune Datte 4. Prune Datte 5. Prune d'Autriche 5. Quetsche Datte 5. Quetsche de Hongrie 5. White Date 2. White Date Plum 1. Yellow Date 2.

During the four centuries in which this variety has been cultivated in Europe numerous strains have arisen which have been designated by the general term Dattelpflaumen. The group is characterized by roundish or oval fruits, yellow or greenish in color, sometimes marked with red on the sunny side; flesh yellow, soft; poor in quality; clingstone; mid-season or later. The original variety is probably obsolete. Datilles. Domestica. 1. Quintinye Com. Gard. 68, 70. 1699.

Little Date 1. Little Date I.

A long-shaped red plum, mentioned by Quintinye, which has either disappeared or is now grown under a different name.

Datte Hongroise Jaune. Domestica. I. Mathieu Nom. Pom. 427. I889. 2. Guide Prat. $159,354.1895$.

This variety was sent into France by M. Bereczki Mate, of Hungary. The tree is vigorous, productive; fruit large, long, greenish-yellow dotted with red; flesh greenishyellow, juicy; good; mid-season.

Dauphine. Domestica. I. Poiteau Pom. Franc I:1846. Prune Dauphine I.

Poiteau says, "Duhamel regarded as synonyms the names Reine Claude and Dauphine. Since then a new plum has been shown, and I know not who named it Dauphine; but it is under this name that it has been introduced and cultivated in the nursery of the Jardin des Plantes and of Luxembourg." 
Davenport. Americana. I. Ia. Sta. Bul. 46:268, 1900. 2. Budd-Hansen Am. Hort. Man. 295. 1903 .

A seedling grown by N. K. Fluke, Davenport, Iowa, from seed of De Soto. Fruit medium in size, oval, sometimes conical; suture a line; skin smooth, clear yellow with pink blush on the sunny side; flesh yellow, firm, sugary; very good; freestone.

Davies Seedling. Domestica. Mentioned in Lond. Hort. Soc. Cat. I46. 1831.

Davies' Seedling.

Davis. Munsoniana. 1. Wis. Sta. Bul. 63:35. 1897. 2. Terry Cat. 1900.

A variety grown from seed of Wild Goose in 1885 by H. A. Terry, Crescent, Iowa. Tree low, spreading, vigorous and productive; fruit large, bright red; quality fair.

Dawson. Species? 1. Gard. Mon. 17:144. I 875 .

At one time a profitable variety grown on the banks of the Ohio.

Dawson City. Nigra? 1. Can. Exp. Farms Rpt. 426.1900.

A seedling raised at Indian Head Experimental Farm, Northwest Territory, Canada. Fruit of medium size.

Dean. Domestica. I. McIntosh Bk. Gard. 2:530. 1855 .

Dean's Jedburgh Seedling I.

A seedling grown at Dean's nursery, Jedburgh, England. Fruit of medium size, round, purple; freestone; adapted for dessert or kitchen; mid-season.

Deaton. Domestica. I. Ia. Sta. Bul. 46:268. 1900. 2. Budd-Hansen Am. Hort. Man. 3 10. 1903 . Tobe's Gage 2.

Grown from a sprout of Reine Claude planted near Des Moines; introduced by J. Wragg \& Sons, Waukee, Iowa. Fruit medium in size, oval, truncate; suture broad and shallow; skin greenish-yellow; dots small, numerous; bloom thin; flesh greenish, firm, juicy; good; clingstone.

Deck. Insititia. 1. Wild Bros. Cat. I 908-09.

Decks Damson I.

An improved strain of Damson introduced by Wild Brothers, Sarcoxie, Missouri. Decker. Hortulana mineri. I. Minn. Hort. Soc. Rpt. 401. 1896. 2. Waugh Plum Cult. 172. 1901 .

Decker's Late Seedling I. Decker's Seedling 2.

A seedling raised about ${ }_{1} 885$ by H. C. Decker of Dresbach, Minnesota, from pits of a variety substituted for German Prune; introduced by W. S. Widmoyer of the same place about 1897 . Fruit medium to large, conical; suture distinct; red; dots many, yellowish; flesh yellow; flavor rich; nearly free; mid-season.

Deep Creek. Americana. 1. Mich. Board Agr. Rpt. I1 1. 1887. 2. Cornell Sta. Bul. 38:37, 86. 1892. 3. Ohio Sta. Bul. 162:254, 255. 1905. Deepcreek 3.

Found growing wild in Kansas; introduced by Abner Allen. Tree slow and irregular in growth; branches thorny; fruit of medium size, roundish-oval, compressed; suture distinct; cavity small; stem short; dull red; skin thick; flesh yellow, firm, sweet; good; stone rough, pointed, free; mid-season; of little value.

De Delice. Domestica. 1. Downing Fr. Trees Am. 360. 1857. 2. Can. Exp. Farm Bul. 2d Ser. 3:55. I 900.

Prune de Delices 2. 
Tree vigorous and productive; fruit of medium size, roundish-oval; suture small; grecn, marbled and shaded with violet; bloom thin; flesh orange yellow, juicy, sugary, luscious; slightly clinging; late.

Defresne. Domestica. I. Mathieu Nom. Pom. 427. 1889. 2. Guide Prat. 158, 354. 1895.

A Belgian variety both vigorous and productive; fruit large, long, purplish; flesh greenish; good; mid-season.

De Gondin. Domestica. 1. Mas Pom. Gen, 2:9r. 1873.

Grown by M. Vaubcrnier of Laval, Mayenne, and introduced in 1862 by M. M. Bruant \& Company, nurserymen at Poiters, France. Tree vigorous, productive; fruit very large, roundish; suture disappearing at maturity; dark purple; bloom thin; flesh yellow, tender, juicy; freestone.

De la Toussaint. Species? 1. Guide Prat. 162, 354. 1895.

A very late and long keeping variety.

Delaware. Triflora. I. Burbank Cat. 18. 1893. 2. Rural N. Y. 59:642. 1900.

3. Ibid. 60:694. 1901. 4. Waugh Plum Cult. 134. 1901.

Burbank produced this variety by crossing Satsuma with Kelsey; first offered for sale in 1893; disseminated in the East by J. L. Childs, Floral Park, New York. Tree semi-dwarf, productive but comes into bearing late; fruit of medium size, roundish-conical, dark purple, with thick bloom; flesh red, juicy, sweet and rich; good; stone clinging; mid-season.

De l'Inde. Domestica. I. Horticulturist 6:561. I851.

Described by Baptiste Desportes of Angers, France, in 1851. Tree vigorous; branches long, upright; fruit large, obovate, violet-reddish; dots gray and blue; flesh reddish-ycllow, firm, juicy, melting; quality fair.

De Montfort. Domestica. 1. Mag. Hort. 12:341, 1846, 2. Pom. France 2: No. 3. 1871. 3. Hogg Fruit Man. 713. 1884. 4. Lucas Vollst. Hand. Obst. 470. 1894. Montfort Pflaume 4. Prune de Montfort 2.

Originated in the nurseries of Madame Ebert, Montfortin, France; named and introduced by M. Prevost, Rouen, France. Tree vigorous, spreading, productive; fruit of medium size, roundish-oval; suture distinct; cavity shallow; dark purple, with russet dots; flesh green, juicy, sweet, rich; good; freestone; mid-season. Mentioned in the American Pomological Society's Catalog from 1877-1897.

De Montmirail. Domestica? I. Guide Prat. 158, 354. 1895.

Tree of moderate vigor, productive; fruit medium in size, long-oval; yellow lightly blushed with red; flesh yellow; good; early.

Denbigh. Domestica. r. Lond. Hort. Soc. Cat. 147. 1831. 2. Hogg Fruit Man. 357. 1866. 3. Gaucher Pom. Prak. Obst. No. 92. 1894. 4. Bartrum Pears and Plums. 65, 71. 1903.

Cox's Emperor 2, 3. Cox's Emperor 4. Denbigk 3. Denbigh-Pflaume 3. Denbigh Seedling 4. Emperor 1. Jemmy Moore 4.

Tree vigorous, productive; fruit large, roundish-oval, bright red to reddish-brown; flesh golden-yellow, sweet, melting, pleasant flavor; freestone; mid-season. 
Dennis. Americana. I. Cornell Sta. Bul. 38:79. 1892. 2. Ia. Hort. Soc. Rpt. 276. 1893. 3. Waugh Plum Cult. 147. 1901.

Dr. Dennis I, 2. Dr. Dennis 3.

Originated with H. A. Terry, Crescent, Iowa, supposedly from seed of Hawkeye; first fruited in 1891 . Fruit round to slightly oblong, medium in size; suture a line; bright red; dots many, minute, white; flesh yellow; good; clingstone; early.

Dennis Seedling No. 13. Hortulana mineri.

Grown at the Iowa Experiment Station. The fruit is of medium size, roundish, dark red; dots conspicuous; suture a line; skin thick, tough; flesh firm, juicy, tender, sweetish; good; clingstone; mid-season.

Denniston Red. Domestica. I. Downing Fr. Trees Am. 296. 1845. 2. Mag. Hort. 13:532. 1847. 3. Thomas Am. Fruit Cult. 337. 1849. 4. Mas Le Verger 6:

133. 1866-73. 5. Mathieu Nom. Pom. 427. 1889.

Denniston's Red 1. Denniston's Red 5. Dennison's Red 5. Denniston's Rote Pflaume 5. Ronge de Denniston 4, 5.

Grown by Isaac Denniston of Albany, New York. The parentage is not known but Thomas thinks it is a seedling of Lombard. Fruit large, roundish-oval; suture distinct; cavity small; light red with yellow dots; bloom thin; flesh amber, juicy, rich, sprightly; good; stone small, oval, compressed, free; mid-season.

Denniston Superb. Domestica. 1. Downing Fr. Trees Am. 275. 1845. 2. Mas Le Verger 6:121. I866-73. 3. Mathieu Nom. Pom. 427. 1889. 4. Bartrum Pears and Plums 63. 1903.

Dennison's Superb 3. Denniston's Superb 2. Denniston's Superb Gage 4. Madison 3. Superbe de Denniston 2, 3.

Grown by Isaac Denniston, Albany, New York, about I 835 or 1840 . Fruit round, larger than Reine Claude of which it is probably a seedling, slightly flattened; suture distinct; cavity shallow; stem of medium length; pale yellow, blotched with red; bloom thin; flesh thick, meaty, moderately juicy, with a rich, vinous flavor; very good; stone small, roundish, thick, free; mid-season; catalogued by the American Pomological Society from 1877 to 1899 .

D'Ente Imperiale. Domestica. I. Guide Prat. I60, 355. 1895.

A variety closely resembling the Agen except that it is more vigorous in tree growth.

Denton. Angustifolia varians. I. Gard. Mon. 13:279. I87I.

A variety introduced many years ago by J. W. Kerr; it closely resembles Yellow Transparent, but is a much smaller tree.

Derbyshire Green Gage. Domestica. Mentioned in Lond. Hort. Soc. Cat. 148. 1831. Deron. Domestica. Mentioned in Lond. Hort. Soc. Cat. I46. I831. Deron's.

De Seigneur. Species? I. Guide Prat. 161, 355. 1895. De Prince (en Lorraine) I.

Tree productive; fruit small, roundish, bluish; bloom heavy; flesh green, finegrained, juicy, sweet; good; late.

Des Moines. Americana. I. Kerr Cat. 1894. 2. Waugh Plum Cult. 147. 1901. 
Originated in Iowa. Fruit small, round-oval; suture a line; dull red over yellow; dots many, minute; flesh yellow; quality poor; stone small, semi-free; mid-season Dewey. Americana. 1. Terry Cat. 1900. 2. Ill. Hort. Soc. Rpt. 136. 1903.

Admiral Dewey r, 2.

A seedling of De Soto grown by H. A. Terry of Crescent, Iowa. Fruit large, round, dark red on an orange ground; clingstone; tree productive.

Diademe Imperial-Isabelle. Domestica? Mentioned in Mathieu Nom, Pom. 427. 1889. Diamond. Americana. I. Neb. Hort. Soc. Rpt. 121 . 1890.

A seedling grown by John A. Hogg, Shelton, Nebraska, about 1880 from pits of a wild plum found in Buffalo County, Nebraska. According to Mr. Hogg, the variety "grows fully as large as most of the tame varieties; ripens the last of September and when fully ripe gets bright red on one side."

Diana. Americana. 1. Wis. Sta. Bul. 63:35. 1897. 2. Ia. Sta. Bul. 46:268. 1900.

A plum of the Van Buren type grown from a seed of Hawkeye by H. A. Terry, Crescent, Iowa; first fruited in 1893 . Tree large, vigorous, upright-spreading; fruit truncate, conical or oval; suture distinct; cavity small, shallow; stem short, stout; yellow, washed and spotted with purple-red; dots indistinct; bloom thin; skin thick and tough; flesh yellow, meaty, sweet and rich; good; stone large, flat, oval, clinging; mid-season.

Diapree Blanche. Domestica. 1. Parkinson Par. Ter. 578, 1629. 2. Langley Pomona 95, Pl. XXIV fig. IV. 1729. 3. Duhamel Trait. Arb. Fr. 2:104, Pl. XX fig. II. 1768. 4. Kraft Pom. Aust. $2: 44$, Tab. 198 fig. 2. 1796. 5. Noisette Man. Comp. Jard. $2: 500$. 1860. 6. Oberdieck Deut. Obst. Sort. 405. 188 r.

Diaper'd Plumb 2. Diaprée Blanche 4. Diaprée Weisse 6. Die Weisse Buntfarbige Pflaume 4. Prune Diaprée Blanche 5. White Diapred r. Yellow Diaprée 2.

This plum has been mentioned by European writers for three centuries. Fruit of medium size, roundish; suture a line; cavity nearly lacking; skin tough; yellow; bloom thin; flesh firm, yellow, sweet, rich; quality good; mid-season.

Diapree Nouvelle De Kook. Domestica. 1. Mas Pom. Gen. 2:155. 1873. 2. Mathieu Nom. Pom. 438. 1889.

Kook's Gelbe Diaprée 2. Kooks Neue Diapre 1. Kook's Neue Diaprée 2.

This plum originated as a second generation seedling with a Mr. Kook of New Brauenfels, Texas, and was named by Liegel to whom he submitted the variety. The fruit is small, oval; cavity small; skin clear yellow; flesh yellow, tender, aromatic; quality good; stone free; season early.

Dictator. Domestica. 1. Mag. Hort. 6:92. 1840. 2. Downing Fr. Trees Am. 403. 1857. 3. Montreal Hort. Soc. Rpt. 55. 1878. Corse's Dictator 3 .

A seedling raised by Henry Corse of Montreal about 1834 . Tree hardy, vigorous; fruit large, brownish-purple; flesh juicy, rich; good; stone small.

Diel Grosse Weisse Damascene. Insititia? 1. Mathieu Nom. Pom. 427. 1889.

Ak Erik 1. Al Erik 1. Dschau Erik 1. Frihe Weisse Aprikosenpflaume 1. GrosDamas Blanc.

Mentioned without description in the preceding reference. 
Dine. Domestica. 1. Parkinson Par. Ter. 576. 1629.

Fruit large, white; dots numerous; late.

Dittisham. Domestica. 1. Lond. Hort. Soc. Cat. 146. 183 I.

Mentioned as cultivated in the London Horticultural Society Gardens.

Dixie. Triflora. I. Horticultural Gleaner I 899.

Grown about 1894 in the vicinity of Whitesville, Georgia, from seed of Burbank, open to cross pollination. Fruit the size of Burbank, bright red; flesh juicy; good; late.

Dixie. Triflora. r. Hood Cat. I9o6.

An early Triflora variety.

Dochnahl Damascene. Domestica. I. Oberdieck Deut. Obst. Sort. 444. 1881. 2. Mathieu Nom. Pom. 427. 1889. Dochnahl's Königs Pflaume 2.

As tested in Germany, very unproductive.

Dojene. Domestica. I. Knoop Fructologie 2:57. 1771 .

Origin unknown. Tree productive; fruit large, oval; yellow; flesh watery; poor; stone clinging.

Dollaner. Domestica. I. Oberdieck Deut. Obst. Sort. 445. 1881. 2. Mathieu Nom. Pom. 427. 1889.

Dollaner Zwetsche 2. Quetsche de Dollan 2.

A variety imported from France by the United States Department of Agriculture. Reported by Oberdieck as "a prune which has borne little fruit since 1856 ."

Domina. Species? 1. Mathieu Nom. Pom. 427. 1889. Domino 1.

Reference found by Mathieu in Monatsschrift fur Pomologie 7. 1858 .

Domine Dull. Domestica. I. Lond. Hort. Soc. Cat. 146. 1831. 2. Downing Fr. Trees Am. 296. 1845. 3. Floy-Lindley Guide Orch. Gard. 302, 383. 1846.

Domine Dull's 1. Domine Dull's Plum 3. Dutch Prune 2. Dutch Quetszen 2, 3. German Prune 2, 3 .

Mr. Dull, a Dutch domine, brought a prune seed from Holland and planted it in Kingston, New York. From this seed sprang the Domıne Dull, a variety often confused with the German Prune. Fruit of medium size, long-oval; suture slight; stem long; cavity small; dark purple; bloom thin; flesh yellow, juicy, rich, sweet; good; clingstone; late. Mentioned in the Catalog of the American Pomological Society in 1867 .

Don. Americana mollis. I. Can. Exp. Farm Bul. 43:30. 1903.

A seedling of Wolf raised at the Central Experimental Farm, Ottawa. Fruit large, roundish; suture a line; uniformly bright red; dots numerous, small, distinct; bloom moderate; flesh deep yellow, juicy; sweet, rich; good; stone of medium size, oval, clinging; late.

Don Alteza. Domestica. I. Parkinson Par. Ter. 576. I629.

According to Parkinson "a very good sort."

Don Carlos. Domestica. Mentioned in Forsyth Treat. Fr. Trees. 21 . 1803 . Don Carlos'.

Dora. Triflora $\times$ Munsoniana. I. Vt. Sta. An. Rpt. 14:270. 1901. 
A seedling from A. L. Bruce, Texas, said to be a cross between Abundance and Wild Goose. Fruit medium to large, cordate; suture faint; skin tender, bright red; dots ninute; bloom heavy; flesh yellow, firm, sweet, rich; good; stone small, oval, clinging. Doree. Domestica. I. Mas Le Verger 6:145. 1866-73. D'Agen Dorée I.

Found by Léo d'Ounous in an orchard planted by his father in Ariege, France; published for the first time by $\mathrm{Mas}$ in Le Verger. Tree vigorous; fruit medium, ovoid; suture shallow; skin tender, not adherent, golden-yellow tinged with rose-violet; stem slender, rather short; cavity shallow; flesh yellow, fine, juicy, very agreeably aromatic.

Dorell. Domestica. 1. Downing Fr. Trees Am. 393. 1857. 2. Ann. Pom. Belge 8:35, PI. I860. 3. Hogg Fruit Man. 374. 1866. 4. Mas Pom. Gen. 2:27. 1873. 5. Oberdicck Deut. Obst. Sort. 409. 1881. 6. Mathieu Nom. Pom. 427. 1889. 7. Lucas Vollst. Hand. Obst. 473. 1894.

Dorrel 2. Dorells Grosse Zwetsche 4. Dorelle's Nene Grosse Zwetsche 3, 6. Dorell's Neue Purpurzwetsche 5. Dorelle's New Purple Prune 6. Dorells Nene Grosse Zwetsche 4, 6. Dorclls grosse neue Zwetsche 7. Grosse Quetsche De Dorell 4. Grosse Quetsche Nouvelle 6. Nouvelle de Dorelle 3. Nouvelle De Dorrel 6. Nouvean De Dorrelle 6. Prune Grosse Quetsche Nouvelle 2. Prune nouvelle de Dorrel 2. Quetsche De Dorelle 6. Quetsche De Dorelle Nouvelle Grand 1. Quctsche Grosse Nouvelle De Dorrel 6. Quctsche De Dorelle Nouvelle Grande 6.

A seedling raised by Dr. Dorell, of Kuttenberg, Bohemia. Tree vigorous, productive; fruit large, oval; suture wide but shallow; cavity small; stem smooth, reddish; skin reddish-violet, marked with numerous russet dots; flesh yellowish, juicy, swect, aromatic, agreeable; good for drying; late mid-season.

Dorell Aprikosenpflaume. Species? Mentioned in Mathieu Nom. Pom. 427. I889.

Abricotée Nouvelle de Dorell. Dorell's Neue Aprikosen Pflaume. Mirabelle de Doerell.

Doris. Species? I. Watkins \& Bros. Cat. 20. 1897-8. 2. Vt. Sta. An. Rpt. 14:271. 1901. 3. Mass. Sta. An. Rpt. 17:161. 1905.

A variety of doubtful parentage from Burbank; introduced by Stark Brothers in 1895 . Fruit small, roundish-oblate; suture faint; light red; dots numerous; flesh yellow, watery; quality poor.

Dorr. Domestica, 1. Cultivator 8:346. 1851. 2. Downing Fr. Trees Am. 909. 1869. Dorr's Favorite 1, 2.

A Reine Claude seedling grown by either Isaac Denniston or Elisha Dorr, both of Albany, New York. Fruit large, oval; suture broad; cavity small; apex sunken; yellow with red dots; bloom thin; flesh yellow, coarse, juicy; good; clingstone; late. Dorr Seedling. Domestica. I. Mathieu Nom. Pom. 428. 1889. Semis de Dorr I.

This may be identical with Dorr.

Dorsett. Munsoniana. 1. Meneray Cat.

A chance seedling from H. A. Terry, Crescent, Iowa; introduced by F. W. Meneray of Council Bluffs, Iowa. Fruit large, yellow blotched with red; skin thin; good; clingstone; early. 
Dosch. Domestica. 1. Am. Pom. Soc. Rpt. 150. 1895. 2. Oregon Sta. Bul. $40: 73$. 1896. 3. Ibid. 45:30. 1897. 4. Washington Cat. 22. 1906. 5. Chico Nur. Co. Cat. 25. 1909. 6. Oregon Cat. 35. 1906.

The Dosch 2.

The Dosch prune grew on the farm of Henry E. Dosch, Hillsdale, Oregon, from a sprout below the union on a Washington plum tree grafted on plum roots. Tree vigorous, round-topped, prolific, similar to Italian; fruit large, roundish-oval; apex flattened, base acute; suture shallow; stem medium; skin firm; dark purple; flesh greenish, firm, sweet; good; freestone.

Double. Domestica. I. Knoop Fructologie 2:60. 1771. Prune de Double 1.

Double differs from Paisin Blanche in that it is a little larger, less yellow in color, and poorer in flavor.

Double Plum. Domestica. 1. Can. Hort. 16:193 fig. 541. I893.

A novelty growing in the gardens of Chernigow, Russia, in which the fruit consists of two plums joined together, but easily separated at maturity; fruit bluish-red, sometimes yellow: flesh orange colored, sweet, juicy; quality fair; two stones, clinging. Dougall Best. Domestica. 1. Rural N. Y. 43:779. 1884. Dougall's Best I.

A chance seedling raised by James Dougall of Windsor, Canada. Tree productive; fruit oblong, tapering to the stalk; suture distinct; clear yellow, touched with carmine toward the sun; good; stone partially free.

Douglass. Americana. I. Meneray Cat.

Grown by H. A. Terry, Crescent, Iowa, from seed of Harrison; introduced by F. W. Meneray, Council Bluffs, Iowa. Fruit large, oblong, yellow blushed with red; flesh yellow, sweet, rich, firm; semi-clinging.

Dove Bank. Domestica. x. Hogg Fruit Man. 358. 1866. 2. Garden 53:265. I898. Caledonian 2 incor.

Hogg could see no difference between this variety and the Goliath, but H. A. Pearson in the Journal of the Royal Horticultural Society, for 1897 , says that they are distinct. Pearson adds, further; "The true variety was grown and distributed by Spencer, of Ilkeston, *** and is said to have been found growing on the banks of the Derbyshire Dove; it differs from Caledonian (Goliath) in growth, and whereas the leaf glands of that variety are well developed and red in color, Dove Bank has small ill-developed glands of a pale color; with regard to the fruit there is no comparison between the two. Caledonian is a somewhat coarse cooking plum. Dove Bank is a splendid cooking plum, and good enough for dessert."

Downing Early. Domestica. 1. Downing Fr. Trees Am. 910. 1869.

Downing's Early r.

Originated at Newburgh, New York. Tree moderately vigorous; branches shortjointed; fruit medium, oval, yellow with slight blush, and crimson dots; flesh yellow, sweet, slightly adherent to the stone; good; mid-season.

Downton Imperatrice. Domestica. I. Kenrick Am. Orch. 259. 1832. 2. Downing Fr. Trees Am. 274 184ङ. 3. Hogg Fruit Man. 358. 1866. 4. Mathieu Nom. Poin. 428. 1889 .

Downton Impératrice 4. Downton's Kaiserin 4. Downtoner Kaiserin 4. 
Grown by the famous horticulturist, Thomas A. Knight, from pits produced by pollinating Yellow Egg with Blue Imperatrice. Fruit medium, oval; suture slightly marked; skin thin, tender, pale yellow; flesh yellow, juicy, melting, agreeably subacid; good for preserving; stone clinging; late.

Drake Seedling. Domestica. I. Can. Hort. 24:406. 1901. Drake's Seedling 1.

A secdling raised in the orchard of George Drake, Clarksburg, Ontario. Skin yellow, dull red on the sunny side; flesh yellow; a good cooking plum.

Drouth King. Munsoniana. I. Kerr Cat. 1894. 2. Waugh Plum Cult. 194. I901.

Of unknown origin. Fruit small, oval, bright red; dots many, conspicuous; flesh yellow; good; stone of medium size, oval, clinging; mid-season.

Dr. Uff. Domestica. 1. Mich. Sta. Bul. 118:51. 1895. 2. Mich. Sta. Sp. Bul. 27: I4. 1904 .

Imported by the United States Department of Agriculture from Hungary. Fruit medium to large, roundish-ovate, dark purple; bloom light; flesh medium firm, juicy, yellow; good; clingstone; early.

Dr. Uff Szilvaja. Domestica. I. Mich. Sta. Bul. 152:209. I898.

Imported from Hungary as Dr. Uff but it differs markedly from this variety. Fruit small to medium, roundish-oblong; skin greenish-yellow with a faint red tinge; stem one-half inch long; flesh greenish-yellow, tender, juicy, sweet, rich; good; freestone. Dry Seedling. Domestica. I. Gard. Chron. 29:898. 1869. 2. Hogg Fruit Man. 698. 1884. 3. Can. Exp. Farm Bul. 2d Ser. 3:51. 1900. 4. Mathieu Nom. Pom. 428 . 1889 .

Dry's Seedling 1, 2. Semis de Dry 2.

A seedling raised by a Mr. Dry, at Hayes, Middlesex, England; awarded a first class certificate by the Royal Horticultural Society in 1869 . Fruit large, roundishoval; suture slight; reddish-purple; bloom thin; flesh dull greenish-yellow, firm yet juicy; freestone; early.

Duke. Munsoniana $\times$ ? 1. Kerr Cat. 1900. 2. Vt. Sta. An. Rpt. 14:271. 1901.

A supposed cross between Pottawattamie and the Duke Cherry, originating with Theodore Williams, Nebraska. Tree vigorous, productive; fruit larger than Wild Goose, of nearly the same form; cavity narrow, deep; suture a line; bright red; flesh yellow, firm, mild subacid; clingstone; mid-season. Waugh states that this variety resembles a Wild Goose crossed with an Americana and that he is unable to detect any cherry characters.

Duke of Devonshire. Domestica. Mentioned in Lond. Hort. Soc. Cat. 146. 1831 . Duke of Edinburgh. Domestica. 1. Jour. Hort. 21:216. 1869. 2. Flor. \& Pom. 7:193. 1871. 3. Hogg Fruit Man. 698. 1884. 4. Mathieu Nom. Pom. 428. 1889. Duc d'Edinbourg 4.

A variety raised by a Mr. Dry, Hayes, Middlesex, England. Fruit large, roundishobovate; suture shallow; skin thin, light purple; flesh reddish-yellow, juicy, richly flavored; freestone; good culinary plum.

Dumberline. Domestica. I. Lond. Hort. Soc. Cat. 146. 1831.

A variety under test in the London Horticultural Society Gardens in ${ }_{1} \$_{3} 1$.

Dummer. Domestica. 1. Hogg Fruit Man. 698. 1884. 
Raised in 1837 by a Mr. Dummer at Canterbury, England. Fruit large, red; like Red Magnum Bonum.

Dumiron. Domestica. I. Cal. Nurs. Co. Cat. I1. 1897.

Imported from Transon Bros., Orleans, France, by the late John Rock of California; not introduced.

Dunkelblaue Kaiserin. Domestica. Mentioned in Mathieu Nom. Pom. 428. 1889.

Violette Kaiserin incor.

Dunlap. Hortulana. 1. Cornell Sta. Bul. 38:79. 1892, 2. Wis. Sta. Bul. 63:36. I897. 3. Waugh Plum Cult. 185. I901.

Dunlap No. 2 3. Dunlap's No. 22.

Originated and introduced by J. P. Dunlap of Nebraska. Fruit large, oval; cavity shallow; suture a line; surface smooth, glossy, bright red; dots many; bloom thin; flesh yellow, soft, juicy, sweet, rich; good; clingstone; mid-scason; reported in the catalog of the American Pomological Society for 1899 .

Dunlap No. 1. Americana. I. Wis. Sta. Bul. 63:36. 1897. 2. Ibil. 87:13. 1900.

3. Waugh Plum Cult. 148. rgor.

Dunlap 2. Dunlap (No. I) 3. Dunlap's No. I I.

Another varicty prođuced by J. P. Dunlap of Nebraska. Fruit medium in size, oblong; suture a line; greenish-yellow covered with dull purplish-red; bloom heavy; flesh tender, juicy, rich, sweet; freestone.

Dunlop Nut. Americana. r. Can. Exp. Farms Rpt. 305. 1893.

A hardy variety tested at the Experimental Farm at Ottawa.

Dunmore. Domestica. r. Mag. Hort. 9:163. 1843. 2. Downing Fr. Trees Am.

380. I857. 3. Hogg Fr. Man. 359. 1866. 4. Mathieu Nom. Pom. 428, 1889.

Dunmore 4.

Fruit medium in size, oval; skin thick, greenish-yellow becoming golden; stem half an inch long; flesh yellow, tender, juicy, sweet; good; freestone; late.

Durazen Zwetsche. Domestica? r. Mathieu Nom. Pom. 428. 1889.

Reference taken by Mathieu from the Pomologische Monatshefte 2. I882.

Eagle. Angustifolia varians. 1. Kerr Cat. 1902-3. 2. Ohio Sta. Bul. 162:254, 255. 1905.

Originated in Texas; tree low, spreading; fruit of medium size, round; suture slight; skin light red; flesh yellow; good; stone clinging; early.

Early. Domestica. 1. Am. Pom. Soc. Rpt. 61. 1887. Skorospielka I.

From Russia.

Early Amber. Domestica. I. Forsyth Treat. Fr. Trees 21. 1803. 2. Floy-Lindley Guide Orch. Gard. 297. 1846.

Fruit small, roundish-oblong, pale greenish-yellow with crimson specks; flesh greenish-yellow, juicy; stone clinging; early.

Early Apricot. Domestica. x. Prince Pom. Man. 2:70. 1832. 2. Mas Pom. Gen. 2:21. 1873. 3. Mathieu Nom. Pom. 430. 1889.

Abricotée Hative 1, 3. Abricotée Hâtive 2. Abricote Hatif 1. Abricotée Précoce 3. Early Apricot Plum 1. Frühe Aprikosenplaume 2. Frühe Aprikosenpflaume 3. Oberdiecks Frïhe Aprikosenpflaume 2, 3. 
The fruit of Early Apricot is small, roundish; suture shallow; cavity distinct; pale red, darker in the sun; dots small, numerous; flesh yellowish-green, slightly juicy, firm; quality fair; clingstone; season early.

Early Blue. Domestica. 1. Ont. Fr. Growers Assoc. 87. 1896. 2. Am. Pom. Soc. Rpt. 52. 1897 .

A Domestica of American origin. Fruit the size of Lombard; very early.

Early Blue. Domestica. 1. Miller Gard. Dict. 2. 1807. 2. Downing Fr. Trees Am. 899. 1869. 3. Mas Pom. Gen. 2:13. 1873. 4. Hogg Fruit Man. 698. I884.

Azure Hâtive 3. Azure Hative 2, 4. Black Perdrigon 2, 4. Blue Gage 3, 4. Blue Gage 1, 2. Cooper's Blue Gage 2, 4. Early Blue 3. Little Blue Gage 2.

An old European variety; rejected by the American Pomological Society in 1858 . Fruit of medium size, roundish, dark purple; flesh greenish-yellow, juicy; flavor brisk and rich; freestone; early.

Early Cherry. Cerasifera $x$ ? 1. Kerr Cat. 21. 1897.

From California; fruit small, round, red; clingstone; early.

Early Cluster. Species? I. Mathieu Nom. Pom. 428. 1889. 2. Guide Prat. 163, 355. I 895 .

Mentioned in the preceding references.

Early Cross. Domestica. 1. Downing Fr. Trees Am. $3^{80 .}{ }_{18} 87$.

Originated with a Mr. Cross, Salem, Massachusetts. Tree vigorous, productive; fruit below medium, roundish, reddish-purple; bloom thick; flesh greenish-yellow, juicy, sweet; clingstone; early.

Early Favorite. Domestica. I. Downing Fr. Trees Am. 3I4. I845. 2. Elliott Fr. Book 419. 1854. 3. Downing Fr. Trees Am. 395. 1857. 4. Mas Le Verger 6:I r. 1866-73. 5. Mathieu Nom. Pom. 447. I889. 6. Guide Prat. 152, 356. I895. 7. Kev. Hort. 548, P1. I 909 .

Early Favorite 4, 5, 6. Early Favourite 6. Early Favourite 4. Favorite Hative 7. Favorite Précoce 4, 5, 7. Favorite Précoce 6. Favorite Précoce de Rivers 5, 6. Précoce de Rivers 5. Prune Early Favorite 7. Rivers Early 5, 6. Rivers Early Fazorite 5. River's Early Favourite 5, 6. River's Early Favourite 3. River's Early No.I I. River's Early No. I 2. Rivers Früh Pflaume 5. Rivers Frühpflaume 6. River's No. $I$ 3 5 .

A seedling of Précoce de Tours raised by Thomas Rivers, Sawbridgeworth, England, about I834. Tree vigorous, productive; fruit small, roundish-oval; suture shallow; bluish-black; dots russet; flesh greenish-yellow, juicy, sweet; good; freestone; very early. Mentioned in the catalog of the American Pomological Society from I 852 to 1891 .

Early Genesee. Domestica. 1. Gen. Farmer 9:232. 1848.

Originated in Brighton, Monroe County, New York. Fruit of medium size, longovate, golden-yellow; very early.

Early Golden Drop. Domestica. 1. Wickson Cal. Fruits 352. I891. 2. Cal. Nur. Cat. I898. Early Golden 2.

"Small, bright yellow, sugary and rich; pit free; ripens early." 
Early Honey. Angustifolia varians. 1. Cornell Sta. Bul. 38:79. 1892. 2. Waugh Plum Cult, 195. $190 \mathrm{x}$.

From Grayson County, Texas.

Early Mirabelle. Insititia. 1. Hogg Fruit Man. 360, 376. 1866. 2. Mas Le Verger 6:1. 1866-73. 3. Oberdieck Deut. Obst. Sort. 410. 1881. 4. Guide Prat. 152 , 360. 1895 .

Frühe von Bergthold 3. Mirabelle Précoce 1. Mirabelle Précoce 4, 5. Précoce de Bergthold 1, 2. Mirabelle de Berthold 4. Précoce de Bergthold 4 .

Thought to be of English origin; first noted by Hogg. Resembles the Mirabelle very closely, with which it is confused. Tree medium in vigor, very productive; shoots downy; fruit small, nearly round; suture indistinct; skin pale ycllow, specked with red on the sunny side; flesh yellowish, sweet, juicy, agreeably aromatic; freestone; early. Early Minnesota. Americana. 1. Wis. Sta. Bul. 63:36. 1897. 2. S. Dak. Sta. Bul. 93:17. 1905 .

Found wild by Joseph Wood of Windom, Minnesota. Tree low, spreading, hardy, very productive; fruit small, round, yellowish-red; flesh sweet, juicy; stone free; very early

Early Normandy. Domestica. 1. Horticulturist 30:256. 1875. 2. Le Bon Jard. 340. 1882.

Normande précoce 2.

Noted in the Horticulturist as originating in France. Tree vigorous; fruit as large as a Reine Claude, purple on the sunny side, light flesh-colored on the shady side; bloom light; flesh greenish, fine and melting, juicy, sweet; good; early.

Early Pale. Species? Letter from Burbank.

Originated with Luther Burbank and sold to Judge S. F. Lieb in 1897 .

Early Pear. Domestica. 1. Parkinson Par. Ter. 577 fig. 1629. 2. Rea Flora 209. 1676.

Prunum Pyrinum praccox 1.

An early strain of White Pear.

Early Perdrigon. Domestica. 1. Lond. Hort. Soc. Cat. 151. 1831. 2. Prince Pom. Man. $2: 65.1832$. 3. Poiteau Pom. Franc. 1. 1846. 4. Hogg Fruit Man. 375. 1866. 5. Downing Fr. Trees Am. 936. 1869. 6. Mas Le Verger 6:147. 1866-73. 7. Mathieu Nom. Pom. 43r. 1889. 8. Guide Prat. 153, 361. 1895.

Früher Perdrigon 7. Früher Violetter Perdrigon 7. Moyeu de Bourgogne ?7, 8. Perdrigon hâtif 1 . Perdrigon hâtif 2, 7, 8. Perdrigon hâtive 2. Perdrigon Violet Hâtif $4,5,6,7,8$. Prune Perdrigon hâtif 3. Prunus Calvellana 3.

There are two plums known under this name. Both are small, oval, purplish and are covered with a thick bloom. One, however, which scems to have been earliest known, is sweet, rich and of very good quality, ripening about the middle of August. The second variety was named by Calvel. It is vastly inferior in quality to the first and ripens in July. Neither variety is well known in America.

Early Red. Angustifolia varians. 1. Am. Pom. Soc. Rpt. 160, 162. 1881. 2. Corncll

Sta Bul. 80:62. 1892. 3. Waugh Plum Cult. 195. 1901.

Grown by G. Onderdonk of Mission Valley, Victoria County, Texas; introduced by the originator in 1879 . Fruit small, roundish; cavity large; suture lacking; 
red; dots few, white; skin thin; flesh soft, yellow, sprightly; quality fair; clingstone; early.

Early Red. Domestica. I. Am. Pom. Soc. Rpt. 6i. I887. 2. Ia. Hort. Soc. Rpt. 86. 189o. 3. Can. Exp. Farm. Bul. 43:33. 1903. 4. Budd-Hansen Am. Hort. Man. 310. 1903 .

Early Red Russian 3. Early Red Russian No. 3 3. Krasnaya Skorospielkaya I. Mixed Arab 2, 3. No. 32 .

Early Red was imported by J. L. Budd from Dr. Regel, St. Petersburg, Russia, in the winter of $1881-82$. The following season it was disseminated with a mixed lot of varieties, all of which became badly confused. Fruit large, oval; cavity small; suture shallow; dark red; bloom thick; dots white; flesh firm, meaty; quality fair; clingstone; early.

Early Royal of Nikita. Domestica. I. Downing Fr. Trees Am. 380. 1857. 2. Mas

Pom. Gen. $2: 25$ fig. 13. 1873. 3. Mathieu Nom. Pom. 429, 430, 441, 449. 1889.

Early Royal of Nikita 3. Friche Königsplaume Pflaume von Nikita 3. Frizhe Nikitaer Königsplaume 3. Nikitaner Frìhe Königspflaume 2. Nikitaer Frühe Königspflaume 3. Nikita's Fruhe Königs Pfanme 3. Royale Hative de Nikita 3. Royal Hative de Nikita 3. Royale Hâtive de Nikita 2.

According to Mas this variety originated in Nikita, Crimea. Fruit small, roundish, reddish-purple; bloom thick; flesh yellow, sweet, juicy; good; semi-clinging; early.

Early St. John. Domestica. I. Downing Fr. Trees Am. 91 2. 1869.

Prune de St. Jean x. St. Jean I. St. John x.

Tree vigorous; fruit medium in size, roundish-oblong, reddish-purple; flesh green, sweet, sprightly; freestone; mid-season.

Early Transparent Gage. Domestica. I. Jour. Hort. N. S. 17:286. 1869. 2. Hogg Fruit Man. 722. 1884. 3. Guide Prat. 153, 364. 1895. 4. Rivers Cat. 34. 1898. 5. Bartrum Pears and Plums 63. 1902.

Early Apricot 3. Early Transparent 4. Early Transparent Gage 2, 3. New Transparent Gage 1. Reine-Claude Diaphane Hative 3. Rivers' Early Apricot 2. Rivers' Early Transparent Gage 5.

This seedling of Transparent Gage was raised by Thomas Rivers, Sawbridgeworth, England, in 1866 . Tree hardy, productive, compact; branchlets pubescent; fruit medium in size, roundish-oblate; suture shallow; stem slender; yellowish-green, mottled with crimson; flesh greenish-yellow, firm, juicy; quality high; freestone; early. Early Yellow Gage. Domestica. I. Downing Fr. Trees Am. App. 2:156. 1876.

Originated with Asahel Foote, Williamstown, Massachusetts. Tree vigorous, upright, productive; fruit of medium size, roundish-oval; suture shallow; cavity small; stem slender; pale yellow; bloom thin; flesh greenish-yellow, rather coarse, juicy. sweet; semi-clinging; early.

Early Yellow Prune. Domestica. 1. Horticulturist 8:536. 1853. 2. Am. Pom. Soc. Rpt. 86. 1854 .

Originated in Bedford County, Pennsylvania. Tree vigorous, prolific; fruit medium, oval; skin yellow; very good; stone free. 
Eason. Domestica. I. Parkinson Par. Ter. 578, 1629.

Described by Parkinson as "small, red and well tasted."

Eberly. Domestica. 1. Am. Pom. Soc. Rpt. 135. 1905 Eberly's Plum 1.

A seedling brought to notice by W. V. Eberly of the California Nursery Company. Fruit large, oval; cavity small; yellow, occasionally slightly russeted; dots numerous, silvery; flesh yellowish, translucent; sweet, rich; good; stone long, flat, free; late. Ebon. Cerasifera $X$ ? I. Kerr Cat. 16. 1899.

Described by Kerr in 1899 . Tree upright, with distinct foliage. Fruit medium in size, round to round-oblong, very dark red; flesh rcd; clingstone.

Ecully. Domestica. I. Cat. Cong. Pom. France 364. 1887. 2. Guide Prat. 153, 364. 1895. 3. Can. Exp. Farms Rpt. 433. 1905. Reine-Claude d'Ecully 1, 2, 3.

A chance seedling grown by M. Luizet, at Ecully-les-Lyon, France; first fruited in 1866 . Tree vigorous, very productive; fruit large, roundish; suture deep; halves unequal; cavity deep and rather wide; stcm medium in length; skin yellow, slightly tinged with red; flesh yellowish, fine, rather firm, juicy, sweet, Reine Claude aroma; good; stone nearly free; mid-season.

Eddie. Species? Letter from J. W. Kerr.

Originated by Theodore Williams of Benson, Ncbraska.

Edith. Americana. I. Ia. Sta. Bul. 46:269. 1900 .

A seedling of Iowa Beauty grown by E. L. Hayden, Oakville, Iowa, about 1895 . Tree upright, vigorous; fruit medium in size, globular; suture indistinct; dark red; dots numerous; bloom thick; good; stone of medium size; mid-season.

Edle Early. Domestica. I. Oberdieck Deut. Obst. Sort. 4 I1. 1881. 2. Mathieu Nom.

Pom. 428. 1889 .

Edle Frühpflaume 1, 2. Noble Précoce 2.

Found in a garden in Brunswick, Germany. Tree large, productive; fruit small, oval; suture a line; brownish-red, with gold-colored dots; flesh golden-yellow, tender, juicy, sweet; freestone; early.

Edouard Seneclauze. Domestica. 1. Hogg Fruit Man. 36r. 1866.

Fruit very small, obovate, golden-yellow; flesh sweet, richly flavored; freestone; early.

Eggles. Triflora $\times$ Hortulana. I. Vt. Sta. An. Rpt. 14:27 1. I901.

Sent out by A. L. Bruce, Texas. Fruit large, round; suture indistinct; bright red; dots many, minute, yellow; flesh yellow; stone oval, compressed, clinging; poor. Eldora. Americana. 1. Ia. Hort. Soc. Rpt. 333. 1894. 2. Waugh Plum Cult. I48. I 901 .

A seedling raised by Judge Samuel Miller of Missouri. Tree rapid in growth; fruit medium to large.

Eldorado. Americana. 1. Ia. Sta. Bul. 46:269. 1900. 2. Ill. Hort. Soc. Rpt. I35. 1903. 3. Ibid. 426. 1905.

A seedling grown by H. A. Terry of Crescent, Iowa, who introduced it in 1899. Fruit small, round; suture lacking; yellow overlaid with red; dots small, grayish; bloom thin; skin thick; flesh firm, yellow, subacid; clingstonc; late. 
Eldridge. Americana. r. Am. Pom. Soc. Cat. 42 . 1883.

$A$ variety from $W$ isconsin listed for eight years by the American Pomological Society. Elfrey. Domestica. 1. Coxe Cult. Fr. Trees 234. 1817. 2. Prince Pom. Man. $2: 98$. 1832. 3. Horticulturist 7:403. 1852. 4. Mathieu Nom. Pom. 429. 1889.

Elfrey's Prune 2. Elfreth's Prune 2. Elfry's Plum 4.

Of unknown origin; quite widely disscminated and highly recommended in the South about fifty years ago. Tree vigorous; fruit medium in size, oval, blue; flesh grcenish, firm, rich, slightly dry; mid-season.

Elisabeth Pflaume. Domestica. Mentioned in Mathieu Nom. Pom. 429. r889.

Elisabcth d'Elsner. Elsner's Elisabeth Pflaume.

Ella. Domestica. 1. Can. Exp. Farm Bul. 2d Ser. 3:52. 1900.

A seedling of the Peach plum grown at the British Columbia Experimental Station; not introduced; closely resembles the parent.

Ellis. Munsoniana $\times$ Hortulana. 1. Cornell Sta. Bul. 38:79. 1892. 2. Waugh Plum Cult. 231. I901.

Ellis is said to be a cross between Wild Goose and Golden Beauty, and to have originated in northern Texas; introduced by T. L. Ellis. Fruit large, round; skin very thin, red; good; semi-clinging.

Ellwood. Domestica. 1. Col., O., Hort. Soc. Rpt. 31. 1892, 2. Ohio Sta. Bul. I62: 254, 255. I905. Elwood I.

Introduced by Augustine and Company, Normal, Illinois; very similar to Lombard if not identical with it.

Elmore. Domestica. I. Gard. \& For, 7:243, 1894.

An early variety from Shasta, Sacramento County, California.

Elsner Grune Zwetsche. Domestica. Mentioned in Mathieu Nom. Pom. 429. 1889. Elsner's Von Gronow Grime Zwetsche. Prune Celeste.

Elton. Domestica. 1. Lonl. Hort. Soc. Cat. 147. 1831 .

Grown on the grounds of the London Horticultural Society.

Emerald. Domestica. 1. Can. Hort. 12:265. I889. 2. Am. Pom. Soc. Rpt. ror. 1891. 3. Smith Cat. 35. 1898. 4. Can. Hort. $22: 340$. 1899.

Early Green $1,2,4$.

Originated with Warren Holton, Hamilton, Ontario; supposedly a seedling of Rcine Claude. It was first called Early Green but was introduced by E. D. Smith of Winona, Ontario, under the name Emerald. Tree hardy and productive; fruit large, roundish; stem slender; suture medium deep; yellowish-green; very good; stone free, smooth; very early.

Emerald. Triflora $\times$ Americana. I. Ia. Sta. Bul. 46:270. 1900. 2. Waugh Plum Cult. 209. 1901. 3. Budd-Hansen Am. Hort. Man. 296. 1903. 4. Ia. Sta. Bul. 114:133. 1910. Burwood 4 .

Emerald came from a cross between Brittlewood and Burbank made by Theodore Williams, Benson, Nebraska, in 1895 . Tree resembles an Early Richmond cherry, hardy, productive; buds conspicuous; fruit large, roundish, yellow marbled with coppery-red; flesh yellowish, tender, fibrous, juicy, mild subacid; good. 
Emerald Drop. Domestica. I. Downing Fr. Trees Am. 275. 1845. 2. Ibid. 913. 1869. 3. Mas Le Verger 6:125. 1866-73. Goutte Emeraude 3.

Emerald Drop is a seedling of Washington grown somctime previous to 1845 by A. J. Downing, Newburgh, New York. Tree moderately vigorous, productive; fruit of medium size, oval; cavity small; suture distinct, sides unequal; yellowish-green; flesh greenish-yellow, juicy; good; clingstone; mid-season.

Emerson. Angustifolia varians. 1. Kan. Sta. Bul. 1ог:131. 19ог, 2. Cornell Sta. Bul. 38:63. 1892. 3. Waugh Plum Cult. 195. 1901. Emerson's Early 3.

Found wild in northern Texas; introduced by A. L. Bruce. Fruit small, round to oval, bright red, with many white dots; flesh yellow, soft; stone rough, clinging; early.

Emerson. Americana. 1. Minn. Hort. Soc. Rpt. 127. 1890.

Originated near Dubuque, Iowa. Tree productive; fruit large, roundish, red, thickly dotted with small gray spots; flesh firm; valuable for preserving.

Emerson Yellow. Angustifolia varians. 1. Kerr Cat. 20. 1897. 2. Waugh Plum Cult. 195. 1901.

A seedling of the Emerson from Texas. Fruit of medium size, round, yellow; inferior. Emigrant. Domestica. I. Am. Pom. Soc. Rpt. 126. 1889. 2. Am. Pom. Soc. Cat. 25. 1897 .

A seedling of Lombard. Fruit large, oval, purple; quality fair; mid-season.

Emily May. Domestica. I. Ia. Sta. Bul. 46:269. 1900.

A large attractive plum of the Pond type grown by Lillian A. Trotter, Owen Sound, Ontario, Canada. Fruit large, oval; suture well marked; clear light yellow; bloom thin; flesh firm, juicy, delicate; good; stone small, rough, free.

Emma. Americana. 1. Ia. Sta. Bul. 46:269. 1900. 2. Terry Cat. 1900.

Grown by H. A. Terry, Crescent, Iowa, in 1896 . Fruit medium in size, almost round; skin thin, reddish color; good; stone large, clinging.

Engle. Domestica. 1. Mich Sta. Bul. 129:32, 33. 1896. 2. Ibid. 187:77, 78. 1901. 3. Budd-Hansen Am. Hort. Man. 311. 1903.

Fruit below medium size, roundish-oval; suture obscure; skin yellow; flesh firm, yellow, flavor rich; very good; very early.

Empereur. Domestica. I. Mas Le Verger 6:63. r866-73. 2. Mathieu Nom. Pom. 429. 1889. Empereur de Mas 2.

Grown by M. Mas, France, from a seed of Golden Drop sown in $185^{\circ}$; reported in $186 \mathrm{I}$ under the name Empereur. Fruit large, obovate; suture indistinct; skin tender, purple, streaked with deeper purple; flesh clear yellow, melting, juicy, sweet; stone small, clinging; early.

Emperor of Japan. Domestica. 1. Mathieu Nom. Pom. 429. 1889.

Empereur du Japan 1. Emperor of Japan 1. Kaiser Von Japan r.

Mathieu found reference to it in Pomologische Monatshefte 134. 1882 and ObstGarten 322. 1882.

Esjum Erik. Domestica. 1. U. S. Dept. Agr. Pom. Bul. 10:21. 1901.

Esjum Erik is an Old World variety imported by the United Statcs Department of Agriculture in r 900 . As tested at this Station it appears to be of little value for New 
York growers. Trce vigorous, unproductive; fruit small, obovate, necked; cavity nearly lacking; suture a line; purplish-black; bloom thick; dots inconspicuous; flesh grcenish-yellow, juicy, firm, sweetish, mild; quality not high; stone small, oval, dark colored, clinging; mid-season.

Essex Bullace. Insititia. 1. Lond. Hort. Soc. Cat. 144. 183x. 2. Hogg Fruit Man. 689. 1884. 3. Rivers Cat. 37. 1909.

New Large Bullace 1, 3. New Large Bullace 2.

Tree vigorous, very productive; fruit large, roundish, greenish-yellow; flesh juicy; late.

Esslinger Fruhzwetsche. Domestica. I. Mathieu Nom. Pom. 429. 1889. 2. Lucas Vollst. Hand. Obst. 473. 1894. Quetsche Précoce d' Esslingen 1.

Tree vigorous; an early and abundant bearer; fruit of medium size, bluish-black; bloom light; valuable for dessert and drying.

Esther. Hortulana mineri. 1. Ia. Hort. Soc. Rpt. 287. x887. 2. Cornell Sta. Bul. 38:79. 1892. 3. Terry Cat. 1900. 4. Waugh Plum Cult. 173. 1901.

A seedling of Miner, grown by H. A. Terry, Crescent, Iowa; first fruited in 1885 . Fruit medium in size, round-oval; suture a line; dark red; dots numerous; bloom thin; flesh yellow; good; stone oval, clinging; late.

Etopa. Prunus besseyi $\times$ Triflora. Cir. S. Dak. Exp. Sta. 1910.

Introduced in 1908 by the originator, N. E. Hansen of the South Dakota Experiment Station. It is a cross of Occident with Prunus besseyi in which the dark purplish flesh of the male parent is conspicuous.

Etta. Americana. 1. Kerr Cat. 1900. 2. Terry Cat. 1900. 3. Wis. Sta. Bul. 85:13. r 1901.

A seedling first fruited in 1895 by H. A. Terry, Iowa. Fruit large, nearly round; suture distinct; skin yellow, striped and splashed with red; flesh sweet, rich; good; stone oval, free; mid-season.

Eureka. Nigra. 1. Ia. Sta. Bul. 46:270. 1900.

Grown in 1896 by Theodore Williams, Benson, Nebraska, from seed of Cheney. Tree upright, vigorous, unproductive; fruit large; roundish, yellowish-red to purple; flesh firm, juicy; good; clingstone; very early.

Eureka. Munsoniana. I. Am. Jour. Hort. 5:148. 1869:

Similar to Wild Goose.

Eva. Nigra. 1. Can. Exp. Farms Rpt. 426. 1900.

From Manitoba; tested at the Indian Head Experimental Farm, Northwest Territory, Canada. Fruit small, red; excellent; mid-season.

Evelyn. Domestica. I. Ont. Fr. Gr. Assoc. Rpt. 73. 1894. 2. Can. Exp. Farms Rpt. 137. $18_{94}$.

A seedling grown in the neighborhood of Owen's Sound, Canada; of local reputation.

Excelsior Damson. Insititia. 1. Green River Cat. 1899.

A freestone introduced in 1892 by the Green River Nursery Company and described in their catalog as being a particularly fine strain of the Damson.

Fairchild. Americana. I. Ia. Sta. Bul. 46:27 r. 1900. 2. Waugh Plum Cult. 148. r 901 . 
A seedling of De Soto supposed to have been fertilized by a wild plum; grown by J. II. Fairchild, Iowa, in 1894 and offered for sale in 1899 by Snyder and Son, Center Point, Iowa. Fruit above medium, roundish-oval, yellowish-red with whitish dots; flesh yellow, firm, juicy; quality fair; mid-season.

Fancy. Munsoniana. x. Ia. Sta. Bul. 46:271. 1900.

From a sprout of Wild Goose, originating with John Brown, Oakville, Louisa County, Iowa, in 1885 . Tree vigorous, very prolific; fruit large, oblong, yellow with shading of red; bloom thin; flesh sweet, juicy; good; stone small, clinging; midseason.

Fanning. Munsoniana, x. Waugh Plum Cult. 185. I901.

A chance seedling found in the yard of a Mr. Fanning, Rockdale, Texas. Fruit medium in size, round-oval, bright red; dots numerous; flesh yellow; quality fair; stone oval, clinging; mid-season.

Fawn. Munsoniana. x. Waugh Plum Cult. 231. 1901.

A variety first grown by David Miller of Camp Hill, Cumberland County, Pennsylvania. Fruit of medium size, roundish; suture a line; bright red; dots numerous, large, yellow, giving a dappled or fawn color; bloom very thin; flesh yellow; quality fair; stone oval, clinging.

Femmonzi. Species? r. Coates Cat. 1910-1 r.

A variety first grown by Frank Femmons of Ahwahnee, California, and introduced by the Leonard Coates Nursery Company, Morganhill, California, in the fall of rgro. Said to be large and handsome.

Field Marshall. Domestica. I. Kenrick Am. Orch. 257. 1832. 2. Downing Fr. Trees Am. 293. 1845. 3. Elliott Fr. Book 426. 1854.

Corse's Field Marshall 1, 2. Corse's Field Marshal 3.

A seedling raised by Henry Corse of Montreal, Canada. Fruit large, oval, bright purplish-red; cavity shallow; flesh greenish-yellow, juicy, subacid; stone long, pointed, clinging.

Figue Grosse Rouge. Domestica. I. Lond. Hort. Soc. Cat. 147. 1831.

Wilmots Early 1 .

Fruit large, obovate; purple; freestone; quality medium; mid-season.

Fin de Siecle. Nigra. I. Can. Exp. Farms Rpt. 426. 1900.

A seedling raised at Indian Head Experimental Farm, Northwest Territory, Canada. Tree productive; fruit large; red; flavor fair; early.

Fine Bonte. Domestica. 1. Downing Fr. Trees Am. 913. 1869. 2. Mas Le Verger 6:35. 1866-73. 3. Mathieu Nom. Pom. 429. 1889.

Feine und Gute 3. Fine Bonte 3.

Originated in the nurseries of Simon Louis, Moselle, France. Fruit small, irregularly ovate; suture indistinct; purple; bloom thin; stem very short, thick; flesh greenish yellow; very good; stone small, free; very early.

Fine Early Plum. Domestica. Mentioned in Forsyth Treat Fr. Trees 21. 1803.

Firba Konigspflaume. Domestica. Mentioned in Mathieu Nom. Pom. $429 . \quad 1889$. 
Firbas Fruhe Schuttenhoferin. Domestica. I. Mathicu Nom. Pom. 429. 1889 .

Mathicu found mention of it in Wiener Garten-Zeitung 287. 1884 .

First. Species? 1. Burbank Cat. 1899. 2. Ibid. 190x. 3. Ga. Sta. Bul. 68:36. 1905.

No. 31,288 I

According to the originator, Luther Burbank, this varicty is one of the second generation of a combination cross of Hawkeye, Hammer, Milton, Wyant, Wayland and Burbank. It was introduced in 1899 under the breeding number 31,288 , but grafting wood was not offered for sale until 1900. This is probably one of the earliest plums, ripening in California about three weeks before Red June. Fruit medium in size, roundish; stem short, slender; yellow with faint blush; flesh yellow, sweet, juicy; earliest.

First Best. Species? r. Childs Cat. 136. 1910.

First Best was grown by R. D. Hoyt of Clearwater, Florida, in 1894 from seed marked "Hill Plum" received from W. Gollen of Saharanfur, India. The tree first fruited in 1904 and was introduced in the spring of 1910 by John Lewis Childs, Floral Park, New York, who states that it is an unusually early, yellow variety.

First Sweet. Nigra? I. Can. Exp. Farms Rpt. 426. 1900.

A seedling raised at the Experimental Farm, Northwest Territory, Canada. Tree productive; fruit of medium size; skin red, thin; flavor excellent; early.

Fitzroy. Americana. ז. Can. Exp. Farms Rpt. 119. 1904.

A seedling of Rollingstone grown at the Central Experimental Farm, Canada. Fruit above medium, roundish, slightly heart-shaped; suture a line; skin yellow washed with red; dots many; bloom moderate; flesh pale yellow, juicy, sweet; good; stone nearly free; cracks when ripe.

Flora Plena. Americana. I. Kerr Cat. $1894^{-97}$.

J. W. Kerr, the introducer, found this plum in the yard of a friend in York County, Pennsylvania, it having been brought from Iowa. Tree dwarf; blooms profusely with beautiful pure white, very double flowers; no fruit.

Flushing Bulleis. Domestica. I. Parkinson Par. Ter. 576. r629.

Noted by Parkinson as a variety producing fruit in elusters like a bunch of grapes. Foote. Insititia. I. Mich. Sta. Sp. Bul. 35:21. 1906.

Fruit small, roundish-oblong; skin black; fiesh rather dry, greenish-yellow; stone small, oval, clinging; mid-season.

Foote. Domestica. 1. Horticulturist 20:324. 1865. 2. Downing Fr. Trees Am. 913. 1869. 3. Mas Pom. Gen. $2: 77 . \quad 1873$.

Footc's Early Orleans 3. Foote's Early Orleans r, 2, 3. Monsieur Hâtif de Foote 3.

$\Lambda$ seedling of Wilmot's Early Orleans raised in $185_{2}$ by Asahel Foote of Williamstown, Massachusetts. Tree large and vigorous; fruit of medium size, roundish-oval; suture absent; very black; flesh greenish, juicy; good; stone oval, flattened, clinging; very early.

Foote Golden Gage. Domestica. 1. Downing Fr. Trees Am. 914. I869.

Raised by Asahel Foote, Williamstown, Massachusetts. Tree very vigorous; shoots slightly downy; fruit large, nearly round; suture shallow; stalk slender; cavity 
small; skin golden-yellow, obscurcly splashed with green and tinged with red; flesh yellow, juicy, sweet, slightly vinous; very good; stone slightly adherent; mid-season. Forest Rose Improved. Hortulana mineri. I. Ohio Sta. Bul. I13:154. 1899.

An improved strain of Forest Rose somewhat larger than the original.

Forewattamie. Hortulana mineri $\times$ Munsoniana. r. Vt. Sta. Bul. 67:11. 1898 .

2. Kerr Cat. 1900.

A cross between Forest Garden and Pottawattamie grown by Theodore Williams, Bcnson, Nebraska. J. W. Kerr, after testing it, states that it disclosed no special mcrits; fruit below medium, oval, dull red; flesh watery; poor.

Formosa. Triflora $X$ ? I. Fancher Crcek Nur. Cat. 7. 1907-8. 2. Fancher Creek Nur. Cat., Burbank's Late Introductions. fig. igon.

Wickson Challenge $\mathrm{t}$.

Grown by Luther Burbank, who states that it is of mixed parentage, including probably from fifteen to eighteen varieties. Tree very vigorous and productive; fruit large, oval to slightly cordatc; suture very prominent; cavity medium; rich yellow with light bloom turning to clear red at maturity; flesh pale yellow, firm, sweet, rich, apricot flavor; good; stone semi-clinging; mid-season.

Forward Damask. Domestica. Mentioned in Quintinye Com. Gard. 70. 1699.

Frankfort Peach. Domestica. I. Koch Deut. Obst. 572. 1876. 2. Downing Fr.

Trees Am. 3rd App. 180. 1881. 3. Mathieu Nom. Pom. 430. 1889.

Francfort Peach 3. Frankfurter Pfirschen Zwetsche 3. Kuchen Pflaume 3. Quetsche de Francfort 3. Quctsche-Pêche de Francfort 3.

Tree spreading, productive; fruit of medium size, oval, compressed; suture shallow; cavity small; black; bloom thick; flesh yellow, coarse, juicy, sweet, good; stone oval, thin, free; mid-season.

Franklin. Triflora $\times$ ? I. Vt. Sta. An. Rpt. 12:223. 1899. 2. Waugh Plum Cult. 210, 2 II fig. I90I.

Originated with A. L. Bruce, Texas, from Abundance crossed with an unknown varicty. Fruit of medium size, oblate; suture a line; bright crimson over yellow; dots numerous; bloom thin; flesh yellow; good; clingstone.

Fraser. Domestica. 1. Am. Gard. 22 :606. 1901. 2. Gard. Chron. 30:1 20. 1901.

Fraser's Early Yellow I.

Raised in the nursery of John Fraser, Woodford, England, about 1895. Tree small; fruit very small, oval; skin bright yellow; flesh soft; flavor poor; freestone; valuable because of its earliness.

Freeman. Munsoniana. 1. Ia. Hort. Soc. Rpt. 276 . 1893. 2. Wis. Sta. Bul. 87:13. I9or.

Freeman's Favorite 1.

Originated in 1885 with H. A. Terry, Crescent, Iowa, from seed of Wild Goose. Tree vigorous, fairly productive; fruit above medium, roundish-oblong; suture distinct; bright crimson, numerous dots on the lower half; flesh very tender, sprightly; good; clingstone; early.

Freestone. Species? I. Ill. Hort. Soc. Rpt. 424. I905.

An inferior native variety; fruit small; clingstone; mid-season. 
Freestone. Americana. r. Terry Cat. 1900.

A secdling grown by H. A. Terry from seed of Harrison. Fruit large, pale yellow becoming light red at full maturity; good; stone semi-clinging.

Freestone Goose. Munsoniana. r. Stark Cat. 29. I9ro.

Originated by Theodore Williams, Benson, Nebraska, and introduced by Stark Brothers, Louisiana, Missouri, in 1910. The fruit is said to be larger and darker colored than the Wild Goose.

Freestone Quetsche. Domestica. r. Mich. Sta. Bul. 152:209. 1898.

Imported by the Department of Agriculture and noted as vigorous.

Friedheim Damascene. Species? Mentioned in Mathieu Nom. Pom. 430. 1889.

Friedhcim's Rote Frih Damascene. Damas Ronge de Friedheim.

Fritze Hermpflaume. Domestica. Mentioned in Mathieu Nom. Pom. 430. 1889.

Frostproof. Cerasifera. 1. Vt. Sta. An. Rpt. 13:369. г900. 2. Waugh Platm Cult. 231. 1901 .

Grown and introduced by J. H. G. Jenkins, Spring Garden, Missouri, about r 896. Fruit small, spherical; suture a fine line; dark crimson; dots minute; bloom thin; flesh yellow; good; clingstone; very early; blossoms resistant to frosts.

Fruhe Englische Zwetsche. Domestica. Listed in Mathieu Nom. Pom. 430. 1889.

Fruhe Gelbe Reine Claude. Domestica. Mentioned in Mathieu Nom. Pom. 430. 1889. Friuhe Gelbe Kaiser Pflaume.

Fruhe Grune Zwetsche. Domestica. r. Oberdieck Deut. Obst. Sort. 445. I88 r. 2. Mathieu Nom. Pom. 430. 1889. Bischtin Erik 2. Herr Pflaume 2.

A German variety said to be suitable for moist soils.

Fruhe Leipziger Damascene. Species? 1. Mathieu Nom. Pom 430. 1889.

Damas de Leipsick I. Fondante Noire I.

Mathieu suggests that this may possibly be identical with Précoce de Tours.

Fuller. Species? r. Wis. Sta. Bul. 63:37. 1897. Fuller's Egg r.

Reported by B. A. Matthews, Knoxville, Iowa, as a large, oval plum.

Fulton. Domestica. 1. Downing Fr. Trees Am. 382. 1857. 2. Cultivator 5:373. 1857 .

A variety of uncertain origin found at Johnstown, Fulton County, New York. Tree vigorous and productive; fruit of medium size, oval; suture distinct; bright yellow; juicy; good; late and hangs to the tree well.

Funk. Triflora $X$ ? 1. Munson Cat. 8. 1902. 2. Text. Dept. Agr. Rpt. 12:102. I 910. Funk's Early 2.

An accidental cross of Abundance raised by J. M. Funk, Grayson County, Texas. Tree vigorous, upright, prolific; fruit medium, heart-shaped, bright red; clingstone; very early.

Furst Damson. Insititia. 1. Hogg Fruit Man. 36r. r866. 2. Downing Fr. Trees Am. 913. 1869. 3. Waugh Plum Cult. 127, r29. 1901. 4. Can. Exp. Farm Bul. 2d Ser. 3:51. 1900.

Eugene Fürst 1, 2. Eugen Fürst 3. Fürst's Damson 4. Quetsche Précoce de Fürst 2. Sweet Damson I, 2. 
This plum is frequently confused with the Furst. The origin of the name and variety is unknown. According to Waugh, it is a German variety introduced in America about sixty years ago. Foliage Damson-like; fruit small, pear-shaped, with a neck; cavity shallow, abrupt; stem slender; suture obsolete; apex slightly pointed; skin tough, purplish-black; flesh greenish-yellow, juicy, slightly acid; quality fair to good; stone nearly free.

Gabriel Combes. Domestica. 1. Rev. Hort. 332, Pl. 1895 .

Prune Reine-Claude Gabriel Combes x.

Of French origin, probably a seedling of the Reine Claude; first mentioned in r895. Tree vigorous, productive; fruit spheroidal-ovoid, large, purple; cavity very small; suture slight; apex pointed; flesh amber-yellow, fine, juicy, sweet, aromatic, excellent; stone small, free; ripens after Reine Claude.

Galbraith. Domestica. I Horticulturist 8:536. I853. 2. Downing Fr. Trees Am. 382. 1857 .

Said to have originated with a Mr. Galbraith near Boalsburg, Pennsylvania. Tree straggling; fruit of medium size, oval, purple; flesh tender, juicy; good; clingstone; early. Gale. Americana. 1. Kerr Cat. 1897-1900. 2. Wis. Sta. Bul. 63:37. 1897. 3. Waugh Plum Cult. 149. I901.

Gale Seedling 2. Gale Seedling 3. Gale's No.3 1.

Introduced about 1890 by I. Gale \& Son, Waukesha, Wisconsin. Tree overbears; fruit below medium, roundish, compressed; suture distinct; apex slightly truncate; dull red; skin thin; flesh yellow, soft; quality fair; stone thick, rounded, nearly free; very early.

Galena. Americana. r. Wis. Sta. Bul. 63:37. 1897. 2. Waugh Plum Cult. 149. 19or.

Introduced by Charles Luedloff, Cologne, Minnesota. Fruit large, oval; yellow ground covered with red.

Galopin. Domestica. 1. Guide Prat. 160, 367. 1895. 2. Waugh Plum Cult. ro2. 1901. Violette de Galopin 2. Violette Galopin I.

A European variety. Tree poor; fruit of medium size, roundish; cavity shallow; stem short, thick; suture shallow; blue; many conspicuous dots; flesh yellow; quality medium; stone of medium size, oval, slightly necked, nearly free.

Garden King. Americana. I. Ia. Sta. Bul. 46:273. 1900. 2. Waugh Plum Cult. 149. 1901 .

Found wild in 1853 ; in 1861 it was put under cultivation by Judge Elias Topliff of De Soto, Wisconsin, and subsequently turned over to A. R. Prescott, Postville, Iowa, who introduced it in 1896 . Tree vigorous, productive; fruit medium, oval, scarlet; flesh sweet, juicy; freestone.

Garfield. Hortulana. 1. Cornell Sta. Bul. 38:48, 86. 1892. 2. Waugh Plum Cult. 179. 19ог. 3. Ohio Sta. Bul. $162: 254,255.1905$.

Reported to have been found wild in Ohio; introduced by Leo Welz, Wilmington, Ohio, in 1887 . Tree unproductive, lacking in hardiness; fruit small, oval; stem slender; cavity shallow; suture a line; bright red; bloomless; flesh yellow, juicy, acid; quality fair; stone small. long-oval, pointed, clinging; late. 
Garlick. Domcstica. I. Lond. Hort. Soc. Cat, I47. 1831. 2. Mag. Hort. 9:164. 1843. Garlick's Early I, 2.

Fruit small, obovate, purple; good; freestone; obsolete.

Garnet. Triflora $\times$ Cerasifera. 1. U. S. D. A. Rpt. Pom. 45. 1895. 2. Waugh Plum Cult. 2 II. $190 \mathrm{I}$.

Found by J. L. Breece, Fayetteville, North Carolina, under a Kelsey tree which was probably pollinated from a Pissardi growing near, the foliage showing the reddish color of the Pissardi; first fruited in 1892 . Fruit large, roundish-oval, dark garnetred with minute russet dots; cavity small; suture indistinct; skin thin and bitter; flesh yellow with a tinge of red; flavor mild; stone medium, oval, clinging; more valuable as an ornamental than for its fruit.

Gates. Amcricana. I. Wis. Sta. Bul. 63:38. 1897 .

Originated at Owatonna, Minnesota. Fruit medium in size, flattened; suture distinct; very dull rcd; dots numerous, yellow; skin thick; flesh yellow; quality fair; stone distinctly margined; late.

Gaunt. Domestica. I. Parkinson Par. Ter. 576, 577 fig. 1629. 2. Rea Flora 208. 1676.

Described in 1629 by Parkinson as "large, reddish, waterish, late."

Gaviota. Triflora $\times$ Americana. I. Fancher Creek Nur. Cat. 1907. 2. Fancher Creek Nur. Cat., Burbank's Late Introductions. fig. I909. Rice Seed I.

Originated with Luther Burbank about I900; probably contains admixtures of other species than the ones mentioned above. Tree vigorous, productive, late bloom. ing; fruit very large, oval; suture shallow; cavity medium; dark red over yellow ground; flesh yellow, firm, sweet, aromatic; good; stone extremely small; mid-season. Gaylord. Americana. 1. U.S. D. A. Rpt. 441. 1889. 2. Wis. Sta. Bul. $63: 24,3^{8}$ fig. I897. 3. Ia. Sta. Bul. 46:273. 1900.

Found growing wild by David Hardman, Nora Springs, Iowa, in 1854 ; introduced by Edson Gaylord of the same place about 1890 . Tree vigorous with a tendency tc overbear; fruit of medium size, oval; cavity small; stem short; suture a line; apex slightly pointed; dull red over yellow; bloom thin; dots numerous, minute; skin thick, bitter; flesh yellow, melting; good; stone large, oval, flat, semi-clinging; mid. season.

Gaylord Gold. Americana. 1. Ia. Sta. Bul. 46:273. 1900.

Found wild in Rock Grove, Iowa, about 1870 by John Henry, Nora Springs, Iowa cions subsequently distributed by Edson Gaylord. Fruit of medium size, golden yellow; good; stone small, free; mid-season.

Gelbe Damascener Pflaume. Species? r. Mathieu Nom. Pom. 431. I889.

Reference taken by Mathieu from Obst-Garten 315. I883.

Gelbe Jerusalempflaume. Species? 1. Mathieu Nom. Pom. 431. 1889. Jaune de Jerusalem I. Prune de Jerusalem I.

A variety of doubtful merit and different from Yellow Jerusalem.

Gelbe Kirschpflaume. Cerasifera. Mentioned in Mathieu Nom. Pom. 432. I889.

Cerisette Blanche. Myrobalan Jaune. Prunus Cerasifera Zanthocarpa. Serdali Irek. 
Gelbe Spatzwetsche. Species? Listed in Mathieu Nom. Pom. 432. I889.

Reitzensteiner Gelbe Zwetsche incor. Quetsche Jaune Tardive.

Gem. Domestica. I. Downing Fr. Trees Am. 915. I869.

Originated near Albany, New York. Fruit small, round; suture and cavity shallow; mottled with purple; flesh yellow, juicy, sweet; clingstone.

Gem. Americana. I. Meneray Cat. The Gem I.

A seedling of Lottie grown by H. A. Terry; introduced by F. W. Meneray, Council Bluffs, Iowa. Fruit of medium size, oblong, red and yellow, with whitish bloom; good; freestone.

Gemeiner Gelbe Spilling. Species? Mentioned in Mathieu Nom. Pom. 432. 1889.

Banern Pflaume. Gelber Bidling. Krieke. Prunus Lutea. Spelge. Spilge. Spindel Pflaume.

Gentleman. Domestica. r. Mas Pom. Gen. 2:41, 1873 .

Probably of American origin as it was sent by Downing to M. Mas, but was not described by the American author. Tree vigorous, productive; fruit medium, oval; suture indistinct; skin thick, intense purple; bloom abundant; stem short; flesh yellowish, juicy, vinous; good; freestone; early.

Georgia. Triflora $X$ ? 1. Cornell Sta. Bul. 175:1 53. x 899. 2. Waugh Plum Cult, 21 2, 1901.

Normand No. 20 I, 2 .

One of the several seedlings sent out by J. L. Normand, Marksville, Louisiana. Named by L. H. Bailey in 1899 . Fruit small, oval, greenish-yellow covered with bright red; flesh yellow, watery, fibrous, sweet; stone large, strongly clinging; fruit drops while green; worthless.

Gerishes Seedling. Domestica. Mentioned in Johnson Cat. Early Bradshaw.

Gersepflaume. Species? I. Mathieu Nom. Pom. 43I. I889.

Reference taken by Mathieu from Wiener Garten-Zeitung 287. I884.

Ghiston. Domestica. 1. Downing Fr. Trees Am. 276. 1845. 2. Am. Pom. Soc. Cat. 222, 244. 1858. Ghiston's Early 1, 2.

Fruit large, oval, yellow; bloom thin; flesh yellow; quality poor; freestone; season early; rejected by the American Pomological Society in $185^{8}$.

Gibson. Domestica. I. Horticulturist 25:319. I870. Gibson's Seedling.

A seedling from W. L. Gibson of Elmira, New York. Tree vigorous, productive; fruit of medium size, deep amber color; bloom slight; skin thick, very astringent; flesh sweet, juicy, mild; good.

Gill. Domestica. I. Ohio Sta. Bul. 94:58. 1909.

Introduced by S. R. Gill, Port Clinton, Ohio, who received it in $188_{2}$ from a nursery with Golden Drop trees. Tree vigorous, spreading and productive; fruit medium in size, round, reddish-purple; bloom light; flesh firm, sweet, rich; good; mid-season; excellent for canning.

Gisborne. Domestica. 1. Lond. Hort. Soc. Cat. 147. 1831. 2. Horticulturist 10:16. 1855. 3. Mas Pom. Gen. 2 :49. 1873. 4. Mathieu Nom. Pom. 432. 1889.

De Gisborne 3. Gisborne's x. Gisborne's 3. Gisborne's Early 2. Gisborne's Early 2, 4. Gisborne's Zwetsche 3. Gisbornes Zwetsche 4. Ovalrunde Spreckel Pflaume 4. Paterson's I, 4 
Tree vigorous, productive; fruit of medium size, oval; suture indistinct; skin golden-yellow, dotted with cherry-red on the sunny side, with pale bloom; flesh bright yellow, juicy, sweet; stone large, oval, free; mid-season.

Glaister. Domestica. 1. Wickson Cal. Fruits 358. 189 I.

A variety from California introduced by Leonard Coates of Napa, California. Fruit very similar to Yellow Egg, but two weeks earlier.

Gloire d'Epinay. Domestica. I. Rev. Hort. 444. 1898 2. Ibil. 86.1899 .

A sucker from a chance seedling found about 1850 by M. Donon of Epinay, France; named and presented to the National Society of Horticulture in 1898 by M. Gorion. Fruit above medium size, roundish-oval; suture shallow; deep blue; similar to Monsieur, but is later and ripens over a period of nearly two months.

Gloire de Louveciennes. Insititia. 1. Rev. Hort. 650. 1900. 2. Ibid. 476, fig. 1901.

Mirabelle Gloire de Louveciennes r, 2.

Noted in the Revue Horticole as a Mirabelle introduced in 1900 by M. Lecointe. Fruit similar to Mirabelle de Nancy in shape and form, but larger; skin citron-yellow, dotted and shaded with red on the sunny side; flesh firm, very sweet, like the Apricot in flavor.

Gloria. Americana mollis. 1. Can. Exp. Farms Rpt. 119. 1904.

A seedling of Wolf; fruit large, oval; cavity narrow; suture a line; bright red or yellow mottled with red; dots few; bloom light; skin thick, tough; flesh yellow, juicy, sweet; good; stone large, nearly free; variety promising.

Gloucestershire Violet. Domestica. I. Jour. Hort. 17:285. 1888

Minsterworth I. Prince I.

A very old variety first known as Prince; it is grown largely on the banks of the Severn, England, where it is propagated from seed or from root-suckers. Fruit small, oval, with slight tendency to a neck; suture distinct; dark mahogany; bloom thin; flesh greenish, tender, sweet, pleasant; stone small; free.

Glow. Maritima $\times$ Subcordata $\times$ Americana $\times$ Nigra. r. Burbank Cat. 14 . I9 I.

From crosses of the species named Burbank grew this variety. Tree of medium size; branches slender and drooping. Fruit large, round, crimson, dotted with yellow; flesh orange color, rich; good; freestone; late.

G. No. 4 Domestica. I. N. Y. Sta. Rpt. 9:347. 189o. 2. Mich. Sta. Bul. 177:42, 43. 1899.

G. No. 44 Jones (unpublished).

In 1890 , Herbert A. Jones, Himrods, New York, sent this variety to a few experiment stations for testing. Fruit of medium size, roundish; suture very shallow; cavity medium deep; stem slender; skin thin; dark purple; bloom thick; dots numerous, sometimes irregular, russet; flesh greenish-yellow, juicy, firm, sourish; poor; clingstone; mid-season; variety not worth propagating.

Goff. Americana. I. Meneray Cat. Prof. Goff I.

A seedling of Hawkeye grown by H. A. Terry; introduced by F. W. Meneray, Council Bluffs, Iowa. Fruit large, red over yellow; good; clingstone

Gold. Americana. 1. Kerr Cat. 1894. 2. Ia. Sta. Bul. 46:273. 1900. 3. Terry Cat. I 900. Golden 3 . 
A variety from H. A. Terry not to be confused with the Golden of Burbank (Gold of Stark Brothers). Fruit of medium size, roundish; cavity shallow, small; orangeyellow and red; bloom thin; skin rather thick, astringent; flesh yellow, firm, meaty, subacid; good; clingstone.

Gold Coin. Americana. I. Terry Cat. 1900.

An unknown variety mentioned by $H$. A. Terry, Crescent, Iowa, as the parent of Coinage.

Gold Colored. Americana. I. Wis. Sta. Bul. 63:39. 1897. 2. Waugh Plum Cult. I50. 1901 .

From Edson Gaylord, Gaylord, Iowa. Fruit of medium size, bright yellow; stone small, free.

Golden Cluster. Domestica. I. Montreal Hort. Soc. Rpt. 93. 1885.

A seedling from Henry Corse of Montreal. Tree slow in growth, with long internodes; fruit of medium size, egg-shaped; hanging in dense clusters by firmly adherent stems; gold, tinged with brown; flesh firm, pleasant; ripening season long.

Golden Gage. Domestica. N. Y. Sta. Rpt. 12:611. х893.

Golden Gage is a seedling of Golden Drop grown by J. T. Macomber, Grand Isle, Vermont. Fruit small, oval; cavity shallow; suture a line; apex round; skin thin; pale yellow with red specks; bloom thin; dots small; flesh yellow, very sweet; good; stone oval, slightly necked; free; mid-season; of little commercial importance because of inferior size and color.

Golden Gem. Species?

A variety originating from seed with P. P. Dawson, Payette, Idaho.

Golden Prolific. Species? I. Ont. Fr. Exp. Sta. Rpt. 5:1 16. г 898.

Tree vigorous, productive; fruit medium, yellow; very good; clingstone; poor shipper.

Golden Prune. Domestica. 1. Wickson Cal. Fruits 360. 1891. 2. Cal. Sta. Bd. Hort. I12. 1891, 3. U.S. D. A. Rpt. 291. 1893. 4. Waugh Plum Cult. 105. I901. Golden 2.

Grown by Seth Lewelling, Milwaukee, Oregon, from a seed of the Italian Prune; mentioned in the last two catalogs of the American Pomological Society. Fruit large, oval; cavity small, round, shallow, abrupt; stem short; suture shallow; apex depressed. sometimes cracking; light yellow; bloom thin; dots numerous, yellow; skin thin; flesh yellow, firm, tender, juicy; good; stone of medium size, long-oval, nearly free; midseason.

Golden Queen. Americana. I. Terry Cat. x 900. 2. Ill. Hort. Soc. Rpt. 426. 1905.

Originated with H. A. Terry; first fruited in 1897 . Tree characterized by its luxuriant foliage; fruit large, roundish-oblong, golden-yellow; good; said to be valuable for dessert.

Golden Transparent. Domestica. I. Gard. World 10:448. 1893. 2. Rivers Cat. 34. 1898. 3. Thompson Gard. Ass't 157. I901.

From Thomas Rivers, Sawbridgeworth, England; closely allied to the Transparent Gage, but is distinctly later and more golden in color; an excellent dessert plum. 
Goldsmith. Domestica. Mentioned in Lond. Hort. Soc. Cat. 147. I831. Goldsmith's Vienna.

Gondin. Domestica? Mentioned in Mathicu Nom. Pom. 432. 1889.

Pflaume Von Gondin. Prune de Gondin.

Gonne. Domestica. 1. Ann. Pom. Belge 6:15, P1. 1858. 2. Downing Fr. Trees Am. 917. I869. 3. Oberdieck Deut. Obst. Sort. 409. 1881 .

Gonne's Rothe Pflaume 3. Prune Gonne I. Prune Gonne 2.

Originated by Dr. Gonne of Fleurus, Belgium. Oberdieck gives the Gonne's Rothe Pflaume, which is evidently the same variety, as a seedling of the Red Egg. Tree vigorous, productive; fruit large, obovate, sometimes spherical; suture shallow to deep; carmine-red, dotted with russet; flesh yellow, juicy, melting, sweet; the pit lies in a large cavity, nearly free; mid-season.

Goose-Dye. Species? 1. Kerr Cat. 11. 1900.

A supposed hybrid between the Wild Goose plum and Dyehouse cherry grown by Theodore Williams. Tree vigorous, productive; fruit larger than Wild Goose, oval, cherry-red; clingstone; mid-season; said to be free from rot.

Goose-0. Munsoniana $\times$ Triflora. x. Kerr Cat. 11. 1900.

A cross between Wild Goose and Ogon made by Theodore Williams, Benson, Nebraska. Tree suckers badly; fruit of medium size, roundish, red on a yellow ground; clingstone; mid-season.

Gordon. Domestica. r. Am. Pom. Soc. Rpt. 46. 1897. Gordon No.3 I.

A seedling of Imperial Gage. Fruit of medium size, roundish; yellow overspread with coppery-red; bloom profuse; skin acid; flesh rich, yellow, meaty, juicy, subacid; good; freestone; mid-season.

Gordon Castle. Domestica. 1. Gard. Chron. 26:364. I866. 2. Garden 54:318. 1898.

A plum of the Reine Claude type which originated at Gordon Castle, England. Fruit large, obovate; greenish-yellow overspread with a reddish blush; flesh firm, sweet; good; midseason.

Gorman. Species? Mentioned in Ia. Hort. Soc. Rpt. 169. 1909.

Govalle. Triflora $X$ ? r. Vt. Sta. Bul. 67:14. 1898. 2. Waugh Plum Cult. 215. I901.

Grown by Joseph Breck, Texas, supposedly from the Kelsey. Introduced by F. T. Ramsey in 1898 . Fruit medium, oval; cavity shallow; bright red; flesh slightly soft, fibrous, sprightly; good; clingstone; early.

Grace. Americana. r. U. S. D. A. Rpt. 263. 1892. 2. Am. Pom. Soc. Rpt. 74. 1895 .

Originated with W. R. Grace, Garden City, Kansas. Fruit of medium size, oblong, yellow striped with red, mottled and washed with dull purple; flesh yellow, melting, juicy; flavor rich, sweet; good; clingstone; mid-season.

Grand Précoce. Domestica? x. Mathieu Nom. Pom. 432. 1889. 2. Guide Prat. I6 3 , 357. I895.

Mentioned in the preceding references. 
Graügrune Frlihpflaume. Species? I. Mathieu Nom. Pom. 432. 1889.

Mathieu found the variety referred to in Wiener Garten-Zeitung 287. 1884.

Gray Damask. Insititia. 1. Quintinye Com. Gard. 68, 70. 1699.

Mentioned by Quintinye as "a round plum of a gray color."

Grayson. Munsoniana $\times$ Americana. I. Sherman Cat. 1897. 2.Vt.Sta.Rpt. 12:22 5. 1899.

A seedling of Wild Goose crossed with some Americana; from A. L. Bruce, Basin Springs, Texas, about 1893 . Fruit of medium size, roundish; suture a line; clear red; dots many, conspicuous, yellow; bloom heavy; flesh yellow, soft; good; clingstone; season follows Wild Goose.

Great Bearer. Domestica. I. Montreal Hort. Soc. Rpt. $5^{6} .1878$.

Corse's Great Bearer I.

Undoubtedly originated with Henry Corse of Montreal, Canada. Fruit small, light blue; flavor fair; very prolific.

Greely. Domestica. I. Me. Pom. Soc. Rpt. 130. 1888. 2. Ibid. 144. 1889. 3. Rural N. Y. 55:512. I896. Greeley I, 3 .

Captain Eliphalet Greely of Portland, Maine, secured the original tree from Montreal ; introduced by O. K. Gerrish of Portland. A large, purple plum so closely resembling Bradshaw that some growers believe them to be identical; its season seems to be earlier than Bradshaw.

Greenfield. Domestica. I. Montreal Hort. Soc. Rpt. 51. 1878.

A seedling of Red Magnum Bonum raised by Mr. Greenfield of Canada. Tree hardy, productive; fruit large, red.

Green Indian. Domestica. I. Willich Dom. Enc. 195. 1903. White Indian I.

Reported in 1803 as a very desirable variety.

Green Italian. Domestica. I. Downing Fr. Trees Am. 3d App. 181. 1869.

From Germany; tree moderately vigorous, fairly productive; fruit medium, oval; suture a line; greenish-yellow splashed with green; bloom thin; cavity small; flesh green, coarse, juicy, sweet, rich; good; semi-clinging; mid-season.

Green Oysterly. Domestica. I. Parkinson Par. Ter. 577 fig., 578. 1629. 2. Rea Flora 207. 1676 .

Described as roundish, of medium size, greenish, juicy, flavor "reasonably good."

Green Perdrigon. Domestica. I. Rea Flora 208. 1676.

Described by Rea nearly two hundred and fifty years ago as "a round plum, of medium size, green; flavor good."

Green Pescod. Domestica. I. Parkinson Par. Ter. 576. 1629.

Parkinson states that "this plum is of medium size, pointed; mid-season."

Grelck. Cerasifera. I. Wickson Cal. Fruits 358. 189r.

Supposedly a seedling grown by John Grelck of Los Angeles, California, who gave it to O. S. Chapin of San Diego County about 1883 . Fruit small, round, light yellow with reddish shade, sprightly; good; season before Myrobalan; decidedly superior to Myrobalan. 
Gros Damas de Tours. Domestica. 1. Quintinye Com. Gard. 70. 1699. 2. Duhamel Trait. Arb. Fr. 2:69. 1768. 3. Knoop Fructologie 2:56. 1771. 4. Forsyth Treat. Fr. Trees 19. 1803. 5. Willich Dom. Enc. 4:300. 1803. 6. Miller Gard. Dict. 3. 1807. 7. Loml. Hort. Soc. Cat. 145, 147, 1831. 8. Prince Pom. Man. 2:86. 1832, 9. Downing Fr. Trees Am. 917. 1869. 10. Mathieu Nom. Pom. 433. 1889 .

Damas de Tours 10. Damas de Tours Gros 7. Damas de Tours Gros 8, 9, ro. Damas gros de Tours 3. Damas Violet of Tours 4. Great Violet Damask de Tours 5. Great Damask Violet of Tours 6, го. Great Damask Violet of Tours 9. Great Plum of Tours 7. Great Violet Tours Damask 1. Gros Damas 6. Grosse Damascene von Tours ro. Gros Damas de Tours 8, 9, 10. Gros Damas Violet de Tours 6. Largest Damask of Tours 8. Largest Damask of Tours 9, Iо.

For historical notes and description see Précoce de Tours.

Gros Damas Noir. Domestica? r. Noisette Man. Comp. Jard, 2:500. I 860.

A small mediocre plum mentioned by Noisette as ripening the last of July.

Grosse Hâtive de Rodt. Domestica? Mentioned in Mathieu Nom. Pom. 433. r889.

Grosse Marange. Domestica. 1. Mathieu Nom. Pom. 433. 1889. 2. Guide Prat. 156, 357. 1895. Hative d'Augny I, 2

This variety was grown by M. Chabardin of Augny near Metz, France, where it is considered very promising because of its high quality and earliness. Fruit medium in size, roundish; purplish; flesh yellowish-green, sweet; quality best of its season; very early.

Grosse Rosspauke. Species? I. Mathieu Nom. Pom. 434. 1889.

Mathieu found it noted in Wiener Garten-Zeitung 287. 1884.

Grosse Surpasse. Domestica. 1. Can. Exp. Farm Bul. 2d Ser. 3:52. 1900. 2. Can. Exp. Farms Rpt. 432. I 905.

A small round plum tested at British Columbia Experimental Farm; yellow; flesh yellow, tender, sweet, pleasant; stone small, clinging; mid-season.

Grosse Violette de Grugliasco. Species? Mentioned in Mathieu Nom. Pom. 434. 1889.

Grüne Dattel Zwetsche. Domestica. r. Oberdieck Deut. Obst. Sort. 444. I881. 2. Mathieu Nom. Pom. 434. I889.

Berliner Pflaume 2. Datte Verte 2. Grüne Dattelzwetsche 1. Grüne Insel Pflaume 2 incor. Susina Verdachia Longa 2. Weisse Indische Pflaume 2.

Mentioned in the preceding references. Grüliche Dattelpflaume von Besançon is given by Guide Pratique, 1895 , as a synonym of the Yellow Egg.

Grüne Herzformige. Domestica. 1. Kraft Pom. Aust. 2:30, Tab. I 76 fig. 1. 1796.

Die grüne herzförmige Pflaume I. Prune coeur de pigeon verd I.

An old European variety. Flowers small; fruit heart-shaped, greenish-yellow; flesh yellow, firm; stone uncommonly rough and uneven.

Grüne Zwetsche Von Monrepos. Species? Listed in Mathieu Nom. Pom. 434. I889. Guilford No. 2. Hortulana mineri. 1. Ill. Hort. Soc. Rpi. 135. 1903 2. Ibid. 422. 1905.

A seedling of Miner from Illinois. Tree moderately vigorous, productive; fruit yellow, with a pink cheek; good; freestone; mid-season. 
Guimaraen. Domestica. I. Lond. Hort. Soc. Cat. 148. 1831.

Fruit medium in size, oval, yellow; good; clingstone; mid-season.

Guinea Egg. Americana. I. Ia. Sta. Bul. 46:263. I900.

Found wild about 1857 by Frederick Albright, near Bangor, Marshall County. Iowa; not introduced. Tree vigorous, hardy; fruit large, dark red; skin thin; flesh firm; good; stone small.

Gundaker. Domestica. 1. Horticulturist 6:524. 1851. 2. Downing Fr. Trees Am. 383. 1857 .

A large, heart-shaped, purple plum grown from seed by Samuel E. Gundaker, Lancaster, Pennsylvania, about 1820 ; of good quality.

Gundaker Prune. Domestica. 1. Horticulturist 6:524. 1851. 2. Downing Fr. Trees Am. 382. 1857. Groundacre 1, 2.

A seedling grown by Samuel E. Gundaker, Lancaster, Pennsylvania, about 1820; sent out by Samuel Carpenter of Lancaster, Ohio, as Groundacre. Tree productive; fruit large, oval, light yellow; good.

Guthrie Apricot. Domestica. 1. Mag. Hort. 12:341. 1846. 2. U. S. Pat. Off. Rpt. 2:449. 1849. 3. McIntosh Bk. Gard. 2:531. 1855 4. Downing Fr. Trees Am. 918. 1869. 5. Mathieu Nom. Pom. 434. 1889.

Abricot de Guthrie 5. Guthrie's Apricot Plum 2. Guthrie's Apricot 5. Guthrie's Golden 4. Guthrie's Golden 5. Guthrie's New Apricot 3.

A seedling raised by Charles Guthrie of Taybank, Dundee, Scotland. Fruit of medium size, roundish; suture slight; cavity small; yellow; bloom thin; dots red: flesh yellow, coarse, juicy. sweet; good; clingstone; mid-season.

Guthrie Russet. Domestica. I. Downing Fr. Trees Am. 919. 1869. 2. Mas Pom. Gen. 2:167. 1873 .

Rousse De Guthrie 2. Guthrie's Russet 2.

A seedling of Reine Claude grown by Charles Guthrie, Taybank, Dundee, Scotland. Fruit large, oval; suture distinct; cavity small; stem slender; yellow, sometimes marbled with red; bloom thin; flesh yellow, juicy, sweet; good; clingstone; mid-season.

Guthrie Topaz. Domestica. I. Mag. Hort. 12:341. 1846. 2. Downing Fr. Trees Am. 919. 1869. 3. Hogg Fruit Man. 728. 1884. 4. Mathieu Nom. Pom. 434. 1889 .

Guthrie's Topaz 4. Guthrie's Topaz 3, 4. Topaz 3. Topaze de Guthrie 4.

Grown by Charles Guthrie, Taybank, Dundee, Scotland, probably from seed of Reine Claude. Tree hardy, productive; fruit of medium size, oval, necked, suture distinct; cavity small; stem slender; yellow, with thin bloom; flesh yellow, juicy, sweet; flavor not high but pleasant; good; clingstone; mid-season.

Gwalsh. Domestica. 1. Lond. Hort. Soc. Cat. 148. 1831. 2. Downing Fr. Trees Am. 301. 1845. 3. Thomas Am. Fruit Cult. 343. 1849.

From Thomas Hancock, Burlington, New York. Fruit large, obovate; suture indistinct; dark purple; flesh yellow, juicy, sprightly; quality fair; clingstone; midseason. 
Haag. Americana. I. Wis. Sta. Bul. 63:24, 39. 1897. 2. Ia. Sta. Bul. 46:274. 1900. 3. Waugh Plum Cult. 150. 1901 .

Purchased from a nurseryman of Minneapolis and introduced as Haag by J. S. Haag, Hosper. Sioux County, Iowa. Tree moderately vigorous, spreading; fruit above medium size, roundish; suture distinct; flesh greenish-yellow, tender, sweet; good; stone oval, clinging; mid-season.

Hackl Grosse Zwetsche. Species? I. Mathieu Nom. Pom. 434. I889.

Reference to this variety found by Mathieu in Wiener Garten-Zeitung 287. 1884. Haferpflaume. Insititia? Mentioned in Mathieu Nom. Pom. 434. 1889.

Blane Krieche Echte Hafer Pflaume. Echte Hafer Zwetsche.

Haffner Herbstpflaume. Domestica? Mentioned in Mathieu Nom. Pom. 434. I889.

Haffner Königspflaume. Domestica? Mentioned in Mathieu Nom. Pom. 434. 1889.

Royale de Haffner.

Haku Botan. Triflora. r. Va. Sta. Bul. 129:113. 1901.

Imported by the United States Department of Agriculture.

Hallenbeck. Domestica. 1. Cultivator 8:309. 1860. 2. Downing Fr. Trees Am. 920. 1869.

Originated with Henry Hallenbeck, East Greenbush, Rensselaer County, New

York. Fruit large, roundish-oval, one side often enlarged, reddish-purple; numerous minute dots; flesh greenish-yellow, very juicy, sugary, brisk flavor; good; clingstone; mid-season.

Halcyon. Triflora $\times$ Munsoniana? 1. Vt. Sta. An. Rpt. 12:225. 1899. 2. Waugh Plum Cult. 215. 1901.

Grown by J. S. Breece, North Carolina. Fruit heart-shaped; suture faint; bright red; dots few; flesh yellow; quality fair; stone large, oval, clinging.

Hanford. Domestica. I. Ill. Hort. Soc. Rpt. 71. 1868. Hanford's Orleans I.

Mentioned in 1868 by Lucius C. Frances in the report of the Illinois Horticultural Society.

Hanska. Americana $\times$ Simonii. I. S. Dak. Sta. Bul. 108: Pl. 5. 1908.

Originated by N. E. Hansen of the South Dakota Experiment Station; first fruited in 1906 on two-year-old trees. Tree very vigorous, fruit of medium size, roundishoblate, halves unequal; suture shallow; bright red; bloom heavy; flesh firm, reddish; stone very small; semi-free.

Hanson. Americana. 1. Kerr Cat. 1894. 2. Waugh Plum Cult. 151, 1901.

Said to be of value in the South. Fruit of medium size; nearly spherical; suture shallow; skin very thick; bright red over yellow; dots numerous; flesh yellow; sweet; goods stone round, slightly flattened, clinging; early.

Happiness. Triflora $X$ ? 1. Griffing Bros. Cat. 1906-1909.

A chance seedling found by Joseph Breck about $\mathrm{r} 899$; introduced by F. T. Ramsey, Austin, Texas; fruit large, bright red; good.

Harlow. Domestica. 1. U. S. D. A. Rpt. 263. 1892. 2. Am. Pom. Soc. Rpt. 74 1895 .

Supposed to be a seedling of Bradshaw; raised by S. C. Harlow, Bangor, Maine. Tree vigorous, hardy, productive; fruit large, oblong-oval; skin smooth, reddish- 
purple; dots numerous, fawn-colored; bloom light; flesh greenish-amber, melting, mildly subacid; mid-season.

Harney. Domestica. I. U. S. D. A. Pom. Rpt. 45. 1895.

Specimens of this plum from H. C. Cook, White Salmon, Washington, were described by the Division of Pomology, Department of Agriculture. Fruit large, roundish; cavity large, regular, deep, abrupt; suture shallow; purplish-red; dots large and small, russet; bloom thin; skin thin, tough; flesh pale yellow, tender, juicy, sweet, rich; very good; stone medium, roundish, nearly free; mid-season.

Harper. Munsoniana? 1. Ga. Hort. Soc. Rpt. 28. 1876. 2. Ibid. 24.1881 .

Harper's $\mathbf{r}$.

Originated about 1870 . Fruit red; clingstone; mid-season.

Harriet. Domestica. I. Gard. Chron. 18:441. 1882. 2. Hogg Fruit Man. 705. I884.

Grown by Thomas Rivers, Sawbridgeworth, England, about I870. Fruit of the Reine Claude type, medium in size; roundish-oblate; cavity deep; suture slight; skin thin but rather tough; golden yellow sometimes specked with red; bloom thin; flesh yellow, juicy, firm, very good; stone of medium size, oval, turgid, clinging; midseason.

Harris. Hortulana mineri. I. Ill. Hort. Soc. Rpt. 225. 1877.

Tree and fruit much resemble Miner, but the ripening season is four weeks earlier; freestone.

Harrison. Americana. I. Am. Pom. Soc. Rpt. I23. 1875. 2. Cornell Sta. Bul. $38: 38$, 86. 1892. 3. Wis. Sta. Bul. 63:39, 40. 1897. 4. Waugh Plum Cult. I70. I 901. Harrison's Peach 1, 2, 3. Harrison's Peach 4.

Found growing wild in Minnesota. Tree unproductive; fruit of medium size, oval; suture a line; cavity shallow; dots small; dull red; bloom thick; flesh yellow, tender, juicy, sweet; quality fair; stone oval, pointed, flattened, semi-clinging; midseason. Harrison is the parent of a great number of varieties.

Hart. Americana. r. Wis. Sta. Bul. 63:40. 1897. 2. Ia. Sta. Bul. 46:274. 1900. 3. S. Dak. Sta. Bul. 93:19. 1905.

Hart's De Soto I. Hart's De Soto 2, 3 .

A sprout taken from a tree bought for De Soto by H. Hart, Sioux County, Iowa, about 1890 ; widely distributed by the Iowa Agricultural College. The fruit resembles De Soto in color and shape, but ripens from ten days to two weeks earlier; somewhat larger in size but inferior in quality.

Hartwick. Americana. I. Kerr Cat. 1894. 2. Waugh Plum Cult. I51. I901.

Noted as of little value.

Hartwiss. Domestica. 1. Downing Fr. Trees Am. 383. 1857. 2. Mas Pom. Gen. 2: 23. 1873. 3. Lauche Deut. Pom. No. 3. P1. 1882. 4. Mathieu Nom. Pom. 453. I889. Hartwiss Gelbe Zwetsche 2, 3. Hartwiss Yellow Prune I. Quetsche Jaune de Hartwiss 2. Quetsche Jaune de Hartwiss 4. Von Hartwiss' Gelbe Zwetsche 4.

Obtained by Liegel from a pit of Quetsche Jaune Précoce and dedicated by him to the Director of the Imperial Gardens at Nikita, Crimea. Tree large, productive; fruit medium in size, irregularly oval; suture broad and shallow; halves unequal; 
skin canary-yellow, rather adherent; bloom thin; flesh yellow, tender, sweet; freestone; mid-season.

Harvest. Americana. I. Minn. Hort. Soc, Rpt. 127. 1890.

Brought in from the wild by H. Knudson, Springfield, Minnesota. Fruit large, roundish-ovate; skin thin, red; quality fair; early.

Hattie. Cerasifera. 1. Am. Pom. Soc. Rpt. 67. 1875. 2. Cornell Sta. Bul. 38:75, 86. 1892. 3. Vt. Sta. An. Rpt. 13:369. 1900 .

Cultivated in the South. Tree dwarfish; branches stiff and rough; leaves small, folded upward, finely serrate; petioles glandless; flowers small and clustered; fruit small, roundish; suture a line; cavity small; stem slender; dull red; bloom thin; dots many, conspicuous; skin thin, tough; flesh yellow, soft, watery; quality fair; clingstone; early.

Hayo-Simoni. Triflora. I. N. Mex. Sta. Bul. 27:124. 1898.

An upright, vasiform tree; fruit above medium, roundish-oblate; suture distinct; dark red; dots minute, yellow; bloom abundant; flesh dull yellow, firm, juicy, subacid; good; clingstone; early.

Hazard. Domestica. I. John Watkins Cat.

Mentioned by John Watkins, nurseryman, Withington, England.

Heaton. Americana. r. Kerr Cat. 1894.

Received by J. W. Kerr about I 894 from H. A. Terry, Iowa. Fruit medium to large, oblong-oval, dark purplish-red; freestone; early.

Hector. Domestica.

A chance seedling found about 1890 by Edward Smith on his farm at Hector, New York; introduced by E. Smith and Sons, Geneva, New York. Tree vigorous, hardy and productive; fruit one and three-quarters inches in diameter, roundish; cavity deep; suture shallow; stem short, thick; skin tender; dark reddish-purple; bloom thick; dots inconspicuous; flesh light yellow, juicy, tender, sweet, mild; quality good; stone semi-clinging, oval, turgid, slightly winged and necked; mid-season.

Heep. Angustifolia varians. I. Waugh Plum Cult. 195. 1901.

F. T. Ramsey, Austin, Texas, offered this sort in his 1897 catalog as an old variety found in the orchard of a Mr. Heep. Tree very vigorous and productive; fruit above medium size, red; quality fair.

Heikes. Triflora. I. Cornell Sta. Bul. 62:23. I894. 2. Ibid. 139:38, 42. 1897.

Burbank No.4 I.

Imported by Luther Burbank, Santa Rosa, California, in $188_{5}$, and named for W. F. Heikes of the Huntsville Nurseries, Huntsville, Alabama. As tested at the Cornell Experiment Station similar to Satsuma if not identical with it.

Heine Superbe. Domestica. Mentioned in Mathieu Nom. Pom. 434. I889.

Helen. Species? I. Am. Pom. Soc. Cat. 36. 1875. Helen's Seedling 1 .

Listed in American Pomological Society catalog for eight years.

Hendrick. Munsoniana? I. Ala. Sta. Bul. N. S. II:12. 1890. Hendrick's I.

Tree vigorous; fruit of medium size, spherical, yellow, blushed with red; flesh tender; good; early. 
Henrietta Gage. Domestica. 1. Gen. Farmer 9:232. 1848. 2. Downing Fr. Trees Am. 920. 1869. 3. Mas Pom. Gen. 2:169. 1873.

Early Genesee 2. Henrietta Gage 3. Reine-Claude D'Henrietta 3.

Originated about 1840 on the farm of a Mr. Brown, Henrietta, Monroe County, New York. Similar to Reine Claude but much earlier.

Henry Clay. Domestica. I. Cultivator 3:20. 1855. 2. Mas Pom. Gen, 2:95. 1873.

A seedling of Howard raised by Elisha Dorr, Albany, New York; named by Dr. Warder of Cincinnati, Ohio; first fruited in $185_{2}$. Fruit large, oval; suture broad and shallow; stem long, rather thick; skin clear yellow, often washed and dotted with red on the sunny exposure; flesh clear yellow, sweet, vinous; good; stone small, clinging; mid-season.

Herbst Kriecke. Insititia? I. Mathieu Nom. Pom. 435. I889.

Mention of the variety found by Mathieu in Wiener Garten-Zeitung 288.1884.

Herbstpflaume. Domestica. I. Oberdieck Deut. Obst. Sort. 445. I88 I.

A German variety; unproductive in dry soils.

Hereford Damson. Insititia. I. Watkins Cat. 48. I892?

Mentioned in the preceding reference as a favorite and very productive.

Herefordshire Prune. Domestica. 1. Thompson Gard. Ass't 4:160. 1901.

Fruit large, obovate; flesh firm, yellowish-green.

Heron. Domestica. I. U.S. D. A. Pom. Rpt. 26. I894. 2. Cornell Sta. Bul. I3I: 187. 1897. 3. Rivers Cat. 35. 1898.

Originated and introduced by Thomas Rivers, Sawbridgeworth, England. Popular in England but on account of its poor foliage it is of little value in this country. Fruit large, roundish, dark purplish-red; dots small; skin sour; flesh greenish-yellow, firm, meaty, moderately juicy, subacid; good; stone large, oval, semi-free; early.

Heroy. Species? Mentioned in Mathieu Nom. Pom. 435. 1889.

Herren. Domestica. I. Can. Exp. Farm Bul. 2d Ser. 3:52. I900.

A vigorous variety of the Reine Claude type grown in Germany. Fruit of medium size, roundish, slightly flattened at both ends; suture distinct; sides of ten unequal; dull yellow; flesh yellowish, firm, coarse, sweet, juicy, pleasant; freestone; mid-season. Herzformige Pflaume. Species? Mentioned in Mathieu Nom. Pom. 435. I889.

Prune Cordiforme.

Heupflaume. Species? I. Mathieu Nom. Pom. 435. 1889.

Reference obtained by Mathieu in Wiener Garten-Zeitung 288. I884.

Hiawatha. Americana. 1. Kerr Cat. 1894. 2. Wis. Sta. Bul. 63:41. 1897. 3. Waugh Plum Cult. 152. I 901 .

Introduced by C. W. H. Heideman, New Ulm, Minnesota, as an example of a staminate-flowered plum; rarely productive. Fruit very large, roundish-oblong, purplish-red; clingstone; early.

Highland. Domestica, I. Cal. State Bd. Hort. Rpt. 8:47. 1897.

A seedling of Agen, grown by Luther Burbank, Santa Rosa, California. Tree vigorous and productive; fruit large, long-oval, purplish-crimson; flesh yellow, firm, sweet; flavor excellent; stone nearly free. 
Highlander. Domestica. 1. Downing Fr. Trees Am. 384.1857.

Fruit large, irregularly ovate, deep blue; bloom thin; dots brown, numerous; yellow, juicy, vinous; semi-clinging; late.

Hilda No. 5. Hortulana mineri $X$ ? I. Ia. Sta. Bul. 46:274. 1900.

Originated under cultivation with J. F. Wagner, Bennett, Iowa, in 1894 , from secd of Miner pollinated by a wild plum; not introduced. Fruit above medium size, dark red; used for jellies.

Hillside. Americana. I. Minn. Hort. Soc. Rpt. 128.1890.

Selected from wild plants by H. Knudson, Springfield, Minnesota. Fruit of medium size; skin thick, deep red, astringent.

Hilltop. Americana. 1. Kerr Cat. 1894. 2. Wis. Sta. Bul. 63:42. 1897. 3. Waugh Plum Cult. 152. 1901.

Fruit small, round-oval; suture a line; skin deep red; dots very minute; thick bloom; flesh yellow; quality fair; stone large, half-free.

Hilman. Americana. 1. Wis. Sta. Bul. 87:13. 1901.

Fruit small, oblong; skin yellow, two-thirds covered with purple; dots conspicuous; flesh yellow, firm, sweet; stone small, oval; mid-season.

Hinkley. Americana. I. Meneray Cat.

A seedling of Harrison grown by H. A. Terry and introduced by F. W. Meneray, Council Bluffs, Iowa. Fruit large, yellow with a red cheek; flesh yellow, rich, sweet, semi-clinging; good.

Hlubeck Aprikosenpflaume. Domestica. Mentioned in Mathieu Nom. Pom. 435. I889.

Hoag's Seedling. Domestica. I. N. Y. Sta. Rpt. 8:356. I889.

Received for testing at the New York Experiment Station in 1889.

Hoffman. Munsoniana? r. Cornell Sta. Bul. 38:63. 1892, 2. Thomas Am. Fruit Cult. 492. 1897 .

A wild variety from southwestern Missouri. Fruit of medium size, roundish, purplish-red; mid-season.

Hofinger Mirabelle. Insititia. Listed in Mathieu Nom. Pom. 435. 1889.

Hofinger's Rote Mirabelle. Roter Spilling incor. Hog.

A common name variously applied to $P$. americana, $P$. umbellata, $P$. hortulana and $P$. gracilis.

Holland. Domestica. 1. Coxe Cult. Fr. Trees 239. 1817. 2. Prince Pom. Man. 2:78. 1832. 3. Downing Fr. Trees Am. 301. 1845. 4. Mathieu Nom. Pom. 435. 1885 ,

Blue Holland 2, 3, 4. Holland Plum 1, 3. Holland Prune 4. Kensington Prune 2. Large Holland 2, 3 .

An old variety supposed to have been brought into this country from Holland by the early Dutch settlers. Tree vigorous, productive; fruit roundish, slightly compressed, blue; stem very adherent; flesh juicy, melting, sweet, rich; freestone; midseason. 
Holland. Triflora $\times$ Angustifolia varians. 1. Vt. Sta, Bul. 67:14, 1898, 2. Kerr Cat. 1900. 3. Waugh Plum Cult. 215. 1901.

A cross between Lone Star and Kelsey, grown by D. H. Watson, Brenham, Texas; introduced by W. A. Yates in 1897 . Fruit resembles Abundance in shape and size; yellowish-green splashed with red; flesh firm, juicy, vinous; semi-clinging; midseason.

Holister. Munsoniana. I. Ia. Hort. Soc. Rpt. 275. 1893. 2. Waugh Plum Cult. 185. 1901. Holister 1.

A variety said to have originated with a Mr. Holister of Cedar County, Iowa. Tree productive; fruit of medium size, roundish-oblong; cavity shallow; suture faint; clear bright red; flesh soft, yellow, sweet; good; clingstone; mid-season.

Holman Prune. Domestica. I. Sarcoxie Nur. Cat. 1892. 2. Can. Exp. Farm Bul. 2d Ser. 3:52. 1900 .

A seedling grown by D. S. Holman, Springfield, Maine. Fruit of medium size, oblong, pointed; greenish-yellow; flesh yellow, firm, sweet, juicy; stone small, pointed, free; mid-season.

Holme. Domestica. I. Peachland Nur. Cat. Holmes Early Blue I.

Introduced by J. Van Lindley, Pomona, North Carolina. Tree hardy, productive; fruit large, dark blue; good; early.

Holt. Americana. I. U. S. D. A. Rpt. 392. 1891. 2. Colo. Sta. Bul. 50:37. 1898.

3. Waugh Plum Cult. 152, rgor.

Originated with B. J. Holt of Rutland, Ohio. Tree vigorous, spreading; fruit large, roundish, yellow shaded with red; flesh yellow, melting, juicy, mild subacid; good; clingstone; mid-season.

Homestead. Americana. I. Minn. Hort. Soc. Rpt. 128. г89o. 2. Wis. Sta. Bul. 63:42. 1897 .

Originated with H. Knudson, Springfield, Minnesota. Fruit small, round, deep red; skin not at all adherent; flavor rich, somewhat resembling a peach; stone small, free.

Honey. Americana. 1. Kerr Cat. 1894. 2. Wis. Sta. Bul. 87:13. rgor. 3. Waugh Plum Cult. 153. I901.

Tree unproductive; fruit small, oblate; cavity shallow; suture a line; yellow washed and shaded with red; flesh sweet; quality fair; clingstone; early.

Honey Julian. Domestica. Listed in Lond. Hort. Soc. Cat. I48. I831.

Hoo Green Gage. Domestica. Mentioned in Lond. Hort. Soc. Cat. 148. 1831 .

Hoosier. Hortulana. I. Sarcoxie Nur. Cat. 1900.

From Greene County, Missouri; introduced by Wild Brothers Nursery. Tree vigorous, spreading; fruit above medium size, roundish; suture a line; dark cherryred; bloom thin; dots distinct; flesh yellow; good; clingstone; late.

Horemoritzer Reine Claude. Domestica. I. Mathieu Nom. Pom. 435. I889.

Reference found by Mathieu in Pomologische Monatshefte 33. 1889 .

Horrigan. Domestica. I. Can. Exp. Farm. Bul. 43:38. 1903.

Mentioned as being tested. 
Horse. Species? r. Knoop Fructologie 62, 1771. 2. Lond. Hort. Soc. Cat. 148. 1831. 3. Prince Pom. Man. $2: 87$. 1832. 4. Kenrick Am. Orch. 263. $188_{32}$. 5. Downing Fr. Trees Am. 30r. 1845. 6. Floy-Lindley Guide Orch. Gard. 303. 1846. 7. Vt. Sta. An. Rpt. 13:335. 1899.

Early Damson 3. Horse Plum 3, 4. Irish Horse Plum 2. Large Early Damson 3. Large Early Damson 5. Large Sweet Damson 4. Prune de Cheval I. Ros-pruim Double 1. Sweet Damson 3, 5.

Plums from at least two and possibly three species are known as the "Horse Plum." In New York the Horse Plum used by nurserymen as a stock is undoubtedly Prunus cerasifera. The plum referred to by Waugh, in the preceding reference, is a variety of Prunus domestica. It is difficult to determine the species referred to by the older writers, but from the frequency with which the word Damson appears as a synonym, it would seem that some at least had in mind Prunus insititia.

The Horse plum brought into this country by the early Dutch or French settlers, propagated by seedlings or suckers was probably an Insititia. During the first half of the last century. this plum was extensively raised in this State and large quantities were sold in the New York market. It is described as follows:-

Fruit of medium size, oval ; suture distinct; reddish-purple; flesh greenish, firm, sweet, dry; poor; usually freestone; mid-season.

Horse Jag. Domestica. 1. Lond. Hort Soc. Cat. 148. 1831. 2. Mag. Hort. 9:164. 1843. Horse Gage r, 2.

Fruit small, round or slightly oval, red; stone clinging; mid-season.

Hoskins. Americana. 1. Wis. Sta. Bul. 63:42. 1897. 2. Ia. Hort. Soc. Rpt. r1o. 1899. 3. Ia. Sta. Bul. $46: 275$. 1900.

Originated by a Mr. Hoskins of Pleasant Plain, Jefferson County, Iowa; and introduced by J. Wragg and Sons, Waukee, Iowa, in 1899 . Tree productive; fruit of medium size, yellow; skin thin, tough; freestone; mid-season.

Houston County. Species? Mentioned in Cornell Sta. Bul. 38:79. 1892.

How Amber. Domestica. I. Mag. Hort. $12: 398,399$ fig. 1846 . 2. Elliott Fr. Book 419. 1854. 3. Downing Fr. Trees Am. 384. 1857 .

How's Amber 1, 2, 3 .

A seedling selected from several hundred brought from New Hampshire and grown by Hall $\mathrm{J}$. How of South Boston in 1838 . Tree vigorous, productive; fruit of medium sizc, round; suture shallow; amber, spotted and mottled with rose; flesh coarsely veined, yellow, melting, juicy, rich; good; clingstone; mid-season.

Howard. Domestica. I. Cultivator 1:316. 1853. 2. Ibid. 3:20. 1855. 3. Mas Pom. Gen. $2: 185 . \quad{ }_{1} 873$.

Howard's Favorite 1, 2. Howard's Favorite 3. Favorite d'Howard 3.

A seedling of unknown parentage produced by Elisha Dorr, Albany, New York. Fruit large, necked, yellow, dotted and shaded with carmine; stem very adherent; skin thick; flesh coarse, sweet, rich; clingstone; mid-season.

Howe. Triflora X? I. Am. Pom. Soc. Rpt. 248 . 1903. 2. Griffing Bros. Cat. 1906. 3. Ibid. 1909. Stumpe 3. Stumpy 1. 
A seedling of Kelsey grown in the yard of a Mrs. Stumpe, Putnam County, Florida; introduced by Griffing Brothers in r 906 . Fruit large, roundish, red; bloom delicate; suture a line; skin thin, leathery; flesh yellow, firm, juicy; good; stone small, oval, clinging; early.

Howell. Domestica. 1. Downing Fr. Trees Am. 302. 1845. 2. Horticulturist 7:402. 1852. 3. Downing Fr. Trees Am. 921. 1869.

Chapin's Early 3. Early Purple 2, 3. Howell's Early 1. Sea 2. Sea 3.

This variety derives its name from B. Howell of Newburgh, New York, who brought the original tree from Virginia as a sucker. It was supposed to have been introduced into the Southern States by cions from Germany. Tree of slow growth; fruit below medium, oval; suture indistinct; red; flesh juicy, rich, sweet; good; freestone; very early.

Hoyo Smomo. Triflora. 1. Cornell Sta. Bul. 62:23. 1894.

A name used by J. L. Normand, Marksville, Louisiana; probably a synonym.

H. T. S. 84,76r. Species? r. Rural N. Y. 61:674. 1902.

One of Burbank's plums. Fruit large, yellow with crimson blush; flesh yellow, firm, sweet, vinous, juicy; clingstone; a good shipper.

Huankume. Triflora. I. N. Mex, Sta, Bul, 39:122, 1901.

Reported from New Mexico as weak in growth; fruit small, roundish, downy; yellowish-red; slightly acid; clingstone; resembles the apricot in flavor and appearance.

Hudson Gage. Domestica. I. Downing Fr. Trees Am. 277. 1845. 2. Hogg Fruit Man. 365. 1866. 3. Guide Prat. 163, 364. 1895.

Hudson 2. Hudson 3. Hudson Gage 2, 3. Hudson's gelbe Früplaume 3. ReineClaude d'Hudson 3.

Hudson Gage is one of several good varieties originated by L. V. Lawrence of Hudson New York. Fruit of medium size, oval; suture slight; yellow, obscurely streaked with green; bloom thin; flesh greenish, juicy, melting, sprightly; good; freestone; early; placed in the catalog of the American Pomological Society in 1877 .

Hughes. Munsoniana. I. Am. Pom. Soc. Rpt. r66. 1885. 2. Waugh Plum Cult. 195-6. 1901. 3. Ga. Sta. Bul. 67:275. 1904.

Originated in northeastern Mississippi where it is said to be one of the best of its species. Fruit of medium size, roundish; stem long, slender; cavity shallow; suture a line; bright red, striped with yellow; dots large, white; skin thin; flesh yellow, fibrous, watery, sprightly, subacid quality fair; stone of medium size, turgid, clinging; late.

Hungarian Musk Prune. Domestica. I. Guide Prat. 158, 363. 1895. 2. Can. Exp. Farms Rpt. 432. 1905 .

Basilic I. Musquée de Besztercze 1. Proune bissioque (Roumanie) I. Quetsche musquée de Hongrie I.

Hungarian Musk Prune is very similar to the German Prune; fruit of medium size, necked; cavity small; suture shallow; deep purple; bloom thick; flesh yellow, juicy, sweet, musky, aromatic; stone small, free; mid-season.

Hungarian No. I. Domestica. I. Ia. Sta. Bul. 31:349. 1895. 
J. L. Budd of the Iowa Experiment Station received this plum from Europe with sprouts of his Ungarish. Fruit of medium size, prune-shape, bright yellow; freestone. Hungarian No. 2. Domestica. I. Ia. Hort. Soc. Rpt. 86. 1890.

Imported by J. L. Budd from Russia; of little value.

Hunn. Triflora. 1. Cornell Sta. Bul. 139:43. 1897. 2. Ibid. 175:147. 1899.

Burbank No.I 1, 2.

A small, round plum named for C. E. Hunn of the New York State College of Agriculture; apex pointed; suture shallow; deep red; dots many, yellow; flesh soft, yellow, aromatic; quality fair; clingstone; mid-season.

Hunt. Munsoniana $\times$ Americana. 1. Am. Pom. Soc. Rpt. 78. 1897. 2. Ia. Sta. Bul. 46:275. 1900. 3. Waugh Plum Cult. I53. I901.

Originated about $\mathrm{r} 880$ by Henry Hunt, De Soto, Dallas County, Iowa, from seed of Wild Goose probably pollinated by the De Soto, trees of which stood near. It was supposed at one time that Lombard was the male parent but no traces of Domestica blood can be detected in either tree or fruit; introduced in 1897 by M. J. Graham, Odel, Iowa. Fruit of medium size, roundish-oval; cavity shallow; suture a line; dark red; bloom heavy; dots large, conspicuous; skin thin, not astringent; flesh yellow, firm, mild; quality fair; stone large, ovate, winged.

Hunt De Soto. Americana. I. S. Dak. Sta. Bul. 93:20. 1905. Hunt's De Soto 1.

Introduced by J. L. Budd of the Iowa Experiment Station; closely resembles De Soto, differing from it in being a little larger, darker red and a better keeper.

Ida. Americana. 1. Cornell Sta. Bul. 38:38. 1892. 2. Colo. Sta. Bul. 50:37. I898.

3. Waugh Plum Cult. 153. I901.

Originated with D. B. Wier of Illinois. Tree very thorny, of slow, irregular growth; fruit medium, roundish-oblong; cavity shallow; stem medium, stout, dull; red over yellow; bloom thick; skin thick; flesh pale yellow; quality fair; stone roundish, rather flat, clinging; mid-season.

Ida Green Gage. Domestica. I. Cole Am. Fr. Book 212. 1849.

A seedling of Reine Claude originating near Mount Ida, New York. It very closely resembles its parent except that it is more strongly blushed and is a few days later; obsolete.

Idall. Munsoniana $\times$ Hortulana mineri. 1. Cornell Sta. Bul. 38:56. 1892. 2. Am. Gard. 19:234. 1898. 3. Waugh Plum Cult. 173. 1901.

Idal 2. Idol I. Idol $\mathrm{1}, 2$.

According to the originator, D. B. Wier, of Illinois, the Idall is a cross between Wild Goose and Miner. Fruit large, roundish-oval; cavity shallow; suture a line: red; dots many; skin tough; flesh yellow; good; stone of medium size, oval, clinging; late.

Imperial. Americana. I. Ia. Sta. Bul. 46:276. 1900.

A small plum of the De Soto type brought to notice by C. B. Ginrich, Laporte, Iowa. Fruit round, conical; cavity broad, deep; suture a line; yellow with red markings; bloom thin; flesh clear yellow, firm, brisk, acid; good; clingstone.

Impériale Alexandrina. Species? Mentioned in Mathieu Nom. Pom. 436. 1889. 
Impériale de Milan. Domestica. 1. Lond. Hort. Soc. Cat. 149. 1831. 2. Hogg Fruit Man. 365. 1866. 3. Mas Le Verger 6:67. 1866-73.

Mailändische Kaiserpflaume 3. Prune de Milan 2, 3.

Originated near the city of Milan, Italy. Tree large, vigorous, spreading; fruit medium, oval; suture distinct; stem short, rather thick; skin tough, dark purple; bloom heavy; flesh grecnish-yellow, juicy, firm, sweet; good; usually freestone; mid-season. Imperial Ottoman. Domestica. 1. Lond. Hort. Soc. Cat. 149. 18 8 1. 2. Horticulturist 1:1 I fig. 1846. 3. Elliott Fr. Book 413. 1854. 4. Mas Pom. Gen. $2: 137$. 1873. 5. Mathieu Nom. Pom. 442. 1889.

Impériale de Turquie 4. Impériale Ottomane 5. Impcrial Ottoman 3, 4, 5. Ottoman 3. Ottomanische Kaiserpflaume 5. Ottomanische Kaiserpflaume 4. Türkische Gelbe Pflaune 5.

Supposed to have been brought into this country from Turkey by William Prince. Tree vigorous, productive; fruit medium, roundish-oval; suture indistinct; stem of medium length, slender; grcenish-yellow, clouded and mottled with darker shades; bloom thin; flesh yellow, juicy, pleasant; good; clingstone; very early.

Imperial Purple. Domestica. 1. Downing Fr. Trees Am. 923. 1869. 2. Mas Pom. Gen. 2:45. 1873. Imperial Purple 2. Pourprée Impérial 2.

Raised by William Prince, Flushing, Long Island. Tree vigorous, productive, fruit medium in size, roundish-oval; suture barely indicated; stem of medium length, slender; intense purple; flesh yellowish, juicy, sweet; clingstone; mid-season.

Imperial Violet. Domestica. I. Duhamel Trait. Arb. Fr. 2 :99. 1768. 2. Kraft Pom. Aust. 2:33, Tab. 181 fig. 1. 1796. 3. Prince Pom. Man. 2:60. 1832. 4. Noisette Man. Comp. Jard. 2:497. r860.

Die violete Kaiserpflaume mit scheckichten Blattern 2. Impériale à Petit Fruit Violet 4. Impériale Violette à feuilles panachees r. Impériale violette à feuilles panachees 2, 3 .

A variety with variegated leaves and fruit, cultivated as an ornamental.

Imperial Washington. Domestica. I. Horticulturist 25:204. I870.

A seedling of Lombard grown by G. P. Peffer of Pewaukee, Wisconsin. Tree vigorous and productive; fruit large, roundish, slightly oblate; suture faint; cavity lacking or small; brownish-red; dots yellow; skin thin, tender; flesh greenish-yellow, firm, juicy, rich; late.

Improved French Prune. Domestica. 1. Coates Cat. 1908. Miller 1.

A seedling of Agen grown by Luther Burbank and sold in 1898 under the name Miller to Leonard Coates, Morganhill, California, who introduced it under the name given above about 1908 . Very similar to its parent but larger and more uniform in size. Incomparable. Domestica. 1. Downing Fr. Trees Am. 924. 1869. 2. Mathieu Nom. Pom. 451. 1889.

Incomparable 2. Incomparable Prune 1. Nonpareil 1, 2. Unvergleichliche 2.

Probably a seedling of the German Prune. Tree vigorous; fruit of medium size, long-oval; suture shallow; cavity small; deep purplish-black; bloom heavy; flesh yellow, sweet; good; clingstone: late. 
Indian. Domestica, 1. Kraft Pom. Aust. 2:36, Tab. 186 fig. I. 1796.

Die grosse indianische braunrothe Pflaume 1. Grosse prune d'Inde rouge $\mathbf{1}$.

Fruit large, obovate, brownish-red; suture distinct; flesh yellow, firm; good; obsolete.

Indiana. Hortulana mineri. 1. Mich. Sta. Rpt. iा 1. 1887. 2. Cornell Sta. Bul. 38:56, 86. I892. 3. Waugh Plum Cult. 173. 1901.

Indiana Red 3. Indiana Red $1,2$.

Supposed to have been found wild in Indiana; introduced by Dr. I. Cramer. Tree tender in severe climates; fruit medium in size, oval; cavity shallow; stem slender; suture a line; red; bloom thin; dots minute, small; flesh yellow, firm; quality fair; stone large; oval, clinging; season late.

Indian Chief. Munsoniana. 1. Am. Pom. Soc. Cat. 36. 1875. 2. Cornell Sta. Bul. 38:49, 86. 1892. 3. Waugh Plum Cult. 186. 1901.

A southern variety of which the place of origin is not certainly known; Munson says southern Texas, Onderdonk thinks Georgia, others consider Arkansas as its birthplace. Tree vasiform, open; leaves short, broad, finely serrate; petiole short, glandular; fruit of medium size, oval; stem short, slender; cavity shallow; suture a line; dots numerous, white; bright red; skin thick; flesh yellow, melting, insipid; poor; stone long-oval, flattened, clinging; early.

Inkpa. Americana $\times$ Simonii. Cir. S. Dak. Exp. Sta. 1910.

Inkpa is a cross between Prunus simonii and Prunus americana made by N. E. Hansen of the South Dakota Experiment Station, who introduced the variety in 19 ro. Iola. Species? I. Cornell Sta. Bul. 38:79. $189^{2}$.

Originated by D. B. Wier, Illinois. Fruit large, oblong, yellow covered with red; flesh firm; freestone; late.

Iona. Hortulana mineri. I. Cornell Sta. Bul. 38:39. 1892. 2. Thomas Am. Fruit Cult. 490. 1897. 3. Waugh Plum Cult. 153. 1901.

Originated with D. B. Wier, from seed taken from a wild bush in southwestern Wisconsin. Tree vigorous, upright; fruit of medium size, oval; cavity shallow; suture a line; flesh yellow, firm, sweet; quality fair; freestone; late.

Iowa. Americana. 1. Wis. Sta. Bul. 63:43. 1897. 2. Minn. Hort. Soc. Rpt. 4r r. 1899. 3. S. Dak. Sta. Bul. $93: 20$. 1905.

From Allamakee County, Iowa, Fruit medium, oval; red over yellow; skin astringent; early.

Iowa Beauty. Americana. I. Kerr Cat. 1898. 2. Ia. Hort. So6. Rpt. 11 r. 1899. 3. Ia. Sta. Bul. 46:276. 1900 .

Taken from the woods about 1860 by Hugo Beyer, New London, Iowa. Fruit of medium size, oval, mottled yellow; flesh melting, juicy, sweet; good; early.

Irby. Hortulana. I. Vt. Sta. An. Rpt. 11:284. 1898. 2. Waugh Plum Cult. 18 1. 190 1.

3. Tex, Nur. Cat. 1907.

Erby September 1, 2. Irby September 3.

Found by Dan Irby of Texas growing on the grounds of an old Indian settlement. Fruit of medium size, bright red; late; similar to Wayland. 
Ireland. Domestica. I. Can. Hort. 21:391. 1898. Ireland's Seedling r.

Fruit of medium size, dark blue; stem slender; cavity deep; suture distinct; flesh green, tender, juicy; good; early.

Ireland Golden. Domestica. 1. Ont. Fr. Exp. Sta. Rpt. 3:120. 1896

Ireland's Golden Gage r.

Tree vigorous, hardy, productive; good; early.

Irene. Hortulana mineri. 1. Cornell Sta. Bul. 38:79. 1892. 2. Waugh Plum Cult. 154. 1901 .

Originated by D. B. Wier, Illinois. Fruit of medium size, oval; bright red; skin thick; flesh yellow, firm; clingstone; late.

Iris. Hortulana mineri. 1. Cornell Sta. Bul. 38:56. 1892. 2. Waugh Plum Cult. 173. I 901 .

Originated and introduced by D. B. Wier of Illinois. Fruit medium in size, oval; cavity shallow; suture a line; red; bloom thin; flesh yellow; poor; clingstone; late. Ironclad. Americana. I. Cornell Sta. Bul. 38:38. I892. 2. Ia. Sta. Bul. 46:275. 1900.

3. Waugh Plum Cult. 154. 1901.

Illinois Ironclad r, 2. Illinois Ironclad 3.

A wild variety from Illinois introduced by Stark Brothers in 1890 . Tree dwarf; fruit of medium size, roundish-oval; stem slender; cavity of medium depth, flaring; suture shallow; dots many, small, yellow; dark red; bloom thick; skin thick; flesh yellow, firm, meaty, sweet; quality fair; stone oval, smooth, flattened, clinging; midseason.

Iroquois. Hortulana mineri? 1. Can. Exp. Farm Bul. 43:39. 1903.

From Charles Luedloff, Cologne, Minnesota. Fruit of medium size, roundishheart-shaped; cavity narrow; suture a line; dark red; dots numerous, small, yellow; bloom thin; skin thick, tough; flesh yellow, juicy, sweet; quality fair; stone oval, slightly flattened, clinging.

Isaac. Americana. 1. Kerr Cat. 1897. 2. Waugh Plum Cult. 154. 1901.

Brought to notice by M. S. Hubbell from a wild tree near Lincoln, Nebraska. Fruit small, roundish, red over a green ground; clingstone.

Isabella. Domestica. I. Pom. Mag. 3:150. 1830. 2. Downing Fr. Trees Am. 305 . 1845. 3. Ann. Pom. Belge 6:93, Pl. 1858. 4. Hogg Fruit Man. 366. 1866.

5 Mathieu Nom. Pom. 436. 1889.

Die Isabelle 5. Prune Isabelle 3.

An English variety popular sixty-five years ago; said to produce three crops a year. Tree vigorous; fruit large, oval; suture distinct; deep, dull red, paler in the shade; dots many. dark colored; flesh yellow, rich, juicy, brisk; good; clingstone; mid-season. Isabella. Americana. I. Kerr Cat. 1900. 2. Terry Cat. 1900

Originated with H. A. Terry, Iowa, in $\mathrm{r} 893$. Tree low, spreading. productive; fruit of medium size. roundish; dark red on a yellow ground; good; clingstone; mid-season. Isle-Verte. Domestica. I. Quintinye Com Gard 68, 70. 1699. 2. Duhamel Trait. Arb. Fr. 2:107. 1768. 3. Prince Pom. Man. 2:94. 1832. 4. Mas Pom. Gen. $2: 39$. 1873 . 
Grosse Grune Pflaume 4. Grune Inselpflaume 4. Ilevert 2, 4. Ile Vert 3. Ile verte 3. Ille verte 3. Illvert 1. Inselpflaume Grüne 4. Isle Vert 3. Isle Verte 2. Prune de Savoye 3. Prune Ileverte 4. Savoy 3.

Tree very prolific; fruit of medium size, oval; suture a line; stem of medium length; skin yellcwish-green, reddish on the sunny side; flesh clear yellow, juicy, sweet; clingstone; used tor preserves and pickles.

Italian Damask. Domestica. 1. Duhamel Trait. Arb. Fr, 2:75, 1768. 2. Kraft Pom. Aust. 2:42, Tab. 195 fig. 1. 1796. 3. Prince Pom. Man. 2:83. 1832. 4. Downing Fr. Trees Am. 302. 1845. 5. Poiteau Pom. Franc. 1846. 6. Hogg Fruit Man. 366. 1866. 7. Guide Prat. 157, 353. 1895.

Damas d'Italie 1, 7. Damas d'Italie 2, 3, 4, 6. Die wälsche Damascenerpflaume 2. Prune Damas d'Italie 5. Prunus italica 5.

Supposed to have originated in Italy. Tree productive, doing especially well in the South; truit of medium size, roundish; cavity small; suture distinct; dark purple; bloom heavy; dots small, light; flesh yellowish-green, juicy, firm, sweet; good; stone thick, free; mid-season.

Itahenische Damascene (Diel's). Species? Listed in Mathieu Nom. Pom. 436. I889. Damas d'Italie.

Italienische Damascene (Liegel's). Species? Mentioned in Mathieu Nom. Pom. 436. $188 \mathrm{~g}$.

Damas d'Italie.

Itasca. Nigra. I. Mich. Sta. An. Rpt. 11 1. 1887, 2. Cornell Sta. Bul. 38:39. 1892. 3. Waugh Plum Cult. 171. 1901. Itaska I, 2.

An inferior variety from Minnesota; introduced by P. M. Gideon, Excelsior, Minnesota, and W. F. Heikes, Huntsville, Alabama. Tree dense and stocky; fruit of medium sıze, oblong, dull purple-red; skin thick; flesh firm; quality fair; clingstone; midseason.

Ithaca. Species? I. Cornell Sta. Bul. 38:79. 1892.

Supposed to have originated with Peter M. Gideon, Minnesota.

Ivason. Americana. I. Kerr Cat. 1897.

From Iowa. Tree vigorous; fruit large, roundish, purplish-red; semi-clinging; mid-season.

Ives. Domestica. I. Mag. Hort. 15:118. 1849. 2. Cole Am. Fr. Book 211.1849. 3. Am. Pom. Soc. Cat. 214.1856 , 4. Downing Fr. Trees Am. 924. 1869.

Ive's Seedling 1, 4. Ive's Washington 4. Ives' Washington Seedling 3. Washington Seedling 2 .

A seedling of Washington raised by J. M. Ives of Salem, Massachusetts; named by C. M. Hovey; first fruited in $\mathbf{1 8 4 5}$. Tree very vigorous; fruit large, roundishoblong; distinct suture; skin yellow, mottled and dotted with red; bloom thin; stem short and slender; flesh amber, melting, rich; excellent; stone medium, ovate, free. Ives. Insititia. I. Am. Gard. 14:148. 1893. Ives Damson I.

Grown locally in southern Connecticut. Tree productive; fruit purple, sour; clingstone; unusually late. 
J. H. Rue. Species? I. Wis. Sta. Bul. 63:43. 1897.

First noted by J. L. Budd of Iowa. Tree productive; fruit the size of Stoddard; flesh firm.

J. Parks. Spccies? I. Ill. Hort. Soc. Rpt. 420. I905.

Fruit small, light red; flesh meaty, firm; good; freestone; not troubled with rot.

Jacinthe. Domestica. I. Duhamel Trait. Arb. Fr. 2:100, Pl. XVI. 1768. 2. Kraft Pom. Aust. 2:28, Tab. 173 fig. 2. I796. 3. Coxe Cult. Fr. Trees 238. 1817 .

4. Prince Pom. Man. $2: 94$. I832. 5. Mas Le Verger 6:123. 1866-73.

Die Hyacinthenpflaume 2. Hyacinth 4. Hyacinthe Pflaume 5. Jacinthe 2. Prune Jacinthe 5 .

An old variety imported from England by William Coxe. Fruit large, elongated; suture indistinct; clear purple; flesh yellow, firm, juicy; good; stone oval, semiclinging; mid-season.

Jacob. Domestica. I. Downing Fr. Trees Am. 925. 1869.

Described only by Downing. Fruit of medium size, oval, necked, sides unequal; suture large; violet; flesh greenish, juicy, sweet; good; freestone; mid-season.

Jap No. 4. Americana $\times$ Triflora. I. Ia. Sta. Bul. 46:276. 1900. 2. Ibid. II4:138. I 9 10. Japan Hybrid No.4 2.

A seedling from De Soto pollinated with some Japanese variety; sent out by the Iowa Experiment Station about 1895 . Fruit of medium size, long-oval; suture distinct; mottled red over a yellow ground; dots none; skin thin, tender; flesh yellow, sweet; good; freestone.

Japan No. I. Americana $\times$ Triflora. I. Kerr Cat. 1899.

A hybrid grown by H. A. Terry, Crescent, Iowa.

Japan No. 3. Americana $\times$ Triflora. I. Kerr Cat. 1899.

Another of Mr. Terry's hybrids.

Japan Hybrid No. 2 (a). Americana $\times$ Triflora. I. Ia. Sta. Bul. I14:137. 1910.

One of a number of hybrids produced by the late J. L. Budd of the Iowa Experiment Station. This one is of the Americana type; fruit medium in size, oval, dark red over yellow; flesh yellow, tender, sweet; good; freestone; mid-season.

Japan Hybrid No. 2 (b). Americana $\times$ Triflora. I. Ia. Sta. Bul. 114:138. I9ro.

From the same lot of hybrids as Japan Hybrid No. 2 (a). Fruit resembles Prunus americana; large, oval, red over yellow; skin thick, tough, bitter; flesh juicy, coarse, pulpy, sweet; fair in quality; mid-season.

Japanese Plum Seedling. Triflora. I. Am. Gard. 14:515. 1893.

A seedling from Luther Burbank produced by pollinating Kelsey with Satsuma. Outwardly resembles Kelsey; flesh red, pleasant, juicy, meaty; vinous; stone small, clinging. Jaspisartige Pflaume. Species? Mentioned in Mathieu Nom. Pom. 436. $188 \mathrm{~g}$.

Lieflandische Grune Zwetsche Weisse Violen Pflaume.

Jaune d'Este. Domestica. I. Flor. \& Pom. 186. 1872. Jean d'Este I.

An old variety deserving of notice because of its earliness.

Jaune Tardive. Domestica. I. Can. Exp. Farm Bul. 2d. Ser 3:53. 1900. 2. Baltet Cult. Fr. 491. r 908.

Tree vigorous; fruit of medium size, oval, amber-yellow; flesh sweet; good. 
Jaune Tres Hâtive Baboud. Domestica. I. Can. Exp. Farm Bul. 2d Ser. 3:52. 1900.

Tree vigorous, productive; fruit below medium, oval; suture shallow; cavity small; clear yellow; flesh yellow, tender, juicy, sweet, pleasant; good; freestone; very early.

Jean Morceau. Domestica. I. Lond. Hort. Soc. Cat. 149. I83

A varicty grown at one time in the London Horticultural Society gardens.

Jennie Lucas. Angustifolia varians. 1. Am. Pom. Soc. Rpt. 160, 162. 1881. 2.

Waugh Plum Cult. 196. 1901. 3. Ohio Sta. Bul. 162:256, 257 . 1905.

Jennie Lucas is a seedling grown by G. Onderdonk, Mission Valley Nurseries, Victoria County, Texas; introduced by the originator in 1875 . Fruit of medium size, roundish; cavity shallow; suture a line; dots numerous, large, white; light yellow; skin thin; flesh yellow, soft, sweetish; quality fair; stone large, round, flattened, clinging; mid-season.

Jerusalem. Domestica. x. Prince Treat. Hort. 27. 1828. 2. Prince Pom. Man. 2:95. 1832. 3. Poiteau Pom. Franc. 1.I846. 4. Noisette Man. Comp. Jard. 2:497 1860. 5. Downing Fr. Trees Am. 926. 1869. 6. Mathieu Nom. Pom. 433. I889. 7. Lucas Vollst. Hand. Obst. 47x. 1894. 8. Guide Prat. 163, 367 . I 895 .

Blaue Eierpflaume 6, 8. De Bordeaux 1, 2, 5. De Jerusalem 4. Jerusalem 6. Oeil de Boeuf 1, 2, 4, 5. Oeuil-de-Boeuf 6. Prune de Bordeaux 6. Prune de Jerusalem 3. Prune Violet de Jerusalem 5. Prunier de Jerusalem 2, 5, 6. Violette de Jerusalem 6. Violette Jerusalem 5. Violette Jerusalems pflaume 6. Violette Jerusalemspflaume 7. Wahre blaue Eierpflaume 6, 8.

The tree and fruit of this variety resemble the German Prune of which it is probably an offspring. Fruit large, oval; suture a line; dark purple; flesh yellowish, prune-like, firm, sweet; good; stone long, flat, free; mid-season.

Jessie. Americana. 1. U.S. D. A. Rpt. 263. 1892. 2. Waugh Plum Cult. х 54. 1901.

A seedling introduced from the wild by the Martin Nursery Company, Winfield, Kansas, about $\mathrm{x} 892$. Tree productive, vigorous, suckers badly; fruit of medium size, oval; cavity shallow; suture a line; wine-red; flesh yellow, melting, fibrous, slightly subacid; good; clingstone; early.

Jewell. Munsoniana. I. Cornell Sta. Bul. 38:79. I892. 2. Wis. Sta. Bul, 87:14. 1901.

3. Waugh Plum Cult. I86. 1901.

A seedling of Wild Goose from H. A. Terry, Crescent, Iowa; first fruited in 1885 . Fruit of medium size, round; cavity shallow; suture indistinct; red over a yellow ground; bloom light; dots numerous; skin thin, not adherent to the pulp; flesh yellow, tender; quality fair; clingstone; mid-season.

Jodoigne Domestica. I. Hogg Fruit Man. 367 . 1866. 2. Ibid. 708. I884. 3. Lucas Vollst. Hand. Obst. 472 . 1894 .

Boulouf ?. Jodoigne Green Gage I, 2. Reine-Clande de Jodoigne 1, 2. ReineClaude von Jodoigne 3. Royal de Vilvorde 1, 2.

Probably a Reine Claude seedling; tree large, vigorous; shoots smooth; fruit large, round, inclining to oblate, greenish-yellow, with brownish-red cheek; suture shallow; flesh whitish-yellow, firm, juicy, tender, sweet, rich; mid-season. 
Joe Hooker. Americana. I. Kerr Cat. 1894. 2. Colo. Sta. Bul. 50:38. 1898.

3. Waugh Plum Cult. I54. 190x.

Tree dwarfish; fruit of medium size, roundish-oval; cavity shallow; suture faint; red on a yellow ground; skin thick; flesh yellow; clingstone; late.

John A. Domestica. 1. Can. Exp. Farms Rpt. 137. 1894. 2. Ont. Fr. Gr. Assoc. Rpt. 72. 1894. 3. Ia. Sta. Bul. 46:276. 1900 .

A cross between Evelyn and Italian Prune; originated with Richard Trotter, Owen Sound, Ontario. Tree vigorous; fruit large, oval or egg-shape; cavity narrow; bronze-red; bloom heavy; flesh greenish-yellow, firm, juicy, subacid; stone large; clinging; hangs well.

Johnny Roe. Domestica. I. Garden 53:263. I 898 .

An English variety propagated from suckers in Nottinghamshire.

Jones. Amerieana? r. Cornell Sta. Bul. 38:79. 1892. 2. Ia. Hort. Soc. Rpt. 334. 1894. 3. Ia. Sta. Bul. 46:277. I900.

Originated in 1880 with Mrs. Owen Jones, Crescent, Iowa, who planted the pits from a quart of "California plums" she had purchased; introduced by H. A. Terry about 1895 . Tree upright, spreading, productive; fruit of medium size, oval; suture indistinct; dark red; bloom light; skin thick, tender; flesh firm, meaty; quality fair; stone smooth, not margined; elinging; mid-season.

Jones Late. Americana. 1. Kerr Cat. 1894. 2. Wis. Sta. Bul. 63:43. 1897.

Introduced by H. A. Terry. Tree productive; fruit large, oval, red; flesh firm; clingstone.

Jordan Seedling. Domestica. I. Can. Hort. 14:329. 1891 .

Supposed to be a seedling of Yellow Egg; originated with F. Jordan of Goderich, Ontario. The variety resembles Hulings so closely as to be almost indistinguishable. Judson. Domestica. 1. Thomas Am. Fr. Cult. 342, 1849. 2. Elliott Fr. Book 427. 1854.

Originated in Lansingburgh, New York, some time in the early "forties." Fruit small, roundish; suture indistinct; cavity small; attractive pink; flesh juicy, rich, vinous; quality high; freestone; season just before Reine Claude.

Julia. Americana. I. Ia. Sta. Bul. 46:277. 1900. 2. Terry Cat. 1900.

Edith of Terry 1 .

A seedling from H. A. Terry in 1896 . Tree productive; fruit large, round, yellow striped with light red; flesh firm; clingstone; mid-season.

Julian. Triflora. Noted in Sweet Cat. 1907.

Julien Gros á Feuilles Panachees. Domestica. Mentioned in Lond. Hort. Soc. Cat. 149. I 83 r.

July Fourth. Domestica? $\times$ Triflora $\times$ Americana. I. Rural N. Y. 59:655 fig. I 900.

A second generation seedling from Luther Burbank; said to rank very high in quality.

July Green Gage. Domestica. 1. Jour. Hort. 9:128. 1865. 2. Hogg Fruit Man. 360, 367. 1866. 3. Downing Fr. Trees Am. 926. 1869. 4. Mas Pom. Gen. $2: 99$. 1873. 5. Mathieu Nom. Pom. 437. r889. 6. Guide Prat. 152, 363. 1895. 
Bavay's Early Gage? I. Bavay's Fruhe Reine-Claude 4, 6. Early Bavay 3, ?5. Early Green Gage? 2. Frühe Reine-Claude 6. Juli Reine-Claude 5. Julius ReineClaude 5. July Green Gage 4, 5. Reine-Claude Davion 4, 6. Reine-Claude de Bavay Hative 2, 3, 4, 6. Reine-Claude de Juillet 6. Reine-Claude Hative 5, of some 6. ReineClaude Hative d'Avion 6. Reine-Clande Hâtive de Bavay 6. Reine-Clande Bavay Hative? 5 .

July Green Gage was introduced into France from Normandy about the middle of the last century by a M. Davion. Tree productive; fruit of medium size, roundish; suture slight; stem short; cavity narrow, deep; yellowish-green sometimes spotted with red; bloom thin; flesh greenish-yellow, juicy, aromatic, sweet; very good; freestone; very early.

Jumelles. Domestica. 1. Can. Exp. Farms Rpt. 432. 1905.

Fruit of medium size, roundish; suture distinct; greenish streaked with yellow; flesh juicy, sweet, rich; stone small, semi-clinging; early.

Jumelles de Liegel. Domestica. I. Mathieu Nom. Pom. 439. 1889. 2. Guide Prat. I $60,35^{8}, \quad$ I 895 .

Jumelles de Liegel $\mathbf{~ . ~ L i e g e l ' s ~ Z w i l l i n g s p f l a u m e ~ r . ~ L i e g e l ' s ~ Z w i l l i n g s p f l a u m e ~} 2$.

Tree productive; fruit large, roundish, red; flesh yellow, juicy, sweet, vinous; good; late.

Kaga. Americana $\times$ Simonii. I. Circ. S. Dak. Exp. Sta. I910.

Introduced in 1910 by the originator, N. E. Hansen, of the South Dakota Experiment Station. It is a cross between Prunus simonii and some Americana.

Kaiser Wilhelm. Domestica. I. Oberdieck Deut. Obst. Sort. 407. 188 I. 2. Gard. Chron. 26:717. 1886. 3. Mathieu Nom. Pom. 428. 1889.

Bamberger Eier Pflaume 3 incor. Blaue Eier 3 incor. Dark Blue Egg 2. Dunkelblaue Eierpflaume 1. Dunkleblaue Eierpflaume 3. Liegel's Marokka? 3. Rodt's Grosse Fruh Pfaumen-Zwetsche 3. Ungarische Blaue Eier 3.

A plum very well known in Germany. Tree large, productive; fruit large, oval; skin thick, not adherent, tough, somewhat sour, bluish-black; flesh yellowish, juicy, slightly sweet; clingstone.

Kampeska. Americana. I. Kerr Cat. I894. 2. Colo. Sta. Bul. 50:38. I898.

Tree productive, slow and stocky in growth; fruit small to medium, round; stem of medium length, thick; skin thick, purplish-red; bloom heavy; of medium quality; clingstone.

Kanawha. Hortulana. I. Am. Pom. Soc. Rpt. 136. I875. 2. Ga. Hort. Soc. Rpt. 24. 1881. 3. Rev. Hort. 535. 1893. 4. Waugh Plum Cult. I80, I81. I901.

Canawa 1. Peach-leaved 2. Prune Kanawa 3. Rains I.

Introduced by P. J. Berckmans who had received it from J. S. Downer of Kentucky in I871. Fruit of medium size, oval; suture a line; dots many, white; bright red with a thin bloom; skin firm; flesh firm, meaty, sprightly; good; clingstone; season late; mentioned in the catalogs of the American Pomological Society from I875 to 1899. Kazan. Domestica. I. Mich. Sta. Rpt. II I. I887.

A foreign plum listed by the Michigan Experiment Station. 
Keindt. Domestica. I. Oberdieck Deut. Obst. Sort. 444. 1881.

Keindt's Frühdamascene r.

A German variety noted as unproductive on dry soil.

Keith. Americana. I. Ia. Hort. Soc. Rpt. 436. 1888. 2 Ia. Sta. Bul. 46:277. 1900.

3. Waugh Plum Cult. 155. 1901. Kieth 3.

Of the De Soto type, from Delaware County, Iowa, previous to 1888 . Fruit large, roundish-oblong; cavity shallow; stem short, thick; skin thin; orange overlaid with red; bloom thin; flesh yellow, firm, sweet, not juicy; good to best; stone large, flattened, clinging; mid-season; does not thrive in the South.

Kelbalan. Triflora $\times$ Cerasifera. 1. Kerr Cat. 1899 . Kelsey No. 3.

Grown by Theodore Williams of Benson, Nebraska, from a seed of Kelsey pollinated with Early Cherry. Tree somewhat like Myrobalan; fruit large, roundish-conic, yellow shaded with red; clingstone; good.

Kelley. Species? I. Van Lindley Cat. 1899.

Originated in South Carolina; introduced by R. Bates of Jackson, South Carolina. Tree prolific; fruit medium in size, yellow; good; early.

Kelmyro. Triflora $\times$ Cerasifera. I. Kerr Cat. 1899. Kelsey No. 1.

From Theodore Williams of Benson, Nebraska; from seed of Kelsey, pollinated with Early Cherry. Very productive; fruit medium, round, pointed, dark red on a yellow ground; stone small, clinging; mid-season.

Kelroba. Triflora $\times$ Cerasifera. I. Kerr Cat. 1899. Kelsey No. 2.

The same origin as Kelmyro. Tree vigorous, upright, productive; fruit above medium, round, pointed, yellow overlaid with light red; high flavor; stone small, clinging.

Kelsaw. Triflora $\times$ Munsoniana. I. Vt. Sta. An. Rpt. 14:271. 1901.

An accidental cross between Kelsey and a "Chicasaw;" from A. M. Augustine, West Point, Mississippi. Tree a rapid and thrifty grower. Fruit the size of Abundance, round-oval; stem an inch long; suture shallow; apex rounded; brilliant transparent red; dots minute; bloom thin; skin thin and tough; flesh yellow with pink markings, firm, sweet and rich; good to very good; clingstone; early.

Kelsey Prune. Domestica. Mentioned in Wild Bros. Cat. 1892.

Kelso. Domestica? 1. Vandevoort Cat.

Kelso is a yellow plum found about 1870 on the farm of Philip Cline of Sabina, Ohio. Peter Kelso, who afterwards purchased the Cline farm, brought the plum to J. M. Vandevoort, who introduced it about twenty-five years ago.

Kenellan. Domestica. Listed in Lond. Hort. Soc. Cat. 149. 1831.

Kennedy Red. Species? 1. Can. Exp. Farm Bul. 2d Ser. 3:53. 1900.

A weak-growing and unproductive variety tested in British Columbia. Fruit small, long-oval; suture distinct; cavity small; dull red with a thin white bloom and golden dots; flesh yellow, sweet, coarse, moderately juicy; pleasant; clingstone; of no value.

Kent. Domestica. I. Hogg Fruit Man. 689. 1884, 2. Mathieu Nom. Pom. 424. 1889 3. Garden 56:355. 1899. 4. Can. Exp. Farm Bul. 2d Ser. 3:50. 1900. 
Bush I. Bush 2. Bush Plum of Kent 4. Kentish Bush 3. Waterloo 1, 2. Waterloo of Kent 2 .

Found in a hedge at Boben, England in $\mathrm{x}_{3} 6$. Tree hardy, strong, very productive, fruit large, round; skin dark maroon; flesh firm; flavor fair; fruit kecps three weeks after being gathered; valuable for market.

Kenyon. Species? r. Mich. Sta. Rpt. III. 1887.

Listed as a native plum being tested at the Michigan Experiment Station.

Kester Green Gage. Domestica. I. Downing Fr. Trees Am. 926. I869.

Keșter's Green Gage r.

Originated with a Mr. Weaver of Mt. Pleasant, Pennsylvania. Fruit small, nearly round, one side enlarged; suture large; pale yellowish-green, splashed with deeper green; bloom thin; stem medium in length; cavity large; flesh greenish, juicy, sweet, rich; very good; semi-clinging.

Kester Yellow Gage. Domestica. I. Downing Fr. Trees Am. 926. I869.

Kester's Yellow Gage I.

Of the same origin as Kester Green Gage. Tree vigorous, upright with smooth branches; fruit medium in size, roundish-oval; suture broad and shallow; light yellow overspread with thick bloom; stem medium; cavity small; flesh greenish-yellow, juicy, sweet, rich; very good; semi-clinging.

Kicab. Species? I. U.S. D. A. Pom. Rpt. 45. 1895. 2. Am. Pom. Soc. Rpt. 46.1897.

A seedling grown by Benjamin Buckman, Farmingdale, Illinois. Fruit medium, roundish-oval; skin thick, crimson with dark purplish stripes, covered with thick bloom; dots numerous, variable; flesh yellow, tender, melting, juicy, mild subacid; good to very good; stone large, oval, clinging; early.

Kickapoo. Americana. I. Penn. Hort. Soc. Rpt. 52. I892. 2. Cornell Sta. Bul. 38:39,

86. 1892. 3. Ohio Sta. Bul. $162: 256,257$. 1905.

Tree an open, straggling grower, very productive; fruit of medium size, oblong to oval; cavity medium; stem short to medium, stout; suture faint; dull red mottled with deeper shades; bloom heavy; flesh yellow, firm; good; stone of medium size, clinging; mid-season; recommended for market.

King. Munsoniana. 1. Am. Jour. Hort. 5:148. 1869.. King of Plums I.

A seedling of the Wild Goose which it closely resembles.

Kingston. Domestica. I. Ellwanger \& Barry Cat. 1888-1894. 2. Waugh Plum Cult. Iг 2. г 90 I. Smith's Prune I.

Kingston closely resembles Diamond; its origin in Ontario, Canada, is about all that distinguishes it.

Kleine Blaue Fruhzwetsche. Domestica? Mentioned in Mathieu Nom. Pom. 437. I 889 .

Kleine Gelbe Eierpflaume. Domestica. Listed in Mathieu Nom. Pom. 437. I889.

Kleine Kirschpflaume. Cerasifera. Mentioned in Mathieu Nom. Pom. 437. I889. Prunus Cerasifera Fructu Minore.

Kleine Rosspauke. Species? I. Mathieu Nom. Pom. 437. I889.

Mathieu records this variety as mentioned in Wiener Garten-Zeitung 288. I884. 
Klondike. Americana. I. Wis. Sta, Bul. 63:44. 1897. 2, Ill. Hort. Soc. Rpt. 242. 1898. 3. Ia. Sta. Bul. 46:277. 1900. Klondyke 2, 3.

Grown by John Wragg \& Sons, Waukee, Iowa, from seed of De Soto; introduced in 1897 by W. F. Heikes, Huntsville, Alabama. Tree productive; fruit medium to small, roundish-oval; cavity narrow, dcep; suture a broad line; skin thin, bright yellow shading into red; bloom thin; dots numerous, small; flesh yellowish, sweetish, watery; quality fair; stone small, clinging; early.

Knudson. Americana. 1. Am. Pom. Soc. Rpt. 162, I891, 2, N. Dak. Sta. Bul. 2: 18. г891. 3. Wis. Sta. Bul. 63:44. 1897.

Kniedsen's Peach I. Knudson's Peach 3. Peach 2.

Grown by H. Knudison, Springfield, Minnesota. Tree unproductive; fruit drops before ripe; of medium size, roundish, purplish-red; flesh sweet; clingstone; midseason. Subject to plum-pocket.

Koa. Domestica. Mentioned in Forsyth Treat. Fr. Trees 21. 1803.

Koa's Imperial.

Kober. Americana. I. Ia. Hort. Soc. Rpt. 228 . 1909.

Kober originated with N. K. Fluke, Davenport, Iowa. Fruit large, mottled and blushed with red; bloom rather thick; flesh moderately firm, sweetish; fair in quality; clingstone; mid-season.

Koch Känigspflaume. Species? Mentioned in Mathieu Nom. Pom. 437. I889.

Karl Koch's Königs Pflaume Royale de Koch Royale du Dr. Koch.

Koch Spate Damascene. Domestica. I. Mas Pom. Gen. 2:161. 1873. 2. Oberdieck

Deut. Obst. Sort. 403. I88I. 3. Mathieu Nom. Pom. 437. I889.

Damas Jaune Tardif de Koch 3. Damas Tardif de Kock 1. Koch's Gelbe Spat Damascene 3. Koch's Späte Aprikosen 3. Koch's Späte Damascene 2. Koch's Späte Damascene 3 .

Liegel grew this variety from seed of Bricette and dedicated it to Koch, secretary of a horticultural society at Gotha. Tree medium, round-topped; fruit below medium, roundish-oval; suture a line; cavity shallow; stem short, slender, glabrous; skin free, yellow spotted with red on the sunny side; flesh yellow, fine, firm, juicy, sweet, rich; freestone; late.

Koepher. Species? 1. Gard. Mon. I0:18. I 868.

Noted as productive and free from curculio.

Kohlenkamp. Domestica. 1. Gard. Mon. 2:313. 1860. 2. Am. Pom. Soc. Rpt. 122. I860. Kohlen Kamp I.

A seedling raised by W. Kohlenkamp, Philadelphia, Pennsylvania. Tree vigorous, very productive; fruit borne in clusters, large, oval; stem short; cavity deep; reddish; bloom thin; flesh yellow, firm, dry; good; freestone; late.

Kopp. Americana. I. U. S. D. A. Rpt. 441. I889. 2. Colo. Sta. Bul. 50:39. I898. 3. Waugh Plum Cult. I55. I 901 .

Introduced by O. M. Lord, Minnesota City, Minnesota. Tree vigorous, productive; fruit large, round; skin thick; purplish-red; flesh firm, sweet; clingstone; midseason. 
Korai. Domestica, 1. U. S. D. A. Pom. Rpt. 26. 1894. 2. Am. Pom. Soc. Rpt. 176.1895.

Quetsche 1, 2.

Reccived from Hungary by the United States Department of Agriculture in 1893 . Tree vigorous; fruit below medium, oblong-ovate; sides unequal; skin thick, tough; purple with numerous small, brown dots; flesh yellowish-green, coarse, melting; subacid; good; stone of medium size, narrow, pointed, clinging; mid-season.

Kroos-Pruim. Species? x. Knoop Fructologie 2:58. I 761 .

Originated in Holland. Fruit of varying colors and sizes, round; insipid, watery. Propagated by pits. Useful only as a stock.

Kume. Triflora. I. Am. Gard. 12:449. г89r.

An early varicty.

Lachine. Domestica. 1. Can. Exp. Farm Bul. 43:38. 1903.

Similar to Yellow Egg; hardy; prođuctive; good; clingstone.

Lady. Insititia. 1. Cultivator 3:20. 1855. Lady Plum 1.

A seedling of Mirabelle from Isaac Denniston, Albany, New York. Tree slender, vigorous, productive; fruit small, oval; stem short, stout; light yellow, with red spots; stone small, free; mid-season.

Lakeside No. $\mathbf{I}$ and No. 2. Hortulana. Letter from Kerr.

Two seedlings from Theodore Williams, Benson, Nebraska.

Lallinger Konigspflaume. Domestica. Listed in Mathieu Nom. Pom. 438. 1889.

Lambert. Americana. 1. Kerr Cat. 1897. 2. Can. Exp. Farm Bul. 2d Ser. 3:53. 1900.

Labert r. Labert's Red r. Lambert's Red 2.

A seedling from Ontario, Canada. Tree weak; foliage poor; fruit small, heartshaped; stem short; cavity lacking; suture a line; reddish; bloom thin; flesh reddishorange, juicy; poor; stone large, clinging; mid-season.

Lammas. Domestica. 1. Ray Hist. Plant. $2: 1529$. 1688. 2. Lond. Hort. Soc. Cat. r 49. 1831 .

Mentioned by Ray as being one of the best sorts of his time.

Lancaster. Munsoniana $\times$ Hortulana mineri? 1. Waugh Plum Cult. I86. 190 r.

Grown by Charles B. Camp of Cheney, Nebraska, from a seed of Wild Goose supposed to have been crossed with Miner.

Lang. Americana. x. S. Dak. Sta. Bul. 93:21. 1905. Rang 1.

Sent to the South Dakota Station by C. W. H. Heideman of Minnesota. Tree vigorous, straggling in growth; fruit large, yellowish; skin thin; flesh sweet, juicy; good; stone small; keeps well; mid-season.

Langdon. Domestica. 1. Mag. Hort. 19:461 fig. 36. 1853. 2. Downing Fr. Trees Am. 386. 1857. 3. Ibid. 927.1869.

Langdon's Seedling 2. Langdon's Seedling 3.

Originated with Reuben Langdon of Hartford, Connecticut; believed to be a seedling of Washington. Tree vigorous, spreading; shoots strong, smooth; leaves large; fruit large, roundish-oval; suture a line; purplish-red to light green in the shade with some mottling; bloom thick; dots small; stem of medium length, stout, hairy; cavity deep; flesh yellow, melting, juicy, sweet, acid next to the skin; semi-clinging; early. 
Lange Violette Damascene. Species? Mentioned in Mathieu Nom. Pom. 438. 1889. Blane Damascenerin. Damas Violet?. Damas Violet Allonge. Damas Violet Longuet. Das Blaue Auge. Langliche Blaue Damascene?. The Great Damask Plum.

Langsdon. Hortulana mineri. 1. Am. Jour. Hort. 5:144. 1869. 2. Barry Fr. Garden 418. 1883. 3. Cornell Sta. Bul. 38:56. $189^{2}$.

Illinois Plum $\mathbf{1}$. Langdon 2.

Grown in Illinois previous to $\mathrm{r} 869$. Tree medium in vigor; leaves obovate or elliptic-obovate, pointed, with small glands; fruit small, roundish-oblong, light red; bloom thin; skin thick; flesh firm; quality fair; stone clinging, small, nearly smooth, turgid, short, pointed; mid-season or later.

Lannix. Triflora $\times$ Munsoniana. I. U.S. D. A. Pom. Rpt. 45. 1895. 2. Vt. Sta. Bul. $67: 15 . \quad 1898$.

Supposed to have been produced from Abundance crossed with Wild Goose. Leaves large, oval, pointed, leathery; petiole short, stout, usually glandless; fruit oval, of medium size, coppery-red; bloom light; skin thin, tough, bitter; flesh yellowish, translucent, tender, juicy, slightly fibrous, mild subacid, rich, slightly bitter at the center; good; stone large, oval, clinging.

La Prairie. Americana. 1. Wis. Sta. Bul. 63:44. 1897. 2. Waugh Plum Cult. 155. 1901

Taken from the woods about 1844 at Shopiere, Wisconsin; brought to notice by B. H. Smith. Tree productive; fruit large, golden, slightly astringent.

Large English Damson. Insititia. Mentioned in Can. Exp. Farm Bul. 2d Ser. 3:51. 1900.

Large Golden Prolific. Domestica. I. Can. Exp. Farm Bul. 2d Ser. 3:53. I900.

2. Albertson \& Hobbs Cat. 1904. 3. Stone \& Wellington Cat. 1907.

Vail's Seedling 3 .

Originated in Canada; a seedling of Yellow Egg. Tree vigorous, spreading; fruit above medium size, oblong, golden-yellow; flesh yellow, juicy, sweet, pleasant; early.

Large Green Drying. Domestica. 1. Lond. Hort. Soc. Cat. 149. 1831. 2. Mag. Hort. 6:94. 1840. 3. Thompson Gard. Ass't 518. 1859. 4. Downing Fr. Trees Am. 927. 1869. 5. Mas. Pom. Gen. $2: 191$. 1873. 6. Guide Prat. 163, 366. 1895. Grosse à sécher de Knight 6. Knight's Green Drying 5, 6. Knight's Large Drying 4, 6. Knight's Large Green Drying 3. Large Green Drying 6. Verte à Secher de Knight 5, 6.

Raised by Thomas Knight; first fruited in 1838 . Fruit large, round; suture shallow; greenish-yellow; bloom thin; flesh yellowish, firm, medium juicy, sweet and well flavored; excellent for dessert; clingstone; mid-season.

Large Queen. Domestica. I. U.S. D. A. Pom. Rpt. 26. 1894. 2. Am. Pom. Soc. Rpt. 176. 1895 .

Imported from Hungary by the United States Department of Agriculture in 1893 and fruited by E. C. Hoskins of Springbrook, Oregon. Fruit of medium size, roundishoblate, dark wine color; bloom light; dots many, conspicuous; skin thick; flesh greenishyellow, coarse, mild subacid; good; clingstone; mid-season. 
Large Sugar Prune. Domestica. I. Koch Deut. Obst. 572. I876. 2. Lange Allgem. Garten. 2:421. I879. 3. Oberdicck Deut. Obst. Sort. 440. 1881. 4. Mathieu Nom. Pom. 434. I889.

Ananas Zuetsche 4 incor. Bely Zwetsche 4. Blane Eier Pfaume 4. Dörell's Grosse Ungarische Pflaume 4. Grosse Zuckerzwetsche 3, 4. Herrenhauser Blaue Eior Pflaume 4. Jacobi Zwetsche 4. Klalrauer Pflume 4. Quetsche Sucree 4.

An carly German prune used for table, market and drying. Tree large, broadheaded, productive; shoots pubescent, straight, dark brown; fruit large, oval, sometimes ovate; suture shallow; sides unequal; stem long, glabrous; skin free, sour, bluishblack; bloom thick; flesh yellow, firm, juicy, rich, sweet; frecstone.

Large White Damson. Insititia. I. Duhamel Trait. Arb. Fr. 2:72, Pl. 3 fig. 2. 1768. 2. Prince Pom. Man, 2:88. 1832. 3. Downing Fr. Trees Am. 952, I869. 4. Hogg Fruit Man. 709. I884. 5. Guide Prat. I6I, 357. I895.

Damas Blanc 3, 4. Damas Blanc Gros 2, 3. Damas Blanc Hatif Gros 3, 4. Damas Blanc Tres Hatif 4. Damas Gros Blanc 5. Gros Damas Blanc 2, 4. Gros Damas Blanc I, 5. Large White Damask 4. Large White Damask 2. White Damask 3.

Probably of French origin; resembles the Small White Damson closely but 1 s larger and longer. Branches smooth; fruit below medium, roundish-oval, greenish-yellow; bloom thin; flesh medium in sweetness and flavor; adapted for cooking; freestone; late.

Late Black Damson. Insititia. 1. Quintinye Com. Gard. 70. I699. 2. Duhamel

Trait. Arb. Fr. 2:73. 1768. 3. Prince Pom. Man. 2:89. 1832. 4. Noisette Man. Comp. Jard. $2: 495$. 1860.

Black Damson 3. Damas .Voir 3. Damas Noir Tardif 2, 4. Damas .Voir Tardif 3. Late Damask? I.

Fruit small, elongated, purplish-black; cavity shallow; suture a line; flesh yellowish-green, acid until thoroughly ripe; nearly freestone.

Late Blood. Triflora. I. Cornell Sta. Bul. 62:23. I894. 2. Ibid. 106:56. 1896 .

Burbank No.3 I, 2. Hale 2. Hale I.

Luther Burbank imported this variety in $188_{5}$; Bailey named it Hale in 1894 but changed it to Late Blood two years later. Similar to Satsuma; later, blooms earlier, is less pointed and differs in leaf-characters,

Late Bolmer. Domestica. I. Downing Fr. Trees Am. 404. 1857. 2. Mathieu Nom. Pom. 439. I889. Winter Bolmar 2.

Fruit of medium size, roundish, yellow, mottled with red in the sun; flesh yellow, iirm, sweet but not rich; freestone; mid-season.

Late Chalons. Domestica. I. Prince Pom. Man, 2 :99. I 832 . 2. Mathieu Nom. Pom. 450. I 889 .

Tardif de Chalons I. Tardive de Chalons 1, 2. Späte von Chalons 2.

Fruit of medium size, oval, light yellow with red blush, deepening to violet; flesh yellowish, mclting, juicy, sweet; stone rough, clinging; very late.

Late Conical. Triflora $\times$ Simonii. I. Vt. Sta. Bul. 67:16 fig. I898.

Originated by Burbank; named in 1898 . Tree of rapid growth; leaves medium to large, broadly oval, abruptly pointed, tapering at the base, rather stiff, margins 
coarsely double-crenulate; petiole large, set with glands; fruit strongly conical, large; cavity shallow, abrupt; stem short; suture shallow; yellow overlaid with purple and red; dots numerous, large; bloom heavy; skin medium in thickness; flcsh yellow, firm, sweet and agreeable; very good; stonc of medium size, flattened, pointed, free.

Late Goose. Munsoniana. 1. Stark Bros. Cat. 1909.

From Theodore Williams of Nebraska. Fruit very large; handsome.

Late Orange. Domestica. I. Gard. Chron. 12:593. 1892. 2. Garden 64:262. 1903. 3. Can. Exp. Farms Rpt. 423. I903.

Late Orange originated with Thomas Rivers, Sawbridgeworth, England, first fruiting in 1888 ; introduced by the originator in 1897 . Tree vigorous; fruit similar to Reine Claude in size and appearance; flesh yellow, juicy, sweet; very good; season very late.

Late Prolific. Domestica. I. Fish Hardy Fr. Bk. 2:56. 1882. 2. Rivers Cat. 35. 1898-99.

3. Can. Exp. Farms Rpt. 423. 1903. River's Late Prolific I.

A seedling of Early Prolific. Tree vigorous; fruit below medium size, round; suture shallow; stem of medium size; cavity lacking; dark purple; bloom heavy; flesh greenish-yellow, juicy; flavor pleasant; stone small; early to mid-season.

Late Red Damask. Domestica. 1. Prince Pom. Man, 2:85. 1832, 2. Kenrick Am. Orch. 261. 1832. 3. Poiteau Pom. Franc. I. 1846.

Damas rouge tardif I. Gros Damas rouge tardif I. Gros Damas Rouge Tardif 2, 3 . Large Late Red Damask 2. Late Red Damson 1.

According to Kenrick and Prince this variety was described in the $18_{25}$ edition of Duhamel's Traité des Arbres Fruitiers. Its description resembles that of Orleans very closely but its season is evidently later. Tree vigorous, productive; fruit large, oval; skin thick, adherent to the flesh, light purple; flesh yellow, melting, slightly coarse, juicy, sweet; good; late.

Late Reine Claude. Domestica. 1. Lond. Hort. Soc. Cat. 148. I831. 2. Horticulturist 2:479. 1847. 3. Downing Fr. Trees Am. 395. 1857. 4. Ibid. 935. 1869.

5. Guide Prat. $162,364.1895$.

Late Gage 4. Late Green Gage 1. Late Green Gage 4. October Green Gage ?2. October Green Gage 4. Reine-Claude d'Octobre ?2, 4. Reine-Claude d'October 3. Reine-Claude Tardive 4. Reine-Claude Tardive 2, 4.

First mentioned in the London Horticultural Society catalog in 1831 . Origin unknown. Tree vigorous; shoots smooth, stout, short-jointed; fruit small, roundish; apex dimpled; skin greenish-yellow, mottled with red on the sunny side; bloom thin; flesh green, juicy, rich, sugary; good; freestone; late.

Late Rivers. Domestica. 1. Hogg Fruit Man. 369. 1866. 2. Nicholson Dict. Gard. 3:166. 3. Thompson Gard. Ass't 4:158. 1901. 4. Mathieu Nom. Pom. 439. 1889. Tardive de Rivers 4.

A seedling from Thomas Rivers of Sarwbridgeworth, England; first fruited in 1865 . Branches smooth; fruit of medium size, round; suture shallow; stem long, slender; dark purple; flesh yellow, rich, sweet, sugary; flavor pleasant; clingstone; very late. 
Late Rollingstone. Americana. I. Cornell Sta. Bul. 38:39, 42. 1892. 2. Colo. Sta. Bul. 50:39. 1898. 3. Waugh Plum Cult. 155. 1901.

A seedling of Rollingstone, grown by O. M. Lord of Minnesota. Tree medium in vigor, with a round, compact head; leaves obovate-oblong, short-acuminate, irregularly crenate; shoots red, smooth, glossy; petioles glandular, pubescent; fruit medium in size, roundish-oblate; cavity shallow; suture faint; yellow background overlaid with red; stem of medium length; dots numerous, yellow; bloom thick; skin thick; flesh ycllow, firm; fair to good; stone of medium size, broad-oval, smooth, flattened; late. Late Transparent. Domestica. I. Nicholson Dict. Gard. 3:167. 2. Cornell Sta. Bul. I31:188. r897. 3. Thompson Gard. Ass't 4:158. 1901.

Late Transparent Gage I.

A seedling of Transparent from Thomas Rivers of Sawbridgeworth, England. Tree dwarf, hardy, productive; fruit large, round, greenish-yellow, with purplish blush in the sun; flesh yellowish, firm, tender, juicy, sweet; high quality; stone very small; season ten days later than its parent.

Laubinger Sugar Prune. Domestica. I. Oberdieck Deut. Obst. Sort. 441. I881. 2. Mathieu Nom. Pom. 439. 1889.

Laubinger's Catharinen Pfaume 2. Laubinger's Zuckerzwetsche 1, 2.

From Germany. A true prune of value for table, compotes and drying. Tree vigorous, productive; shoots glabrous, violet-brown; fruit large, long-oval; suture shallow or lacking, divides the plum equally; stem not hairy; skin free, sourish; violetbrown to bluish-black; bloom thin; flesh yellow, firm, rather juicy, slightly tart; mid-season.

Laura. Species? I. Vt. Sta. An. Rpt. 14:271. 1901.

From Theodore Williams, Nebraska; said to be a cross between Quackenboss and Red Glass. Tree apparently a pure Americana according to Mr. Williams.

Lawrence Early. Domestica. 1. Lond. Hort. Soc. Cat. 149. 1831 . 2. Downing Fr.

Trees Am. 928. 1869. 3. Mathieu Nom. Pom. 439. 1889.

Lawrence 1. Lawrence's Early I. Lawrence's Early 2, 3. Lawrence's Früh Rote Pflaume 3.

This plum differs from the well-known American variety, Lawrence, in that it is smaller, of poorer quality, purple and earlier.

Lawson. Domestica. 1. McIntosh Bk. Gard. 2:531. 1855. 2. Downing Fr. Trees Am. 928. 1869. 3. Mas Le Verger 6:141. 1866-73. 4. Lange Allgem. Garten. 421. 1879. 5. Hogg Fruit Man. 7 10. 1884.

Anna Lawson 3. Anna Lawson 4. Damas Lawson 2, 5. Dorée de Lawson 3. Golden Gage Lawson 2. Lawson's Golden 1, 5. Lawson's Golden 3. Lawson's Golden Gage $x$.

A seedling of Reine Claude pollinated with Golden Drop, grown in 1842 by Archibald Gorrie of Annat Gardens, Errol, Perthshire, Scotland; named in honor of Charles Lawson a nurseryman of Edinburgh. Tree hardier than either parent; fruit of medium size, oval; suture a line; cavity small; yellow with dull reddish blush; bloom thin; flesh yellow, sweet, juicy; good; clingstone; mid-season. 
Le Duc. Americana. 1. Am. Pom. Soc. Rpt. 134. 1887. 2. Waugh Plum Cult. ${ }_{5} 6$. 1901. 3. Ohio Sta. Bul. $162: 256,257$. 1905. La Duc 1.

Le Duc was found growing wild at Hasting, Minnesota; introduced by W. G. Le Duc. Fruit of medium size, roundish; suture faint; cavity small; bright red; bloom thin; flesh yellow, swect, pleasant; quality fair; stone large, semi-clinging; mid-season.

Legal Tender. Americana. I. Ia. Sta. Bul. 46:277. 1900.

Originated under cultivation with H. A. Terry, Crescent, Iowa in 1896; first fruited in r899; parentage unknown. Tree vigorous, productive; fruit large, round, golden-yellow blotched with dark red; skin thin; fine quality; semi-clinging; midseason.

Leib Sour. Simonii $\times$ Triflora. 1. Vt. Sta, An. Rpt. 14:272, 1901.

One of Burbank's hybrids; of the type of Wickson. Fruit large, round or slightly oblate; stem strong; cavity wide; suture shallow; apex slightly depressed; light red with thin bloom; dots many, prominent; flesh yellow, firm, meaty; flavor peculiar, aromatic, subacid; good to very good; stone medium, oval, flattened, clinging.

Leonard. Americana. I. Montreal Hort. Soc. Rpt. 9o. 1885. 2. Colo. Sta. Bul. 5o: 40. 1898. 3. Waugh Plum Cult. 156. 1901.

Originated with Charles Gibb, Montreal, Canada, in 1873 from a wild plum root obtained from Wisconsin. Fruit medium, round; cavity shallow; stem slender; dull dark red, mottled; dots small; flesh yellow, not firm, acid; quality fair; stone small, round-oval, smooth, semi-clinging; mid-season.

Leopard. Triflora $\times$ ? 1. Vt. Sta. An. Rpt. 14:272. 1901.

From Theodore Williams, of Nebraska, from a "Botan pit pollinated with Red Glass." Fruit large, round-oval; stem medium long, set in a shallow cavity; skin thick; light rich red; flesh yellow, firm; flavor Miner-like, rich and sweet; good to very good.

Lepine. Insititia. 1. Koch Deut. Obst. 570. 1876. 2. Lange Allgem. Garten. 2:420. 1879.

A variety of the Damson type raised by Lepine in Belgium; probably not known in this country; very similar to Norbet and by some said to be the same. Tree large, productive; fruit of medium size, round, somewhat compressed; suture shallow; skin removable, not sourish; dark blue; flesh greenish-yellow, firm, sweet, wine-like; stone free; late.

Leptune. Hortulana. I. Cornell Sta. Bul. 38:56, 86. 1892. 2. Bailey Ev. Nat. Fr. 203, 206, 208. 1898. 3. Vt. Sta. An. Rpt. 11:284. 1898.

Introduced by J. D. Morrow \& Sons of Arkansas. Leaves elliptic-ovate to ellipticobovate, very long-pointed and coarsely scrrate; stalks either glandless or glandular; fruit of medium size, round; skin thick, dark red; dots yellow; flesh yellow, meaty; stone medium, nearly smooth, short-pointed, clinging.

Letta. Species? 1. Am. Pom. Soc. Rpt. 133. 1891.

Found in Buchanan County, Iowa; introduced by J. Wragg \& Son of Waukee, Iowa. Fruit as large as Hawkeye.

Lewis. Domestica. I. U. S. D. A. Pom. Rpt. 46.1895. 
Received by the United States Department of Agriculture from H. C. Cook, White Salmon, Washington. Fruit large, roundish-oval; stem short, sct in a moderately deep, abrupt cavity; red, a little darker than Lombard; bloom thin; dots numerous; flesh pale yellow; good to very good; stone large, oval, free; late.

Lewiston Egg. Domestica. I. Downing Fr. Trees Am. 404. 1857. 2. Am. Pom. Soc. Cat. 222, 244. 1858. Lewiston's Egg 2.

According to Downing, from Lewiston, New York. Tree vigorous, productive; fruit medium, oval, pale yellow; flesh yellow, not very sweet; flavor medium; clingstone; mid-season. Rejected by the American Pomological Society in 1858 .

Lex Plum. Domestica. 1. Kenrick Am. Orch. 263.1832.

Noted as a large blue plum with rich, sweet, yellow flesh; very productive.

Liegel Rote Damascene. Species? Mentioned in Mathieu Nom. Pom. 439. I889.

Runde Rote Damascene.

Liegel Apricot. Domestica. 1. Hogg Fruit Man. 369. 1866. 2. Mathieu Nom. Pom. 439. 1889. 3. Guide Prat. 163, 351. 1895.

Abricotée de Braunau Nouvelle 1, 2. Abricotée de Liegel 3. New Apricot of Braunau 2.

Liegel Apricot was grown by Dr. Liegel of Braunau, Germany. Fruit of medium size, roundish; suture deep; yellowish; bloom thin; flesh greenish-yellow, melting, juicy, sprightly; good; freestone; late.

Liegel Gage. Domestica. 1. Mathieu Nom. Pom. 439. 1889. 2. Guide Prat. 161, 359. 1895.

A variety said to have been imported into France from England. Fruit of medium size, roundish, greenish; bloom thin; flesh yellow, juicy, rich; very good; late.

Liegel Unvergleichliche. Domestica? 1. Mathieu Nom. Pom. 439. 1889. 2. Guide Prat. 162, 359. 1895.

Received in France from Bohemia.

Lillian Augusta. Domestica. 1. Ont. Fr. Gr. Assoc. Rpt. 72. 1894. 2. Can. Exp. Farms Rpt. 136. 1894 .

Grown by Richard Trotter, Owen Sound, Ontario. Tree hardy, productive; fruit large, egg-shaped; cavity small and shallow; stem nearly long; suture a line; greenishyellow with a few broken stripes of deeper shade; flesh light yellow, firm, meaty, juicy, slightly acid; good to very good; stone medium to small, oval, turgid, roughened, partly free.

Lillie. Americana. I. Ia. Hort. Soc. Rpt. 276. 1893. 2. Waugh Plum Cult. 156. I 901.

A seedling of Hawkeye, grown by H. A. Terry, Crescent, Iowa; first fruited in 1893. Tree vigorous and upright; fruit of medium size, round sometimes conical; cavity broad, shallow; stem slender; apex rounded; yellow overspread with mottled light and dark red; dots numerous; bloom thick; flesh sweet, melting; quality best; stone pointed, free; mid-season.

Lindow'sche Fruhe Werder'sche Pflaume. Species? Mentioned in Mathieu Nom. Pom. 439. 1889 .

Lindsay. Species? 1. Can. Hort. 27:22, 1904. Lindsay's Seedling I.

Reported as a new plum from Guelph, Canada; large; good. 
Little. Americana. 1. Cornell Sta. Bul. 38:39. 1892. 2. IVis. Sta. Bul. 63:45. 1897. Little Seedling $1,2$.

Introduced by Charles Leudloff, Carver, Minnesota, but discarded by him on account of its size. Fruit small, red; stone small, rough, cherry-like.

Livland. Domestica. I. Am. Pom. Soc. Rpt. 61. 1887.

Livlandscher bierpflaume $\mathrm{I}$.

A Russian variety imported by the Iowa Agricultural College in 1882 .

Lizzie. Americana. I. Meneray Cat.

A seedling of Harrison, grown by H. A. Terry; introduced by F. W. Meneray of Council Bluffs, Iowa. Tree vigorous, spreading; fruit large, pale yellow, with a red blush; flesh yellow, rich, no acidity; good; semi-clinging.

Lockey. Americana. I. Kerr Cat. 1894.

Tree dwarfish, lacks in adaptability, blights badly, short-lived; fruit of medium size, greenish-yellow overlaid with red; good; clingstone.

Lone Star. Angustifolia varians. I. Am. Pom. Soc. Rpt. 154. 1883 .2. Cornell Sta. Bul. 38:63, 86, 1892. 3. Waugh Plum Cult. 106. 1901.

Grown by E. W. Kilpatrick, Texas, from wild seed produced in eastern Texas. Fruit of medium size, oval; cavity broad, shallow; stem slender; suture lacking; red; bloom thin; dots numerous, white; skin thin; flesh soft, yellow, sweet; good; stone oval, clinging; early. Mentioned in the American Pomological Society catalog in 1897.

Long Blue. Domestica. I. Ia. Hort. Soc. Rpt. 86. 189o. 2. Mich. Sta. Bul. I18:54. 1895. 3. Wis. Sta. An. Rpt. 13:214. 1896. 4. Kan. Sta. Bul. 101:121. 1901. Orel No.20 2, 3. Orel No.2O I.

One of the Russian varieties imported by J. L. Budd about 1882. Tree hardy, vigorous, unproductive; fruit medium to large, oblong-oval; purplish-red with light bloom; dots numerous, small; flesh yellow, juicy, subacid, pleasant; quality fair; stone rough and strongly margined, semi-clinging.

Long Leaf Wonderful. Domestica. 1. N. Y. Sta. An. Rpt. 12:611. 1893.

Long Leaf Wonderful was sent out in 1893 by Luther Burbank; no description is available and the variety is probably extinct.

Long Red. Domestica. 1. Ia. Hort. Soc. Rpt. 86. 189o. 2. Can. Exp. Farms Rpt. 401. 1898. 3. Kan. Sta. Bul. 101:119, 122 fig. 1901.

Orel No. 19 2, 3. Orel 19 1.

Introduced from Russia by J. L. Budd of Iowa about $188_{2}$. Tree hardy, vigorous; fruit medium to large, roundish-oblong, purplish-red; flesh greenish-yellow, juicy, sweet, pleasant; excellent for culinary use; stone semi-clinging.

Long Scarlet. Domestica. I. Mag. Hort. I:365. 1835. 2. Downing Fr. Trees Am. 303. 1845. 3. Am. Pom. Soc. Cat. 36. 1875.

Red Gage (incorrectly of some) 2. Scarlet Gage 2, 3. Scarlet Gage 1, 2.

Downing states that the original tree was first noted in the vicinity of Newburgh about 1823 and that the variety was disseminated by him. Tree very hardy, an abundant bearer; shoots downy; fruit medium, oblong-obovate; cavity narrow, very shallow; stem three-fourths of an inch long; bright red or purplish-crimson on the sunny side, 
pale yellowish-red on the shaded side; flesh deep yellow, juicy, becoming rich and sweet if allowed to hang; clingstone; mid-season. Listed in the catalog of the American Pomological Society in 1875 , but dropped in 1897 .

Long Violet Damascene. Domestica. 1. Oberdieck Deut. Obst. Sort. 444. I88I.

Unproductive on dry soil as tested in Jeinsen, Germany.

Longworth. Domestica. I. U.S. D. A. Rpt. 392, 1891. 2. Am. Pom. Soc. Rpt. 74. 1895.

Said to have originated many years ago with Nicholas Longworth, Cincinnati, Ohio. Resembles Lombard and is better in quality. Fruit of medium size, roundishoval, purplish-red; flesh yellow, sweet, pleasant; mid-season to late.

Lot d'Ente. Domestica. I. Wickson Cal. Fruits $35^{6}$ fig. I891. D'Ente r.

This variety is of the same type if not the same as the Agen.

Lottie. Americana mollis. I. Terry Cat. igoo. 2. Can. Exp. Farms Rpt. I20. 1904. 3. Ill. Hort. Soc. Rpt. 424. I905. Lotta 3.

Originated with H. A. Terry, Crescent, Iowa, from seed of Van Buren. Fruit large, white or pale yellow; good; freestone.

Louisa. Americana. 1. Downing Fr. Trees Am. 930. 1869. 2. Am. Pom. Soc. Cat. 37. I899. 3. Waugh Plum Cult. 156. 1901.

Found growing wild in Missouri about I860; introduced by Samuel Miller, Bluffton, Missouri. Fruit of medium size, roundish; suture a line; cavity small; stem short; dull red; bloom thick; dots numerous; flesh firm, yellow; quality fair; stone large, flat, clinging; mid-season.

Louise-Brune. Insititia? 1. Mas Pom. Gen. 2:71. 1873. 2. Mathieu Nom. Pom. 439. I 889 .

Louise Brune 2. Louisen's Braune Damascene 2.

Raised by M. de Maraise, a Belgian pomologist. Tree vigorous, productive; fruit round-oval; suture narrow and very shallow; skin purple; bloom thick; flesh yellowish-green, firm, rather sweet; good; stone oval, thick, free; type of the Damsons.

Louisiana. Triflora $X$ ? I. Cornell Sta. Bul. 139:43. 1897. 2. Waugh Plum Cult. 2I7. 1901. Normand No.15 I.

One of the several seedlings sent out by J. L. Normand, Marksville, Louisiana, who states that it is the offspring of a Triflora variety crossed with a native; named by Bailey in 1897 . Tree spreading, weak and slender in habit; fruit of medium size, heart-shaped; suture faint; cavity shallow; greenish with dull blush; dots many, whitish; flesh yellow, fibrous, sprightly subacid; quality fair; clingstone; fruit drops before ripe

Lovett. Domestica. I. Gard. Mon, 29:47. I887.

A seedling of Reine Claude from York County, Pennsylvania, about r867. Tree very vigorous and productive; fruit very large, roundish; suture slight; cavity shallow; dark red; dots minute, yellow; flesh yellow, firm, sweet; semi-clinging; very early.

Lovett. Triflora. I. Lovett Cat. I898. Fourth of July I.

A chance seedling from the Lovett homestead in Pennsylvania; introduced in I 898 by J T. Lovett, Little Silver, New Jersey. Fruit of medium size, roundish; suture 
indistinct; bright red; bloom light; flesh yellow, firm, rich, sweet, vinous, highly aromatic; good; freestone; very early.

Lovett Late. Domestica. I. Cole Am. Fr. Book 218 . 1849.

Lovett's Late Long Red I.

An excellent long-keeping variety mentioned by Cole in 1849 .

Lowry. Domestica. I. Smith Cat. 1899. Lowry's Gage r.

A chance seedling found growing in a fence corner at St. Davids, Ontario; introduced by E. D. Smith in I899. Fruit of medium size, yellow; good; early.

Lucas Konigspflaume. Domestica. r. Oberdieck Deut. Obst. Sort. 421. I88I. 2. Mathieu Nom. Pom. 439. I889. Royale de Lucas 2.

A table and market variety in Germany. Tree vigorous, productive in moist soils; fruit large, oval; suture shallow, divided unequally; skin somewhat sourish, easily removed, bluish-red to dark blue on the sunny side; dots fine, yellowish, numerous; flesh soft, golden-yellow, sweet, highly flavored; stone not always free; ripens before the Reine Claude.

Luedloff. Americana. I. Wis. Sta. Bul. 63:46. 1897. 2. Ibid. 87:14. 1901.

Luedloff's Seedling I, 2.

From Charles Luedloff, Cologne, Minnesota. Fruit medium in size, oblong; suture distinct; yellow overspread with bright red; dots small, numerous; quality hardly fair; stone oval, sharply pointed, nearly free.

Luedloff Green. Americana. 1. Cornell Sta. Bul. 38:40. 1892, 2. Wis. Sta. Bul. 63:46. 1897. Luedloff's Green I, 2.

From Charles Luedloff, Cologne, Minnesota, about 1889 ; discarded by him later. Tree regular and abundant in bearing; fruit medium to small, oblong, flattened; skin thick, mottled with deep red; flesh firm, sweet; fair quality; stone small, nearly free; medium late. Luedloff Red. Americana. 1. Cornell Sta. Bul. 38:40. 1892, 2. Wis. Sta. Bul. 63: 46. 1897. Leudloff's Red 1, 2.

Much like Luedloff Green but red in color. Tree moderately productive; fruit very good; medium season. Good for culinary purposes.

Lunn. Domestica. I. Can. Exp. Farm Bul. 43:35. 1903. 2. Quebec Pom. Soc. Rpt. 9. 1905. Montreal No. 60 I.

From W. W. Dunlop, Outremont, Quebec. Fruit large, oval; cavity shallow; suture a distinct line; dark purple; dots indistinct, brownish; skin tough; flesh ycllowish-green, firm, juicy, sweet, rich; very good; clingstone; mid-season.

Luscombe. Domestica. Mentioned in Lond. Hort. Soc. Cat. 149. 1831.

Luscombe's Seedling.

Lutts. Triflora. 1. Cornell Sta. Bul. 175:131 fig., 132. 1899. 2. Mass. Hort. Soc. Rpt. 1:106. 1900. 3. Ga. Sta. Bul. 68:5 fig., 31. 1904.

Wasse-Botankio I, 2, 3 .

Sent out under the name Wasse-Botankio but renamed in 1899 by Bailey after Henry Lutts of Youngstown, New York. Tree vigorous, productive; fruit small, roundish, dark red with numerous fine, golden, dots; bloom heavy; flesh yellow, soft, with a slight almond flavor; good; clingstone; one of the earliest. 
Lyon. Domestica. I. Mich. Sta. Bul. 104:100. 1894. 2. Mich. Hort. Soc. Rpt. 367. 1896. 3. Mich. Sta. Bul. 169:246. 1899.

Bailey 1. Bailey 2, 3 .

Brought to notice by S. S. Bailey of Grand Rapids, Michigan, and grown for a number of years by the Michigan sub-station at South Haven under the name Bailey; renamed Lyon by the Michigan Horticultural Society in 1896 . Tree vigorous, upright, spreading, productive; fruit large, roundish; suture slight; cavity shallow; clear yellow with light bloom; flesh yellow, tender, rich, sweet, moderately juicy; good; scmi-clinging; mid-season.

Lyon Apricot. Domestica. I. Can. Exp. Farm Bul. 2d Ser. 3:53. 1901.

Received by the British Columbia Experiment Station at Agassiz from a Mr. Spaath of Berlin, Germany. Fruit above medium in size; roundish; suture shallow; bright red; bloom thin; flesh yellow, firm, juicy, sprightly; good; stone slender, free; early M. J. De Wolf. Species? I. S. Dak. Sta. Bul. 93:25, 52 fig. I 905.

The most promising from a lot of seedlings grown by M. J. De Wolf, Letcher, South Dakota, from seed taken from the orchard of H. J. Gurney, Elk Point, South Dakota. Fruit large, roundish; cavity wide, shallow; suture a line; red marbled on the shady side with yellow; dots many, large, conspicuous; flesh dark yellow, tender, sweet, juicy; good; freestone; mid-season.

Macedonia. Munsoniana. I. Kerr Cat. 19. 1897. 2. Waugh Plum Cult. 186. 1901. Transparent 2.

Fruit of medium size, roundish-oval; suture faint; cavity shallow; light red; bloom thin; flesh yellow; quality fair; clingstone; mid-season.

Mackland. Americana. r. Kerr Cat. 1899.

Tree vigorous; fruit above medium size, red over yellow; clingstone; rots badly. Macomber. Domestica. Listed in Am. Pom. Soc. Cat. 39. I899.

Macomber No. I and No. 2. Americana. Letter from Kerr.

Two inferior seedlings from a Mr. Macomber of Vermont.

Madame Henri Deschars. Insititia? 1. Mathieu Nom. Pom. 439. 1889.

Mirabelle Tardive Mme. H. Deschars 1.

Mathieu's notice refers to Journal de la Societe Nationale et Centrale d'Horticulture de France 608. 1878 .

Madame Nicolle. Domestica. 1. Mathieu Nom. Pom. 439. I889. 2. Can. Exp. Farm Bul. 2 d Ser. 3:53. 1900. Sonvenir de Madame Nicolle 1.

A European variety tested on the grounds of the British Columbia Experimental Station; inferior.

Madam Leeds. Species? I. Fa. Sta. Bul. 46:279. 1900.

A seedling unintroduced and of unknown parentage grown by George Temple, presumably of Iowa. Tree resembles Poole Pride, productive; fruit the size of Wild Goose, bright red; drops easily; late.

Madeleine. Domestica? I. Mathieu Nom. Pom. 439. 1889. 2. Guide Prat. 156, 359. 1895.

Tree vigorous, moderately productive; fruit large, oval; yellow with reddish spots; good; early. 
Madison. Domestica. I. Cultivator 6:355. 1849. 2. Horticulturist 4:214. 1849 . 3. Thomas Am. Fruit Cult. 355. 1867 .

A chance seedling from the garden of Isaac Denniston, Albany, New York; first fruiting in 1847 and supposed to be a cross between Bleeker and Blue Gage. Tree vigorous, productive; fruit of medium size, oval; suture shallow; cavity small; yellow with reddish blush; bloom thin; flesh yellow, firm, juicy, rich, sweet, pleasant; good; freestone; very late.

Mainzer Fruhzwetsche. Species? Mentioned in Mathieu Nom. Pom. 439. 1889.

Majestic Damson. Insititia. I. Stone \& Wellington Cat. 1907.

Introduced by Stone and Wellington of Toronto, Ontario. Fruit large, purple; bloom heavy; freestone; early.

Mallard. Domestica. 1. Mich. Hort. Soc. Rpt. 289. 1889. 2. Cornell Sta. Bul. 131: 189. 1897. 3. Rivers Cat. 34. 1898.

A seedling from Thomas Rivers, Sawbridgeworth, England. Tree of moderate vigor and hardiness; fruit large, oval; suture distinct; deep purple; flesh yellow, rich, juicy; good; freestone; early; said to rot but little; not hardy.

Mamelonnée. Domestica. 1. Gen. Farmer 10:241. 1849. 2. Hogg Fruit Man. 371. 1866. 3. Guide Prat. $157,359.1895$.

Die Brustwarzenpflaume 3. Mamelon 3. Mamelon Sageret 2.

Raised by M. Sagaret of Paris, France. Tree of medium size; fruit roundish-oval, strongly necked, yellowish-green, mottled with red; light bloom; flesh yellowish, firm, juicy, sweet; similar to Reine Claude except in shape.

Manitoba. Americana. I, Kerr Cat. 1894.

Fruit of medium size, roundish-oval, clear red; freestone.

Manitoba No. I. Americana. I. Kerr Cat. 1897. 2. S. Dak. Sta. Bul. 93:22. 1905.

A wild variety from Manitoba, Canada. Fruit of medium size, bright red; skin thick and bitter; very early.

Manitoba Seedlings. Americana. I. Kerr Cat. 1897-1900. 2. S. Dak. Sta. Bul. 93 : 22. 1905 .

Several seedlings bearing the numbers 2, 4, 5, 6 and 7 were grown by N. E. Hansen of the South Dakota Station from seed obtained in Manitoba. Early bearing and productivity are their chief desirable characters.

Mankato. Americana. I. Minn. Hort. Soc. Rpt. 332, 481. 1896. 2. Waugh Plum Cult. 157. 1901. 3. Minn. Hort. Soc. Rpt. 228.1903.

German Prune Seedling 3.

Originated on the farm of Louis J. Eider, four miles north of Mankato in Nicollet County, Minnesota; introduced by S. D. Richardson and Son of Winnebago City, Minnesota, in 1890 . Tree vigorous, fairly productive; fruit above medium size, oval; cavity shallow; suture faint; skin free from the pulp; dull red; dots yellow; flesh yellow, sometimes red next the stone, sweet, rich; good; semi-clinging; late.

Manning. Domestica. I. Manning Book of Fruits 103. 1838. 2. Thomas Am. Fruit Cult. 335. 1849. 3. Downing Fr. Trees Am. 930. 1869. 
Large Long Blue 1. Large Long Blue 2, 3. Manning's Long Blue 2, 3. Manning's Long Blue 3. Mannings Long Blue Prune 3. Manning's Long Blue Prune 2. Manning's Prune 3.

Received by Robert Manning from Landreth's Nursery, Philadelphia, Pennsylvania, without a name; probably a seedling of the German Prune. Tree vigorous; fruit large, long-oval; suture obscure; cavity small; dark purple; bloom thick; flesh greenish-ycllow, firm, juicy, sweet, sprightly, pleasant; good; stone long, pointed, frec; mid-season; ripening period long.

Marais des Cygne. Americana. I. Kerr Cat. 5. 1900.

Introduced by J. W. Kerr in 1900 . Tree vigorous and productive; fruit of medium size, roundish, purplish-red; good; clingstone; subject to rot; mid-season.

Marange. Species? 1. Mathieu Nom. Pom. 440. 1889. 2. Guide Prat. 156, 359. 1895.

Petit-Monsieur? I, 2.

Tree small, very productive; fruit small, round, reddish-violet; skin unusually free; flesh yellow; very good for its season; very early.

Marble. Hortulana mineri $\times$ Hortulana. r. Vt. Sta. An. Rpt. 12:225. I899. 2. Waugh Plum Cult. 217. 1901. Fourth of July 1 .

Grown by A. L. Bruce of Texas, who states that it is a cross between Weaver and Crimson Beauty, but Waugh considers Mr. Bruce's Weaver to be Miner. Fruit small, heart-shaped; cavity medium deep; suture shallow; dark wine-red; skin tough; flesh yellow, sweet, rich; good; stone small, clinging.

Marble. Species? ז. Minn. Hort. Soc. Rpt. 412. 1899.

Originated in Brown County, Minnesota; tree vigorous and productive; fruit small, round, mottled red; good; mid-season; subject to rot.

Marbled-Plum. Domestica. 1. Rea Flora 207. 1676. 2. Ray Hist. Plant. 1529. 1688.

Marble Plum 2,

Fruit mottled yellow and red at full maturity becoming a uniform red; flesh firm; good.

Marcellus. Americana mollis. 1. Kerr Cat. 9. 1898. 2. S. Dak. Sta. Bul. 93:24, 50, $5^{1}$ fig. 1905. 3. Ohio Sta. Bul. $162: 256,257.1905$.

Grown by H. A. Terry of Crescent, Iowa from seed of Van Buren; first fruited in 1893. Tree vigorous, upright-spreading; fruit of medium size, roundish; cavity small; suture lacking; light red; bloom light; flesh yellow; quality fair; clingstone; midseason.

Marcus. Americana. I. Ia. Hort. Soc. Rpt. 333. 1894. 2. Wis. Sta. Bul. 63:47. 1897. 3. S. Dak. Sta. Bul. 93:24, 50 fig. 1905.

Originated with M. E. Hinckley, Marcus, Iowa, from seed gathered from a grove of wild plums on the Little Sioux River in 1870 . Tree vigorous, upright; fruit large, round, dark red, resembling Miner; flesh firm, meaty; good; early.

Mardy. Domestica. r. Ohio Hort. Soc. Rpt. 9. I 890.

A scedling from West Virginia grown by a Mr. Mardy. Fruit large, oval, red.

Margate. Domestica. I. Parkinson Par. Ter. 578 . 1629.

Parkinson says of it "the worst of a hundred." 
Marietta. Triflora X ? I. Ga. Sta. Bul. $67: 264$ fig. 1904. 2. Ibid. $68: 7$ fig., 36. 1905.

A chance seedling found growing on the grounds of the Kennesau Wholesale Nursery Company, in $\mathbf{1 9 0 0}$, at the edge of a block of Triflora varieties. Tree very vigorous, productive; fruit of medium size, broadly conical, yellow overlaid with red; dots yellow; skin slightly waxy; flesh soft, juicy, pleasant; quality fair; clingstone; free from rot.

Marjorie. Americana. 1. Terry Cat. I900.

A seedling of Lottie grown by H. A. Terry, Crescent, Iowa. Fruit large, round, light yellow partly overspread with red; dots small; flesh yellow, rich, sweet; semiclinging.

Marigan. Domestica. I. Quebec Pom. Soc. Rpt. 9. 1905.

Tree productive. Fruit large, round, greenish-yellow with a blush; good.

Marion. Americana. 1. Kerr Cat. 1897. 2. Colo. Sta. Bul. 50:40. 1898. 3. Waugh Plum Cult. I57. I901.

Tree productive; fruit of medium size, roundish, flattened at the apex; suture a line; cavity shallow; stem long, slender; red on a yellow ground; bloom thin; skin thick; flesh sweet, juicy; good; clingstone; mid-season.

Marketman. Triflora. r. Burbank Cat. 1893. 2. Waugh Plum Cult. 138. Igor.

Shipper $\mathbf{1}, 2$.

A seedling of Satsuma grown by Luther Burbank and sold under the name Shipper but changed by Waugh to prevent confusion with an older Shipper. Tree moderate in growth, sturdy and upright; fruit oval, light red; bloom light; flesh firm, sweet, juicy; fruit keeps and ships well.

Marmorierte Eierpflaume. Domestica. Listed in Mathieu Nom. Pom. 440. I889. Prune d'Oeuf Marbrée.

Marster. Domestica? I. Am. Pom. Soc. Rpt. 96. 1887. 2. Brown Bros. Cat. 1900. Marster's 2.

Supposed to have originated in South Carolina about 1883 ; reported four years later by J. R. Hart from Nova Scotia; introduced by Brown Brothers of Ontario. Tree hardy, productive; fruit of medium size, oval, dark purple; flesh fine-grained, rich; good; mid-season.

Marten. Domestica. I. Horticulturist $6: 133$. I851. 2. Cultivator $6: 268$. $185^{8}$.

3. Downing Fr. Trees Am. 931. 1869.

Marten's Seedling 3. Marten's Seedling I, 2.

A chance seedling found growing in the garden of a Mr. Marten, Schenectady, New York, by Professor Jackson of Union College. Tree very vigorous, productive; fruit large, roundish-oblong; suture deep; cavity small; yellow, streaked with green and dotted with red in the sun; flesh yellow, slightly coarse, juicy, sprightly; very good; freestone; mid-season.

Mary. Domestica. I. Gard. \& For. 7 :19. I894. 2. Storrs \& Harrison Cat. I898.

A supposed cross between Duane and Yellow Gage grown by R. A. Hunt, Euclid, Ohio, about 1882 ; introduced by Storrs \& Harrison in 1898 . Tree very productive; fruit of medium size, yellow; bloom delicate; flesh yellow; good; mid-season. 
Mary. Americana mollis. I. Kerr Cat. I900. 2. Terry Cat. I900.

Grown from seed of Van Buren in 1893 by H. A. Terry, Crescent, Iowa. Tree productive, spreading; fruit light red on a yellow ground; good; mid-scason.

Maryland. Angustifolia watsoni $\times$ (Prumus besseyi $\times$ Angustifolia watsoni). I. Kerr

Cat. 1894. 2. Colo. Sta. Bul. 50:41. 1898. 3. Vt. Sta. Bul. 67:17. 1898.

Grown by J. W. Kerr from seed of Utah Hybrid; introduced by the originator in I894. Tree larger than the parent; fruit small, round; suture lacking; dark brownishred; flesh soft, watery, sweet, pleasant; quality fair; clingstone.

Mas. Domestica? I. Mathieu Nom. Pom. 440. 1889. 2. Guide Prat. 163, 359. 1895. Similar to De Montfort.

Mason. Angustifolia varians. 1. Kerr Cat. 1897. 2. Can. Exp. Farms Rpt. 464. 1900. 3. Waugh Plum Cult. 196. I901.

Originated near Leander, Williamson County, Texas, with a Mr. Mason; introduced about 1896 by F. T. Ramsey. Tree vigorous; fruit of medium size, heartshaped, red; flesh firm; good; clingstone; very early.

Matchless. Domestica. I. Rea Flora 208. 1676. 2. Langley Pomona 93, 97, P1. 24 fig. I. I729. White Matchless 2.

Fruit yellow; bloom white; excellent flavor; very productive.

Mathews. Hortulana. I. Stark Bros. Cat. I902. 2. Ill. Hort. Soc. Rpt. 211 . 1906. 3. Ia. Sta. Bul. I14:139. I gro. Matthews 2.

Grown by B. A. Mathews of Knoxville, Iowa, as a sport from Peach Leaf; introduced by Stark Brothers, Missouri. Tree hardy; fruit small, ruby-red; recommended for jellies and preserves.

Mauchete. Domestica. r. Prince Pom. Man. 2:93. 1832. Mouchetée I.

A French variety of the Reine Claude type. Fruit small, oval; suture a line; cavity minute; greenish; bloom heavy; flesh green, firm, sweet; freestone; midseason.

Maude Lacy. Americana. x. Terry Cat. I900.

A seedling of Hawkeye grown by H. A. Terry, Crescent, Iowa; fruit large; bright yellow with a red cheek; flesh firm; semi-clinging.

Maugeron. Domestica. 1. Duhamel Trait. Arb. Fr. 2:76. 1768, 2. Knoop Fructologie 2:52, 57. 1771. 3. Kraft Pom. Aust. 2:42, Tab. I95 fig. 2. 1796. 4. Poiteau Pom. Franc. r. 1846. 5. Prince Pom. Man. $2: 8$ r. 1832. 6. Downing Fr. Trees Am. 931. 1869. 7. Hogg Fruit Man. 694. 1884. 8. Mathieu Nom. Pom. 426. 1889 .

Damascene Maugeron 6, 8. Damascene von Mangeron 8. Damascene von Maugeron 8. Damas de Mangeron 6, 8. Damas de Mangeron 7. Damas de Maugeron 3, 5, 8 . Damas de Maugerou I, 4. Damas de Maugerou 8. Damas de Mangiron 8. Damas Violet 2. Die Damascenerpflaume von Maugeron 3. Königs Pflaume von Mangerou 8. Mangeron 6, 7, 8. Mangeron 4, 8. Maugeron Damask 5. Maugeron Damask 6, 8. Maugiron 2.

An old variety, probably of French origin. Tree vigorous; fruit large, roundishoblate; stem slender; cavity shallow; suture a line; purplish; bloom thick; flesh 
grecnish-yellow, firm, sweet and agreeable; freestone; Septcmber. Prince states that there are two varicties under this name, differing in size, but no other writer mentions the two.

Mayerboeck Zwetsche. Species? Mentioned in Mathieu Nom. Pom. 440. I889.

Mayerboeck's Rote Zwetsche.

Mayer Hellrote. Species? I. Mathieu Nom. Pom. 440. I889. 2. Guide Prat. 163, 359. 1895. Mayer's Hellrothe Damascene.

"A variety of little merit."

Mayer Konigspflaume. Species? Mentioned in Mathieu Nom. Pom. 440. 1889.

Royale? Die Königin? Royale de Mayer.

Mayers Rothe Damascene. Domestica. 1. Mas Pom. Gen. 2:87. 1873. 2. Guide Prat. I63, 359. 1895 .

Damas Rouge de Mayer 1. Damas Ronge de Mayer 2. Damas Rouge de Moyer I. Mayers Braunrothe Königsplaume 2. Mayers Rothe Damascene 1.

A seedling of Red Magnum Bonum raised by Liegel and dedicated to his colleague

A. J Mayer. Tree of normal vigor; fruit large, thick-ellipsoid, slightly truncated; suture wide, shallow; stem medium in length and size; cavity shallow; skin tender, not adherent; purple; flesh yellowish, fine, melting, juicy, sweet and aromatic; clingstone; mid-season.

McCartney. Angustifolia varians. 1. Munson Cat. 1898. 2. Waugh Plum Cult. 197. 1901.

Brought to notice by F. T. Ramsey, Austin, Texas; fruit of medium size, roundish; suture visible; dots whitish; golden-yellow; flesh sweet, melting; very good; clingstone.

McGillivray. Species ? I. Can. Exp. Farms Rpt. 424. 1897.

Tree vigorous, unproductive; fruit small, oval, light red; flesh yellow, juicy, slightly astringent; clingstone; early.

McPherson. Species? I. Tex. Sta. Bul. 32:479. 1899.

Tree low, bushy, thorny, hardy; fruit small, round, golden-yellow; flesh yellow; quality fair; elingstone.

McRea. Triflora. I. Glen St. Mary Cat. 21. I91 .

McRea was grown near Lake City, Columbia County, Florida, from seed of Kelsey; introduced in the fall of 19 ro by the Glen Saint Mary Nursery Company. Fruit of medium size, roundish; yellow, washed with dull red in the sun; dots numerous; bloom thin; flesh yellow, firm, juicy, subacid; good; mid-season.

Meads. Triflora. 1. Rural N. Y. 64:711. 1905. Meads Seedling Plum I.

A seedling grown by H. O. Mead, Lunenburg, Massachusetts. Fruit large, light reddish-purple; flesh yellow, firm, juicy; good; stone semi-clinging; mid-season.

Mediterranean. Domestica. I. Horticulturist $6: 133$. 185r. 2. Downing Fr. Trees Am. 93 1. 1869 .

Originated in central New York. Tree vigorous, hardy, productive; fruit medium in size, ovate, necked; cavity small; light crimson; flesh yellow, sweet, sprightly; good; freestone; mid-season.

Meigs. Domestica. I. Thomas Am. Frr, 'थ/t. 342. 1867. 
Fruit large, roundish-oval; suture indistinct; dull reddish-purple, with numerous gray dots; stalk long, slender, curved; cavity small; flesh greenish-yellow, rich, excellent; clingstone; late.

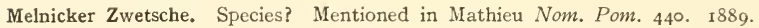

Melon. Americana. I. Kerr Cat. I898. 2. Ia. Sta. Bul. 46:280. 1900. 3. Wis. Sta. Bul. $87: 14$ 1901.

From Iowa. Fruit medium in size, roundish; cavity lacking; suture slight; yellowish-red; bloom thin; flesh fibrous; quality fair; freestone; mid-season.

Meneray. Species? I. Meneray Cat.

A seedling of unknown parentage from H. A. Terry, Crescent, Iowa; introduced by F. W. Meneray of Council Bluffs, Iowa. Fruit and foliage indicate a fusion of Americana and Triflora blood. Fruit large, oblong, pear-shaped, yellow tinged with red; good. Mereton. Species? I. Can. Exp. Farm Bul. 2d Ser. 3:54. 1900. 2. Can. Exp. Farms Rpt. 432. 1905. Mereton's Egg. 1. Merton's Egg 2.

Fruit small, oval; cavity small; yellow; flesh yellowish; poor; of no value.

Meroldt. Domestica. I. Oberdieck Deut. Obst. Sort. 436. 1881, 2. Lauche Deut. Pom. Pl. IV, 13. 1882, 3. Hogg Fruit Man. 712. 1884. 4. Mathieu Nom. Pom. 440. 1889 .

Meroldt's Gelbe Reine-Claude 4. Meroldt's Golden Gage 3. Meroldt's Golden Gage 4. Meroldt's Reineclaude 1, 2, 4. Reine-Claude de Meroldt 4.

This variety was grown by Dr. Meroldt, Lischnitz, Bohemia, probably from the seed of the Apricot plum. Tree grows quickly, medium in size; fruit medium, roundish; suture shallow; skin adherent; yellow, sometimes with reddish spots; cavity shallow; stem extremely short, finely hairy; flesh yellow, firm, juicy, sweet, with Reine Claude flavor; freestone; mid-season.

Merryweather. Insititia. I. Garden 74:527, Col. Pl. 1910.

This plum originated with H. Merryweather and Sons of Southwell, Notts, England, and received an award of merit in 1907 from the Royal Horticultural Society. Tree vigorous, productive; fruit large, juicy, purple; Damson-like flavor; good; excellent for preserving.

Merunka. Domestica. 1. Lond. Hort. Soc. Cat. 152. I831. 2. Am. Pom. Soc. Rpt. 61. 1887. 3. Ia. Hort. Soc. Rpt. 86. 1890. 4. U. S. D. A. Pom. Rpt. 46. 1895. 5. Ia. Sta. Bul. $46: 279,280.1900$.

Leipsic 2, 5. Leipzig 3. Leipzig Early Quetsche ז. Marunka 4. Quetsche de Leipzig 2. $I_{13}$ Riga 3. Zwetsche Leipziger 2.

In $1884 \mathrm{~J}$. L. Budd of the Iowa Experiment Station introduced several plums from Russia. Among these the Merunka and Leipsic proved to be identical. The name Merunka is retained because Leipsic has been used as a synonym of German Prune. Fruit of Lombard type, medium in size, oval; cavity deep, narrow; suture faint; apex depressed; purplish-red; bloom thin; skin thin; flesh yellow, tender, sweet; good; clingstone; mid-season.

Merville d'Automne. Domestica? I. Mathieu Nom. Pom. 440. 1889. 2. Guide Prat. 162, 359. 1895 .

A large yellow variety of good quality ripening about mid-season. 
Meyer. Americana. x. Kerr Cat. 1894-1900.

Tree vigorous and productive; fruit large, round; cavity small; purplish-red over yellow; clingstone; mid-season.

Miama. Domestica. x. Kerr Cat. 1894. 2. Ohio Sta. Bul. 162:256, 257. 1905.

Miami 1.

Miama as tested at the Ohio Experiment Station proved to be identical with Lombard. J. W. Kerr of Denton, Maryland, who introduced the varicty in 1894 writes: "When I first received cions from the West, I thought it was a native; but finding it to be a Domestica, dropped it at once."

Mignonne. Domestica. 1. Lond. Hort. Soc. Cat. 149. I831.

Reported by the London Horticultural Society as growing on their grounds.

Miles. Species? 1. Cornell Sta. Bul. 38:79. 1892, 2. Ill. Hort. Soc. Rpt. 135. 1903. 3. Ibid. 424. 1905.

Said to have originated in Illinois from seed secured in North Carolina. Tree productive; fruit small, light red; quality fair; clingstone.

Miller. Americana. 1. Kerr Cat. 1894.

Tree vigorous and productive; fruit large, round, red on an orange ground; clingstone; mid-season.

Miller. Domestica. 1. Ohio Sta. Bul. $162: 241,256,257.1905$.

Fruit very large, roundish, sides unequal; cavity narrow, deep; stem short, stout; suture distinct; dark purple on a dark green ground; dots numerous, bronze; bloom heavy; flesh greenish-yellow, rich, sweet; good; clingstone; mid-season.

Miller. Species? x. Glen St. Mary Nur. Cat. 1907.

Introduced by the Glen St. Mary Nursery Company of Florida in 1907. Fruit of medium size, greenish-yellow; very good.

Miller No. I. Domestica.

Miller No. I is an unintroduced seedling of German Prune supposedly crossed with Jefferson; grown by D. J. Miller of Millersburg, Ohio. Fruit of medium size, long-oval tapering to both ends; suture a line; cavity shallow; deep yellow; bloom thin; dots conspicuous; flesh yellow, tender, sweet, good; stone large, long-oval, scmi-clinging, pointed; mid-season; resembles the German Prune in shape and size.

Miller No. 5. Munsoniana. Letter from Kerr.

Grown by David Miller, Camp Hill, Pennsylvania. Tree productive; fruit of medium size, red; clingstone.

Millett. Americana. x. S. Dak. Sta. Bul. 93:25. 1905. Millett's Wild Plum 1.

From South Dakota. Tree vigorous, productive; fruit small.

Millett Early Red. Americana. I. S. Dak. Sta. Bul. 93:25. 1905.

Millett's Early Red I.

A variety found growing wild near Pierre, South Dakota. Trees low and bushy, hardy, unproductive; fruit small, red on a yellow ground; skin thick; flesh firm, sweet; quality fair; stone large; early.

Millett T. T. Americana. I. S. Dak. Sta. Bul. 93:25. 1905.

From South Dakota; fruit very small. 
Millett Very Early Red. Americana. I. S. Dak. Sta. Bul. 93:25. 1905.

Millett's Very Early Red r.

Not as early as Millett Early Red.

Mills. Domestica. I. Waugh Plum Cult. i 16. I901.

Fruit medium in size, oval; cavity shallow; suture faint; purplish-red; dots prominent, white; flesh greenish; quality fair; freestone; late.

Mills Seedling. Nigra? 1. Can. Exp. Farm Bul. 43:39. 1903.

Fruit roundish heart-shaped, below medium in size; cavity narrow, moderately deep; suture a line; deep red; dots obscure; bloom light; skin moderately thick, tender; flesh deep yellow, juicy, slightly sweet, astringent; poor; stone of medium size, oval, flattened, nearly free.

Milton Gage. Domestica. I. Mag. Hort. 6:94. I 840.

Reported by C. M. Hovey as fruiting in the nursery of Charles Downing, Newburgh, New York, seventy years ago.

Minco. Hortulana mineri $\times$ Hortulana. I. Vt.Sta. An. Rpt. 14:272. I901. 2. Munson Cat. 1902 .

A cross between Miner and Wayland from T. V. Munson in 1896 . Tree vigorous and productive; fruit of medium size, roundish-oval; cavity lacking; suture a line; bright, dark red faintly striped; dots many, distinct; bloom light; flesh yellow, firm, rich, sweet, meaty; very good; freestone; late.

Minion. Domestica. I. Quintinye Com. Gard. 69. 1699.

Mentioned by Quintinye as a "yellowish-white" plum.

Minnesota. Domestica. I. Ia. Sta. Bul. 31:348. 1895. 2. Budd-Hansen Am. Hort. Man. 2:319. 1903.

A European variety introduced into Minnesota from Denmark. Tree vigorous, very hardy; fruit large, ovate; suture distinct; cavity deep, narrow; dark blue; flesh yellow, juicy, subacid; very good; stone small, free.

Minnesota Seedling. Americana. Letter from J. W. Kerr.

An inferior variety from a Mr. Macomber of Vermont.

Minnetonka Americana. 1. Cornell Sta. Bul. 38:40. 1892. 2. Kerr Cat. 1897. 3. Colo. Sta. Bul. 5o:41, I898.

Introduced by Peter Gideon of Minnesota. Tree small, slow-growing, bushy top; fruit small, oval, red on a yellow ground; skin thick; flesh firm, acid; clingstone; midseason.

Minnie. Domestica. 1. Ia. Sta. Bul. 46:280. 1900.

From H. Knudson, Springfield, Minnesota, who raised it from the seed of a large blue Domestica plum. Tree vigorous, upright; fruit medium in size, necked, greenishyellow; good; late.

Minnie. Triflora $\times$ Munsoniana. I. Vt. Sta. Bul. 67:17. 1898. 2. Waugh Plum Cult. $219.190 \mathrm{r}$.

Originated in North Carolina with J. S. Breece, who considers it an offspring of Abundance pollinated with Wild Goose. The foliage resembles that of Abundance. 
Mirabelle De Bohn. Insititia. 1. Mas Pom. Gen.2:177. 1873. 2. Lucas Vollst. Hand. Obst. 472. 1894. 3. Mathicu Nom. Pom. 423. 1889.

Bohns Gestreifte Mirabelle 1, 3. Bohns Mirabelle 2, 3. Bohns Mirabelle 1. Mirabelle de Bohn 3. Mirabelle Rayee 3.

Liegel received this variety from Henry de Bohn of Upper Austria. Tree of medium vigor, productive; fruit small, roundish; suture a line; skin tender, yellow, marbled with red; stem slender; flesh yellow, tender, melting, juicy, sweet, aromatic; freestone; mid-season.

Mirabelle de Flotow. Insititia. x. Mas Pom. Gen. 2:105, fig. 1873. 2. Rev. Hort. 476. Igor.

Flotows Allerfrüheste Mirabelle 1. Mirabelle La Plus Hâtive de Flotow 1. Von Flotows Mirabelle 1.

According to Mas, "this variety was obtained from a seed of Perdrigon Violet by Liegel and dedicated by him to M. de Flotow, of Dresden, one of the first collaborators of The Illustrirtes Handbuch." Tree vigorous, very productive; fruit small, spherical, yellow, dotted with red on the sunny side; stem medium in length and size; cavity shallow; flesh yellow, tender, soft, sweet, of Apricot flavor, very pleasant; early.

Mirabelle de Ronvaux. Insititia. I. Guide Prat. I63, 359. 1895.

"A variety of little merit."

Mirabelle Double de Herrenhausen. Insititia. 1. Oberdieck Deut. Obst. Sort. 426. 188r. 2. Guide Prat. 155, 360. 1895. 3. Rev. Hort. 476. 1901.

Herrnhauser Doppelte Mirabelle r. Herrnhauser doppelte Mirabelle 2.

Tree vigorous, very productive; fruit small to medium, yellow mottled with red; flesh yellow, sweet; good; late, following Drap d'Or.

Mirabelle Précoce de Flaford. Insititia. x. Mathieu Nom. Pom. 440. 1889. 2. Guide Prat. $163,360.1895$.

Reported as being similar to Early Mirabelle.

Mirabelle Verte. Insititia. I. Mas Le Verger 6:91. 1866-73. 2. Guide Prat. 162, 360. 1895. Grüne Mirabelle I, 2.

From a Herr Commans of Cologne, Prussia. Tree moderately vigorous; fruit small, roundish-oblate; suture deep; cavity deep, wide; skin tender, free; green marbled with yellow; stem short; flesh green, fine, soft, sweet, aromatic; freestone. Resembles Reine Claude and may contain Domestica blood.

Mission Prune. Domestica. I. Bailey Cyc. Hort. 3:1376. I901.

A large number of plums were planted over a century ago around the old Mission at Santa Clara, California; after the abandonment of the Mission this variety was found propagating itself by suckers and was cultivated as late as 1870 .

Mississippi. Munsoniana. I. Ga. Hort. Soc. Rpt. 50. 1885. 2. Waugh Plum Cult. 187, 188 fig. I901. Mississippi Red 2.

Introduced by J. M. Shell of Georgetown, Texas, about 1875. Fruit large, oval; cavity very shallow; suture lacking; clear red; dots many, yellow; skin thin, tough; flesh soft, yellow; good; clingstone; mid-season. 
Missouri. Munsoniana? 1. Ga. Hort. Soc. Rpt. 39, 41, 99. 1889. 2. Ala. Col. Sta. Bul. rr:12. 18go.

An unimportant variety occasionally found in Alabama and Georgia. Fruit of medium size, oblong, red; flesh firm; good; clingstone; late.

Missouri Green Gage. Domestica. 1. Bailey Ann. Hort. 196. 1891. 2. Ohio Sta. Bul. 113:160. 1899. 3. Ibid. $162: 239,256$. 1905.

Introduced in 1891 by Stark Brothers, Louisiana, Missouri. As tested by the Ohio and New York Experiment Stations it appears to be either identical with or a strain of the Impcrial Gage.

Mistake. Domestica. 1. Mich. Sta, Bul. 152:210. 1898. 2. Can. Exp. Farms Rpt. 548. 1901 .

Fruit above medium size, oblong-oval; suture distinct; sides unequal; purple; flesh yellow, coarse, juicy, sweet, pleasant; mid-season.

Mitchelson. Insititia. 1. Gard. Chron. 892, 894. 1860. 2. Flor. \& Pom. 152. 1862.

3. Downing Fr. Trees Am. 932. 1869. 4. Mas Pom. Gen. 2:65. 1873.

De Mitchelson 4. Mitchelson 3. Mitchelson's 1, 2. Mitchelson's 4.

Raised by a Mr. Mitchelson, at Kingston on the Thames, England; a seedling of a Damson. Fruit above medium size, oval; suture indistinct; dark purple; dots few, fawn-colored; bloom thin; flesh yellow, tender, very juicy and sweet; freestone; excellent for culinary purposes.

Mivian. Domestica. Listed in Lond. Hort. Soc. Cat. 150. I83r.

Mollie. Americana. 1. Kerr Cat. 1900. 2. Ill. Hort. Soc. Rpt. 422, 424. 1905.

Molly 2.

Originated with Theodore Williams of Benson, Nebraska. Fruit small, round, red, watery; clingstone; mid-season.

Monon. Americana. 1. Kerr Cat. II. 1897.

Tree very productive; fruit small, greenish with dull red blotches; poor; clingstone; subject to rot.

Monona. Species? r. Wis. Sta. Bul. 63:24, 48. I 897 .

From Christian Steinman, Mapleton, Iowa; said to be the size of Miner but two weeks earlier.

Monolith. Triflora? X Munsoniana? x. U.S. D. A. Pom. Rpt. 46. 1895. 2. Vt. Sta. Bul. $67: 17 . \quad 1898$.

Originated by J. S. Breece of North Carolina; thought to be a cross between Abundance and Wild Goose although it does not show Triflora characters. Fruit of medium size, roundish; cavity medium; suture shallow; coppery-red, striped with darker red; skin thin, bitter; flesh yellowish, translucent, meaty, tender, juicy, fibrous, mild, subacid, rich; good; stone semi-clinging.

Monsieur á Fruit Vert. Species? r. Mathieu Nom. Pom. 44r. I889.

Mathieu found it referred to in Journal de la Societie Nationale et Centrale d'Horticulture de France $28 \mathrm{I}$. $188_{3}$.

Mont Barbat d'Ente. Domestica. 1. Wickson Cal. Fruits 356. 189 1. 
An improved type of Agen coming from the Mont Barbat orchard in the Lot Valley, France.

Montgomery. Domestica. I. Horticulturist $6: 187,294,524$. 1851 .

Montgomery Prune I.

Found by E. W. Carpenter of Lancaster, Pennsylvania, growing on the premises of a Mr. Montgomery about 1830 . Tree very productive; fruit large, oval, purple; quality very good.

Montmorency. Domestica. 1. Can. Exp. Farm Bul. 43:35. 1903. 2. Quebec Pom. Soc. Rpt. 9, 66, 68. 1905.

Reine-Claude de Montmorency 2. Reine-Claude de Montmorency I.

Montmorency is thought to be a seedling of the Reine Claude, imported into Canada in 1790 by Lord Dorchester; extensively cultivated in the eastern part of Quebec but unknown in the United States. Tree very hardy, productive; fruit medium in size, roundish; cavity narrow, shallow; stem medium in length; suture indistinet; skin tough, greenish-yellow, blushed with red; flesh yellow, very juicy, moderately firm, sweet, rich; very good; stone small, oval, nearly free.

Montreal. Species? 1. Ont. Fr. Exp. Sta. Rpt. 64. 1897.

Mentioned by Harold Jones of Martland, Ontario, in the report of the Fruit Experimental Station for 1897 .

Moody. Domestica. 1. Mich. Sta. Sp. Bul. 27:15. 1904.

Tree productive; fruit large, reddish-purple, good; mid-season.

Moon. Americana. I. Kerr Cat. 1894. 2. Colo. Sta. Bul. 5o:42. 1898.

Fruit of medium size, round; no suture; deep red over a yellow ground; skin thin; flesh moderately firm, subacid; clingstone; mid-season.

Moore Early. Insititia. I. Ont. Fr. Exp. Sta. Rpt. 5:116. 1898.

Moore's Early I.

An extremely hardy variety of the Damson type. Tree spreading; fruit of medium size; grows in clusters; dark purple; good; nearly freestone; desirable for jellies and preserves.

Moreman. Hortulana. 1. Kerr Cat. 13. 1899-1900. Moreman Cherry I.

Originated by Theodore Williams, Benson, Nebraska. Tree vigorous; fruit large, bright red; clingstone.

Morines. Domestica. I. Quintinye Com. Gard. 70. 1699.

A red plum noted only by Quintinye.

Morin Hâtif. Cerasifera? I. Knoop Fructologie 2:59. 177 I.

Fruit of medium size, round, red; resembles the Myrobalan plum except that its leaves are larger and its season a little later.

Mountain. Domestica. 1. Can. Exp. Farm Bul. 43:35. 1903.

A promising variety from W. W. Dunlop, Outremont, Quebec. Fruit of medium size, roundish; cavity medium; suture distinct; greenish-yellow more or less overspread with dull coppery-red; dots yellow, distinct; bloom thin; flesh yellowish-green, sweet, rich; very good; clingstone; mid-season. 
Mountain Plum. Munsoniana? 1. Am. Pom. Soc. Rpt. 86. 1871. 2. Gard. Mon. $20: 177 . \quad 1878$.

$\Lambda$ late variety of the "Chicasaw" group.

Mount Royal. Domestica. I. Can. Exp. Farm Bul. 43:35. 1903.

Dunlop 54 I.

A secdling from W. W. Dunlop, Outremont, Quebec. Fruit of medium size, roundish; cavity medium deep; suture distinct; dark purple; dots numerous, distinct; flesh greenish-yellow, juicy, firm, sweet; good; clingstone; mid-season.

Moyen. Domestica. I. Quintinye Com. Gard. 68, I699. Pitch Plum r.

Mentioned by Quintinye as "a dry plum having a sharp and sourish taste."

Moyen de Bourgoyne. Domestica. I. Prince Pom. Man, 2:95. 1832.

Moyen de Bourgogne 1 .

Probably not the same as the Moyen of Quintinye. According to Prince it is a large, oval, yellow plum, of indifferent quality; late. This name applied to a purple variety is a synonym of Early Perdrigon.

Moyer. Domestica. I. Can. Exp. Farm Bul. 2d Ser. 3:54. 1900.

Tree vigorous, unproductive. Fruit of medium size, roundish; stem short; cavity small, shallow; suture shallow; dark reddish-purple; flesh greenish-yellow, firm, juicy, sweet, pleasant; clingstone.

Moyret. Domestica. I. Mas Le Verger 6:3 I fig. 16. 1866-73. 2. Downing Fr. Trees Am. 933. 1869. 3. Mathieu Nom. Pom. 441. 1889.

Moyret's Gage 2. Moyrets Gage 3. Moyret's Reine Claude 3. Reine-Claude Moyret 1. Reine-Claude Moyret 2, 3 .

A chance seedling of the Reine Claude obtained on M. Moyret's place at Neuville-sur-Ain, France. Tree vigorous, productive; fruit medium, roundish, reddish to violet-purple; suture wide, shallow; cavity wide, deep; stem rather short; flesh green, fine, a little firm, juicy, sweet, aromatic; of high quality; freestone; mid-season.

Mudson. Angustifolia varians? 1. Ga. Hort. Soc. Cat. 13. 1905.

A productive variety recommended for family use by the Georgia Horticultural Society; fruit yellowish-red, juicy; clingstone; very early.

Mulberry. Domestica. I. Downing Fr. Trees Am. 282. 1845. 2. Mag. Hort. 13: 530. 1847. 3. Thomas Am. Fruit Cult. 332. 1849 .

Originated in the garden of Isaac Denniston, Albany, New York. Tree moderately vigorous; fruit large, oval, strongly necked, pale with a few crimson spots; dots white; bloom thin; flesh greenish-yellow, coarse, melting, juicy, rich, sugary; good; clingstone; mid-season.

Muldraugh. Americana. I. Am. Jour. Hort. 5:146. I869.

Muldraugh's-hill Plum 1.

Found growing wild on Muldraugh's Hill, Harden County, Kentucky. Tree vigorous, large, unproductive; the clusters of flowers which appear before the leaves are mostly staminate; fruit large, light red.

Mule. Munsoniana $\times$ Prunus persica. 1. Kerr Cat. 8 . 1899. 2. Waugh Plum Cult. 219. I9Or. 
A hybrid produced by J. W. Kerr from seed of Wild Goose plum pollinated by the Troth Early peach; introduced by the originator in 1896 . Tree resembles the plum; foliage very much like that of the peach; worthless, inasmuch as the buds do not open and contain only deformed anthers and no pistil.

Muncy. Americana. 1. Cornell Sta. Bul. 38:80. 1892. 2. Kerr Cat. 1894. 3. Tex. Dept. Agr. Bul. 12:103. г91о. Muncey 3.

Tree vigorous; fruit medium in size; dull red; clingstone; mid-season.

Munson. Angustifolia varians, 1. Cornell Sta. Bul. 38:80. 1892, 2. Tex. Sta. Bul. 32:479. 1894. 3. Am. Pom. Soc. Cat. 38. 1899. 4. Waugh Plum Cult. r97. r9ro.

Originated under cultivation by G. Onderdonk, Victoria, Texas; introduced by the originator in 1888 . Tree not hardy as far north as Ames, Iowa; fruit of medium size, oval; cavity shallow; stem slender; suture a line; bright red; bloom thin; dots many; skin thin; flesh yellow, soft; quality fair; stone oval, flattened, clinging; early. Murdy. Domestica. 1. Mich. Sta. Bul. 169:247. I899. 2. Ohio Sta. Bul. 162:256, 257. 1905 .

The Murdy as tested by the Ohio Experiment Station is considered identical with the Pond, but as tested at the Michigan Experiment Station, it ripens two weeks later, has a deeper cavity, finer texture and lighter colored spots on its skin.

Muscat Free. Domestica. 1. Mich. Sta. Bul. 118:52, 1895. 2. Mich. Sta. Sp. Bul. 27:1 $5 . \quad$ I 904 .

Evidently a strain of the Italian Prune; imported from Hungary in 1894 by the Department of Agriculture and tested at the Michigan Experiment Station. Tree low, spreading, slow-growing; fruit of medium size, long-oval, flattened on one side; suture broad, distinct; black with thick bloom; flesh greenish-yellow, moderately firm, juicy; very good; freestone; not as sweet as Italian Prune and a week later.

Muscle. Domestica. 1. Parkinson Par. Ter. 576, 577 fig. 1629. 2. Rea Flora 207. 1676. 3. Ray Hist. Plant. 1529. 1688. 4. Prince Pom. Man. 2:105. I832. 5. Watkins Cat.

Red Mussel1 I. Black Muscle 4. Black Mussell I. Mussel 4. Mussell 5. Mussell Plum I. Red Muscle 2, 3. White Mussell I.

Of very early European origin, once considered of value but now only used as a stock; the old writers described both a red and a black form. Fruit small, oval, dark red; flesh not juicy; poor; stone large.

Musk Damson. Insititia? I. Quintinye Com. Gard. 68, 70. 1699. 2. Duhamel Trait. Arb. Fr. $2: 74$. 1768. 3. Kraft Pom. Aust. 2:33, Tab. 180 fig. 2. 1796. 4. Noisette Man. Comp. Jard. 2:495. I860. 5. Downing Fr. Trees Am. 933. 1869. 6. Mathieu Nom. Pom. 425. I889.

Christ's Damascene 6. Damas Fin 6. Damas Musque 2, 3, 4. Damas Musque 5, 6. Damasquinée 6. De Chypre 5. Die musquat Damaskusplaume 3. Feine Damascene 6. Musk Damask 6. Musk'd Damask x. Muskierte Damascene 6. Musque de Malta ?5, 6. Prune de Chypre 2, 5, 6. Prune de Malte 2, 6. Prune de Malthe 5. Schwarze Muskateller Pfaume 6. Späte Schwarze Damascene 6. Suisina Grossella Piccola 6. 
Noisette suggests Damascus, Syria, as the probable place of origin of Musk Damson. Fruit small, roundish; suture distinct; cavity small; dark purple; bloom thick; flesh yellow, juicy, sweet, musky; good; semi-clinging; mid-season.

Musk Perdrigon. Domestica. I. Langley Pomona 92, Pl. 23 fig. 3. 1729.

Fruit nearly black, with a bloom; freestone; early.

Mussey. Americana. 1. Cornell Sta. Bul. 38:40. 1892.

Found wild in Kansas; introduced by Abner Allen. Fruit large, roundish-oblong, yellow, mottled with red; flesh firm, good; semi-clinging; very late.

Nagate-Maru. Triflora, 1. Va. Sta. Bul. 129:1r4. 1901. 2. Ga. Hort. Soc. Cat. I3. 1904. 3. Ga. Sta. Bul. 68:13 fig., 31. 1905.

Nagatus maru 2. Nagats-Maru 2.

Resembles Abundance but is three weeks later. Fruit large, oblate-conical, red over yellow; dots numerous; flesh yellow, firm; good.

Naples. Domestica. I. Wild Bros. Cat. 26. 1892. 2. W. \& T. Smith Nur. Cat. 24. 1897. 3. Storrs \& Harrison Cat. 138. I893-98.

Beauty of Naples I, 2, 3 .

Naples as catalogued by nurserymen is of the Yellow Egg type although Lyon ${ }^{1}$ and Thomas ${ }^{2}$ knew a purple variety of this name. Tree vigorous and productive; fruit of medium size, oval; cavity small; skin thin, tender; golden yellow mottled with red in the sun; bloom thin; flesh light yellow. firm, sweet, mild; good; stone oval, rough, clinging; late.

Native Red. Species? I. Ont. Fr. Gr. Assoc. Rpt. 87. 1896.

Received by the Fruit Growers' Association of Ontario from W. N. Snelling of Ottawa. A very attractive bright red plum of medium size.

Nebraska. Hortulana mineri. I. Kerr Cat. 1894. 2. Waugh Plum Cult. 174. I901. 3. Ga. Sta. Bul. $67: 278$. 1904.

Tree spreading, vigorous, short-lived, productive; fruit medium in size, roundishoval; cavity shallow; red with numerous yellow dots; skin thick, tough; flesh yellow, juicy, melting; fair to good; stone medium in size, oval, clinging; late.

Nebraska Seedling. Species? I. Country Gent. 26:238. I865.

Reported in 1865 by R. O. Thompson of Nebraska as a freestone plum of great excellence; trees very productive and free from curculio.

Nebraska Wonder. Americana. I. Ia. Sta. Bul. 46:281. I 900 .

Found wild in 1892 by A. Webster, Golden, Burt County, Nebraska; introduced by H. P. Sayles, Ames, Iowa, in 1897 . Tree dwarf, spreading, prolific, bears early; fruit large, round, slight yellow tinge, mottled red when over-ripe, without astringency when fully ripe; ships well; early.

Neils. Species? I. Can. Exp. Farm Bul. 2d Ser. 3:54. I 9oo.

Under test at the Canadian Experimental Farm at Agassiz, British Columbia.

Nellie. Americana. 1. Kerr Cat. I894. 2. Wis. Sta. Bul. 63:49. 1897. 3. Waugh Plum Cult. 158. 1901. Nelly I, 2.

'Mich. Sta. Bul. 118:52, 54. I 895.

${ }^{2}$ Thomas Am. Fruit Cult. 493. 1897. 
Fruit large, oblate; suture faint; stem medium; yellow blushed with pink; flesh firm, yellow; good; stone of medium size, round, semi-clinging; medium to late.

Neliie Blanche. Americana. I. Terry Cat. 1900. 2. Rural N. Y. $65: 726$ fig., 730. 1906. 3. Ia. Sta. Bul. 114:141. 19ro. Blanche 3.

Grown by H. A. Terry, Crescent, Iowa; fruited first in 1897 . Tree vigorous, upright, productive, bears early; fruit large, oblong; stem medium, set in a small cavity; skin thick; yellow mottled with red; flesh meaty, very sweet and rich; good; stone large, clinging; mid-season.

Nelson. Domestica. 1. Lond. Hort. Soc. Cat. 150. 1831. 2. Hogg Fruit Man. 373. 1866. 3. Mas Pom. Gen. 2:55. 1873. 4. W. N. Y. Hort. Soc. Rpt. $21: 20$. 1876 .

Knevett's Late Orleans 2, 3. Monsieur tardif de Knevett 3. Nelson's Victory 1, 2, 4. Nelson's Victory 3. Victoire de Nelson 3.

An old variety renamed in honor of the famous English admiral. Fruit of medium size, round, deep purple; flesh sweet and pleasant; freestone; mid-season; suitable for culinary purposes.

Never Fail. Americana. I. Ia. Sta. Bul. 46:281. 1900.

Purchased of an Eastern nurseryman for Wolf but proved not true to name; introduced by J. S. Haag, Hosper, Iowa. Tree vigorous, slightly spreading; fruit large, round, red; good; ripe with De Soto.

New American. Americana. r. S. Dak. Sta. Bul. 26:14. I891. 2. Ibid. 93:26. 1905.

Of no value in South Dakota because of its lateness.

New Goderich. Domestica. 1. Ont. Fr. Exp. Sta. Rpt. 4:66, 102, 110. 1897.

Thought to be a seedling of Lombard. Tree vigorous, spreading, hardy, productive; fruit medium to large, round; stem short, inserted in a shallow cavity; suture distinct; brownish-red with heavy bloom; flesh yellow, coarse; quality poor.

New Green Gage. Domestica. 1. Lond. Hort. Soc. Cat. 148. I831.

Mentioned; probably obsolete.

New Large Bullace. Insititia? Mentioned in Mathieu Nom. Pom. 433. I889.

Grosse Prunelle Nouvelle New Large Bullace.

Newton. Americana. I. Munson Cat. 8. 1894. 2. Ohio Sta. Bul. 162:256, 257. 1905. 3. Am. Pom. Soc. Rpt. 23. 1905.

Received by T. V. Munson from Theodore Young of Wichita Falls, Kansas. Munson says this variety is distinct from Newtown Egg. Tree vigorous, healthy, productive; fruit large, oblong, irregular; stem short and stout, set in a small cavity; suture indistinct; dull red; bloom thin; flesh yellow; good; freestone; late.

Newtown Egg. Americana. I. Cornell Sta. Bul. 38:40. 1892. 2. Waugh Plum Cult. 153. 1901. Newton Egg 2.

Originated with Charles Luedloff, Carver, Minnesota. Tree open, straggling, productive; fruit medium to large, oblong-oval, purplish-red over yellow, thickly sprinkled with many yellow dots; flesh yellow, firm; good; stone long, nearly flat, smooth, semiclinging; niid-season. 
New Wine Sour. Domestica. Listed in Lond. Hort. Soc. Cat. 154. 1831 .

Nienburger Egg Plum. Domestica. 1. Mas Pom. Gen. 2:183. 1873. 2. Koch Deut. Obst. 570. 1876. 3. Oberdieck Deut. Obst. Sort. 408. 1881. 4. Can. Exp. Farms Rpt. 548. 1901 .

Niemburg Egg 4. Nienburger Eierpflanme 1. Nienburger Eierpflaume 3. Oeuf de Nienburg $\mathbf{1}$.

Found in the garden of a priest at Nienburg, Hanover, Germany, by M. Oberdieck, Tree vigorous, an early and abundant bearer; fruit large, obovate; suture broad and deep; dark brownish-red; bloom thin; flesh yellow, firm, sweet; stone small, free; mid-season. Good for dessert and drying.

Nikitaer Blaue Fruhzwetsche. Species? Mentioned in Mathieu Nom. Pom. 441. 1889. Bal Erik. Blauer Spilling. Gus Erik.

Nikitaer Dattelzwetsche. Domestica. 1. Oberdieck Deut. Obst. Sort. 444. 1881. 2. Mathieu Nom. Pom. 441. 1889. Bardak Erik 2.

Mentioned as unproductive in dry soil at Jeinsen, Germany.

Nikitaer Hahnenpflaume. Species? Mentioned in Mathieu Nom. Pom. 441. 1889. Hahnenhode. Nikitaner Hahnenhode. Rognon-de-Coq de Nikita.

Nikko. Species? I. Vt. Sta. Bul. 67:18. 1898.

Originated by Burbank and introduced in 1898 ; parentage unknown. Said to be " a good, dark red, red-fleshed, conical plum."

Nimon. Hortulana $\times$ Munsoniana. I. Munson Cat. 7. 1896. 2. Waugh Plum Cult. 181. 1901. 3. Ia. Hort. Soc. Rpt. 167. 1905.

A seedling of Wayland pollinated by Wild Goose; from T. V. Munson, Denison, Texas. Tree moderately hardy, vigorous; fruit medium in size, ovate; cavity shallow; crimson; dots numerous, white; flesh yellow, firm, meaty, sweet; good; stone small, clinging; mid-season.

Noire Americaine. Species? Mentioned in Mathieu Nom. Pom, 441. 1889.

Noire de Montreuil. Domestica. 1. Duhamel Trait. Arb. Fr. 2:68. 1768. 2. Prince Pom. Man. 2:92. 1832. 3. Hogg Fruit Man. 714. 1884. 4. Mathieu Nom. Pom. 437. 1889 .

Bieler Pflaume 4. Damas Noir Hâtif 4. Early Large Black 1. Frihe Schwarze Pflaume 4. Fruhe Grosse Schwarze Plflaume 4. Grosse Frïh Pflaume 4. Grosse noir de Montreuil 2. Grosse noire hative 2, 3, 4. Grosse Noire hâtive 1. Large Early Montreuil 2. Johannispflaume 4. Large early black 2. La Madeleine 3. Morocco Pfaume (of some) 4. Montreuil 2. Noire de Montreuil 1, 2, 4. Prune de Saint-Jean 4. Saint-Jean 4. Waran Erik 4.

According to Duhamel, this name is used for two varieties. One is of medium size, elongated, purplish-black, strongly resembling Gros Damas de Tours; flesh firm, yellowish with a rather agreeable flavor; nearly freestone; early. The other is large, round, of the same color as the first, but its season is later and its flesh is coarse and insipid. For historical notes see Précoce de Tours.

Nolan. Munsoniana. I. Am. Jour. Hort. 5:148. 1869.

Probably a seedling of Wild Goose which it resembles very closely. 
Nolton Ungarische. Species? I. Mathieu Nom. Pom. 441. 1889.

Reference found by Mathieu in Monatsschrift fur Pomologie 9. 1861.

Nome. Americana. 1. Meneray Cat.

From H. A. Terry, Crescent, Iowa. Tree vigorous; fruit large, round, red over vellow; good.

Nona. Triflora? $\times$ Munsoniana. I. Vt. Sta. An. Rpt. 12:226. 1899. 2. Ibid. 14:274, 277. 1901. 3. Olio Sta. Bul. 162:252. 1905.

Originated with D. H. Watson, Brenham, Texas; introduced by W. A. Yates, 1897. Tree healthy, upright; foliage healthy, abundant; fruit medium to large, oval; cavity abrupt; stem short; suture obscure; apex slightly pointed; dark red, obscurely striped; dots numerous, small, yellow; bloom light; skin thick, somewhat astringent; flesh yellow mottled with red, fibrous, juicy; good; stone medium, roundish-oval, flattened, clinging; early.

Norbert. Domestica. I. Hogg Fruit Man. 373. I866. 2. Mas Pom. Gen. 2:73. 1873.

3. Mathieu Nom. Pom. 441. 1889. 4. Guide Prat. 161, 360. 1895.

De Prince 4. Lepine 3 and 4 incor. Norbert 3. Norbert's Pflaume 3. Prune de Lepine 1, 3. Prune de Prince 1, 3. Schwarze Mirabelle 3.

Found wild in the woods of Halanzy, Luxembourg, France. Mas distinguishes Prune de Lepine as a separate variety. Fruit very small, round; suture obscure; dark purple; bloom thick; flesh greenish-yellow, firm, sweet; stone small, free. Useful for drying.

Norby. Americana. I. Budd-Hansen Am. Hort. Man. $2: 298$. 1903.

Originated with A. Norby, Madison, South Dakota; No. 13 of his seedlings. Fruit large, roundish; sides unequal; dark red; stone round, flat; mid-season.

Norby No. 1. Americana. I. S. Dak. Sta. Bul. 93:28. 1905.

Originated with A. Norby, Madison, South Dakota. Under test at the South Dakota Experiment Station. The variety bears large, fine fruit of good quality; midseason.

Norby No. 11. Americana. I. Ia. Sta. Bul. 46:283. 1900. 2. S. Dak. Sta. Bul. 93:28. 1905. No.II I.

Another of A. Norby's seedlings; grown from seed of selected varieties in 1895 . Reported by the South Dakota Experiment Station to be worthy of propagation. Tree upright, hardy, productive; fruit above medium size, oval to roundish-oblong; rich yellow overspread with red; bloom thin; dots small, white, numerous; flesh yellow, firm; good; stone long, oval, nearly free; early.

Norman. Munsoniana? I. Gard. Mon. 20:177. 1878.

Mentioned by W. S. Carpenter of Rye, New York, in 1878 as an improved variety of the "Chicasaw" group.

Normand Perdrigon. Domestica. 1. Duhamel Trait. Arb. Fr. 2:87. 1768. 2. Kraft Pom. Aust. 2:30, Tab. 177 fig. 1. 1796. 3. Prince Pom. Man. 2:65. 1832. 4. Poiteau Pom. Franc. 1. 1846. 5. Mathieu Nom. Pom. 441. 1889.

Der blaue Rebliuhn aus der Normandie 2. Normannischer Perdrigon 5. Norman Perdrigon 5. Norman Perdrigon 3. Perdrigon de Normandie 5. Perdrigon Normand 1. 
Perdrigon Normand 2, 3, 5. Prune Perdrigon Normand 4, 5. Prunus neustriensis 4. Schwarzer Perdrigon 5.

A very good French variety. Fruit of medium size, roundish; suture shallow; cavity small; reddish-purple; bloom heavy; flesh yellow, melting, sweet; good; clingstone; mid-season.

Normand's Seedlings. 1. Cornell Sta. Bul. 175:151. 1899.

J. L. Normand, ${ }^{1}$ Marksville, Louisiana, disseminated twenty hybrid seedlings, numbered from one to twenty, which were selected from over 30,000 seedlings; most of these are crosses between Triflora and selected native sorts.

Normand No. 5. See Alabama.

Normand No. 11. Triflora $x$ ?

Fruit above medium size, oval to oblong-conic; apex pointed; stem medium, set in a small cavity; yellow overspread with bright red; dots numerous, yellow; flesh yellow, firm, juicy, aromatic, sweet, good; stone long and narrow, clinging; late. Drops before ripe.

Normand No. 12. Triflora $\times$ ?

Inferior to No. 11 in color, flesh-characters and keeping quality. Drops before ripe and has a tendency to crack.

Normand No. I5. See Louisiana.

Normand No. 16. Triflora $X$ ?

Fruit resembles No. 12; greenish-white with red blush; flesh pale yellow, soft, juicy, bitter; clingstone; drops before fully ripe.

Normand No. ${ }_{17}$. Triflora $x$ ?

${ }^{1}$ Joseph L. Normand was born at Marksville, Louisiana, January 14,1853 . He was educated in the public schools of the parish in which he lived. After leaving school he followed the vocation of a printer for a number of years, though from childhood horticulture had been an a vocation with him. Before middle life he gave up office work to begin actively the growing of nursery and fruit trees. His work in horticulture early developed into plant-breeding and towards the close of his life all of his energies were devoted to the production of new types of plants. In his plant-breeding Mr. Normand became noted as a hybridizer and a great majority of the fruits and ornamentals sent out by him were hybrids. Among these may be named the Carnegie Orange, a hybrid more or less frost resistant, which he obtained by crossing the Louisiana Sweet Orange with Citrus trifoliata. Mr. Normand also devoted much time to the testing of figs and sent out the New French Fig, selected from some seventy varieties which he had grown. Pears, apples and plums received his attention and in all these fruits he developed original types by hybridization. Possibly his most meritorious work with the plum has been in testing Triflora and native varieties, although he has sent out not a few hybrids of this fruit most of which, however, do not thrive in northern climates. Mr. Normand did for his region what Kerr, Munson, Terry, Lord and Williams have done in other parts of North America in testing plums. All who knew Mr. Normand say that in this day of commercialism he worked almost wholly for the love of plants-to improve them for his fellow fruit-growers regardless of the money to be made in his calling. He lived and worked in a region where his achievements were at first little known and little understood, quite content to work for his work's sake, but in the end he gained distinction among the fruit-growers of his State and attracted the attention of plant-breeders all over the United States. Mr. Normand died in the town of his birth, April 17, 1920. 
Fruit the size of Burbank, somewhat similar in shape but less pointed, greenishyellow thinly covered with dark red, spattered with dots and broken lines of paler color; flesh greenish, tinged with yellow, very juicy, somewhat acid; poor; clingstone; drops before ripe.

Normand No. 18 . Triflora $\times$ ?

Equal to No. $1 \mathrm{I}$ in size but inferior in quality; keeps and ships well.

Normand No. 19. Triflora $X$ ?

Fruit about the size of Wild Goose, but not as regular in form; color and bloom much the same as that variety; flesh of the same color but firmer and of better quality than Wild Goose; stone medium, clinging; late.

Normand No. 20. See Georgia.

North. Domestica. I. Downing Fr. Trees Am. 934. 1869. 2. Mas Pom. Gen. $2: 143$. 1873. North's Seedling I.

Raised by Professor North, Clinton, New York. Tree vigorous, bears early, productive; fruit large, roundish-oval; suture broad and shallow; reddish-purple; bloom thin; flesh yellow, melting, juicy, sweet; good; clingstone; early.

North Carolina. Hortulana mineri. I. Kerr Cat. 1894. 2. Wis. Sta. Bul. 63:50. 1897.

3. Kerr Cat. 1897.

N. C. Seedling 1. North Carolina Seedling 2, 3.

J. W. Kerr says this variety is subject to twig-blight; reported of value in Iowa; fruit large, deep red.

North Star. Americana. 1. Wis. Sta. Bul. 63:50. 1897. 2. Ibid. 87:14. 1901.

Originated with Martin Penning, Sleepy Eye, Minnesota, from seed of Surprise; resembles its parent very closely. Tree hardy, dwarfish; fruit large, juicy, sweet; clinging; mid-season.

Nota Bene. Domestica. 1. Kenrick Am. Orch. 257. 1832. 2. Downing Fr. Trees Am. 293. 1845. 3. Mathieu Nom. Pom. 425. 1889.

Corse's Nota Bena I. Corse's Nota Bene 2, 3. Nota Bene de Corse 3.

One of the best of the seedlings raised by Henry Corse, Esq., Montreal, Canada. Tree very vigorous, productive and hardy, short-lived; fruit large, round, pale brown sometimes shading to green; flesh greenish, firm, juicy, sweet and rich; good; freestone. November Gage. Domestica. I. Mag. Hort. 6:92. I 840.

Raised by Henry Corse of Montreal and distributed at the same time as his Nota Bene.

Noyes. Americana? I. Kerr Cat. 1897. 2. Ia. Sta. Bul. 46:283. 1900. 3. Wis. Sta. Bul. 87:14. 1901. Noyes' Seedling 1. Noyes Seedling 2.

Originated with a Mrs. Noyes, Springville, Iowa, about 1881 , from pits purchased for California plums; introduced by a Mr. Osborn about 1888 . Craig places Noyes in Prunus hortulana and Waugh, while classifying it with the Americanas, suggests that it is Hortulana mineri. Tree vigorous, productive; fruit large, roundish to oblong; apex sometimes flattened or depressed; cavity shallow; suture distinct; skin thick, tough, rather acid; yellow nearly overspread with red; dots numerous, yellow; flesh tinged with red, melting, rich and sweet; good; stone large, clinging; early to mid-season. 
Nutmeg Insititia. I Parkinson Par. Ter. 576. 1629. 2. Rea Flora 209. 1676.

Fruit the shape of a nutmeg, no larger than a Damson, greenish-yellow; good; late; obsolete.

Oakıey Park Wild. Species? Listed in Lond. Hort. Soc. Cat. I50. 1831.

Oatey Americana. I. Kerr Cat. 1894 .

In answer to an inquiry Kerr states that "The Oatey is above medium to large, dull purplish-red when fully matured; clinging. Tree does not succeed here."

Oberdieck Gestreifte Eierpflaume. Domestica? I. Mathieu Nom. Pom. 442, 1889. 2. Guide Prat. 157, 360. 1895 .

Introduced into France by M. Oberdieck, the German pomologist. Fruit large, long-oval, yellow blushed with red; flesh yellow, juicy, sweet; good; early.

Oberley. Domestica. I. Gard. Mon. 2:120. 1860. 2. Downing Fr. Trees Am. 934. 1869. 3. Mas Pom. Gen. $2: 13$ r. 1873.

Oberley's Greenwood 2. Oberley's Greenwood 1.

Originated in Northampton County, Pennsylvania, on the farm of a Mr. Oberley. Tree thrifty, very productive; fruit medium in size, round; suture distinct; skin amber, but nearly covered with rosy red; bloom thin; flesh juicy; quality fair; clingstone.

October. Domestica. 1. Can. Hort. 20:454 fig. 1257. I897.

Sent to the office of the Canadian Horticulturist by A. M. Smith of St. Catherines. Fruit medium in size, roundish; skin thin, dark purple; flesh yellow, tender, juicy, rich sweet and very agreeable.

Oddy. Domestica. Listed in Lond. Hort. Soc. Cat. 150. 1831. Oddy's.

Odegard. Nigra. I. Wis. Sta. Bul. 63:50. 1897. 2. Minn. Hort. Soc. Rpt. 411. 1899. 3. S. Dak. Sta. Bul. 93:28, 49 fig. 1905. Odegaard 2.

Originated about 1888 near Brookings, South Dakota; found among a lot of seedlings grown from wild plum pits sent from Minnesota; bought by H. T. Odegard of Brookings; introduced by A. Norby of Madison, South Dakota. Tree very productive, hardy and vigorous; foliage large; fruit large, oblong; suture very shallow from basin to apex; dark red; flesh yellow, juicy, sweet; good; early.

Odell. Domestica. I. Col., O, Hort. Soc. Rpt. 31. г892. 2. Ohio Sta. Bul. I13:160. 1899. 3. Mich Sta. Sp. Bul. 30:19. 1905.

According to the introducers, Augustine and Company, Normal, Illinois, this variety was found as a seedling growing in a fence corner at Odell, Illinois; introduced about 1890 . Resembles and may be identical with Lombard; ripens at the same time. Ogeechee Angustifolia varians. 1. Cornell Sta. Bul. 38:64. I892.

Found wild in Georgia; introduced by G. Bourquin. Fruit of medium size, round, red; clingstone; early.

Oglesby. Species? r. Ill. Hort. Soc. Rpt. 135. I903. 2. Ibid. 424. I905.

Reported by H. T. Thompson of Marengo, Illinois, as a small, handsome red plum; freestone; very late. 
Ohio. Munsoniana. 1. Am. Pom. Soc. Rpt. 154. 1883. 2. Waugh Plum Cult. 187. I901. 3. Ga. Sta. Bul. 67:279. 1904.

Ohio Prolific 2. Ohio Prolific 1, 3 .

Tree vigorous, productive, irregular in growth; foliage dense; fruit medium in size, roundish. yellow overspread with bright red; dots numerous, yellow; flesh yellow, juicy, melting; fair in quality; clingstone; mid-season.

Okaw. Species? Noted in Bailey Ann. Hort, 175. 1890.

Oku Botan, Triflora. r. Va. Sta. Bul, 129:114. I901.

A variety sent out by the United States Department of Agriculture.

Old Gold. Americana. 1. Kerr Cat. 1894. 2. Wis. Sta. Bul. 87:14. 1901. 3. S. Dak. Sta. Bul. 93:30. 1905.

Introduced by C. W. H. Heideman of Minnesota. Tree hardy, productive, subject to shot-hole fungus; fruit medium in size, round to slightly oblong; cavity shallow; stem slender; clear yellow with a dark red blush; dots small; skin thick, tough; flesh ycllow; quality fair; stone roundish-oval, smooth, clinging; mid-season.

Olive. Domestica. I. Parkinson Par. Ter. 578. 1629.

Noted by Parkinson as "shrubby; fruit like an olive in color and size; very good; late."

Ollie. Hortulana $\times$ Munsoniana. 1. Vt. Sta. An. Rpt. 12:226. 1899.

Grown by A. L. Bruce, Basin Springs, Texas; from seed of Wayland crossed with Wild Goose. Fruit medium, oval; cavity shallow; suture obscure; dark red; flesh yellow with some red; stone medium, round, flattened, clinging.

Olson. Species? r. S. Dak. Sta. Bul. 93:30. 1905.

Found on the Vermilion River, near Vermilion, South Dakota. Tree productive; fruit of fair size; stone very large; late.

Omaha. Triflora $\times$ Americana. 1. Vt. Sta. An. Rpt. 14:272. 1901. 2. Ibid. 15:266. 1902 .

From Theodore Williams, Benson, Nebraska; a cross between Abundance and Brittlewood. Fruit variable in size, nearly spherical; cavity deep, rounded; stem long; suture faint; apex rounded; light red, a shade darker than Wild Goose; dots many, small; bloom considerable; flesh moderately firm, yellow, juicy, rich and sweet; stone rather large, oval, flattened; early; not introduced.

Omega. Americana. r. Terry Cat. 1900. 2. Ill. Hort. Soc. Rpt. 424. 1905.

Originated by H. A. Terry of Iowa. Tree vigorous, productive; fruit large, slightly oblong, red over yellow with numerous light dots; good; late.

Onderka Damascene. Species? Mentioned in Mathieu Nom. Pom. 442, 1889.

Damas d'Onderka. Onderka.

Ontario. Species? 1. Mich. Pom. Soc. Rpt. 38. 1874. 2. Can. Exp. Farm Bul. 2nd Ser. 3:54. 1900.

Tree vigorous, very productive; fruit medium to large, roundish-oval, marbled yellow; flesh yellow, juicy, sweet; good; clingstone; early to mid-season.

Opata. Prunus besseyi $\times$ (Munsoniana $\times$ Triflora). r. Circ S. Dak. Exp. Sta. 19 ro. 
Opata was grown by N. E. Hansen of the South Dakota Experiment Station from a cross between Golden and Prumus besseyi; introduced in a small way in rgo8. Tree productive; fruit of medium size, roundish; cavity wide; dark red; bloom rather heavy; flesh green; said to be good; stone small; very early.

Orange. Domestica. I. Knoop Fructologie 2:59. 1771. Prune de Orange I.

Fruit of medium size, oval, yellow blushed with red; flesh soft and juicy; good; freestone.

Orange Cherry. Species? I. Kerr Cat. 18. 1899. Orange's Cherry Plum I.

Originated in Florida where it is grown as a substitute for the cherry.

Orel No. 2 r. Domestica. I. S. Dak. Sta. Bul. 93:30. I905.

Introduced from Russia by Professor J. L. Budd of Iowa about I882. Unproductive and deficient in hardiness.

Orenge. Domestica, I. Parkinson Par. Ter. 576, 577 fig. 1629.

Mentioned by Parkinson as "a yellowish plum, moist and somewhat sweetish."

Oriental. Triflora. I. Rural N. Y.64:743. 1905. 2. Am. Pom. Soc. Rpt. 234. I907. Perry's Seedling r.

Introduced by F. L. Perry of Bridgeport, Connecticut, as a cross between Burbank and Satsuma. Tree hardy, vigorous; fruit large; skin thin; flesh dark, sweet; good; ripens two or three weeks earlier than Satsuma and hangs a month after ripening.

Orillia. Domestica. I. Can. Hort. 26:422, I903.

A seedling shown at the Orillia fruit exhibit in 1903; grown from a Lombard seed by Frank Kean. Tree vigorous, bears regularly; fruit similar in size and appearance to Quackenboss with a smaller stone and heavier bloom.

Osage. Munsoniana. I. Kerr Cat. 1894. 2. Me.Sta. An. Rpt. 12:66. 1896. 3. Waugh Plum Cult. 188. г9ог. 4. Tex. Dept. Agr. Bul. 12:1оз. г9го.

Osage $4^{8}$ 2. Wonder 4 .

Tree productive, tender; fruit medium in size, round to oval; cavity shallow; stem slender; bright red with numerous light dots flesh yellow; quality fair; stone medium, oval, flattened, clinging; mid-season.

Ottoman Seedling. Domestica. I. N. Y. Sta. Rpt. 9:347. I900.

Received by this Station for testing in 1890 from L. M. Macomber, North Ferrisburgh, Vermont, as a seedling of Imperial Ottoman. Tree productive; fruit medium to large, oval, suture slight or lacking; stem an inch long, slender, inserted with scarcely a depression; dull red or greenish-red; bloom thin; flesh yellowish-green, juicy, sweet; very good; stone medium, oval, small wing; early to mid-season.

Outremont. Domestica. I. Can. Exp. Farm Bul. 43:38. 1903.

Under test at the Central Experimental Farm, Ottawa.

Overall. Domestica. r. Hogg Fruit Man. 7 I6. 1884.

Fruit large, oval; suture faint; stem three-quarters of an inch long inserted without a depression; dark purple; flesh coarse, pleasantly flavored; clingstone; mid-season.

Owatona. Americana. 1. Wis. Sta. Bul. 63:52. 1897. 2. Wis. Hort. Soc. Rpt. 137.

1899. 3. S. Dak. Sta. Bul. 93:31. 1905. 
A wild variety from Owatonna, Minnesota. Trces hardy, productive; fruit medium in size, oblong; suture distinct; red; flesh yellow, tender, bitter; lacking in flavor; mid-season.

Owen Sound. Species? I. Can. Hort. 11:259. 1888. 2. Ibid. 14:350. 1891.

Owen Sound Beauty I, 2.

A seedling grown by R. Trotter of Owen Sound, Ontario, from pits of an unnamed plum. Tree strong, healthy; fruit large, roundish-oblong; suture distinct, dividing the plum into unequal parts; brownish-purple; dots light, numerous; bloom thick; flesh orangc, very juicy, rich and excellent; freestone; late.

Oxford. Nigra. 1. Wis. Sta. Bul. 63:52, 1897. 2. S. Dak. Sta. Bul. 93:30. 1905.

This variety is from Minnesota and resembles Aitken, but is more vigorous; lacks productiveness; fruit large, roundish-oval, deep red; flesh orange-yellow; good; stone large, thin, clinging; very early.

Oyama. Triflora. 1. Can. Exp. Farms Rpt. 119. 1904. 2. Am. Pom. Soc. Rpt. 66. 1905.

A seedling of the Red June grown at the Central Experimental Farm, Ottawa, Canada, from seed planted in 1895 . Fruit of medium size, roundish to broad-oval; cavity narrow, of medium depth, abrupt; suture a distinct line, not depressed; apex rounded; deep red; dots obscure; bloom thin; flesh yellow, firm, juicy; sweet, not rich; quality medium; stone small, oval, clinging.

Paddock Magnum Bonum. Domestica. I. Floy-Lindley Guide Orch. Gard. $420 . \quad$ I846.

Originated from a pit brought from Russia in 1805 by a Captain Paddock. Closely resembles the Red Magnum Bonum of which it may be a seedling; clingstone.

Paine. Domestica. 1. Am. Jour. Hort. 3:97. 1868. Paine's Seedling 1.

A chance seedling raised by A. W. Paine of Bangor, Maine. Fruit medium to large; oval; cavity shallow, one-sided with a small lip; stem long, stout; suture slight; golden-yellow, blotched with red; bloom thin; flesh yellow, coarse, rich, sweet; clingstone; early.

Faisan Blanche. Domestica. I. Knoop Fructologie 2 :60. I 77 1.

Paisan Blanche et Double I. Prune de Paisan blanche and simple 1 .

Fruit large, round; suture large, deep; greenish-yellow; flesh soft, juicy; good; clingstone; very productive.

Paisan Noire. Domestica. I. Knoop Fructologie 2:60. 1771.

Prune de Paisan Noire 1 .

Said to resemble "Paisan Blanche" in form, size and productiveness but is purple and the suture is a little dceper, flesh more watery and inferior in flavor.

Palmer. Triflora. 1. U.S. D. A. Pom. Rpt. 46. 1895. 2. Am. Pom. Soc. Rpt. 47. 1897.

Probably a seedling of Abundance, grown by J. S. Breece of Fayetteville, North Carolina, about 1892 . Fruit of medium size, roundish-conical, coppery-red with numerous russet dots; bloom light; skin thin, bitter; flesh yellowish, translucent with yellow veins, meaty, tender, juicy, fibrous, mild subacid, rich; good to very good; stone large, long, oval, clinging; very early.

Pander. Triflora. I. Am. Pom. Soc. Rpt. 47. 1897. 
A seedling of Abundance grown by J. S. Brece, Fayetteville, North Carolina. Fruit large, roundish, light to dark crimson; dots minute russet, raised; bloom slight; skin thin, slightly bitter; flesh yellow, translucent, rather firm, meaty, juicy, sugary vinous, rich; very good; stone oval, medium in size, clinging; season with Wild Goose. Pappaconi. Domestica. x. Noisette Man. Comp. Jard. 2:499. 1860.

Imported into France from the Royal Gardens of Naples. Fruit larger than Dame Aubert, brilliant yellow, ripens in September.

Papeleu. Domestica. 1. Hogg Fruit Man. 716. 1884.

Fruit medium in size, round, symmetrical; stem moderately long, set in a narrow depression; suture very shallow; golden-yellow when ripe, mottled with pale straw color; dots small, crimson; bloom light; flesh yellow, tender and juicy, rich, sugary and highly flavored; freestone; mid-season.

Paquet. Domestica. I. U. S. D. A. Pom. Rpt. 26, Col. Pl. I894.

Originated in 1889 with Peter Paquet, Oregon City, Oregon. Fruit very large, oval; cavity large, deep, regular; stem about an inch long, rather stout, curved; suture moderate; apex truncated; yellow washed with red; dots many, yellow; skin thick; flesh yellow; very good; stone oval, semi-clinging; early.

Park. Domestica $X$ ? 1. Kerr Cat. 1894. 2. Ibid. 25. 1897. 3. Ohio Sta. Bul. $162: 256,257$. 1905 .

Kerr says this is reputed to be a hybrid of Prunus domestica with a native variety. Tree upright-spreading; fruit above medium size, oblong-oval; cavity broad and deep; stem of medium length, stout; greenish-yellow; flesh yellow; good; stone of medium size, clinging; mid-season.

Parker. Species? x. Wis. Sta. Bul. 63:52. r 897.

Reported as very productive and regular in bearing; fruit large; good; early.

Parrott. Species? 1. Kan. Hort. Soc. Rpt. 30:63. 1908-09.

Parrott originated with A. H. Griesa, Lawrence, Kansas. Fruit small, bright red; bloom thin; stone small; very late.

Parsonage. Domestica. x. Downing Fr. Trees Am. 367 . 1857.

Originated at Rhinebeck, Dutchess County, New York. Tree very vigorous, upright, productive; fruit medium to large, oval; stem medium; cavity small; pale yellow splashed with green; flesh yellow, juicy, rich; freestone; mid-season.

Partridge. Species? I. Can. Exp. Farm Bul. and Ser. 3:54. 1900. 2. Can. Exp. Farms Rpt. 548. 1901.

Grown at the Experimental Farm, Agassiz, British Columbia. Tree vigorous; fruit medium, round; suture distinct; red with white bloom; flesh yellowish, sweet, pleasant; early.

Pasqua. Nigra? I. Can. Exp. Farms Rpt. 426. 1900.

Sent out by Thomas Frankland, Stonewall, Manitoba. Fruit large, red; late. Pathfinder. Triflora $\times$ (Triflora $\times$ Simonii?) 1 . Rural N. Y. 68:752. 1909.

Pathfinder, a cross between Chabot and Wickson, was grown by William Strong Arkansas. Fruit heart-shaped, strongly pointed, dark colored; flesh firm, fine-grained and sweet. 
Patten A. Munsoniana. x. Ia. Sta, Bul. 46:286. I goo.

Received by the Iowa Experiment Station from C. G. Patten, Charles City, Iowa, with whom the variety originated. Fruit medium in size, ellipsoidal, flattened at both ends; cavity deep; suture a well-marked groove; bright red to purplish-red; dots small, numerous; bloom thin; flesh firm, meaty; good; stone of medium size, winged, flat, clinging; not introduced.

Patten B. Americana. I. Ia. Sta. Bul. 46:286. I 900.

Of the Stoddard type, from C. G. Patten, Charles City, Iowa. Fruit medium to large, conical, somewhat pointed; cavity shallow; stem long; suture clearly outlined; apex pointed; dark purplish-red; dots numerous, small; bloom thick; skin thick, brittle; flesh yellow-brown; good; stone large, flat, clinging.

Peach Leaf. Hortulana. 1. Wis. Sta. Bul. 63:52, I897. 2. Vt. Sta. An. Rpt. Ir :285. 1898. Peachleaf 2.

A variety of unknown origin grown for many years by B. A. Mathews of Iowa. Given as synonymous to Kanawha by the American Pomological Society. Waugh says this is an error. Fruit medium in size, round; cavity slight; suture a faint line; deep wine red; dots many, small; flesh yellow, firm; good; stone medium, rough.

Peach-plum. Domestica. x. Ray Hist. Plant. 2:1529. 1688. 2. Rea Flora 208. 1676.

Peach Plum I.

A yellow variety grown in the Seventeenth Century.

Peake. Domestica. I. Parkinson Par. Ter. 578, 1629.

Parkinson says of it, "long, whitish and very good."

Pearl. Americana mollis. x. Kerr Cat. II. I898. 2. Terry Cat. 5. 1900. 3. Ill. Hort. Soc. Rpt. 424. 1905.

From H. A. Terry, Crescent, Iowa; grown from seed of Van Buren planted about I89I. Tree very productive, vigorous, upright; fruit large, white becoming pale red; of best quality; ripens last of August.

Pear Plum. Domestica. x. Kraft Pom. Aust. 2:45, Tab. I99 fig. 2. 1796. 2. N. E. Farmer Dict. 266. 1797 .

Die veilchenfarbige Birnpflaume I. Prune poire grosse violette I.

Kraft in 1796 described a little-known Pear plum. Tree medium in size, unproductive; fruit very large, pear-shaped; suture distinct; stem long; reddish-purple; flesh juicy, unpleasant; freestone. This may or may not be the same as the New England variety of this name mentioned in the references.

Peasant. Species? I. Can. Exp. Farm Bul. 2nd Ser. 3:55. I9oo.

Tested by the Experimental Farm at Agassiz, British Columbia. Tree vigorous; fruit small, roundish, purple; flesh yellowish, juicy, sweet; mid-season.

Peerless. Americana. 1. Meneray Cat.

A seedling of Harrison grown by H. A. Terry and introduced by F. IW. Menera:, Council Bluffs, Iowa. Fruit large, oblong, dark red; skin thin; flesh yellow, firm; good; freestone.

Pekin. Species? Letter from Kerr.

Originated by Theodore Williams, Benson, Nebraska. 
Pendent. Munsoniana $\times$ Hortulana mineri. 1. Kerr Cat. 19. 1898. 2. Vt. Sta. Bul. $67: 18 . \quad 1898$.

A cross between Pottawattamie and Forest Garden from Theodore Williams of Benson, Nebraska; introduced by J. W. Kerr in I898. Tree slender, a rapid grower, productive; fruit medium to large, roundish inclined to oblong, red; semi-clinging; mid-season.

Penning. Americana. I. Kerr Cat. Ir. I897. 2. Waugh Plum Cult. I60. I901.

Penning's Free 2. Penning's Free 1.

Originated with Martin Penning of Minnesota; a perfect freestone.

Penning Peach. Americana. I. Kerr Cat. 7. I896. 2. Wis. Sta. Bul. 63:52. 1897.

3. Kerr Cat. זx. 1899.

C. W. H. Heideman of Minnesota says this variety was introduced about thirty years ago as the Peach plum and was sold under that name by Northwestern nurserymen; he added the name Penning to avoid confusion; it closely resembles Harrison and is by some considered identical with that variety. Tree hardy and healthy, a shy bearer; fruit medium to large, oblong, purplish-red; flesh sweet; semi-clinging; midseason.

Penobscot. Domestica. I. Horticulturist 1:196. I846. 2. Elliott Fr. Book 428, 1854 . 3. Am. Pom. Soc. Cat. $222,244.1858$.

Originated about $184^{\circ}$ with James McLaughlin of Bangor, Maine. Rejected by the American Pomological Society in $185^{8}$. Tree productive; fruit large, oval; suture distinct; cavity small; stem of medium length; greenish-yellow with a red blush in the sun; bloom thin; flesh yellow, sweet; flavor pleasant; stone long, pointed at both ends, clinging; early.

Pennock. Prunus besseys $\times$ Domestica? 1. Vt. Sta. Bul. 67:18, 1898, 2. Colo. Sta. Bul. 50:43. I898. Pennock's Hybrid 2.

Pennock was raised in 1893 by C. E. Pennock of Fort Collins, Colorado, from seed of Prumus besseyi supposed to have been pollinated by Arctic. Tree dwarfish, upright; leaves of medium size, ovate, coarsely serrate, thickish, finely tomentose on either side; petiole short, stiff, sometimes with one gland at the base of the blade; fruit small, roundish; suture slight; deep blue; bloom heavy; flavor intermediate between the plum and cherry; stone small, round and cherry-like.

Peoly Early Blue. Domestica. I. Downing Fr. Trees Am. 309. 1845. 2. Thomas Am. Fruit Cult. 346 . I849.

From Massachusetts. Fruit medium in size, oblong; stem short; suture obscure; dark blue; bloom light; flesh yellow; pleasant; fair quality; semi-clinging; early.

Perdrigon des Alpes. Domestica. 1. Lond. Hort. Soc. Cat. 151. 1831.

The London Horticultural Society listed Perdrigon des Alpes and Perdrigon Violet des Alpes as distinct varieties but there seems to be little difference between them.

Perdrigon of Cernay. Domestica. I. Quintinye Com. Gard. 68, 69. 1699.

Cernay Perdrigon $\mathbf{I}$.

Mentioned in the preceding reference as round or oblate, with a dry and mealy flesh. 
Perdrigon Tardif. Domestica. r. Quintinye Com. Garl. 67. 1699. 2. Lond. Hort. Soc. Cat. 151. 1831. 3. Mas Pom. Gen. 2:125. 1873. 4. Mathieu Nom. Pom. 450. 1889 .

Damas de Septembre 4 incor. Königs Pflaume aus Paris 4 . Königspflaume von Paris 3. Later Perdrigon I. Royale de Paris Tardive 4. September Damascene 4 incor. Spāte Herrn Pflaume 4. Späte Königs Pflaume 4. Spate Königs Pflaume aus Paris 4. Später Perdrigon 4. Spater Perlrigon 3.

Quintinye, in 1699 , mentioned a Later Perdrigon which is probably this variety. Duhamel confused this variety with the Impératrice but they are distinct. In America this Perdrigon is unknown. Tree small; leaves small, obovate; flowers very small; fruit small, roundish-ellipsoid; suture distinct; skin thick, purplish-black; stem short; cavity shallow; flesh yellowish, fine, firm, sweet; freestone; late.

Pershore. Domestica. 1. Hogg Fruit Man. 375. 1866. 2. Mlas Pom. Gen. 2 :111. 1873. 3. Garden 49:225. 1896. Pershore Yellow Egg 3.

Grown largely in the Pershore district, Worcester County, England. Tree vigorous, productive; fruit medium, obovate; suture indistinct; golden-yellow; flesh clear yellow, neither juicy nor sweet; quality fair; stone small, clinging; fit only for culinary purposes; propagated by suckers.

Petite Quetsche Sucrée. Domestica. 1. Mas Pom. Gen. 2:181. 1873. 2. Mathieu Nom. Pom. 437. 1889.

Ananas Zwetsche 2. Kleine Zuckerzwetsche 2. Kleine Zucker Zwetsche 1.

A German variety produced from seed of Violette Diaper. Fruit small, oval; suture shallow; cavity small; stem slender; dark purple; bloom thick; flesh yellow, fine-grained, juicy, sweet; freestone; mid-season.

Phiolenartige Gelbe Zwetsche. Species? I. Mathieu Nom. Pom. 442. 1839.

Mathieu found the name of this variety in Wiener Garten-Zeitung 288. 1884.

Pilot. Americana. r. Wis. Sta. Bul. 63:24, 52. 1897. 2. Ibid. 87:15. 1901. 3. Dak. Sta. Bul. 93:31. 1904.

Originated with M. E. Hinckley at Marcus, Iowa, from seed of a wild plum gathered on the Little Sioux River near Cherokee, Iowa; seed planted in 1870 . Tree open, spreading, drooping; fruit large, oblong-oval with rounded apex; suture distinct; yellow mottled with light and dark red; skin thick, tough; flesh firm, rich and sweet; good; stone long-oval, pointed, margined; mid-season; cracks and rots in wet seasons.

Pink Damson. Insititia? I. Montreal Hort. Soc. Rpt. 93. 1885.

Fruit small, pinkish-red; flesh light pink, soft; quality fair; very early.

Pioneer Prune. Domestica. I. Pioneer Nur. Cat. 1900.

A variety grown for several years by the Pioneer Nursery Company, Salt Lake City, Utah; discarded because of its close resemblance to the Italian Prune.

Piper. Americana. 1. Am. Pom. Soc. Rpt. 162. 1891. 2. Wis. Sta. Bul. 63:52. 1897. 3. Ia. Sta. Bul. 46:287. 1900. 4. Wis. Sta. Bul. $87: 15,16$ fig. 4. 1901.

Piper's Peach 1, 2, 3. Piper's Peach 4.

Found wild near Mankato, Blue Earth County, Minnesota, about 1887 by J. S. Harris of Crescent, Minnesota. Tree vigorous, upright, hardy, productive; fruit large, 
round, bright red; flesh orange-yellow, sweet and rich; good; stone roundish, slightly margined, nearly free; mid-season; mentioned in the catalog of the American Pomological Society in 1899 .

Piram. Angustifolia varians. I. Cornell Sta. Bul. 38:80, 1892, 2. Tex. Sta. Bul. 32:490, 491. 1894. 3. Waugh Plum Cult. 197. 1901.

A seedling from Goliad County, Texas, originated by G. Onderdonk; named after Piram Hall about I875. Tree hardy, productive; fruit medium to large, roundish; suture indistinct; light yellow; dots white; bloom thin; skin thin and tender; flesh yellow, soft, sweet; fair to good; clingstone; mid-season.

Pissardi. Cerasifera. x. Rev. Hort. 191. 1881. 2. Gard. Mon. 25:367. 1883. 3. Rural N. Y. 44:479. 1885. 4. Gard. and For. 1:178. 1888. 5. Garden 55:314. 1899.

6. Bailey Cyc. Hort. 1447. I901.

Prunus Cerasifera Atropurpurea 5. Prunus Pissardi 5. Prunus Pissardii 3. Purple-leaved Plum 3. The Purple Myrobalan 5. Prunus Pissardi I, 2, 4.

See Prunus cerasifera, p. ooo. Tree large; shoots purplish; foliage while unfolding tinged with red, later becoming dark purple; fruit medium in size; skin purplish, showing color in unripe stage, thin, tough; suture obscure; flesh firm, juicy, moderately acid, inferior in quality; clingstone.

Plantz. Domestica. I. Cal. State Bl. Hort. Rpt. 129, I30 fig. I891.

Plantz's Seedling I.

A chance seedling found by W. A. Plantz of New Castle, California, about r 883. Tree thrifty, productive; fruit large, oval, tapering towards the stem, reddish-purple; flesh yellow sugary, rich, juicy and sweet; ripens in California about three weeks before the Hungarian Prune.

Plunk. Americana. I. Wis. Sta. Bul. 63:44. 1897. 2. Kerr Cat. 9. 1897. 3. Waugh Plum Cult. r6o. Igor. Large Red Sweet 3. Large Red Sweet I, 2.

Introduced by Charles Luedloff, Cologne, Minnesota. Tree a rapid grower with good foliage; fruit large, round, dark red or purplish-red; flesh reddish, not juicy, very sweet; good; clingstone; early.

Pomaria. Domestica. 1. Am. Pom. Soc. Rpt. 189. 1867.

A seedling of the Reine Claude from South Carolina, about 1867. Tree productive; fruit medium in size, blue; bloom heavy; superior to its parent in flavor.

Pomona. Americana $\times$ Hortulana mineri? x. S. Dak. Sta. Bul. 93:31. 1904.

Originated by E. D. Cowles, Vermilion, South Dakota; under test at the South Dakota Experiment Station. Said to be "a natural cross of Forest Garden and Miner."

Pond Purple. Domestica. 1. Kenrick Am. Orch. 209. 1835. 2. Downing Fr. Trees Am. 309. 1845. 3. Thomas Am. Fruit Cult. 344 fig. 368. 1867.

Pond's Purple 2. Pond's Seedling 2, 3.

Grown in the garden of Henry Hill, Boston; introduced by Samuel Pond of Cambridge, Massachusetts. As it resembles the well-known Pond, it has been confused with that variety. Young branches downy; fruit of medium size, roundish; stem 
short; purple; flesh yellowish, rather dry, sweet, mingled with acid; quality fair; freestone; early.

Pontbriant. Domestica. 1. Pom. France 7:30 fig. 1871. 2. Cat. Cong. Pom. France 344. 1887. De Pontbriant 2. Prune De Pontbraint 1.

Raised by M. F. Morel, Lyons, France, from seed of the Purple Gage planted in 1851 . Tree of medium vigor; fruit large, round, a little more truncated at the base than at the apex; cavity narrow, shallow; stem long and stout; suture shallow and wide; reddish-purple, deeper on the sunny side; bloom heavy; flesh pale yellow, medium fine grained, melting, very juicy, with a very sweet and aromatic flavor; freestone.

Pontford. Domestica. 1. Watkins Cat. 46. 1892?

Tree very productive; fruit of medium size, purple; mid-season; suitable for market

Pontotoc. Hortulana. I. Vt. Sta. An. Rpt. I1:286. 1898.

Ifentioned in the catalog of F. T. Ramsey in 1898 as not yet well tested.

Porsch Rote Zwetsche. Species? Listed in Mathieu Nom. Pom. 443. I889.

Potter. Americana? 1. Waugh Plum Cult. 233. I901.

Mentioned by Waugh who says it originated in Cherokee County, Iowa, and is probably an Americana.

Poupart. Domestica. 1. Hogg Fruit Man. 717. 1884. Poupart's 1.

Mr. Poupart, market gardener at Brompton, grew this variety, according to Hogg, who says it is an enormous bearer and an excellent preserving plum. Fruit medium, nearly round, resembling Purple Gage; light purple, dotted and streaked with darker shades; flesh reddish, firm, sweet, with a Sloe flavor; freestone.

Powell Damson. Insititia. I. Watkins Cat. 48 . 1892?

Mentioned in the preceding reference as a new variety. Tree vigorous, productive and large.

Prairie Flower. Hortulana mineri. I. Col., O., Hort. Soc. Rpt. 5:10. 189o. 2. Ia. Hort. Soc. Rpt. 276. 1893. 3. Mich. Sta. Bul. 118:54. 1895. 4. Waugh Plum Cult. 175. I 901. Prairie 3. Prairie Flower 3.

Prairie Flower, a supposed seedling of Miner, originated in Adrian County, Missouri; introduced by Stark Brothers about 1884 . Fruit of medium size, roundishoval; suture a line; cavity shallow; skin thick, red over yellow; bloom thin; flesh yellow; good; stone oval, slightly flattened, clinging; season late. Mentioned in the last two issues of the catalog of the American Pomological Society.

Prairie Rose. Nigra? I. Can. Exp. Farms Rpt. 426. 1900.

A seedling raised at the Experimental Farm at Indian Head, Northwest Territory, Canada. Fruit of medium size, red; good; mid-season.

Précoce Defresne. Species? Mentioned in Mathieu Nom. Pom. 443. I889.

Précoce de Freudenberg. Domestica. I. Mathieu Nom. Pom. 430. 1889. 2. Guide Prat. 156, 361. 1895.

Freudenberger Früh Pflaume 1. Fremlenberger Früh Pfaume 2. Précoce de Freudenberg 1.

This variety is of German origin. Fruit of medium size, oval, reddish-brown; flesh yellow, firm; good; early. 
Précoce de Lucas. Domestica. 1. Downing Fr. Trees Am. 2d App. 156. 1876. 2. Mathicu Nom. Pom. 439. 1889. 3. Lucas Vollst. Hanl. Obst. 474. 1894.

Lucas Frühzwetsche 2, 3. Précoce de Lucas 2. Quetsche Précoce de Lucas 2.

Of foreign origin; tree vigorous, an early and abundant bearer; fruit large, oval; stem long, slender; dark blue; bloom heavy; flesh greenish, juicy, sweet; freestone; mid-season.

Précoce de Reutlinger. Domestica. Can. Exp. Farms Rpt. 433. T905.

Précoce de Reutlinger Prune I.

Tested at the Experimental Farm at Agassiz, British Columbia. Fruit below medium size, oval; stem short; cavity small; suture well defined and one side enlarged; deep purple; flesh yellowish, tender, sweet, juicy, rich; stone small, free; mid-season.

Premium. Americana. I. Cornell Sta. Bul. 38:41. 1892, 2. Colo. Sta. Bul. 50:43. I 898 . Peffer's Premium s, 2.

Introduced by George P. Peffer of Pewaukee, Wisconsin. Tree vigorous with an open top, productive; leaves of medium size, broad-ovate; fruit medium in size, round or inclining to oblate; cavity very shallow; stem medium; suture nearly obsolete; deep red over orange-yellow; dots numerous, small; bloom thin; flesh yellow, firm; fair to good; stone circular, smooth, clinging; mid-season.

Preserver. Triflora $\times$ Angustifolia varians. 1. Vt. Sta. Bul. 67:18. 1898. 2. Kerr Cat. II. 1900 .

A supposed cross between Kelsey and Early Red; from D. H. Watson, Brenham, Texas; introduced by William A. Yates in 1897 . Tree vigorous, compact; fruit of medium size, roundish, dark red; flesh red, firm; mid-season.

President. Americana. I. Meneray Cat. The President I.

A seedling of Harrison grown by H. A. Terry, and introduced by F. W. Meneray, Council Bluffs, Iowa. Tree productive; fruit large, yellow, covered with red; flesh yellow, sweet, rich, firm; semi-clinging.

President. Domestica. 1. Gard. World 12:123. 1895. 2. Garden 58:294. 1900. 3. Ibid. $64: 262$. 1903 .

Raised by Thomas Rivers of Sawbridgeworth, England; first fruited in I894 and introduced in 1901 by the originator. Tree compact, productive; fruit large, oval, deep purple almost black; bloom heavy; flesh with a sweet, rich flavor; freestone; late. Recommended for culinary and market use.

President. Triflora $\times$ Simonii. I. Vt. Sta. An. Rpt. 12:226. 1899 .

Grown by Luther Burbank as a seedling of Wickson; named by Waugh in 1899. Fruit large, heart-shaped; cavity deep, rounded; stem short, very stout; suture shallow; apex pointed; dark, fire-red; dots many, minute; bloom thin; skin thin; flesh firm, meaty, yellow; flavor peculiar, a trifle like musk-melon; quality poor; stone large, oval, pointed, flattened, semi-clinging.

President Courcelles. Domestica. 1. Guide Prat. 162, 36r. 1895. 2. Can. Exp. Farms Rpt. 401. 1898. 3. Can. Exp. Farm Bul. and Ser. 3:55. 1900.

President Courcelle 3 . 
Tested at the Experimental Farm at Agassiz, British Columbia. Tree vigorous; fruit of medium size, globular or sometimes heart-shaped; suture shallow; purple; flesh pale yellow or greenish, juicy, sweet, pleasant; mid-season.

Presley. Hortulana mineri $\times$ Hortulana. x. Vt. Sta. An. Rpt. 12:227. I899.

From A. L. Bruce, Basin Springs, Texas. Waugh says its parentage is probably Miner by Wayland. Fruit of medium size, inclined to oval; cavity shallow; bright red; dots numerous, indistinct; flesh yellow; good; stone small, round, flattened, clinging. Price. Americana. r. Meneray Cat. Prof. Price 1.

A seedling grown by H. A. Terry; introduced by F. W. Meneray, Council Bluffs, Iowa. Fruit large, oblong, yellow, tinged with red; good; clingstone.

Pride of Waterloo. Domestica. 1. Downing Fr. Trees Am. 3rd App. 182 fig. 1881. 2. IV. N. Y. Hort. Soc. Rpt. 44:92. 1899. Pride of Waterloo? 2.

Raised by A. H. Doles, Waterloo, New York, from seed of Smith Orleans; distinct from Pond with which it is sometimes confused. Tree upright, vigorous, very productive; branches smooth, reddish-brown; fruit large, oval, narrowing towards the stem; suture indistinct; cavity large; stem medium in length and thickness; reddish-purple; bloom thin; flesh deep yellow, coarse, juicy, sweet, sprightly, not rich; stone slightiy adherent; mid-season.

Primate. Domestica. I. Rivers Cat. 35. I898-9. 2. Thompson Gard. Ass't 4:159. 1901. 3. Can. Exp. Farms Rpt. 433. 1905.

A seedling first fruited by Thomas Rivers, Sawbridgeworth, England, in r 890 , and introduced by him in $\mathbf{1} 897$. Fruit large, round; stem short, set in a medium cavity; suture distinct; sides often unequal; purplish-red; dots numerous, small, golden; bloom thin; flesh yellowish, juicy, sweet; good: stone small, free; ripens late and hangs well after maturing.

Prince. Domestica. 1. Ray Hist. Plant. 2:1529. 1688. Violet.

Ray mentions a variety by this name. It may be the same as Gloucestershire

Prince Early Damson. Insititia. I. Prince Pom. Man. $2: 87 . \quad$ I 832 .

Prince's Early Purple I.

A seedling raised by William Prince. Fruit of medium size, ovate, dark purple, pleasant; freestone; early.

Prince Orange Egg. Domestica. 1. Downing Fr. Trees Am. 392. 1857. 2. Mas Pom. Gen. $2: 187.1873$.

Oeuf Orange De Prince 2. Prince's Orange Egg 2.

Grown by William Prince. Tree vigorous, productive; fruit large, globular; cavity medium; stem short, stout; reddish-purple; dots brownish-yellow; bloom thick; flesh greenish-yellow, a little coarse, juicy, sweet and sprightly, not rich; semi-clinging; mid-season.

Prince Orange Gage. Domestica. I. Downing Fr. Trees Am. 405. 1857.

Noted only by Downing, who describes it as follows: "Fruit medium, roundishoval; suture moderate; skin yellow; stalk long, set in an open cavity; flesh light yellow, coarse, juicy, pleasant, but not rich; adheres to the stone; first of September." 
Prince Primordian. Domcstica. 1. Prince Treat. Hort. 25. 1828. 2. Prince Pom. Man. 2:79. 1832 .

Prince's Blue Primordian I. Prince's Blue Primordian 2.

A seedling of White Primordian, grown by William Prince. A very early varicty, of about the same size as its parent, oval in shape, blue; flesh pleasantly flavored.

Pringle. Insititia? 1. U. S. D. A. Rpt. 503, P1. 63. I905.

Pringle is a Damson-like variety originating as a sprout from the stock of a Lombard tree in the orchard of A. C. Pringle, Mears, Michigan; introduced by E. Hawley \& Sons of IIart, Michigan, about 1896 .

Pringle Blue. Domestica. I. N. Y. Sta. Rpt. 12:612. I893.

Received by the New York Experiment Station in 1890 from L. M. Macomber, North Ferrisburg, Vermont. Tree very productive; fruit large, irregular-oval; cavity medium; suture shallow; skin thin, tender; purplish-black; bloom thick; dots small, numcrous; flesh pale yellow, dry, firm; flavor flat; fair; stone semi-clinging; midseason; of no value.

Pringle Purple. Domestica. I. N. Y. Sta. Rpt. 9:347. I89o.

Received by the New York Experiment Station in 1890 from L. M. Macomber, North Ferrisburg, Vermont. Tree productive; fruit of medium size, roundish, compressed; cavity small; suture a line; skin thin, tender; reddish-purple, unattractive; bloom thinnish; dots small, numerous; flesh light yellow, moderately juicy, slightly fibrous, firm, mild; good; stone nearly free; mid-season; of no value.

Procureur. Domestica. 1. Mas Pom. Gen. 2:63. 1873.

Platte Hellrothe Konigsplaume 1 .

Probably of French origin. Tree vigorous, early, productive; fruit large, round, flattened at the ends; suture well defined; dull yellow, almost covered with bright purple; bloom thin; flesh pale yellow, juicy, sweet, aromatic; quality fair; stone small, free; mid-season.

Profuse. Species? Letter from Kerr.

Originated by Theodore Williams, Benson, Nebraska.

Prof. Wittmack. Insititia? $\times$ Domestica? 1. Gard. Chron. 3:364. I 888 .

The parentage of this variety is not definitely known but it is thought to be a Mirabelle crossed with Italian Prune; grown by Herr Ulhorn, Grevenbroich, Lower Rhenish Prussia. A sweet plum of the prune type; freestone; good for either dessert or drying.

Pruneau. Species? 1. Am. Pom. Soc. Rpt. II 7 . I875.

Reported from Quebec, Canada, in 1875; commonly grown from suckers.

Prune d'Agen Double. Domestica. Mentioned in Mathieu Nom. Pom. 420. I889.

Prune d'Amour. Domestica. Listed in Mathieu Nom. Pom. 421. I889.

Prune d'Automne. Domestica. 1. Mas Ponn. Gen. 2:9. I873. Herbstplaume I.

Raised by Dr. Dorell of Kuttenberg, Bohemia. Tree of capricious growth; fruit small, globular; suture indistinct; purplish-black; flesh greenish-yellow, juicy; good; freestone; late.

Prune de Laghouat. Domestica? Mentioned in Mathieu Nom. Pom. 438. 1889. 
Prune d'Ente Impériale. Domestica. Mentioned in Mathieu Nom. Pom. 429. I889. Prune de Rudolphe. Domestica. I. Mas Pom. Gen, 2:189. 1873.

Rudolph's Pflaume I.

Liegel received this variety in $188_{2}$ from Count Bressler of Hungary. Origin uncertain. Tree vigorous, an early and prolific bearer; fruit medium in size, obovate; suture indistinct; golden-yellow, dotted with red; flesh clear ycllow, sweet, juicy; good; stone obovate, clinging; mid-season.

Prune de Seigneur. Species? Mentioned in Mathieu Nom. Pom. 450. I889. Prune de Prince.

Prune Tardive. Domestica, I. Downing Fr. Trees Am. 2nd App. I57. 1876.

Tree vigorous, very productive; fruit below medium size, oval; stem long, slender, set in a small cavity; black; bloom thick; flesh greenish-yellow, juicy, swect; freestone; very late.

Pseudo Mirabelle. Insititia. Mentioned in Lond. Hort. Soc. Cat. 152. I831.

Purple Favorite. Domestica, I. Downing Fr. Trees Am. 307. fig. 126, 1845.

2. N. Y. Agr. Soc. Rpt. 293 fig. 1848. 3. Mag. Hort. $16: 455,456$ fig. 27.1850.

4. Mas Le Verger 6:83, fig. 42. 1866-73

Favorite Pourpre 4. Purple Favourite 4.

The original tree of Purple Favorite was planted at Newburgh, New York, by the father of A. J. Downing; from whence it came is not known. Fruit of medium size, roundish; cavity slight; suture lacking; brownish-purple; bloom thin; flesh pale ycllow, tender, juicy, sweet; quality very good; stone small, round, free; mid-season. Listed in the American Pomological Society catalog since $185^{2}$.

Purple Flesh. Triflora. I. Stark Bros. Cat. I 909.

A purple-fleshed variety introduced by Stark Brothers and recommended by them as being hardy.

Purple-leaved Hybrid. Triflora $\times$ Cerasifera. I. Burbank Cat. I6 fig. 1893.

K. P. I93 I.

A scedling of Kelsey pollinated by Pissardi; from Luther Burbank, Santa Rosa, California. Resembles the male parent in wood, bark, leaves, flowers and fruit; very ornamental on account of its large purple leaves. Fruit larger than Pissardi, dark purple with many white dots; bloom thin; flesh reddish-purple throughout, firm, subacid; good; ripens several weeks before Kelsey.

Purple Panhandle. Angustifolia watsoni. I. Kerr Cat. 1894. 2. Ibid. 21. 1897.

3. Bailey Ev. Nat. Fruits 222, 223. 1898. 4. Waugh Plum Cult. 233. 1901.

Introduced from the Panhandle of Texas by F. T. Ramsey, Austin, Texas. Tree small, rapid in growth; fruit below medium in size, round-oblong, inclining to conic, purplish-red; quality poor; clingstone; early to mid-season.

Purple Yosemite. Species? I. Gard. Mon. 20:176. 1878. 2. Penin. Hort. Soc. Rpt. 65. 1891. 3. Can. Exp. Farm Bul. 43:32. 1903.

Yosemite 1. Yosemite Purple 3.

Introduced by W. S. Carpenter of Rye, New York, who secured it from the " Rocky Mountains." Fruit large, roundish; cavity shallow; suture a line; skin thick, deep, 
dull red; dots yellow, distinct; bloom medium thick; flesh yellow, juicy, sweet; quality fair; stone oval, flattened, clinging; mid-season.

Puymirol d'Ente. Domestica. 1. Wickson Cal. Fruits 356. $189 \mathrm{r}$.

Originated at Puymirol in the southwest of France; introduced into California; a type of the Agen. Tree productive; fruit large, inclined to oblong; flesh very sweet; ripens a little earlicr than Agen.

Quaker. Americana. 1. Ia. Hort. Soc. Rpt. 308. 1884. 2. Waugh Plum Cult. 160. 1901.

Found in the wild by Joseph Bundy of Springville, Linn County, Iowa; introduced about 1862 by H. C. Raymond, Council Bluffs, Iowa. Fruit large, roundish; cavity shallow; suture a line; stem long; skin thick, dark red; bloom thick; dots many; flesh yellow, sweet, pleasant; good; stone large, oblique-oval, flattened, semiclinging; mid-season.

Quality. Americana. 1. Wis. Sta. Bul. 63:24, 55. 1897. 2. Ia. Sta. Bul. 46:287. 1900. 3. Wis. Sta. Bul. 87:15. 1907. Gaylord Quality 2.

Of unknown origin; top-grafted about 1880 by Edson Gaylord of Nora Springs, Iowa, who afterwards distributed the variety. Fruit below medium in size, round, dull purplish-red; dots white; bloom heavy; flesh soft; quality fair; stone turgid; mid-season.

Quebec. Domestica. Mentioned in Can. Exp. Farm Bul. 43:38. 1903.

Queen. Americana. 1. Can. Exp. Farm Bul. 43:31. 1903. Gollen Queen r.

From H. A. Terry coming from unknown parents and bearing its first crop in 1897 . Tree upright; fruit large, round, bright golden-yellow; very good; said to be excellent for canning or dessert.

Queen May. Domestica. 1. Can. Exp. Farm Bul. 43:36. 1903.

First grown by Thomas Clark, Chateaugay, Quebec. Tree strong and productive; fruit large, round; cavity narrow; suture indistinct; greenish-yellow; bloom thin; dots indistinct; flesh greenish-yellow, juicy, firm, sweet, rich; very good; clingstone.

Queen Mother. Domestica? 1. Parkinson Par. Ter. 576, 577, 578. 1629. 2. Rea Flora 207. 1676. 3. Ray Hist. Plant. 2:1529. 1688. 4. Quintinye Com. Gard. 69, 70. 1699. 5. Langley Pomona 94, Pl. XXiv fig. 3. 1729. 6. Prince Pom. Man. 2:87. 1832. 7. Downing Fr. Trees Am. 310. 1845. 8. Floy-Lindley Guide Orch. Gard. 291. 1846. 9. Mas Le Verger 6:41. 1866-73. 10. Hogg Fruit Man. 719. 1884. I1. Mathieu Nom. Pom. 437, 448. 1889. 12. Guide Prat. I60, 361. I895.

Cherry of some ?1, ?3. Coeur de Pigeon ir. Damaske Violet ?1. Damas Violet 7, I1, 12. Königin Mutter 11. Moschatelle of some 3. Muscadine ?1. Petit Damas Rouge 9, 12. Petit Damas Rouge 6, 11. Pigeon's Heart 7, 10, 11, 12. Pigeons Heart 4. Queene Mother of some 1. Queen Mother 9, 11, 12. Red Queen Mother 7, 11. Rotes Taubenherz i1. Rotes Taubenherz i1. Small Red Damask 6. Small Red Damson 6.

Qucen Mother and Damas Violet have been confused for nearly three centuries, yet they are distinct, as our descriptions show. Hogg thought the Queen Mother 
mentioned by Ray and pictured as a cordate-shaped fruit by Parkinson, was the Myrobalan. Tree medium in size, compact, spherical; fruit small, nearly round; suture slightly pronounced, halves equal; cavity nearly lacking; stem medium in length; skin red to violet on the sunny side; flesh yellow, firm, juicy, sweet; good; freestone; mid-season.

Queen of Arkansas. Species? Mentioned in Tex. Sta. Bul. 32:490. I894.

Quetsche à feuille argentee. Species? I. Guide Prat. 162, 362. I895.

Frïhzwetsche mit Silberblatt I. Silberblattrige Zwetsche 1.

A variety from Hungary having silvery-colored leaves; said to ripen two weeks before the German Prune.

Quetsche Aplatie. Domestica. 1. Mas Pom. Gen. 2:23, 1873. 2. Mathieu Nom. Pom. 423. 1889 .

Breitgedrückte Zwetsche 2. Breitgedrückte Kaiser Zwetsche 2. Breitgedrickte Zwetsche 1. Donauers Zusammen Gedrückte Zwetsche I, 2. Plattrunde Zwetsche I, 2. Quetsche Aplatie 2.

Found in a garden by M. Donauer of Saxe-Cobourg, Gotha. Fruit of medium size, obovate, compressed; suture broad, shallow; dark purple; bloom thick; flesh green, sweet, aromatic; good; stone rough, free; mid-season.

Quetsche Buhl-Eltershofen. Domestica. I. Mas Le Verger 6:159. 1866-73.

A seedling raised by M. Liegel of Germany and named in honor of M. Buhl-Eltershofen. Fruit above medium size, long-ovate; suture distinct; deep purple; bloom light; flesh greenish-white, juicy; quality good; stone large.

Quetsche Datte des Allemands. Domestica. I. Guide Prat. 160, 362. 1895.

Fruit large, irregular-oval, darker color than German Prune; flesh yellow, sweet; good; late.

Quetsche de Dobrowitz. Species? I. Guide Prat. 160, 362. 1895.

Dobrowitzer Frühzwetsche I. Quetsche de Doubrawie I.

A Hungarian variety maturing about fifteen days earlier than German Prune.

Quetsche de Kreuter. Domestica? I. Mathieu Nom. Pom. 438. r889. 2. Guide Prat. 163,363 . I895.

Kreuter's Zwetsche r. Kreuters Zwetsche 2. Quetsche de Kreuter 1.

A variety of little merit.

Quetsche de Millot. Domestica. 1. Baltet Cult. Fr. 496. 1908.

Mentioned by Baltet as a better variety than the German Prune.

Quetsche De Ransleben. Domestica. I. Mas Pom. Gen. $2: 153$. I873.

Ranslebens Pflaume ז. Ranslebens Zwetsche r.

A seedling of Reine Claude raised by M. Ransleben of Berlin, Germany. Tree vigorous, an early and abundant bearer; fruit small, long-oval; suture indistinct; purplish-brown; thick bloom; flesh green, juicy; stone rough, free.

Quetsche de Transylvanie. Species? 1. Mathieu Nom. Pom. 450. 1889. 2. Guide Prat. $163,362.1895$.

Quetsche de Transilvanie 2. Siebenburger Zwetsche 1. Siebenburger Zwetsche 2. Mentioned as "of very doubtful value." 
Quetsche Dr. Létricourt. Domestica. 1. Le Bon Jard. Preface XLVII. 1882. 2. Mathieu Nom. Pom. 455. 1889. 3. Guide Prat. 161, 362. 1895.

De Pologne 3. Impériale Blanche ? 2, 3. Prune de Pologne 2. Quetsche de Létricourt 2. Quetsche de Létricourt 3. Quetsche Jaune 2, 3. Zwetsche Von Létricout 2.

Fruit elliptical, elongated at both ends; skin yellow, sometimes washed red; flesh yellowish, very juicy, sweet.

Quetsche Freestone. Domestica. 1. Mich. Sta. Bul. 205:37. 1903. 2. Mich. Sta. Sp. Bul. 27:15. 1904.

Probably a seedling of German Prune imported by the United States Department of Agriculture in 1894. Fruit small, oval; suture distinct; dark blue; flesh yellow, juicy, tart; late; inferior to German Prune.

Quetsche Hâtive. Domestica. I. Baltet Cult. Fr. 494. 1908.

A medium sized, long-oval, dark purple prune; good; early.

Quetsche Jaune Précoce. Domestica. I. Mas Le Verger 6:99, fig. 50. 1866-73.

2. Mathieu Nom. Pom. 431. I889.

Gelbe Frühzwetsche 1. Gelbe Frühzwetsche 2. Quetsche Jaune Précoce 2.

Fruit of medium size, oval, yellow; flesh yellow, sprightly, tender, juicy; said to make good prunes; early.

Quetsche Longue Précoce. Species? 1. Mathieu Nom. Pom. 444. 1889. 2. Guide Prat. 163,362 . 1895 .

A variety of little merit.

Quetsche Maraichére. Domestica. I. Mas Pom. Gen. 2:107. I873. 2. Mathieu Vom. Pom. 431. 1889. 3. Guide Prat. 163, 362. 1895.

Die Gartenzwetsche 3. Gartenpflaume 2, 3. Garten Pflaume 1. Garten Zwetsche 1, 2. Maraichère 3. Prune Maraichìre 1, 2. Quetsche Maraichère 2.

From M. M. Bauman \& Sons, Bollwiller, Germany. Tree of medium vigor, an early and abundant bearer; fruit medium, ellipsoidal; suture indistinct; skin dark purple; bloom thin; flesh yellow, sweet, aromatic; freestone; excellent for drying.

Quetsche Pointue. Domestica. I. Mas Pom. Gen. 2:51. 1873. 2. Mathieu Nom. Pom. 450. 1889.

Provinz Zwotsche 2. Quetsche de Province 1. Spitszwetsche 1. Spitzzwetsche 2.

Liegel received this variety in 1816 from M. Grob of Eichelstadt, Bavaria, under the name of Quetsche de Province. Tree vigorous, an early and productive bearer; fruit large, long-ovate, obtuse at the stem end, acutc-pointed at the apex; suture broad, deep; deep purple; bloom thick; flesh yellowish, sweet; good for culinary purposes; stone long, narrow, clinging.

Quetsche Précoce de Buhlerthal. Domestica? I. Guide Prat. 164, 363. 1895 .

Frithrwetsche von Buhlerthal 1 . Zwetsche Frithe Von Buhlerthal 1.

A new variety from Germany maturing very early.

Quetsche Précoce De Frauendorf. Domestica. I. Mas Pom. Gen. 2:97. 1873.

Franendorfer Friihe Zwetsche 1 .

Introduced by Eugene Furst, Frauendorf, Bavaria; distinguished from the German Prune by its larger size, earlier maturity and superior quality. 
Quetsche Précoce Liegel. Domestica. I. Mas Pom. Gen. 2:53. 1873. 2. Mathieu Nom. Pom. 439. 1889 .

Liegels Frihzwetsche 1. Liegels Frühzwetsche 2. Quetsche Hâtive de Liegel 2. Quctsche Précoce de Liegel 2.

Found growing among German Prune trees by M. Liegel; differs from the German Prune only in that its fruit matures a few days earlier.

Quetsche Précoce De Schamal. Domestica. I. Mas Pom. Gen. 2:5. I873.

Schamals Frihzwetsche 1.

Originated by M. Schamal of Jungbunzlau, Bohemia. Fruit small, obovate; suture narrow, shallow; dark purple; flesh yellow, sweet, perfumed; good; freestone.

Quetsche Ronde. Domestica. I. Knoop Fructologie $2: 62$. 1771.

A strain of the German Prune.

Quetsche Verte D'Italie. Domestica. I. Kraft Pom. Aust. 2:34, Tab. 182 fig. 2. 1796.

2. Lond. Hort. Soc. Cat. 152. 1831. 3. Mas. Le Verger 6:97. 1866-73.

4. Guide Prat. 162, 363. I895.

Die lange, grüne und grosses welsche Pflaume? I. Grüne Eierpflaume 4. Grüne Zwetsche 4. Italienische Grine Zwetsche 3, 4. Verdage D'Italie 3, 4. Vertage d'Italie tres-grosse $\mathrm{I}$.

A European plum of unknown origin. Tree large; fruit large, ellipsoidal; suture very shallow; skin tender, not adherent, greenish-yellow, specked with red; stem short; flesh greenish-yellow, melting, juicy, aromatic; of first quality; clingstone; mid-season. Quitique. Species? Letter from F. T. Ramsey.

Selected from the wild near Quitique, Texas.

Rachel. Hortulana mineri. I. Cornell Sta. Bul. 38:58, 86. 1892. 2. Waugh Plum Cult. 175. 1901. 3. Ga. Sta. Bul. 67:280. 1904.

Fruit small, roundish; suture a line; cavity shallow; bright red; dots yellow, conspicuous; blue; flesh yellow, melting; quality fair; clingstone; mid-season.

Rademakers. Domestica. I. Mathieu Nom. Pom. 444. 1889. 2. Can. Exp. Farm Bul. and Ser. 3:53. 1900. Brugnon de Neerveteren I. Rademaker's Prune 1. Under test at the British Columbia Experimental Station.

Ragland. Triflora $\times$ Angustifolia varians. I. Vt. Sta. Bul. 67:19. 1898. 2. Kerr Cat. 11. 1900. 3. Waugh Plum Cult. 223. 1901.

A hybrid grown by D. H. Watson, Brenham, Texas, supposedly from seed of Kelsey pollinated by Yellow Transparent; introduced by W. A. Yates in 1897. Fruit of medium size, oblate; cavity broad, rounded; suture lacking; bright clear yellow; dots yellow; bloom white; flesh yellow, firm, juicy, sweet, rich; very good; stone small, clinging; early.

Raisin. Domestica. 1. Lond. Hort. Soc. Cat. 152, 1831. 2. Mag. Hort. 9:165. 1843.

An old European variety now obsolete. Fruit small, round, greenish; of medium quality; clingstone.

Ramsey Last. Munsoniana. Letter from Kerr.

Originated with F. T. Ramsey, Austin, Texas. Fruit small; good; late for its group. 
Ranette. Species? I. Mathieu Nom. Pom. 444. 1889. 2. Guide Prat. 160, 363. 1895. Fruit large, roundish-oval, reddish-brown; flesh yellow, juicy, good; freestone; late.

Rangheri. Insititia. 1. Koch Deut. Obst. Sort. 571. 1876. 2. Lange Allgem. Garten 2:420. 1879. 3. Mas Le Verger 6:155. 1866-73. 4. Lauche Deut. Pom. Pl. IV. 14. 1882. 5. Mathieu Nom. Pom. 444. 1889. 6. Can. Exp. Farms Rpt. 465. 1900.

Mirabelle de Rangheri 3. Mirabelle Hâtive de Rangheri 5. Mirabelle Rangheri 5. Mirabelle de Rangheri 5. Mirabelle Rangheris 2. Rangheri's Aprikosen Pflaume 5. Rangheri's Frihe Gelbe Mirabelle 4, 5. Rangheri's Fruhe Mirabelle 5. Rangheri's Gelbe Mirabelle 5. Rangheris Mirabelle 1. Rangheris Mirabelle 3. Rangheri's Mirabelle $4,5,6$.

Raised by Liegel from the stone of the Abricoteé de Braunau plum, and dedicated by him to M. Henri Rangheri, a merchant at Prague, Bohemia. Tree of medium vigor; fruit medium, roundish-oval; suture indistinct; cavity shallow; skin golden-yellow with red spots on the sunny side; flesh yellow, juicy, tender, sweet, aromatic; of first quality; freestone; mid-season; valuable for table and household purposes.

Rareripe. Americana. I. S. Dak. Sta. Bul. 26:14. 1891. 2. Ibid. 93:32. 1905.

Rare Ripe $\mathbf{r}$.

Tree hardy and productive; fruit small, dark red; flesh sweet; clingstone; inferior to Harrison but better than De Soto; mid-season.

Ray. Hortulana mineri $\times$ Munsoniana. I. Vt. Sta. An. Rpt. 12:227. 1899 .

A supposed cross between Miner and Wild Goose from A. L. Bruce of Basin Springs, Texas. Fruit small to medium, oval to roundish; cavity medium deep; suture faint; dark red; flesh yellow; clingstone.

Raymond. Species? 1. Cornell Sta. Bul. 38:80. 1892.

Mentioned by Bailey in 1892 in an unclassified list of plums.

Raynes. Domestica. 1. Can. Exp. Farm Bul. 43:36. 1903. 2. Am. Pom. Soc. Rpt. 66. 1905. Dunlop 53 1.

Disseminated by W. W. Dunlop, Outremont, Quebec. Fruit of the prune type, above medium size, oval; suture distinct; dark reddish-purple; bloom moderate; flesh yellowish-green, firm, sweet; good; freestone; mid-season.

Reagan. Hortulana $\times$ Americana. I. Tex. Cat. 1907.

An offspring of Wayland crossed with an Americana; introduced by the Texas Nursery Company in 1907. Fruit large, red, rich; good; very late.

Reagles Gage. Domestica. I. Cultivator 6:269. 1858. 2. Downing Fr. Trees Am. 941. 1869. 3. Hogg Fruit Man. 720. 1884. Reagles' Gage I, 2.

A seedling of Washington raised by C. Reagles, Schenectady, New York. Tree vigorous, upright; fruit of medium size, spherical; suture broad, shallow; greenishyellow, splashed with darker green; bloom light; flesh greenish-yellow, juicy, sweet, vinous; good; freestone; mid-season.

Rebecca. Americana. I. Kerr Cat. 1894-1900. 
Fruit above r.edium in size, roundish-oblong, purplish-red; clingstone; mid-season. Reche. Americana. I. Kerr Cat. 1894-1901.

Tree strong and productive; fruit large for the species, globular; dull purplishred; clingstone.

Red Cloud. Americana. 1. Kerr Cat. 1897-1900.

Fruit small, roundish, mottled red; inferior; clingstone.

Red Gage. Domestica. 1. Am. Gard. Cal. 588, 1806. 2. N. Y. Agr. Soc. Rpt. 292

fig. 1848. 3. Hooper W. Fr. Book 251. 1857. 4. Mathicu Nom. Pom. 443.

1889. 5. Guide Prat. 157, 162, 364. I895.

Auserlesene Rote Reine-Claude 4. Auserlesene rothe Reineclaude 5. Lombard 3 incor. Prince's Red Gage 2, 4, 5. Prince's Rote Reine-Claude 4. Prinzens rothe Reineclaude 5. Red Gage 4, 5. Reine-Claude Rouge Americaine 5. Reine-Claude rouge de Prince 5. Reine-Claude Rouge de Prince 4.

Red Gage was grown from a seed of Reine Claude in 1790 by William Prince, Flushing, Long Island, New York. Fruit of medium size, oval; suture lacking; stem short; dark red in the sun ranging to pale red in the shade; flesh greenish, tender, juicy, sweet; very good; stone small, free; mid-season.

Red Gage of Dutchess County. Domestica. 1. Downing Fr. Trees Am. 942. 1869.

Originated in Dutchess County, New York. Fruit of medium size, roundish-oval. slightly compressed; suture distinct; cavity large; color yellow overlaid with a light reddish-purple; dots numerous; flesh yellow, juicy; good; clingstone; mid-season.

Red Glass. Hortulana mineri $\times$ Domestica. 1. Vt. Sta. An. Rpt. 14:272. 1901. 2. Ia. Sta. Bul. 114:1 43. 1910.

Red Glass originated with Theodore Williams of Benson, Nebraska, as a seedling of Miner pollinated by Quackenboss. Fruit large, oval, red; bloom thick; flesh firm, meaty, tender, sweet; good; mid-season.

Red Glass Junior. (Hortulana mineri $\times$ Domestica) $\times$ Domestica. 1. Am. Br. Assoc. Rpt. $2: 185 . \quad 1906$.

A hybrid from Theodore Williams of Benson, Nebraska, from seed of Red Glass crossed with Quackenboss. The variety is hardy and gives promise of value in Nebraska.

Red Horse. Americana. I. Kerr Cat. 1897.

Fruit of medium size, roundish-oblong, dull red; inferior; clingstone.

Redick. Americana. Mentioned in Ia. Hort. Soc. Rpt. 228. 1909.

Red Magdalene. Domestica. Mentioned in Watkins Cat. 1892.

Red May. Triflora $\times$ Munsoniana. I. Sherman Cat. 1898. 2. Waugh Plum Cult. 224. 1901 .

A seedling of Abundance fertilized by Wild Goose from A. L. Bruce ${ }^{1}$, Texas; introduced by J. S. Kerr, Sherman, Texas, in 1898 . Fruit of medium size, oblong, pointed, deep red; similar to Red June but ten days earlier.

${ }^{1}$ A. L. Bruce, whose name appears so frequently in the pages of The Plums of New York as a breeder of native plums, is of Scotch descent. His father, however, came from Illinois to Texas, settling at Basin Springs, Grayson County, in 1845 , where he planted the first orchard in that part of Texas. The son, subject of this sketch, was born October 6, 1861, and was educated in the 
Red October. Specics? I. Tex. Dept. Agr. Bul. 12:103. I9ro. A varicty reported as worthless in Hale County, Texas.

Red Panhandle. Angustifolia watsoni. I. Kerr Cat. I894. 2. Ibid. 1897. 3. Bailey Ev. of Nat. Fr. 222, 223. 1898. 4. Waugh Plum Cult. 233. 1901.

Of the same origin as Purple Panhandle. Tree irregular and straggling in habit, very productive; fruit small to medium, irregular-oval or oblong, dull dark red with scattering dots; bloom thick; skin tough; flesh reddish-yellow; very poor; stone large, roundish-oval, slightly flattened, clinging; early.

Red Pear. Domestica. I. Parkinson Par. Ter. 576. 1629. 2. Rea Flora 208. ${ }_{1676 .}$ 3. Ray Hist. Plant. $2: 1528.1688$.

Mentioned as poor in quality. May be identical with the Pear Plum.

Red Peascod. Domestica. I. Parkinson Par. Ter. 576, 577. 1629. 2. Rea Flora 208. 1676. 3. Ray Hist. Plant. 2:1529. r688. Red Pescod I.

Cultivated in the Seventeenth Century. Fruit elongated, watery; poor in quality; very late.

Red Perdrigon. Domestica. 1. Duhamel Trait. Arb. Fr. 2:86. 1768. 2. Kraft Pom. Aust. 2:27, Tab. 172 fig. 2. 1796. 3. Willich Dom. Enc. 4:299. 1803. 4. Downing Fr. Trees Am. 312. 1845. 5. Oberdieck Deut. Obst. Sort. 445. 1881. 6. Mathieu Nom. Pom. 448. I889.

Die rothe Rebhuhnpflaume 2. Perdrigon rouge 1 . Perdrigon rouge 2, 4, 6. Podiebrader Pflaume 6. Red Perdrigon 6. Roter Perdrigon 6. Rother Perdrigon 5.

Red Perdrigon was first described by Duhamel; probably introduced into America during the latter part of the Eighteenth Century. Tree very productive; fruit small, oval; cavity small; suture lacking; dark red; dots small; bloom heavy; flesh yellow, firm, juicy, sweet, aromatic; freestone; late mid-season.

Red Primordian. Domestica. 1. Parkinson Par. Ter. 575. 1629. 2. Floy-Lindley Guide Orch. Gard. 286, 382. 1846. 3. Downing Fr. Trees Am. 943. 1869. 4. Mas Pom. Gen. 2:149, fig. 75. 1873 .

Early Red Primordian 2. Red Primordian 2, 4. Rouge Hâtive 4.

Common in Europe nearly three centuries ago. Fruit of medium size, pear-shaped, reddish, pleasant; good; early. Downing and Mas described a variety under this name supposed to have originated with William Prince. It is very similar to the older variety of which it may be a seedling.

common schools at Basin Springs, Texas. His work in growing and breeding trees began in his youth, for in 1877 he established himself as a grower and collector of native plums to which he added many of the Triflora varieties that were soon after introduced from Japan. Mr. Bruce's first definite problem in breeding plums was to find extra early and extra late sorts for Texas; his Six Weeks, Red May, Dayton and several other plums were the results of these efforts. In I902 Mr. Bruce moved to Donley County in the Panhandle of Texas from which place he has sent out and continues to send out Triflora, native and hybrid plums of unusual merit. Beside working with plums Mr. Bruce is a breeder of peaches, pears, raspberries, dewberries and apples, to all of which fruits he has made more or less notable contributions. Mlr. Bruce is still in the prime of life, has many plant-breeding problems projected and his work promises much for horticulture in the Southwest and in the country at large. 
Red Prune. Domestica. 1. Horticulturist 8:536, I853. Bottle Plum 1 .

From Pennsylvania. Fruit long-pyriform, with a slender neek; suture distinct; pale red; good; it elosely resembles the Red Date.

Red Skin. Munsoniana. Letter from Kerr.

Originated by Theodore Williams, Benson, Nebraska.

Red Violet. I. Ray Hist. Plant. 2:1 $528 . \quad$ I 688.

Mentioned by Ray in the preeeding reference together with blue and amber sorts but without deseription.

Red Virginal. Domestica. r. Lond. Hort. Soc. Cat. 153. 1831. 2. Prince Pom. Man. 2:74. 1832. 3. Elliott Fr. Book 429. 1854. 4. Downing Fr. Trees Am. 950. 1869. 5. Mathieu Nom. Pom. 448. 1889.

Rote Jungfernpflaume 5. Virgin 2. Virgin 3, 4. Virginal a Fruit Blanc 4 incor. Virginal à gros Fruit blanc 4 ineor. Virginal Blanc 4 incor. Virginale 3. Virginale a Fruit Rouge 5. Virginale Blanc 4 incor. Virginale Rouge 2, 5. Virginal Rouge r. White Virginale 4 incor.

Fruit of medium size, roundish, reddish-purple; bloom thick; flesh greenishyellow, juicy; good; semi-free.

Red Winter. Domestica. 1. Am. Pom. Soc. Rpt.61. 1887. Krasnaya osimaya 1. Imported by the Iowa Agricultural College.

Reed. Hortulana. 1. N. J. Hort. Soc. Rpt. 12. 1882. 2. Vt. Sta. An. Rpt. II:286 fig. 1898 .

Originated with P. H. Reed of Hightstown, New Jersey, from pits brought from Illinois; introduced by Charles Black of the same place. Tree vigorous; leaves large, dark green; fruit small, round; suture a faint line; skin thick; dark red; dots yellow; flesh yellow, meaty; quality fair; stone turgid, semi-clinging; late.

Reel. Americana mollis. 1. Kerr Cat. 1898. 2. Terry Cat. I 900.

Grown by H. A. Terry of Crescent, Iowa; a seedling of Van Buren; first fruited in 1896 . Tree vigorous, productive; fruit large, pale yellow with a red cheek; good. Regina. Nigra? I. Can. Exp. Farms Rpt. 426. 1900.

A seedling raised at Indian Head Experimental Farm, Northwest Territory, Canada. Fruit small, red; skin thick; good.

Reine-Claude Abricotine. Domestica. I. Mathieu Nom. Pom. 445. 1889. 2. Guide Prat. ${ }_{5} 6,363.1895$.

Fruit small, whitish; flesh light yellow, sweet; good; early.

Reine Claude d'Écully. Domestica. 1. Mathieu Nom. Pom. 445. 1889. 2. Guide Prat. I $53,364 . \quad 1895$.

Tree vigorous; fruit large, round; cavity small; suture distinct; greenish-yellow; bloom thin; flesh firm, sweet, juiey; good; freestone; mid-season.

Reine Claude d'Oberdieck. Domestica. Mentioned in Mathieu Nom. Pom. 446. ${ }_{1889}$.

Reine Claude de Brignais. Domestica. 1. Mathieu Nom. Pon. 452. 1889. 2. Guide Prat. 162, 364. 1895 .

Reine-Clande de Brignais I. Violette Reine-Claude Von Brignais I.

Said to be superior to Reine Claude. 
Reine Claude de l'Echoisier. Domestica. I. Can. Exp. Farm Bul. 2nd Ser, 3:55. 1900.

Of French origin. Not hardy in Canada.

Reine Claude de Mezel. Domestica. I. Can. Exp. Farm Bul. 2nd Ser. 3:55. I goo.

Of French origin. Tree vigorous; fruit medium, globular; suture shallow; skin greenish-yellow; flesh yellow, juicy, sweet; early.

Reine Claude de Razaimbaut. Domestica. I. Mathieu Nom. Pom. 446. 1889. 2. Can. Exp. Farm Bul. 2nd Ser. 3:55. 1900.

Reine-Claude de Razaimbaut I. Reine-Claude de Razimbaud I. Reine-Ctaude Précoce de Razimband I.

Imported from France by the Canadian Experimental Farm at Agassiz, British Columbia. Tree vigorous; fruit small, roundish; skin green; flesh green, juicy, sweet; mid-season.

Reine Claude de Saint-Avertin. Domestica. 1. Mathieu Nom. Pam. 446. 1889. 2. Guide Prat. 155, 364. I895.

Fruit rather large, roundish, greenish-yellow blushed with red; flesh yellow, juicy, sweet, aromatic; very good; late.

Reine Claude de Vandenbrok. Domestica. Mentioned in Mathieu Nom. Pom. 446. 1889 .

Reine Claude de Wazon. Domestica. I. Guide Prat. 160.364, 1895. 2. Baltet Cult. Fr. 491. 1908 .

Tree vigorous, productive; fruit nearly large, obovate, greenish-yellow, washed with red; flesh juicy, sweet and acidulated; very good; mid-season.

Reine Claude Descarde. Domestica. I. Mathieu Nom. Pom. 445. 1889. 2. Guide Prat. $163,364.1895$.

An inferior variety of the Reine Claude type.

Reine Claude Hamaitre. Domestica. 1. Mathieu Nom. Pom. 446. 1889. 2. Guide Prat. 163,364 . 1895 .

A variety of the Reine Claude type of doubtful value.

Reine Claude Monstrueuse de Mezel. Domestica. Mentioned in Mathieu Nom. Pom. 446. I 889 .

Reine Claude Sagot. Domestica. I. Can. Exp. Farm Bul. 2nd Ser. 3:56. 1900.

Probably of French origin; as tested in Canada, tree weak; foliage small, scanty; fruit medium in size, globular; stem one-half inch long; cavity small; suture distinct; skin whitish-yellow; flesh yellowish, rather dry, tender, fine-grained, very sweet; stone small, roundish, free; mid-season.

Reine Claude Von Bollwiller. Domestica. Mentioned in Mathieu Nom. Pom. 445. I 889 .

Reine des Mirabelles. Insititia $\times$ Domestica. 1. Guide Prat. 164, 364. 1895. 2. Rev. Hort. 476. 1901. Königin der Mirabellen I.

Produced by crossing the Mirabelle and the Reine Claude. Tree vigorous and productive; fruit large, yellow, dotted with red on the sunny side, juicy; good; midseason. 
Reine Victoria. Domestica. I. Hogg Fruit Man. 38o. 1866.

According to Hogg this is a French variety distinct from Victoria. Fruit roundishoval, reddish-purple; flesh juicy, rich, agreeable, freestone; similar to Kirke but two or three weeks later.

Reisenzwetsche. Species? I. Mathieu Nom. Pom. 447. 1889.

Reine-Claude Geante I.

Mathieu gives reference to Monatsschrift fur Pomologie $281 \quad 1858$.

Reizenstein Yellow Prune. Domestica. I. Downing Fr. Trees Am. 943. I869.

2. Mas Le Verger 6:119. 1866-73. 3. Mathieu Nom. Pom. 446. 1889. 4. Guide Prat. 161, 362. 1895.

De Reizeinstein 4. Jaune de Reizenstein 4. Pruneau Jaune de Reizenstein 2, 3. Prune de Reizenstein 2, 3. Quetsche Jaune de Reizenstein 3. Quetsche Jaune de Reizenstein 2, 4. Reizensteiner Gelbe Zwetsche 3. Reizensteiner Gelbe Zwetsche 2, 4. Reizensteiner Pflaume 2, 3, 4. Reizensteiner Zwetsche 3, 4. Reizenstein's Yellow Prune 2, 3, 4. Susina Settembrica Quialla 3, 4.

Probably originated in Italy. Tree of medium vigor, very prolific, not hardy; fruit of medium size, irregularly ovate; suture indistinct; skin golden-yellow; flesh yellow, juicy, sweet; stone rough, free.

Reutlinger Frühzwetsche. Domestica? I. Mathieu Nom. Pom. 447. 1889. 2. Guide

Prat. $15_{2}, 36_{3} .1895$.

Quetsche Précoce de Reutlingen 2 Reutlinger Frühzwetsche 2.

An attractive variety ripening in early mid-season.

Rhinebeck Yellow Gage. Domestica. I. Downing Fr. Trees Am. 405. 1857

Rhinebeck Yellow Gage I.

Originated at Rhinebeck, New York. Tree vigorous; fruit large, oval; suture deep; cavity shallow; yellow; flesh coarse, juicy, sweet, pleasant; clingstone; midseason.

Rhodes. Domestica. x. Quintinye Com. Gard. 68, 69. 1699.

Mentioned by Quintinye " as long and black."

Rhue. Domestica. x. Downing Fr. Trees Am. 944. 1869.

Rhue's Seedling 1.

A seedling from Pennsylvania. Fruit large, oval; suture broad, shallow; cavity deep; reddish-purple; flesh greenish-yellow, coarse, juicy, sweet, vinous; semi-clinging; good; early.

Richard Trotter. Domestica. I. Can. Exp. Farms Rpt. 98. 1898.

Reported as one of the hardiest of the European varieties tested by the Experimental Farm at Ottawa, Canada.

Richland. Domestica. x. Gard. Mon. I:2, $\mathrm{I}_{54}$ fig. 1859. 2. Ibid. 5:18. 1863. 3. Downing Fr. Trees Am. 944. 1869. 4. Can. Exp. Farm. Bul. 43:36. 1903. Copper 2.

Originated on the farm of Randall Elden, Richland, Bucks County, Pennsylvania, about 1820 . Tree hardy, vigorous, productive and said to be resistant to the curculio; fruit medium in size, oval; cavity small; suture a line; skin thick, bluish; dots small; 
flesh greenish-yellow, firm, slightly swect; quality fair; stone large, oval, flat, clinging; mid-season; listed in the catalog of the American Pomological Society in 1875 .

Riga I1. Domestica. I. Mich. Sta. Rpt. 111. 1887.

Imported from Russia by J. L. Budd of the Iowa Experiment Station.

Rigny. Domestica. 1. Hogg Fruit Man.683. 1884. 2. Mathieu Nom. Pom. 420. 1889.

Admiral Rigny 2. Admiral de Rigny 1. Amiral de Rigny 2. Georg IV 2. Jackson? 2.

Described as of medium size, roundish-oval; suture shallow; yellowish-green flaked and striped with darker green, with a few crimson dots on the sunny side; stem of medium length; cavity shallow; flesh yellow, tender, melting, juicy and rich; nearly freestone; early.

Rising Sun. Domestica. I. Kenrick Am. Orch. 258.1832.

Corse's Rising Sun r.

Originated by Henry Corse, Montreal, Canada. Fruit large, bright yellow, tinged with red next to the sun; good; productive.

Rivers Early. Insititia. I. Jour. Hort. N. S. 29:177. 1875. 2. Hogg Fruit Man.

695. 1884. 3. Mathieu Nom. Pom. 447. 1889. 4. Rivers Cat. 35. 1898.

Damas Précoce de Rivers 3. Rivers' Early Damson I, 3, 4.

Grown by Thomas Rivers, Sawbridgeworth, England, from a seed of St. Etienne. Fruit of medium size, sweet and juicy; good.

Robert. Americana. I. Wis. Sta. Bul. 87:15. I gor. Robert's Freestone I.

Fruit of medium size, oblong, flattened; suture a line; light greenish-yellow overlaid with purplish-red; skin thick, tough; flesh moderately firm, sweet but not rich; stone nearly free.

Roby Yellow. Domestica. I. Downing Fr. Trees Am. 944. 1869.

A seedling raised by H. R. Roby, Fredericksburg, Virginia. Tree moderately vigorous; fruit small, round; suture broad, shallow; cavity small; greenish-yellow; bloom heavy; flesh greenish-yellow, juicy, sweet; good; clingstone; mid-season.

Rockford. Americana. 1. U. S. D. A. Rpt. 392. r891. 2. Waugh Plum Cult. 161 fig. 1901. 3. Ia. Hort. Soc. Rpt. 128. 1906.

Introduced in 1889 by C. G. Patten of Charles City, Iowa, who found the variety in $187_{1}$ on the farm of $\mathrm{O}$. J. Green who, in turn, had brought it as a young tree from a grove near Rockford. Tree productive; fruit medium in size, roundish; cavity medium; suture shallow; skin thick, tough; dark and somewhat purplish-red; bloom thick; dots small; flesh yellow; good; stone large, oval, flattened, clinging; mid-season; listed by the American Pomological Society since 1897 .

Rocky Mountain. Species? I. Can. Hort. 15:157. 1892. 2. Cornell Sta. Bul. 38:So. 1892. Rocky Mountain Seedling 2.

Reported in the Canadian Horticulturist as a "heavy cropper and of first quality." Bailey mentions a "Rocky Mountain Seedling" in an unclassified list. The Rocky Mountain described by Waugh is not to be confused with these two varieties as it is undoubtedly a Sand Cherry.

Rodney. Domestica. 1. Lond. Hort. Soc. Cat. 152. 1831. Rodney Gage I. 
Described in the London Horticultural Society catalog as large, oval, purple; quality fair; clingstone.

Rodt Blaue Zwetsche. Spccies? 1. Mathieu Nom. Pom. 447. 1889. 2. Guide Prat. $163,365.1895$.

"A variety of little merit."

Rodt Fruhe Grosse Pflaumenzwetsche. Species? Mentioned in Mathieu Nom. Pom. 447. 1889. Grosse Hative de Rodt.

Rognon D'Ane. Domestica. 1. Prince Pom. Man. 2:100. 1832.

Fruit large, oval, dark purple; mid-season; similar to Yellow Egg except in color. Rógnon de Coq. Domestica. I. Quintinye Com. Gard. 68. 1699. 2. Miller Gard. Dict. 3:1754. 3. Lond. Hort. Soc. Cat. 152. 1831.

Quetsche Rognon de Coq 3.

Mentioned only by the earlier writers. Fruit long; suture deep, prominent; light yellow streaked with red; clingstone; late.

Rollande Galloppi. Domestica. I. Downing Fr. Trees Am. 944. 1869.

Fruit of medium size, long-oval, necked; suture distinct; cavity small; yellowishgreen, dotted with crimson in the sun; bloom light; flesh yellowish-green, juicy, sweet; good; clingstone; late.

Ronald Fancy. Domestica. $\quad$ x. Downing Fr. Trees Am. 945. 1869.

Fruit of medium size, oval; suture distinct; cavity medium deep; yellow, striped with green; bloom thin; flesh greenish-yellow, juicy, sugary, vinous, sprightly; good; freestone; very late.

Roselle. Americana. x. Ia. Sta. Bul. 46:287 igoo. Hoffman Seedling I.

A chance seedling grown by Ernest Hoffman, Roselle, Carroll County, Iowa, in I892. Fruit large, roundish-oval, yellow blushed with red; sweet; semi-free; midseason.

Ros-Prium Double. Domestica. 1. Knoop Fructologie 2:62. 1771 .

Similar to the Horse plum except that it is smaller.

Ross. Domestica. r. Can. Hort. 23:438. 1900. Ross Seedling I.

A seedling, supposedly of Bradshaw, grown by J. T. Ross, Hamilton, Canada Fruit of much the same appearance as Bradshaw but inferior in quality; earlier in season.

Rossy Fruhe Zwetsche. Species? Listed in Mathieu Nom. Pom. 447. 1889.

Rossy's Frïh Zwetsche.

Rostrave Bell. Domestica. x. Downing Fr. Trees Am. 945. 1869.

Originated with John D. Stephens, Westmoreland County, Pennsylvania. Tree vigorous, productive; fruit large, roundish-oval; suture broad, shallow; cavity deep; reddish-purple; dots brown; flesh yellow, coarse, rather dry, vinous; good; semiclinging; mid-season.

Rote Mirabelle. Species? Mentioned in Mathieu Nom. Pom. 448. 1889.

Damasine Kleine Kirsch Pfaume Mirabelle Rouge.

Rotes Zeiberl. Species? I. Mathieu Nom. Pom. 448. I889.

Rote Herbst Zeiberl r.

Referenced by Mathieu from Wiener Garten-Zeitung 288 , 1884. 
Rote Zwetsche. Species? Mentioned in Mathieu Nom. Pom. 448. I889.

Rosinen Pflaume. Spitzige Rote Pflaume. Spitz Pflaume.

Rothe Jungfernpflaume. Domestica. I. Oberdieck Deut. Obst. Sort. 445. I88I.

A German variety said to be unproductive in dry soil.

Rouge Hátive de Nitka. Domestica. I. Am. Pom. Soc. Rpt. 96. 1877.

Mentioned in the preceding reference as of medium size, purple, juicy, rich; good; mid-season.

Roulette. Munsoniana. I. Cornell Sta. Bul. 38:50, 86. 1892. 2. Am. Pom. Soc. Rpt. 142, 1897. 3. Waugh Plum Cult. 188. 1901. Rowlett 2.

Supposed to have originated in Texas. Fruit of medium size, oval; cavity small; suture a line; skin thin; bright red; dots numerous; bloom thin; flesh yellow; quality fair; stone oval, flattened, clinging; mid-season. Listed in the catalog of the American Pomological Society since 1899 .

Round. Species? I. Ill. Hort. Soc. Rpt. 83. I 888.

J. Webster of Centralia, Illinois, states that he received this varicty from a Mr. Spears of Cedar Rapids, Iowa. Of high quality; especially adapted for canning.

Round Leaf Wonderful. Domestica. I. N. Y. Sta. Rpt. 12:612. I893.

An obscure variety found only in a few collections. Fruit of medium size, longoval; suture a line; cavity small; dark purple; bloom thick; dots small; flesh yellow, fine-grained, tender, sweet, mild; very good; stone flattened, oval, free; mid-season. Rowley. Domestica. I. Can. Exp. Farm Bul. 43:36. I903.

Originated with Jos. Rowley, Cummings Bridge, Ontario. Tree very productive; fruit above medium size, round; suture a line; purplish-red; flesh yellow, moderately juicy, firm, swect, rich; good; clingstone; mid-season.

Royal. Domestica. I. Rea Flora 207. 1676. 2. Quintinye Com. Gard. 69. 1699. 3. Langley Pomona 92, Pl. XX fig. 8. 1729. 4. Kraft Pom. Aust. 2:40, Tab. I91 fig. 1. 1796. 5. Downing Fr. Trees Am. 945. 1869. 6. Mathieu Nom. Pom. 438. 1889 .

Die Königliche grosse Pflaume 4. French Royal 4, 5, 6. Kings Plum 1. Königspflaume 6. La Royale 5, 6. La Royal 2. Prune Royale 5, 6. Royal tres-grosse 4, 6. Royal Red 5, 6. Royal 5, 6. Royal 2. Royal Plumb 3. Royale 5. Royale 6. Sir Charles Worsley's 3, 5, 6. Wahre Königspflaume 6.

Royal is an Old World variety supposed to have originated in France. Tree a slow grower; top bushy; shoots pubescent; fruit medium in size, roundish; suture distinct; cavity narrow; reddish-purple; dots small, brownish; bloom thick; flesh yellow, melting, juicy, rich, subacid; quality very good; stone small, roundish, pointed, free; mid-season. Royal Bullace. Insititia. 1. Hogg Fruit Man. 689. 1884.

Royal Bullace is the largest of the Bullaces. Fruit round; suture faint; cavity wide, deep; stem short, slender; greenish-yellow, mottled with red; bloom thin; flesh green, sprightly; good; freestone; late.

Royal Dauphine. Domestica. 1. Miller Gard. Kal. 184. 1734. 2. Forsyth Treat. Fr.

Trees $21 . \mathrm{I}^{8} \mathrm{O}_{3}$.

Royal Dauphin 2, Royale Dauphin r. 
Fruit large, oval, dark red shading to light red, mottled; bloom thick; flesh greenish-yellow, sweet; good; freestone; mid-season.

Royal de Braunac. Domestica. I. Downing Fr. Trees Am. 2nd App. 157. 1876.

Fruit of medium size, roundish-oval; suture very slight; light red with dark purple blush; dots numerous, brown; bloom heavy; flesh greenish-yellow, coarse, rather firm, juicy, rich; clingstone; mid-season.

Royale de Behrens. Domestica. I. Mathieu Nom. Pom. 422. I889. 2. Guide Prat. $163,365.1895$.

Behren's Königspflaume 1. Behrens Königsplaume 2. Royale de Behrens 1.

Listed in the preceding references.

Royale de Siebenfreud. Domestica? 1. Nathieu Nom. Pom. 450. 1889. 2. Guide Prat. $15^{8}, 365.1895$.

Royale de Siebenfreund r. Siebenfreund's Königspflaume r. Siebenfrend's Königsplanine 2.

Grown by Liegel and named by him in honor of M. Siebenfreud, of Tyrnau, Hungary. Fruit large, long-oval, brownish-red; flesh pale yellow, juicy; good; midseason.

Royale Hâtive de Liegel. Domestica. I. Oberdieck Deut. Obst. Sort. 420. 188x.

2. Mathieu Nom. Pom. 430. 1889. 3. Guide Prat. 163, 365. 1895.

Frühe Königspflaume 2. Frühe Königspflaume 3. Königspflaume Frühe 1. Ronge de Liegel 2. Royale Hâtive de Liegel 2. Royale Hâtive 2.

Similar to the Royal Hâtive but inferior in quality.

Royale Violette de Keindl. Species? I. Mathieu Nom. Pom. 437. 1889. 2. Guide Prat. 157, 365. 1895 .

Keindl's Violette Königsplaume 2. Keindt's Violette Königspflaume r. Royale Violette de Keindt 1 .

Originated by Liegel and named after Mr. Keindl, a German pomologist. Fruit large, oval, violet; flesh greenish-yellow, firm, juicy; good; early.

Royal Pea. Domestica. Mentioned in Forsyth Treat. Fr. Trees, 21. 1803.

Royer Aprikosen Pflaume. Domestica. Listed in Mathieu Nom. Pom. 449. I889. Abricotée de Royer. Prune-Abricot de Royer.

Ruben Burgunder Zwetsche. Species? Mentioned in Mathieu Nom. Pom. 449. 1889.

Ruby. Domestica. 1. Gard. and For. 7:243. 1894 .

Charles H. Shinn of Berkeley, California, describes this variety as a dark red prune coming from Lake County, California.

Ruby. Triflora $\times$ Munsoniana. I. U.S. D. A. Pom. Rpt. 4 6. 1895. 2. Vt. Sta. An. Rpt. 12:228. 1899. 3. Waugh Plum Cult. 224. 1901.

Originated by J. S. Breece, Fayetteville, North Carolina, from seed of Abundance pollinated with Wild Goose; fruit borne in 1894 . Fruit of medium size, oval; suture faint; dark, wine-red; skin thick; fiesh yellow, firm, meaty, slightly fibrous, sweet, rich; good; clingstone.

Ruby. Munsoniana. I. Orchard Home Nur. Cat. 7. 1891. 2. Terry Cat. 8. 1900. 
A seedling of Wild Goose introduced by L. T. Sanders of the Orchard Home Nursery, Plain Dealing, Louisiana, in 1891 . Fruit slightly smaller than the parent, round, red with small dots; flesh solid; good; a good shipper.

Rudolph. Domestica. r. Oberdieck Deut. Obst. Sort. 438. 1881. 2. Mathieu Nom. Pom. 449. I 889 .

Frankfurter Pfaume 2. Rudolphspflaume 1. Rudolph Pflaume 2.

In Germany considered valuable for dessert, compotes and market. Tree quick in growth, large; shoots almost glabrous, dark brownish-red; fruit large, of prune shape; suture shallow; halves usually equal; stem hairy; cavity shallow; skin easily removed, yellow often flecked with red, sometimes reddish; flesh yellow, tender, juicy, very sweet, sprightly; nearly freestone; mid-season.

Rue. Americana. т. Ia. Sta. Bul. 46:288. 1900. 2. Budd-Hansen Am. Hort. Man. 300. 1903. 3. S. Dak. Sta. Bul. 93:34. 1905. J. B. Rue r, 2, 3.

Originated with J. B. Rue, Pottawattamie County, Iowa; distributed by Professor J. L. Budd. The fruit closely resembles Stoddard except in the stone, that of the latter being large and flat, while that of the former is small and round.

Ruff Choice. Domestica. 1. Tex. Sta. Bul. 32:484. I894.

Under test at the Texas Experiment Station.

Ruff Spanish. Species? 1. Tex. Sta. Bul. 32:490. 1894.

Under test at the Texas Experiment Station.

Russian Mirabelle. Insititia. 1. Budd-Hansen Am. Hort. Man. 324. 1903.

Described by Budd and Hansen as a Russian plum; hardier than the Mirabelle of western Europe and differing in tree and fruit. Fruit small, roundish-oblate, bright yellow; suture indistinct to distinct at the apex; cavity narrow; stem medium in length and thickness; flesh yellow, juicy, rich; quality best; freestone.

Russian No. 2. Domestica. I. Mich. Sta.Rpt. III. IS87. 2. Colo. Sta. Bul. 50:45. I898.

Imported from Russia. Fruit of medium size, irregular in shape; suture a line; deep purple with heavy bloom; flesh firm, subacid; quality fair; freestone.

Russian No. 3. Domestica. 1. Mich.Sta. Rpt. I1 1. 1887. 2.S. Dak. Sta. Bul. 93:35. I905.

Said to be unproductive and not hardy.

Sada. Americana mollis. 1. Wis. Sta. Bul. 63:59. 1897. 2. Ibid. 87:15. 1901.

3. Waugh Plum Cult. I63. I901.

A seedling of Van Buren grown by H. A. Terry, Crescent, Iowa; first fruited in r893. Fruit large, round; suture a line; cavity shallow; red over a yellow ground with many conspicuous dots; skin thick, tough, astringent; flesh dark yellow, mushy; quality fair; semi-clinging; mid-season.

Saffold. Species? 1. Am. Gard. 14:5r. I893. 2. Bailey Ev. Nat. Fruits 175. 1898.

A variety brought into Texas from Alabama about 1853 by General Saffold of Sequin, Texas, where for years it was the only cultivated plum. Although inferior to later introductions, it is excellent for preserves and still retains a place among Texan varieties.

Sagetsuna. Triflora. I. Normand Sp. Cir. 1895. 2. Kerr Cat. 8. 1901. 3. Ga. Sta. Bul. 68:6, 33. r905. Sagetsuma 3. Wasse Botankyo 2. 
A variety imported from Japan by J. L. Normand, Marksville, Louisiana. In 1901, J. W. Kerr fruited Sagetsuna and Wasse Botankyo and found them identical. Tree vigorous with straggling habit; fruit large, conic, red over a yellow ground, with numerous dots; flesh yellow, firm ; good; clingstone; earlier than Abundance.

St. Anne. Domestica. 1. Am. Pom. Soc. Cat. 40. 1899. Bonne St. Ann r.

Originated in Vermont; catalogued by the American Pomological Society in 1899 and 1901. Fruit blue; good.

Saint Antoine. Domestica. I. Traité Prat. Sech. Fruits 172. I893.

Prune de Bordeaux 1 .

A plum found in the neighborhood of Gironde, France. The prunes from this variety are know as Prunes de Bordeaux. The fruits are less esteemed than those of the Agen. Saint Antonio. Domestica. Mentioned in Lond. Hort. Soc. Cat. 153. 1831.

St. Aubert. Domestica. 1. Gard. Chron. 36:1 205. 1873. 2. Guide Prat 157, 365. 1895. Saint Aubert 2.

Of Belgian origin; resembles Golden Drop but is a month earlier and is superior in quality and productiveness; fruit oval, rounded at both ends, greenish spotted and marked with a crimson blush; color and flavor of the flesh like Reine Claude.

Sainte Therese. Species? 1. Mathieu Nom. Pom. 449. 1889. 2. Guide Prat. 160, 365. 1895.

Tree vigorous, productive; fruit large, long-oval, reddish-purple; flesh fine-grained; good; clingstone; mid-season.

St. Etienne. Insititia. 1. Hogg Fruit Man. 381. 1866. 2. Oberdieck Deut. Obst. Sort. 431. 1881. 3. Gard. Chron. 24:187. 1885. 4. Guide Prat. 160, 365. 1895.

5. Can. Exp. Farms Rpt. 480.1904.

Mamelonnee? 4. Pfaume von St. Etienne 4. Pflaume von St. Etienne 2.

Tree vigorous; fruit globular or frequently roundish-oval; suture distinct dividing the sides equally; stem medium; cavity narrow; skin not adherent; yellow blushed and spotted with red on the sunny side; flesh yellow, tender, melting, juicy, sweet with a fine flavor; stone small; free; early.

St. James. Domestica. 1. Lond. Hort. Soc. Cat. 152. 1831. 2. Mag. Hort. 9:165. 1843. 3. Downing Fr. Trees Am. 311. 1845.

St. James' Quetsche 1, 2, 3.

A strain of the German Prune; tree very productive; fruit of medium size, oblong, purple; good; clingstone; mid-season.

St. John. Domestica. 1. Willich Dom. Enc. 4:195. 1803. 2. Horticulturist 3:396. 1848. 3. Elliott Fr. Book 429. 1854.

Prune de St. Jean 3. Prune de St. Jean 2.

A foreign variety of unknown origin. Tree very productive; fruit of medium size, round, purplish-blue; flesh greenish-yellow; early.

St. Lawrence. Domestica. I. Mich. Pom. Soc. Rpt. 38. 1874. 2. Barry Fr. Garden 416. 1883. 3. Waugh Plum Cult. 122. 1901.

A seedling of Smith Orleans grown on the grounds of Ellwanger \& Barry, Rochester, New York. Tree vigorous and productive; fruit variable in size, averages medium, 
roundish-oval; cavity deep, rounded; stem short; suture shallow; dark reddish-purple; bloom heavy; flesh yellow, juicy, melting, sweet; quality poor to fair; clingstone; mid-season.

Saint Martin Quetsche. Domestica. 1. Lond. Hort. Soc. Cat. 152. 1831. 2. Downing Fr. Trees Am. 283. 1845. 3. Am. Pom. Soc. Cat. 55. 1852. 4. Elliott Fr. Book 4I4. 1854. 5. Mas Le Verger 6:49. 1866-73.

Coe's Late Red 5. Prune Violette D'Octobre 5. Rouge Tardive De Coe 5. SaintMartin 5. Saint Martin's 4. Saint Martin's Quetsche 4. Violette October Pflaume 5.

Of German origin; introduced into this country during the second quarter of the Nineteenth Century. Fruit of medium size, ovate, yellow, sometimes blushed; covered with a thin bloom; flesh yellowish, juicy, rich; good; late; fruit hangs to the tree long after maturity.

Saint Pierre. Species? 1. Mathieu Nom. Pom. 449. 1889. 2. Guide Prat. 156, 366.1895.

Fruit resembles Mirabelle, though it is larger; yellow marbled with red; flesh yellow; good; stone nearly free; very early.

St. Reme. Domestica. I. Lond. Hort. Soc. Cat. 153. 1831 .

Cultivated in the garden of the Horticultural Society of London.

Sandalls. Domestica. I. Jour. Hort. N. S. 15:247. 1868. 2. Gard. Chron. 30:1 3 II, 1347. I870. Sandall's Plum 2.

Originated about 1800 with a Mr. Sandall at Crab Tree, Fulton, England. Tree vigorous and attains great size; fruit of medium size, round, dark purple; flesh firm, reddish-yellow, juicy, pleasant; good; clingstone; very late.

Sanders. Angustifolia varians? 1. Waugh Plum Cult. 200. I901. Honey Grove I. Introduced by J. S. Kerr, Sherman, Texas, in 1898. Fruit small, purplish-red; quality fair; very early.

Sanderson. Americana. r. Budd-Hansen Am. Hort. Man, 300. 1903.

Originated in Minnesota. Fruit large, roundish-oval, light red over a yellow ground; skin slightly astringent; good; semi-clinging.

Sandle. Domestica. Mentioned in Watkins Cat. 1892?

Sandoz. Species? r. Crete Cat. 1906.

Introduced by E. F. Stephens of the Crete Nursery, Crete, Nebraska. Tree hardy; productive; fruit red; early.

Sand Plum. Angustifolia watsoni. x. Downing Fr. Trees Am. 889. г869. 2. Ncb. Hort. Soc. Rpt. I73. I895. 3. Kansas "The Plum" 20,45. I 900.

Sand Plum is the common name for Prumus angustifolia watsoni.

Sannois. Domestica. I. U. S. D. A. Div. Pom. Bul. ro:20. 1901.

Sannois Quetsche r.

Originated in Sannois, France. A rather unattractive plum in appearance, but with a fine flavor and high quality. As grown at this Station the tree is small, vigorous, upright-spreading; fruit above medium to large, roundish-oblate, slightly compressed; suture shallow; stem medium in thickness and length; cavity wide, deep ; apex flattened; dull, reddish-purple with darker shades in the sun; bloom moderate; dots numerous, 
brownish; skin thick, tough; flesh dark coppery-yellow, juicy, rather coarse, very fibrous, tough, firm, sweet; very good; stone medium, irregular-oval, turgid, rough, clinging; very late.

Sansoto. Prunus besseyi $\times$ Americana. 1. Cir. S. Dak. Sta. I 1 Iо.

Sansota originated in 1907 as a cross between De Soto and Prunus besseyi made by N. E. Hansen of the South Dakota Experiment Station; introduced in rgro. Tree productive; fruit small, round, black; bloom heavy; flesh yellowish-green, sprightly; clingstone.

Santa Rosa. Triflora. x. Fancher Creek Nur. Cat. 1907. 2. Ibid. 1909.

Originated by Burbank; introduced by the Fancher Creek Nursery Company in 1907 . Fruit very large, round, suture distinct; cavity medium deep; dark purplish crimson with thin bloom; flesh reddish near the skin shading to amber near the center; good; clingstone; keeps and ships well.

Sapa. Prunus besseyi $\times$ Triflora. r. S. Dak. Sta. Bul. 1о8. I908.

Grown by Hansen of the South Dakota Experiment Station from a cross of Sultan and a selected seedling of the Prunus besseyi; fruited in 1907. Fruit small, round, glossy, dark purple; flesh dark red.

Saratoga. Domestica. I. Bailey Ann. Hort. 103. 1889. 2. Am. Pom. Soc. Cat. 25. 1897. 3. Mich. Sta. Bul. 169:243, 247. 1899. 4. Waugh Plum Cult. 121. I901. 5. Ohio Sta. Bul. $162: 256,257$. 1905 .

Introduced by Green's Nursery Company in I889. Found in a garden at Saratoga Springs, New York, in 1897 . The American Pomological Society placed it on its fruit catalog list. As tested at this Station it is identical to the Lombard in fruit-characters but differs in foliage. It is safe to assume that it is a seedling of the Lombard.

Saskatchewan. Nigra? x. Can. Exp. Farms Rpt. 426. I900.

Taken from the wild by Thomas Stonewall, Manitoba; tested at the Indian Head Experimental Farm, Northwest Territory. Fruit of medium size, red; good; early.

Satin. Hortulana $\times$ Triflora. I. Vt. Sta. An. Rpt. 12:228. I 899 .

Grown by J. S. Breece, Fayetteville, North Carolina, supposedly from a cross between Moreman and some Japanese variety. Fruit of medium size, roundish-oval; suture a line; red with numerous large, yellow dots; skin thick, tough; flesh firm, yellow; good; clingstone.

Satsugon. Triflora. I. Rural N. Y. 64:677. I905.

Originated in 1900 with Levi Bell, Sparkill, New York, from a cross between Ogon and Satsuma. Fruit large, roundish; cavity deep; dark red; flesh red, firm, meaty; freestone; quality good; mid-season. The originator states that this variety will keep in an ordinary cellar for two months after picking.

Satsuland. Triflora $\times$ Domestica.? r. Rural N. Y. 64:677. 1905.

A cross between Satsuma and Richland grown by Levi Bell, Sparkill, New York, about I900. Fruit below medium size, oval, cavity lacking; stem long; purplishred; clingstone.

Sauvageon. Domestica. I. Montreal Hort. Soc. Rpt. 94. 1885 .

Corse's Sauvageon I. 
Raised from seed by Henry Corse of Montreal, Canada. Tree strong, vigorous, hardy, productive; fruit dark blue; flesh reddish tinged, firm, sweet and pleasant; late.

Sayer Favorite. Domestica. 1. Am. Pom. Soc. Rpt. 94. 1877.

In $1877 \mathrm{~J}$. E. Johnson in a report to the American Pomological Society mentioned this as a very fine seedling variety growing in Utah.

Scaldatone. Domestica. Mentioned in Lond. Hort. Soc. Cat. 153. 1831.

Scanarda. Species? Mentioned in Mathieu Nom. Pom. 449. I889.

Die Scanarda. Scanarda.

Scaudatella. Domestica. 1. Lond. Hort. Soc. Cat. 153. 1831. 2. Gallesio Pom. Ital. 2: P1. 1839 .

Scaldatello I. Susino Scaudatella 2.

An old variety well known in Italy. Fruit medium, obovate, yellow; flesh yellow, meaty, juicy and sweet.

Schamal. Domestica. I. Ann. Pom. Belge 7:3 1, Pl. 1859. 2. Downing Fr. Trees Am. 897. 1869. 3. Le Bon Jard. LII. 1884. 4. Guide Prat. 161, 354. 1895.

Automne de Schamali 2. Damascena Schamali 1, 2, 4. D'Automne de Schamal 2. Prune d'Automne de Schamal 1, 3, 4. Prune d'Automne de Schamali 2. Schamal 4. Schamals Herbstpflaume 4 .

Obtained by M. Schamal, nurseryman and pomologist at Jungbunzlau, Bohemia; first noted by Liegel in $\mathbf{I} 844$. Tree vigorous, productive; young branches smooth, brownish-red; fruit large, pear-shaped; suture deep; halves unequal; stem slender, smooth; purplish-red; flesh yellowish, juicy, tender, sweet, vinous; stone oval, free; mid-season.

Schenectady. Domestica. I. Mag. Hort, 446, 1847. 2. Thomas Am. Fruit Cult. 342. I849. 3. Elliott Fr. Book 4I4. 1854. 4. Cultivator 6:52, 269 . $185^{8}$. 5. Downing Fr. Trees Am. 947. 1869. 6. Oberdieck Deut. Obst. Sort. 402. 1881. Catharinenpflaume von Schenectady 6. Schenectady Catharine 4. Schenectady Catherine Plum 1, 2, 5. Schenectady Catherine 3.

Originated at Schenectady, New York, about r800; introduced by Dr. Herman Wendell. It was described in the American Pomological Society's catalog for twenty-two years. Tree vigorous, productive; fruit small, roundish-oval; suture shallow; cavity small; reddish-purple; bloom thin; flesh greenish-yellow, melting, juicy, rich, sweet; very good; freestone; mid-season; said to reproduce itself from seed.

Schieblers Eier Pflaume. Domestica. Mentioned in Mathieu Nom. Pom. 449. I889.

Schiebler Luisante. Domestica. 1. Oberdieck Deut. Obst. Sort. 409. I881.

A seedling of the Red Egg plum, similar, but not an improvement.

Schlachter Frü Zwetsche. Domestica? I. Mathieu Nom. Pom. 449. 1889. 2. Guide Prat. $163,366.1895$.

A variety resembling German Prune.

Schley. Munsoniana. x. Cornell Sta. Bul. 38:65, 87. 1892. 2. Waugh Plum Cult. I88. I9or. Schley's Large Red I, 2. 
Originated near Augusta, Georgia; introduced by J. W. K. Nelson of that state. Fruit of medium size, roundish-oval; suture slight; cavity of medium depth; bright red with numerous dots; skin tough; flesh yellow; poor; clingstone; mid-season.

Schmidt Rote $Z$ wetsche. Domestica. I. Mathieu Nom. Pom. 449. 1889.

Quetsche Rouge de Schmidt r.

Mathieu found it referred to in Wiener Garten-Zeitung 289. 1884 .

Schoenthal. Americana. x. Kerr Cat. 1894-1900.

Fruit of medium size, globular, dull red; stone semi-clinging.

Schöne von Riom. Domestica. r. Oberdieck Deut. Obst. Sort. 445. I88I.

Mentioned as an unproductive variety on dry soils.

Schuyler Gage. Domestica. I. Lond. Hort. Soc. Cat. 147. 1831. 2. Cultivator 1:306. I844. 3. Ibid. 3:19. 1855. 4. Downing Fr. Trees Am. 947. 1869. 5. Mas Le Verger 6:103. 1866-73.

Reine-Claude de Schuyler 5. Schuyler Gage 5.

A seedling of Reine Claude grown at Albany, New York, by General Schuyler of revolutionary fame, who refused to disseminate it. His successor in the ownership of the tree, John Bryan, also guarded the variety jealously, so that it was not until about 1847 when E. C. McIntosh came into possession of the estate that the variety was introduced. Fruit of medium size, oval; suture shallow; cavity small; yellow splashed with green and dotted with red; bloom thin; flesh yellow, juicy, rich, sweet; very good; freestone; late.

Scioto. Insititia. I. U. S. D. A. Yearbook 502. 1905.

Mussel I. Chickasaw I.

Cultivated for nearly eighty years in the noted Damson district at Chillicothe, Ohio. It was brought there in $\mathrm{r}_{3} \mathrm{I}$ by Miss Palace Hill from the nursery of her brother, Joseph C. Hill, Petersburg, Virginia, who in turn had found it on the farm of Thomas Hill near Bollings Bridge, North Carolina. The variety is of the Damson type and the seed of it was probably brought from Europe by the early colonists. Fruit small, oval, necked; suture slight; cavity lacking; dark bluc; bloom heavy; good.

Scribner. Triflora $\times$ Munsoniana. I. U. S. D. A. Pom. Rpt. 46, Col. Pl. 1895.

2. Vt. Sta. Bul. 67:19. 1898. 3. Waugh Plum Cult. 225. 1901.

From J. S. Breece, Fayetteville, North Carolina, supposedly from a cross of Abundance pollinated by Wild Goose. Fruit large, roundish-oval; suture faint; cavity large; stem short, stout; dark red with many small dots; bloom heavy; flesh yellow, firm, meaty; quality very poor; clingstone.

Sea-Egg. Triflora. 1. Cornell Sta. Bul. 106:62. ז906.

Bailey mentions this variety as coming from Burbank and describes it as; "globular heart shaped in outline and mottled red; flesh very thick and meaty; orangeyellow, sweet and excellent, with a slight muskiness, cling."

Semiana. Domestica. 1. Forsyth Treat. Fr. Trees 21. 1803. 2. Thomas Am. Fruit Cult. 344, 346. 1849. 3. Cole Am. Fr. Book 217. 1849. 4. Downing Fr. Trees Am. 947. 1869 .

Blue Impératrice 2, 3, 4. Semiana of Boston 4. Semina 1. Simiana 2. 
At one time grown extensively around Boston; often confused with Blue Impératrice and the Semiana or Stisse of Europe. It is, however, much inferior to either of the above. Tree vigorous, very productive; fruit of medium size, oval, necked; cavity very small; deep purple; flesh greenish, juicy, subacid, not rich; clingstone; very late. Seper. Nigra? I. Kerr Cat. 1897-1900. 2. Waugh Plum Cult. I71. I gor.

Seper's Peach 2. Seper's Peach 1.

Introduced by J. W. Kerr, Denton, Maryland. Fruit large, roundish-oblong, dark red; quality poor; clingstone.

September. Americana. I. Meneray Cat.

One of H. A. Terry's numerous varieties; introduced by F. W. Meneray of Council Bluffs, Iowa. Fruit large, round, bright red; fair quality.

September Damask. Insititia. 1. Duhamel Trait. Arb. Fr, 2:77. 1768. 2. Kraft Pom. Aust. 2:45, Tab. 200 fig. I. I796. 3. Prince Pom. Man. $2: 84.1832$. 4. Poiteau Pom. Franc. 1. 1846. 5. Hogg Fruit Man. 357. 1866. 6. Downing Fr. Trees Am. 947. 1869. 7. Mas Pom. Gen. 2:1. 1873. 8. Mathieu Nom. Pom. 45I. I889.

Damas de Septembre 1, 2, 5, 7. Damas de Septembre 3, 6, 8. Die späte oder September Damaskpflaume 2. Michaelis Pflaume 8. Munchenpflaume 8. Prune Damas de Septembre 4. Prune de Vacance 1, 2, 3, 4, 5, 6, 7, 8. Prunier des Vacances 3, 6, 8. Sankt-Michel's Pfaune 8. September Damascene 8. September Damask 3. September Damask 7, 8. Septeniber Damson I. Vakanzpflaume 8.

An old variety probably of French origin. Tree of medium vigor, productive; shoots downy; fruit small, roundish to slightly elongated; suture shallow; stem short; cavity shallow; skin tender, purplish-black, covered with a thick bloom; flesh greenish, fine, melting, sweet, agreeable when well ripened; freestone; late.

Shaker. Americana? 1. Ill. Hort. Soc. Rpt. 8o. 1880.

Grown in Iowa from seed brought from Ohio. Fruit red, coloring a month before maturity; ripening period very long.

Shaw. Species? r. Bailey Ann. Hort. 103. 1889.

Mentioned by Bailey in the Annals of Horticulture as introduced by Lovett in 1889; not listed in Lovett's catalogs.

Shedd Cluster. Munsoniana? Letter from F. T. Ramsey.

A prolific variety resembling Robinson selected from the wild on the line between Lampasas and Coryelle counties, Texas, by a Mr. Shedd.

Sheldon. Domestica. I. Downing Fr. Trees Am. 948. 1869.

Originated on the farm of Wareham Sheldon, Huron, Wayne County, New York. Tree vigorous and prolific; fruit large, oval; suture a line; cavity small; purplishblack; bloom thick; flesh greenish-yellow, juicy, aromatic; good; freestone; midseason.

Shepherd Bullace. Insititia. I. Watkins Nur. Cat. 48. 1892 ? 2. Thompson Gard. Ass't 4:160. 1901. Shepherd's White 2.

A large Bullace mentioned without description in the preceding references.

Shepway Bulleis. Insititia. I. Parkinson Par. Ter. 576. 1629. 
Parkinson mentions under this name a large "dark bluish-brown" plum of the Bullace type inferior to the common variety.

Shilling. Domestica. x. Kerr Cat. 1894. 2. Ohio Sta. Bul. $162: 256,257.1905$.

A variety introduced by $\mathrm{J}$. W. Kerr in 1894. Fruit of medium size, oblong-oval, pointed at the apex; cavity shallow; suture a line; stem short, stout; dull red; bloom light; flesh yellow; quality poor; clingstone; mid-season.

Shipper. Triflora. 1. Burbank Cat. 18. 1893. 2. Childs Cat. 62. 1896.

A seedling of Satsuma grown by Burbank; introduced in 1896 by John Lewis Childs, Floral Park, New York. Fruit oval, light red; flesh very firm, juicy, sweet; keeps and ships well; mid-season.

Shirata Bene. Triflora. 1. Lovett Cat. 1892. 2. Ohio Sta. Bul. 162:256, 257 . 1905. Introduced as a crimson plum but described at the Ohio Experiment Station as yellow.

Shviata Bene. Triflora. I. Gard. Mon. 367. I887.

Uwase 1. Blood Plum 1.

H. H. Berger states that the above name and synonyms were applied to a redfleshed variety indigenous to Japan. Probably a class name.

Siamese. Domestica. r. Downing Fr. Trees Am. 284. 1845 .

Fruit in pairs firmly attached on one side and hanging from a single stem. The original tree grew in the garden of Wm. Roe, Newburgh, New York. Fruit of medium size, obovate; cavity small; skin pale yellow; flesh yellow, juicy, sprightly; quality fair; clingstone; mid-season.

Sidone. Species? Mentioned in Mathieu Nom. Pom. 450. 1889.

Siebenburger Pflaume. Species? 1. Mathieu Nom. Pom. 450. 1889. 2. Guide Prat. I6 3 , 366. I 895 .

"A variety of little merit."

Sierra. Subcordata. I. Can. Hort. 19:405. 1896. Sierra Crimson I.

Reported in the preceding reference by S. S. Watkins, Grizzly Flats, California, as a very good wild plum growing high up in the Sierra Nevada Mountains. Said to bear beautiful crimson fruit about the size of the Reine Claude, of good quality; highly recommended for jelly.

Silassy. Domestica. 1. Mich. Sta. Bul. 118:52. 1895. 2. Ibid. 152:211. 1898.

Imported from Hungary by the Michigan Experiment Station.

Silas Wilson. Americana. 1. Cornell Sta. Bul. 38:80. 1892. 2. Can. Exp. Farms Rpt. 105. I900. 3. Terry Cat. 1900.

Grown by H. A. Terry, from seed of Hawkeye; first fruited in 1891 . Fruit large, oval; cavity shallow; suture a line; red over a yellow ground; dots numerous; flesh yellow, juicy; good; clingstone; mid-season.

Silva Koning Claudie. Domestica, I. Wickson Cal. Fruits 358. I89 I.

Miller's Early r.

Described by Wickson as an undetermined variety brought from Germany by Dr. L. E. Miller, of California, in 1854 ; introduced by C. M. Silva \& Son of Newcastle, California, in 1887. Fruit purplish-black; fine flavor; similar in size to the Early Royal, and about a month earlier. 
Sirocco. Triflora X? 1. U. S. D. A. Pom. Rpt. 47. 1895. 2. Vt. Sta. Bul. 67:19. 1895.

J. S. Breece, of Fayetteville, North Carolina grew this varicty as a cross between Abundance and Marianna. Fruit of medium size, roundish-oval; cavity small; suture a line; coppery-red with streaks of yellow; dots minute, russet; flesh reddish near the skin but yellow towards the stone, juicy; good.

Sisson. Subcordata kellogii. I. Bailey Ev. Nat. Fruits 216, 217. 1898.

Fruit larger than the wild Subcordata; yellow or red; flesh soft and palatable. Sce the discussion of Prmnus subcordata, page 74 .

Sixby. Americana. I. Wis. Sta. Bul. 87:15. 1901.

Sent out by Edson Gaylord, Nora Springs, Iowa. Fruit small; suture distinct; bright red with conspicuous dots; skin adherent; flesh deep yellow tinged with red, crisp, rich; stone oval.

Six Weeks. Triflora $\times$ Angustifolia varians? 1. Kerr Cat. 1o. 1901-2. 2. Tex. Nur. Cat.

8. 1907. 3. Tex. Dept. Agr. Bul. 12:102. 1910. Early Six Weeks.

Grown from seed of Abundance crossed with an early "Chicasaw;" named and introduced by J. S. Kerr of Texas. Tree vigorous, upright, rapid in growth, resembles the native variety more than Triflora; fruit large, oblong, yellow tinged red; early. Skuya. Triflora $\times$ Americana. I. S. Dak. Sta. Bul. ro8. 1908.

A cross between De Soto and Red June made by Hansen of the South Dakota Experiment Station resulted in eight seedlings of which the above was the first to fruit. Fruit large, dark, dull red and yellow, sweet; good; stone small.

Sloe. Americana. 1. Kerr Cat. 1894-1900. 2. Wis. Sta. Bul. 63:59. 1897.

Sloe is a small native variety that has been given the common name of the wild European plum. (See the following name.) Fruit small, roundish-oblong; skin thick, dark red; clingstone; mid-season. The name is also applied in one locality or another to nearly all of the American species of plums as they grow wild.

Sloe. Spinosa. I. Parkinson Par. Ter. 576. 1629. 2. Ray Hist. Plant. 1529. 1688.

3. Knoop Fructologie 2:63. 1771. 4. Prince Pom. Man, $2: 106.1832$.

Blackthorn 4. Black Prunella 2. Conmon Sloe 4. Épine noire 4. Petit prunallier 4. Pruneola 1. Prunelle 3. Prune Sawvage 3. Prumus silvestris 3. Prunus spinosa, foliis lanceolatis 3. Prunelier 4. Prunus spinosa 4. Prunier èpinenx 4. Prunallier 4. Slee-Pruim 3. White Prunella 2. White Blossomed Sloe 4.

See Prunus spinosa.

Small Green Drying. Domestica. I. Lond. Hort. Soc. Cat. 153. 1831.

A variety under test in the garden of the London Horticultural Society.

Small White Damson. Insititia. I. Duhamel Trait. Arb. Fr. 2:81. 1768, 2. Kraft Pom. Aust. 2:44, Tab. 198 fig. 1. 1796. 3. Floy-Lindley Guide Orch. Gard. 300. 1846. 4. Noisette Man. Comp. Jard. 2:496. 1860. 5. Mas Le Verger 6:127. 1866-73. 6. Hogg Friti Man. 726. 1884. 7. Mathieu Nom. Pont. 427. 1889.

Damas blane petit 6, 7. Damascenen Mirabelle 7. Die Kleine Weisse Damascenerpflaume 2. Kleine Weisse Damascene 7. Klein Weisse Damassener Pflaume 5. Petit 
Damas Blanc 1, 5. Petit Damas Blanc 2, 3, 7. Prune Petit Damas Blanc 5. Prunier Damas aे petit fruit blanc 4. Small White Damask 6. Small White Damask 7. White Damask 3.

Probably a French variety. Tree of medium productiveness; shoots smooth; fruit small, roundish, inclining to ovate; stem medium in length, slender; skin yellowish, tinged with red on the sunny side; flesh yellow, firm, juicy, sweet and well flavored; freestone; mid-season; culinary.

Smiley. Munsoniana. 1. Cornell Sta. Bul. 38:80. 1892. 2. Am. Pom. Soc. Cat. 40. 1899. 3. Waugh Plum Cult. 188. 1901. 4. Ga. Sta. Bul. 67:281, 282. 1904.

Thought to have originated in Alabama. Tree vigorous with an open and spreading habit, very productive; fruit medium or above, roundish-oval to roundish-oblong; cavity shallow, rounded; suture a line; red with numerous small, yellow dots; skin tough; flesh yellow, soft; quality fair to good; stone medium, oval, somewhat flattened, clinging; mid-season.

Smith. Americana. 1. Kerr Cat. 1894. 2. Wis. Sta. Bul. 87:18, 1901. 3. Waugh Plum Cult. 164. 1901 .

A seedling of Quaker grown by C. A. Smith, Caroline County, Maryland. Tree of straggling, open growth, vigorous and productive; fruit large, sometimes very large, roundish-oval to roundish-oblong; suture a line; apex rounded; cavity shallow, narrow; stem short and stout; yellow overspread with dark red; dots small, yellow; bloom heavy; skin thick, tough; flesh deep yellow, juicy, firm, sweet; good to best; stone large, oval, nearly free; medium early. Waugh says, "One of the best Americanas I ever saw."

Smith October. Domestica. I. Can. Exp. Farms Rpt. 146. 1896.

A seedling grown by A. M. Smith, St. Catherines, Ontario. Fruit of medium size, slightly one-sided; suture obscure; black, somewhat mottled; bloom light; flesh dark yellow, firm, subacid; quality fair; stone small, globular with a deep hollow alongside a thickened margin.

Smith Prolific. Domestica. I. Can. Exp. Farm Bul. 2nd Ser. 3:56. 1900. 2. Can. Exp. Farms Rpt. 433. 1905.

Under test at the Experimental Farm at Agassiz, British Columbia. Fruit medium in size, globular; cavity deep; stem short; suture distinct and terminating in a depression; yellowish with a purple-red cheek; bloom thin; flesh yellowish, juicy, sprightly; stone of medium size, clinging; mid-season.

Smith Red. Nigra? 1. Wis. Sta. Rpt. II:345. 1894. 2. Wis. Sta. Bul. 63:59,60. 1897 . 3. Waugh Plum Cult. 17r. 1901. Smith's Red 1, 2.

Sent to the Wisconsin Experiment Station in 1890 by I. F. Gale \& Son, Waukesha, Wisconsin. Tree vigorous, productive; fruit large, round-oval; suture a line; stem short and stout, set in a shallow cavity; purplish-red, shading to orange; dots minute; bloom thin; skin thick with a very slight harshness; flesh yellow, firm, sweet; fair to good; stone large, oval, thin, clinging; mid-season.

Snelling. Nigra. 1. Can. Exp. Farms Rpt. 136. 1894. 2. Can. Exp. Farm Bul. 43:39. 1903 . 
Grown by W. H. Snelling, New Edinburgh, Ontario, about I880 from a sprout of an old tree growing at Gatineau Point, Quebec. Fruit medium to large, usually round; stem an inch long, set in a round cavity; suture distinct; yellowish-red, mostly covered with darker red; bloom light; skin thin, tender, apt to crack when fully ripe, slightly astringent; flesh soft, very juicy, sweet; good; stone large, flat; mid-season.

Snyder. Americana. 1. Ia. Sta. Bul. 46:288. 1900. 2. Budd-Hansen Am. Hort. Man. 301. 1903.

A seedling of De Soto; originated in 1893 with J. A. Fairchild, Coggon, Linn County, Iowa. Tree vigorous, upright; fruit large, roundish, oblique-truncate; suture a line; apex depressed; stem stout set in a shallow cavity; light red with darker shades of red; dots large; bloom thin; flesh yellow, firm, brisk subacid; fair to good; stone large, oval, flat, clinging.

Souris. Nigra? I. Can. Exp. Farms Rpt. 426. 1900.

Under test at Indian Head, Northwest Territory, Canada.

South Cumberland. Species? I. Am. Pom. Soc. Rpt. 15r. r89r.

P. J. Berckmans of Augusta, Georgia, says in the above reference that this variety has been known for twenty-six or twenty-seven years in his section. Fruit golden yellow; very good.

Southern Beauty. Species? I. Wild Bros. Cat. 1892. 2. Kerr Cat. I894.

Tree peach-like in growth and general appearance; wholly barren; possibly the Blackman renamed; worthless.

Southern Golden. Species? I. Ala. Sta. Bul. Ir:12. I8go.

Noted in the preceding reference as a feeble grower; fruit medium in size, oblong, yellow, tender; quality best; early.

Spanish Damask. Domestica. 1. Kraft Pom. Aust. 2:129, Tab. 175 fig. 2. 1796.

2. Forsyth Treat. Fr. Trees 21. 1803. 3. Willich Dom. Enc. 4:300. 1803.

4. Poiteau Pom. Franc. 1. 1846 . 5. Hogg Fruit Man. 693. 1884. 6. Mathieu Nom. Pom. 439. 1889.

Damas d'Espagne 1, 6. Damas D'Espagne 5. Die Damaskpflaume aus Spanien I. Liegel's Spanische Damascene 6. Prune Damas D'Espagne 4. Prunus hispanica 4. Spanish Damascene 2. Spanish Damask 6. Spanish Red Damask 3.

Fruit small, roundish; suture shallow; cavity small; stem short; purplishblack; bloom thick; flesh yellow, tender, juicy, not rich; quality fair; freestone; midseason.

Spanish King. Domestica. I. Ia. Hort. Soc. Rpt. 355. 1878. 2. Ibid. 145. 1880. 3. Mich. Sta. Bul. 169:243, 247. I899. 4. Ia. Sta. Bul. 46:279. 1900. 5. BuddHansen Am. Hort. Man. 326. 1903. Rex 1, 2. Spanish 3.

Introduced into Marion County, Iowa, by John Laike, a German, under the name Rex, through cions obtained in $187_{2}$ from a Spanish consul. Several tests show this variety to be identical with the Lombard. If the origin given is correct, the belief that the Lombard is an old European variety is substantiated.

Späte Zwetsche Von Karlstadt. Species? Mentioned in Mathieu Nom. Pom. 450. 1889. Speckled Gage. Domestica. I. N. Y. Sta. An. Rpt. 7:92. 1888. 
Originated as a sucker from trees secured in Montreal by James Tobias. Fruit small, round, purplish, speckled with conspicuous dots; very sweet; good.

Speer. Americana. I. Cornell Sta. Bul. 38:42, 1892. 2. Colo. Sta. Bul. 50:45. 1898 . 3. Can. Exp. Farms Rpt. 305. 1898 .

Found wild by J. A. Speer, Cedar Falls, Iowa. Tree small, very hardy, spreading, productive, apt to overbear; fruit medium or below, irregular-oval to oblong; suture distinct; cavity shallow; stem short, slender; purplish-red on a yellow ground; dots numerous, small; bloom heavy; flesh yellow, firm and sweet; good; stone large, oval, flat, ends blunt, semi-clinging; medium late.

Spicer. Munsoniana. I. Can. Exp. Farm Bul. 2nd Ser, 3:56. I900.

Originated with Charles Luedloff of Minnesota; according to the above reference of no value in British Columbia.

Spilling Jaune-double. Insititia. I. Knoop Fructologie $2: 63$. I 771 .

Except in its larger size and poorer quality this variety closely resembles the White Wheat.

Splendid. Americana. I. Ia. Sta. Bul. 46:288. 1900. 2. Kerr Cat. 6. 1900.

Found wild by I. K. Teeter near Magnolia, Harrison County, Iowa, in 1878; introduced by J. W. Kerr in 1900 . Tree dwarfish, bears early, productive; fruit medium in size, dark red; skin tough; flesh yellow, very firm, sweet; good; semiclinging; medium to late.

Splendor. Domestica. I. Burbank Cat. 15 fig. 1893. 2. Cal. State Bd. Hort. Rpt. 47. 1897-98. 3. Am. Gard. $21: 36$. 1900. 4. U. S. D. A. Yearbook 274, $\mathrm{Pl}$. XXXVI. I903. Cross-bred Prune A.P.-31 8 r.

Splendor was originated by Luther Burbank in 1886 from a cross between Pond and Agen. In 1893 it was sold under the name Cross-bred Prune A.P.-3I 8 to Stark Brothers of Louisiana, Missouri, who introduced it the following year under its present name. The fruit is twice the size of Agen, ovoid, compressed, dark purple; bloom heavy; flesh yellow, rich, sweet; freestone; hangs well to the tree and ripens its crop all together.

Spotted Gage. Domestica. I. Downing Fr. Trees Am. 949. 1869.

Tree vigorous, very productive; fruit medium or above, oval; suture shallow; greenish-yellow shaded, mottled and splashed with crimson and lilac; dots numerous, light; bloom thin; flesh coarse, yellow, sugary, juicy, a little vinous; good; semiclinging; mid-season.

Springer. Americana. r. Wis. Sta. Bul.87:8. 1901. 2. Wis. Hort. Soc. Rpt. 91, 94. 1901.

Found wild by Wm. A. Springer of Fremont, Wisconsin; sent to the Wisconsin Experiment Station in 1890 and named by Professor E. S. Goff. Tree productive; fruit of large size, deep purplish-red shading to yellow; dots numerous, yellow; bloom moderate; skin thick, tender, not harsh; flesh deep yellow, sweet and rich; stone large, thick margined, clinging; mid-season.

Stabeler Seedling. Species? r. Elliott Fr. Book 429. I854.

According to Elliott, an American variety; fruit medium in size, oval, greenishyellow with white specks; flesh yellowish, adhering to the stone; mid-season. 
Standard. Domestica. 1. Gard. Chron. 13:600. 1853. 2. McIntosh Bk. Gard. $2: 533$. 1855. 3. Ann. Pom. Belge 8:25, P1. 1860. 4. Hogg Fruit Man. $3_{82 .} 1866$. 5. Mathieu Nom. Pom. 429. 1889 .

Etendard d'Angleterre 5. L'Etendard De L'Angleterre 3. Standard of England 5. Standard of England I, 2, 4 .

An English variety raised from seed about 1845 by Henry Dowling of Woolston. Fruit above medium size, obovate; suture shallow; stem medium; cavity small; bright red, shading to purplish-red; dots yellow; bloom thin, violet; flesh greenish, firm, juicy, brisk flavor; good; stone small, oval, nearly free; mid-season.

Standard. Domestica. I. Burbank Cat. I I. IgII.

This Standard is a cross between Tragedy and Sugar recently sent out by Luther Burbank. Professor E. J. Wickson of the College of Agriculture at Berkeley, California, describes it as follows: "Freestone, pit small $\frac{5}{8}$ inch by $\frac{5}{8}$ inch. Flesh yellowish, melting, fine-grained; very juicy and sweet; skin dark blue, sub-color dark red, medium texture." Stark Green Gage. Domestica. r. Bailey Ann. Hort. 196. I8gr. 2. Stark Bros. Cat. I 89 .

Stark Green Gage is said to be a seedling of Missouri Green Gage; introduced by Stark Brothers in $189 \mathrm{I}$. As tested at this Station both of these varieties are identical with Imperial Gage.

Steinman. Americana. I. Wis. Sta. Bul. 63:59. 1897. 2. Ia. Sta. Bul. 46:288. 1900. 3. Ibid. I14:I44. I910. Steinman No.2 3.

Of the type of Stoddard, originated in $\mathrm{I} 88_{3}$ by C. Steinman, Mapleton, Iowa, from a mixed lot of seed of De Soto, Quaker and Forest Garden. Tree productive; fruit of medium size, oval, conical, one-sided; stem short; suture distinct; apex pointed; crimson with numerous dots; bloom thick; skin thin; flesh yellow, watery, sweet; good to very good; stone medium, oval, pointed; late.

Stella. Americana. 1. Kerr Cat. 6. I900. 2. Waugh Plum Cult. I64. Igor.

Grown by Theodore Williams of Benson, Nebraska. Tree spreading, very productive; fruit large, globular, purplish-red; season medium.

Steptoe. Domestica. I. Oregon Sta. Bul. 45:3 I. I897. 2. Mich. Sta. Bul. 152:21 I. I898. 3. Can. Exp. Farms Rpt. 548. I901.

Originated with Calvin Throop near Steptoe Butte, Washington; introduced by George Purdy, Colfax, Washington. Tree upright, vigorous, bears every year; fruit resembles Italian Prune very much but is larger and ripens two weeks earlier; ovate, purple; bloom thin; flesh yellowish, juicy, sweet, pleasant.

Sterling. Americana. I. Kerr Cat. I2. 1898.

Cataloged by J. W. Kerr for three years; not described.

Stickney. Species? I. Wis. Sta, Bul. 63:60. I897.

A tender-fleshed variety of the season and size of Rollingstone, grown by Franklin Johnson of Baraboo, Wisconsin.

Stint. Domestica. 1. Garden 52:261. 1897. 2. Can. Exp. Farm Bul. 2nd Ser. 3:56. 1900. 3. Garden $62: \mathrm{x}_{33}$. I902. 4. Mathieu Nom. Pom. 450. I8s9.

Stintpflaume 4 . 
Introduced by Thomas Rivers of Sawbridgeworth, England, in 1885. Tree dwarfish, very productive; fruit small, roundish, red or reddish-purple; flesh orange, juicy, sweet, fine; good; stone free; early.

Stonewood. Domestica. I. Mag. Hort. 9:165. 1843 .

Listed in the catalog of the London Horticultural Society. Fruit of medium size, roundish, purple; good; freestone; mid-season.

Stout. Domestica, I. Kerr Cat. 1894.

An inferior blue variety originated by Mr. Stout of Kent County, Delaware; tested by J. W. Kerr.

Strawberry. Angustifolia watsoni. I. Cornell Sta. Bul. 38:65. 1892. 2. Waugh Plum Cult. 234. $190 \mathrm{r}$.

Tree dwarf, symmetrical, much subject to twig-blight. Fruit small, roundish; cavity shallow; stem slender; skin thin, red; bloom thin; flesh yellow, soft; quality poor; stone roundish, clinging.

Striped-leaved. Domestica? r. Forsyth Treat. Fr. Trees. 21.1803.

Mentioned by Forsyth as one of the sorts commonly grown in England in his time.

Sucker State. Hortulana. 1. Cornell Sta. Bul. 38:50, 87. 1892. 2. Col., O., Hort. Soc.

Rpt. 82. 1892. 3. Waugh Plum Cult. 182. 1901.

The origin of this variety is not known, but it is thought to have come from Illinois. Tree vigorous, fairly productive; fruit medium or above, round-oblong; suture a line; cavity shallow; stem slender; dark red; dots numerous, small, yellow; bloom very thin or lacking; skin thick; flesh yellow, firm; good; stone of medium size, clinging; late.

Suisse. Domestica. 1. Duhamel Trait. Arb. Fr. 2:82, 1768, 2. Forsyth Treat. Fr. Trees 21. 1803. 3. Prince Pom. Man. 2:63. 1832. 4. Downing Fr. Trees Am. 949. 1869. 5. Hogg Fruit Man. 726. 1884. 6. Mathieu Nom. Pom. 450. 1889.

Altesse 3, 5, 6. La Prune Suisse 2. Monsieur Tardif 4, 5, 6. Monsieur Tardive 3, 4. Prune d'Altesse 4, 6. Prune de Monsieur Tardive 3. Prune Suisse 1. Prune Suisse 3, 4. Swiss Plum 3, 4, 6. Semiana 6. Simiana 4. Schweizer Pflaume 6. Switzer's Plum 4, 5, 6 .

An old European variety known under many names. In the French nurseries, it has been badly confused with the Blue Impératrice so common in England. Tree vigorous and productive; fruit small, oval, dark purple shading to dark red; bloom heavy; flesh greenish-yellow, juicy and melting; good; clingstone; late.

Sultan. Domestica. I. Jour. Hort. $21: 243$. 1871. 2. Flor. and Pom. 145, Pl. 1875.

3. Hogg Fruit Man. 727. 1884 .

Raised by Thomas Rivers, Sawbridgeworth, England, from seed of Belle, about 1871 . Tree vigorous, very productive; fruit medium to large, round with a deep suture; stem medium; cavity wide; deep red; bloom thick; flesh greenish-yellow, firm, juicy, brisk and plcasant; clingstone; early mid-season; said to be an excellent culinary plum.

Sultaneck Erick. Species? Mentioned in Mathieu Nom. Pom. 451. 1889.

Sunrise. Domestica. 1. Am. Pom. Soc. Rpt. 78. 1897 . 
Exhibited by C. C. Stirling, Grand Rapids, Michigan, at the meeting of the American Pomological Society in 1897 . Fruit of medium size, round, yellow and lilac; of the Reine Claude type.

Sunrise. Americana. 1. Can. Exp. Farms Rpt. 102. 1902. 2. Can. Exp. Farm Bul. 43:32. $\quad$ r 903 .

A seedling of De Soto from the Central Experimental Farm, Ottawa, Canada. Fruit large, oval; cavity narrow, shallow, abrupt; suture distinct, but not depressed; apex rounded; yellow more or less covered with bright red; dots few, yellow, distinct; bloom medium; skin thick, moderately tough; flesh deep yellow, juicy, sweet; good; stone large, flat, oval, free or nearly so; late.

Sunset. Americana. 1. Colo. Sta. Bul. 50:46. 1898. 2. Ia. Sta. Bul. 46:289. I900.

Originated by Charles E. Pennock of Bellevue, Colorado, in 1892 . Tree vigorous, hardy, very productive; fruit large, oval or oblong; suture distinct; stem rather long, slender; deep red on a yellow ground, beautifully shaded; flesh firm, of excellent quality; mid-season.

Surpasse Monsieur. Domestica. I. Prince Pom. Man. 2:63. I832. 2. Noisette Man. Comp. Jard. 2:498. 1860. 3. Le Bon Jard. 341. 1882.

A hybrid between Monsieur and Jerusalem raised by M. Noisette of Paris; first fruited in I8rg. Tree very vigorous; fruit above medium size, round, purplish-black; flesh yellow, a trifle harsh; excellent; mid-season.

Svedske Tidlig Leipziger. Domestica. I. Lond. Hort. Soc. Cat. 153. 1831.

Grown in the gardens of the London Horticultural Society prior to 1831 .

Svedske Ungersk. Domestica. Listed in Lond. Hort. Soc. Cat. I53. I831.

Swan. Domestica. 1. Rivers Cat. 35. 1898. 2. Can. Exp. Farm Bul. 2nd Ser. 3:56. I goo. Raised by Thomas Rivers of Sawbridgeworth, England. Tree very productive; fruit large, red; freestone; mid-season.

Swan Golden. Domestica. I. Can. Exp. Farm Bul, 2nd Ser. 3:56. 1900. 2. Can. Exp. Farms Rpt. 548. 1901. 3. Ibid. 433. r905. Swan 3. Swan's Yellow 2.

Found only in the preceding reports. Fruit of medium size, roundish; suture distinct; cavity small; stem short; yellow; flesh yellow, juicy, sweet, tender; stone small, mid-season.

Sweet Damson. Insititia. I. Lond. Hort. Soc. Cat. 146. 1831. 2. Mag. Hort. 9:163. 1843 .

An English variety similar to Shropshire except in its sweetness.

Swift. Americana. I. Can. Exp. Farms Rpt. I19. 1904.

A seedling of De Soto grown at the Central Experimental Farm, Ottawa, Canada. Fruit large, broad-oval, much flattened; cavity narrow, shallow; suture a line; apex slightly flattened; yellow, mottled and washed with deep red; dots obscure; bloom light; skin thick, moderately tough; flesh pale yellow, juicy, sweet, pleasant; stone above medium, oval, almost free.

Szillassy Piros. Domestica. I. Mich. Sta. Bul. 152:211. 1898.

Noted in the preceding reference as a variety imported from Hungary. 
Tardive de Corny. Species? 1. Mathieu Nom. Pom. 451. 1889. 2. Guide Prat. I55, 366. 1895 .

This variety is a seedling grown by Victor Simon of Corny, Metz, France. Tree rather small in trunk, but forms a large head, regularly productive; fruit of medium size, roundish, clear yellow blushed with red; bloom thin; flesh yellow, firm, juicy, sweet and aromatic; good; late.

Tardive de Fourqueux. Species? I. Mathieu Nom. Pom, 451. I889.

Mathieu took his references from the Journal de la Societe Nationale et Centrale d'Horticulture de France 169. I885.

Tardive de Genes. Domestica. I. Mathieu Nom. Pom. 451. 1889. 2. Guide Prat. I62, 366.1895 .

An Italian variety noted for its size, lateness and color. Tree vigorous, productive; fruit very large, roundish-oval, yellow; flesh firm, sour; very late.

Tardive Musquee. Domestica. I. Mas Pom. Gen. 2:147. 1873. 2. Cat. Cong. Pom.

France 370. 1887. 3. Rev. Hort. 536, 561. 1893. 4. Lucas Vollst. Hand.

Obst. 470. 1894. Spate Muskateller Pfaume 4.

Originated by M. M. Baltet, a nurseryman at Troyes, France, about 1859 . Tree weak, productive; fruit medium to above, round-oval with an indistinct suture, very deep purple; bloom thick; flesh greenish, melting, with aroma of musk; good; midseason. This may be the Late Muskatelle of Lucas.

Tarleton. Cerasifera. I. Kerr Cat. 21. 1897. 2. Vt. Sta. An. Rpt. 13:370. 1900.

Waugh says this variety, which comes from Georgia, is very similar to Early Cherry. Tree vigorous, spreading and irregular in growth; fruit small, round; suture indistinct; stem medium, set in a shallow cavity; red; bloom thin; flesh yellow, soft, sweet; quality fair; stone small, clinging; very early.

Tatge. Domestica. 1. Penin. Hort. Soc. Rpt. 12, 1892, 2. Ia. Hort. Soc. Rpt. 76. I895. 3. Ia. Sta. Bul. 46:289. 1900. 4. Budd-Hansen Am. Hort. Man. 326. 1903. 5. Ohio Sta. Bul. I62:258. I905.

Tatge is said to have originated at Belle Plains, Benton County, Iowa. In 1892 , J. W. Kerr of Maryland mentioned this plum as a new variety, brought to notice about I 890 . Tatge is so similar to the Lombard that many authorities have noted them as identical. J. L. Budd of Iowa considered it somewhat hardier and less subject to rot.

Tawny. Domestica. I. Ray Hist. Plant. 2:1528. 1688.

Given by Ray in a list of the best sorts of plums cultivated in his time.

Taybank. Domestica. I. Mag. Hort. 12:34I. 1846. 2. McIr tosh Bk. Gard. 2:532. 1855. 3. Hogg Fruit Man. 727. 1884.

Guthries Taybank I, 2, 3.

Grown by Charles Guthrie, of Taybank, Dundee, Scotland; probably an offspring of Reine Claude. Fruit nearly large, ovate; suture faint; stem medium, inserted almost without a depression; greenish-yellow with specks of russety-red on the sunny side; flesh yellow, juicy, tender, melting, very sweet, approaching Reine Claude in flavor but not equal to that variety; clingstone; mid-season. 
Tecumseh. Americana. r. Kerr Cat. 13. 1897. 2. Can. Exp. Farm Bul. and Ser. 3:52. 1900. Hughes Late 1.

J. W. Pool of Indiana who introduced this plum named it Hughes Late but later changed the name to avoid confusion with the variety named Hughes. Fruit medium in size, round, yellow mottled with bright red changing to coppery-red when fully ripe; clingstone; mid-season.

Temple. Species? 1. Am. Pom. Soc. Cat. 1875-1899.

Listed by the American Pomological Society in its catalog from 1875 to 1899 .

Tenneha. Species? Mentioned in Cornell Sta, Bul. 38:80. 1892.

Tennessee. Munsoniana. I. Am. Jour. Hort. 5:148. 1869. Tennessee Plum 1. A strain of Wild Goose.

Terrell. Triflora $\times$ ? I. Am. Pom.Soc.Rpt. 249. 1903. 2. Glen.St.Mary Nur.Cat. 1904.

A seedling of Excelsior from Jay Terrell, Hastings, Florida; introduced by the Glen St. Mary Nurseries, Glen St. Mary, Florida. Tree healthy, vigorous, similar to Excelsior, bears heavy crops annually; fruit medium to large, nearly round; suture a line; apex blunt; cavity medium in depth; stem short and slender; reddish-yellow, somewhat mottled and deepening to wine-red; dots minute, yellowish; skin thin, tough; flesh greenish-yellow, meaty, subacid, rich; excellent; stone small, broadly oval, turgid, clinging; ripens in June in the South.

Terry. Americana mollis. I. Stark Bros. Cat. 1896. 2. Ia. Sta. Bul. 46:271. 1900. 3. Ia. Hort. Soc. Rpt. 224.1902 . 4. S. Dak. Sta. Bul. 93:40. 1905.

Free Silver 2. Free Silver 1, 3, 4 .

H. A. Terry of Crescent, Iowa grew this variety from seed of Van Buren; first fruited about 1896 . Tree vigorous, upright, open; fruit large, regular, oval; cavity small, shallow; suture indistinct; dark red; dots small, gray; bloom thin; flesh yellow, firm but melting; good; stone large, oval, clinging; mid-season; ripens very evenly. Terry De Soto. Americana. 1. Terry Cat. 1900. 2. Ia. Sta. Bul. 46:289. Igoo.

Terry's Desota I.

A seedling of De Soto, grown by H. A. Terry. Tree vigorous, upright, productive; fruit large, golden-yellow overspread with light crimson, mottled with darker shades; flesh yellow, rich and sweet; clingstone; early.

Texas Belle. Munsoniana. I. Ga. Hort. Soc. Rpt. 34, 57. 1888. 2. Cornell Sta. Bul. 38:50. 1892. 3. Tex. Sta. Bul. 32:481. r894.

Belle 2. Paris Belle 1,3 .

Grown by Stephen H. Turner of Texas; introduced by Dr. W. W. Steele of Paris, Texas. Tree small, drooping, hardy and productive; fruit medium to large, roundish, light red; flesh yellow, firm, sweet and pleasant; stone short and turgid, clinging; last of June in Texas. Mentioned in the catalog of the American Pomological Society in 1897 .

Texas Gage. Domestica. 1. Tex. Sta. Bul. 32:484. 1894.

Noted in the preceding reference as having been grown at the Texas Experiment Station. 
Thanksgiving. Domestica. 1. Green Cat. 8. 1902, 2. W. N. Y. Hort. Soc. Rpt. 25. 1904. Thanksgiving Prune 1.

Thanksgiving originated with a Mr. Gridley of Chili, New York; introduced in 1902 by Charles A. Green of Rochester, New York. Fruit of medium size, oval; suture distinct; purplish-black; sweet; good; late; shrivels and keeps for some time after picking.

Theresa. Domestica? 1. U. S. D. A. Rpt. 264. 1892. 2. Am. Pom. Soc. Rpt. 74. 1895 .

Originated at Bloomingburgh, Ohio; named for Mrs. Theresa M. Morris of that place. Tree bears heavily and regularly, hardy; fruit of medium size, roundish-oval, reddish-purple; bloom heavy; flesh yellowish-green, very mild, sweet; good; early. Thomas. Domestica. I. Mag. Hort. 7:388. 1841. 2. Downing Fr Trees Am. 3 I5. 1845. 3. Mag. Hort. 14:155. 1848. 4. Hovey Fr. Am. I:95. 1851. 5. Oberdieck Deut. Obst. Sort. 439. I881. Thomaspflaume 5.

Found in the garden of $\mathrm{Wm}$. Thomas of Boston for whom it was named by the Massachusetts Horticultural Society; first fruited about 1840. Tree vigorous, productive, bears early; fruit large, roundish-oval inclined to oblong; suture shallow with sides unequal; cavity small and narrow; stem medium, rather stout; deep amber mottled and shaded with soft red; dots white, numerous, bloom thin; flesh yellow; juicy, somewhat coarse with a mild pleasant flavor; quality medium; stone rather large, roundish-ovate, light in color, free; mid-season.

Thomas October. Domestica? I. Am. Pom. Soc. Rpt. 85. 1854 .

Said to have originated in Upper Dublin Township, Montgomery County, Pennsylvania. Fruit medium in size, pale red; good.

Thompsons Golden Green. Species? I. Country Gent. 26:238. 1865.

From R. O. Thompson, Nebraska. Fruit bronze or gold in color, dotted with red in the sun; very sweet, juicy; freestone.

Thorndyke Gage. Domestica. I. Downing Fr. Trees Am. 950. I869.

Originated near Newburgh, New York. Tree moderately vigorous; fruit below medium size, roundish; suture slight; pale green; flesh greenish, juicy, sweet, pleasant; clingstone; good; mid-season.

Thousand-and-one. Munsoniana. 1. Kerr Cat. 1894. 2. Waugh Plum Cult. 189. 1901.

Origin unknown. Fruit small, round; suture indistinct; cavity small; bright red with many small, conspicuous dots; flesh yellow, soft; stone small, oval, clinging; mid-season or earlier.

Thresher. Domestica. I. Pioneer Nur. Cat. 1900.

An improved strain of Agen grown by a Mr. Thresher of California.

Throop. Domestica. 1. Mich. Sta. Bul. 152:211. 1898. 2. Can. Exp. Farms Rpt.

547. 1901. 3. Mich. Sta. Sp. Bul. 27:16. 1904.

From George E. Ruedy, Colfax. Washington, in 1896 . Tree vigorous, upright, productive; fruit of mediun size, ovate; cavity small; suture shallow; dark purple; bloom thin; flesh yellow, firm, coarse, sweet, pleasant; quality fair; freestone; mid-season. 
Throop No. I. Domestica. I. Can. Exp. Farm Bul. 2nd Ser. 3:57. I900.

Tree vigorous, productive; fruit large, oval; suture broad, distinct; cavity usually lacking; red with thin bloom; flesh yellow, firm, juicy, sweet, rich; stone roundish, free; early.

Throop No. 2. Domestica. I. Mich. Sta. Sp. Bul. 27:16. I904.

Tree vigorous, unproductive; fruit large, roundish; sides unequal; suture broad; cavity small; reddish-purple; bloom heavy; dots few, yellow; flesh greenish-yellow, firm, a little coarse, sweet; good; stone semi-clinging; mid-season.

Throssel. Americana. I. Ia. Sta. Bul. 46:290. 1900.

Found wild on the Des Moines River by a Mr. Throssel, Pierson, Woodbury County, Iowa. Tree vigorous, hardy; fruit large; suture distinct; late.

Tillemond. Domestica. I. Prince Pom. Man. 2:93. 1832.

Belle Tillemond I. Prunier de Tillemond I.

Fruit very large, oval; cavity slight; stem large; light purple, with a darker cheek; flesh greenish, somewhat melting, sharp and acid, not pleasant; late.

Tobias Gage. Domestica. I. N. Y. Sta. Rpt. 12:612. I893.

Tobias Gage is a supposed seedling of Reine Claude received for testing at this Station in I 888 from J. T. Macomber, Grand Isle, Vermont. Tree moderately vigorous and productive; fruit below medium in size, oblate; suture and cavity shallow; dark coppery-yellow with a dull mottled red blush; bloom thin; flesh yellow, slightly fibrous, firm, sweet; quality good; stone small, semi-clinging; not equal to Reine Claude in appearance or quality.

Togo. Triflora. I. Can. Exp. Farms Rpt. I19. 1904.

A seedling of Red June from the Central Experimental Farm, Ottawa, Canada, from seed planted in 1895; named in honor of Admiral Togo. Fruit above medium, roundish; suture usually indistinct; cavity narrow, medium in depth, abrupt; yellow overlaid with deep red, with many small, inconspicuous dots; flesh yellow, firm, juicy, sweet; good; stone of medium size, oval, flattened, clinging.

Tokeya. Prunus besseyi $\times$ Simonii. I. S. Dak. Sta. Bul. 108. 1908.

One of a lot of hybrids originated at the South Dakota Experiment Station, first fruiting in 1906 . Fruit one and threc-eighths inches in diameter, flat, dark red; flesh green, sprightly subacid, intermediate between that of the two parents; good; stone very small; early.

Tomato. Cerasifera. I. Vt. Sta. An. Rpt. 13:370. I900.

According to Waugh, a seedling of Pissardi, from A. L. Bruce, Basin Springs, Texas. Fruit small to medium, spherical; cavity shallow; stem short, slender; dark red; dots very minute; bloom thin; flesh soft, yellow; poor to fair; stone large, oval, flattened, clinging; mid-season.

Tomlingson. Species? I. Cornell Sta. Bul. 38:80. 1892.

Given by Bailey in a list of native plums.

Towakong. Rivularis. I. Bailey Ev. Nat. Fruits 223. 1898 .

Creek I. Rivularis I.

The Indian name of Prunus rivularis. 
Trabesche. Domestica. x. Ia. Sta. Bul. 28:231. 1895. 2. Ibid. 31:348. 1895.

Trabeshe 2.

A Russian variety introduced into this country by Charles Gibb; tested at the Iowa Agricultural Experiment Station. Tree hardy, bears early; fruit large, oval, blue; quality best; freestone; mid-season.

Transparente. Species? 1. Oberdieck Deut. Obst. Sort. 406. 1881. 2. Guide Prat. I $57,366.1895$.

Durchsichtige 1. Die Durchsichtige 2. Frühe Gelbe Reine Claude 2.

Distinct from the English variety, Transparent. Fruit of medium size, oval clear greenish-yellow; flesh yellow, firm, juicy, aromatic; good; clingstone; early.

Trapps Konigspflaume. Domestica. I. Oberdieck Deut. Obst. Sort. 423. 1881.

2. Mathieu Nom. Pom. 45I. 1889.

Königspflaume von Trapp's 1. Royale de Trapp 2. Von Trapp's Königs Pflaume 2.

Produced by Liegel. Tree vigorous; fruit medium in size, oblate; suture shallow; halves equal or nearly so; stem with short hairs; cavity wide, deep; skin easily removed, sourish; bluish-black; dots fine, numerous, golden; bloom thick; flesh greenish-yellow, fine, juicy, sprightly, pleasant; freestone; ripens before the Reine Claude.

Traubenpflaume. Species? I. Mathieu Nom. Pom. 45 I. 1889. Usum Erreck I.

Reference found by Mathieu in Obst-Garten 47. 1885 .

Trauttenberg. Domestica. 1. Mas Pom. Gen. 2:81. 1873. 2. Mathieu Nom. Pom. 453. 1889 .

Die Zückersïsse 2. König Zwetsche 2. Sucree de Tranttenberg 2. Sucree-Douce De Trauttenberg I, 2. Trauttenberg Ziickersïsse I. Von Trauttenberg's Zückersüsse 2.

Originated in Bohemia; named in honor of Baron Trauttenberg, a zealous pomologist. Fruit medium in size, obovate and flattened; suture a line; skin brownishpurple; bloom thick; flesh yellowish-green, juicy, very rich, aromatic; excellent for dessert; stone rough, free; mid-season.

Trianon. Domestica. Listed in Lond. Hort Soc. Cat. 153. 1831.

Trinkle No. 4. Triflora. 1. Am. Pom. Soc. Rpt. 135. 1905.

John W. Trinkle of Madison, Indiana, grew this plum from seed of Burbank about I897. Tree vigorous, spreading; fruit large; suture medium; apex small; cavity large, regular, deep; yellowish; dots small, yellow; skin thick, tenacious, bitter; flesh yellowish, slightly translucent, meaty, moderately juicy, mild subacid; good to very good; mid-season.

Trostle. Species? 1. Waugh Plum Cult. 234. I90г.

Known only in the vicinity of Kingsley, Iowa. Fruit dark red.

Trouvée de Vouêche. Species? I. Downing Fr. Trees Am. 398. 1857. 2. Mathieu Nom. Pom. 451. 1889.

Trouvée de Vaunêge 2. Trouvée de Vonêche 2.

Found wild by Gregoire (probably of Belgium) and introduced by him. Tree moderately vigorous; fruit medium to small, oval, regular, reddish-violet with a darker cheek; bloom violet; flesh juicy, sweet; very good; mid-season. 
Truro. Americana $\times$ Hortulana mineri. I. U.S. D. A. Pom. Rpt. 47. 1895. 2. Waugh Plum Cult. 164. I901.

From Ezra W. Tucker, Williamsfield, Illinois, about 1895. A scedling of Weaver crossed with Miner. Tree upright, hardy; fruit large, oblong; suture shallow; cavity small, shallow; red with many, small, russet dots; flesh yellowish with yellow veins, tender, melting, juicy, mild subacid; very good; stone medium, oval, clinging; late. Tucker. Species? I. U. S. D. A. Pom. Rpt. 26. I894.

Another seedling from Ezra W. Tucker; said to be grown from seed taken from a cluster of trees containing Weaver, Miner, Wild Goose and two prune trees; first fruited in 1894 . Tree resembles Wild Goose; fruit medium to large, pyriform, greenish-yellow, overspread with light purplish-red; dots many, small; skin thick, tender, almost sweet; very good; stone large, angular, clinging; mid-season.

Tudor. Munsoniana? I. Tex. Sta. Bul. 32:481. 1894.

Tested at the Texas Experiment Station. Tree vigorous and productive; fruit above medium size, oblong, light red; skin very thin; flesh acid unless fully ripe.

Turkey. Domestica. I. Parkinson Par. Ter. 576,577, 1629. 2. Rea Flora 208. 1676. 3. Ray Hist. Plant. 2 :1529. 1688. 4. Langley Pomona 95, 97, Pl. XXV fig. V. I 729.5 . Abercrombie Gard. Ass't i3. 1786.

Turkie I. Turky 2. Turkey Plumb 4.

From the brief descriptions of the Seventeenth Century writers, it appears that Turkey was a large blue plum of the German Prune type but the variety has either long since been buried under the hosts of new sorts that have been developed or a new name has been given it.

Turkish Prune. Domestica. I. Lond. Hort. Soc. Cat. 152. 1831. 2. R. G. Chase Cat. 3. Rice Bros. Cat. I908. Quetsche Turkish I.

The name "Turkish Prune," although sometimes applied to the Italian Prune does not seem to be connected with any particular variety. It may be a synonym of the "Jerusalem Prune" or it may have developed, as a corruption of the still older "Turkey" plum mentioned by Parkinson and other writers in the Seventeenth Century. Twice Bearing. Domestica. 1. Duhamel Trait. Arb. Fr. 2:113. 1768. 2. Prince Pom. Man. 2:103. 1832. 3. Lond. Hort. Soc. Cat. 144. 1831. 4. Poiteau Pom. Franc. 1:1846. 5. Mas Le Verger 6:79. 1866-73. 6. Nicholson Dict. Gard. 3:235. 7. Mathieu Nom. Pom. 455. 1889.

Bifere 2, 7. Bifere 5. Bon deux fois l'an? 2. Bonne deux fois l'an 3. De Deux Saison 5. Deux fois l'an 2. P. biferum 6. Prune bifere 2. Prune de Deux Saisons 2, 7. Prune qui fructifie deux fois l'an 5, 7. Prunier bifere 4. Prunier Fleurissantet Poussant Deux Fois 5, 7. Prunier qui fructifie deux fois par an ${ }_{1}, 2$. Prunus bifera 1. Zweimal Blühende und Zweimal Tragende Bunte Pflaume 5, 7. Zweimal Tragende 7 .

A Domestica of ancient origin grown more as a curiosity and an ornamental than for utility. Fruit long, almost olive-form; suture faint; skin reddish-yellow, heavily tinged with brown; bloom heavy; flesh coarse, yellow, green beneath the suture, juice insipid; stone almost smooth, acutely pointed, clinging. The first crop is borne the beginning of August; the second very late; both worthless. 
Twins. Domestica. 1. Montreal Hort. Soc. Rpt. 55. 1878. Corse's Twins I.

A curious double plum which originated with Henry Corse, Montreal, Canada; inferior.

Tzaueron. Insititia? I. Rev. Hort. 357. I891.

Le Prunier Tzaneron I. Tzaneron I.

Very generally grown throughout southeastern Europe. Tree below medium size; branches upright; leaves small; glabrous, oval, deep green in color; fruit grows in clusters, small, pale yellow; flesh firm, juicy, sprightly, refreshing. This variety is an important commercial sort in the country where it is grown.

Ulysses. Domestica. I. Downing Fr. Trees Am. 950. I869.

From western New York; fruit above medium size, roundish-oval, whitish, shaded and mottled with violet-purple; bloom thin; flesh yellow, juicy, sweet; good; clingstone; mid-season.

Uncle Ben. Domestica? I. Gard. and For. 7:243. I894. 2. Kansas "The Plum" 29. 1900.

Originated in Stanislaus County, Mapa Valley, California; fruit medium to large, golden-yellow, spotted with red; flesh sweet, juicy, very good; freestone; late.

Ungarische Dattel Zwetsche. Domestica? Mentioned in Mathieu Nom. Pom. $45^{x}$. r889. Ungarische Späte Bouteillen Zwetsche.

Union. Domestica. 1. Cultivator 6:269 fig. 1895. 2. Ont. Fr. Exp. Sta. Rpt. I 20. 1898. 3. Ohio Sta. Bul. I13:161. I899. 4. Waugh Plum Cult. I24. Igor.

Reagles' Union Purple I. Union Purple 2, 3. Union Purple 4.

Union originated about 1850 with C. Reagles of Schenectady, New York. Tree hardy, productive; fruit medium in size, roundish-oval, dark purple; bloom thick; stem adheres strongly to the fruit; flesh dark yellow, firm, tender, sweet, mild; quality fair; stone oval, turgid, clinging; mid-season.

Uryany. Domestica.

Introduced from Ammassia, Turkey, by the United States Department of Agriculture in 1904 and sent to this Station for testing. Tree vigorous, upright with a dense top; fruit variable in size, roundish to roundish-ovate; suture a line; cavity narrow, deep, abrupt; stem rather thick, short; dark purple; dots numerous, very small, yellowish; bloom heavy; skin thin, tough, astringent; flesh yellow, tender, very juicy, sweet, pleasant; good; stone of medium size, somewhat flattcned, clinging; scason late. U. S. Americana. I. Kerr Cat. 6. 1900. 2. Waugh Plum Cult. 165. 1901. 3. Wis. Hort. Soc. Rpt. 109. 1903.

Brittlewood No. 2 3. United States 3.

Originated by Theodore Williams of Benson, Nebraska. Tree vigorous and productive; fruit large, spherical, dark purplish-red; flesh a trifle coarse; good; clingstone; medium to late.

Valence. Domestica. I. Mag. Hort. 9:163. 1843. 2. Lond. Hort. Soc. Cat. I45, I53. 183r. Damas de Valence 1,2 . Saint Loo 2.

Fruit small, roundish, purple; clingstone; late. 
Valentia. Domestica. I. Forsyth Treat. Fr. Trees 21.1803.

Mentioned as a plum of value by Forsyth.

Valienciennes. Species? Mentioned in Mathieu Nom. Pom. 451. 1889.

Die Valienciennes. Edle Königs Pflaume.

Value. Americana. 1. Kerr Cat. 6. 1902-3. 2. Can. Exp. Farm Bul. 43:39. 1903. Originated by Theodore Williams of Benson, Nebraska; introduced in 1902 by J. W. Kerr, Denton, Maryland. Tree vigorous, healthy and productive; fruit large, round or sometimes inclined to oblong, dark red; good; clingstone; mid-season.

Van Benschoten. Domestica.

Van Benschoten was introduced by a Mr. Snyder of Kingston, New York. Fruit of medium size, roundish, greenish-yellow with russet spots; good; stone small, free. Van Buren. Americana mollis. I. Ia. Hort. Soc. Rpt. 286. 1887. 2. Cornell Sta. Bul. 38:42, 1892. 3. Colo. Sta. Bul. 50:46, P1. XV. 1898. 4. Can. Exp. Farm Bul. 43:32. 1903.

Van Buren came from a wild seedling in Van Buren County, Iowa; introduced by $\mathrm{J}$. Thacher. Tree spreading, moderately productive and slow growing; fruit of medium size, roundish; cavity small; suture a line; skin thick; red over yellow; bloom thin; flesh yellow, juicy, firm, sweet; quality good; clingstone; season late.

Van Deman. Americana. 1. U. S. D. A. Rpt. 392. 1891. 2. Am. Pom. Soc. Rpt.

88. 1895. 3. Terry Cat. 1900. 4. Waugh Plum Cult. 165. 1901.

Van Dieman 2.

Van Deman is a seedling of Hawkeye grown by H. A. Terry, Crescent, Iowa; first fruited in $189 \mathrm{I}$. Fruit large, oval; cavity small; suture a line; skin thick; dark red; bloom thick; flesh yellow; quality fair; stone oval, flattened, clinging; season late.

Van Houten. Species? I. Terry Cat. 5. 1900.

A plum of unknown parentage from H. A. Terry, Crescent, Iowa; first fruited in 1895; dwarfish; productive; fruit very large, round, bright red; mid-season.

Venetianische $Z$ weimal Tragende. Species? Mentioned in Mathieu Nom. Pom. 452. I 889 . La Bonne Deux Fois l'An. La Venitienne.

Venus. Munsoniana. 1. Terry Cat. 8. I900.

From H. A. Terry; of unknown parentage. Tree upright, productive; fruit very large, yellow overspread with light pinkish-red becoming darker red; dots numerous, white; flesh yellow, very sweet and rich; good; clingstone; early.

Verdacchio. Domestica. I. Parkinson Par. Ter. 576. 1629. 2. Rea Flora 208. 1676.
3. Gallesio Poin. Ital. 2 :fig. 1839.
Verdock 1,2 .

An old Italian variety. A few of the modern writers hold it to be the Reine Claude but according to Gallesio, it is a distinct plum. Fruit medium in size, obovate, greenish; flesh crisp, sweet, agreeable; very good.

Verdache. Species? I. Mathieu Nom. Pom. 451. I889. 2. Guide Prat, 16 I 366.1895.

Tree very productive; fruit small, oval, yellowish olive-green with flesh the same color, sweet; late; said to be excellent for making prunes or for cooking.

Vermilion. Americana. 1. Kerr Cat. I894. 2. Wis. Sta. Bul. 63:44. 1897. 3. Waugh Plum Cult. 165. I901.

Le Duc Vermillion 1, 2. Le Duc Vermillion 3. 
Grown for some years by J. W. Kerr, but dropped in $190 \mathrm{r}$. Fruit medium in size, roundish-oblong, bright red; flesh yellow, very good; clingstone; late.

Vermilon Hatif. Species? Mentioned in Mathieu Nom. Pom. 452. I889.

Vesuvius. Cerasifera $X$ ? 1. Fancher Creek Nur. Cat. 1907-8. 2. Ibid. rgog.

Foliage Plum 1, 2.

Grown by Luther Burbank from a cross between Pissardi and some native or Triflora sort; introduced by the Fancher Creek Nurseries in 1907. Tree vigorous. elm-like in habit of growth, not productive; fruit small, roundish, purplish-red; flesh yellow; quality fair; stone small; valuable only as an ornamental.

Vick. Munsoniana $\times$ Americana? I. Ia. Hort. Soc. Rpt. 287. 1887. 2. Ibid. 276. 1893.

3. Wis. Sta. Bul. 87:14. 190r. James Vick 1, 2, 3 .

Supposed to be a seedling of Wild Goose crossed with some Americana; originated by H. A. Terry, Crescent, lowa, about I 880 . Fruit of medium size, roundish-oval; dots numerous; suture distinct; bright red; bloom light; flesh yellowish-green, tender; quality fair; stone small, clinging; mid-season.

Victor. Nigra? I. Can. Exp. Farms Rpt. 426. 1900.

$A$ seedling raised at Indian Head Experimental Farm, Northwest Territory, Canada. Fruit of medium size; mid-season.

Victoria. Species? Letter from Kerr.

Originated by Theodore Williams, Benson, Nebraska; fruit large, firm; poor.

Violet. Domestica. 1. Parkinson Par. Ter. 578. 1629. 2. Langley Pomona 92, fig. VII. 1729. 3. Garden 50:223. 1897. 4. Mich. Sta. Sp. Bul. 27:16. 1904.

Early Violet 3. Violette 4. Violet Plumb 2.

This variety is possibly the same as Précoce de Tours but we are unable to identify it positively with this or any other known variety. The "Violette" mentioned in the fourth reference above may not be identical with the Violet of the older writers but it seems to be similar. According to Parkinson the Violet is " a small and long blackish blew plum, ripe about Bartholomew tide, a very good dry eating plum."

Victor Sand Cherry. (Prunus besseyi $\times$ Munsoniana) $\times$ Domestica. I. Am. Br. Assoc. Rpt. $2: 184 . \quad 1906$.

Theodore Williams of Benson, Nebraska pollinated Prunus besseyi with Wild Goose and the resulting seedling was fertilized with pollen from Quackenboss. This final cross resulted in the variety under discussion. Fruit nearly two inches in diameter; apparently of value.

Violet Imperial. Domestica. I. Horticulturist 4:196. I849.

Die Violette Kaiserpflaume 1. Impériale Violette 1.

Violet Imperial is usually considered the same as Red Magnum Bonum but Liegel describes it as distinct in that its leaves are shorter, its fruit smaller, darker and ripening period three or four weeks later.

Violet Royal. Domestica. Mentioned in Miller Gard. Kal. 155. 1734.

Violette Americaine. Species? I. Mathieu Nom. Pom. 452. 1889.

Mathieu found reference in Revue Horticole 351. 1869 .

Virgata. Species? I. Ga. Hort. Soc. Rpt. 51. 1889. 
A tender shrub of value only as an ornamental. Flowers semi-double, rose colored; fruit of medium size, oblong, yellow; flesh yellow, juicy, subacid; quality fair; clingstone; very early.

Virgie. Hortulana mineri $\times$ Hortulana. I. Vt. Sta. An. Rpt. 12:229. 1899.

Originated with A. L. Bruce of Texas; a cross between Miner and Crimson Beauty. Fruit medium, nearly round; suture a line; cavity very shallow; deep crimson with many yellow dots; flesh yellow; good; stone small, round, slightly flattened, clinging. Virginia Damson. Insititia. I. Am. Pom. Soc. Rpt. 151. I891.

Mentioned in the preceding reference as doing well in Virginia.

Von Berlepsch Zwetsche. Domestica. Mentioned in Mathieu Nom. Pom. 453. 1889. Berlepsch's Violette Zwetsche.

Von Bose Rote Zwetsche. Species? Mentioned in Mathieu Nom. Pom. 453. 1889.

Von Lade Späte Mirabelle. Insititia. Listed in Mathieu Nom. Pom. 453. I889.

Von Moro Reine Claude. Domestica. I. Mathieu Nom. Pom. 453. I889.

Mathieu's reference taken from Pomologische Monatshefte I. 1878 .

Voslauer Zwetsche. Domestica. I. Mathieu Nom. Pom. 453. 1889. 2. Guide Prat. $163,367.1895$.

Similar to the Italian Prune.

Vulcan. Triflora $X$ ? I. Vt. Sta. An. Rpt. 12:229. 1899.

A hybrid grown by Luther Burbank; much like Wickson. Fruit very large, oval, with sides unequal; cavity large, abrupt; stem short, very stout; suture deep at the top; purple with darker shades; dots numerous, yellow; flesh red next the skin, sweet and pleasant; excellent; stone large, elliptical, slightly flattened, clinging.

Wabash. Species? 1. Ind. Hort. Soc. Rpt. 72. 1868.

Noted as a native variety grown in Gibson and Posey Counties, Indiana. Tree low and shrubby, bearing early; fruit large, conical.

Wady. Species? I. Ia. Hort. Soc. Rpt. 286. 1887. 2. Cornell Sta. Bul. 38:80. 1892. 3. Wis. Sta. But. 63:62. 1897. Wady's Early 1, 2, 3 .

Reported as of little value except for early ripening and productiveness; fruit small; good for canning.

Wagner. Americana. I. Ia. Sta. Bul. 46:291. I 9o0.

Wagner No.9 1 .

A seedling of Weaver fertilized with a wild variety; grown by J. F. Wagner, Bennett, Iowa, in 1894. Fruit small, ovate; cavity broad, shallow; suture clearly defined; yellowish-red; bloom thin; flesh brownish-yellow, sugary, sweet; quality best; stone large, flattened, clinging; mid-season.

Wahre Fruhzwetsche. Domestica. I. Lucas Vollst. Hand. Obst. 473. ${ }_{1894 .}$

2. Mathieu Nom. Pom. 453. 1889.

August Zwetsche 2. Conetsche Précoce 2. Contetsche Précoce La Vraie 2. Diel's August Zwetsche 2. Frihe Gemeine Zwetsche 2. Frihe Haus Zwetsche 2. Frühe Zwetsche 2. Précoce Veritable 2,

Tree large, a quick grower; fruit medium, oval, dark blue; stone completely free; valuable for dessert and drying. 
Wahre Weisse Diaprée. Species? Mentioned in Mathicu .Vom. Pom. 453. r 889.

Dorell's Neue Weisse Diaprée.

Wakapa. Triflora $\times$ Americana. I. S. Dak. Sta. Bul. 108. 1908.

A hybrid between De Soto and Red June reported by Hansen, the originator, in the preceding reference as worthy of further testing.

Walker Seedling. Domestica. I. Can. Hort. $21: 390.1898$.

A seedling raised by A. W. Walker, Clarksburg, Ontario. Fruit of medium size, dark maroon; flesh greenish, tender, moderately juicy, sweet, pleasant; freestone; early. Wallace. Americana. 1. Meneray Cat.

A seedling of Harrison grown by H. A. Terry; introduced by F. W. Meneray, Council Bluffs, Iowa. Tree healthy, vigorous and productive; fruit large, inclined to oblong, bright yellow overspread with red; flesh firm; good; semi-clinging; mid-season. Walter. Domestica. I. Oberdieck Deut. Obst. Sort. 431. 1881.

Produced by Herr Walter in Altenburg, Germany; valuable for table and market purposes. Tree vigorous; shoots glabrous; fruit roundish-oval, medium; suture deep; halves usually equal; stem thick, straight, strongly hairy; skin not adherent, dark brown; bloom thick; flesh yellow, tender, very juicy; like Reine Claude in flavor; early.

Walther Pflaume. Species? I. Mathieu Nom. Pom. 453. 1889.

The reference by Mathieu came from Monatsschrift für Pomologie 281. $185^{8}$.

Ward October Red. Rivularis X ? I. Munson Cat. 10. 1902-3.

Found in Clay County, Texas, by Robert Ward; introduced by T. V. Munson, Denison, Texas. Tree very vigorous and hardy, spreading habit, very productive; fruit dark bright red with meaty flesh; excellent quality; stone small; ripens in Texas in September and October.

Warner. Domestica. 1. W. N. Y. Hort. Soc. Rpt. 3 1:60. 1886. 2. Cornell Sta. Bul. 131:193. 1897.

Warner's Late I. Warner's Late Red 2.

Warner originated in Schoharic County, New York, and was introduced by S. D. Willard, Geneva, New York. It is a late variety too small and unattractive for commercial purposes. Fruit below medium in size, roundish; cavity shallow; suture a line; stem three-quarters of an inch long; skin moderately thick, dull greenish-red; bloom thin; flesh yellow, juicy, firm, sweet, mild; quality fair to good; stone oval, slightly flattened, elinging; season very late.

Warren. Americana. I. Terry Cat. 5. 1900.

Grown from seed of Hawkeye by H. A. Terry; first fruited in 1897. Fruit large, mottled light red, with thin bloom; late.

Wastesa. Species? 1. Cir. S. Dak. Exp. Sta. 1910.

State Fair No.I6 1.

A scedling of some native plum; grown and sent out by N. E. Hansen of the South Dakota Experiment Station.

Waterloo Pflaume. Domestica? 1. Mathieu Nom. Pom. 453. I889.

Duc de Waterloo 1. Prune de Waterloo 1.

This may be identical with Golden Drop although Mathieu separates them. 
Watson. Triflora $\times$ Angustifolia varians? 1. Vt. Sta. Bul. 67:21. 1898.

A seedling of Kelsey thought to have been pollinated by Lone Star; originated with D. H. Watson, Brenham, Texas; introduced by W. A. Yates in 1897 . Tree vigorous, open; fruit large, pointed, red when fully ripe; flesh yellow, juicy, melting; stone nearly free, small.

Watts. Species? I. Am. Pom. Soc. Rpt. I66. I885.

Mentioned as grown by Dr. D. S. Watts of Madison County, Mississippi.

Waugh. Triflora $\times$ Hortulana. 1. Vt. Sta. An. Rpt. 14:273. 1901. 2. Rural N. Y. $61: 65^{8}$. 1902. 3. Ibid. 65:730. 1906.

Grown by J. W. Kerr, Denton, Maryland, from seed of Chabot fertilized with Wayland; introduced in I901. Favorably reported where tested. Tree vigorous, rapid and shapely in growth; fruit medium to large, roundish inclining to oblong; cavity shallow; stem slender; dark purplish-red; dots few and indistinct; flesh yellow, firm, meaty; very good; stone small, semi-clinging; mid-season or early.

Wax. Domestica. I. Cultivator 3:19. 1855. 2. Mathieu Nom. Pom. 425. I889.

Cire 2. Wax Plum 2.

Raised by Elisha Dorr of Albany, New York; thought to be a cross between Bleeker and Denniston Superb; resembles Bleeker in growth and productiveness of tree; fruit large, slightly oval; stem very long; deep yellow overspread with carmine; flesh greenish-yellow, juicy, firm, sweet with a sprightly flavor; clingstone; late.

Wazata. Nigra? I. Cornell Sta. Bul. 38:42. 1892. 2. Bailey Ev. Nat. Fruits 19o. 1898. 3. Waugh Plum Cult. 171. 1901.

Found wild in Minnesota; introduced by P. M. Gideon and W. F. Heikes. Tree upright, very ornamental in bloom; fruit small to medium, round, dull red; flesh yellow; inferior; clingstone; mid-season to late.

Webster Gage. Domestica. I. Watkins Cat. 1892. 2. Guide Prat. 157, 364. 1895. 3. Garden 56:344. 1899 .

Reine-Claude de Webster 2. Webster Gage 2. Webster's Gage I, 3.

Tree bears regularly but sparsely; fruit larger than Reine Claude, a little more oval in shape, yellowish-green; flesh yellowish, tender, soft, juicy, rich: mid-season.

Weeping Blood. Triflora. I. Hill Side Nursery Sp. Cir. I895-6.

From J. L. Normand of Marksville, Louisiana; produces blood-red plums of good quality; valuable only as an ornamental.

Weisses oder Grunes Zeiberl. Species? I. Mathieu Nom. Pom. 454. I889.

Weisse Zeiberl I.

Mathieu found reference to this variety in Wiener Garten-Zeitung 290. I884.

Welch. Americana. I. Meneray Cat.

Grown by H. A. Terry from seed of Hammer; introduced by F. W. Meneray, Council Bluffs, Iowa. Tree upright, vigorous; fruit large, bright red on a yellow ground; flesh yellow, rich; clingstone; mid-season.

Welcome. Americana. I. Can. Exp. Farms Rpt. roo. 1903.

A handsome seedling of De Soto grown by the Central Experimental Farm, Ottawa, Canada. Tree vigorous and productive; fruit above medium size, oval, 
fiattened; cavity narrow, shallow; rich yellow, more or less washed with red; dots very small, yellow, indistinct; bloom thin; skin moderately thick, tough; flesh yellow, juicy, sweet, pleasant; good; mid-season.

Weisse Kaiserin. Domestica. 1. Oberdieck Deut. Obst. Sort. 418. 1881. 2. Mathieu Nom. Pom. 431. 1889.

Datte Jaune 2. Gelbe Marunke 2. Grosse Gelbe Dattel Pfaume 2. Grosse Gelbe Dattel Zwetsche 2. Imperial Jaune 2. Prune Datte 2. Weisse Kaiserin 2.

Probably of German origin; tree medium in size, a rapid grower, productive; fruit medium in size, roundish-oval; suture shallow; stem short, glabrous; skin not adherent, whitish-yellow, the sunny side dull red, sometimes dotted with red; dots numerous, fine, yellowish; bloom thin; flesh whitish-yellow, firm, very juicy, highly flavored; good for dessert and cooking; clingstone; late.

Werder'sche Fruhzwetsche. Species? Mentioned in Mathieu Nom. Pom. 454. I889. Stengel Pflaume.

Wetherell. Domestica. I. Mag. Hort. 6:92. I840. Col. Wetherell I.

Originated by Henry Corse, Montreal, Canada, about I830. Spoken of highly at the time of its origin; valuable for commercial purposes.

Wetherill's Sweet. Insititia. 1. Prince Treat. Hort. 27. 1828. 2. Lond. Hort. Soc. Cat. 154. 1831 .

A Damson-like plum; small, sweet and delicious; clingstone; early.

Whatisit. Prunus bessevi $\times$ Americana. I. Kerr Cat. 18. 1899-1900.

Grown by Theodore Williams of Nebraska from seed of Prunus besseyi pollinated by an Americana; introduced by J. W. Kerr. Tree upright and vigorous, bears early, productive; fruit small, spherical inclining to oblong, dark purplish-red.

Wheat. Insititia. 1. Parkinson Par. Ter. 576. 1629. 2. Rea Flora 209. 1676. 3. Ray Hist. Plant. $2: 1529$. 1688. 4. Lond. Hort. Sac. Cat. I54. I831. 5. Floy-Lindley Guide Orch. Gard. 293, 383. 1846. 6. Downing Fr. Trees Am. 913. 1869. 7. Hogg Fruit Man. 730. 1884.

English Wheat 6. Great Whitton 4. Nutmeg 2. Nutmeg 4, 5, 6. Red Wheate x. Wheaten 3. Wheaten 4, 5. Whitton 4, 5. Wheat Plum 5. Wheat Plum 6. Wheaton 6. Whitlow 6.

During the Seventeenth Century this name was applied to all Insititia plums and is still so used in parts of Europe.

Whitaker. Munsoniana. x. Cornell Sta. Bul. 38:51, 86. 1892. 2. Am. Pom. Soc. Rpt. 74. 1895. 3. Waugh Plum Cult. 190. 1901. 4. Ill. Hort. Soc. Rpt. 212. 1904. Whitacre 4.

Whitaker is a seedling of Wild Goose raised and introduced by J. T. Whitaker of Tyler, Texas. Fruit of medium size, oval; cavity shallow; suture a line; skin thin; bright red; bloom thin; dots many, distinct; flesh yellow, sweet; quality fair; stone small, long-oval, pointed, flat, clinging; mid-season. Listed in the catalog of the American Pomological Society since 1899 .

Whitby. Species? I. Can. Hort. 18:350. IS95. 
A seedling exhibited at the Toronto Industrial Fair in 1895 by the originator, J. K. Gordon, Whitby, Canada.

White Corn. Domestica. Mentioned in Lond. Hort. Soc. Cat. I54. 1831.

White Diaper. Domestica. I. Downing Fr. Trees Am. 952. 1869.

Diapre Blanc I. Diaprée Blanche I.

This variety seems to have been known only by Downing who says it is a small, round plum with a whitish-green skin covered with bloom; flesh rather firm, pale yellow, sweet; good; mid-season.

White Honey Damson. Insititia. 1. Wild Bros. Cat. 1892.

A sweet yellow Damson.

White Muscle. Domestica. I. Parkinson Par. Tor. 576. 1629. White Mussell 1.

A strain of the Muscle plum differing from it only in its greenish-white color.

White Otschakoff. Domestica. r. Am. Pom. Soc. Rpt. 6r. r887. 2. Bailey Ann. Hort. 18. 1889. Bielaya Otschakorskaya 1.

One of the numcrous varieties imported from East Europe by the Iowa Agricultural College about 1882. At one time recommended for the prairie states by Profossor Budd.

White Pear. Domestica. 1. Parkinson Par. Ter. 576. 1629. 2. Langley Pomona 96, 97. 1729. 3. Lond. Hort. Soc. Cat. 154. 1831. 4. Prince Pom. Man. 2: 104. I831. Late White Pcar I.

A variety of ancient and unknown origin. Fruit medium in size, obovate; flesh adhering to the stone.

White Peascod. Domestica. I. Parkinson Par. Ter. 576. 1629. 2. Rea Flora 208. 1676. Peascod Plum 2. White Pescod r.

IIentioned by the early writers; similar to the Green and Red Peascod.

White Prune. Americana. I. Ia. Hort. Soc. Rpt. 228. I 909.

Grown by H. A. Terry, Crescent, Iowa; not yet introduced. Fruit long-oval, yellow, partly over-spread with red; bloom thick, conspicuous; skin thick, tough, acrid; flesh very firm, meaty, sweetish; good; freestone.

White Queen. Domestica. 1. Ann. Pom. Belge 7:95, P1. 1859. 2. Mas Le Verger 6:101, fig. 1866-73. 3. Hogg Fruit Man. 721. 1884. 4. Nathieu Nom. Pom. 454. I889. 5. Mich. Sta. Bul. 177:42, 43. 1899.

Nene Weisse Kaiserin 4. Prune Reine Blanche 1. Reine Blanche 2, 3. Reine Blanche 2, 4. Reine Blanche de Galopin 4. Weisse Königin 2. Weisse Königin 4.

Raised by M. Galopin, a nurseryman of Liege, Belgium, about 1844 ; introduced into America by the United States Department of Agriculture about 1890 . Tree vigorous, upright; fruit medium in size, roundish-ovate, flattened at the ends, yellowishwhite, somctimes tinged with red; suture shallow; cavity shallow, wide; flesh greenishyellow, juicy, aromatic; good; stone small, oval, clinging; late.

White Sweet Damson. Insititia. I. Mag. Hort. 6:123. 18.40.

Originated as a seedling in Essex County, New York, sometime previous to 1840 . 
White Wheat. Insititia. I. Parkinson Par. Ter. 576. 1629. 2. Knoop Fructologie $2: 63$. 1771. Spilling Jaune-simple 2. White Wheate 1 .

A yellow variety of the Wheat plum of Europe. Fruit small, oval, yellow; fair quality.

White Virginal. Domestica. I. Prince Pom. Man. 2:73. 1831. 2. Poitcau Pom. Franc. 1. 1846 . 3. U. S. Pat. Off. Rpt. 306. 1854. 4. Bridgeman Gard. Ass't 130. 1857. 5. Mas Le Verger 6:129. 1866-73. 6. Mathieu Nom. Pom. 454. 1889. 7. Guide Prat. 158, 367. 1895.

Altesse Blanche? 6, 7. Double Beurre IVitte? 6, 7. Peach 3. Précoce 7. Prune Précoce? 6. Prune Virginale 2. Virginal à gros fruit blanc 1. Virginal blanc 1. Virginale 4. Virginale à Fruit Blanc 6, 7. Virginale à gros fruit blanc 5, 6, 7. Virginal Blanche 6. Virginale blanche 3, 5, 7. Virgin 6. White Virginal 4. White Virginale 6. Weisse Jungfernpflaume 6. Weisse Jungfernpflaume 5, 7.

A variety confused by Downing with the Red Virginal. Fruit medium in size, roundish-oblate; suture a line; greenish-yellow; bloom heavy; flesh pale greenish, juicy, melting, sweet, pleasant; good; clingstone; mid-season.

Whyte. Nigra. 1. Can. Exp. Farm. Bul. 2nd Ser. 3:57. 1900. 2. Ibid. 43:39. 1903.

Whyte's Red Seedling I.

Grown by R. B. Whyte, Ottawa, Canada; under test at the Central Experimental Farm, under the name "Whyte R. B., No. 3." Fruit medium in size, roundish; cavity narrow; suture a line; apex rounded; deep red; dots and bloom lacking; skin thin, tender; flesh yellow, juicy, sweet; good; stone long, semi-clinging; mid-season.

Whitley. Domestica. I. Hogg Fruit Man. 731. I884. Whitley's I.

Fruit below medium size, round; suture faint; stem on a slight elevation, of medium length, slender; red with yellow dots, darker on the side next the sun; flesh yellow with white veins, juicy, sweet and well flavored; clingstone; late.

Wier. Americana. 1. Am. Gard. 13:460. I892. 2. Cornell Sta. Bul. 38:45, 86. I392.

3. Wis. Sta, Bul. $63: 63$. 1897 .

Wier Large Red I. Wier's Large Red 2, 3.

Originated by D. B. Wier of Illinois; resembles Miner, but is no better than that variety. Fruit large, round; skin thin, red; flesh yellow, moderately firm; fair to good; clingstone.

Wier No. 5o. Americana. I. Kerr Cat. I 894 . 2. IVis. Sta. Bul. 63:63. 1897.

Wier's No. 50, I, 2.

From D. B. Wier of Illinois. Tree vigorous, healthy, productive, bears annually; fruit large, round, dark red over yellow; good; clingstone; mid-season.

Wilde. Domestica. I. Horticulturist 7:402, 1852. 2. Downing Fr. Trees Am. 953. 1869. Wilde's r.

Raised by a Mr. Comack from a stone brought from Italy by R. H. Wilde. Tree productive; fruit medium to large, oval-oblong, greenish-yellow; flesh yellowish-green, firm, dry, sweet; clingstone; early.

Wilder. Munsoniana. I. Cornell Sta. Bul. 38:78, 1892. 2. Terry Cat. 1899. 3. Ala. Coll. Sta. Bul. 112:178. 1900. 4. Waugh Plum Cult. 175. 1901.

Col. Wilder 1, 2. Colonel Wilder 4. President Wilder 3. 
Wilder was grown from seed of Wild Goose in 1885 by H. A. Terry, Crescent, Iowa. Fruit of medium size, roundish-oval; suture a line; skin firm, dark red; bloom thin; dots distinct; flesh yellow, juicy, sweet; quality good; stone large, oval, clinging; midseason.

Wild Goose Improved. Munsoniana. r. Stark Cat. 29. 1910.

An improved strain of Wild Goose introduced by Stark Brothers, Louisiana, Missouri, in 1910 .

Wildrose. Americana. I. Am. Pom. Soc. Rpt. 134. 1887. 2. Cornell Sta. Bul. 38: 45, 86. 1892, 3. Wis. Sta. Bul. 63:64. 1897 .

A wild seedling found in Minnesota; introduced in 1880 by $\mathrm{A}$. W. Sias, Rochester, Minnesota. Fruit large, round, yellow blushed with red; flesh firm; clingstone; early to mid-season.

Wilkinson. Domestica. x. Downing Fr. Trees Am. 400. 1857.

Tree vigorous; branches smooth, rather slender; fruit of medium size, oval, slightly necked; skin reddish-purple; bloom thick; stalk medium, set in a small cavity; flesh dark yellow, firm, sweet, not rich; semi-clinging; late.

Willamette. Domestica.

For a discussion of this plum see the Pacific.

Williams. Nigra? 1. Kerr Cat. 1894. 2. Ibid. 15. 1897. 3. Wis. Sta. Bul. 63:64. I897.

Tree vigorous, healthy, moderately productive; fruit large, oblong, pointed, red; clingstone; early.

Wilmeth Late. Species? I. Tex. Sta. Bul. 32:490. 1894.

Noticed in the preceding reference as on trial.

Wilson. Americana. 1. Wis. Sta. Bul. 63:64. 1897 .

Noted in the preceding reference as a very early fine plum.

Wine Plum. Domestica. I. Coxe Cult. Fr. Trees 237. 1817. 2. Prince Pom. Man. 2 : 101. $18_{32}$.

Much like the Yellow Egg in appearance but smaller, oblong, pale green; stem long; flesh rich, juicy and well flavored; early.

Winesour. Insititia, 1. Forsyth Treat. Fr. Trees 21. 1803. 2. Prince Pom. Man. 2:101. 1832. 3. Floy-Lindley Guide Orch. Gard. 294, 383. 1846. 4. Mas Pom. Gen. 2:17. 1873. 5. Mathieu Nom. Pom. 453. 1889. 6. Guide Prat. 163, 367. I895.

Rotherham 3, 5, 6. Sanere Weinplaume 4. Sanere Wein Pflaume Von Yorkshire 5, 6. Sour Wine Plum of Yorkshire 5, 6. Vineuse acidule 4, 5. Vineuse-Acidule 6. Vinisour 6. Weinsauerliche Pflaume 5. Weinsanerliche Zwetsche 4, 6. Winesour 6. Winesour Plum 5. Yorkshire Winesour 5, 6.

An old English variety from Rotherham in Yorkshire, where it is highly esteemed for making preserves. Fruit of the Damson type, small, oval; stem one-half inch long; dark purple; dots dark colored; flesh greenish-yellow, sometimes tinged with red towards the stone, sour; stone long, slender, pointed, clinging; late.

Winnebago. Americana. 1. Ia. Hort. Soc. Rpt. 286. 1887. 2. Wis. Sta. Bul. 63:64. 1897. 3. Colo. Sta. Bul. 50:47. 1898 . 
From Minnesota; tree vigorous, rigid and thorny, moderately productive; fruit medium in size, round, irregular; stem long, slender; cavity deep; yellow overspread with deep red; skin thin; flesh yellowish, soft, of inferior flavor; stone elliptical, somewhat oblique, rather flat, rounded at both ends, clinging; mid-season.

Winter Creke. Domestica. I. Parkinson Par. Ter. 576. I629.

Noted by Parkinson as very late.

Winter Damson. Insititia. 1. Lond. Hort. Soc. Cat. 146. 1831. 2. Prince Pom. Man. 2:89. 1832. 3. Downing Fr. Trees Am. 297. 1845. 4. Hooper W. Fr. Book 244. 1857. 5. Mas Pom. Gen, 2:145. I873.

Black Damson 3. Blue Damson 2. Blue Damascene 2. Common Blue Damson 2. Common Damson 3. Damas d'Hiver 5. Damson 2. Damson 2, 3. Damson Winter 4. Early Damson 3. Late Damson 2. Late Purple Damson 2. Purple Damson 3. Purple Winter Damson 2. Winter Damson 2, 5 .

Mas thought that this variety originated in America, but since it was first noted in England it is probably an importation to the New World from that country. Downing distinguished it from the common Damson by its extreme lateness. Tree medium in size; fruit roundish, small; suture a line; purplish-black; bloom thick; flesh greenishyellow, juicy, acid, with a slight astringency; good for preserving; clingstone.

Wiseman. Domestica. Mentioned in Wild Bros. Cat. 1908. Wiseman's Prune.

Wohanka. Triflora $\times$ Americana. $\quad$. S. Dak. Sta. Bul. 108. 1908.

A hybrid between De Soto and Red June grown by Hansen of the South Dakota Experiment Station who considers it worthy of trial.

Wolf and Japan. Triflora $\times$ Americana mollis. I. Ill. Hort. Soc. Rpt. 424. 1905.

Listed with a number of plums which were tested by H. T. Thompson, Marengo, Illinois.

Wolf Clingstone. Americana mollis. 1. Wis. Sta. Bul. $87: 18$. 1901. 2. S. Dak. Sta. Bul. 93:13. 1905. Clingstone Wolf. Wolf Cling 1.

Propagated and sent out in many cases as the true Wolf which it much resembles except that it is darker in color and is a clingstone. It seems to be more resistant to diseases and insects than Wolf.

Woolston. Domestica. I. McIntosh Bk. Gard. 2:53. 1855. 2. Horticulturist 13:168. 1858. 3. Mas Le Verger 6:153, fig. 77. 1866-73. 4. Mathieu Nom. Pom. 454. 1889. 5. Can. Exp. Farms Rpt. 433. 1905.

Reine-Claude de Woolston 5. Reine-Claude Noire de Woolston 3. Woolston Black 4. Woolston Black Gage 1. Woolston Gage 2. Woolston's Black Gage 3, 4. Woolston's Violette Reine-Claude 4.

Raised by a Mr. Dowling of Southampton, England. Tree vigorous, productive; fruit medium in size, roundish, purplish-black; suture not pronounced; cavity deep and wide; stem medium in length, slender; flesh yellow, juicy, sweet, sugary, tender, aromatic; very good; freestone; mid-season.

Wooster. Munsoniana. I. Wis. Sta. Bul. 63:65. 1897.

Mentioned in the preceding reference as not being hardy in Minnesota. 
Wooten. Munsoniana. 1. Cornell Sta. Bul. 38:65. 1892. 2. Thomas Am. Fruit Cult. 492. 1897. 3. Waugh Plum Cult. 191. 1901. Wootton 2.

Wooten was found growing wild in Burnet County, Texas, in 1876 , by F. T. Ramsey; introduced by A. N. Ramsey \& Son. Fruit oval; cavity shallow; suture a line; skin thin; bright red; bloom thin; flesh yellow; quality good; stone large, clinging; mid-season.

Worth. Americana. I. Kerr Cat. 7. 1902-3.

Originated by Theodore Williams of Nebraska; named and introduced by J. W. Kerr in 1902 . Trce vigorous, healthy and productive; fruit large, round-oblong, purplish-red on a greenish-yellow ground; semi-clinging; mid-season.

Wragg. Americana. 1. Meneray Cat.

A seedling of Hawkeye grown by H. A. Terry; introduced by F. W. Meneray, Council Bluffs, Iowa. Tree vigorous, healthy, productive; fruit very large, yellow blotched with dark red; flesh yellow, firm, rich; good; clingstone; mid-season.

Wragg Freestone. Species? I. Wis. Sta. Bul. 87:18, I 901.

Received by the Wisconsin Experiment Station from Edson Gaylord, Nora Springs, Iowa. Fruit medium to small, roundish, dark purplish-red with numerous elongated yellowish markings; bloom heavy; stem long, slender; skin tender, not harsh; flesh greenish-yellow, crisp, very rich but harsh near the center; stone round, grooved, semiclinging.

Wunder von New York. Species? Mentioned in Mathieu Nom. Pom. 454. 1889.

Merville de New York.

Wyandotte. Species? I. Mich. Hort. Soc. Rpt. 290. I889.

Professor Budd of Iowa mentioned this plum as hardy and as bearing continuously. Wyant and Japan. Triflora $\times$ Americana. 1. Ill. Hort. Soc. Rpt. 420.1905.

Mentioned in a list of varieties under test by H. T. Thompson, Marengo, Illinois. Said to be a hybrid seedling; fruit light red; fair quality; freestone; mid-season.

Wyckoff. Munsoniana. r. Linn County Nur. Cat.

Wyckoff was found growing wild along the Cedar River, Iowa, by a Mr. Wyckoff; introduced by Snyder Brothers, Center Point, Iowa.

Wyedale. Domestica. 1. Hogg Fruit Man. 732. 1884. 2. Garden 58:395. 1900.

3. Thompson Gard. Ass't 4:I59. $190 \mathrm{r}$.

From Yorkshire, England; much grown in the northern parts of England. Tree very productive, strong and upright in growth; fruit small, oval; cavity small; dark purple, almost black; flesh greenish-yellow, brisk, juicy, agreeably flavored; clingstone; late.

Wyzerka. Domestica. 1. Kan. Sta. Bul. 73:191. 1897. 2. Ibid. 101:121, Pl. 6 fig. x. I901. 3. Budd-Hansen Am. Hort. Man. 328 . 1903 .

Wiezerka $\mathbf{I}, 2$.

Wyzerka is one of the numerous Russian varieties imported by J. L. Budd of the Iowa Experiment Station. There seems to have been some confusion in the distribution of this plum, for Budd and Hansen, in reference three, describe Wyzerka as a large, oval, yellow plum with a fine peach-like flavor; the variety sent to this Station under 
this name bears a small, purplish-black, Damson-like fruit, long-oval in form, cavity shallow; suture a line; skin thin; bloom very heavy; flesh yellow, juicy, slightly fibrous, sweet, mild; flavor good; stone oval, small, free; mid-season.

Yates. Triflora $\times$ Angustifolia varians, 1. Vt. Sta. Bul. 67:22. 1898, 2. Vt. Sta. An. Rpt. 14:275. 1901.

From seed of Kelsey thought to have been pollinated with Lone Star; originated with D. H. Watson, Brenham, Texas; introduced by W. A. Yates, 1897 . Tree thrifty, healthy; fruit large, roundish, red when fully ripe; clingstone; mid-season.

Yellow Americana. Species? Letter from Kerr.

Originated by Theodore Williams, Benson, Nebraska.

Yellow Egg. Species? I. Wis. Sta. Bul. 63:66. 1897.

Goff mentions a variety under this name which differs from the older plum of the same name. Tree of weeping habit, productive; fruit long; freestone.

Yellow, 43 Fischer. Domestica. 1. Bailey Ann. Hort. 18. 1889.

Introduced into this country from Russia by Professor J. L. Budd of Ames, Iowa.

Yellow Impératrice. Domestica. 1. Ann. Pom. Belge 55, Pl. 1853. 2. Pom. France $7:$ No. 11. 1871. 3. Mas Le Verger 6:113, fig. 1866-73. 4. Hogg Fruit Man. 732. 1884. 5. Mathieu Nom. Pom. 431. I889. 6. Cat. Cong. Pom. France 46 r. 1906.

Altsse Blanche 4, 5. D'Altesse Blanche 6. De Monsieur Jaune 3. Gelbe Herm Pflaume 5. Impératrice Jaune 3, ?5. Jaune de Monsieur 2. Jaune de Monsieur 5, 6. Monsieur à Fruits Janne 4, 5. Monsieur à Fruits Jaunes 3. Monsieur à Frnits Jannes 5, 6. Monsieur Jaune 6. Prune de Monsieur Janne 5. Prune de Monsieur Jaune I. Prune de Monsieur, Varietè Jaune 5. Prune Monsieur Jaune 2. Prune d'Altesse Blanche 2, 5. Virginale Blanche 4, ?5. Yellow Impératrice ?3, 5 .

M. Jacquin, nurseryman of Paris, France, obtained this plum from seed of a cross between the Orleans and the Reine Claude planted about 1820; brought to notice in 1845. Mas considered Hogg's and Downing's Yellow Impératrice as different from the French variety. Tree medium in vigor; fruit medium in size, usually roundish-oval; suture broad; halves unequal; skin not adhering, golden-yellow, dotted and streaked with carmine-red; flesh yellow, juicy, very sweet and aromatic; freestone; mid-season. Yellow Imperial. Domestica. 1. Prince Pom. Man. 2:59. 1832.

Imperial jaune I. Impériale jaune I.

Described by Prince as distinct from Yellow Egg which it much resembles but differing in that it is somewhat smaller, about two weeks earlier and slightly more acid. Yellow Jack. Domestica. Mentioned in Lond. Hort. Soc. Cat. 154. 1831.

Yellow Jerusalem. Domestica. 1. Hogg Fruit Man. 732. 1884. 2. Mathieu Nom. Pom. 436. 1889 .

Jahns Gelbe Jerusalems Pflaume 2. Jahn's Jerusalems Pfaume 2. Jerusalem Jaune 1, 2. Jahn's Gelbe Jerusalems-pflaume I. Yellow Jerusalem 2.

Fruit of medium size, roundish-oval; suture a line; cavity deep; deep yellow with crimson specks next the sun; flesh yellow, with white veins, tender, juicy, brisk, sweet, very good; clingstone; mid-season. 
Yellow Magnum Bonum. Domestica. I. Jour. Hort. N. S. 17:228. I869.

According to the preceding reference this variety is distinct from the Yellow Egg (White Magnum Bonum). Fruit medium in size, oval, dull yellow sprinkled with red dots; rich; clingstone; young shoots smooth.

Yellow Nagate. Triflora. 1. Am. Pom. Soc. Rpt. 106. 1891. 2. Can. Exp. Farm Bul. 2nd Scr. 3:57. 1900 .

A little known Triflora very closely resembling if not identical with some of the standard yellow Trifloras.

Yellow Oregon. Hortulana. 1. Wis. Sta. Bul. 63:66, 1897. 2. Vt. Sta. An. Rpt. $11: 287.1898$.

Described by Waugh from specimens received by him from B. A. Matthews, Iowa. Fruit small, nearly spherical; suture a faint line; bright golden-yellow; dots many, whitish; skin thick and strong; flesh yellow and not very firm; quality medium; stone large, smooth, clinging; inferior in size and quality to Captain or Cumberland.

Yellow Panhandle. Angustifolia watsoni. r. Wis. Sta. Bul. 63:66. 1897. 2. Bailey Ev. Nat. Fruits 222, 223. 1898. 3. Waugh Plum Cult. 234. 1901. 4. Ga. Sta. Bul. $67: 285$. 1904.

A variety from the Panhandle of Texas; introduced by F. T. Ramsey of Austin, Texas. Tree forms a close symmetrical head; fruit small, roundish-oblong, yellow overspread with clear bright red; dots few, indistinct; skin tough; flesh yellow, hard; quality poor; stone medium, oval, turgid, clinging.

Yellow Roman Bullace. Insititia. Mentioned in Lond. Hort. Soc. Cat. I44. I8 31 .

Yellow Sweet. Americana. 1. Cornell Sta. Bul. 38:46. 1892. 2. Colo. Sta. Bul. 5o: 47. 1898 . 3. Waugh Plum Cult. 168. 1901.

Thought to have originated in Minnesota. Tree small; fruit large, round inclining to oblong; suture distinct; stem short and stout; yellow more or less mottled and shaded with red; bloom thin; flesh firm, juicy, rich, sweet; good; stone round, flat, clinging.

Yellow Transparent. Angustifolia varians. I. Am. Pom. Soc. Rpt. I62. I881. 2. Am. Pom. Soc, Cat. 25. 1897. 3. Ohio Sta. Bul. 113:156. 1899. 4. Waugh Plum Cult. 200. 1901 .

Transparent 4 incor. Transparent Yellow 2.

Selected from a seedling orchard of two thousand trees planted near Denison, Texas, by J. L. Freeman. Tree vigorous, forming a handsome top, productive; fruit medium in size, oblong, bright yellow; skin thin and tough, reported to crack badly in some localities; flesh soft and watery, sweet and good; clingstone; early.

Yellow Wildgoose. Munsoniana? I. Van Lindley Cat. 42. I899.

Said to have been introduced by $\mathrm{R}$. Bates of Jackson, South Carolina. Fruit large, equal in size to Wild Goose with better quality; ripens at the same time.

Yellow Yosemite. Species? 1. Gard. Mon, 20:176. 1878, 2. Mich. Sta. Bul. 118:52,

55. 1895. Yosemite 1. Yosemite Yellow 2.

Yellow Yosemite came from the "Rocky Mountains" about i 870 with the Purple Yosemite; introduced by W. S. Carpenter, Rye, New York. Fruit roundish; suture 
a line; skin thick, tough, yellow, with reddish tinge; flesh yellow, sweet, tender; stone roundish-ovatc, clinging; mid-season.

Yohe. Domestica. 1. Downing Fr. Trees Am. 954. 1869. Yohes Eagle 1.

Noticed by Downing who says it is an accidental scedling in the garden of Caleb Yohe, Bethlehem, Pennsylvania.

York State Prune. Domestica. I. Thomas Am. Fruit Cult. 504, 505. I897. 2. Greenc

Cat. 1897. 3. Sweet Cat. I3. 1897. 4. IV. N. Y. Hort. Soc. Rpt. 44:92. 1899.

Large German Prune 3. York State Prune 3.

A seedling grown near Dansville, New York. As tested at this Station and by many fruit-growers it is identical with Italian Prune.

Young. Domestica. I. Downing Fr. Trees Am. 955. 1869. Young's Seedling I.

From Pennsylvania. Tree vigorous; fruit medium in size, roundish-oval, deep reddish-purple; flesh yellow, sweet; good; freestone; mid-season.

Yukon. Nigra? 1. Can. Exp. Farms Rpt. 426. 1900.

A seedling grown at Indian Head Experimental Farm, Canada. Fruit of medium size, red; skin thick; good; early.

Yuteca. Species? I. Cir. S. Dak. Exp. Sta. 1910. South Dakota No.8 I.

A very early ripening seedling of some native plum grown by N. E. Hansen of the South Dakota Experiment Station; sent out in 1907.

Zahlbruckner Damascene. Species? Mentioned in Mathieu Nom. Pom. 455. I889. Zahlbruckner's Violette Damascene.

Zekanta. Species? r. Cir. S. Dak. Exp. Sta. rgro.

A large yellow seedling of some native plum grown and introduced by N. E. Hansen of the South Dakota Experiment Station.

Zucchetta Gialla. Species? Listed in Mathieu Nom. Pom. 455. I889.

Zulu. Species? r. Vt. Sta. An. Rpt. 12:230. 1899.

Grown by Luther Burbank who says in regard to its parentage "It is a mystery, being three or four generations from innumerable crosses, and resembles no other known species or variety." Fruit medium in size, round or somewhat oblate; suture shallow; cavity broad, open; stem short, strong; very dark dull red, almost black; dots many, minute, whitish; bloom thick; skin thin and tender; flesh firm, juicy, red, rich and sweet; quality good to best; stone medium large, rounded, only slightly flattened, clinging.

Zuzac. Domestica. 1. Kerr Cat. 25. 1897.

Similar in appearance to Townsend.

Zwergpflaume. Domestica. 1. Kraft Pom. Aust. 2:35, Tab. 183 fig. 2. 1796.

Die kleine Zwergpflaume r. Prune nain I.

Tree low; leaves lance-shaped, short-stemmed; flowers small, fragrant; petals long, not widely opened; fruit hanging on a long stem, the size and appearance of a cherry except that it is more elongated; pleasant; sometimes sourish and flat.

Zwetsche Professor Wittmack. Species? 1. Ilathieu Nom. Pom. 455. 1889.

Referenced by Mathieu from Garten-flora 142. 1888 . 
Zwetsche Von der Worms. Species? I. Mathieu Nom. Pom. 455. 1889. 2. Guide Prat. 163,368 . 1895 .

Grosse Blaue Zwetsche Von der Worms I, 2. Quetsche Grosse Blaue de la Worms I, 2. Tree vigorous, productive; fruit large, oval, bluish-black; flesh greenish-yellow, juicy, firm; mid-season. 


\section{BIBLIOGRAPHY AND REFERENCES, WITH ABBREVIATIONS USED.}

In this list it is hoped that there will be found all horticultural books in America dealing with the plum. No attempt has been made to include botanical works. Only such European books are recorded as were found useful in preparing the volume. All the agricultural and horticultural periodicals to which references are to be found in the preceding pages are given, but no more. The reports and bulletins of experiment stations and horticultural societies are not included since the abbreviations used for such publications are readily recognized. The date of copyright has been preferred to that of publication though sometimes it has been necessary to use the latter, as when there were several editions from the same copyright.

Abercrombie, Gard. Ass't.... The Gardeners Daily Assistant. By John Abercrombie. London: 1786 .

Am. Gard ............. American Gardening. New York: 1892-1904. (Before its union with Popular Gardening in 1892 , was known as American Garden. Both Popular Gardening and American Garden resulted from the union or absorption of several other horticultural periodicals.)

Am. Gard. Mag........... American Gardener's Magazine. See Mag. Hort.

Am. Hort. An........... American Horticultural Annual. A Year Book of Horticultural Progress, etc., under the gencral editorial care of Dr. George Thurber. New York: 1867-1871. Am. Jour. Hort.......... The American Journal of Horticulture and Florist's Companion. Boston: 1867-1869. Continued as Tilton's Journal of Horticulture and Floral Magazine, $1869-18 ;$ r.

Am. Pom. Soc. Rpt........ American Pomological Society Report. Issued usually biennially from $185_{2}$ to date.

Ann. Hort............. Annals of Horticulture and ycarbook of information on practical gardening. London: $1846-50.5$ vols.

Ann. Pom. Belge ......... Annales de Pomologie Belge et Etrangère; publiées par la Commission royale de Pomologie, instituée par S. MI. le Roi des Belges. 8 vols. Bruxellcs: $1853^{-1860 .}$ Bailey, Ann. Hort.......... Annals of Horticulture in North America. $A$ record of Horticultural Progress, appearing annually from 1889-1893. By L. H. Bailey. New York. 
Bailcy, Cyc. Hort........... Cyclopedia of American Horticulture. By L. H. Bailey, assisted by Wilhelm Miller. In Four Volumes. New York: 1900 .

Bailey, Ev. Nat. Fruits..... A sketch of the Evolution of Our Native Fruits. By L. H. Bailey. New York: 1898 .

Bailey, Sur. Unlike......... The Survival of The Unlike. By L. H. Bailey. New York: 1906.

Baltet, Cult. Fr.......... Traité de la Culture Fruitière Commerciale et Bourgeoise. Par Charles Baltet. Quatrième Edition. Paris: 1908 .

Barry, Fr. Garden......... The Fruit Garden. By P. Barry. New York: 1851 . Revised edition, $188_{3}$.

Bartrum, Pears \& Plums.... The Book of Pears and Plums. By E. Bartrum. London and New York: igo3. Being Volume XI of Handbooks of Practical Gardening, edited by Harry Roberts.

Bradley, Gard............ New Improvements of Planting and Gardening, both Philosophical and Practical. In three parts. By Richard Bradley. Seventh edition, London: 1739.

Bridgeman, Gard. Ass't..... The Young Gardener's Assistant. Three parts. By Thomas Bridgeman. New York: 1857 .

Brookshaw, Pom. Brit....... Pomona Brittanica or a collection of the Most Esteemed Fruits at Present cultivated in Great Britain. By George Brookshaw. London: $18 \mathrm{I} 7$.

Budd-Hansen, Am. Hort. Man. American Horticultural Manual, etc. By J. L. Budd and N. E. Hansen. In 2 vols; vol. 2. New York and London: 1903 .

Cal. Fr. Grower. . . . . . . . The California Fruit-Grower. San Francisco: I 888 to date. Can. Hort............ Canadian Horticulturist. Toronto: 1878 to date.

Cat. Cong. Pom. France...... Société Pomologique de France. Catalogue descriptif des fruits adoptés par le Congrès pomologique. Lyon: 1887. Ibid.: 1906 .

Cole, Am. Fr. Book. ........ The American Fruit Book. By S. W. Cole. Boston: 1849 .

Country Gent........... Country Gentleman. Albany: $18_{53-1865}$. The Cultivator and Country Gentleman. Albany: 1866-1897. The Country Gentleman. Albany: 1898 to date.

Coxe, Cult. Fr. Trees........ A View of the Cultivation of Fruit Trees. By William Coxe. Philadelphia: 1817 .

Cultivator............ Albany: ${ }_{1} 8_{34-1865}$. In 1866 united with the Country Gentleman.

Decaisne \& Naudin, Man. Am. des Jard............... Manuel de L'Amateur des Jardins. By Jh. Decaisne and Ch. Naudin. Tome quatrième. Paris. 
De Candolle, Or. Cult. Plants., Origin of Cultivated Plants. By Alphonse De Candolle. Geneva [Switzerland]: 1882 . New York: 1885.

Downing, Fr. Trees. Am.... The Fruits and Fruit Trees of America. By A. J. Downing. New York and London: 1845. Second edition, same text, with colored plates, 1847. First revision, by Charles Downing. New York: 1857 . Second revision, by Charles Downing. New York: 1869. First appendix, 1872. Second appendix, I876. Third appendix, 1881 .

Duhamel, Trait. Arb. Fr.... Traité des Arbres Fruitiers. Par M. Duhamel du Monceau. Tomes 1 et 2. Paris: i 768. Edition publie en ${ }_{1} 8_{2}$ en trois tomes. Nouvelle Edition en six tomes, $1807-1835$.

Elliott, Fr. Book.......... Elliott's Fruit Book: or the American Fruit-Growers' Guide. By F. R. Elliott. New York: 1854 . Revised edition, 1859 .

Fish, Hardy-Fr. Bk........ The Hardy-Fruit Book. By D. T. Fish. Two volumes. London: probably I 882 .

Flor. \& Pom ............ The Florist and Pomologist. A Pictorial Monthly Magazine of Flowers, Fruits and General Horticulture. Conducted at first by Robert Hogg and John Spencer, later by Thomas Moore and William Paul. London: $1862-84$.

Floy-Lindley, Guide Orch. Gard. A Guide to the Orchard and Fruit Garden. By George Lindley; edited by John Lindley. American edition by Michael Floy. New York; 1833 . New edition with an appendix, 1846 .

Forsyth, Treat. Fr. Trees, .... A Treatise on the Culture and Management of Fruit Trees. By William Forsyth. London: 1802 . Same with Introduction and Notes, by William Cobbett. Albany: I803. Scventh edition [English] London: 1824 .

Gallesio, Pom. Ital. ........ Pomona Italiana Ossia Trattato Degli Alberi Fruttiferi Di Giorgio Gallesio. Tomo Secondo. Pisa: $18_{39}$. Volume 2 includes two large books, Testo 2, which contains the fruit descriptions and Tavole 2, which contains the plates.

Gard. and For........... Garden and Forest. Charles S. Sargent, editor. New York: $\mathrm{r} 888-1897$.

Gard. Chron............. Gardeners' Chronicle, etc. London: $1 \delta_{4} 1$ to date.

Garden................ Garden. London: 1872 to date.

Gardening............. Gardening. Chicago: 1893 to date.

Gard. Mon............. Gardener's Monthly, etc. Thomas Mechan, editor. Philadelphia: $1859^{-188} i$. 
Gard. World............. Gardening World, illustrated. A weekly paper exclusively devoted to all the branches of practical gardening. London: $1884^{-1909 . ~ I n ~ V o l . ~} 20,1903$, the title was changed to The Gardening World, an illustrated journal for country gentlemen and professional gardeners. The editor from May, 1895, has been John Fraser; previously the editor had been Brian Wynne, but in the earlier years the editor's name is not given.

Gaucher, Pom. Prak. Obst.... Pomologie der Praktischen Obstbaumzüchters. Von N. Gaucher. Stuttgart: 1894 .

Gen. Farmer. ............ Genesee Farmer. Edited by Luther Tucker. Rochester: 1831-1839. Then consolidated with the Cultivator. Another periodical of the same name was published in Rochester from 1845 to 1865 . Also New Genesee Farmer and Monthly Genesee Farmer.

Gerard, Herball.......... The Herball or Generall Historie of Plantes. By John Gerard. Enlarged and amended by Thomas Johnson. London: 1636 .

Goodrich, N. Fr. Cult....... The Northern Fruit Culturist, or Farmers' Guide. By Chauncey Goodrich. Burlington, Vt.: 1849 .

Guide Prat............. Guide Pratique de L'Amateur de Fruits. Description et Culture des Variétés de Fruits Classées Par Séries de Mérite. Composant les Collections Pomologiques de L'Êtablissement Horticole Simon-Louis Frères. A Plantières-lès-Metz. (Lorraine Annexée) Deuxième Édition. Revue et Corrigée par les Chefs de Culture de L'Établissement. Paris and Nancy: I 895.

Hoffy, N. Am. Pom......... Hoffy's North American Pomologist. Edited by William D. Brinckle. Book No. I. Philadelphia: 1860. Hoffy, Orch. Com.......... Hoffy's Orchardist's Companion or Fruits of the United States. A quarterly journal. Vol. 1, I $84 \mathrm{I}-2$, Vol. 2, 1842-3. Alfred Hoffy, Editor and Publisher. Philadelphia.

Hogg, Fruit Man......... The Fruit Manual. By Robert Hogg. First edition, London: 1860. Second edition, 186r. Third edition, 1866. Fourth edition, 1873 . Fifth edition, 1884.

Hooper, W. Fr. Book........ Hooper's Western Fruit Book. By E. J. Hooper. Cincinnati: 1857 .

Horticulturist. . . . . . . The Horticulturist and Journal of Rural Art and Rural Taste. Albany, Philadelphia and New York: $1846-$ 1875. Founded by A. J. Downing. Other editors were Barry, Smith, Mead, Williams and the Woodwards. 
Hovey, Fr. Am......... The Fruits of America. Two Volumes. C. M. Hovey. Boston: 1851 .

Jour. Hort............. Journal of Horticulture began as: The Cottage Gardener; or Amateurs' and Cottagcrs' guide to out-door gardening and spade cultivation. London: $1849-1861.25$ vols. (Edited Vols. $1^{-1} 3$ by G. W. Johnson, vols. r 4-25 by G. W. Johnson and R. Hogg.) Continued as The Journal of Horticulture, Cottage Gardener and Country Gentleman. ... New Series. London: $186 x-$ 1880. 38 vols. (edited by G. W. Johnson and R. Hogg) - continued under the same title as ... Third Series. London: 1880-1909. 59 vols. (edited by R. Hogg).

Jour. Roy. Hort. Soc........ Journal of the Royal Horticultural Society. London: 1846 to date. Vols. $1-9 ; 1846-55$, bear the title of Journal of the Horticultural Socicty of London.

Kenrick, Am. Orch........ The New American Orchardist. By William Kenrick. Boston: $18_{32}$. Second edition revised, $18_{35}$. Seventh edition, enlarged and improved, with a supplement, I 844 .

Knoop, Fructologie........ Part 1. Pomologie ou Description des Meilleures Sortes de Pommes et de Poires. Part II. Fructologie ou Description des Arbres Fruitiers. Par Jean Herman Knoop. Amsterdam: 1771 .

Koch, Deut. Obst......... Die Deutschen Obstgeholze. By Karl Koch. Two Parts. Stuttgart: 1876 .

Kraft, Pom. Aust.......... Pomona Austriaca. Abhandlung von dem Obstbaumen. By Johann Kraft. Wein: 1792 .

Lange, Allgem. Garten....... Allgemeines Gartenbuch. By Theodore Lange. Two Volumcs. Second Edition, Leipsic: 1879 .

Langley, Pomona.......... Pomona; or the Fruit Garden Illustrated. By Batty Langley. London: 1729.

Lauche, Deut. Pom........ Deutsche Pomologie. Von W. Lauche. Berlin: r882. Le Bon Jard............. Lc Bon Jardinier. I 26th Edition Almanach Horticole, 1882 and the r 29 th Edition, r884. Paris.

Lond. Hort. Soc. Cat........ A Catalogue of the Fruits Cultivated in the Garden of the Horticultural Society of London. London: 1826 . Second edition, 1831 . Third edition, 1842 . A supplement was published in 1853 .

Loudon, Arb. Frut. Brit.... Arboretum et Fruticetum Britannicum. By J. C. Loudon. Second Edition, Volume 2. London: 1844. Loudons Enc. Gard......... An Encyclopedia of Gardening, etc. By J. C. Loudon. New cdition. London: 1834 . 
Lucas, Vollst. Hand. Obst.... Vollständiges Handbuch der Obstkultur. Von Ed. Lucas. Stuttgart: First cdition, I880; second edition, 1886; third edition, I893. Third edition edited by Fr. Lucas. 1894 .

Mag. Hort.............. Magazine of Horticulture. Boston: 1837-1868. First published under name American Gardener's Magazine, 1835-6. Edited by C. M. Hovey with P. B. Hovey, Jr., associate editor during $1835-6$.

Manning, Book of Fruits..... Book of Fruits. By Robert Manning. Salem: $18{ }_{3} 8$. Second edition with title, New England Fruit Book. Revised by John M. Ives. Salem: 1844 .

Mas, Le Verger........... Le Verger. Par M. Mas. Tomes 8. Paris: $1866-1873$. Tome 6. Prunes.

Mas, Pom. Gen............ Pomologie Générale. Par M. Mas. Tomes 12. Paris: $1872-8$. Tome 2, 1873 . Prunes.

Mathieu, Nom. Pom.......... Nomenclator Pomologicus. Von Carl Mathieu. Berlin: I 889 .

Miller, Gard. Dict......... Gardener's Dictionary. By Philip Miller. London: 754 . Revised edition, Volumes I and II. By Thomas Martyn. London: 1807 .

Miller, Gard. Kal. .......... Gardener's Kalendar. By Phillip Miller. London: I734. MeIntosh, Bk. Gard........ The Book of the Garden. By Charles McIntosh. Two Volumes. London: 1855 .

MeMahon, Am. Gard. Cal... The American Gardener's Calendar. By Bernard MeMahon. Philadelphia: ISo6.

Nat. Hist. N. Y . . . . . . . Natural History of New York. Part V. Agriculture. By Ebenezer Emmons. Vol. III devoted to fruits. Albany: I8 5 I.

Nat. Nur............... National Nurseryman. Edited by R. T. Olcott and later by John Craig. Rochester: I 893 to date.

N. E. Farmer Dict......... The New England Farmer or Georgical Dictionary. By Samuel Deane. Second Edition. Worcester, Mass.: 1797 .

Nicholson, Dict. Gard....... The Illustrated Dictionary of Gardening. By George Nicholson, assisted by J. W. H. Trail and J. Garrett. Four volumes, London. Supplement to same. By George Nicholson et al. London: 1900.

Noisette, Man. Comp. Jard... Manuel Complet du Jardinier. Par M. Louis Noisette. Paris: 5860 .

Oberdieck, Deut. Obst. Sort. . Deutschlands beste Obst-Sorten. Von. F. G. C. Oberdieck. Leipzig: I88r.

Oregon Agric............. Oregon Agriculturist. Edited by W. E. Williamson. Portland: 189 I to date. 
Parkinson, Par. Ter.

Phillips, Com. Orch..

Poiteau, Pom. Frane.

Pom. Franee...........

Pom. Mag.

Popular Gard

Prince, Treat. Hort

Prince, Pom. Man.

Quintinye, Com. Gard....... The Complete Gard'ner; or Directions for Cultivating and Right Ordering of Fruit Gardens and Kitchen Gardens. By Monsieur De la Quintinye. Second edition. London: 1699 .

Ray, Hist. Plant........... Historia Plantarum. By John Ray. London: I688.

Rea, Flora.............. Flora: Seu, De Florum Cultura; or A Complete Florilege. By John Rea, Gent. London: 1676.

Ree. Hort. . . . . . . . . . . . Woodward's Record of Horticulture. Edited by A. S. Fuller. (An annual.) New York: 1866-1868.

Rev. Hort . . . . . . . . . Revue Horticole. Paris: 1829 to datc.

Rural N. Y. . . . . . . . . . . Rural New Yorker. Rochester and New York: 1850 to date.

Soc. Nat. Hort. France Pom... Société Nationale d'Horticulture de Franec. Section Pomologique. Les Meilleurs Fruits au début du $\mathrm{XY}^{\circ}$

Siècle. Paris: 1904 .

Sou. Cult. ............. Southern Cultivator. Augusta, Ga.: $18+3$. 
Thomas, Am. Fruit Cult..... American Fruit Culturist. By John J. Thomas. First edition, Geneva and Auburn, N. Y.: 1846 . Edition of 1849 , Auburn, N. Y. Edition of $1867,1875^{-1} 885$, New York. Twentieth edition, revised and enlarged by William H. S. Wood. New York: 1897 .

Thompson, Gard. Ass't..... The Gardener's Assistant. By Robert Thompson. Two volumes. London: 1859. Same, revised by William Watson. Six volumes. London: r 901 .

Traité Prat. Scch. Fruits.... Traité Pratique du Séchage des Fruits et des Légumes. Par J. Nanot et L. Tritschler. Paris: 1893.

U. S. D. A. Rpt.......... Reports of the United States Department of Agriculture: I 862 to 1894 .

U. S. D. A. Yearbook........ Reports of the United States Department of Agriculture: I 894 to date.

U. S. Pat. Off. Rpt........ Reports of the Agricultural section of the United States Patent Office: 1837 to 1861 .

Waugh, Plum Cult........ Plums and Plum Culture. By F. A. Waugh. New York: 1901 .

Wickson, Cal. Fruits........ California Fruits. By Edward J. Wickson. Second Edition. San Francisco: 1891 . Same, Fourth edition. Los Angeles: 1909 .

Willich, Dom. Enc......... Domestic Enclycopedia or a Dictionary of Facts, etc. By A. F. M. Willich. First American edition with additions by James Mease. In five volumes. Vol. 4, Philadelphia: 1803 . 


\section{N D EX.}

(Names of varieties in this index, if necepted names, appear in Roman type; if synonyms, in italics.)

\begin{tabular}{|c|c|c|}
\hline $\begin{array}{l}\text { Abricotée Sageret (syn. of Reine } \\
\text { Claude), } 327 \\
\text { Abricot Princesse, } 391 \\
\text { Abricot Verd or Vert (syn. of Reine } \\
\text { Claude), } 327 \\
\text { Abundance, } 136 \\
\text { Abundance (syn. of Abundance), } 136 \\
\text { Adair, D. L., var. orig. by, } 292 \\
\text { Admirable, } 391 \\
\text { Admiral, } 391 \\
\text { Admiral Rigny or de Rigny (syn. of } \\
\text { Rigny), } 532 \\
\text { Admiral Dewey (syn. of Dewey), } 432 \\
\text { Admiral Schley, } 391 \\
\text { Advance, } 392 \\
\text { Acchte Gclbe Fierffiame (syn. of } \\
\text { Yellow Egg), } 386 \\
\text { A Fleur Dowble (syn. of Red Date), } \\
322 \\
\text { African }\end{array}$ & 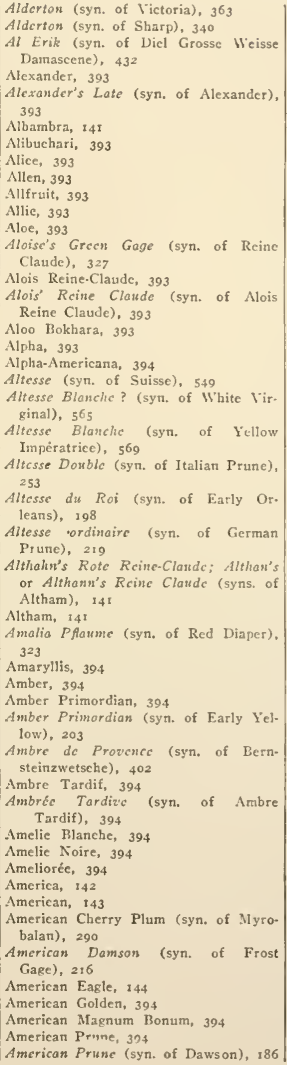 & 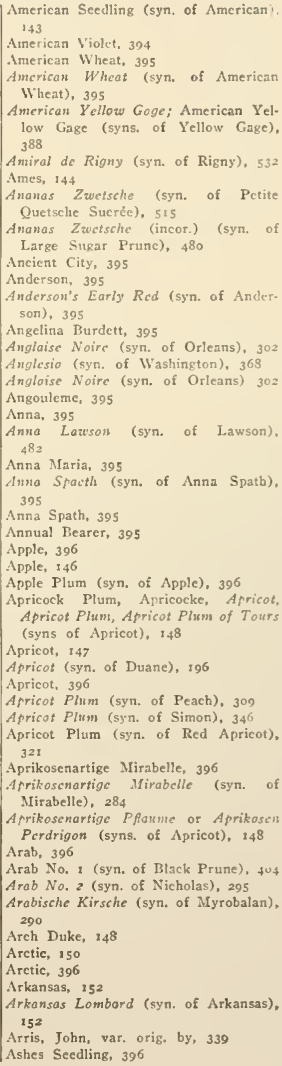 \\
\hline
\end{tabular}




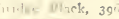

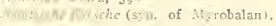

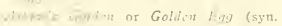
of linther ligg), $3^{86}$

Istew's lar, lc Egg (syn. of Red Magnum I:m(t+1), 325

N-inib i.1, w

Sw' 11,306

AnNn Green Gage, 396

Ay:ur, 396

Now9, 397

Aviluert. 307

Anbertiana (syn. of Yellow Egg), 386

Auburn, 397

Auchtertyre, 397

August, 397

Ingustc Zictsche (syn. of Italian

Prune), 253

Augustine, A. M., var. orig. by, 475

interust Pfaunc (syn. of Damson), 186

August Red (syn, of August), 397

Angust Zwetsche, 397

August Zuctsche (syn. of Wahre

Frühzwetsche), 560

August Zovetsche (syn. of Italian

Prune), 253

Aunt Ann, 397

Aunt Ann (syn, of Aunt Ann), 397

Aurora, 397

Auserlescne Gelbe Reinc-Clande (syn.

of Yellow Gage), 388

Auscrlescre Rote Reine-Claude or rotlte Reineclaude (syn. of Red

Gage), 527

Austrian Quetsche, 397

Automne de Schamali (syn, of

Schamal), s4o
Autriche Violettc (Pr. d.) (syn. of

Hungarian), 246

Autumn Beauty (syn. of Belle), 158

Autumn Compote (syn. of Autumn

Compote), 153

Autumn Compote, 153

Autwmn Gage (syn. of Autumn Gage), 308

Antumn Gage, 397

Avant Prunc blanche (syn. of Early

Yellow), 203

Azure, 398

Azure Hätive (syn. of Early Blue), 438

Babcock (?) (syn. of Abundance), 136 Babcock (syn. of Chabot), 172

Backpfiaume (syn. of German Prune), 219

Eailey, 398

Bailey (syn, of Chabot), 172

Bailoy (syn, of Iyon), 488

Bailcy, Liberty Hyde, plum investigations of, 64 ; quoted, $63,65,99,541$

Baker, 39:

Baker, var, orig. by, 398

Baker (syn. of Stoddard), 352

Baker Damson (syn. of Baker), 398

Baker's German Prune (syn. of Baker), 398

Baldwin, 398

Bal Erile (syn. of Nikitaer Blaue

Friblizwetsche), so4

Ballonartige Gelbe Zwetsche, 398

Ballomartige Rote Damascenc, 398
Ifiltet, M. M., var. orig. by, 551

Bambergor Eicr Pflume (syn. of Blue Egg), 405

Bamberger Eicr Pfaumc (incor.) (syn. of Kaiser Willicim), 474

Bankglari Frith Damascenv, 398

Bankaluri's Rotc Fräh Damascene (syn. of Bankalari Früh Damascene, 398

Danker's Gave, 399

Bant Spate Reine Claude, 399

Bunt's Late Grecn Gago (syn, of Bant Späte Reine (laude), 399

Baraboo, 399

Barbary, 399

Barberry (syn. of Barbary), 399

Bardak Erik (syn. of Nikitaer Dattelzwetsche), 504

Barkhausen Violette Reine Claude, 399 Darkley, 399

Barnsliack, 399

Barnsbcck (syn. of Rarnsback), 399

Baronne II len Trauttenberg, 399

Barry, quoted, 167

Bartlett, 154

Bartlctt (syn, of Oren), 300

Basaricatta, 399

Basilic (syn, of Hungarian Musk

Prune), 465

Bassett, I 55

Bassctt's American (syn. of Bassett). I5s

Bastle, 399

Batchelor Damson, 399

Battle Monumcut (syn. of Blue Perdri gon), 164

Baucrn Pflaume (syn. of Gemeiner Gelbe Spilling), 45 i

Batcorupfaume (syn. of German

Prune), 210

Bavay, 155

Bavay's Early Gage or Bavay's Frïhe Rcinc-Clande (syns. of July Green Gage), 474

Bazay's Green Gagc, Reine Claude or ronkloic: Barays Rcine-Claude (syns. of Bavay), 155

Bazalicza, 399

Bazalicza Damson or Zuctsche; Bazalicza's Grosse Blaue Zwotsche of Prune (syns, of Bazalicza), 399

Beach Plum, 400

Beals, 400

Beals, George F., var, orig. by, 400 Bean, 400

Bcotty (syn, of Aitkin), 140

Reatty, James, var. orig. by, 396

Beaty, 400

Beaty, Lee, var. orig. by, 400

Beaty Choice; Bcaty's Choicc; Beauty, Best, var. orig. by, 307

Beauty's Choice (syn. of Beaty), 400 Best Black Blood, 402

Reauty of Naples (syn. of Naples), 502

Bechstein Spitzpflaume, 400

Fedford, 400

Bccf's Hcart (syn. of Coeur de Boeuf),

420

Beckman's Scarlet (syn. of Lombard), 268

Beer Plum, 400

Behren's Königspflaume: Bchrens Königspfoume (syns. of Royale de

Behrens), 535

Bèjonnières, 157
Toeluarian Ptune (syn, of Dulgarian), 21

Be. in Purple, 157

Bu, , : Purple (5yn. of Belgian Pur. W.1. 157

I las ha Damascenc (syn. of Belgian Purplic), 157

Bell, 400

Bell, Levi, var, orig, by, 530

Belle, 158

Balle (sya of Tuxas Belle) $55^{2}$

Bclle d'Albany (synt. of Albany Beauty).

Bclle de Doue (syn. of Chauviere). 417

Belle de Jaróy, 400

Belle de Lonvain, 400

Belle de Paris, 401

Belle de Riom, 40 r

Bclle de Schöneberg, 40 i

Bcllc de Schöncberg (syn. of Belle de Schöneberg), 40:

Belle de Scptembre (syn. of Belle), $15^{8}$

Bclle Tillemond (syn. of Tillemond) 554

October (syn, of Bell), 400

Belsiana, 4 or

Belvoir, 401

Bcly Zauctsche (syn. of Iarge Sugar Prune), 480

Bender, 40I

Benedict, 408

Beni Botan, 40 r

Beri-Smono No, 3 (syn, of Blood Plum), 405

Beni Smono No. 4 (syn. of Satsuma),

Benschoten, 40

Dienson, 401

Benson Market (syn, of Benson), 40 '

Perckmans, 159

Berckmans, P. J., life of, $159 \cdot 160$;

var. orig. by, 159

Berger, 160

Berlepsch, 402 Grosse Grüne Reine-

Claude (syn, of Berlepsch), 402

Berletclis Reuclode Grosse Grïne (syn. of Berlepsch), 492

Berlet Früh Damascene, 402

Berliner Pfaume (syn. of Grüne Dattel Z wetsche), 456

Bernsteinzwetsche, 402

Bernsteinzactsche (syn, of Bernsteinzwetsche), 402

Berry Plum, 402

Berrylill, 402

Best of All, 402

Bestovall (syn. of Best of Al1), 402

Beta, 402

Betterave, 402

Beverly, quoted, 21, $\&_{4}$

Beztercser Grosse Zwetsche, 402

Biconical, 402

Biclaya Nicholskaya (syn. of Nicbolas), 295

Biclaya Otschakarskaya (syn. of White

Otschakoft), 56. 
Bieler Pfaume (syn. of Noire de Montreuil), 504

Bicry, 403

Biferc (syn. of Twice Bearing), 556

Big Bluc (syn, of Gueii), 234

Big Rose, 403

Bilbos (syn. of Early Yellow) 203

Biles, II. A., var. orig. by, 403

Bilona, 403

Biltern (syn. of Bittern), 403

Bingoman (syn. of Oren), 300

Bingham, 403

Bingham (syn, of Jefferson), 255

Bingham's Pflaume (syn. of Bingham), 403

Biondeck, 403

Biondeck's Frührwetsche; Biondcck's rothe Frithzuctsche (syns. of Piondeck), 403

Birchland, 403

Biscbofsmütze (syn. of Bonnet d'Eveque), 407

Bischtin Erik (syn. of Frübe Grüne Zwetsche), 448

Bittern, 403

Bixby, 403

Black Arab (syn. of Black Arabka),

Black Arab (syn. of Black Arabka), 404

Black Arabka, 404

Black Ball, 404

Black Bullace, I $6 \mathrm{x}$

Black Bulleis (syn. of Black Bullace), $16 t$

Black Damask, 404

Black Damesk (syn, of Morocco), 288

Black Damask Hasting, 404

Black Damosine (syn, of Damson), 186

Black Damison (syn. of Damson), I86

Block Damson (syn. of Late Black Damson), 480

Black Domson (syn. of Winter Damson), 567

Black or Blacke Damascene (syn. of Damson), 186

Black Domask (syn. of Morocco), 288

Black Diamond (syn. of Diamond), 191 Black Diapred (syn. of Violet Diaper), 365

Black Hawk, 404

Black Hill, 404

Black Imperial (syn. of Bradsbaw), 166

Black-knot, discussion of, 126,127

Blackman (syn. of Charity Clark), 417

Blackman, Dr., var. orig. by, ${ }_{163}$

Black Morocco (syn. of Morocco), 288

Black Muscle (syn. of Muscle), 50 i

Black Mussell (syn. of Muscle), $50 \mathrm{r}$

Black Orlcans (syn. of Late Orleans) 265

Black Pear, 404

Black Perdrigon, 404

Block Perdrigon (syn. of Early Blue), 438

Black Prune, 40.4

Black Prune (syn. of Black Arabka), 404

Black Prunella, 404

Black Prunella (syn, of Sloe), 544

Black Prunc No. I (syn. of Black Prune), 404

Black Utal Hybrid (syn, of Utah), 362

Black Vengerka (syn. of Black Prune) 404
Blackman, 163

Blackthorn (syn, of Sloe), 544

Blaisdon, 40.4

Blaisdon's Red (5yn. of Blaisdon), 404

Blanche Grossc Espice (syn. of Reinc (laude), 327

Blawe Domascencrin (syn. of Lange

Violettc Damascenc), 479

Blouc Dattel Pfoume (syn. of IIungarian), 246

Bloue Dioprice (syn, of Violet Diaper), 365

Blauc Eicr (incor.) (syn, of Kaiser

Wilhelm), 474

Blaue Eierpflaume (syn. of Blue Egg). 405

Blove Eicr Pfoume (syn. of Large Sugar Prune), 480 Blane Eicr Pfaume (syn, of Red Mag. num Bonum) 325

Blanc Eicrpfoumc (syn. of Jerusalem), 472

Blauc Fosanen Pfoume (syn. of Blue Perdrigon), 164

Blaue Herzformige Pfaume (syn. of

Violet Diaper), 365

Blave Kaiserin (syn. of Imperatrice), 249

Blauc Kaiser Pfaume (syn. of Blue Egg), 405

Bloue Koiscrpfoume (syn. of Red

Magnum Bonum) 3 as

Blane Kricche (syn. of Haferphaume), 458

Blaue Reine Claude, 405

Blane Reine-Cloude (syn. of Purple Gage), 318

Blove Ricscnzwetsche (syn. of Italian Prunc), 253

Blaucr Perdrigon (syn, of Blue Perdrigon), 164

Blawer Spilling (syn. of Nikitaer Blaue

Frühzwetsche), 504

Blaue von Belgien (syn. of Belgian Purple), 157

Blanc Zipper (syn. of Bechstein Spitz. pflaume), 400

Blaugh, 405

Blcecker's; Blecker's Gage, Germon Gage, Ycllow, or Ycllow Gage; Blecker's; Bleeker's Gage, Gclbc Reine-Cloude, Gelbe Renklode, Galbe Zuctsche, Ycllow, or Yellow Gage (syns, of Bleeker), ${ }^{16} 3$

Blecker's Rothe Pfoume; Blecker's Scarlct; Bleeker's Rotepflaume or Scarlet; Blecker's Rothe Pflaume (syns, of Lombard), 268

Blecker, 163

Blecker, Mrs., var. orig. by, I64, 405

Bleeker Large Red, 405

Bleu de Belgique; Blcu de Bergucs or de Perguc; Blewe de Belgique, de Bergucs, de Peck or de Pcrk (syas. of Belgian Purple), 157

Bleue de Persc, 405

Blouc d'Italic (syn, of Italian Prune), 253

Blew Damask or Damson (syn. of Damson), 186

Blew Perdrigon (syn, of Blue Perdrigen), 164

13lood Plum, q05
Blienl I'hm ryph, of Satsuma), 337

Blend Plum (syn. of Shviata Bene), 543

Blood Plum No. 3 (syn. of Blood Plum), 405

Blood Plum No. 4 (syn. of Satsuma). 337

Blubenthal, 405

Bluberthal Damson (syn. of Blubenthal). 405

Blucher's Gage (syn. of Blecker), 163

13lu. Apricot, 405

Blue Damascenc (syn, of Winter DamSon), 567

Bluc Damson (syn, of Damson), 186

Blue Damson (syn. of Winter Damson), 56

Blue Eg8, 405

Blue Egg.Plum (syn. of IIungarian),

246

Blue Eye, 405

Bluc Goge (syn. of Early Blue), 438

Bluc Holland (syn. of Ilolland), 462

Bluc Imperatrice (syn. of Imperatrice),

Bluc Imperatrice (syn. of Red Magnum Bonum), 325

Bluc Impiratrice (syn. of Semiana),

$54:$

Bluc Imperial (syn, of Bradshaw), 166

Blise Magnum Bonum (syn. of Gueii) 234

Blue Matchless, 405

Blue Moldavka, 405

Bluemont, 405

Blue Perdrigon (syn. of Imperatrice) 249

Blue Perdrigon, 164

Blue Perdrigon (syn, of Blue Perdrigon), I64

Blue Perdrigon (syn. of Early Tours), 202

Blue Plum, 406

Blue Prolific, 406

Blue Prolific (syn. of Blue Prolific), 406

Blue Primordian, 406

Blue Prune, 406

Blue Rock, 406

Blue Tweens, 406

Blue Violet, 406

Blum, 406

Bocksdutten or Bockshoden (syns. of

Red Magnum Bonum), 325

Boddaert, 165

Borldaert's Green Gage or Reine Claude; Boddart's Green Gage (syns. of Boddaert), 165

Bobemian Prunc, 406

Bohns Mirabcllc or Gestrciftc Mirabelle (syns. of Mirabelle De Bohn), 496

Bolc (syn. of Bowle), 407

Bolmar; Bolmer; Bolmar's or Bolmer's or Bolmore's W'ashington (syns. of Washington), 368

Bomberger, 406

Bon dewr fois lan (syn. of Twice Bearing), 556

Bongoume, 407

Bonne Bouche, 407

Bonne de Bry, 407 
Bonnemain de la Digue, 407

Bonne Rouge, 407

Bonne St. Ann (syn. of St. Annc), 537

Bonnet d'Eveque, 407

Bonnet d'Exeque (syn, of Bonnet d'Eveque), 407

Bonne Verte (syn. of Reine Claude), 327

Bonum Magnum (syn, of Red Magnum Bonum), 325

Bontm Magnum (syn. of Ycllow Egg), 386

Bossland, 407

Botan (syn. of Abundance), 136

Botan (syn, of Berckmans), 159

Botan (syn. of Red June), 324

Botan (syn, of Willard), 379

Botan No. 26 (syn. of Willard), 379

Botan White (syn. of Berckmans), 159

Botonkin (syn, of Kelsey), 258

Botankio (syn. of Abundance), ${ }_{13} 6$

Bottle Plum (syn. of Red Prune), 529

Boulouf (syn. of Jodoigne), 472

Bouloff (syn. of Boulouf), 407

Boulouf, 407

Bouncer, 407

Bourgeois, M., var. orig. by, 174

Bower, 407

Bower, yar, orig, by, 407

Bozuer's Gage (syn. of Bower), 407

Bowle, 407

Brackett, 408

Bradford Gage, Green Gage or Onec Gage (syns, of Reine Claude), 327

Bradley's King or King of Damsons (syns, of King Damson), 259

Bradshaw, 166

Bradshaw (syn. of Bradshaw), 166

Bradshavo (syn. of Gueii), 234

Bradshaze (syn. of Nectarine), 29

Braliy, 408

Brahy's Grocn Gage (syn, of Brahy), 408

Brainerd, 408

Brainerd's Best (syn. of Brainerd), 408

Brandon Ruby, 408

Brandy Gace, 408

Brant of Naples, 408

Brauman, 408

Braunauer Aprikosenartige; Brawnouer Aprikosenartige Domosccuc or Ncuc Kerinfrucht (syns, of Abricotée de Braunau), 391

Braunauer Damascenenartige Pflaume, 408

Braunouer Königs Pfaume or Violetter Perdrigan (syns. of Buchner Königs pflaume), 410

Breck, 408

Breck, Joseph, var, orig, by, 454

Breece, J. S., var. oris, by, $4 \mathrm{~T} 4,42 \mathrm{t}$, $425,458,496,498,511,512,535,539$, $5+1,544$

Breitgedrückte Kaiser Zwetsche or Zuctsche (syn. of Quetsche Aplatie), 523

Bremen Prunc (syn. of Austrian Quetsche), 397

Brevoort, IIenry, var. orig. by, 408

Brevoort Purple, 408

Brezioart's Purple, Purple Bolmar or Buchner Königspflaume, 4 Io

Purple Washington; Brevorts; Bro- Buckman, Benjamin, var. orig. by, 476

vort's Purfle; Brovorts Purple Bol. Budd, 4 to of Brevoort Purple), 408

Briancon, 409

409

Brignole (syn. of Orleans), 302

Brignolc or Brignolle (syns, of Whitc

Perdrigon), 375

Brignole Jaune (syn. of Brignole), 409

Brignolc Plin (syn. of Brignole), 409

Brignole Violette, 409

Brignolc Violcttc (syn. of Blue Perdri gon), 164

Brignole Violctte (syn. of Orleans) 302

Brill, 409

Brisctte (syn, of Late Mirabelle, 263: of Saint Catherine, 334 )

Bristol, 409

Briton Secdling, 409

Brittlewood, 409

Brittlcwood No, I (syn. of Brittlewood), 409

Brittleutood No. 2 (syn. of U. S.), 557

Brittlewood No, 3, 410

Britzer Egg, 4 to

Brock, 4 to

Brodie, R., var. orig. by, 4to

Brodie, 410

Brompton, 410

Brooklyn, 410

Brown, var. orig. by, 46

Brown, John, var. orig. by, 445

Brown-rot, discussion of, I 27

Brown's Crimson Drop (syn, of Crim. son Drop), 424.

Bruce, A. L., life of, 527-528; var. orig. by, $402,423,425,434,447,455$, $490,509,519,526,527,554,560$

Bruce, Philip Alexander, quoted, 84, 85

Brugnole (syn. of Brignole Violette), 409

Brugnole (syn. of Orleans), 302

Brugnon de Neerveteren (syn. of Rademakers), 525

Brugnon Gage (syn. of Reine Claude), 327

Brugnon Green Goge (syn. of Reine Claude), 327

Brünner Zwetsche, $4^{10}$

Brunswick, 4 io

Brussels, 4 to 327

Bryanston, I 68

Bryanston Gage: Bryanstone; Bryan. stone Gage; Bryanston's Gage (syns. of Bryanston), 168

\section{Buchanan, 410}

mar; Brcvorts' Purplc Bolmar (syns. Budd, Prof. J. L., life of, 145; quoted,

Bricet (syn. of Late Mirabelle), 263 Buel, Judge, var. orig. by, 256

Bricet (syn. of Saint Catherine), 334 Buel's Favorite; Buel's Liebling's

Bricctta or Bricettc (syns, of Late Zwctsche (syns. of Buel), 4 II

\begin{tabular}{l|l} 
Mirabelle), 263 & Juffalo Bill, 4 iI
\end{tabular}

Bricettc (syn, of Saint Catherine), 334 13ull]-Eltershofen, 4 1.

Brignole, 409
Brignole (syn, of Brignole Violette),

Burchardt Gelbe Früb Zwetsche, 412

Bruyn Gage (syn, of Reine Claude), $\begin{aligned} & \text { Burford, } 4^{12} \\ & \text { Burgnon Gage (syn. of Reine Claude), }\end{aligned}$

Bryan, 410
Buhl-Eltershofon Zwotsche (syn, of Bubl-Eltershofen), 4 is

Buhler's Early Prune (syn, of Bubler), 411

lah No. 4,411

Bulgaria, $41 \mathrm{r}$

Dulgarian, 4 i I

Bullace (syn. of White Bullace), 373

Bullace (syn, of Damson), 186

Bullace group, 40

Bullesse (syn, of Black Bullace), 16 s

Bullman, 411

Bullock, Jesse, var, orig. by, 173

Bullock, 4I

Bullock's Ileart (syn. of Bullock), 411

Bull Plum, 4it

Bunker Hill, 411

Bunte Früh Pflaume, 411

Bunte Hersformige Pflaume (syn. of Red Diaper), 323

Bunter Perdrigon, 412

Euntfarbige Violitte Pfianne (syn. of

Violet Diaper), 365

Buon-Boccone (syn. of Catelano

Giallo), 415

Burbank, 169

Burbank First, 412

Burbank, Luther, life of, 170-171; quoted, $76,77,95,96,146,147,333$, 571 ; var. orig. by, $141,142,146,147$, $154,170,171,179,222,225,237,257$, $275,285,296,297,333,337,343$, $354,377,393,402,416,420,421$, $430,446,447,450,452,461,465$, $467,471,473,480,483,485.49 \mathrm{r}$, $504,518,521,539,543,547,548$, $559,560,571$

Burbank's First (syn. of Tithank First), 412

Burbank ${ }_{136}$

Burbenk No. 3 (syn, of Late Blood), 480

Burbank No. 4 (syn. of Heikes), 460

Burbank No. 7, 412

Burbank No. 11, 4 I 2

Burbank X Redick, 412

Burbank's Sultan (syn. of Occident), 295

327

Burgunder Zwetsche (syn. of Burgundy Prune), 412

Burgundy Prune, 412

Burgundy Prune (syn. of Burgundy Prunc), 412

Burlington Gage, 413

Burnet, 4 t 3

Burrettes (syn. of Purettes), 412

Bursoto, 4 I3 
Burwood (syn. of Emerald), 442 Bury Seedling (syn. of Golden Drop) 228

Bush; Bush Plum of Kent (syns, of Kent), 476

Byefield, 413

Caddo Chief, 413

Caldwell Golden Drop, 413

Caldwell's Golden Drop (syn. of Cald well Golden Drop), $4^{13}$

Caldwell's White Gage (syn. of Cald. well White Gage), 413

Caldwell White Gage, 4 I 3

Calcdonian (syn. of Dove Bank, 435; of Goliath, 231; of Nectarine, 231; of Peach, 309)

California (syn, of Agen), 138

California, 413

California Seedling; Cal. Seedling (syns, of California), 413

Calvels Pfirschenpfiatme (syn. of Peach), 309

Cambell, $4^{14}$

Combell's Scedling (syn. of Cambell), $4 t^{t}$

Camp, Charles B., var. orig. hy, 478

Camphell, 414

Canada Blue, $4 \pi 4$

Canada Egg (syn. of Canada Orleans), 414

Canada Orleans, $4^{14}$

Canadian Apricot, 414

Canas'a (syn. of Kanawha), 474

Candelaria, $\$ 14$

Candelaria Prune (syn. af Candelaria), 414

Cant's Late Grees Gage (syn. of Reine Claude), 327

Caper, 4t4

Capitaine Kirchhof, 4 I4

Copitaine Kirckhof or Kirckkof (syns. of Capitaine Kirchhof), 414

Captain, 414

Capt. Bacon, 415

Capt. Watrous, 4IS

Caradeuc (syn, of De Caradeuc), 188

Caro, 4is

Caroline, 415

Carpenter, 4:5

Carriere, quoted, 336

Carson, 4 T5

Carstesen, H. P., var. orig. by, 4:5

Carstesen, 415

Cartier, Jacques, quoted, 70

Carver, 415

Costelane; Castellan (syns. of Early (iellow), 203

Catalana Prapria, 415

Cotalano-Susina (syn. of Catalano), $4^{\text {15 }}$

Catalana Toscana (syn. of Catalana Propria), 415

Catolane; Catalonia; Catalonian; Catalonische Kricke or Pflaume; Catalonischer Spilling (syns. of Early Yellow), 203

Catalano, 415

Catelana Morella (syn, of Catelano Violaceo), 416

Cotelane (syn. of Catalano), 415

Catelane Giallo, 415

Catelano Violaceo, 416
Catharinenpflawme (syn. of Saint Catb-|Chinook, 4 t8

erine), $334 \quad$ Cbippewa, 418

Catharinenpflaume von Schenectady Chippeway (syn. of Chippewa), 418

(syn. of Schenectady), 54a

Catherine, 416

Choptank, 418

Christian, 418

Catherine (Prune de Ste.) (syn, of Christie, 418

Saint Catherine), $334 \quad$ Christ's Damascene (syn. of Musk

Catherine violette (syn. of Saint Mar-- Damson), sor

(in), 336

Cavel's Pfirschenpfiaume (syn. of Nectarine), 298

Cel, 416

Centennial, 416

Centralia, 416

Cerasus nigra, 69

Cerasus umbellata, 78

Cerasus pubescens, 92

Cerise; Cerisette; Cerisette Blanche;

Cerizette (syns, of Myrobalan), 290

Cerisctte Blanche (syn. of Geibe Kirschpflaume, 45a; of Early Yellow, 203)

Cernay Perdrigon (syn, of Perdrigon of Cernay), 514

Cernay Perdrigan (syn. of Cerney Perdrigon), 416

Cerney Perdrigon, 416

Ceur de Beuf, 416

Chabardin, M., var, orig. by, 456

Chabot (syn. of Chabot), 172

Chahot, 172

Chabot Blood, 426

Chalco, 174

Chambourey, 174

Champion, 175

Champion, 416

Champion Prune (syn. of Champion) 175

Chancellor Gage, 416

Chapin, Aaron, var. orig. by, 416

Chapin, 416

Chapin's Early (syn. of Howell), 465

Chapman, var. orig. by, 367

Chapman's Prince of Wales; Chapman's Prince of Wales' Plum (syns. of Wales), 366

Chariot, 4I7

Charity Clark, 417

Charles Downing (syn. of Downing), 193

Chorlotte (syn. of Cbarlotte) 417

Charlotte, 417

Charmer, 417

Chase (syn. of Abundance), 236

Chautauqua, 4I 7

Chauviere, M., var. orig. by, 417

Chauviere, 417

Cheney, 176

Cheresato, $4^{17}$

Cherakee, 4 I 7

Cherry, 417

Cherry (syn. of Cheney, 176; of Myrobalan, 290; of Queen Mather, 522)

Cherry Plum (syn. of Myrobalan), 290

Chester, 417

Chester County Prune, 418

Chestnut, 418

Cheston; Cheston Motchless; Cheston's

Plumb (syns. of Violet Diaper), 365

Chicasaw Chicf (syn. of Miner), $28 \mathrm{r}$

Chickasaw (syn. of Scioto), 541

Chicrigland, 418

Chili (syn. of Pond), 314
Churchill, 4 t9

Chypre, 418

Cinnamon, 419

Cire (syn, of Wax), 562

Cirisclle (syn. of Myrabalan), 290

Cistena, 419

City, 419

Cloirac Mammoth (syn, of Imperial Epineuse), 250

Clara, 419

Clarendon, 419

Clark, Thomas, var. orig. by, 522

Clark, 419

Claudia (syn. of Reine Claude), 327

Cleavinger, 419

Cleveland, 419

Clifford, Mrs., var. orig. by, 420

Clifford, 419

Climate, effects of, 1ar-109

Climax, 178

Climax's Brotlier, 420

Clingstone Wolf (syn, of Wolf Clingstane), 567

Cling Stem, I79

Clinton, 420

Cloth of Gold; Cloth of Gold Plwm (syn. of Drap d'Or), 194

Cloth of Gold; Cloth of Gold Esperen (syn. of Esperen), 206

Cluck, 420

Cluck, Gearge, var. orig. by, 420

Cluster (syn. of Crittenden), 184

Cluster, $42 a$

Cluster Damson (syn. of Crittenden), 18.4

Clyman, 180

Clyman, Mrs. Hannah, var. orig. hy, 184

Cochet, 420

Cochet Pére; Cacbets Pflaume (syns. of Cachet), 420

Coe (syn. of Golden Drop), 228

Coe, Jervaise, var, orig. by, 229.

Coe d Fruit Violet (syn. of Coe Violet), 420

Cae Golden Drop (syn. of Golden Drap), 228

Coe (Pr. de); Coe's; Coe's Golden Drop; Coe's Golden Drop Plum; Coe's Imperial: Coc's Plum; Coe's Rotgefleckte Pflaume; Coe's Rothge. fleckte Pflaumc; Coc's Scedling (syns. of Golden Drap), 228

Cae's Fine Late Red (syn. of Saint Martin), 336

Coc's Golden Drop Violette (syn. of Coe Violet), 420

Coe's Latc Red (syn. of Saint Martin Quetsche), $53^{8}$

Coe's Late Red (syn. of Saint Martin), 336

Cö̈s sehr spätc rothe Pflaume (syn. of Saint Martin), 336

Coc Violette; Cae's Violet; Coc's Via lette (syns, of Coe Violet), 420

Cae Violet, 420

Coeur de Boeuf, 420 
Couter Prenon (syn. of Queen Cooper's Large Red (syn. of Cooper, Motlici, 522

(ioferer, 421

(ofercrs (syn. of Coferer), 421

linage, 421

Col. Wetherell (syn. of Wetherell), 563

Col, Young's Scedling (syn. of Jiellow Egg), 380

Coletta, 421

Coleus, $42 \mathrm{I}$

Collman (syn, of Colman), 421

Collo-Torto (syn. of Basaricatta), 399

Colman, 421

Colonel Brvan (syn. of Bryan), 410

Colonel or Col. Wilder (syns. of (Vilder), 565

Colorado (syn. of Colorado Queen), 421

Colorado Queen, 42 I

Columbia, $18 \mathrm{I}$

Columbia (syn. of Captain), 414

Columbia Gate; Colusio Pfonme; Columbian Gage (syns. of Columbia), 181

Columella, quoted, 28, 36

Combination, 421

Comfort, 421

Common Blte Danson (syn, of Winter Damson), 567

Common Damson (syn. of Damson, I86; of Winter Damson, 567)

Common Orleans (syn. of Orleans), 302

Common Quctsche (syn. of German Prune), 219

Common Saint Julien (syn, of Saint Julien), 335

Common Sloc (syn. of Sloe), 544

Communia, 421

Cotupass, 422

Corupass, 182

Compass Cherry (syn. of Compass), 182

Compass Cherry (syn. of Compass), 422

Compote d'Automne (syn. of Autumn Compote), 253

Comptine, 422

Comte Gustave d'Egger, 422

Consul, 422

Cope, John, var. orig, by, 423

Cooch, 422

Cooch, var. orig. by, 422

Cook, 422

Cook (syn. of Cook Choice), 422

Cook Choice, 422

Cook's Choice; Cook's Faz'orite (syns. of Conk Choice), 422

Cook's Early (syn, of Cook), 422

Cooper, 422

Cooper, Joseph, var, orig. by, 423

Cooper's (syn. of Smith Orleans), 348

Cooper's (syn, of Cooper), 423

Cooper's Blue Gage (syn, of Early Blue), 438

Cooper's Grosse Pflaume (syn. of Cooper), 423

Cooper's Grosse Rothe Zuctsche (syn. of Cooper), 423

Cooper's Large (syn. of Cooper, 423; of Golden Drop, 228; of Smith Or. leans, $3.4 \mathrm{~S}$ )

Cooper's Large Americans (syn. of Cooper), 4:3
423; of Sinith Orleanis $3+8)$

voper's Lurge Red Amcrican (syn. of (ooper), $\$ 23$

Coopers Plum (syn, of Cooper), 423

croper's Plum (syn. of Cooper), 423 Cooper's Red (syn, of Cooper, 423; of Smith Orlcans, 348)

Cope, $4 \cdot 3$

Coupe's Secdling (syn. of Cope), 423 Copper (syn. of Copper, 183 ; of Rich. land, 532)

Conper, 183

Copper Plum (syn. of Red Magnum Tionutm), 325

Cornell, J. R., quoted, 244

Cornemuse, 423

Corse, Henry, var, orig. by, 391, 432, 445. 453, 455, 507, 532, 540, 557. 563

Corse's Admiral (syn. of Admiral).

39

Corse's Dictator (syn, of Dictator). 432

Corse's Ficld Morshel. Corce's Field Culberson. 405

Marshall (syns. of Field Marshall). Cumberland. $4^{25}$

445 Curlew, 423

Corse's Great Bearer (syn. of Great Curry, 425

Bearer), 455

Corse's Nota Bena or Nota Bene (syn. of Nota Bene), 507

Corse's Rising Sun (syn, of Rising Sun), 532

Corse's Souvogeon (syn. of Sauvageon), 539

Corse's Tatins (syn, of Twins), 557

Corymbus, 423

Cottrell, 423

Cottrell, R. T., var. orig. by, 423

Couctch; Conetche; Couctsche (syns. of German Prune), 219

Couctsche d'Itolic: Conctsche Follenberg (syns. of Italian Prune), 253

Conetsche Ordinaire (syn. of German

Prune), 219

Conetsche Prícoce; Conctsche Précoce Lo Vroie (syns. of Wabre Frübzwetsche), 560

Couler, $4 \geq 3$

Couler, William, var. orig. by, 423

Coulommiers, 423

Conlommiers Pflaume (syn. of Coulommiers), 423

Coulon Reine Claude, 423

Curry, S. L., var, orig. by, 425

(yea Mono, 425

Cyclone, 425

Cydemarine, 425

Cyprian (syn. of Chypre), 418

Cyprische Pfloume (syn. of Red Diaper), 323

Czar, 184

D'Abricot of Strcets of Paris (syn. of Peach), 309

D'Agen (syn. of Agen), 138

D'Agen Ameliorée (syn. of Ameliorée), 394

D'Agen Dorée (syn. of Dorée), 434

Dahlgreen, 425

Daisy, 425

Dakota, 425

D'Allemogne (syn. of German Prune), 219

Dalrymple, 426

Dalrymple Damson (syn. of Dalrymple). 426

D'Altcsse Blanohe (syn. of Yellow Impératrice), 569

Damas Ambre, 426

Coulon's Reine Claude (syn. of Coulon Damas Aubcrt (syn. of Yellow Egg), Reine Claude), 423

Coul Orleans, 423

Count Althann's Gage (syn. of Altham), I4I

Court Royal, 424

Cover-crops, value of, 121

Corctche (syn, of German Prune), 219 Coretsche (syn, of German Prune), 219 Cowles, E. D., var. orig. by, 516

Cowperthwait Green Gage, 424

Cox, Mrs., var. orig. by, 424

Cox, 424

Coxc, William, quoted, 25

Cox's Emperor (syn. of Denhigh), 430 Cox's Seedling (syn. of Cox) $4_{424}$

Crable, 424

Craig, 424

Crcscent, 424
386

Damos-Ballon Joune (syn, of Ballonartige Gelbe Zwetsche), 398

Damas-Ballon Rouge (syn, of Ballon-

Damos.Bollon Panochéc Varicte (syn.

of Ballonartige Gelbe Zwetsche), 398

Damas Blone, Blane Gros. Blane Hötif Gros, Blone Tres Hàtif (syns. of Large White Damson), 4 So

Damas blanc petit (syn. of Small White Damson), $5+4$

Damas Commun (syn, of Damson), 186

Domos ac Dieffenbach (syn. of Damas de Diffenbach), 426

Damas de Diffenbach, 426

Leipziger Damascene), 448 artige Rote Damascene), 398

Damas de Leipsick (syn. of Frübe 
Damas de Mangeron; Damas de Man-11)amas Rouge Ilitif, 427 (syn. of Damat Winter Damson, 567)

or de Maugiron, Damescene Mau- Rouge Ilatif), +27 Danson, 185

geron, von Mangeron or von Mau- Damas rouge tardif (syn. of Late Red Damson Cluster (syn. of Crittenden), geron (syns, of Mlaugeron), 492

Damas de Provence, $\$ 26$

Damas de Protence or de Provence Hatif (syns, of Damas de Provence). 426 Damask) 48 ,

Damas Tardif de Kock (syn, of Köch Juamson group, deseription of, 3n-40 Späte Damasccne). $477 \quad$ Damson Plum (syn. of Shropshire), Damas Verd or Vert (syns, of Reine 344

Claude), $327 \quad$ Jamson Riley, 427

Damas de Septembre (syn. of Per- Damos Vert (syn. of Mirabelle), 284 drigon Tardif, 515; of September Damas Violet, 427 Damask, 542)

Damas d'Espagne (syn. of Spanish Damask), 546

Damas d'Ete, $4=6$

Damos de Tours (syn. of Royal Tours), 332

Damas de Tours (syn. of Early Tours), 202

Damas Violet (syn. of Damas Violet, 427; of German Prune, 219; of Mau.

427: of German Prune, 219; of Mau. Tana, Rev., var. orig, by, $4=8$ Gollow Goge Quecn Mother, 522)

Damas Violit Allonge (syn. of Lange Violette Damascene), $4 \pi 9$

Domos de Tours or de Tours Gros (syns. of Gros Damas de Tours), 456

Damas de Valence (syn. of Valence), 557 Damos Violet Gros (syn. of German Prune), 219

Damson Royal, 427

Damson Winter (syn, of Winter Damson), 567 (syns. of Dana Yellow (iage), 428

Dana Yellow Gage, 427

Danicl, Dr., var, orig. by, 428

Danicl Weeping, 428

Danish Damson, 428

Domos Viotet Longuet (syn, of Lange Durk Blue Eigg (syn. of Kaiser WilViolette Damascene), 479 helm), 474

Damas Violet of Tours (syn, of Gros Darst, 428

Damas de Tours), 456 Darst, var, orig, by, 428

Damas d'Iliver (syn. of Winter Damson), 567

Domos d'Itolie (syn. of Italian Damask), 470

Damas d'Onderlia (syn, of Onderka Damascene), 509

Damas Dronet, 426

Domas Dronet (syn. of Damas Dronet), 426

Damas Dronet de Merlet, 427

Damas Fin (syn. of Musk Damson) 50

Damas Gris (syn. of Reine Clande),

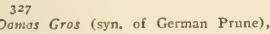
219

Damas gros de Tours (syn. of Gros Damas de Tours), 456

Damas Hảtif (syn. of Morocco), 288

Dames Jaune (syn. of Drap d'Or), 194

Damas Jaune Musque, 427

Domos Josrne Tardif de Koch (syn. of Köch späte Damascene), 477

Damas Lazison (syn. of Lawson), 482

Damas Long (syn. of German Prune), 219

Damas Musque (syn. of Musk Damson), 501

Damas Noir (syn. of Morocco), 288

Damos noir (syn. of Late Black Damson), 480

Damas Noir (syn. of Damson), 186

Domas Noir de Dieffenbach (syn, of Damas de Diffenbach), 426

Damas Noir de Tours, $4 \geq 7$

Damos Noir Hàtif (syn. of Noire de Montreuil), 504

Damas Noir Hatif (syn. of Morocco), 288

Damos Noir Tardif (syn. of Late Black Damson), 480

Damos Pricoce de Rivers (syn. of Rivers Early), 532

Damas Rouge (syn. of Orleans), 302

Damas Rouge de Biondeck, $4=7$

Damos Rouge de Friedheim (syn. of Friedheim Damascene), 448

Damas Violet Tardif (syn. of Damas Violet), 427

Damascena Armeniaca or Amenioce (syns. of Mirabellc), 284

Domascena Dominicalis Praceor (syn) of Early Orleans), 198

Damascena Scliamali (syn. of Scliamal), 540

Domoscene (syn. of Damson), 186

Damascene (syn. of Sbrophire), 344

Domoscenc Mangeron, von Mangeron or von Maugerau (syns. of Maugeron), 492

Darwin Peach (syn, of Yellow Egg), 386

Dos Blotte Auge (syn, of Lange Violette Damaseene), 479

D'Ast (syn. of Agen), 138

Date, 428

Date (syn. of Agen), 138

Date de Hangrie: Dote Plum; Datte de Hongric or Hungrie; Dotte Violctte; Dottelewetsche (syns. of Hungarian). 246

Date Plum (syn. of Date), 428

Datilles, 428

Datte Hongroise Jaune, 428

Damascenen Mirabelle (syn. of Small Datte Jouse (syn. of Weisse Kaiserin), White Damson), 544

Damaschina d'Estate (syn, of Damaschino Estivo), 426

Damaschino Estivo, 426

Damaschino Settembrino, 426

Damaseus (syn. of Damson), 186

Damosine (syn. of Myrobalan), 290

Damosine (syn. of Rote Mirabelle), 533

Damosk (syn. of German Prune), 219

Damask Violet (syn. of Queen

Mother), 522

Damosk of Provence (syn. of Damas de Provence), 426

Damasquitićc (syn. of Musk Damson). 501

Damatic Rouge, 427

Dame Ambert, Ambert Blanche or Anbert Jasne, Aubert, Aubert Blanche, Aubert Grosse Lsisante, or Aubert Jaune (syns, of Yellow Egg), 386

Dame Aubert, Aubert Rouge or Aubert Vielette (syns, of Red Magnum Bonum), 325

Dasne Aubert Jaune (syn. of Aubert). 397 Alsbert Rougc (syn, of Red

Dome Alubert Rouge (syn. of Red
Diaper), 323 Danc-Aubert Rorgc (syn. of Blue

Egg), 405
Dame Aubcrt Violct (syn, of Duane), $\$ 96$

Damas Rouge de Mayer or de Moyer (syns, of Mayers Rotlie Damascenc), 493

D'Amerique Rouge (syn. of Myro. balan), 290 563

Dottel Pfanme or Zwetscle (syns. of

Red Date), 322

Dattelpflaumen; Dattelaxelsche (syns. of Date), 428

Datte Verte (syn. of Grüne Dattcl Zwetsclie), 456

Dotte Violette (syn, of Agen), ${ }_{13} 8$

Dauphin (syn. of Victoria), 363

Douplin (syn. of Sharp), 340

Douplin a Flesurs doubles; Dasphin d Fleters scmi-doubles (syns. of Double Flowering Gage), 192

Dauphine, 428

Douphinc; Douphiny (syns, of Reine Claude), 327

D'Automne de Schantial (sy'n. of Schamal), 540

D'Autriche (syn. of IIungarian), 246

D'Autriche (syn. of Date), 428

Davenjort, 429

Davics Seedling, 420

Daviest Scedling (syn. of Davies Seedling), 429

Davis, 429

D'Avoine (syn. of Early Yellow), 203 Dawson, 186, $4=9$

Dawson, P. P., var, oris, by, 187

Dawson City, 429

Darson Secdling (syn. of Dawson), 186

Dc Baray (syn. of Bavay), 155

De Bcsonçon (syn. of Yellow Egg), 386

De Bordeanx (syn. of Jerusalem), 472 
De Briançon (syn. of Briançon), 409 Denbigh-Pfaumc; Denbigh Secdling; Die Abrikosenartige Pflaume (syn. of De Briancon (syn. of Red Diaper), 323

De Brignole (syn. of Agen), ${ }_{13} 8$

DcCaisne, 187

Decaisnes Plasme (syn. of DeCaisne), 187

De Caradeuc, 188

De Caradeuc, A. var. orig. by, 188

Dc Catalogue (syn. of Early Yellow),

203

Dc Chypre (syn. of Chypre, 418; of Red Diaper, 323; of Mlusk Damson, 50 :)

De Coc (syn. of Golden Drop), 228

De Délice, 429

De Deur. Saison (syn. of Twice Bear. ing), 556

Dc Gisborme (syn. of Gisborne), 451

De Gondin, 430

De Jerusalem (syn. of Terusalem), 472

De Kirke (syn. of Kirke), 260

De la Toussaint, 430

De la Saint-Martin (syn. of Saint Martin), 336

Delaware, 430

De l'inde, 430

(syn. of Normand Perdrigon), 505

284 Der Bunter Perdrigon (syn. of Bunter

De Mitchelson (syn, of Mitchelson), 498 Perdrigon), 412

De Monsicur (syn. of Yellow Egg, 386; Derbyshire Green Gage, 431

Farly Tours, 202; Orleans, 302; Deron, 43T

Early Orleans, 108) Deron's (syn. of Deron), 43a

De Monsicur Hatize (syn. of Early Des Bćjonnières (syn. of Béjonnières),
Orlcans), 198

De Monsicur Jaunc (syn. of Yellow Des Burctes (syn. of Purettes), 412 Inpératrice), 569

Dc Montfort, 430

De Montmirail, 430
De Polognc (syn. of Quetsche Dr. Dent fois l'an (syn. of Twice BearLétricourt), 524

De Pontbriant (syn. of Pontbriant), 517

De Prince (syn. of Norbert), 505

De Prince (en Lorrainc) (syn. of De Seigneur), $43 \mathrm{I}$

De Reizcinstcil (svn. of Reizenstein Yellow Prune), $53 \mathrm{I}$

Dc Sainte-Catherine (syn. of Saint (atherine), 334

De Seigneur, 431

De Soto, 189

De Sota $X$ Oregon No. 3 (syn. of Ames), 144

De Virginic (syn. of Myrobalan), 29o

De Wargenheim (syn, of Wangenheim), 368

De Wolf, M. J., var, orig, by, 498

Dean, 429

Deanc, Samuel, D. D., quoted, 21, 38

Dean's Jedburgh Seedling (syn. of Dean), 429

Deaton, 429

Deck, 429

Decks Damson (syn. of Deck), 429

Decker, 4:9

Decker, H. C., var. orig. by, 429

Deeker's Late Seedling (syn, of Decker), 429

Decker's Secding (syn, of Decker), 429 Deep Creek, 429

Deepcreck (syn. of Deep Creek), 429

Defresne, 430

Denbigh, 430

Des Moines, 431

Apricot), 148

Die Albertus Damenpflaume (syn. of Y(llow Egg), 386

Die Aprikosenplaume (syn. of Red Apricot), 321

Dic Bischofsmütze (syn. of Bonnet d'Eveque), 407

Dic Blauc Dattclpfaume (syn. of Agen), ${ }_{13} 8$

Die Blutfarbege Pfoume (syn. of Red 1)inger), 323

Dic Brisctfe (syn. of Late Mlirabclle), 263

Die Brustwarsenffaume (syn. of Mamcionnćc), 489

Dic Damascenerpflaume von Maugeron (syn, of Maugeron), 492

Die Damaskpflaume aus Spanien (syn.

of Spanish Damask), 546

Die Durchsichtige (syn. of Transparente), 555

Die frühe Pflaume von Tours (syn. of Early Tours), 20z

Dic Gartcnzactsche (syn. of Quetsche Maraichère), 524

Dic gelbe frühacitige Pfaumc (syn. of Early Yellow), zo3

Die grosse indianische braunrothe Pflaume (syn. of Indian), $46 \mathrm{~S}$

Die grosse Königin Claudiapflaume, die grüne Abrikose (syn, of Reine Claude), 327

Die grosse Königin Klaudia Pflaume mit halbgefullter Bluthe (syn. of Double Flowering Gage), 192

Die grosse rothe Feigenpflaume (syn. of Red Date), 322

Die grosse Weisse Glanzende (syn. of Yellow Egg), 386

ing), 556

Diademe; Diadcne Imperial or Im- of Grüne Herzformige), 456 periale (syns. of Red Diaper), 323 Dic Hauszuctsche (syn. of German Diademe Imperial-Isabelle, $432 \quad$ Prune), 219

Diamant; Diamantpflaume (syns. of Die Iterrnpflaume (syn. of Orleans), Diamond), 191

Diamant; Diamantpflaume (syns, of Die Hyacinthenpflaume (syn, of JaPond), 314

Diamond, 191,432

Diamond, var, orig. by, 191

Diana, 432

Diaper; Diaper Rouge; Diapre Ronge, Diaprea rubra; Diapric de Rochc Corbon; Diaprée Rouge (syns. of Red Diaper), 323

Diaper'd Phumb (syn. of Diaprée Blanche) 432

Diaphane (syn. of Transparent), 360

Diaphane Laffay (syn. of Transparent),

360

Diapre Blanc (syn. of White Diaper), 564

Diapréc Blanche; Diaprée Weisse (syns. of Diaprée Blanche), 432

Diapréc Blanche (syn. of White Dia-

per, 564; of White Perdrigon, 375)

Diaprée Blanche, 432

Diaprée noire: Diapre Violet; Diapréc Violette (syns. of Violet Diaper). 365

Diapree Nouvelle De Kook, 432

Dictator, 432

cinthe), 47

Die Isabelle (syn. of Isabella), 469

Die Kaiserliche veilchenfarbige Pflaume (syn. of Red Magnum Bonum), 325

Die Kaiserliche Weisse Pflaume (syn. of Yellow Egg), 386

Die kleine Königin Clandia (syn, of Small Reine Clande), 347

Die kleine langlichte Damaskuspflaume (syn. of Damas Dronet), 426

Die kleine Zwergpflaume (syn. of Zwergptlaume), 571

Die Kleine Wcisse Damascenerpflaume (syn. of Small White Damson), 544

Dic Königin (syn. of Mlayer Konigsptlaume), 493

Die Königin Klaudia (syn. of Reine Claude), 327

Die Königliche grosse Pflaume (syn. of Royal), 534

Die königliche Pflaume von Tours (syn. of Royal Tours), 332

Die lange, grüne und grosses welsche Pflaume? (syn. of Quetsche Verte D'Italie), 525 
Die Morillenpflaume (syn. of Apricot), Dochnahl's Künigs Pfoume (syn. of Dougall Best, 435

148 Dochnahl Damascene), 433

Die musquuat Damaskuspflaume (syn. of

Mfusk Damson), sor
Die Pflaume aus Cypern (syn. of Yellow Egg), 386 Yellow Figg), 386

Die Pflaume ohne Stein (syn. of Stone. less), 353

Die Rothe Eierflaume (syn. of Red

Diaper), 323 Dollaner, 433

D'Ocuf Violctte (syn, of Red Magnum Bonum), 325

Dojene, 433

Dic Rothe Eierfloume (syn, of Red Dollaner Zwetsche (syn. of Dollaner),

Mfagnum Bonum), 325

Die Rothe Kaiserpflaume (syn. of Red Magnum Bonum), 325

Dolphin (syn. of Sharp, 340; of Victoria, 363)

Die rothe Rebluhnpflaume (syn. of Red Domina, 433 Perdrigon), 528

Domina, 433
Domine Dull, 433

Die Sconardo (syn. of Scanarda), 540 Domine Dull's; Domine Dull's Plum

Die späte oder September Damaskpflaume (syn. of September Damask), 542

Die Volienciennes (syn. of Valienciennes), 558

Die veilchenfarbige Birnpflaume (syn. of Pear Plum), 513

Die veilchenfarbige Damascenerpflatme (syn. of Damas V'iolet), 427

Die Veischenfarbige Kaiserinnpflaume (syn, of Imperatrice), 249

(syns, of Domine Dull), 433

Domino (syn. of Domina), 433

Don, 433

Don Alteza, 433

Donoucrs Zusommen Gedrückte Zwct. Drake's Seedling (syn. of Drake Seedsche (syn. of Quctsche Aplatie), 523 Don Carlos, 433

Dougall's Best (syn. of Dougall Best), 435

Douglos (syn, of Abundance), 136

Douglas (syn. of Chabot), 172

Douglass, 435

Dove Bank, 435

Dowling, Ilenry, var, orig. by, 395,548 , 567

Downing, A. J., quoted, 519; var. orig.

by, 443

Downing, 193

Downing Early, 435

Downing's Early (syn. of Downing Early), 435

Downton Impératrice, 435

Downton's Kaiserin; Dezentoner Koi scrin (syns. of Downton Impératrice). 435

Drake, George, var, orig, by, 436

Drake Seedling, 436

ling), 436

Drap d'Or (syn. of Drap d'Or), 194

Don Carlos' (syn. of Don Carlos), 433 Drap d'Or (syn. of Reine Claude), 327

Doppelte Mirabelle (syn. of Drap Drap d'Or, 104 d'Or), 194

Dora, 433

Die violete Kaiserpflaume mit scheckich- Dorće, 434 ten Blattern (syn. of Imperial Vio- Doric de Lazuson (syn. of Lawson), let), 467

Dic Violctte Diaprée (syn. of Violet Dorell, 434 Diape:), 365

Dorell, 434
Dorell, Dr., var. orig. by, 434,520

Dic Yiolette Keiserpfoume (syn. of Dorell Aprikosenpflaume, 434

Violet Imperial), $559 \quad$ Dorill's Neue Aprikosen Pfoume (syn.

Die Violette Königin Claudia (syn. of Purple Gage), 318

Die Violette Königin Cloudic (syn. of Purple Gage), 318

Die Violette oder Blane Rencelode (syn. of Purple Gage), 318

Dic Violette oder Blauc Renoclode (syn. of Purple Gage), 318

Die wälsche Damascene pflaume (syn. of Italian Damask), 470

Dic Wongenheim (syn. of Wangenheim), 368 of Dorell Aprikosenpflaume), 434 Dorelle's Neue Grosse Zwetsche or New Purple Prune; Dorells grosse neue Zwetsehe, or Grossc Zwetsche, or Neue Grosse Zwetsche; Dorell's Neue Purpur Zwetsche; Dorrel (syns. of Dorell), 434

Dörell's Grosse Ungarische Pflaume (syn. of Large Sugar Prune), 480

Dorcll's Neue Weisse Dioprée (syn. of

Wahre Weisse Diaprée), 561

Doris, 434

Die Weisse Buntfarbige Pflaume (syn. Dorr, 434

of Diaprée Blanche) 432

Dorr, Elisha, var. orig. by, $46 t, 464$

Die weisse Duranzen pflaume (syn. of 562

White Perdrigon), 375

Dorr Seedling, 434

Drop d'Or d'Esperen; Esperen, of Es.

peren, or of Esperin (syns. of Es. peren), 206

Drop d'Or Pfoume (syn. of Drap d'Or),

194

Dr. Dennis (syn. of Dennis), 43 i

Dronet Damask (syn. of Damas Dronet), 426

Drouth King, 436

Dr. Uff, 436

Dr. Uff Szilvaja, 436

Dry, var. orig, by, 436

Dry Seedling, 436

Dry's Seedling (syn. of Dry Seedling), 436

Dschau Erik (syn. of Diel Grosse

Weisse Damascene), 432

Duane, 196

Duane, James, var. orig. by, 197

Duane's French Purple, Large Orleans. Large Purple, or Purple French (syns. of Duane), 196

Duone's Purple (syn. of Duane, 196: of Peach, 309; of Smith Orleans, 348 )

Die Weisse Kaiserinnpflaume; Dic Dorr's Favorite (syn. of Dorr, 434; of IVcisse Kaiserpfoume (syns. of Pond, 314)

White Imperatrice), 375

Dic Zückersiisse (syn. of Trauttenberg), Dosch, 435 555

Dosch, Henry E., var, orig. by, 435

Dieffenbachs Damascene; Dicffenbachs Double, 435

Schwarze Domascene (syn. of Damas Double Blockpruim (syn. of Italian de Diffenbach), 426 Prune), 253

Diel Grosse Weisse Damascene, 432

Dicl's August Zuetsche (syn. of Wahre Frühzwetsche), 560

Diels Königpfoume or Dicl's Königs: pflaume (syns, of Royal Tours), 332

Differbochs Domascene (syn, of Damas de Diffenbach), 426

Dine, 433

D'Itolic (syn. of Italian Prune), 253

Dittisham, 433

Dixic, 433

Dobrostitzer Frülazwetsche (syn, of Quetsche de Dobrowitz), 523

Docbnahl Damascene, 433

Double-blossomed; Double-blossomed Plum (syns. of Double Flowering Gage), 192

Double Beurre Wittef (syn. of White Virginai), 565

Double Drop d'Or (syn. of Drap d'Or), 194

Double Flowering Gage, 192

Double Imperial Gage (syn, of Washington), 368

Double Mirobelle (syn. of Drap d'Or),

Duboise, var. orig, by, 216

Dre d'Edinbourg (syn. of Duke of Edinburgh), 436

Duc de Watcrloo (syn, of Waterloo Pflaume), $56 \mathrm{r}$

Duke, 436

Duke of Devonshire, 436

Dull, var, orig, by, 433

Dumberline, 436

Dumiron, 437

Dummer, 436

Dummer, var. orig. by, 437

Dunkelblowe Eierpfoume (syn. of

Kaiser Wilbelm), 474

Dunkelblaue Kaiserin, 437

Dunlap, 437

Dunlap, J. P., var. orig. by, 437

19.4

Double Plum, 435

Dougall, James, var. orig. by, 435

Duniap (syn. of Dunlap No. 1), 437

Dunlap (No. 1) (syn. of Dunlap No.

1), 437

Dunlap No. I, 437 


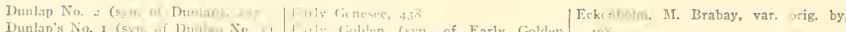
194 437

1. Giklen (4yn. of Early Golden $10 \sin 2,438$ Farly Golden Drop, 438 $40 \mathrm{~S}$ Ecully, $44 \mathrm{I}$ Eddic, $44^{\mathrm{I}}$

Dunlap's No. 2 (syn. if Dunlap), A:- Early Grcen (5\%n of Emerald), 442 Durslop. W. W., var, oxig. by, 499, 5 vo Eariy Gireen (iage? (syn. of July Junloy Nut, 437 Early Gireen (iage? (syn. of July
Green Giage), 474 Farly 11 oncy, 439

runtop 53 (syn of Rayuss), 526 Larly John (syn. of Early Yellow), zo3 lunlop 5. (syn. of Mount Royal), 500 Dummarc, 437

/'аните (syn. of Dunmore), 437

J)!yuts, August, var, orig, by, 394

1)urand, var. orig. by, 187

Durazen Zwetsche, 437

Durchscheinesde Reinclande (syn, of Transparent), 360

Durchsichtige (syn. of Transparente), 555

Durham, Miss, var. orig. by, 287

D) Roi (syn, of Agen), 138 Farly Large Black (syn, of Nuire de Montrevil), 504

Farly Minnesota, 439

Fiarly Mirabulle, 439

Early .Monsicur (syn. of Early Orleans), 198

Farly Morocca (syn. of Morocco), 288

Early Nurmandy, 439

Earlv Orlcans (syn. of Early Orleans). i 98

Farly Orleans, 198

Du Roi (syn, of Early Orleans), 198 Farly Pale, 439

Dutch Plum or Plumb (syns, of Jellow Early Pear, 439

Egg), 386 Farly Perdrigon, 439

Dutch Pranc (syn. of Domine Duth, Early Prolific (syn. of Early Rivers), 433; of German Prunc, 210)

Dutch Quetszcn (syn. of Domine Dull), 433

Dymond (syn, of Diamond), 191 200

arly Purple (syn. of IIowell), 465 Farly Red, 439, 440

Early Red Primordian (syn. of Red Primordian), 528

Eagle, 437

Earley's Noscmber (syn. of D Black

Bullace), I $6 \mathrm{x}$

Earlicst of AII (syn. of Earliest of Al1), 108

Earliest of All, 198

Early, 437

Eariy Amber, 437

Early Apricot (syn. of Early Transparent (iage), 440

Farly Apricot, 437

Early Apricot Plum (syn. of Early $\Lambda$ pricot), 437

Early Baźay (syn. of Tuly Green (aage), 474

Early Black Domask (syn. of Morocco), 288

Early Black Morocco (syn. of Mo* rocco), 288

Early Blue, 438

Early Blue (syn. of Early Blue), 438

Early Bradshaw (syn. of Gerishes Seedling, 451; of Field, 208)

Early Cherry, 438

Early Cluster, 438

Early Cross, 438
Early Damask (syn, of Morocco), $288 \quad$ Early Whitc Plum (syn, of Early Ycl.

Early Damasli of Prosence (syn. of low), 203

Damas de Provence), $426 \quad$ Farly Yellow, 203

Early Damson (syn. of Damson, 286; Early Ycllow (syn. of Early Yellow), of Horse, 464; of Morocco, 288; of 203

Winter Damson, 567) Tarly Yellow Gage, 440

Early Damson (syn. of Morocco), 288 Early Yellow Prune, 440

Early dc Tours (syn. of Early Tours), Eason, 441 203

Early Favorite, 438

Eberly, 44I

Eberly's Plum (syn. of Eberly), 44 r

Early Fanoritc, or Farourite (syns, of Ebert, Madame, var. orig. by, 430

Early Favorite), 438

Ebon, 441

Edith, $44 \mathrm{I}$

Edith of Terry (syn. of Julia), 473

Elle Early, 4+t

Edle Frühpflaume (syn. of Edle Early), $44 \mathrm{I}$

Edle Gelbe Fogr Pfaumc; Edle Gelbc Eicr Pflaume (syns, of Yellow Egg), 386

Edlc Königs Pfoume (syn. of Valienciennes), 558

Edouard Seneclanze, $44^{1}$

Eggles, 441

Egg Plum (syn. of Yellow Egg), 386 Egner'sche Eicr Zuctsche (syn. of Comte Gustave d'Egger), 422

Eict Pflamme (syn. of Blue Egg, 405; of Yellow Egg, 386)

Eldora, $44^{\mathrm{I}}$

Eldorado, 441

Eldridge, 442

Elfreth's Prunc (syn. of Elfrey), 442

Elfrey, 442

Elfrey's Prune; Elfry's Plum (syns, of Elfrey), 443

Elisabeth Pflaume, 442

Elisobcth d'Elsnor (syn. of Elisabeth Pflaume), $44^{2}$

Ella, 442

Elliott, quoted, $25^{6}$

Ellis, 442

Ellwood, 442

Elmore, 442

El Paso (syn. of Beaty), 400

Elsner Grüne Zwetsche, 442

Elsucr's Elisabcth Pfoumc (syn. of

Elisabeth Pflaume), 442

Elsncr's Von Gronow Griinc Zwetsche (syn. of Elsner Grüne Zwetsche), 442

Elton, 442

Elwood (syn. of Ellwood), 442

Emerald, 442

Emerald Drop, 443

Emerson, 443

Emorson's Early (syn. of Emerson), 443

Emerson Yellow, 443

Emigrant, 443

Emily May, 443

Emma, 443

Empereur, 443

Emporcur de Mas (syn. of Empereur). 443

Empercur de Sharp (syn. of Sharp), 340

Empercur du Japan (syn. of Emperor of Japan), 443

Emperor (syn. of Denbigh, 430; of Goliath, 23I)

Emperor of Japan, 443

Emparor of Japan (syn. of Emperor of Japan), 443

Empire, 203

Early Forcing (syn. of Red Magnum Eslite Gelbe Eicr Pfaume (syn. of licl. 13ontum), 325 low Egg), 386

Early Fruchtbare (syn, of Early Riv Echte Grosse Reinc-Claude (syn. of (crs), 200

Reine Claude), 327

pire,

Empress (syn. of Imperatrice), 249

gre, 206

Engle, 443

Early Gincsect

(syns. of Haferpflaume), 458

Englehert, 204

Englobert (syn. of Englebert), 204 
Englische Zwetsche (syn. of Large|Fellenberg; Fellenberg Quetsclie; Fcl-| Frasu: Early Yullow (syn. of Fraser), English), 262

English Orleans (syn. of Orleans), 302

English Pond's Seedling (syn, of Pond), 314 lenberger Zactsche; Fellenburg; Folt-
cmberg (syns. of Italian Prune), 253 Fratendorfer Frible Zuetsehe (syn. of

English Pond's Secdling (syn, of Fcrtheringham (syn. of Belgian Purple), Duane), 196

Englisli Wheat (syn. of Wheat), 563 Fertile Bleue (syn, of Blue Prolific), 406

English Yellow Gage (syn. of Small Fertile Pricoce (syn. of Early Rivers), Reine (laude), 347

Eukclde Backspruim; Enkelde Black. pruim (syns. of German Prune), 219

Epinc noire (syn. of Sloc), 544

Erby Scptember (syn. of Irby), 468

Esjum Erik, 443

Esperen, 206

Esperen's Goldpflaume (syn. of Es. peren), 206

Esperin, Major, var. orig. by, I56, 207

Essex Bullace, 4.44

Esslinger Frühzwetsche, 444

Esther, 444

Etendard d' Angleterre (syn. of Standard), 548

Etopa, 444

Etta, 44.4

Eugen Fürst: Eugene Fürst (syns. of Fürst Damson), $44^{8}$

Eugen Fiirsts Frühawctsche (syn. of Furst), 217

Eureka, 444

Eurcko (syn. of Wickson), 376

Europcan Cherry Plum (syn. of Myrohalan), 290

Eva, 444

Evelyn, 444

Excelsior, 207

Excelsior Damson, 44

Exoascus, diseases caused by, 127,128

Fairchild, 444

Fairchild, J. A., var. orig. by, 546

Foir's Golden or Golden Drop (syn. of Golden Drop), 228

Forleigls Prolific (syn. of Crittenden), 184

Fancy, 445

Fanning, 445

Farleigh (syn. of Crittenden), 184

Farleigh Castle (syn. of Pond), $3 i 4$

Farleigh Damson (syn. of Crittenden), 184

Fousse Altesse (syn. of Italian Prune) 253

Fovorite de Buel (syn. of Buel), $4: 1$

Fan'orite de Lowrence (syn. of Lawsence), 266

Fovorite d'Howord (syn. of Howard)

Favorite Hâtive, Précoce, Précoce de Risers (syns. of Early Favorite)

$43^{8}$
Favorite Pourpre (syn. of Purple Favorite), 521

Fawn, 445

Feine Damoscene (syn. of Musk Damson), 501

Feine Und Gute (syn. of Fine Rontè), 445

Fell, quoted, 387

Fellemberg (syn. of German Prune, 219; of Italian Prune, 253) Fennons, Frank, var. orig. by, 445 Femmonzi, 445

Quetsehe Précoce De Frauendorf). 524

Frecman, 212, 447

Freeman, var. orig. by, 212

Frceman's Favorite (syn. of Frecman),

447

Free Silzer (syn. of Terry), 552

Fircestone, 213,447, 448.

Freestone Damson (syn. of Freestone). 213

Freestone Goose, 448

Ficld Marshall, 445

Figue Grosse Rouge, 445

Figue Grose Rouge (syn. of Red Date), 322

Figue Grosse Rouge (syn. of Red Date), 322

Fin de Siecle, 445

Fine Bonté, 445

Fine Early Plum, 445

Firha Königsplaume, 4.45

Firbas Frübe Schuttenhoferin, 446

First, $44^{6}$

First Best, 446

First Sweet, 446

Fisher, J. E., var. orig. by, 365

Fitze, Charles G., var. orig. by, 274

Fitzhugh, William, quoted, 85

Fitzroy. 446

Flora Plena, 446

Florence (syn. of Red Magnum

Bonum), 325

Flotows Allcrfriiliestc Mirabelle (syn. of Mirabelle de Flotow), 497

Fluke, N. K., var, orig, by, $394,429,477$

Flushing Bulleis, 446

Flushing Gage (syn. of Imperial Gage), 25

Foderingham; Foderingham Plum (syns, of Fotheringham), 212

Foliage Plum (syn. of Vesuvius), 559 Fondantc Noire (syn, of Frühe Leip ziger Damascene), 448

Fonthill (syn. of Pond), 3is

Foote, 446

Foote, Asahel, var. orig. by, 440,446 Foote's Early Orleans (syn, of Foote), 446

Foote Golden Gage, 446

Forest Garden, 209

Forest Rose, 210

Forest Rose Improved, 447

Forewattamie, 447

Formosa, 447

Forward Damask, 447

Fotheringay (syn. of Fotberingham), 212

Fotheringham, 212

Fourth of July (syn. of Lovett), $4^{86}$

Fourth of luly (syn. of Marble), 490 Francfort Pcachi: Frankfurter Pfirschen Zwetsche (syns. of Frankfort Peach), 447

Frankfort Peach, 447

Frankfurter Pflaunte (syn. of Rudolph) 536

Frankland, Thomas, var. orig. by, 396

Franklin, 447

Franklin (syn. of Washington), 368

Fraser, 447

Fraser, John, var, oris. by, 447
Freestone Quetsche, $44^{8}$

French, 214

Freuch (syn. of $\Lambda \mathrm{gen}$ ), ${ }_{13} 8$

French Apricot (syn. of Apricot), 148

French Copper (syn. of Copper), 183

Erench Damson (syn. of French), 214

French Orleans (syn. of Orleans), 302

French Prunc (syn. of Agen), 138

French Royal (syn, of Royal), 534

French St. Julien (syn. of Saint Julien), 335

Freudenberger Friih Pflatme (syn. of

Friars (syn. of Violet Diaper), 365

Friar's Plum (syn. of Violet Diaper), 365

Eriedheim Damascene, $44^{8}$ (syn. of Friedheim Damascene), 448

Fritze IIernpflaume, 448

Frogmore, 215

Frogmore Damson: Frogmore Prolific Damson (syns, of Frogmore), 215

Froment American (syn. of American (Vheat), 395

Frost Gage, 216

Frost Plum (syn. of Frost Gage, 216:

of White Damson, 374)

Frostproof, 448

Friilie Aprikosenpfanme (syn, of Early Apricot, 437

Frülie Dattelzwetsche (syn. of Hunga. rian), $24^{6}$

Frühe Englische Zwetsche, 448

Frïhe Fruchtbare (syn. of Early Rivers), 200

Friilic Gelbs Kaiser Pfoume (syn. of Apricot), 148

Frïhe Golbe Kaiser Pflaume (syn. of Frühe Gelbe Reine (laude), $44^{8}$

Frube Gelbe Reine Claude, 448

Friile Gelbe Reine Claude (syn. of Transparente), 555

Friilie Gemeine Zwetsche (syn, of Wahre Frühzwetsche), 560

Frïhe Grosse Schicarze Pflanme (syn. of Noire de Montreuil), 504

Frühe Grüne Zwetsche, 448

Frühe Hous Zwetsche (syn. of Wahre Frühzwetsche), 560

Fribite Herrupfaume (syn. of Early Orleans), 198

Friihe Herrn Pfoume (syn. of Royal Tours), 332

Frühe Herrnpflaume (syn. of Early

Frithe Herruphounte (syn. of Early Orleans), 198 Précoce de Freudenherg), 517

Fricdlacim's Rote Friils Damasecne Orleans), 198 
Friihe Herzogspflaume (syn. of Early Orleans), 198

Frihle Königspfaume (syn. of Royale Ilätive de Liegel), 535

Frühe Königspfaume ion Nikita (syn. of Early Royal of Nikita), 440

Frühe Leipziger Damascene, $44^{8}$

Frïhe Nikitaer Königsplaume (syn. of

Early Royal of Nikita), 440

Frithe Platte Damescenc (syn. of Moroc $(0), 288$

Frithe Reine-Clande (syn. of July

Green Gare), 474

Früher Perdrigon; Früher Violetter Perdrigon (syns. of Early Perdrigon), 439

Frihc Schwarze Pfaumc (syn. of Noire de Montreuil), 504

Frühe Schwarze Pflaume (syn. of Mornceo), 288

Frïhe Trcibrwetsche; Frühe Treib Zuctsche (syns, of Red Magnum Bonum), 325

Frülie von Bergthold (syn. of Early Nirabelle), 439

Frithe Weissc Aprikoscnpfaume (syn. of Diel Grosse Weisse Damascene), 432

Frïhe Zuetsche (syn. of Walire Frïh$z$ wetsche), 560

Friih Zuctsche (syn. of Red Date), 323 Frïhacetsche mit Silberblott (syn. of Quetsche à ieuille argentce), 523

Frühwetscite zon Buhlerthal (syn. of Ouetsche Précoce de Buhlerthal), 52.4

Fuiler, 448

Fuller's Egg (syn. of Fuller), 448

Fulton, 448

Funk, 448

Funk, I. M, var, orig, by, 448

Funk's Early (syn. of Funk), $44^{8}$

Furst, 217

Fürst Damson, 448

Fiirstenzeller Pfantme; Fïrstenzeller Reine-Claude (syns, of Red Apricot), 321

Fürsten Zwetsche; Fürstenzwctsche (syns, of Imperatrice), 249

Fürst's Damson (syn. of Fürst Damson), $4: 8$

Fürst's Frühzwetsche (syn. of Furst), 217

Furugiva (syn, of Chabot), 172

Gabriel Comhes, 449

Gagc Verte (syn, of Reine Claude), 327

Galbraith, 449

Galbraith, var. orig. by, 449

Gale, 449

Galena, 449

Gale Secdling (syn. of Gale), 449

Gale's No. 3 (syn. of Gale), 449

Gallesio, quoted, 28

Galopin, 449

Galopin, M., var. orig, by, 564

Garden King, 449

Garficld, 449

Garlick, 450

Garlick's Early (syn. of Garlick), 450 Gornet (syn. of Occident), 295

Garnet, 450

Garriel, var. orig. by, $35^{t}$
Garten Pfaumc or Zwetsche (syns. of German Quetsche (syn. of German Quetsche Maraichère), 524

Gates, 450

Gaunt, 450

Gaviota, 450

Gaylord, 450

Gaylord, Edson, var. orig. by, 395, 453

Gaylord Gold, 450

Geibe Apricosenartige Pfaume; Gelbe Aprikosenpflaurne: Gelbe Douphins (syns. of Apricot), 148

Gelbe Catharinenffiaume (syn. of Saint Catherine), 334

Gille Danascener Pflaume, 450

Gelbe Eger Pfaume; Gclbe Egg; Gelbe Eierpfasme (syns, of Yellow Egg). 386

Golbe frïhe Pfounte; Golbe Friihzcilige (syns, of Early Yellow), 203

Gclbe Fribusetsche (syn. of Quetsche Jaune Précoce), 524

Gelbe IIerm Pflaume (syn. of Yellow Impératrice), 569

Gelbe Jerusalempflaume, 450

Gelbe Katharinenpflatume (syn. of Saint Catherine), 334

Gelbe Kirsclipflaume, 450

Golbe Malonke (syn. of Yellow Egg), 386

Gclbe Marunkc (syn. of Weisse Kaiserin, 563; of Yellow Egg, 386)

Gclbc Mirabelle (syn. of Mirabelle), 284

Gclber Bidling (syn. of Gemeiner Gelbe Spilling), 45

Golbe Reinc-Claude (syn. of Apricot), 148

Gelbe Rencclode Mit Gefullter Bluthe (syn. of Double Flowering Gage), 19

Gelbe Spatawetsche, $45 \mathrm{I}$

Gelbe Ungarische Eier Pfaume: Gclbe Ungarische Ejerpflanme (syns. of Yellow Egg), 386

Gem, $45 x$

Gencine Hanswctsche (syn. of German Prune), 219

Gemeiner Gelbe Spilling, 451

Gencine Zuctsche (syn. of German Prune), 219

General Brock (syn. of Brock), 4:0

Gen. Iland; General Hond; Genl. Hand (syns. of Hand), 239

General Jackson (syn. of Miner), 281 Gentleman, 451

Georgeson, 217

Georgeson, C. C., quoted, 55

Gcorg IV (syn. of Rigny), 532

Georgia, $45^{\mathrm{I}}$

Geperlte Mirabelle (syn. of Mirabelle), $-8$

Gerard, quoted, 162

Gerishes Seedling, $45 \mathrm{I}$

Gorman Gage (syn. of Blecker), 163

German Plum (syn. of German Prune), 219

Geruar Prune, 219

German Pranc (syn. of Domine Dull. 433; of German Prune, 219; of Italian Prune, 253)

German Prune Secdling (syn. of Mankato), 489
Prune), 219

Gersepflaume, 45 !

Geuii (syn. of Gueii), 234

Ghiston, 451

Gbiston's Early (syn. of Ghiston), 451 Giant, 222

Giant Prone (syn. of Giant), 222

Gibb, Charles, var. orig. by, 395,483

Gibson, 45r

Gibson, W. L., var. orig. by, 454

Gideon, Peter M., var, orig. by, 470

Gifford, var. introduced by, 261

Gifford's Lafayette (syn. of Lafayette), 261

Gill, 451

Gillett (syn. of Miner), $28 \mathrm{I}$

Gisborne, 45 I

Gisborne's; Gisbornc's Early; Gisborne's Zuetsche (syns, of Gisborne), 451

Glaister, 452

Drap d'Or), 194

Glass, 223

Glass, Alexander, var. orig. by, 224

Glass Scedling (syn. of Glass), 223

Glawzende gelbe Mirabelle (syn. of

Drap d'Or), 194

Gloire de Louveciennes, 452

Gloire dc New York (syn. of Hulings),

245

Gloire de Schöncberg (syn. of Belle de Schöneberg), 401

Gloire d'Epinay, 452

Gloria, 452

Gloucestershire Violet, 45

Glow, 452

Glwhende Kohle (syn. of Red Diaper),

323

G. No. 4,452

G. No. 44 Jones (unpublished) (syn. of G. No. 4), 452

Goff, 452

Goff, Emmett Stull, life of, $355-356$

Gold, 452

Gold (syn. of Golden), 224

Gold Coin, 453

Gold Colored, 453

Golden, 224

Golden (syn. of Gold), 452

Golden Beauty, 226

Golden Cherry, 228

Golden Cherry Plum (syn. of Golden

(herry), 228

Golden Cluster, 453

Golden Drop, 228

Golder Drop; Golden Drop Plum; Golden Gage (syns. of Golden Drop), 228

Golden Esperen (syn. of Esperen), 20 o

Golden Esperen Plum (syn. of Esperen), 206

Golden Gage, 453

Golden Gagc Lawson (syn. of Lawson), 482

Golden Gem, 453

Golden Prolific, 453

Golden Prune, 453

Golden Queen, 453

Golden Transparent, 453

Gold Pfanmc; Goldfarbige Pfaume

(syns, of Drap d'Or), 194
Glanzende Gelbe Mirabclle (syn. of

Golden (syn. of Golden Prune), 453 
Goldsmith, 454

Goldsmith's V'ienna (syn. of Goldsmith), 454

Goldstoff (syn, of Drap d'Or), 194

Goldzeno (syn. of Drap d'Or), 194

Goliath (syn. of Goliath, 231; of Nectarine, 291)

Goliath, 23 I

Gondin, 454

Gonne, 454

Gonne, Dr., var. orig. by, 454

Gonne's Green Gage (syn. of Small

Reine Clautde), 347

Gonne's Rothe Pflaume (syn. of Gonne), 454

Gonzales (syn, of Gonzales), 232

Gonzales, 232

Goose-Dye, 454

Goose- O, 454

Goose Plum, 59

Gordon, 454

Gordon, J. K., var. orig. by, 410,564

Gordon Castle, 454

Gordon $\mathrm{No}_{3} 3$ (syn. of Gordon), 454

Goring's Golden Gage (syn. of Reine (laude), 327

Gorman, 454

Gorric, Archibald, var. orig. by, 482

Gough, quoted, 164

Goutte d'Or, 228; Gowtte d'Or de Coc, 229 (syns. of Golden Drop)

Goutte d'Or Violette (syn. of Coe Vio-

let), 420

Goutte Emeraude (syn. of Emerald

Drop), 443

Govalle, 454

Grace, 454

Grace, W. R., var. orig. by, 454

Graf Althann's Resile-Clowde; Grof Althan's Reinc-Cleude (syns, of Altham), 141

Graf Gustav von Egger (syn. of Comte Gustave d'Egger), 422

Grond-Duc (syn. of Grand Duke), 233

Grand Duke, 233

Grand Précoee, 454

Graugrūne Frïhpflaume, 455

Gray, quoted, 99

Gray Damask, 455

Grayson, 455

Great Bearer, 455

Greol Domosk Violet of Tours (syn. of Gros Damas de Tours), 456

Great Date (syn. of Date), 428

Great Green Domosk; Great Green Domaski (syns. of Reine Claude), 327

Great Imperial Plum (syn. of Red Magnum Bonum) 325

Great Mogul (syn. of Yellow Egg) 386

Great Plum of Tours; Great Violet Damask de Tours; Great Violet Tours Damask (syns. of Gros Damas de Tours), 456

Great Queen Cloudio (syn. of Reine Claude), 327

Greot Whitton (syn. of Wheat), 563

Greeley (syn. of Greely), 455

Greely, 455

Greely, Captain Eliphalet, var. orig. by, 455

Green Damask (syn, of Mtirabelle), 284
Greene, quoted, 77

Greenfield, 455

Greenfield, var. orig. by, 455

Green Gage (syn. of Reine Claude), 327

Green Gage (syn. of Reine Claude Group), 27

Green Indian, 455

Green Italian, 455

Green Oysterly, 455

Green Perdrigon, 455

Green Pescod, 455

Green Spanish (syn. of Reine Claude). 327

Gregoire, M., var, orig. by, 412

Grelck, John, var, orig, by, 455

Grelck, 455

Gridley, var. orig. by, 553

Griesa, A. It., var, orig, by, 512

Grimwood Eorly Orlcons; Grimwood's Early Orlcans (syns, of Early Orleans), 198

Groot, S. C., var. introduced by, 320 Gros Damas: Gros Damos de Tours; Gros Damos Violet de Tours (syns, of Gros Damas de Tours), 456

Gros Damas Blone (syn. of Large White Damson), 480 Gros Damas de Tours (syn. of Farly

Tours), 202

Gros Damas de Tours, 456

Gros Damas Noir, 456

Gros Domas ronge tordif (syn. of Late

Red Damask), $48 \mathrm{z}$

Gros Damos Vert (syn. of Reine Claude), 327

Gros Luisonte (syn, of Yellow $\mathrm{Egg}$ ), 386

Gros Prunc (syn. of Pond), 3+4

Gros Reine-Claude (syn. of Reine Claude), 327

Gros Rouge de Septenibre (syn. of Belle), 158

Gros Saint-Julien (syn. of Saint Julien), 335

Gros-Damos Blonc (syn. of Diel Grosse

Weisse Damaseene), 432

Grosse a sécher de Kuight (syn. of

Large Green Drying), 479

Grosse 3lawe Eicr Pfoumc isyn. of Blue Egg), 405

Grosse Blase Zactsche Von der IVorm. (syn. of Zwetsche Von der Worms) 572

Grosse Damoscene vou Tours (syn. of Gros Damas de Tours), 456

Grosse Datte (syn. of Yellow Egg), 386

Grosse De Cooper (syn, of Cooper), 423

Grosse Englische Pfoumen Zustsche: Grosse Englische Zwetsche (syns, of Large English), 262

Grosse Früh Pfoume (syn. of Noire de Montreuil), 504

Grossc Friih Zuctsche (syn. of II un garian, 246; of Italian Prune, 253; of Red Mlagnum Bonum, 325)

Grossc Gelbe Dottcl Pfoumc; Grosse Gelbe Dattel Zwetsche (syns. of Weisse Kaiserin), 563

Grossc Golbc Eicr Pfoume (syn. of Yellow Egg), 386
Grosse German Prune (syn, of Ger-

man Prune), 219

Grosse Glanzende; Grosse Glanzende Alberts Pfoume: Grossc Glan=ende Pfiaume (syns, of Vellow Egg), 386 Grosse Grǜc Pfanme (syn. of IsleVierte), 470

Grossc Grīnc Reinc-Cloude (syn. of Reine (laucle), 327

Grosse llative de Rodt, 456

Grosse IIative de Rodt (syn. of Rodt Frühe Grosse Pflaumenzwetsehe), 533

Grosse Hauspfuume (syn. of German Prune), 210

Grosse Künigin Claudiapflaume (syn. of Reine (laude), $3=7$

Grossc-Luisante (syn. of Yellow Egg), 386

Grosse Marange, 456

Grossc Mforanke; Grosse Marouk; Grosse Marunke (syns. of Yellow Eeg), 386

Grosse Mirobille (syn. of Drap d'Or),

Grossc Mirobelle Drop d'Or (syn. of Drap d'Or), 194

Grosse noir de Montreatl: Grosse Noire hative (syns, of Noire de Montrenil), 504

Grossc Prune Blanche (syn. of Yellow E.gg), 386

Grosse Prune d'Agen (syn. of Pond), 314

Grosse prune d'Inde rougc (syn. of Indian), 468

Grosse Prunelle Nouvelle (syn. of New Large Bullace), so3

Grosse Quetsche De Dorell: Grosse Quetsche Nonvelle (syns. of Dorell), 434

Grosse Reinc; Grosse Rcine-Cloude (syns, of Reine Claude), 327

Grosse Reine-Claude Verte $\mathrm{De} \mathrm{Bi}_{\text {, }}$ lepsch (syn. of Berlepsch), 402

Grosse Rosspauke, 456

Grosse Rote Feigen Pfaume (syn of Red Date), 322

Crosse rouge de Cooper (syil of (ooper), 423

Grosse Schwarze Kaiser Pfaumio (syn. of Bradshaw), 166

Grosse Surpasse, 456

Grosse u. Lange Fräh Zuctsche (syn. of Hungarian), 2.46 Grossc Ungarische Zwetsclic (syn. of Red Magnum Bonum), 325

Grosse Violette de Grugliasco, 456

Grosse Weisse Glanzende (syn. of Yellow Egg), 386

Grosse Zuckerzwetsche (syn. of Large Sugar Prune), 480

Grosse Zwetsche (syn. of Jarge English), 262

Grosslierzog's Pflaume (syn. of Grand Duke), 233

Groundocre (syn. of Gundaker Prune), 457

Crose Honse Purple (s3n. of Fotlicr. ingham), 212

Grïnc Abrikose or Aprikose (Ev) of Reine (laude), 327

Grüne Dattelzwetsche (syn. of Grüne

Dattel Zwetsche), 456 
Grine Dattel Zwetsclir. 456

Grïnc Eicrpfoumc (4yn. of Qutacbe Verte D'Italie), 525

firüne llerzformige, 456

Girine Insclpfloume (syn. of Isle-lerte) $\$ 70$

Grïnc Inscl Pflawme (syn, of Grüne

Dittel Zwctsche), 456

Grïnc Mirabcllc (syn. of Mirabelle Vertc), 497

(iriur Reincclaude (syn. of Reine

(laude), 327

Griine Zeectschc (syn. of Duetsche

Verte D'Italie)

Girune Zwetsche Von Monrepos, 456

Griinliche Dattel Pfanme z'on Besonson (syn. of Yellow Egg), 386

Fucii, 234

Guait: Guii (syns, of Gueii), 234

Guilford No. 2, 456

Guimaracn, 457

Giuinca Egg, 457

Gundaker, 457

Gunclaker, Samucl E., var. orig. by, 457

liundaker Prune, 457

Cus Erik (syn, of Nikitaer Blaue Frübzwetsche), 504

Gutc Grüne (syn. of Reine Claude), 327

Gutc Kathe (syn. of Saint Catherine), 334

Gutheries Taybank (syn. of Tayluank), 551

Guthrie, Charles, var. orig. by, 236 , $397,457,551$

Guthrie Apricot, 457

Guthrie Green (syn. of Gutbrie Late) 236

Githrie Late, 236

Guthrie Russet, 457

Githrie Topaz, 457

Gutluric's Apricot: Guthrie's Apricot Plum; Guthric's Goldcu; Guthrie's New Apricat (syns. of Guthrie Apricot), 457

Guthric's Aunt Ann (syn. of Aunt Ann), 307

Guthric's Late Grean; Guthrie's Minette (syns. of Guthrie Late), 236

Guthric's Russct (syn. of Guthric Russet), 457

Guthric's Topoz (syn. of Gutbrie Topaz), 45z

Gwalsh, 457

Gucii (syn. of Gueii), 234

Haag, 458

Haber Pflatuc (syn. of Damson), 186

Hackl, Prof. Pater, var. orig. by, 217

Ilackl Grosse Zwetsche, 458

Inaferpfaume, 458

Hafer Schlche (syn, of Damson), 186

Hafcrkicche (syn, of Damas Rouge Hitif), 427

Ilafiner Herbstpflaume, 458

IIaffner Königspflaume, 458

Ilagaman, var, orig. by, 235

Hahnenhode (syn. of Nikitaer Habnenpflaume), 504

IItikuyt, quoted, 164

Haku Botan, 458

Inale, 236

Halc (syn. of Late Blood), 480
IIallenbeck, 458

IIallenbeck, IIenry, var. orig. by, 458 IIalcyon, $45^{8}$ IIammer, 238

IIammond, quoted, 75

Ilampton Court (syn, of Early Orleans) to8

Ilancock, Thomas, var, orig, by, 457

IIand, 239

IIand, fiencral, yar, orig, by, 240

IIanford, 458

IIanford's Orlcans (syn. of Ilanford) $45^{8}$

Hankka, $45^{9}$

Hanson, 458

Hanson, N, E., quoted, 116, 117; var. orig. by, $417,419,444,458,468$. $474,489,509,539,544,561,567,571$ Happiness, 458

Hardow, P. L., var. orig, by, 296

Hare, Thomas, var. orig. by, 209

IIarlow, $45^{8}$

Harlow, S. C., var. orig. by, 458

Ilarney, 459

Harper, 459

Ilarper (syn. of Impcrial Gage), 251

Iarper's (syn, of Harper), 459

Harrict, 241, 450

Harris, 459

IIarrison, 459

Harrison's Pcach (syn, of Harrison) 459

Hart, 459

Hart, H., var, orig. by, 459

Hart Prine (syn. of Bradshaw), 166

Hort's DC Soto (syn, of Hart), 459

Hartwick, 459

Hartwiss, 459

Hortwiss Gclbe Zusctsche: Hartwiss Yellow Prune (syns, of Hartwiss), 459 Harvest, 460

Horn'st Gage (syn, of Yellow Gage), 388 Hathen's Red Gage (syn, of Altham).

I ${ }^{\mathrm{I}}$
Hôtite d'Augny (syn. of Grosse Marange), 456 (syn of Early Tours) Hâtive dc Tours (syn. of Early Tours), 202

Hotton; Hattankin No. 2: Hattonkin; Hattonkin No. 2; Hattonkio; Hattankio No. 2; Hattankio Oblong Hytan-Kayo; Hytankio (syns. of Kerr), 259

Hattankin No. I (syn. of Georgeson), 218

Hattonkin (syn, of Georgeson), 218

Hattarlio (syn, of Abnndance), 136

Hattonkin No. I (syn. of Georgeson), 218

Hattantio (syn. of Georgeson), 218

Hattanlio (syn. of Abundance), 136

Hattankio (syn. of Kelsey), 258

Hottankio No. I (syn. of Georgeson). 218

IIattic, 460

Hauptmann Kinchhof's Pfaumo (syл. of Capitaine Kirchhof), 414

Hauspfoume: Houszuctsche (syns. of German Prune), 219

Hawkeye, 242

Hayden, E. I., var. orig. by, 44I

Hayo-Simoni, 460

Hazard, 460
Haztiva, D. C., vas, otig, by, 140

Heaton, 460

II cetor, 460

Ileep, 460

Heideman, C. W. H., var, orig, by, 294, 415

Heideman Sand Cherry (syn. of Com-

pass), 182

Heikes, 460

Heine Superbe, 460

Helen, 460

IIelen's Seedling (syn. of IIteren), 460

Ilendrick, 460

IIendrick's (syn. of IIendrick), 460

Henrictta Gage (syn. of Ilenrictta

Gage), $46 \mathrm{I}$

Henrintta Gage, 46 t

Henry Clay, $46 \mathrm{I}$

IIerbst Kriecke, 46

Herbstpflaume, $46 \pi$

Hcrbstpflaunc (syn. of Prune d'Automne), 520

Herbst Reine Claude (syn. of Autumn Gage), 398

Hereford Damson, 46

Herefordshire Prune, 461

Hernnpflaume (syn. of Orleans), 302

Heron, $46 \mathrm{r}$

Heroy, 461

Herren, $46 \mathrm{I}$

Herrutfaume (syn, of Orleans), 302

Herrenhäuser Blauc Eicr Pfaumc (syn. of I-arge Sugar Prune), 480

Herrnhauser Doppelte Mirabelle (syn. of Mirabelle Double de Herrenhausen), 497

Herzformige Pflaume, $46 \mathrm{r}$

Hersog von Orlcans (syn. of Orleans), 302

Heupflaume, $46 \mathrm{t}$

Herr Pfannc (syn, of Frïhe Grūne Zwetsche), 448

Hiawatba, 461

Hick's large Egg? (syn. of Yellow

Egg), 386

Higginson, Francis, quoted, 20, 93

Highland, $46 \mathrm{r}$

Hishlander, 463

Hilda No. 5,462

Hillside, 462

ITilltop, 462

IIilman, 462

Hinckley, M, E., var. orig. by, 490 , 515

Hincklcy (syn. of Miner), $28:$

Hinkley, $46 z$

IIlubeck Aprikosenpflaume, 462

Hoag's Seedling, 462

Hoffnan, 462

Iloftman, Ernest, var. orig. by, 533

IIofinger Mirabelle, $4^{62}$

Hofinger's Ratc Mirabcllo (syn. of Hofinger Mirabelle), 463

Ilog, 462

Hogg, Jobn A., quoted, 200, 260, 363, 364, 432 ; var. orig. by, 432

Hog Plum, 59

Hohcitspfiarme (syn. of Imperatrice), 249

Holncits Pfaume (syn. of Red Diaper), 323

Holnster (syn. of Hollister), 463

Holister, var. orig. by, 463 
Holland, 462,463

Holland Plum; Holland Prune (syns. of Ilolland), 462

Hollister, 463

Holman, D. S., var. orig. by, $4^{63}$

Holman Prune, 463

Holne, 463

Holmes Early Blue (syn. of IIolme), 463

Holt, B. J., var. orig. by, 463

Holt, 463

Holton, Warren, var. orig. by, 442

Homestead, 463

Honey, $4^{6} 3$

Honcy Drop (syn. of Golden Beauty), 226

Honcy Grotic (syn, of Sanders), 538

Honcy Julian, 463

Honsmono (syn. of Berger, 160; of Satsuma, 337)

Hon-smomo (syn. of Chabot), 172

Hoo Green Gage, 463

Hooker, quoted, 37

Hoosier, 463

Horemoritzer Reine Claude, 463

Horrigan, 463

Ilorse, 464

Horse Gage (syn. of Horse Jag), 464

Horse Jag, 464

Horse Plun, 59

Horse Plm (syn. of Horse), ${ }_{464}$

Hoskins, 464

Hoskins, var, orig, by, 464

Houston County, 46

Hovey, C. M., quoted, 167,229

How. IIall J., var. orig. by, ${ }_{4} 64$

Howard, 464

Howard's Favorite (syn. of Howard). 464

Howe, ${ }_{4} 64$

Howell. 465

Howell's Early (syn. of Ilowelt), 465 Howell's Large (syn. of Nectarine, 292: of Peach, 309)

Howel's (syn. of Nectarine), $29 \mathrm{r}$

How Amber, 464

How's Amber (syn. of How Amber). 464

Hoyo Smomo, 465

Hoyt, R. D., var. orig. by, 446

H. T. S. $84,76 \mathrm{I}, 465$

Huankume, 465

Hudson, 243

Hudson, quoted, 93

Hudson; Hudson Goge; Hudson's gelb Friilspfiaume (syns, of Hudson Gage), 465

IIudson Gage, 465

Hudson River Purple; Hudson River Purple Egg (syns, of Hudson), 2.43 Hughes, 465

Hughes Late (syn. of Tecumseh), 552

Ifulings, 245

Huling's Reine Claude (syn. of Reine (laude), 327

Hulug's Reinc-Claudia (syn. of Reine Claude), 327

Hulirg's Supcrb (syn. of IIulings), 245

llungarian, 245

Hungarian (syn. of Pand), 314

IIungarian (syn. of Ungarish), $36 \mathrm{r}$

IIungarian Date (syn. of Hungarian), 246
II ungarian Musk Prune, 465

IIungarian No. 1, 465

Ifungarian No. 2, 466

Hungarian Plum (syn, of Ilungarian), 246

Hungarian Prune (syn. of IIungarian, 2.46; of Pond, 314; of Ungarish, 361)

IInngarica (syn, of Hungarian), 246

Il ungary (syn. of Ungarish), $36 \mathrm{~s}$

IItunn, 466

II unt, 466

Ilunt, Ilenry, var. orig. by, 466

Il unt, R. A., var. orig. by, 49

Ilunt De Soto, 466

Ilunt's De Soto (syn. of IIunt De Soto), 466

Hyacinth; Hyacinthe Pfarme (syns. of Jacintlie), 47

II ytankayo (syn. of Abundance), 136

Hytenkayo (syn, of Chabot), 172

II. lankayo (syn. of Red June), 324

Hitan-Kayo (syn. of Kerr), 259

Hytankio (5yn, of Kerr), 259

Ickworth, 247

Ickworth Impcralrice (syn. of Iekworth), 247

1 da, 466

Ida Gage; Ida Green Gage (syns. of

Reine (laude), 327

Ida Green Gase, 466

Idol (syn, of Idall), 466

ldall, 466

Idol (syn, of Idall), 466

Icnuta (syn. of Date), 428

Ilewert; Ile Vert; Ile zert: Ille verte;

Illwert (syns, of Isle.Verte), 470

Illinais Ironclad (syn. of Ironclad),

469

Illinois Plwm (syn. of Langsdon), 479 Impératrice, 248

Int'ćrafrice (syn. of Red Diaper), 323 Inpérotrice; Impératrice Blue; Impératrice Violette (syns. of Impératrice), 2.49

Impératrice Blanche (syn. of Wbite Inpératrice), 375

Impératrice group, 33

Impératrice Ickzerth (syn. of Ick. worth), 247

Imperatrice Janne (syn. of Ycllow Im pératrice), 569

Impératrice Jckworth (syn. of Ick worth), 247

Imperatrice Violctte (syn. of German Prune), 219

Impiratrice liolctte Grosse (syn. of German Prune), 219

Imperial (syn. of Red Magnum Bonum). 325

Imperial, 466

Imperia! Blanc; Imperiale Blanche: (sy'ns. of Yellow Egg), 386

Impcrial de Sharp (syn. of Sharp, 340:

of Victoria, 363)

Imperial Diadem; Imperial Diademe (syns. of Red Diaper), 323

imperial Jaune (syn. of Weisse Kaiserin), 563

Imperial Epineusc, 250

Iniperial Epineux (syn. of Imperial

Epineuse), 250
Imperial Gabc, 251

Imperial Goge (syn. of Wasbington), 368

Imperial Gage; Imperial Green Gage

(syns. of Imperial Gage), 25 t

Imperial jatuc (syn. of Yellow $1 \mathrm{~m}$. perial), 569

Imperiall (syn. of Red Magnum Bonum). 325

Imperial Ottoman, 467

Imperial Ottoman (syn. of Imperial Ottoman), 467

Imperial Purple, 467

Imperial Purple (syn. of Imperial Purple), 467

Impcrial Rougc; Imperial Violet (syns.

of Red Magnum Bonum), 325

Imperial Violet, 467

Inperial IVashington, 467

Impiriale (syn. of Red Magnum Bonum), 325

Impiriale Alexandrina, 466

Impériale à Petit Fruit Violet (syn. of Inperial Violet), 467

Impériale Blanclic (syn, of Quetsch, Dr. Létricourt, 524; of Yellow Egg. 386)

Imperiale de Mann (syn. of Brandy Gage), 408

Impériale de Milan, 467

Impćriole Ottomane (syn. of Imperial Ottoman), 467

Imperiale de Sharp (syn. of Sharp), 340

Imperiale de Turquie (syn, of Imperial Ottoman), 467

Impćriale Hâtice (syn. of Red Magnum Bonum), 325

Impériale jaune (syn. of Yellow Imperial), 560

Impériale Ronge; Impériale Violette (syns, of Red Magnum Bonum), 325 Impiriale Violetfe (syn, of Violet $1 \mathrm{~m}$ perial), 559

Impériale Violette à feuilles panachees (syn. of Imperial Violet), 467

Improved French Prune, 467

Incomparable, 467

Incomparable de Iucombe (syn. of Lueombe), 271

Incomparable Prunc (syn. of Incom. parable), 467

Indian, 468

Indian Chicf, 468

Indiana, 468

Indiana Rcd (syn. of Indiana), ${ }_{4} 68$

Infertility, eauses of, in plums, 1 10-112

Inkpa, ${ }_{4} 68$

Insclpfaume Grüne (syn. of Isle.Verte),

470

Iola, 468

Iona, 468

Iowa, 468

lowa Beauty, 468

Irhy, 468

Irby September (syn. of Irby), 468

Ircland, 469

Ireland Golden, 469

Ireland's Golden Gage (syn. of Ireland Golden), 469

Ireland's Scedling (syn. of Ireland),

469

Irene, 469 
Iris, $4^{69} \quad$ Jaune de Catologne (syn. of Early Jumelles de Liegel, 474 Irish Horse Plum (syn, of Horse), $464 \begin{array}{cl}\text { Ycllow), } 203 \\ \text { Ironclad, } 469\end{array}$

Ironclad, 469

Iroquois, 469

Irring's Bolmor or Bolmer (syns, of Jatue de Monsieur (syn. of Yellow

Washington, 368

leanc, 469

Isabel (syn. of Miner), 281

Istabella, 469

Isle Vert: Isle Verte (syns. of Islc- Jaune Hative (syn. of Early Yellow), (ierte), $\$ 70$

I.le-Verte; 460

Islezeorth Grecn Gage (syn. of Reine (laude), 327

Italian Damask, 470

Itation Damosk (syn. of Mlorocco, 288; Jackworth Imperatrice (syn. of 1ckof Orleans, 302)

Itolian Guctsche (syn. of Italian Jenn d'Este (syn. of Jaune d'Este). Prune), 253

Italionische blanc Zuctschc, blane Jan Hâtize (syn. of Early Yellow), Zuetsche, Zwetscle: Italian Prane 203 or Quetsche; Italieniscle Zuctsche

Jean Morceau, $47^{2}$

Kaiser Von Jopan (syn. of Emperor of Japan), 443

Kaiser Wilhelm, 474

Kalm, Peter, quoted, 20

Kampeska, 474

Kanawha, 474

arume précoce (syn. of Early Yellow), Korl Kocli's Königs Pflaume (syn. of Koch Kortigspflaume), 477

Kazan, 474

Kcindl's Violette Königspfaume (syn. of Royale Violette de Keindl), 535 Keindt, 475

Keindt's Frühdamascene (syn, of Keindt), 475

Kcindt's Violette Königspflaume (syn. of Royale Violette de Keindl), 535 Keith, 475

Jcan Morccau (syn. of Stoneless), 353

Italienische Damascene (Diel's), 4\%0 Jean White (syn, of Early Yellow), 203

Italienisehe Damascene (Liegel's), 470 Jefferson, 255

(syn of Hulings), 243 uten Zuctsche (syns. of Italian Jenkins, J. H. G., var, orig. by, 448 Prune), 253

Italian Prune, 252

Jenkin's Imperial (syn, of Nectarine, 291; of Peach, 309 )

Itaticnische Griinc Zwetsche (syn. of Jerkinson's Impcrial (syn. of Imperial Quetsche Verte D'Italie), 525

Itasca (syn, of Aitkin), 140

Itasca, 470 Gage, 251

Jennie Lucas, 472

Jerusalem, 472

Jorusalem (syn. of Jerusalem), 472 Jorusalem Joune (syn. of Yellow Jeru-

Ithaca, 470

Ivason, 470

Ives, 470

Ives, J. M., var. orig, by, 470

Ives Damson (syn. of Ives), 470

Irc's Seedling (syn. of Ives), 470

I'c's Washiugton (syn. of Ives), 470

Ives' Washington Seedling (syn. of Ives), 470

Jacinthe (syn. of Jacinthe), 471

Jacinthe, $47 \mathrm{x}$

Jocksom? (syn. of Rigny):332; of Wasbington, 368)

$\mathrm{Jacob}, 47 \mathrm{I}$

Jacabi Zwetsche (syn. of Large Sugar Prune), 480

salem), 560

Jessie, 472

Jewell, 472

$J$ (syn. of Halc), 237

J. B. Rue (syn. of Rue), 536

J. H. Rue, 472

Jodoigne, 472

Jodoigne Green Gage (syn, of

Jodoigne), 472

Joe Hooker, 473
Johannispflaume (syn. of Noire de

Montreuil), $504 \quad 98,115,118,171,422,495,508$ :

Jolin $\Lambda, 473$

Johnny Roe, 473

Jolin's Gelbe Jerusalcms-Pfoume (syn. of Yellow Jerusalem), 569

Jahns Gelbe Jertisalems-Pflatue (syn. of Yellow Jerusaleni), 560

Jahn's Jerusalems Pfanne (syn. of Yellow Jerusalem), 569

Johnson, Franklin, var. orig. by, 548

Johnson, J. E., var. orig. by, 362

Jatiobs Pfloume (syn. of Damson), 186

James Vick (syn, of Vick), 559

Jamin, var. orig. by, I 87

Jaran Blood Plum (syn. of Satsuma). 337

Japanese Plum Seedling, 47I

Japanese Seedling X (syn. of Japex) 255

Jones, 473

Jones, Herbert A., var. orig. by, 452

Jones, Mrs. Owen, var. orig. by, 473

Jones Late, 473

Jordan. F., var. orig. by, 473

Jordan Seedling, 473

Josselyn, John, quoted, 20

J. Parks, 473

Judson, 473

Juicy, 257

Jopan Hybrid No. 3 (syn. of Ames), Julia, 473 144

Japan No. 1, 47 I

Japan No. 3, $47 \mathrm{I}$

Japan Hybrid No. 2 (a), 471

Japan Hybrid No. 2 (b), 47 I

Japex, 255

Jap No. 4, 47 I

Jaspisartige Pflaumc, 471

Julian, 473

Julien Gros à Feuilles Panachees, 473

Juli Reine-Claude; Julius Reine-Claude (syns. of July Green Gage), 474

July Fourth, 473

July Green Gage, 473

July Green Goge (syn, of July Green Gage), 474

Kelroba, 475

Kelsaw, 475

Kelsey, 258

Kelsey No. : (syn. of Kelmyro), 475

Kelsey No. 2 (syn. of Kelroba), 475

Kelsey No. 3 (syn. of Kelbalan), 475

Kelsey Prune, 475

Kelsey's Japan (syn. of Kelsey), $25^{8}$

Kelso, 475

Kenellan, 475

Kennedy Red. 475

Kensington Prune (syn. of Holland), 462

Kent, 475

Kentish Bush (syn of Kent), 476

Kentish Diamond (syn. of Diamond),

Kenyon, 476

98, its, I1 $8,171,422,495,508$;
var, orig. by, $349,418,446,492,501$; 559, 562

Kester Green Gage, 4-6

Kester's Green Gage (syn, of Kester Green Gage), 476

Kester's Yellow Gage (syn. of Kestcr Yellow Gage), 476

Kester Yellow Gage, 4-6

Keyser, var. orig. by, 245

Keyser's Plum (syn. of Hulings), 245

Kibitzenci (syn. of Small Reine

(laude), 347

Kicab, 476

Kickapoo, 476

Kieth (syn. of Keith), 475

Kilpatrick, E. W. var. orig. by, 485

King, 476

King Damson, 259

King of Damsons (syn. of King Dam. son), 259

King of Plums (syn. of Golden Drop, 229; of Reine Claude, 327)

King of Plums (syn, of King), 476

Kings Plum (syn. of Royal), 534

Kings Plum of Tours (syn. of Royal

Tours), $33^{2}$ 
Kingron (syn, of Diamond), 191

Kingston, 476

Kirchhof's Pfoume (syn. of Capitaine Kirchhof), 414

Kirke, 260

Kirke (syn, of Kirke), 260

Kirke's; Kirke's Pfawme; Kirke's Plum; Kirk's Plum (syns. of Kirke), 260

Kirke's Stoncless (syn. of Stoneless), 353

Kirschfflaume (syn. of Myrobalan), 290 Klodroner Pflatme (syn, of large Sugar Prune), 4 so

Klein Hcisse Damosscuer Pfoume (syn. of Small White Damson), 544

Kleine Blaue Frühzwetsche, 476

Kleine Blauc Julians Pfaume (syn. of Damson, 186; of Saint Julien, 335)

Kleine Brisette (syn. of Late Mirabelle), 263

Kleine Douphine (syn. of Small Reine (laude), 347

Kleine Gelbe Eierpflaume, $\$=6$

Klciuc aelbe Friih Pfaume (syn, of Early Vellow), 203

Klcine Grïne Reinc-Clande (syn. of Small Reine Claude), 347

Kleine Kirschpflaume, 476

Kleine Kirseltpfoume (syn, of Myrobalan), 290

Klcine Kirsch Pfoume (syn. of Rote Mirabelle), 533

Klcine Mirabelle (syn. of Mirabelle), 284

Klcine Reine.Clonds (syn, of Small Reine Claude), 347

Kleine Rosspauke, 476

Kleine Weisse Damascene (syn. of Korai, 478

Small Reine Claude, 347 ; of Small $K . P .{ }_{193}$ (syn. of Purple-leaved White Damson, 544)

Kleine Zucker Zwetsche (syn. of Petite Outetsche Sucrée), 5is

Klcinstc Mirobelle (syn. of Mirabelle), 284

Ǩlondike, 477

Klondyke (syn. of Klondike), 477

Knesett's Lote Orlcans (syn Ne(son), 503

Kniedsen's Peach (syn. of Knudson), 477

Knight, var, orig. by, $248,436,479$

Knight's Green Drying, Large Drying or Large Green Drying (syns. of Large Green Drying), 479

Knight's No. 6 (syn. of Ickworth), 247

Knudson, 477

Knudson, H., var, orig, by, 182, 422 , $460,462,463,477,496$

Knudson's Peach (syn. of Knudson), 477

Koa, 477

Koa's Inıperial (syn. of Koa), 477

Kober, 477

Koch, quoted, 17, 18

Koch's Golbe Spöt Danioscene (syn. of Käch Spate Damascene), 477

Koch Königspflaume, 477

Köch Spate Damascene, 477

Koch's Späte Aprikosen: Koch's Späte Damascene (syns, of Köch Spate Damascene), 477

Koepher, 477

Koctsche (syn. of German Prune), 219

Kohlenkamp, 477

Kaok, var. orig. by, 432

Krosnaya osimayo (syn. of Red Winter), 529

Krastajo Skorospiclkara (syn. of

Early Red), 440

Krieche (syn. of Damson), 186

Kricke (syn. of Gemeiner Gelbe Spilling), 45 s

Kroh, P. H., var. orig. hy, 316

Krolt (syn. of Poole Pride). 315

Kroos-Pruim, 478

Kruger's Seedling (syn. of Cruger

Scarlet), 424

Kuclien Pfoume (syn. of Frankfort Peach), 447

Kume, 478 (laude), 327
Kohlenkamp, W. Lo Modcleine (syn. of Noire de Mon-

Kolaten treuil), 504

477 La Prairie, 479

Königin Cloudia or Kloudio (syns, of La Prune Suisse (syn, of Suisse), 549 Reine Claude), 327 Lo Rochc-Corbon (syn. of Red Diaper), unigin der Mirabellen (syn, of Reine 323

des Mirabelles), $530 \quad$ La Royal (syn, of Royal), 534

Künigin Mlutter (syn. of Queen La Rovale (syn. of Royal), 534 Mother), 522 Lo l'cuiticnne (syn. of lenetianische fonigin Victorio (syn. of Victoria), Zweimal Tragende), 558

363 La Victorine (syn. of Victoria), 363

Königin von Tours (syn, of Royal Labert (syn. of Lambert), 478

Tours), 332 Labcrt's Red (syn, of Lambert), 478

Cünigliche Grossc Pflaunc; Kërintiche Lachine, 478

Pfaume von Tours; Känigs Pfounte; Ladies' Plum (syn. of Damas Violet), Königspfaume son Tours (syns. of 427

Royal Tours), $332 \quad$ Lacly, $47^{-8}$

Königspflaume (syn. of Early Oricans), Lady Lucy (syn, of Cooper), 423 198 Lady Plum (syn. of Lady), 478

Königspflaume (syn. of Royal), 534 Lafay, M., var, orig, by, 360

Königs Pfaume atrs Paris: $K$ nis,s. Lafayette, 261 foume zon Poris (syns. of Perdrigon Laite, $=62$

Tardif), 5is Lakenile No, \& No. 2, 478

Königspflaume Frühe (syn. of Royale I.allinger Königspflaume, 478

\begin{tabular}{l|l} 
Il itive de Liegel), 535 & Jambert, 478
\end{tabular}

Königs Pfaume von Mangcrou (swn, of Lambert's Red (syn. of Lambert), 478

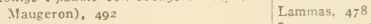

Königspflaume von Trapp's (syn. of Iancaster, 478

$\begin{array}{lll}\text { Trapps Königspflaumc), } 555 & \text { Lang. } 478\end{array}$

König Zwetsche (syn. of Trauttenberg), I.angdon, 478

555 Lanndon, Reuben, var. orig. by, 478

Kook's Gelbe Diopric: Kools Nenc Longdon's Scedling (syn. of Langdon), Diopre (syn, of Diaprée Nouvelle De 478

Larges Aprikosenffaume (syn. of Abricotée de Lange), $39:$

Lange Violette Damascene, 479

Lange Violette Dattel Pflaume; Longe Violctte Dottel Zwetsclic (syns. of Red Date), 322

Lange Violette Dottel Zwetsche (syn.

Kreger (syn, of Danish Damson), 428

Kreke (syn. of Damson), 186 Kreuters Zwetsclic (syn. of Quetsche
de Kreuter), 523

Krucger (syn, of Danish Damson), 428 Large Early Domison (syn. of Horse),

of Hungarian), 246

Lancley, quoted, 302

Langsdon, 479

Langliche Blone Damoscene? (syn. of

Lange Viofette Damascene), 479

Lannix, 479

Large Block Imperiol? (cyn. of Belle de Louvain. 400; of Bradshaw, 166)

Lorge Early Block (syn. of Nectarine). 297

Large early black (syn. of Noire de Montrevil), 504

Large English, 262

Irarge Enclish, 262
Large Enclish Damson, 479

Large German Prune (syn. of York State Prune), 5\%:

Larac Cerman Prune (syn. of German Prune, 210: of Italian Prune, 253)

Lo Bonne Deux Fois l'An (syn. of Large Golden Prolific, 479 Venetianische Zweimal Tragende), Lorge grcen cloudio (syn. of Reine 558 Claude), 327

Lo Brictte (syn. of Late Mirabelfe). Large Green Drying, 479

${ }_{263}$ Large Green Drying (sya. of Large Lo Courbon (syn. of Red Diaper), 323 Green Drying), 479

Lo Delicieuse (syn. af Cooper, $\$ 23$; of Large Hollond (syn. of Holland), 462

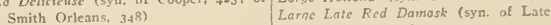
La Duc (syn. of 1.e Duc), 483 Red Damask), 48 :

La Grosse Reine-Cloude (syn. of Reine Large Long Blue (syn. of Manning),
489 


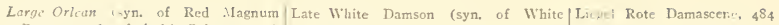
Bomun, 326: of Sinith Orleans, 348) Damson), 374 $\quad$ Liegcl Apricot, 484

Lorge Piach (cyn. of Peach), 309 Late White Pear (syn. of White Pear), Liegel, Dr., var. orig. hy, 391,399,

Large Peach Plum (syn. of Peach), $364,402,403,422,477,484,493,523$,

Large Purplo (syn. of Sinith Orleans), Late Vellote Damsan (syn. of White $526,535,555$

348

I.rsge Quecn, 479
Lwac Quecn Claude; Large Queen Latz fermin Prune-Sce German Liegols Frïhzactsche (syn. of Quetsche Damsin), $374 \quad$ Liegel Gage, 484 Claudia (syns, of Reine Claude). 327 Prune, 220 Précoce Lie - 11$), 525$

Large Ked Orlians (syn. of (Mleans), Laubinger Sugar Prune, 482 $\quad$ Licgcl's Marokko (syn. of Kaiser Wil$302 \quad$ Lawbinin's Catharinen Pflanme (syn. Iarg. Red Sn re: (syn. of Plunk), $5+6 \mid$ of Laubinger Sugar Prune), 482 Large Saint Julien (syn. of Saint Laubinper's Zuckerzwetsche (syn. of Julien), 335

Largest Damask of Tonrs (syn. of Gros Damas de Tours), 456 Laubinger Sugar Prune), 482

Lauche, quoted, 221,254

Jaura, 482

Large Sugar Prune, 480 $\quad$ Lawrence, 266

Large Sweet Damson (syn, of IIorse). Lawrence, L. Y., var. orig. hy, 182, 266, 464 465

helin), 474

Liegel's Spanische Damascene (syn. of

Spanish Damask), 546

Licgel's Zuillingsffaume (syn. of Jumelles de Liegel), 474

Liegel Unvergleichliche, 484

Lillian Augusta, $4^{84}$

Lillic, 484

Lincoln, 266

Large White Damasli (syn. of Large Lawrence; Laverence's Early; Law. Lindley, quoted, 229

W'ite Damson), 480

Large II'tite Damson. 480

Large Yclloze Egg (syn. of Yellow Egg), 386

Late lilack Damson, 480

Late Black Orlcaus (syn. of Late Orleans), 265

Late Blood, 4 So

Late Bolmer, 480

I.ate Chalons, 480

Late Cluster (syn. of White Damson), 374

Late Conical, 480 ronce's Friih Rote Pflaume (syns, of Lawrence Early), $4^{82}$

Lawrence Early, 482

Lindow'sche Frühe

Pflaume, 484

Laterence Early. (syn. of Belle), $15 \mathrm{~S}$ Lindsay's Seedling (syn. of Lindsay),

Lazcence or Laurence's Favorite; 484 Lawrence Gage; Laurcnce's Gagc; Little, $48_{3}$

Lawrences Reine Cloude (syns, of Little Black Damask (syn. of Black Lawrence), 266 Damask), 404

Lawson, 482

Lawson, John, quoted, 84, 93

Likle Blue Gage (syn. of Early Blue), 438

Laztson's Golden (syn, of Lawson), 482 Little Date (syn. of Datilles), 428

Lawson's Golden Gage (syn. of Law- Little Mirabelle (syn. of Mirabelle), son), $4^{82}$

Late Damask? (syn. of Late Black Le Czar (syn. of Czar), 184

Damson), $480 \quad$ Le Duc, 483

Late Damison (syn. of Winter Dam- Le Duc Vermillion (syn. of Vermilion), son). $567 \quad 558$

tate Diamond (syn, of Arch Duke), Le Prunier Tzaneron (syn. of Tzau. 148

I.Jte Goge; Late Green Gage (syns. of Late Reine (laude), 48 :

Late Goose, $4 \mathrm{St}$

Late Green Gage (syn. of Late Reine Claude), 481

t.ate Klondike (syn. of Golden), 224

l.atc Kloudike (syn. of Shiro), 342

Late Mirabelle, $2 \mathrm{f}_{3}$

Late Monsicur (syn. of Orleans), 302

Tate Muscatel (syn. of Late Muscatelle), 264

Late Muscatelle, 264

Late Orange, $48 \mathrm{I}$

Late Orleans (syn. of Late Orleans), $26=$

Late Orleans, 265

Late Prolific. $4 \mathrm{~S}_{1}$

Late Purnte Namison (syn. of Winter Damson), 567

Tate Red Damask, 481 eron), 557

L'Etendard De L'Angleterre (syn. of Standard), 548

Legal Tender, $48_{3}$

I.eih Sour, 483

Leipsic (syn. of Merunka), 494

Leipeic (syn. of German Prune), 219

Lcipzin (syn. of German Prune), 210

Leipzig Early Quetsche (syn. of Merunka), 494

Leirziger Zwetsche (syn. of German Prune), 219

L.conard, ${ }_{4} 8_{3}$

Leopard, 483

Lepine, $48_{3}$

Lepine, yar, orig. by, 483

Lepine (syn. of Norbert), 505 Leptune, $48_{3}$

Lerichenci (syn. of Mirabelle), 28 4

Leroy, André, var. orig. by. 157

Letta, 483

L.c Red Damson (syn. of Late Red

Jamack), $4 S_{1}$

Lewelling, Seth, var. orig. by, 453 28.4

Little Quecn Claude or Claudia; Little Reine Cloude (syns, of Small Reine (laude), 347

Little Seedling (syn. of Little), $4^{8_{5}}$

Liringston Manor (syn. of Reine (laude), 327

Lislondscher bierpflaume (syn. of Livland), 485

Livland, 485

Lizzie, 485

Lockey, $4 \mathrm{~S}_{5}$

Lombard, 268

Lombard group, 33. 34

Lombard Plum (syn. of Lombard), 268

Lomkard (syn. of Lombard), 268

Lombard (syn, of Red Gage), 527

London Plum or Plumb (syn. of Early Yellow), 203

Lone Star, 485

Long Blue, 485

Long Damson (syn. of Shropshire), 344

Long Fruit, 2\%0

Lowy Fruit (syn. of Red Tune), 324

Long Fruited (syn. of Long Fruit), 270

Long I.eaf Wonderful, 485

Long Red. ${ }_{4} 85$

Long Scarlet, ${ }_{4} \mathrm{~S}_{5}$

Long Violet Damascene, 486

$\begin{array}{ll}\text { (rice). } 249 & \text { Lewiston's Egg (syn. of Lewiston Egg), } \\ \text { Lewal (syn. of Impera. }\end{array}$ i. to Rvine Claude 481

Halc. Nivers, as

I 1.. Rnllingstone, 482 into Transparent, ${ }_{4} 8_{2}$

Lite T1: msparent Gase (syn. of Late Tranyarent). $4 \mathrm{~S}_{2}$

Lewiston's Egg (syn. of Lewiston Egg),

Lex Plum, ${ }_{4} 84$

Licfandor Golbe Pfanme (syn. of Apricot), $1+8$

Late Jiclat ( 4 H. of Imperatrice, 2:19: of Late Tian f...itut, $\downarrow 8 z$ )

Liefiat: ische Griine Zuctsche (syn. of Jaspisartige Pflaume), 471

Long Vialet Damask (syn. of Damas Violet), 427

Longworth, ${ }_{486}^{86}$

Longwerth, Nicholas, var, orig. by, 486

Lord, Orville Morell, life of, 331;

var, orig. by. 331,482

Lot d'Ente, 4 \&6

Jugal's tumst Zivotsche (syn. of Au- Lot d'Ente (syn, of .Igen), I38

Lotta (syn, of Lottie), $4^{86}$ 
Lottie, 486

Louis, Simon, var. orig. by, 445

Louisa, 486

Louis Brun (syn. of Reine Claude). 327

Louise-Brune, 486

Louisc Brune (syn, of Louise-Brune), 486

Louisen's Braune Damascene (syn, of Louise-Brune), 486

Louisiana, 486
Louis Philips or Philippe (syns, of

Washington), 368

Louis Philippe (syn. of Nectarine), 291 Lovett, 486

Lovett Late, 487

Lavelt's Late Long Red (syn. of Lovett Late), 487

Lowry, 487

Lowry's Gage (syn. of Lowry), 487

Lucas Frulizwetsche (syn. of Précoce de Lucas), 518

Lucas Königspflaume, 487

Luccombe's Nonesuch (syn. of Lucombe), $27 x$

Lucombe, 27 I

Lucombe, yar, orig. by, $27 x$

Lucombe's Nonesuch (syn, of Liscombe), $27 \mathrm{t}$

Lucombc's Nonsuch (syn, of Lucombe), 27

Lucambe's Unvergleichliche (syn, of Lucombe), 271

Luedloff, 487

Luedloff, Charies, var, orig. by, 406 $469,487,503,547$

Luedloff Green, 487

I. uedloft Red, 487

Luedloff's Green (syn. of Luedloff Green), 487

Luedioff's Red (syn. of Luedloff Red) 487

Luedloff's Seedling (syn. of Luedloff) 487

Luizet, M., var. orig. by, $44^{1}$

Lunn, 487

Luscombe, 487

Luscombe's Seedling (syn. of Luscombe) 487

Lutts, 487

Lyon, 488

Lyon Apricot, 488

Macedonia, 488

Macliland, 488

MacLanglin (syn. of McLaughlin), 276

MacLaugblin (syn. of McLaughlin), 276

Maconiber, 488

Macomber, J. T., var. orig. by, 453

Macomber, L. M., var. orig. by, I8o, 510,520

Macomber No, 1 and No. 2, 488

Madame Henri Descluars, 488

Madame Nicolle, 488

Madam Leeds, 488

Madeleine, 488

Madeline (syn. of Early Tours), 202

Modison (syn. of Denniston Superb). 431

Madison, 488

Magnum Bonum (syn. of Yellow Egg), $3^{96}$
Mailändiscle Kaiserpfoume (syn. of Mauchete, 492

Impériale de Milan), 467 Maude Lacy, 492

Iainzer Frühzwetsclie, 489

Maude Lacy, 492
Maugeron, 492

Maugiron; Maugcron Damask (syn.

of Maugeron), 492

Vougiron (syn, of Maugeron), 492

Mayerboeck Zwetsclie, $49=$

Woyerbocel's Rote Zwitsche (syn. of Mayerboeck Zwetsche), 492

Mayer IIellrote, 493

Nayer Künigspflaume, 493

Moyers Brounrothe Kiniy sffaume (syn. of Mayers Rothe Damascene), 493.

Majer's Hellrothe Damascenc (syn. of Mayer IIellrote), 493

Mayers Rothe Damascene, 493

Vayers Rothe Damoscenc (s)'n. of Mayers Rothe Damascene), 493

Maynard, 275

McCance, M, E., var, orig. by, 378

McCartney, 493

McCaulcy's Secdling (syn. of Cambell), 414

MeGillivray, 493

MeLaughlin, 276

IcLaughlin, James, var. orig. by, 277 , 514

McLaughlin's Gage Plum (syn. of Mc.

Laughlin), 276

Me.Malion, Bernard, quoted, 30, 38

IIcPherson, 493

MIcRea, 493

Mead, H. O., var, orig. by, 493

Meads, 493

Meads Seedling Plum (syn. of Meads), 493

Vediterranean, 493

Meigs, 493

Melon, 493

Melnicker Zwetsche, 493

Mencray, 494

Mereton, +94

Mereton's Eg8 (syn. of Mereton), 494

Meroldt, 494

Meroldt, Dr., var, orig. hy, 494

Meroldt's Gelbc Rcinc-Clonde: Mcroldt's Golden Gage: Meroldt's Reineclaude (syn. of Meroldt), 494

Merryweather, 494

Merryweather, II., var. orig, by, 494

Merton's Egg (syn. of Mereton), 494

Meruaka, 494

Merville d'Automne, 494

Meyer, 494

Miama, 494

Miami (syn. of Miama), 494

Vichaclis Pfoumc (syn, of September Damask), 547

Mriddlehurg, 278

Middlcburgh (syn. of Mildt bure), $2-8$

Mignonne, $\$ 95$

Mikado (syn, of Gcorgeson), 218

Miles, 495

Miller (syn. of Improved French

Prunc), 467

Miller, 495

Miller, Colonel Charles, var. oris, by, 279

Miller, David J., var. orig. by, 475.499

Miller No. 1, 495

Miller No, 5, 495

Miller's Early (syn. of Silva Köning Claudie), $5+3$ 
Miller Superb, 279

Millett, 495

Millett Early Red, 495

Millett's Early Red (syn. of Millett Farly Red), 495

Millett, T. T., 495

Millett Very Early Red, 495

Millett's Very Early Red (syn. of Mfillett Very Early Red), 495

Milletl's Wild Plum (syn. of Millett), 495

Mills, 496

Mills Seedling, 496

Milton, 280

Milton Gage, 496

Mimms; Mrimms Pfatome: Mimms Plum (syn. of Red Diaper), 323

Minco, 496

Miner, 281

Mincttc (syn. of Guthrie Late), 236

Minion, 496

Minner (syn. of Miner), 281

Minnesota, 496

Minnesota Seedling, 496

Minncsoto (syn, of Rollingstone), 330

Minnetonka, 496

Minnie, 496

Minstiratherth (syn, of Gloucestetshire Violet), 452

Mirabobelle; Mirabel; Mirabelle; Mirabcllc abricotéc, Blanche, de Mets de Vicnne, Jounc, Perle, Perléc, Pctite, pricoce, Simple, Verte (syns. of Mirabelle), 284

Mirahelle, $28_{3}$

Mirabcllc (syn of Drap d'Or), 194

Mirabcllc Abricotéc (syn. of Aprikosenartige Mirabelle), 396

Mirabelle de Berthold (syn. of Early Mirabelle), 439

Mirabelle de Bohn, 496

Mirobclle dc Boltn (syn. of Mirabelle de Bohn), 496

Mirabclle de Docrell (syn, of Dorell Aprikosenpflaume), 434

Mirabelle de Flotow, 497

Mirabclle de Metz (syn, of Mirahelle). 284

Miralselle de Nancy (syn. of Drap d'Or), 194

Mirabelle de Rangheri (syn. of Rangheri), 526

Mirabelle de Ronvaux, 497

Mirabelle d'Octobre (syn. of Late Mirabelle), 263

Mirabelle Double, Double de Metz, Drap d'Or. Grossc, Grossc de Naucy, arosse doulyle de Metz. lo grosse, Perléc: Mirabellen (syns. of Drap 1'Or), 104

Winahelle Double de Herrenhausen, 497

Mirahelle Gloire de Lorveciennes (syn. of (iloirc de Louveciennes), 452

Mirabelle grotip, disetsssion of, 40,41

ivirabelle Hâtice de Rangheri (syn. of Rangheri), 526

Mirabelle Lo Plus Hátise de Flotow (syn, of Mirabelle de Flotow), 497

Mirabille Pricocc (syn. of Early Mira belle), 439

Mirabelle Pricoce de Flaford, 407

Mirablle Rangheri: Mizhell Ran. sheris (syns, of Ran, h-ti),
Mirabelle Rayec (syn. of Mirabelle de Monsicur à Fruits Jowne; Monsicur d

Bohn), 496

Mirabelle Rouge (syn. of Myrobalan,

290; of Rote Mirabelle, 53.3)

Mirabelle Tardize (syn. of Late Mira. belle, 263; of Saint Catherine, 334)

Mirabelle Tordive I/me. II. Doschars (syn. of Madame IIenri Descliars) , 488 Mirabelle Vert Double (sy'n. of Reine

(laude), 327

Mirabelle Verte, 497

Mirabclie von Metz (syn. of Drap d'or) 194

Mirabilon; Mirabolan; Mirabolanc; Mirabolancupfaumc; Mirobalan (syns. of Myrobalan), 290

Miracle, 285

Wiriam (syn. of Early Royal), sol

Wirion (syn, of Early Royal), zor

Miser; Miser Plum (syns. of Myro.

balan), 290

Mission Prune, 497

Mississippi, 497

Mississippi Red (syn. of Mississippi), 497

Missouri, 497

Missouri Apricot (syn. of Golden Beauty), 226

Missouri Green Gage, 498

Mistake, 498

Mitchelson, 498

Mitchclson; Mitchelson's (syns. of Mitchelson), 498

Mitcbelson, var. orig. by. 49 S Miriam; Mivian (syns, of Farly Royal),

201

Mivian, 498

Fruits Jauncs (syns, of Yellow Im. peratrice), 569

Monsieur de Smith (syn. of Smitb Or. leans), 348

Monsieur Hitif de Foote (syn. of Foote), 446

Monsieur Jaune (syn. of Early Yellow), 203

Monsicur Jaune (syn. of Yellow Imperatrice), 569

Monsieur Noir Tardif (syn. of Late Orleans), 265

Monsieur Tardif (syn. of Sisisse), 549 Monsieur tardif (syn. of German Prune), 219

Monsicur tordif de Kitestt (syn. of Nelson), 503

Monsicur Tardize (syn. of Suisse), 519

Monstreuse de Baia $;$ Monstracuse de Bozay (syns, of Pavay), 155

Nonstrucuse d'Oullins (syn. of Oullins), 303

Mont Barbat d'Ente, 400

Montfort Pfotmc (syn. of De Montfort), 430

Montgomery (syn, of IIand), 239

Montgomery, 409

Montgomery Prune (cyn. of Lombard, 268; of Montromery, 490)

Montmorency, 400

Montrcuil (syn. of Noire de Montreuil), 504

Montrcal Wo. 60 (syn, of Lunn), 487

Montreal, 499

Moon, 499

Moody, 499

Mooncy (syn, of Bradshaw), 166

ixcd Arab (syn. of Black Arabka) 404

Moore, A T., var. orig, by, I5:

Monre Early, 499

Moore's Early (syn. of Moore Farly'),

I. De Wolf, 498

M'Laugblin (syn. of McLaughlin),

Mogol Plum: Mogole Pforme; Mogo! Mogul Plum; Wogul's Pfinunc: To. gute; Mogule Plunb (syns, of Yellow $\mathrm{Egg}), 386$

Mogul (syn. of Morocco), 298

Mogul Rouge (syn. of Red Magnum

Bonum), 326

Moldavka (syn. of Blue Moldavka), 405

Moldavka (syn. of Voronesh), 365

Mollie, 498

Molly ( $s y n$, of Mollie), 498

Monarch, 286

Monarque (syn. of Monarch), 286

Monolith, 498

Monon, 498

Monona, 498

Monroe, 287

Monroc Eng; Monroc Goge (syns, of Monroe), 287

Monsicur (syn. of Early Tours), 202

Monsieur i Fruit Vert, 498

Monsicur; Monsicur Ordinaire (syns. of Orleans), 302

Monsicur; Mensieur Hatif; Monsicus

Hâtif de Montmorency; Monsicur Mountain, 499

Hottin'c (syns of Farly. O-leans), 198 Mountain Plum, 500

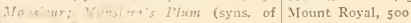

Moyen, 500 
Moycs de Boturgogne (syn. of Moyen Nectarinc, 291

de Bourgoyne), 500

Moyen de Bourgoyne, 500

Moyer, 500

Moweu de Bourgogne (syn. of Early Perdrigon), 439

Moyret, 500

Moyret's Gage: Moyret's Reine Claude (syns, of Moyret), 500

Mrs. Cleveland (syn, of Cleveland), 419

Mrs, Blecker's Large Red (syn. of Bleeker Large Red), 405

Mrs. Clifford (syn. of Clifford), 419

Mudson, 500

Nulberry, 500

Muldraugh, 500

Muldraugh's-hill Plum (syn, of MIuldraugh), 500

Mule, 500

Muncey (syn. of Muncy), sor

Mïnchenpflaume (syn. of September Damask), 542

Muncy, 501

Iunson, sor

Munson, Thomas Volney, plum investigations of, 88,89 ; var. orig. by, 402 , 412,496

Munson (syn. of Abundance), 136

Murdy, 50 z

Murroy's Reine Clande or Claudia (syns, of Reine Claude), 327

MLuscadine (syn. of Mlyrobalan, 290; of Queen Mfother, 522$)$

Musk Damosk (syn. of Musk Damson). 501

Musk Damson, 50t

Musk'd Damask: Mtrskicrte Domoscene (syns, of Musk Damson), 501

Mrskirte Gelbe Damoscene (syn. of

Damas Jaune Musque), 427

Muscat Free, 50:

Musk Perdrigon, 502

Muscle, 501

Mussel (syn. of Scioto), 54t

Musscl: Mussell; Mussell Plum (syns. of Muscle), 501

Nussey, 502

Musquic de Malto (syn. of Musk Damson), 501

Miusquice de Besztercse (syn. of Hungarian Musk Prune), 465

Myrobalan; Myrobalanc; Myrobolan: Myrobalans (syns, of Myrobalan), 290

Myrobalan, 290

Myrobolon Jaune (syn. of Gelbe Kirsch. pflaume), 450

Nagate-Maru, 502

Nagate-Maru, 502
Nagatc no Botonkyo (syn. of Red Nikko, 504
Nimon, 50

June), 324

Nagats-Maru (syn. of Nagate-Maru), 502

Nagatus maru (syn. of Nagate-Maru), 502

Naples, 502

Native Red, 502

N. C. Seedling (syn. of Nortb Carolina), 507

Xebraska, 502

Nebraska Seedling, 502

Nebraska Wonder, 502

Neils, 502

Nellie, 502 199 199 503 $44^{I}$
Nectorine (syn. of Goliath, 231; of
Nona, 505 Nectarine, 291; of Pcacb, 309) Nonesuch; Nonsuch (3yns, of Lucombe), Nectarine Plum (syn. of Nectarine), $27 t$

291 Nonparcil (syn. of Incomparable), 467

Nectarine Rouge (syn. of Peacb), 309 Norbert, 505

Nellie Blanche, 503

Nelly (syn. of Nellie), 502

Nelson, 503

Nelson's Victory (syn. of Nelson), 503

Neue Weisse Koiscrin (syn. of White Queen), 564

NeH Orlcons (syn of Early Orleans)

Never Fail, 503

New Ancrican, 503

New Apricot of Braunau (syn. of Lic. gel Apricot), $4^{8} 4$

Newark, 29 t

Nowe Early Orlcons (syn. of Early Orleans), 198

New Goderich, 503

Nesu Goldcn Drop (syn, of Golden Drop), 229

Sew Green Gage, 503

New Large Bullace, 503

New Large Bullace (syn. of New Large Bullace), 503

Newruan, 292

Ncru Orlcans (syn, of Early Orleans),

Newton, 503

Newton Egg (syn. of Newtown Egg),

Newtown Egg. 503

Norbert; Norbert's Pflaume (syns. of Norbert), 505

Norby, 505

Norhy, A., var, orig. by, 505

Norby No. 1, 505

Norby No. 11, 505

Norman, 505

Normand, Joseph L., life of, 506; var. orig. hy, 451, 486,506

Normand; Normand Japan; Normand's Japon; Normand Ycllow (syns, of Georgeson), 218

Normande prícoec (syn. of Early Normandy), 439

Normand No. 5 (syn. of Alahama), 392

Normand No. 15 (syn. of Louisiana), 486

Normand Perdrigon, 505

Normand No. 5, 506; No. 11, 506; No. 12, 506; No. 15, 506; No. 16, 506 No, 17, 506; No, 18, 507; No. 19. 507; No. 20, 507

Normand's Seedlings, 506

Normannischer Perdrigon; Norman Pcrdrigon (syns, of Normand Perdrigon), 505

North, 507

North, Professor, var. orig. by, 507

North Carolina, 507

North Carolina Seedling (syn. of North Carolina), 507

North's Scedling (syn. of North), 507

North Star, 507

Nota Bene, 507

Transparent Gage (syn. of Early

Transparent Gage), $44{ }^{\circ}$

Ncw Woshington (syn. of Washing: ton), 368

New Wine Sour, 504

Naw York Purple (syn. of Brevoort Purple), 408

Niogoro (syn. of Bradshaw), 166

Nicholas, 295

Niemburg Egg; Nienburger Eicrpfoume (syns, of Nienburger Egg Plum), 504 Nienhurger Egg Plum, 50.4

Nikitaer Blaue Frühzwetsche, 50.4

Nikitaer Dattelzwetsche, 504

Nota Bcric de Corse (syn. of Nota Bene), 507

Nouvelle; Nouvelle Dc Dorrel: Nouvelle De Dorelle: Nouzcau De Dor. relle (syns, of Dorell), 434

Nowzclle Goutte d'Or (syn. of Golden Drop), 229

November Gage, 507

Noyes, 507

Noyes, Mrs., var. orig. by, 507

Noyes' Scedling (syn. of Noyes), 507

No. 3 (syn. of Early Red), 440

No. II (syn. of Norby No. it), 505

Nruhe Konigspflaume: Frille Königs Pflane (syns, of Early Royal of Nikita), 440

Nikitaer Hahnenpflaume, 504

II3 Rigo (syn. of Merunka), 49

II6 Riga (syn. of Red Magnum Bonum), 326

No. 31,288 (syn, of First), 446

Nikitoner Halnenlode (syn. of Nikitaer Hahnenpflaume), 504

Nobic Prícoce (syn. of Edle Early),

Noire Americaine, 504

Noirc de Montreuil (syn, of Noire de Montreuil), 50.4

Noire de Montreuil, 504

Noirc Hatif (syn. of Morocen). 2SS

Noire Hätive (syn. of Early Tours), 202

Noisette, M., var, orig, by, 550

Nolan, 504

Nolcn Plum (syn. of Wild Goose), 378

Nolton Ungarische, 505
Nurseries, commercial, early origin of, 323-325

Nutmeg (syn. of Christian, 4t8; of

W'heat, 563)

Nutmeg, 508

Oakley Park Wild, 508

Oatcy, 508

Oberdieck, quoted, 263,433

Obcrdiccks Frithe Aprikosenffoume (syn. of Early Apricot), 437

Oherholtzer, George U., var. orig. by, 416

Oberley, 508
Oherdieck Gestreifte Eierpflaume, $50 \$$ 


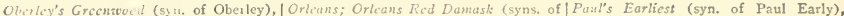
508

Oecident, 295

Othesla (syn, of Ocheeda), 296

Ocliecela, 20 ,

October, 297, 508

October Gage (synt. of Frost Gage), 216

Octater Grich Gage (syn. of Late Reine (laude), t8

Octoher Mirabelle (syn, of Late Miralietle), 26.3

October Purple (syn. of October), 297

Oddy, $50 \AA$

Oddy's (syn. of Oddy), 508

Odckand (syn, of Odegard), 508

Oile-gard, $50 \$$

Odell, 508

Ocil de Bocuf; Ocuil-de-Bocuf (syns. of Jerusalem), $47^{2}$

Ocuf Roure (syn. of Red Magnum Bonum), 326

Ogan (syn, of Ogon), 298

Ogden (syn. of Ogon), 298

Ogeechee, 508

Oglesby, 508

Ogon, $29 \mathrm{~S}$

Oron (syn, of Ogon), 298

Orleans), 302
Orlechs Latc Black (syn. of I

Orleans Latc Black (syn. of Latc Or- Paul Wolf (syn. of Bender), 401

leans), $265 \quad$ P. bifcrun (syn. of Twice Bearing),

Osage, 510

Osage 48 (syn. of Osage), sto $\quad$ P. Damasccna Armeniacca (syn. of

Osterreichische Pfaume (syn. of llun. Mirabelle), 284

garian), 246

Oswego (syn. of Pond), 314

Ottoman; Ottomanische Kaiserpflaume (syns. of Imperial Ottomon), $4^{G} 7$ Ottoman Seedling, 510

Ouillin's Gage, Golden, Golden Cagc or Green Gage (syns, of Oullins), 303 Oullins, 303

Outremont, sto

Oval 13lood (syn, of Occident), 295

Ovalrunde Spreckel Plaume (syn. of (iisborne), 451

Overall, 510

Owatonna, 5 io

Owen, 5 II

Owen Sound Beauty (syn. of Owen),

511

Oxford, 5 II

Oyama, 5 I I

Pacifie, 305

O-Hatankyo; O.hattankio (syn. of Cbabot), 172

Ohio, 509

Ohio Prolific (syn. of Ohio), 509

Okaw, 509

Oktoberfficume (syn. of Saint Martin), 336

Oku Botan, 509

Old Apricot (syn, of Apricot), I4 8

Old Gold, 509

Old Hickory (syn. of Miner), 28r

Old Orlcans (syn. of Orleans), 302

Olive, 509

Ollie, 509

Olson, 509

Omaha, 509

Omega, 509

Onderdonk, Gilbert, life of, 392; var. orig. by, 392, 421, 439, 472, 501, $5+6$

Onderka Damascene, 509

Onderka (syn. of Onderka Damascene), 509

Ontario, 509

Opata, 509

Orange, 300,510

Orange; Orange Gage (syns. of

Orange), 300

Orange Clierry, 510

Orange's Cherry Plum (syn, of Orange Cherry), 510

Orel 19: Otel No. 19 (syn. of Long IRed), 485

Orel No. 20 (syn. of Long Blne), 485

Orel No, 21, 510

Oren, J. K., var. orig. by, 301

Oren, 300

Orenge, 5 Io

Orient (syn. of Chabot), 172

Oriontal, 510

Orillia, 510

Oriole (syn. of Abundance), 136

Orleans, 302

Orleans (syn, of Early Orleans), Igg

Pacific; Pacifie Prune (syns. of Pacific), 305

Paddock, Captain, var, orig, by, $51 t$

Paddock Magnum Bonum, 5 I I

Paine, 511

Paine, A. W., var, orig. by, 5 I

Peach (syn. of Kindson), 477

Peach (syn. of Nectarine, 291; of

Peach, 309; of White Virginal, 565)

Peach, 309

Peach Leof, 513

Peachlicaf (syn. of Peach Leaf), 513

Pcacli-leaz'cd (syn. of Kanawha), 474

Peach Plum (syn. of Nectarine, 29s;

of Peach, 309)

Peach Plum (syn. of Peach-plum), 513

Peach-plum, 513

Peake, 513

Pearl, 310, 513

Pear Plum, 513

Pearson, H. A., quoted, 340,435

Peasant, 5 I3

Peascod Plum (syn. of White Peascod),

564

Pêchic; Pêche de Calecl (syns, of Nec-

tarine, 291; of Peach, 309)

Peerless, 513

Peffer, G. P., var. orig. by, 406,467

Peffer's Premium (syn. of Premium),

518

Pekin, 513

Pendent, 514

Penn, William, quoted, 20

Penning, 514

Paine's Seedling (syn, of Paine), Penning, Martin, var. orig. by, 356, 511507,514

Paisan Blanche, 511

Paisan Blanche et Double (syn. of Penning's Frec (syn. of Penning), 514

Paisan Blanche), 511

Paisan Noire, 511

Palatine, 307

Palmer, 511

Pander, 5 in

Papeleu, 512

Pappaconi, 512

Paquet, 512

Paquet, C. G., var. orig. by, 513

Paragon (syn, of Chabot), 172

Pardee, S. D., var. orig. by, 395

Paris Belle (syn. of Texas Belle), $55^{2}$

Park, 512

Parker, 512

Parker's Mammoth (syn. of Washing. ton), 368

Parkinson, John, quoted, 28, 32, 373, $394,421,433,441,450,455,490$, $509,510,513,543,559$

Parmentier (syn. of Golden Drop), 229 Parrott, 5 I2

Parsonage, $5 \mathrm{r} 2$

Parsons (syn. of Miner), $28 \mathrm{I}$

Partridge, 512

Pasqua, 512

Paterson's (syn. of Gisborne), 45

Pathfinder, 512

Patten, A, 513

Patten, B.t 513

Patten, C. G., var. orig, by, 513

Patten No. 40 (syn, of Apple), 396

Paul, T. M., var. orig. by, 308

Paul Early, 308

Pennock, 514

Pennock, C. E., var, orig, by, 514, 550

Pennock's Hybrid (syn, of Pennock), 5 I 4

Penobscot, 5I4

Peoly Early Blue, $5 \mathrm{I} 4$

Perdigesena; Pcrdigon; Perdrigon: Perdrigon Violet or Violcite (syns. of Blue Perdrigon), 164

Perdrigon Bariolc (syn. of Bunter Perdrigon), 412

Perdrigon blanc (syn. of White Perdrigon), 375

Perdrigon de Brignole; Perdrigon de Brignole Gros (syns. of Brignole), 409

Perdrigan de Normandie (syn. of Nor. mand Perdrigon), 505

Perdrigon des Alpes, 514

Perdrigon group, 31, 32

Perdrigon Hâtif (syn. of Drap d'Or), 10.4

Perdrigon hatif or hative (syns. of Early Perdrigon), 439

Perdrigon Joune (syn. of Drap d'Or), 195

Pcrdrigon Normand (syn. of Normand Perdrigon), 506

Perdrigon of Cernay, 514

Pordrigon rouge (syn. of Red Perdrigon), 528

Perdrigon Tardif, 515

Perdrigon Violet (syn. of Early Tours), 202 
Perdrigon Violet Ilätif (syn. of Early|Platman's Bunker Hill (syn. of Pratt, D. U., var. orig. by, 396

Perdrigon), 439

Perfection (syn. of Wickson), 376

Perry's Secdling (syn, of Oricntal), 510

Pershore, 515

Pershore Yellow Egg (syn. of Pershore), 515

Persing Nos. 1, z (syn. of Burbank), t;o

Peters, 312

Peter's Large Yellow; Pcter's Ycllow Goge; Peters' Yellow Gage; Peters Yellow Gage (syns. of Peters), $3: 2$

Peterson, var, orig, by, 143

Petit Bricettc (syn. of Late Mirabelle). 263

Petit Damas Blanc (syn. of Small White Damson), 545

Petit Damas Rouge (syn. of Queen Mother), 522

Petit Danas Vert (syn, of Small Reine Claude), 3.47

Pctif Drap d'Or (syn. of Mirabelle), 284

Petite (syn, of Agen), ${ }_{13} 8$

Petite Bricctte (syn. of Saint Catherine, 334; of Late Mirabelle, 263)

Petite d'Agen (syn. of Agen), 138

Petite Mirabcllc (syn. of Mirahelle) 28.4

Petite Prune or Prune d'Agen (syns, of Agen), 138

Petite Quetsche Sucrée, 515

Petite Reine-Cloudc (syn. of Small Reine (laude), 347 Bunker Ilill, $+11 \quad \begin{aligned} & \text { Pratt, D. U., Var. Orig. by, } 396 \\ & \text { Pricoce (syn. of Wbite Virginal), } 565\end{aligned}$ Pluttruude Zacitsche (y)n. of Quetsche Précoce Biondeck (syn. of Biondeck), Aplatic), 523

\begin{tabular}{l|l} 
Pliny, 7 sted, 16, 17, 28, 36 & Pricoce De Bergthold (syn. of Early
\end{tabular}

Plumeot (syn. of Rutland Plumcot), 333 .Nirabelle), 439

Plunn crop, production of, in U. S. in Precoce lefresne, 517 1S99, 100

Plum de l'Inde (syn. of Pond), 314 Plum growing, location of, in New York, 100

Plum of Louroin (syn. of Belle de Louvain), 400

Plums, blooming dates and season of Pricoce de Reutlinger Prune (syn. of ripening of, 105-109; characteristics Précoce de Reutlinger), 518 of, 6-9; conspectus of species of. Précoce de Riscrs (syn, of Early 9-11; cultivation of, 120-121; dis- Favorite), 438

cussion of insects detrimental to, Pricoce de Tours (syn. of Early Tours), $13:-135$; diversity of kinds of, $4-6: \quad \begin{array}{r}202 \\ 202\end{array}$

hardiness of, zoz-104; harvesting and Précoce Veritable (syn. of Wabre marketing of, 122-125; locations and soils for, 113,114 ; minor diseases of I29-13r; pollination, of, 110 ; setting of trees of, r2o; sexual affinities of

varieties of, I12-113; subjection of, President Courcelle (syn. of President to discases, 125 ; varieties of, grown in New York, ror

Plum Simon (sуn. of Simon), 346

Plunk, 516

Podicbreder Pflasme (syn. of Red

Perdrigon), 528

Poiteau, quoted, 428

Pomology, origin of, in America, $18-26$

Pomona, 516

Pomaria, 516

Petit-Monsicttr (syn. of Marange), 490 Pomeranzen Zwetsche (syn, of Orange).

Petit prunallicr (syn. of Sloe), $544 \quad 300$

Petit Soint Julicn (syn. of Saint Pond, $3 r_{3}$

Julien), 335

Pfirschenpflaume (syn. of Goliath), 231

Pflaume Mit den Pfirsichblat or mit dem Pfirschenblatt (syns. of Italian Prune), 253

Pfoume Olne Stcinc (syn. of Stoneless), 353

Pflaume Von Gondin (syn. of Gondin), 454

Pfiaume von St. Eticnne (syn. of St. Etienne), 537

Plilippe I (syn, of Washington), 368

Pliillips, Ilenry, quoted, 29

Phiolenartige Gelbe Zwetsche, 515

Pickett, var, orig. by, 329

Pickett's July (syn. of Early Yellow), 203

Pigeon's Heart (syn. of Queen Motber) 522

Pilot, 5 rs

Pink Damson, 515

Pioneer Prune, 515

Piper, 515

Piper's Peach (syn. of Piper), 515

Piram, 516

Pissardi, 516

Pitch Plitm (syn, of Moyen), 500

Pitless (syn. of Stoncless), 353

Plantz, 516

Pond, var. orig. by, $3 t 4$

Pond Secdling; Pond's Purple; Pond's Samling: Pond's Scedling (syns. of Pond, 314

Pond Purple, 516

Pond's Purple (syn. of Pond Purple), 516

Pond's Seedling (syn. of Pond Purple), 516

Pond's Secdling (English) (syn. of Pond), 314

Pontbriant, 517

Pontford, 517

Pontotoc, 517

Poole; Poole's Pride (syns, of Poole Pride), 315

Pocle Pride. 315

Porseh Rote Zwetsebe, 517

Pottawattamie, 3-6

Potter, 517

Poupart, 517

Poupart's (syn, of P'oupart), = 7

Pourprée De Duane; Pourpré Duone (syns, of Duane), 176

Pourprée de Pond (syn. of Pend), 314 Pourprée Impériale (syn. of Imperial

Purple), 467

Powcll Damson, 517

Plantz's Secdling (syn. of Plantz), 516 Prairie (syn. of Prairie Flower), 517

Platt, Judge, var, orig. by, 260

Prairic Flower, 517

Platte Hellrothe Königsflaume (syn. Proiric Flozver (syn. of Prairie Flower),

of Procurcur), 520

Plattman, J. H., var. orig. by, 41 I

Prairie Rose, $5 \pi 7$

Frïhzwetsche), 560

Prcmium, 518

Preserver, 518 Courcelles), 518

President Courcelles, 518

President Wilder (syn. of Wilder), 565

Presley, 519

Price, 519

Pride of Watcrloo (syn. of Pond), 3it Pride of Waterloo? (syn. of Pride of

Pride of Waterloo, 519

Primate, sig

Primordian (syn. of Early Yellow), 203

Prince (syn. of Gloucestershire Violet). 452

Prince, 519

Prince, William, life of, 389 ; quoted, $23,24,30,38,23 \mathrm{r}, 310,369,417$; var. orig. by, $252,369,389,467,519$. s20, $5 \geq 7$

Prince, William Robert, life of, 24 ; quoted, $3 t$

Prince Albert? (syn. of Wales), 366

Prince De Galles (syn. of Wal s), : 6 Prince Engelbert: Prince Englebert (syns. of Finglebert), 204

Prince of W' Wales (syn. of Wales), 366 Prince's Bluc Primordion (syn. of Prince Primordian), $5 \geq 0$

Prince Early Damson, 519

Prince's Early Purple (syn. of Prinec Early Damson), 519

Prince's Gage (syn, of Yellow Gage), 3.88 Prince's Gage (syn. of Imperial Gage), 251

Prince's Gelbe Reine.Claude (sin. of Yellow Gage), 388

Prince's Imperial Gage (sy'n. of Iri* nerial Gage), $25 \mathrm{r}$

Prince's Kaiser Reine-Claude (syn. of lumperial Gage), 25 :

Prince Orange Egg, 519

Prince's Orange Egg (syn. of Prince Orange Egg), 519

Prince Orange Gage, 519

Prince Primordian, 520

Prince's Red Gage (syn, of Red Gage), 
Prince's Rote Reine-Claude (syn. of Prune Celeste (syn. of Elsner Grüe Prune de Brigantiaca (syn. of Brian. \begin{tabular}{l|l|l} 
Red Gage), 527 & Zwetsche), 442 & çon), 409
\end{tabular}

Prinec's White Gage (syn. of Imperial Prune Cerisc, Ceriset, Cerisette or Prune de Brignole (syn. of Brignole), Gage), 251

Prince's Yellow Gage (syn. of Yellow Prune cocur de pigeon verd (syn. of Prunc de Brignole (syn. of Agen), 138 Gage), 388

Pringle, 520

Pringle Blue, 520

Pringle Purple, 520

Prins Engelbert (syn. of Englcbert), 204

Prinsens Kaiser Reine Claudc (syn. of

Iinperial Gage), $25:$
Princens rothe Reineclaude (syn, of Red Gage), 527

Prinzossinpflawme (syn. of Red Magnum Bonum), 326

Prinzessin Pflatme (syn. of Impera. trice, 249; of Red Diaper, 323)

Prinz Von Wales (syn. of Wates), 366 Procliaska, Herr, var. orig. by, 142

Procureur, 520

Prof. Budd (syn. of Budd), 410

Prof. Craig (syn. of Craig), 424

Prof. Cioff (syn. of Goff), 452

Prof, Price (syn. of Price), 5 tg

Prof. Wittmack, 520

Profuse, 520

Prolific (syn. of Crittenden, 184; of Prunc d"Altesse Blanche (syn. of Yel-

Hale, 237)

Prolific Damson (syn. of Crittenden), 184

Prolifigue Hâtize (syn. of Early Rivers), 200

Pronne bissioguc (Roumanie) (syn. of Hungarian Musk Prune), 465

Prozence Damask (syn. of Damas de Provence), 426

Prune Damas de Septenbre (syn. of

Damas de Provence), 426 (syn. of $\begin{gathered}\text { September Damask), } 542 \\ \text { Prune Damas D'Espagne (syn. of }\end{gathered}$

Proving Zrotsclic (syn, of Quctsche

Pointue), 524

Pruine Damson? (syn, of Shropshire). 344

Prusiallicr (syn, of Sloe), 5.4

Prune (syn. of Shropshire), 344

Prune-Abric ot; Prunc Abricote, Abri.

cotée, Abricotce Blanche, Abricotie de Tours (syns, of Apricot), 148

Prunc-Abricot de Rover (syn, of Royer Aprikosen Pflaume), 535

Prune Abricotée Rouge (syn. of Red Apricot), $32 \mathrm{I}$

Prune d Flcurs Doubles or à feurs semi-doubles (syns, of Double Flowering Gage), 192

Prute Allemand (syn. of German Prune), 219

Pruneau, 520

Pruncau de Tours (syn. of Saint (atherine), 334

Princau Jaune de Reizcnstcin (syn of Reizenstein Yellow Prune), 531

Prune Autumn Gage (syn. of Autumn Gage), 398

Pruncaur de Tours (syn. of Saint Catherine), 334 Grüne Iferzformige), 456 Pflanme), 461 Prune d'Abricos (syn. of Red Apricot), 321

Prune d'Abricot (syn. of Nectarine) 291

Prise d'Abricot, d'Abricot bicarrec Blanch, de France or Ordinaire (syns, of Apricot), 148 Apricot), 321

Prune d'Agen Double, 520 come d'Allomagnc: d"Allcmagne la 219

Prunc d'Altesse (syn. of German Prune, 219; of Suisse, 549)

Prune de Altesse (syn. of Imperatrice) 249 Prune d'Altcese blanche (syn. of Early Yellow), 203

low Impératrice) 56

Prunc d'Anerique Rouge (syn. of Myrolualan), 290

Prune d'imour, $5=0$

Prune Damas d'1talie (syn, of 1talian Dimask), 470

Prune Damas de Provence (syn of

Prune Decaisne (syn. of DeCaisne), 187

Prune de Cataloghe (syn. of Early Yellow), 203

Prunc de Cheval (syn, of Horse), 464 Prune de Chypre (syn. of Chypre, 418; of Musk Damson, 501 ; of Red Diaper, 323)

Prane de Conlommiers (syn. of Coulom. miers), 423

Prune de Délices (syn. of De Délice), 429

Prunc de Deur Saisons (syn. of Twice Bearing), 556

Prune $d c$ Donble (syn. of Double), 435

Prune de Gaillon (syn. of Early Tours), 202

Prunc de Goudin (syn. of Gondin). 454

Prune de Jcrisalem (syn. of Gelbe Jerusalempflaume, 450 ; of Jerusalem, 472)

Prute de Kirclihof (syn. of Capitaine Kirchhof), 414

Prune de Kirke (syn. of Kirke), $=60$

Prune de Laphowat, 520

Prune de la Gallissionicre (sun. of $P$ ancricana), 59

Prute de la Madcleine (syn. of Early

Prunc de la St. Martin (syn. of Saint

Prunc de la St.

Prunc de Lefinc (syn. of Norbert). (syn. of 505 Spanish Damask), $54^{6} \quad$ Prute de Lourain (syn. of Delle de

Prune Dame Auhert or d'Aubert (syn. Louvain), 400 of Yellow Egg), 386

Prune de Malte or de Malthe (syns, of Musk Danison), sot

Prute d'Ante or d'Ast (syns, of Agen), Prunc de Milan (syn. of Impiciale de Milian), 467 ${ }^{1} 38$

Prune Datte (syn. of Date, 428; of Prune de Mirabcllc (syn. of Mirabelle). Red Date, 322; of Wcisse Kaiserin, 284 563)

Prunc-Datte (syn, of Hungarian), 246 Pruse Datte Violctte (syn. of Hungarian), 246

Prune Dauphine (syn. of Dauphine), 428

Prune d'Automne, 520

Prune d'Automne de Schamal; Prune d'Automne de Sclamali (syns. of Schamal), 540

Prune d'Autriche (syn, of Date, 428: of IIungarian, 246; of Red Date, 322) Prane d'Avoine (syn. of Early Yellow), 203

Prunc de Baiay (syn, of Bavay), 155 Prunc De Bcsanson (syn. of Yellow Egr), 386

Prune Blese de Pelgique (syn of Prune de Bordeaux (syn of Saint Belgian Purple), $157 \quad$ Antoine), 537

Prunc bifere (syn. of Twice Bearing), Prunc de Bourgoyne (syn. of Bur556

Prune Duel's Favorite (syn. of Buel), 411

gundy Prunc) 412

Prune De Brianson (syn. of Briançon, 409; of Red Dianer, 302)

Prunc de Monsicur (syn. of Farly Tonrs, 202: of Orfeans, 302; of Yel. low E\&g, 386)

Prune de Monsicur Hátif or Háliè (syns, of Early Orleans), 599

Prunc de Monsicur Jaune or Pari. ch $^{2}$ Jaune (syns. of Yeflow Imperatrice), 560

Prunc de Ironsicur Tardive (syn. of Suisse), 549

Prune de Montfort (syn. of De Montfort), 430

Pruse d'Eute (syn. of Agen), 138

Prune d'Ente (svn, of Sergeant), 339

Prune d'Ente Impériale, 521

Prune de Orange (syn. of Orange), 5 to Prunc de Paisan blanche and simple (syn. of Paisan Blanche), 511

Prune de Paisan Noire (syn. of Paisan Noire), 5 Is

Prune de Pologne (syn. of Quetsche Dr. Jétriconrt), 524

Prune De Ponthriant (syn. of Pontbriant), 517

Prune de Prince (syn. of Norbert), 505 
Prune de Prinee (syn. of Prune de|Prune Impćratrice Blanclie (syn, of Prune Reine Victoria (syn. of Victoria), Seigneur), 52

White Impératrice), 375

Prune de Reine Claude (syn. of Reine Claude), 327

Prune de Rudolphe, 521

Pruse de Reizenstein (syn. of Reizenstein Yellow Prune), 53t

Prune de St. Barnabe (syn. of Early Ýllow), 203

Prune de Sainte Cotherive (syn. of Saint Catherine), 334

Prune de St. Jcon (syn. of Early St. John), 440

Prune de Soint-Jeon (syn. of Noire de Montreuil), 504

Princ de St. Jeon (syn. of St. John), 537

Prune de Sovoye (syn. of Isle-Verte), 470

Prune des Béjonnic̀res (syn. of Béjonnières), 157

Prune Des Burettes (syn. of Burettes). 412

Prune de Seigneur, $52 \mathrm{I}$

Prune de Vocance (syn. of September Damask), 542

Prune de Virginie (syn, of Myrobalan), 290

Prune de Wongenheim (syn. of Wangenheim), 368

Prine de Waterloo (syn. of Waterloo Pflaume), 56

Prune Diademe (syn. of Red Diaper) 323

Prune Diophane or Diaphane Loffoy (syns. of Transparent), 360

Prune Diaprée Blanche (syn. of Diaprée Blanche), 432

Prune Diaprée Rouge (syn. of Red Dianer), 323

Pruse d'Inde Blanc or Blanche, d'Ocuf, or d'Ocuf blanche (syns, of Yellow Egg), 386

Prunc d'ltalie (syn. of Italian Prune), 253

Prune d'oeuf or d'Oenf Violette (syns. of Red Magnum Bonum), 326

Prune d'Oeuf Marbréc (syn. of Marmorierte Eierpflaume), 491

Prune d'Orleons (syn. of Orleans), 302 Prunc du Roi (syn. of Agen, 138; of Early Orleans, 109)

Prune Early Favorite (syn. of Early Favorite), 438

Prune Eugene Sinton (syn. of Simon), ${ }_{34} 6$

Prunc-figue (syn. of Red Magnum Bonum), 326

Prune Figue: Prute figue grosse rouge (syns, of Red Date), 322

Prune Gonne (syn. of Gonne), 454

Prune Goutte d'Or De Coe (syn. of Golden Drop), 229

Prune Gros-Damas Violet (syn, of Damas Violet), 427

Prune Grosse Quetsche Nouvelle (syn. of Dorcll), 434

Prune group, history of, in America, 30, 31 ; origin of, 30 ; specific characters of, 31 ; typical varieties of, $3 \mathrm{t}$

Prune Ileverte (syn. of Isle-Verte), 470

Prune Impératrice (syn. of Red Diaper), 323

Prune Impératrice Violette (syn. of Prune Rougc De Blccker (syn. of Lom. German Prunc), 219

Prune Impériale de Sliarp (syn. of Prune Royole (syn. of Royal), 534 Sharp), 340

Prune Impériale Violette (syn. of Red

Magnum Ionum), 326

Prunes, definition of, 30; process of

of Isabella), 469 making, $124-126$

Prone Kanowo (syn. of Kanawha), 474 Catheriue Jaune (syns. of Sain

Kirke (syn, of Kirke), $260 \quad$ Catherine), 334

Prune Lawrence's Gage (syn. of Law- Prune Sans-Noyau (syn. of Stoneless), rence), 266

Prunclict (syn, of Sloe), 544 Prune Sowroge (syn. of Sloc), 544 544)

Prune-making, growth of, 31

Prane Maraichire (syn. of Duetsche Maraichère), 524

Prune-Massot (syn. of Oullins), 303

Prune Monarque (syn. of Monarch). 286

Prune Monsicur (syn. of Orleans), 302

Prune Monsieur Joune (syn. of Early Yellow, 203; of Yellow Impératrice, 569)

Prune noin (syn. of $Z$ wergpflatume), 571

Prutte noire hative (syn. of Early Prunc Zuctschen (syn, of German Tours), 202

Prune nouvelle de Dorrel (syn. of Prunicr aे ficur semi-double (syn. of

Dorell), 434

Prunc OEuf (syn. of Yellow Egg), 386

Prune-ocut (syn. of Red Magnum Bonum), 326

Pruneola (syn. of Sloe), 544

Prune-Pêche (syn. of White Perdrigon), $37 \%$

Prune Pêclte (syn. of Nectarine, 291; of Peach, 309)

Prune-Péche (syn. of Goliath), 231.

Prunc-Pêche De Calvel (syn. of Peach), 309

Prune Perdrigon hàtif (syn. of Early Perdrigon), 439

Prune Perdrigon Normand (syn, of Prunier de Simon (syn. of Simon), 346 Normand Perdrigon), 506

Prune Pctit Damas Blane (syn. of Small White Damson), 545

Prune Plum (syn. of German Prune), 219

Prune poire grosse violctte (syn. of Pear Plum), 513

Prune de Pologne (syn. of Duetsche Dr. Létricourt), 524

Prune Précoce? (syn. of White Vir. Prunier Myrobolan (syn. of Myroginal), 565

Prune Prince of Whales (syn. of Prtuicr awi fructific deux fois par lou Wales), $366 \quad$ (syn. of Twice Bearing), 556

Prune qui fructific deux fois l'on (syn. Prunicr Sainte-Catherine (syn. of Saint of Twice Bearing), 556 Catherine), 334

Prune Quetsch (syn. of German Prune), Prunier Saint-Julien (syn. of Saint 219

Julien), 335

Prune Reine Blanche (syn. of White Prumum Pyrinum praccox (syn. of

Queen), 564

Early Pear), 430

Prune Reine.Claude Gabriel Combes Prunus, differences between fruits of, (syn. of Gabriel Combes), 449

Prune Reine Claude Violette (syn. of Purple Gage), 318 tory of, 1, 2; horticultural value of. 4; variability of, 3,4 
Prunus acutifolia, 48 alleghanicnsis, characters of, 72 , 73: comparison of, with $P$. ancricana, 73 ; habitat of 73,74 i specific description of, $72-74$

Ancricana (syn, of $P$. hortulana), 6.4 ; (syn. of $P$. nigra), 69 ; aclaptation of, to cross-pollina* tion, 62, 63; characters of, 56 , 57 ; history of, 58-61; introduction of, into Europe, 59; natural habitat of, 57,58 ; specific description of, $56-63$; true and fruit characters of, 6t, 6a

Amcricana lanata (syn, of $P$. ancricana mollis), 63

Americana Mollis, specific deseription of, 63,64

Ancricana Nigra (syn. of $P$. nigra), 60

angustifolia, cliaracters of, $82 ;$ original liabitat of $, 8_{2}, 83$; specific description of, $8 \geq-S 5$

angustifolia s'arians, characters, 87, 88 ; specific description of, 87,8 . angustifolia watsoni, characters of, 85, 86: habitat of, 86; specific description of, $85-87$

armeniaca desycarfa, 48

bifera (syn, of Twice Bearing), 556 bolktaricnsis, 50

Calacllana (syn. of Tearly Perdrigon), 439

Catalana (syn. of Early Yellow), 203

Catalanica (syn. of Catalana), 415

Catalonica (syn. of Early Yellow). 203

Catclana (syn. of Early Ycllow), 203

cirasifera (syn. of Myrobalan), 200; characters of, 45,46 ; early history of, 46,47 ; specific description of, $45-48$; tree and fruit cliaracters of, 47,48

cerasifera atropur purea, 48

Cerasifcra Atropterpurea (syn. of Pissardi), 516

Cerasifcra fructu majorc (syn, of Myrobalan), 290

Ccrasifera Fructu Minore (syn. of Klcine Kirschpflaume), 476

Cerasifera Zauthocarpa (syn. of Gelbe Kirschpflaume), 450

chicasa (syn, of $P$. angustifolia), $\mathrm{S}_{2}$

chicaso var. normalis (syn. of $P$. gracilis), 98

cocomilia, characters of, 44,45 ; specific description of, 44,45 cocontilia brutia, 45

cocomilia pubcrula. 45

recomilia typica, 45

-ommunis (syn of $P$. insititia), 34 ; (syn. of $P$. triffora), 40 communis domestica (syn, of $P$. domestica), 12

contorta, 48

curdica, specific deseription of, 44 damascona dominicalis praccox (syn. of Early Orleans), 199

dasvearpa, 48

divaricata, 46,47
Prunus domostica (syn. of P. trifora), Prunus mollis (syn. of $P$. nigra), 49; characters of, 12 ; division of and how divided, 36 ; history of, in America, 18-26; origin of, 12-18; specific description of, $12-34$

Donestica Cercola (syn. of Reine (laude), $3 \geq 7$

domestica insititia (syn. of $P$. insititia), 34

Dentestica Juliana (syn, of Saint Julien), 335

damestica myrobalas (syn. of $P$. cerasifera), 45

Demestica var. cercola (syn, of Rcine Claude), $3=7$

Donestica var. Clandiana (syn. of Reine (laude), 327

elcgans, $4 \mathrm{~S}$

exigna, 13

fruticans, 43

gitantica, $4^{8}$

groctis, cliaracters of, 98 ; natoral lutilitat of, 98 ; specific descriptiun of, 98,99

grasesii, comparison of, with $D$. maritime, 96, 97; characters of, 96: specific description of, 96 . 97

trattan Tamari (syn. of $P$. triffora),

hispanica (syn. of Spanish Damask), $5+6$

hortulana (syn, of $P$. munsori. ana), 88; characters of, 64.65 ; groups of hybrids included in, 65,66 ; habitat of 66,67 ; specifie description of, $64-68$; value of to American pomology, 67

hortulana mincri, specific descrip tion of, 68, 69

hortulana rotusta, 232

hortulana robusta, discussion of group of, 67,68

ichangana, 50

injucuenda (syn, of $P$. tumbcllata injucunda), 79

insititia (syn. of Damson), ${ }_{186}$ claracters of, $34:$ comparison of, with $P$. domestica, 35, 36; discussion as to sub-species included in, 34, 35; groups included in, 39; hahitat of, in the Old World, 37; history of, in America, 37-39; specific deseription of, $34-42$

insititia glabcrrima, 36

Insititio zar. (syn. of Saint Julien), 335

italicg (syn, of Italian Damask). 470; (syn, of $P$, domestica), is japonica (syn. of $P$. triflora), 49

lanata (syn. of $P$. amcricana mol. lis), 63

littoralis (syn. of $P$. maritima), 92

latca, 13: (syn. of Gemeiner Gelbe Spilling), 451

maritima, characters of, 92 ; habitat of, 93, 94; specific description of, $92-96$; value of, 94,95 mitis, characters of, 80 ; specific description of, $80,8 \mathrm{I}$ monticola, cluaracters of, 49; specifie description of, 49

mussoniana, claracters of, 88,89 ; comparison of, with $P$. augusti. folic, 90; habitat of, 90; horticultural value of, 21; leading varieties of, 91,92 ; specific des. cription of, 88-92

Myrobalan (syn, of $P$. ccrasifcra), 45

Myrobalana (syn. of Myrobalan), 290

Myrobolana (syn. of Myrobalan), 200

ncustricnsis (syn. of Normand Perdrigon), so6

tigra, characters of, 69, 70; comparison of with $P$. amcricana 71,$72 ;$ habitat of, 70,71 ; specific deseription of, $60-72$

oeconomica (syn. of German Prune). 219; (syn, of $P$. domestica), 12 orthosepala, characters of, 97 ; specific description of, $97-98$

o.rycarpa, 13; (syn. of Becbstein Spitziflaume), 400

pendtula, 48

Pissardi (syn. of Pissardi), 516

Pissardii (syn, of Pissardi), 516

plantericnsis, 48

pomaritm, 36

provincialis (syn. of Damas de Provence), 426

pscudoarmeniaca, 45

pubcscons (syn. of $P$. maritima),

${ }^{92}$ rimularis, characters of, 99; specific description of, 99

rubella, 13

Simoni (syn, of Simon), $34^{6}$

Simonii (syn. of Simon), 346; characters of, 55 : history of, 56 ; specific description of, 55,56

Spinosa (syn. of Sloe), 544 ; characters of, 42 ; general discussion of 43,$44 ;$ specific description of, $42-44$

Spinosa coatanca, 42

Spinosa dasyphylla, 42

Spinosa flore-plcno, 42, 43

Srinosa, folits lancelatis (syn. of Sloe), 544

Spinosa macrocarpa, 43

Spinosa praecox, 42

Spinosa purpurea, 43 spinosa sessilifiora, 42

spinosa tupica, 42

subcordata, claracters of, 74 ; habi tat of, 74, 75; specific description of, $74-77$; typical form of , 76

subcordala kclloggii, specific description of, $77,7 S^{\circ}$

subrotunda, $t_{3}$

subsylacstris, 36

sylvestris, 13

syriaca, 36

torda, characters of, 81 ; specific description of, 81,82

thibctica, 50 silwestris (syn. of Sloe), 544 


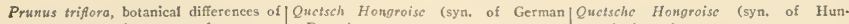
53. 54: characters of, 49, 50; Prune), $219 \quad$ garian), 246 early history of, 50-52; intro- Quetsch Longue (syn, of German Quctsche Jounc (syn. of Quetsche Dr, duction of, into America, 52; Prune), $219 \quad$ Létricourt), 524

natural habitat of, 51; specific Quctsche (syn. of German Prunc, 219; Quctsche Jaunc de Hortwiss (syn. of description of, 49-55; value of of Italian Prune, 253i of Korai, 478) fruit of, 52,53 ; varialility of, 54. 55

umbellato, characters of, 78 ; habitat of, 79; specific description of, 78,79

umbclloto injucsinda, characters of, 79. 80 ; specific description of, 79. 80

ursino, 45

ursina flava, 45

vinaria, 13

zuatsoni (syn. of $P$. angustifolio

ivotsoui), $8 \mathrm{~s}$

Pseudo Mirabelle, $52 \mathrm{I}$

Purple Domson (syn. of Damson, 186;

of Winter Damson, 567)

Purple Diaper (syn. of Violet Diaper), 365

Purple Egg (syn. of Red Magnum Bonum), 326

Purple Egg (syn. of Hudson), 243

Purplc Egg (syn. of Duane; of Red

Magnum Bonum, 326)

Purple Favorite, 521

Purple Fovouritc (syn. of Purple Favorite), 521

Purple Flesh, 521

Purple Gage, 318

Purple-leaved Hybrid, 521

Purple-leaved Plum (syn. of Pissardi). 516

Purplc Magnum Bonum (syn. of Duane,

196; of Red Magnum Bonum, 326; of Smith Orleans, 348)

Purple Panhandle, 521

Purplc winter Domson (syn. of Winter Damson), 567

Purple Yosemite, 521

Purfur Pfaume (syn. of Red Date) 322

Puymirol d'Ente, 522

P. violette americaine (syn. of Ameri(an Violet), 394

Quackenbos (syn. of Quackenboss), 319

Quetscbe à feuille argentíc, 523

Quetsehe Aplatic, 523

Quetsche Blcke d'Itolic (syn. of Italian Prune), 253

Quetsche Rognon de Coq (syn, of Rognon de Coq), 533

Quetsche Buh]-Eltershofen, 523

Quctsche Communc; Quetsclie D'Nlle. magne; Quctsche d'Allemagne Grossc

(syns, of (icrman Prunc), 219

Quctsche Datte (syn. of Date, 428 ; of Ilungarian, 246)

Quetsche Datte des Allemands, 523

Quctsche Dattc Violettc (syn. of llungarian), $24^{6}$

Quctsche de Basalicza (syn. of Bazalicza), 399

Quctsche de Breme (syn. of Austrian Quetsche), 397

Quetsche de Dobrowitz, $\$ 23$

Quctsche de Dollon (syn. of Dollaner). 433

Quctsclic De Dorclle; De Dorelle Nouvelle Grand; De Dorclle Nonácll: Grande (syns. of Dorell), 434

Quetsche de Doubrauic (syn. of Quetsche de Dobrowitz), 523

Quctscic de Francfort (syn. of Frankfort Peach), 447

Quctsche de Horgric (syn. of Date. 428 ; of Hungarian, 246; of Ungarisb. 36 )

Quetsche de Kreuter, 523

Quetsche de Kreuter (syn. of Quetsche de Kreuter), 523

Quctsche de Litricourt (syn. of Ouetsche Dr. Létricourt), 524

Quetsche de Leipzig (syn. of Merunka), 494

Quctsche de Lorraine, de Mologne, or de Mcta (syns, of German Prune), 220

Quetsche de Nillot, 523

Quctsche de Prozince (syn. of Quet. sche Pointue). 524

Quetsche De Ransleben, 523

Quetsche des Allcmands (syn. of German Prune), 220

Quetsche de Transylvanie, 523

Quaker, 522

Quality, 522

Orostche (syn, of German Prune), 219

Quebec, 522

Queen, 522

Quecn Claude or Cloudia (syns, of Reine (laude), $32 \%$

Queen Claude of Bavay (syn. of Bavay), 155

Quccre Mother (syn. of Myrobalan, 290; of Queen Mother, 522)

Queen May, 522

Qucen Mother (syn, of Queen Motber). 522

Queen Mother, 522

Queen of Arkansas, 523

Qucen Victoria (syn. of Sharp, 340; of Victoria, 363)

Quetsch; Quetsch Allcmande (syns, of German Prune), 219

Quctsche de Transilranie (syn. of Quetsche de Transylvanie), 523 Quctsche d'Italic (syn. of Italian Prune), 253

Quetsche Domestique (syn. of German Prune), 220

Quetsche Dr. Létricourt, 524

Ouetsche Freestone, 524

Quetsche Grosse (syn. of German Prune), 220

IIartwiss), 459

Quetsclic Joune de Reizcrstcin (syn of Reizenstcin Yellow Prunc), 53 I

Quetsclic Jaune Prćcoce, 524

Quctsclie Jaunc Pricace (syn. of Quetsche Jaune Précoce), 524

Quetsche Jounc Tordize (sya. of Gelbe Spitzwetsche), 451

Quctsche L.ongne Précoce, 524

Quetsche Maraichére, $5 \geq 4$

Quetsche musquéc de IIongrie (syn. of lfungarian Musk Prune), 465

Quetsche-Piche de Francfort (syn. of Frankfort Peacls), 447

Quetsche Pointue, 524

Quetsche Pricoce de Buhlerthal, 52.

Quetsclie Précoce De Frauendorf, 524

Quctsclic Pricace de Biondcek (syn, of Biondeck), 403

Quetsche Précoce de Fürst (syn. of Fürst), 217

Quctsclic Prícoce de Fürst (syn. of

Fürst Danison) 448

Quetsche Précoce Liegel, 525

Quctsche Précoce de Licnel (syn, of

Quetsche Precoce Licgel), 525

Quetsche Pricoce de Lircos (syn. of

Pricoce de Lucas), 518

Quetsche Pricoce de Reutlingen (syn. of Rentlinger Frühzwetsche), 531

Quetsclie Précoce De Schamal, 525

Ouctsche Precoce d'lisslingen (syn. of Esslinger Frühzwetsche), $4+4$

Onctsche Prícocc de I'angenteim (syn. of Wangenheim), 368

Quetsche Ronde, 525

Ouctsche Rowge de Sclimidt (syn. of Schmidt Rote Zwetsche), 54:

Quctsclic Suréc (syn. of Large Sugar Prunc), 480

Quctsche Turkish (syn. of Turkish Prune), 556

Quetsche Verte D'Italie, 525

Quctschen (syn. of German Prune), 219

Quetzen (syn. of German Prunc), 220

Ouintinye, quoted, 455, 496, 500, 53: Quitique, 525

Rache!, 525

Rademakers, 525

Rademaker's Prune (syn. of Rademakers), 525

Ragland, 525

Rainfall, effects of, 104

Rains (syn. of Kanawha), 474

Raisin, 525

Ramsey, F. T., var. orig. by, 525

Ramsey Last, 525

Ranctte, 526

Quctsche Grossc Blauc de la Iforms (syn. of Zwetsche von der Worms), 572

Quctsche Grosse Nouvclle De Dorrct (syn, of Dorell), 434

Quetsche Hàtive, 524

Quetsche Hátive de Licgel (syn. of Ronslebens Pfoume or Zuctsclic (syn. Quetsche Précoce Liegel), 525

Rong (syn, of Lang), 478

Rangheri, 526

Rangheri's Aprikosen Pfiaume: Rong. Icri's Friilic Golbe Mirabelle; Ranaheri's Frïle Mirobelle: Rangheri's Gelbe Mirobelle; Rangheris Mira. belle: Rongheris Mirabelle (syns, of Rangheri), 526

of Quetsche Dc Ransleben), 523 
Rareripe, 526

Rare Ripe (syn. of Rareripe), 526 Ray, 526

Raymond, 526

Raynes, 526

Rea, John, quoted, 32, 407, 455

Reagan, 526

Reagles, C., quoted, 320; var. orig. by, 395, 526, 557

Reagles' Ancient City (syn. of Ancient City), 395

Reagles' Gage (syn. of Reagle Gage), 526

Reagle Gage, 526

Reagles' Union Purple (syn. of Union), 557

Rebecca, 526

Reche, 527

Red Apricot, $32 \mathrm{I}$

Red Apricot (syn. of Apricot), ${ }_{148}$

Red Apricot; Red Apricot Plum (syns. of Red Apricot), 321

Red Aubert (syn, of Red Magnum Bonum), 326

Red Bontm Magnum (syn, of Red Magnum Bonum), 326

Red Cloud, 527

Red Damask (syn, of Orleans), 302

Red Date, 322

Red Date-plum (syn. of Red Date), 322

Red Diaper, 322

Red Diaper; Red Diaper Plum; Red Egg Plum (syns. of Red Diaper), 323

Red Egg; Red Egg Plum (syns, of Red Magnum Bonum), 326

Red Fotheringham (syn. of Fotheringham), 212

Red Gage, 527

Red Gage (syn. of Long Scarlet), 485

Red Gage (syn. of Red Gage), 527

Red Gage of Dutchess County, 527

Red Glass, 527

Red Glass Junior, 527

Rcd Gold (syn. of Gonzales), 232

Red Horse, 527

Redick, 527

Red Impcrial (syn. of Impératrice, 249; of Red Diaper, 323)

Red Imperial (syn. of Red Magnum Bonum), 326

Red June, 323

Red June (syn. of Red June), 324

Red Magdalene, 527

Red Magnum (syn. of Red Magnum Bonum), 326

Red Magnum Bonum, 325

Red Magnum Bonum (syn, of Cooper. 423; of Impératrice, 249; of Red Magnum Bonum, 326; of Smith Orleans, 348 )

Red Magnum Bonum (syn. of Duane), I96

Red May, 527

Red Mirabelle (syn, of Myrobalan), 290

Red Mirobalane (syn. of Myrobalan), 290

Red Muscle; Red Mussell (syns. of Muscle), 5or

Red Nagate (syn. of Berger, 160; of Cbabot, 172; of Red June, 324)

Red October, 528

Red Orlcans (syn. of Early Orleans), 199 Red Orlcans; Red Orleans Plum (syns. of Orleans), 302
Red Panhandle, 528

Red Pear, 528

Red Peascod, 528

Red Perdrigon, 528

Red Perdrigon (syn. of Red Perdrigon), 528

Red Pescod (syn. of Red Peascod), 528

Red Plum, 59

Red Primordian, 528

Red Primordian (syn, of Red Primor. dian), 528

Red Prune, 529

Rod Queen Mother (syn. of Ducen Mother), 522

Red Saint Martin or St, Martin (syns, of Saint Martin), 336

Red Skin, 529

Red Violet, 529

Red V'irginal, 529

Red Wheate (syn. of Wheat), 563

Red Winter, 529

Reed, 529

Reed, P. H., var, orig. by, 529

Reel, 529

Reeves. Samuel, var, orig. by, 228

Regina, 529

Regina noüa; Reina Nora (syns, of Eelle), 158

Reina Nova or Reine Nara (Berre) (syns, of Bclle), 158

Reine Blanche; Reine Blanche de Galopin (syns. of White Oueen), 564

Reine Claud: Reine-Claude (syns, of Reine Claude), 327

Reine Claude, 326

Reine Claude (syn, of Bavay, 155; of Small Reine Claude, 347)

Reine-Claude Abricotine, 529

Rcine-Claude d Fleurs Semi-donble or Reine-Clande de Juillet (syn. of July feur scmi-double (syns, of Double Flowering Gage), 102

Reine-Claude Aler. Dumas (syn. of Purple Gage), 318

Rinc-Claude Aloise (syn. of Alois Reine Claude), 393

Reine-Claude Althan's (syn. of Alt-

ham), $14 \mathrm{t}$

Reine-Claude Ancienne, Blanche Blanche Grosse Espece, Blanche lo Grossc (syns, of Reine Clande), 3.27 Reine-Claude Azurée (syn. of Azure) 398

Reine+Claude Bavay Hâtize (syn, of July Green Gage), 474

Rcine-Claude Blanche (syn. of Small

Reine Claude), 347

Reinc-Claude Blanche de Boston (syn. of Imperial Gage), $25 \mathrm{I}$

Reine.Clatsde Blanche Pctitc Espece (syn. of Small Reine Claude), 347 Reine-Claude Bletce (syn. of Blaue Reine Claude), 405

Rcine-Claude Boddacrt (syn. of Boddaert), 165

Reinc-Claude Braunati (syn, of Abricotée de Brannau), 39 r

Reine-Claude Bryanston (syn. of Bryanston), 168

Reine-Claude Cbauviere (syn. of Chanviere), $4^{\mathrm{I} 7}$

Reine-Claude Comte Althan or d'Althan Reine-Claude d'Althan: Reine Claude d'Althanst (syns, of Altham), 141
Reine Claude Coulon (syn. of Coulon Reine (laude), 423

Reine-Claude d'Alais (syn. of Alois Reine Claude), 393

Reine-Claude d'Angoulcme (syn. of Angoulcme), 395

Reine-Claude d'Automne (syn. of Autumn Gage), 398

Reine-Claude Davion (syn. of July Green Gage), 474

Reine Claude de Bavay (syn. of Bavay), I 55

Reine-Claude de Baray Hâtive (syn. of July Green Gage), 474

Reine-Claude De Berger (syn. of Peach), 309 Bleeker (syns, of Blceker), ${ }_{163}$

Rcinc-Claude de Boddacrt (syn. of Boddaert), 165

Reine-Claude de Brahy (syn. of Brahy), 408

Reine Claude de Brignais, 529

Reinc-Claude de Brignais (syn. of Reine Claude de Brignais), $5=9$ Reine.Claude de Cbambourcy (syn. of (hambourcy), 174

Rcine-Claude de Conte Hathen (syn.

Reine Claude d'Ecully, 529

Reine-Claude de Flushings (syn. of $1 \mathrm{~m}$. perial Gage), 25 I

Reine-Claude De Guigne (syn. of Trans. parent), 360

Reine-Claude d'Ecully (syn, of Ecully), $44^{1}$

Reine-Claude de Jodoigne (sy'n. of Jodoigne), 472

Reine-Clande de Juillot (syn. of July Reinc-Claude de Lazurence (syn, of Lawrence), 266

Reine Claude de l'Echoisier, 530

Rcinc-Clande de Mcroldt (syn. of Meroldt), 494

Reine Claude de Mezel, 530

Reine-Clande de Monroe (sy'n. of IIonroe), 287

Reine-Claude de Montmorency (syn. of Montmorency), 499

Reine Claude de Razaimbaut, 530

Reine-Clande de Razaimbant (syn. of Reine Claude de Razaimbaut), 530

Reine Claude de Saint-Avertin, 530

Reine Claude Descarde, 530

Reine-Clande de Schuyler (syn. of

Schuyler Gage), 541

Reine Claude de Vandenbrok, 530

Reine Claude de Wazon, 530

Reine-Claude de Webster (syn. of Webster Gage), 562

Reine-Claude de Woolston (syn. of Woolston), 567

Reine-Claude D'Henrietta (syn, of Henrietta Gage), $46 \mathrm{I}$

Reine-Claude d'Hudson (syn. of Hudson Gage), 465

Reine-Claude Diaphane (syn. of Transparent), 360

Reinc-Claude Diaphane Hätisce (syn. of Early Transparent Gage), 440

Reine Claude d'Oberdieck, 530
Reine-Claude de Bleecker or de of Altham), I4t 
Reine-Claude d'October; Reinc-Claude|Rcine-Cloude Scmi-Double (syn. of Rivers, Thomas, var. orig. by, 149, 153 , d'Octobre (syns, of Late Reine Double Flowering Gage), 192 $185,200,233,24 \mathrm{I}, 286,406,425$, (lande), 481

Reine-Cloude Dore; Reine Cloude Daréc; Reinclaude d'oree (syns. of Reine Claude), 327

Reine-Claude d'Oullins (syn, of Onllins), 303

Reine-Cloude du Comte d'Althan or Hothen (syns, of Altham), 14t

Reine.Clande Geonte (syn. of Reisen2wetsche), $53 \mathrm{I}$

Reine-Claude Grosse (syn, of Reine Clande), 327

Reine Claude group, 27-29; origin of, 27-29: character of, 29: leading varieties of, 29

Reinc.Cloude Hátièe (syn. of Jirly Green Gaze), $4 i 4$

Reine Claude Hamaitre, 530

Reinc-Claude Hótive d'Avion (syn. of July Green Gage), 474

Reine-Claude Hátize de Bavay (syn. of July Green Gage), 474

Reine-Cloude Impériale or Impériale de Prince (syns. of Imperial Gage), 25 t

Rcine.Claude Jaune De Dana (syn, of Dana Yellow Gage), 428

Reine-Clande Jaune De Prince (syn. of Yellow Gage), 388

Reine-Cloude Lotinois (syn. of Chambonrcy), 174

Reinc-Cloude mit Halbgefullter Bluthe (syn. of Double Flowering Gage), 192

Reine-Cloude Monot (syn, of Bavay), 155

Reine-Claude Monstreuse de Bavey (syn. of Bavay), 155

Reine Claude Monstrueuse de Mezel, 530

Reine.Claude Moyret (syn. of Moyret), 500

Reinc-Cloudcnartige Aprikosen Pflaume (syn. of Apricot), 1.48

Reine-Claude Noire de Woolston (syn. of (Woolston), 567

Reine-Cloude Petite or Petite Espice (syns. of Small Reine Clande), 347

Rcine Cloude Précoce (syn. of Oullins), 303 cine-Clowde tordive (syn. of Chambourcy), 174

Reine-Cloude Tordize (syn. of Late Reine (lande), $48 \mathrm{I}$

Reine-Clande Tardive de Chambonrcy: Reinc-Cloude Tordivo Lotinois (syns. of Chambourcy), 174

Reine Cloude Tronsporent: Reinc Clasde Tronsporente (syns. of Trans. parent), 360

Reinc-Cloude Verde Perdrigon (syn. of Reine Clande), 327

Reinc-Cloude Verte (syn. of Cham bourcy, 174; of Reine Clande, 327)

Reinc-Claude Verte Imfirialc or Verte Supericure (syns. of Imperial Gage),

Reire-Claude Verte Tiquetée (syn. of Reine Claude), 327

Reine-Claude Violette (syn, of Blaue Reine Claude, 405; of Purple Gage, 318)

Reine-Claude von Bavays (syn. of Bavay), 155

Reine-Claude von Boddaert (syn. of Boddaert), 165

Reine Claude von Bollwiller, 530

Reine Claude Von Rralıy (syn. of Brahy), 408

Reine-Claude von Jodoigne (syn, of

Jodoigne), $47^{2}$
Reine-Claude von Onllins (syn. of Oullins), 303

Reine-Claudia; Reinc-Claudia Blonche Robinson (syn. of Miner), 28t Lo Grosse (syns, of Reine Claude) Robinson, 329 327

Reine de Chypre (syn. of Red Diaper) 323

Reine des Mirabelles, 530

Reinctte Claude d'Althan or Comtc d'Althan (syns. of Altham), 14 t

Reine Victoria, $53 \mathrm{I}$

Reine Victorio (syn. of Vietoria), 363

Reisenzwetsche, $53 \mathrm{t}$

Reitenstciner Gelbe Zuctsche (syn. of Gelbe Spätzwetsche, $45 \mathrm{t}$; of Reizen stein Yellow Prune, 531)

Reizenstein Yellow Prune, 53I

Reizenstcin's Ycllow Prune (syn. of Reizenstein Yellow Prune), $53 \mathrm{r}$

Rensleben, M., var. orig. by, 523

Rine-Clande Précoce de Rasimbar baut), 530

Reine-Cloude Rouge (syn. of Belle), 158

Reine-Claude Ronge Americaine (syn. of Red Gage), 527

Reine-Claude Rouge Comte Althan; Rouge de Hathen; rouge du conte Hethon: Rouge du Comtc Hcthan (syns, of Altham), ${ }^{14}$ I

Reinc*Claude Rouge de Prince (syn. of Red Gage), 527

Reine-Cloude Rowge de Septembre (syn. of Belle), I5 8

Reinc-Claude Rouge de Van Mons (syn. of Belle), 158

Reine-Clande Rouge of September: Reine-Cloude Rouge Van Mans (syns. of Belle), 158

Reine Clande Sagot, 530

Renssclaar, Rensselaer or Reussclvar Goge (syns. of Reine Claude), 3 7

Reutlinger Frühzwetsche, 531

Reutlinger Friblizwetsche (syn, of Reutlinger Frühawetsche), 531

Rex (syn. of Spanish King), 546

Rhinebeck Yellow Gage, 53 I

Rhodes, $53 \mathrm{I}$

Rhue, $53 \mathrm{I}$

Rhwe's Secdling (syn. of Rhue), 531

Rice Seed (syn. of Gaviota), 450

Richard Trotter, 531

Richland, $53 \mathrm{I}$

Riga 11, 532

Riga IIS (syn. of Aubert), 397

Rigny, 532

Rising Sun, 532

Rivers, Francis, var. orig. by, 403

$438,440,453,459,461,481,482$,

$489,518,532,549,550$

Rivers' Bluc Prolific; Rivers' No. 4 (syns, of Blne Prolific), 406

ivers' Blue Prolific: Rivers' Early Rizers' Eorly No. 2: Rizers' Eorly Prolific or Early Prolific Plum, Rivers" Frīhe Fruchtbare; Rivers Fruhpflaume; Riters' No. 2 (syns. of Early Rivers), 200

Rivers Early, 532

Riters Eorly; Rivers Eorly Fatorite: River's Early Favouritc; River's Eorly No. I: Ritecrs Frïhplowme; Rivers Früh Pflanme; River's No. : (syns, of Early Favorite), 438

Rivers' Early Apricot (syn. of Early Transparent Gage), 440

Rivers' Early Damson (syn. of Rivers

Early), 532

Fruhpflatume; Rivers' No. 2 (syns. of Rivers' Early Transparent Gage (syn. of Farly Transparent Gage), 44

River's Late Prolific (syn. of Late

Prolific), 481

Rivularis (syn. of Towakong), 554

Robe de Sorgent or Sergent (syn. of Agen), 138

Robe de Sergcant or Sergent (syn. of

Sergeant), 339

Robert, 532

Roby, H. R., var, orig. by, 532

Roby Yellow, 532

Roch-eourbon: Roche-Carbon; Roche Corbon; Roche Courbon (syns, of Red Diaper), 323

Rockford, 532

Rocky Mountain, 532

Rocky Mountoin Sccdling (syn. of

Rocky Mountain), 532

Rodney, 532

Radncy Goge (syn. of Rodney), 532

Rodt Blaue Zwetsche, 533

Rodt Frühe Grosse Pflaumenzwetsche, 533

Rodt's Grosse Friihe Pflowmen-Zwetsche (syn. of Kaiser Wilhelm), 474

Roe, William, var. orig, by, 398

Roe's Autumn: Roc's Autumn Goge (syns. of Autumn Gage), 398

Rognon D'Ane, 533

Rognon de Coq, 533

Rognon-dc-Coq de Nikito (syn. of

Nikitaer Ilahnenplaume), 504

Roi (syn, of Royal Tours), 332

Roi-Claude (syn. of Onllins), 303

Roi d'Agen (syn, of Agen), 138

Rollande Galloppi, 533

Rollingstone, 330

Rolling Stone (syn. of Rollingstone), 330

Ronald Faney, 533

Rood (syn. of Empire), 203

Rood, Ezra, var, orig. hy, 204

Ros-Pruim Double, 533

Ros-pruim Double (syn. of Ilorse), 464

Roselle, 533 
Rosunen Pfaume (syn. of Bechstein Rowge de Blecther (syn. of Lombard), Royale Hative de Liegel, 535 Spitzpflaume, 400 ; of Rote Zwetsche, 268 534)

Ross, 533

Ross, J. T., var. orig, by, 533

Ross Seedling (syn. of Ross), 533

Rossy Fruhe Zwetsche, 533

Rossy's Frith Zwetsche (syn. of Rossy Frube Zwetsche), 533

Rostraye Bell, 5.33

Jote Aprikosenpflaume or Aprikosenzwetsche (syns, of Red Apricot), $32 \mathrm{I}$ Rote Claude (syn. of Relle), 158

Rote Cuprische Pfoumc (syn. of Red Diap̣er), 323

Rote Dattelzwetsche (syn. of Red Date), 322

Rote Diapré: Rote Eier Pflaume; Rote Nartuke; Rote Masche; Rote Osterci; Rote Ross Pfaume; Rothe Diapre or Diaprie; Rothe Eicrpfiaume; Rothe Morunke; Rothe Sirse Pfoume; Rothe Violen Pfaume; Rosige Corbon (syns, of Red Diaper), 323

Rote Eier Pfloume; Rote Kaiserpflaume; Rote Kaiser Zuctsche; Rothe Koiserpflawe; Rothe Kaiscrawetsche (syns. of Red Magnum Bonum), 326

Rote Feigen Pfoumc (syn. of Red 1)ate), 322

Rote Fruli Damascene (syn. of Damas Rouge IJatif), 427

Rotc Herbst Zcibcrl (syn. of Rotes Zeiberi), 533

Rote Jungfernpflaume (syn. of Red Virginal), 529

Rouge de Brevoort (syn. of Brevoort Purple), 408

Rougc de Denxiston (syn, of Denniston Red), 431

Roupe de Liegcl (syn. of Royale JIative de Liegel), 535

Rouge Hitive (syn. of Red Primor. dian), 528

Rouge llative de Nitka, 534

Rouge tardive de Coe (syn. of Saint Royalc Hative de Nikita (syn. of Early Martin), 336

Rongc Tardive De Coc (syn. of Saint Martin Quetsche), 538

Roulette, 534

Round, 534

Round Black Damson (syn. of Dam son), 186

Round Damson (syn, of Damson), 186

Round Leaf Wonderful, 534

Rousse De Guthrie (syn. of Guthrie Russet), 457

Rowlett (syn. of Roulette), 534

Rowley, Jos, var. orig. by, 534

Ruwley, 534

Roxburgh, quoted, $5 \mathrm{I}$

Royal, 534

Royal (syn. of Climax, I78; of Royal, 534)

Royal Bullaee, 534

Royal Dauphin (syn. of Royal Dauphin). 534

Royal Dauphin, 534

Royal Dauphine (syn. of Sharp, 340 of Victoria, $36_{3}$ )

Royal de Braunac, 535

Rote Kirschpflaume (syn. of Myrohalan), 290

Rote Mirabelle, 533

Rote Nectarine (syn. of Nectarine), 29 I

Rote Washington (syn. of Brevoort Purplc), 408

Rote Zipper; Rote Zuctschie (syns. of Bechstein Spitzpflaume), 400

Rote Zwetsche, 534

Roter Perdrigon: Rother Perdrigon (syns. of Red Perdrigon). 5=8

Roter Spilling (syn. of Hofinger Mirabelle), 462

Rotes Toubcnhers (syn. of Queen (lother), 522

Rotes Zeiberl, 533

Rothgcficlite Goldpfounc (syn. of Belle de Schöencberg), 401
othe Aprikosenpflaume (syn. of Red

Rothe Aprikose

Rothe Frithdamascene (syn. of Damas Rouge Hatif), 427

Rothe Jungfernpflaume, 534

Rothe Königspflaume (syn. of Royai Tours), 332

Rothe Mirobelle (syn. of Myrobalan), 290

Rothe Nectarine (syn. of Nectarine), 201

Rothe Nektarine (syn, of Peach), 309 Rotharhon (syn. of Winesour), 566 Rotgcfleckte Gold Pfaume (syn. of Belle de Schöcneberg), 401

Rouge Corbon (syn. of Red Diaper), 323

Royal de Vilvorde (syn. of Jodoigne), 472

Rovale (syn. of Mayer Königspflaume, 493; of Royal, 534; of Royal Tours. 332)

Royalc Dauphin (syn. of Royal Dauphin), 534

Royale de Behrens, 535

Rovale de Belrens (syn, of Royale de Behrens), 535

Royale de Brounou (syn, of Bucliner Konigspflaume), 410

Royale de Haffner (syn. of Haffne Königspflaume), 458

Rosale de Koch (syn. of Koch Königspflaume), 477

Rovale de Lucos (syn. of Lucas Königs. pflaume), 487

Rovale de Mayer (syn. of Mayer Königspflaume), 493

Royale de Peris Tordive (syn. of Perdrigon Tardif), 515

Royale de Siebenfreud, 535

Royale de Sicbenfreund (syn. of Royale de Siebenfreud), 535

Royale de Tours (syn, of Royal Tours), 332

Royale de Tropp (syn. of Trapps Königspflaume), 555

Rovale du Dr. Koch (syn. of Koch Königspflaume), 477

Rovole Hative (syn. of Early Royal), zor

Rovale Hátice or Hitize de Liegal (syns. of Royale Hative de Liegel), 535

Royal Hative de Nikita (syn, of Early Royal of Nikita), 440

Royale tres-grosse (syn. of Royal), 534

Royale Violette de Keind1, 535

Royale Violette de Kcindt (syn. of Royale Violette de Keindl), 535

Roval Green Gage (syn. of Reine Claude), 327

Royal Hàtive (syn. of Early Royal),

Royal of Nikita), 440

Royal of Tours (syn. of Royal Tours). 332

Royal Pea, 535

Royal Plumb; Royal Red (syns. of Royal), 534

Royal red Plum; Royal Tours (syns. of Royal Tours), 332

Royal Tours, 332

Royer Aprikosen Pflaume, 535

Ruben Burgunder Zwetsche, 535

Ruby, 535

Rudolph, 536

Rudolph's Pfaume (syn. of Prune de Rudolphe), $52 \mathrm{I}$

Rudolphspflaume (syn. of Rudolph), 536

Rue, 536

Rue, I. B., yar, orig. by, 536

Ruff Choice, 536

Ruff Spanisb, 536

Runde Brisette (syn. of Late Mirabelle), 263

Runde Rote Damascene (syn. of Liegel Rote Damaseene), 484

Runyon, O. R., var. orig. by, 359

Russian Mirabelle, 536

Russian No. 2, 536

Russian No. 3, 536

Russian plum 20 M. (syn. of Burbank),

170

Rutland Plumcot, 333

Sabel Pfoume (syn. of Hungarian),

2,46

Sada, 536

Saffold, 536

Sagetsuma (syn. of Sagetsuna), 536

Sagetsuna, 536

St. Anne, 537

Saint Antoine, 537

Saint Antonio, 537

Saint Aubert (syn. of St. Aubert), 537

St. Aubert, 537

Sainte Barnabé; St. Barrabée (syns. of Early Sellow), 203

Saint Catherine, 33

St. Catbarine; Soint Cotherine; Sainte Catherine; Sainte-Catherine; SainteCatherine joune, ordinaire or de Tours; St. Katharine (syns. of Saint Catherine), 334

Sointc-Catherine (Belgien) (syn. of Red Magnum Bonum), 326

Soint Clair; St. Claire; Saint Claire

Saintc-Claire (syns, of Bavay), 155

Saiut Clowd (syn, of Goliatb), 231

Soint Cyr (syn, of Morocco), 288

St. Etienne, 537

St. James, 537

St. James' Quetsche (syn. of St. James), 537 
Soint-Jean (syn. of Noire de Mon-|Schamal, M1., var. orig, by, 525, 540 September, 542

trevil), 504

Saint Jcan (syn. of Early Tours), 202

St. Jcen (syn. of Early St. John), 440

St. John, 537

St. Julian; St. Julien; Soint Julien; Saint Julien Petit (syns. of Saint Julien), 335

Saint Julien, 335

St. Julien group, discussion of, $4 \mathrm{I}, 42$ St, Lawrence, 537

Soint Loo (syn. of Valence), 557

Saint Martin, 336

Soint (or St.) Martin or Mortin Ronge (syns, of Saint Martin), 336

Saint-Martin; Saint Martin's; Saint Martin's Quctsche (syns, of Saint Martin Quetsche), 538

Saint Martin Quetsehe, 538

Saint Maurin; St. Maurin; Saint Mauriniano (syns. of Agen), ${ }_{13} 8$

Saint Pierre, $53^{8}$

St. Reme, 538

Sainte Therese, 537

Sandall, var, orig, by, 538

Sandall, 538

Sandall's Plum (syn. of Sandall), 538

Sanders, 538

Sanderson, 538

Sandle, $53^{8}$

Sandoz, 538

Sand Plum, 538

Sangrine (syn, of Satsuma), 337

Sonkt-Julians Pfaumic (syn. of Damson), 186

Sankt-Michel's Pflowme (syn. of September Damask), 542

Sannois, $53^{8}$

Sannois Quetscbe (syn. of Sannois), 538

Sans Noyau (syn. of Stoneless), 353

Sans-Noyau (syn. of Stoneless), 353

Sansoto, 539

Santa Rosa, 539

Sapa, 539

Saratoga, 539

Sargent, quoted, 97

Saskatchewan, 539

Satin, 539

Satsugon, 539

Satsuland, 539

Satsuma, 337

Sotsimo (syn, of Berger), 160

Satsuma Blood (syn, of Satsuma), 337

Sauere Weinffoumc (syn. of Winesour), 566

Schamol (syn. of Schamal), 540

Schamals Frühzwetsche (syn. of Quct- gon Tardif), 515

sche Précoce De Schamal), 5-5 Scpicmber Domoscenc, Damosk or Dom:

Schamals Herbstpfioumc (syn. of son (syns. of September Damask). Schamal), $54^{\circ}$

Scheidweiler, M., var. orig. by, 205 September Damask, 542

Schenectady, 540 Sirdoli Irek (syn. of Gelhe Kirsch.

Schenctady Cathorite, Cotherine or plaume), 450

Catherine Plum (syns, of Schenec- Sergeant, 339

tady), 540

Schieblers Eier Pflaume, 540

Schiebler Luisante, 540

Schlachter Früh Zwetsche, 540

Schlchen Pfaume (syn. of Damson), Sharp; Sharpe's Emperor; Sharp's Em186

Schley, 540

Schley, Philip, var, orig, by, 425

Schloy's Lerge Red (syn, of Schley), 540

Schmidt Rote Zwetsche, 54 t

Schneider, quoted, 44

Schoenthal, $54 \mathrm{r}$

Schönc September Königsffaume (syn. of Belle), 158

(syn. of Belle de Louvain), 400

Schüne von Riom, 54

Schöne von Schöncberg (syn, of Belle Shepler (syn. of Red Magnum Bonum).

de Schöeneberg), 401 - 326

Schuyler, General, var, orig. by, 541 Shepway Bulleis, 542

Schuyler Gage, $541 \quad$ Shilling, 543

Schuyler Gage (syn, of Schuyler Gage), Shipper, 3+1, 543 54

Shifper (syn. of Marketman), 49 t

Schuyler or Schuyler's Gage (syns. of Shipper Pride; Sbipper's Pride; Ship.

Reine Claude), 327

Schwarze Mirobelle (syn. of Norbert).

Schwarze Muskatcller Pflaume (syn. of MLusk Damson), 5or

Schuarse Reine-Clande (syn. of Blaue Reine Claude), 405

Schwarser Perdrigon (syn. of Nor-

mand Perdrigon), 506

Schweizer Pflaume (syn. of Suisse) 549

pers' Pride (syns. of Shipper), 34

Shirata Bene, 543

Shiro, 342

Shire Smomo (syn, of Berger, 160; of Ogon, 298; of Red June, 324)

Shropshire, 344

Shropshirc Demson (syn. of Slaropshire), 344

Shviata Bene, 543

Siamese, 543

Sidone, 543

Scliweizer Zuctsche; Schweizerawetsche

(syns, of Italian Prune), 253

Schweizer Zwetsche (incor.) (syn. of

Large Englisb), 262

Scioto, $54 \mathrm{I}$

Scott \& Co., var. orig. by, 211

Scribner, 54 I

Sea (syn. of Howell), 465

Sea-Egg, 541

Semiana, 541

Semiana (syn. of Suisse), 549

Siebenbürger Pflaume, 543

Sicberourger Pfoume (syn. of Early Yellow), 203

Sicbonburger Zectsche (syn, of Quetsche de Transylvanic), 523

Sicbenfrcud's Königsffoume; Sieben. freund's Königspllaume (synts. of Royale de Siebenfreud), 535

Sicrra, 543

Sierra Crimson (syn. of Sierra), 543

Silassy, 543

Sancre Wein Pfaume Von Yorkshirc (syn. of Winesour), 566

Saunders, 339

Saunders Seedling (syn. of Saunders). 339

Sauvageon, 539

Savoy (syn. of Isle-Verte), 470

Sayer Favorite, $54^{\circ}$

Scaldatello (syn. of Scaudatella), $54^{\circ}$

Scaldatone, 540

Scanarda, 540

Sconarda (syn. of Scanarda), 540

Scorlet Gege (syn. of Long Scarlet). 485

Scaudatella, 540

Schamal, 540

Scmiana (syn, of Italian Prutte), 253

Semiana of Boston (syn, of Semiana),

ilson, 543 $54 !$

Sillerblattrine Zutetsclte (syn. of Quctsche à feuille argentẻe), 523

Semi-double flowering Reine Cloude Silva Köning Claudic, 543

(syn. of Double Flowering Gage), Silver Prure (syn. of Golden Drop), 192

Semina (syn. of Semiana), $54 t$

Semis de Bury (syn. of Golden Drop), 220

Semis de Dorr (syn. of Dorr Seejling),

434

Semis de Dry (syn. of Dry Seedling). 436

Semis de Pond (syn, of Pond), 314

Seper, 542

Sefer's Peach (syn. of Seper). 542 229

Simiano (syn. of Semiana, 541; of Suisse, 549)

Simon, 345

Simon, Victor, var. orig. by, 55x

Simon: Simon's Chinese Apricot Plum; Simon's Peach; Simon's Plum (syns. of Simon), 346

Simpson, $34^{6}$

Simpson, IV. B., var. orig. by, 414

Sinomo (syn. of Kelsey), 258 
Sir Charles Worsley's (syn. of Royal), SPäte Dattel Pfoume (syn. of Hun534

Silucco, 54.

Sisson, 544

Sixby, 5.44

Six Wueks, 544

Skorospiclka (syn, of Early), 437

Skuya, 54t

Slec-Pruim (syn. of Sloc), 544

Sloe, 5.44

Sloc Plum, 59

Small, quoted, 80

Small Black Damask (syn, of Black

Damask), 40.

Small Damas (syn. of Black Damask),

404

Small Green Drying, 544

Smoll Grecn Gage (syn, of Small Reine Claude), 347

5 mall Mfirabelle (syn. of Mirabelle), $28_{4}$

Small Oreen Cloude (syn. of Small Reine Claude), 347

Small Red Domask: Small Red Damson (syns, of Queen Mother), 522

Small Reine Claude, $3 \$ 7$

Small Round Damson (syn. of Damson, 186; of White Damson, 374)

Small White Damask (syn. of Small

White Damson), 545

Small White Damson, 54.4

Smiley, 545

Smith, Captain John, quoted, 84, 93

Sunith, var. orig, by, 348

Smith, 5*5

Smith, A, M., var, orig, by, 545

Smith, C. A., var. orig. by, 545

Sinith, E. F., quoted, I31

Smith, W. \& T. Co, quoted, 118

Smith October, 545

Smith Orleans, 348

Smith Prolific, 545

Smith Prune (syn, of Diamond), I91

Smith Red, 545

Smith's Herrn Pfaume; Smith's large Orleans; Smith's Orleans; Smith's Orleans Pflaume (syns. of Smith Orleans), 348

Smith's large October (syn. of Impératrice), 249

Smith's Orleans (syn, of Cooper), 423 Smith's Prune (syn. of Diamond), 191 Smith's Prunc (syn. of Kingston), 476 Smith's Red (syn. of Smith Red), 545 Snelling, 545

Snelling, W. II., var. orig. by, 546

Snooks (syn. of New Ulm), 293

Snyder, $5 \$ 6$

Sophic, 349

Souris, 546

Sour Wine Plum of Yorkslite (syn.

of Winesour), 566

South Cumberland, 546

Southern Beauty, $54^{6}$

Southern Golden, 546

Sowitenir de Madame Nicolle (syn. of

Madame Nicolle), 488

Spanish (syn, of Spanish King), 546

Spanish Damascene: Spanish Damask;

Spanish Red Damask (syns. of

Spanish Damask), 546

Spanish Damask, 546

Spanish King, 546

Spanish King (syn. of Lombard), 268

Stabeler Seedling, 547

Stark Green Gage, 5.48 garian), $2+6$
Späte Herrn Pfoume: Spütc Könios

Pfoume; Späte Königs Pfatume ous

Paris; Später Perdrigon (syns, of

Perdricon Tardif), 5is

Späte Mirabelle (syn. of Late Mira.

belle, 263; of Saint Catherine, 334)

Späte Muskateller; Spāte Muskatellerpflaume (syns. of Late Muscatelle), 264

Spüte Mfrskatcller Pfanme (syn. of Tardive Musquée), 551

Späte Schrorac Damascene (syn. of Musk Damson), 5or

Spate von Chalons (syn. of Late Chalons 480

Spate Zwetscte Von Karlstadt, 546

Spath, M., var. orig. by, 395

Spaulding, 350

Speckled Gage, 546

Speer, 547

Spclge (syn. of Gemeiner Gelbe Spilling), $45 \mathrm{x}$

Spicer, 547

Spilge (syn. of Gemeiner Gelbe Spill. ing), 45 t

Spilling Jaune-double, 547

Spilling Jaune-simple (syn. of White Wheat), 565

Spindel Pfaume (syn. of Gemeiner Gelbe Spilling), 451

Spitszzetsche (syn. of Quetsche Pointue), 524

Spitzigc Rotc Pfounc; Spitz Pfaume (syns. of Rote Zwetsche), 534

Sritaige Rote Pfaumc (syn, of Bechstein Spitzphaume), 400

Sfitz Pflowme (syn. of Bechstein Spitzpflaume), 400

Spitzzwetsche (syn. of Quetsche Pointue), 524

Splendid, 547

Splendor, 547

Spotted Gage, 547

Springer, 547

Stambul Erik oder Irek (syn. of Myro-

balan), 290

Standard, 548

Standard of England (syn. of Stan- Sirsina Massina Piccola (syn. of Apridard), 548

Stanton, 352

Stanton's Seedling (syn. of Stanton), 352

Stark Brotbers, quoted, 116,213

Starnes, H. N., quoted, $13 \mathrm{r}, 376$

Steer's Emperor: Steers' Emperar

(syns, of foliath), 231

Steinlose Zwetsche (syn. of Stoneless) 353

Steinman, 548

Steinman, C., var. orig. by, 548

Stella, $54^{8}$

Stengel Pfoume (syn, of Werder'sche Frühzwetsche), 563

Stephens, Jobn D, var. orig. by, 533

Steptoe, 548

Sterling, 548

Stickney. 548

Stint, $54^{8}$

Stintplaume (syn, of Stint), $54^{8}$
Stocks, varicties of, 114-120

Stoddard, 352

Stoddart (syn. of Stoddard), 352

Stoncless, 353

Stoneless (syn. of Stoneless), 353

Stonewood, 549

Stout, var. orig. by, 549

tout, 549

Strachey, quoted, 84

Strawberry, 549

Strawberry (syn. of Berger), 160

Striped-leaved, 549

Strong, William, var. orig, by, 512

Stumpe (syn, of Howe), 464

Stumpe, Mrs., var. orig. by, 465

Stumpy (syn. of Howe), 464

Sucker State, 549

Sucree de Trauttenberg, or SucreeDouce De Trauttenberg (syns, of Trauttenberg), 555

Sucrin Vert (syn. of Reine Claude), 327

Sugar, 354

Sugar Prune (syn. of Sugar), 354

Suisina Grossella Piccola (syn. of Musk

Damson), 50 i

Suisse, 549

Sultan, $5 \$ 9$

Sultan (syn, of Occident), 295

Sultaneck Erick, 549

Sultaneck Erik (syn. of Reine Claude),

327

Summer Damson (syn. of Damas

d'Ete), 426

Sunrise, 549,550

Sunset, $\mathbf{5 5 0}$

Superbe de Denniston (syn. of Denniston Superb), 431

Superbe de Huling (syn. of Hulings), 245

Superior Gage; Superiour or Supcrior Green Gage (syns. of of Imperial Gage), 251

Superior Gage; Superior Green Gage (syns. of Washington), 368

Supreme (syn. of Yellow Egg), 386

Surpasse Monsieur, 550

Surprise, 355

Susina Di Santa Caterina (syn. of Saint 327

Susina Settembrica Ouialla (syn. of Reizenstein Yellow Prune), 531

Susina Torla d'Nova di Borgogna (incor.) (syn. of Burgundy Pruse), 412

Susina or Susino Vecchietti (syns. of

Catelano Violaceo), 416

Susira Verdachio Longo (syn. of Grüne Dattel Zwetsche), 456

Susino Catalano (syn. of Catalano), 415

Susino Damaschino Settembrino (syn.

of Damaschino Settembrino), 426

Susino Scaudatella (syn. of Scauda. tella), 540

Survance (syn. of Wild Goose), 378

Svedske Tidlig Leipziger, 550

Svedske Ungersk, sso

Swan, 550

Swan (syn, of Swan Golden), 550 $\begin{aligned} & \text { cot), } t+8 \\ & \text { Susina Regina (syn, of Reine Claude), }\end{aligned}$ 
Swan Golden, 550

Swan's Yellow (syn. of Swan Golden), 550

Swect Botan (syn. of Abundance, 136: of Berckmans, 159)

Sweet Damson, 550

Succt Damson (syn. of Fürst Damson, 448 ; of Ilorse, 464$)$

Sweet Prunc (syn, of German Prune), 220

Swift, 550

The Coe's Plum (syn. of Golden Transparcnt Yallow (syn. of Yellow Drop), 229

The Cook's Choice (syn, of Cook Trapps Konigspflaume, 555

(hoice), $\$ 22$

The Crar (syn. of Cxar), 184

The Dosch (syn. of Dosch), 435

The Gem (syn. of Gem), 45:

Traubenpflaume, 555

Trauttenberg, 555

Trauttenbergs Aprikasenffaume (syn. The Great Damosk Plum (syn. of Trauttenberg Zuckersüsse (syn. of Lange Violette Damascenc), 479 Trauttenberg), 5.5

The Green Damosine Plum (syn. of Trayer (syn. of De Soto), 289 Mirabelle), $284 \quad$ Trianon, 555

Stuiss or Suitzer's Phum (syns, of The Impératrice Plum (syn, of ImpéraSuisse), 549

Stuiss Prunc (syn. of Italian Prune), 253 trice), 249 num Bonum), 326

Syrische Pfanme (syn. of Mirahelle), 284

Szillassy Piros, 550

Tahor, G. L., var, orig. by, 207

Tante Anne (syn. of Aunt Ann), 397

Tardif or Tardive de Chalons (syns. of Late Chalons), 480

Tordite de Chambourcy (syn. of Cham. bourcy), 174

Tardive de Corny, 55t

Tardive de Fourqueux, 55

Tardive de Genes, 551

Tardive de Rivers (syn. of Late Rivers), $48 \mathrm{t}$

Tardive Musquée, 552

Tarleton, 55:

Tatge, 55 !

Tawny, 55 I

Taybank, 55

Tehernaya Arabskcya (syn. of Black Arabka), 404

The Myrobalane Plum (syn. of Myrobalan), 290

The Nectarine Plum (syn, of Nectarine), 291

The New Apricot Plum (syn. of Apricot), 148

The Purple Myrohalan (syn. of Pis. sardi), 516

The St. Julian Plum (syn, of Saint Julien), 335

The Washington Plum (syn, of Washington), 368

The White Impératrice Plum (syn. of

White Impératrice), 375

Theresa, 553

Thomas, 553

Thomas Octoher, 553

Thomaspflaume (syn. of Thomas), 553 Thompson's Golden Green, 553

Thorndyke Gage, 553

Thousand-And-One, 553

Thresher, 553

Prune), 404

Tecumseh, 552

Temperature, phases of, 202

Temple, 552

Tenant or Tennant Prune (syns. of Tennant), 357

Tennant, 357

Tennant, Rev. John, var. orig. by, 357

Tenneha, 552

Tennessee, 552

Tennessee Plum (syn. of Tennessee), 552

Terrell, $55^{2}$

Terry, 552

Terry, H. A., life of, 242; var, orig. hy, 193, 238, 242, 280, 39t, 393. $402,406,408,410,415,416,419$, $421,422,424,425,429,431,432$,

$434,435,441,443,444,447,448$,

$45 \mathrm{x}, 453,462,469,47 \mathrm{x}, 473,473$.

$483,484,485,486,490,491,492$,

$494,503,509,513,518,519,522$,

$529,536,542,543,552,558,559$. $561,562,564,566,568$

Terry De Soto, 552

Terry's Desota (syn. of Terry De Soto), 552

Teutsche blase Zwetsche (syn. of German Prune), 220

Texas Belle, 552

Texas Gauge, 552

Thanksgiving, 553

Thanksgiving Prune (syn. of Thanks. giving), 553

The Beauty (syn. of Corymbus), 423

Throop, Calvin, var. orig. by, 548

Throop No. I, 554

Throop No. 2, 554

ThrosseI, 554

Tillemond, 554

Tinsley, J. H., var, orig, by, 383

Tobe's Gage (syn. of Deaton), 429

Tohias Gage, 554

Togari (syn. of Kelsey), 258

Togo, 554

Tokeya, 554

Tomato, 554

Tomlingson, 554

Tomlinson's Charlotte (syn. of Char

lotte), 417

Topaz (syn. of Guthrie Topaz), 457

Topaze de Guthrie (syn. of Guthrie

Topaz), 457

Torlo d'Ovo or d'Uovo (syns. of Saint

Catherine), 334

Towakong, 554 .

Townscud (syn. of Miner), $28 \mathrm{z}$

Trabesche, 555

Trabeshe (syn. of Trahesche), $5 \$ 5$

Tragedy, $35^{8}$

Traer (syn. of De Soto), 189

Tradescant, John, var. orig. by, 326

Tragedy Prune (syn. of Tragedy), 358

Transparent, 360

Transparent (syn, of Macedonia, 488 ; of Yellow Transparent, 570)

Transparente, 555

Transparent Gage, Gage Plum or Green Gage (syns, of Transparent), 360
Trinkle, John W, var, orig, by, 555

Trinkle No. 4. 555

Triomphe Garcon or Valct: Trompe Garcon or Valct; Tromp.Valst (syns. of Reine (laude), 327

Trostle, 555

Trotter, Lillian A., var, orig, by, 443

Trotter, Richard, var. orig. hy, 473 . 484,512

Trouvéc de Vautềge or Vonéche (syns. of Trouvce de Voueche), 555

Trouvée de Voueche, 555

True Large Germon Prunc (syn, of German Prune), 220

True Sucet Boton (syn. of Berckmans), 159

Truro, 556

Tucker, 556

Tucker, Ezra W., var. orig. by, 556

Tudor, 556

Tupper, var, orig. by, 190

Turkey, 556

Turkey Plumb (syn. of Turkey), 556

Turkie (syn, of Turkey), 556

Turkische Gelbe Pflaume (syn. of $\mathrm{Im}$. perial Ottoman), 467

Turkische Kirsche (syn. of Myrobalan), 290

Turkische Zwetsche (syn. of Hungarian, 246; of Red Date, 322)

Turkish Prune (syn. of Italian Prune). 253

Turkish Prune, 556

Turkish Quctsche (syn. of German Prune), 220

Turky (syn. of Turkey), 556

Turner, Stephen 11., var. orig. by, 552

Twice Bearing, 556

Twins, 557

Tzaueron, 557

Uchi Bene; Uchi-Beni (syns. of Ber. ger), 160

Uchi Beni (syn. of Chabot), 172

Ulysses, 557

Uncle Ben, 557

Ungarische (syn. of Ungarish), $36 \mathrm{t}$

Ungarische Blaue Eicr (syn. of Kaiser Wilhelm), 474

Ungarische Dattelzwetsche (syn. of Hungarian), 246

Ungarische Dattel Zwetsche, 557

Ungarische Pflaume, Sabel Pfoume or Zwetsche (syns, of Ilungarian), 246

Ungarische Spüte Boutcillen Zwetsche (syn. of Ungarische Dattel $Z_{\text {wetsche), }}$ 557

Ungarische Zwetsche (syn, of Red

Date), 322

Ungarish, $36 \mathrm{I}$ 
Ungarsh Prune (syn. of Ungarish), Vincuse acidule (syn. of Winesour), Vwetter Perdrigon (syn. of Smith Or361

Union, 557

Unios Purplc (4yn. of Union), 557

L'uited States (syn. of U. S.), 557

Ura-Beni (syn. of Berger), 160

Tryany, 557

L. S., 557

Litin frreck (syn. of Trauben-

pflauns), 555

Litili, 362

Utah llybrid (syn, of Utah), 362

Uwasc (syn. of Shviata Bene), 543

Vail's Seedling (syn. of Large Golden I'rolific), 4 ,

Vakanzpllaume (syn. of September

Damask), 542

Valence, 557

Vialentia, 558

Valienciennes, 558

Vialue, 558

Van Renschoten, $55^{8}$

Van Buren, $55^{8}$

Van Deman, 558

Van Dieman (syn. of Van Deman), 558

Van IIouten, 5.58

Yan Mons, var, oris, by, I5s

Van Mons Königspfaume (syn. of Belle), 158

Van Mons' Red; Von Mons Red Gage (syns, of Belle), 158

Variegated Plum (syn. of Lombard), 268

Vilchen Pfaume (syn, of Violet Diaper). 365

Venetianische $\mathrm{Z}$ weimal Tragende, 558

Venus, 558

Verdaccinio rotondo (syn. of Rcine

Claude), 327

Verdacchio, $5^{88}$

Verdache, $55^{8}$

Verdacia (syn, of Reine Claude), 327

Verdage D'Italie (syn. of Quetsche

Verte D'Italie), 525

Verdoch; Verdochia; Verdochio; Verducio (syns. of Reine Claude), 327 Verdock (syn. of Verdacchio), 558

$V$ critable Imperatrice (syn, of Imperatrice), 249

Vermilion, 558

Vermilon Hatif, 559

Vertage d'Italic tres.grosse (syn. of Quetsche V'erte D'Italie), 525

Vert or Verte Bonnc; Verte d'Espagne: Verte Tiquetéc (syns. of Reine Claude), 327

Verte à Secher de Knight (syn, of Large Green Drying). 479

Vorte Tardise de Guthric (syn. of Guthrie Late), 236

Vesuvius, 559

Vick, 559

Victoire de Nelson (syn. of Nelson), 503

Victor, 559

Victoria, 362, 559

Victoria (syn. of Sharp, 340; of Victoria, 363)

Victoria-Pflaume; Victorio's Kaisersacetsche (syns. of Victoria), 363

Victor Sand Cherry, 559

Vilmot's Grecr Gage, Late Green Goge (syns. of Reine Claude), 327

566

inesour (syn. of Winesour), 566

Violet (syn. of Early Tours), 202

Violet, 559

Yiolet Damask (syn. of Damas Violet),

427

Violet de Tours (syn. of Early Tours),

Violet Diaper, 365

Violet Diaper (syn. of liolet Diaper),

365

Violct Empress (syn. of Imperatrice),

249

Violct Gage (syn. of Purple Gage), $3: 8$

"iolet Imperial, 559

Violet Perdrigon (syn, of Blue Perdrigon, 164; of Cooper, 423; of Smith Orleans, 348)

Violet Plumb (syn, of Violet), 559

Violst Qucen Cloude (syn. of Purple Gage), 318

iolet Royal, 559

Violette Hâtive (syn. of Early Tours), $2 \mathrm{da}^{2}$

Violctte (syn. of Imperatrice), 249

Violette (syn. of Violet), 559

Violette Americaine, 559

Violctte Dattclawetsclic (syn. of Agen, 138; of Hungarian, 246)

Violette de Galopin (syn. of Galopin), 449

Violctte de Jcrusolens (syn. of Jerusalem), 472

Violette de Tours (syn. of Early Tours), 202

Violette Diaprée (syn. of Violet Diaper), $3^{65}$

Violctte d'Octobre (syn, of Saint Mar. tin), 336

Violette Fasarenpfoume, Fasanen Pfoume, Hulinerpfoume, Huhuer Pfoune, or Robhuth Pfoume; Violetter Perdrigon; Violettes Rebhïhnerei (syns. of Bluc Perdrigon), 164 Violette Galopin (syn. of Galopin), 449 Violctte Hâtive (syn. of Early Tours), 202

Violette Jerusalem (syn. of Jerusalem), 472

Violette Jerusalcmspfaume (syn. of Jerusalem), 472

Violctte Kaiscrin (syn. of Dunkel. blaue Kaiserin, 437; of Impératrice, 249)

Violette Kaiser Pfanme (syn. of Blue Egg), 405

Violette Königspflaume (syn. of Early Royal), 201

Violettc October Pflaunte (syn. of Saint Martin Quetsche), 538

Violctte Octorcrpfoume (syn. of Saint Martin), 336

Violette oder Blaue Kaiscrpflanme (syn. of Red Magnum Bonum), 326

Vislettc Oktobcrpflaume (syn. of Saint Martin), 336

Violcttc Ouccu Cloudc; Violette ReineClaude (syns. of Purple Gage), 318 Violette Reine-Claude Von Brignais (syn, of Reine Claude de Brignais), 529 leans), 348

Violette Violen Pfoume (syn. of liolet Diaper), 365

irgata, 559

irgie, 560

Virgin (syn. of Red Virginal, 529; of White Virginal, 565)

Kirninal a Fruit Blanc or Rouge, d gros Fruit blanc, Blanc; Virginale; Vir. ginale d Frwit Ronge; Virginale Blanc or Rouge (syns. of Red Vir ginal), 529

Virginal d gros fruit blanc; Virginal blans: Vircinale; Virginale d Fruit Blauc, d gros fruit blanc, Virginale blanche (syns. of White Virginal), 565

Virginale (syn. of Apricot), 148

irginale (syn. of Red Virginal), 520

Virginalc Blanclic (syn. of Yellow Impératrice), 569

Virginia Damson, 560

Virginion Cherry (syn. of Myrobalan), 290

Virginisclie Ludwig's Pflaume (syn. of IIungarian), 2.46

Virginische Pfloume (syn. of Red Diaper), 323

Von Flotozus Mirabclle (syn. of Mirabelle de Flotow), 497

Von Berlepseb Zwetscbe, 560

Von Base Rote Zwetsche, 560

Von Lade Späte Mirabelle, 560

Von Hartwiss' Gelbe Zwetsche (syn. of Hartwiss), 459

Von Moro Reine Claude, 460

Von Trapp's Königs Pflaume (syn. of Trapps Königspflaume), 555

Von Tranttenberg's Aprikosenpflaume (syn. of Abricotée de Trauttenberg), 391

Von Trauttenberg's Zückersüsse (syn. of Trauttenberg), 555

Von Wangenteim Pfoume (syn. of Wangenheim), 368

Voronesh, 365

Voronesh Blue (syn, of Blue Moldavka), 405 (syn. of Voronesh), 365

oslaner Zwetsche, 560

Vulcan, 560

Wabash, 560

Wady, 560

Wady's Early (syn. of Wady), 560

Wager (syn, of Orange), 300

Wagner, 560

Wagner, J. F., var. orig. by, 411,462 , 560

Wagner No. 9 (syn. of Wagner). 560

Wahre Aprikoscn Pfoume (syn. of Apricot), I 48

Waltre blauc Eierfflaume (syn. of Jerusalem), 472

Walure Calcdonion (syn. of Goliath), $23 I$

Wahre Fiühzwetsehe, 560

Wohre Königspfoume (syn. of Royal), 534

Wahre Schlehen Damascene (syn. of Damson), 186 
Wahre Weisse Diaprćc, 56, Wahre Zuctsclic (syn. of Prune), 220

Wakapa, 56

Walker Seedling, 36 i

Wallace, 56r

Wales, 366

Walker, A. W., var, orig. by, 561

Walter, 56I

Walter, Herr, var. orig, by, 561

Walther Pflaume, 56

Wangenheim, 367

Wangcnhcim Ilâtìte, Wangenhcims Frïl: avetsche (syrns, of Wangenheim), 368

Wangenheins Früh Zwetsche (syn. of Wangenheim), 368

Woran Erik (syn. of Noire de Nontreuil), 504

Ward October Red, 561

Warner, 56:

Warner's Late or Late Red (syns. of Warner), 56 :

Warren, 56

Warren (syn. of Newman), 292

Washington, 368

Washington: IToshington Bolmar, Gage, Joune, Mammot, or Yellow (syns. of Washington), 368

Washington or Washingson Purple (syns, of Brevoort Purple), 408

Washington Seedling (syn. of lves), 470

Wasse-Botankio (syn. of Lutts), 487

Wosse Botankyo (syn. of Sagetsuna), 536 Wossc Sumamo (syn. of Earliest of Al1), 198

Wossu (syn. of Burbank), 170

Wastesa, 561

Waterloo Pflaume, 56

Wotcrioo (syn. of Golden Drop, 229 :

of Kent, 476; of Reine Claude, 327)

Watcrioo of Kent (syn. of Kent), 476

Watson, 562

Watson, D. H., var. orig. by, 463505 .

$518,525,562,569$

Watts, 562

Watts, Dr. D. S., var, orig. by, 562

Waugh, 562

Waugh, Frank A., Jife of, $85-86$, quoted, $65,66,86,87,99,141,393$

Wax, 562

Wax Plum (syn. of Wax), 562

Wayland, 370

Wayland, Dr., var, orig. by, 288

Wayland, Prof. H. B., var, orig. by, 371

Wazata, 562

Weaver, 372

Weaver, var. orig. by, 372,476

Webster, I. B. var, orig, by, 416

Webster Gage; Webster's Gage (syns. of Webster Gage), 562

Webster Gage, 562

Weedsport German Prune, 220

Weeping Blood, 562

Weichharige Schlehen Damoscene (syn. of Saint Julien). 335

Weinsauerliche Pflaume or Zwetsche (syns. of Winesour). 566

Wcisse Aprileosen Pfoume (sym. of Apricot), 148

Weisse Diapré (syn. of White Perdrigon), 375
Wcisse Hollondisclie Pfaume; Wrisse White Gage of Boston (syn. of $\mathrm{Jm}$. Kaiserin or Mognum Bonum; Weis- pierial (iage), zst ser Koiser (syns. of Yellow Egg), 386 White Iloney Damson, 564 W'cissc Indische Pflaumc (syn. of Grüne White Imperatrice, 375

Dattel Zwetsche), 456 IVhite Imperolrice (syn, of White

Weisse Jungferupfoume (syn. of White Imperatrice), 375

Virginal), 565 Hhite Iudion (syn. of Green Indian).

Weisse Kaiserpflaume (syn. of White 4 is

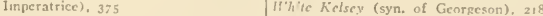

IV Cisse Kaiser Pfloume (syn. of Yellow White Motchless (syn. of Matchless), Egg), 386

Weisse Kaiserin, 563

II'cisse Kaiscrin (syn. of Wcisse Kaiserin), $56_{3}$

I'cisse Königin (syn. of White Queen) 56 \%

Weisser Perdrigon; Wcisses Rebluhnerci (syn, of White Perdrigon), 375 Weisse Zeiberl (syn. of Weisses oder Grünes Zeiberl), 562

Weisses oder Grünes Zeiherl, 562

Weisse Violen Pflaume (syn. Jaspisartige $\mathbf{P}$ (laume), 471

Welch, 562

Welcome, 562

W'entivorth: Wientworth Plumb (syns. of Yellow Eigg), 386

Werder'sche Frübzwetsche, 563

Wetherell, 563

Wetherill's Sweet, $56_{3}$

Whatisit, $56_{3}$

Wheat, 563

Wheoten; Wheoton; Wheat Plum White Sweet Damson, 564

(syns, of Wheat), $563 \quad$ White Virginal, 565

Whitacre (syn. of Whitaker), 563 White Virginale (syn. of Red Vir

Whitaker, 563

Whitby, 563

White Apricot or Apricot Plum (syns. of Apricot), 148

White Bonum Magnum (syn. of Yellow Egg), 386

White Blossomed Sloe (syn. of Sloe), 544

White Bullace, 373

White Bulleis (syn, of White Bullace) 373

White Corn, 564

White Damascene or Domson; White Damask (syns, of White Damson), 374

White Damask (syn. of Large White Damson, 48a; of Small White Damson, 545)

White Damson, 374

White Date or Date Plum (syn. of

Date), 428

Wbite Diaper, 564

White Diapred (syn. of Diaprée Blanche), 432

Whitc Egg or Egg Plum, Hollond, Imperiol or Imperial Bonum Magnum, Magnum Bonum, Mogul (syns, of Yellow Egg), 386

White Emprcss (syn. of White Impera trice). 375

Whitc-Acshed Botan (syn. of Berckmans), 159

Whitc Gagc (syn. of Small Reine (laude), 347 ginal, 529; of White Virginal, 565

White Wheat, 565

White Wheate (syn. of White Wheat). 565

White Winter Damson (syn. of White Damson), 374

Whitley, 565

Whitlorw; Whitton (syns, of Wheat). ${ }_{563}$

Whyte, 565

Whyte, R. B, var, orig, by, 565

Whyte's Red Seedling (syn. of Whyte) 565

Wiekson, 376

Wickson, E. J., quoted, 75. $-6,5.48$

Wickson Challenge (syn. of Formosa),

447

Wiener Mirabelle (syn. of Mirabelle) 284

Wier, 565

Wier, D. B., var, orig. by, 466,468 ,

469,563

Wier Large Red (syn. of Wier), 565

Wier No. 50, 565

Wier's No. 50 (syn. of Wier No, 50), 565

Wier's Large Red (syn, of Wier), 565

Wiezerka (syn. of Wyzerka), 568

Wilder, 565

Wilde, 565

Wild Goose, $37^{8}$

Wild Goose Improved, 5 C6

Wildrose, 566

Wilkinson, 566

Willamette (syn. of Pacific), 305

White Gage (syn of Yellow Gage), 388 W'illamette, 566

White Goge (syn. of Imperial Gage), 251/Willamette Prune (syn. of Pacific), 305 


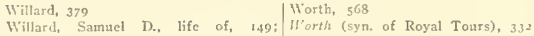
funoted, 208; var. orig. hy, 214 Wragg, 568

Willard Japan: Willard Plum (syns, of Wragg. Jolnn, var. orig. by, 477 Willard), 379

Williom Dodld (syn, of Miner), 281 Wunder von New York, 568

Williams, 566

thedore, var. orig. by, 392, Wyant, 38

397, 402, 407, 409, 412, 113,436 , Wyant, J. B., var. orig, by, 38,

$441,442,444,447,448,454,475$. Wyant and Japan, 568

$478,481,482,483,498,499,509$. Wyckoff, 568

$513,514,520,527,529,548,557$, Wyedale, 568

$558,559,563,568,569 \quad$ Wyzerka, 568

Williamson, II. M., quoted, 305

Wilmeth Late, 566

Yates, 560

Wilmot's Early Orleans, Large Orleans, Ycddo (syn. of Georgeson), 218 Latc Orleans, New Farly Orleans or Yellow Americana, 569 Orlcans (syns, of Early Orleans), 199

Ycllow Apricot (syn. of Apricot), ${ }_{14}^{8}$ Ycllow Aubcrt (syn. of Auhert), 397

Wilmot's Grecn Gage, Late Green Gage or New Grecn Gage (syns. of Reine Claude), 327

Wilmot's Latc Orlcans (syn. of Goliath), 23 !

Wilmot's Russian (syn. of Red Date), 322

Wilson, 566

Wine Plum, 566

Wincsour (syn. of Winesour), 566

Winesour, 566

Wincsour Plum (syn. of Winesour), 566

Winnebago, 566

Winslow, Edward, quoted, 93

Winsor, E. W., var, orig, by, 393, 402

Winter Creke, 567

Winter Damson, 567

Winter Damson (syn, of Winter Damson), 567

Wiseman, 567

Wiseman's Prane (syn, of Wiseman), 567

W. J. Bryan (syn. of Rryan), 4 to

Wohanka, 567

Wolf, 380

Wolf, D. B., var. orig. by, 380

Wolf and Tapan, 567

Wolf Cling (syn. of Wolf Clingstone), 567

Wolf Clingstone, $56 \%$

Wolf Frce or Frecstonc (syns, of Wolf), 380

IVonder (syn, of Osage), 510

Wood, 381

Wood, Joseph, var. orig. by, 382

Woolston, 567

Woolston Black: Woolston Black Gage; II'oolston's Black Gagc; Woolston's

Violette Reine-Claude (syns. of

Woolston), 567

Woolston Gage (syn. of Woolston), 567

Wooster, 567

Wnoten, 568

Wootton (syn. of Wooten), 568

World Beater, $3 \mathrm{~S}_{3}$
Egg), 386

Ycllo: Damask (syn, of Drap d'Or), I95

Ycllow Damison (syn. of White Damson), 374

Yellow Date (syn. of Date), ${ }_{42} 8$

Yellow Diaprée (syn. of Diaprée

Blanche), 432

Yellow Egg, 385, 569

Yellow Egg (syn. of Yellow Egg), 386

Vellow Egg group, 32; origin of, 32 : specific characters of, 32

Ycllow Flcshed Botan (syn. of Abundance), 136

Yellow Gage, 388

Yellow Gage (syn. of Drap d'Or, 195: of Small Reine Clande, 347)

Yellow Impératrice, 569

Yellow Impératrice (syn. of Yellow Im. pératrice), 569

Yellow Imperial, 569

Yellow Jopan (syn. of Abundance, 136 ; of Chabot, 172)

Yellow Jerusalem, 569

Yellow Magnum Bonum, 570

Ycllow Magnum Bonum (syn. of Yellow Egg), 386

Yellow Moldavka (syn. of Voronesb), 365

Vellow Nagate, 570

Yellow Nagate (syn, of Ogon), 298

Yellow Oregon, 570

Yellow Panhandle, 570

Ycllow Perdrigon (syn. of Drap d'Or) I95

Yellow Plum, 59

Yellow Roman Bullace, 570

Catherine), 334

Yellow Sweet, 570

Yellow Transparent, 570

Yellow Voronesh (syn. of Voronesh), 365

Yellow Wildgoose, 5\%0

Yellow Yosemite, 570

Yellow, 43 Fischer, 560
Ycllow Bonum Magnum (syn. of Yellow

$Y$ cllow St. Cathorinc (syn. of Saint
Yohe, 571

Yohes Eagle (syn. of Yohe), 571

Yoncmomo; Yonesmomo (syns, of Satsuma). 3.37

Yorkshirc Wincsour (syn. Winesour), 566

York State Prune, 571

York Statc Prunc (syn, of York State

Prune), 571

Yosibe (syn, of Farliest of All), 198

Yosemite (syn. of Purple Yosemite,

521; of Ycllow Yosemite, 570)

Yosemite Purple (syn. of Purple Yosemite), 521

Yosemite Yellow (syn. of Yellow Yosemite), 570

Yosete (syn. of Earliest of A11), 198

Yesobe (syn of Earliest of Al1), 198

Young, 57

Youngken Golden; Younken's Golden

Cherry; Yunkin Golden (syns, of Golden Cherry), 228

Young's Scedling (syn. of Young), $57 \mathrm{I}$

Young's Supcrior Egg (syn, of Yellow Egg), 386

Yukon, 571

Yuteca, $57 x$

Zahlbruckner Damascene, 571

Zahlbruckuer's Violette Damasecne (syn. of Zablbruckner Damascene), 57 I

Zekanta, 571

Zipperle or Zipperlein (syns. of Damson), 186

Zuccherina (syn. of Damaschino Estivo), $4 \geq 6$

Zucchetta Gialla, 57

Zucker Zwetsche (syn. of Red Date). 322

Zulu, 571

Zuzac, 57

Zweinal Blühende und Zucimal Tragende Bunte Pfaune (syn, of Twice Bearing), 556

Zweimal Tragende (syn. of Twice Bearing), 556

Zwergpflaume, $57 \mathrm{t}$

Zuespe (syn. of German Prune), 220

Zuctsche, Zwetschen or Zuetschke (syns, of German Prune), 220

Zwetsche Frühe Von Buhlerthal (syn. of Quetscbe Précoce de Buhlerthal), 524

Zwetsche Leipriger (syn. of Merunka), 494

Zwetscbe Professor Wittmack, 572

Zwetsche Ungarische (syn. of $\mathrm{Un}$. garish), $36 \mathrm{r}$

Zwctscitc von Dätlikon (syn. of Italian

Prune), 253

Zwetsche Von der Worms, 572

Zwetsche Von Létricourt (syn. of

Quetsche Dr. Létricourt), 524 

. 




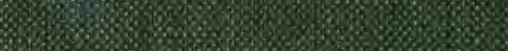

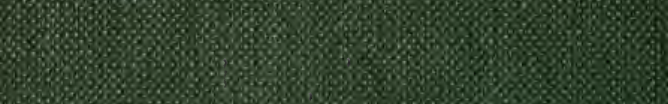

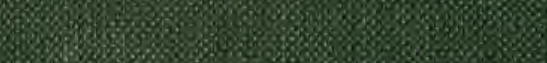
Hor.

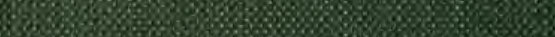

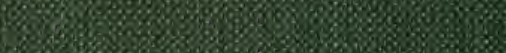

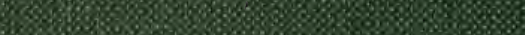

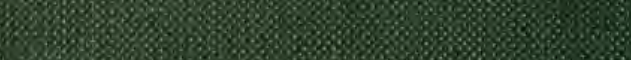

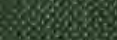

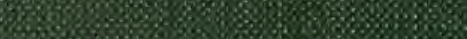

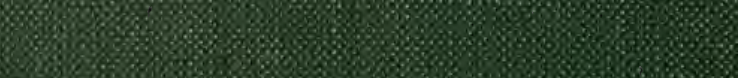

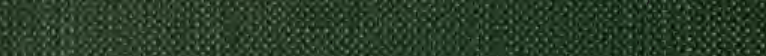

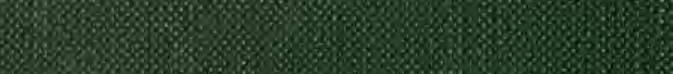

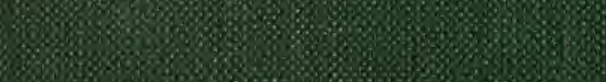

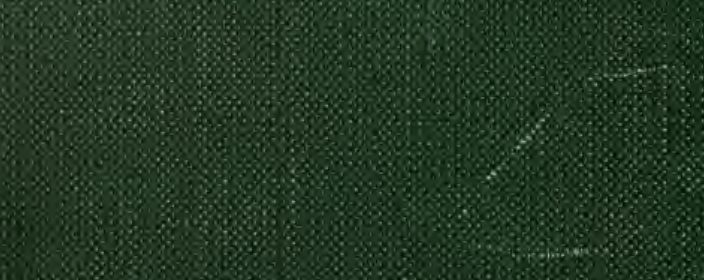

8.

$6 \times$

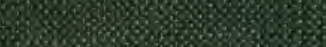

$8 \%$ \%

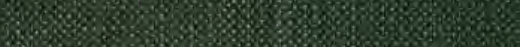

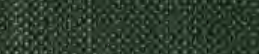

